DƠE/ER-0313/14

Fusion

Reactor

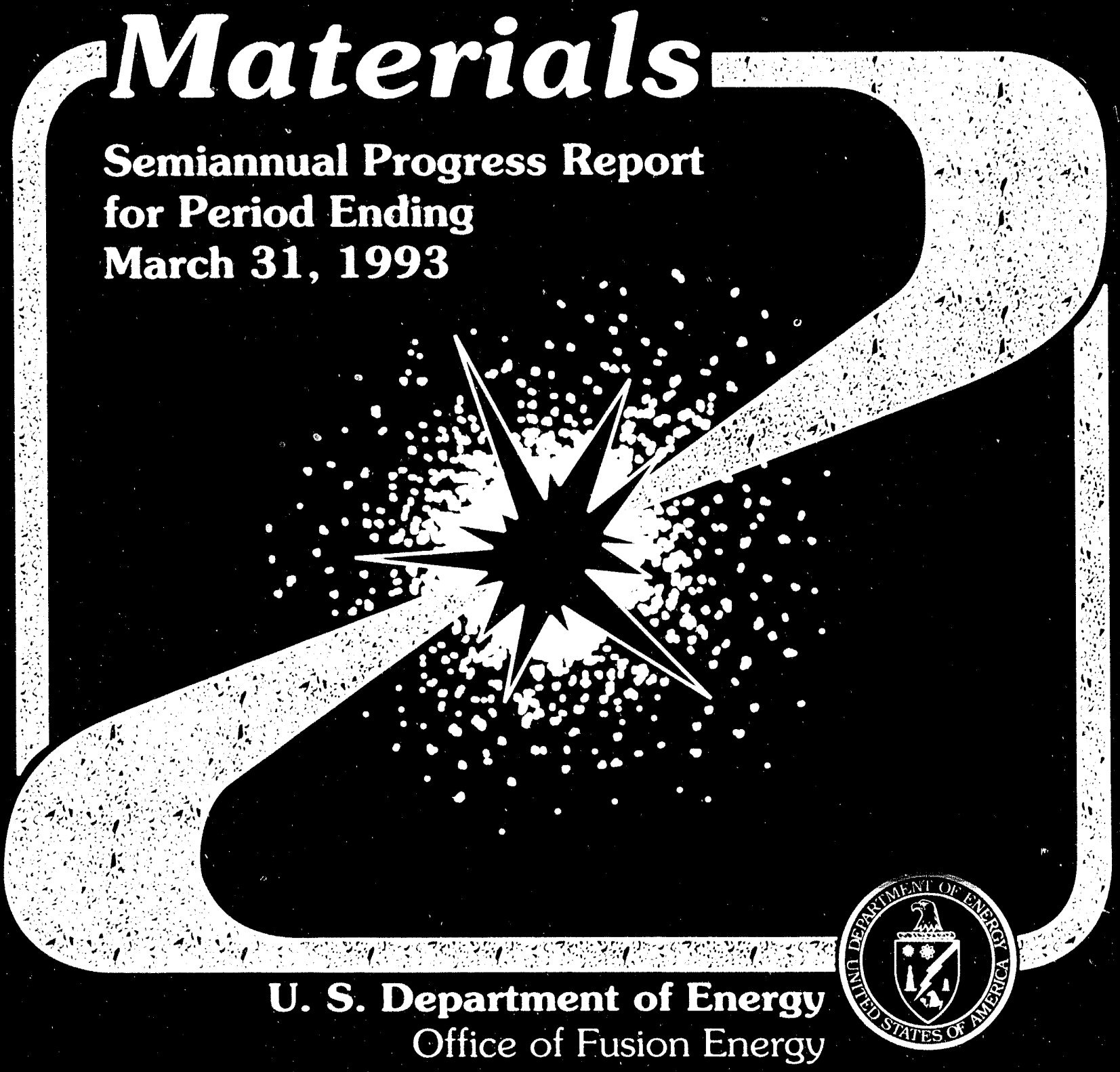


This report has been reproduced directly from the best available copy.

Available to DOE and DOE contractors from the Otfice of Scientific and Technical Information, P.O. Box 62, Oak Ridge, TN 37831; prices available from (615) 576-8401, FTS 626-8401.

Avallable to the public from the National Technical Information Service, U.S. Department of Commerce, 5285 Port Royal Rd., Springfield, VA 22161.

This report was prepared as an account of work sponsored by an agency of the United States Government. Neither the United States Government nor any agency thereof, nor any of their employees, makes any warranty, express or implied, or assumes any legal liability or responsibility for the accuracy, completeness, or usefulness of any information, apparatus, product, or process disclosed, or represents that its use would not infringe privately owned rights. Reference herein to any specific commercial product, process, or service by trade name, trademark, manufacturer, or otherwise, does not necessarily constitute or imply its endorsement, recommendation, or favoring by the United States Government or any agency thereof. The views and opinions of authors expressed herein do not necessarily state or reflect those of the United States Government or any agency thereot. 
DOE/ER-0313/14

Distribution

Categories

UC-423, -424

\title{
FUSION REACTOR MATERIALS \\ SEMIANNUAL PROGRESS REPORT \\ FOR THE PERIOD ENDING \\ MARCH 31, 1993
}

Prepared for

DOE Office of Fusion Energy

(AT $150203 \mathrm{~A}$ )

DATE PUBLISHED: July 1993

\author{
Prepared for \\ OAK RIDGE NATIONAL LABORATORY \\ Oak Ridge, Tennessee 37831 \\ Managed by \\ MARTIN MARIETTA ENERGY SYSTEMS, INC. \\ for the \\ U.S. DEPARTMENT OF ENERGY \\ under Contract DE-AC05-84OR21400
}




\section{FOREWORD}

This is the fourteenth in a series of semiannual technical progress reports on fusion reactor materials. This report combines research and development activities which were previously reported separately in the following progress reports:

- $\quad$ Alloy Development for Irradiation Performance

- Damage Analysis and Fundamental Studies

- Special Purpose Materials

These activities are concerned principally with the effects of the neutronic and chemical environment on the properties and performance of reactor materials; together they form one element of the overall materials programs being conducted in support of the Magnetic Fusion Energy Program of the U.S. Department of Energy. The other major element of the program is concerned with the interactions between reactor materials and the plasma and is reported separately.

The Fusion Reactor Materials Program is a national effort involving several national laboratories, universities, and industries. The purpose of this series of reports is to provide a working technical record for the use of the program participants, and to provide a means of communicating the efforts of materials scientists to the rest of the fusion community, both nationally and worldwide.

This report has been compiled and edited under the guidance of A. F. Rowcliffe, G. L. Burn, and S. S. Knee', Oak Ridge National Laboratory. Their efforts, and the efforts of the many persons who made technical contributions, are gratefully acknowledged.

F. W. Wiffen

Division of Advanced Physics and Technology 
Reports previously listed in this series are as follows:

DOE/ER-0313/1

DOE/ER-0313/2

DOE/ER-0313/3

DOE/ER-0313/4

DOE/ER-0313/5

DOE/ER-0313/6

DOE/ER-0313/7

DOE/ER-0313/8

DOE/ER-0313/9

DOE/ER-0313/10

DOE/ER-0313/11

DOE/ER-0313/12

DOE/ER-0313/13

DOE/ER-0313/14
Period ending September 30, 1986

Period ending March 31, 1987

Period ending September 30, 1987

Period ending March 31, 1988

Period ending September 30, 1988

Period ending March 31, 1989

Period ending September 30, 1989

Period ending March 31, 1990

Period ending September 30, 1990

Period ending March 31, 1991

Period ending September 30, 1991

Period ending March 31, 1992

Period ending September 30, 1992

Period ending March 31, 1993 
CONTENTS

1.0 IRRADIATION FACILITIES, TEST MATRICES, AND EXPERIMENTAL METHODS. . . 1

1.1 PREPARATION OF COBRA 1 A FOR INSERTION IN'YO EBR-II -- M. L. Hamilton and R. M. Ermi (Pacific Northwest Laboratory) and C. R. Eiholzer (Westinghouse Hanford

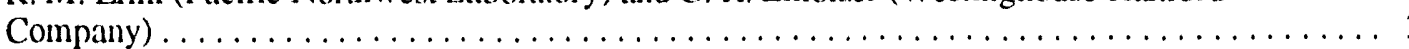

COBRA $1 \mathrm{~A}$ was built to support the research and development efforts of the U.S. DOE Neutron Interactive Matterials (NIMs) progran. COBRA was inserted into the EBR-Il for irradiation beginning in run 162 . The specimen loading is documented here.

1.2 FABRICATION AND OPERA'TION OF HFIR-MFE RB* SPECTRALLY TAILORED IRRADIATION CAPSULES -- A. W. Longest, J. E. Pawel, D. W. Heatherly, R. G. Sitterson,

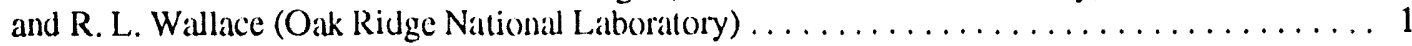

Fabrication and operation of four IIFIR-MFE RB* capsules (60, 200, 330, and $400^{\circ} \mathrm{C}$ ) to accommodate MFE specimens previously irradiated in spectrally lailored experiments in the ORR are proceeding satisfactorily. Irradiation of the 60 and $330^{\circ} \mathrm{C}$ capsules, which started on July 17, 1990, was completed on November 14, 1992, after 24 cycles of irradiation to an incremental damage level of approximately 10.9 displacements per atom (dpa).

Assembly of the follow-up 200 and $400^{\circ} \mathrm{C}$ capsules was completed in November 1992, and their planned 20 -cycle irradiation 10 approximately 9.1 incremental dpa was started on November 21,1992 . As of February 11,1993 , the 200 and $400^{\circ} \mathrm{C}$ capsules had successfully completed three cycles of irradiation 10 approximately 1.4 incremental dpa.

1.3 STATUS OF U.S.JJAPAN COLLABORATIVE PROGRAM PHASE II HFIR TARGET CAPSULES --J. E. Pawel and R. L. Senn (Oak Ridge National Laboratory and K. Shiba (Japan Atomic Energy Research Institule .

Capsules JP) through JP 16 were installed in the High Flux Isotope Reactor (HFIR) target July 20, 1990, for irradiation beginning with HFIR fuel cycle 289. Of these eight target capsules, JP10,11, 13, and 16 compleled their scheduled number of cycles (11) and were removed from the reactor in September 1991. In addition, JP14 was removed from the reactor at the end of cycle $310(9 / 18 / 92)$ after 21 cycles.

Three new capsules in this series, JP20, 21, and 22, have been designed. The new capsules will contain transmission electron microscope (TEM) disks and SS-3 tlat tensile specimens at $300-600^{\circ} \mathrm{C}$ and will achieve doses of 8,18 , and $35 \mathrm{dpa}$, respectively.

2.0 DOSIMETRY, DAMAGE PARAMETERS, AND ACTIVATION CALCULATIONS .....

2.1 HELIUM MEASUREMENTS FOR THE MOTA $1 \mathrm{G}$ DISCHARGE OF THE ${ }^{59} \mathrm{Ni}$ ISOTOPIC TAILORING EXPERIMENT--F. A. Garner (Pacific Northwest Laboratory) and B. M. Oliver

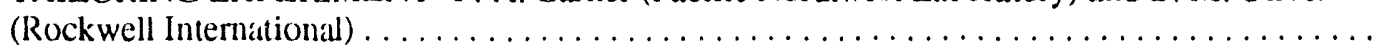

The final measurements of helium generation in specimens used in the ${ }^{59} \mathrm{Ni}$ isotopic tailoring experiment have been completed. The results show that the target generation rates were sustained throughout the experimental series. It was also demonstrated that helium generation rates grow continuously in u udoped specimens, reaching levels substantially larger than usually quoted in most other studies. 
2.2 NEUTRON DOSIMETRY FOR THE MO'TA-1G EXPERIMENT IN FFIF .. L. R. Greenwood and L. S. Kellogg (Pacific Northwest Laboratory) . . . . . . . . . . . . . . . . . .

Neutron fluence and spectral measurements and radiation danage calculations are reported for the MOTA-1G experiment in the Fast Flux Test Facility (FFTF). The irradiation was conducted from January 4, 1990, 10 March 19, 1991, for a total exposure of 299.7 EFPD. The maximum fluence was $15.8 \times 10^{22} \mathrm{n} / \mathrm{cm}^{2}, 10.0 \times 10^{22}$ above $0.1 \mathrm{MeV}$ producing 43.0 dpa in iron. Neutron fluence and radiation daunage maps are presented for the entire MOTA assembly based on the analysis of ten neutron spectual measurements and seven additional llux gradient measurements.

2.3 MEASUREMENT OF HELIUM GENERATED IN V-B ALLOYS IRRADIATED IN FFTF/MOTA --F. A. Garner (Pacilic Northwest Laboratory), B. M. Oliver (Rockwell International Corporation), and $\mathrm{N}$. Sekimura (University of Tokyo) $\ldots \ldots \ldots \ldots \ldots \ldots \ldots$

V-B and V-5Cr-B alloys have been irradiated in FTTF to assess the inpact of helium generation rate on microstructural evolution of vanadium-base alloys. Using this method it is somewhat difficult to separate the various effects of the original boron as well as the lithium and helium products of the ${ }^{10} \mathrm{~B}(\mathrm{n}$, a) reaction. Post-irradiation measurements of helium concentrations have been completed for two sets of V-B alloys, one irradiated in-core and one below core. It appears that the boron doping technique used to produce the various alloys was reasonably successful in reaching the desired helium/dpa variations.

2.4 NEW ACTIVATION (CROSS SECIIION DATA -- 1: M. Mamn and D. E. Lessor,

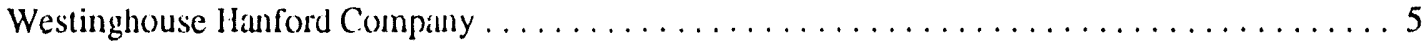

New nuclear section libraties (known as USACI\%2) have been created for activation calculations. A point-wise file wats crealed from merging the previous version of the activation library, the U.S. Nuclear Data Library (ENDF/B-VI), and the European Activation File (EAF-2). 175 and 99 multi-group versions were adso crealed. All the data are available at the National Energy Research Supercomputer Center.

2.5 TRANSMUTATION OF TUNGSTEN IN IFFIF, IIIIR AND STARFIRE -. F. A. Garner and

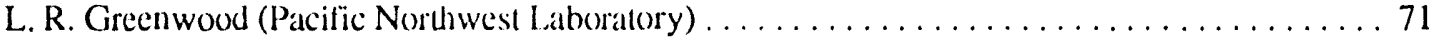

Tungsten has been used in a variely of low activation ferritic alloys and also in copper composite alloys, both currenlly being irradiated in various fusion materials experiments. It has been proposed as an armor material also. However, in a manner that is strongly dependent on neutron spectra, lungsten trassinutes strongly to rhenium and then osmium. This adds significant complexity to the interpretation of data developed in one spectral enviroment but intended for application to another environment.

2.6 SUMMARY OF IONIZING AND DISPLACIVE IRRADIATION FIELDS IN VARIOUS FACILITIES -- S. J. Zinkle (Oak Ridge National Laboratory) and L. R. Greenwood (PNL) . . . . . 74

Calculations have been performed to estimate the ionizing and displacive irradiation fields that will occur in ceramics during irradiation in accelerators and fission and fusion reactors. A useful measure of the relative strength of ionizing vs. displacive radiation is the ratio of the absorbed ionizing dose to the displacement daunage dose, which in the case of ion irradiation is equal to the ratio of the electronic stopping power to the nuclear stopping power. In ceramics such as $\mathrm{Al}_{2} \mathrm{O}_{3}$, this ratio is about 20 at a fusion reactor first wall, and has a typical value of about 100 in a fusion reactor blanket region and in mixed spectrum reactors such as HFIR. Particle accelerator sources typically have much higher ionizing to displacive radiation ratios, ranging from about 2000 for $1 \mathrm{MeV}$ protons to $>10,000$ for $1 \mathrm{MeV}$ electrons. 
2.7 IMPROVEMENT OF DECAY AND CROSS-SECTION DATA LIBRARIES FOR ACTIVATION CALCULATIONS--H. Altaya (Argonne National Laboratory) . ............

A new decay data library has been completed. The new library contains up-to-date decay information (half-lives, branching ratios, decay energies, $\gamma$ 's energies and intensities). Activation responses such as the air and water biological hazard polentials, the waste disposal rating, and the biological dose are also included in this library. Recently developed crosssection libraries have been acquired to be used together with the decay data library.

2.8 ACTIVATION ANALYYSES FOR DIFFERENT STRUCTURAL ALLOYS CONSIDERED FOR ITER--H. Attaya and D. Smith (Argonne National Laboratory) ................ 85

Activation calculations have been made for the austenilic steel 316 SS, the ferritic alloys HT-9, the titanium alloy Ti6 $14 \mathrm{~V}$, and the vanadium alloy V $5 \mathrm{Cr} 5 \mathrm{Ti}$ in a liquid metal (Na) design suggested recently for ITER. The calculations show that the vanadium alloy has the minimum short and long-term radioactivity and BIIP. It also has the minimum decay heat all the time. The titanium alloy has less radicactivity than the austenitic and the ferritic alloys. However, the decay heat of this alloy could exceed that of the conventional alloys.

3.0 MATERIALS ENGINEERING AND DESIGN REQUIREMENTS

No contributions

4.0 FUNDAMENTAL MECHANICAL BEHAVIOR .

4.1 MECHANICAL PROPERTIES ALONG INTERFACES OF BONDED STRUCTURES IN FUSION REACTORS -- M. H. Hassan and G. L. Kulcinski (Universily of Wisconsin) . . . . . . 95

Proper assessment of the mechanical properties along interfaces of bonded structures currently used in many fusion reactor designs is essential to compare the different fabrication techniques. A Mechanical Properties Microprobe (MPM) was used to measure hardness and Young's modulus along the interfaces of $\mathrm{Be} / \mathrm{Cu}$ bonded structure. The MPM was able to distinguish different fabrication techniques by a direct measurement of the hardness, Young's modulus, and $\mathrm{H} / \mathrm{E}^{2}$ which reflects the ability of deformation of the interfacial region.

4.2 GREEN'S FUNCTION METHODOLOGY FOR FRAC'TURE MECHANICS OF SiC-SiC COMPOSITE STRUC.TURES -- A. El-Azab and N. M. Ghoniem (Universily of California, Los Angeles)

A fundanental solution of plane elasticity in a linite domain is developed in this paper. A closed-form Green's function for the elastic field of an edge dislocation of arbitrary Burger's vector at an arbitury point in an orthotropic finite electric domain, that is free of traction, is presented. the method is based on the classical theory of potential fields, with an additional distribution of surface dislocations to satisfy the free traction boundary conditions. A solution is first developed for a dislocation in a semi-infinite half-plane. The resulting field is composed of two parts: a singular contribution from the original dislocation, and a regular component associated with the surface distribution. The Schwarz-Christoffel transformation is then utilized to map the field quantities to a finite, polygonal domain. A closed form solution containing Jacobi elliptic functions is developed for rectangular domains, and applications of the method to problems of fracture and plasticily are emphasized. 


\subsection{FACTORS WHICH CONTROL THE SWELLING OF Fe-Cr-Ni TERNARY AUSTENITIC} ALLOYS -.F. A. Garner and D. J. Edwards (Pacific Northwest Laboratory) . . . . . . . . . . 12

In agreement with limited earlier studies, a comprehensive irradiation experiment conducted in EBR-II demonstrates that while cold-working decreases swelling of Fe-15Cr$\mathrm{XNi}(\mathrm{X}=12-45 \mathrm{wt} \%)$ alloys at relatively low irradiation temperatures, it increases swelling at higher temperatures. Aging of cold-worked specimens to produce polygonized dislocation networks tends to further increase swelling, especially at higher nickel $(>25 \%)$ levels. Swelling at lower nickel levels also appears to be sensitive to details of the annealing treatment.

5.2 THE INFLUENCE OF COLD WORK LEVEL ON SWELLING OF PURE COPPER IRRADIATED BY FAST NEUTRONS OR ELECTRONS -- F. A. Garner (Pacific Northwest Laboratory) and B. N. Singh (Risø National Laboratory) . . . . . . . . . . . . . . . . .

Pure copper has been irradiated in a varicty of stating conditions by either $1.0 \mathrm{MeV}$ electrons or fast neutrons in FIFIF-MOTA. Electron irradiation at 250 and $350^{\circ} \mathrm{C}$ produces a non-monotonic swelling behavior as a function of cold work level, increasing swelling at lower cold work levels and decreasing swelling at higher cold-work levels. In FFTF at 365 and $430^{\circ} \mathrm{C}$, however, $10 \%$ cold-work reduces swelling initially, with little additional influence at higher cold-work levels. Swelling at 520 and $600^{\circ} \mathrm{C}$ is less than $1 \%$ at 35.9 and $13.6 \mathrm{dpa}$, respectively, with little effect of cold work level.

5.3 THE INFLUENCE OF DETAILS OF REACTOR HISTORY ON MICROSTRUCTURAL DEVELOPMENT DURING NEUTRON IRIRADIATION -- F. A. Garner (Pacific Northwest Laboratory), N. Sekimura (Univ. of T(okyo), M. L. Grossbeck (Oak Ridge National Laboratory), A. M. Ermi (Westinghouse Hanford Company), J. W. Newkirk (U. of MORolla), H. Watanabe (Kyushu University) and M. Kiritani (Nagoya University) . . . . . . . . .

Microstructurally-oriented irradiation experiments are shown in this paper to be strongly dependent on details of reactor history that liequently are not brought to the experimenter's attention. In some cases, these details can dominate the experiment so as to produce very misleading results. To aid in the design and interpretation of microstructurallyoriented experiments, a number of studies are reviewed to highlight history effects and then guidelines are presented to mininize the impact of reactor history in new experiments.

5.4 NEUTRON-INDUCED SWELLING OF PURE NICKEL AND NICKEL BINARY ALLOYS

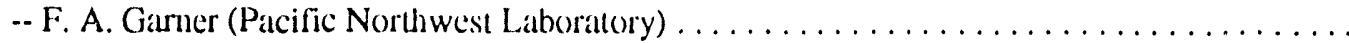

The second and last phase of the EBR-II A $\triangle-14$ experiment confirms many of the trends observed in Phase I of the experiment. Phase I reached 12 to 14 dpa for pure nickel and nickel-binary alloys at 425,500 , and $600^{\circ} \mathrm{C}$. Phase II reached 31.1 to $31.8 \mathrm{dpa}$ at the same temperatures.

5.5 DEFECT PRODUCTION IN IRRADIATED METALS -- H. L. Heinisch (Pacilic Northwest

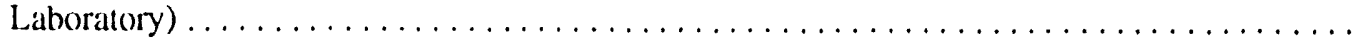

Our knowledge of the processes involved in creating defects during cascade-producing irradiations is reviewed. Molecular dynanics simulations within the past few years have led to an understanding of the creation and survival of point defects in the critical first picoseconds of the cascade process, through the quenching of the thermal spike. The concept that "freely migrating defects" arise only from isolated Frenkel pairs produced in a cascade is critically discussed. 
5.6 MOLECULAR DYNAMICS CALCULATIONS OF DEFECT ENERGETICS IN B-SIC* -. Hanchen Huang, Anter El-Azab, and Nasr Ghonicm (University of California, Los Angeles) . . . 150

The Molecular Dynamics (MD) method is used to calculate defect energetics in Bsilicon carbide. Many-body interaction effects in this covalent material are accounted for by using a hybrid of two-body and three-body potentials. Calculated bulk properties of $\mathrm{B}-\mathrm{SiC}$ based on this potential are in agreement with experimental data to within 17\%. A microcrystal is constructed to represent the computational cell and external forces are applied to the micro-crystal so that it behaves as a part of an infinite medium. The potential energy for the unperturbed computational cell is first calculated. The cell is then set at a defect configuration and relaxed, and the potential energy of the relaxed cell is calculated. The difference between the potential energy of the unperturbed cell and that of the defect-containing cell is used to calculate the formation and binding energies of point defects, defect clusters, and heliumvacancy clusters in $\mathrm{SiC}$.

6.0 DEVELOPMENT OF STRUCTURAL ALLOYS

6.1 FERRITIC STAINLESS S'TEELS .

6.1.1 EFFECTS OF HYDROGEN AND LOADING MODE ON THE FRACTURE TOUGHNESS OF A REDUCED ACTIVATION FTRRRITIC STAINLESS STEEL -- H. Li (Washington State University), R. H. Jones (Pacilic Northwest Laboratory), J. P. Hirth (Washington State University), and D. S. Gelles (Pacilic Northwest Laboratory) . . . . . . . . . . . . . . . . .

The full spectrum of fracture toughness (J integrals), including pure mode I, different mixed mode I/III and pure mode III, will be examined for a ferritic/martensitic stainless steel with $0.1 \mathrm{C}-8 \mathrm{C}-\mathrm{r}-2 \mathrm{~W}-0.2 \mathrm{~V}-0.04 \mathrm{~T} \mathrm{a}-\mathrm{Fe}$ (by wl\%), designated as $\mathrm{F}-82 \mathrm{II}$. The J integrals of pure mode I $\left(J_{I C}\right)$ and mixed mode $\mathrm{I} / \mathrm{III}\left(\mathrm{J}_{\mathrm{Inixed}}\right)$ are detcrmined wilh single specimen method using standard compact tension specimens and modilied compact tension specimens, respectively. The pure mode III integral is measured with multiple specimen method using "triple-pantleg" specimens. Effects of hydrogen on the J integrals of pure mode I and mixed mode I/LI are also going to be studied. $9 \mathrm{ppm} \mathrm{H}$ (about $500 \mathrm{appm}$ ) is pre-charged into specimens cathodically. The preliminary results showed that addition of mode III stress (shear stress) to mode I loading had a significant negative effect on the fracture toughness of F-82H.

\subsubsection{IRRADIATION CREEP AND SWELLING OF THE FUSION HEATS OF HT9 AND 9Cr-} 1 Mo TO 208 DPA AT $\sim 400^{\circ} \mathrm{C}$-- F. A. Garner (Pacilic Northwest Laboratory), M. B. Toloczko (University of Cadifornia at Santa Barbara) and C. R. Eiholzer (Westinghouse

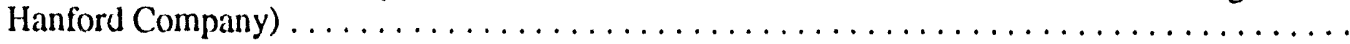

The irradiation creep behavior of the fusion heats of HTY and $9 \mathrm{Cr}-1 \mathrm{Mo}$ at $\sim 400^{\circ} \mathrm{C}$ has been measured to exposures as large as $208 \mathrm{dpa}$. HT9 is somewhat nonlinear in its response to hoop stress level in the range $0-200 \mathrm{MPa}$, but $9 \mathrm{Cr}$-1 Mo exhibits only slightly greater than linear behavior with stress level. The strain data of both alloys appear to include some contributions from precipitate-related density changes. Swelling may have occurred in $9 \mathrm{Cr}$ $1 \mathrm{Mo}$.

6.1.3 EFFECT OF VANADIUM AND TITANIUM ON MECHANICAL PROPERTIES OF LOWCHROMIUM, REDUCED-ACTIVATION FERRITIC STEELS--R. L. Klueh and

D. J. Alexander .

Tensile and Charpy impact tests were made on three normalized-and-tempered $21 / 4 \mathrm{Cr}$ $2 \mathrm{WV}(0.1 \% \mathrm{C}$ ) steels with $0.1,0.25$, and $0.5 \% \mathrm{~V}$ (all concentrations are in weight percent). Increasing vanadium from $0.1100 .25 \%$ increased the yield stress up to twenty percent. A 
higher ductile-britle transition temperature (DBTT) accompanied the higher strength of the $0.25 \% \mathrm{~V}$ steel when both were tempered at $700^{\circ} \mathrm{C}$. Tempering at $750^{\circ} \mathrm{C}$ gave similar DBTTs. Increasing vanadium from 0.25 to $0.5 \%$ caused a slight increase in strength with a large decrease in toughness. Thus a balance between strength and inpact toughness is achieve with an intermediate vanadium concentration. Addition of $0.02 \% \mathrm{Ti}$ to $21 / 4 \mathrm{Cr}-0.25 \mathrm{~V}, 21 / 4 \mathrm{Cr}$ $2 \mathrm{~W}$, and $21 / 4 \mathrm{Cr}-2 \mathrm{~W}-0.25 \mathrm{~V}(0.1 \% \mathrm{C})$ steels caused a yield stress decrease of 10 to $30 \%$, which was attributed to the effect of tilanium on the MC precipitate distribution. The strength loss was accompanied by an increase in impact toughness, which may also have been affected by a decrease in prior austenite grain size. Furthermore, there was little difference in the DBT $\Gamma$ of the Ti-moditied steels tempered at 700 or $750^{\circ} \mathrm{C}$. If it were possible to use a Timodified steel temperated at $700^{\circ} \mathrm{C}$, this might offset the strength advantage of steels without titanium, which have to be tempered at the higher temperature.

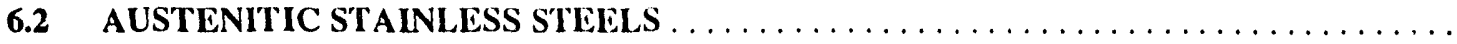

6.2.1 STRESS-MODIFIED WELDING PROCIESS FOR IILLIUM-BEARING TYPE 316

STAINLESS STEELS -- C. A. Wang and B. A. Chin (Auburn University), and

M. L. Grossbeck (Oak Ridge National Laboratory) $\ldots \ldots \ldots \ldots \ldots \ldots \ldots \ldots \ldots \ldots$

Experiments have shown that Type 316 stainless steel is susceptible to heat-affectedzone (HAZ) cracking upon cooling when welded using the gas tungsten arc (GTA) process under lateral constraint. The cracking has been hypothesized to be caused by stress-assisted helium bubble growth and rupture at grain boundaries. This study utilized an experimental welding setup, which enabled different compressive stresses to be applied to the plates during welding. Autogeneous GTA welds were produced in Type 316 stainless steel doped with 256 appm helium. The application of a compressive stress, $55 \mathrm{MPa}$, during welding suppressed the previously observed catastrophic cracking. Detailed examinations conducted after welding showed a dranatic change in helium bubble morphology. Grain boundary bubble growth along directions parallel to the weld was suppressed. The results suggest that stressmodified welding techniques may be used to suppress or eliminate helium-induced cracking during joining of iradiated matterials.

\subsubsection{RELATIONSHIP BETWEEN SWELLING AND IRRADIATION CREEP IN COLD} WORKED PCA STAINLESS STEEL TO 178 DPA AT $\sim 400^{\circ} \mathrm{C}$ - - M. B. Toloczko (University of California at Santa Barbaua) and F. A. Ganer (Pacific Northwest Laboratory) ...

At 178 dpa and $\sim 400^{\circ} \mathrm{C}$, the imadiation creep behavior of $20 \%$ cold-worked PCA has become dominated by the creep disappearance phenomenon. The total dianetral deformation rate has reached the limiting value of $0.33 \% / \mathrm{dpa}$ at the three highest stress levels. The stressenhancement of swelling tends to camoullage the onset of creep disappearance, however.

\subsubsection{DENSITY CHANGES OBSERVED IN PURE MULYBDENUM AND MO-41RE AFTER} IRRADIATION IN FFTF/MO'T'A -. F. A. Gauner and L. R. Greenwood (Pacific Northwest

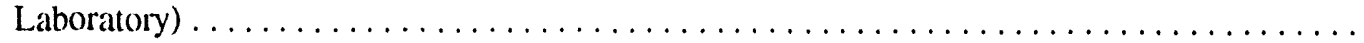

Pure molybdenum and $\mathrm{Mo}-41 \mathrm{wt} \% \mathrm{Re}$, in both the 20\% cold-worked and aged and the annealed and aged conditions, were irradiated in FFTF/Mota to exposures as high as 111 dpa. Pure molybulenum appears to approach a saturation swelling level that is independent of the starting state. Cold-worked and aged molybdenum initially swells at a higher rate than that of solution-annealed and aged molybdenum and overshoots the saturation level at lower irradiation temperatures. This requires that part of the accumulated swelling be removed to approach saturation, probably by void shrinkage. The alloy Mo-41Re exhibits a more complex behavior with the annealed and aged condition initially swelling faster, but eventually the density change of both conditions begins to turn downward and tends toward densification. The role of solid transmutation to $\mathrm{Tc}, \mathrm{Re}$, and $\mathrm{Os}$ is thought to be very 
important in the irradiation behavior of these two metals. Calculations of transmutant generation are provided for FFTF, HFIR and STARFIRE spectra.

\subsubsection{IRRADIATION CREEP OF RUSSIAN HEDERATION PRESSURIZED TUBES IN MOTA-} 2B -- F. A. Garner (Pacific Nortlwest Laboratory), C. R. Eiholzer (Westinghouse Hanford Company), E. V. Demina and L. I. Ivanov (Biukov Institute) $\ldots \ldots \ldots \ldots \ldots \ldots \ldots \ldots \ldots$

Irradiation has been completed in MOTA-2B for creep lubes constructed from a candidate reduced activation austenitic alloy supplied by the Baikov Institute in Moscow. The total strains are strongly dependent on irradiation temperature in the range $425-600^{\circ} \mathrm{C}$, but are not completely linear with stress level.

\subsubsection{DENSITY MEASUREMEN'TS PERIFORMED ON ISPRA SECOND GENERATION AMCR} ALLOYS IRRADIATED IN MOTA-2A -- F. A. Garner (Pacific Northwest Laboratory), P. Schiller (Ispra Establishment), and H. Takahashi (Hokkaido University) .

Density change measurements have been completed on the Ispra second generation AMCR alloys irradiated in MOTA-2A. The various compositional modifications induce a wide variation of swelling behavior in the range $423-600^{\circ} \mathrm{C}$ at $32-36$ dpa.

\subsubsection{THERMAL STABILITY OF MANGANESE-STABILIZED STAINLESS STEELS--} R. L. Kluch and E. A. Kenik (Oak Ridge National Laboratory) . . . . . . . . . . . . . . . . . . .

Previous work on a series of experimental high-manganese reduced-activation austenitic stainless steels demonstrated that they had improved tensile properties relative to type 316 stainless steel in both the annealed and 20\% cold-worked conditions. Steels were tested with an Fe-20Mn-12Cr-0:25C (in weight percent) base composition, to which various combinations of Ti, W, V, P, and B were added. Tensile tests have now been completed on these steels after thermal aging at $600^{\circ} \mathrm{C}$. Thermal stability varied with composition, but the alloys were as stable or more stable than type 316 stainless steel. The strength of the annealed steels increased slightly after aging $105000 \mathrm{~h}$, while a strength decrease occurred for the cold worked steel. In both conditions, a steel containing a combination of all the alloying elements was most stable and had the best strength after thermal aging $5000 \mathrm{~h}$ at $600^{\circ} \mathrm{C}$. Despite having much higher strength than 316 stainless steel after aging, the ductility of the strongest experimental alloy was still as good as that of 316 stainless steel.

6.2.7 COMPARISON OF MICROSTRUCTURAL EVOLUTION IN REACTOR-IRRADIATED AUSTENITIC STAINLESS STEELS WITH AND WITHOUT SPECTRAL TAILORING -S. Jitsukawa, T. Sawai, K. Shiba, S. Hanada, and A. Hishinuma (Japan Atomic Energy

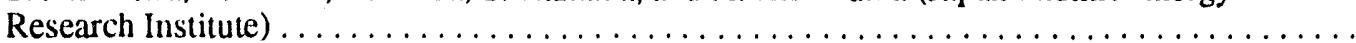

The effects of He/dpa ratio on swelling behavior were examined on three austenitic stainless steels. Materials were solution-annealed JPCA and Iwo low carbon containing alloys ( $\mathrm{C}$ and $\mathrm{K}$ ) modified with titanium and niobium. These steels were neutron-irradiated in ORR and HFIR with and without spectrally tailoring, respectively. Achieved dannage level was 7.4 dpa in ORR irradiation with average He/dpa of about 21 appm/dpa. In case of HFIR irradiation, they were $33 \mathrm{dpa}$ and $76 \mathrm{appm} / \mathrm{dpa}$, respectively. Alloy to alloy variation and temperature dependence of swelling behavior are far more distinctively detected in ORR irradiation than in HFIR irradiation, in spite of the lower damage level of ORR irradiation. In the case of ORR-irradiation, JPCA exhibited small swelling values of $<0.01$ and $0.03 \%$ at 603 and $673 \mathrm{~K}$, respectively, while a low carbon alloy $\mathrm{K}$ showed relatively larger swelling; $0.2 \%$ at $603 \mathrm{~K}$ and $0.6 \%$ at $673 \mathrm{~K}$. Number densities of cavities in HFIR-irradiated alloys were larger than those observed in ORR by one to two orders. On the other hand, number densities and sizes of dislocation loops produced by ORR irradiation were two to five times as large as those by HFIR irradiation. These facts suggest that in ORR condition with closer He/dpa to 
that of fusion, mutual annihilation rate of point defects was reduced and then bias driven cavity growth might the enhanced compared with HFIR condition.

\subsubsection{MICROSTRUCTURES OF A WELDED JOINT USING AN IRRADIATED WRAPPER} TUBE--S. Hamada, K. Watanabe, A. Hishinuma, I. Takahashi and T. Kikuchi (Japan Atomic

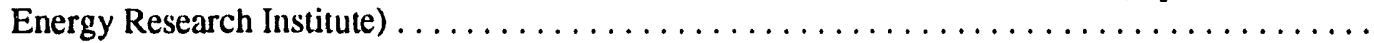

The behavior of helium in welded joint fabricated using tungsten inert gas (TIG) welding process for a type 316 stainless stcel wrapper tube irradiated in a fast reactor was investigated. The wrapper tube was irradiated to $(1.5-4.2) \times 10^{26} \mathrm{n} / \mathrm{m}^{2}$ (helium level of 3 to 9 appm) at $395-410^{\circ} \mathrm{C}$. All welded joints fractured in the heat-affected zone (HAZ). The microstructures of each portion of the base metal, the $\mathrm{HAZ}$ and the fusion zone in a welded joint were examined through a transmission electron microscope. Small helium bubbles were observed in number density of $2 \times 10^{20} \mathrm{~m}^{-3}$ in the matrix and rarely found on the grain boundaries of the base metal. In the HAZ, small and large helium bubbles mixed and lined up along the grain boundaries. In particular, some of them elongated along the grain boundary. In the matrix of the fusion zone, delta-ferrite phases and unresolved carbides were scattered. Large cavities vere attached to these precipitates and also occurred along grain boundaries. These results suggest that the failure in the HAZ of welded joints is attributed to the preferential growth ard coalescence of helium bubbles in the grain boundaries of the HAZ caused by weld heat input and stress during welding.

\subsubsection{DOSE DEPENDENCE OF THE MICROSTRUCTURAL EVOLUTION IN NEUTRON-} IRRADIATED AUSTENITIC STAINLESS STEEL -- S. J. Zinkle, P. J. Maziasz, and R. E Stoller (Oak Ridge National Laboratory) $\ldots \ldots \ldots \ldots \ldots \ldots \ldots \ldots \ldots \ldots$

Microstructural data on the evolution of the dislocation loop, cavity, and precipitate populations in neutron-irradiated austenitic stainless steels are reviewed in order to estimate the displacement damage levels needed to achieve the "steady state" condition. The microstructural data can be conveniently divided into two temperature regimes. In the low temperature regime (below about $300^{\circ} \mathrm{C}$ ) the inicrostructure of austenitic stainless steels is dominated by "black spot" defect clusters and faulted interstitial dislocation loops. The dose needed to approach saturation of the loop and defect cluster densities is generally on the order of 1 displacement per atom (dpa) in this regime. In the high temperature regime $(\sim 300$ to $700^{\circ} \mathrm{C}$ ), cavities, precipitates, loops in excess of 10 dpa are generally required to approach a "steady state" microstructural conditions. Due to complex interactions between the various microstructural components that form during irradiation, a secondary transient regime is typically observed in temperatures. This slowly evolving secondary transient may extend to damage levels in excess of 50 dpa in typical 300-series stainless steels, and to $>100 \mathrm{dpa}$ in radiation-resistant developinental steels. The detailed evolution of any given microstructural component in the high-temperature regime is sensitive to slight variations in numerous experimental variables, including heat-to-heat composition changes and neutron spectrum.

\subsubsection{FRACTURE TOUGHNESS OF IRRADIATED CANDIDATE MATERIALS FOR ITER} FIRST WALL/BLANKET STRUCTURES: PRELIMINARY RESULTS -- D. J. Alexander, J. E. Pawel, M. L. Grossbeck, and A. F. Rowcliffe (Oak Ridge National Laboratory) . . . . . . . .

Candidate materials for first wall/blanket structures in ITER have been irradiated to damage levels of about $3 \mathrm{dpa}$ at temperatures of either 60 or $250^{\circ} \mathrm{C}$. Preliminary results have been obtained for several of these materials irradiated at $60^{\circ} \mathrm{C}$. The results show that irradiation at this temperature reduces the fracture toughness of austenitic stainless steels, but the toughness remains quite high. The unloading compliance technique developed for the subsize disk compact specimens works quite well, particularly for materials with lower toughness. Specimens of materials with very high toughness deform excessively, and this results in experimental difficulties. 


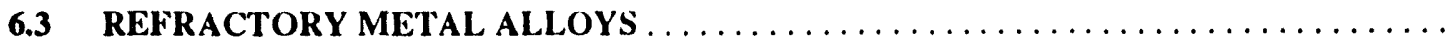

\subsubsection{DENSITY CHANGES INDUCED BY NEUTRON IRRADIATION IN DYNAMICALLY} COMPACTED TUNGSTEN AND PCA -- F. A. Garner (Pacilic Northwest Laboratory) and J. Megusar (Massachusetts Institute of Technology) .........................

Dynamically compacted tungsten with a sturting density of $95.3 \%$ of the theoretical value densified 2 to $3 \%$ when irradiated in FFIF/MOT $\Lambda-2 \Lambda$ at unree temperatures between 423 and $600^{\circ} \mathrm{C}$ and displacement levels corresponding to 32 and $36 \mathrm{dfpa}$ in stainless steel. Rapidly solidified and dynamically compacted PCA with high levels of titanium and carbon were also irradiated at hese conditions. The density changes were small enough to determine that significant swelling had not occurred but, microscopy is necessary to determine whether void growth occurred in addition to precipitate-related strains.

6.3.2 DENSITY CHANGES OBSERVED IN Nb-1Zr AFIER IRRADIATION IN FFTF-MOTA -F. A. Garner (Pacific Northwest Laboratory) . . . . . . . . . . . . . . . . . . . . .

$\mathrm{Nb}-1 \mathrm{Zr}$ has been proposed for polential application to ITER. Whereas previous irradiation studies on $\mathrm{Nb}-1 \mathrm{Zr}$ were focused on the annealed condition, this study involved a comparative irradiation of both the annealed and aged, and the cold-worked and aged conditions. Based on measurements of density change, the cold-worked and aged condition appears to first undergo a phase-related dilation prior to the onset of void swelling, while the annealed condition densified prior to swelling and in some cases does not swell at all.

\subsubsection{ASSESSMENT OF NIOBIUM-BASE ALLOYS FOR STRUCTURAL APPLICATIONS IN} THE ITER DIVERTOR--I. M. Purdy (Argonne National Laboralory) . . . . . . . . . . . . . ... 294

The corrosion and embrillement of pure $\mathrm{Nb}, \mathrm{Nb}-1 \mathrm{Zr}, \mathrm{Nb}-5 \mathrm{Mo}-1 \mathrm{Zr}$, and $\mathrm{Nb}-5 \mathrm{~V}-1.25 \mathrm{Zr}$ (alloy elements in wt.\%) werc evaluated in high-purity (HP) deoxygenated water at $300^{\circ} \mathrm{C}$ for up to 120 days. One heat of the Nb-5V-1.257r alloy ("O" lol) exhibited both a modest corrosion rate and good resistance to embritlement relative to other $\mathrm{Nb}$-base alloys. At present, $\mathrm{Nb}-5 \mathrm{~V}-1.25 \mathrm{Zr}$ is the most promising $\mathrm{Nb}$-base alloy on the basis of both corrosion and embritlement characteristics in IIP deoxygenated water at $300^{\circ} \mathrm{C}$.

\subsubsection{MICROSTRUCTURAL EVOLUTION INDUCED BY BORON TRANSMUTATION IN NEUTRON-IRRADIATED VANADIUM-BASE ALLLOYS--H. M. Chung (Argonne National} Laboratory)

Microstructural evolution associated with transmutation of ${ }^{10} \mathrm{~B}$ to helium and lithium has been characterized to provide a better understanding of the boron-doping technique, frequently used to simulate the effect of helium generation under fusion reactor conditions. Transmission electron microscopy (TEM) was used to examine specimens of V-20Ti alloy after irradiation at $600^{\circ} \mathrm{C} 10 \approx 44-80$ dpa in the Fast Flux Test Facility (FFTF). In the earlier stage of irradiation to low fluence, concentric shells of He-damage and $\mathrm{Li}$-damage zones are produced around a $\mathrm{V}_{3} \mathrm{~B}_{2}$ precipitate or a ${ }^{10} \mathrm{~B}$-rich cluster. On further irradiation, helium atoms diffuse away from the danage shell either to be dissolved in the matrix or to form microcavities, leaving a shell rich in $\mathrm{Li}$, defect clusters, and dislocations. Oxygen atoms in solid solution migrate toward the Li-rich shells, and $\gamma-\mathrm{LiV}_{2} \mathrm{O}_{5}$ shells precipitate subsequently. In view of this behavior, neither boron nor $\mathrm{Li}$ produced from the transmutation is likely to result in a detrimental weakening of grain boundaries. 
6.3.5 STATUS OF THE DYNAMIC IIELIUM CHARGING EXPERIMENT (DIICE)--H. Tsai, H. M. Chung, B. A. Loomis, D. L. Smith (Argonne National Laboratory), H. Matsui (Tohoku University), M. L. Hamilton, L. R. Greenwood, and R. Ermi (Pacitic Northwest Laboratory) . . 306

Irradiation of the seven DHCE capsules was completed in the Materials Open Test Assembly (MOTA)-2B at the end of Cycle 12B in the Fast Flux Test Facility (FFTF). The accrued exposure was 203.3. effective full-power days (EFPDs), vis-a-vis the target exposure of 300 EFPDs. Peak damage in the samples was $\approx 29$ displacement per atom (dpa). All seven capsules have been discharged from the IFTF and are being shipped to Argonne National Laboratory (ANL), where the samples will be retrieved from the capsules and distributed to the experimenters, including Monbusho of Japan, for examination and testing. A substantial effort is underway at ANL to retrieve the samples from the highly tritiated capsules.

6.3.6 THERMAL CREEP BEHAVIOR OF V-5CR-5TI AND V-1OCR-5TI ALLOYS -H. M. Chung, B. A. Loomis, L. J. Nowicki, and D. L. Smith (Argonne National Laboratory) .. .

The thermal creep rates and stress-rupture life of $\mathrm{V}-5 \mathrm{Cr}-5 \mathrm{Ti}$ and $\mathrm{V}-10 \mathrm{Cr}-5 \mathrm{Ti}$ alloys were determined at $600^{\circ} \mathrm{C}$ and the impurity composition and microstructural characteristics of creep-tested specimens were analyzed and correlated with the measured creep properties. The results of these lests show that $\mathrm{V}-5 \mathrm{C}-\mathrm{r}-5 \mathrm{Ti}$, which contains imputity compositions typical of a commercial vanadium-base alloy, exhibits creep strenglh substantially superior to that of $\mathrm{V}$ 20'Ti, HT-9, or Type 316 stainless stecl. The V-10Cr-5'li alloy exhibits creep strength somewhat higher than that of V-5C.t-5Ti.

\subsubsection{DUC'TILE-BRITTLE TRANSITION TTMPIRA'TURES OF UNIRRADIATED}

VANADIUM ALLOYS, BASED ON C.IIARPY-IMPACT TESTING--B. A. Loomis, L. J. Nowicki, J. Gazda, and D. L. Smilh (Argomne National Laboratory) . . . . . . . . . . . .

Ductile-britte transition temperatures (DBTTs) were determined by Charpy-impact tests for dehydrogenated and hydrogenated $\mathrm{V}-3 \mathrm{Ti}, \mathrm{V}-5 \mathrm{Cr}-3 \mathrm{Ti}$, and $\mathrm{V}-5 \mathrm{Cr}-5 \mathrm{Ti}$ alloys. These DBTT data complement the data previously obtained by Loomis et al. on Charpy-impact testing of unalloyed V, V-1Ti, V-3Ti-1Si, V-5Ti, V-10'li, V-18Ti, V-4Cr-4Ti, V-8Cr-6Ti, V9Cr-5Ti, V-10Cr-9Ti, V-14Cr-5Ti, V-15Cr-5Ti, V-7Cr-15Ti, and Vanstar-7 alloys. The results show that $V$ alloys with Ti additions $(0-18 \mathrm{wt} . \%)$ have a minimum DB'T $\left(\approx-250^{\circ} \mathrm{C}\right)$ in an alloy containing 3-5 wt.\% $\mathrm{Ti}$, Wat addition of 4 to $1.5 \mathrm{wt} . \% \mathrm{Cr}$ to $\mathrm{V}-(4-6) \mathrm{Ti}$ alloy results in a substantial increase $\left(25-215^{\circ} \mathrm{C}\right.$ ) of the $\mathrm{DB}^{\prime} \mathrm{I}^{\mathrm{Y}}$, and that 0.5 and $1.0 \mathrm{wt} . \% \mathrm{Si}$ additions to $\mathrm{V}$ 3 Ti alloy result in a significant increase $\left(\approx 100^{\circ} \mathrm{C}\right.$ ) in DBIT. In addition, the results show that the presence of 400-1200 appm II in unalloyed $V$ and $V$-base alloys causes a significant increase $\left(\approx 400\right.$ ppon $0, \approx 200$ ppin $C^{\prime}$, and $\approx 900 \mathrm{ppm}$ Si for use as structural material in a fusion reactor.

6.4 COPPER ALLOYS

6.4.1 STATUS OF FATIGUE STUDIES ON IRRADIATLD COPPER ALLOYS -- F. A. Ganer and M. L. Haunilton (Pacilic Northwest Laboratory), J. F. Stubbins and A. Singhal (University of

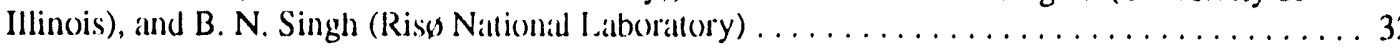

Irradiation continues in the EBR-II and DR-3 reactors of pure copper and GlidCop CuAl25 in the form of subsize lensile latigue specinens. The first phase of the EBR-II irradiation sequence has been completed. A size elfects experiment conducted on unirradiated CuA125 fatigue specinens is nearing completion. Early results on the fatigue behavior of subsize specimens are presented in this report. 
6.4.2 The Response of Dispersion-Strengthened Copper Alloys to High Fluence Neutron Irradiation at $415^{\circ} \mathrm{C}$-- D. J. Edwards, J. W. Newkirk (Univ. of MO-Rolla), F. A. Garner, M. L. Hamilton (Pacific Northwest Laboratory), A. Nadkauni, and P. Samal (SCM Melal Products) . . . . . . . 331

Various oxide-dispersion-strengthened copper alloys have been irradiated to $150 \mathrm{dpa}$ at $415^{\circ} \mathrm{C}$ in the Fast Flux Test Facility (FFTF). The $\mathrm{Al}_{2} \mathrm{O}_{3}$-strengthened GlideCop ${ }^{\mathrm{TM}}$ alloys, followed closely by a $\mathrm{HfO}_{2}$-strengthened alloy, displayed the best swelling resistance, electrical conductivity, and tensile properties. The conductivity of the $\mathrm{H}_{2}$-strengthened alloy reached a plateau at the higher levels of irradiation, instead of exhibiting the steady decrease in conductivity observed in the other alloys. $A$ high initial oxygen content resulted in significantly higher swelling for a series of castable oxide-dispersion-strengthened alloys, while a $\mathrm{Cr}_{2} \mathrm{O}_{3}$-strenguhened alloy showed poor resistance to radiation.

\subsubsection{NEUTRON-INDUCED SWELLING OBSERVED IN COPPIER ALLOYS IRRADIATED IN} MOTA's 2A AND 2B -. F. A. Gauner (Pacific Northwest Laboratory), D. J. Edwards (University of Missouri-Rolla), B. N. Singh (Risø Nattional Laboratory), and H. Watanabe

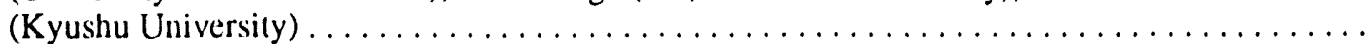

Density measurements have been completed on copper alloys irradiated in MOTA 2A and MOTA $2 \mathrm{~B}$ at $\left(375^{\circ} \mathrm{C}, 12.7 \mathrm{dpa}\right.$ and $\left.21.2 \mathrm{Jpa}\right)$ and $\left(423^{\circ} \mathrm{C}, 48.0\right.$ and $\left.95.4 \mathrm{dpa}\right)$. While most of the density changes observed are consistent with those of earlier studies, there were several surprises. Addition of $5 \% \mathrm{Ni}$ appears to accelerate the swelling rate initially at $423^{\circ} \mathrm{C}$ but depresse: swelling at $375^{\circ} \mathrm{C}$. The suppressing action of cold work on swelling of $\mathrm{Cu}-5 \mathrm{Ni}$ is relatively small, and Cu-5Mn resists swelling very strongly in both the annealed and coldworked conditions.

6.4.4 IRRADIATION OF COPPER ALLOYS IN THE SM-3 REACTOR--S. J. Zinkle (Oak Ridge National Laboratory), F. A. Garner (PNI), V. R. Barabash (D.V. Efremov), S. A. Fabritsiev

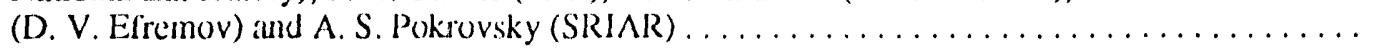

A total of 74 alloys of varying composition and thermomechanical condition have been prepared for a joint US-Russia irradiation experiment in the SM-3 reactor in Dimitrovgrad, Russi?. The alloys will be irradiated in the form of TEM disks and sheet tensile specimens at temperatures of about 120,250 , and $340^{\circ} \mathrm{C}$ for one 45 -day cycle in the core and Channel 2 irradiation positions. This will produce dannage levels of about 7 and $1 \mathrm{dpa}$, respectively. Cadmium shielding will be used in the Channel 2 position to shield the thermal neutrons and thereby reduce the anount of solid transmutation products in copper.

\subsubsection{EFFECT OF ION IRRADIATION ON THE STRUCTURAL STABILITY OF} DISPERSION-STRENGTHENED COPPER ALLOYS -- S. J. Zinkle (Oak Ridge National Laboratory), E. V. Nesterova, and V. V. Rybin (Central Reseruch Institute for Structural Materials), and V. R. Barabash and A. V. Naberenkov (D. V. Efremov Scientific Research

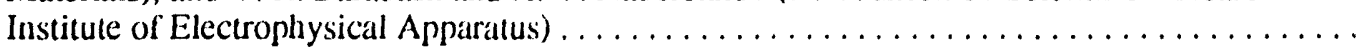

Transmission electron microscopy was used to compare the microstructure and particle distributions of two commercial oxide dispersion-strengthened copper alloys, GlidCop Al25 and MAGT 0.2. Measurements were made on specimens in their as-wrought condition, after thermal annealing for $1 \mathrm{~h}$ at $900^{\circ} \mathrm{C}$, and after $3 \mathrm{MeV} \mathrm{Ar}^{+}$ion irradiation at 180 and $350^{\circ} \mathrm{C}$ to damage levels of 20 to 30 displacements per atom (DPA). All of the annealed and ionirradiated specimens were found to be resistant to recrystallization. In addition, void formation was not observed in any of the irradiated specimens. The GlidCop oxide particle geometry was transformed from triangular platelets to circular disks by the ion irradiation. The MAGT particle geometry consisted of circular disks and spheres before and after irradiation. The oxide particle edge length int he unirradiated GlidCop alloy was about $10 \mathrm{~nm}$, whereas the mean particle dianneler in both the MAGI and GlidCop alloys was about $6 \mathrm{~nm}$. 
6.4.2 The Response of Dispersion-Strengthened Copper Alloys to High Fluence Neutron Irradiation at $415^{\circ} \mathrm{C}$-- D. J. Edwards, J. W. Newkirk (Univ. of MO-Rolla), F. A. Garner, M. L. Hamilton (Pacific Northwest Laboratory), A. Nadkarni, and P. Sanal (SCM Metal Products) . . . . . . . . .

Various oxide-dispersion-strengthened copper alloys have been irradiated to $150 \mathrm{dpa}$ at $415^{\circ} \mathrm{C}$ in the Fast Flux Test Facility (FFIF). The $\mathrm{Al}_{2} \mathrm{O}_{3}$-strengthened GlideCop ${ }^{\mathrm{T} M}$ alloys, followed closely by a $\mathrm{HfO}_{2}$-strengthened alloy, displayed the best swelling resistance, electrical conductivity, and tensile properties. The conductivity of the $\mathrm{HFO}_{2}$-strengthened alloy reached a plateau at the higher levels of irradiation, instead of exhibiting the steady decrease in conductivity observed in the oher alloys. A high initial oxygen content resulted in significantly higher swelling for a series of castable oxide-dispersion-strengthened alloys, while a $\mathrm{Cr}_{2} \mathrm{O}_{3}$-strengthened alloy showed poor resistance to radiation.

\subsubsection{NEUTRON-INDUCED SWELLING OBSERVED IN COPPER ALLOYS IRRADIATED IN} MOTA's 2A AND 2B -- F. A. Garner (Pacific Northwest Laboratory), D. J. Edwards (University of Missouri-Rolla), B. N. Singh (Risø) National Laboratory), and H. Watanabe

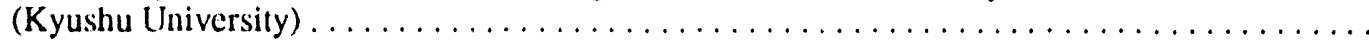

Density measurements have been completed on copper alloys irradiated in MOTA $2 \mathrm{~A}$ and MOTA $2 \mathrm{~B}$ at $\left(375^{\circ} \mathrm{C}, 12.7 \mathrm{dpa}\right.$ and $\left.21.2 \mathrm{dpa}\right)$ and $\left(423^{\circ} \mathrm{C}, 48.0\right.$ and $\left.95.4 \mathrm{dpa}\right)$. While most of the density changes observed are consistent with those of earlier studies, there were several surprises. Addition of $5 \% \mathrm{Ni}$ appears to accelerate the swelling rate initially at $423^{\circ} \mathrm{C}$, but depresses swelling at $375^{\circ} \mathrm{C}$. The suppressing action of cold work on swelling of $\mathrm{Cu}-5 \mathrm{Ni}$ is relatively small, and $\mathrm{Cu}-5 \mathrm{Mn}$ resists swelling very strongly in both the annealed and coldworked conditions.

6.4.4 IRRADIATION OF COPPER ALLOYS IN THE SM-3 REAC TOR--S. J. Zinkle (Oak Ridge National Laboratory), F. A. Garner (PNL), V. R. Barabash (D.V. Efremov), S. A. Fabritsiev (D. V. Efremov) and A. S. Pokrovsky (SRIAR) ............................

A total of 74 alloys of varying composition and thermomechanical condition have been prepared for a joint US-Russia irradiation experiment in the SM-3 reactor in Dimitrovgrad, Russia. The alloys will be irradiated in the form of TEM disks and sheet tensile specimens at temperatures of about 120,250 , and $340^{\circ} \mathrm{C}$. for one 45 -day cycle in the core and Channel 2 irradiation positions. This will produce damage leve!s of about 7 and 1 dpa, respectively. Cadmium shielding will be used in the Channel 2 position to shield the thermal neutrons and thereby reduce the anount of solid transmutation products in copper.

\subsubsection{EFFECT OF ION IRRADIATION ON TIIE STRUCTURAL STABILITYY OF} DISPERSION-STRENGTHENED COPIPER ALLOYS -- S. J. Zinkle (Oak Ridge National Laboratory), E. V. Nesterovat, and V. V. Rybin (Central Research Institute for Structural Materials), and V. R. Barabash and A. V. Naberenkov (D. V. Efremov Scientific Research

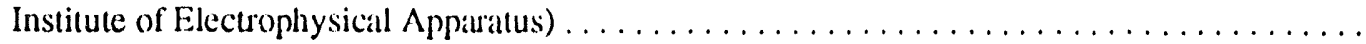

Transmission electron microscopy was used to compare the microstructure and particle distributions of two commercial oxide dispersion-strengthened copper alloys, GlidCop Al25 and MAGT 0.2. Measurements were made on specimens in their as-wrought condition, after thermal annealing for $1 \mathrm{~h}$ at $900^{\circ} \mathrm{C}$, and after $3 \mathrm{MeV} \mathrm{Ar}^{+}$ion irradiation at 180 and $350^{\circ} \mathrm{C}$ to damage levels of 20 to 30 displacements per atom (DPA). All of the annealed and ionirradiated specimens were found to be resistant to recrystallization. In addition, void formation was not observed in any of the irradiated specimens. The GlidCop oxide particle geometry was transformed from triangular platelets to circular disks by the ion irradiation. The MAGT particle geometry consisted of circular disks and spheres before and after irradiation. The oxide particle edge length int he unirradiated CilidCop alloy was about 10 


\subsubsection{MASS TRANSFER IN LITHIUM/STAINLESS STEEL TEST LOOP-.P. R. Luebbers and} O. K. Chopra (Argonne Nationad Laboratory) . ..........................

The plugged pipe removed from the cold-trap purification loop of the forcedcirculation lithium system was examined to study mass transfer/deposition behavior and to establish the cause of plugging. Several intermetallic compounds were identified in residue collected from the plugged cold-trap pipe. Plugging was caused by deposition of calcium/zinc/nickel crystals in the pipe sections within the pump coil and flow-meter magnet. Addition of calcium as a getter to reduce the concentration of nitrogen in the lithium leads to formation of $(\mathrm{Ca}, \mathrm{Zn}) \mathrm{Ni}_{5}$ crystals and subsequent plugging of the cold-taap loop. Deposits of manganese/iron/nickel globules and manganese/zinc/nickel dendrites, as well as $\mathrm{Li}_{9} \mathrm{CrN}_{5}$ and possibly $\mathrm{Ca}_{3} \mathrm{~N}_{2}$, were also identilied in the residue. These phases may have reduced flow through the cold-trap loop but were not abundant enough to plug the loop. The results indicate that the use of a dissolved getter, such as calcium, to reduce nitrogen content in an austenitic stainless steel loop may not be effective. Elements in the lithium from structural alloys (e.g., due to corrosion) and those added (e.g., calcium) to reduce the concentration of nonmetallic impurities (e.g., nitrogen) play an important role in the mass transfer/deposition behavior in circulating lithium systems.

\subsubsection{COMPATIBILI'TY OF CANDIDATIE STRUCTURAL MA'IERIALS WITH STATIC} GALLIUM--P. R Luebbers, W. F. Michaud, and O. K. Chopra (Argonne National Laboratory) . 370

Scoping tests were conducted on compatibility of gallium with candidate structural materials, e.g., Type $316 \mathrm{SS}$, Inconel 62.5, and Nb-5 Mo-1 Zr alloy, as well as Arnco iron, Nickel 270, and pure chromium. Type 316 stainless steel is least resistant and Nb-5 Mo-1 Zr alloy is most resistant to corrosion in static gallium. At $400^{\circ} \mathrm{C}$, corrosion rates are $\approx 4.0,0.5$, and $0.03 \mathrm{~mm} / \mathrm{y}$ for Type $316 \mathrm{SS}$, Inconel 625 , and $\mathrm{Nb}-5 \mathrm{Mo}-1 \mathrm{Zr}$ alloy, respectively. The pure metals react rapidly with gallium. In contrast to tindings in earlier studies, pure iron shows greater corrosion than dexs nickel. The corrosion rates at $400^{\circ} \mathrm{C}$ are $\geq 90$ and $17 \mathrm{~mm} / \mathrm{y}$, respectively, for Armco iron and Nickel 270. The results indicate that at temperatures up to $400^{\circ} \mathrm{C}$, corrosion occurs primarily by dissolution accompanied by formation of metal/gallium intermetallic compounds.

\subsubsection{AQUEOUS STRESS CORROSION OF CANDIDATE AUSTENITIC STEELS FOR ITER} STRUCTURAL APPLICATIONS--W. K. Soppet, D. M. French, and T. F. Kassner (Argonne

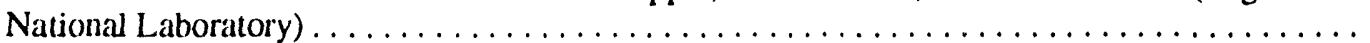

Susceptibility of crevice-weldment specimens of Types $316 \mathrm{~L}$ and $316 \mathrm{NG}$ stainless steel (SS) to SCC was investigated in slow-strain-rate-tensile (SSRT) tests in water that simulates important parameters anticipated in tirst-wall/blanket systems. The SSRT tests were performed in oxygenated water containing 0.06-10 ppm chloride at temperatures of 95 to $225^{\circ} \mathrm{C}$ to establish the effects of water purity and temperature on SCC resistance. These steels, including weldments, exhibit good resistance to SCC under crevice conditions at temperatures of $<150^{\circ} \mathrm{C}$ in water containing $\leq 0.1 \mathrm{ppm}$ chloride. It appears that Type 316NG SS is somewhat more resistant to SCC than Type $316 \mathrm{~L} \mathrm{SS}$ at temperatures $>150^{\circ} \mathrm{C}$ in oxygenated water containing 0.1-10 ppin chloride. Most specimens fractured in the base metal, and several others fractured in the heat-affected zone (HAZ) of the weld, but non failed in the weld metal. 
6.5.4 FORMATION OF ELECTRICALLY INSULATING COATINGS ON ALUMINIDED VANADIUM--BASE ALLOYS IN LIQUID LITHIIUM--J.-H. Park and G. Dragel (Argonne

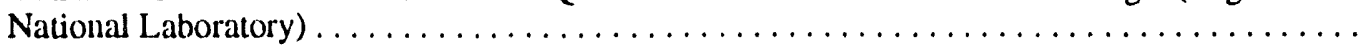

Aluminide coatings were produced on vanadium and vanadium-base alloys by exposure of the materials to liquid lithium that contained 3-5 at.\% dissolved aluminum in sealed capsules at temperatures between 775 and $880^{\circ} \mathrm{C}$. Reaction of the aluminide layer with dissolved nitrogen in liquid lithium provides a means of developing an in-situ electrical insulator coating on the surface of the alloys. The electrical resistivity of A1N coatings on aluminided $\mathrm{V}$ and $\mathrm{V}-20 \mathrm{wt}$.\% Ti was determined in-situ.

6.5.5 CORROSION FATIGUE OF CANDIDATE AUSTENITIC S'IEELS FOR ITER STRUCTURAL APPLICATIONS.-W. E. Ruther and T. F. Kassner (Argonne National Laboratory)

Crack-growuh-rate (CGR) lests were performed on 1-in.-thick (1'T) compact-tension (CT) specimens of Types $316 \mathrm{NG}$ and $316 \mathrm{~L}$ stainless steel (SS) in oxygenated water containing $0-5 \mathrm{ppm} \mathrm{C1}{ }^{-}$at 150,185 , and $225^{\circ} \mathrm{C}$. The results obtained under cyclic loading conditions at stress intensity factors of $\approx 27$ to $39 \mathrm{MPa} \cdot \mathrm{m}^{1 / 2}$ indicate that environmental enhancement of the rates increases with $\mathrm{C}^{-}$concentrations $>0.1 \mathrm{ppm}$ at $150^{\circ} \mathrm{C}$ in comparison with calculated rates in air under the specilic loading conditions. In contrast, at the higher temperatures the CGRs were not affected by $\mathrm{C.}^{-}$in oxygenated water but were greater than the predicted rates in air by one order of magnitude.

\subsubsection{DEVELOPMENT OF ALUMINIDE COATINGS ON VANADIUM-BASE ALLOYS IN} LIQUID LITHIUM--J.-H. Pauk and G. Dragel (Argomme National Lahoratory)

Aluminide coatings were produced on vanadium and vanadium-base alloys by exposure of the materials to liquid lithium that contained 3-5 at.\% dissolved aluminum in sealed V and V-20 wt.\% Ti capsules at temperatures between 775 and $880^{\circ} \mathrm{C}$. After each test, the capsules were opened and the samples were exiunined by oplical microscopy and scanning electron microscopy (SEM), and analyzed by electron-energy-dispersive spectroscopy (EDS) and $\mathrm{X}$-ray diffraction. Hardness of the coating layers and bulk alloys was determined by microindentation techniques. The nature of the coatings, i.e., surface coverage, thickness, and composition, varied with exposure time and temperature, solute concentration in lithium, and alloy composition. Solute elements that yielded adherent coatings on various substrates can provide a means of develoning in-situ electrical insulator coatings by reaction of the reactive layers with dissolved nitrogen in liquid lithium.

7.0 SOLID BREEDING MATERIALS AND BERYLLIUM

No contributions.

8.0 CERAMICS

8.1 CERAMICS RADIATION EFIECTSS ISSUIES FOR ITER -- S. J. Zinkle (Oak Ridge National

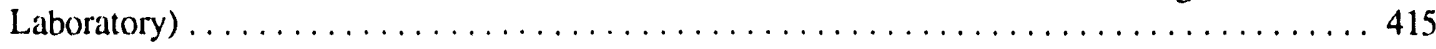

The key radiation effects issues associated with the successful operation of ceramic materials in components of the plamned Intemationad Thermonuclear Experimental Reactor (ITER) are discussed. Radiation-induced volume changes and degradation of the mechanical properties should not be a serious issue for the fluences planned for ITER. On the other hand, radiation-induced electrical degradation effects may severely limit allowable the exposure of 
ceramic insulators. Degradation of the loss angent and thermal conductivity may also restrict the location of some components such as ICRH feedurough insulators to positions far away from the first wall. In-situ measurements suggest that the degradation of physical properties in ceranics during irradiation is greater than that measured in postirradiation tests. Additional in-situ data during neutron irradiation are needed before engineering designs for I'TER can be finalized.

8.2 EFFECT OF IRRADIATION SPECTRUM ON THE MICROSTRUCTURAL EVOLUTION

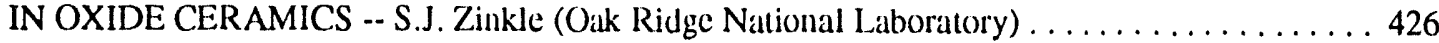

Cross section transmission electron microscopy was utilized to examine the radiationinduced microstructural changes in oxide ceramics after irradiation with a wide variety of ion beams. The microstructure showed a strong dependence on ion mass and energy. The microstructural results have been correlated with the calculated depth-dependent partitioning between ionization and displacement daunage. This correlation indicales that defect clusters do not forn in $\mathrm{MgAl}_{2} \mathrm{O}_{4}$ if the ratio of encrgy deposited into electronic ionization to atomic displacements is greater than about 10. The comresponding ratio needed to suppress defect cluster formation in $\mathrm{MgO}$ and $\mathrm{Al}_{2} \mathrm{O}_{3}$ is 500 to 1000. Additional microstructural evidence obtained on the ion irradiated ceranic specimens suggests that the physical mechanism responsible for the lack of defect clusters in highly ionizing radiation environments is associated with ionization-enhanced diffusion (IED), which promotes annihilation of the point defects created by displacement dunage during the irradiation. The most important parameter for IED is the ratio of ionizing to displacive radiation, since this is roughly proportional to the amount of ionization per upa. Ilowever, the absolute magnitude of the ionizing radiation flux is also important.

8.3 ELECTRICAL CONDUCTIVITY OF CERAMIC INSULATORS DURING EXTENDED ION IRRADIATION WITH AN APPLIED ELEC'TRIC. FIELD--S. J. Zinkle (Oak Ridge National Laboratory) and $W$. Kesternich (Forschungszentum Juelich) $\ldots \ldots \ldots \ldots \ldots \ldots \ldots$

The initial results are presented from a cyclotron ion irradiation program investigating radiation-induced conductivity (RIC) and radiation-induced electrical degradation (RIED) of ceramic insulators. Polycrystalline specimens of $\mathrm{Al}_{2} \mathrm{O}_{3}, \mathrm{MgNl}_{2} \mathrm{O}_{4}, \mathrm{AlN}$ and $\mathrm{Si}_{3} \mathrm{~N}_{4}$ were irradiated with either $28 \mathrm{MeV} \mathrm{He} \mathrm{He}^{++}$or $20 \mathrm{MeV} \mathrm{H}^{+}$ions at temperatures between 150 and $600^{\circ} \mathrm{C}$ with an applied dc electric field of 100 to $500 \mathrm{~V} / \mathrm{mm}$. A large prompt increase in the electrical conductivity was observed in all of the specimens during irradiation. However, there was no evidence for permanent electrical degradation in any of the specimens for damage levels up to about $5 \times 10^{-3}$ displacements per atom.

8.4 IRRADIATION OF $\mathrm{MgAl}_{2} \mathrm{O}_{4}$ SPINEL IN FFTF-MOTA -- F. A. Garner and G. W. Hollenberg (Pacific Nordhwest Laboratory), C. A. Black and R. C. Bradt (University of

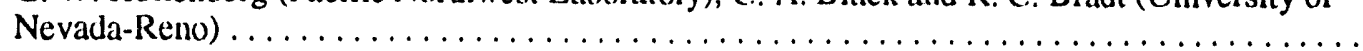

$\mathrm{MgAl}_{2} \mathrm{O}_{4}$ spinel specinens irradiated in FFIF-MOTA at temperatures between 385 and $750^{\circ} \mathrm{C}$ to fluences ranging from $2.21024 .9 \times 10^{22} \mathrm{n} \mathrm{cm}^{-2}(\mathrm{E}>0.1 \mathrm{MeV})$ darken significantly, but do not develop any loss in weight or change in dimensions. Measurements of Knoop hardness and its dependence on crystalline orientation, neutron fluence and irradiation temperature are in progress. Measurements of elastic properties are also nearing completion.

8.5 HIGH-TEMPERATURE PROPERTIES OF SiC/SiC FOR FUSION APPLICATIONS -R. H. Jones and C. H. Henager, Jr. (Pacific Northwest Laboratory) . . . . . . . . . . . . . . .

$\mathrm{Si} / \mathrm{SiC}$ composites exhibit novel mechanical properties relative to their monolithic counterparts. The crack velocity (da/dt) versus stress intensily $(\mathrm{K})$ relationship for monolithic 
ceramics can be described by a simple power law relationship where $\mathrm{SiC} / \mathrm{SiC}$ was found to exhibit a multi-stage da-dt versus $\mathrm{K}$ relationship similar to that for stress corrosion of metals. A K independent stage Il was followed by a strongly $\mathrm{K}$ dependent state III, which paralleled the monolithic behavior. Experiments to determine the threshold $\mathrm{K}$ or stage I were not conducted; however, it is expected that they exist 'ior these materials. There is also evidence that the fracture resistance of these materials is g,reater if cracks are produced by subcritical growth processes relative to machined notches. Oxygen was found to increase $\mathrm{da} / \mathrm{dt}$ and decrease the $\mathrm{K}$ for the stage II to stage III transition while cyclic loads produced little damage at low $\mathrm{K}$ values but there was some evidence for increasing damage with increasing number of cycles and $\mathrm{K}$.

8.6 MEASUREMENT OF DC ELECTRIC.AL CONDUC'TIVITY OF ALUMINA DURING SPALLATION-NEUTRON IRRADIATION -- E. H. Farnum, F. W. Clinard, Jr., J. C. Kennedy, III, W. F. Sommer, and M. D. Dammeyer (Los Alamos National Laboratory) . . .

An irradiation experiment was carried out during the summer of 1992 at the Los Alamos Spallation Radiation Effects Facility (LASREF). In situ measurements of electrical conductivity in alumina, sapphire, and mineral-insulated electrical cables were made at $640^{\circ} \mathrm{C}, 590^{\circ} \mathrm{C}$, and $400^{\circ} \mathrm{C}$. Both $\mathrm{DC}$ and $\mathrm{AC}(100 \mathrm{~Hz} 101 \mathrm{MHz})$ measurements were made to a fluence of approximately $3 \times 10^{23} \mathrm{n} / \mathrm{m}^{2}$. Optical absorption from $300 \mathrm{~nm}$ to $800 \mathrm{~nm}$ was measured in pure silica- and OH-doped silica-core optical fibers during the irradiation. A large number of passive samples were included in the irradiation, some at the furnace temperatures and some at anbient temperature. This report describes preliminary analysis of the DC conductivity measurements. The $\mathrm{AC}$. measurements are analyzed in the companion report.

8.7 MEASUREMENT OF AC ELECTRICAL CONDUCTIVITY OF SINGLE CRYSTAL $\mathrm{Al}_{2} \mathrm{O}_{3}$ DURING SPALLATION-NEU'TRON IRRADIATION .- J. C. Kennedy, III, E H. Farnum, W. F. Sommer, and F. W. Clinard, Jr. (Los Alamos National Laboratory) . . . . . . . . . 465

Samples of single crystal $\mathrm{Al}_{2} \mathrm{O}_{3}$, commonly known as sapphire, and polycrystalline $\mathrm{Al}_{2} \mathrm{O}_{3}$ were irradiated with spallation neutrons at the Los Alamos Spallation Radiation Effects Facility (LASREF) under various temperature conditions and with a continuously applied alternating electric field. This paper describes the results of measurements on the sapphire samples. Neutron fluence and thux values are estimated values pending recovery and analysis of dosimetry packages. The conductivily increased approxinatcly with the square root of the neutron flux at fluences less than $3 \times 10^{19} \mathrm{n} / \mathrm{m}^{2}$ at fluxes less than $1 \times 10^{16} \mathrm{n} / \mathrm{m}^{2}$-sec. Conductivity initially decreased at low fluences with minimums near fluences of $1 \times 10^{20}$ $\mathrm{n} / \mathrm{m}^{2}$. Incubation periods with a gradual increase in conductivity preceded the onset of an accelerated increase in conductivily beginning at lluences as low as $10^{21} \mathrm{n} / \mathrm{m}^{2}$. The increase in conductivity reached salturation levels as high as $2 \times 10^{-2}(\text { ohm-m })^{-1}$ at fluences as low as $2 \times 10^{22} \mathrm{n} / \mathrm{m}^{2}$. Frequency swept inpediunce measurements indicated a change in the electrical properties from capacitive lo resistive bchavior wilh increasing fluence.

8.8 IRRADIATION EFFECTS IN CERAMICS: TRANSITION FROM LOW TO HIGH DOSE BEHAVIOR -- F. W. Clinard, Jr., and E. H. Farnum (Los Alaunos National Laboratory) . . . . . .

Ceranics subjected to irradiation show a wide variety of daunage responses, depending on composition, nature of bonding, crystal stucture, impurity levels, starting microstructure, number of phases, and type of hombarding particle. As doses reach high levels (a condition that varies in magnitude from one material to another) major changes in physical properties can occur, and atomic arrangements may even change from crystalline to disordered. However, some ceramics show marked resistance to danage, and some properties may improve. More work is needed to fully understand these phenomena, but it is currently 
possible in many cases to predict at least qualitatively both microstructural damage response and observed property changes.

\subsection{THE EFFECT OF RADIATION INDUCED ELECTIRICAL CONDUC'TIVITY (RIC) ON} THE THERMAL CONDUCTIVITY OF SAPPIIIRE AT 77K -- D. P. White (Oak Ridge

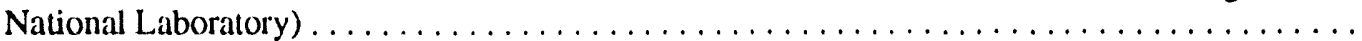

Microwave heating of plasmas in fusion reactors requires the development of microwave windows through which the microwaves can pass without great losses. The degradation of the thermal conductivity of alumina in a radiation environment is an important consideration in reliability studies of these microwave windows. Several recent papers have addressed this question at higher temperatures and at low temperatures. The current paper extends the low temperature calculations to deternine the effect of phonon-electron scattering on the thermal conductivity at $77 \mathrm{~K}$ due $10 \mathrm{RIC}$. These low temperature calculations are of interest because the successful application of high power $(>1 \mathrm{MW})$ windows for electron cyclotron heating systems in fusion reactors will most likely require cryogenic cooling to take advantage of the low loss tangent and higher thermal conductivity of candidate window materials at these temperatures.

\subsection{SURFACE PREPARATION EIFIEC.'IS IN NEAR SURFACI: MODULUS} MEASUREMENT FOR CVD SiC. -- M. Osborne (Rensselaer Polytechnic Institute), L. L. Snead (Oak Ridge National Laboratory), and D. Steiner (Rensselaer Polytechnic Institute)

Surface preparation has an observable effect on the data obtained from the Nanoindenter for shallow $(20 \mathrm{~mm})$ indents on C.VD SiC when polished with Syton TM. This observed effect is significantly less for $1 / 2$ micron dianond polished CVD SiC and for deep $(160 \mathrm{~nm})$ indents. These eflects were inanilested by the relative variations in the experimental modulus and hardness data. An analytical analysis of the anticipaled variation in the modulus and hardness is performed and shown to correlate well with the observed trends. The observed variations appear to be the result of $\mathrm{SiC}$ malterial properties, as well as surface preparation, since the predicted variations are much smaller than the observed variations.

\subsection{MICROMEC.HANICS OF FIBER PULL-OUT AND C.RACK BRIDGING IN SCS-6 SiC-} CVD SiC COMPOSITE SYSTEM AT IIIGII-TEMPERATURE -- A. El-Azab and N. M. Ghoniem (University of Cadifornia, Los Angeles)

A micro mechanical model is developed to study liber pull-out and crack bridging in fiber reinforced $\mathrm{SiC}-\mathrm{SiC}$ composites with time dependent thermal creep. By analyzing the creep data for monolithic CVD SiC (matrix) and the SCS-6 SiC fibers in the temperature range $900-1250^{\circ} \mathrm{C}$, it is found that the matrix creep rates can be ignored in comparison to those of fibers. Two important relationships are oblained: (1) a time dependent relation between the pull-out stress and the relative sliding distance between the fiber and matrix for the purpose of analyzing pull-out experiments, and (2) the relations between the bridging stress and the crack opening displacement to be used in studying the mechanics and stability of matrix crack bridged by fibers at high temperatures. The present analysis can be also applied to Nicalon-reinforced C.VD SiC matrix system since the Nicalon tibers exhibit creep characteristics similar to those of the SC.S-6 fibers. 
1.0 IRRADIATION FACILITIES, TEST MATRICES, AND EXPERIMENTAL METHODS 
DREPARATIOR, OF COBRA IA FOR INSERTION INTO EBR-1I . H. L. Hamilton and R. H. Frmi (Pacific Northwest Laboratory) and C. R. Eiholzer (Westinghouse Hanford Company)

\section{OBJECTIVE}

The purpose of this effort is to document the preparation of the COBRA IA experiment ror irradiation in the Experimental Breeder Reactor II (EBR-II) for irradiation beginning in run 162.

SUMMARY

COBRA IA was built to support the research and development efforts of the U.S. COE Neutron Interactive Materials (NIMS) program and the Japanese university fusion materiais program. COBRA was inserted into the EBR-II for irradiation beginning in run 162 . The specimen loading is documented here.

\section{PROGRESS AND STATUS}

\section{Introduction}

The anticipated shutdown of the Fast Flux Test Facility (FFTF) necessitates a transfer of the Fusion Materials irradiation programs from the FFTF to EBR.II. This requires the development of a MOTA-type vehicle for EBR-[1, i.e., one that is capable of performing instrumented, temperature controlled irradiations in a fast neutron environment. The assembly being developed will be referred to as a Uaterials Instrumented Iest Assembiy, or MITA. Due to the two year lead time required for the development of such a vehicle and the desire to continue accumulating neutron exposure in the interim. another irradiation vehicle that utilizes existing technology is being used in the meantime. it is referred to as a Cold B7A Radiation Assembly, or COBRA. The first irradiation of the first COBRA will be referred to as COBRA $1 \bar{A}$. Reconstituted irradiations of the first COBRA

will increment the letter designation, i.e., IB, IC, etc.. where the "CO" in COBRA will then refer to "cont inuing" irradiations. A new COBRA-type of irradiation vehicle will increment the number designation, i.e., $2 A$.

The U.S. Neutron Interactive Materials (NIMS) program and the Japanese university fusion materials community (funded by the US/Japan Collaborative Program on Fundamental Studies of Irradiation Effects in Fusion Materials Utilizing Fission Reactors) are partners in the MITA and COBRA efforts. The goal of these two programs is to develop improved materials for use in many different components of proposed fusion devices and to facilitate the prediction of their performance limits in a fusion environment. These programs focus on metallic or ceramic specimens for post-irradiation determination of swelling, mechanical properties and microstructure.

\section{COERA Loading}

Experiment Description. COBRA $1 \mathrm{~A}$ is referred to by All. $-W$ as subassembly $X+516$. It comprises seven B7A capsules in a standard B7A assembly. The Pill and WHC identification codes for the seven capsules. A through $G$, correspond to the All -W identificat on codes. 3.338 through B-394.

inree capsules (D, F and $G$ ) are filled with inert gas to provide irradiation at elevated temperatures $(800,500$ and $500^{\circ} \mathrm{C}$ respectively). The remaining four capsules ( $A$. $B, C$ and $E$ ) are weeper capsuies designed to maintain the test specimens at ambient temperature $\left(-400^{\circ} \mathrm{C}\right)$. The capsules are being irradiated in a hexagonal duct with capsule $C$ $(8-390)$ located at the center, as shown in figure 1.

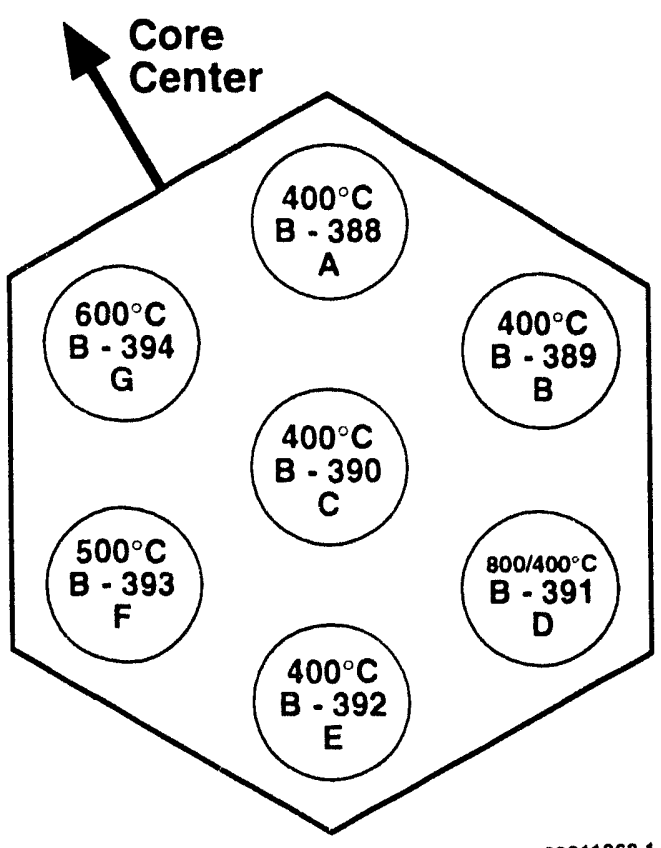

39211068.1

The temperature of the inerted subcapsules is controlled by the size of the gap between the outer wall of the subcapsule and the inner wall of the capsule, as well as
Figure 1. Capsule arrangement in COBRA IA (subassembly $\times 516$ ).

'Pacific Northwest Laboratory is operated for the U.S. Department of Energy by Battelle Memorial institute under Contract DE-ACO6-76RLO 1830. 
the composition of the insulating gas that fills this gap. Direct contact with sodium will maintain the temperature of the specimens in the weeper capsules as close as possible to ambient. Some of the subcapsules in the $800^{\circ} \mathrm{C}$ capsule (D) will be gas gapped in such a way as to achieve a temperature as close as possible to the ambient weeper temperature. Specimens provided by the two partners are being irradiated above and below as well as within the core region. Three capsules (E, $F$ and $G$ ) will be irradiated for about 150 EFPD, while the remaining four (A through D) will be irradiated for approximately twice as long. The B7A capsules were designed, fabricated and assembled by Westinghouse Hanford Company. Standard B7A assembly hardware was supplied by EBR-II.

COBRA $1 A$ will be irradiated in row 2, sector B, position $2 B 1$ in EBR-11. A core mad for run 162 is shown in Figure 2. The estimated nominal flux at reactor midplane in this position is $2.339 \times 10^{.} \mathrm{n} / \mathrm{cm} / \mathrm{sec}(\mathrm{E}>$ $0.111 \mathrm{HeV})$ for run 162 , based on reactor physics calculations. The most recent fiux normalization profile for row 2 was determined in 1978 after run 750. It is shown in Figure 3.

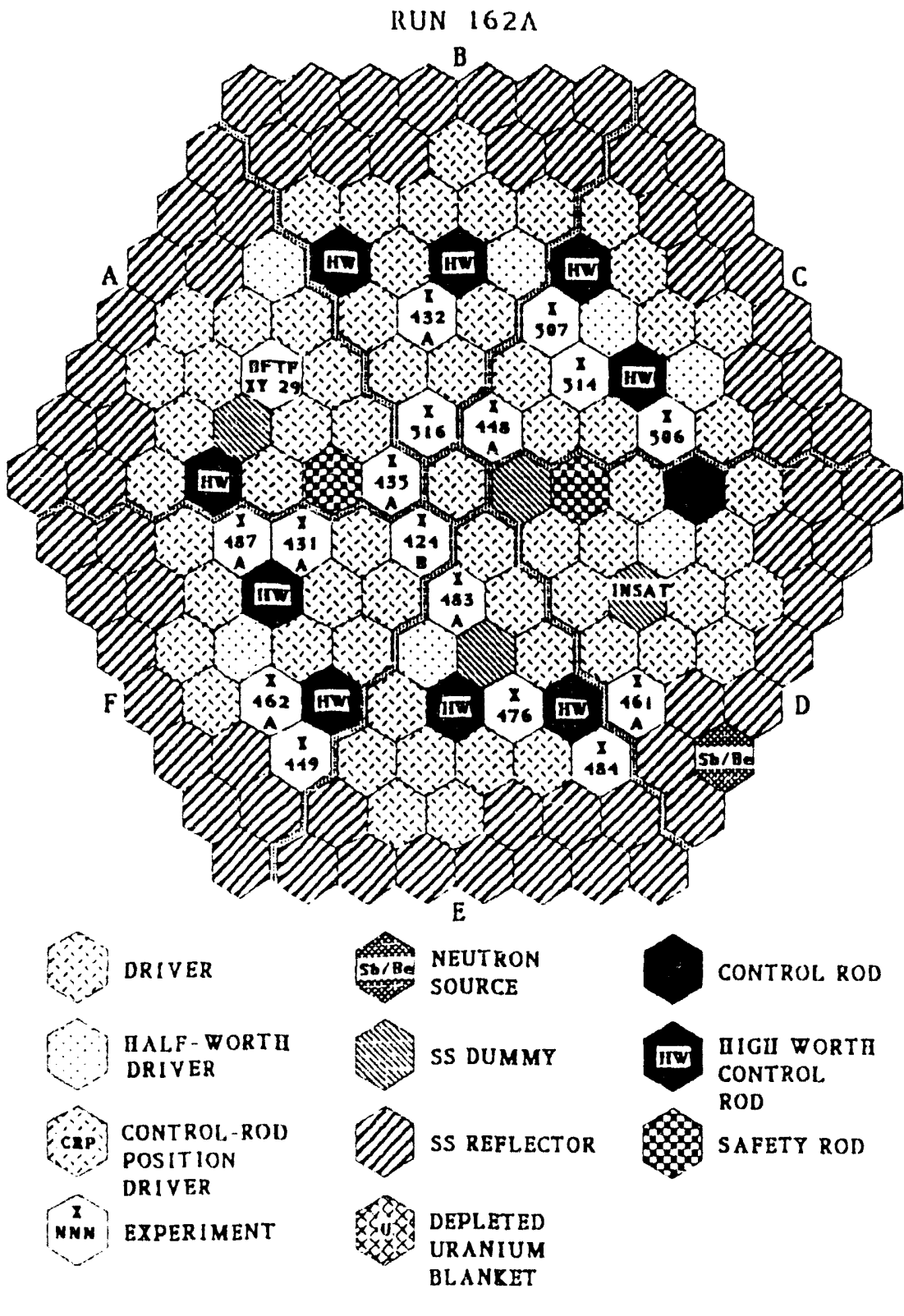




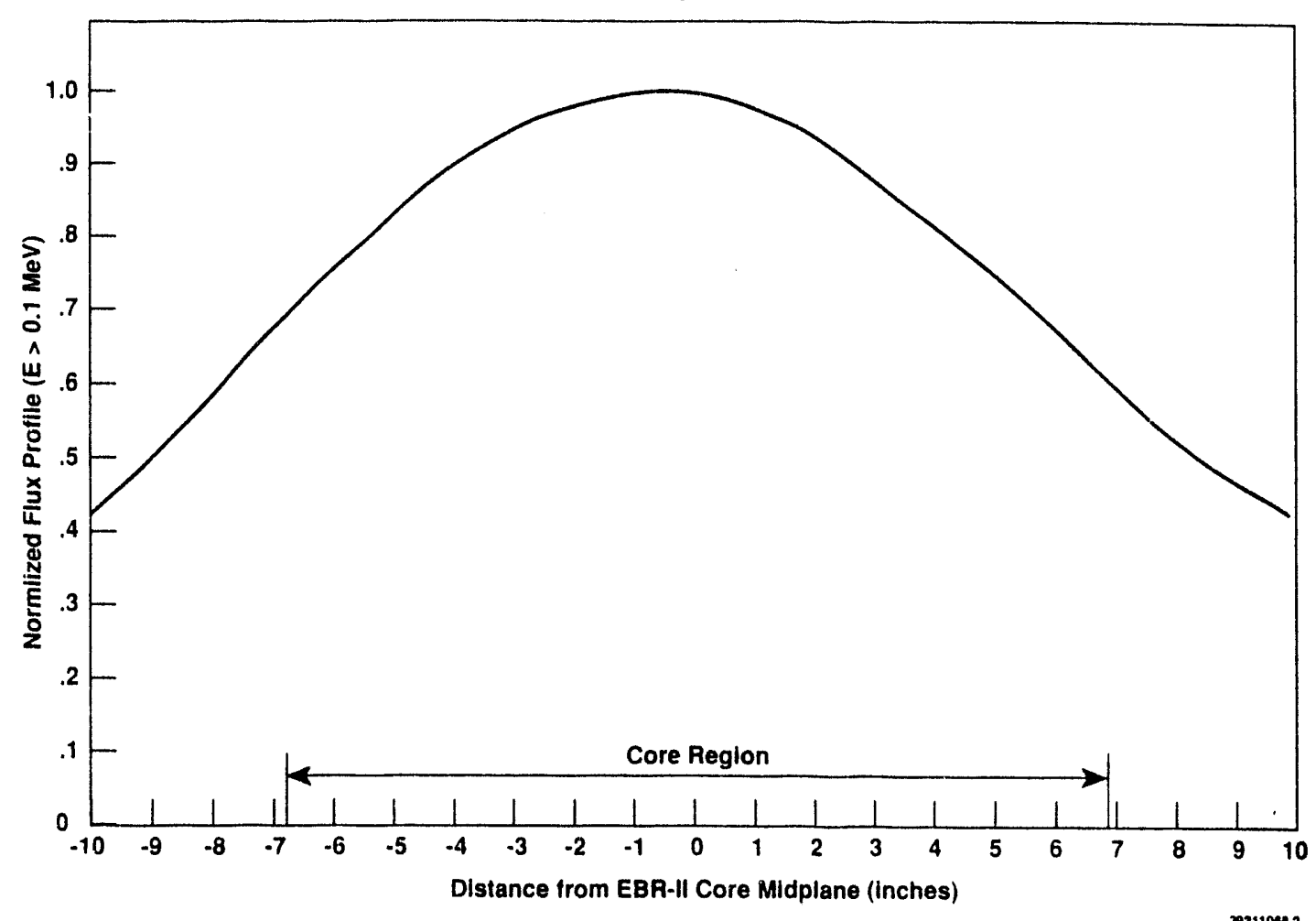

Figure 3. Flux normalization profile for row 2 (from 1978:.

Capsule Allocation. The capsule matrix for COBRA $1 \mathrm{~A}$ is shown in Fiqure 4 as a $5 . \mathrm{r} 5 \mathrm{.}$. of the division of ach capsule into subcapsules or baskets. The codes given in the upper lot corng ach element of the matrix designate the basket or subcapsule identification. The lotters $5, \quad \cdots, \cdots$ lower left corner indicate whether the element refers to a subcapsule or a basket. The number immodat." below the " $\$$ " or " $B$ " is the length of the subcapsule or pasket. The number in parentheses in the "xper moht corner of each element indicates the position of the bottom of the subcapsule or basket. 1.e.. inc 1:ation of the bottom of the specimens, relative to the middle of the core. Eoth dimensions are given in, iras. the units in which the components were specified.

Easkets allow sodium to flow through them and are typically used for irradiation ner aceper conditions. while subcapsules are sealed and are typically used for irradiation under aas gacoes inditions.

subcapsules are also used for specimens to be irradiated under weeper conditions : at annot be allowed to come into contact with the reactor sodium. All baskets and subcapsiles are made $0^{\circ}$ sinless steel except for those subcapsules with a superscripted asterisk next to the " $S$ ": these are "ace $2: 7 M$.

The letters given in the upper right corner of some elements indicate the presenco of asimetry packages (S=spectral set, $G=g r a d i e n t$ wire) or thermal measuring devices (TED = thermal exparsion device. T-MON = rectangular SiC bar used as a thermal monitor). Both types of dosimetry were packades in helium-filled. stainless steel, sealed containers. TEDs are sodium-filled stainless steel or incone: tubes that acquire a Dermarent deformation that corresponds to the maximum temperature to which they are exscied during irradiation. The thermal monitors are extra SiC bars that will be analyzed for therma! exposure.

Specimen Matrix. The objective of the U.S. HIMs program is to develop improved materials for use in fusion devices and predict their performance limits in a fusion environment. The long term effort focuses on aroviding an increased understanding of damage mechanisms through experiment, data analysis and modelling. A short term effort is focussed on meeting the near-term matcrials needs for the Irter-ational Thermonuclear Experimental Reactor (ITER).

The emphasis in the U.S. is primarily on (but is not limited to) alloys for first wall blanket applications. Major areas include 1) supplying high fluence, engineering data for current or potential fusion candidate heats of ferritic steels, 2) exploring reduced activation alloys of several types

(erritic ron-based steels as well as zanadium alloys and SiC/SiC). 3) developing concer alloys 


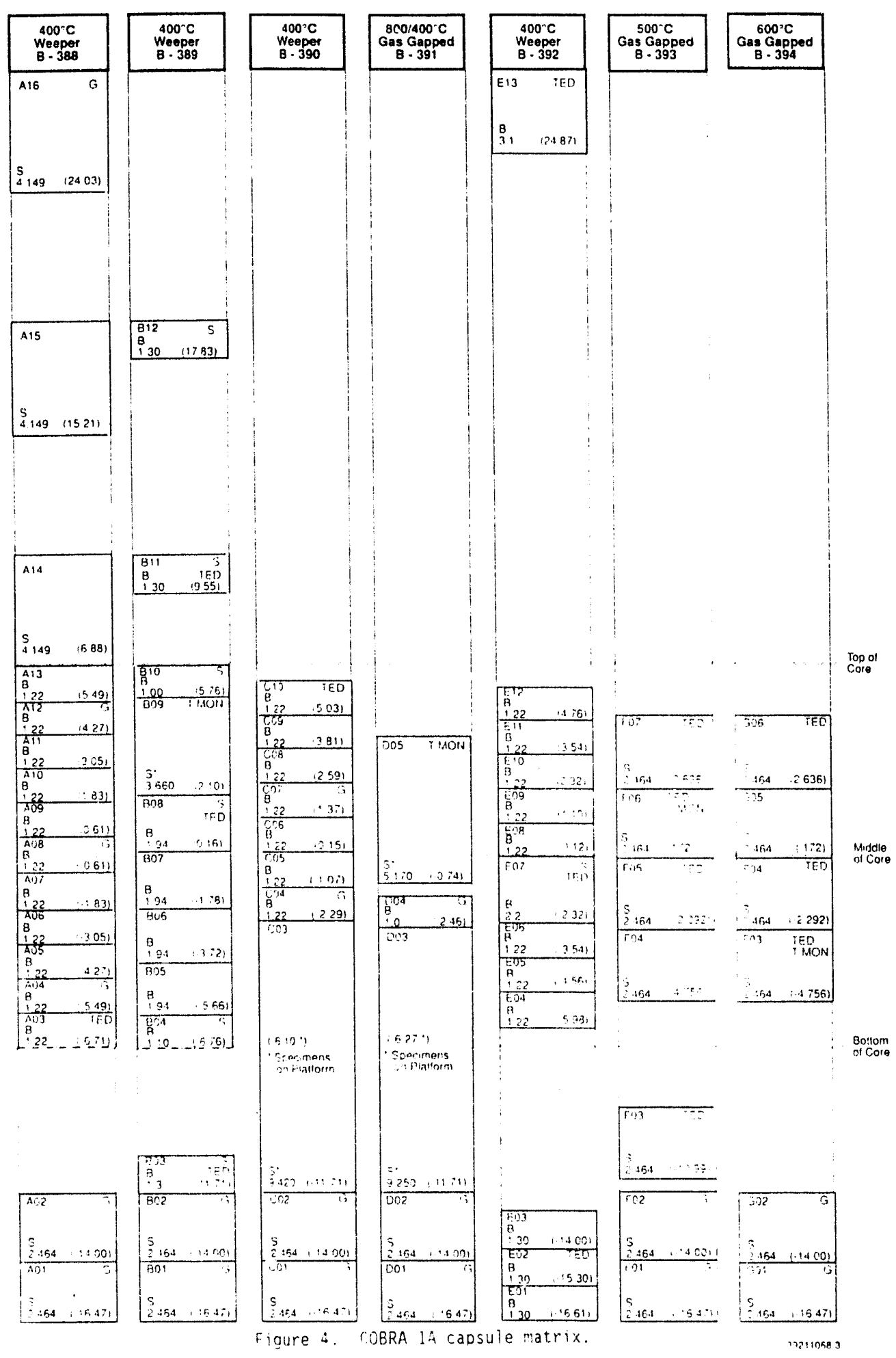


for high heat flux applications and an understanding of their fundamental radiation response, and 4) clarifying the role of helium. Smaller efforts are directed toward the development of berylijum for neutron multiplier or plasma interactive components, and the development of composite materials for high heat flux applications.

The Japanese university program for the development of fusion reactor materials is using the FFTF/MOTA as part of a larger program to attain an understariding of the various radiation responses that control materials' behavior. Specifically, their program is designed 1) to establish correlations between high and low exposure irradiations in fission and fusion neutrons and 2) to determine the mechanisms governing microstructural and microchemical evolution and their relation to property changes in materials.

Six sub-groups have been designated responsible for such efforts in Japan for different classes of materials:

a) Ferrous materials

b) Refractory metals and alloys, high heat flux materials,

c) Pure metals and model alloys for fundamental studies,

d) Isotopic tailoring experiments,

e) Ceramics and composite materials, and

f) Dosimetry.

A summary of the combined U.S. and Japanese specimen matrix is shown in Table 1, arranged by alloy type. The geometries of the U.S. and Japanese specimens are listed in Table 2. Table 1 shows the programmatic affiliation (U.S., Japanese, or collaborative) of each specimen as well as the specimen type and COBRA 1A position. U.S. programmatic affiliations are broken down to show the distribution between laboratories. No collaborative affiliations are shown in this table other than with the US/Japan Collaborative Program on Fundamental Studies of Irradiation Effects in Fusion Materials Utilizing Fission Reactors.

\section{CONCLUSIONS}

The COBRA IA experiment was successfully prepared and inserted into EBR-II for irradiation starting with run 162 .

FUTURE WORK

Planning will continue for the development of both COBRA $1 B$ and MITA. 
Table 1. COBRA IA Specimen Matrix

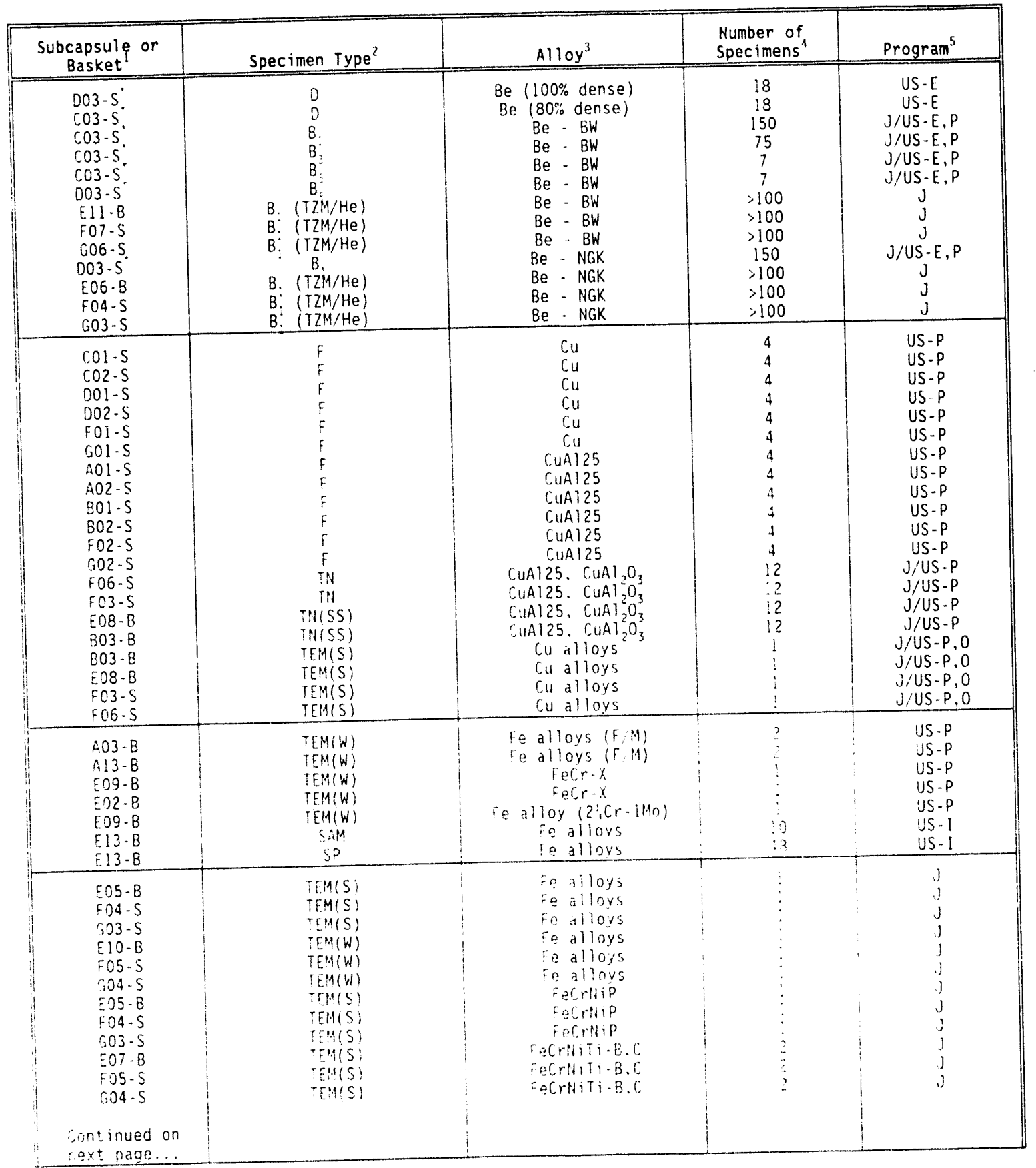


Table 1. COBRA 1A Specimen Matrix

\begin{tabular}{|c|c|c|c|c|}
\hline $\begin{array}{c}\text { Subcapsule or } \\
\text { Basket }\end{array}$ & Specimen Type & Alloy 3 & $\begin{array}{l}\text { Number of } \\
\text { Specimens }\end{array}$ & Program ${ }^{5}$ \\
\hline $\begin{array}{l}\text { cont inued from } \\
\text { previous } \\
\text { rage... }\end{array}$ & & 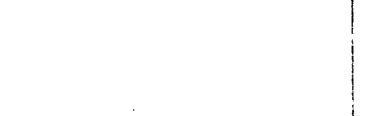 & & \\
\hline $\begin{array}{r}13-B \\
.09-B \\
306-B \\
009-B \\
008-B \\
504-B \\
505-B \\
112-B \\
\end{array}$ & $\begin{array}{l}\text { TEM(W) } \\
T(S S-3) \\
:(S S-3) \\
(S S-3) \\
(S S-3) \\
T(S S-3) \\
:(S S-3) \\
T(S S-3) \\
\end{array}$ & 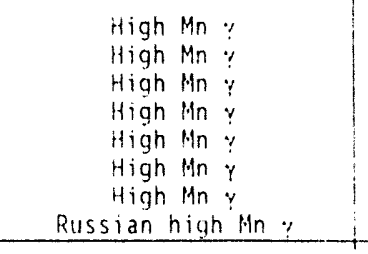 & $\begin{array}{l}1 \\
3 \\
3 \\
\vdots \\
9 \\
6 \\
8 \\
5 \\
5 \\
\end{array}$ & $\begin{array}{l}\text { US -0 } \\
\text { US -0 } \\
\text { US -0 } \\
\text { US-0 } \\
\text { US -0 } \\
\text { US-0 } \\
\text { US -0 } \\
\text { US -0 }\end{array}$ \\
\hline $\begin{array}{l}205-E \\
106-B \\
407-B \\
209-B \\
A 10-B \\
A 11-B \\
\end{array}$ & $\begin{array}{l}C T \\
C T \\
C T \\
C T \\
C T \\
C T \\
\end{array}$ & $\begin{array}{ll}\text { HT9, } & \text { RAF } \\
\text { HT9, RAF } \\
\text { HT9, RAF } \\
\text { HT9. RAF } \\
\text { HT9, RAF } \\
\text { HT9, RAF } \\
\end{array}$ & $\begin{array}{l}3 \\
3 \\
3 \\
0 \\
3 \\
3 \\
3 \\
\end{array}$ & $\begin{array}{l}\text { US - P } \\
\text { US.P } \\
\text { US.P } \\
\text { US - P } \\
\text { US.P } \\
\text { US-P }\end{array}$ \\
\hline $\begin{array}{l}A \cup 3-B \\
A 13-B \\
B 08-B \\
B 08-B \\
A 04-B \\
A 08-B \\
30 E-B \\
E 07-B \\
C 04-B \\
C 05-B \\
C 06-B \\
C 07-B\end{array}$ & $\begin{array}{l}T(S S-3) \\
T(S S-3) \\
T(S S-3) \\
T(S S-3) \\
T(S S-3) \\
T(S S-3) \\
T(S S-3) \\
T(S S-3) \\
T(S S-3) \\
T(S S-3) \\
T(S S-3) \\
T(S S-3)\end{array}$ & $\begin{array}{c}\text { HT9, RAF } \\
\text { HTg, RAF } \\
\text { Fe alloys }(9-12 \text { (r F } / M) \\
\text { RAF } \\
\text { RAF } \\
\text { RAF } \\
\text { RAF } \\
\text { RAF } \\
\text { RAF } \\
\text { RAF } \\
\text { RAF } \\
\text { RAF } \\
\end{array}$ & $\begin{array}{l}15 \\
16 \\
4 \\
4 \\
5 \\
5 \\
2 \\
5 \\
4 \\
3 \\
3 \\
1 \\
\end{array}$ & $\begin{array}{l}\text { US - P } \\
\text { US -P } \\
\text { US-0 } \\
\text { US -0 } \\
\text { US -0 } \\
\text { US-0 } \\
\text { US-0 } \\
\text { US-0 } \\
\text { US -0 } \\
\text { US-0 } \\
\text { US-0 } \\
\text { US-0 }\end{array}$ \\
\hline $\begin{array}{l}r 06-B \\
r 07-B \\
08-B \\
09-B \\
10-B \\
204-B \\
\Delta 08-B \\
212-B \\
B 04-B \\
305-B \\
B 06-B \\
807-B \\
C 04-B \\
C O 5-B \\
\end{array}$ & 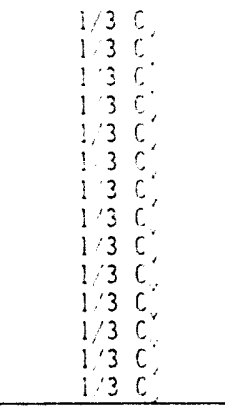 & 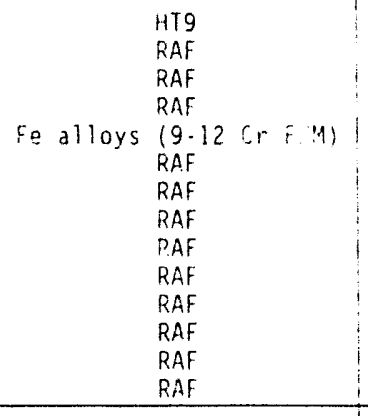 & $\begin{array}{l}: 2 \\
\vdots \\
\vdots \\
\vdots \\
\vdots 2 \\
2 \\
2 \\
2 \\
2 \\
2 \\
\vdots \\
\vdots \\
5 \\
5 \\
2 \\
2 \\
2 \\
\end{array}$ & $\begin{array}{l}\text { US -P } \\
\text { US -P } \\
\text { US -P } \\
\text { US - P } \\
\text { US -0 } \\
\text { US -0 } \\
\text { US -0 } \\
\text { US -0 } \\
\text { US -0 } \\
\text { US -0 } \\
\text { US -0 } \\
\text { US -0 } \\
\text { US -0 } \\
\text { US -0 }\end{array}$ \\
\hline $\begin{array}{l}603-S \\
206-S \\
510-B \\
F 04-S \\
F 07-S \\
\text { E06-B } \\
\text { ontinued on } \\
\text { rext page... }\end{array}$ & $\begin{array}{l}\text { In } \\
\text { In } \\
\text { +11 } \\
\text { T!l } \\
\text { TH } \\
\text { TH }\end{array}$ & $\begin{array}{l}\text { RAF } \\
\text { RAF } \\
\text { RAF } \\
\text { RAF } \\
\text { RAF } \\
\text { RAF }\end{array}$ & $\begin{array}{c}1 \\
11 \\
\vdots \\
1 \\
11 \\
1\end{array}$ & $\begin{array}{l}J \\
j \\
j \\
j \\
j \\
J\end{array}$ \\
\hline
\end{tabular}


Table 1. COBRA IA Specimen Matrix

\begin{tabular}{|c|c|c|c|c|}
\hline $\begin{array}{c}\text { Subcapsule or } \\
\text { Eastat }\end{array}$ & Specimen Type & Alloy ${ }^{3}$ & $\begin{array}{l}\text { Number of } \\
\text { Specimens }\end{array}$ & Program 5 \\
\hline \multicolumn{5}{|l|}{$\begin{array}{l}\text { Contirued from } \\
\text { srevious } \\
\text { rage... }\end{array}$} \\
\hline $\begin{array}{r}504-5 \\
506-8 \\
008-8 \\
705-5 \\
506-5 \\
707-5 \\
605-8 \\
504-5 \\
603-5 \\
010-8 \\
\end{array}$ & 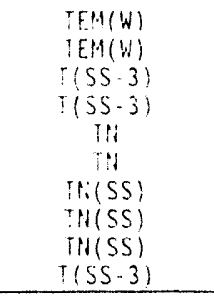 & $\begin{array}{c}\text { RAF, JPCA, J316 } \\
\text { RAF. JPCA, J315 } \\
\text { JPCA, J316 } \\
\text { JPCA, J316 } \\
\text { JPCA. J316 } \\
\text { JPCA. J316 } \\
315 \text { var } \\
316 \text { var } \\
316 \text { var } \\
316 \\
\end{array}$ & $\begin{array}{l}1 \\
\vdots \\
\vdots 5 \\
\vdots 5 \\
0 \\
0 \\
23 \\
23 \\
23 \\
\vdots 3 \\
1 \\
\end{array}$ & $\begin{array}{l}J \\
j \\
j \\
j \\
j \\
j \\
j \\
j \\
j \\
\text { US-0 }\end{array}$ \\
\hline $\begin{array}{l}E 02-B \\
C 03-B \\
E 09-B \\
E 12-B\end{array}$ & $\begin{array}{l}13 c \\
13 c(0) \\
13 c \\
13 c(3) \\
\end{array}$ & $\begin{array}{l}\text { HT9 } \\
\text { HT9 } \\
\text { HT9 } \\
\text { HT9 } \\
\end{array}$ & $\begin{array}{l}3 \\
\vdots 0 \\
2 \\
\vdots \\
\end{array}$ & $\begin{array}{l}\text { JUS - } \\
\text { J/US - } \\
\text { JUS - } \\
\text { JUS - } \\
\end{array}$ \\
\hline $\begin{array}{r}01-8 \\
04-8\end{array}$ & $\begin{array}{r}136 .(3) \\
138(3) \\
\end{array}$ & $\begin{array}{l}\text { JHMS } \\
\text { JFMS }\end{array}$ & $\begin{array}{l}\vdots 9 \\
\vdots \\
\end{array}$ & $\begin{array}{l}\text { J/US - P } \\
\text { J/US - P }\end{array}$ \\
\hline $\begin{array}{r}501-8 \\
103-B \\
004-8 \\
E 12-B \\
\end{array}$ & $\begin{array}{l}1.5 c \\
1.5 c \\
1.5 c \\
1.5 c \\
\end{array}$ & $\begin{array}{l}\text { JFMS } \\
\text { HT9 } \\
\text { JFMS } \\
\text { HT9 } \\
\end{array}$ & $\begin{array}{r}0 \\
1 \\
10 \\
0 \\
\end{array}$ & $\begin{array}{l}\text { J/US - } \\
\text { J/US - } \\
\text { J/US - } \\
\text { J/US - } \\
\end{array}$ \\
\hline $\begin{array}{l}506-8 \\
F 04-5 \\
603-5 \\
026-5 \\
04-5 \\
07.5 \\
006-5 \\
003-5\end{array}$ & 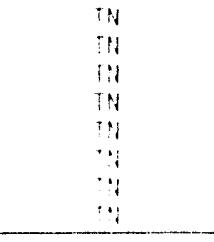 & $\begin{array}{l}\text { HT9 } \\
\text { HT9 } \\
\text { HT9 } \\
\text { JFMS } \\
\text { JFMS } \\
\text { iFMS } \\
\text { IFMS } \\
\text { IFMS }\end{array}$ & $\begin{array}{c}5 \\
\vdots \\
\vdots \\
\vdots \\
\vdots \\
\vdots\end{array}$ & $\begin{array}{l}j \\
j \\
j \\
j \\
j \\
j \\
. \\
j \\
j\end{array}$ \\
\hline $\begin{array}{l}\because 14-5 \\
\therefore 15-5 \\
\therefore 16-5 \\
\end{array}$ & 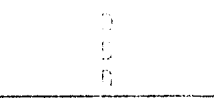 & $\begin{array}{l}\text { nculators } \\
\text { nulutars } \\
\text { noulatar }\end{array}$ & $\begin{array}{c}\vdots \\
\vdots \\
\end{array}$ & $\begin{array}{l}y S-L \\
35-1 \\
3 S-L\end{array}$ \\
\hline $\begin{array}{r}05-5 \\
004-5 \\
03-5 \\
05-5 \\
74-5 \\
3.5 \\
\end{array}$ & 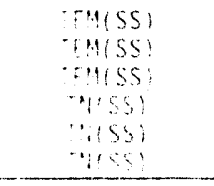 & 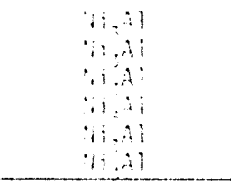 & $\begin{array}{l}\vdots \\
\vdots \\
\vdots\end{array}$ & $\begin{array}{l}3 \\
1 \\
y \\
\vdots \\
3 \\
3 \\
3\end{array}$ \\
\hline $\begin{array}{r}05 \cdot 5 \\
25 \cdot 5 \\
05 \cdot-3 \\
25 \cdot 5 \\
05 \cdot 5 \\
05 \cdot 8 \\
05\end{array}$ & $\begin{array}{l}3 \\
3 \\
3 \\
3\end{array}$ & 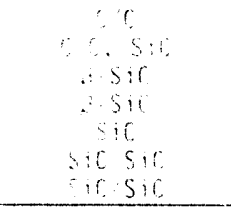 & $\begin{array}{l}\ddots \vdots \\
\vdots \\
\vdots \\
\vdots \\
\vdots \\
\vdots\end{array}$ & $\begin{array}{l}i \\
j \\
j \\
j \\
U S-P \\
\text { US-P } \\
\text { US - P }\end{array}$ \\
\hline $\begin{array}{l}-10-5 \\
07-5 \\
05-5 \\
510 \cdot 8 \\
77-5 \\
05-5\end{array}$ & $\begin{array}{r}4155 \\
-455 \\
+4155 \\
-155 \\
-455 \\
455\end{array}$ & 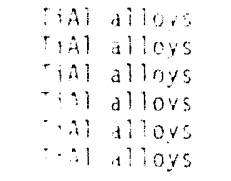 & $\begin{array}{l}\vdots \\
\vdots \\
\vdots \\
\vdots \\
\vdots\end{array}$ & $\begin{array}{l}j \\
j \\
j \\
j \\
j \\
j\end{array}$ \\
\hline $\begin{array}{l}: \text { tinued on } \\
\therefore \text { reae. } \\
\end{array}$ & & & & \\
\hline
\end{tabular}


Table 1. COBRA 1A Specimen Matrix

\begin{tabular}{|c|c|c|c|c|}
\hline $\begin{array}{c}\text { Subcapsule or } \\
\text { Basket }\end{array}$ & Specimen Type ${ }^{2}$ & Alloy ${ }^{3}$ & $\begin{array}{l}\text { Number of } \\
\text { Specimens }\end{array}$ & Program 5 \\
\hline \multicolumn{5}{|l|}{$\begin{array}{l}\text { Cont inued from } \\
\text { previous } \\
\text { page... }\end{array}$} \\
\hline $\begin{array}{l}\text { E11-B } \\
\text { F07-S } \\
\text { G06-S } \\
\text { E05-B } \\
\text { E11-B } \\
\text { F04-S } \\
\text { F07-S } \\
\text { G03-S } \\
\text { G06-S } \\
\end{array}$ & $\begin{array}{l}\text { TEM(W) } \\
\text { TEM (W) } \\
\text { TEM(W) } \\
\text { TN } \\
\text { TN } \\
\text { TN } \\
\text { TN } \\
\text { TN } \\
\text { TN } \\
\end{array}$ & $\begin{array}{l}\text { TiNi alloys } \\
\text { TiNi alloys } \\
\text { TiNi alloys } \\
\text { TiNi alloys } \\
\text { TiNi alloys } \\
\text { TiNi alloys } \\
\text { TiNi alloys } \\
\text { TiNi alloys } \\
\text { TiNi alloys } \\
\end{array}$ & $\begin{array}{l}1 \\
1 \\
1 \\
12 \\
12 \\
12 \\
12 \\
12 \\
12 \\
\end{array}$ & $\begin{array}{l}\mathrm{J} \\
\mathrm{J} \\
\mathrm{J} \\
\mathrm{J} \\
\mathrm{J} \\
\mathrm{J} \\
\mathrm{J} \\
\mathrm{J} \\
\mathrm{J}\end{array}$ \\
\hline $\begin{array}{l}B 09-S^{\circ} \\
B 05-B \\
B 06-B \\
B 07-B \\
B 08-B \\
E 13-B \\
E 05-B \\
F 04-S \\
603-S \\
E 07-B \\
F 05-S \\
G 04-S\end{array}$ & $\begin{array}{c}\text { CT } \\
1 / 3 C_{v}, S S-3, \text { TEM (TZM/Li) } \\
1 / 3 C_{v}, S S-3 \text {, TEM }(T Z M / L i) \\
1 / 3 C_{v}, S S-3 \text {, TEM (TZM/Li) } \\
\text { SS-3, TEM (TZM/Li) } \\
\text { SAM, SP (TZM/Li) } \\
\text { TEM(S) } \\
\text { TEM(S) } \\
\text { TEM(S) } \\
\text { TN, TEM (TZM/Li) } \\
\text { TN, TEM (TZM/Li) } \\
\text { TN, TEM (TZM/Li) }\end{array}$ & $\begin{array}{l}V \text { alloys } \\
V \text { alloys } \\
V \text { alloys } \\
V \text { alloys } \\
V \text { alloys } \\
V \text { alloys } \\
V \text { alloys } \\
V \text { alloys } \\
V \text { alloys } \\
V \text { alloys } \\
V \text { alloys } \\
V \text { alloys }\end{array}$ & $\begin{array}{l}12 \\
1 \\
1 \\
1 \\
1 \\
1 \\
1 \\
1 \\
1 \\
1 \\
1 \\
1\end{array}$ & $\begin{array}{l}\text { US -A } \\
\text { US-A } \\
\text { US-A } \\
\text { US-A } \\
\text { US-A } \\
\text { US-I } \\
\text { J } \\
\text { J } \\
\text { J } \\
\text { J } \\
\text { J } \\
\text { J }\end{array}$ \\
\hline
\end{tabular}

1. " $-B "$ and "-S" indicate that the specified segment within the capsule is either a basket (weeper) or a subcapsule (sealed), respectively. A superscripted "*" indicates that the subcapsule is hel ium-filled TZM.

2. $1 / 3 C_{v} \quad 1 / 3$ size charpy specimen ( $J$ in parenthesis indicates the dapariese $1 / 3$ size geometry) $1.5 C_{v} \quad 1.5 \mathrm{~mm}$ charpy impact specimen

$B_{1}, B_{3}, B_{5}$ ball specimens measuring 1,3 , and $5 \mathrm{~mm}$ in diameter respectivaly

$B B$ bend bar specimen

CT compact tension specimen

D $\quad-0.4^{\prime \prime}$ diameter disks

f fiber specimen

$F$ fatigue specimen

SAM Scanning Auger microscopy specimen

SP Small punch specimen

$T(S S-3) \quad S S-3$ tensile specimen

$\operatorname{TEM}(S)$ sealed TEM packet

TEM(W) weeper TEM packet

TN S-l tensile specimen

(SS) specimens in helium filled, sealed stainless steel container

(TZM/He) specimens in helium-filled, sealed TZM container

(TZM/Li) specimens in lithium-filled, sealed TZM container

3. RAF reduced activation ferritic

Be - NGK Be made by NGK

Be - BW Be made by Brush Wellman

4. Refers to one of the following, depending on the entry type:

number of specimens, or

number of TEM packets, or

number of TZM containers

5. J

US -A

Japanese

US-A ANL - E

US-L LANL

US-I

University of lowa at Ames

$\begin{array}{ll}\text { US - O } & \text { ORNL } \\ \text { US -P } & \text { PNL. }\end{array}$ 
Table 2. Specimen Geometries in COBRA IA

\begin{tabular}{|c|c|c|c|}
\hline SPECIMEN TYPE & DIMENSIONS $\mathrm{mm}(\mathrm{in})$ & $\begin{array}{c}\text { MATERIAL } \\
\text { TYPE } \\
\end{array}$ & $\begin{array}{c}\text { AVERAGE MASS } \\
\text { (gms) }\end{array}$ \\
\hline Fatigue & $600 \times 501(0.2400 \times 1.971)$ & Cu alloys & 8.58 \\
\hline TEM disks & $\begin{array}{l}300 \times .25 \mathrm{t}(0.11800 \times 0.010 \mathrm{t}) \\
300 \times 1 \mathrm{t}(0.11800 \times 0.04 \mathrm{t}) \\
300 \times 0.08 \mathrm{t}(0.11800 \times 0.003 \mathrm{t})\end{array}$ & $\begin{array}{l}\mathrm{Fe} \text { alloys } \\
\mathrm{Cu} \\
\mathrm{V} \text { alioys } \\
\mathrm{SiC} \text { and } \mathrm{C} \\
\mathrm{Ti}-50 \mathrm{AT} \\
\mathrm{Cu}\end{array}$ & $\begin{array}{l}0.012 \\
0.013 \\
0.008 \\
0.005 \\
0.006 \\
0.045 \\
\end{array}$ \\
\hline $\begin{array}{l}\text { SS }-3 \text { tensiles } \\
\text { S-1 tensiles }\end{array}$ & $\begin{array}{l}25.41 \times 4.95 \mathrm{w} \times 0.76 \mathrm{t}[7.6 \mathrm{gl} \times 1.5 \mathrm{gw}] \\
(1 \mathrm{1} \times 0.195 \mathrm{w} \times 0.03 \mathrm{t}[0.3 \mathrm{gl} \times 0.06 \mathrm{gw}]) \\
161 \times 4 \mathrm{w} \times 0.25 \mathrm{t}[5 \mathrm{gl} \times 1.2 \mathrm{gw}] \\
(0.631 \times 0.157 \mathrm{w} \times 0.01 \mathrm{t}[0.2 \mathrm{~g}] \times 0.047 \mathrm{gw}])\end{array}$ & $\begin{array}{l}\mathrm{Fe} \text { alloys } \\
\mathrm{V} \text { alloys } \\
\mathrm{Fe} \text { alloys } \\
\mathrm{V} \text { alloys } \\
\mathrm{Cu} \\
\mathrm{Ti} \text { - SOAl } \\
\mathrm{Ti}-\mathrm{Ni}\end{array}$ & $\begin{array}{l}0.48 \\
0.3 \\
0.08 \\
0.06 \\
0.09 \\
0.04 \\
0.06 \\
\end{array}$ \\
\hline 1/3 size Charpy - PNL & $23.6 \times 3.33 \times 3.33(0.930 \times 0.131 \times 0.131)$ & Fe alloys & 2.08 \\
\hline 1/3 size Charpy - ORNL & $25.4 \times 3.33 \times 3.33(1 \times 0.131 \times 0.131)$ & $\begin{array}{l}\mathrm{Fe} \text { alloys } \\
\mathrm{V} \text { alloys }\end{array}$ & $\begin{array}{l}2.24 \\
1.65\end{array}$ \\
\hline $1 / 3$ size Charpy - J & $23 \times 3.3 \times 3.3(0.905 \times 0.13 \times 0.13)$ & Fe allovs & 2.00 \\
\hline $1.5 \mathrm{~mm}$ Charpy & $20 \times 1.5 \times 1.5(0.787 \times 0.059 \times 0.059)$ & Fe alloys & 0.32 \\
\hline Compact tension (CT) & $\begin{array}{l}1600 \times 2.54 \mathrm{t}(0.6300 \times 0.1 \mathrm{t}) \\
1600 \times 3.81 \mathrm{t}(0.6300 \times 0.15 \mathrm{t}) \\
\end{array}$ & $\begin{array}{l}\mathrm{Fe} \text { allo:.5 } \\
\text { y allovs }\end{array}$ & $\begin{array}{l}3.5 \\
3.92 \\
\end{array}$ \\
\hline Ceramic disks & $\begin{array}{l}12.700 \times 2.56 \mathrm{t}(0.50100 \times 0.101 \mathrm{t}) \\
1000 \times 0.91 \mathrm{t}(0.39300 \times 0.036 \mathrm{t}) \\
1000 \times 0.99 \mathrm{t}(0.39300 \times 0.039 \mathrm{t}) \\
1000 \times 0.99 \mathrm{t}(0.39300 \times 0.039 \mathrm{t}) \\
10.400 \times 0.76 \mathrm{t}(0.4100 \times 0.030 \mathrm{t}) \\
12.3900 \times 1.34 \mathrm{t}(0.48800 \times 0.053 \mathrm{t}) \\
12.700 \times 9.5 \mathrm{t}(0.500 \times 0.374 \mathrm{t}) \\
7.7500 \times 4 \mathrm{t}(0.30500 \times 0.157 \mathrm{t}) \\
12.700 \times 1.02 \mathrm{t}(0.500 \times 0.040 \mathrm{t})\end{array}$ & 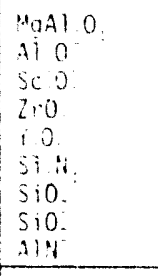 & $\begin{array}{l}1.145 \\
0.284 \\
0.292 \\
0.427 \\
0.293 \\
0.187 \\
2.79 \\
0.436 \\
0.421 \\
\end{array}$ \\
\hline Disk & $\begin{array}{l}7.6200 \times 20.31 \quad(0.300 \times 0.81) \\
7.6200 \times 6.35 \mathrm{t}(0.300 \times 0.25 \mathrm{t}) \\
10.200 \times 1.85 \mathrm{t}(0.40300 \times 0.073 t) \\
10.1300 \times 3 \mathrm{t}(0.39900 \times 0.118 \mathrm{t}) \\
10.1600 \times 1.27 \quad(0.400 \times 0.05 \mathrm{t}) \\
10.000 \times 1.28(0.3900 \times 0.05) \\
10.200 \times 1.02 \mathrm{t}(0.40200 \times 0.04 t) \\
10.200 \times 3.17 \mathrm{t}(0.40200 \times 0.125 \mathrm{t})\end{array}$ & $\begin{array}{l}\text { se } \\
\text { Be } \\
\operatorname{sic} \text { sic } \\
\text { sic } \\
\text { sic } \\
\text { sic } \\
\text { sic } \\
\text { sic si }\end{array}$ & $\begin{array}{l}1.55 \\
0.49 \\
0.37 \\
0.53 \\
0.21 \\
0.32 \\
0.20 \\
0.83 \\
\end{array}$ \\
\hline Balls & \begin{tabular}{|llll}
1 & 00 & $(0.04$ & $00)$ \\
3 & 00 & $(0.12$ & $00)$ \\
5 & 00 & $(0.2$ & $00)$ \\
\end{tabular} & $\begin{array}{l}2 e \\
5 e \\
80\end{array}$ & $\begin{array}{l}0.001 \\
0.03 \\
0.14 \\
\end{array}$ \\
\hline $\begin{array}{l}\text { Bend bars } \\
\text { Cont inued on next } \\
\text { page... }\end{array}$ & $\begin{array}{l}3.175 \times 6.35 \times 38.1(0.125 \times 0.25 \times 1.5) \\
3.27 \times 1.68 \times 38.1(0.129 \times 0.056 \times 1.5) \\
3.05 \times 5.91 \times 36.32(0.120 \times 0.233 \times 1.43) \\
3.7 \times 1.9 \times 25.4(0.147 \times 0.075 \times 1) \\
1 \times 5 \times 40(0.04 \times 0.2 \times 1.57) \\
1.7 \times 4 \times 25(0.07 \times 0.16 \times 98) \\
1.9 \times 3.7 \times 25(0.075 \times 0.147 \times 1) \\
1.7 \times 4 \times 25(0.066 \times 0.16 \times 0.98)\end{array}$ & $\begin{array}{l}\operatorname{sic} \text { sic } \\
\text { sic sic } \\
\text { sic sic } \\
\text { sic sic } \\
\text { cic } \\
\text { oic } \\
\text { co } \\
\text { ic }\end{array}$ & $\begin{array}{l}2.17 \\
0.51 \\
1.715 \\
0.445 \\
0.342 \\
0.33 \\
0.383 \\
0.335\end{array}$ \\
\hline
\end{tabular}


Table 2. Specimen Geometries in COBRA 1A

\begin{tabular}{|c|c|c|c|}
\hline SPECIMEN TYPE & DIMENSIONS min (in) & $\begin{array}{l}\text { MATERIAL } \\
\text { TYPE } \\
\end{array}$ & $\begin{array}{l}\text { AVERAGE MASS } \\
\text { (gms) }\end{array}$ \\
\hline \multicolumn{4}{|l|}{$\begin{array}{l}\text { Cont inued from } \\
\text { previous page... }\end{array}$} \\
\hline Fiber tubes & $\begin{array}{l}2.5400 \times 38.1(0.10000 \times 1.5) \\
3.17500 \times 31.75(0.12500 \times 1.25) \\
3.17500 \times 20.3(0.12500 \times 0.8) \\
\end{array}$ & $\begin{array}{l}\mathrm{SiC} / \mathrm{SiC} \\
\mathrm{SiC} / \mathrm{SiC} \\
\text { Carbon }\end{array}$ & $\begin{array}{l}0.50 \\
0.38 \\
0.25 \\
\end{array}$ \\
\hline Temperature monitors & $0.32 \times 1.6 \times 25.4 \quad(0.0125 \times 0.0625 \times 1)$ & $\mathrm{SiC}$ & 0.41 \\
\hline $\begin{array}{l}\text { Scanning auger } \\
\text { microscopy (SAM) } \\
\text { specimens }\end{array}$ & $\begin{array}{l}16.51 \times 1.9 \mathrm{t} \times 3.17 \\
(0.651 \times 0.075 \mathrm{t} \times 0.125)\end{array}$ & $\begin{array}{l}\mathrm{Fe} \text { alloys } \\
\mathrm{V} \text { alloys }\end{array}$ & $\begin{array}{l}0.7 \\
0.57\end{array}$ \\
\hline $\begin{array}{l}\text { Small punch (SP) } \\
\text { specimens }\end{array}$ & $8.0500 \times 0.5 \mathrm{t} \quad(0.31700 \times 0.02 \mathrm{t})$ & $\begin{array}{l}\text { Fe alloys } \\
V \text { alloys } \\
\end{array}$ & $\begin{array}{l}0.19 \\
0.14 \\
\end{array}$ \\
\hline TEM packets - weepers & $\begin{array}{l}3.6500 \times 22.3 \times 0.18 t \\
(0.14400 \times 0.879 \times 0.007 t)\end{array}$ & 316 & 0.35 (empty) \\
\hline TEM packets - sealed & $\begin{array}{l}3.6500 \times 22.3 \times 0.18 t \\
(0.14400 \times 0.88 \times 0.007 t)\end{array}$ & 316 & 0.41 (empty) \\
\hline Sealed tubes & $\begin{array}{l}9.400 \times 20.3 \times 0.38 \mathrm{wall} \\
(0.3700 \times 0.80 \times 0.015 \mathrm{wal1})\end{array}$ & 316 & 2.56 (empty) \\
\hline \multirow[t]{4}{*}{ TZM containers } & $\begin{array}{l}9.5300 \times 521 \times 0.635 \text { wall } \\
(0.37500 \times 2.051 \times 0.025 \text { wall })\end{array}$ & TZM & $\begin{array}{l}10.3 \text { (with } \\
\text { lithium) }\end{array}$ \\
\hline & $\begin{array}{l}9.5300 \times 25.41 \times 0.635 \text { wall } \\
(0.37500 \times 11 \times 0.025 \text { wall })\end{array}$ & TZM & $\begin{array}{l}5.4 \text { (with } \\
\text { lithium) }\end{array}$ \\
\hline & $\begin{array}{l}9.5300 \times 44.451 \times 0.635 \text { wall } \\
(0.37500 \times 1.751 \times 0.025 \text { wall })\end{array}$ & $T 2 \mathrm{M}$ & $\begin{array}{l}8.9 \text { (with } \\
\text { lithium) }\end{array}$ \\
\hline & $\begin{array}{l}9.5300 \times 73.71 \times 0.635 \text { wall } \\
(0.37500 \times 2.91 \times 0.025 \text { wall }) \\
\end{array}$ & $T Z M$ & $\begin{array}{l}14.3 \text { (with } \\
\text { lithium) }\end{array}$ \\
\hline
\end{tabular}


FABRICATION AND OPERATION OF HFIR-MFE RB* SPECTRALLY TAILORED IRRADIATION CAPSULES - A. W. Longest, J. E. Pawel, D. W. Heatherly, R. G. Sitterson, and R. L. Wallace (Oak Ridge National Laboratory).

\section{OBJECTIVE}

The objective of this work is to fabricate and operate irradiation capsules for irradiating magnetic fusion energy (MFE) candidate first-wall materials in the High Flux Isotope Reactor (HFIR) removable beryllium (RB*) positions. Japanese and U.S. MFE specimens were transferred to RB* positions following irradiation to $7.5 \mathrm{dpa}$ at temperatures of $60,200,330$, and $400^{\circ} \mathrm{C}$ in Oak Ridge Research Reactor (ORR) experiments ORR-MFE-6J and -7J.

\section{SUMMARY}

Fabrication and operation of four HFIR-MFE RB* capsules $\left(60,200,330\right.$, and $\left.400^{\circ} \mathrm{C}\right)$ to accommodate MFE specimens previously irradiated in spectrally tailored experiments in the ORR are proceeding satisfactorily. With the exception of the $60^{\circ} \mathrm{C}$ capsule, where the test specimens were in direct contact with the reactor cooling water, specimen temperatures (monitored by 21 thermocouples) are controlled by varying the thermal conductance of a thin gas gap region between the specimen holder outer sleeve and containment tube.

Irradiation of the 60 and $330^{\circ} \mathrm{C}$ capsules, which started on July 17,1990 , was completed on November 14,1992 , after 24 cycles of irradiation to an incremental damage level of approximately 10.9 displacements per atom (dpa). Assembly of the follow-up 200 ) and $400^{\circ} \mathrm{C}$ capsules was completed in November 1992, and their planned 20-cycle irradiation to approximately 9.1 incremental dpa was started on November 21, 1992. As of February 11, 1993, the 200 and $400^{\circ} \mathrm{C}$ capsules had successfully completed three cycles of irradiation to approximately 1.4 incremental dpa.

\section{PROGRESS AND STATUS}

\section{Introduction}

A series of spectrally tailored irradiation capsules are being fabricated and operated as part of the U.S./Japan collaborative program for testing MFE candidate first-wall materials in mixed-spectrum fission reactors. The test specimens are being irradiated in the $\mathrm{RB}^{*}$ facility ${ }^{1}$ of the HFIR.

Four HFIR-MFE RB* capsules were designed to accommodate Japanese and U.S. MFE specimens previously irradiated to $7.5 \mathrm{dpa}$ at temperatures of $60,200,330$, and $400^{\circ} \mathrm{C}$ in the ORR in spectrally tailored experiments ORR-MFE-6J and -7J. Details of these ORR experiments, including descriptions of the test matrix, mechanical property specimens, and techniques of spectral tailoring, have been reported elsewhere. ${ }^{23}$ Hafnium liners are being used in the HFIR-MFE RB* experiments to tailor the neutron spectrum to closcly match the helium production-to-atom displacement ratio (14 appm/dpa) expected in a fusion reactor first wall.

The HFIR-MFE RB capsules are being irradiated in pairs (first the 60 and $330^{\circ} \mathrm{C}$ capsules, then the 200 and $400^{\circ} \mathrm{C}$ capsules) to total damage levels on the re-encapsulated specimens of approximately 18.4 (24 HFIR cycles) and 16.6 dpa (20 HFIR cycles), respectively. Previously", the target exposure level was 17.5 tolal dpa on the re-encapsulated specimens (22 HFIR cycles) for all four capsules; 
however, the 60 and $330^{\circ} \mathrm{C}$ irradiations were extended for two additional cycles until the 200 and 40()$^{\circ} \mathrm{C}$ capsules were ready to replace them.

\section{$\underline{60^{\circ} \mathrm{C} \text { Capsule }}$}

The $60^{\circ} \mathrm{C}$ capsule, designated HFIR-MFE-60J-1, was an uninstrumented capsule with the test specimens in contact with the reactor cooling water. Capsule design, assembly, and details of the specimen loading were described previously."

Irradiation of this capsule was started on July 17, 1990, and was completed on November 14, 1992, after 24 cycles of irradiation to a total damage level on the re-encapsulated specimens of approximately 18.4 dpa. A cycle-by-cycle summary of the irradiation history of the $60 \mathrm{~J}-1$ capsule is given in Table 1. Specimen operating temperatures in this capsule were predicted to be within $10^{\circ} \mathrm{C}$ of $60^{\circ} \mathrm{C}$.

\section{$\underline{330^{\circ} \mathrm{C} \text { Capsule }}$}

The $330^{\circ} \mathrm{C}$ capsule, designated HFIR-MFE-330J-1, was an instrumented and singly contained capsule where the specimen temperatures were monitored by 21 thermocouples and controlled by adjusting the thermal conductance of a thin gas gap region between the specimen holder outer slecve and containment tube. This capsule was cooled with $49^{\circ} \mathrm{C}$ reactor cooling water flowing downward over the containment tube surface. Capsule design, assembly, and details of the specimen loading were described previously. ${ }^{6.7}$

Irradiation of this capsule was started on July 17, 1990, and was completed on November 14, 1992, after 24 cycles of irradiation to a total damage level on the re-encapsulated specimens of approximately $18.4 \mathrm{dpa}$. A cycle-by-cycle summary of the irradiation history of the $330 \mathrm{~J}-1$ capsule is given in Table 1.

Typical thermal operating data for the $330 \mathrm{~J}-1$ experiment were presented in detail previously ${ }^{8}$. During this report period, measured temperatures in the aluminum alloy specimen holder continued to indicate specimen operating temperatures within about $25^{\circ} \mathrm{C}$ of $330^{\circ} \mathrm{C}$, which satisfies the temperature criterion for these experiments.

\section{$\underline{200 \text { and } 400^{\circ} \mathrm{C} \text { Capsules }}$}

The 200 and $400^{\circ} \mathrm{C}$ capsule desig.2s are basically the same as that of the $330^{\circ} \mathrm{C}$ capsule. The main differences in the three capsule designs are associated with (1) the number and spacing of the specimen holder slots and holes to accommodate differences in the numbers of specimens of the various types, (2) the width of the temperature control gas gap region between the specimen holder outer sleeve and containment tube to obtain the desired specimen operating temperatures, and (3) the instrumented test piece included in the aluminum plug and holder above the test specimen holder to obtain extra information.

Horizontal and vertical sections through the 200 and $400^{\circ} \mathrm{C}$ capsules, designated HFIR-MFE-200J-1 and $-400 \mathrm{~J}-1$, are shown in Figures 1 through 4 . In addition to the main test specimen loadings, a simulated packet of transmission electron microscopy (TEM) specimens in the $200^{\circ} \mathrm{C}$ capsule and a simulated hourglass fatigue specimen in the $400^{\circ} \mathrm{C}$ capsule are located in the aluminum plug and 
Table 1. IRRADIATION HISTORY OF US/JAPAN SPECTRAL. TAILORED CAPSULES HFIR-MFE-60J-1, -330J-1,- 200J-1, AND -400J-1

\begin{tabular}{|c|c|c|c|c|c|c|c|}
\hline & \multicolumn{3}{|c|}{ HFIR OPERATION } & \multicolumn{2}{|c|}{$60 \mathrm{~J}-1,330 \mathrm{~J}-1$} & \multicolumn{2}{|c|}{$200 \mathrm{~J}-1,400 \mathrm{~J}-1$} \\
\hline \multirow{2}{*}{$\begin{array}{c}\text { CYCLE } \\
\text { NO. }\end{array}$} & \multirow{2}{*}{$\begin{array}{l}\text { START } \\
\text { DATE }\end{array}$} & \multirow{2}{*}{$\begin{array}{l}\text { END } \\
\text { DATE }\end{array}$} & \multirow{2}{*}{$\begin{array}{l}\text { MWd/ } \\
\text { Cycle }\end{array}$} & \multicolumn{2}{|c|}{ INCREMENTAL } & \multicolumn{2}{|c|}{ INCREMENTAL } \\
\hline & & & & MWd & dpa* & MWd & dpa * \\
\hline 289 & $07-17-90$ & $09-07-90$ & 1879 & 1879 & 0.46 & & \\
\hline 290 & $09-19-90$ & $10-11-90$ & 1852 & 3731 & 0.91 & & \\
\hline 291 & $10-17-90$ & $11-13.90$ & 1838 & 5569 & 1.36 & & \\
\hline 292 & $11-25-90$ & $12-10-90$ & 1847 & 7416 & 1.82 & & \\
\hline 293 & $12-27-90$ & $01-23-91$ & 1965 & 9381 & 2.30 & & \\
\hline 294 & $02-01-91$ & $02-25-91$ & 1906 & 11287 & 2.77 & & \\
\hline 295 & $03-01-91$ & $03-24-91$ & 1908 & 13195 & 3.23 & & \\
\hline 296 & $04-06-91$ & $04-28-91$ & 1874 & 15069 & 3.69 & & \\
\hline 297 & $05-19-91$ & $06 \cdot 15 \cdot 91$ & 1845 & 16914 & 4.14 & & \\
\hline 298 & $06-20-91$ & $07-11-91$ & 1747 & 18661 & 4.57 & & \\
\hline 299 & $07-25-91$ & $08-15 \cdot 91$ & 1741 & 20402 & 5.00 & & \\
\hline 300 & $08-28-91$ & $09-17-91$ & 1724 & 22126 & 5.42 & & \\
\hline 301 & $09-27-91$ & $10-19-91$ & 1851 & 23977 & 5.87 & & \\
\hline 302 & $10-27-91$ & $11-21-91$ & 1829 & 25806 & 6.32 & & \\
\hline 303 & 12.01 .91 & $12 \cdot 22 \cdot 91$ & 1821 & 27627 & 6.77 & & \\
\hline 304 & $12-31-91$ & $01-24-92$ & 1826 & 29453 & 7.22 & & \\
\hline 305 & 01.30 .92 & $02 \cdot 27-92$ & 1876 & 31329 & 7.68 & & \\
\hline 306 & 03.31 .92 & $04 \cdot 27 \cdot 92$ & 1845 & 33174 & 8.13 & & \\
\hline 307 & $05-01-92$ & $05-28-92$ & 1842 & 35016 & 8.58 & & \\
\hline 308 & $06-02-92$ & $06-30-92$ & 1938 & 36954 & 9.05 & & \\
\hline 309 & $07-03-92$ & $08-01-92$ & 1949 & 38903 & 9.53 & & \\
\hline 310 & $08-27.92$ & 09.18 .92 & 1849 & 40752 & 9.98 & & \\
\hline 311 & $09-25-92$ & $10-12-92$ & 1856 & 42608 & 10.44 & & \\
\hline 312 & $10 \cdot 22.92$ & $11 \cdot 14.92$ & 1842 & 44450 & 10.89 & BEGIN & LE 313 \\
\hline 313 & $11-21-92$ & $12-15-92$ & 1850 & REMOVED & 312 & 1850 & 0.45 \\
\hline 314 & $12 \cdot 20-92$ & $01-12-93$ & 1866 & & & 3716 & 0.91 \\
\hline 315 & $01-19.93$ & $02-11.93$ & 1861 & & & 5577 & 1.37 \\
\hline 316 & & & & & & & \\
\hline 317 & & & & & & & \\
\hline 318 & & & & & & & \\
\hline 319 & & & & & & & \\
\hline 320 & & & & & & & \\
\hline
\end{tabular}

- DPA levels based on achieving $0.000245 \mathrm{dpa} / \mathrm{MWd}$. 
ORNL-DWG-89-7850
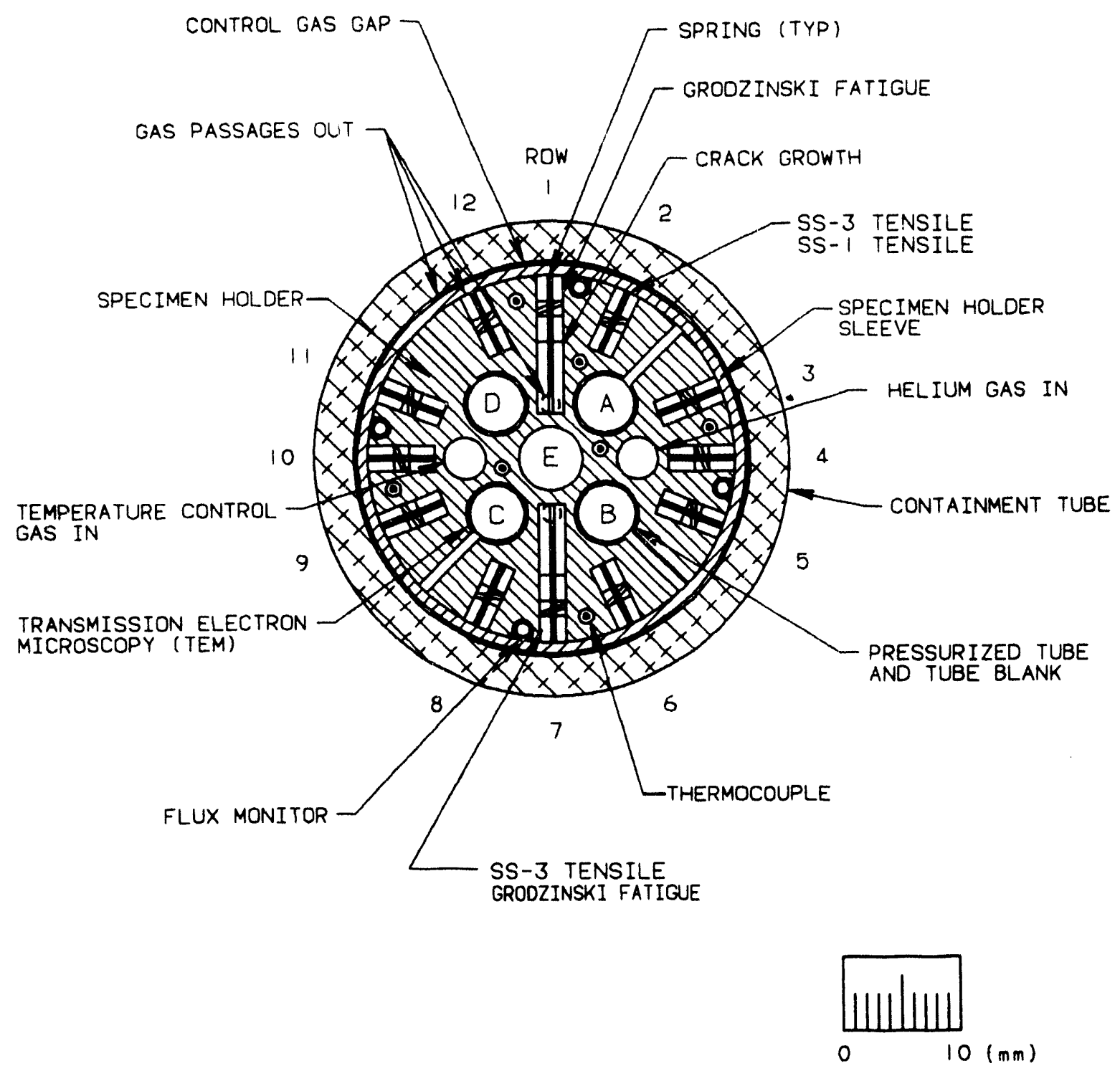

Fig. 1. Horizontal section through the HFIR-MFE-200J-1 capsule. 


$$
\text { ORNL-DWG-89-7852 }
$$
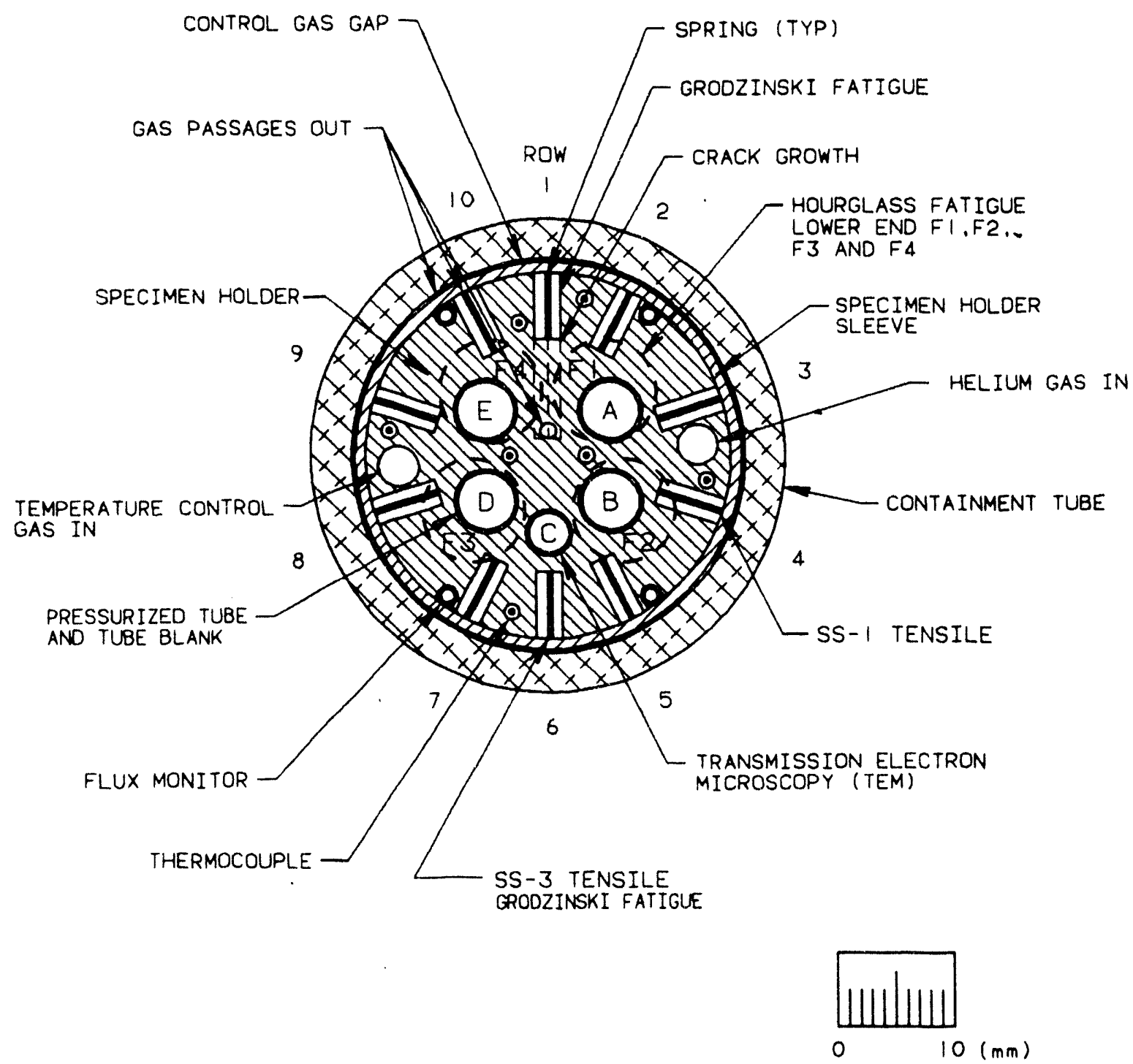

Fig. 2. Horizontal section through the HFIR-MFE-400J-1 capsule. 


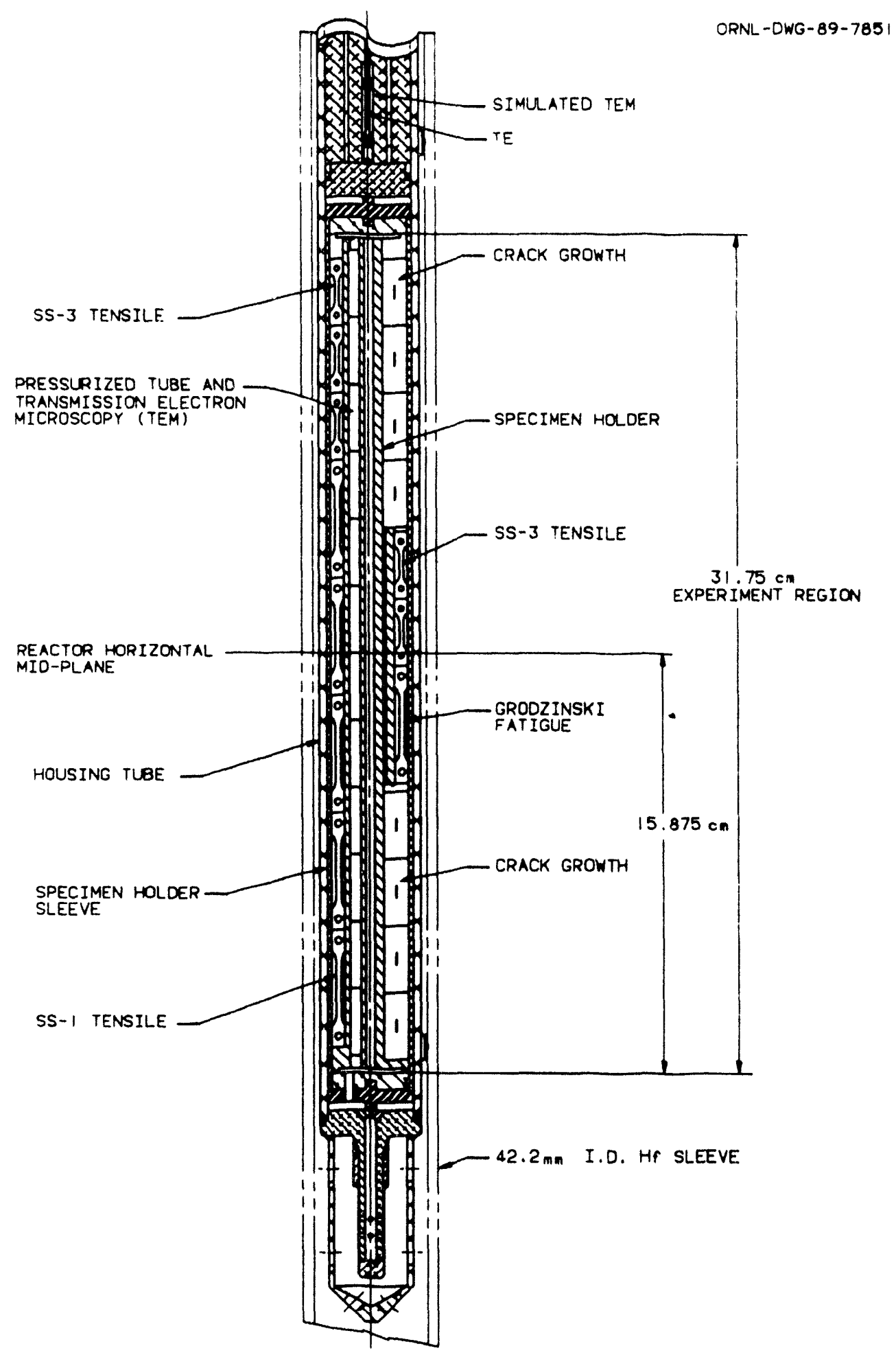

Fig. 3. Vertical section through the HFIR-MFE-200J-1 capsule. 


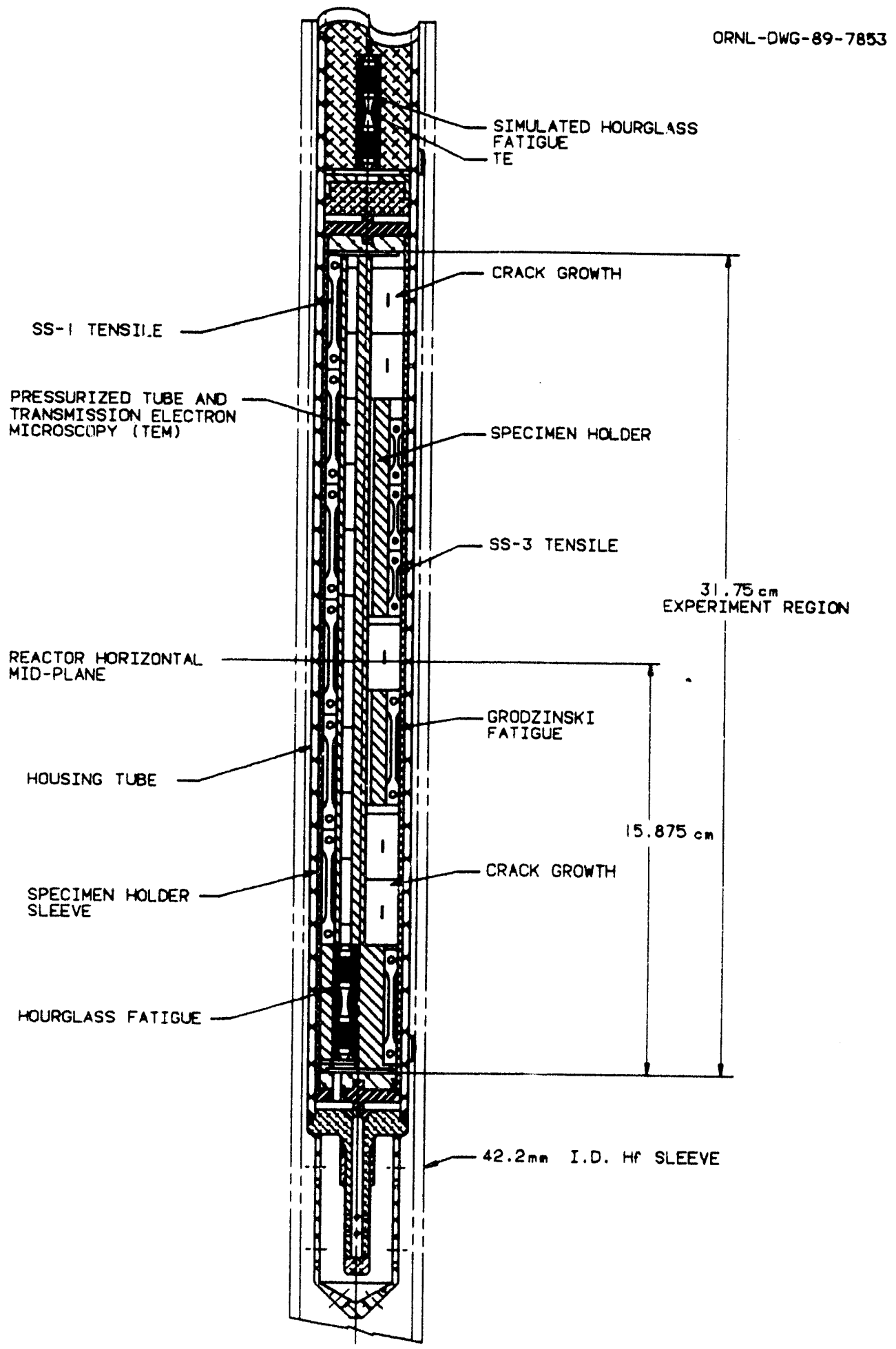

Fig. 4. Vertical section through the HFIR-MFE-400J-1 capsule. 
holder above the test specimen holder and instrumented with three thermocouples to obtain temperature rise data for these respective specimen-specimen holder configurations.

Assembly of the 200 and $400^{\circ} \mathrm{C}$ capsules was completed this report period as planned, after having been delayed by approximately two months because of the aluminum welding difficulties described in the last report ${ }^{9}$. After partial assembly of the capsules and loading of non-radioactive test specimens on the bench, the radioactive test specimens were successfully loaded in the hot cell and capsule assembly completed in about two weeks for each capsule. Special fixtures developed for hot cell loading of radioactive specimens into the $330^{\circ} \mathrm{C}$ capsule were again used for these capsules.

Specimen loading lists showing specimen identification numbers as a function of position in the capsule are given in Tables 2 and 3 for the 200 and $400^{\circ} \mathrm{C}$ capsules, respectively. Position is given by row number or hole designation (see Figs. 1 and 2 ) and level number. Level numbers in increasing order indicate the stacking order from top to bottom of the specimen holder. Detailed specimen information is given in Table 4 for the various types of specimens, respectively, loaded into these capsules. The individual specimens listed in Table 4 are categorized by type of specimen, source of material, and alloy type. Alloy conditions include solution annealed (SA) and cold worked (CW). Specimens denoted by an asterisk were re-encapsulated into these experiments and have already received $7.5 \mathrm{dpa}$ in the ORR-MFE-6J and $-7 \mathrm{~J}$ experiments. The transmission electron microscopy (TEM) disks in each new (previously unirradiated) TEM holder tube are also listed. Several specimen materials in these capsules were not in the 60 and $330^{\circ} \mathrm{C}$ capsules. These new specimen materials include vanadium and copper alloys.

Irradiation of the 200 and $400^{\circ} \mathrm{C}$ capsules began on November 21,1992 , at the start of HFIR cycle 313. As of February 11, 1993, these capsules had successfully completed three cycles $(1.37 \mathrm{dpa})$ of their planned 20-cycle (9.1 dpa) irradiation to a total damage level of approximately $16.6 \mathrm{dpa}$ on the re-encapsulated specimens. A cycle-by-cycle summary of their irradiation history through HFIR cycle 315 is given in Table 1. Both capsules are operating as designed. Measured temperatures from the 21 thermocouples in the aluminum alloy specimen holder in each capsule indicate the specimen operating temperatures are within about $25^{\circ} \mathrm{C}$ of 200 and $400^{\circ} \mathrm{C}$, respectively, which satisfies the temperature criterion for these experiments.

\section{$\underline{\text { HFIR-MFE RB* Facilities }}$}

Facility preparations required for operation of two instrumented HFIR-MFE RB* capsules (200 and $400^{\circ} \mathrm{C}$ capsules) simultaneously were completed during the report period. These preparations included upgrade and final checkout of Materials Irradiation Facility No. 4 (MIF-4), connection of the instrumented $400^{\circ} \mathrm{C}$ capsule to MIF-4, disconnection of the $330^{\circ} \mathrm{C}$ capsule from MIF-3, and connection of the $200^{\circ} \mathrm{C}$ capsule to MIF-3.

\section{FUTURE WORK}

Design, preparation of fabrication drawings, procurement of parts, and assembly of a capsule for reencapsulating specimens from the above capsules into a dual-temperature capsule (probably 200 and $400^{\circ} \mathrm{C}$ ) is planned for FY 1994. 
Table 2. HFIR-MFE-200J-1 Loading List

\begin{tabular}{|c|c|c|c|c|c|c|c|c|c|c|c|c|c|c|c|c|c|c|c|}
\hline \multirow[b]{2}{*}{ Level 1} & \multicolumn{2}{|c|}{$\operatorname{Row} 1$} & \multirow{2}{*}{$\begin{array}{r}\text { Row } 2 \\
\begin{array}{c}F 3 \\
\text { X3 }\end{array} \\
\end{array}$} & \multirow{2}{*}{$\begin{array}{l}\text { Row } 3 \\
r_{1} \\
x_{1} \\
\end{array}$} & \multirow{2}{*}{$\begin{array}{l}\text { Row 4 } \\
A^{2} 201 \\
A^{203} \\
\end{array}$} & \multirow{2}{*}{$\begin{array}{l}\text { Row } 5 \\
\text { w3 } \\
C 2\end{array}$} & \multirow{2}{*}{$\begin{array}{l}\text { Row o } \\
\text { Wr }_{2} \\
\text { F2 } \\
\end{array}$} & \multicolumn{2}{|c|}{ Row 7} & \multirow{2}{*}{$\begin{array}{l}\text { Row } 8 \\
\begin{array}{l}8201 \\
\text { B103 }\end{array} \\
\end{array}$} & \multirow{2}{*}{$\begin{array}{l}\text { Row } 9 \\
\text { D402 } \\
\text { D301 }\end{array}$} & \multirow{2}{*}{$\begin{array}{c}\text { Row } 10 \\
\begin{array}{c}\text { A104 } \\
\text { H03 }\end{array}\end{array}$} & \multirow{2}{*}{$\begin{array}{l}\text { Row } 11 \\
\begin{array}{l}\text { A301 } \\
\text { D305 }\end{array}\end{array}$} & \multirow{2}{*}{$\begin{array}{c}\text { Row } 12 \\
\begin{array}{l}F 1 \\
\mathrm{T3}\end{array} \\
\end{array}$} & \multirow{2}{*}{$\begin{array}{l}\text { Hole A } \\
\text { spacer } \\
(218)\end{array}$} & \multirow{2}{*}{$\begin{array}{l}\text { Hole B } \\
\text { spacer } \\
(.218)\end{array}$} & \multirow{2}{*}{$\begin{array}{l}\text { Hole C } \\
\begin{array}{c}\text { pacer } \\
(.55 \sigma)\end{array} \\
\end{array}$} & \multirow{2}{*}{$\begin{array}{l}\text { Hote D } \\
\text { ppocer } \\
(.960)\end{array}$} & \multirow{2}{*}{$\begin{array}{l}\text { Hole E } \\
\text { ppacer } \\
(\text { soor) }\end{array}$} \\
\hline & $\begin{array}{l}\mathrm{HO1} \\
\mathrm{H} 02\end{array}$ & $\begin{array}{l}A 0 B \\
A 00\end{array}$ & & & & & & & & & & & & & & & & & \\
\hline Level 2 & $\begin{array}{l}\mathbf{B 2 0 3} \\
\text { B2044 } \\
\end{array}$ & $\begin{array}{l}\mathrm{C}^{201} \\
\mathrm{COOA}\end{array}$ & $\begin{array}{l}\mathrm{T} \\
\mathrm{C}\end{array}$ & $\begin{array}{l}w_{1} \\
c_{1}\end{array}$ & $\begin{array}{c}\text { EL.48 } \\
\text { GFA-47 }\end{array}$ & $\begin{array}{l}A 101 \\
A 202\end{array}$ & $\begin{array}{l}\text { D401 } \\
\text { A302 } \\
\end{array}$ & & & $\begin{array}{l}\text { A303 } \\
\text { DSO1 }\end{array}$ & $\begin{array}{l}\text { PAN } \\
\text { PAN } \\
\end{array}$ & $\begin{array}{l}\text { DS02 } \\
\text { A304 } \\
\end{array}$ & $\begin{array}{c}\text { PITCH } \\
\text { PAN } \\
\end{array}$ & $\begin{array}{l}\mathbf{A} 102 \\
\text { A } 304 \\
\end{array}$ & $\mathrm{C} 300$ & PSOP & J8 & 318 & 1 \\
\hline Level 3 & $\begin{array}{l}\text { B102 } \\
\text { C203 } \\
\end{array}$ & $\begin{array}{l}\mathbf{B}+101 \\
\mathbf{B} 403 \\
\end{array}$ & $\begin{array}{l}\mathbf{L} 01 \\
\text { A07 }\end{array}$ & $\begin{array}{l}103 \\
102 \\
\end{array}$ & $\begin{array}{l}\text { DL.S2 } \\
\text { DL.S3 } \\
\end{array}$ & $\begin{array}{c}\text { Dh-AS } \\
\text { GFD.so }\end{array}$ & $\begin{array}{l}\text { C103 } \\
\text { B202 } \\
\end{array}$ & & & $\begin{array}{l}\text { PrTCH } \\
\text { PrTCH } \\
\end{array}$ & $\begin{array}{l}\text { GFC.44 } \\
\text { E13.07 }\end{array}$ & $\begin{array}{l}\mathrm{A} 103 \\
\mathrm{D} 302\end{array}$ & $\begin{array}{l}\text { B3-.07 } \\
\text { CL-S4 } \\
\end{array}$ & $\begin{array}{l}E 4.07 \\
\text { B7.07 } \\
\end{array}$ & S2A7 & CIAG & $F$ & 2 & 3 \\
\hline Leved 4 & $\begin{array}{l}\text { TU.24 } \\
\text { EK.40 }\end{array}$ & & $\begin{array}{c}\text { GFD }+48 \\
\text { DL.+8 }\end{array}$ & $\begin{array}{l}\text { FL. } 43 \\
\text { E12-07 }\end{array}$ & $\begin{array}{l}\text { B13.07 } \\
\text { GFB-44 }\end{array}$ & $\begin{array}{l}\text { EL-Ay } \\
\text { E10.07 }\end{array}$ & $\begin{array}{c}\mathrm{GFC} .48 \\
11.49\end{array}$ & & & $\begin{array}{c}\text { GFA-49 } \\
\text { FL-44 }\end{array}$ & $\begin{array}{c}\mathbf{X} 2 \\
\text { EC.100 }\end{array}$ & $\begin{array}{l}\text { EL-53 } \\
\text { B11.07 } \\
\end{array}$ & $\begin{array}{l}\text { CL.53 } \\
\text { B10.07 }\end{array}$ & $\begin{array}{l}\text { EL.so } \\
\text { CL-A9 }\end{array}$ & $\mathrm{C} 3 \mathrm{~B} 1$ & 3505 & $\mathbf{E}$ & PS142 & 319 \\
\hline level 5 & $\begin{array}{l}\mathrm{HV} 03 \\
\mathrm{EL} \cdot 03 \\
\end{array}$ & & $\begin{array}{c}\text { HL.9 } \\
\text { GFA.48 } \\
\end{array}$ & $\begin{array}{l}\text { GFB-49 } \\
\text { GFA-45 }\end{array}$ & $\begin{array}{l}\text { B1-07 } \\
\text { E\&-07 } \\
\end{array}$ & $\begin{array}{l}\text { EL-52 } \\
\text { E2-07 } \\
\end{array}$ & $\begin{array}{c}\text { GFB }-47 \\
\text { FL }-46\end{array}$ & & & $\begin{array}{l}\text { CL-A8 } \\
\text { EL-sS }\end{array}$ & $\begin{array}{r}\text { E11.07 } \\
\text { B2.07 } \\
\end{array}$ & $\begin{array}{l}\text { GFB-18 } \\
\mathrm{CL}-47\end{array}$ & $\begin{array}{l}\text { FLSO } \\
\text { EL S1 }\end{array}$ & $\begin{array}{l}\text { B6-07 } \\
\text { FL-51 }\end{array}$ & FASP & C4A9 & 37 & $\mathrm{CB} 2$ & $\begin{array}{l}\text { Al ood } \\
(9.45)\end{array}$ \\
\hline Laels & $\begin{array}{c}\text { GFA }-44 \\
\text { DA- }-47\end{array}$ & & $\begin{array}{l}\text { E14.07 } \\
\text { FL.55 } \\
\end{array}$ & $\begin{array}{c}\mathrm{KL}-8 \\
\mathrm{BS}-07 \\
\end{array}$ & $\begin{array}{l}\text { TR.23 } \\
\text { HV.-07 } \\
\end{array}$ & $\begin{array}{c}\text { GFD }-49 \\
\text { FL }-40 \\
\end{array}$ & $\begin{array}{r}\text { 1L-8 } \\
\text { EQ907 }\end{array}$ & & & $\begin{array}{l}E \infty 007 \\
\text { DL- }\end{array}$ & $\begin{array}{c}\text { GFB. } 56 \\
\text { Es.07 } \\
\end{array}$ & $\begin{array}{l}\text { CL.52 } \\
\text { DL.50 } \\
\end{array}$ & $\begin{array}{l}\text { HL-8 } \\
\text { EL-54 } \\
\end{array}$ & $\begin{array}{r}\text { E1-07 } \\
\text { FL-53 } \\
\end{array}$ & FA48 & PSCO & 312 & $3 C 12-2$ & $\begin{array}{l}\text { spacer } \\
\text { (.500) }\end{array}$ \\
\hline Level? & & & $\begin{array}{l}\text { KL.9 } \\
\text { FL.S2 }\end{array}$ & $\begin{array}{l}\text { Cl.s1 } \\
\text { CL.w.18 }\end{array}$ & $\begin{array}{l}\text { EL.00 } \\
\text { EK-41 }\end{array}$ & $\begin{array}{l}\text { TR-24 } \\
\text { TW-10 } \\
\end{array}$ & $\begin{array}{l}82.07 \\
\text { E3.07 } \\
\end{array}$ & & & $\begin{array}{l}\text { GFB-45 } \\
\text { GFC-49 }\end{array}$ & $\begin{array}{l}\text { B12.07 } \\
\text { GFA.40 }\end{array}$ & $\begin{array}{l}49 \\
15 \\
\end{array}$ & $\begin{array}{l}\mathrm{B} 209 \\
\mathrm{~B} 109 \\
\end{array}$ & $\begin{array}{l}\text { MH-08 } \\
\text { EC-06 } \\
\end{array}$ & 3510 & FAOZ & 310 & $\mathrm{CC} 2_{2}$ & \\
\hline Lovel 8 & $\begin{array}{l}77 \cdot 24 \\
\pi \cdot 30\end{array}$ & $\begin{array}{l}\text { SB. } 37 \\
\text { SB.38 }\end{array}$ & $\begin{array}{l}\text { MH-.07 } \\
\text { EC.21 } \\
\end{array}$ & $\begin{array}{l}\infty \\
45 \\
\end{array}$ & $\begin{array}{l}\text { TZ.23 } \\
\text { HV.at }\end{array}$ & $\begin{array}{l}47 \\
47 \\
\end{array}$ & $\begin{array}{l}\mathrm{EC} \cdot 0 \mathrm{0w} \\
\mathrm{AE} \cdot 37 \\
\end{array}$ & & & $\begin{array}{l}\mathrm{AE}-3 \mathrm{SS} \\
\mathrm{EK} \cdot 42\end{array}$ & $\begin{array}{l}\text { HV.18 } \\
\text { EK } 43 \\
\end{array}$ & & $\begin{array}{l}\text { MH.05 } \\
\text { M11-06 }\end{array}$ & $\begin{array}{l}\mathrm{TL} \cdot 21 \\
\mathrm{TP} \cdot 2 \mathrm{2l}\end{array}$ & C2AG & S3AS & Jo & SIAS.2 & \\
\hline Lene' 9 & $\begin{array}{l}\text { SD. } 37 \\
\text { SD.38 } \\
\end{array}$ & $\begin{array}{l}\text { Th.7 } \\
\text { T.8. }\end{array}$ & & & & & & $\begin{array}{l}\mathrm{C} 100 \\
\mathrm{C} 200 \\
\end{array}$ & $\begin{array}{l}3104 \\
\text { C205 } \\
\end{array}$ & & & & & & PSO2 & 3502 & 19 & $3513-2$ & \\
\hline $\begin{array}{c}\text { Level } \\
10\end{array}$ & $\begin{array}{l}42 \\
43 \\
\end{array}$ & $\begin{array}{l}50 \\
41 \\
\end{array}$ & & & & & & $\begin{array}{l}\text { DL.-49 } \\
\text { DL.+4 }\end{array}$ & & & & & & & PSOS & 3009 & J11 & $\mathrm{CA} 2$ & \\
\hline $\begin{array}{c}1 \text { Level } \\
11\end{array}$ & & & & & & & & $\begin{array}{l}\text { TP.2.2 } \\
\text { TU.23 }\end{array}$ & & & & & & & $\mathrm{SA}_{30}$ & 3500 & 1 & $\operatorname{SA} 28-2$ & \\
\hline $\begin{array}{c}\text { Level } \\
12 \\
\end{array}$ & & & & & & & & $\begin{array}{l}\mathrm{TX} \cdot 1 \mathrm{1} \\
\mathrm{TE} \cdot 18 \\
\end{array}$ & & & & & & & $\mathrm{C}_{1 \mathrm{~B} 3}$ & cics & $\mathrm{J} 16$ & FA2 & \\
\hline $\begin{array}{c}\text { Level } \\
13\end{array}$ & & & & & & & & $\begin{array}{l}\mathrm{AE}-32 \\
\mathrm{AE}-34 \\
\end{array}$ & & & & & & & SA21 & $\mathrm{Csco}$ & 317 & $3 \cos$ & \\
\hline $\begin{array}{c}1 \text { Invel } \\
14\end{array}$ & & & & & & & & $\begin{array}{l}\text { Clul } \\
\text { C2012 }\end{array}$ & $\begin{array}{l}8+12 \\
C 105 \\
\end{array}$ & & & & & & $\begin{array}{l}\text { specer } \\
(.218) \\
\end{array}$ & $\begin{array}{l}\text { spacer } \\
(.218)\end{array}$ & $\begin{array}{l}\text { spacer } \\
\text { (SSsr) }\end{array}$ & C3B2 & \\
\hline $\begin{array}{c}\text { Ievel } \\
15\end{array}$ & & & & & & & & $\begin{array}{l}\mathrm{B}+04 \\
\mathrm{C} 101\end{array}$ & $\begin{array}{l}\mathrm{C}_{201} \\
\mathrm{BnOS}\end{array}$ & & & & & & & & & $\begin{array}{l}\text { pacer } \\
\left(I . I^{\prime}\right)\end{array}$ & \\
\hline $\begin{array}{c}\text { Level } \\
10\end{array}$ & & & & & & & & $\begin{array}{l}12 \\
40\end{array}$ & $\begin{array}{l}47 w \\
47 w\end{array}$ & & & & & & & & & $\begin{array}{l}\text { spacer } \\
\text { (14.095) }\end{array}$ & \\
\hline
\end{tabular}


Table 3. HFIR-MFE-400J-1 Loading List

\begin{tabular}{|c|c|c|c|c|c|c|c|c|c|c|c|c|c|c|c|c|c|}
\hline & \multicolumn{2}{|c|}{ Row 1} & Row 2 & Row 3 & Row 4 & Row $S$ & Row 6 & Row 7 & Row 8 & Row 9 & Row 10 & Hote A & Hok B & Hole C & Hote D & Hole E & Hote $\mathbf{R}$ \\
\hline Level 1 & \multicolumn{2}{|c|}{ PrnCH } & $\begin{array}{l}\text { GFB-23 } \\
\text { DL-28 }\end{array}$ & $\begin{array}{l}\mathrm{X} 6 \\
\mathrm{C7} \\
\end{array}$ & $\begin{array}{l}\text { LOO } \\
\text { HOS }\end{array}$ & $\begin{array}{l}\text { GFB-21 } \\
\text { GFA-24 }\end{array}$ & $\begin{array}{l}\mathrm{CB} \\
\mathrm{XS} \\
\end{array}$ & $\begin{array}{l}\text { A09 } \\
\text { Al0 }\end{array}$ & $\begin{array}{l}\text { Ho6 } \\
\text { L.07 }\end{array}$ & $\begin{array}{l}\text { PrTCH } \\
\text { PITCH }\end{array}$ & $\begin{array}{l}L 08 \\
\text { A11 }\end{array}$ & $\begin{array}{l}\text { spacer } \\
(0.5)\end{array}$ & $\begin{array}{c}\text { spacer } \\
(0.5)\end{array}$ & $\begin{array}{l}\text { pacer } \\
(1.25)\end{array}$ & $\begin{array}{l}\text { spacer } \\
\text { (0.5) }\end{array}$ & $\mathrm{CC2}$ & $\begin{array}{l}\text { spacer } \\
(1.25)\end{array}$ \\
\hline Level 2 & \multicolumn{2}{|c|}{ PITCH } & $\begin{array}{l}\text { GFB-24 } \\
\text { CLW-10 } \\
\end{array}$ & $\begin{array}{l}\mathrm{F} 4 \\
\mathrm{T4} \\
\end{array}$ & $\begin{array}{l}\text { Cl-27 } \\
\text { CL-29 } \\
\end{array}$ & $\begin{array}{c}\text { DL-30 } \\
\text { GFC-19 }\end{array}$ & $\begin{array}{l}\text { Fs } \\
\text { F6 }\end{array}$ & $\begin{array}{l}\text { EL-19 } \\
\text { DL.25 } \\
\end{array}$ & $\begin{array}{c}\text { GFB-19 } \\
\text { DL-22 } \\
\end{array}$ & $\begin{array}{c}\text { PITCH } \\
\text { PAN } \\
\end{array}$ & $\begin{array}{c}\mathrm{H} O 4 \\
\mathrm{D}+104 \\
\end{array}$ & FA:32 & $\mathrm{C} 3 \mathrm{~B} 4$ & $\begin{array}{l}\text { spacer } \\
(1.25)\end{array}$ & FAn1 & $3511-2$ & $\begin{array}{l}\text { spacer } \\
(1.25)\end{array}$ \\
\hline Level 3 & \multicolumn{2}{|c|}{ A07 } & $\begin{array}{l}\text { EL-20 } \\
\text { FL-12 }\end{array}$ & $\begin{array}{l}X_{4} \\
\text { C6 }\end{array}$ & $\begin{array}{l}\text { GFA-20 } \\
\text { GFD-23 }\end{array}$ & $\begin{array}{c}1 L-3 \\
E L-17 \\
\end{array}$ & $\begin{array}{l}\mathrm{TS} \\
\mathrm{T} 6 \\
\end{array}$ & $\begin{array}{l}\mathrm{HL}-3 \\
\mathrm{FL}-4\end{array}$ & $\begin{array}{c}\text { DL-24 } \\
\text { FL-5 }\end{array}$ & $\begin{array}{l}\text { PAN } \\
\text { PAN } \\
\end{array}$ & $\begin{array}{l}\text { A305 } \\
\text { A208 } \\
\end{array}$ & $\mathrm{C}^{\prime A} 7$ & C2A4 & $\begin{array}{c}\text { spacer } \\
(I))\end{array}$ & $\mathrm{PSO} 07$ & $\mathrm{CB2}$ & 7 \\
\hline Level 4 & \multicolumn{2}{|c|}{$A 0 B$} & $\begin{array}{c}\text { GFB-22 } \\
\text { FL-11 }\end{array}$ & $\begin{array}{c}\text { TL-10 } \\
\text { TL-9 }\end{array}$ & $\begin{array}{l}\text { CL-28 } \\
\text { FL-7 }\end{array}$ & $\begin{array}{l}\mathrm{CL} 2 \mathrm{~S} \\
\mathrm{ML}-3\end{array}$ & $\begin{array}{l}\text { B406 } \\
\text { W6 }\end{array}$ & $\begin{array}{l}\text { DL-27 } \\
\text { CL-23 }\end{array}$ & $\begin{array}{l}\text { FL.9 } \\
\text { FL.8 }\end{array}$ & $\begin{array}{l}71-32 \\
\text { SB-40 }\end{array}$ & $\begin{array}{l}\text { A108 } \\
\text { D503 }\end{array}$ & C3A6 & SIAO & Jn1 & $\mathrm{CAB} 6$ & $\mathrm{Csc}_{6}$ & 8 \\
\hline Levels & \multicolumn{2}{|c|}{ Lot } & $\begin{array}{l}\text { DL-23 } \\
\text { DL-29 }\end{array}$ & $\begin{array}{l}\text { B } 405 \\
\text { B207 } \\
\end{array}$ & $\begin{array}{l}\text { CL-24 } \\
\mathbf{K} L-4 \\
\end{array}$ & $\begin{array}{l}\text { CLW-9 } \\
\text { GFD-24 }\end{array}$ & $\begin{array}{l}\text { SD-40 } \\
\mathrm{TI}-31 \\
\end{array}$ & $\begin{array}{l}\text { GFA-19 } \\
\text { GFC-17 }\end{array}$ & $\begin{array}{l}\text { CL- } 30 \\
\text { EL-18 }\end{array}$ & $\begin{array}{l}\text { B205 } \\
\text { C109 } \\
\end{array}$ & $\begin{array}{l}\text { D306 } \\
\text { DS504 } \\
\end{array}$ & $\mathrm{SA}_{31}$ & FA12 & $\mathrm{E}$ & $\mathrm{C}_{2} \mathrm{C} 7$ & $\mathrm{C}_{4} \mathrm{Cl}^{3}$ & 6 \\
\hline Level 6 & \multicolumn{2}{|c|}{ L.07 } & $\begin{array}{l}\text { GFA-23 } \\
\text { GFB-20 }\end{array}$ & $\begin{array}{l}\text { B10K } \\
\text { B107 }\end{array}$ & $\begin{array}{l}\text { CL.22 } \\
\text { CL.26 }\end{array}$ & $\begin{array}{c}\text { IL-4 } \\
\text { GFC-18 }\end{array}$ & $\begin{array}{l}\mathrm{C}^{2007} \\
\mathrm{C} 20 \mathrm{R}\end{array}$ & $\begin{array}{c}\text { DL-26 } \\
\text { GFA.21 }\end{array}$ & $\begin{array}{c}\text { ML-A } \\
\text { GLA-22 }\end{array}$ & $\begin{array}{l}\mathrm{C} 209 \\
\mathrm{~B} 40 \mathrm{O}\end{array}$ & $\begin{array}{l}\text { D403 } \\
\text { D204 } \\
\end{array}$ &. $\mathrm{COA}$ & or & $F$ & cico & PSOM & 5 \\
\hline Level? & $\begin{array}{l}\text { ws } \\
\text { w4 }\end{array}$ & & & $\begin{array}{l}\text { B106 } \\
\text { C108 }\end{array}$ & & & $\begin{array}{l}\text { A308 } \\
\text { A } 105\end{array}$ & & & $\begin{array}{l}\text { A307 } \\
\text { A106 }\end{array}$ & & $\mathrm{C} 3 \mathrm{~A} 2$ & $\mathrm{SA}_{32}$ & $\mathrm{J8}$ & SA11: & $C 4 A 2$ & 320 \\
\hline Level 8 & $\begin{array}{l}\text { SB-39 } \\
\text { SD-39 }\end{array}$ & & & $\begin{array}{l}\text { B108 } \\
\text { C110 } \\
\end{array}$ & & & $\begin{array}{l}\text { A306 } \\
\text { A2066 }\end{array}$ & & & $\begin{array}{l}\text { A107 } \\
\text { A205 }\end{array}$ & & S2A4 & $\operatorname{CSA2}$ & J10 & C4BA & C4B30 & 321 \\
\hline Level 9 & $\begin{array}{l}\text { C107 } \\
\text { C210 }\end{array}$ & & & $\begin{array}{l}\mathrm{B} 200 \\
\mathrm{~B} \neq 07\end{array}$ & & & $\begin{array}{l}\text { A207 } \\
\text { D.303 }\end{array}$ & & & $\begin{array}{l}41 \\
40 \\
\end{array}$ & & $3 \mathrm{CO} 7$ & $\mathrm{C} 4 \mathrm{~B} 2$ & $\mathrm{J12}$ & 3507 & $C S B O$ & 322 \\
\hline $\begin{array}{c}\text { Lever } \\
10\end{array}$ & \multicolumn{2}{|c|}{$\begin{array}{l}\text { CGB-3 } \\
\text { CGB-4 }\end{array}$} & & $\begin{array}{l}43 \\
47\end{array}$ & & & $\begin{array}{l}82006 \\
47 \mathrm{~W}\end{array}$ & & & & & S2AO & $\mathrm{CrCH}_{4}$ & $\begin{array}{l}\text { pacer } \\
\text { (0.5) }\end{array}$ & SIA1 & SA 37 & $32 ?$ \\
\hline $\begin{array}{l}\text { Level } \\
11\end{array}$ & $\begin{array}{l}\mathrm{KL}-3 \\
\mathrm{HL}-4\end{array}$ & & & & & & & & & & & SAS8 & FAOS & $\begin{array}{l}\text { pacer } \\
(269)\end{array}$ & SAS3 & FA10 & $\begin{array}{l}\text { ppacer } \\
(20 \%)\end{array}$ \\
\hline $\begin{array}{l}\text { Level } \\
12\end{array}$ & \multicolumn{2}{|c|}{ w3 } & & & & & & & & & & SXAX2 & PS11-2 & & $3 \mathrm{C10-2}$ & 3504 & \\
\hline $\begin{array}{l}\text { Level } \\
13\end{array}$ & \multicolumn{2}{|c|}{$w_{4}$} & & & & & & & & & & \multirow{4}{*}{$\begin{array}{c}\text { A02 } \\
\text { Lo1 } \\
\mathbf{W Z} \\
\text { A01 } \\
\text { W1 } \\
\text { PITCH } \\
\text { PTTCH }\end{array}$} & $\mathrm{FE}-31$ & & FE-18 & FA2 & \\
\hline $\begin{array}{c}\text { Level } \\
14\end{array}$ & $\begin{array}{l}\mathrm{C} 112 \\
\mathrm{BA10}\end{array}$ & $\begin{array}{l}\text { B210 } \\
\text { B110 }\end{array}$ & & & & & & & & & & & & & & CA2 & \\
\hline $\begin{array}{c}\text { Level } \\
15\end{array}$ & $\begin{array}{c}\text { FL-10 } \\
\text { GFD-18 }\end{array}$ & & & & & & & & & & & & & & & SA2 & \\
\hline $\begin{array}{l}\text { Level } \\
16\end{array}$ & & & & & & & & & & & & & & & & FE-19 & \\
\hline
\end{tabular}




\section{REFERENCES}

1. K. R. Thoms et al., "HFIR Irradiation Facilities Improvements--Completion of the HIFI Project," J. Nucl. Mater., 155-157 (1988) 1340-45.

2. J. L. Scott et al., pp. 12-20 in ADIP Semiann. Prog. Rep., March 31, 1985, DOE/ER-0045/14, U.S. DOE, Office of Fusion Energy.

3. J. L. Scott et al., Second Annual Prog. Rep. on United States-Japan Collaborative Testing in the High Flux Isotope Reactor and the Oak Ridge Research Reactor, Sept. 30, 1985, ORNL/TM-10102.

4. A. W. Longest et al., "Fabrication and Operation of HFIR-MFE RB* Spectrally Tailored Irradiation Capsules," in Fusion Reactor Materials Semiann. Prog. Rep., March 31, 1992. DOE/ER-0313/12, U.S. DOE, Office of Fusion Energy.

5. A. W. Longest et al., "Design and Fabrication of HFIR-MFE RB* Spectrally Tailored Irradiation Capsules," in Fusion Reactor Materials Semiann. Prog. Rep., March 31, 1988, DOE/ER-0313/4, U.S. DOE, Office of Fusion Energy.

6. A. W. Longest et al., "Design and Fabrication of HFIR-MFE RB* Spectrally Tailored Irradiation Capsules," in Fusion Reactor Materials Semiann. Prog. Rep., Sept. 30, 1987, DOE/ER-0313/3, U.S. DOE, Office of Fusion Energy.

7. A. W. Longest et al., "Design and Fabrication of HFIR-MFE RB* Spectrally Tailored Irradiation Capsules," in Fusion Reactor Materials Scmiann. Prog. Rep., Sept. 30, 1988, DOE/ER-0313/5, U.S. DOE, Office of Fusion Energy.

8. A. W. Longest et al., "Fabrication and Operation of HFIR-MFE RB" Spectrally Tailored Irradiation Capsules," in Fusion Reactor Materials Semiann. Prog. Rep., Sept. 30, 1991, DOE/ER-(0313/11, U.S. DOE, Office of Fusion Energy.

9. A. W. Longest et al., "Fabrication and Operation of HFIR-MFE RB* Spectrally Tailored Irradiation Capsules," in Fusion Reactor Materials Semiann. Prog. Rep., Sept. 30, 1992, DOE/ER-0313/13, U.S. DOE, Office of Fusion Energy. 
Table 4. Detailed specimen information for HFIR-MFE-200J-1 and $-400 \mathrm{~J}-1$ capsules

\begin{tabular}{|c|c|c|c|}
\hline \multicolumn{4}{|c|}{ SS-3 Tensile Specimens (1 in. long) } \\
\hline Program & Alloy (Condition) & $\begin{array}{c}200 \mathrm{~J}-1 \\
\text { Specimens }\end{array}$ & $\begin{array}{c}400 \mathrm{~J}-1 \\
\text { Specimens }\end{array}$ \\
\hline US/ORNL* & PCA $(25 \% \mathrm{CW})$ & EK-41* & - \\
\hline - & PCA (25\%CW) & EK-4:- & . \\
\hline$\cdot$ & PCA $(25 \% \mathrm{CW})$ & EK-43* & - \\
\hline$\cdot$ & PCA $(25 \% \mathrm{CW})$ & EK-46. & . \\
\hline$\cdot$ & $316(20 \% \mathrm{CW})$ & $A E-32^{*}$ & $\cdot$ \\
\hline$\cdot$ & $316(20 \% \mathrm{CW})$ & $\mathrm{AE}-\mathbf{3 4 ^ { * }}$ & . \\
\hline " & $316(20 \% \mathrm{CW})$ & $\mathrm{AE}-35^{*}$ & - \\
\hline$\cdot$ & $316(20 \% \mathrm{CW})$ & $\mathrm{AE}-37^{\circ}$ & . \\
\hline$\cdot$ & PCA (25\% CW $)$ & EC- $06^{*}$ & . \\
\hline " & $\operatorname{PCA}(25 \% \mathrm{CW})$ & EC-ne* & . \\
\hline$\cdot$ & PCA (2S\%CW) & EC-09. & - \\
\hline$\cdot$ & PCA $\left(25 \% \mathrm{CW}^{\prime}\right)$ & EC-21* & - \\
\hline$n$ & PCA (B3) & EL-00* & - \\
\hline " & PCA (B.3) & EL-03* & $\cdot$ \\
\hline$\cdot$ & PC- $-20(25 \% \mathrm{CW})$ & HV-03* & - \\
\hline$\cdot$ & PCA-20 $(25 \% \mathrm{CW})$ & $\mathrm{HV}-04^{*}$ & - \\
\hline • & $\mathrm{PCA}-20(25 \% \mathrm{CW})$ & $\mathrm{HV}-07^{\circ}$ & - \\
\hline - & PCA-20) (25\%CW) & $\mathrm{HV}-\mathrm{OS} \mathrm{S}^{\circ}$ & - \\
\hline$\cdot$ & PCMA-6 $(2) / \mathrm{CW})$ & MH-OS• & . \\
\hline$"$ & PCMA-6 $(20) \% \mathrm{CW}_{1}$ & $\mathrm{MH}-\left(16^{*}\right.$ & . \\
\hline$\cdot$ & PCMA-6 $(20 \% \mathrm{CW})$ & МH-07" & - \\
\hline. & PCMA-6 $(20 \% \mathrm{CW})$ & MH-OR: &. \\
\hline US/PNL" & VO-2262 (a) & TE-18* & - \\
\hline$\cdot$ & VO- $2267(b)$ & TL-21* & - \\
\hline$"$ & $v 0-2266(b)$ & TP-21" & - \\
\hline$\cdot$ & $v 0.2266(\mathrm{~b})$ & TP-22* & - \\
\hline
\end{tabular}

\begin{tabular}{|c|c|c|c|}
\hline \multicolumn{4}{|c|}{ SS-3 Tensile Specimens (1 in. long) } \\
\hline Program & Alloy (Condituon) & $\begin{array}{c}2001 \mathrm{~J}-1 \\
\text { specimen }\end{array}$ & $\begin{array}{c}4(x) j-1 \\
\text { Specimens }\end{array}$ \\
\hline US/PNL* & $v 0.226 \times(h)$ & TR.2.3* & . \\
\hline$\cdot$ & $v 0.226 x(h)$ & TR-24: & . \\
\hline$\cdot$ & $v 0.2269(\mathrm{~h})$ & TU.2."* & - \\
\hline$\cdot$ & VO-22kg (h) & TU.24* & . \\
\hline " & VO-2754 (c) & TW-16* & . \\
\hline$\cdot$ & VO.2755 (c) & TX-16* & . \\
\hline- & $U C-1 y(3)$ & $\mathrm{TZ} \cdot 23^{*}$ & . \\
\hline JAERI & F82H (hanc metul, & B101 & B115 \\
\hline " & F82H (hase metal) & $\mathrm{B} 102$ & Bik, \\
\hline$=$ & $\mathrm{F} \times 2 \mathrm{H}$ (hase metut, & B 10.3 & $\mathrm{~B} \mid 17$ \\
\hline$\cdot$ & Fr2H (hase me: $: 1$ ), & BuH & B1ths \\
\hline " & $\mathrm{F} \times 2 \mathrm{H}$ (hianc metul, & $B !(k)$ & B1111 \\
\hline * & FX2H (TIG weld jount) & B2(0): & B215 \\
\hline " & FX2H (TIG weld yount) & $\mathrm{B} 2132$ & B2ok \\
\hline$\cdot$ & FX2H (TKG weld gom ) & B2u3 & $\mathrm{B} 2117$ \\
\hline " & FX2H (TIG wald foin!) & B2(H & $\mathrm{B} 211 \mathrm{x}$ \\
\hline$\cdot$ & FS2H (TIG weid man! & $B 2(k)$ & $\mathrm{B} 210$ \\
\hline " & FX2H llaser ucld went, & $B+411$ & $\mathrm{~B}+105$ \\
\hline - & FS2H tiacer ucld fount & $B+102$ & $B+(k)$ \\
\hline - & F\&2H (baser weld gomn & $\mathrm{B}+113$ & B4i17 \\
\hline$*$ & F $22 \mathrm{H}$ (laser weld jornt) & B.414 & B4AS \\
\hline$\cdot$ & FX2H dlaser ueld yount! & . & $B+11$ \\
\hline$\cdot$ & $J P C A(S A)$ & $\mathrm{Clul}$ & $\mathrm{Cl} 17$ \\
\hline " & $J P C A(S A)$ & $\mathrm{ClO}$ & $\operatorname{clos}$ \\
\hline$\cdot$ & JPCA ISA & $\mathrm{CHO}$ & $\mathrm{Cl} 1 \mathrm{OH}_{4}$ \\
\hline$\cdot$ & $J P C A(S A)$ & $\mathrm{Cl} 1 \mathrm{H}$ & $\mathrm{Cl} 16$ \\
\hline
\end{tabular}


Table 4. Continued

\begin{tabular}{|c|c|c|c|}
\hline \multicolumn{4}{|c|}{ 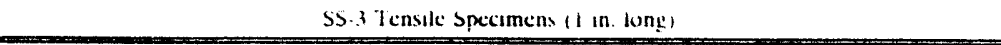 } \\
\hline Program & Alky icondituon, & $\begin{array}{c}200 \mathrm{~J} \cdot 1 \\
\text { specomen. } \\
\end{array}$ & $\begin{array}{c}40001-1 \\
\text { Specimen } \\
\end{array}$ \\
\hline JAERI & $J P C A(S A)$ & Clus & $\mathrm{C} 112$ \\
\hline$\cdot$ & $J P C A(S A)$ & Clik & . \\
\hline • & JPCA $\left(\mathrm{CW}_{1}\right.$ & $\mathrm{C} 201$ & $\mathrm{Car}^{2}$ \\
\hline$\cdot$ & JPCA (CH) & $\mathrm{CsOz}_{2}$ & $\mathrm{C} 2 \mathrm{~m}$ \\
\hline " & JPCAICW: & $\cos$ & CatK \\
\hline • & JPCA (CW) & $\mathrm{C} 2 \mathrm{M}$ & call \\
\hline$\cdot$ & JPCA ICW' & C205 & . \\
\hline$\therefore$ & JPCAICU, & $\mathrm{C}_{2}(\mathrm{x}$, & \\
\hline USIORNL & WTHIMOVNH & TL.- & TL.y \\
\hline - & YCr-IMOVNH & TL- $\times$ & $\mathrm{TL} \cdot 10$ \\
\hline • & $4(\mathrm{Cr}-1 \mathrm{M} 0) \mathrm{Nh}-2 \mathrm{~N}$ & $\mathrm{Tl} \cdot 2 \mathrm{O}$ & $\mathrm{Tl}-31$ \\
\hline • & $x_{r-1 M o N N R}-2 N$ & $\mathrm{TH}-3 \mathrm{~B}$ & $\mathrm{TI} \cdot 32$ \\
\hline - & $12 \mathrm{Cr}-1 \mathrm{MovH}$ & SB-i: & SB-34 \\
\hline " & $12 \mathrm{Cr} \cdot \mathrm{MovN}$ & SB-3x & SB-411 \\
\hline$\cdot$ & $12(1-1 M n N W \cdot 2 v$ & SD.37 & SD. 34 \\
\hline$\cdot$ & $12 \mathrm{Cr}-1 \mathrm{MuVH}-2 \mathrm{Ni}$ & SD-3x & $S D-41$ \\
\hline US/ORNI & Gludop $A 125+B$ (a) wrought, & $u^{\prime} 1$ & u. \\
\hline$\cdot$ & Glaceps $A 25+B$ (as wroughi) & $w=$ & $w 5$ \\
\hline - & Glducoup Alבs + B (a) wroughi) & $w 3$ & $w_{n}$ \\
\hline - & Gildudop Al2s + B (cold rolled & $\mathrm{Cl}$ & $c h$ \\
\hline$\cdot$ & Ghdcon $A \mid 25+B$ (cold rolled) & $\mathrm{C}^{2}$ & $\mathrm{C}^{7}$ \\
\hline$\cdot$ & Gitudop AI25+B (cold rolled) & 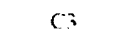 & $c x$ \\
\hline$\cdot$ & Gildcup AIZS (cold rolled) & $x !$ & $x_{4}$ \\
\hline •" & Glideop ALS (cold rolled) & $x=$ & $x 5$ \\
\hline • & Glidcup AlPS (cold rolled) & $x_{3}$ & xo \\
\hline$\cdot$ & MACIT 0.2 cold rolled: & $\mathrm{T}$ & $\mathrm{TH}$ \\
\hline
\end{tabular}

\begin{tabular}{|c|c|c|c|}
\hline \multicolumn{4}{|c|}{ SS-3 Tenstle Specimens if in. long, } \\
\hline Prouram & Allon (Conditton) & $\begin{array}{c}2(x)]-1 \\
\text { specimen }\end{array}$ & $\begin{array}{c}4(0)]-1 \\
\text { Specimens }\end{array}$ \\
\hline \multirow{2}{*}{$\begin{array}{c}\text { US/ORNL } \\
\cdot\end{array}$} & MAGT 0.2 (cold rolled) & $T_{2}$ & TS \\
\hline & MACiT (1.2 rould rolled, & $\mathrm{T}, 3$ & To \\
\hline \multirow{2}{*}{. } & Gildeor Al15+B as extruded. hrazed, & $\mathrm{Fl}$ & $F_{4}$ \\
\hline & Gilidcop Al15+B (as extruded brazed & $\mathrm{F}:$ & F5 \\
\hline - & Glidcon Al15+B as exiruded hrazdd & F3 & Fo \\
\hline \multirow{2}{*}{. } & MER (U-Al:O,-graphite ipatch P121) & blank & blank \\
\hline & MER CU-A), O,-graphite (pitch P12(1) & blank & blank \\
\hline$"$ & 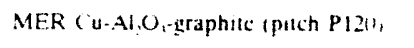 & blank & blank \\
\hline \multirow[t]{2}{*}{ " } & MEK (U-Al,O,-graphite Ipan IMy) & notched & notched \\
\hline & MER CU-Al.O,-graphutc Ipan IMY, & notched & notched \\
\hline - & MER CU-AIO, graphate ipan IMU, & nutched & notched \\
\hline US:ANL & V.10T & BL-12 & \\
\hline \multirow[b]{2}{*}{$"$} & Witi & BL-15 & $\cdot$ \\
\hline & V. $15 \mathrm{Cr} .5 \mathrm{Th}$ & $B L-41$ & BL-4! \\
\hline - & $1.371 .11 .5 \mathrm{~s}$ & $B L-4=$ & $\cdot$ \\
\hline . & $\therefore .10 \mathrm{Ct}-5 \mathrm{TH}$ & $\mathrm{BL}-43$ & $B L-43$ \\
\hline - & V.MTIS: & BL-45 & - \\
\hline$\cdot$ & $\therefore 51$ & $B L-40$ & - \\
\hline . & $\therefore \mathrm{SCr}-5 \mathrm{TH}$ & BL-4: & $B L-47$ \\
\hline - & V.SCr.STi & $B L-47$ & - \\
\hline \multirow{2}{*}{. } & V.SCr.5Ti , TKG ucid zon: & BL. $47 \mathrm{~W}$ & $B L-47 W$ \\
\hline & V. $5 \mathrm{Cr}-5 \mathrm{~T}$ (TIG weld sonc: & $B L-47 \mathrm{~W}$ & $\cdot$ \\
\hline \multirow[t]{2}{*}{ - } & $V-7 \mathrm{Cr}-5 \mathrm{Tl}_{1}$ & $B L-4 y$ & BL-f4 \\
\hline & $V-1 T_{1}$ & BL-50) & - \\
\hline$\cdot$ & $\checkmark .3 T i-0.1 \mathrm{C}$ & BL_-(x) & - \\
\hline Conditic & 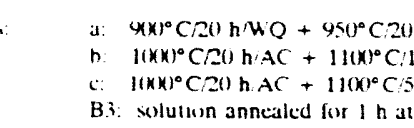 & $\begin{array}{l}+6511^{\circ} 2 \mathrm{~h} \\
\mathrm{C}+7(0)^{\circ} \mathrm{Cl} \\
+650^{\circ} \mathrm{C} / \\
\text { aged } \mathrm{s} \text { h at }\end{array}$ & $+25 \% \mathrm{Cu}$ \\
\hline
\end{tabular}


Table 4. Continued

\begin{tabular}{|c|c|c|c|}
\hline \multicolumn{4}{|c|}{ Ss 17 ensile specimens (1.75 in. long) } \\
\hline Program & Allov (Condituon) & $\begin{array}{c}2(x) j-1 \\
\text { specimen }\end{array}$ & $\begin{array}{c}\mathcal{H}(\boldsymbol{k}) \mathrm{J} \cdot \mathrm{:} \\
\text { Specimen }\end{array}$ \\
\hline JAER!• & $J P C A(S A)$ & $\mathrm{CL}-4^{\circ}$ & $\mathrm{CL}-22=$ \\
\hline$\cdot$ & $J P C A$ (SA) & $\mathrm{CL}-4 \mathrm{x}^{*}$ & $\mathrm{CL} \cdot 23^{\circ}$ \\
\hline$\cdot$ & $J P C A(S A)$ & $C L .49^{*}$ & $\mathrm{CL} \cdot 24^{\circ}$ \\
\hline$\cdot$ & $J P C A(S A)$ & $\mathrm{CL}-51^{\circ}$ & CL.25. \\
\hline$\cdot$ & $J P C A(S A)$ & CL.-5?: & $\mathrm{Cl}-2 \mathrm{n}^{\circ}$ \\
\hline$\cdot$ & $J P C A(S A)$ & $\mathrm{CL} .53^{-}$ & $\mathrm{CL}-27$ \\
\hline$\cdot$ & $J P C A(S A)$ & CL-S. & $\mathrm{Cl}-2 \mathrm{x}^{*}$ \\
\hline$\cdot$ & JPCA $\{S A\}$ & & $\mathrm{Cl} .2 \psi^{*}$ \\
\hline$\cdot$ & $J P C A \mid S A)$ & . & $\mathrm{CL} \cdot 3)^{\circ}$ \\
\hline$\cdot$ & JPCA $\left.11^{\prime} ; C H\right)$ & DL-6* & DL.2:" \\
\hline - & JPCA (15:iCW) & DL.4." & $\mathrm{DL} \cdot 23^{*}$ \\
\hline$\cdot$ & JPCA $115 \% C 4:$ & DL- $46^{\circ}$ & $D L-24^{\circ}$ \\
\hline$\cdot$ & 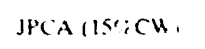 & DL-47" & $D L .25 \cdot$ \\
\hline$\cdot$ & IPCA 11S\%:CW: & $\mathrm{DL}-4 \mathrm{~s}$ & $\mathrm{DL} \cdot 2 \mathrm{n}^{\circ}$ \\
\hline$\cdot$ & IPCA $115 \%$ CW: & DL.s.". & DL.27• \\
\hline$\cdot$ & JPCA $1159 \mathrm{CU}$ & DL-50* & $D L-2 x^{*}$ \\
\hline$\cdot$ & JPCA 115rFCU! & DL-5?" & DL $: ? *$ \\
\hline$\cdot$ & APCA $11^{\prime} ; C H$ & DL.5.3. & $\mathrm{DL} \cdot 3 \cdot$ \\
\hline$\cdot$ & MOSS ISA, & $E L-4 S^{\prime}$ & EL-H \\
\hline - & $316 S S$ (SA) & $E L-44^{\circ}$ & EL-1K• \\
\hline$\cdot$ & BI(LSS $(S, A)$ & $E L-51^{\circ}$ & EL-14* \\
\hline$\cdot$ & $3 \mid 6, S S(S A)$ & EL-.5." & EL.2." \\
\hline$\cdot$ & $3 \ln S S(S A)$ & EL.5." & \\
\hline$\cdot$ & $316 S S$ (SA) & EL-.5." & . \\
\hline$\cdot$ & $3 \mid(1) S$ (SA) & EL-54' & . \\
\hline
\end{tabular}

\begin{tabular}{|c|c|c|c|}
\hline \multicolumn{4}{|c|}{ SS-1 Tensule Specimens (1.75 in. long: } \\
\hline Program & Allur kcondition) & $\begin{array}{l}2\{k i j \cdot 1 \\
\text { specimin. }\end{array}$ & $\begin{array}{c}\text { Hould } 1 \\
\text { Spicimin. }\end{array}$ \\
\hline JAER $1^{\circ}$ & $316 S S$ (SA) & EL $55^{\circ}$ & \\
\hline$\cdot$ & $1310(20 \mathrm{r}: \mathrm{Cw})$ & FL-4!" & $\mathrm{FL}-4^{*}$ \\
\hline$\cdot$ & $\mathrm{J} 316(20 \% \mathrm{CW})$ & $\mathrm{Fl}-43^{\circ}$ & FL s. \\
\hline - & $J 310$ (2) & $\mathrm{FL} \cdot \mathbf{4}^{*}$ & $\mathrm{FL} \rightarrow$ \\
\hline • & $J 316(21) \% \mathrm{CW})$ & $\mathrm{Fl}-4 \mathrm{~s}^{\circ}$ & FL.x. \\
\hline$\cdot$ & J36 sar:cu, & FL. $-51 \cdot$ & FL. $\varphi^{*}$ \\
\hline - & Jisto $2019 \mathrm{CW}\}$ & FL .51 & FL- $11 \cdot$ \\
\hline$\cdot$ & Jisth $120(1): C W$ & $\mathrm{FL} \subseteq$ & 1111 \\
\hline$\cdot$ & $J 36,2(1 \%: C 4$, & $\mathrm{FL} .53$ & FL-12' \\
\hline$\cdot$ & $J 316120, \mathrm{CW}$ & $\mathrm{FL} 5 \%$ & \\
\hline$\cdot$ & SIIIISAR: & $H 1 \times$ & Hil. \\
\hline - & JilnISAR, & HI" & $\mathrm{HIL}+4$ \\
\hline$\cdot$ & dual phase $K$ is $A$ : & $11 \%$ & II. 3 \\
\hline - & dual pham $K$ isA, & $11 . \%$ & 114 \\
\hline$\cdot$ & all markensuls (neat trealed) & & ML : : \\
\hline " & all martenuste theat treated & & $M L-4$ \\
\hline$\cdot$ & 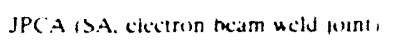 & KL.s. & $\mathrm{Kl}: 3$ \\
\hline$\cdot$ & JPCA ISA. clectrun heam weid gornt, & 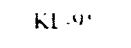 & $\mathrm{kl.H}$ \\
\hline$\cdot$ & JPCA ISA. TKG weld metal, & CLU'LN & CLWu. \\
\hline$\cdot$ & JPCA ISA. TKG Welu metali & . & CLW: $111^{\circ}$ \\
\hline USIORNL. & $B \mid$ ISA, & B1.tr & \\
\hline$\cdot$ & $B=(B A)$ & $\mathrm{BZ}-\mathrm{C}^{-} \cdot$ & . \\
\hline$\cdot$ & $B:(S A)$ & $B 3,11 \%$ & \\
\hline$\cdot$ & $B 5(S A)$ & $B 5.117$ & . \\
\hline$\cdot$ & $B 6|S A|$ & $B h-117 \cdot$ & \\
\hline
\end{tabular}


Table 4. Continued

\begin{tabular}{|c|c|c|c|}
\hline \multicolumn{4}{|c|}{ SS $17 \mathrm{ens}$ ke specimens 11.75 in. Jong } \\
\hline Program & Aliny IConditwon, & $\begin{array}{c}2(x) J-1 \\
\text { specimen }\end{array}$ & $\begin{array}{c}4(0) 1-1 \\
\text { specimen- }\end{array}$ \\
\hline USOORNL. & $B 7\{S A\}$ & $B>-(1)=$ & . \\
\hline$\cdot$ & $B^{4}(S A)$ & By-(1) & . \\
\hline$\cdot$ & $B(1,(S A)$ & $B 10-07$. & . \\
\hline & BII SA: & B11.1." & \\
\hline " & $B 12$ (SA) & B12-1 17 & \\
\hline$\cdot$ & $B 13\{S A\}$ & Bi3-1) & \\
\hline$\cdot$ & $E-1(S A)$ & E.t. & . \\
\hline$\cdot$ & $E 2 S A$ & $E=-0^{7}$ & $\cdot$ \\
\hline$\cdot$ & $E ; i S A$, & $E:-1^{-}$ & \\
\hline$\cdot$ & $E+\operatorname{CA}$ & E.t.". & \\
\hline$\cdot$ & $1=(S A)$ & ES.10 & \\
\hline " & focts) & E-6.1 & \\
\hline$\cdot$ & EXISA & Ex-11- & \\
\hline$\cdot$ & EYISA, & $E^{4.117}$ & \\
\hline$\cdot$ & $k-1101 s+$ & Ell1:(1). & \\
\hline$\cdot$ & EHA: & E.11.1\%? & . \\
\hline • & $E \cdot 1213 A$ & E12.11: & \\
\hline$\cdot$ & $1 \cdot 1 ; 13 .+1$ & E13-11. & . \\
\hline . & $1+1+15 x$ & Eis $\|^{-}$ & \\
\hline JAERI & Al: & Alul & Alls \\
\hline$\cdot$ & $A F=$ & $A !(1)=$ & $A \mid l k)$ \\
\hline$\cdot$ & Ar: & Ali? & All: \\
\hline$\cdot$ & $A F:$ & AllH & Alux \\
\hline " & $\mathrm{AF}$ & $\mathrm{A} 2011$ & $\mathrm{~A}^{2}(1)^{5}$ \\
\hline
\end{tabular}

\begin{tabular}{|c|c|c|c|}
\hline \multicolumn{4}{|c|}{ SS-1 Tenstle specimens (1.75 in. tong) } \\
\hline Program & Alton icendituon: & $\begin{array}{c}20013 \cdot 1 \\
\text { Specimen: }\end{array}$ & $\begin{array}{c}4(x)]-1 \\
\text { Specamen. }\end{array}$ \\
\hline JAERI & AFs & $A 212$ & A2(k \\
\hline$\cdot$ & AF5 & A20: & A20: \\
\hline$\cdot$ & AF5 & A2(H & Aztux \\
\hline$\cdot$ & AF & $A 3 i !$ & A305 \\
\hline - & AF & A3): & A316 \\
\hline$\cdot$ & AF & 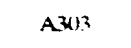 & Aख) \\
\hline$\cdot$ & $\mathrm{AF}^{-}$ & A 344 & Aओयू \\
\hline$\cdot$ & $3 \mid \sigma-M=$ & D.311 & DW/; \\
\hline$\cdot$ & $310-M=$ & D.1) $=$ & DWH \\
\hline$\cdot$ & $316 \cdot \mathrm{M}$ & Dw: & D. $3 *$. \\
\hline$\cdot$ & $3 / 6 \cdot M^{-}$ & $D+11$ & D413 \\
\hline " & $316.1 \varphi^{-}$ & $D+12$ & DHA \\
\hline$\cdot$ & in.Ml" & D501 & DSt: \\
\hline$\cdot$ & $316-\mathrm{MH}$ & DSU: & DS14 \\
\hline USORNL. & Copner MRC Mats grade is wrought, & $A(x)$ & $A(*)$ \\
\hline$\cdot$ & Copper. MRC Mar/ grade ia wrought, & An: & All: \\
\hline - & Cenper N:RC Marz grade a wrough: & Alm & All \\
\hline$\cdot$ & 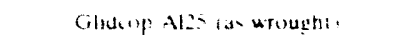 & Hol & $\mathrm{H}(\mathrm{H}$ \\
\hline - & chlocuen $A 2=$ a wreughn, & HU: & HeS \\
\hline - & Gltwor Alzs a urought & $\mathrm{Hos}$ & $H(k$ \\
\hline$\cdot$ & Glidcop $A d s+B$ (urought shech & Li1! & Les \\
\hline - & Gilduen $A D S+B$, wrought shect & LUI & Lo? \\
\hline " & Ginderen $A ! 2-B$ B wrought sheer: & Lo: & Ler \\
\hline
\end{tabular}


Table 4. Continued

\begin{tabular}{|c|c|c|c|}
\hline \multicolumn{4}{|c|}{ Pressurizzd Tube and Tube Blank Specimens (1 in or 0.25 in. Jong) } \\
\hline Program & Alloy rCondwen, & $\begin{array}{c}2(x))-1 \\
\text { Specimen L.D } \\
\text { (Stress. MPa) }\end{array}$ & $\begin{array}{c}4(x)]-1 \\
\text { Spectmen l.D } \\
\text { (Stress. MPa) }\end{array}$ \\
\hline US/ORNL* & PCA $120 \% \mathrm{CH}$, & $\mathrm{FA}^{2}(0)^{*}$ & FAZ (11)* \\
\hline • & PCA $2015 \mathrm{CW})$ & FAsy $(50)^{\circ}$ & FAU1 $(\mathbf{S O})^{*}$ \\
\hline$\cdot$ & $\mathrm{PCA}(20) \mathrm{CH})$ & FA4K $(100)^{\circ}$ & FA32 $(100))^{\circ}$ \\
\hline$\cdot$ & PCA (20\%CU) & FA62 $(200))^{\circ}$ & FAlO $(200)^{\circ}$ \\
\hline$\cdot$ & PCA $20 \% \mathrm{CW}$ ) & . & FAus $(3(x))^{\circ}$ \\
\hline • & PCA (20\%CW) & . & FA12 $(+40))^{\circ}$ \\
\hline$\cdot$ & HT.U (tempered martenstie) & SA2X-2 $(0)^{\circ}$ & $\mathrm{SA}^{2}(0)^{\circ}$ \\
\hline$\cdot$ & HT.V (tempered martensule) & SA21 $(2(x))^{\circ}$ & SAS8 (50). \\
\hline$\cdot$ & $H T \cdot Y$ (tempercu martenste) & $S A B(+1))^{\circ}$ & SA.37 (110) \\
\hline$\cdot$ & HT.y (Iempered mariensite) & & SA3 $32(20))^{\circ}$ \\
\hline$\cdot$ & HT.Y tempered marticnstle, & . & SAS3 $(3(x))^{\circ}$ \\
\hline$\cdot$ & HT.4 (tempered martensite) & & SAU3 $(4(x))^{\circ}$ \\
\hline$\cdot$ & HT.4 (tempered martensate) & & $\left.S_{A} 31(40)\right)^{\circ}$ \\
\hline$\cdot$ & $1 B(S A)$ & CA2 III. & $C A 2(0)^{\circ}$ \\
\hline$\cdot$ & $1 B(S A)$ & CIAG $(5)^{\circ}$ & $\operatorname{csa} 2(5)^{\circ}$ \\
\hline$\cdot$ & $\mathrm{BB}, \mathrm{SA})$ & $\operatorname{czan}(111)^{\circ}$ & C.3At (110) \\
\hline 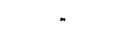 & IB \&A: & CHAY 311 & $C+A 2: 21 ;$ \\
\hline$\cdot$ & $1 \mathrm{~B}(\mathrm{SA})$ & & C2At (B), \\
\hline$\cdot$ & IB iSA: & & $C 3 A=(4) \cdot$ \\
\hline$\cdot$ & $\mathrm{IB}, \mathrm{SA}:$ & . & C1AT(स) \\
\hline$\cdot$ & $2 \mathrm{~B}(\mathrm{SA})$ & $\mathrm{CB} 2(1))^{\circ}$ & $C B=(0)^{\circ}$ \\
\hline$\cdot$ & $2 B(S A)$ & $\mathrm{C} 3 \mathrm{~B} 2(5)^{\circ}$ & $C+B+(5)^{\circ}$ \\
\hline$\cdot$ & $2 \mathrm{~B}(\mathrm{SA})$ & $\operatorname{CJB} 3(10)^{\circ}$ & $\cos (10)^{\circ}$ \\
\hline$\cdot$ & $2 \mathrm{~B}(\mathrm{SA})$ & C3BI (30) & $C 4 B 2(20)^{\circ}$ \\
\hline$\cdot$ & $2 B(S A)$ & $\cdot$ & $\mathrm{C} A \mathrm{BO}^{\prime}(3)$ \\
\hline$\cdot$ & $2 \mathrm{~B}(\mathrm{SA})$ & . & $\operatorname{csB}(130)^{\circ}$ \\
\hline
\end{tabular}

\begin{tabular}{|c|c|c|c|}
\hline \multicolumn{4}{|c|}{ Prasurized Tume and Tube blank Specimen if in or 025 in long, } \\
\hline Program & Alkn IConditun & $\begin{array}{c}2(x)]-1 \\
\text { Spcimen } 1 \text { ) } \\
\text { (Stress. MPas } \\
\end{array}$ & 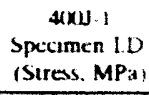 \\
\hline USSORNL" & $2 B(S A)$ & . & $\operatorname{CsBn}(41)^{\circ}$ \\
\hline • & $3 B(S A)$ & $\mathrm{CC}(0))^{\circ}$ & $\operatorname{cc} 2(1)^{\circ}$ \\
\hline$\cdot$ & $3 B(S A)$ & $\csc (20)^{\circ}$ & $\mathrm{ClCu}(10)^{\circ}$ \\
\hline$\cdot$ & $3 B(S A)$ & $\operatorname{ctc}(50))^{\circ}$ & $\mathrm{C}^{2} \mathrm{C} 4(2)^{\circ}$ \\
\hline • & $\left.{ }^{3} B{ }_{1} S_{A}\right)$ & $\mathrm{C} 3 \mathrm{Co}(1 \mathrm{x})\}^{\circ}$ & $\mathrm{C} 3 \mathrm{Co}(50) !^{\circ}$ \\
\hline$\cdot$ & $3 B(S A)$ & - & $\operatorname{coc}(5) 1)^{\circ}$ \\
\hline$\cdot$ & $i B(s+)$ & & Cscrann: \\
\hline$\cdot$ & SAISA & SIA.5-2 $1110^{\circ}$ & $\operatorname{SXAX} 2(0)^{\circ}$ \\
\hline$\cdot$ & $S A_{B A}$ & $S 3 A^{5} 1200^{\circ}$ & SIAl! $(10)^{\circ}$ \\
\hline$"$ & $S A|S A|$ & $S 2 A>(x+)^{\circ}$ & $6120)^{\circ}$ \\
\hline " & SAISA, & & S2A4 $(5,1)^{\circ}$ \\
\hline$\cdot$ & $S A, S A$ & - & SZAll $\left(B 0_{1}\right)^{+}$ \\
\hline$\cdot$ & $S A|S A|$ & $\therefore$ & SIAl (I (m) \\
\hline JAERI' & $\ln \mid \ln (\mathrm{SA})$ & $3513-2\left(n h^{\circ}\right.$ & $3511.2(11)^{\circ}$ \\
\hline “ & $J i 3 \mid(S A)$ & $\left.{ }^{3} \operatorname{Sin}(x)\left(x_{1}\right)\right)^{-}$ & $3 \mathrm{~S}(1 \mathrm{t}(1)(x))^{\circ}$ \\
\hline$\cdot$ & Jinisis & $35021100 y^{\circ}$ & $3 \sin (120)^{\circ}$ \\
\hline$"$ & $3: 16 \cdot 64$ & : & \\
\hline " & $1: 16,3 x$ & $35110(1501)^{\circ}$ & \\
\hline$\cdot$ & $J i n, 2 \pi, c h$ & $3 \mathrm{Cl} 2 \cdot 2(0,)^{\circ}$ & $3010-260^{\circ}$ \\
\hline “ & Jathisicu & $3(15)(2(x))^{\circ}$ & 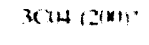 \\
\hline$\cdot$ & 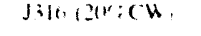 & $3 C(\cos (3))^{\circ}$ & $300 \%(t+k))^{\circ}$ \\
\hline$"$ & $J P C A|D A|$ & PSit.2 $2(1)^{\circ}$ & PS11.2101 \\
\hline$\cdot$ & JPCA ISA & PS(M) $(11 x))^{\circ}$ & PSin (1101) \\
\hline * & JPCA ISA & $P S U=113 \|^{\circ}$ & $P S O^{-}=1501^{\circ}$ \\
\hline • & JPCA ISA & PSis $(1601)^{\circ}$ & \\
\hline$\cdot$ & JPCA ISA & $\left.\operatorname{PS}(N)(1) \times()_{1}\right)^{\circ}$ & \\
\hline
\end{tabular}


Table 4. Continued

\begin{tabular}{|c|c|c|c|}
\hline \multicolumn{4}{|c|}{ Crimtansh Falugue specimens 11.75 in long: } \\
\hline Program & Allon (Conditson, & $\begin{array}{c}2(k)]-1 \\
\text { specimen } 1.1) \\
\end{array}$ & $\begin{array}{c}\mu(x)]-! \\
\text { spectmen ID }\end{array}$ \\
\hline JAER $\left.\right|^{\bullet}$ & $J P C A|S A|$ & GFA.4.4. & GFA-19* \\
\hline - & JPCA ISA & GFA-4S. & GFA.2I" \\
\hline - & $J P C A(S A)$ & GrA.4t: & GFA.21" \\
\hline - & $J P C A$ ( $S A)$ & GFA-47* & GFA. $2=$ \\
\hline$\cdot$ & $J P C A(S A)$ & GFA.4 $4 x^{\circ}$ & GFA.23. \\
\hline$\cdot$ & JPCA $\mid \mathrm{SA}$, & GFA-40. & GFA.2. \\
\hline$r$ & JPCA $115 \% \mathrm{CU}$, & GFB-4." & GFB. $14^{\bullet}$ \\
\hline$\cdot$ & JPCA $15 \% \mathrm{CH}$ & GFB-45. & GFB-20* \\
\hline$\cdot$ & JPCA 15 r: CW & GFB-4t, & GFB:2:" \\
\hline$\cdot$ & JPCA115\% & $\mathrm{GFB}_{-4}^{-\cdot}$ & GFB. $2=$ \\
\hline$\cdot$ & JPCA $15 \% \mathrm{CH}$ & GFB-4N" & GiFB-23. \\
\hline$\cdot$ & $J P C A 115 \% ; C H$ & (iFB-4) & GFB: $24^{\circ}$ \\
\hline$\cdot$ & $J i|C| B A$ : & GiFC. $-44^{\circ}$ & GFC $1^{-\cdot}$ \\
\hline - & $J i 1615 A$ & GifC. $4 x^{-}$ & GFC-1 $\mathbb{N}^{*}$ \\
\hline r & Jimisal & Gef ctu & GFC. $1 \%$ \\
\hline$\cdot$ & 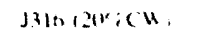 & GFD $-4 x^{\circ}$ & GFD $1 x^{\circ}$ \\
\hline - & Jisurar. $\mathrm{CW}$. & GFD.4u. & GFD $: 2{ }^{\circ}$ \\
\hline$=$ & $\mathrm{J}: 16,2 \mathrm{NO}^{\prime}: \mathrm{CH}$ & GFlD. .1. & GFD. $24^{\circ}$ \\
\hline
\end{tabular}

\begin{tabular}{|c|c|c|c|}
\hline \multicolumn{4}{|c|}{ Hiourglass Faugue Specimens ( 1.78 in. long) } \\
\hline Program & Allow r Condiewn & $\begin{array}{c}20(1)-1 \\
\text { specumen } 1.0\end{array}$ & $\begin{array}{c}4(x)-1 \\
\text { Specimen 1.D }\end{array}$ \\
\hline JAERI* & JPCA (15\%CW' & . & FE-18* \\
\hline$\cdot$ & JPCA $115 \% C H$ & . & FE-1We \\
\hline$\cdot$ & JPCA $\left(15 \sigma_{7} \mathrm{CW}\right.$, & . & $\mathrm{FE}-31^{\circ}$ \\
\hline \multicolumn{4}{|c|}{ Crack Growth Specimens (1 in. long) } \\
\hline Prugram & Allos iCondituon, & $\begin{array}{c}20(x)-1 \\
\text { Specimen ID }\end{array}$ & $\begin{array}{c}400 \mathrm{~d}-1 \\
\text { Specimen 1.D }\end{array}$ \\
\hline JAERI" & JPCA (15\%CW) & CGD.1* & CGB-3* \\
\hline$\cdot$ & JPCA (15\%CH) & CGD-2* & CGB-4* \\
\hline
\end{tabular}


Table 4. Continued

\begin{tabular}{|c|c|c|c|}
\hline \multicolumn{4}{|c|}{ Thermal Conductivily Cylinder Specimens ( 24 in. dia. $\times .24$ in. thack) } \\
\hline Program & Alloy (Condition) & $\begin{array}{c}200 \mathrm{~J}-1 \\
\text { Specimen } 1 . \mathrm{D} .\end{array}$ & $\begin{array}{c}4(00 \mathrm{~J}-1 \\
\text { Specimen I.D }\end{array}$ \\
\hline US/ORNL & Copper. MRC Marz grade (as wrought) & . & A01 \\
\hline$\cdot$ & Cupper. MRC Marz grade (as wrought) & . & $A 02$ \\
\hline$\cdot$ & MER CU-AJ:O,-graphite (pitch P120) & . & blank \\
\hline$\cdot$ & MER CU-AJ:O-graphite (pitch P120) & . & blank \\
\hline • & Glideop A Als+B (wrought sheet) & - & $u n$ \\
\hline$\cdot$ & Glidarp $A 125+B$ (as wrought) & - & $w_{1}$ \\
\hline$\cdot$ & Glidcup $A 225+B$ (as wrought) & . & w2 \\
\hline
\end{tabular}

\begin{tabular}{|c|c|c|c|}
\hline \multicolumn{4}{|c|}{ Thermal Cunductivity Disk Specimens ( 0.36 in. dia. $\times 0.1775$ in. thick) } \\
\hline Program & Alkey (Condition) & $\begin{array}{c}200 \mathrm{~N}-1 \\
\text { Specimen I.D }\end{array}$ & $\begin{array}{c}4001-1 \\
\text { Specimen I.D }\end{array}$ \\
\hline USHORNL & Copper. MRC Marz grade (as wrought) & $A(0)$ & A07 \\
\hline$\cdot$ & Copper. MRC Marz grade (as wrought) & A0s & $A(x)$ \\
\hline - & MER Cu-Al,O,-graphite (pitch P120) & blank & blank \\
\hline$\cdot$ & MER CU-Al:O,-graphite (pitch P120) & biank & blank \\
\hline$\cdot$ & Glidcop Al15+B (wrought sheet) & Lo1 & Lot \\
\hline " & Glidcop $A 115+B$ (wroughr sheet) & 102 & L07 \\
\hline - & Glidcop A125+B (as wrought) & $w_{1}$ & w3 \\
\hline$\cdot$ & Gludtop $A 125+B$ (as wroughl) & $w z$ & W4 \\
\hline
\end{tabular}

\begin{tabular}{|c|c|c|c|}
\hline \multicolumn{4}{|c|}{ TEM Specimen Holder: } \\
\hline Program & $\begin{array}{l}\text { Length of Holde? } \\
\text { tnchu. }\end{array}$ & $\begin{array}{c}2(K)-1 \\
\text { Specumen I. } \\
\text { (No. Disks) }\end{array}$ & $\begin{array}{c}4001-1 \\
\text { Specomen I.D } \\
\text { (No. Disk:) }\end{array}$ \\
\hline JAERI• & 1 & $56^{*}(70)$ & $3 x \cdot(73)$ \\
\hline$\cdot$ & 1 & $57^{*}(70)$ & $J 10^{*}(75)$ \\
\hline . & 1 & $3 x^{*}(70)$ & $J 11 \cdot(7 x)$ \\
\hline • & 1 & $39^{*}(70)$ & $J 12 *(76)$ \\
\hline - & 1 & $3111^{\circ}(70)$ & - \\
\hline$\cdot$ & 1 & $J_{11} \cdot(82)$ & . \\
\hline$\cdot$ & 1 & $312 \cdot(301)$ & . \\
\hline \multirow[t]{3}{*}{ US/ORNL" } & w.t. & $E^{*}(3 \times)$ & \\
\hline & 0.65 & $F \cdot(38)$ & - \\
\hline & $0-5$ & & $E \cdot(52)$ \\
\hline . & 0175 & - & $F \cdot(52)$ \\
\hline JAERI & : & $J 16(44)$ & J20 (55) \\
\hline$\cdot$ & $i$ & $317(44)$ & $321(56)$ \\
\hline$\cdot$ & 1 & $J 1 \times 164)$ & $122(56)$ \\
\hline. & 1 & $J 14(64)$ & $523(54)$ \\
\hline US/ORNL & 1 & $1(5 x)$ & $5(5 x)$ \\
\hline$\cdot$ & a: & +12 & $8(12)$ \\
\hline$\cdot$ & 105 & $3(20)$ & $7(20)$ \\
\hline US/ANL & 1 & $2(51)$ & 6145, \\
\hline
\end{tabular}


Table 4. Continued

\begin{tabular}{|c|c|c|c|}
\hline \multicolumn{4}{|c|}{ TEM Disks } \\
\hline Program & Allow (Canduluon) & $\begin{array}{c}2001 \mathrm{~J} \cdot 1 \\
\text { Specimens (*1) }\end{array}$ & $\begin{array}{c}400 \mathrm{~s}-1 \\
\text { Specimens (*5) }\end{array}$ \\
\hline US/ORNL & Copper (JMC Puratsonic. cold rolted) & P1 & $\mathbf{P 3}$ \\
\hline$\cdot$ & Copper (JMC Puratronic. cold rolied) & $P 2$ & P4 \\
\hline$\cdot$ & Copper (JMC Puratronk. rexl'd $4(0)^{\circ} \mathrm{C}$, in) & Kı & $\mathrm{K}^{3}$ \\
\hline$\cdot$ & Cupper (JMC Puratronec, rexl'd $40\left(\mathrm{r}^{\circ} \mathrm{C}, \mathrm{lh}\right.$ ) & $\mathrm{K}^{2}$ & K4 \\
\hline • & Copper (JMC Puratronic, oxygenated $950^{\circ} \mathrm{C}$ ) & K9 & K10 \\
\hline$\cdot$ & Copper (A.D. Mackay, cold rulled) & MI & M3 \\
\hline • & Copper (A.D. Mackay. cold rolled) & $\mathbf{M}_{2}$ & M4 \\
\hline • & Glucup Alls + B (FED. wrought sheal) & $\mathrm{F} 1$ & $F^{3}$ \\
\hline$\cdot$ & Gludeop Alls + B (FED. wrought sheel) & $F=$ & $F^{4}$ \\
\hline " & Gildcup Alts+B (Sandia. wrought sheet) & S1 & S.3 \\
\hline$\cdot$ & Gludoep Alls+B (Sandia, wrought sheel) & S2 & S4 \\
\hline • & Gitscop Alts+BiSCM Metals, wrought snect) & G1 & $\mathrm{G}^{3}$ \\
\hline " & Gitucop Alts+BtSCM Mctuls. wrought sheet) & $\mathrm{G}^{2}$ & $\mathrm{G}+\mathrm{t}$ \\
\hline$\cdot$ & Glidcup Al15+ B(PNI VOsolutuon annealed & Hil & HI3 \\
\hline - & Glidcop Al15+B(PNL VO.solutuen annealed) & $\mathrm{H} 12$ & HIA \\
\hline • & Glidcop AL20) (PNL. 20\% cold rolled) & DI & D.3 \\
\hline$\cdot$ & Glidcep Alzli (PNL. 20\%; colut rolled & D2 & Ds \\
\hline . & Gitdcop $A D 25+B$ al wrought & wi & w: \\
\hline * & Gildcop Al $25+$ B (as wrought) & $w=2$ & $w_{4}$ \\
\hline$\cdot$ & Glidcop $A l z S+B(x d y)$ & $\mathrm{Cl}$ & $\mathrm{c}^{3}$ \\
\hline " & Ghdiop Al2s+B (xil); CU; & $\mathrm{C} 2$ & $c t$ \\
\hline$\cdot$ & MAGT 0.0S (Technolug : & vi & $v_{3}$ \\
\hline$\cdot$ & MACiT 0.05 (Technolog 2) & $v_{2}$ & $\mathrm{~V}_{4}$ \\
\hline$\cdot$ & MAGT 0.2 (Technolgen 1) & $\mathrm{Tl}$ & Ts \\
\hline • & MAGT 0.2 (Technolug 1 ) & $T=$ & $\mathrm{T} 4$ \\
\hline " & MAGT 0.2 (Technokg 2 ) & $\mathrm{Zl}$ & $\mathrm{Z} ;$ \\
\hline " & MAGT 0.2 (Technolog 2) & 22 & $\mathrm{Z4}$ \\
\hline " & Gludcup $A l l s+B$ (as extruded + brazed & F11 & $\mathrm{F} 13$ \\
\hline$\cdot$ & Glidcop Alls+B (as extruded+brazed) & $\mathrm{F} 12$ & Fis \\
\hline$\cdot$ & Copper (Ris $\Phi$ OFHC. annealed $550^{\circ} \mathrm{C}, 2 \mathrm{~h}$ ) & Cu-Ris\$ & Cu-Risø \\
\hline
\end{tabular}

\begin{tabular}{|c|c|c|c|}
\hline \multicolumn{4}{|c|}{ TEM Disks } \\
\hline Program & Alloy (Condition) & $\begin{array}{c}2(x) J-1 \\
\text { Specimens }(*: 1)\end{array}$ & 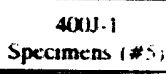 \\
\hline US/ORNL & Copper (Ris $\phi$ OFHC, annealed $\left.550^{\circ} \mathrm{C} .2 \mathrm{~h}\right)$ & Cu-Ris\$ & Cu-Rus \\
\hline * & $\mathrm{Cu}-1.0 \% \mathrm{Ni}$ (rexl'd $\left.800^{\circ} \mathrm{C}, 4 \mathrm{~h}\right)$ & Cu-1.tom $\mathrm{N}_{1}$ & $\mathrm{Cu}-1.0 \% \mathrm{Ni}$ \\
\hline$\cdot$ & 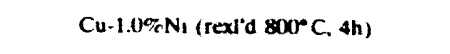 & $C_{U-1.0 \% N_{1}}$ & $\mathrm{Cu}-1.0 \% \mathrm{Ni}$ \\
\hline$\cdot$ & $\mathrm{Cu}-2.0 \% \mathrm{Ni}$ (rexl'd $\left.8000^{\circ} \mathrm{C}, 4 \mathrm{~h}\right)$ & $\mathrm{Cu} \cdot 2.0 \% \mathrm{~N}_{1}$ & $\mathrm{Cu}-20 \% \mathrm{~N}_{\mathrm{I}}$ \\
\hline$\cdot$ & $\left.\mathrm{Cu} \cdot 2 .\left(1 \% \mathrm{~N}_{1}(\mathrm{rex})^{\prime d} 80\right)^{\circ} \mathrm{C}, 4 \mathrm{~h}\right)$ & $\mathrm{Cu}-2.0 \% \mathrm{Ni}$ & $\mathrm{Cu}-2.0 \% \mathrm{Ni}_{\mathrm{i}}$ \\
\hline$\cdot$ & Cu-5.0\% $\% \mathrm{~N}_{1}\left(\right.$ rexl'd $\left.800^{\circ} \mathrm{C}, 4 \mathrm{~h}\right)$ & $\mathrm{Cu}-5.0 \% \mathrm{Ni}$ & $\mathrm{Cu}-5.0 \% \mathrm{~N}_{\mathrm{i}}$ \\
\hline$\cdot$ & Cu-s.om Ni (rexi'd $800^{\circ} \mathrm{C}, 4 \mathrm{~h}$ ) & $\mathrm{Cu}-5.0 \% \mathrm{~N}_{1}$ & $\mathrm{Cu}-5.0 \% \mathrm{Ni}_{1}$ \\
\hline$\cdot$ & $\mathrm{Cu}-10 \%: \mathrm{N}_{2}$ (rex)'d $8000^{\circ} \mathrm{C}$. th) & $\therefore u-10.0 \% \mathrm{~N}_{1}$ & $\mathrm{Cu}-10.0 \% \mathrm{Ni}_{1}$ \\
\hline$\cdot$ & $\left.\mathrm{Cu}-1(0 \% \mathrm{Ni} \text { (rex)'d } 8(0))^{\circ} \mathrm{C}, 4 \mathrm{~h}\right)$ & $\mathrm{Cu}-10.0 \% \mathrm{Ni}$ & $\mathrm{Cu}-10.0 \% \mathrm{Ni}_{\mathrm{i}}$ \\
\hline$\cdot$ & 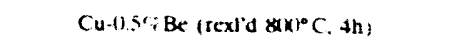 & $\mathrm{Cu}-0.5 \% \mathrm{Br}$ & $\mathrm{Cu}-0.5 \% \mathrm{Bc}$ \\
\hline • & $\left.(u-1) .5 \% B c(\operatorname{sex})^{\circ d} z(x)^{\circ} \mathrm{C}, \mathrm{Jh}\right)$ & $\mathrm{Cu}-0.5 \% \mathrm{Br}$ & $\mathrm{Cu}-0.5 \% \mathrm{Bc}$ \\
\hline$\cdot$ & 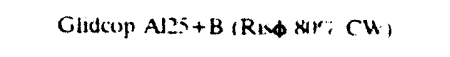 & $\mathrm{Cu}-0.25 \% \mathrm{Al}+$ & $\mathrm{Cu}-0.25 \% \cdot \mathrm{Al}+$ \\
\hline " & 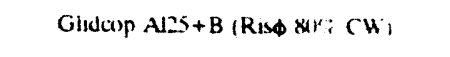 & $\mathrm{Cu}-0.25 \% \mathrm{Al}+$ & $\mathrm{Cu}-0.25 \% \mathrm{Al}+$ \\
\hline * & Gluteop AI2S (PNL RH. So\%; $\mathrm{rW}$ ) & $x_{1}$ & $x^{3}$ \\
\hline • & Ghdcop Al2S (PNL. RH. $S(1) ; \mathrm{CW}$ ) & $x=$ & $x_{4}$ \\
\hline$\cdot$ & 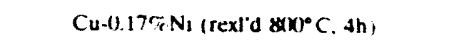 & E5 & E? \\
\hline$\cdot$ & Cu- $0.1 \% \mathrm{~N}_{1}\left(\right.$ rexld $8(x)^{\circ} \mathrm{C}$. th) & En & Ex \\
\hline - & Copper (MRC Marh, as wrought) & $A(I=$ & $A=7$ \\
\hline$\cdot$ & Copper (MRC Mars, as wroughn) & All 3 & Al: \\
\hline$\cdot$ & Glidcop $A 115+B$ (B/G wrought shect) & wis & Lis \\
\hline$\cdot$ & Glidcop $A 15+B$ i $B / G$ wrought sheet & Lo: & LNo \\
\hline$\cdot$ & Glidcop Al25 (R1.\$/PNL. an wrought) & $\mathrm{H} 01$ & Hos \\
\hline - & Glidcop AI2S (RIS\$PNL, as wrought, & $\mathrm{H}\left(\mathrm{I}_{2}\right.$ & $H(x)$ \\
\hline - & MER Cu-Al:O,-graphite (Pitch P120) & piuch & puch \\
\hline$\cdot$ & MER CU-Al:O,-graphite (Putch P120) & pitch & puch \\
\hline$\cdot$ & MER CU-Al:O,-graphute (Pan IMY) & pan & pan \\
\hline$\cdot$ & MER Cu-Al:O,-graphite (Pan !MY) & pan & pan \\
\hline
\end{tabular}


Table 4. Continued

\begin{tabular}{|c|c|c|c|}
\hline \multicolumn{4}{|c|}{ TEM Disk: } \\
\hline Program & Alloy (Condition) & $\begin{array}{c}2001 \mathrm{~J} \cdot 1 \\
\text { Specimens (\#2) }\end{array}$ & $\begin{array}{c}400 \mathrm{-1}-1 \\
\text { Specimens (\#6) } \\
\end{array}$ \\
\hline US/ANL & $v$ & BLSI & BL51 \\
\hline . & 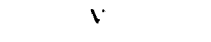 & BL51 & BLSI \\
\hline " & v & BL20 & BL20 \\
\hline$\cdot$ & $v$ & BL20 & - \\
\hline$\cdot$ & $\mathrm{V}-1 T_{i}$ & BL50 & BLSO \\
\hline " & $\mathrm{V} \cdot 1 \mathrm{Ti}$ & BLSO & . \\
\hline$\cdot$ & $\mathrm{V}-15 \mathrm{Cr}-5 \mathrm{Ti}_{\mathrm{i}}$ & BL24 & BL24 \\
\hline$\cdot$ & $\mathrm{V}-15 \mathrm{Cr}-5 \mathrm{Ti}$ & BL24 & BL24 \\
\hline " & $\mathrm{V} \cdot 15 \mathrm{Cr}-5 \mathrm{Ti}$ & BLA1 & BL41 \\
\hline$\cdot$ & $\mathrm{V}-15 \mathrm{Cr}-5 \mathrm{Ti}$ & BL4I & BLA1 \\
\hline$\cdot$ & $\mathrm{V}-15 \mathrm{Ti}-7.5 \mathrm{Cr}$ & BL11 & BL10 \\
\hline$\cdot$ & $V-111 \mathrm{Cr}-5 \mathrm{~T}_{1}$ & $\mathrm{BL}+3$ & BL4.3 \\
\hline$\cdot$ & $V-10 \mathrm{Cr}-5 \mathrm{TI}$ & BL43 & BLA3 \\
\hline 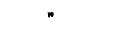 & $V \cdot 3 T_{1}-0.5 S_{1}$ & BLA? & BLA2 \\
\hline$"$ & $\therefore .3 \mathrm{Ti}-0.5 \mathrm{~S}$ & BLA2 & BLA2 \\
\hline " & $V \cdot 3 \mathrm{~T}_{1}-1 \mathrm{~S}_{1}$ & BL45 & BLAS \\
\hline$\cdot$ & V.3Ti-1Si & BLA5 & BLA5 \\
\hline$"$ & 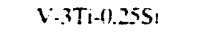 & $B L 27$ & BL27 \\
\hline •" & $V-3 T_{1}-0.25 S_{1}$ & BL27 & BL27 \\
\hline$\cdot$ & $V-11 \mathrm{Cr}^{-10 T 1}$ & BLA4 & - \\
\hline$"$ & $\mathrm{~V}-10 \mathrm{Cr}-10 \mathrm{Ti}$ & BLA4 & $\cdot$ \\
\hline • & $V-5 \mathrm{Cr}-57 \mathrm{~T}$ & BL47 & BL47 \\
\hline$"$ & $\mathrm{~V}-5 \mathrm{Cr}-5 \mathrm{Ti}$ & BL47 & BL47 \\
\hline$\cdot$ & V.sTi & BLA6 & BL46 \\
\hline$\cdot$ & $\mathrm{V} \cdot 5 \mathrm{Ti}$ & BLA6 & BLA6 \\
\hline$\cdot$ & $\mathrm{V} \cdot 10 \mathrm{Ti}$ & BL12 & BLI2 \\
\hline
\end{tabular}

\begin{tabular}{|c|c|c|c|}
\hline \multicolumn{4}{|c|}{ TEM Dask } \\
\hline Program & Alloy (Condition) & $\begin{array}{c}200)]-1 \\
\text { Specimens (\#2) }\end{array}$ & $\begin{array}{c}4(x) s-1 \\
\text { Specimens }(* t),\end{array}$ \\
\hline US/ANL & V.liti & BL12 & . \\
\hline$\cdot$ & $\mathrm{V} \cdot 20 \mathrm{Ti}$ & BL15 & BL1S \\
\hline$"$ & $\mathrm{~V} \cdot 20 \mathrm{Ti}$ & BL1S & BL15 \\
\hline$\cdot$ & $V-20 T_{1}$ & BLIK & BLiK \\
\hline$\cdot$ & $\mathrm{V} \cdot 20 \mathrm{TI}_{\mathrm{I}}$ & BL18 & BL18 \\
\hline$\cdot$ & $V-15 \mathrm{Ti}$ & BL13 & BLI3 \\
\hline$\cdot$ & $V-15 \mathrm{TI}$ & BL1.3 & BL13 \\
\hline$\cdot$ & $\mathrm{V}-12 \mathrm{Cr}-5 \mathrm{Ti}$ & BLAH) & BLA $(9$ \\
\hline$\cdot$ & $\mathrm{V}-12 \mathrm{Cr}_{-} .5 \mathrm{~T}_{1}$ & BLAl! & BLA4! \\
\hline " & V. 7 Cr-5T & BLAY & BLAY \\
\hline " & $V \cdot 7 \mathrm{Cr}-5 \mathrm{Ti}$ & BLAY & BLAY \\
\hline " & $V-15 C \mathrm{r} \theta 3 \mathrm{~T}$ & $B L 25$ & BL2S \\
\hline$\cdot$ & $V-15 \mathrm{Cr}-1) .3 \mathrm{Th}$ & BL25 & . \\
\hline$\cdot$ & V.iscr.lTi & BL2*, & $B L 26$ \\
\hline$"$ & $\because 15 \mathrm{Cr}-1 \mathrm{TH}$ & $B L 2$, & $\mathrm{BL} 2 \mathrm{6}$ \\
\hline " & v. $15 \mathrm{Cr}^{-5} .5 \mathrm{~T}$ & $\mathrm{BL} 2 \mathrm{i}$ & $\mathrm{BL} 21$ \\
\hline$\cdot$ & V-15Cr.5T: & $\mathrm{BL} 21$ & $B L 21$ \\
\hline " & $\therefore-15 C_{1} .5 \mathrm{TH}$ & $B L 22$ & BL:2 \\
\hline " & $\because-15 \mathrm{Cr}-5 \mathrm{~T}_{1}$ & $\mathrm{BL} 22$ & BL22 \\
\hline$\cdot$ & V.15Cr.5T & $B L 23$ & BL23 \\
\hline$\cdot$ & $\mathrm{V} .15 \mathrm{Cr} .5 \mathrm{Ti}$ & BL 23 & BL23 \\
\hline " & $\mathrm{V}-10 \mathrm{Cr}$ & BLA & BLA \\
\hline$\cdot$ & $\mathrm{V} \cdot 110 \mathrm{Cr}$ & BLA & BLA \\
\hline$\cdot \cdot$ & $v-15 \mathrm{Cr}$ & $B L 5$ & $\mathrm{BL} 5$ \\
\hline$\cdot$ & $\mathrm{V}-15 \mathrm{Cr}$ & $\mathrm{BL}=$ & $B L_{5}$ \\
\hline
\end{tabular}


Table 4. Continued

\begin{tabular}{|c|c|c|c|c|c|c|c|}
\hline \multicolumn{4}{|c|}{ TEM Disks } & \multicolumn{4}{|c|}{ TEM Disks } \\
\hline Program & Alloy (Condition) & $\begin{array}{c}2000)-1 \\
\text { Specimens (\#3) } \\
\end{array}$ & $\begin{array}{c}400 \mathrm{~J}-1 \\
\text { Specimens }(\# 7)\end{array}$ & Program & Alkoy (Condition) & $\begin{array}{c}200 \mathrm{~J}-1 \\
\text { Specimens }(* 4)\end{array}$ & $\begin{array}{c}400 \mathrm{~J}-1 \\
\text { Specimens (\#8) }\end{array}$ \\
\hline US/PRC & $316 \mathrm{~L}(\mathrm{SA})$ & R2-(1) & R2-06 & US/ORNL & $9 \mathrm{Cr}-\mathrm{IMoVN}$ & $T L-80$ & TL-37 \\
\hline$\cdot$ & $316 \mathrm{~L}(\mathrm{SA})$ & R2-02 & R2.07 & $\cdot$ & $9 \mathrm{Cr}-1 \mathrm{MoVNh}$ & TL-88 & TL-77 \\
\hline • & $316 \mathrm{~L}(\mathrm{SA})$ & R2-03 & R2-08 & • & $9 \mathrm{Cr}-1 \mathrm{MoVNb}-2 \mathrm{Ni}$ & TM-74 & TM-43 \\
\hline 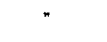 & $316 \mathrm{~L}(\mathrm{SA})$ & R2-04 & R2-0y & " & $y \mathrm{Cr}-1 \mathrm{MoVNh}-2 \mathrm{Ni}$ & TM-82 & TM-53 \\
\hline$*$ & $316 \mathrm{~L}(\mathrm{SA})$ & R2-05 & R2-10 & $\cdot$ & $12 \mathrm{Cr}-1 \mathrm{MoVw}$ & SS-57 & SS-16 \\
\hline$\cdot$ & $316 \mathrm{~L}(\mathrm{CW})$ & R3-01 & R3-06 & $"$ & $12 C_{r}-1 \mathrm{MoVW}$ & SS-96 & SS-28 \\
\hline • & $316 \mathrm{~L}(\mathrm{CW})$ & R3-02 & R3-07 & $\cdot$ & $12 \mathrm{Cr}-1 \mathrm{MnVW}-1 \mathrm{Ni}$ & ST-24 & ST -63 \\
\hline$\cdot$ & $316 \mathrm{~L}(\mathrm{CW})$ & R3-03 & R.3-0x & · & $12 \mathrm{Cr}-1 \mathrm{MnVW}-1 \mathrm{Ni}$ & ST- 53 & ST -83 \\
\hline$\cdot$ & $316 \mathrm{~L}(\mathrm{CW})$ & R.3.-14 & R3-09 & " & $12 \mathrm{Cr}-1 \mathrm{MoVW}-2 \mathrm{Ni}$ & SU-2.3 & SU-43 \\
\hline • & $316 \mathrm{~L}(\mathrm{CW})$ & R3-(1)5 & R3-10 & $"$ & $12 \mathrm{Cr}-1 \mathrm{MoVW}-2 \mathrm{Ni}$ & SU-94 & SU-63 \\
\hline$\cdot$ & $316 \mathrm{Ti}$ (SA) & R4-(0) & R4-06 & $\cdot$ & $12 \mathrm{Cr}-1 \mathrm{MoVW}-2 \mathrm{Ni}$ adjusted & SV-33 & SV-74 \\
\hline - & $316 \mathrm{Ti}(\mathrm{SA})$ & R4-02 & R4.07 & $\therefore$ & $12 \mathrm{Cr}-1 \mathrm{MnVW}-2 \mathrm{Ni}$ adjusted & SV-93 & SV-94 \\
\hline " & $316 \mathrm{Ti}$ (SA) & R4-03 & R4.08 & & & & \\
\hline - & $316 \mathrm{Ti}$ (SA) & R4-1/4 & R4-(x) & & & & \\
\hline " & $316 \mathrm{Ti}$ (SA) & $R+-05$ & R4-10 & & & & \\
\hline " & $316 \mathrm{Ti}\left(\mathrm{CW}_{1}\right.$ & R5-01 & R5-06 & & & & \\
\hline 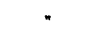 & $316 \mathrm{Ti}(\mathrm{CW})$ & R5-02 & R5-07 & & & & \\
\hline - & $316 \mathrm{Ti}\left(\mathrm{CW}^{\prime}\right)$ & R5-10.3 & R2-1x & & & & \\
\hline • & $316 \mathrm{Ti}(\mathrm{CH})$ & R5-144 & R5-(x) & & & & \\
\hline$\cdot$ & $316 \mathrm{Ti}(\mathrm{CW})$ & R5.05 & R5-10 & & & & \\
\hline
\end{tabular}


Table 4. Continued

\begin{tabular}{|c|c|c|c|}
\hline \multicolumn{4}{|c|}{ TEM DISh } \\
\hline Program & Alker ronditun & $\begin{array}{c}2(x)]-1 \\
\text { specimen: } \\
(\# J 16)\end{array}$ & $\begin{array}{c}4(x)]-1 \\
\text { specimen- } \\
(\# \sqrt{20})\end{array}$ \\
\hline JAER! & Duplex AF: & $A 1-11$ & $A|-| k$, \\
\hline - & Duplex AF: & Al-1: & Al-107 \\
\hline • & Dupiex AFS & A2.11 & A2.16 \\
\hline - & Duplex AF5: & $A^{2}-11=$ & $A 2-11 ?$ \\
\hline- & Duplex AF" & $A^{3-101}$ & $A^{3}-(K)$ \\
\hline - & Duplex AF & $\left.A^{3}-1\right)=$ & $A^{3}-07$ \\
\hline - & $\mathrm{FS}=\mathrm{H}$ & B1. 111 & $B 1.21$ \\
\hline - & $\mathrm{F} \times 2 \mathrm{H}$ & $B 1 \cdot 0 ?$ & B1.22 \\
\hline - & Finll fance weld furn: & $B 2.11 !$ & $B 2-1 k_{1}$ \\
\hline$\cdot$ & FEבH laner uctu gorr. & $B 2-112$ & $B 2 \cdot(1)$ \\
\hline • & HT. & $B ; .11$ & B.3.21 \\
\hline$\cdot$ & HT. & B3.112 & $B ?: 2$ \\
\hline$\cdot$ & $\operatorname{PPCA}(S)$ & $\mathrm{Cl} \cdot 11$ & $\mathrm{Cl} \cdot 2 \mathrm{I}$ \\
\hline - & $J ! x+1 s x$ & (1-1): & $\mathrm{Cr}=2$ \\
\hline$\cdot$ & IPCAiCW. & $C^{2} \cdot 111$ & $c 2=2$ \\
\hline r & $\mathrm{APC}+1 \mathrm{CH}$ & C2-11: & $C 2.23$ \\
\hline - & JPCAn & & $C 3-(1)$ \\
\hline$\cdot$ & $J P C A K$ & & $\cos ()_{2}$ \\
\hline$\cdot$ & JPCAC & & $C 4-0) 1$ \\
\hline - & JPCAC & - & C4-02 \\
\hline - & $316 \mathrm{~F}$ ISA & Di.01 & DI-2I \\
\hline
\end{tabular}

\begin{tabular}{|c|c|c|c|}
\hline \multicolumn{4}{|c|}{ TEM DiN: } \\
\hline Program & Alloy rondinon & $\begin{array}{c}2(n)\}-1 \\
\text { specimen- } \\
(\# J \mid f)\end{array}$ & $\begin{array}{c}4(x)] \cdot 1 \\
\text { specimen } \\
(* 12(j)\end{array}$ \\
\hline JAERI & $316 F(S A)$ & $D 1-(1)=$ & $D 1 \cdot 2=$ \\
\hline$\cdot$ & $310 F(C)$ & D2-111 & $\mathrm{D} 2.22$ \\
\hline$\cdot$ & $316 \mathrm{~F}$ iCW, & $\mathrm{D} 2-112$ & $\mathrm{D} 2 \cdot 23$ \\
\hline r & $316 \mathrm{M5}$ & D? $3-(11$ & D3.-15 \\
\hline - & $316 \mathrm{ML}$ & $D^{3}-(1)$ & $\mathrm{D} 3 \mathbf{3}(\boldsymbol{x})$ \\
\hline$\cdot$ & $316 \mathrm{M}^{-}$ & D4.(1)1 & DA-ikn \\
\hline- & $316 \mathrm{N1}^{-}$ & D4t.1: & $\mathrm{D} 4-117$ \\
\hline$\cdot$ & s/o Mi: & DS-11: & D5.1\%) \\
\hline " & SHAM: & DS.-13 & Dif \\
\hline . & JHI) (SA, & & $F 111$ \\
\hline * & JHD ISA) & & Fill: \\
\hline - & $\mathrm{JHD} / \mathrm{CH}$ & . & Fan \\
\hline - & JHD ICM. & & FE. \\
\hline . & IHF ISA & . & Fini \\
\hline- & JHF ISA & . & F3. U: \\
\hline$\cdot$ & IHF ICW: & . & $F_{4} \cdot 11$ \\
\hline$"$ & $\mathrm{JHF}=1 \mathrm{CH}$ & & $F+1:$ \\
\hline$\cdot$ & JHicish. & & FS. \\
\hline$\cdot$ & JHG isA. & - & F5-112 \\
\hline$\cdot$ & JHGiCll. & & Fhent! \\
\hline • & JHCI ICU. & . & $F(x-1)$ \\
\hline$\cdot$ & JHH ICU: & . & $F \cdot(1)$ \\
\hline
\end{tabular}


Table 4. Continued

\begin{tabular}{|c|c|c|c|}
\hline \multicolumn{4}{|c|}{ HEMlak } \\
\hline Proveram: & Alln a ond:turs & $\begin{array}{c}2(n) 1 \\
\text { specimen } \\
\text { (\#) Jin) }\end{array}$ & 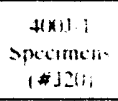 \\
\hline JAF KI & HAt:Al: & & FA: \\
\hline . & $x: a$ & & E: +6 \\
\hline & sis: & & E1:? \\
\hline - & $S x<a$ & & Eill: \\
\hline & $\checkmark s \pi_{1}$ & $\mathrm{~F} 34 \mathrm{CO}$ & Fac, \\
\hline . & VTris: & F.35e, & Fan \\
\hline . & $121: 1 x$ & F.54t & Frint \\
\hline & $1 \because l_{1}, 1$, & Fost & FSTH \\
\hline- & W.tin $1 / 4$ & $\mathrm{Fl}+4$ & $\mathrm{HF}+\mathrm{H}$ \\
\hline " & Mu, then $12 x$ & $\mathrm{FrO}$ & FFlit \\
\hline & $M \cdot<k_{1}$ & Fits & Prow \\
\hline . & Musto & Fyst & $F(x)=$ \\
\hline & 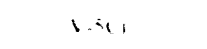 & ARZ: & \\
\hline$\cdot$ & W" & Axin & \\
\hline & 1 & AKS: & \\
\hline . & 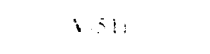 & ANY: & \\
\hline & $1 \therefore$ & All:: & \\
\hline & 1.1/: & A7IfK & \\
\hline & $1 \therefore$ & $A+t h$ & \\
\hline$\cdot$ & 121 & A.SH & \\
\hline " & $x+1,19$ & $A X \angle A$ & \\
\hline$\cdot$ & 11 & $A \times N R$ & . \\
\hline
\end{tabular}

\begin{tabular}{|c|c|c|c|}
\hline \multicolumn{4}{|c|}{ TEM Disk: } \\
\hline Propram & Aliov (Conditur) & $\begin{array}{c}2001-1 \\
\text { Specimens } \\
(\# J 17)\end{array}$ & $\begin{array}{c}400 J-1 \\
\text { Specsmens } \\
(\# J 21)\end{array}$ \\
\hline JAER & $\mathrm{Fe}-15 \mathrm{Cr}-16 \mathrm{Ni}$ & BIBY & $\mathrm{B} 2 \mathrm{~B} 1$ \\
\hline . & $F c \cdot 15 \mathrm{Cr} \cdot 16 \mathrm{Ni}_{1}$ & $\mathrm{~B} 1 \mathrm{BZ}$ & B2B2 \\
\hline$\cdot$ & Fe-15Cr-16Ni-0.25Ti-0.05C-10uappmB & GiGi & G1G.3 \\
\hline$\cdot$ & $\mathrm{FC}-15 \mathrm{Cr}-10 \mathrm{Ni}-0.25 \mathrm{Ti}-0.05 \mathrm{C}-10 \mathrm{KappmB}$ & $\mathrm{G} 1 \mathrm{G} 1$ & G1G4 \\
\hline . & $\mathrm{Fe}-15 \mathrm{Cr}-16 \mathrm{Ni}-0.25 \mathrm{Ti}-0.05 \mathrm{C} \cdot 50 \mathrm{uappmB}$ & $\mathrm{H} \mathrm{H}_{7}$ & HIHA \\
\hline$\cdot$ & $\mathrm{Fe} \cdot 15 \mathrm{Cr}-1 \mathrm{ANi}-0.25 \mathrm{Ti}_{1}-0.05 \mathrm{C}-51 \mathrm{xtappmB}$ & HIHS & HIHD \\
\hline$\cdot$ & $\mathrm{Fc}-15 \mathrm{Cr}-1 \mathrm{nNi}-0.25 \mathrm{Ti}-(1.05 \mathrm{C}-254 \mathrm{kappmB}$ & KIKo & $\mathrm{K}_{1} \mathrm{~K}^{3}$ \\
\hline - & $\mathrm{Fe}-15 \mathrm{Cr}-16 \mathrm{~N}_{1}-(1.25 \mathrm{Ti}-0.05 \mathrm{C}-25(\mathrm{k}) \mathrm{appmB}$ & $\mathrm{KIK} \mathfrak{}$ & KIK4 \\
\hline$\cdot$ & Fe-15Gr-16Ni-50KappmB & LIL? & LILA \\
\hline - & $F \cdot-15 C r-16 N i-50$ KappmB & LiLX & LILB \\
\hline$\cdot$ & Fe-15Cr-10Ni-0.25Ti-5(KappmB & $M 1 M^{7}$ & MIMA \\
\hline r & Fi- $15 \mathrm{Cr}-1 \mathrm{t} \mathrm{Ni}_{1}-0.25 \mathrm{Ti}-5 \mathrm{ikappmB}$ & MIMS & MIMB \\
\hline$\cdot$ & $\mathrm{FC} \cdot ! 5 \mathrm{Cr} \cdot 16 \mathrm{Ni}-0.25 \mathrm{Ti}$ & $\mathrm{HIOH}$ & H103 \\
\hline . & F-15Cr-16Ni-0.2sT & Hitr & $\mathrm{H} 104$ \\
\hline " & $F(-15 \mathrm{C}-10 \mathrm{Ni}-1) \geq 5 \mathrm{TT}-0.05 \mathrm{C}$ & $\mathrm{H} 201$ & $\mathrm{H} 203$ \\
\hline$\cdot$ & 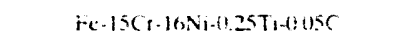 & $\mathrm{H} 2 \mathrm{O} 2$ & $\mathrm{H} 204$ \\
\hline . & $\mathrm{Fenc}-2 \mathrm{~m}$ & $\mathrm{H} 301$ & $\mathrm{H} 33 \mathrm{H}$ \\
\hline - & $\mathrm{Fu}-\mathrm{i} 5 \mathrm{Cr}-2 \mathrm{ON}$ & $\mathrm{H} 3 i \mathrm{i}$ & H30S \\
\hline - & $3 \ln 51$ (SA) & $\mathrm{H}+1) 1$ & $\mathrm{H} 4104$ \\
\hline - & $B S O S A$ & $\mathrm{H} 4(12$ & $\mathrm{H} 405$ \\
\hline - & $316 \mathrm{SI}(\mathrm{CH})$ & $\mathrm{H} 501$ & $\mathrm{HSOH}$ \\
\hline * & 31 sl (CH) & $\mathrm{H} 502$ & H505 \\
\hline$\cdot$ & $316 S_{2}(S A)$ & HoOl & $\mathrm{H} 604$ \\
\hline . & $316 \mathrm{~S} 2(\mathrm{SA})$ & $\mathrm{H} \times 02$ & H605 \\
\hline$\cdot$ & $316 \$ 2(\mathrm{CW})$ & $\mathrm{H} 701$ & $\mathrm{H} 704$ \\
\hline$\cdot$ & $316 \mathrm{~S} 2(\mathrm{CW})$ & $\mathrm{H} 7 \mathrm{~N}$ & $\mathrm{H} 705$ \\
\hline$\cdot$ & $\mathrm{Fe}-16 \mathrm{Cr}-17 \mathrm{Ni}$ & $Y(000)$ & Y006 \\
\hline
\end{tabular}


Table 4. Continued

\begin{tabular}{|c|c|c|c|c|c|c|c|}
\hline \multicolumn{4}{|c|}{ TEM Disks } & \multicolumn{4}{|c|}{ TEM Disks } \\
\hline Program & Alliy (Conditon) & $\begin{array}{c}200 \mathrm{~J}-1 \\
\text { Specimens } \\
(\# \mathrm{~J} 17)\end{array}$ & $\begin{array}{c}400 \mathrm{-1}-1 \\
\text { Specimens } \\
(\#]_{21)}\end{array}$ & Program & Alloy $\{$ Condition i & $\begin{array}{c}2(x)] \cdot 1 \\
\text { specimen: } \\
(\# J 18)\end{array}$ & $\begin{array}{c}4(x)]-1 \\
\text { Specimem } \\
(\# J 22)\end{array}$ \\
\hline JAERI & $\mathrm{Fc}-16 \mathrm{Cr}-17 \mathrm{Ni}$ & YoOl & $Y(x) 7$ & JAERI & Duplex AF? & Al. 18 & $A 1-118$ \\
\hline$\cdot$ & $\mathrm{Fe}-16 \mathrm{Cr}-17 \mathrm{Ni}-0.1 \mathrm{P}$ & Y002 & Yoox & $\cdot$ & Duplex AF? & Al-(14) & $A \mid-(x)$ \\
\hline$\cdot$ & $\mathrm{Fe} \cdot 16 \mathrm{Cr}-17 \mathrm{Ni}-0.1 \mathrm{P}$ & Yoos & YOMY & " & Dupicx AF? & $\mathrm{A} 1 \cdot 1 \mathrm{~s}$ & $\mathrm{Al} \cdot \mathrm{B1}$ \\
\hline$\cdot$ & $\mathrm{Fe}-16 \mathrm{Cr}-17 \mathrm{Ni}-0.25 \mathrm{Ti}-10.1 \mathrm{P}$ & YOOA & Y100 & $\cdot$ & Duplex AFS & A2- -03 & A2-(1) \\
\hline$\cdot$ & $\mathrm{Fe}-16 \mathrm{Cr}-17 \mathrm{Ni}-(1.25 \mathrm{Ti}-(0.1 \mathrm{P}$ & Yoos & Y 101 & " & Duplex AFs: & A2-14 & $A 2-(n)$ \\
\hline$\cdot$ & JPCA: & A0AL. & AOAS & . & Duplex AFs & A2-115 & $A 2-10$ \\
\hline$\cdot$ & $J P C A 2$ & Al)AM & ADAT & $\cdot$ & Duplex AF & $A^{3} \cdot(13$ & $A 3-18$ \\
\hline$\cdot$ & $F \cdot-i n C r-14 N_{1}$ & AlnF & AllF & $\cdot$ & Dupicx AFT & A.3.1L & $A \cdot z-\left(K_{2}\right)$ \\
\hline$\cdot$ & $F \cdot-16 C-14 n i$ & $\mathrm{~A} 20 \mathrm{~F}$ & A21F & $\cdot$ & Duplex AF: & A3.115 & $A 3-16$ \\
\hline$\cdot$ & $F(-18 \mathrm{C} T-1+\mathrm{Ni}-2.5 \mathrm{Mol}$ & $\mathrm{A} 30 \mathrm{~F}$ & A31F & $\cdot$ & $\mathrm{F} \times 2 \mathrm{H}$ & $\mathrm{Bi}-(1) \mathrm{Z}$ & $B 1.23$ \\
\hline$\cdot$ & $\mathrm{Fe}-18 \mathrm{Cr}-14 \mathrm{Ni}-2.5 \mathrm{Mr}$ & $\mathrm{A} 40 \mathrm{~F}$ & A41F & - & $\mathrm{F} X 2 \mathrm{H}$ & $\mathrm{Bl}-114$ & B1-24 \\
\hline . & $F C \cdot 1 \times C r-1+N \mathrm{~N}-2.5 \mathrm{M}(\mathrm{i}-0.3 \mathrm{Zr}$ & ASOF & ASIF & $\cdot$ & $\mathrm{F} \times 2 \mathrm{H}$ & $B 1-(15$ & $B 1.25$ \\
\hline$\cdot$ & $F(-18 \mathrm{Cr}-14 \mathrm{Ni}-2.5 \mathrm{Mo}-0.3 \mathrm{Zr}$ & A $60 \mathrm{~F}$ & A61F & ${ }^{*}$ & Fs2ti & $B 1-\left(K_{2}\right.$ & $\mathrm{B} 1-20$ \\
\hline " & $F(-1 K C r-14 \mathrm{Ni}-2.5 \mathrm{Mo}-0.3 \mathrm{~T} \mathrm{~T}$ & A70F & $A 71 F$ & " & FX2H & $\mathrm{Bl} \cdot 1 \mathrm{17}$ & $\mathrm{B} 1.27$ \\
\hline$\cdot$ & $\mathrm{Fe}-18 \mathrm{Cr}-14 \mathrm{Ni}-2.5 \mathrm{MO}-(0.3 \mathrm{Ti}$ & $\mathrm{AXOF}$ & A81F & $\cdot$ & $\mathrm{F} 2 \mathrm{2H}$ & $\mathrm{B1}-(2)$ & $\mathrm{B} 3-2 \mathrm{x}$ \\
\hline$\cdot$ & $\mathrm{Fe}-1 \mathrm{MCr} \cdot 14 \mathrm{Ni}-2.5 \mathrm{Mov}-0.3 \mathrm{Nh}$ & $A 9) F$ & A91F & $\cdot$ & $\mathrm{F} \times 2 \mathrm{H}$ & B1-1k4 & $B 1.29$ \\
\hline - & $\mathrm{Fe}-1 \mathrm{xCr}-14 \mathrm{Ni}-2.5 \mathrm{M}(0-0.3 \mathrm{Nn}$ & AnlF & $A 02 F$ & $"$ & $F \times 2 H$ & B1-11, & $\mathrm{Bl} \cdot 3 \mathrm{H}$ \\
\hline r & $\mathrm{V}-5 \mathrm{Cr}$ & . & ARZ7 & " & FX:H & $\mathrm{B} 1-11$ & $B 1-31$ \\
\hline • & $v-(0.5 Y$ & . & AROR & “ & $\mathrm{F} \times 2+1$ & $B 1.12$ & $B i-32$ \\
\hline$\cdot$ & $v$ & - & AKY6 & $"$ & $\mathrm{~F} \times 2 \mathrm{H}$ & $B 1 \cdot 1:$ & $B 1-3=$ \\
\hline$\cdot$ & $V .5 T_{1}$ & . & AMY4 & - & $\mathrm{F} \times 2 \mathrm{H}$ & $\mathrm{Bl}-1+$ & $\mathrm{B} 1-.34$ \\
\hline$\cdot$ & $V .2 Y$ & . & $\mathrm{A} 01 \mathrm{M}$ & - & $\mathrm{FS} 2 \mathrm{H}$ & B1-15 & $\mathrm{Bl}-35$ \\
\hline " & $\mathrm{V} \cdot 1 \mathrm{Zr}$ & . & A70M & $\therefore$ & $\mathrm{F} 82 \mathrm{H}$ & $\mathrm{B1} \cdot 16$ & $\mathrm{BI}-3 \mathrm{th}$ \\
\hline$\cdot$ & $\mathrm{V} \cdot 2 \mathrm{Si}$ & - & $A 40 R$ & & & & \\
\hline • & $V \cdot 2 \mathrm{Al}$ & . & $\mathrm{A} 50 \mathrm{R}$ & & & & \\
\hline " & V-5Ti-1Y & . & AZZB & & & & \\
\hline$\cdot$ & $\mathrm{SiC}(\mathrm{B})$ & . & $E 2.01$ & & & & \\
\hline • & $\mathrm{SiC}(\mathrm{B})$ & - & E2-02 & & & & \\
\hline 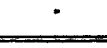 & $\mathrm{SiC}(\mathrm{B})$ & - & E2-03 & & & & \\
\hline
\end{tabular}


Table 4. Continued

\begin{tabular}{|c|c|c|c|}
\hline \multicolumn{4}{|c|}{ IEN DMn. } \\
\hline Program & Allun (cond:thon. & $\begin{array}{l}2601-1 \\
\text { specimen- } \\
\text { i Jjis }\end{array}$ & $\begin{array}{c}4(x)]: \\
\text { spicimen } \\
(\# 122)\end{array}$ \\
\hline \multirow{2}{*}{ JAERI } & $F \times 2: 1$ & $\mathrm{Bl} \cdot \mathrm{i}=$ & 31.3 \\
\hline & FX:H & B1-1s & $\mathrm{Bl} \cdot 3 \mathrm{~s}$ \\
\hline$\cdot$ & $\mathrm{F} 2 \mathrm{H}$ & B!:14 & B1. $\cdots$ \\
\hline$\cdot$ & FXIH & $B 1.21$ & $\mathrm{Bi}-4 \mathrm{i}$ \\
\hline$\cdot$ & FSzH diaser weld jomi, & & B2. $1 \mathrm{ix}$ \\
\hline - & FXOH flaser weld jom & & $\mathrm{B} 2-(\mathrm{Ni}$ \\
\hline$\cdot$ & F82H tlascer ucle rom: & & $\mathrm{B} 2 \cdot 111$ \\
\hline$\cdot$ & $\mathrm{HT} \cdot{ }^{;}$ & B.3.113 & $B 3-2 ;$ \\
\hline 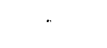 & $117 \cdot$. & B3-iH & 33.24 \\
\hline$\cdot$ & $i \cdots \cdot$ & Bist & $B:=$ \\
\hline - & HT" & $B=.1 k$, & $B 32+$ \\
\hline - & Ho & B: $: 0^{-}$ & $B \because 2-$ \\
\hline$\cdot$ & HI 4 & $B \cdots$ Bis & $B 3 . x$ \\
\hline - & $H 7 \%$ & B.t.th & $B: 2,4$ \\
\hline$\cdot$ & $\mathrm{HT}$ & B.3-10 & B.3.31 \\
\hline . & Hr. & B.3.11 & $B 3.3 i$ \\
\hline . & $H T^{\prime}$ & $B: 12$ & B: : \\
\hline - & HT." & $B 3-13$ & $B=3$ \\
\hline$\cdot$ & HT. .4 & B.3.14 & B3. it \\
\hline$\cdot$ & HT.W & Bi-15 & $B 3-35$ \\
\hline " & HT. & $B=16$ & B.3.3n \\
\hline$\cdot$ & H7." & Bi.1: & $B 3.3=$ \\
\hline - & HT:G & $B:-18$ & B3. 3x \\
\hline$\cdot$ & HT.9 & B...14 & B.3. 30 \\
\hline$\cdot$ & HT.4 & 83.20 & $B 3+41$ \\
\hline
\end{tabular}

\begin{tabular}{|c|c|c|c|}
\hline \multicolumn{4}{|c|}{ TEM DISK: } \\
\hline Program & Alling icundituen, & $\begin{array}{c}2(x) 1.1 \\
\text { specimen. } \\
\text { 1\#Jisi }\end{array}$ & $\begin{array}{c}4(1)(1) \cdot 1 \\
\text { specimen } \\
(* J \geq 2)\end{array}$ \\
\hline IAERI & JPCA ISA. & $\mathrm{Cl} \cdot 1)$ & $\mathrm{Cl}-23$ \\
\hline$\cdot$ & $J P C A|S A|$ & $\mathrm{Cl}-14$ & $\mathrm{Cl} \cdot 24$ \\
\hline$\cdot$ & JPCA ISA & Clis: & $\mathrm{Ci}=25$ \\
\hline - & JPCA $\&$ S & $\mathrm{Cl} \cdot \mathrm{k}$. & $\mathrm{C} 1.26$ \\
\hline - & JPCA ISA: & C1.1): & $(1.2)$ \\
\hline$\cdot$ & $J P C A \mid S A)$ & $\mathrm{Cl} \cdot(\mathrm{ks}$ & $\mathrm{Cl}-2 \mathrm{x}$ \\
\hline - & JHCAISA & Ciss & $(1.21)$ \\
\hline - & $I P C A|S A|$ & $(1 \cdot 1)$ & $\mathrm{Cl} \cdot 31$ \\
\hline · & JHCA & $\mathrm{Ci} \cdot \mathrm{H}$ & - \\
\hline 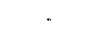 & $J P C A|S A|$ & C112 & . \\
\hline$\cdot$ & JPCA $(S A)$ & $\mathrm{Cl}-1:$ & - \\
\hline . & JPCACA & C.1. & \\
\hline . & JPCABA: & C1: & \\
\hline & 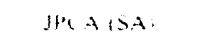 & c1.1n & \\
\hline$\cdot$ & $J P C A$ ist & $\mathrm{Cl}^{-}$ & . \\
\hline - & IPCA (SA) & $\mathrm{Cl} 1 \mathrm{~N}$ & . \\
\hline & $A B+1,1$ & C1.14 & \\
\hline & $M P A S A$ & C.211 & . \\
\hline & Hed 120 & $\mathrm{H} 34:$ & . \\
\hline - & $316.9215 A$ & $H(x):$ & \\
\hline - & ithSICHi & $\mathrm{H} 70 \mathrm{~B}$ & . \\
\hline . & $J P C A=$ & Al/AR & \\
\hline$\cdot$ & $310 S 1(S A)$ & Hais & . \\
\hline$\cdot$ & $316 \mathrm{~S} 11 \mathrm{CW}$ & $\mathrm{Hsul:}$ & . \\
\hline
\end{tabular}


Table 4. Continued

\begin{tabular}{|c|c|c|c|c|c|c|c|}
\hline \multicolumn{4}{|c|}{ TEM Disk: } & \multicolumn{4}{|c|}{ TEM Disks } \\
\hline Program & Alloy (Conditurn) & $\begin{array}{c}200 J-1 \\
\text { Specimens } \\
(* J 19)\end{array}$ & $\begin{array}{c}4(x)-1 \\
\text { Specimens } \\
(* J 23)\end{array}$ & Program & Alloy (Condition) & $\begin{array}{c}2(x) J-1 \\
\text { Specimens } \\
\text { (\#J19) }\end{array}$ & $\begin{array}{c}4(x) J-1 \\
\text { Specimens } \\
(\# J 23)\end{array}$ \\
\hline JAERI & F82H (iaser weld joint) & B2-03 & - & JAERI & $316 \mathrm{~F}(\mathrm{SA})$ & DI-(K) & DI.24 \\
\hline$\cdot$ & F82H (laser weid jounI) & B2-144 & . & • & $316 \mathrm{~F}$ (SA) & DI.10 & D1-31) \\
\hline " & FX2H (laser weld joint) & B2-05 & - & - & $316 \mathrm{~F}(\mathrm{SA})$ & DI-11 & . \\
\hline$\cdot$ & JPCA $(\mathrm{CW})$ & C2.03 & $\mathrm{C} 2 \cdot 24$ & $\cdot$ & $316 \mathrm{~F}(\mathrm{SA})$ & D1-12 & . \\
\hline$\cdot$ & JPCA $(\mathrm{CW})$ & $C 2-(24$ & C2-25 & $\cdot$ & $316 \mathrm{~F}(\mathrm{SA})$ & D1.13 & - \\
\hline$\cdot$ & JPCA (CW) & C2.05 & $C 2.26$ & $\cdot$ & $316 \mathrm{~F}(\mathrm{SA})$ & D1-14 & \\
\hline • & JPCA (CW) & $\mathrm{C2}-116$ & $\mathrm{C} 2.27$ & " & $316 \mathrm{~F}(\mathrm{SA})$ & D1-15 & $\cdot$ \\
\hline$\cdot$ & JPCA (CU) & $C 2-1) 7$ & $C 2-2 x$ & $"$ & $316 \mathrm{~F}$ (SA) & D1-16 & - \\
\hline$\cdot$ & JPCA (CW) & $\mathrm{C2}-11 \mathrm{~s}$ & C2.24 & $\cdot$ & $316 \mathrm{~F}(\mathrm{SA})$ & D1.17 & - \\
\hline$\cdot$ & $J P C A, C W$, & $C 2-6 y$ & $\mathrm{C} 2-30$ & " & $316 F(S A)$ & DI.1K & - \\
\hline$\cdot$ & JPCA $\left(C^{\prime}\right)$ & $C 2-10$ & $C 2.31$ & " & $316 \mathrm{~F}(\mathrm{SA})$ & DI.14 & . \\
\hline * & $J P C A(C W)$ & $C_{2}-11$ & - & r & $316 \mathrm{~F}$ (SA) & D1.21 & - \\
\hline$\cdot$ & JPCA (CW) & $C_{2-12}$ & . & $\cdot$ & $316 F\left(\mathrm{CH}_{1}\right.$ & D2.117 & D2-24 \\
\hline$"$ & JPCA (CW) & $\mathrm{C}_{2}-13$ & . & - & $316 \mathrm{~F}(\mathrm{CW})$ & D2-124 & D2-25 \\
\hline$\cdot$ & JPCA (CW) & $\mathrm{C}_{2-14}$ & . & $\cdot$ & $316 \mathrm{~F}(\mathrm{CW})$ & D2-05 & D2.26 \\
\hline$\cdot$ & $J P C A\left(\mathrm{CH}^{\prime}\right)$ & $C 2-15$ & . & $\cdot$ & $3 \operatorname{lnF}\left(\mathrm{CH}^{\prime}\right)$ & $D 2-1 x_{6}$ & D2.27 \\
\hline$\cdot$ & JPCA $(\mathrm{CH})$ & $C 2 \cdot 16$ & . & - & $316 \mathrm{~F} / \mathrm{CU}_{i}$ & D2.17? & $\mathrm{D} 2 \cdot 2 \mathrm{x}$ \\
\hline$\cdot$ & $J P C A(C U)$ & $\mathrm{C}^{2} \cdot 1 \mathrm{Z}$ & . & $\cdot$ & $316 \mathrm{~F}(\mathrm{CW})$ & D2-1K & $D 2.29$ \\
\hline - & JPCA $(\mathrm{CW})$ & C2.1s & - & $\cdot$ & $316 F(C W)$ & $D 2-109$ & D2-30 \\
\hline$\cdot$ & JPCA $/ \mathrm{CU}_{1}$ & $C 2-14$ & . & $"$ & $316 \mathrm{~F}\left(\mathrm{CW}^{\prime}\right)$ & D2.16 & D2-32 \\
\hline$\cdot$ & $J P C A(C W)$ & $C_{2}-21$ & . & $\cdot$ & $316 \mathrm{~F}(\mathrm{CW})$ & $D=-11$ & - \\
\hline$\cdot$ & JPCAK & . & $C,-(1) 3$ & $\cdot$ & $316 \mathrm{~F}(\mathrm{CW})$ & $D 2-12$ & - \\
\hline$\cdot \cdot$ & JPCAC & - & $\mathrm{C}+(03$ & $"$ & $316 \mathrm{~F}(\mathrm{CW})$ & D2.13 & \\
\hline$\cdot$ & $316 F(S A)$ & DI.n\} & D1.23 & $\cdot$ & $316 \mathrm{~F}(\mathrm{CW})$ & D2.14 & \\
\hline " & $3 ! 6 F(S A)$ & D1.04 & D1.24 & $"$ & $316 \mathrm{~F}(\mathrm{CW})$ & D2-15 & . \\
\hline$\cdot$ & $316 \mathrm{~F}(\mathrm{SA})$ & D1.05 & $\mathrm{D} 1.25$ & " & $316 \mathrm{~F}(\mathrm{CW})$ & D2-16 & $\cdot$ \\
\hline$\cdot$ & $316 \mathrm{~F}(\mathrm{SA})$ & D1-16 & DI. 26 & $\cdot$ & $316 \mathrm{~F}(\mathrm{CW})$ & $\mathrm{D} 2 \cdot 17$ & - \\
\hline " & $316 \mathrm{~F}$ (SA) & D1-10? & D1.27 & $\cdot$ & $316 \mathrm{~F}(\mathrm{CW})$ & D2-18 & . \\
\hline$\cdot$ & $316 \mathrm{~F}(\mathrm{SA})$ & DI- $-0 \mathrm{x}$ & D 1.28 & $\cdot$ & $316 \mathrm{~F}(\mathrm{CW})$ & $D 2-19$ & - \\
\hline
\end{tabular}


Table 4. Continued

\begin{tabular}{|c|c|c|c|}
\hline \multicolumn{4}{|c|}{ TEM Disks } \\
\hline Program & Alloy (Condition) & $\begin{array}{c}200 \mathrm{~J}-1 \\
\text { Specimens } \\
(\# J 19)\end{array}$ & $\begin{array}{c}4000-1 \\
\text { Specimens } \\
(\# J 23)\end{array}$ \\
\hline JAERI & $316 \mathrm{~F}(\mathrm{CW})$ & $\mathrm{D} 2.20$ & - \\
\hline " & $316 \mathrm{MS}$ & D.3-0.3 & D3-07 \\
\hline$\cdot$ & $316 \mathrm{MS}$ & D.-n 14 & D3-0. \\
\hline$\cdot$ & $316 \mathrm{Ms}$ & - & D3-10 \\
\hline - & $310 \mathrm{M7}$ & D4-(14) & D4-0x \\
\hline$\cdot$ & $310 \mathrm{M} 7$ & D4-1)s & D4-(1) \\
\hline$\cdot$ & $316 \mathrm{M7}$ & . & D4-10 \\
\hline$=$ & $316 \mathrm{MIO}$ & DS-14 & D5-(188 \\
\hline • & $316 \mathrm{M10}$ & DS.05 & D5-(0) \\
\hline$\cdot$ & $316 \mathrm{MIO}$ & & D5-11 \\
\hline$\cdot$ & $\mathrm{F}-15 \mathrm{Cr}-16 \mathrm{~N}$ & B2B1 & B2B3 \\
\hline$\cdot$ & Fe-15Cr-16Ni-0.25Ti-0.05C-10kappmB & G1G2 & Gigs \\
\hline$\cdot$ & 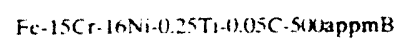 & H1HQ & $\mathrm{HIHB}$ \\
\hline$\cdot$ & Fe-15Ci-16N-11.25Ti-11.05C-256kappmB & $\mathrm{kik2}$ & KIKS \\
\hline " & $F \cdot 15 C_{r} \cdot 10 N_{1}-5$ (KapppmB & LILY & LILD \\
\hline . & $F c-15 C r-16 N i-1.25 T$ T -5 ShappmB & MIMY & MIMD \\
\hline - & $J P C A 2$ & & A)AV \\
\hline - & $F e \cdot 15 C r .20 N$ & . & $\mathrm{H} 306$ \\
\hline$\cdot$ & $310 S i(S A)$ & . & $\mathrm{H} 4 \mathrm{~K}$ \\
\hline - & 30 SI $/ \mathrm{CH}$ & . & $\mathrm{H} 50 \mathrm{O}$ \\
\hline - & $316, S 2(S A)$ & . & $H 606$ \\
\hline - & $316 \mathrm{S2}(\mathrm{CH})$ & - & $H 706$ \\
\hline$\cdot$ & $J H D(S A)$ & . & F1-03 \\
\hline$\cdot$ & JHD (CW) & . & $F 2-0.3$ \\
\hline$\cdot$ & $\mathrm{JHF}(\mathrm{SA})$ & . & $\mathrm{F} 3-03$ \\
\hline . & JHF (CW) & . & F4-1)3 \\
\hline$\cdot$ & $\mathrm{JHG}(\mathrm{SA})$ & . & F5- 03 \\
\hline$\cdot$ & $\mathrm{JHG}(\mathrm{CW})$ & . & $F 6-03$ \\
\hline$\cdot$ & $\mathrm{JHH}(\mathrm{CW})$ & . & F7-1)3 \\
\hline
\end{tabular}


STATUS OF U.S./JAPAN COLLABORATIVE PROGRAM PHASE II HFIR TARGET CAPSULES - J. E. Pawel and R. L. Senn (Oak Ridge National Laboratory) and K. Shiba (Japan Atomic Energy Research Institute)

\section{OBJECTIVE}

The objective of this program is to determine the response of various U.S. and Japanese austenitic and ferritic stainless steels with different pretreatments and alloy compositions to the combined effects of displacement damage and helium generation at temperatures in the range of 300 to $600^{\circ} \mathrm{C}$ and doses of 18 to $70 \mathrm{dpa}$.

\section{SUMMARY}

A complete description and details of the design, construction, and installation of capsules JP9 through JP16 have been previously reported. ${ }^{1.2 .3}$ The capsules were installed in the High Flux Isotope Reactor (HFIR) target July 20, 1990 for irradiation beginning with HFIR fuel cycle 289. The capsules were removed and stored in the reactor pool during HFIR cycle $293(12 / 27 / 90-1 / 23 / 91)$ to provide room for required isotope production. They were reinstalled for HFIR cycle 294 for continued irradiation. Of these eight target capsules, JP10, 11, 13, and 16 completed their scheduled number of cycles (11) and were removed from the reactor in September 1991. In addition, JP14 was removed from the reactor at the end of cycle $310(9 / 18 / 92)$ after 21 cycles.

Three new capsules in this series, JP20, 21, and 22, have been designed. These capsules were added to the program in order to complete the experimental matrix included in the JP9 through JP16 capsules. The new capsules will contain transmission electron microscope (TEM) disks and SS-3 flat tensile specimens at $300-600^{\circ} \mathrm{C}$ and will achieve doses of 8,18 and $35 \mathrm{dpa}$, respectively. The preliminary experiment matrix is described in detail in a previous report. ${ }^{4}$

\section{PROGRESS AND STATUS}

\section{Capsules JP9 through JP16}

The as-built specimen matrix for the JP9 through JP16 series capsules can be found in a previous report. " These capsules contain primarily transmission electron microscopy disks (TEM) and SS-3 tensile specimens. A wide variety of alloys and thermomechanical conditions are included. Many of the TEM disks were made from isotopically tailored alloys to produce a range of $\mathrm{He} / \mathrm{dpa}$ ratios $(<0.1$, $10,20,70)$. Details of the irradiation history of these capsules are shown in Table 1.

Many of the specimens from the JP10, 11, 13, and 16 capsules have been tested in the Irradiated Materials Examination and Testing Facility hot cells. Of 104 SS-3 tensile specimens removed from these four capsules, 52 have been tested during this reporting period. Reduction-in-area measurements are currently underway on the broken halves. Analyses of these data are in progress and are expected to be reported in September 1993. The alloys tested include JPCA and type 316 (316F) stainless stecls in solution annealed, cold worked, and welded conditions.

Density measurements have been taken on specimens removed from the JP10 Position 6 TEM tube and the JP16 Position 6 TEM tube using the ORNL precision densitometer. The JP11 and JP13 Position 6 tubes have already been opened and are scheduled for sorting and densitometry during the 
Table 1. Irradiation history of the US/Japan Phase II HFIR Target Capsules.

\begin{tabular}{|c|c|c|c|c|c|c|c|c|c|}
\hline \multicolumn{4}{|c|}{ HFIR OPERATION } & \multicolumn{2}{|c|}{ JP-10,-11,-13,-16 } & \multicolumn{2}{|c|}{ JP-14 } & \multicolumn{2}{|c|}{$J P-9,-12,-15$} \\
\hline \multirow{2}{*}{$\begin{array}{l}\text { CrCLE } \\
\text { NO. }\end{array}$} & \multirow{2}{*}{$\begin{array}{l}\text { START } \\
\text { DATE }\end{array}$} & \multirow{2}{*}{$\begin{array}{l}\text { END } \\
\text { DATE }\end{array}$} & \multirow{2}{*}{$\begin{array}{c}M W \mathrm{~d} / \\
\text { Cych }^{\prime}\end{array}$} & \multicolumn{2}{|c|}{11 CYCLE IRR. } & \multicolumn{2}{|c|}{21 CYCLE IRR. } & \multicolumn{2}{|c|}{37 CYCLE IRR. } \\
\hline & & & & MWd & dpa" & MWd & dpa* & MWd & dpa" \\
\hline 289 & $07-20-90$ & $09-07.90$ & 1879 & 1879 & 1.64 & 1879 & 1.64 & 1879 & 1.64 \\
\hline 290 & $09 \cdot 19.90$ & $10.11-90$ & 1852 & 3731 & 3.26 & 3731 & 3.26 & 3731 & 3.26 \\
\hline 291 & $10-17-90$ & $11.13-90$ & 1838 & 5569 & 4.86 & 5569 & 4.86 & 5569 & 4.86 \\
\hline 292 & $11-25-90$ & $12-10-90$ & 1847 & 7416 & 6.47 & 7416 & 6.47 & 7416 & 6.47 \\
\hline 293 & $12 \cdot 27 \cdot 90$ & $01.23-91$ & 1965 & \multicolumn{6}{|c|}{ CAPBULES OUT OF REACTOR FOA THLS CYCLE - } \\
\hline 294 & $02-01-91$ & $02 \cdot 25-91$ & 1906 & 9322 & 8.14 & 9322 & 8.14 & 9322 & 8.14 \\
\hline 295 & $03-01.91$ & $03 \cdot 24-91$ & 1908 & 11230 & 9.80 & 11230 & 9.80 & 11230 & 9.80 \\
\hline 296 & $04-06-91$ & $04.28 \cdot 91$ & 1874 & 13104 & 11.44 & 13104 & 11.44 & 13104 & 11.44 \\
\hline 297 & $05-19-91$ & $06-15 \cdot 91$ & 1845 & 14949 & 13.05 & 14949 & 13.05 & 14949 & 13.05 \\
\hline 298 & $06-20-91$ & 07.11 .91 & 1747 & 16696 & 14.58 & 16696 & 14.58 & 16696 & 14.58 \\
\hline 299 & $07-25-91$ & $08-15-91$ & 1741 & 18437 & 16.10 & 18437 & 16.10 & 18437 & 16.10 \\
\hline 300 & $08-28-91$ & 09.17 .91 & 1724 & 20161 & 17.60 & 20161 & 17.60 & 20161 & 17.60 \\
\hline 301 & $09 \cdot 27 \cdot 91$ & $10 \cdot 19-91$ & 1851 & \multicolumn{2}{|c|}{ AEMOVED EOC 300} & 22012 & 19.22 & 22012 & 19.22 \\
\hline 302 & 10.27.91 & 11.21 .91 & 1829 & & & 23841 & 20.81 & 23841 & 20.81 \\
\hline 303 & $12-01-91$ & $12-22-91$ & 1821 & & & 25662 & 22.40 & 25662 & 22.40 \\
\hline 304 & $12-31.91$ & $01.24-92$ & 1826 & & & 27488 & 24.00 & 27488 & 24.00 \\
\hline 305 & $01-30-92$ & $02-27.92$ & 1876 & & & 29364 & 25.63 & 29364 & 25.63 \\
\hline 306 & $03-31-92$ & $04-27-92$ & 1845 & & & 31209 & 27.25 & 31209 & 27.25 \\
\hline 307 & $05-01-92$ & $05-28-92$ & 1842 & & & 33051 & 28.85 & 33051 & 28.85 \\
\hline 308 & $06-02-92$ & $06-30-92$ & 1938 & & & 34989 & 30.55 & 34989 & 30.55 \\
\hline 309 & 07-03-92 & $08-01-92$ & 1949 & & & 36938 & 32.25 & 36938 & 32.25 \\
\hline 310 & $08-27-92$ & $09-18.92$ & 1849 & & & 38787 & 33.86 & 38787 & 33.86 \\
\hline 311 & $09-25-92$ & 10.12 .92 & 1856 & & & \multicolumn{2}{|c|}{ REMOVED EOC 310} & 40643 & 35.48 \\
\hline 312 & $10-22-92$ & 11.14 .92 & 1842 & & & & & 42485 & 37.09 \\
\hline 313 & 11.21 .92 & $12-15-92$ & 1850 & & & & & 44335 & 38.70 \\
\hline 314 & $12-20-92$ & 01.12 .93 & 1866 & & & & & 46201 & 40.33 \\
\hline 315 & $01-19-93$ & $02-10-93$ & 1861 & & & 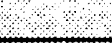 & & 48062 & 41.96 \\
\hline $\begin{array}{l}316 \\
317\end{array}$ & $02-18-93$ & $04-03-93$ & 1807 & & & & & 49869 & 43.54 \\
\hline 318 & & & & & & & & & \\
\hline 319 & & & & & & & & & \\
\hline 320 & & & & & & & & & \\
\hline
\end{tabular}

- DPA levels based on achieving $0.000873 \mathrm{dpa} / \mathrm{MWd}$.

- Correction from previous issues of this document. The experiments were out of reactor for cycle 293 rather than 292. This slightly reduces the previously reported MWd and dpa values. 
next reporting period. These four tubes contain isotopically tailored alloys from both the ORNL and JAERI programs as well as other candidate fusion alloys. This experiment addresses the long-standing questions on the role of helium in microstructural evolution and will explore the high fluence swelling behavior of the most swelling-resistant materials currently available.

Capsule JP14 is scheduled to be disassembled in May 199.3. This capsule, which achieved 34 dpa, contains SS-3 tensile specimens and TEM disks of many of the alloys included in the JP10,11, 13 and 16 set of capsules, which achieved 18 dpa.

\section{Capsules JP20 through 22}

Three new capsules, JP20, 21, and 22, have been designed to complete the original experiment matrix of the JP9 through JP16 serics capsules. It is planned to irradiate the three capsules in inner target positions for 5,11 , and 22 cycles, respectively, to achieve peak doses of approximately 8,18 , and 35 dpa. Specimen temperatures in each capsule will be $300,400,500$, or $600^{\circ} \mathrm{C}$.

\section{PRESENT STATUS}

Installation of JP20, 21, and 22 in the HFIR is currently scheduled for August 1993.

\section{REFERENCES}

1. $\quad$ R. L. Senn, "Status of U.S./Japan Collaborative Program Phase II HFIR Target Capsules," pp. 8 -20 in Fusion Reactor Materials Semiann. Prog. Rep. Sept. 30, 1987, DOE/ER-0313/3, U.S. DOE Office of Fusion Energy.

2. $\quad$ R. L. Senn, "Status of U.S./Japan Collaborative Program Phase II HFIR Target Capsules," pp. 7.9 in Fusion Reactor Materials Semiann. Prog. Rep., March 31, 1988, DOE/ER-0313/4, U.S. DOE Office of Fusion Energy.

3. R. L. Senn, "Status of U.S./Japan Collaborative Program Phase II HFIR Target Capsules," pp.6-13 in Fusion Reactor Materials Scmiann. Prog. Rep., Sept. 30, 1988, DOE/ER-0313/5, U. S. DOE Office of Fusion Energy.

4. J. E. Pawel and R. L. Senn, "Status of U.S./Japan Collaborative Program Phase II HFIR Target Capsules," pp. 15-2.3 in Fusion Reactor Materials Semiann. Prog. Rep., March 31 , 1992, DOE/ER-0313/12, U. S. DOE Office of Fusion Energy. 
2.0 DOSIMETRY, DAMAGE PARAMETERS, AND ACTIVATION CALCULATIONS 
HELIUM MEASUPEMENTS FOR THE MOTA IG DISCHARGE OF THE NI ISOTOPIC TRILORIHG EXPERIMENT F. A. Gamer Pacific Northwest Laboratory) and B. M. Oliver (Rockwell International)

\section{OBJECTIVE}

The objective of this effort is to determine the role of helium on radiation-induced nicrostructural evolution and associated changes in mechanical properties of model $\mathrm{Fe} \cdot \mathrm{Cr} \cdot \mathrm{Ni}$ alloys.

SUMMARY

The final measurements of helium generation in specimens used in the Ni isotopic tailoring experiment have been completed. The results show that the target generation rates were sustained throughout the experimental series. It was also demonstrated that helium generation rates grow cont inuously in undoped specimens, reaching levels substantially larger than usually quoted in most other studies.

\section{PROGRESS AND STATUS}

\section{intraduction}

In a previous report it was shown that the ${ }^{52} \mathrm{Ni}$ isotopic talloring experiment conducted in ffTf was very successful in showing that the role of the helium generation rate on neutron-induced property changes was of second order importance compared to the action of other variables examined in the experiment (1). Such a conclusion, of course, depends on demonstrating that the target generation rates were indeed maintained throughout the experiment. In an earlier report the helium/dpa rates for specimens from MOTA 10 . IE, and If were presented (2). This report

presents the measurements for the final discharge from MOTA IG and also makes an assessment of the entire experiment.

The helium measurement techniques have been described earlier (2). For each specimen, two separate measurements were made, each on a one-quarter section of the specimen.

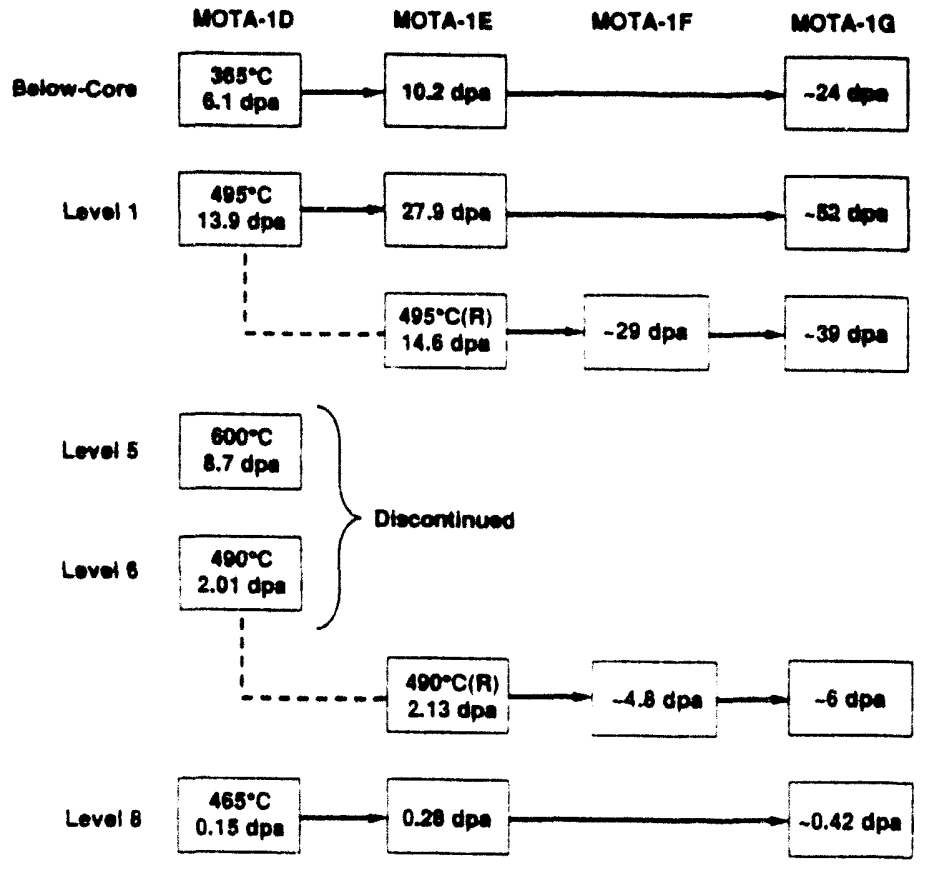

The damage levels and temperatures explored in this experiment are oresented in Fig. 1. The new neasurements correspond to the right nand column of final irradiation sequences of Fig. 1 . The level 8 low dose series at $465^{\circ} \mathrm{C}$ in MOTA 10 was not measured, however, since all specimens were sent to Japan for microscopy examination by Professor H. Kawanishi of the University of Tokyo.

\section{Results}

Table I presents a compilation of the helium measurements. In one case ( $\mathrm{Fe}$ $5 \mathrm{Cr}-25 \mathrm{Ni}$ without ${ }^{\circ} \mathrm{Ni}$ at $495^{\circ} \mathrm{C}$ and 52 toa) a specimen was not available but the helium generation rate $c$ an be alculated at $25 / 45$ of the generation rate in the $\mathrm{Fe}-15 \mathrm{Cr}-45 \mathrm{Ni}$ specimen. Two separate $\mathrm{Fe}-15 \mathrm{Cr}-45 \mathrm{Ni}$ specimens at this set of irradiation conditions were examined to check on the reproducibility of the helium generation rate from specimen to specimen. The repoducibility appears to be quite good. fielding $62.6 \pm<0.1$ and $63.1 \pm 0.3 \mathrm{appm}$ for the two specimens.

Fig. 1. Schematic representation of irradiation sequences for the "Ni isotopic tailoring experiment. " $495^{\circ}(R)$ " and

"490. $\mathrm{C}(4)^{\prime}$ " refer to the replacement sequences substituted for the original compromised sequences at 495 and $490^{\circ} \mathrm{C}$. Damage levels shown represent the cumulative totals. 
Toble

tholium Concentrations in IEM Samples hom MOIA is

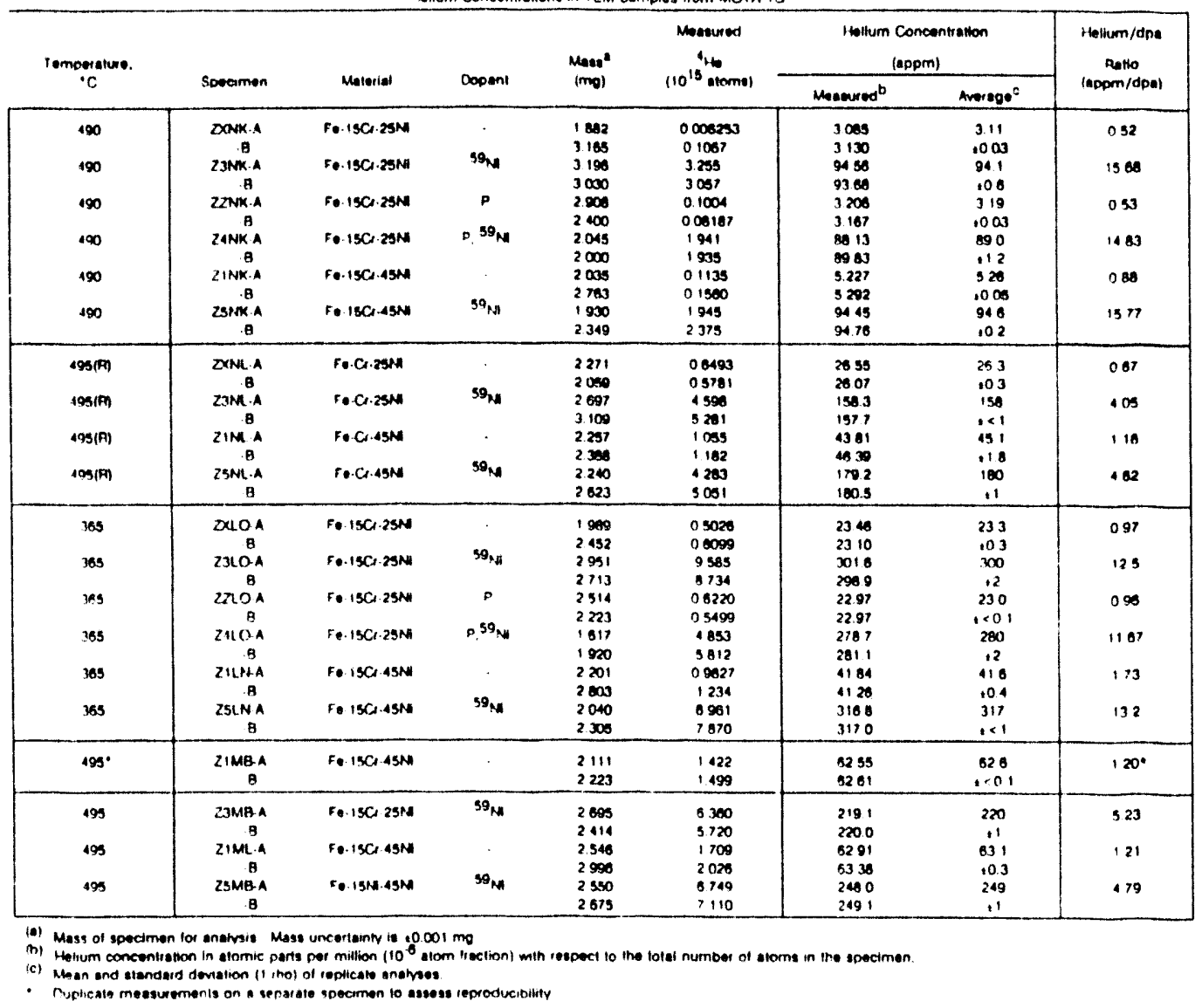

iabio 2

Hellum Generation Antor Determined in Fo. $15 \mathrm{Cr} 25 \mathrm{Nh}$

- telitum Genecalion Rale (acom/dpa)

\begin{tabular}{|c|c|c|c|c|c|c|c|c|}
\hline \multirow{2}{*}{$\begin{array}{c}\text { empernture } \\
\left({ }^{\circ} \mathrm{C}\right)\end{array}$} & \multicolumn{2}{|c|}{ MOTA 10} & \multicolumn{2}{|c|}{ MOIA IE } & \multicolumn{2}{|c|}{ Mota if } & \multicolumn{2}{|c|}{ :IOSIA IO } \\
\hline & Undoned & topped & indoosd & Doped & Indoped & oped & Inctooed & Coped \\
\hline 265 & 030 & 139 & $\begin{array}{l}069^{(n)} \\
1251^{(n)}\end{array}$ & $\begin{array}{l}190^{(4)} \\
1911\end{array}$ & \multicolumn{2}{|c|}{ to Discharoe } & : & $\begin{array}{l}125 \\
19 \mathrm{An}\end{array}$ \\
\hline 195 & 0.35 & 159 & $\begin{array}{l}04 r^{31} \\
0591\end{array}$ & $\begin{array}{l}17\}^{|x|} \\
\mid 473\}\end{array}$ & \multicolumn{2}{|c|}{$\because \because$ Dischargo } & $\begin{array}{l}26,101 \\
2001\end{array}$ & $\begin{array}{l}123 \\
1351\end{array}$ \\
\hline $495(R)^{(C)}$ & & & 0.44 & 471 & $\begin{array}{l}057^{n !} \\
0701\end{array}$ & $\begin{array}{l}108^{(A)} \\
345\}\end{array}$ & $\begin{array}{l}067 \\
19961\end{array}$ & $\begin{array}{r}405 \\
(396)\end{array}$ \\
\hline 600 & 040 & 44 & & & \multicolumn{2}{|c|}{. } & & - \\
\hline 490 & 028 & 198 & & & & & & \\
\hline${ }_{4 \infty}(m|m| c \mid$ & & & 021 & 101 & $\begin{array}{l}034^{(a)} \\
206\}\end{array}$ & $\begin{array}{l}137^{|a|} \\
(172)\end{array}$ & $\begin{array}{l}032 \\
1124)\end{array}$ & $\begin{array}{r}137 \\
1237\end{array}$ \\
\hline 465 & 014 & 513 & $\begin{array}{l}026^{(4)} \\
0401\end{array}$ & $\begin{array}{l}521^{(a)} \\
\mid>111\end{array}$ & \multicolumn{2}{|c|}{ No Discharge } & \multicolumn{2}{|c|}{ "Int Messured } \\
\hline
\end{tabular}

a) He dos ievel gien is the everage for a two precle irradiation sequence

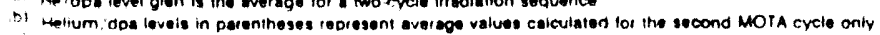

of a denoles iedacemont selies

di catculated by anding the $45 \mathrm{Nin}$ iosult by 19 
Fig. 2 shows the average helium generation rates over the entire experiment for both the doped and undoped specimens. Fig. 2 a shows that at 600 and $495^{\circ} \mathrm{C}$ (both the original and repeat isothermal sequences), the helium/dpa ratios are close to the original target of 5.0 al though the ratio falls slowly as more ${ }^{3} \mathrm{Ni}$ is burnt out than is formed from ${ }^{j 8} \mathrm{Ni}$. In the below-core $\left(365^{\circ} \mathrm{C}\right)$ and level $6\left(490^{\circ} \mathrm{C}\right)$ sequences the ${ }^{\circ} \mathrm{Ni}$ burn. out reaction rate is comparable in magnitude to the rate of formation of ${ }^{53} \mathrm{Ni}$ from ${ }^{\mathrm{Ni}}$. The net generation rates are thus more sensitive to the accumulated exposure and the details of surrounding experiments in this softer spectral environment, producing both increases and decreases in the net generation rate. The helium generation rates are much higher in these two levels, but exceed somewhat the 10 appm/dpa target level throughout the experiment. Not shown in $\mathrm{Fig} .2 \mathrm{a}$ is the very low fluence experiment in level 8 at $465^{\circ} \mathrm{C}$, which reached $54.3 \mathrm{appm} / \mathrm{dpa}$ at 0 to $14 \mathrm{dpa}$ and $62.1 \mathrm{appm} / \mathrm{dpa}$ at $0.26 \mathrm{dpa}$. This is close to the target level of -50 . As mentioned earlier, measurements were not made at the final 0.42 dpa level of this irradiation sequence.

$\mathrm{Fig}$. $2 \mathrm{~b}$ demonstrates that in the non-doped alloys, it is the burn-in of ${ }^{59} \mathrm{Ni}$ from ${ }^{53} \mathrm{Ni}$ that dominates the helium generation rate. Thus, the average helium/dpa ratis increases throughout the experiment, with the rate of increase increasing as the neutron spectra become softer, and the dpa rate decreases with increasing distance from the core boundary. The competition between burn-out and burn-in of ${ }^{53} \mathrm{Ni}$ is discussed in more detail elsewhere (3).

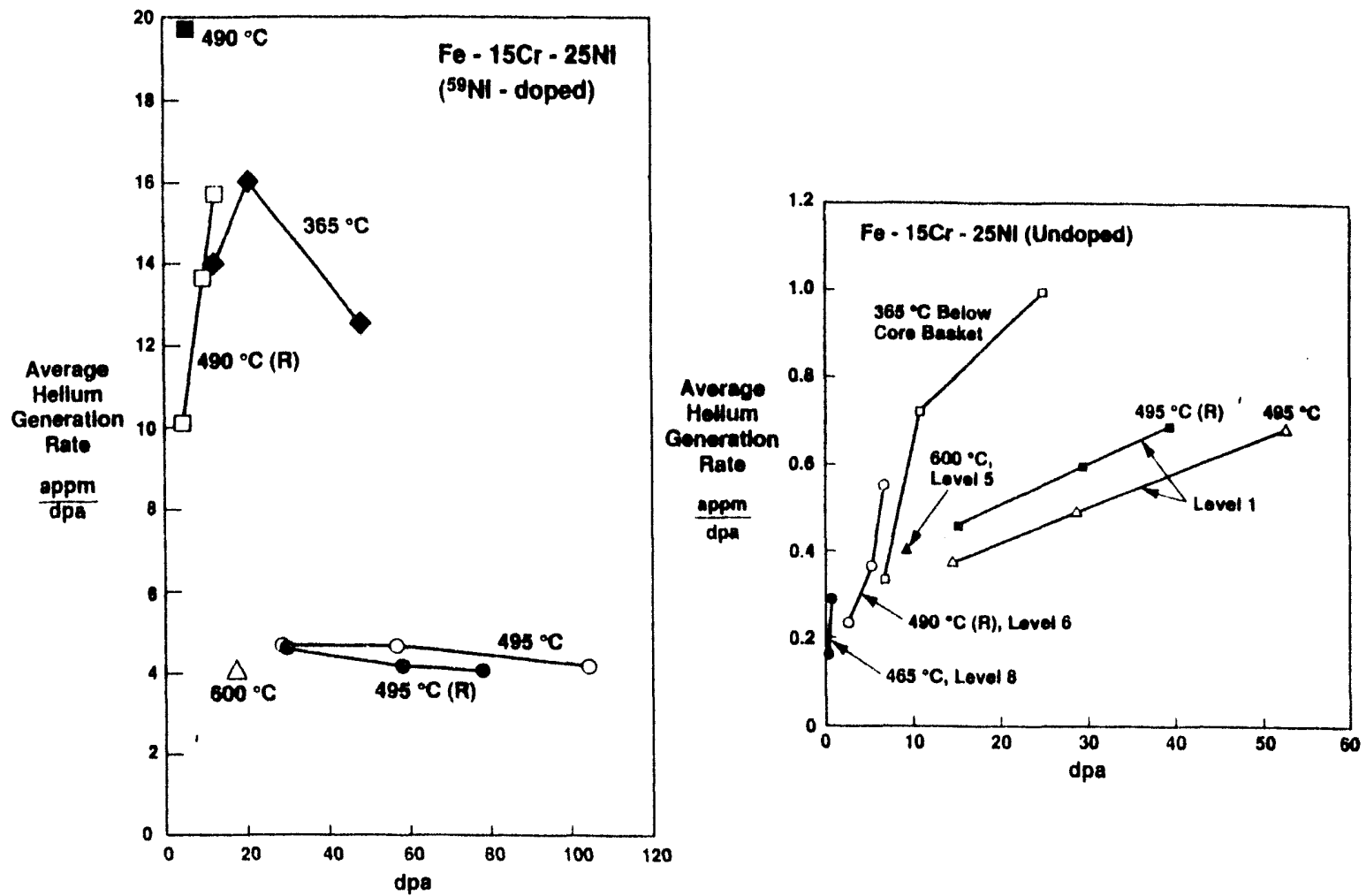

Fig. 2. Helium generation rates measured from the ${ }^{53} \mathrm{Ni}$ lsotopic Tailoring Experiment averaged over the full duration of the various discharges of the experiment, left) doped specimens and right) undoped specimens.

\section{Discussion}

It thus appears that the conclusions drawn earlier, concerning the second order role of helium on microstructural evolution, are correct. It is possible at this time, however, to also assess the performance of this experiment with respect to several criteria used to design the experiment. These are listed below:

1) Criterion \#1: The helium generation rate should not vary significantly with nickel content in the doped alloys, and thus should allow a clean separation between the effects of helium and 
nickel. Nickel is the major source of helium in the undoped alloys. Thus both $25 \mathrm{Ni}$ and $45 \mathrm{NI}$ alloys were doped with $0.4 \%$ of ${ }^{59} \mathrm{Ni}$.

The success of this goal can be tested using the MOTA 16 data for the 490,365 and 495 (R) sequences. Calculating the ratio of the helium in the two alloys generated only from ${ }^{59} \mathrm{Ni}$ $\left[\left(C_{25 \mathrm{M}} 5 C_{25 \mathrm{Mj}}\right) /\left(C_{45 \mathrm{Ni} .59}-C_{45 \mathrm{~N}}\right)\right]$, we find that the ratios are $0.982,1.024$, and 1.005 for the $490^{25 \mathrm{M}} 495(R)$ and $365^{45 \mathrm{~N}}$ sequences, respectively. If we assume that we can calculate $C_{25 \mathrm{Ni}}$ from $25 / 45$ of $C$ then the ratio of the doped helium generation rates for the $495^{\circ} C$ sequence is 0.995 . Thus, for the four irradiation series, the ratio of helium generation rates in the two alloys is $1.00 \pm 0.02$, and the experiment may be judged a success based on this criterion.

2) The undoped specimens should exhibit helium generation rates that depend only on nickel level. Thus the $25 \mathrm{Ni}$ and $25 \mathrm{Ni}+0.04 \mathrm{P}$ alloys should exhibit identical generation rates and the $45 \mathrm{Ni}$ alloys should have 1.8 times more helium than the $25 \mathrm{Ni}$ alloys.

Referring to Table 1 , we can calculate $C_{45 N} / C_{24 N}$ ratios of $1.69,1.71$, and 1.79 for the 490 , 495 and $365^{\circ} \mathrm{C}$ sequences, respectively. The small differences from the expected ratio of 1.8 probably reflect the fact that each alloy occupies a separate but nearby packet, and the three packets do not all experience exactly the same neutron environment.

The helium generation rates in the phosphorous-containing alloys were determined only for the $490^{\circ} \mathrm{C}$ and $365^{\circ} \mathrm{C}$. The ratio of generation rates $\left(C_{25 \mathrm{~N}+\mathrm{p}} / \mathrm{C}_{25 \mathrm{Ni}}\right)$ for the undoped alloys were 1.03 and 0.99 respectively. For the doped alloys the ratio was 0.95 at $490^{\circ} \mathrm{C}$ and 0.93 at $365^{\circ} \mathrm{C}$. Thus, the separate effects of helium generation rates and phosphorous could be successfully examined in this experiment.

\section{CONCLUSIONS}

It appears that the ${ }^{59} \mathrm{Ni}$ isotopic tailoring concept can be successfully used to study the separate and synergistic effects of helium and other important variables in $\mathrm{Fe}-\mathrm{Cr}-\mathrm{Ni}$ alloys. The helium generation rates in undoped alloys increase continualiy during irradiation, reaching values consistently larger than normally quoted for fast reactor irradiation.

FUTURE WORK

Only a small amount of microscopy examination is required to complete this experiment.

\section{References}

1. F. A. Garner, M. L. Hamilton, L. R. Greenwood, J. F. Stubbins, and B. M. Oliver in Effects of Radiation on Materials: 16th International Symposium. ASTM STP 1175, A. S. Kumar. D. S. Gelles, R. K. Panstad and E. A. Little, Eds., American Society for Testing and Materials, 1993, in press.

2. M. L. Hamilton, F. A. Garner, and B. M. Oliver, in Fusion Reactor Semiannual Progress Report DOE/ER0313,9 (1991) pp. 61-68.

3. L. R. Greenwood, F. A. Garner, and B. M. Oliver, J. Nucl. Mater. 191-194(1992)1051-1055. 
MEUTRON DOSIMETRY FOR THE MOTA-1G EXPERIMENT IN FFTF - L.R. Greenwood and L.S. Keliogg iPacific Northwest Laboratory)

\section{OBJECTIVE}

io provide dosimetry and damage analysis for fusion materials irradiation experiments.

SUMMARY

Neutron fluence and spectral measurements and radiation damage calculations are reported for the MOTA-1G experiment in the Fast Flux Test Facility (FFTF). The irradiation was conducted from January 4 , 1990 , to March 19.1991, for a total exposure of 299.7 EFPD. The maximum fluence was $15.8 \times 10^{2 \%} \mathrm{n} / \mathrm{cm}^{2}$, $10.0 \times 10^{22}$ above $0.1 \mathrm{MeV}$ producing $43.0 \mathrm{dpa}$ in iron. Neutron fluence and radiation damage maps are presented for the entire MOTA assembly based on the analysis of ten neutron spectral measurements and seven additional flux gradient measurements.

\section{DROGRESS AND STATUS}

ileutron dosimetry for the Materials Open Test Assembly (MOTA)-IG experiment in the Fast Flux Test Facility (FFTF) at Hanford provided comprehensive measurements over the entire assembly with a total of seventeen capsules positioned at different axial locations in the assembly spanning a distance of -66 to $+122 \mathrm{~cm}$. This irradiation occurred simultaneously with the MOTA-2A experiment reported previously. Fach stainless steel capsule measured about $2.1 \mathrm{~cm}$ long by $0.48 \mathrm{~cm} 0 . \mathrm{d}$. and contained dosimetry wires for either spectral or gradient measurements. The ten spectral capsules contained small wires of $\mathrm{Fe}$. Ii. Ni. Cu, $0.1 \%$ CO-Al alloy, $0.825 \% .2 \mathrm{~V}$ in $\mathrm{V} .0 .936 \%{ }^{39} \mathrm{Pu}$ in $\mathrm{MgO}$, and $0.42 \%{ }^{\circ} \mathrm{Np}$ in $\mathrm{MgO}$ whereas the twenty gradient capsules contained Fe and $0.1 \%$ CO-Al alloy wires. The Co, U. Pu, and $\mathrm{Np}$ materials were separately encapsulated in vanadium. In addition, small amounts of $B e, B$, and $L$ if were included in some of the spectral capsules for helium analyses and three of the spectral sets contained small $\mathrm{Nb}$ wires. Altogether, there were a total of 95 radiometric manitor wires and 18 helium monitors.

Following irradiation, each dosimetry capsule was opened in a hot cell and each individual monitor was centified and mounted for gamma analys is. The measured activities were then converted to saturated activities by correcting for the sample weight, atomic weight, isotopic abundance, gamma absorption, reactor power history, and fission yield, as needed. Neutron self.shielding effects were not significant since the Co, $U$. and PU were dilute alloys and the FFTF neutron spectrum has few neutrons at lower neutron energies. For the $\therefore$ Pu, and Np fission monitors. the gamma measurements detected four fission products. namely, $2 r$, Ru.

Cs, and : Ce. The standard deviation from the mean fission rate was generally iess than $5 \%$ except for the Hid reactions at out-of-core locations, as discussed below.

leutron burnup effects were found to be quite significant for the fission monitors and a small correction was necessary for the " $\mathrm{Co}(n, y)$ and fission reactions. In the case of co this correction can be applied using an iterative procedure since the reaction itself is the sole source of the burnup. as described previously. in the case of the $\mathrm{Co}(n, y)$ reaction, the burnup effect varied from $0.4 \%$ at midplane to $2.6 \%$ in the below-core basket. Burnup effects for the fission monitors were very similar to those determined for the MOTA-2A experiment. In most cases. the burnup corrections for the fission monitors were about $20 \%$ at midplane and decreased away from core center. For Np, there appears to be a significant effect from the iower energy neutrons at the out-of-core positions due to inbreeding of $y$ and eventually ipu. as evidenced by the large atater in the four measured fission products. Hence, the No data was discarded at the out-of-core positions aril was not used in the spectral analyses.

The corrected reaction rates are listed in Tables 1-3. All values are normalized to 29 ! Mw operation and the a i ues nave an estimated absolute uncertainty of about $5 \%$. ai though there is an adoitional uncertainty of about $5 \%$ for the fission reactions due to problems in determining the burnup rates. These rates appear to be in aasonabie agreement with previous measurements.. except for the fission reactions. lieither of the earlier axperiments (MOTA-IA,IB and IE) made any attempt to determine neutron burnup corrections for the fission reactions. Hence, values measured for MOTA-IF, $2 \mathrm{~A}$ and $1 \mathrm{G}$ are about $20-30 \%$ higner than the earlier measurements. When allowances are made for differences in reactor power (400 MW rather than $291 \mathrm{MW}$ ) and other sore chariges.

'Pacific Northwest Laboratory is operated for the U.S. Department of Energy by Battelle Memorial Institute inder Contract DE-ACO6-76RLO 1830. 
Jable 1 . Activation Measurements in MOTA-1G (atoms/atom-s)

\begin{tabular}{|c|c|c|c|c|c|}
\hline \multicolumn{2}{|c|}{$\begin{array}{c}\text { Sample/ } \\
\text { Level-Pin }\end{array}$} & $\mathrm{Ht}, \mathrm{cm}$ & $\begin{array}{c}{ }^{54} \mathrm{Fe}(\mathrm{n}, \mathrm{p}){ }^{54} \mathrm{Mn} \\
(\times \mathrm{E}-11)\end{array}$ & $\begin{array}{c}{ }^{58} \mathrm{Fe}(n, y)^{59} \mathrm{Fe} \\
(x E-11)\end{array}$ & $\begin{array}{c}{ }^{67} \mathrm{Co}(n, y){ }^{68} \mathrm{Co} \\
(x E-10)\end{array}$ \\
\hline $\begin{array}{l}M 1 \\
M 81 \\
M 3 \\
M 82 \\
M 7 \\
M 10 \\
\times 35 \\
M 4 \\
\times 36 \\
M 11 \\
M 83 \\
M 80 \\
M 5 \\
M 6 \\
M 79 \\
\times 37 \\
M 78\end{array}$ & $\begin{array}{l}B C-F B \\
B C-F B \\
1-F B \\
1-F T \\
2 \cdot F T P \\
3-C \\
3-D M P \\
3-B M \\
3-F M P \\
3-E \\
4-F M P \\
5-F B \\
5-F T \\
6-F B \\
6-F T \\
8-F B \\
8-F T\end{array}$ & $\begin{array}{r}-66.3 \\
-58.4 \\
-39.2 \\
-35.8 \\
-21.9 \\
-5.3 \\
-2.1 \\
-1.1 \\
-1.1 \\
2.1 \\
19.9 \\
40.5 \\
50.7 \\
74.3 \\
79.3 \\
109.4 \\
122.3\end{array}$ & $\begin{array}{l}0.14 \\
0.32 \\
1.00 \\
2.29 \\
3.09 \\
3.30 \\
3.55 \\
3.33 \\
3.81 \\
3.17 \\
2.53 \\
1.63 \\
0.77 \\
0.068 \\
0.044 \\
0.0045 \\
0.0019\end{array}$ & $\begin{array}{l}3.65 \\
4.01 \\
4.05 \\
3.21 \\
3.46 \\
3.99 \\
3.62 \\
4.15 \\
3.92 \\
3.56 \\
3.73 \\
2.36 \\
2.62 \\
1.55 \\
1.32 \\
0.53 \\
0.37\end{array}$ & $\begin{array}{l}18.81 \\
18.52 \\
11.71 \\
3.95 \\
2.22 \\
2.01 \\
2.56 \\
2.18 \\
2.32 \\
1.92 \\
1.97 \\
2.63 \\
4.46 \\
7.05 \\
6.68 \\
2.86 \\
2.23\end{array}$ \\
\hline
\end{tabular}

Table 2. Activation Measurements in MOTA-1G (atoms/atom-s)

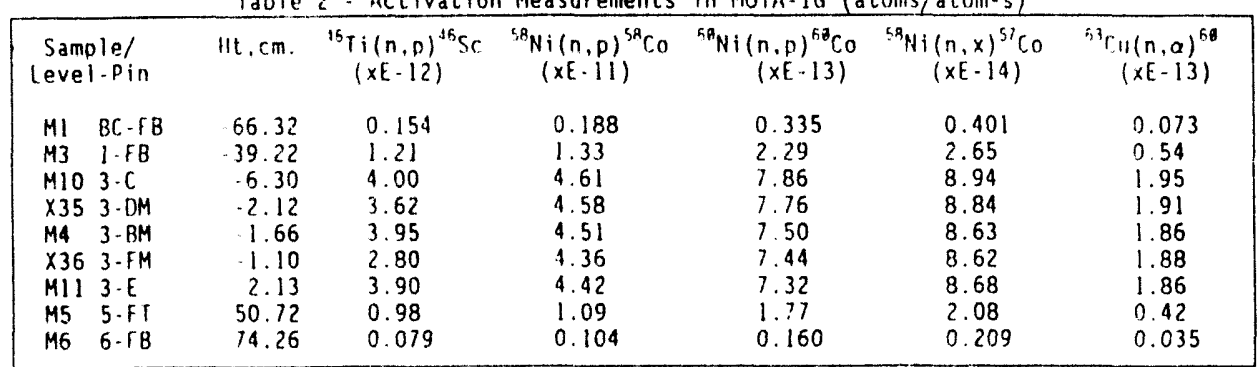

Table 3. Fission Peaction Measurements in MOIA. IG (fission/atom-s)

\begin{tabular}{|c|c|c|c|c|c|}
\hline \multicolumn{2}{|c|}{$\begin{array}{l}\text { Sample' } \\
\text { level-Pin }\end{array}$} & ilt .cm. & $\begin{array}{c}\text { Non }(n, f) \\
(\times E-9 !\end{array}$ & $\begin{aligned} & 31(n, f) \\
& (\times F-9)\end{aligned}$ & $\begin{array}{l}{ }_{191} P_{1}(n, f) \\
(x E-9)\end{array}$ \\
\hline MI & BC. 18 & 56.32 & 0.89 & 6.67 & 7.06 \\
\hline 113 & $1 \cdot 5 B$ & 39.22 & 0.86 & 7.12 & 6.62 \\
\hline MIO & $3-c$ & 5.30 & 2.04 & 8.42 & \\
\hline$\times 35$ & $3 \cdot 0 \mathrm{M}$ & .2 .12 & 2.15 & 7.97 & 7.64 \\
\hline 114 & $3-B M$ & .1 .66 & $i .21$ & Q. 44 & 8.68 \\
\hline$\times 36$ & $3 \cdot I M$ & 1.10 & 1.95 & 3.12 & 7.92 \\
\hline$M \|$ & $3 \cdot E$ & 2.13 & 1.83 & 7.85 & \\
\hline M5 & $5 . F$ & 50.12 & 0.64 & 4.42 & 1.28 \\
\hline 116 & $6+8$ & 74.26 & 0.129 & 2.76 & 2.55 \\
\hline$\times 37$ & $8 \cdot 1 B$ & 109.37 & 0.015 & 0.997 & 0.973 \\
\hline
\end{tabular}

Table 4 Heutron Fluence and Displacement Oamage for MOTA-2A

\begin{tabular}{|c|c|c|c|c|c|c|}
\hline \multicolumn{2}{|c|}{$\begin{array}{l}\text { ansula } \\
\text { Onsition }\end{array}$} & $111, \mathrm{~cm}$ & $\begin{array}{l}\text { Total Fluence } \\
x+22 \mathrm{n} / \mathrm{cm}^{2}\end{array}$ & $\begin{array}{l}\text { last rluence } \\
(\therefore 1 \mathrm{MeV}) \\
\mathrm{rF}+22 \mathrm{n} / \mathrm{cm}^{?}\end{array}$ & $\begin{array}{l}\text { Iron } \\
\text { dpa }\end{array}$ & $\begin{array}{c}\text { Patio } \\
\text { doa/fluence } \\
(>0.1)\end{array}$ \\
\hline 141 & $B C \cdot A B$ & 66.32 & 3.74 & 1.37 & 5.35 & 3.9 \\
\hline 113 & $1.5 B$ & 39.22 & 7.48 & 410 & 16.8 & 4.1 \\
\hline$M 10$ & $3-6$ & .6 .30 & 12.42 & 803 & 35.8 & 4.5 \\
\hline$\times 35$ & 3 Nㅐ & 2,12 & 11.39 & 7.58 & 35.3 & 4.7 \\
\hline$M 4$ & $3 \cdot 6.4$ & -1.56 & 12.51 & 8.25 & 37.0 & 4. 5 \\
\hline$\times 36$ & $3-F M$ & -1.10 & 11.52 & 7.33 & 34.1 & 4.7 \\
\hline$M 11$ & $3 \cdot E$ & 2.13 & 11.61 & 7.49 & 33.1 & 4.4 \\
\hline M5 & $5 . F T$ & 50.72 & 4.87 & 2.73 & 11.5 & 4.2 \\
\hline$M 5$ & $6 .+B$ & $74 \quad 26$ & 1.63 & 0.100 & 2.68 & 3.8 \\
\hline$\times 37$ & 8.18 & 109.37 & 0.43 & 0.123 & 0.48 & 3.9 \\
\hline
\end{tabular}


The neasured activities were used as input to the STAY'SL computer code to adjust the calculated neutron spectra determined for cycle 9A. STAY'SL performs a generalized least-squares adjustment of all measured and calculated values including the measured activities, calculated spectra, and neutron cross sections. Neutron cross sections and their uncertainties were generally taken from ENDF/B.V. although new data were available from ENDF/B-VI for the $T i(n, p)$ and ${ }^{53} \mathrm{Cu}(n, \alpha)$ reactions. The adjusted neutron fluence values are listed in iable 4 . The neutron spectral adjustments for the ten spectral positions are illustrated in Figure ! which shows neutron spectra results at midplane, the edge of the core, and for the below-core basket. In comparisons with the calculated spectra, the agreement is reasonable $(20-30 \%)$ for in-core positions. However, at out-of-core positions, the disagreement becomes progressively worse, as seen in earlier experiments. At level $8(+109 \mathrm{~cm})$, the measured flux is about :wice the calculated flux.

Damage calculations were performed at all spectral positions using the SPECTER computer code. Dpa rates for iron are shown in Table 4 as well as the ratio of dpa per $10^{22} \mathrm{n} / \mathrm{cm}^{\circ}$ fast flux above $0.1 \mathrm{MeV}$. Damage parameters for 40 other elements and several compounds have been calculated and will be made avallable on request.

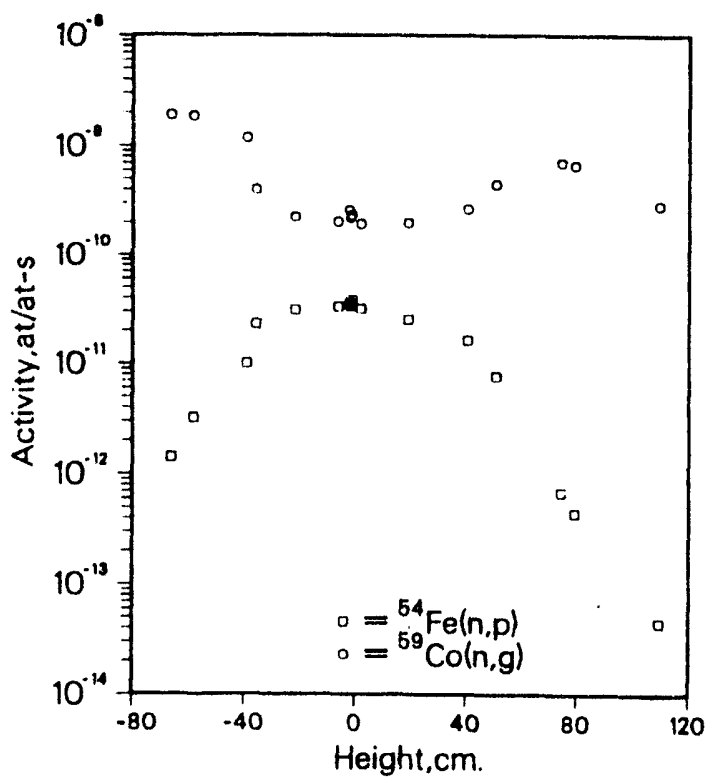

Eig. 2. Activity values are shown for the $: \mathrm{Fe}(n, p)$ $\mathrm{Mn}$ and $\mathrm{Co}(n, y){ }^{6 / 2} \mathrm{Co}$ reactions as a function of axial location in the MOTA-IG assembly. Some of the scatter is due to radial flux gradients. capsules from the MOTA-2B irradiation and $p l a n s$ are being
Tade their analysis. Dosimetry work is in progress for a variety of US/Japanese experiments in the High

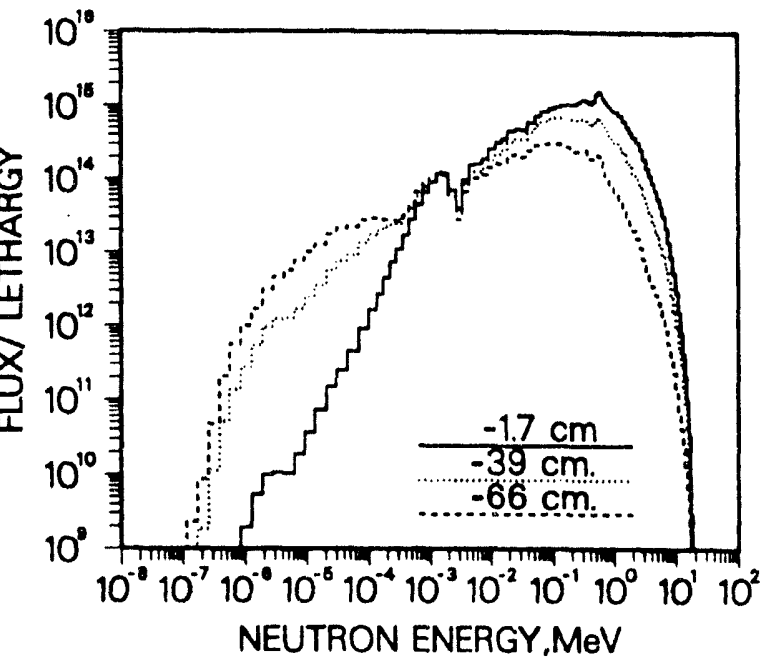

Fig. 1. Adjusted neutron flux spectra are shown at three axial locations in the Mota-lG assembly. The solid line is at $1 \mathrm{~cm}$. the dotted line is at $-39 \mathrm{~cm}$, and the dashed line is at $-66 \mathrm{~cm}$. Note the drop in fast flux and increase in low-energy flux at out-ofcore locations.

The flux and damage values at gradient positions were calculated from the activity gradient data in Table 1 , which are shown in rigure 2. Note that the ${ }^{8} \mathrm{Fe}$ and co(n,y) reactions peak outside the core since they are sensitive to the lower-energy neutrons. The unusual behavior of the co reaction is due to resonance effects. Fast fluence and dpa gradients from Table 4 are plotted in Figure 3. The apparent scatter in the data is caused by the radial flux gradients, as discussed below.

Close examination of the activity data indicates the presence of radial flux and spectral gradients. The letters $A$ to $F$ under the position column in Table 4 indicates the radial position at the neight indicated. The MOTA basket has six radial positions ( $A$ to $F$ ); hence. for example, 4 and $D$ are the furthest adart while $A$ and $B$ or $F$ are adjacent. The maximum radial flux differences are on the order of $10 \%$; however. we also see clear indications of spectral differences in the ratio of the fast flux to the fe(n.p) activity rate. Such differences are complex and we are now studying these effects to construct a more complete flux and damage map of the entire MOTA assembly.

\section{FUTURE WORK}

We plan to construct more detailed flux and damage maps for the entire MOTA-1G assembly. Damage parameters will al so be provided for a variety of elements and alloys on request. Data from the MOTA- $1 G$ and $-2 A$ irradiations is being used to help reanalyze previous data from MOTA-1A through $1 E$, especially to include burnup effects for the fission monitors. We have received the dosimetry capsules from the MOTA-2B irradiation and plans are being 
Flux Isotopes Reactor at Oak Ridge National Laboratory.

REFERENCES

1. L. R. Greenwood and L. S. Kellogg. Neutron Dosimetry for the MOTA-2A Experiment in FFTF, Fusion Reactor Materials Semiannual Progress Report, DOE/ER. 0313/12. pp.49-53, March 1992.

2. L. R. Greenwood and L. S. Kellogg, Neutron Dosimetry for the MOTA-IF Experiment in FFTF, Fusion P.eactor Materials Semiannual Progress Report, DOE/ER0313/9. pp. 31-36, 1990.

3. L. S. Kellogg, W. M. Mc Elroy, and W. Y. Matsumoto, FERRET-SAND II Physics-Dosimetry Analys is for the FTR MOTA-1E Experiments, PNL-NDC Report, December 1989.

4. R. L. Simons, Analys is of Damage Exposure Rates in the MOTA of the FFTF, Damage Analys is and Fundamental Studies Quarterly Progress Report, DOE/ER-0046/21, pp. $10-14$, May 1985.

5. F. G. Perey, Least Squares Dosimetry Unfolding: The Program STAY'SL, ORNL/TM-6062, 1977.

o. L. R. Greenwood and R. K. Smither. SPECTER: Neutron Damage Calculations for Materials irradiations. ANL/FPP-TM-197, January 1985.

PUBLICATIONS

1. L. R. Greenwood, F. A. Garner, and H. L. Heinisch, The Impact of Spectral Effects in Fast Reactors on Cata Analysis and Development of Fission-Fusion Correlations, jou. Hucl. Mater. 191-194. pp. 1096-1100 (1992).

2. L. R. Greenwood. F. A. Garner, and B. M. Oliver, Helium Generation Rates in Isotodicaily Tailored Fe-Cr-Ni Hioys Irradiated in FFTF/MOTA, Jou. Nucl. Mater, 191-194, pp. 1051-1055 (1992).

3. T. B. O'Hearn, A. S. Kumar, and L. R. Greenwood. Comparison of Measured and Calculated Transmutation in opper at Spallation Neutron Sources. Jou. Nucl. Mater. 191-194. pp. 1383-1386 (1992)

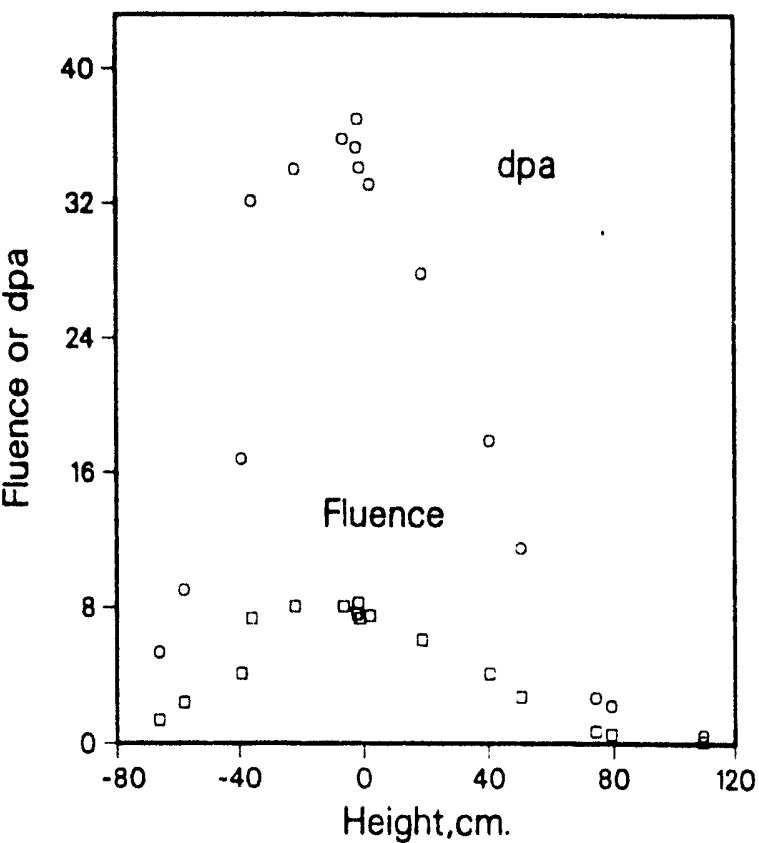

Fig. 3. Fast fluence $\left(\times 10^{23} \mathrm{n} / \mathrm{cm}^{\prime},>0.1 \mathrm{MeV}\right)$ and dpa in iron are shown as a function of axial location in the MOTA-1G assembly. The apparent scatter is indicative of the radial gradients. 
IEASUREMENT OF HELIUM GENERATED IN V-B ALLOYS IRRADIATED IN FFTF/MOTA - F. A. Garner (PaCific Northwest Laboratory ${ }^{3}$ ), B. M. 01 iver (Rockwell International Corporation), and N. Sekimura (University of Tokyo).

\section{OBJECTIVE}

The objective of this effort is to determine the role helium plays in the microstructural evolution of vanadium base alloys.

SUMMARY

$V-B$ and $V-5 C r-B$ alloys have been irradiated in FFTF to assess the impact of helium generation rate on nicrostructural evolution of vanadium-base alloys. Using this method it is somewhat difficult to separate the various effects of the original boron as well as the lithium and helium products of the $: B_{B}(n, \alpha)$ reaction. Post-irradiation measurements of helium concentrations have been completed for two sets of $V$-B alloys, one irradiated in-core and one below core. It appears that the boron doping technique used to produce the various alloys was reasonably successful in reaching the desired helium/dpa variations.

\section{DROGRESS AND STATUS}

\section{Introduction}

Swelling in FFTF-MOTA of $V-B$ and $V-5 C r-B$ alloys, where nominal boron levels of $0,100,500,2500$ and 10000 appm were used, was reported previously. Note that the boron content increases a factor of five between each doped alloy. In that report the swelling data were plotted against nominal boron content, but the boron levels were not measured directly after the production of the alloys. The actual helium generation rates in these alloys will be a function not only of the local neutron spectra but also the actual level of boron dopant in each alloy. At low dopant levels there is some uncertainty of the actual concentrations attained. Therefore it was decided to measure the helium concentrations at Rockwell International Corporation using well-defined procedures ${ }^{(2.3)}$.

Note in Table 1 that four irradiation conditions were employed for each of the $V-B$ and $V-5 C r-8$ alloy series. Three of the four conditions were nominally similar in-core positions with no large variations in neutron spectra expected. Therefore, it was decided that measurements would be performed for one representative in-core condition $\left(600^{\circ} \mathrm{C}, 7.8 \times 10^{22} \mathrm{~m} / \mathrm{cm}^{2} \mathrm{E}>0.1 \mathrm{MeV}\right)$ and the below-core position. The latter was expected to have a much higher helium/dpa ratio than the in-core condition since the ${ }^{2} B(n, \alpha) c r o s s$ section increases at lower neutron energies. Only the $V-B$ alloys were measured for economy. It was assumed that their response would be typical of the $V-5 C r-B$ alloys.

Table 1. Irradiation Conditions

\begin{tabular}{|c|c|c|}
\hline $\begin{array}{c}\text { Temperature } \\
{ }^{\circ} \mathrm{C}\end{array}$ & $\begin{array}{c}\text { Neutron Fluence } \\
\mathrm{n} \mathrm{Cm}^{-2}(\mathrm{E}>0.1 \mathrm{MeV})\end{array}$ & $\begin{array}{c}\text { Displacement } \\
\text { level. } \mathrm{dpa}^{*}\end{array}$ \\
\hline $600^{\star \star}$ & $7.8 \times 10^{22}$ & 42.1 \\
\hline 520 & $7.7 \times 10^{22}$ & 41.6 \\
\hline 427 & $8.6 \times 10^{22}$ & 46.4 \\
\hline $411^{\star *}$ & $2.9 \times 10^{22}$ & 15.1 \\
\hline
\end{tabular}

**Helium concentrations measured for $V-B$ alloys only.

\section{Results and Discussion}

Table 2 presents the results of helium measurements for $V-B$ allays at $600^{\circ} \mathrm{C}$ and $411^{\circ} \mathrm{C}$. As anticipated, the below-core irradiation at $411^{\circ} \mathrm{C}$ produced more helium/dpa than the in-core irradiation at $600^{\circ} \mathrm{C}$. The "ratio" shown in Table 2 represents the calculated variations in helium production from boron for each factor of five in boron content. It appears that the $V-1 \% 8$ alloy may have somewhat less than a factor of 5.0 increase in boron compared to the $2,500 \mathrm{appm}$ boron alloy. The larger deviations in this ratio at $600^{\circ} \mathrm{C}$ are thought to reflect the greater scatter or measurement error at lower helium generation rates.

Altogether. it appears that the boron doping technique employed to produce these alloys was successful.

'Pacific Northwest Laboratory is operated for the U.S. Department of Energy by Battelle Memorial Institute under Contract De-ACO6-76RLO 1830. 
Table 2. Helium Measurements on Pure Vanadium + Boron Alloys

\begin{tabular}{|c|c|c|c|}
\hline $\begin{array}{r}600^{\circ} \mathrm{C}, 7.8 \times \\
\text { Specimen identity }\end{array}$ & $\begin{array}{l}\text { (in-core) } \\
\text { appm. Boron }\end{array}$ & appm He & Ratio* \\
\hline $\begin{array}{l}\text { MH25 } \\
\text { MHBA } \\
\text { MK22 } \\
\text { MKBA** } \\
\text { ML1A }\end{array}$ & $\begin{array}{c}0 \\
100 \\
500 \\
2.500 \\
10.000 \\
\end{array}$ & $\begin{aligned} & 1.21 \pm 0.01 \\
& 5.54 \pm 0.32 \\
& 22.7=0.5 \\
& 82.6 \pm 4.7 \\
& 368 \pm 1 \\
&\end{aligned}$ & $\begin{array}{l}\cdots \\
\cdots \\
4.95 \\
3.79 \\
4.51 \\
\end{array}$ \\
\hline $\begin{array}{l}411^{\circ} \mathrm{C}, 2.87 \\
\text { Specimen ident ity }\end{array}$ & $\begin{array}{l}\text { (below-core) } \\
\text { appm. Boron }\end{array}$ & appm He & Ratio* \\
\hline $\begin{array}{l}\text { MHOO } \\
\text { MHAO } \\
\text { MKOO } \\
\text { MKAO } \\
\text { MLOI }\end{array}$ & $\begin{array}{c}0 \\
100 \\
500 \\
2.500 \\
10.000\end{array}$ & $\begin{array}{c}1.07 \pm 0.02 \\
7.64 \pm 0.03 \\
34.9 \pm 1.2 \\
165 \pm 8 \\
754 \pm 1\end{array}$ & $\begin{array}{c}\cdots \\
\cdots \\
5.145 \\
4.852 \\
4.598\end{array}$ \\
\hline
\end{tabular}

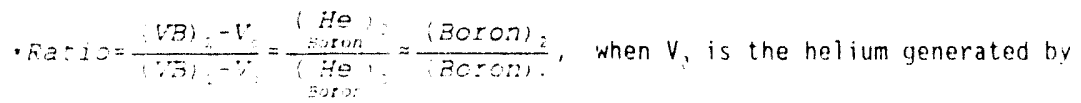

vanadium in the absence of boron

* Average of four separate arid ingependent determinations to assess ariabilit. of boron in any given specimen. All other measurements involved only two separate determinations.

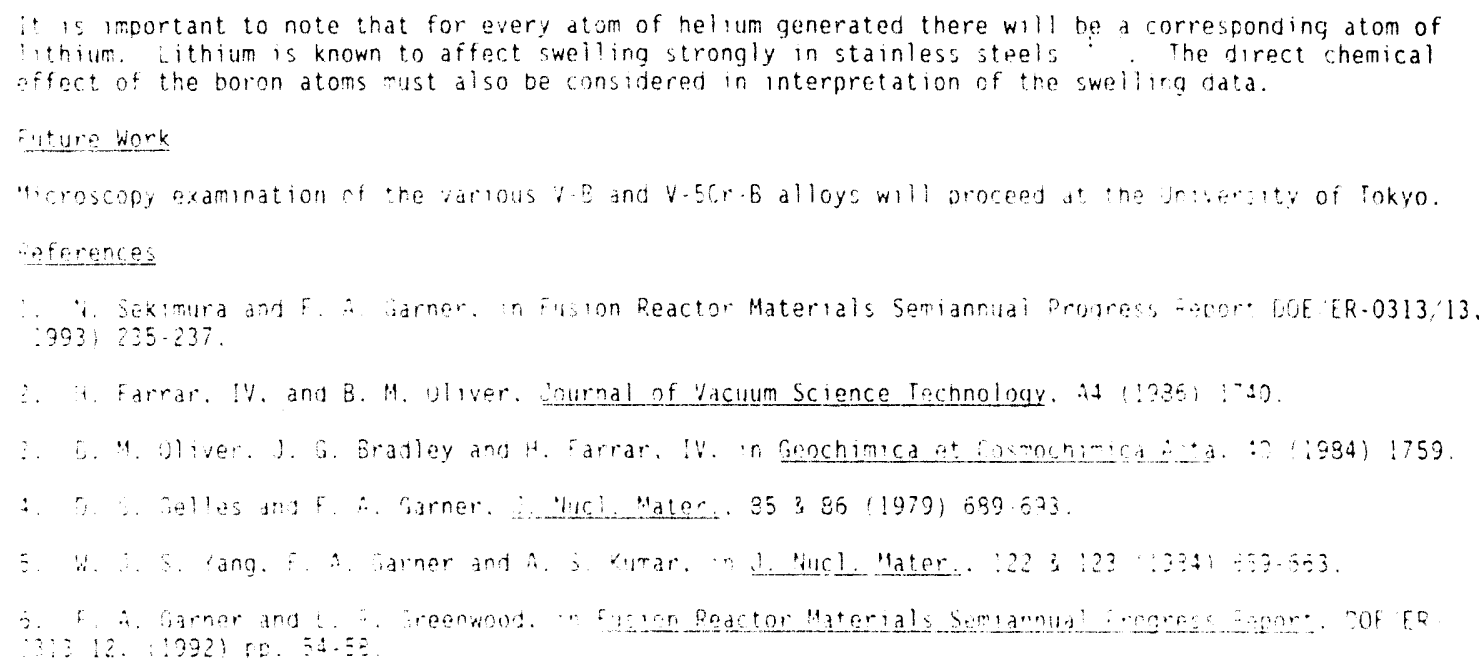


HEW ACTIVATION CROSS SECTION DATA - F. M. Mann and D. E. Lessor, Westinghouse Hanford Company

\section{OBJECTIVE}

The objective of this work is to provide nuclear data for the fusion materials community, with an emphasis on the development of low-activation materials.

SUMMARY

New nuclear cross section libraries (known as USACT92) have been created for activation calculations. A point-wise file was created from merging the previous version of the activation library, the U.S. Nuclear Data Library (ENDF/B-VI), and the European Activation File (EAF-2). 175 and 99 multi-group versions were also created. All the data are available at the National Energy Research Supercomputer Center.

\section{PROGRESS AND STATUS}

\section{Introduction}

Nuclear activation cross sections are needed to calculate the transmutation of isotopes. The last set of activation cross sections for the REAC transmutation code system (ref. 1) was created in December, 1990 and was based mainly on ENDF/B-V (ref. 2) and THRESH (ref. 3) calculations. The new set covering about 625 target isotopes is based upon ENDF/B-VI (ref. 4) and European efforts (ref. 5). Point-wise as well as 99 and 175 group cross sections were created along with libraries suitable for REAC calculations. The new set of 1 ibraries are denoted USACT92.

Target isotopes included in this library are all stable isotopes and isotopes having half-lives greater than -1 day. The energy range covered is $10^{-5} \mathrm{eV}$ to $40 . \times 10^{6} \mathrm{eV}$, except for the $(n, g)$ reaction where the upper limit is $20 . \times 10^{6} \mathrm{eV}$. All energetically allowed reactions below $20 \mathrm{MeV}$ are included. Cross sections to the production of isomeric states (that is, states with a half-life greater than $-0.001 \mathrm{~s}$ ) are also included.

\section{Point-wise cross Sections}

The general approach in creating the new set of point-wise files was to merge ENDF/B-VI evaluations with European files and the old REAC point-wise cross sections. The steps were

1) Correct the old REAC files,

2) Convert the European files to the required format,

3) Convert the resonance parameters of ENDF/B-VI into point-wise values, and

4) Merge the files.

The most recent REAC point-wise cross section files were retrieved from the Common File system (CFS) at the National Energy Research Supercomputer Center (NERSC). The reaction number (mt) was corrected on the $\left(n, n^{\star}\right)$ reactions (mt $=4 \rightarrow 304$ ) as needed. These reactions were then manually moved to the proper location so that the mt numbers were in numerical order. The FORTRAN program CONVH had previously been used to put the headings of these files into a new format.

The Energie Centrum Nederland (ECN) has the responsibility for creating activation files for the European effort. The ECN files were converted from upper case to lower case to make them consistent with the old REAC cross section files before the two sets were merged. The order of the sections also needed to be changed in some of the ECN files for consistency. The reactions producing isomeric states (Ex. n, $g^{\star}$ ) were moved from immediately following the corresponding ground-state reactions to the position in which the mt numbers were in numerical order. A FORTRAN program ORDRMT was written to do this re-ordering of ECN files.

A FORTRAN program CHGCRS was written to merge the two sets of files. This program read one mt section at a time from each of two files. If an mt section was missing from one file, the mt section from the other file was used without change. If the section was present in each file, the data from the primary file was kept in the common energy range and the other data was normalized to the primary file data. Each time one nt section was written to the newly created file a new one would be read in for processing until all sections had been merged and written to the new file.

In general the ECN files were treated as the primary and the old REAC files as the secondary files for the merging; however the source for each isotope was checked individually before merging. For each isotope, if the old REAC source for a given mt section was known to be more correct or up to date, the corresponding mt section in ECN was deleted before merging.

There were some ECN files for which no USA file existed. These files were run through the FORTRAN program $A D D S E Q 2$ to add a sequence number to each 1 ine. The files were then processed with CONVH which read each of the section headings and rewrote them in the same format used in the USA files. The merged files were 
also processed with CONVH to correct the section headings from Ecil files ard make all section headings consistent.

The NJOY nuclear data processing code system (ref. 6) was used to convert those FNDF/E-VI evaluations having resolved or unresolved parameter descriptions into an evaluation having only a smooth description. Only the ( $n$,gamma) reaction is affected.

The merging of ENDF/B-VI files and ECN files was done as explained above except that the ENDFiB-VI file, were used as the primary files.

Appendix c contains a list of all the isotopes in the new Activation Cross Section Litrary and the number of reactions for each isotope.

The format for the point-wise cross sections is that of ENDF/B-VI file 3 (ref. 7 ) with the exception of two (2) added header cards at the beginning of each reaction and a modification of the mt numbers for reactions leading to isomeric products. The format of the two header cards is

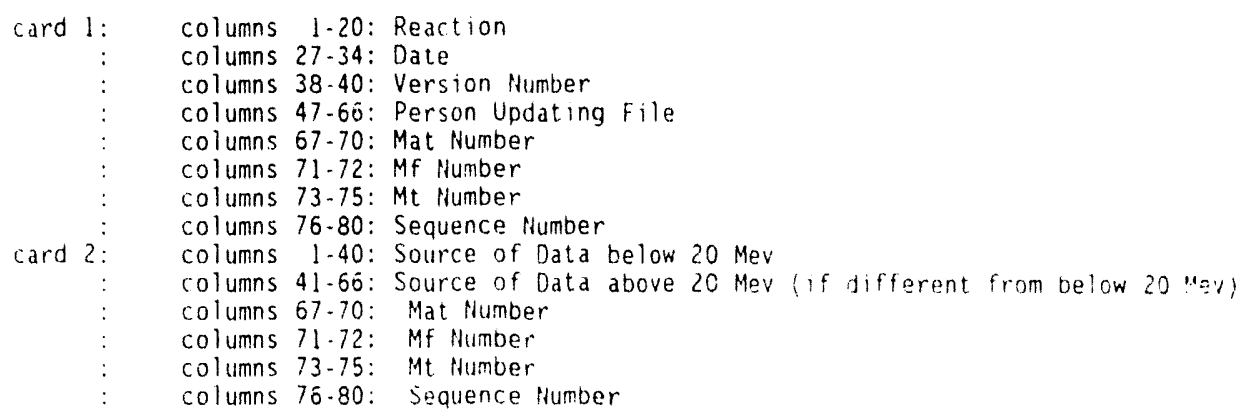

The reaction numbir $m$ t is modified for roactions leading to an isoneric state t:

$$
m t(\text { isomeric) }=\text { nt (ground state) }+(n * 300) \text {. }
$$

where $n$ denotes the $n$th isomeric state. Thus the $m t$ number for the (n. np) reaction iading to the first isomeric state is $328(=28+(1 * 300))$. Note that $n$ must be 1 or 2

\section{Group-wise Cross Sections}

The multigroup cross sections wero calculated by the NUI. IAV code from Doint-wise cross sections described above. MULTAV is a FORTRAN code wnich reads ENOF'B file 3 -formatted cross sectior iles and a usersupplied weighing function. MULAAV then calculates the group averaged value aitrer aralytically or using adaptive Romberg integration. Calculations were made for 99 group and 175 group s:ructures. The energy structure is displayed in Appendix A for the 99 group structure and in Appendix 5 tor :he 175 group structure. The flux used for group welghing is that used in the vitamin-t groub generation (ref. 3 ) as implemented in the NuOY processing code.

The 99 group structure is a group structure now in use a: Hanford. : combines tre fat structure used for FFTF andyses with the thermal structure used for thermal ractor. The 175 yitam. group structure has been informally adonted ds a standard for fusion transport studies. Ihus it is a "atural choice

Similariv. the choice of the vitamin-j weighing flux which contains thermal. fast. and fusion conponents is a natural one given the fusion experience.

The format for group-wise cross sections is the same as the format for pount-wise soss sections.

interpolation law 2 (linear I near interpolation) is used. for each grolip. both ta igwer and upper energy bound is used with the value for tnat group scross section reneated for each eneruv alue.

\section{PEAC Cross sections}

The FORTRAN code MILACT was sed to convert the above multigroun format into the rollerith version of the REAC cross sections. The FORTRAN code BINLIB (ref. 1) then was used to croate the oinary version of the FEAC cross section ibrary.

Location of files

All of the files are located on CFS at NERSC. Table l shows the location of the files used and those generated. 
Table 1

Location of Files

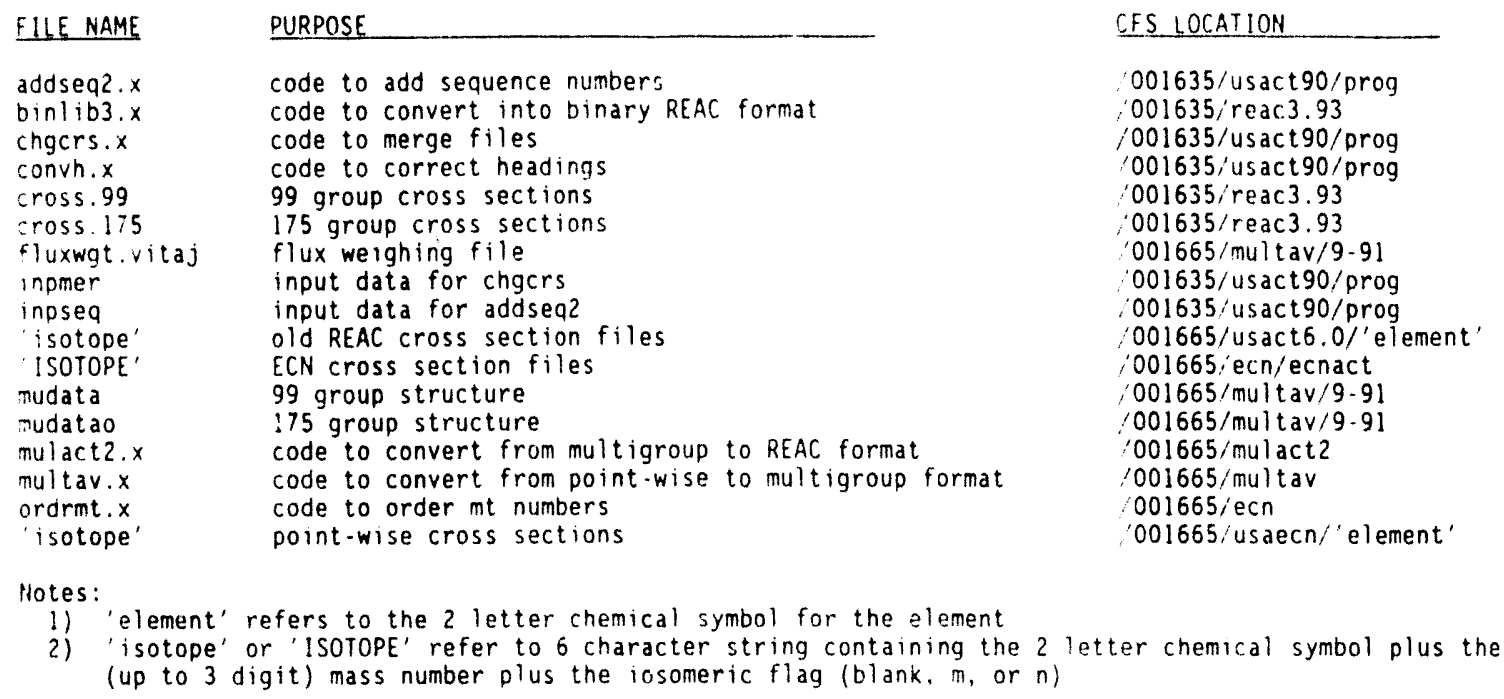

Summary

A new point-wise activation cross section set has been created from ENDF/B-VI and ECN activation files. Furthermore, new group-wise cross sections using both the Hanford 99 group structure and the international 175 group Vitamin-J structure has been created.

\section{References}

1. F. M. Mann, REAC $\approx$ : Users Manual and Code Description, WHC-EP-0282. West inghouse Hanford Company, Richland, Wa, December, 1989

2. R. Kinsey (compiler), ENDF/B Sumary Documentation. BHL-UCS-1;541 (ENDF-221), 3/1 Edition (ENDF/B-V), Brookhaven National Laboratory, Upton. HY, July, 1979.

3. S. Pearlstein, Journal of Nuclear Energy, 27 (1973) 81 .

4. P. F. Rose (compiler), ENDF/B-VI Summary Documentation. BNL-NCS-17541 (ENDF-201; 4th Eoition (ENDF/B-VI), Brookhaven National Laboratory, Upton, HY, October. 1991.

5. J. Kopecky, H. A. J. van der Kamp, H. Gruppelaar, and Nierop. The European Activation File EAF-2 with Neutron Activation and Transmutation Cross Sections, ECN-C-91-073, Netherlands Energy Jesearch Foundation ECN, Petten, the Netherlands, July, 1991.

5. R. E. MacFarlane, D. W. Muir, and R. M. Boicourt, The NJoY Nuclear Data Processing System, Volume I: User's Manual, LA-9303-M, Los Alamos National Laboratory, Los Alamos. MM. May. 1982.

7. P. F. Rose and C. L. Dunford (editors), Data Formats and Procedures for the Evaluated Nuclear Data File ENDF-6, BNL-NCS 44945, Brookhaven National Laboratory, Upton. NY, October. 1991.

8. C. R. Weisbin, R. W. Roussin, J. J. Wagschal, J.E. White, and R.Q. Wright, Vitamin-E: An ENDF/B-V Multigroup Cross Section Library for LMFBR Core and Shield, Dosimetry, and Fusion Blanket Technology, ORNL5505, Oak Ridge National Laboratory. Oak Ridge, TN, February. 1979.

FUTURE WOR.K

Future work includes finishing documentation on this cross section set and on the decay set produced last year. Documentation will also be produced for the latest version (REAC3.93) of the REAC activation and transmutation code system. 
Appendix A

99 Group Energy Structure

$1.0000 e-5 \quad 5.0000 e-3 \quad 1.0000 e-2 \quad 1.5000 e-2 \quad 2.0000 e-2 \quad 2.5000 e-2$

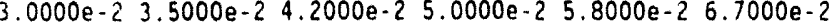
$8.0000 \mathrm{e}-2 \quad 1.0000 \mathrm{e}-1 \quad 1.4000 \mathrm{e}-1 \quad 1.8000 \mathrm{e}-1 \quad 2.2000 \mathrm{e}-1 \quad 2.5000 \mathrm{e}-1$ $2.8000 \mathrm{e}-13.0000 \mathrm{e}-1 \quad 3.2000 \mathrm{e}-1 \quad 3.5000 \mathrm{e}-1 \quad 4.0000 \mathrm{e}-1 \quad 5.0000 \mathrm{e}-1$ $6.2500 \mathrm{e}-17.8000 \mathrm{e}-1 \quad 8.5000 \mathrm{e}-1 \quad 9.1000 \mathrm{e}-1 \quad 9.5000 \mathrm{e}-19.7200 \mathrm{e}-1$ $9.9960 \mathrm{e}-1 \quad 1.02000 \mathrm{e} 0 \quad 1.04500 \mathrm{e} 0 \quad 1.07100 \mathrm{e} 0 \quad 1.09700 \mathrm{e} 0 \quad 1.12300 \mathrm{e} 0$ $\begin{array}{llllll}1.15000 \mathrm{e} 0 & 1.30000 \mathrm{e} 0 & 1.50000 \mathrm{e} & 2.20000 \mathrm{e} 0 & 2.60000 \mathrm{e} 0 & 3.30000 \mathrm{e} 0\end{array}$ $4.00000 \mathrm{e} 0 \quad 5.04348 \mathrm{e} 0 \quad 8.31529 \mathrm{e} 01.37096 \mathrm{el} 2.26033 \mathrm{el} 3.72665 \mathrm{el}$ $6.14421 \mathrm{el}$ l.0130le2 l.67017e2 2.75365e2 4.53999e? $7.48518 \mathrm{e} 2$

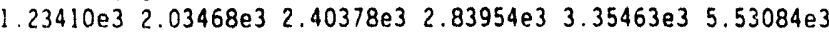
$9.11882 \mathrm{e} 3 \quad 1.50344 \mathrm{e} 4 \quad 1.98925 \mathrm{e} 4 \quad 2.55424 \mathrm{e} 4 \quad 4.08677 \mathrm{e} 4 \quad 6.73795 \mathrm{e} 4$ $1.11090 \mathrm{e} 5 \quad 1.83156 \mathrm{e} 5 \quad 3.01974 \mathrm{e} 5 \quad 3.87742 \mathrm{e} 5 \quad 4.97871 \mathrm{e} 5 \quad 6.39279 \mathrm{e} 5$ $8.20850 \mathrm{e} 5 \quad 1.10803 \mathrm{e} 6 \quad 1.35335 \mathrm{e} 6 \quad 1.73774 \mathrm{e} 6 \quad 2.23130 \mathrm{e} 6 \quad 2.86505 \mathrm{e} 6$ $3.67879 \mathrm{e} 6 \quad 4.96585 \mathrm{e} 6 \quad 6.0653 \mathrm{le} 67.40818 \mathrm{e} 6 \quad 8.60708 \mathrm{e} 6 \quad 1.00000 \mathrm{e} 7$ $1.16183 \mathrm{e} 7 \quad 1.34986 \mathrm{e} 7 \quad 1.49182 \mathrm{e} 7 \quad 1.64872 \mathrm{e} 7 \quad 1.82211 \mathrm{e} 7 \quad 2.00000 \mathrm{e}$ $2.25000 \mathrm{e} 72.50000 \mathrm{e} 72.75000 \mathrm{e} 73.00000 \mathrm{e} 73.25000 \mathrm{e} 73.50000 \mathrm{e} 7$ $3.75000 \mathrm{e} 74.00000 \mathrm{e} 74.50000 \mathrm{e} 75.00000 \mathrm{e}$

Appendix B 175 Group Energy Structure

$\begin{array}{llllll}1.000 \mathrm{e}-5 & 1.000 \mathrm{e}-1 & 4.140 \mathrm{e}-1 & 5.316 \mathrm{e}-1 & 6.826 \mathrm{e}-1 & 8.764 \mathrm{e}-1 \\ 1.1254 \mathrm{e} 0 & 1.4450 \mathrm{e} 0 & 1.8554 \mathrm{e} 0 & 2.3824 \mathrm{e} 0 & 3.0590 \mathrm{e} 0 & 3.9279 \mathrm{e} 0 \\ 5.0435 \mathrm{e} 0 & 6.4760 \mathrm{e} 0 & 8.3153 \mathrm{e} 0 & 1.0677 \mathrm{e} 1 & 1.3710 \mathrm{e} 1 & 1.7603 \mathrm{e} 1 \\ 2.2603 \mathrm{e} 1 & 2.9023 \mathrm{e} 1 & 3.7267 \mathrm{e} 1 & 4.7851 \mathrm{e} 1 & 6.1442 \mathrm{e} 1 & 7.8893 \mathrm{e} 1 \\ 1.0130 \mathrm{e} 2 & 1.3007 \mathrm{e} 2 & 1.6702 \mathrm{e} 2 & 2.1445 \mathrm{e} 2 & 2.7536 \mathrm{e} 2 & 3.5358 \mathrm{e} 2 \\ 4.5400 \mathrm{e} 2 & 5.8295 \mathrm{e} 2 & 7.4852 \mathrm{e} 2 & 9.6112 \mathrm{e} 2 & 1.2341 \mathrm{e} 3 & 1.5846 \mathrm{ee} 3 \\ 2.0347 \mathrm{e} 3 & 2.2487 \mathrm{e} 3 & 2.4852 \mathrm{e} 3 & 2.6126 \mathrm{e} 3 & 2.7465 \mathrm{e} 3 & 3.0354 \mathrm{e} 3 \\ 3.3546 \mathrm{e} 3 & 3.7074 \mathrm{e} 3 & 4.3074 \mathrm{e} 3 & 5.5308 \mathrm{e} 3 & 7.1017 \mathrm{e} 3 & 9.1188 \mathrm{e} 3 \\ 1.0595 \mathrm{e} 4 & 1.1709 \mathrm{e} 4 & 1.5034 \mathrm{e} 4 & 1.9305 \mathrm{e} 4 & 2.1875 \mathrm{e} 4 & 2.3579 \mathrm{e} 4 \\ 2.4176 \mathrm{e} 4 & 2.4788 \mathrm{e} 4 & 2.5058 \mathrm{e} 4 & 2.7000 \mathrm{e} 4 & 2.8500 \mathrm{e} 4 & 3.1828 \mathrm{e} 4 \\ 3.4307 \mathrm{e} 4 & 4.0868 \mathrm{e} 4 & 4.6309 \mathrm{e} 4 & 5.2475 \mathrm{e} 4 & 5.6562 \mathrm{e} 4 & 6.7379 \mathrm{e} 4 \\ 7.2000 \mathrm{e} 4 & 7.9500 \mathrm{e} 4 & 8.2500 \mathrm{e} 4 & 8.6517 \mathrm{e} 4 & 9.8037 \mathrm{e} 4 & 1.1109 \mathrm{e} 5 \\ 1.1679 \mathrm{e} 5 & 1.2277 \mathrm{e} 5 & 1.2907 \mathrm{e} 5 & 1.3569 \mathrm{e} 5 & 1.4264 \mathrm{e} 5 & 1.4996 \mathrm{e} 5 \\ 1.5764 \mathrm{e} 5 & 1.6573 \mathrm{e} 5 & 1.7422 \mathrm{e} 5 & 1.8316 \mathrm{e} 5 & 1.9255 \mathrm{e} 5 & 2.0242 \mathrm{e} 5 \\ 2.1230 \mathrm{e} 5 & 2.2371 \mathrm{e} 5 & 2.3518 \mathrm{e} 5 & 2.4724 \mathrm{e} 5 & 2.7324 \mathrm{e} 5 & 2.8725 \mathrm{e} 5 \\ 2.9452 \mathrm{e} 5 & 2.9720 \mathrm{e} 5 & 2.9850 \mathrm{e} 5 & 3.0197 \mathrm{e} 5 & 3.3373 \mathrm{e} 5 & 3.6883 \mathrm{e} 5 \\ 3.8774 \mathrm{e} 5 & 4.0762 \mathrm{e} 5 & 4.5049 \mathrm{e} 5 & 4.9787 \mathrm{e} 5 & 5.2340 \mathrm{e} 5 & 5.5023 \mathrm{e} 5 \\ 5.7844 \mathrm{e} 5 & 6.0810 \mathrm{e} 5 & 5.3928 \mathrm{e} 5 & 5.7206 \mathrm{e} 5 & 7.0651 \mathrm{e} 5 & 7.4274 \mathrm{ee} 5 \\ 7.8082 \mathrm{e} 5 & 8.2085 \mathrm{e} 5 & 8.6294 \mathrm{e} 5 & 9.0718 \mathrm{e} 5 & 9.6164 \mathrm{e} 5 & 1.0026 \mathrm{e} 6 \\ 1.1080 \mathrm{e} 6 & 1.1648 \mathrm{e} 6 & 1.2246 \mathrm{e} 6 & 1.2873 \mathrm{e} 6 & 1.3534 \mathrm{e} 6 & 1.4227 \mathrm{e} 6 \\ 1.4957 \mathrm{e} 6 & 1.5724 \mathrm{e} 6 & 1.6530 \mathrm{e} 6 & 1.7377 \mathrm{e} 6 & 1.8268 \mathrm{e} 6 & 1.9205 \mathrm{e} 6 \\ 2.0190 \mathrm{e} 6 & 2.1225 \mathrm{e} 6 & 2.2313 \mathrm{e} 6 & 2.3069 \mathrm{e} 6 & 2.3457 \mathrm{e} 6 & 2.3653 \mathrm{e} 6 \\ 2.3852 \mathrm{e} 6 & 2.4660 \mathrm{e} 6 & 2.5924 \mathrm{e} 6 & 2.7253 \mathrm{e} 6 & 2.8050 \mathrm{e} 6 & 3.0119 \mathrm{e} 6 \\ 3.1664 \mathrm{e} 6 & 3.3287 \mathrm{e} 6 & 3.6788 \mathrm{e} 6 & 4.0657 \mathrm{e} 6 & 4.4933 \mathrm{e} 6 & 4.7237 \mathrm{e} 6 \\ 4.9659 \mathrm{e} 6 & 5.2205 \mathrm{e} 6 & 5.4881 \mathrm{e} 6 & 5.7695 \mathrm{e} 6 & 6.0553 \mathrm{e} 6 & 6.3763 \mathrm{e} 6 \\ 5.5924 \mathrm{e} 6 & 6.7032 \mathrm{e} 6 & 7.0469 \mathrm{e} 6 & 7.4082 \mathrm{e} 6 & 7.7880 \mathrm{e} 6 & 8.1873 \mathrm{e} 6 \\ 8.6071 \mathrm{e} 6 & 9.0484 \mathrm{e} 6 & 9.5123 \mathrm{e} 6 & 1.0000 \mathrm{e} 7 & 1.0513 \mathrm{e} 7 & 1.1052 \mathrm{e} 7 \\ 1.1618 \mathrm{e} 7 & 1.2214 \mathrm{e} 7 & 1.2480 \mathrm{e} 7 & 1.2523 \mathrm{e} 7 & 1.3499 \mathrm{e} 7 & 1.3840 \mathrm{e} 7 \\ 1.4191 \mathrm{e} 7 & 1.4550 \mathrm{e} 7 & 1.4918 \mathrm{e} 7 & 1.5683 \mathrm{e} 7 & 1.6487 \mathrm{e} 7 & 1.6905 \mathrm{e} 7 \\ 1.7333 \mathrm{e} 7 & 1.9640 \mathrm{e} 7 & & & & \end{array}$


Appendix C

List of Isotopes in Activation Cross Section tibrary

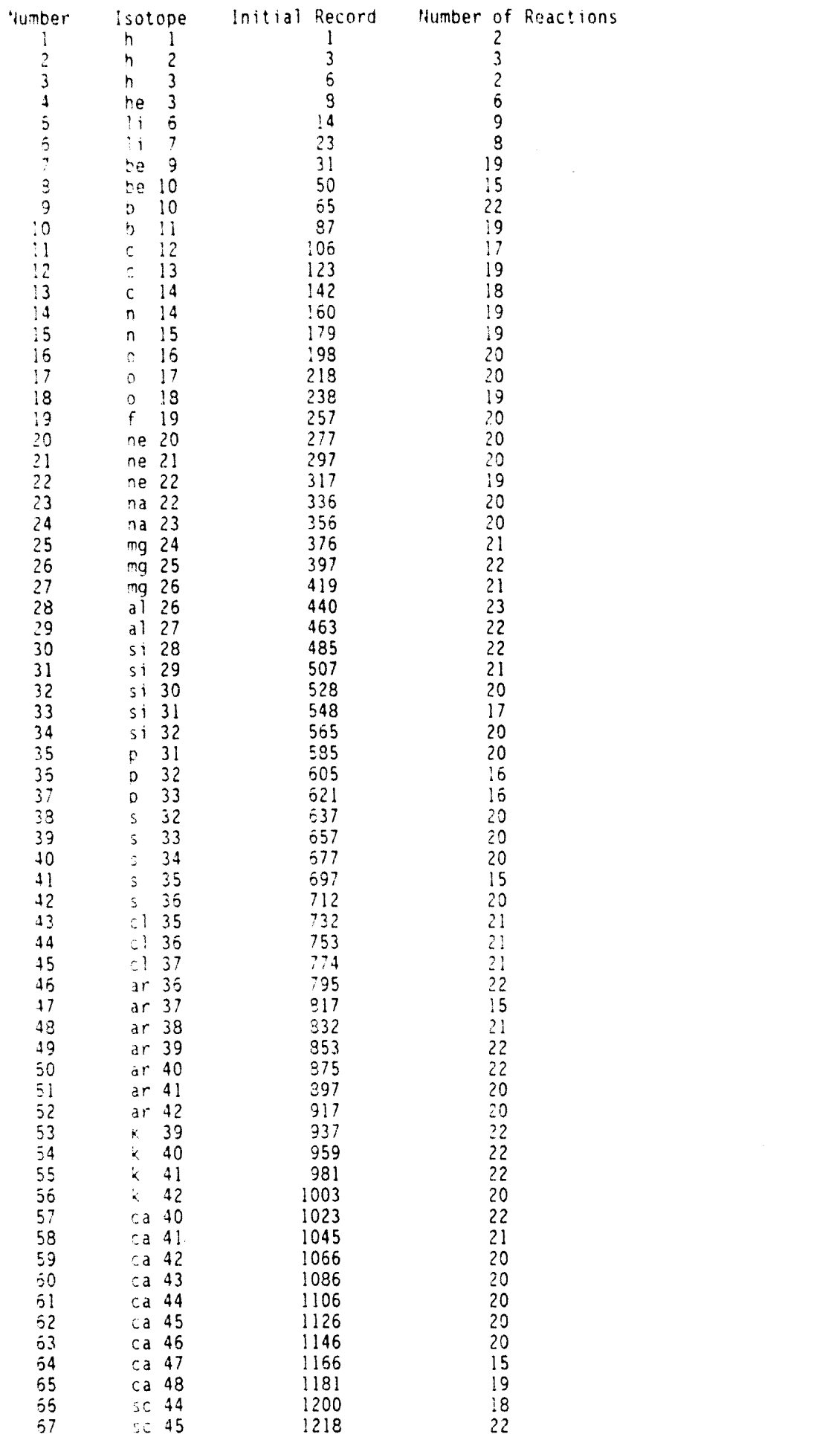


List of Isotopes in Activation Cross Section Library

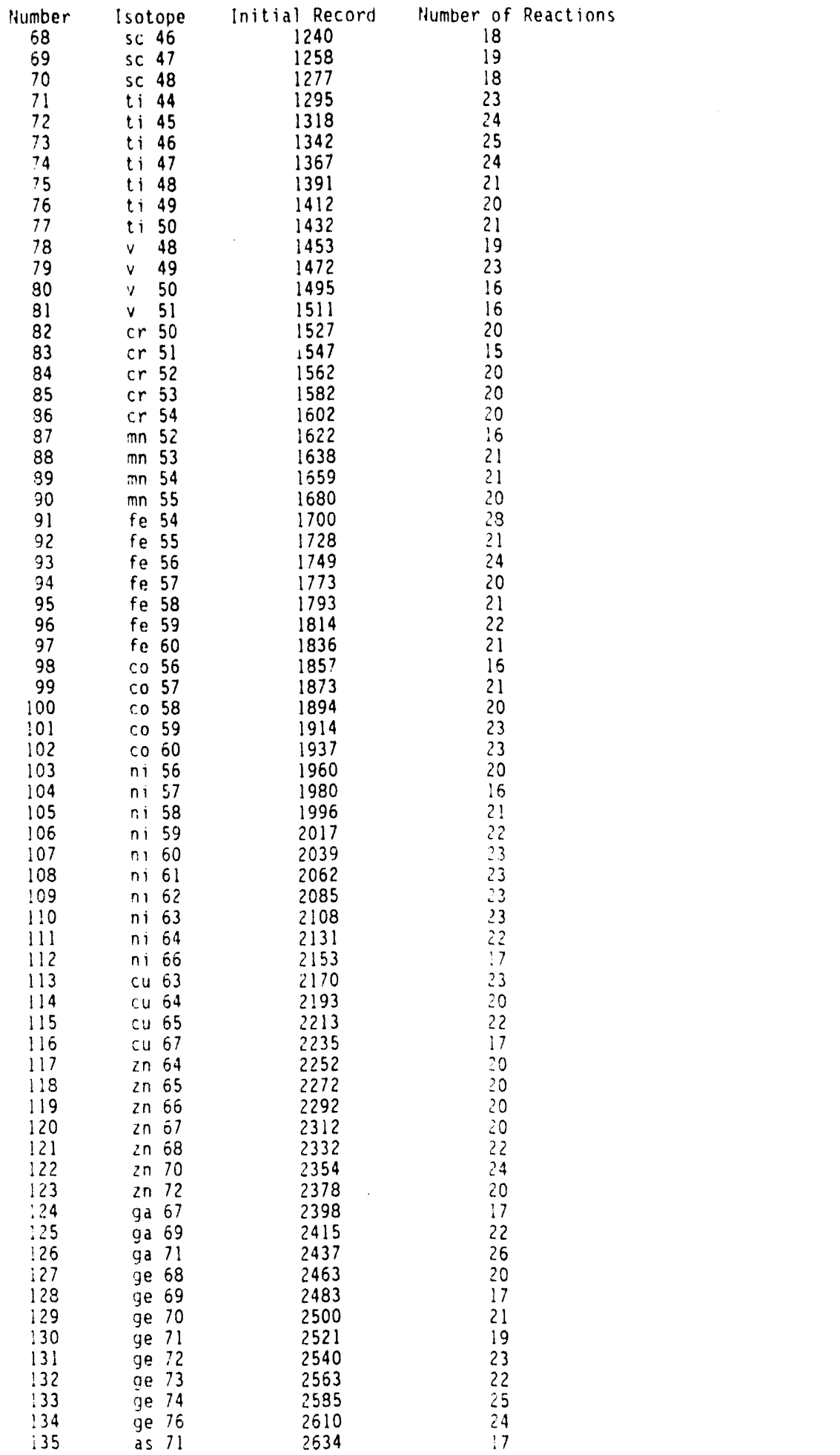


List of lsotopes in activation ross Section Librar.

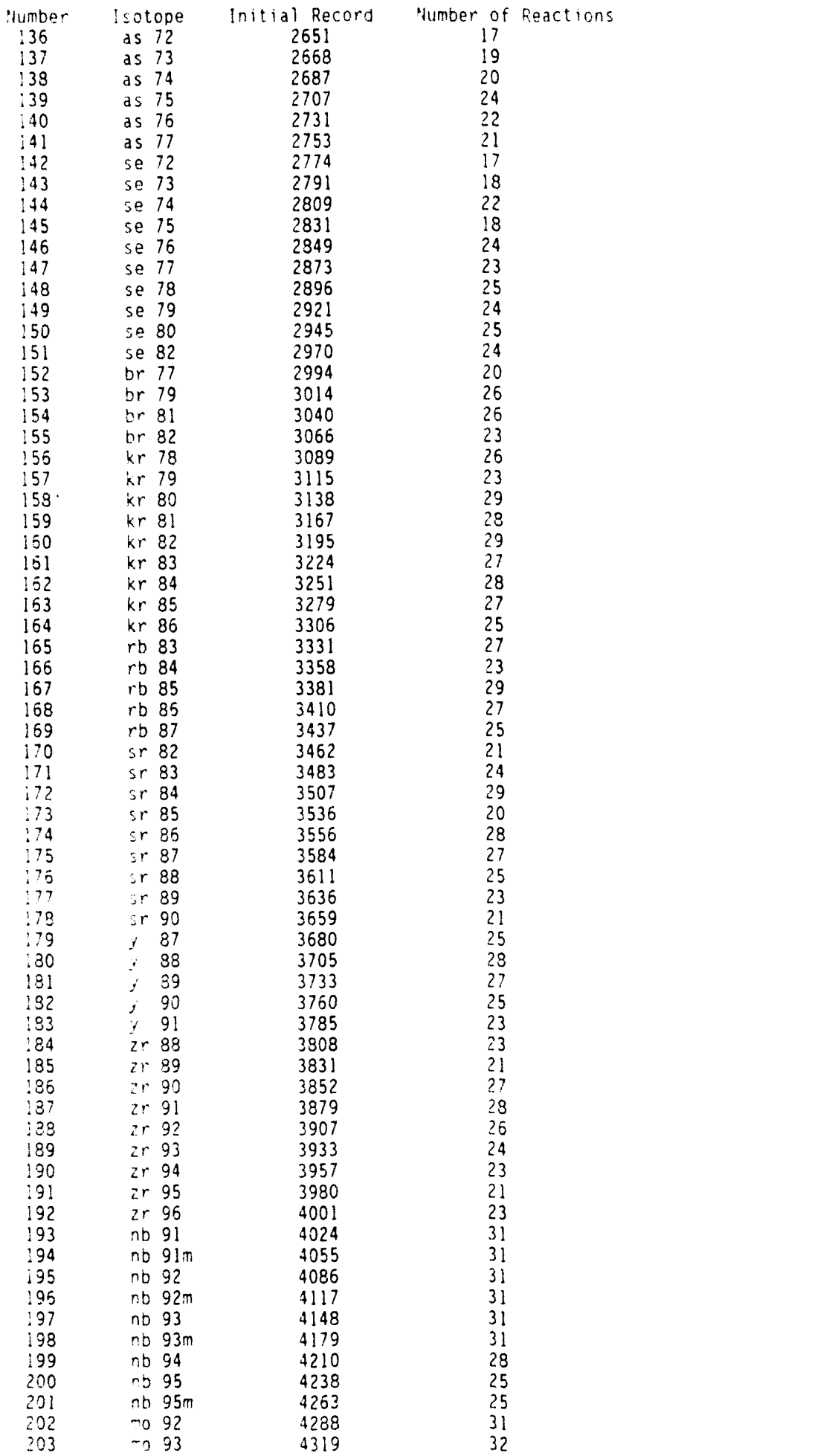


List of Isotopes in Activation Cross Section Library

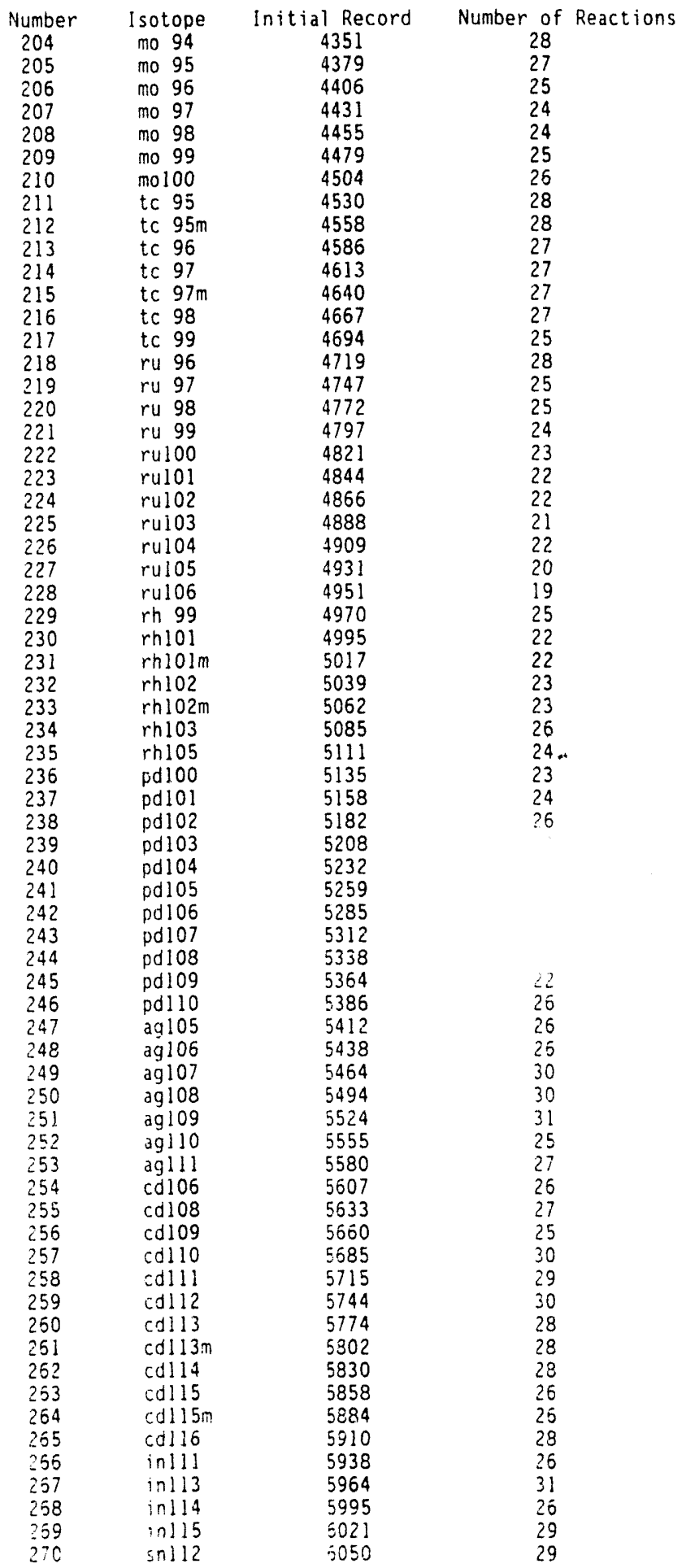


List of Isotopes in Activation Cross Section Library

\begin{tabular}{|c|c|c|c|}
\hline $\begin{array}{l}\text { Pumber } \\
271 \\
272 \\
273 \\
274 \\
275 \\
275 \\
277 \\
278 \\
279 \\
280 \\
281 \\
282 \\
283 \\
284 \\
285 \\
286 \\
287 \\
288 \\
289 \\
290 \\
291 \\
292 \\
293 \\
294 \\
295 \\
296 \\
297 \\
298 \\
299 \\
300 \\
301 \\
302 \\
303 \\
304 \\
305 \\
306 \\
307 \\
308 \\
309 \\
310 \\
311 \\
312 \\
313 \\
314 \\
315 \\
316 \\
317 \\
318 \\
319 \\
320 \\
321 \\
322 \\
323 \\
324 \\
325 \\
325 \\
327 \\
328 \\
329 \\
330 \\
331 \\
332 \\
333 \\
334 \\
335 \\
336 \\
337\end{array}$ & 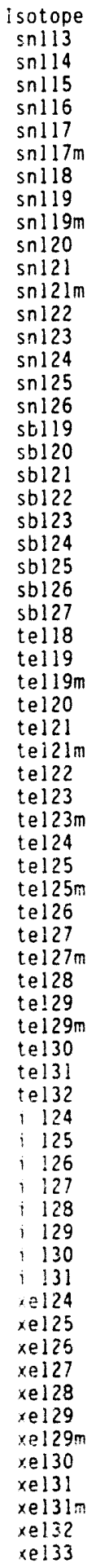 & 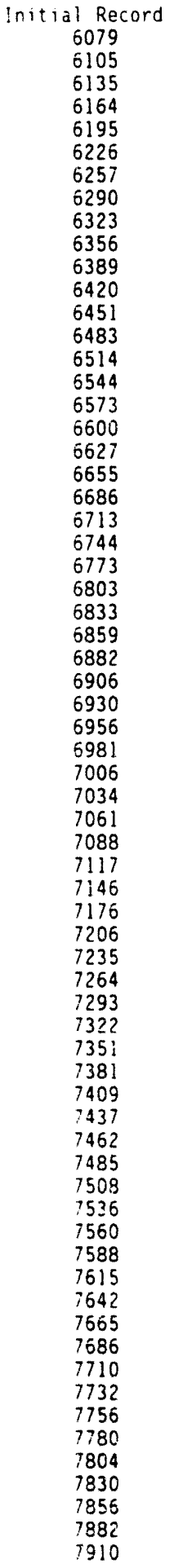 & $\begin{array}{l}\text { ilumber of Reactions } \\
26 \\
30 \\
29 \\
31 \\
31 \\
31 \\
33 \\
33 \\
33 \\
33 \\
31 \\
31 \\
32 \\
31 \\
30 \\
29 \\
27 \\
27 \\
28 \\
31 \\
27 \\
31 \\
29 \\
30 \\
30 \\
26 \\
23 \\
24 \\
24 \\
26 \\
25 \\
25 \\
28 \\
27 \\
27 \\
29 \\
29 \\
30 \\
30 \\
29 \\
29 \\
29 \\
29 \\
29 \\
30 \\
28 \\
29 \\
25 \\
23 \\
23 \\
29 \\
24 \\
28 \\
27 \\
27 \\
23 \\
21 \\
24 \\
22 \\
24 \\
24 \\
24 \\
26 \\
25 \\
25 \\
28 \\
28 \\
\\
\\
\\
\end{array}$ \\
\hline
\end{tabular}


List of Isotopes in Activation Cross Section Librar.

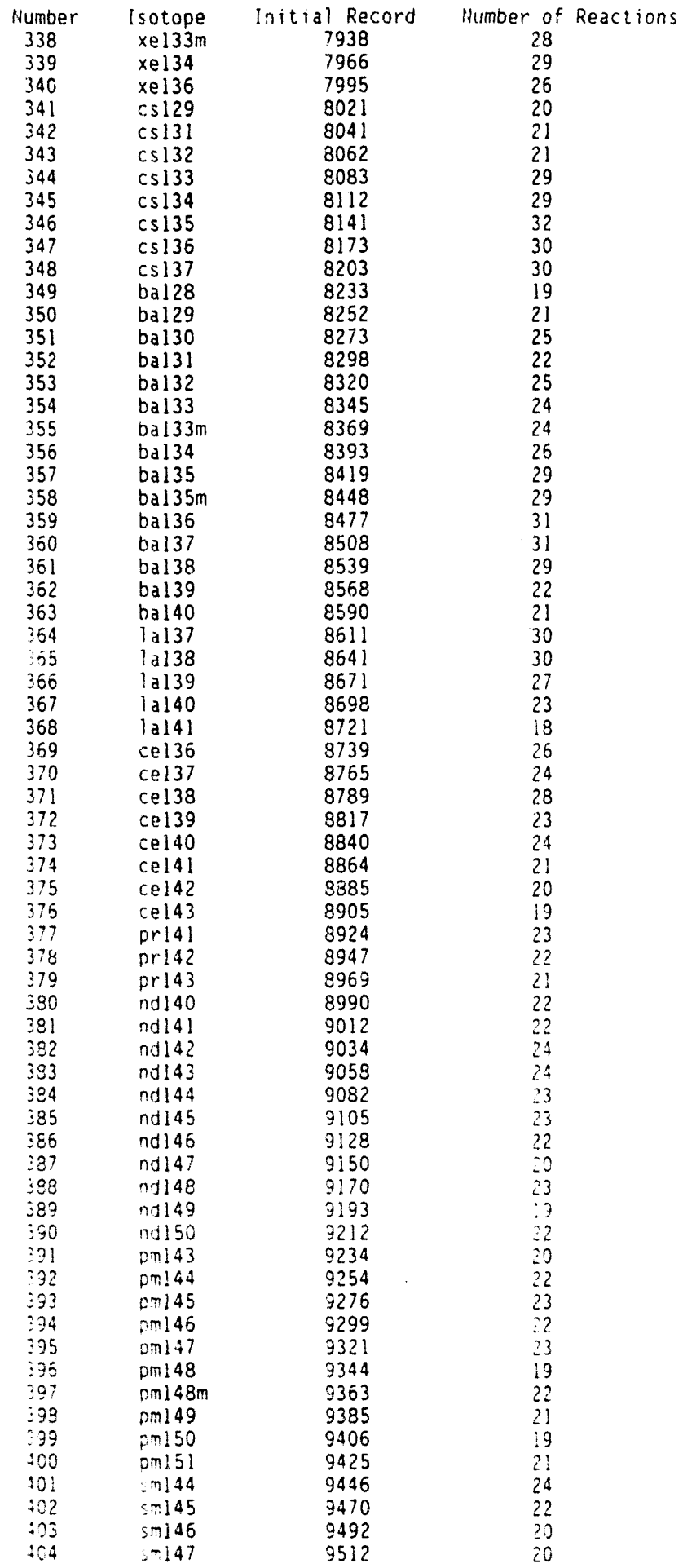


List of Isotopes in Activation Cross Section Library

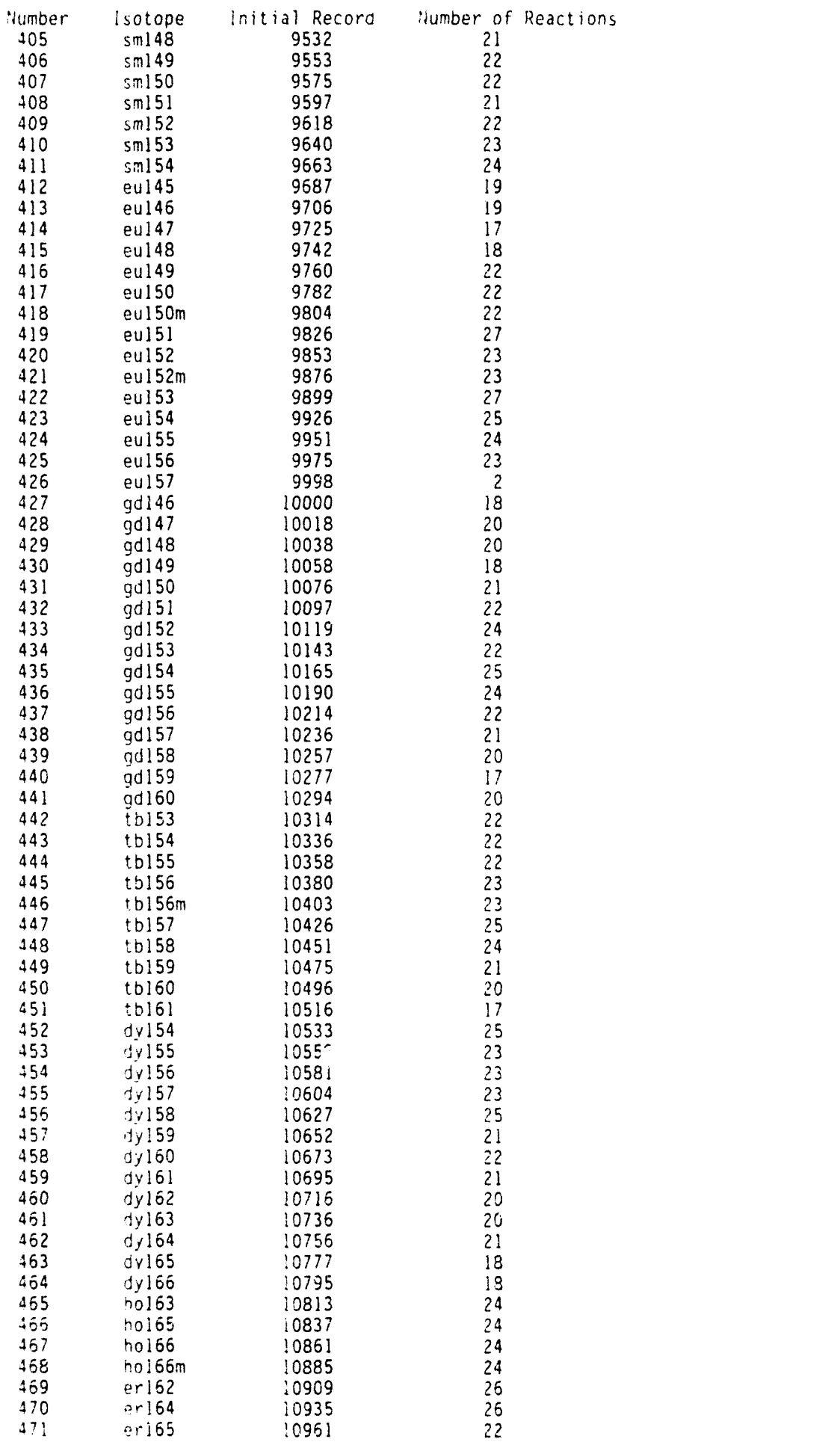


List of Isotopes in Activation Cross Section Library

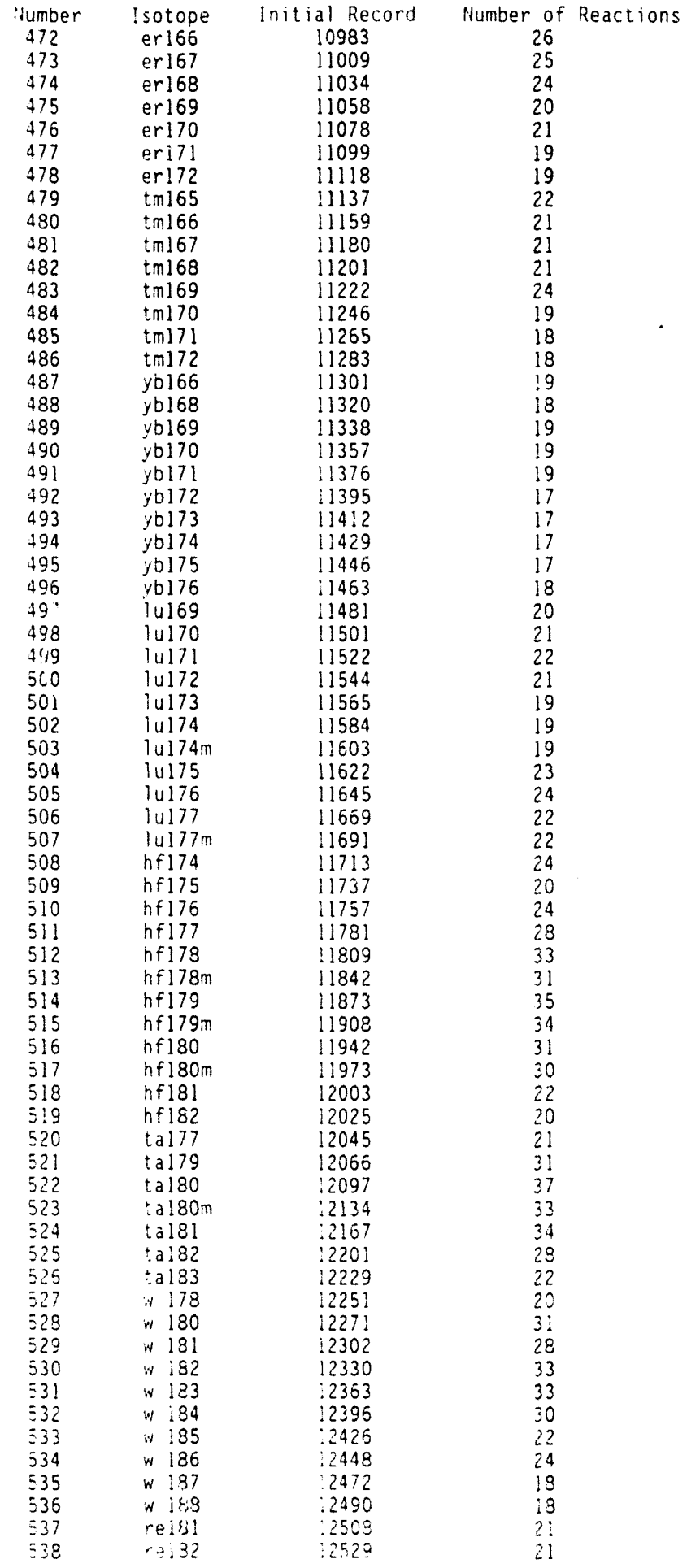


List of isotopes in Activation Cross Section Litrar.

\begin{tabular}{|c|c|c|c|}
\hline $\begin{array}{l}\text { Number } \\
539 \\
540 \\
541 \\
542 \\
543 \\
544 \\
545 \\
546 \\
547 \\
548 \\
549 \\
550 \\
551 \\
552 \\
553 \\
554 \\
555 \\
556 \\
557 \\
558 \\
559 \\
560 \\
561 \\
562 \\
563 \\
564 \\
565 \\
566 \\
567 \\
568 \\
569 \\
570 \\
571 \\
572 \\
573 \\
574 \\
575 \\
576 \\
577 \\
57 \\
579 \\
50 \\
580 \\
581 \\
583 \\
584 \\
585 \\
586 \\
587 \\
588 \\
589 \\
590 \\
591 \\
592 \\
593 \\
594 \\
595 \\
596 \\
597 \\
598 \\
599 \\
600 \\
501 \\
502 \\
503 \\
504 \\
505\end{array}$ & 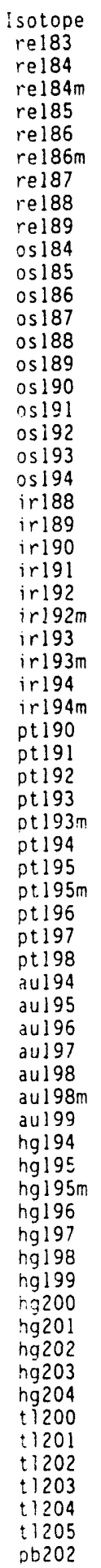 & $\begin{array}{c}\text { initial Record } \\
12550 \\
12572 \\
12596 \\
12620 \\
12651 \\
12678 \\
12705 \\
12731 \\
12751 \\
12769 \\
12794 \\
12816 \\
12842 \\
12867 \\
12893 \\
12919 \\
12945 \\
12968 \\
12993 \\
13013 \\
13033 \\
13053 \\
13073 \\
13096 \\
13128 \\
13162 \\
13195 \\
13227 \\
13259 \\
13284 \\
13309 \\
13332 \\
13357 \\
13390 \\
13425 \\
13460 \\
13494 \\
13525 \\
13556 \\
13585 \\
13610 \\
13637 \\
13665 \\
13694 \\
13723 \\
13756 \\
13784 \\
13812 \\
13837 \\
13867 \\
13895 \\
13923 \\
13957 \\
13987 \\
14020 \\
14050 \\
14078 \\
14104 \\
14123 \\
14148 \\
14167 \\
14192 \\
14214 \\
14234 \\
14256 \\
14274 \\
14295 \\
1429\end{array}$ & 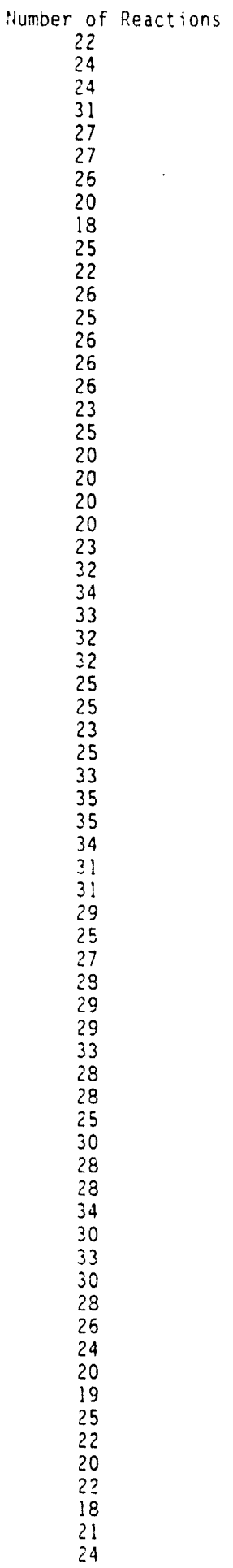 \\
\hline
\end{tabular}


List of Isotopes in Activation Cross Section Library

$\begin{array}{cccc}\text { Number } & \text { Isotope } & \text { Initial Record } & \text { Number of Reactions } \\ 606 & \text { pb203 } & 14319 & 21 \\ 607 & \text { pb204 } & 14340 & 24 \\ 608 & \text { pb205 } & 14364 & 23 \\ 609 & \text { pb206 } & 14387 & 23 \\ 610 & \text { pb207 } & 14410 & 24 \\ 611 & \text { pb208 } & 14434 & 24 \\ 612 & \text { pb209 } & 14458 & 23 \\ 613 & \text { pb210 } & 14481 & 21 \\ 614 & \text { bi205 } & 14502 & 24 \\ 515 & \text { bi206 } & 14526 & 21 \\ 616 & \text { bi207 } & 14547 & 23 \\ 617 & \text { bi208 } & 14570 & 25 \\ 618 & \text { bi209 } & 14595 & 27 \\ 619 & \text { bi210 } & 14522 & 25 \\ 620 & \text { bi210m } & 14647 & 25 \\ 521 & \text { po206 } & 14672 & 21 \\ 522 & \text { p0207 } & 14693 & 22 \\ 523 & \text { po208 } & 14715 & 22 \\ 524 & \text { po209 } & 14737 & 24 \\ 625 & \text { po210 } & 14761 & 20\end{array}$


tRANSMUTATION OF TUNGSTEN IN FFTF, HFIR AND STARFIRE - F. A. Garner and L. R. Greenwood (Pacific Northwest Laboratory).

\section{OBJECTIVE}

The objective of this effort is to determine the role of transmutation on the interpretation of fission data and its extrapolation toward fusion goals.

\section{SUMMARY}

Tungsten has been used in a variety of low activation ferritic alloys and also in copper composite alloys, both currently being irradiated in various fusion materials experiments. It has been proposed as an armor material also. Tungsten transmutes strongly to rhenium and then osmium, however, in a manner that is strongly dependent on neutron spectra. This adds significant complexity to the interpretation of data developed in one spectral environment but intended for application to another environment.

\section{PROGRESS AND STATUS}

\section{Introduction}

Tungsten is currently being used in a variety of fusion materials now under irradiation in the U.S. and Japanese materials programs. Examples are:

1) Tungsten-containing low activation ferritic alloys (PNL, ORNL, NRIM, Monbusho, irradiating in HFIR, EBRII, FFTF, JoYo).

2) Comparative irradiations of alloys such a HTg in HFIR, EBR-II and FFTF (PNL, ORNL).

3) Tungsten metal as an armor for plasma-facing components (MIT and PNL, irradiating in FFTF).

4) $\mathrm{Cu}-\mathrm{W}$ composite alloys (ORNL and PNL, irradiating in FFTF, SM-2).

It has been recently recognized, however, that significant amounts of transmutation occur in tungsten. The spectral sensitivity of this transmutation will require that care be taken in the application to fusion environments of data generated in various fission reactor facilities. Differences in transmutation will also complicate the comparison of data from various fission reactors.

Tungsten has three isotopes which produce significant transmutation via $(n, y)$ reactions. The isotopes $184-W$ and $186-W$ have large reactions rates leading to Re. Much of the Re produced will, in turn, transmute to Os, especially in HFIR. The isotopic $180-W$ produces $181-W(121$ d) which decays to $181-$ ia. During a long irradiation. 181-Ta will transmute to $182-\mathrm{Ta}(114 \mathrm{j})$ which decays to $182-\mathrm{W}$. The isotopic 181-W may also transmute directly to $182 \mathrm{~W}$. The net effect thus depends on the details of the irradiation; however, the abundance of $180-W$ is only $0.12 \%$, so this reaction is not very important. Burnup is also severe for $182-W$ and 183-W. In these cases, 182-W captures to $183-W$ which in turn captures to $184-W$, thus increasing the fraction of $184-\mathrm{W}$, which in turn transmutes to $185-$ Re and so on. It is also necessary to include the decay of three isotopes. namely, 181-W (121 d to 181-Ta); 182-Ta (114 d to 182-W); and 185-W (75d to $185-R e)$. All of these will continue to decay after the irradiation, leading to significant changes in composition after reactor shutdown.

A spreadsheet program was developed to include all of the above effects of burnup and decay. The $(n, p)$ reactions on $W$ all lead to products which eventually decay back to $W$, as do many of the ( $n, \alpha)$ reaction channels. Small amounts $(<1 \mathrm{appm})$ of $\mathrm{Ta}$ and $\mathrm{Hf}$ will be produced; however, these reactions are not well-known and have thus been neglected.

The reaction data were obtained from ENDF/B-V or VI and, in some cases, were estimated from known flux spectra and evaluated neutron cross sections. Calculations were performed for FFTF at the midplane and the middle of the MOTA below-core canister $(-66 \mathrm{~cm})$. The HFIR calculations are for the PTP position at midplane with the reactor operating at $85 \mathrm{MW}$. The STARFIRE calculations are for the first wall position at a wall loading of $3.8 \mathrm{MW} / \mathrm{m}^{2}$.

Some of the highest transmutation rates can be significantly moderated by neutron self-shielding, especially in thick structures. In HFIR, the rates are so large that this is a moot point, however. Many of the Re and $w$ isotopes will eventually burn up, thus having the same net long-term effect in changing composition. In FFTF, self-shielding is not so important; however, some of the resonance region reactions will be moderated and this should be explored in more detail. The nearby presence of other strong neutron moderators (eg - Cd, Sd. B. Li, etc.) would also reduce the transmutation rates of these isotopes.

Pacific Northwest Laboratory is operated for the U. S. Department of Eneray by Battelle Memorial institute under contract DE-ACO6-76RLO 1830. 


\section{Results and discussion}

Table 1 presents the results of these calculations as a function of full power days (FPD), total neutron fluence, and dpa $(\mathrm{Fe})$. The results are also plotted in Figure 1-3. It is obvious, that the transmutation is strongest in FFTF in the below-core position (Figure 1). Unfortunately, much of ferritic data currently being generated in FFTF is being derived in this location. The strong spectral sensitivity of transmutation in tungsten will definitely complicate the comparison of data from below-core and in-core canisters.

In HFIR irradiations, the transmutation is even stronger, but the primary transmutant soon shifts from Re to Os, a development that further complicates comparison of data generated in the HFIR and FFTF reactors. In the STARFIRE spectrum, a large level of transmutation also occurs, but it takes approximately three full power years for the osmium to surpass rhenium in concentration.

There is little doubt that such large changes in composition during irraciation w1ll affect the performance of tungsten. Tungsten-rhenium thermocouples $(5,11,25 \%$ Re) are known to quickly decalibrate during irradiation $\cdots$, primarily due to radiation-induced precipitation of rhenium-rich chi zhase. The role of transmutation-induced changes in rhenium level and the influence of osmium on phase stability have not yet been investigated, however.

\section{References}

1. R. K. Williams, F. W. Wiffen, J. Bentley, and J. 0. Steigler, Met. Trans. 14A (1983) 655.666.

2. D. C. Thompson. N. C. Hoitink, and J. L. Jackson in Fast Flux Test Facility Quarterly Technical Report, July-August 1968, BNWL-917,pp. 4.31-4.35.

Table 1 Calculated Transmutation Products in Tungsten (Atomic percent)

FFTF Midplane FFTF Below Core HFIR Midplane STARFIRE

$\begin{array}{lllllllll}\text { FPD } & 244 & 288 & 833 & 244 & 488 & 833 & 365 & 355 \\ \begin{array}{lllllll}\text { Fruence } \\ \text { dpa, Fe }\end{array} & 1.0 & 2.1 & 3.4 & 0.30 & 0.61 & 1.02 & 0.36 & 0.58 \\ \text { Re } & 30 & 60 & 100 & 4.4 & 8.7 & 14.5 & 27.0 & 42.0 \\ \text { OS } & 0.49 & 0.92 & 1.43 & 4.1 & 7.0 & 9.5 & 2.1(5.1) & 10.1 \\ \text { Ta } & 0.024 & 0.095 & 0.26 & 0.30 & 1.2 & 3.0 & 32.7 & 2.5 \\ & 0.0009 & 0.0017 & 0.0027 & 0.007 & 0.014 & 0.020 & 0.048 & \therefore 17\end{array}$

Full Power Days

Total Fluence in FFTF. E $>0.1 \mathrm{MeV}$ fluence in HFIR.

The Re eventually increases from 2.1 to $5.1 \%$ due to the decay of $185 . \mathrm{W} 1 \mathrm{t}$ : $=5 \mathrm{ars}$

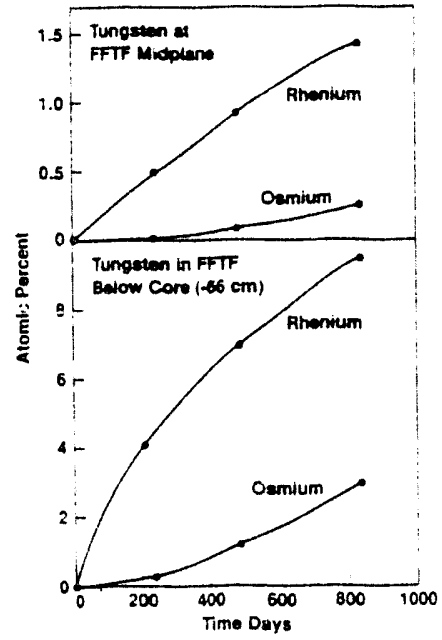

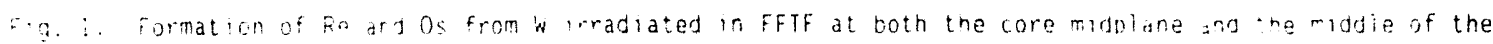
ni in-core oasket of MOTA. 


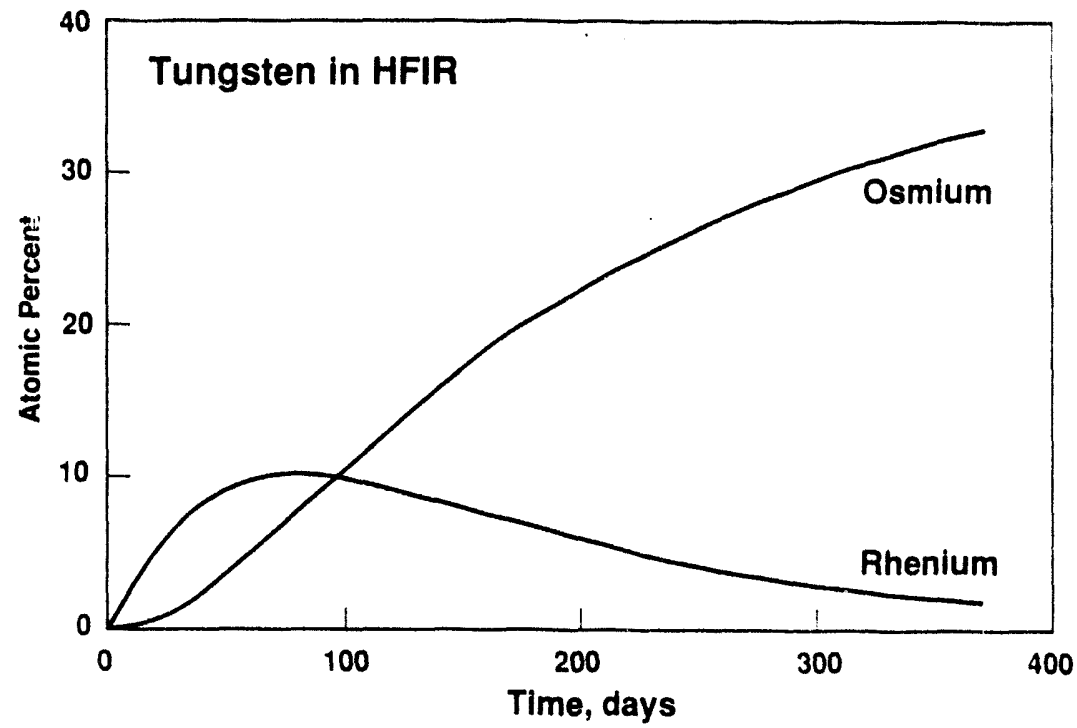

Fig. 2. Formation of Re and OS from irradiated in the PIP position of HFIR at $85 \mathrm{MW}$.

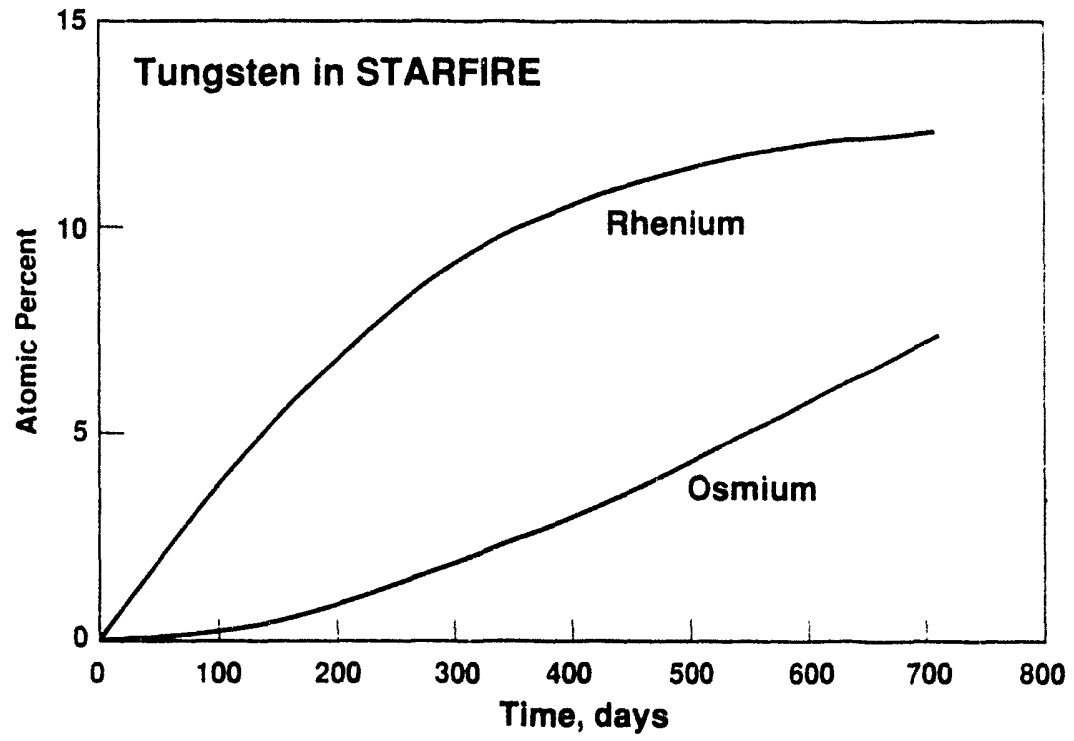

Fig. 3. Formation of Re and 0 s from $W$ irradiated at the first wall position of STARFIRE at $3.8 \mathrm{MW} / \mathrm{m}^{2}$. 


\section{SUMMARY OF IONIZING AND DISPLACIVE IRRADIATION FIELDS IN VARIOUS FACILITIES -- S.J. Zinkle (ORNL) AND L.R. Greenwood (PNL)}

\section{OBJECTIVE}

The purpose of this report is to summarize the ionizing radiation and displacement damage fluxes present in representative materials irradiation facilities.

\section{SUMMARY}

Calculations have been performed to esumate the ionizing and displacive irradiation fields that will occur in ceramics during irradiation in accelerators and fission and fusion reactors. A useful measure of the relative strength of ionizing vs. displacive radiation is the ratio of the absorbed ionizing dose to the displacement damage dose, which in the case of ion irradiation is equal to the ratio of the electronic stopping power to the nuclear stopping power. In ceramics such as $\mathrm{Al}_{2} \mathrm{O}_{3}$, this ratio is about 20 at a fusion reactor first wall, and has a typical value of about 100 in a fusion reactor blanket region and in mixed spectrum reactors such as HFIR. Particle accelerator sources typically have much higher ionizing to displacive radiation ratios, ranging from about 2000 for $1 \mathrm{MeV}$ protons to $>10,000$ for $1 \mathrm{MeV}$ electrons.

\section{INTRODUCTION}

Considerable progress has been made over the past twenty years toward accurately characterizing the irradiation spectra in facilities used for materials science radiation effects studies [1-4]. Almost all of the emphasis in these spectral characterization studies has been devoted to analysis of the displacement damage component, in order to calculate standardized damage parameters such as displacements per atom (dpa) for various materials. There is a second major component of the irradiation spectrum, namely the ionizing radiation field, that has been largely ignored in irradiation spectrum tabulations. Ionizing radiation does not affect the radiation response of metals (other than to contribute to volumetric heating), because metals have a high concentration of electrons in their conduction band. The displacement damage effects associated with gamma rays in a nuclear reactor are generally negligible compared to neutron-induced displacements.

The response of insulators to ionizing radiation is considerably different from the case of metals. Due to high band gap energies, the concentration of valence electrons in the conduction band in polymers and ceramics is generally very low. Ionizing radiation can excite significant concentrations of these valence electrons into the conduction band. This produces very large changes in the electrical properties of the insulator during irradiation [5,6]. In some insulators such as the alkali halides, ionizing radiation can indirectly produce significant amounts of displacement damage from the decay of self-trapped excitons [7].

Several recent studies on ceramics indicate that the irradiation spectrum can have a pronounced effect on the radiation-induced changes in the microstructure or electrical properties $[8,9]$. In particular, irradiation spectra which produced a large amount of ionization relative to the amount of displacement damage were found to significantly enhance the amount of point defect diffusion (ionization-enhanced diffusion, IED) [8]. The ionization-rich radiation sources also produced an apparent acceleration in radiationinduced electrical degradation of $\mathrm{Al}_{2} \mathrm{O}_{3}$ [9]. These observations highlight the importance for fusion ceramics of a complete characterization of the ionizing radiation environment in addition to the primary knock-on atom (PKA) characterization. Calculations were performed in an attempt to assess the magnitude of the ionizing and displacive radiation components in ceramics for a wide range of irradiation sources. 


\section{RESULTS}

Two parameters can be used to characterize the relative magnitudes of ionizing radiation and displacement damage for materials exposed to radiation. The most straightforward approach is to examine the ratio of the absorbed dose from gamma rays (which are primarily ionizing) to the absorbed dose from neutrons (which produce the displacement damage). However, this simple approach ignores the substantial amount of ionization that is produced via the PKAs generated by the neutrons. In addition, this ratio can only be applied to neutron irradiation facilities. A more appropriate measure of the ionizing and displacive radiation fields is the spectrum-averaged ratio of the electronic stopping power $\left(S_{\mathfrak{e}}\right)$ to the nuclear stopping power $\left(S_{n}\right)$. The spectrum-averaged nuclear stopping power (damage energy) contains only the fraction of deposited energy that induces displacement damage. The electronic stopping power includes ionization effects from both PKAs and gamma rays. In the following the spectrum averaged ratio of $S_{\mathrm{e}} / S_{\mathrm{n}}$ will be referred to as the ionizing to displacive absorbed dose (IDAD) ratio:

$$
\operatorname{IDAD}=\int \phi(E) S_{\mathrm{e}}(\mathrm{E}) / \int \phi(E) S_{n}(E)
$$

where the integration is carried out for both the neutron and gamma ray spectra.

The IDAD ratio is a convenient parameter for comparing the relative strength of ionizing radiation in different irradiation facilities such as fission reactors and electron and ion accelerators. One shortcoming of this ratio (as with dpa calculations) is that it does not provide information of the spatial uniformity of the radiation fields. Just as displacement cascade effects have been shown to be an important factor associated with defect production in metals [10], spatially localized ionization "cascades" in the tracks of energetic incident or knock-on atoms may modify the resultant ionization effect. However, given the present lack of information on ionization effects as a whole, the IDAD ratio is a worthwhile first-order correlation parameter.

The TRIM-90 computer code [11] was used to calculate the energy deposited into ionizing and displacive events in $\mathrm{Al}_{2} \mathrm{O}_{3}$ for energetic ions ranging from $1 \mathrm{MeV}$ protons to $4 \mathrm{MeV} \mathrm{Zr}^{+}$ions. The third possible component of deposited energy, phonons (heat) was generally found to be insignificant except for irradiation with massive ions with energies below $200 \mathrm{keV}$. A total of 3000 to 10000 ion trajectories were run for each condition. The calculations used an electron binding energy of $2 \mathrm{eV}$ and a sublattice-averaged threshold displacement energy of $40 \mathrm{eV}$. Identical results were obtained when the TRIM calculations were repeated for the lightest and heaviest ions using the measured [12] Al and $\mathrm{O}$ sublattice displacement energies of 24 and $79 \mathrm{eV}$, respectively. The results of the calculations are summarized in Table 1. Due to the high stopping powers of the incident ions, the ionizing to displacive absorbed dose showed a strong depth dependence--the IDAD ratio decreased rapidly with increasing depth as the ions slowed down and approached values $\leq 1$ at the depth where the ions came to rest [13]. The IDAD ratios given in Table 1 refer to values for the incident surface.

The corresponding IDAD ratio for $1.8 \mathrm{MeV}$ electrons is given in Table 1 for comparative purposes. Published results [14] on the displacement damage (dpa) and ionizing dose (Gy) associated with $1.8 \mathrm{MeV}$ electron irradiation of $\mathrm{Al}_{2} \mathrm{O}_{3}$ were converted to nuclear and electronic stopping powers using the conversion factor for $\mathrm{Al}_{2} \mathrm{O}_{3}$ of

$$
\mathrm{IDAD}=2.12 \times 10^{-9} *(\mathrm{~Gy} / \mathrm{DPA})
$$

This conversion factor makes use of the $\mathrm{Al}_{2} \mathrm{O}_{3}$ atomic density of $1.17 \times 10^{29} / \mathrm{m}^{3}$ and assumes a sublatticeaveraged threshold displacement energy of $40 \mathrm{eV}$. The extrapolated range for $1.8 \mathrm{MeV}$ electrons given in 
Table 1 was calculated using the well-known experimental results for $\mathrm{Al}$ [15] and correcting for the difference in density between $\mathrm{Al}_{2} \mathrm{O}_{3}$ and $\mathrm{Al}$.

Table 1. Ionizing and displacive radiation fields for $\mathrm{Al}_{2} \mathrm{O}_{3}$ in various irradiation sources

\begin{tabular}{|c|c|c|c|c|c|}
\hline Irradiation Source & $\begin{array}{c}\text { Ion } \\
\text { Range }\end{array}$ & $\begin{array}{c}\text { Gammal } \\
\text { Neutron } \\
\text { Absorbed Dose } \\
\end{array}$ & $\begin{array}{c}\text { Ionization } \\
\text { Displacements } \\
\text { Absorbed Dose } \\
\end{array}$ & $\begin{array}{c}\text { Damage } \\
\text { Rate } \\
\text { (dpa/s) }\end{array}$ & $\begin{array}{c}\text { Ionizing } \\
\text { Dose Rate } \\
(\mathrm{Gy} / \mathrm{s}) \\
\end{array}$ \\
\hline $1.8 \mathrm{MeV}$ electrons & $2.1 \mathrm{~mm}$ & - & $-10,000$ & - & - \\
\hline $20 \mathrm{MeV}$ protons & $1.3 \mathrm{~mm}$ & - & $3800^{\circ}$ & $1.2 \times 10^{-8 * *}$ & $2.2 \times 10^{4 * *}$ \\
\hline $10 \mathrm{MeV}$ protons & $0.39 \mathrm{~mm}$ & - & $4400^{\circ}$ & $1.8 \times 10^{-8 * *}$ & $3.8 \times 10^{4 * *}$ \\
\hline $1 \mathrm{MeV}$ protons & $8.7 \mu \mathrm{m}$ & - & 1900 & $2.1 \times 10^{-7 * *}$ & $2.0 \times 10^{5 * *}$ \\
\hline $28 \mathrm{MeV} \mathrm{He}^{+}$ions & $0.21 \mathrm{~mm}$ & - & 3400 & $1.2 \times 10^{-7 * *}$ & $2.0 \times 10^{5 * *}$ \\
\hline $1 \mathrm{MeV} \mathrm{He}^{+}$ions & $2.0 \mu \mathrm{m}$ & - & 820 & $3.8 \times 10^{-6 * *}$ & $1.5 \times 10^{6 * *}$ \\
\hline $3 \mathrm{MeV} \mathrm{C}^{+}$ions & $1.8 \mu \mathrm{m}$ & - & 280 & $4.3 \times 10^{-5 * *}$ & $5.7 \times 10^{6 * *}$ \\
\hline $2 \mathrm{MeV} \mathrm{Al}^{+}$ions & $1.2 \mu \mathrm{m}$ & - & 33 & $4.1 \times 10^{-4 * *}$ & $6.3 \times 10^{6 * *}$ \\
\hline $4 \mathrm{MeV} \mathrm{Fe}^{+}$ions & $1.5 \mu \mathrm{m}$ & - & 15 & $1.4 \times 10^{-3 * *}$ & $1.0 \times 10^{7 * *}$ \\
\hline $4 \mathrm{MeV} \mathrm{Zr}^{+}$ions & $1.1 \mu \mathrm{m}$ & - & 3.9 & $4.0 \times 10^{-3 * *}$ & $7.5 \times 10^{6 * *}$ \\
\hline $\begin{array}{l}\text { Mixed spectrum fission } \\
\text { reactor (HFIR } R B^{*} \text { ) }\end{array}$ & - & 23 & 107 & $3.2 \times 10^{-7}$ & $1.6 \times 10^{4}$ \\
\hline $\begin{array}{l}\text { Fast fission reactor } \\
\text { (FFTF MOTA) }\end{array}$ & - & 1.0 & 4.4 & $3.8 \times 10^{-6}$ & 8000 \\
\hline $\begin{array}{l}\text { Fusion Reactor } \\
\text { - 1st wall } \\
\text { - magnet coils }\end{array}$ & - & $\begin{array}{c}0.14 \\
0.7 \text { to } 210\end{array}$ & $\begin{array}{c}13 \\
40 \text { to } 330\end{array}$ & $\begin{array}{l}1.5 \times 10^{-6} \\
<2 \times 10^{-9}\end{array}$ & $\begin{array}{l}9300 \\
<300\end{array}$ \\
\hline $\begin{array}{l}14 \mathrm{MeV} \text { neutrons } \\
\text { (R'INS-II) }\end{array}$ & - & 0.01 & 35 & $6.8 \times 10^{-9}$ & 110 \\
\hline
\end{tabular}

- These calculations neglect displacements due to nuclear reactions, which can be significant for light ion energies $>10 \mathrm{MeV}$ (see D. W. Muir and J. M. Bunch, in Radiation Effects and Tritium Technology for Fusion Reactors, p. II-517).

**Displacive and ionizing dose rates calculated for a bean current of $1 \mu \mathrm{A} / \mathrm{cm}^{2}$ of singly charged ions.

The IDAD and gamma ray to neutron absorbed dose ratios for several neutron irradiation facilities are shown in Table 1. The ionizing and displacive absorbed doses in $\mathrm{Al}_{2} \mathrm{O}_{3}$ due to neutrons were calculated 
using the SPECOMP code [16]. The energy deposited by gamma rays in the fission reactor facilities was obtained by subtracting the neutron absorbed dose from the measured volumetric heating rates. The gamma

ray absorbed dose was calculated for $\mathrm{Fe}$, since volumetric heating has not been measured in materials such as $\mathrm{Al}_{2} \mathrm{O}_{3}$. Since the gamma ray mass absorption coefficients for $1 \mathrm{MeV}$ gammas are nearly constant for elements with atomic weights between $\mathrm{C}$ and $\mathrm{Ag}$ [17], it was assumed that the gamma ray portion of the volumetric heating (absorbed dose) was equivalent for $\mathrm{Fe}$ and $\mathrm{Al}_{2} \mathrm{O}_{3}$. The volumetric heating rates in $\mathrm{Fe}$ for the HFIR RB* position (85 $\mathrm{MW}_{\text {th }}$ power) and FFTF MOTA facility are 16000 and $4500 \mathrm{~Gy} / \mathrm{s}$, respectively (16 and $4.5 \mathrm{w} / \mathrm{g}$ ) [18].

Table 1 also summarizes the absorbed dose ratios for $14 \mathrm{MeV}$ neutrons and for 2 positions in a fusion reactor. The absorbed dose ratios for positions near the superconducting magnet coils in a fusion reactor depend strongly on the choice of blanket and shielding materials, and also depend on exact location due to radiation streaming effects $[19,20]$. As shown in Table 1, calculated IDAD ratios in $\mathrm{Al}_{2} \mathrm{O}_{3}$ between 40 and 330 at the superconducting magnet can be obtained for different combinations of blanket and shielding materials [19].

\section{DISCUSSION}

The calculated ionizing radiation parameters for the neutron irradiation facilities need further study to evaluate their quantitative accuracy. For example, calculations by Dell and Goland [4] for $\mathrm{Al}_{2} \mathrm{O}_{3}$ irradiated in the $14 \mathrm{MeV}$ neutron source RTNS-II give an IDAD ratio of 5.5 as opposed to the value of 35 calculated in the present work. Similar (although smaller in magnitude) discrepancies appear between Dell and Goland and the present work for mixed spectrum and fast reactor irradiation sources. In all cases, the $\mathrm{Al}_{2} \mathrm{O}_{3}$ displacement damage calculations from the two studies are in good agreement. The main source of the discrepancy lies in the calculations of the amount of ionizing radiation produced by neutrons. The values obtained by Dell and Goland are consistently smaller than the values calculated in the present study by a factor of 2 to 6 , depending on the neutron spectrum. The source of this discrepancy is unknown at the present time. This highlights the need for better characterization of the ionizing radiation environments in irradiation facilities.

It is worth noting that even "pure" neutron sources such as RTNS-II are highly ionizing (IDAD ratio 35 ). The high amount of ionization is due to the dense ionization associated with the high average PKA energy created by energetic neutrons. The fraction of absorbed dose associated with ionization increases rapidly with increasing neutron energy. For example, the IDAD ratio for $\mathrm{Al}_{2} \mathrm{O}_{3}$ in a fast fission reactor is only about 4.4 , whereas the value is $\sim 35$ for $14 \mathrm{MeV}$ neutrons.

The IDAD values presented in this report are only valid for $\mathrm{Al}_{2} \mathrm{O}_{3}$. Significantly different results will be obtained for different ceramic materials such as $\mathrm{SiC}$, and the appropriate values for polymers will be much different.

A range of irradiation facilities may be needed to obtain data appropriate for insulators to be used in different locations in a fusion reactor. According to the present calculations, the range of IDAD ratios relevant for $\mathrm{Al}_{2} \mathrm{O}_{3}$ vary between $\sim 15$ for applications near the first wall to $\sim 100$ for blanket applications. Further work is needed to determine the sensit: jity of ceramic insulators to slight variations in the IDAD ratio. Scoping studies performed to date have shown that significant differences in the microstructural and electrical property evolution can be obtained when the IDAD ratio is varied by a factor of ten or more [8,9]. It remains to be seen if detectable differences will occur when the IDAD ratio is altered by a factor of $\sim 2$. 


\section{REFERENCES}

1. T.A. Gabriel, B.L. Bishop and F.W. Wiffen, Calculated Irradiation Response using Fission Reactor (HFIR, ORR, and EBR-II) Neutron Spectra, ORNL-TM-6361 (August 1979).

2. L.R. Greenwood, J. Nucl. Mater. 141-143 (1986) 654.

3. D.G. Doran, Report of the LASREF Evaluation Committee, PNL-SA-18584 (July 1990).

4. G.F. Dell and A.N. Goland, J. Nucl. Mater. 102 (1981) 246.

5. V.A.J. van Lint et al., Mechanisms of Radiation Effects in Electronic Materials, Vol. 1 (Wiley and Sons, New York, 1980).

6. R.E. Stoller, R.H. Goulding and S.J. Zinkle, J. Nucl. Mater. 191-194 (1992) 602.

7. N. Itoh, K. Tanimura and Y. Nakai, Nucl. Instr. Meth. B65 (1992) 21.

8. S.J. Zinkle, Effect of Irradiation Spectrum on the Microstructural Evolution of Oxide Ceramics, this semiannual.

9. S.J. Zinkle and W. Kesternich, Electrical Conductivity of Ceramic Insulators during Extended Ion Irradiation, this semiannual.

10. S.J. Zinkle and B.N. Singh, J. Nucl. Mater. 199 (1993) 173.

11. J.F. Ziegler, J.P. Biersak and U.L. Litumark, The Stopping and Range of Ions in Solids (Pergamon Press, New York, 1985).

12. P. Agnew, Phil. Mag. A 65 (1992) 355.

13. S.J. Zinkle, Fusion Reactor Materials Semiann. Prog. Report for period ending March 31, 1991, DOE/ER-0313/10.

14. S.J. Zinkle and E.R. Hodgson, J. Nucl. Mater. 191-194 (1992) 58.

15. R.D. Evans, The Atomic Nucleus (McGraw-Hill, New York, 1955) p. 625.

16. L.R. Greenwood, "Radiation Damage Calculations for Compound Materials", in Effects of Radiation on Materials, Vol. I, ASTM STP 1046, N.H. Packan, R.E. Stoller and A.S. Kumar, Eds. (ASTM, Philadelphia, 1990) p. 633.

17. J.R. Lamarsh, Introduction to Nuclear Engineering (Addison-Wesley, Reading, MA, 1977) p. 86

18. G.R. Hicks, B.H. Montgomery, K.R. Thoms and C.D. West, J. Nucl. Mater. $141-143$ (1986) 1018.

19. M.E. Sawan and L.A. El-Guebaly, "Magnet Shielding Perfornance", ITER First Wall/Blanke/Shield Meeting, Argonne, IL, Feb. 19, 1993.

20. R.T. Santoro, J.S. Tang, R.G. Alsmiller, Jr., and J.M. Barnes, Nucl. Technol. 37 (1978) 65. 
IMPROVEMENT OF DECAY AND CROSS-SECTION DATA LIBRARIES FOR ACTIVATION CALCULATIONS-H. Attaya (Argonne National Laboratory).

\section{OBJECTIVE}

The objective of this work is to upgrade and improve the activation decay and cross-sections data libraries to provide accurate and more comprehensive estimates of fusion reactor activation.

\section{SUMMARY}

A new decay data library has been completed. The new library contains up-to-date decay information (half-lives, branching ratios, decay energies, $\gamma$ 's energies and intensities). Activation responses such as the air and water biological hazard potentials, the waste disposal rating, and the biological dose are also included in this library. Recently developed cross-section libraries have been acquired to be used together with the decay data library.

\section{STATUS AND PROGRESS}

\section{Introduction}

To enhance the safety of fusion reactors, materials' activation characteristics became an important factor in selecting the materials for use in fusion reactors. Therefore, the evaluation of the materials activation characteristics must be accurate and reliable. Decay and cross-section libraries are primary and essential inputs for activation calculations. Thus, the quality of these calculations depends on the quality of these libraries as well as the method of solution and the accurate modeling of the problem under consideration.

\section{Activation Data Library}

The activation data library contains information that is essential in constructing the decay and transmutation chains. This information includes the half-lives, the decay modes, and the branching ratios of the different decay modes. In addition, the decay energies of the emitted radiation are required to calculate the decay heat generation rate, and the $\gamma$ 's energies and intensities are required to calculate the biological dose.

We have utilized the computer data bases of the Isotope Project in Lawrence Berkeley Laboratory (which is reflected in the Table of Radioactive Isotopes ${ }^{1}$ ) and of the National Nuclear Data Center at Brookhaven to generate an up-to-date activation data library. The genetic feedings (which are the branching ratios of a particular decay mode to different isomeric states) used in this library ae from the Table of Isotopes ${ }^{2}$.

Several activation responses are included in this library. These are the air and water maximum permissible concentrations ${ }^{3}$ to calculate the inhalation and ingestion biological hazard potential, the waste disposal limits ${ }^{4}$ to calculate the waste disposal rating, and the biological dose rates at 1 meter from a point source. The decay data library contains 2682 isotopes (521 isomers) compared to only 166 isotopes ( 26 isomers) in the old decay data library.

\section{Activation Cross-Section Data Library}

Several activation cross-section data libraries have been acquired to be used with the new decay data library. The most recent ones are, the new REAC-3 cross-section library and the European Activation File EAF- $3^{5}$. The latter library has 10456 reactions' cross section data for 729 isotopes. Both libraries were made available by F. Mann ( Westinghouse Hanford Company). 


\section{Activation of Pure Elements}

Figures 1 and 2 show the radioactivity of some elements that are important in the development of fusion reactor materials. These results have been calculated using the radioactivity code RACC ${ }^{6}$. The calculations are based on average neutron wall loading of $5 \mathrm{MW} / \mathrm{m}^{2}$ and 5 years of continuous operation using the first wall neutron flux of the TPSS conceptual design 7 . Figures 3 and 4 show the air-BHP of these elements.

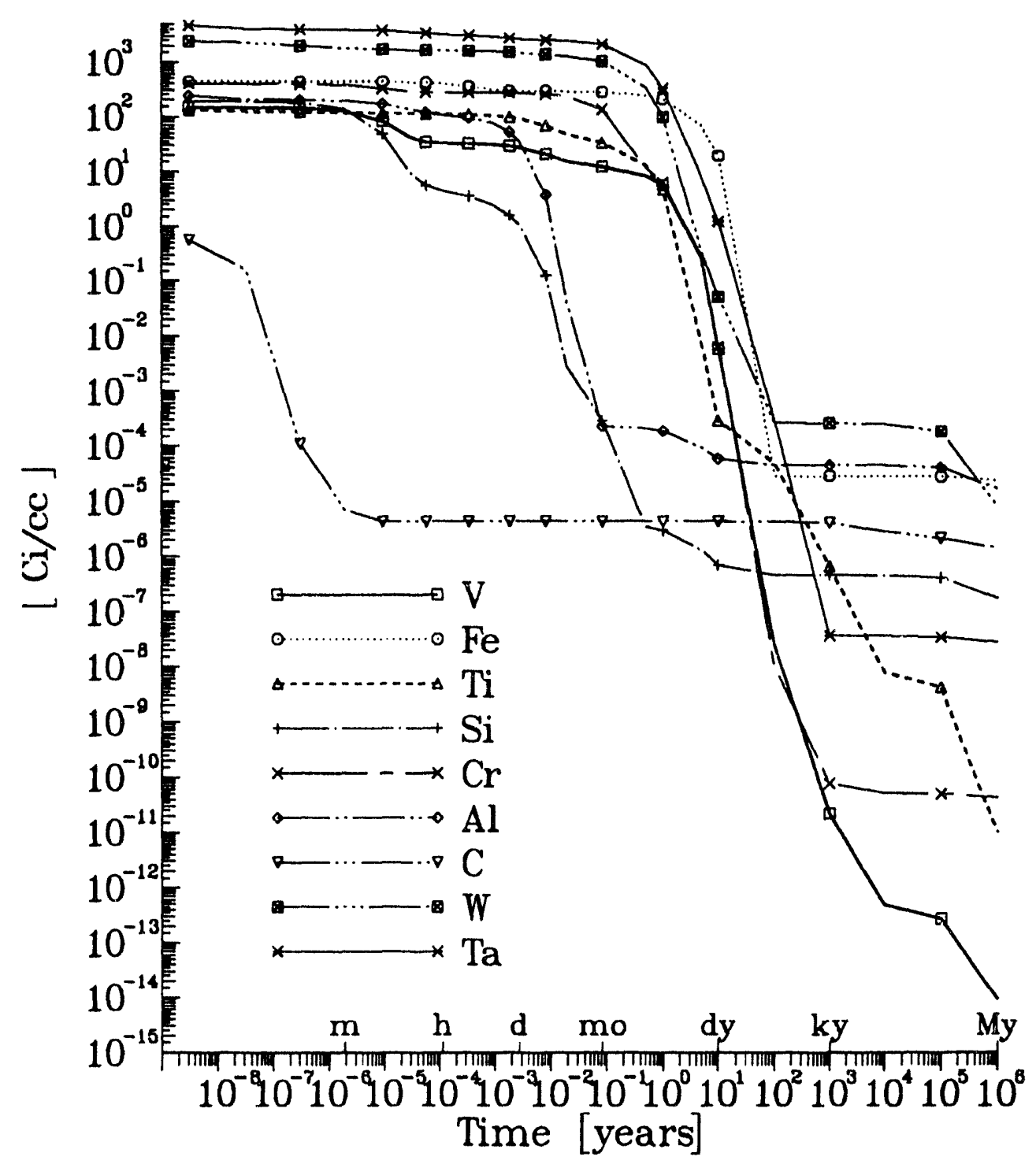

Fig. 1. Inducted activities in pure $\mathrm{V}, \mathrm{Fe}, \mathrm{Ti}, \mathrm{Si}, \mathrm{Cr}, \mathrm{Al}, \mathrm{C}, \mathrm{W}$, and Ta. 


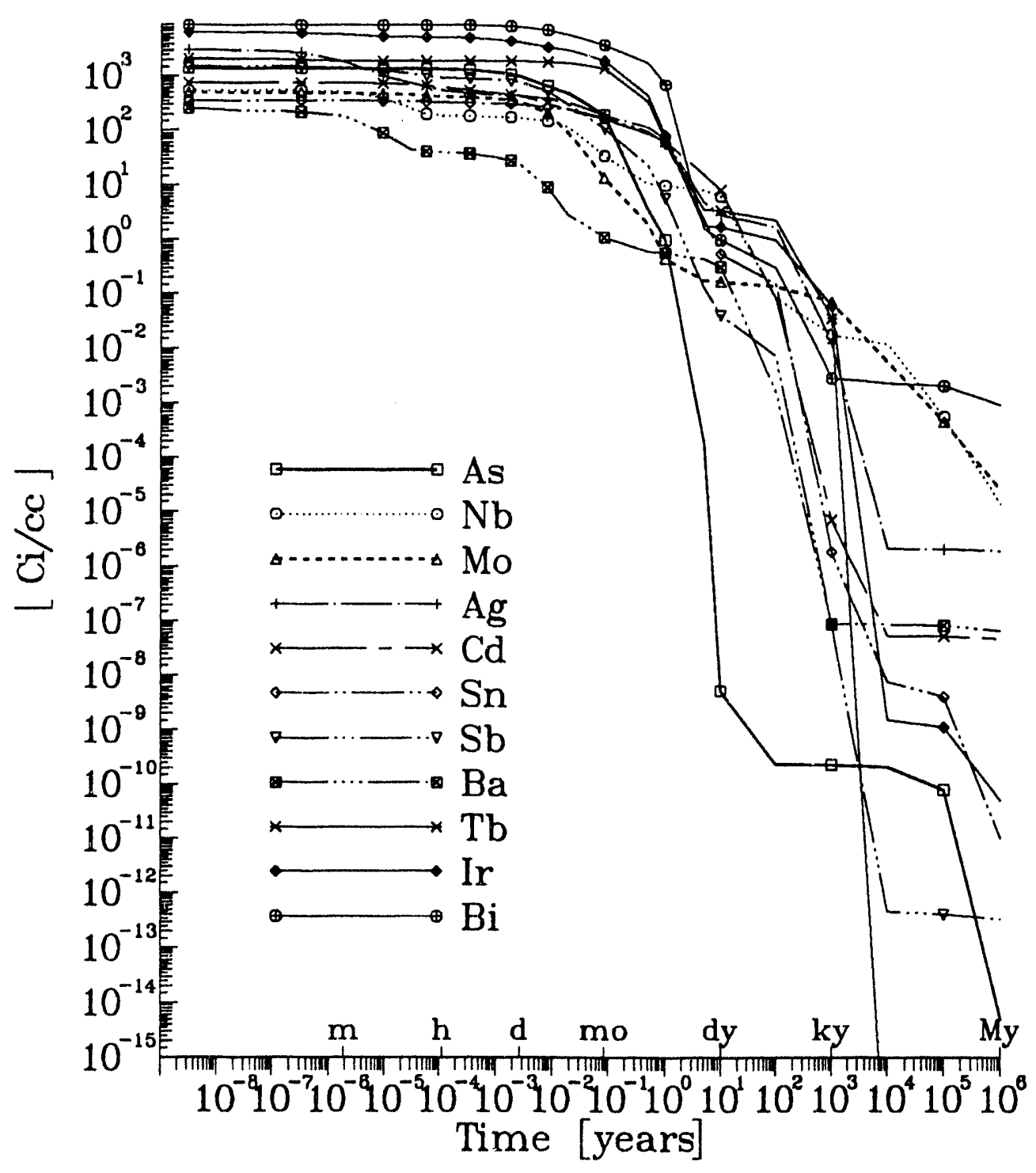

Fig. 2. Inducted activities in pure $\mathrm{As}, \mathrm{Nb}, \mathrm{Mo}, \mathrm{Ag}, \mathrm{Cd}, \mathrm{Sn}, \mathrm{Sb}, \mathrm{Ba}, \mathrm{Tb}, \mathrm{Ir}$, and $\mathrm{Bi}$. 


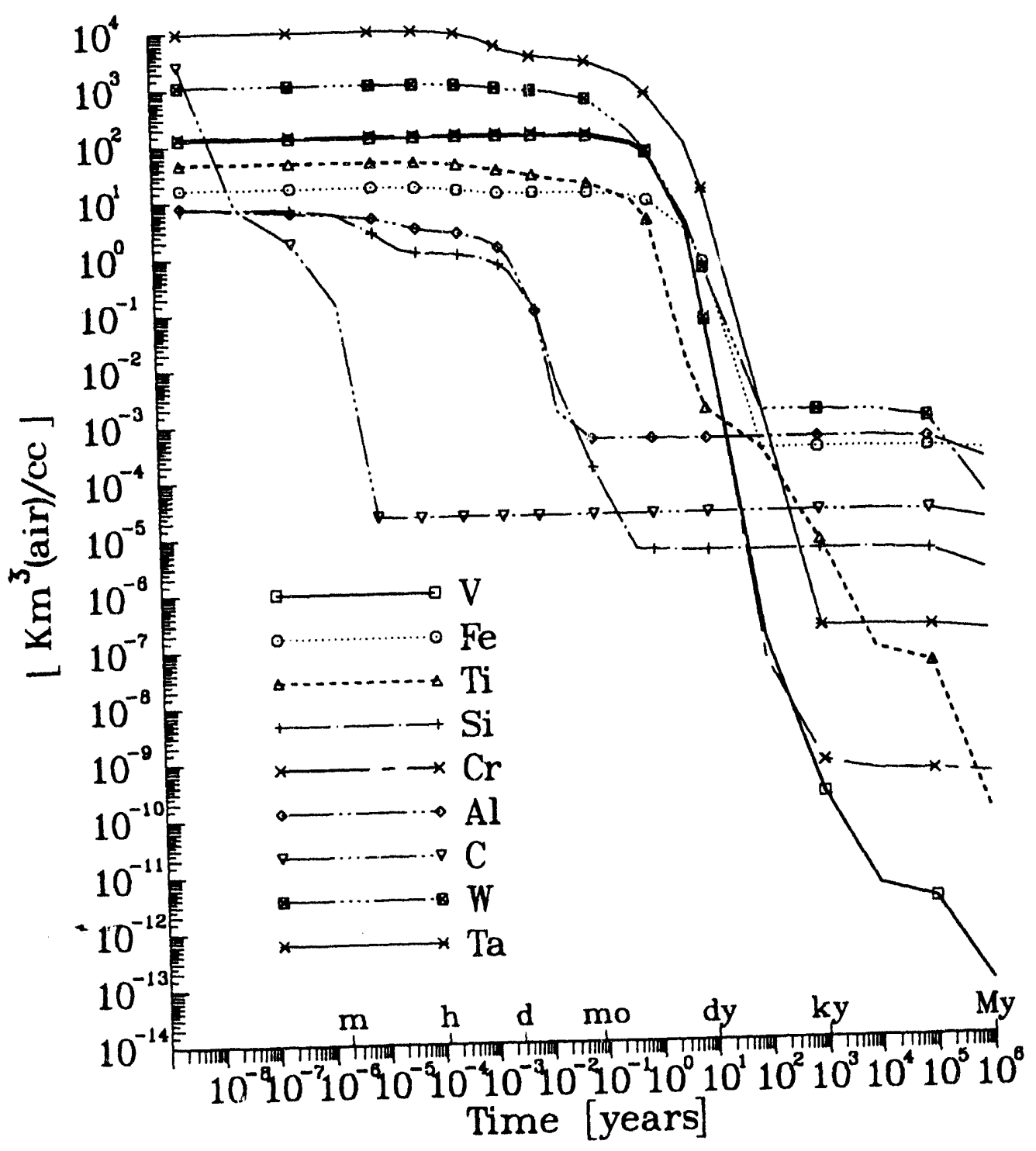

Fig. 3. Air biological hazard potential of V, Fe, Ti, Si, Cr, Al, C, W, and Ta. 
?

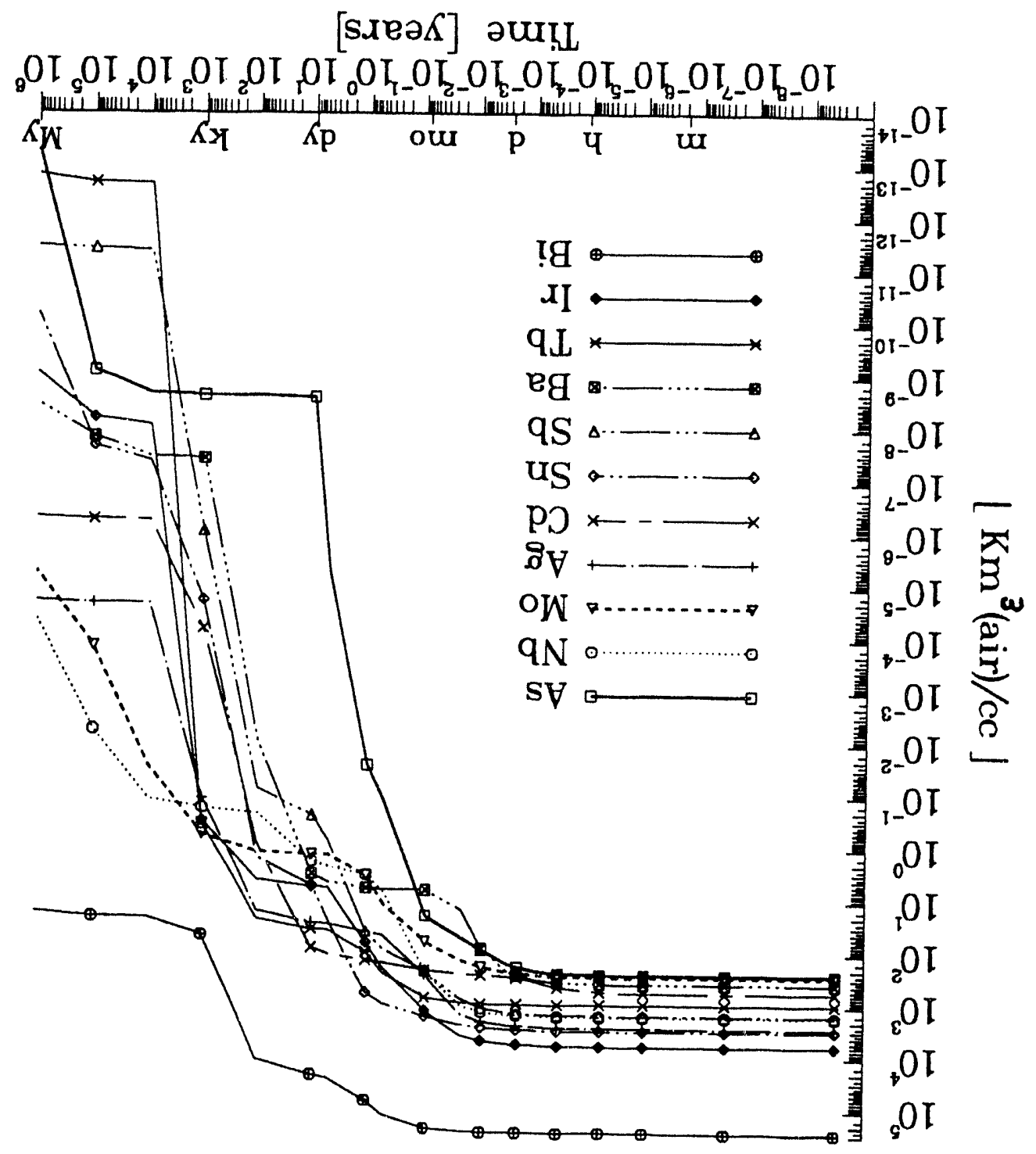




\section{FUTURE WORK}

Available dosimetric experimental results will be used to verify the activation calculations.

\section{REFERENCES}

1. E. Browne and R. Firestone, "Table of Radioactive Isotopes," John Wiley and Sons, Inc., New York (1986).

2. C. M. Lederer and V. S. Shirley, Editors, "Table of Isotopes," Seventh Edition, Wiley-Interscience, New York (1978).

3. "Standards for Protection Against Radiation," Code of Federal Regulations, Title 10, Part 20.

4. "Licensing Requirements for Land Disposal of Radioactive Waste," Code of Federal Regulations, Title 10, Part 61.

5. F. Mann, private communications.

6. J. Jung, "Theory and Use of the Radioactivity Code RACC," ANL/FPP/TM-122, Argonne National Laboratory (1979).

7. D. Ehst et al., Argonne National Laboratory, ANL/FPP/86-1 (1987). 
ACTIVATION ANALYSES FOR DIFFERENT STRUCTURAL ALLOYS CONSIDERED FOR ITERH. Attaya and D. Smith (Argonne National Laboratory).

\section{OBJECTIVE}

The objective of this work is to evaluate the activation characteristics of different structural alloys that are being considered for I'TER.

\section{SUMMARY}

Activation calculations have been made for the austenitic steel 316 SS, the ferritic alloy HT-9, the titanium alloy Ti6Al4V, and the vanadium alloy V5Cr5Ti in a liquid metal (Na) design suggested recently for ITER. The calculations show that the vanadium alloy has the minimum short and long-term radioactivity and BHP. It also has the minimum decay heat all the time. The titanium alloy has less radioactivity than the austenitic and the ferritic alloys. However, the decay heat of this alloy could exceed that of the conventional alloys.

\section{STATUS AND PROGRESS}

\section{$\underline{\text { Introduction }}$}

Several structural alloys have been considered for I'TER. In addition to the austenitic, ferritic, and vanadium alloys, there is an interest in considering the titanium alloys. The interest in the titanium alloys is due to the fact that these are less radioactive than the conventional austenitic and ferritic alloys. In this work, using a recently suggested liquid metal design (Na) for ITER, different activation responses of these alloys are examined and compared.

\section{Activation Calculations}

Several liquid metal; $\mathrm{Na}, \mathrm{NaK}, \mathrm{K}, \mathrm{Pb}$, and $\mathrm{li}$ have been envisaged for a liquid metal coolant design of ITER. The sodium coolant appears to have the minimum activation (for times $>1$ day after shutdown). An optimized inboard design that protects the magnet consists of $0.5 \mathrm{~cm} \mathrm{FW}, 65 \mathrm{~cm}$ shield $(50 \% \mathrm{Na}, 50 \%$ structure), and $35 \mathrm{~cm}$ vacuum vessel (62\% structure, $38 \%$ water). Using this design, the radioactivity, the air-BHPs, and the decay heat generation rates in the inboard first wall are calculated for the four alloys using the radioactivity code RACC. ${ }^{1}$ The calculations are based on 3 years of ITER operation with 1 $\mathrm{MW} / \mathrm{m}^{2}$ neutron wall leading.

The radioactivity of the four alloys after shutdown is shown in Fig. 1. It is clear in this figure that the long-term radioactivity of the vanadium alloy is several orders of magnitude less than the radioactivity of any other alloy. It is only in the period from 2 years to 20 years after shutdown, that the titanium alloys radioactivity is less than that of the vanadium. This is due to the fact that the radioactivity of the vanadium alloy is dominated by ${ }^{49} \mathrm{~V}$ isotope, see Fig. 2, which is produced mainly by ${ }^{50} \mathrm{~V}(\mathrm{n}, 2 \mathrm{n})^{49} \mathrm{~V}$ reaction. The titanium alloy's radioactivity, however, is much less than the radioactivity of the ferritic and the austenitic alloys. Figures 2 and 3 identify the dominant isotopes in the vanadium and the titanium alloys, respectively. The air biological hazard potentials of the four alloys are shown in Fig. 4. Here, again, the short and the long-term vanadium's BHP is less than that of the other alloys. However, the period over which the titanium alloy's BHP is less than the vanadium alloy's BHP is longer and extends from just a few hours to 20 years. This is because the vanadium alloy's BHP is dominated by the isotope ${ }^{49} \mathrm{~V}$ from the onset of the cooling period ( $80 \%$ at shutdown and $\sim 100 \%$ at $\sim 4$ years). 


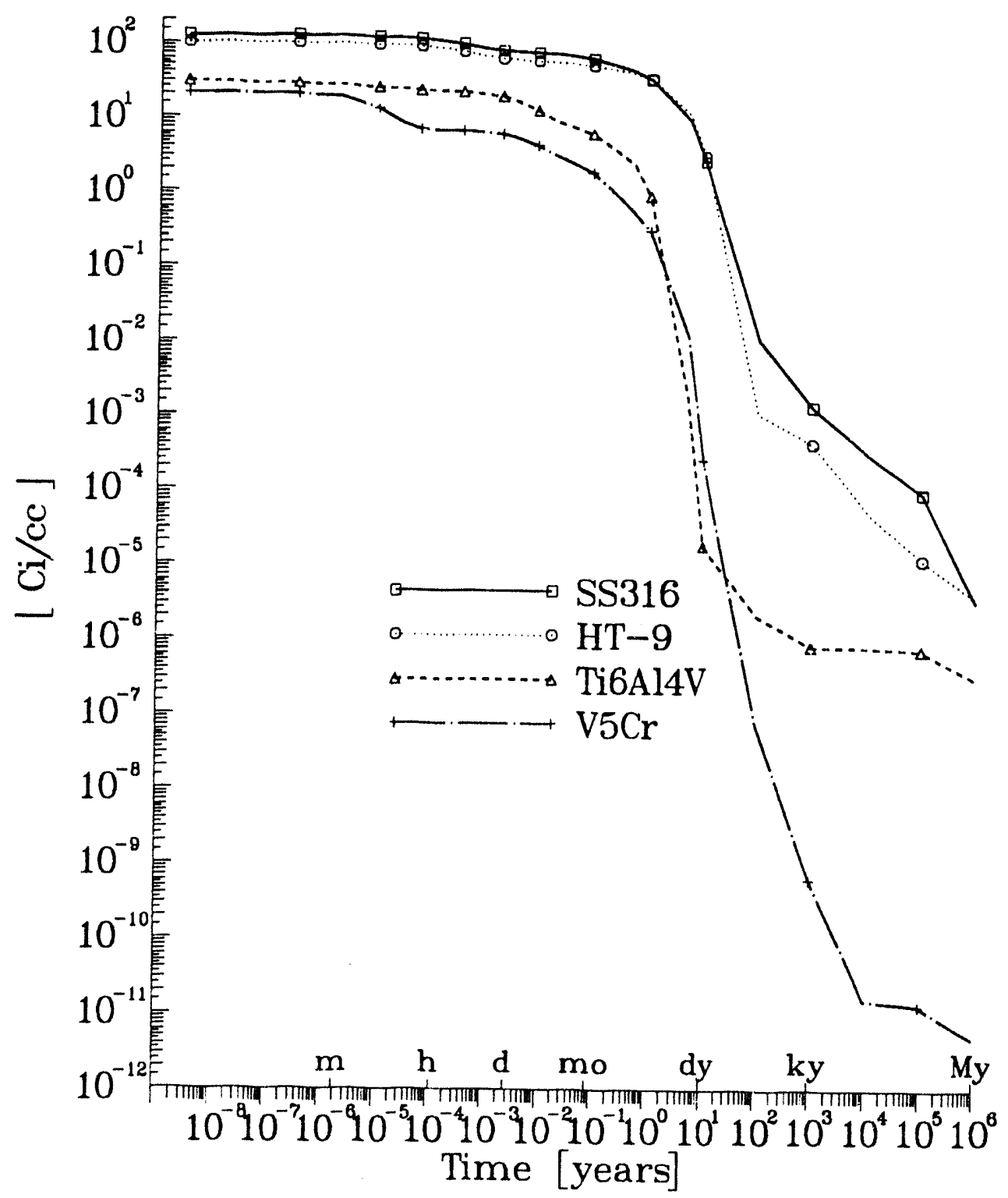

Fig. 1. The specific radioactivity in the first wall for the four alloys. 


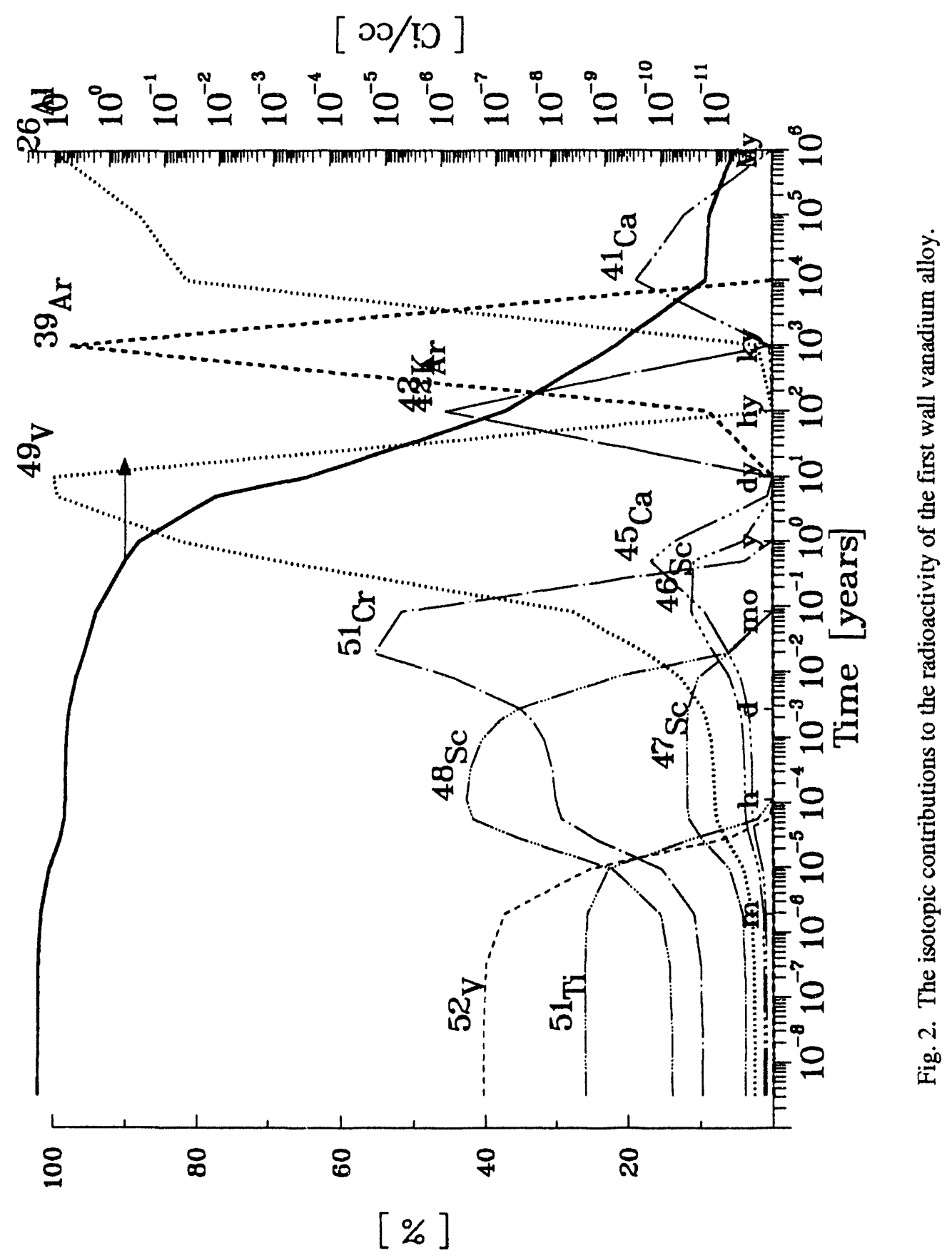




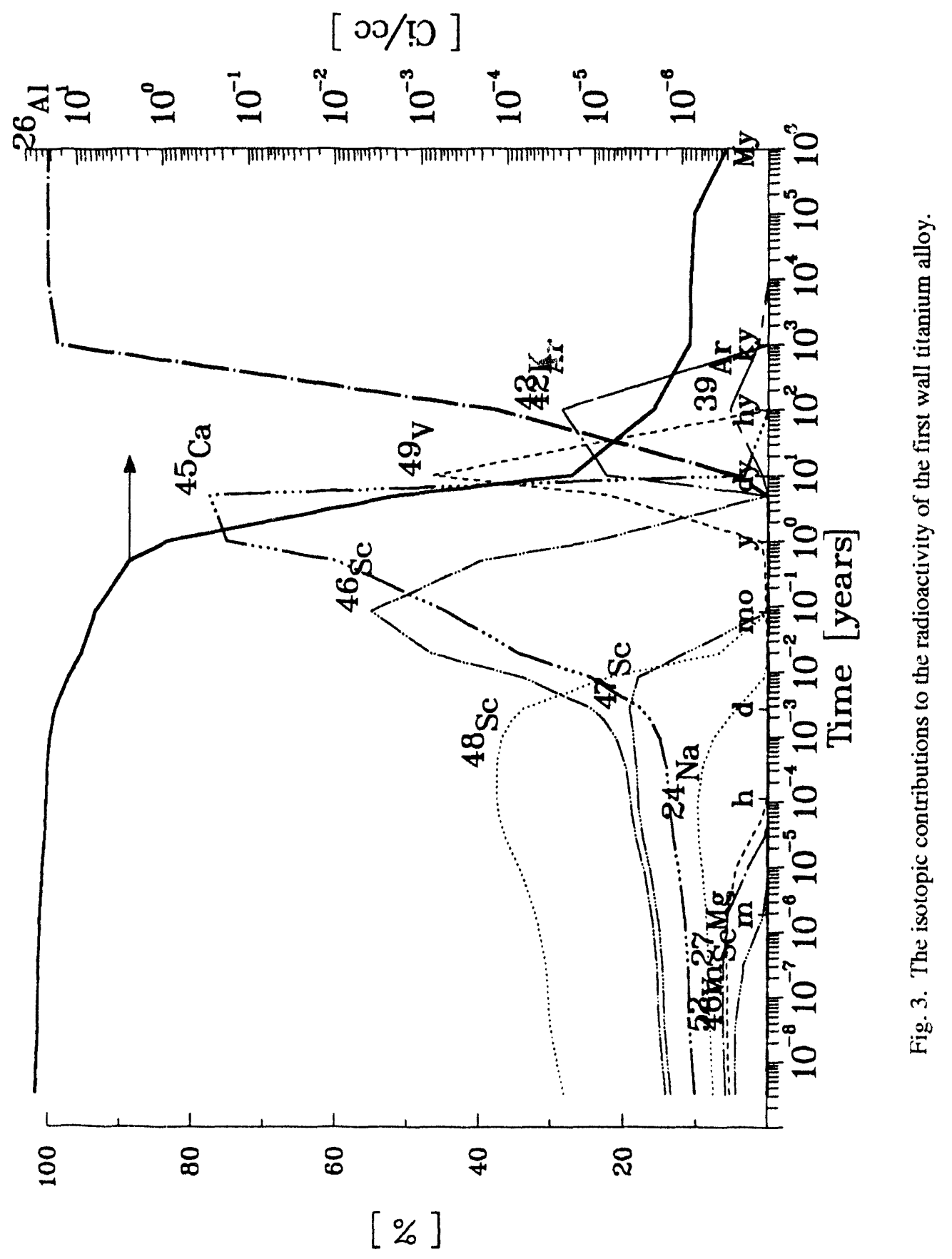




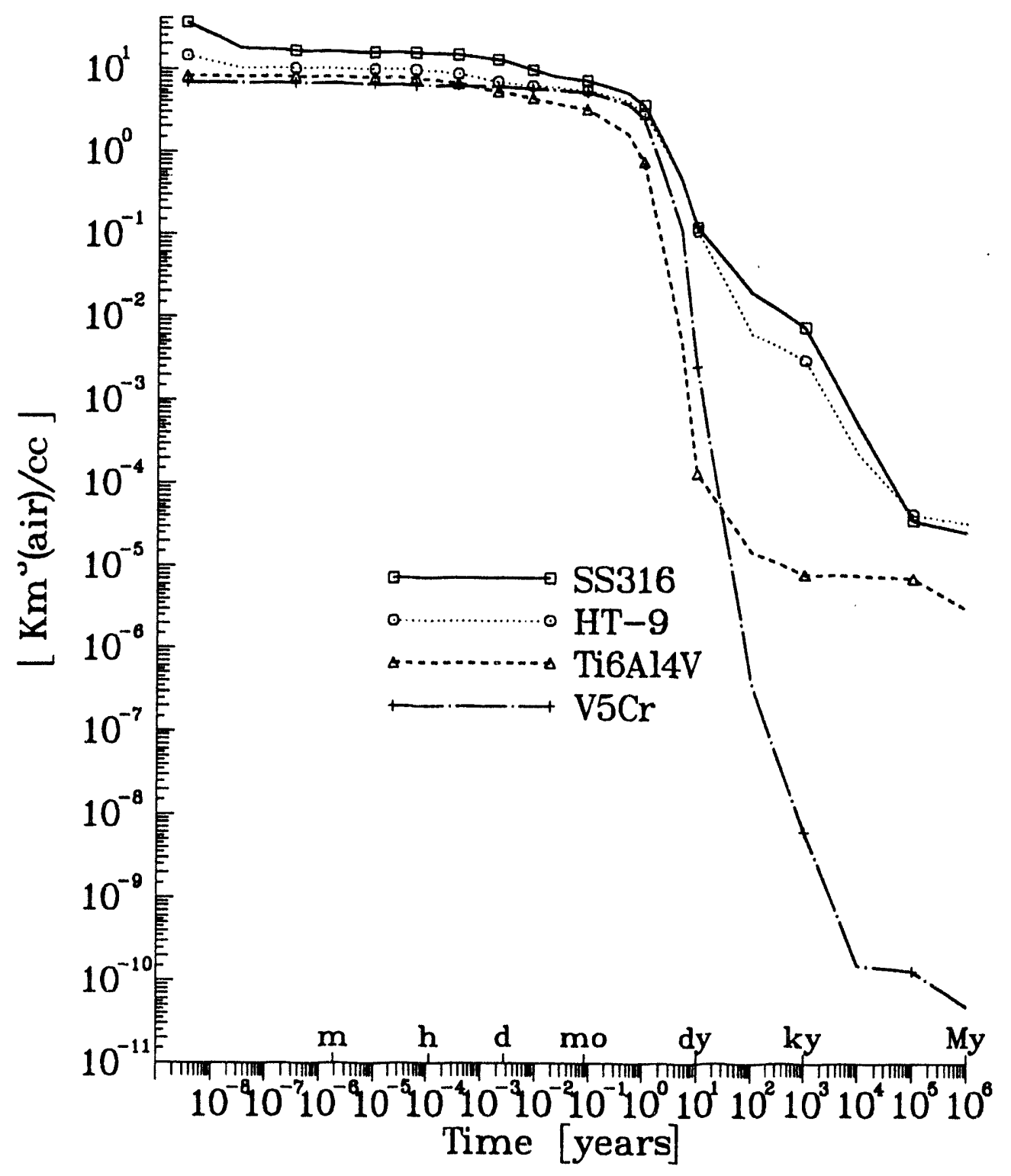

Fig. 4. The air-BPH of the first wall for the four alloys. 
The decay heat generation rates (DHGRs) of the four alloys are shown in Fig. 5. The vanadium alloy has the least DHGR all the times after shutdown. Only the ferritic alloy's DHGR comes close to that of the vanadium at about 1 day after shutdown. The DHGR of the titanium alloy is dominated by the isotopes ${ }^{48} \mathrm{Sc}\left(\mathrm{T}_{1 / 2}=1.82 \mathrm{~d}, 3.35 \mathrm{MeV} \gamma, .221 \mathrm{MeV} \beta\right)$ and ${ }^{46} \mathrm{Sc}\left(\mathrm{T}_{1 / 2}=33.83 \mathrm{~d}, 2.01 \mathrm{MeV} \gamma, .121 \mathrm{MeV} \beta\right)$. These strong $\gamma$ and $\beta$ emitters make the DHGR of the titanium alloy larger than the DHGR of HT9 in the period from 2 hours to $\sim 1$ month after shutdown. The DHGR of the titanium alloy even exceeds that of the 316SS alloy from 2 hours to about 1 week after shutdown.

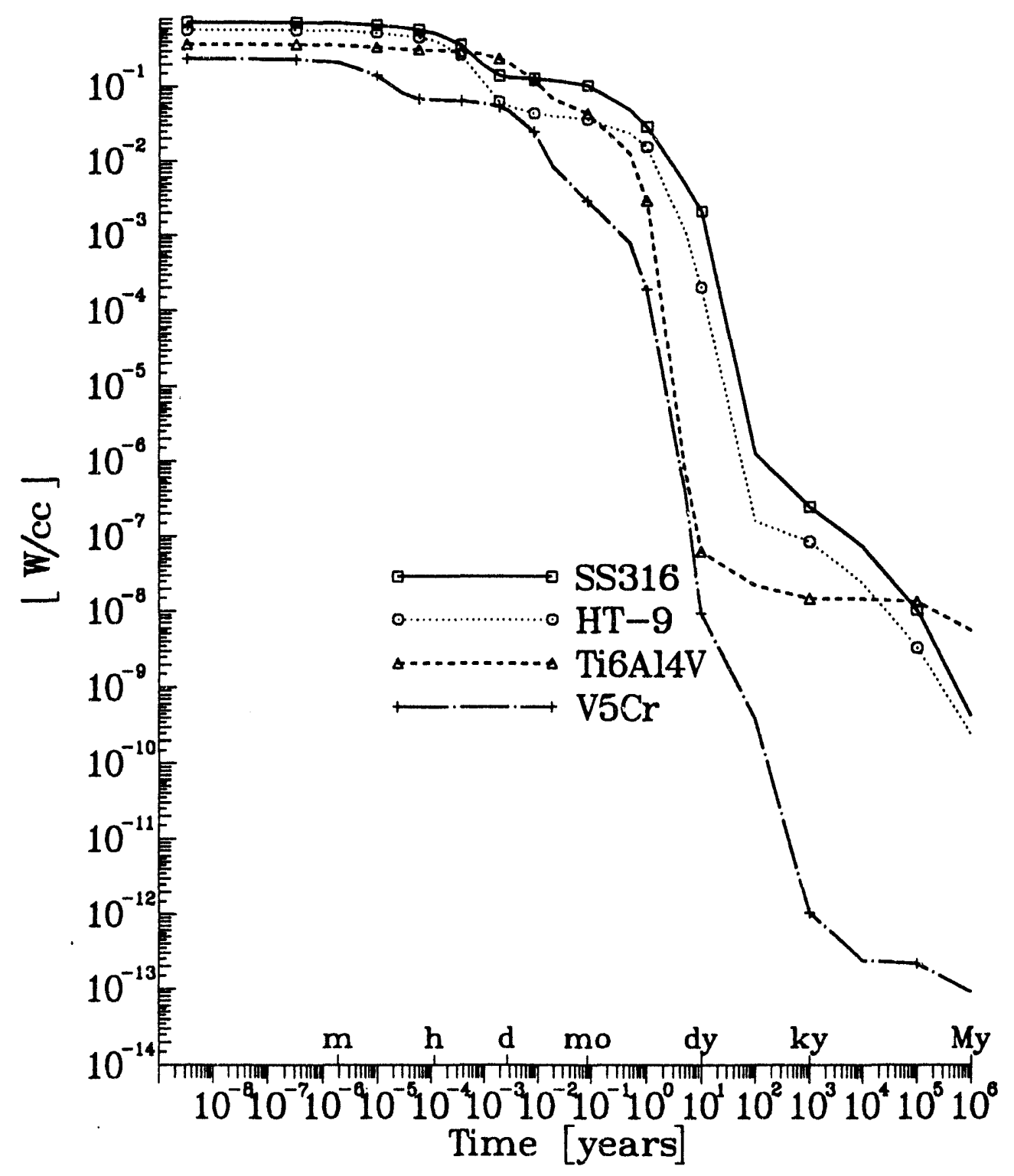

Fig. 5. The decay heat generation rates in the first wall for the four alloys.

\section{REFERENCES}

1. J. Jung, "Theory and Use of the Radioactivity Code RACC," ANL/FPP/TM-122, Argonne National Laboratory (1979). 


\subsection{MATERIALS ENGINEERING AND DESIGN REQUIREMENTS}

No contributions. 
MECHANICAL PROPERTIES ALONG INTERFACES OF BONDED STRUCTURES IN FUSION REACTORS - M. H. Hassan and G. L. Kulcinski (University of Wisconsin)

\section{OBJECTIVE}

The objective of this work is to be able to characterize unirradiated bonded structures used in fusion reactors based on differences in mechanical properties along interfaces due to fabrication techniques.

\section{SUMMARY}

Proper assessment of the mechanical properties along interfaces of bonded structures currently used in many fusion reactor designs is essential to compare the different fabrication techniques. A Mechanical Properties Microprobe (MPM) was used to measure hardness and Young's modulus along the interfaces of $\mathrm{Be} / \mathrm{Cu}$ bonded structure. The MPM was able to distinguish different fabrication techniques by a direct measurement of the hardness, Young's modulus, and $H / E^{2}$ which reflects the ability of deformation of the interfacial region.

Introduction

Current proposals for high heat flux fusion components (such as divertor plates) include duplex thin walled structures. The structure may be subjected to high temperatures, high temperature gradients, thermal and irradiation creep, swelling, sputtering, and thermal expansion. A major point of concern for these bonded structures is the initial adhesion along the interfaces and the relevant mechanical properties. These properties, if properly assessed before irradiation, can help in screening the different fabrication techniques. This will ultimately reduce the time needed for irradiation testing by only considering joints that are compatible with the needed specifications.

For fusion material characterization programs, a Miniaturized Specimen Technology had to be developed to account for smaller irradiation volumes, lower post-irradiation testing doses to personnel, etc. A wide variety of tests have been developed for determining strength, ductility, and fracture-related data. ${ }^{1}$ Measurement of mechanical properties of interfacial zones is very complicated and usually requires the support of mathematical micromechanical models. ${ }^{2}$ Adhesion tests based on fracture mechanics principles are the most likely source of quantitative data. However, currently available adhesion tests are of restricted application and are too complex for most purposes. ${ }^{3}$

Despite the difficulty of predicting the serviceability of a coating from its microhardness value, it is probably the mechanical property most often measured. ${ }^{4}$ Conventional microhardness has several characteristics that make it attractive for mechanical property characterization in small specimens. ${ }^{5}$ Primarily, the volume of material "sampled" during the test is small. Also, conventional microhardness data have been shown to be related to mechanical properties of the test material, such as ultimate tensile strength, largely by empirical means. It should be noted that conventional microhardness testers require direct imaging of the indentations to obtain hardness and large errors are introduced due to measurement of the diagonal lengths, especially when the indentations are small. ${ }^{6}$

Elastic properties along interfaces are very important for several reasons. First: modelling of bonded structure behavior is very complicated since some of the critical input parameters such as bond strength and interface compliance are not well known and the lab testing of these properties is believed to be even more critical than it would be for a simple structure. ${ }^{7}$ Second: fabrication techniques, like brazing or plasma spray, do not produce sharp interfaces, and a certain degree of elemental mixing along the 
interfaces takes place. Elastic properties are known to depend on the composition, especially along interfaces where elemental mixing may be promoted. ${ }^{8}$ There are two extreme cases to consider for bonded structures. At the one extreme, a stress is applied transverse to the interface and the other, the load is applied parallel to the interface. It is important to remember that many bonded structures will deform by a combination of the two cases.

Radiation damage in bonded structures is expected to induce certain changes in elastic properties. Swelling can reduce the elastic properties by up to $2 \%$ for every $1 \%$ swelling in AISI 316 Stainless Steel. ${ }^{9}$ Designers usually do not allow swelling to exceed $5-10 \%$. Based on this figure, we may expect a maximum of $10-20 \%$ reduction in Young's modulus by the end of the component lifetime. Detecting changes in Young's modulus from small material volumes along interfaces thus becomes a necessity to forecast the irradiation behavior of certain structures, especially interfaces of bonded structures. Collisional mixing due to neutron irradiation may also cause elemental mixing along interfaces of bonded structures. These changes need to be quantified and measured.

\section{The Nanoindenter}

An automated system with the ability to evaluate the mechanical response of a sample with submicron spatial resolution has an extremely wide range of applications. A testing system must have certain characteristics to be considered a Mechanical Properties Microprobe (MPM). ${ }^{10}$ It can measure the required properties from volumes of material at least as small as one micron in diameter. Ideally, the system could determine a constitutive equation for that volume of material; hence, it must measure both the elastic and plastic mechanical properties. To do this reproducibly, the system must control or measure all the parameters affecting such properties. These parameters include the strain, strain rate, temperature, stress, and the environment. Finally, the system must take these measurements with reasonable precision and with reasonable investment of time and effort.

At the present time, only one type of mechanical test can potentially satisfy all of the above requirements. ${ }^{10}$ Properly instrumented and controlled, a (depth sensing) microindentation test can accomplish many of these goals. During an indentation test, both elastic and plastic strains are generated. For many materials the strains from both fields are of sufficient magnitude to be measured. The test can be scaled down so that submicron volumes of materials are sampled. Microindentation tests have been used to measure an extremely wide variety of material properties: yield strength, creep resistance, stress relaxation, modulus, fracture toughness, and even fatigue tests. In addition, because the material being tested is close to a surface, environmental effects can be measured. With the proper combination of microindentation tests, a nearly complete constitutive equation of the sample's mechanical response can be mapped.

A schematic of a commersially available ultralow force indentation system, the Nanoindenter, is shown in Figure 1.6 A typical loading curve is shown in Figure 2. The depth plotted represents the total displacement of the indenter relative to the initial position of the surface. The displacement has components of both elastic and plastic deformation. ${ }^{.1}$

\section{Cross sectional measurement of mechanical properties along interfaces}

There is a great need for the determination of hardness and elastic profiles along the interface of bonded structures as well as to probe certain microstructures like the intermetallic compounds formed in some of the brazing joints. If the specimens are prepared in cross section, the Nanohardness unit, with its high accuracy in the placement of indents, can be used to probe the mechanical properties along interfaces. Regardless of the fact that the measurement of hardness on cross sectioned samples was suggested early in the literature, ${ }^{12}$ there has only been a substantial activity in this arca in the last few years as the use of coatings as well as composite materials has increased. ${ }^{13-16}$ 


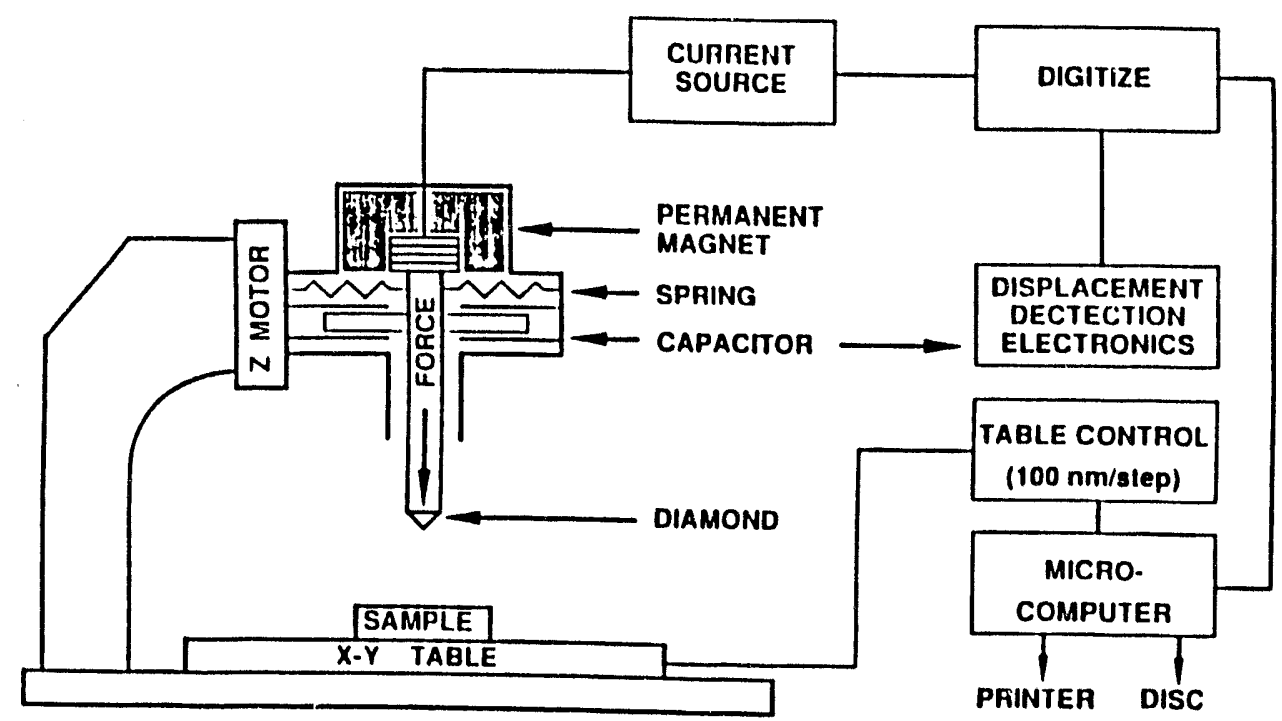

Fig. 1. Schematic diagram of the Nanoindenter.

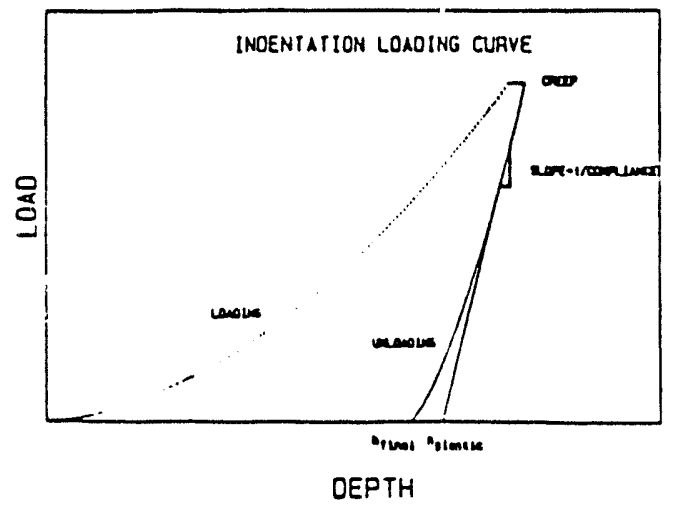

Fig. 2. Typical load-displacement curve obtained using the Nanoindenter showing the difference between the plastic and final depth. ${ }^{6}$

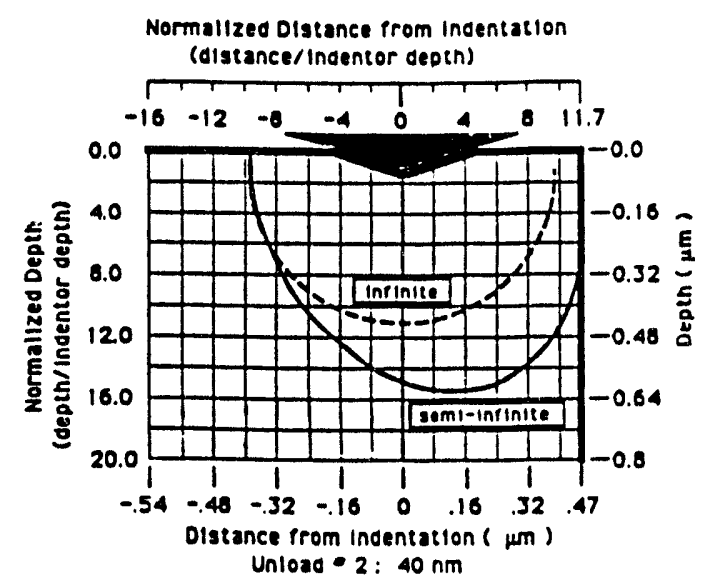

Fig. 3. Elastic plastic boundaries for indentations on infinite and semi-infinite media. ${ }^{15}$

A major point of concern for cross sectional measurements of mechanical properties, especially along interfaces, is how close successive indents can be to each other and how close an indent comes to a material discontinuity such as an edge or an interface without interference. Standard specifications for macroindentations require that the center spacing of pyramidal indentations be at least three indentation diagonals (3D). ${ }^{17}$ The origin of this value seems to be lost in the early history of the development of hardness testing, and there appears to be no modern published reports of experimental investigation to support the value of $3 .{ }^{17}$

Samuels and Mulhearn ${ }^{18}$ experimentally quantified these limits using Vickers-pyramid and Brinell-ball indentations for 70:30 brass. Since the iso-strain contours below the indenter are independent of indenter geometry away from the plastic imprint, their results apply also to the Berkovich pyramid of the Nanoindenter. ${ }^{15}$ Figure 3 shows the elastic-plastic boundaries for an infinite and semi-infinite 
material. The indenter geometry is that of the Berkovich pyramid which has an imprint diagonal to depth ratio of 6.5. From the figure it is apparent that for the infinite medium the elastic plastic-boundary is spherical for infinite material.

The knowledge that is available on the plastic zone associated with the indentations permits an assessment to be made of what should be an acceptable spacing. As a starting point, it might be said that the elastic-plastic boundaries of adjoining indentations should not overlap. ${ }^{17}$ This criterion would permit a center spacing of about $3 \mathrm{D}$ for metals of moderately low yield stress, and $1 \mathrm{D}$ for metals of moderately high yield stress. But these would be conservative values because hardness is not sensitive to small plastic strains even in materials which work-harden considerably. A more realistic criterion perhaps would be that the iso-strain boundaries for something approaching Tabor's equivalent strain should not overlap. To be on the safe side, one might require that the $5 \%$ iso-strain boundaries should not overlap. By this criterion, the indentations could nearly touch one another without error, except perhaps in the very softest of materials. As a guide, it can be assumed that a serious error has not been introduced if the shape of the preexisting indentation has not been distorted noticeably by the new indentation. This criterion is particularly likely to be acceptable with microindentations in which there is so many other experimental uncertainties. ${ }^{17}$

The iso-strain contours are deformed significantly for indents close to the edge of a sample. From Figure $3^{15}$ it is seen that the elastic-plastic boundary for a semi-infinite sample is skewed such that the boundary contacts the edge of the sample at a distance/indenter depth ratio of 11.7. The minimum approach distance to an edge should therefore be 11.7 times the depth of the indent. While this would lead to the conclusion that the shallowest indents are the best, considerations of surface roughness must also be addressed. A tradeoff must be made between decreased volume averaging below the indenter and the inaccuracy due to surface imperfections. ${ }^{19}$ Once more, Samuels suggested that the standards are certainly excessively conservative for microindentation testing. ${ }^{17}$

Another point of concern for the cross-sectional measurement of mechanical properties of bonded structures is the anisotropy of these properties. ${ }^{20}$ For example, there is a typically crystallographic variation in Young's modulus. The reported values of elastic properties are usually average values taken from polycrystalline materials with a random orientations of the individual grains. ${ }^{10}$ The question that is usually addressed is whether to average over the elastic constants (Voight averages) or over the elastic compliances (Reuss a verages). The former is appropriate for a polycrystal in which the grains have the

same state of strain; the latter for the case when they have the same stress. ${ }^{21}$ If one is interested in probing the anisotropy along interfaces for bonded structures in fusion reactors, where the structures at the interfaces are subject to the same strain, the use of the Voight average is more suitable.

\section{Mechanical properties along the interfaces of $\mathrm{Be} / \mathrm{Cu}$ structures}

The Mechanical Properties Microprobe (MPM) at the University of Wisconsin was used in measuring the mechanical properties along interfaces of $\mathrm{Be} / \mathrm{Cu}$ structures fabricated at Sandia National Laboratory. Samples of two fabrication techniques were studied:

1. Beryllium hipped (Hot Isostatic Pressed) to Oxygen Free High Conductivity (OFHC) copper.

2. Beryllium brazed to OFHC using a silver based brazing alloy.

The samples were polished using $1 \mu \mathrm{m}$ diamond paste. Hardness and Young's modulus were then measured using the Nanoindenter.

$\mathrm{Be} / \mathrm{Cu}$ Brazed structure. Thirty two indentations were first made in two runs in $\mathrm{Be}$ and $\mathrm{Cu}$ bulks away from the interface to compare the bulk and interface values. Fifty indentations were then made starting from the Be side into the interfacial zone in two runs (20 and 30 indentations respectively). The large number of indentations is needed to assess the variation along the interface and also to increase the 


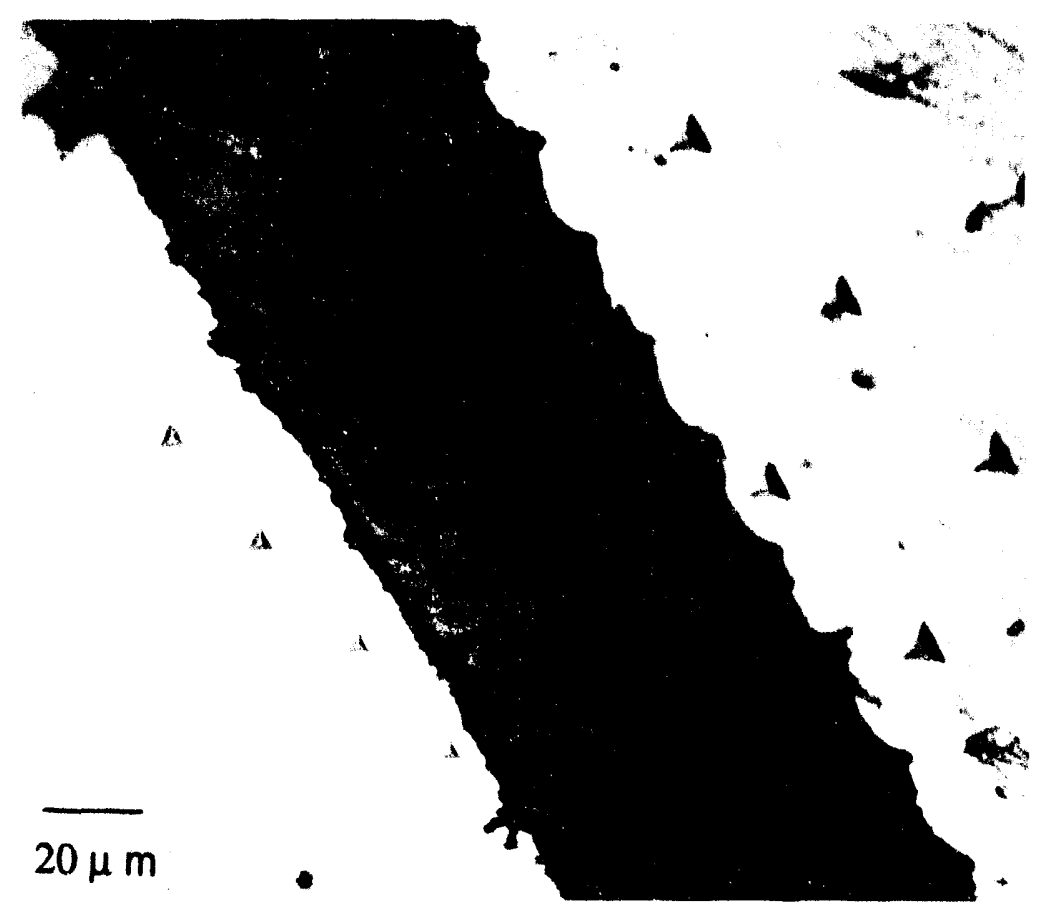

Fig. 4. Indentation run along the interfacial zone of a $\mathrm{Be} / \mathrm{Cu}$ brazed joint.

statistical certainty in the results. The high load range $(0-120 \mathrm{mN})$ was used to obtain indentation depths of 500,750 , and $1000 \mathrm{~nm}$. The minimum spacings between indents were $53,34 \mu \mathrm{m}$ for the two runs respectively ( $>30$ times depth). The distance to the interface was approached at nearly 10 and $7 \mu \mathrm{m}$ per indentation for the two runs respectively. As shown in Figure 4, indentations were made at an angle to the interface so that a proper assessment of the properties along the interface could be made (notice that indentation size reflects the different hardness values). Forty indentations were then made starting from the interfacial zone into the $\mathrm{Cu}$ side in two runs (20 each) at indentation depths 500,1000 , and $1500 \mathrm{~nm}$. Minimum spacing of indentations in this case was $51 \mu \mathrm{m}$. The interface was approached at nearly 12 and $10 \mu \mathrm{m}$ per indentation for the two runs respectively. Table 1 represents the indentation segments for both the Be-Interfacial zone and Interfacial zone-Cu regions.

Be/Cu hipped structure. The same techniques were used for the other type of structure (the brazed type). Indentations were first made in the $\mathrm{Be}$ and $\mathrm{Cu}$ bulk regions away from the interface to compare the bulk and interface values. In this case, a separate run had to be done for the interface since its thickness varies from 400 to $450 \mu \mathrm{m}$.

\section{Results}

Figures 5, 6, and 7 show the variation of hardness (H), Young's modulus $(E)$, as well as the load over the compliance squared (i.e. $\mathrm{H}_{/} \mathrm{E}^{2}$ ) for indentation depth $1000 \mathrm{~nm}$ for the brazed structure. Several points can be observed:

1. The jump in the mechanical properties between the Be side and the interfacial zone is quite obvious compared with the smooth transition along the interface between the copper and the interfacial zone. 
Table 1. Indentation Test Configuration Used for $\mathrm{Be}, \mathrm{Cu} B u l k s$ and the Interfacial Zone.

\begin{tabular}{c|l|ccc}
\hline $\begin{array}{l}\text { Segment } \\
\text { Number }\end{array}$ & $\begin{array}{l}\text { Segment } \\
\text { Type }\end{array}$ & $\begin{array}{c}\text { Rate } \\
\text { (nm/se })\end{array}$ & $\begin{array}{c}\text { Depth Limit } \\
\text { (Loading Segment) } \\
\text { (nm) }\end{array}$ & $\begin{array}{c}\text { Unloading } \\
\text { (Unloading Segment) } \\
\text { (\% of final load) }\end{array}$ \\
\hline 1 & Approach & 10 & $\ldots$ & $\ldots$ \\
2 & Loading & 5 & 500 & $\ldots$ \\
3 & Hold & 25 data points; 1 sec delay between logging points & \\
4 & Unloading & $50 \%$ & $\ldots$ & 80 \\
5 & Loading & 5 & $750(1000)^{* *}$ & $\ldots$ \\
6 & Hold & 25 data points; 1 sec delay between logging points & \\
7 & Unloading & $50 \%$ & $\ldots$ & 80 \\
8 & Loading & 5 & $1000(1500)^{* *}$ & $\ldots$ \\
9 & Hold & 25 data points; 1 sec delay between logging points & \\
10 & Unloading & $50 \%$ & $\ldots$ & 80 \\
11 & Hold & $100^{*}$ data points; 1 sec delay between logging points & \\
12 & Unloading & 300 & $\ldots$ & 100 \\
\hline
\end{tabular}

*For copper, a $25 \mathrm{~min}$. Hold period was performed to avoid creep effects.

**Values between parentheses represent depth limits for $\mathrm{Cu}$ bulk and $\mathrm{Cu}$-Interfacial zone interface.

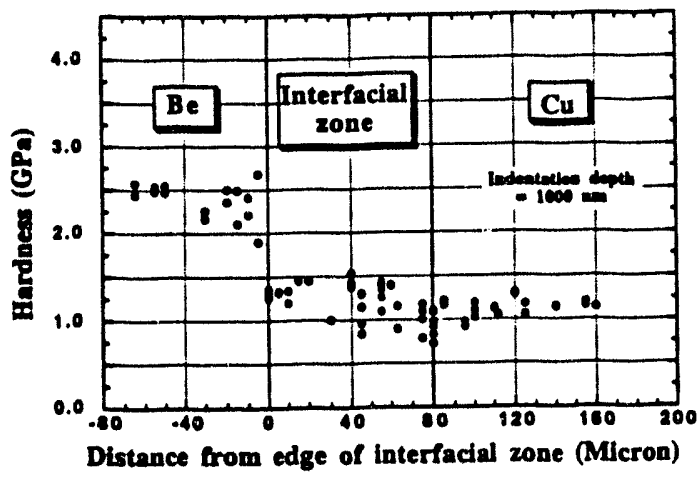

Fig. 5. Variation of hardness along interface of a Be/Cu brazed joint.

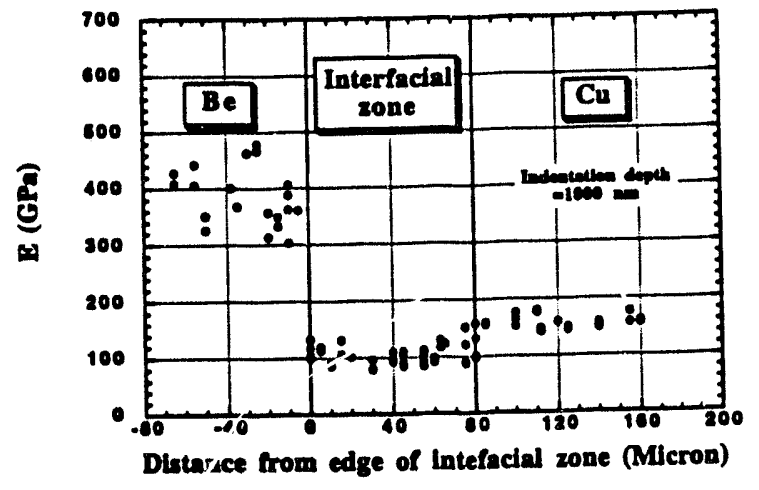

Fig. 6. Variation of $\mathrm{E}$ along interface of a Be/Cu brazed joint.

2. The lowest hardness value occurred at the edge of the interfacial zone with the copper side. As for the Young's modulus, the lowest value occurred in the interfacial zone which further widened the difference in Young's modulus values between the copper and the beryllium parts.

3. The largest values of hardness and Young's modulus occurred in the beryllium bulk.

4. Values of $\mathrm{H} / \mathrm{E}^{2}$ are considered to be a good representation of the resistance for plastic deformation as mentioned by Oliver. ${ }^{22}$ Thus, the high values of $\mathrm{H} / \mathrm{E}^{2}$ in the interfacial zone, compared with the beryllium and copper bulk region, is a good indication of its ability to resist plastic deformation.

As for the hipped structure, several interesting points were observed. First, as shown in Figures 8 and 9, there are some microstructural islands in the interface between the filler metal and the $\mathrm{Be}$ side. These extend for about $100 \mu \mathrm{m}$ as shown from the metallographic picture in Figure 10. The Nanoindenter successfully detected these changes in the microstructure that was reflected in discontinuities in the mechanical properties. 


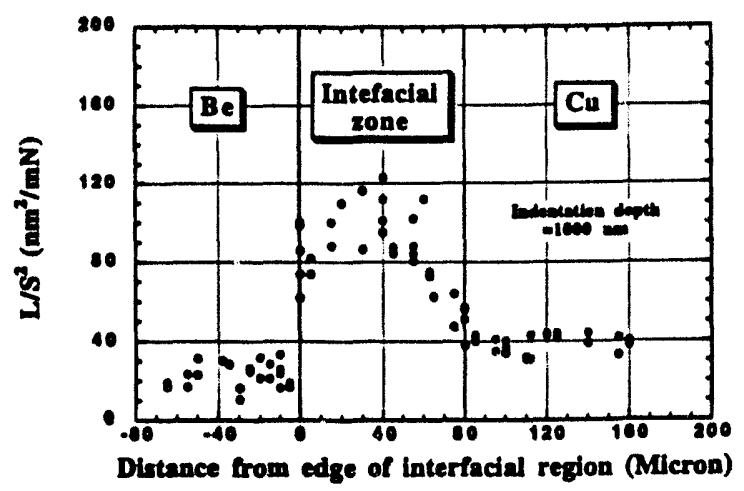

Fig. 7. Variation of $\mathrm{L} / \mathrm{S}^{2}$ along interface of a Be/Cu brazed joint.

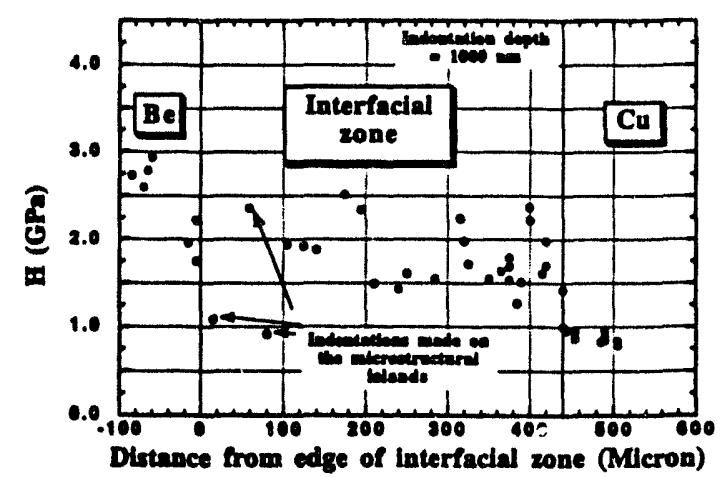

Fig. 8. Variation of hardness along interface of a Be/Cu hipped joint.

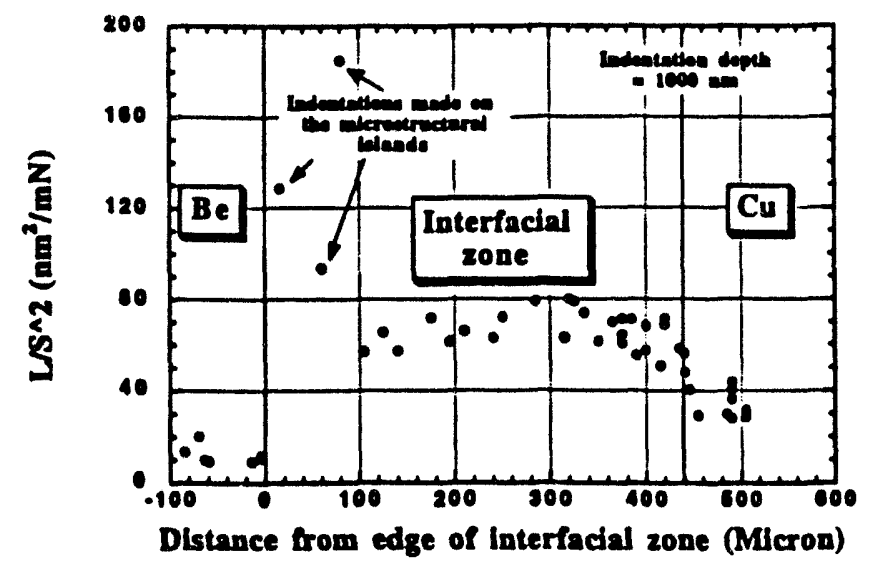

Fig. 9. Variation of $\mathrm{L} / \mathrm{S}^{2}$ along interface of a Be/Cu hipped joint.

The following points can be observed in the hipped structure:

1. The discontinuity in the mechanical properties along the edge of the interfacial zone with beryllium still exists. It is even much more dramatic than in the hipped joint due to the existence of the microstructural islands.

2. The smooth transition along the edge of the interfacial zone with the copper still exists. However, a mismatch in hardness values can still be observed.

3. Away from the microstructural islands, Young's modulus values are slightly higher in the interfacial region for the brazed joint compared with the hipped joint. This bridges the large gap between the Young's modulus values of the $\mathrm{Be}$ and the $\mathrm{Cu}$. The same trend is also observed for the hardness values. Also, the $\mathrm{H} / \mathrm{E}^{2}$ values of the interfacial zone in the brazed joint are lower than the hipper joint.

The microstructural islands are believed to be intermetallic formations due to interdiffusion between beryllium and copper. It is well known that in case of beryllium joining, as atoms in the base metal migrate by diffusion into the other metal and vice versa, changes in the properties of the boundary layer between the two metals may occur. This can sometimes affect the joint strength by formation of britule intermediate phases. In other cases, on the contrary, one can obtain, deliberately or not, higher qualities of the joint. ${ }^{23}$ In this case, the strength of the joint no longer depends on the bond strength between the two metals. Instead it depends on the bond strength between either of these and the newly formed intermediate layer..$^{23}$ 


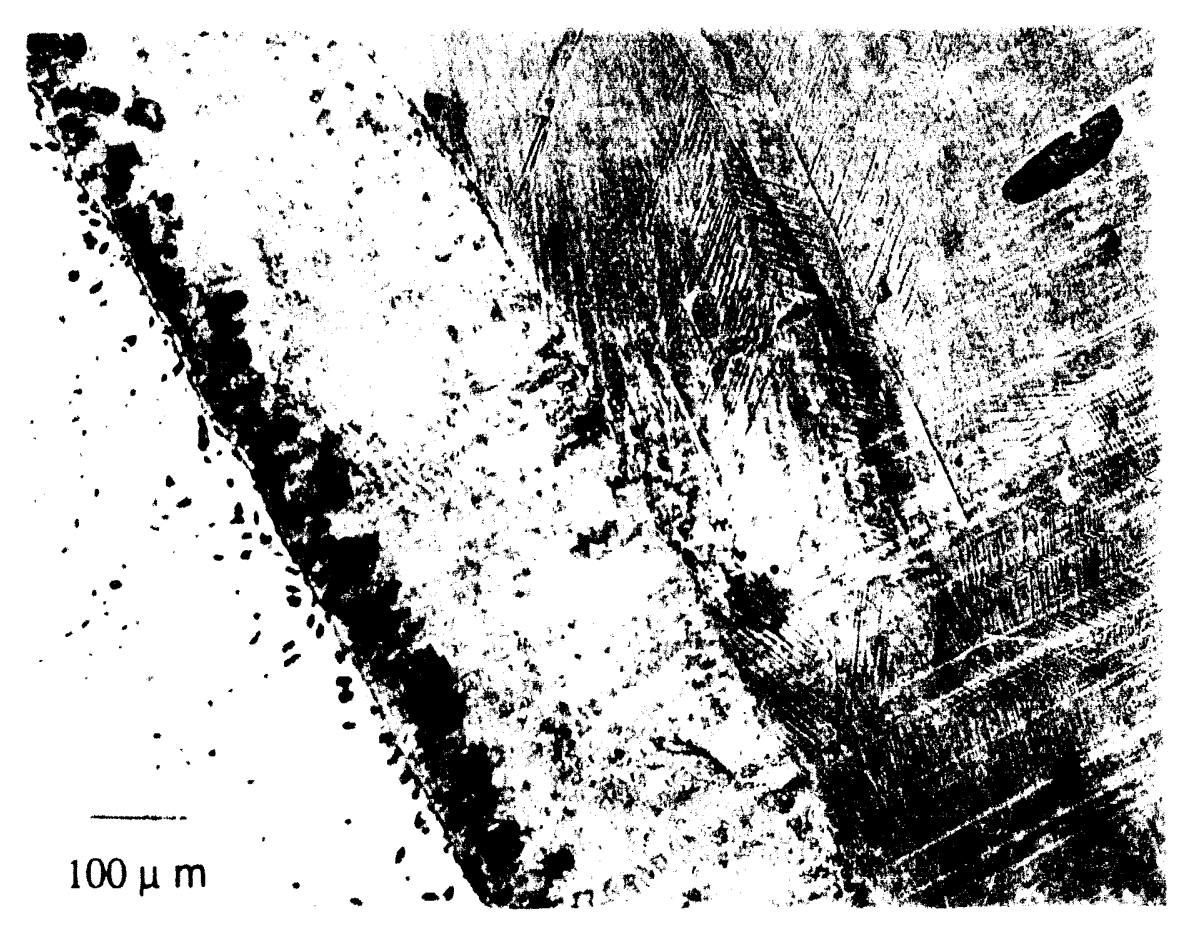

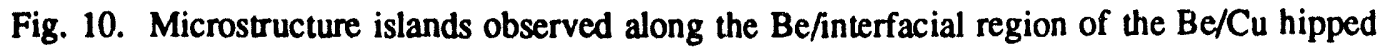
joint.

Based on the above observations, it can be stated that the unirradiated brazed joint is more suitable than the unirradiated hipped joint due to (1) more uniform mechanical properties, (2) smoother transition of mechanical properties along the edge of the interfacial zone with the copper part, (3) less mismatch in mechanical properties between the interfacial zone and the beryllium bulk, and (4) high deformation ability of the interfacial zone (as shown in Figure 11).

\section{FUTURE WORK} islands.

TEM samples from the hipped joint will be tested to verify the nature of the microstructural

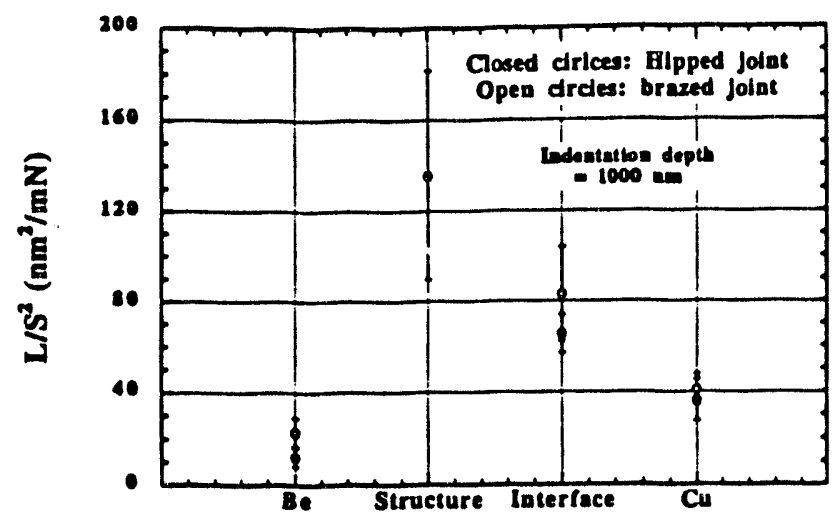

Fig. 11. Comparison of the ability of deformation for $\mathrm{Be} / \mathrm{Cu}$ hipped and brazed joints. 


\section{ACKNOWLEDGEMENT}

Financial support for this work has been provided by the University of Wisconsin and the U.S. Department of Energy.

\section{REFERENCES}

1. G.E. Lucas and G.R. Odette, Nucl. Eng and Design/Fusion 2 (1985) 145.

2. A. Denuyttere and L. Froyen (eds.) in Proc. on Interfaces in Materials, Brussels (1988).

3. S. S. Chiang, et al., in Materials Science Research, Surfaces and Interfaces in Ceramic and Ceramic-Metal Systems (J. Pask and A. Evans, eds.) 14 (1980) 603.

4. G. A. Di Bari, in ASTM 947, Testing of Metallic and Inorganic Coatings (W. B. Harding and G. A. Di Bari, eds.) (1986) 4.

5. G. E. Lucas, et al., ASTM 888 (1986) 112.

6. M. F. Doerner and W. D. Nix, L. Mater. Res 4 (1986) 601.

7. J. B. Whiltley, L Nucl. Mat. 85 (1979) 40.

8. C. R. Barrett, ct al., The Principles of Enginnering Materials, Prentice-Hall, Inc. (1973).

9. M. O. Marlowe and W. K. Appleby, Trans. Am. Nucl. Soc 16 (1973) 95.

10. W. C. Oliver, MRS Bulletin, XI, (1986) 15.

11. W. D. Nix, Met. Trans, 20A (1989) 2217.

12. K. L. Mittal, in ASTM 640, Adhesion Measurement of Thin Films, Thick Films, and Bulk Coatings (K. L. Mittal, ed.) (1976) 5.

13. R. P. Martukanitz, et al., in Proc. of the International Metallographic Society on Structural Science 14 (1987) 53.

14. A. David, et al., Welding Res. Suppl, 236s (1987).

15. L. L. Snead, DOE/ER-0313/10 (1991) 320.

16. L. L. Snead and S. J. Zinkle, DOE/ER-0313/11 (1991) 316.

17. L. E. Samuels, in Microindentation Techniques in Materials Science and Engineering, eds. Blau/Lawn, ASTM STP 889 (1984) 5.

18. L. E. Samuels and T. O. Mulhearn, Lof Mechanics and Physics of Solids 5 (1957) 125.

19. L. Snead, unpublished work (1992).

20. R. A. Dodd, private communications (1988).

21. J. P. Hirth and J. Lothe, Theory of Dislocations, McGraw-Hill, New York (1968).

22. D. L. Joslin and W. C. Oliver, L. Mater. Res. 5 (1990) 123.

23. M. M. Schwartz (Ed.), Source Book on Brazing and Brazing Technology, American Society for Metals, Metals Park (1987). 
GREEN'S FUNCTION METHODOLOGY FOR FRACTURE MECHANICS OF SiCSiC COMPOSITE STRUCTURES ${ }^{1}$ A.El-Azab and N.M. Ghoniem, University of California, Los Angeles

\section{OBJECTIVE}

The purpose of this work is to develop new methods for the analysis of fracture processes in SiC$\mathrm{SiC}$ composite structures under fusion conditions. Presently, no satisfactory method is available for determination of crack growth characteristics in real structures, where crack-crack interaction is important.

\section{SUMMARY}

A fundamental solution of plane elasticity in a finite domain is developed in this paper. A closedform Green's function for the elastic field of an edge dislocation of arbitrary Burger's vector at an arbitrary point in an orthotropic finite elastic domain, that is free of traction, is presented. The method is based on the classical theory of potential fields, with an additional distribution of surface dislocations to satisfy the free traction boundary condition. A solution is first developed for a dislocation in a semi-infinite half-plane. The resulting field is composed of two parts: a singular contribution from the original dislocation, and a regular component associated with the surface distribution. The Schwarz-Christoffel transformation is then utilized to map the field quantities to a finite, polygonal domain. A closed form solution containing Jacobi elliptic functions is developed for rectangular domains, and applications of the method to problems of fracture and plasticity are emphasized.

\section{PROGRESS AND STATUS}

\section{Introduction}

The concept of a dislocation was first introduced by Weingarten [1], Timpe [2] and Volterra [3] as a mathematical device to deal with the possibility of solutions which satisfy the governing equations of the theory of elasticity, but possess the property of a multi-valued displacement field. For many years after its introduction, the mathematical device was termed a volterra dislocation [4]. On the other hand, the existence of crystal dislocations was found to be necessary for explaining the fact that most ductile materials yield and fail at stress levels that are at least three orders of magnitude smaller than the theoretical values predicted by atomic potential considerations alone [5-8]. The advent of analytical techniques in materials science proved, beyond doubt, the important role which crystal dislocations play in deformation, micromechanics of fracture, and other materials properties. The materials science applications of the theory of dislocations are extensively reviewed by Hirth and Lothe [9] and Nabarro [10]. A detailed work on the use of dislocation theory in modeling materials phenomena such as twining, grain boundaries [11,12], interfacial energy and surface tension $[13,14]$ was conducted by Marcinkowski and Jagannadham. More recently, Amodeo and Ghoniem $[15,16]$ developed a dynamical method for the study of the micromechanics of plasticity in ductile materials. They termed their method Dislocation Dynamics, in which they solved for the simultaneous equations of motion of distributions of dislocations under a variety of applied stress conditions. In their work, however, they used elasticity solutions for dislocations in an infinite isotropic medium.

\footnotetext{
${ }^{1}$ This material is based upon work supported by the U.S. Department of Energy under award number DE-FG0391-ER54114 at UCLA
} 
Applications of dislocation theory to fracture mechanics, deals with dislocations in a continuum. The continuum theory of dislocations is reviewed by Hirth and Lothe [9], Nabarro [10], Mura [17, 18], and Lardner [19]. In fracture applications closed form solutions can be obtained by modeling cracks by continuous ( or discrete) distributions of dislocations. However, the proper dislocation elastic fields (Green's function) in the crack domain must be available. Examples on application of dislocation theory to fracture mechanics are reported by A. N. Stroh [20], J. Qu and Q. Li [21], J. R. Willis [22], Delale and Erdogan [23], Lardner [24], Atkinson [25], and Vitek [26]. A review of dislocation models in fracture is given by Lardner [19], Vitek and Chell [27], Jagannadham and Marcinkowski [28] and Bilby and Eshelby [29], where dislocation Green's functions developed for infinite domains were used. In Ref. [28] extensive use of dislocation theory in modeling elastic and elastic-plastic fracture problems has been made.

In some cases dislocation fields are obtained for finite (circular, infinite strip of finite width) domains using the image dislocation method $[9,10]$. Marcinkowski et al [30] argued that the image dislocation method is inadequate to obtain dislocational fields in finite domains since the resulting elastic fields do not vanish outside the domain of solution. They also introduced the method of surface dislocations to obtain dislocation fields in semi-infinite domains. The idea of the surface dislocation technique is based on the use of a correcting field, which yields the field in a finite domain if added to the infinite domain solution, with the boundary conditions satisfied. Marcinkowski et al $[30,31]$ used distributions of dislocations along a semi-infinite domain boundary to generate the additional correcting field. They developed analytical expressions for edge dislocations in isotropic half-planes. Their method proved to be exact and realistic in the sense that the dislocation fields identically vanish outside and on the domain boundaries. For rectangular domains, they used numerical methods to obtain the solution [32]. These approaches are based upon the classical theory of potential fields, and rely on solving an integral equation for the surface dislocation distribution. Other authors obtained the dislocational fields in half-space using the analytic continuation technique $[33,34]$. In this method, additional correcting fields are determined so as to satisfy the free traction boundary condition on the domain boundary. However, Miller [33] and J. C. Lee [34] used two different methods to find the correcting fields, which yielded different expressions.

In applying dislocation theory to fracture mechanics or other materials science phenomena, the importance of development of an accurate solution to the governing equations of elasticity for a dislocation cannot be underestimated. It is from this prespective that we develop our present dislocation Green's function in a finite orthotropic domain. The problem formulation makes use of the classical theory of potential fields, with the surface dislocation technique to obtain the solution in a half-piane. The Schwarz-Christoffel transformation [35-37] is then utilized to obtain the solution in a finite (rectangular) domain. As will be shown here, only the elastic field of a dislocation in an infinite domain is a necessary ingredient in our present formulation.

\section{Green's function for a dislocation in an infinite domain}

For elastic anisotropic continua with material constants $s_{m n}(m, n=1,2,6)$ Hooke's law is written as :

$$
\begin{aligned}
\epsilon_{x} & =s_{11} \sigma_{x}+s_{12} \sigma_{y}+s_{16} \sigma_{x y}, \\
\epsilon_{y} & =s_{12} \sigma_{x}+s_{22} \sigma_{y}+s_{26} \sigma_{x y}, \\
2 \epsilon_{x y} & =s_{16} \sigma_{x}+s_{26} \sigma_{y}+s_{66} \sigma_{x y}
\end{aligned}
$$

The stresses and complex displacement, $\mathcal{U}$, are written in terms of the complex potentials, $\phi_{1}\left(z_{1}\right)$ and $\phi_{2}\left(z_{2}\right)$ as follows $[33,34]$ :

$$
\sigma_{x}=2 R e\left[\lambda_{1}^{2} \phi_{1}^{\prime}\left(z_{1}\right)+\lambda_{2}^{2} \phi_{2}^{\prime}\left(z_{2}\right)\right]
$$




$$
\begin{aligned}
\sigma_{y} & =2 \operatorname{Re}\left[\phi_{1}^{\prime}\left(z_{1}\right)+\phi_{2}^{\prime}\left(z_{2}\right)\right] \\
\sigma_{x y} & =-2 \operatorname{Re}\left[\lambda_{1} \phi_{1}^{\prime}\left(z_{1}\right)+\lambda_{2} \phi_{2}^{\prime}\left(z_{2}\right)\right] \\
\mathcal{U} & =p\left(\lambda_{1}\right) \phi_{1}\left(z_{1}\right)+p\left(\lambda_{2}\right) \phi_{2}\left(z_{2}\right)+p\left(\bar{\lambda}_{1}\right) \bar{\phi}_{1}\left(\bar{z}_{1}\right)+p\left(\bar{\lambda}_{2}\right) \bar{\phi}_{2}\left(\bar{z}_{2}\right)
\end{aligned}
$$

in which $R e=$ real of and the overbar represents complex conjugation. The primed variables are derivatives with respect to $z_{1}$ or $z_{2}$. The constants $\lambda_{1}$ and $\lambda_{2}$ and their complex conjugates are the roots of the following characteristic equation [38]:

$$
s_{11} \lambda^{4}-2 s_{16} \lambda^{3}+\left(2 s_{12}+s_{66}\right) \lambda^{2}-2 s_{26} \lambda+s_{22}=0
$$

and $z_{1}$ and $z_{2}$ are complex variables defined as:

$$
\begin{aligned}
& z_{1}=x+\lambda_{1} y=\left(\gamma_{1} z+\delta_{1} \bar{z}\right) / 2, \\
& z_{2}=x+\lambda_{2} y=\left(\gamma_{2} z+\delta_{2} \bar{z}\right) / 2
\end{aligned}
$$

where $z=x+i y, \gamma_{j}=1-i \lambda_{j}$ and $\delta_{j}=1+i \lambda_{j}, j=1,2$. The functions $\phi_{1}\left(z_{1}\right)$ and $\phi_{2}\left(z_{2}\right)$ are the complex potentials of the dislocation and are analytic within the body except at $z_{0}$. The polynomial $p(\lambda)$ is given by $[38]$ :

$$
p(\lambda)=\left(s_{12}-s_{16} \lambda+s_{11} \lambda^{2}\right)+\frac{i}{\lambda}\left(s_{22}-s_{26} \lambda+s_{12} \lambda^{2}\right)
$$

The complex potentials at a point $z$ (or alternatively $z_{1,2}$ ) due to a single dislocation at $z_{0}=$ $x_{0}+i y_{0}$ in an infinite anisotropic plane are given by $[33,34]$ :

$$
\begin{aligned}
& \phi_{1 s}\left(z_{1}\right)=A_{1} \log \left(z_{1}-z_{10}\right) \\
& \phi_{2 s}\left(z_{2}\right)=A_{2} \log \left(z_{2}-z_{2 o}\right)
\end{aligned}
$$

where $z_{10}$ and $z_{20}$ are related to $z_{0}$ by the set of equations (4). The subscript $s$ is added to indicate that the infinite domain potentials are singular at the location of the dislocation $z_{0}$. The complex constants $A_{1,2}$ are determined by the conditions that the deformation due to a single dislocation is not single-valued (dislocational), and the traction integral along any arbitrary contour surrounding the dislocation vanishes (self-equilibrium). The dislocational condition can be expressed as :

$$
b=2 \pi i\left[p\left(\lambda_{1}\right) A_{1}-p\left(\bar{\lambda}_{1}\right) \ddot{A}_{1}+p\left(\lambda_{2}\right) A_{2}-p\left(\bar{\lambda}_{2}\right) \bar{A}_{2}\right]
$$

where $b=|b| e^{i \theta}$ is the Burger's vector of the dislocation. The self-equilibrium condition yields the following eqration :

$$
\delta_{1} A_{1}-\bar{\gamma}_{1} \bar{A}_{1}+\delta_{2} A_{2}-\bar{\gamma}_{2} \bar{A}_{2}=0
$$

By taking the complex conjugate of equations (7) and (8), two additional equations are obtained. The four equations can be solved for $A_{1}, \bar{A}_{1}, A_{2}$, and $\bar{A}_{2}$. El-Azab and Ghoniem [39] obtained a solution for $A_{1}$ and $A_{2}$ for the case of an orthotropic domain, where $s_{16}=s_{26}=0$, which is written as :

$$
\begin{aligned}
& A_{1}=c_{11} \operatorname{Im}(b)+i c_{12} \operatorname{Re}(b) \\
& A_{2}=c_{21} \operatorname{Im}(b)+i c_{22} \operatorname{Re}(b)
\end{aligned}
$$

where $c_{i j}$ are real constants which depend on the material constants $s_{m n} . \operatorname{Re}(b)$ and $\operatorname{Im}(b)$ are the real and imaginary parts of the Burger's vector, respectively. 


\section{Dislocation in a finite domain : General formulation}

Consider an edge dislocation of arbitrary Burger's vector, $b=|b| e^{i \theta}$, which is located at $z_{o}$ in the finite domain $D^{+}$bounded by the contour $L$, as shown in Figure (1). The Green's function in an unbounded medium automatically satisfies the governing field equations. Any linear combination of the infinite domain Green's functions, which also satisfies specified boundary conditions for a finite domain, must be the Green's function in that finite domain. The solution, therefore, will be constructed as a linear combination of the singular, infinite domain solution, and an additional distribution of surface dislocations, such that the boundary is free of forces (i.e., zero surface tractions).

Let $F(t)$ be a distribution function of surface dislocations, which is complex, and written as:

$$
F(t)=f_{1}(t)+i f_{2}(t)
$$

where $t$ is a complex variable describing the domain boundary $L$, and $f_{1}(t)$ and $f_{2}(t)$ are real functions of the complex variable $t$. Physically, $F(t) d s$ is defined as the Burger's vector of the surface dislocation in the interval $d s$, where $s=s(t)$ is the scaler distance along the domain boundary. The traction caused by the original dislocation and the surface distribution, evaluated at any arbitrary point along the boundary, must be equal to any prescribed boundary tractions. For the case of a free surface, this condition is written as :

$$
X_{d}(t)+i Y_{d}(t)+\oint_{L}\left[X_{s}\left(t_{o}, t\right)+i Y_{s}\left(t_{o}, t\right)\right] d s_{o}=0
$$

where $s_{o}=s\left(t_{o}\right)$ and $X_{d}+i Y_{d}$ is the residual complex traction at $t$ on $L$ due to the original dislocation at $z_{o}$ inside $D^{+} . X_{s}\left(t_{o}, t\right)+i Y_{s}\left(t_{o}, t\right)$ is the complex traction at $t$ on $L$ due to a surface dislocation of Burger's vector $F\left(t_{o}\right)$ at $t_{o}$ on $L$. If the surface experiences any localized or distributed forces, $T(t)$, the right hand side of equation (11) is no longer zero, but rather $=T(t)$. Here, we consider only free surfaces. Equations (2), (6) and (9) will be used to determine $X_{d}+i Y_{d}$ at any point $t$ on $L$. The same equations will be used to determine $X_{s}\left(t_{o}, t\right)+i Y_{s}\left(t_{o}, t\right)$ at $t$ on $L$, with one difference, that is; $\operatorname{Re}(b)$ and $\operatorname{Im}(b)$ in equation (9) will be replaced by $f_{1}\left(t_{o}\right)$ and $f_{2}\left(t_{0}\right)$. This means that the complex quantities $A_{1}$ and $A_{2}$ are no longer constants when dealing with surface dislocations. Let these quantities be denoted by $B_{1}$ and $B_{2}$, and be written as :

$$
\begin{aligned}
& B_{1}(t)=c_{11} f_{2}(t)+i c_{12} f_{1}(t), \\
& B_{2}(t)=c_{21} f_{2}(t)+i c_{22} f_{1}(t)
\end{aligned}
$$

Equation(11) can now be rewritten in terms of $f_{1}(t)$ and $f_{2}(t)$, and can be utilized to determine these two functions. Once $f_{1}(t)+i f_{2}(t)$ is determined the total stress field can be determined at any point in the domain $\mathrm{D}^{+}$by adding together the singular field and the additional field due to surface dislocations.

When a rectangular domain is considered, as shown in Figure (2), two mathematical difficulties arise;

1. the residual singular traction, $X_{d}+i Y_{d}$, will have different expressions at $t$ describes different sides of the rectangle, and

2. the contour $L$ is not smooth.

Because of that, a suitable numerical method may be used to solve equations (11) and (12) for the complex function $f_{1}(t)+i f_{2}(t)$. Such an approach was used by Jagannadham and Marcinkowski [32], to predict the stress field for an edge dislocation in an isotropic rectangular domain. Their solution yielded inaccurate results outside and close to the domain boundary, and they were able to satisfy the boundary conditions in an approximate point collocation fashion. The reader is advised to compare the present results with those of Ref [32]. From the mathematical point of view, there 


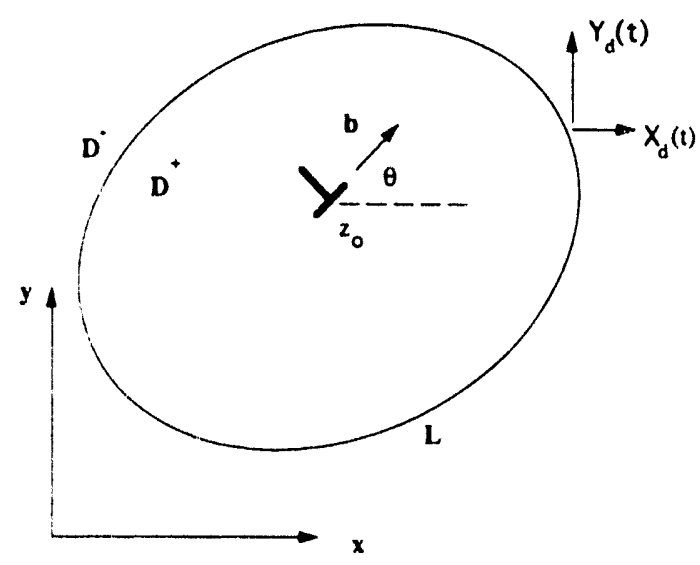

Figure 1: Arbitrary dislocation in a finite domain

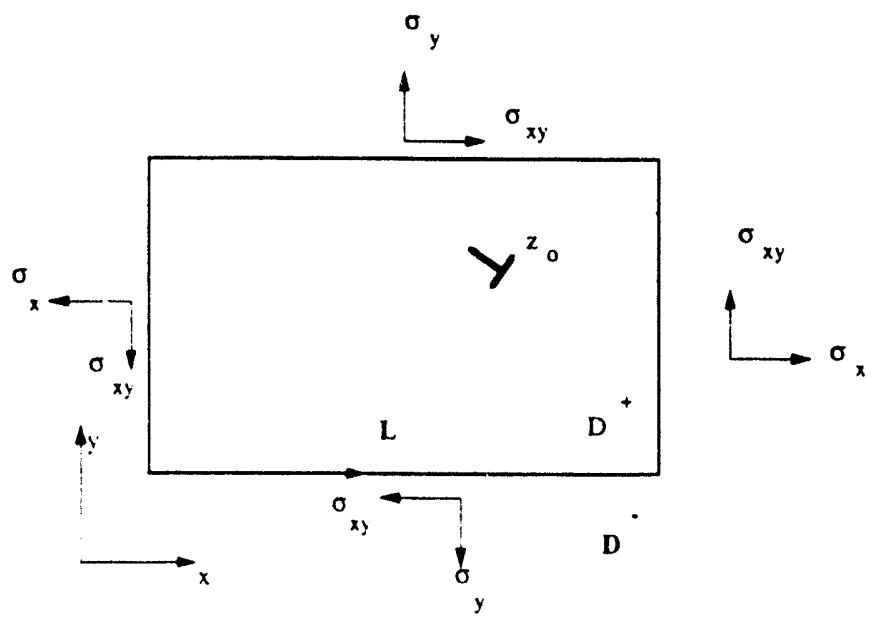

Figure 2: Variation of the residual surface traction for a dislocation in a rectangular domain

is an inherent difficulty associated with the problem of finding the elastic field of a dislocation in a polygonal domain. As can be noticed from the forms of the functions $\phi_{1}\left(z_{1}\right)$ and $\phi_{2}\left(z_{2}\right)$, the field is a cylinderical potential field, which is to be fit onto a geometrically incompatible polygonal boundary. However, the approach taken here is to obtain the solution in a semi-infinite domain and then use the Schwarz-Christoffel transformation to map the solution onto a polygon. This approach is illustrated in the next two sections.

\section{Dislocation solution in an orthotropic semi-infinite domain}

\section{Distribution function of surface dislocations}

Consider a dislocation of an arbitrary Burger's vector $b=|b| e^{i \theta}$ at the point $z_{0}=x_{0}+i y_{0}$, as shown in Figure (3). The domain of solution $D^{+}$is the upper half-plane, $\operatorname{Im}(z) \geq 0$, so that the contour $L$ is taken to be the $x$-axis from $-\infty$ to $+\infty$. In this case the residual singular traction $X_{d}(t)+i Y_{d}(t)$ is given by : 


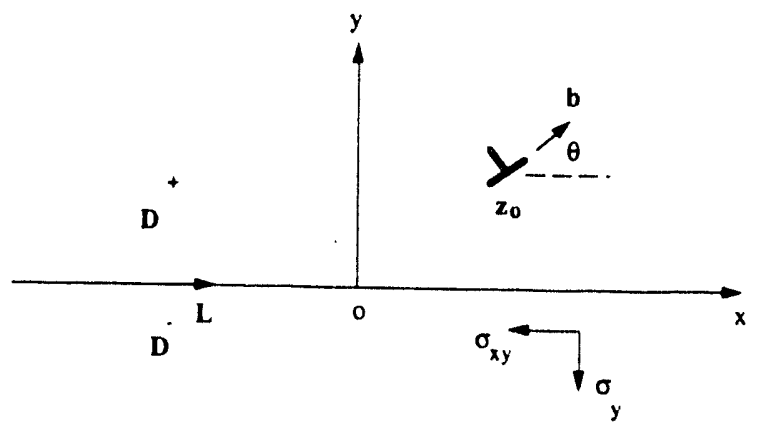

Figure 3: Dislocation in a semi-infinite domain

$$
X_{d}(t)+i Y_{d}(t)=\sigma_{x y}\left(z_{o}, x\right)+i \sigma_{y}\left(z_{o}, x\right)
$$

similarly,

$$
X_{s}\left(t_{o}, t\right)+i Y_{s}\left(t_{o}, t\right)=\sigma_{x y}\left(x_{o}, x\right)+i \sigma_{y}\left(x_{o}, x\right)
$$

so that equation (11) is rewritten as :

$$
\sigma_{x y}\left(z_{o}, x\right)+i \sigma_{y}\left(z_{o}, x\right)+\int_{-\infty}^{+\infty}\left(\left(\sigma_{x y}\left(x_{o}, x\right)+i \sigma_{y}\left(x_{o}, x\right)\right)\right) d x_{o}=0
$$

Using equations (2), for stresses in terms of the complex potentials, expressions for $\sigma_{x y}\left(z_{o}, x\right)$ and $\sigma_{y}\left(z_{o}, x\right)$ are written as :

$$
\begin{aligned}
\sigma_{x y}\left(z_{o}, x\right) & =-2 R e\left[\frac{\lambda_{1} A_{1}}{x-z_{10}}+\frac{\lambda_{2} A_{2}}{x-z_{2 o}}\right], \\
\sigma_{y}\left(z_{o}, x\right) & =2 \operatorname{Re}\left[\frac{A_{1}}{x-z_{10}}+\frac{A_{2}}{x-z_{2 o}}\right]
\end{aligned}
$$

where $A_{1,2}$ are given by equations (9). Similar expressions can be written for $\sigma_{x y}\left(x_{0}, x\right)$ and $\sigma_{y}\left(x_{0}, x\right)$, by replacing $A_{1}$ and $A_{2}$ by $B_{1}$ and $B_{2}$ given by equations (12). The result is stated as follows:

$$
\begin{aligned}
\sigma_{x y}\left(x_{o}, x\right) & =-2 \operatorname{Re}\left[\frac{\lambda_{1} B_{1}\left(x_{0}\right)}{x-x_{0}}+\frac{\lambda_{2} B_{2}\left(x_{0}\right)}{x-x_{0}}\right], \\
\sigma_{y}\left(x_{0}, x\right) & =2 \operatorname{Re}\left[\frac{B_{1}\left(x_{0}\right)}{x-x_{0}}+\frac{B_{2}\left(x_{0}\right)}{x-x_{0}}\right]
\end{aligned}
$$

If equation (12) is used in (17), the following simplified expressions for $\sigma_{x y}\left(x_{0}, x\right)$ and $\sigma_{y}\left(x_{0}, x\right)$ are obtained for the case of orthotropic domains :

$$
\sigma_{x y}\left(x_{o}, x\right)=\frac{2\left(\beta_{1} c_{12}+\beta_{2} c_{22}\right) f_{1}\left(x_{0}\right)}{x-x_{0}}=\frac{a_{1} f_{1}\left(x_{o}\right)}{x-x_{o}}
$$




$$
\sigma_{y}\left(x_{o}, x\right)=\frac{2\left(c_{11}+c_{21}\right) f_{2}\left(x_{o}\right)}{x-x_{o}}=\frac{a_{2} f_{2}\left(x_{o}\right)}{x-x_{0}}
$$

where $\sigma_{x y}$ and $\sigma_{y}$ in equations (16) and (18) are real quantities. $\beta_{1}$ and $\beta_{2}$ are the imaginary parts of the roots $\lambda_{1}$ and $\lambda_{2}$. Note that $\lambda_{1}$ and $\lambda_{2}$ are pure imaginary in the case of orthotropic materials (see Appendix B).

The integral Equation (15) can then be rewritten as :

$$
\sigma_{x y}\left(z_{o}, x\right)+i \sigma_{y}\left(z_{o}, x\right)+\int_{-\infty}^{+\infty} \frac{a_{1} f_{1}\left(x_{o}\right)+i a_{2} f_{2}\left(x_{o}\right)}{x-x_{o}} d x_{o}=0
$$

which is a singular integral equation with a Cauchy-type kernel. The integral part exists in the sense of its principal value. The integral equation (19) can be directly solved for $a_{1} f_{1}(x)+i a_{2} f_{2}(x)$. Alternatively, the real and imaginary parts of the integral equation can be separated to obtain two real integral equations for $f_{1}(x)$ and $f_{2}(x)$. Following Muskhelishvili's methods for the solution of singular integral equations $[40,41]$, and excluding mathematical details, the following two expressions are obtained for $f_{1}(x)$ and $f_{2}(x)$ :

$$
\begin{aligned}
& f_{1}(x)=\frac{-i}{\pi a_{1}}\left[\frac{\lambda_{1} A_{1}}{x-z_{10}}-\frac{\bar{\lambda}_{1} \bar{A}_{1}}{x-\bar{z}_{10}}+\frac{\lambda_{2} A_{2}}{x-z_{20}}-\frac{\bar{\lambda}_{2} \bar{A}_{2}}{x-\bar{z}_{2 o}}\right], \\
& f_{2}(x)=\frac{i}{\pi a_{2}}\left[\frac{A_{1}}{x-z_{10}}-\frac{\bar{A}_{1}}{x-\bar{z}_{10}}+\frac{A_{2}}{x-z_{20}}-\frac{\bar{A}_{2}}{x-\bar{z}_{20}}\right]
\end{aligned}
$$

where $f_{1}(x)$ and $f_{2}(x)$ are real quantities. The complex function $\left.F^{\prime} x\right)=f_{1}(x)+i f_{2}(x)$ must satisfy overall material compatibility condition, i.e., conservation of Bu.ger's vector [30], which can be examined using the following integral :

$$
\begin{aligned}
\int_{-\infty}^{x} F\left(x^{\prime}\right) d x^{\prime}=b_{s}(x) & \\
b_{s}(x)=-b+\left(\frac{-i}{\pi a_{1}}\right) & {\left[\lambda_{1} A_{1} \log \left(x-z_{10}\right)-\bar{\lambda}_{1} \bar{A}_{1} \log \left(x-\bar{z}_{10}\right)\right.} \\
+ & \left.\lambda_{2} A_{2} \log \left(x-z_{20}\right)-\bar{\lambda}_{2} \bar{A}_{2} \log \left(x-\bar{z}_{20}\right)\right] \\
+\left(\frac{-1}{\pi a_{2}}\right) & {\left[A_{1} \log \left(x-z_{10}\right)-\bar{A}_{1} \log \left(x-\bar{z}_{10}\right)\right.} \\
& \left.+A_{2} \log \left(x-z_{2 o}\right)-\bar{A}_{2} \log \left(x-\bar{z}_{20}\right)\right]
\end{aligned}
$$

It can be shown that $b_{s}(x) \rightarrow-b$ as $x \rightarrow+\infty$.

The results are specialized for an orthotropic domain for which $s_{16}=s_{26}=0$. To test the theory presented here, the properties of the Nicalon/CVD-SiC (fiber/matrix), which is an orthotropic material, are chosen. The elastic constants are evaluated using the rule of mixture for the fiber and matrix properties given in Ref. $[43,44]$. The plane stress compliance constants are determined to be $s_{11}=3.125 \times 10^{-12}, s_{22}=3.503 \times 10^{-12}, s_{12}=-6.563 \times 10^{-13}$, and $s_{66}=9.31 \times 10^{-12} \mathrm{~Pa}^{-1}$.

In presenting the results all distances are normalized to the magnitude of the burgers vector. Figure (4) shows a typical surface distribution as a function of the distance along the free surface, for a dislocation at $z_{o}=+i 50$ with a purely real Burger's vector. It is obvious that $F(x) \rightarrow 0$ as $x \rightarrow \pm \infty$. The effect of varying the distance $y_{0}$ from the free surface on $|F(x)|$ is shown in figure (5). The distribution becomes sharper as $y_{0}$ becomes smaller and localized at $x=0$. It also broadens as 


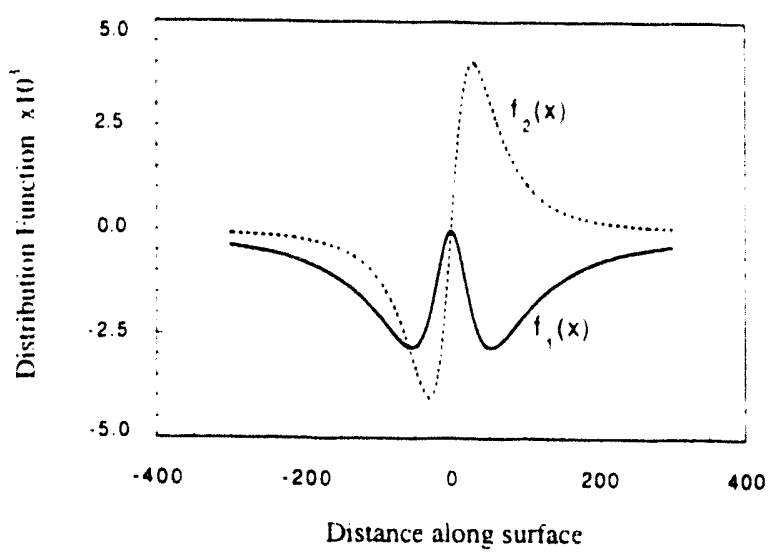

Figure 4: The surface distribution $\left(F(x)=f_{1}(x)+i f_{2}(x)\right)$ as a function of distance along the surface, $z_{0}=+i 50$. The Burger's vector is real

$y_{0}$ becomes large. In fact, this is a fundamental difference between the surface dislocation technique and the image dislocation method for which the image dislocation represents an extremely localized distribution at the point $x=0$. In figure (6), the integral surface Burger's vector $b_{s}(x)$, which is given by equation (21) is shown on an Argand diagram for different orientation of the Burger's vector of the lattice dislocation. $x$ describes one curve as it varies from $-\infty$ to $+\infty b_{a}(x)$ is given by the vector drawn from the point $(0,0)$ to any point on a curve. The results clearly indicate that the condition of material compatibility is satisfied. That is to say $b+\int_{-\infty}^{+\infty} F\left(x^{\prime}\right) d x^{\prime}=0[30]$

\section{Field Quantities in a semi-infinite domain}

The complex potentials due to surface dislocations will be denoted by $\phi_{1 r}\left(z_{1}\right)$ and $\phi_{2 r}\left(z_{2}\right)$. These potentials will be evaluated as integrals over the distribution function of surface dislocation on $x$-axis, as follows:

$$
\phi_{j r}\left(z_{j}\right)=\int_{-\infty}^{+\infty} B_{j}(x) \log \left(z_{j}-x\right) d x
$$

where $j=1,2$. Since the stresses are determined in terms of the derivatives of two complex potentials, it is convenient to develop an expression for $\phi_{j r}^{\prime}\left(z_{j}\right)$, which is written as :

$$
\phi_{j r}^{\prime}\left(z_{j}\right)=\int_{-\infty}^{+\infty} \frac{B_{j}(x)}{z_{j}-x} d x
$$

where, again, $B_{j}$ is determined in terms of $f_{1}(x)$ and $f_{2}(x)$ using equations (12). Omitting mathematical details, expressions for $\phi_{1 \Gamma}^{\prime}\left(z_{1}\right)$ and $\phi_{2 r}^{\prime}\left(z_{2}\right)$ are obtained as follows :

$$
\begin{aligned}
\phi_{1 r}^{\prime}\left(z_{1}\right) & =\left(\frac{2 i c_{12}}{a_{1}}\right)\left[\frac{\bar{\lambda}_{1} \ddot{A}_{1}}{z_{1}-\bar{z}_{10}}+\frac{\bar{\lambda}_{2} \bar{A}_{2}}{z_{1}-\bar{z}_{20}}\right]+\left(\frac{-2 c_{11}}{a_{2}}\right)\left[\frac{\bar{A}_{1}}{z_{1}-\bar{z}_{10}}+\frac{\bar{A}_{2}}{z_{1}-\bar{z}_{20}}\right] \\
& ;\left(z_{1} \in D^{+}\right), \\
& =\left(\frac{2 i c_{12}}{a_{1}}\right)\left[\frac{\lambda_{1} A_{1}}{z_{1}-z_{10}}+\frac{\lambda_{2} A_{2}}{z_{1}-z_{20}}\right]+\left(\frac{-2 c_{11}}{a_{2}}\right)\left[\frac{A_{1}}{z_{1}-z_{10}}+\frac{A_{2}}{z_{1}-z_{20}}\right]
\end{aligned}
$$




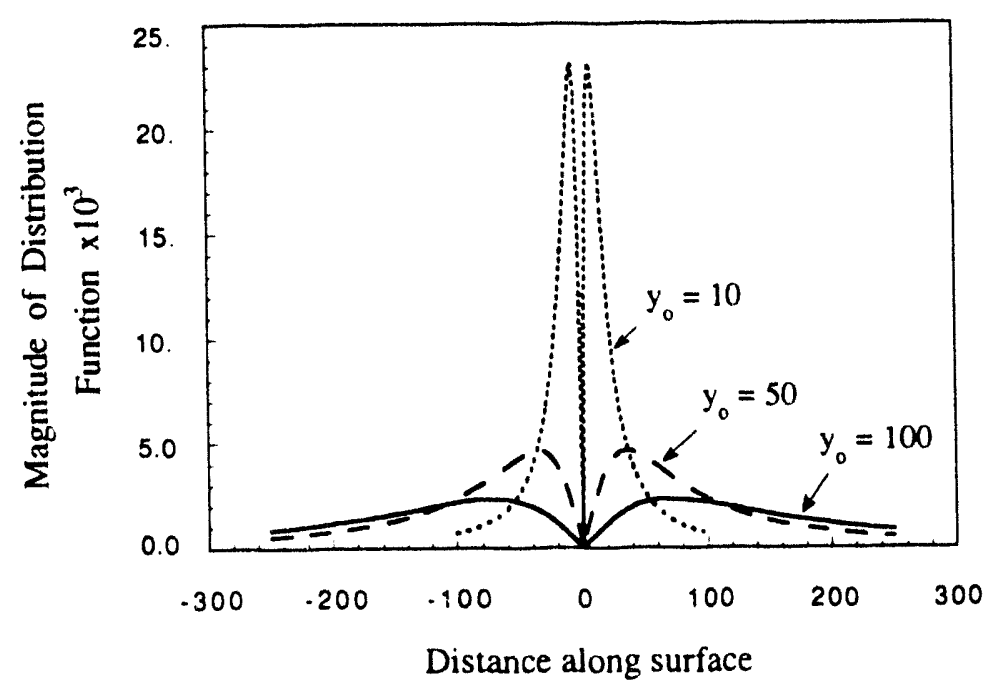

Figure 5: Magnitude of $F(x)$ as a function of distance along the surface for different positions of the dislocation $\left(z_{0}=+i y_{0}\right)$. The Burger's vector is real

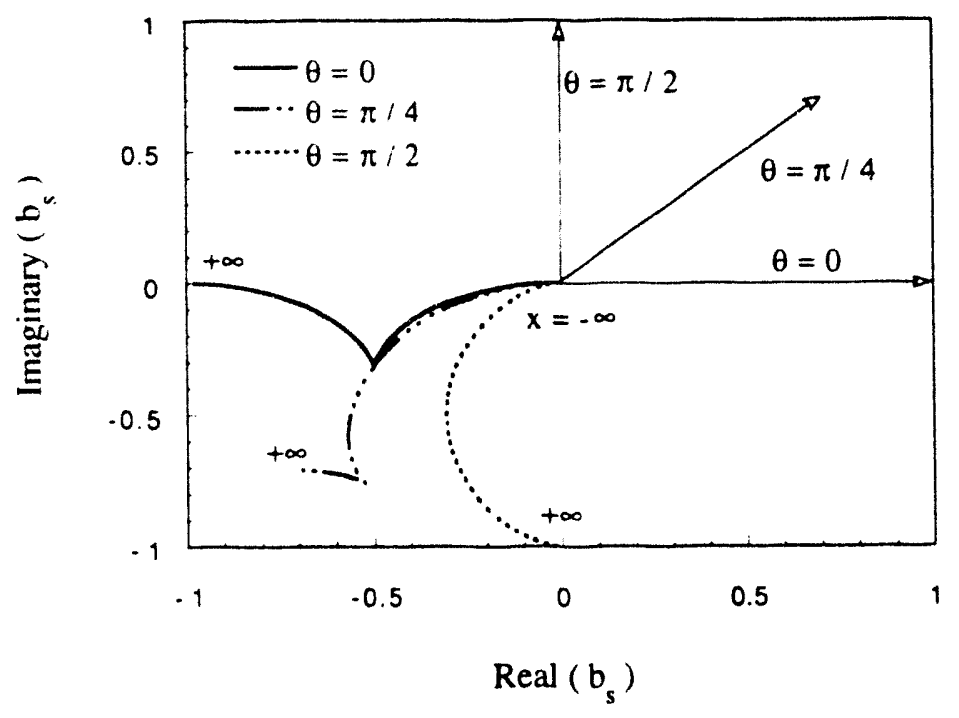

Figure 6: Argand diagram for $b_{s}$ as given by (21) for three different orientations of the Burger's vector $b$. The curves represent $b_{s}(x)$, where $x$ varies form $-\infty$ to $+\infty$. The arrows represent the Burger's vectors $b$ of the lattice dislocation. As $x \rightarrow+\infty b_{s} \rightarrow-b$. 


$$
\begin{gathered}
;\left(z_{1} \in D^{-}\right) \\
\phi_{2 \Gamma}^{\prime}\left(z_{2}\right)=\left(\frac{2 i c_{22}}{a_{1}}\right)\left[\frac{\bar{\lambda}_{1} \bar{A}_{1}}{z_{2}-\bar{z}_{10}}+\frac{\bar{\lambda}_{2} \bar{A}_{2}}{z_{2}-\bar{z}_{20}}\right]+\left(\frac{-2 c_{21}}{a_{2}}\right)\left[\frac{\bar{A}_{1}}{z_{2}-\bar{z}_{10}}+\frac{\bar{A}_{2}}{z_{2}-\bar{z}_{20}}\right] \\
\quad ;\left(z_{2} \in D^{+}\right), \\
=\left(\frac{2 i c_{22}}{a_{1}}\right)\left[\frac{\lambda_{1} A_{1}}{z_{2}-z_{10}}+\frac{\lambda_{2} A_{2}}{z_{2}-z_{20}}\right]+\left(\frac{-2 c_{21}}{a_{2}}\right)\left[\frac{A_{1}}{z_{2}-z_{10}}+\frac{A_{2}}{z_{2}-z_{20}}\right] \\
;\left(z_{2} \in D^{-}\right)^{\circ}
\end{gathered}
$$

The two derivatives $\phi_{j,}^{\prime}\left(z_{j}\right), j=1,2$ are regular everywhere in the entire $z_{1}$ and $z_{2}$ (or $z$ ) planes, including boundary points because the poles lie outside the respective domains. The total field is now constructed as the superposition of the singular and regular fields, as follows:

$$
\phi_{j}^{\prime}\left(z_{j}\right)=\phi_{j s}^{\prime}\left(z_{j}\right)+\phi_{j r}^{\prime}\left(z_{j}\right)
$$

where $\phi_{j s}^{\prime}\left(z_{j}\right)$ are given by equations (6). The stress tensor components in the half-plane are given by equations (2), where derivatives of the complex potential functions are given by equations (26). With some laborious algebra, the derivatives of the total potentials given by (26) can be shown to be identically zero at any point in the lower half-plane $(\operatorname{Im}(z) \leq 0)$. The stress tensor components, $\sigma_{x}, \sigma_{y}$ and $\sigma_{x y}$, will therefore vanish outside the domain boundary.

Figures (7), (8) and (9) show equi-stress contours for different stress components for a dislocation in a semi-infinite domain. $x$ and $y$ refer to the real and imaginary axes of the complex $z$-plane, respectively. The stresses and distances are normalized to the shear modulus $G_{12}=1 / s_{66}$, of the material, and the magnitude of the Burger's vector, respectively. Only zero stress contours of the stress components $\sigma_{y}$ and $\sigma_{x y}$ intersect with the boundary (real-axis), which means that the stress field satisfies the free traction boundary condition. These results illustrate the usefulness of the powerful complex potential field theory, when contrasted with the method of image dislocations [9], analytic continuation techniques $[33,34]$ and spectral expansion methods [42]. In the immediate neighborhood of the dislocation, the singular stress component (infinite domain field) dominates, which is clearly shown by the behavior of the contour lines close to the point $z_{0}$.

\section{Green's function for a dislocation in a rectangular orthotropic domain}

In this section the Schwarz-Christoffel transformation, which maps the upper half-plane onto a polygon, will be applied to the semi-infinite domain solution to obtain the solution in a rectangular domain. We will consider the case where the boundaries of the rectangular domain are free of tractions. If a set of surface tractions are subsequently applied, a convenient method can be used, and the total solution is obtained by superposition. 


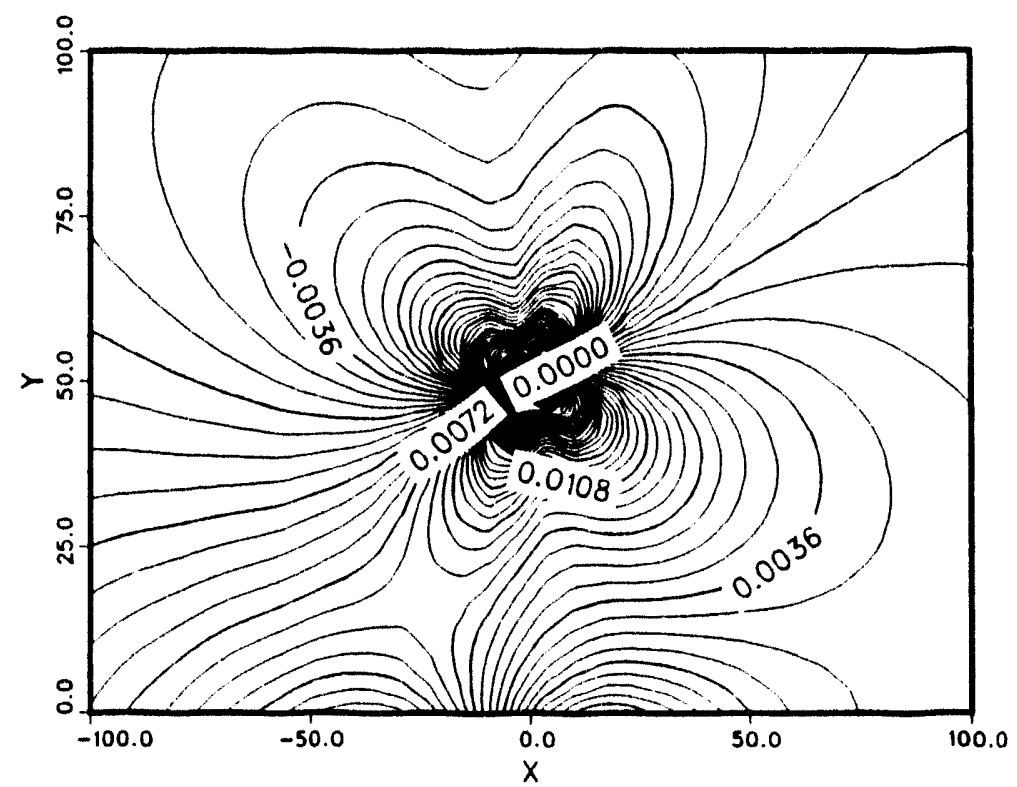

Figure 7: $\sigma_{x}$ for a dislocation $\left(b=e^{i x / 4}, z_{0}=+50 i\right)$ in a semi-infinite domain. The free surface is the real axis.

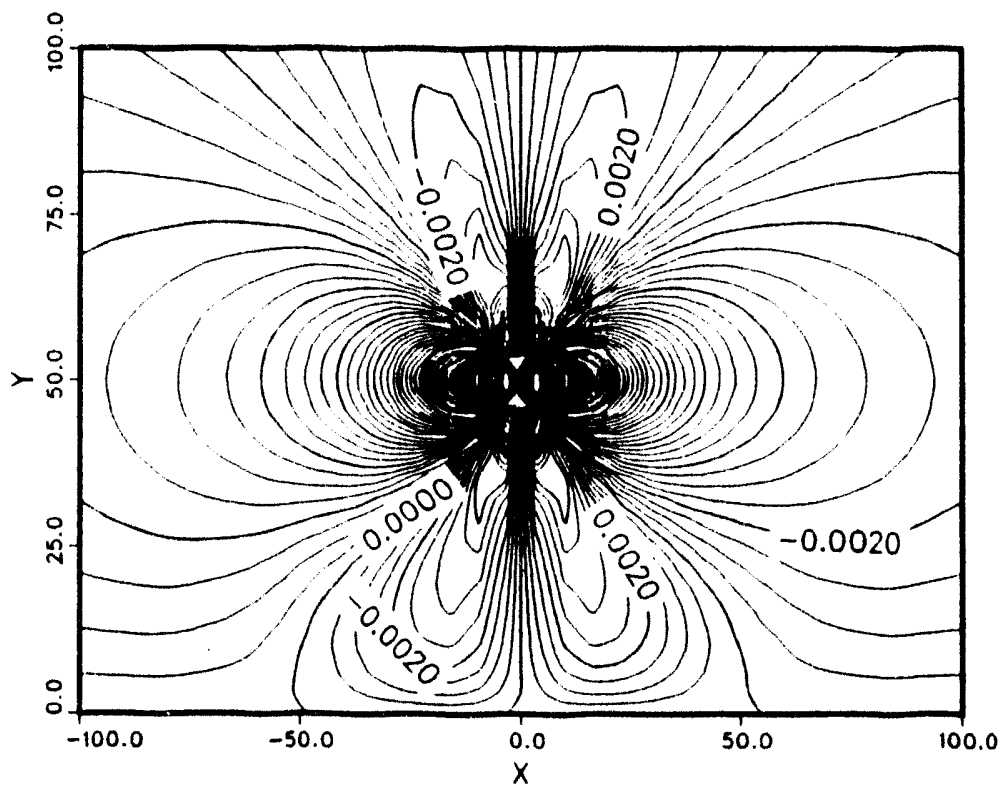

Figure 8: $\sigma_{x y}$ for a dislocation $\left(b=e^{2 x}, z_{0}=+50 i\right)$ in a semi-infinite domain. Only zero stress contours intersect with the free surface (real axis). 


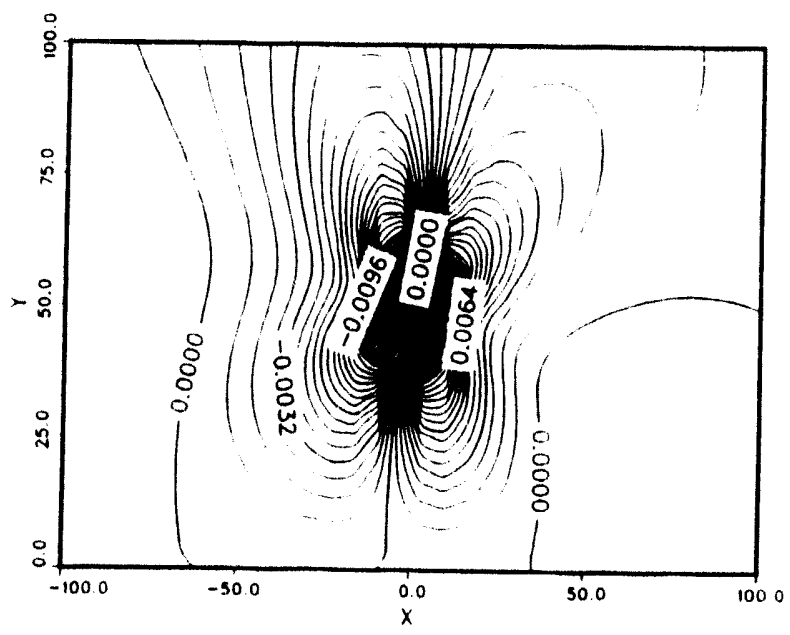

Figure 9: $\sigma_{y}$ for a dislocation $\left(b=e^{i x / 4}, z_{0}=+50 i\right)$ in a semi-infinite domain. Only zero stress contours intersect with the free surface (real axis).

\section{The Schwarz-Christoffel transformation}

The general form of the Schwarz-Christoffel transformation is written as [35-37] :

$$
w=f(z)=C_{1} \int_{0}^{z} \prod_{j=1}^{n}\left(z-a_{j}\right)^{\alpha_{j}-1} d z+C_{2}
$$

This transformation maps the upper half of the $z$-plane onto a polygon on $n$ vertices in the $w$-plane. $C_{1,2}$ are complex constants which adjust the size, orientation and location of the polygon. The points $a_{j}$ on the $x$-axis ( $z$-plane) transform to the vertices of the polygon, and $\alpha_{j} \pi$ are the interior angles of the polygon. With this transformation, solutions in polygonal domains (e.g. hexagons, pentagons, etc) can be obtained from the semi-infinite domain solution.

In the special case of a rectangle, $\alpha_{j}=\frac{1}{2}$, and $n=4$. Equation (27) can be written as [36] :

$$
\begin{aligned}
w=f(z) & =\int_{0}^{z} \frac{d \xi}{\sqrt{\left(1-\xi^{2}\right)\left(1-k^{2} \xi^{2}\right)}} & \\
& =F(z, k) & ; 0<k<1
\end{aligned}
$$

where $F(z, k)$ is the elliptic integral of the first kind $[45,46]$. The integral $(28)$ maps the upper half of the $z$-plane onto a rectangle in the $w$-plane for any $k$, Figure (10). The vertices of the rectangle in the $w$-plane are $\pm K(k)$ and $\pm K(k)+i K\left(k^{\prime}\right) ; k^{2}+k^{\prime 2}=1$, where $K(k)$ is a complete elliptic integral of the first kind, which is written as :

$$
K(k)=\int_{0}^{1} \frac{d \xi}{\sqrt{\left(1-\xi^{2}\right)\left(1-k^{2} \xi^{2}\right)}}
$$

and $K\left(k^{\prime}\right)$ is the complementary complete elliptic integral of the first kind defined by (29) for $k^{\prime}$. The vertices of the rectangle are mapped to the points \pm 1 and $\pm 1 / k$, on the $x$-axis in the $z$-plane.

Let the actual rectangular domain which contains the dislocation be defined in the $w^{*}$-plane, where $w^{*}=u^{*}+i v^{*}$, as shown in Figure (10). Let the vertices of the rectangle be given by $\pm H_{1}$ and $\pm H_{1}+i H_{2}$, which correspond to the four vertices in the $w$-plane. Consequently, it is necessary to establish a relationship between the $w^{*}$-plane and the $w$-plane before actually using equation (28) to 

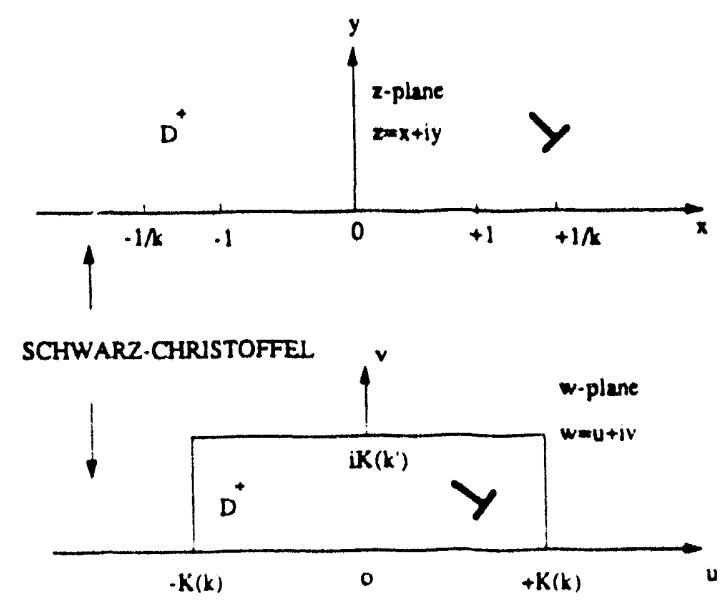

Figure 10: Schernatic of the different complex planes and their interrelationships

perform the mapping. In fact the mapping process will be multi-stcp, fruni $w^{*}$-plane to the $w$-plane, and then to the $z$-plane. Let the $w^{*}$ and the $w$ (where $w=u+i v$ ) be related as follows:

$$
\begin{aligned}
u^{*} & =\frac{H_{1}}{K(k)} u, \\
v^{*} & =\frac{H_{2}}{K\left(k^{\prime}\right)} v \\
w^{*} & =u^{*}+i v *=\frac{H_{1}}{K(k)} u+i \frac{H_{2}}{K\left(k^{\prime}\right)} v
\end{aligned}
$$

If we arbitrarily choose $\frac{H_{1}}{K(k)}=\frac{H_{2}}{K\left(k^{\prime}\right)}=c$, i.e., $w^{*}=c w$, then the transformation between the $w^{*}$ and $w$-planes is linear, where the constant $c$ will be determined once the parameter $k$ is determined. The latter is found by solving the following transcendental equation :

$$
\frac{H_{2}}{H_{1}}=\frac{K\left(k^{\prime}\right)}{K(k)}
$$

where $k^{2}+k^{\prime 2}=1$.

\section{Ficld quantities in a rectangular domain}

The fundamental stress combinations, $\Theta_{z}$ and $\Phi_{z}$, in the $z$-plane are written as $[38,40]$ :

$$
\begin{aligned}
& \Theta_{z}=\sigma_{y}+\sigma_{x}, \\
& \Phi_{z}=\sigma_{y}-\sigma_{x}+2 i \sigma_{x y}
\end{aligned}
$$

Under conformal transformation from the $z$-plane to the $w$-plane, the fundamental stress combinations transform according to the following relations :

$$
\begin{aligned}
& \Theta_{w}=\Theta_{z}, \\
& \Phi_{w}=\Phi_{z} e^{2 \imath} \psi
\end{aligned}
$$

It is clear that $\Theta_{z}$ ia an invariant of the transformation, while $\Phi_{z}$ has the transformation Jacobian given by:

$$
e^{2 \cdot \psi}=\left(\frac{d z}{d w}\right) /\left(\overline{\frac{d z}{d w}}\right)
$$


The stress components in the $w$-plane are determined in terms of $\Theta_{w}$ and $\Phi_{w}$ as follows :

$$
\begin{aligned}
\sigma_{u} & =\frac{\Theta_{w}}{2}-\frac{1}{4}\left(\Phi_{w}+\bar{\Phi}_{w}\right), \\
\sigma_{v} & =\frac{\Theta_{w}}{2}+\frac{1}{4}\left(\Phi_{w}+\Phi_{w}\right), \\
\sigma_{u v} & =-\frac{i}{4}\left(\Phi_{w}-\bar{\Phi}_{w}\right)
\end{aligned}
$$

Since the transformation between the $w$ and $w^{*}$ plane is linear with the constant $c$ is real, the corresponding jacobian is unity and, in turn, the field quantities are identical in these two planes. The derivative $\frac{d z}{d w}$ is found from (28) as :

$$
\frac{d z}{d w}=\sqrt{\left(1-z^{2}\right)\left(1-k^{2} z^{2}\right)}
$$

The transformation works as follows: to determine the stress field at a point $w^{*}, w$ is found using equation (30) as $w=w^{*} / c$ then the inverse of the relation (28) is used to find $z$. Once $z$ is determined, equations (32) through (35) are used to completely determine the stress field in the $w$-plane (i.e., in the $w^{*}$-plane). The inverse of the relation (28) is known as the Jacobi elliptic sine function, which is written as follows:

$$
z=\operatorname{sn}(w, k)
$$

The form of the elliptic sine function, and the associated numerical accuracy of the computation are given in [39]. Note that the dislocation solution in the w-plane is recovered from the solution in the $z$-plane. Let the displacement vector in the $z$ - and $w$-planes be denoted by $\mathcal{U}_{z}$ and $\mathcal{U}_{w}$, respectively. The displacement vector transforms as :

$$
\mathcal{U}_{z}=\mathcal{U}_{w} e^{i \psi}
$$

The Burger's vectors must have the same relation. Let the burgers vector in the $z$ - and $w$-planes be denoted by $b_{z}$ (at the point $z_{0}$ ) and $b_{w}$ (at the point $w_{o}$ ), respectively. Therefore, the Burger's vector in the $z$-plane is given by :

$$
b_{z}=b_{w} e^{2 \psi}
$$

where $b_{w}$ is the prescribed one, and $\psi$ is given by (34) evaluated at $z_{0}$.

\section{Discussion and Conclusions}

Representative results for the stress field in a rectangular orthotropic domain are shown in figures (11) through (16). $u^{*}$ and $v^{*}$ refer to the real and imaginary axes of the complex $w^{*}$ plane, which is the actual domain of the dislocation. The stresses are normalized to the shear modulus $G_{12}$. In calculating the stress field a value of $k^{2}=0.5$ is chosen, for which $K(k)=K\left(k^{\prime}\right)=1.85407467$. It is important to note that the shear and normal stresses identically vanish on the domain boundary. Also, the stress field shows the proper singularity at the location of the dislocation (Fig. (16).

The solution presented here is general in the sense that it accounts for the domain orthotropy and geometry effects, which is an essential factor in boundary value problems of elasticity, as well as the arbitrariness in specifying the Burger's vector (magnitude and direction). The solution can be easily extended to domains of general anisotropy. With this solution, a large number of materials macro/micromechanics problems can be accurately treated in the sense that more realistic dislocational fields in domains of finite sizes (present work) can replace the infinite domain field. Among these problems are the following: 


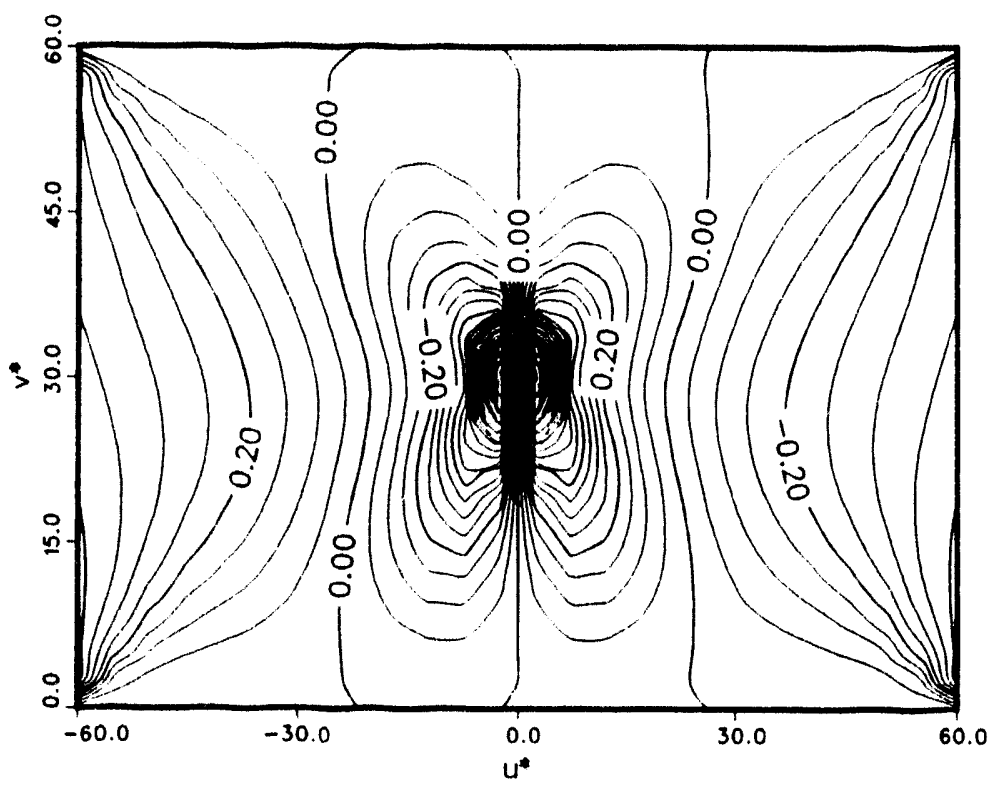

Figure 11: $\sigma_{v}$ for a dislocation $\left(b=e^{2 x / 2}, u_{0}^{*}=+30 i\right)$ in a rectangular domain. $\sigma_{v}$ identically vanishes on the upper and lower sides of the rectangle.

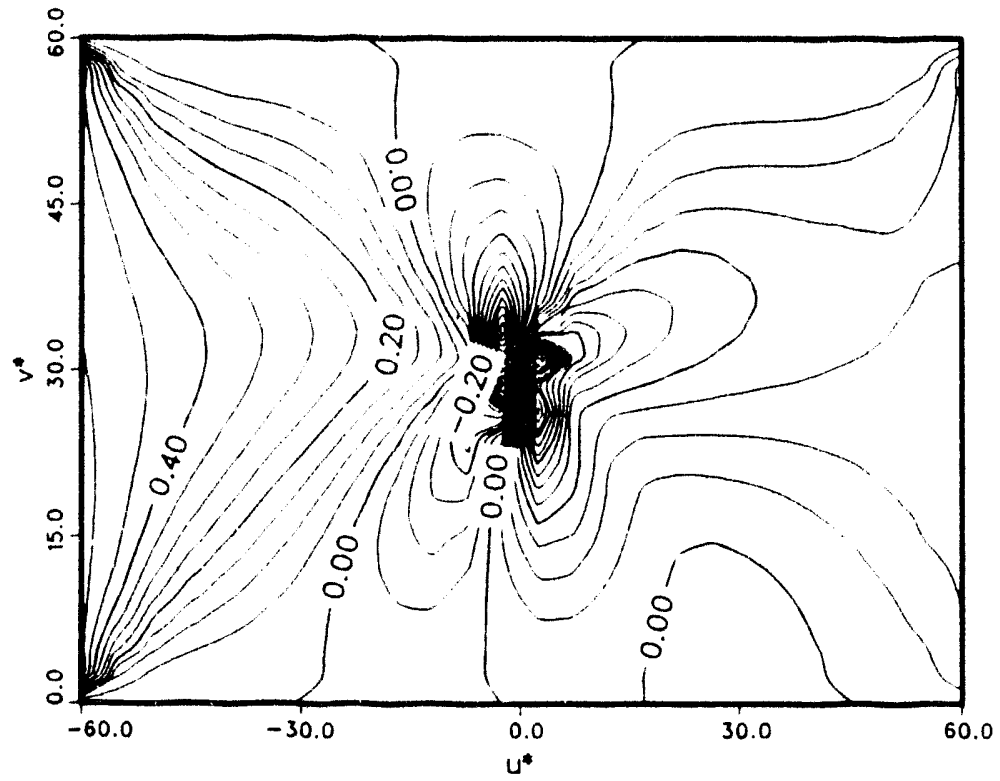

Figure 12: $\sigma_{v}$. for a dislocation $\left(b=e^{\imath x / 6}, w_{0}^{*}=+30 i\right)$ in a rectangular domain. $\sigma_{v}$. identically vanishes on the upper and lower sides of the rectangle. 


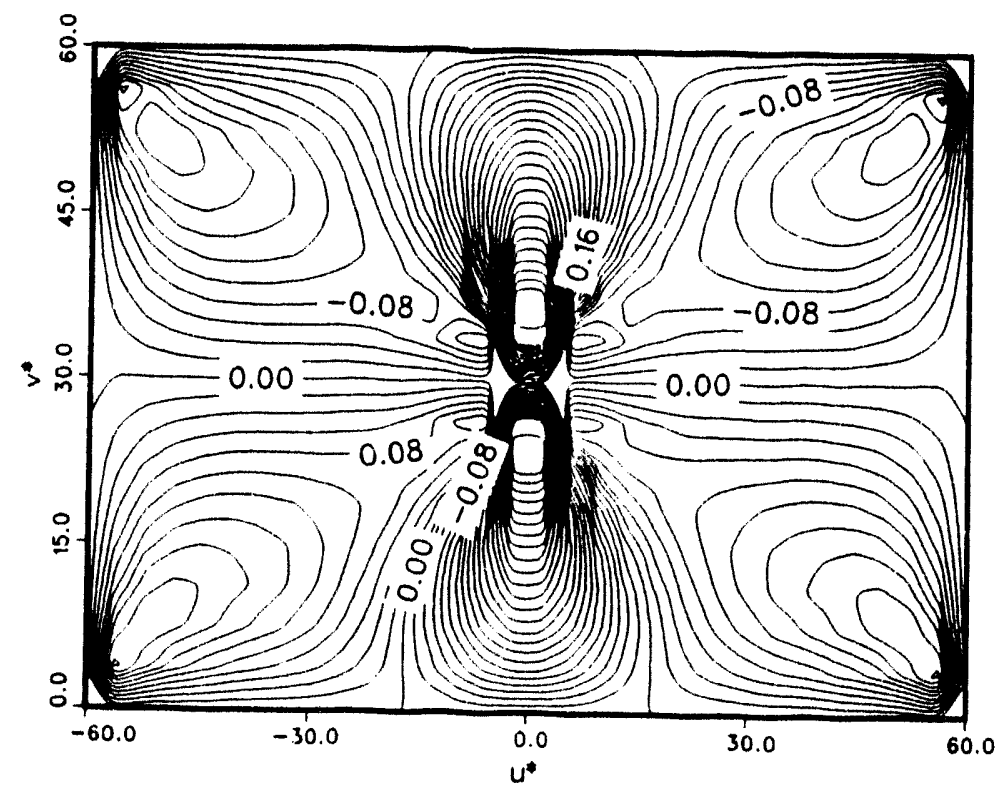

Figure 13: $\sigma_{u^{*} v^{*}}$ for a dislocation $\left(b=e^{i x / 2}, w_{0}^{*}=+30 i\right)$ in a rectangular domain. $\sigma_{u^{*} v^{*}}$ identically vanishes on all sides of the rectangle.

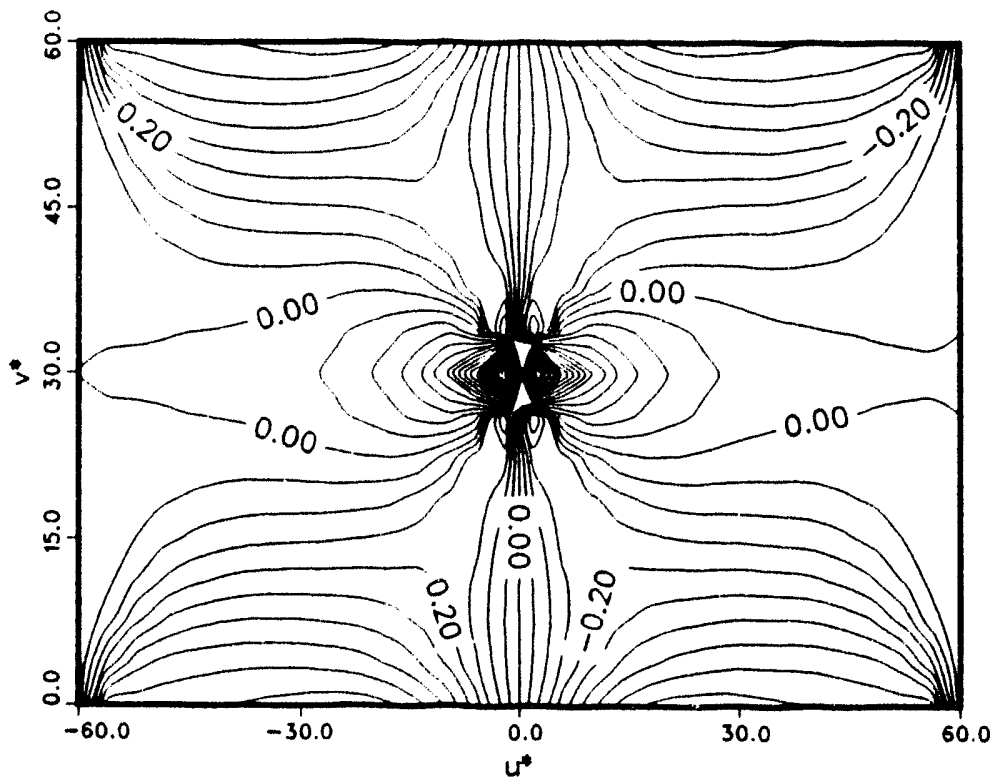
Figure 14: $\sigma_{u}$ for a dislocation $\left(b=e^{i x / 2}, w_{0}^{*}=+30 i\right)$ in a rectangular domain. $\sigma_{u_{v}}$ identicaliy
vanishes on the right and left sides of the rectangle. 


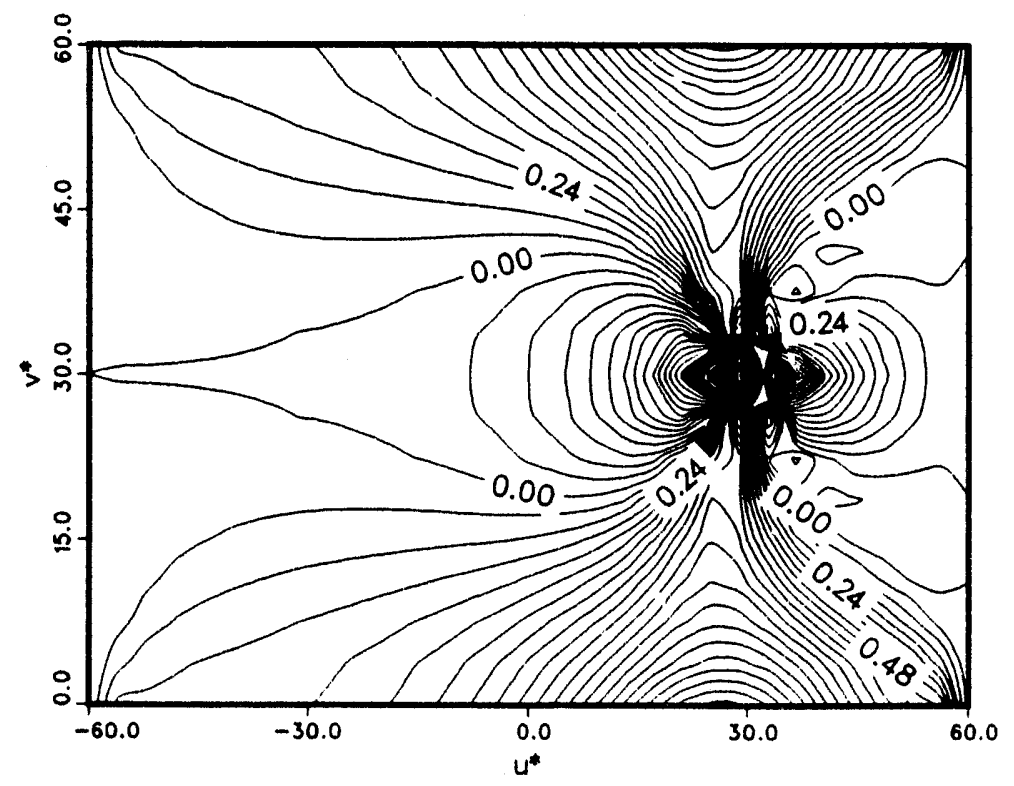

Figure 15: $\sigma_{u^{*}}$ for a dislocation $\left(b=e^{i x / 2}, w_{0}^{*}=30+30 i\right)$ in a rectangular domain. $\sigma_{u_{i} \text {. identically }}$ vanishes on the right and left sides of the rectangle.

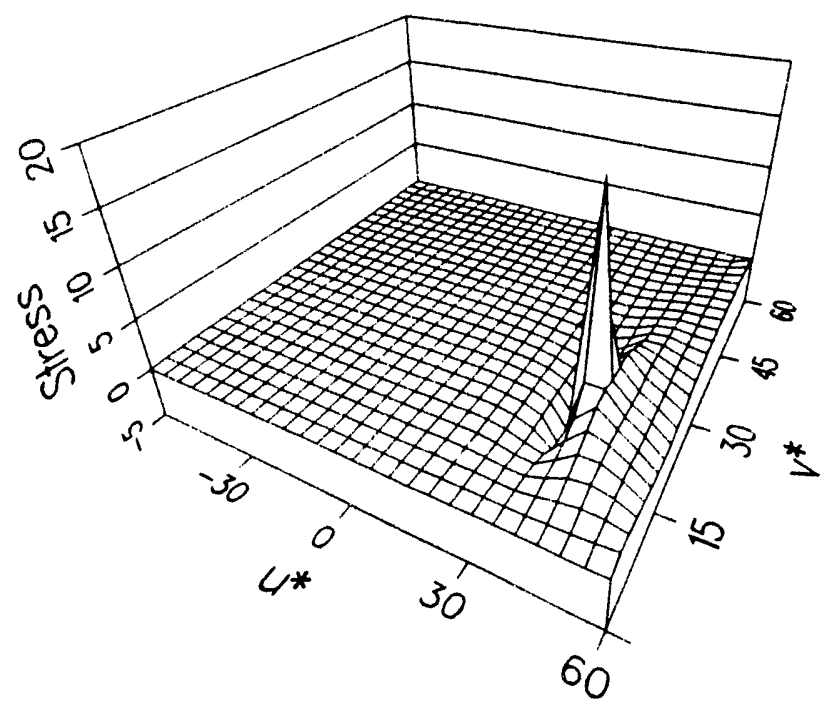

Figure 16: $\sigma_{u}$. for a dislocation $\left(b=e^{i x / 2}, w_{0}^{*}=40+30 i\right)$ in a rectangular domain showing the singular behavior of the stress field at $w_{0}$. 
1. Elastic and elastic-plastic fracture mechanics problems, where cracks of any size, shape and under generalized loading are modeled using distributions of dislocations, in finite size structural elements. Ref. [27 contains a list of the most important applications of dislocation theory in fracture. The reader is also advised to check the book written by Lardner [19] as well as Bilby and Eshelby's article [29].

2. Dislocation-crack interaction problems, such as the spread of plastic yield from crack tips [47], cleavage, dislocation emission and crack shielding under generalized loading conditions [48].

3. Problems of micromechanics of plasticity and viscoplasticity (dislocation creep), which involve detailed description of dislocation motion as well as dislocation-dislocation interactions in real crystals or in specimens of finite sizes $[15,16,49]$.

A major outcome of the present work is that it demonstrates the weakness of the infinite domain dislocation solution in a large number of problems in which the range of interest for the dislocational field is comparable to the domain size. This is illustrated in figure (11), where the stress component $\sigma_{v^{*}}$ changes between tensile and compressive on one side of the $v^{*}$ axis, which is not a feature of the infinite domain solution. Also, a rotation of the burgers vector can dramatically change the features of the stress field for the same geometry. This is shown by comparing figures (11) and (12). Another important effect is the behavior of the stress field close the domain corners and edges (Figs. (13) to (15)).

It must be noted that the general method developed in this paper is also applicable for obtaining the Green's function for screw dislocations, and for dislocations of mixed-mode character in finite domains.

\section{FUTURE WORK}

The method will be applied to solutions for the elastic stress field, crack opening displacement and stress intensity factors for cracks in $\mathrm{SiC}-\mathrm{SiC}$ composites under mixed mode $\mathrm{I} / \mathrm{ll}$ loading conditions.

\section{References}

[1] G. Weingarten, Atti Accademia Nazionale die Lincie 10(1901)57-61.

[2] A. Timpe, Zeitschrift fur Mathematik und Physik 52(1905) 348-383.

[3] V. Volterra, Annale Scientifiques de l' Ecole Normale Superieure(Paris) 24(1907)401-517.

[4] A. E. H. Love, A Treatise on the Mathematical Theory of Elasticity, Cambridge University Press, Cambridge, (1927).

[5] Th. v. Karman and L. Föppl, Enzyklopadie Der Mathematischen Wissenschaften Mechanik 4(1913)695-770.

[6] L. Prandtl, Zeitschrift fur Angewandte Mathematik und Mechanik 8(1923)85-106.

[7] G. I. Taylor, Transactions of the Faraday Society 24(1928)121-125.

[8] E. Orowan, Diplomarbeit, T. H. S. Berlin (1929).

[9] J. P. Hirth and J. Lothe, Theory of Dislocations, Second Edition, John Wiley and Sons (1982).

[10] F. R. N. Nabarro, Dislocations in Solids, North-Holland Publishing Company, 1979.

[11] M. J. Marcinkowski et al, Physica Status Solidi (a) 17(1973) 423-433.

[12] M. J. Marcinkowski et al , Physica Status Solidi (a) 18 (1973) 361-375.

[13] K. Jagannadham and M. J. Marcinkowski, Joumal of Materials Science 15 (1980) 563-574.

[14] K. Jagannadham and M. J. Marcinkowski, Journal of Materials Science 14 (1979) 1717-1732.

[15] R. J. Amodeo and N. M. Ghoniem, Physical Review B, 41(1990) 6958-6967.

[16] R. J. Amodeo and N. M. Ghoniem, Physical Review B, 41(1990) 6968-6976. 
[17] T. Mura, in Advances in Materials Research, vol. 3, Editor: H. Herman, John Wiley and Sons (1968)1-108.

[18] T. Mura, Micromechanics of Defects in solids, Martinus Nijhoff Publishers (1987).

[19] R. W. Lardner, Mathematical Theory of Dislocations and Fracture, University of Toronto Press (1974).

[20] A. N. Stroh, Philosophical Magazine 3(1958)625-646.

[21] J. Qu and Q. Li, Journal of Elasticity 26(1991)169-195.

[22] J. R. Willis, Journal of Mechanics and Physics of Solids 19(1971)353-368.

[23] F. Delale and F. Erdogan, International Journal of Fracture 20(1982)251-265.

[24] R. W. Lardner, International Journal of Fracture Mechanics 4(1968)299-319.

[25] C. Atkinson, International Journal of Fracture Mechanics 2(1968)567-575.

[26] V. Vitek, International Journal of Fracture 13(1977)481-501.

[27] V. Vitek and G. G. Chell, in Dislocation Modelling in Physical Systems, Proceedings of International Conference, Gainesville, Florida, USA, June 22-27, 1986. Editor: M. F. Ashby, R. Boullough, C. S. Hartly, and J. P. Hirth (1986) 92-109.

[28] K. Jagannadham and M. J. Marcinkowski, Unified Theory of Fracture, Trans Tech Publications (1983).

[29] B. A. Bilby and J. D. Eshelby, in Fracture, An Advanced Treatise, Vol. 1, Editor: H. Liebowitz, Academic Press, New York and London (1968)99-182.

[30] K. Jagannadham and M. J. Marcinkowski, Physica Status Solidi (a) 50 (1978) 293-302.

[31] K. Jagannadham and M. J. Marcinkowski, Joumal of Materials Science 14 (1979) 1052-1070.

[32] K. Jagannadham and M. J. Marcinkowski, Materials Science and Engineering 38 (1979) 259270.

[33] G. R. Miller, Journal of Applied Mechanics 53 (1986) 368-389.

[34] J. C. Lee, Engineering Fracture Mechanics 37(1990) $209-219$.

[35] L. Volkovyski, G. Lunts, and I. Aramanovich, Problems in the Theory of Functions of a Complex Variable, Mir Publishers, Moscow (1972).

[36] Zeev Nehari, Conformal Mapping, Dover Publications Inc, New York (1952).

[37] Ruel V. Churchill and James Ward Brown, Complex Variables and Applications, Fifth Edition, McGrow-Hill (1990).

[38] L. M. Milne-Thomson, Plane Elastic Systems, Springer Verlag (1968).

[39] A. El-Azab and N. M. Ghoneim, Green's Function for the Elastic Field of an Edge Dislocation in a Finite Orthotropic Medium, accepted for publication in Int. J. Fract. 1993.

[40] N. I. Muskhelishvili, Some Basic Problems of the Mathematical Theory of Elasticity, P. Noordhoff Ltd. (1963).

[41] N. I. Muskhelishvili, Singular Integral Equations, Moscow (1946).

[42] R. Solecki, in Yamada Conference IX on Dislocations in Solids, Editor : H. Suzuki, University of Tokyo Press (1985)25-28.

[43] J. A. Dicarlo and Gregory N. Morscher, in Failure Mechanisms in High Temperature Composite Materials, AD - Vol - 122, ASME (1991)15-22.

[44] T. D. Gulden, Journal of the American Ceramic Society 52(1969) 585-590.

[45] M. Abramowitz and I. A. Stegun, Handbook of Mathematical Functions with Formulas, Graphs and Mathematical Tables, Ninth Edition, Dover Publications Inc, New York (1972).

[46] Harold T. Davis, Introduction to Nonlinear Differential and Integral Equations, Dover Publications Inc, New York (1962).

[47] V. Vitek, Journal Mechanics and Physics of Solids 24(1975)67-76.

[48] I.-H. Lin and R. Thomson, Acta Metallurgica 34 (1986)187-206.

[49] E. H. Jordan and K. P. Walker, Journal of Engineering Materials and Technology ASME $114(1992) 19-26$. 
5.0 RADIATION EFFECTS, MECHANISTIC STUDIES, THEORY AND MODELING 
FACTORS WHICH CONTROL THE SWELLING OF Fe-Cr-Ni TERNARY AUSTENITIC ALLOYS - F. A. Garner and D. J. Edwards (Pacific Northwest Laboratory) ${ }^{3}$.

\section{OBJECTIVE}

The objective of this effort is to determine the factors which control the response to irradiation of materials used in fusion environments.

\section{SUMMARY}

In agreement with limited earlier studies, a comprehensive irradiation experiment conducted in EBR-II demonstrates that while cold-working decreases swelling of $\mathrm{Fe}-15 \mathrm{Cr}-\mathrm{XNi}(\mathrm{X}=12-45 \mathrm{wt} \%)$ alloys at relatively low irradiation temperatures, it increases swelling at higher temperatures. Aging of cold-worked specimens to produce polygonized dislocation networks tends to further increase swelling, especially at higher nickel (>25\%) levels. Swelling at lower nickel levels also appears to be sensitive to details of the annealing treatment.

\section{PROGRESS AND STATUS}

\section{Introduction}

There is a very general perception, developed primarily from research on stainless steels, that cold-working a metal prior to irradiation always reduces swelling, exerting a monotonic but diminishing influence with increasing cold-work level. It is also generally accepted that factors which promote void nucleation, such as high helium generation rates, can at least partially overcome the suppressive effect of cold-work on void nucleation.

In a recent review, however, it was shown that the role of starting dislocation density and dislocation arrangements, as well as their interactions with variables such as helium generation rate, are much more complex than previously assumed. In many cases, cold-working can actually increase swelling, especially in pure metals such as $\mathrm{Ni}$ and $\mathrm{Al}$ and also in simple ternary and quaternary austenitic alloys.

Instead of delaying swelling, Garner and coworkers have recently shown that cold-working often increases swelling of $\mathrm{Fe}-\mathrm{Cr}-\mathrm{Ni}$ model alloys, especially under conditions where void nucleation is relatively difficult, i.e., for relatively high nickel or phosphorus levels and at relatively high irradiation temperatures ${ }^{(2.3)}$. At lower nickel levels and temperatures, where void nucleation is relatively easy, cold-working usually reduces swelling.

The current interest in cold-work's influence on swelling arisessfrom the use of both annealed and cold-worked alloys in on-going isotopic tailoring (4) and spectral tailoring ${ }^{5.6}$ experiments directed toward determining the separate and synergistic influence of helium on radiation-induced microstructural evolution in competition with various important material and environmental variables.

To aid in the understanding of such relationships, a series of $\mathrm{Fe}-\mathrm{Cr}-\mathrm{Ni}$ specimens irradiated in the EBR-II AA14 experiment was examined. Seven $\mathrm{Fe}-15 \mathrm{Cr}-\mathrm{XNi}$ alloys $(X=12-45 \mathrm{wt} \%)$ were irradiated in the form of $3 \mathrm{~mm}$ microscopy disks at $425^{\circ} \mathrm{C}$ to $31 \mathrm{dpa}$ and to $32 \mathrm{dpa}$ at 500 and $600^{\circ} \mathrm{C}$. Each alloy was irradiated side-by-side in three conditions: annealed $\left(975^{\circ} \mathrm{C} / 10 \mathrm{~min} / \mathrm{WQ}\right), 30 \%$ cold-worked, and $30 \%$ cold-worked and aged $\left(650^{\circ} \mathrm{C} / 10 \mathrm{hr} / \mathrm{WQ}\right)$. Measurements of density changes were made using an immersion density technique known to be accurate to $\pm 0.16 \%$ change in density.

\section{Results}

The swelling values calculated from measured density changes are presented in figure 1 . The following features of these data should be noted.

1. The strong decrease of swelling with increasing nickel content usually coserved in $\mathrm{Fe}-\mathrm{Cr}-\mathrm{Ni}$ austenitic alloys" is preserved in this experiment in all three starting conditions, but with one important exception. Note that in eight of the nine sets of data, swelling decreases at the lowest nickel levels, producing a peak in swelling vs. nickel content.

2. The swelling at $31-32$ dpa of annealed $\mathrm{Fe}-\mathrm{Cr}-\mathrm{Ni}$ steels at 425 and $500^{\circ} \mathrm{C}$ is relatively independent of temperature, but decreases significantly at $600^{\circ} \mathrm{C}$, in agreement with earlier studies ${ }^{\text {. }}$.

${ }^{3}$ Pacific Northwest Laboratory is operated for the U. S. Department of Energy by Battelle Memorial Institute under Contract DE-ACO6-76RLO 1830 
3. Swelling is decreased by cold-working at 425 and $500^{\circ} \mathrm{C}$ but at $600^{\circ} \mathrm{C}$ it is increased at higher nickel levels.

4. Under some conditions, cold-working followed by aging can also significantly increase swelling.

\section{Discussinn}

The peak in swelling observed at $12-15 \%$ nickel is incons istent with the behavior observed in earlier studies ${ }^{(7)}$, where swelling either increased monotonically with decreasing nickel content, or exhibited a plateau at low nickel levels and relatively low temperatures. It is felt that this difference may arise from the fact that the specimens in the earlier study were better annealed, $1030^{\circ} \mathrm{C}$ for $0.5 \mathrm{hr}$ and air cooled, as opposed to the $975^{\circ} \mathrm{C}$ for $10 \mathrm{~min}$ and water quenched treatment used in the current study. One possible consequence of this difference is the fact that specimens appeared to be increasingly magnetic at lower nickel levels, as indicated by their interactions with the electron beam during microscopy examination. The cold-worked and aged specimen at $12 \% \mathrm{Ni}$ did not exhibit magnetic behavior in the unirradiated condition, while the annealed and the coldworked specimens were found to be very magnetic. Thus, there is an apparent correlation of magnetic behavior with the peaked swelling behavior observed at $425^{\circ} \mathrm{C}$.

In the review mentioned earlier, ${ }^{(1)}$ it was shown that the role of cold-work in increasing swelling arose from the establishment of stable dislocation networks at higher temperatures where networks are slow to develop from radiation alone. The influence of aging was thought to be in the development of polygonal cellular dislocation-networks, with relatively dislocation-free areas for void nucleation to occur within the cells. Freliminary results of microscopy examination confirm that this interpretation is valid for the $\mathrm{Fe}-\mathrm{Cr}-\mathrm{Ni}$ alloys irradiated in the AA-14 experiment.

\section{Future Work}

Microscopy analysis of starting dislocation microstructures will proceed.

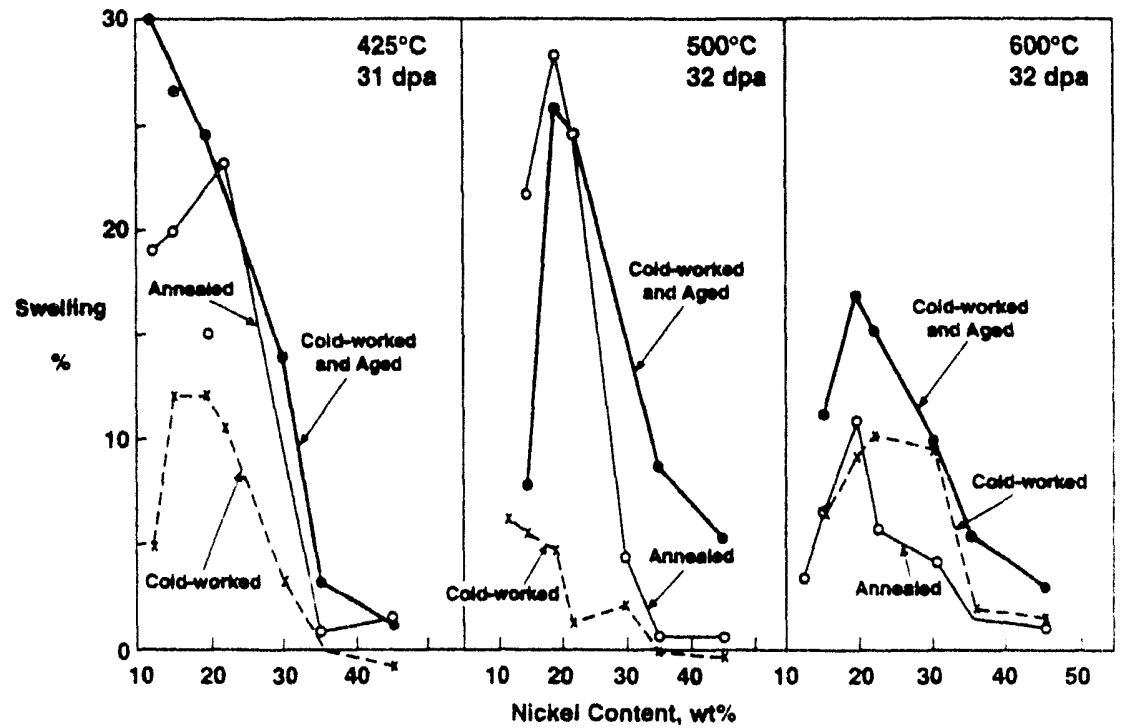

Fig. 1. Swelling observed in Fe-15Cr-Ni alloys irradiated in EBR-II as part of the AA-14 experiment.

\section{REFERENCES}

: F.A. Garner, "Evolution of Microstructure in Face Centered Cubic Metals during Irradiation: A Review," accepted for publication in J. Nuc. Mater.

2. F.A. Garner, M. Miyahara, J.W. Newkirk, and H. Kinoshita, J. Nuc. Mater., 199 (1993) 132-142.

3. F.A. Garner and H.P. Brager, in Damage Analys is and Fundamental Studies Quarterly Progress Report, DOE/ER-0046/19 (1984) pp. 62-65.

4. M.L. Hamilton and F.A. Garner, J. Nuc Mater., 191-194 (1992) 1239-1243.

5. N. Sekimura, F.A. Garner and R.D. Griffin, J. NuC. Mater., 191-194 (1992) 1234-1238.

6. M.L. Hamilton, A. Okada and F.A. Garner, J. Nuc. Mater., 179-181 (1991) 558-561.

F.A. Garner and A.S. Kumar, in Radiation-Induced Changes in Microstructure: 13 th international symposium (Part I), ASTM STP 955, F.A. Garner, N.H. Packan, and A.S. Kumar, Eds., American Society for Testing and Materials, Philadelphia PA, 1987, pp. 287-314. 
THE INFLUENCE OF COLD WORK LEVEL ON SWELLING OF PURE COPPER !RRADIATED BY FAST NEUTRONS OR ELECTRONS - F. A. Garner (Pacific Northwest Laboratory ${ }^{a}$ ) and B.N. Singh (Risp National Laboratory).

OBJECTIVE

The objective of this effort is to determine the factors which influence the radiation response of copper high heat flux components in fusion reactors.

SUMMARY

Pure copper has been irradiated in a variety of starting conditions by either $1.0 \mathrm{MeV}$ electrons or fast neutrons in FFTF-MOTA. Electron irradiation at 250 and $350^{\circ} \mathrm{C}$ produces a non-monotonic swelling behavior as a function of cold work level, increasing swelling at lower cold-work levels and decreasing swelling at higher cold-work levels. In FFTF at 365 and $430^{\circ} \mathrm{C}$, however, $10 \%$ cold-work reduces swelling initially, with little additional influence at higher cold-work levels. Swelling at 520 and $600^{\circ} \mathrm{C}$ is less than $1 \%$ at 35.9 and 13.6 dpa, respectively, with little effect of cold work level.

\section{PROGRESS AND STATUS}

\section{introduction}

Leffers, Singh, and Barlow showed that the swelling of pure copper (99.999\%) during electron irradiation was sensitive to cold-work level at 250 and $350^{\circ} \mathrm{C}$. As shown in Figure 1 , both the incubation period and steady. state swelling rate were functions of cold work level. In general, cold-working first increased swelling at these temperatures, but the swelling reached a peak and then declined with increasing cold work.?

It was not certain, however, that such behavior would be typical of that expected at the higher temperatures and lower displacement rates typical of neutron irradiation. Therefore, specimens that were archives of those employed in the electron study were irradiated in FFTF MOTA-2B at 365, 423, 520 and $600^{\circ} \mathrm{C}$. The starting conditions used in the FFTF study were annealed $\left(600^{\circ} \mathrm{C}\right.$ for $\left.2 \mathrm{hrs}\right), 10,25$ and $50 \%$ cold-worked, and $25 \%$ cold work followed by aging at $300^{\circ} \mathrm{C}$ for $2 \mathrm{hrs}$. The specimens were irradiated in the form of standard $3 \mathrm{~mm}$ microscopy disks contained in sealed helium-filled stainless steel capsules. Density changes were measured using an immersion technique known to be accurate to $\pm 0.16 \%$ swelling.

\section{Results and Discussion}

igures $2 a$ and $2 b$ show the swelling observed in neutron-irradiated pure copper as a function of irradiation temperature and cold-work level. At 365 and $433^{\circ} \mathrm{C}$ and 47.3 and 16.9 doa. respectively. cwell ing is initially reduced by $10 \%$ cold-working, with very little influence of cold-work observed at higher levels. Based on density measurements, there appears to be a small amount of swelling at 520 and $600^{\circ} \mathrm{C}$. but the influence of cold-work level is small. The small peak at $520{ }^{\circ} \mathrm{C}$ for $10 \%$ cold work may represent some measurement error. Microscopy is necessary to confirm that swelling and not transmutation is responsible for the observed smali changes in density at 520 and $600^{\circ} \mathrm{C}$. Aging at $300^{\circ} \mathrm{C}$ for $2 \mathrm{hrs}$ appeared to have no significant effect on swelling of $25 \%$ cold-worked copper.

The different behavior with respect to cold-work level observed in electron and neutron irradiations may arise from the differences in temperature and displacement rate employed in the two types of experiments. Another possible factor may be the strong role played by the two specimen surfaces on dislocation evolution in the very thin foils employed during electron irradiation. Loss of dislocations to the surface will be large, and preexisting cold-work induced dislocation networks may assist in the development and maintenance of a stable dislocation network during electron irradiation. Stabilization of the dislocation structure against surface iosses would then lead to earlier swelling at low cold-work levels. The absence of such surfaces during neutron irradiation would then simplify the role of cold-work on swelling, allowing it to exert its normaliy suppressive influence.

\section{Fiture Work}

Microscopy examination will proceed at the Riso National Laboratory.

\section{DEFERENCES}

$\therefore \quad$ I. Leffers. E. H. Singh, and P. Earlow, Riso llational Laboratory Report Ris0-4.1937. 4ay, 1977

2. F. Aarner et al. Fusion Reactor Materials Semiannual Progress Redort DOE/ER 0313/10 (1991) pp. 186. 191.

Pacific Northwest Laboratory is operated for the U.S. Department of Energy by Battelle Memorial Institute under ContraCt DE-ACO6-76RLO 1830. 


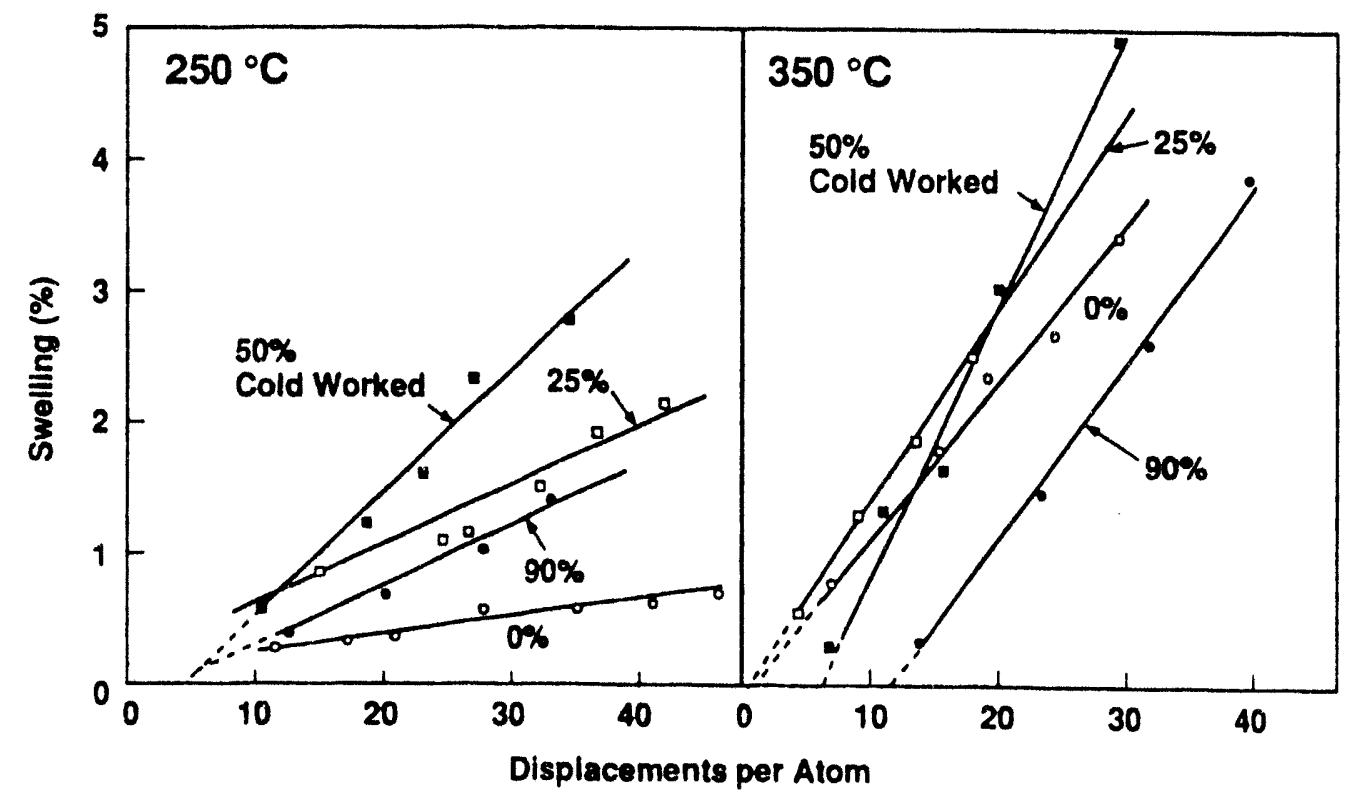

Fig. 1. Effect of cold-work level on electron-induced swelling of $99.999 \%$ copper $(1,2)$.
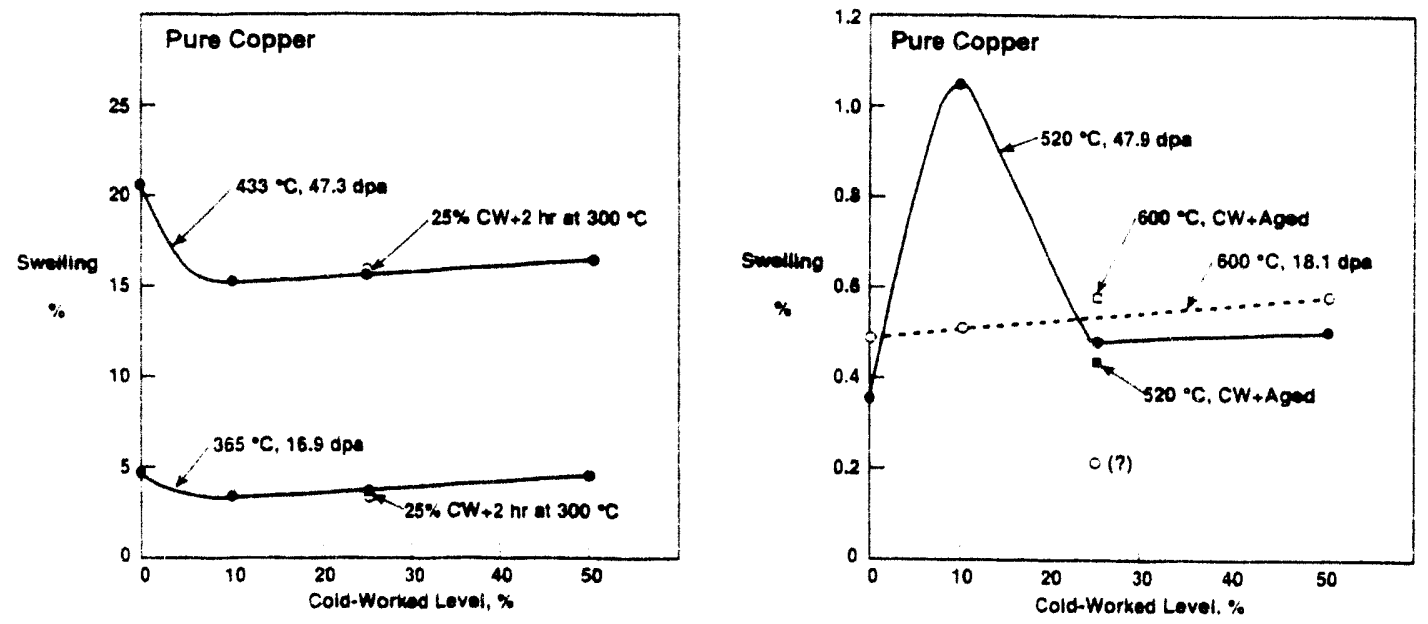

Fig. 2. Effect of cold-work 'ovel ard aging on neutron-induced swelling of $39.999 \%$ copper in FFTF. MOTA. 
the Influence of Details of Reactor History on Microstructural Development During Neutron Irradiation F. A. Garner, (Pacific Northwest Laboratory) ${ }^{\text {a }}$. N. Sekimura, (Univ. of Tokyo), M. L. Grossbeck, (Oak Ridge Hational Laboratory), A. M. Ermi, (Westinghouse Hanford Company), J. W. Newkirk, (U. of Mo-Rolla),

14. Watanabe, (Kyushu University), and M. Kiritani, (Nagoya University)

\section{OBJECTIVE}

The objective of this effort is to determine the influence of irradiation temperature history on the neutron-induced evolution of microstructure in metals.

SUMMARY

Microstructurally-oriented irradiation experiments are shown in this paper to be strongly dependent on details of reactor history that frequently are not brought to the experimenter's attention. In some cases, these details can dominate the experiment so as to produce very misleading results. To aid in the design and interpretation of microstructurally-oriented experiments, a number of studies are reviewed to highlight history effects and then guidelines are presented to minimize the impact of reactor history in new experiments.

\section{PROGRESS AND STATUS}

\section{Introduction}

Materials scientists conducting experiments in nuclear reactors rely on information provided by reactor operators concerning the environment in which the experiment will be conducted. In addition to well known uncertainties associated with the determination of temperature and atomic displacement level in reactor experiments, small details of reactor operation that ensure safe, reliable operation of the reactor can often have large, unanticipated consequences on microstructural evolution. In some cases these details can dominate the microstructural evolution and lead to misperceptions concerning the variables thought to be under study. Start-up and shut-down procedures are especially important in this respect.

The realization that previously neglected details of temperature history could exert a strong influence on microstructural evolution arose from the studies of kiritani and coworkers, who predicted and then demonstrated that such details could dominate microstructurally-oriented experiments, especially on simple model materials. ${ }^{1.2}$ Using an in-core irradiation rig with active temperature control in the japanese Materials Testing Reactor (JMTR), Kiritani showed that small increments of irradiation at lower-than-target temperatures during reactor start-up and shut-down often yielded microstructures that were completely different from those developed during totally isothermal irradiation. Two examples from Kiritani's studies are shown in Figs. 1 and 2 .

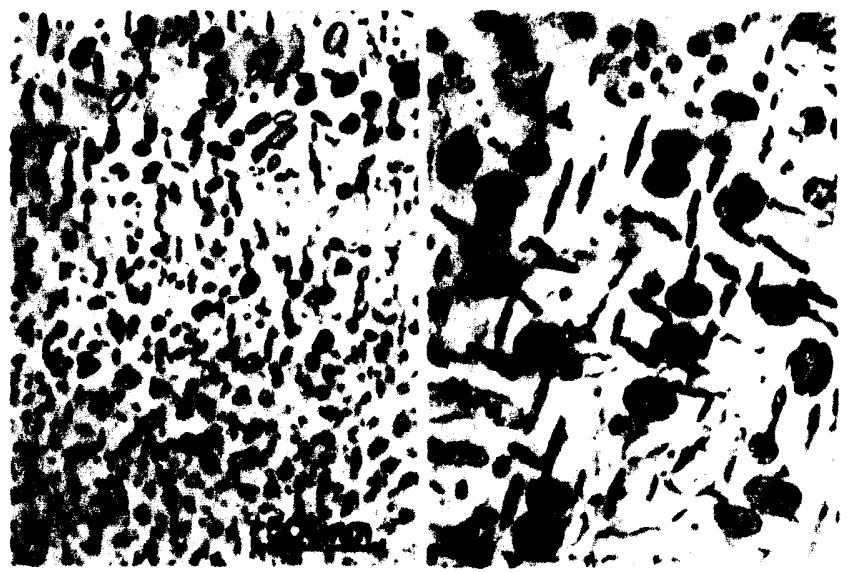
E>1.0 MeV); (b) Improved control $\left(0.96 \times 10^{24} \mathrm{n} / \mathrm{m}^{2}\right)$.

(a) Conventional control $\left(0.92 \times 10^{24} \mathrm{n} / \mathrm{m}^{2}\right.$

'Pacific Northwest Laboratory is operated for the U.S. Department of Energy by Battelle Memorial institute under Contract DE-ACO6-76RLO 1830. 


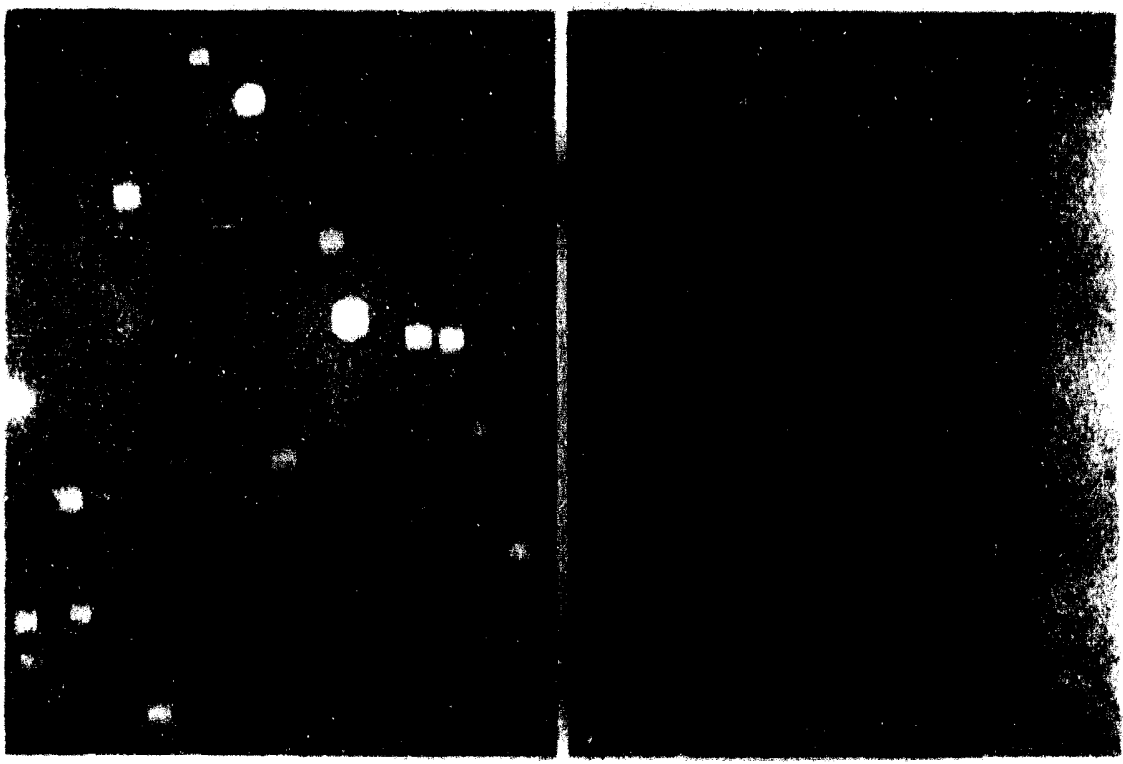
improved control. Same dose levels as Fig. 2.

(a) Conventional control; (b)

When the results of these studies were first presented in a joint Japan/U.S. Experimenters Workshop as an argument that better temperature control during power ascent was required for the operation of the Materials Open Test Assembly (MOTA) in the Fast Flux Test Facility (FFTF), the U.S. side was initially very skeptical. Whereas the joint Japan/U.S. fusion materials program was very fundamentally oriented and focused strongly on low fluence microstructural response as a measure of neutron spectral recoil and transmutation effects, previous U.S. fast reactor studies had focused on macroscopic engineering property changes at high exposure. This latter approach tended to minimize the impact of small "off-normal" or transient irradiation segments.

Subsequent experience has shown, however, that Kiritani's concerns and predictions were valid. At the request of the Japanese side, the MOTA start-up procedure was modified within the limits of the MOTA design. Procedures were also chosen to minimize the impact of interim and shut-down history effects. As will be shown in this paper, however, the influence of lower-than-target irradiation temperatures still persists to some degree.

As the radiation damage community has become more sophisticated in its approach to design and interpretation of microstructurally-oriented experiments, it has become obvious that other routine and apparently inconsequential procedures during the irradiation can strongly influence the microstructural development. The experimenter is often unaware of these procedures. In some cases, the experiment itself can perturb the environment in ways that do not impact reactor operation and, therefore, do not come to the attention of the experimenter or the reactor operator. Frequently, it was the receipt of anomalous microstructural data that signaled that some facets of the irradiation environment were not as well known or as stable as originally assumed.

A series of recent examples from microstructura! studies conducted in various reactors are presented in this paper, concentrating on the microstructural consequences observed in each. Guidelines are then presented to aid in minimizing the impact of temperature history and its associated uncertainties.

\section{Impact of gamma heating}

The temperature experienced in a given irradiation capsule is determined by the local coolant temperature, the gamma heating level and the thermal resistance between specimen and coolant, providing auxillary heating or cooling is not involved. Gamma ray absorption heats materials in a manner analogous to the famous "greenhouse effect", depositing energy that crosses the capsule boundary easily as a photon but which, once converted to thermal energy, must overcome the thermal resistance of the experiment before reaching the coolant. To a first approximation the gamma heating is proportional to the reactor power

Experimenters Workshop on FFIF/MOTA Utilization. Ho proceedings were issued. Workshop was held at the University of Tokyo, on August $24 \cdot 26,1987$. 
Sevel, or more appropriately, to the local neutron flux. While gamma heating values are usually supplied by the reactor staff. these are most probably calculated values for an idedized core loading and are easily perturbed by surrounding subassemblies or by the experiment itself. Many of the gamma rays arise not from fission events but from inelastic scattering events between neutrons and the coolant or solid aterials in the experiment. In water-cooled reactors the major source of the gamma nating arises from neutron interactions with the water coolant. One usually knows the characteristics : the neutron spectra and fluxes better than those of the gamma ray spectra and fluxes.

Three types of experiments can be categorized with respect to the confidence placed in their temperature history. The first of these involves those heated passively by the gamma flux and no: monitored by thermocouples. Therefore, the temperatures are calculated. The second also involves passive heating but is monitored, and the third employs both active temperature measurement and control. :he latter either by supplementary heating or cooling. In the first two categories the temperature will rise or fall as the local neutron and gamma fluxes change. While changes in power level will obviously cause changes in temperature, not-so-obvious changes can arise from the progressive movement of controi rods, changes in surrounding experiments or fuel loading, or from the burnup of nearby fuel, which changes the power distribution within the core.

Actively controlled experiments can also suffer unwanted changes in temperature, especially those experiments that utilize changes in coolant conductivity. In general, actively heated experiments can be designed to have more flexibility than passively heated experiments in resisting changes in temperature.

Thus, for most reactor experiments the most important factors determining the irradiation temperature are the local gamma heating rate and its time-dependent history. For example, the temperature assignments reported for many early experiments conducted without thermocouples in the High Flux !sotope Reactor (HFIR) were later found to be very low compared to their actual values. Because of this problem, Garner has shown that early comparisons of HFIR and fast reactor data are quite inconclusive with resfect to the influence of helium on microstructural development.". Whereas the original calculations for tris water-moderated. highly thermalized neutron spectrum yielded an estimate of 35 watts/gram for stainless steel, it was later determined experimentally that 54 watts per gram was a more correct value. A more recent thermal analysis indicates that the temperatures were from 70 to $125^{\circ} \mathrm{C}$ higher than originally calculated. The more accurate values have been used in HFIR temperature calculations since about 1981 . The realization that the calculated gamma heating rate was too low arose from microstructural observations by "Iaziasz that the precipitate microstructures developed in 316 stainless steel during HFIR irradiation were characteristic of those at higher temperatures, especially those of the intermetallic phases.

The very high gamma heating rates characteristic of HFIR and other highly thermalized water-moderated reactors leads to a very unforgiving irradiation environment. Small changes in thermal resistance during irradiation yield very large changes in temperature. Changes in gas gap wioth between the inner and outer capsules can arise from the temperature dependence of yoid swelling and irradiation creen. At high gamma heating rates, the resulting difference in temperature between the inner and outer cassule walls can be very large and therefore differential swelling can also be large. Even precipitate-ralated densification or dilation of the capsule walls can have a very large impact on the temperature. aelling of the specimen itself can also change the thermal resistance. As a consequence, the dearee of data scatter is generally larger in experiments conducted in such reactors compared to those with lower gamma heating ievels.

Changes in reactor operation beyond the boundaries of the reported experiment can aiso exert a large and sometimes unrealized influence on both the neutron exposure and irradiation temperature. Such changes involve the sometimes strong influence of neighboring experiments, changes in core oading patterns and changes in reflector materials over the course of long irradiation programs. Sometimes, the experimental program itself leads to significant changes in displacement rate and gamma heating. For example, the U.S. Breeder Reactor Materials Program in its buildup phase involved the progressive insertion of non-fueled experiments in the central region of EBR.1I, displacing some of the power generation and the associated gamma heating toward the outer rows, thereby gradually lowering the temperature and noutron flux in each jubcapsule. "The total neutron exposures were measured and reported to the experimenters but the impact of the flux displacement on temperature changes took much longer to be realized. Thus the temperature assignments reported in many early papers had to be revised in later publications. $\therefore$ : the irradiation program peaked and subassemblies were progressively removed, the gamma heating rate and neutron flux again increased for the remiaining experiments.

Changes in irradiation temperature in a given irradiation experiment can arise not oniy from changes in gamma heating and thermal resistance but also from changes in coolant characteristics. often resulting from the experiment itself. Both gradual and abrupt decreases in temperature have been shown to have pronounced effects on neutron-induced microstructural evolution of stainless steels and thereby strongly enhance their roid swelling and irradiation creep behavior. In this group of studies it was shown that a slowly falling temperature, after irradiation had initially proceeded at higher temperatures, was a very effective way to nucleate and grow the $\gamma^{\prime}$ ( $N i$ Si) phase. Formation of this sluggishly growing phase has been identified as a precursor to rapid swelling in 316 stainless steels. 
The potential impact of both deliberate or unintentional changes in irradiation teroerature depends not only on the steel being studied. as well as the magnitude and direction of the temeerature change, but also on the accumulated exposure when the change was initiated. Somet mes the effect on ricrostructural evolution is small and sometimes it is very large.

\section{Enfluence of details of reactor history}

Even in highly thermalized reactors operating at lower power levels or in high flux fast reactors with inherently lower gamma heating rates. it is possible that substantial temperatura history effects can tovelop in esponse to apparently inconsequential operations. often without the knowledae of the aperimenter. The root cause of many of these situations is that most currently avaliable reactors do not nave as their primary responsibility the conduct of materials-related experiments. For instance. HFiR axists primarily to produce radioisotopes and the Fast flux Test Facility (ffTf) operates vrimarily to test ast reactor fuel assemblies. Most materials experiments operate in a parasitic mode and their -equirements cannot be used to dictate all aspects of operational procedure. Even more important, many reactor procedures are directed toward safety or economic considerations which cannot be relaxed to accommodate the needs of the experimenter.

i gr instance, reactor operators are often required to run reactivity feedback tests at a fraction of full Ower or to reduce the power level when off-normal conditions are detected. Reduction in power or iermination of power can occur for a wide variety of reasons. For example. FfTF has experienced power aterruptions as a result of minor operator errors, large brush fires in the vicinity and lightning strikes on the Pacific Northwest electrical distribution grid. HFIR has also experienced occasional shutdowns, specially during the electrical storm season.

An example of economic considerations having a strong impact on a microstructura 11 , -or 1 ented experiment was sovided by yoshida and co-workers. "Who compared the very different microstructures developed in irradiation of AISI 316 at $290^{\circ} \mathrm{C}$ in the Omega West Reactor and the 14 MeV Rotating larget lleutron Source (RTMS-11). The latter experiment was essentially a continuous irradiation with independent temperature control. but the Omega West Reactor was operated for a cost-effective single 8-hour shift each day, and a adily ascent to full power was required. This introduced repeated transients in atomic displacement rate and, more important, temperature. Whereas the spectral effects comparison of Heinisch on these same cocimens was originally interpreted in terms of recoil spectra and the possible influence of displacement rate at higher temperatures, it appears that temperature history actually played the major role.

Even in reactors operated for long continuous periods, there are often unrecognized effects of temperature bistory. Kiritani. Yoshida and coworkers were the first researchers to spotlignt ine impact of temperature nictory during the early power-up stages and to clearly demonstrate experimentally :he impact of such history on microstructural evolution. .: ${ }^{2}$. They showed that most of the microstructure observed in oas ively pperated experiments to relatively low fluences was actuall nucleated at lower temperatures luring the power-up phase. When compared in the same irradiation secuence with ape results of active - mperature-controlled irradiations, the microstructures obtained in cassive experiments were often found to he very different. One quote of Kiritani of significance to later sections of this oaper is that "only exerai percent of exposure to neutrons at lower temperature was found to result in one hundred percent : ference in the final defect structures in some cases, while it causes on iv a s? int difference in thers. xiritan also demonstrated that most researchers reoort the bare hiniram ot anormation anerning the temperature history of their experiments, ath the molicit but in 30 uertantly incorrect is sumption that a completely isothermal history was involved.

Thare are several ways to avoid or at loast minimize the oroolems defined by kir:anl aurirg the power ascent stage. ine method is to employ electrical heating to bring the specinens to semperature prior to tartuc. This was the solution emploved by kiritani and coworkers in alf. In noner nower roactors. nowever. jestaners are often reluctant to employ such heating. sceina it a tinre lable. ath the neating als possibly jegrading at higher displacement levels. in diternate afproacn is to icand to power as anckl, as cossible. This latter method is often limited by sateti and ite extension onsiderations. for

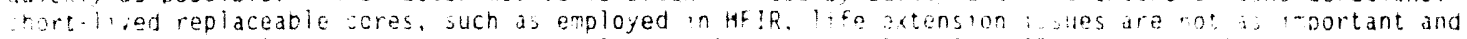

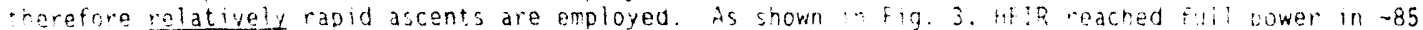
deutes diring an experiment designed to measure the adma neating ievel. this corresconcs to 0.003 doa.

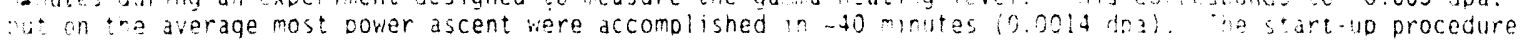
in tip rradiations nas recently been modified to use oure roon or aroon as the control adj during an actendes start up in order to keep the temperature as close to the operating temporature as possibie.

$\therefore$; moortant to note. however. that HFIR underqoes cote reoiacements approximatei:sievy trenty-two days - mintain efficient production of crf. (The high flux and oower level in Hfip turn out the fuel in this colt oeriod). When unanticipated power outages during a core lifetime are added inis means repeated coconts and ascents in power during the lifetime of a nign fluence experinent.

: he exel of regulatory scrutiny and emphasis on safety and startuo checks incraases, however, the cont to power times have tenced to increase. Curing a six jonth deriod between tarch and September loge $\therefore$ tnstarce. the fourteen ascent to power times ranged from 30 rinutes to 3.5 hours. he iongest period

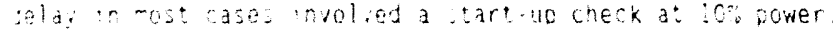




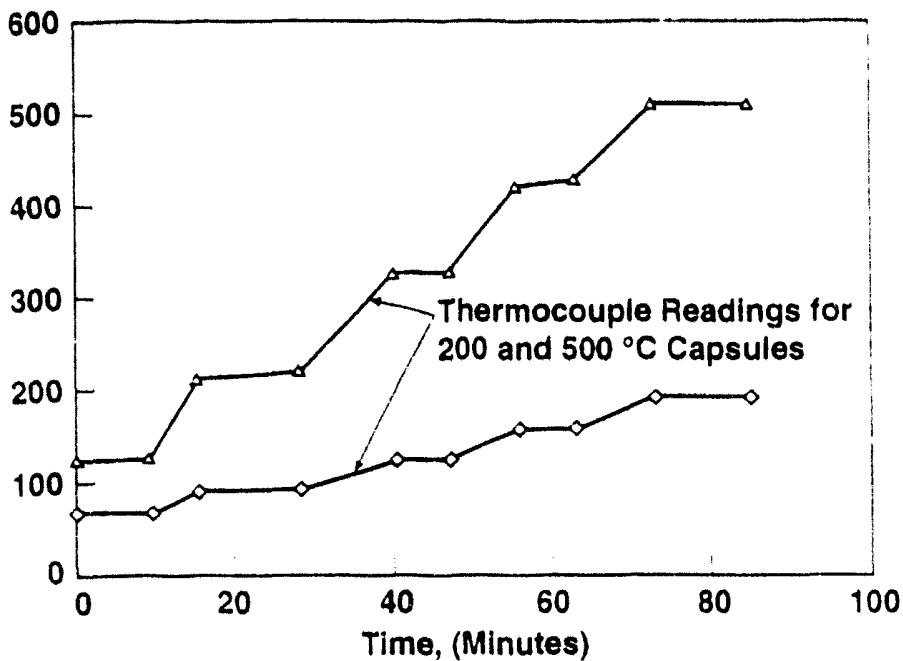

Fig. 3. Ascent to power history of the HFIR Target Nuclear Heating Experiment.

in larger cores. such as that of FFTF, the approach to power is typically on the order of 1-2 days. This is done to assess the impact of new core loadings on reactor reactivity and to minimize thermal shock of components as the temperature rises. In response to Kiritani's concerns. it was not possible to motify the power ascent procedure of FFTF but the operational procedure of the ilaterials Open. Test Assembly (MOTA) was modified, placing the temperature control system into operation at the eariliest cpportunity, instead of aditing unt il the reactor approaches full power. MOTA achieves temperature control $0=5: C$ by measuring the temperature of each canister ard then modifying, if necessary, the thermal resistince by choosing farying mixtures of helium and argon cooling gases. Purging with loon hellum dum reactor operation leads to the lowest oossible temperature in each canister.

since the initial studies of kiritani, yoshida and their covorkers in Mik and ofa. . ras come to the attention of the materials community that temperature history offacts have occurrer in other reactors, both juring irradiation and upon shutdown. A series of recentlv observed exampies are a on in the following sections.

\section{influence of FFTF shutdown procedures}

Eradiations conducted using thw MOTA in FFTF typically involve three one-huncred da irradiation savences. separated by controlled shutdowns and interim zero-power periods for fuel rotation and other aintenance operations. These segments are typically designated as subcycles such as $10 a$. 10b and loc, were cycle 10 is the designation for a particular 300 day cycle.

There are a number of ways in which the MOTA temperatures anu FFTf power can vary during an FFTf cycle

shutdown. Various combinations that have occurred are as follows:

1) Controlled reactor shutdown over a period of Eeveral hours: Mota not he hum curaed.

(2) Controlled reactor shutdown over a period of several hours: 100TA helium curged before shutdown.

3) Reactor scrammed by dropping the rends: Yota not purqed.

4) Feactor scrammed by runnug the control rods into the core over a oeriod of ninutes: M0TA not ourqed.

(5) Peactor power and flow reduced to $75 \%$ during a reactivity feedback measurement test. followed by a controlled reactor shutdown over a period of several hours: MOTA not purged.

Controlled shutdowns involve reducing the power level several percent at a time and then holding each new cower level for 20-25 minutes. This produces an approximate ramp-down in power with "stairstep" reductions in temperature occurring in the MOTA canisters. 
The controlled stutdowns without hellum purging of lie itf. (1) and (5) above. are the preferred methods of shutdown. The procedures employed for MOTA operation now require this kind of shutdown. The controlled sutdown of the reactor is used to minimize thermally.induced stresses in piping, instrument trees and irive lines. Peactor scrams are permitted and sometimes required to demonstrate fall-safe behavior, but excessive numbers of reactor scrams can reduce the plant ife and are thus normally reserved for safety considerations involving the termination or avoidance of off-normal behavior.

Purging the MOTA before a controlled shutdown, (2) above, was the policy on earlier MOTAs, and was used orimarily to obtain end-of-cycle helium purge data. Although this is no longer considered to be desirable, this procedure was used as recently as cycle loc. Reactor scrams occasionally occur during cycles, but an FFTF cycle and MOTA irradiation sequence sometimes also end on a reactor scram. as was the case for MOTA-IG and MOTA.2A. both conducted in FFTF Cycle $11 \mathrm{C}$.

sekimura and Ishino recently noted that $\mathrm{Fe}-15 \mathrm{Cr}-16 \mathrm{Ni}$ and two $\mathrm{Fe}-15 \mathrm{Cr}-16 \mathrm{Ni}$ solute-modif ied alloys irradiated to -30 dpa in MOTA-1F during FFTF Cycle 10 had developed many small dislocation $100 p 5$ at 520 and $600^{\circ} \mathrm{C}$ that were atvpical of irradiation at such temperatures. ... Based on the loop size, density, and independence of alloy composition, as shown in Fig. 4. Sekimura and Ishino deduced thai these loops were formed at lower temperatures at the end of the irradiation. "Note that the density of the loops is larger for the specimens irradiated at $600^{\circ} \mathrm{C}$ than those irradiated at $520^{\circ} \mathrm{C}$, a behavior which is also atypical of isothermal irradiation. Specimens irradiated at $420^{\circ} \mathrm{C}$ did not exhibit the anomalous loop behavior. As shown in Fig. 5. a comparable irradiation conducted in MOTA-2A did not exhibit the anomalous loop formation observed in MOTA-1F. In the first case MOTA-IF was purged with helium and then the reactor was reduced to $-5 \%$ power over a six hour pericd. In the second case MOTA was held in control and the reactor scrammed by running in the rods. Aropping both the neutron flux and temperature in severa! rinutes. A full description of the temperature nistory for both MOTAs is presented elsewhere.

4s shown in Fig. 6. similar anomalous loop formation was also observed in Fa-15i.r. $25 \mathrm{ili}$ - xp alloys irradiated in another subcapsule in MOTA-IF." indicating that the observation of sekimura and lstino was not an axceptional case

After helium ourging of MOTA-If, six hours was required for the power level to be reduced from 100 to $5 \%$. ihis was equivalent to 3 effective full-power-hours of neutron irradiation, during which an additional 0.02 doa was accumulated. In the " $500^{\circ} \mathrm{C}$ " capsule, there was an immediate drop of $-110^{\circ} \mathrm{C}$ upon helium purging, followed by a much rore gradual decline over the next. six hours. In the " $520^{\circ} \mathrm{C}^{\prime}$ capsule. the initial drop was onty $-50^{\circ} \mathrm{C}$. Followed by a less rapid decline. These different temperature drops account in part for the atypica? Dehavior shown in $\mathrm{Fig}$. 4, where more loops were formed at $600^{\circ} \mathrm{C}$ than at $520^{\circ} \mathrm{C}$. Radiationinduced nicrostructural densities are known to increase at lower target irradiation temperatures, providing roater numbers of sinks for absorption of point defects produced during the shutgown oeriod. Thus, the inndency toward nucleation of new dislocation loops decreases at lower target cemperatures. Based on the * wo considerations of higher sink strength and lower temperature drop unon nurgun. . is not surprising inat small isops were absent after iradiation at -420 : by Sekimura and ishino. : $: \cdots$ ila observation was ade in the Fe-15Cr-25lli-kP ailoys irradiated at 420 C D Garner and owerere.

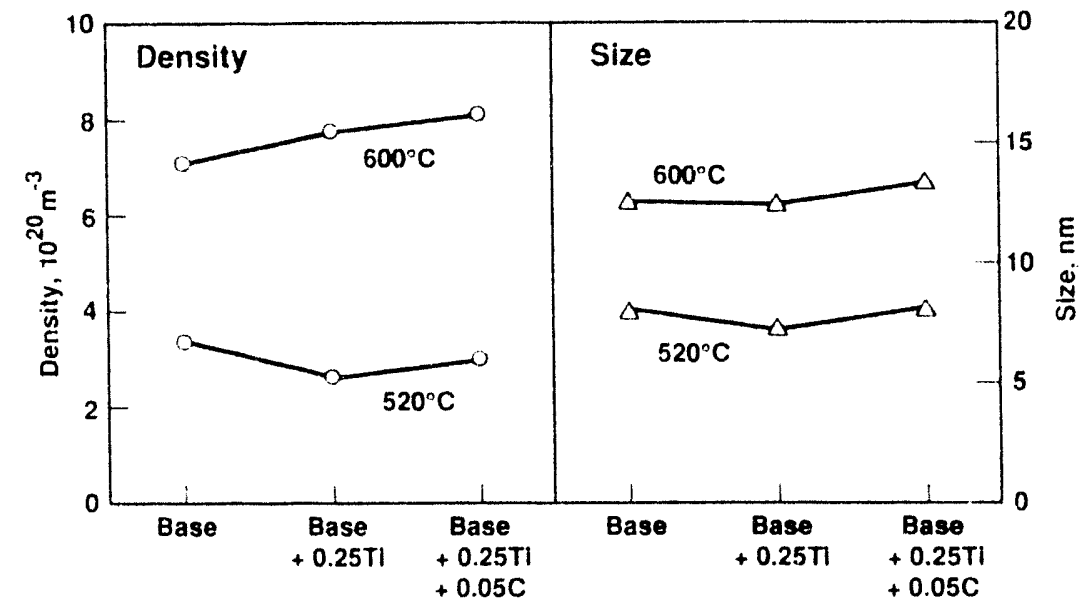


MOTA-IF

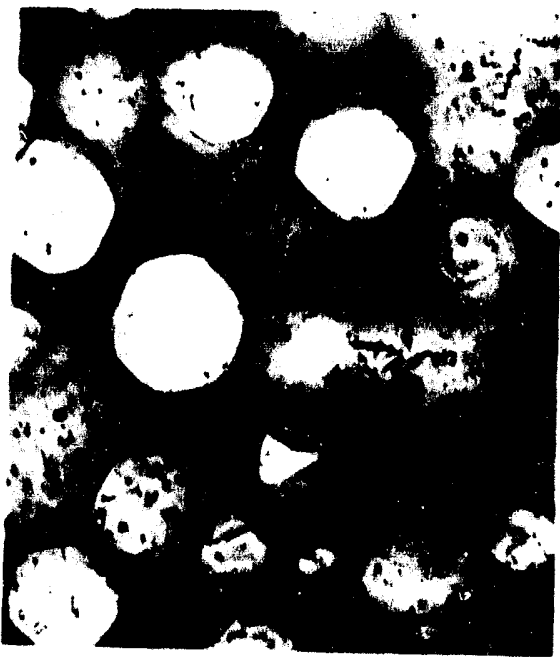

\section{MOTA Helium Purged Before Slow Shutdown at $\mathbf{4 0 . 5} \mathrm{dpa}$}

MOTA-2A

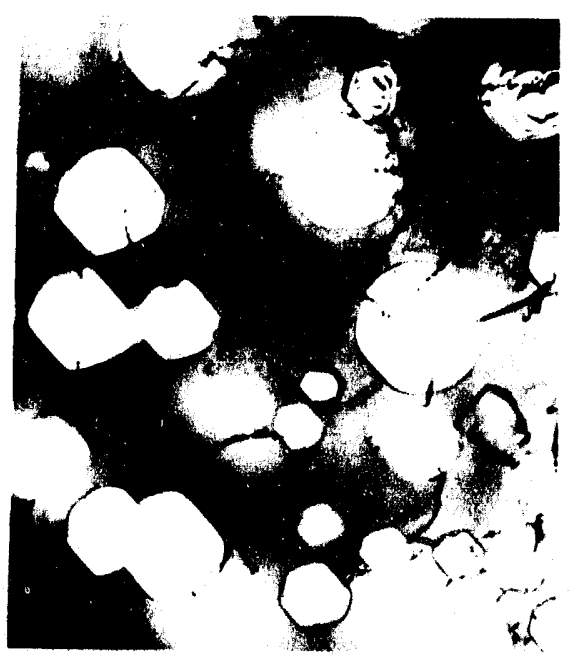

Reactor Scrammed at $36.1 \mathrm{dpa}$

Fig. 5. Small loops formed in Fe-15Cr-16Ni irradiated at $600^{\circ} \mathrm{C}$ in MOTA-1F, but not formed in MOTA-2A. ${ }^{19}$

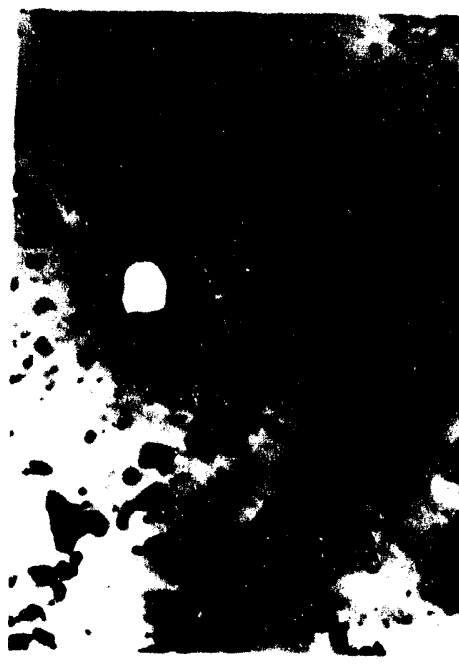

$20 \%$ CW $<0.005 P$
0.013P

\section{Annealed}

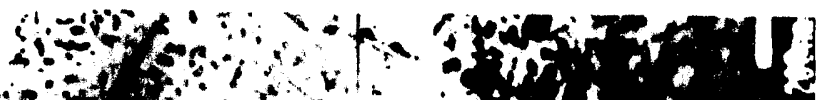

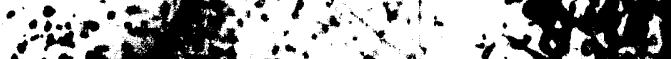

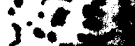

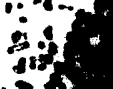

23
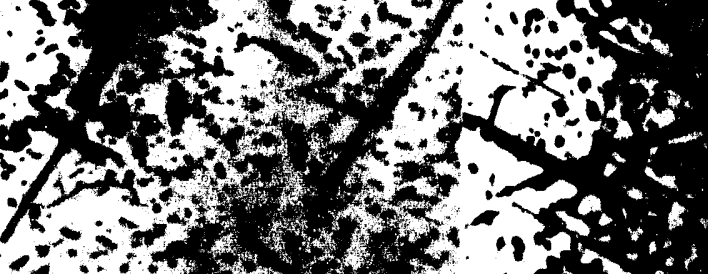

$-1,-3,+\infty$

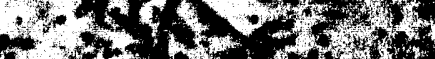

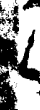

중

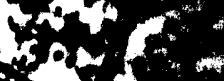

thy

Annealed

0.10P

Fig. 6. Anomalous loop production observed in three $\mathrm{Fe}-15 \mathrm{Cr}-25 \mathrm{Ni}-\mathrm{XP}$ alloys after irradiation at $600^{\circ} \mathrm{C}$ to $31.8 \mathrm{dpa}$ in FFTF Cycle 10 using MOTA-1F. Increasing concentrations of phosphorus in solution increase both the precipitate and the loup production." 
Since helium purging was not involved at the end of Cyciles $10 \mathrm{~A}$ and $10 \mathrm{~B}$, it is expected that the influence of temperature history in the first two cycles would be small since the -0.02 dpa irradiation during shutdown proceeded at temperatures closer to the target temperature. It is also anticipated that any accumulated lower temperature microstructure would quickly be dissolved at the beginning of the next reactor subcycle. This also implies that final shut-down procedures may be more important than start-up procedures or earlier shut-downs. It cannot be said for certain, however, that the intermittent nucleation of this atypical microstructure did not have any consequence on cavity evolution. Sekimura and Ishino noted that the short term accumulation of small loops during the three shutdown sequences of Cycle loc may or may not have influenced the void swelling or precipitation very much, but the addition of small loops at the end of the last irradiation segment would strongly affect mechanical property measurements because of their associated hardening.

Even a controlled reactor scram does not guarantee that the shutdown procedure will not influence the microstructure, however. Fig. 7 shows the microstructure of $20 \%$ cold-worked $\mathrm{Fe}-17 \mathrm{Cr}-16 \mathrm{Ni}$ irradiated to 36 dpa at $600^{\circ} \mathrm{C}$ in MOTA-2A. ${ }^{\circ}$ This sequence was terminated by a controlled scram. The temperature reached by the specimens following the scram was $325^{\circ} \mathrm{C}$, the normal preheat temperature from which power ascent begins. The sodium temperature in FFTF is maintained at this temperature by a combination of coolant pump speed, resistive heating and baffle control on the dump heat exchangers. One day after the scram these parameters were adjusted to drop to the standby temperature of $210^{\circ} \mathrm{C}$, at which MOTA resides for periods ranging from 2 to 29 days before being removed from FFTF.

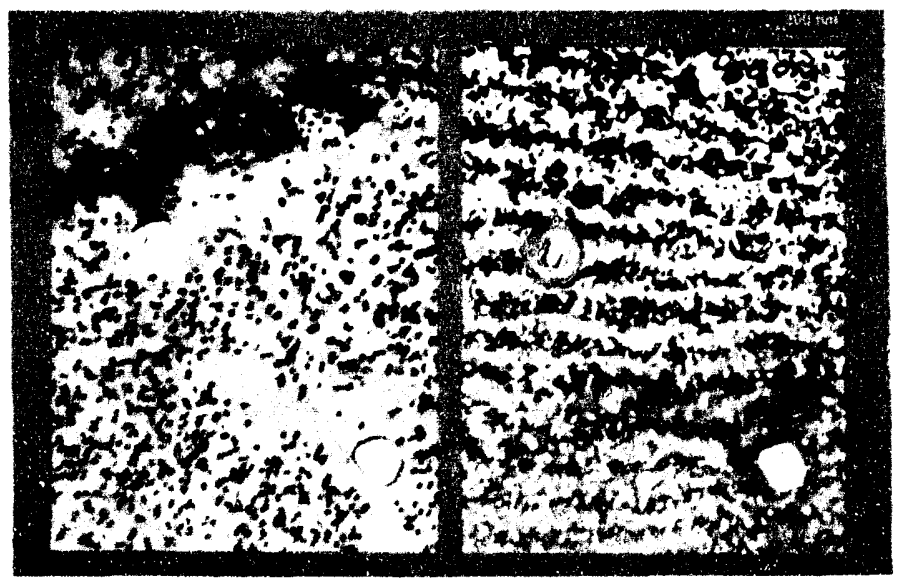

Fig. 7. Stacking fault tetrahedra observed to form in cold-worked Fe-17Cr-16Ni following irradiation at $600^{\circ} \mathrm{C}$ to $36 \mathrm{dpa}$ in FFTF Cycle 11 using MOTA-2A, (a) bright field and (b) dark field images.

During the 24 -hour period at $325^{\circ} \mathrm{C}$ extensive formation of vacancy stacking fault tetrahedra developed in this pure quaternary alloy as shown in Fig. 7. These tetrahedra probably arise from a vacancy supersaturation resulting from the relatively quick drop in temperature. A great?y reduced and almost overlooked density of tetrahedra was observed in a companion specimen irradiated in the annealed condition. "The much larger swelling level (-20\%) in the annealed steel provided extensive cavity sinks for the vacancies that otherwise would agglomerate and form tetrahedra. Note in Fig. 7 that the few voids observed in the cold-worked specimen appear to denude the adjacent regions of tetrahedra. As would be expected, alloys containing significant levels of solutes did not form tetrahedra.

\section{Power setbacks in ORR}

Comparative irradiation studies were recently -onducted in the Experimental Breeder Reactor II (EBR-II) and the Oak Ridge Research (ORR) reactor to study the influence of helium/dpa ratio and displacement rate on the microstructural evolution of $\mathrm{Fe}-15 \mathrm{Cr}-\mathrm{XNi}(X=10-45 \mathrm{wt} \%)$ and $\mathrm{Fe}-\mathrm{YCr}-35 \mathrm{Ni}(Y=7.5,15$ and $22 \mathrm{wt} \%)$. ${ }^{21-23}$ As shown in $\mathrm{Fiq} .8$ there was an unprecedented refinement of the cavity microstructure in the ORR experiment which was ccaducted at nickel-dependent helium/dpa levels ranging from 27 to 58 appm/dpa. In EBR-II the levels were 0.66 to $1.2 \mathrm{appm} / \mathrm{dpa}$. As shown in Fig. 9 one consequence of this refinement was a substantial difference in the radiation-induced hardening in the two irradiations.?

When compared to the much less responsive behavior with helium content observed in the ${ }^{53} \mathrm{Ni}$ isotope tailoring experiment conducted in FFTF/MOTA, ${ }^{25-25}$ it was decided to review the operational history of the ORR experiment, which also has a low inlet temperature and a relatively high gamma heating rate. It was discovered in this review that there were indeed frequent and large reductions in power (designated as "setbacks") throughout the irradiation history in response to various routine or non-routine operating 


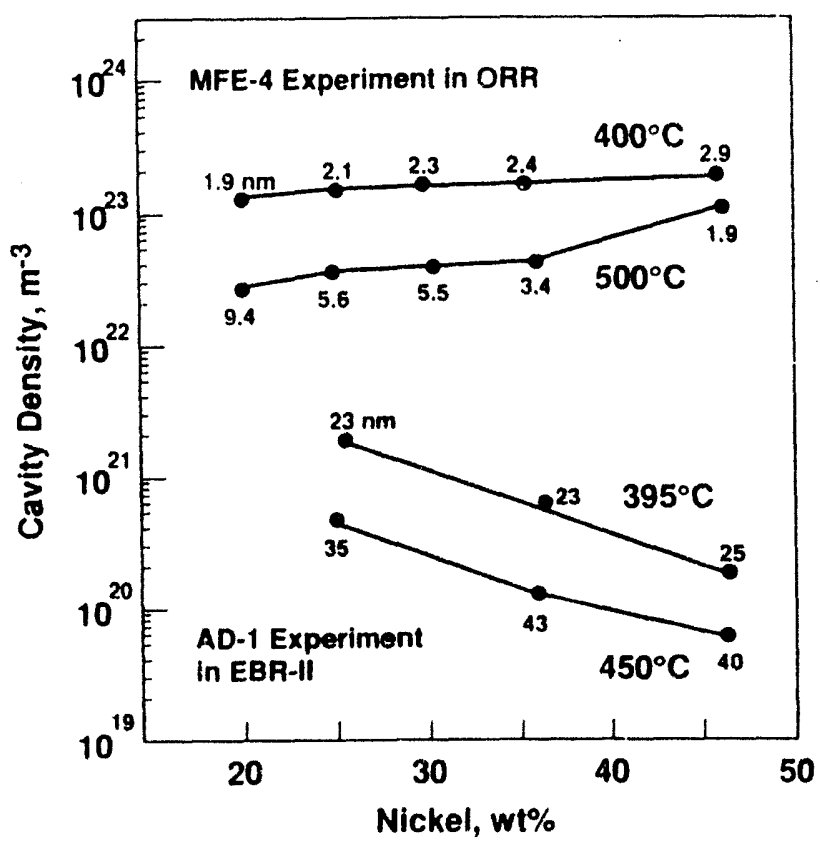

Fig. 8. Cavity densities observed in $\mathrm{Fe}-\mathrm{i} 5 \mathrm{Cr}-\mathrm{XN1}$ alloys irradiated in the A.D-1 experiment in EBR-1I $(9.5$ to 11.332 Mean cavity sizes in nm are shown next to each data point.

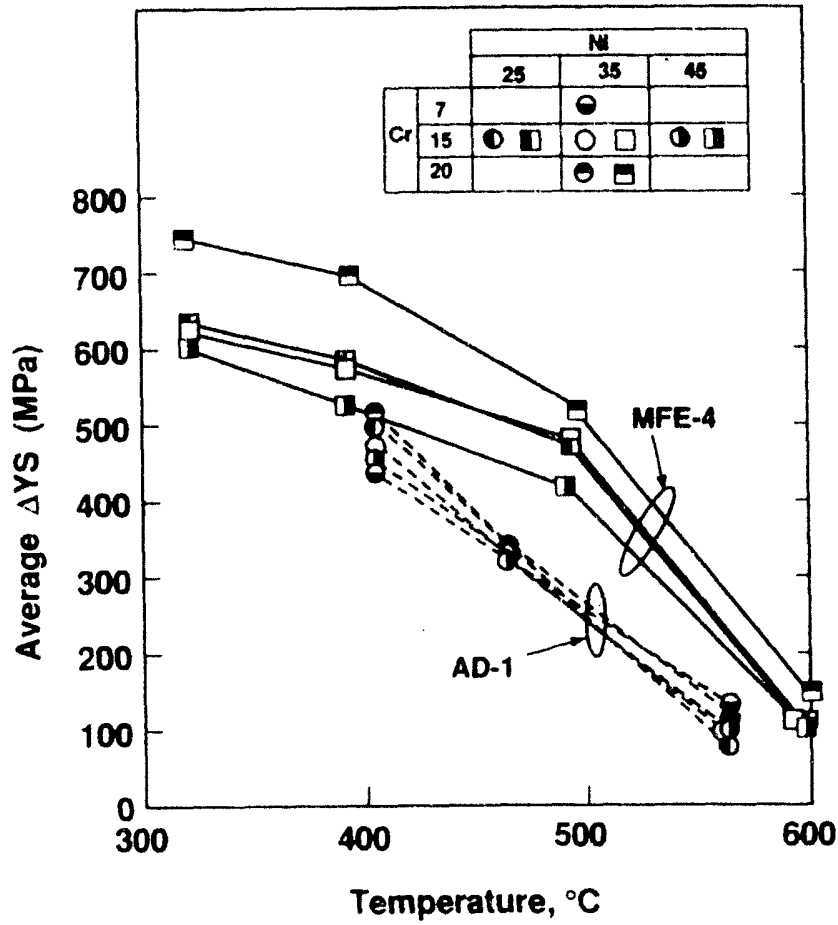

Fig. Comparison of yield strength changes of $\mathrm{Fe}-\mathrm{YCr}$.

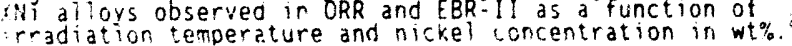

- ontungencies, examples of which are shown in Tables 1 and 11 . The $600^{\circ} \mathrm{C}$ irradiation. for instance, was interrupted by 237 cutbacks in temperature during just one year of the three year experinent. Thus, 0.12 dpa of the 3.5 dpa accumulated that year was at temperature well below $600^{\circ} \mathrm{C}$. This is much larger than the levels shown by the separate studies of Kiritani, Sekimura. Garner and their coworkers to proquce large densities of small loops.

It is proposed that the frequent intermittent reductions in temperature caused periodic and profuse production of small dislocation locps, known to be efficient nucleation sites for helium bubbles" in this high He/dpa

experiment. Once formed, these bubbles are sessile and remain after the loop disappears when the target temperature is re-established. By this mechanism the cavity microstructure is refined to an unprecedented extent, and the resultant cavity mic ostructure is completely atypical of that attained in isothermal irradiation

\section{Impact of operational choices}

Results of extensive void swelling studies conducted on simple $\mathrm{Fe}-\mathrm{YCr} \cdot \mathrm{XNi}$ ternary alloys in FFTF/MOTA employing the early MOTA vehicles are now being analyzed. One unusual feature of these results is that more swelling is observed at $600^{\circ} \mathrm{C}$ than at $520^{\circ} \mathrm{C}$. This is in conflict with the results of identical studies conducted in EBR-II.

studies there was always a monotonic increase in the duration of the transient regime of sweiling with increasing temperature, especially at higher nickel levels $(\geq 25 \% \mathrm{~N}$ ). There were also other striking differences in behavior observed between specimens irradiated in the two reactors.

Since there was ample prececent established for emperature history effects when this disparity was observed, the early MOTA temperature history was remewed in detali. it was found that several prolonged, unannounced helium purgings of MOTAS $1 B$ and IC had occurred. This example demonstrates how the primary mission of a ractor is sometimas in conflict with the goals of minor experiments. The neces: $1: y$ io make such a choice arnse because the wirlous Motas also contained large numbers of jas-cressurized stress-rupture tudes jesigned to fall during irradiation, with each ingividuai fallure detected by the ralease and detection of a mixture of various isotopes of xenon and krypton tag gases." A 5 milar but slightly different system was also used to identify fallure of individuai fuel ins in FFTF since the major mission of fiff was to conduct fue? oin evaluations. the identification of each detected fuel pin fallure in the ear?, stages of the FFTF program became the immediate and paramount objective of the reactcr uperations staff. To ensure that no competing gas tag signals occurred to interfere with easy identification of the 
Table 1. Setbacks recorded in the $600^{\circ} \mathrm{C}$ capsule of the MFE-4 experiment in ORR during the first year.

\begin{tabular}{|c|c|c|}
\hline $\begin{array}{c}\text { Temperature Reached } \\
\left({ }^{\circ} \mathrm{C}\right)\end{array}$ & Number of Setbacks & $\begin{array}{c}\text { Total dpa during } \\
\text { setback } \\
\left(\times 10^{\circ} \text { doa }\right)\end{array}$ \\
\hline $50-100$ & 1 & 1.7 \\
$100-150$ & 10 & 20.2 \\
$150-200$ & 6 & 21.7 \\
$200-250$ & 8 & 51.3 \\
$250-300$ & 6 & 37.5 \\
$300-350$ & 18 & 101.2 \\
$350-400$ & 46 & 3237 \\
$400-450$ & 77 & 458 \\
$450-500$ & 20 & 759 \\
$500-550$ & 45 & $11.894 .6=0.12$ doa \\
\hline Total & 237 & \\
\hline
\end{tabular}

Table 2. Setbacks recorded in the $330^{\circ} \mathrm{C}$ capsule of the MFE-4 experiment during a six month period.

\begin{tabular}{|c|c|c|}
\hline $\begin{array}{l}\text { Temperature Reached } \\
\qquad(C)\end{array}$ & Number of Setbacks & $\begin{array}{c}\text { Total dpa during } \\
\text { settack } \\
(\times 10 \text { doa })\end{array}$ \\
\hline $\begin{array}{l}50-i 60 \\
100-150 \\
150-200 \\
200-250 \\
250-300 \\
\end{array}$ & $\begin{array}{c}7 \\
3 \\
3 \\
12 \\
25 \\
\end{array}$ & $\begin{array}{l}18.5 \\
10.1 \\
36.5 \\
315.5 \\
1506 . \\
\end{array}$ \\
\hline Total & 50 & $1887.5=0.019 \mathrm{dod}$ \\
\hline
\end{tabular}

loaking fuel plri, the decision was made to purge the MOTA with helium for $2-3$ days at a time, lowering the :emperatures of all specimens substantially, and thereby discouraging the rupture of creep tubes in MOTA. of course, this lowered the temperature of all specimens in the MOTA.

One of the most effective ways to nucieate voids in Fe-cr-Ni austentic alioys at "gr senperatures is to Gevelop disiciation microstructures at the target temperature and then drop to lower emneratures where ,nd nucleation is mucn easier. Radiation-induced segregation and raludiffusion a co : lay roles in void ucleation and both of these increase with irradiation temperature. re ret rasuit. - . at a stable void copulation begins to develop sooner at a target temperature of $600^{\circ} \mathrm{C}$ following a strora tomoerature induction than it does it $520^{\circ} \mathrm{C}$.

ame operational procegures invoiving day-to-day mantenance of an nuluduai experiment by reactor staff arry the risk of errors. Jne of the most significant exampies involves the inadvertert aciostitution by

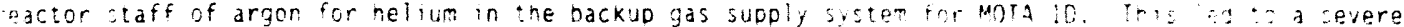

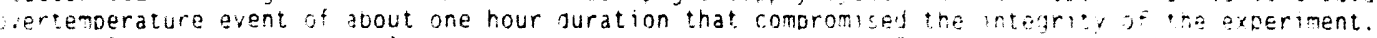

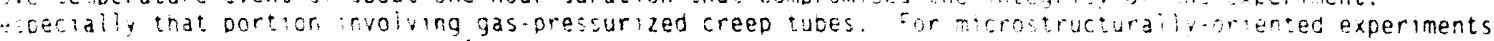
-his excursion may have been overlooked or incorporated into the interpretation of the experiment. ine ifluence of the overtemperature was overshadowed, however. Dy the joint jecisun of ing experimenters and

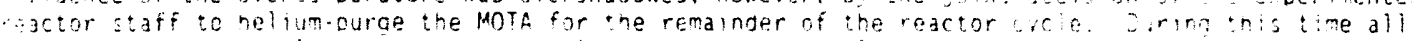

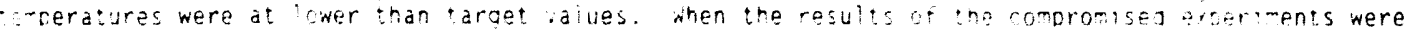

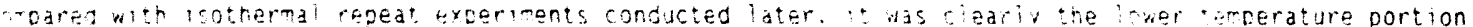

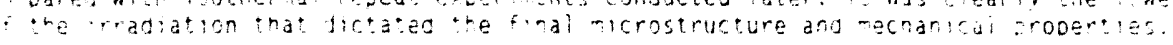

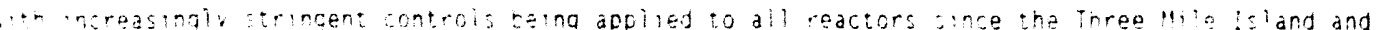

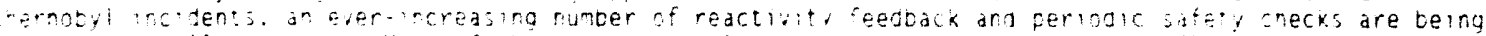

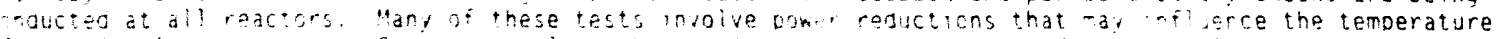

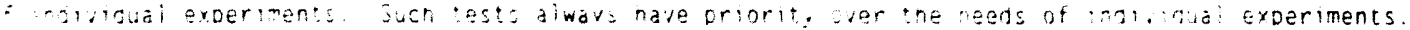

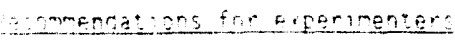

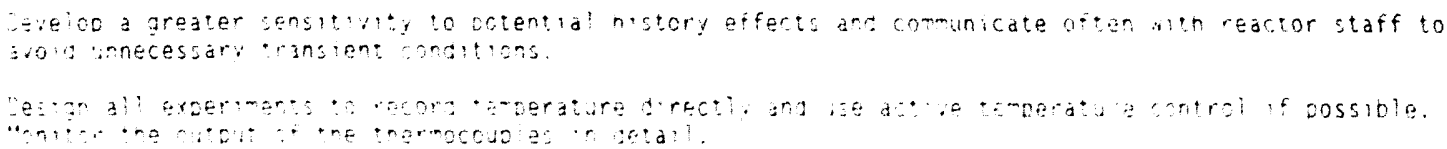


3. Avold irradiating during periods of off-normal reactor testing. Ctherwise, design the experiment to be removed from the reactor for these periods.

4. Modify the temperature control of the experiment to minimize the effect of reduced power operation.

5. Develop contingency plans with reactor staff for foreseeable contingencies involving power variations and interruptions.

6. Design individual experiments such that temperature history is not the dominant yariable, assessing other variables in side-by-side irradiations.

\section{Discussinn and conclusions}

As the radiation damage scientific community has become more aware of the many factors that influence the evolution of radiation-induced microstructure, the impact of the details of temperature history has assumed a larger role, especially for experiments where relatively low levels of total exposure are used to study the effects of neutron spectra or damage rate. There is also some concern that repeated transients in temperature over the lifetime of an irradiation experiment will yield a microstructure at high fluence that is atypical of that produced during completely isothermal operation. It should aiso be noted that many published theoretical explanations of the temperature dependence of nucleation of microstructural components do not in general include the influence of the kinds of temperature history discussed in this paper. Thus, the material parameters derived in these experiments, especially energies of formation, migration and binding of point defects. may have been strongly affected by the small increments of irradiation at lower temperatures.

While it appears that low temperature microstructure produced at low fluence levels will tend to dissolve at higher temperatures and higher fluences, several examples have been presented in this paper where significant microstructural alteration persisted. This was shown to be especially important when high rates of helium generation were involved.

The extensive high fluence data base on dimensional instabilities and mechanical properties that were generated in the reactors discussed in this paper is not necessarily invalidated by anomalies related to temperature history. When such data are applied in design situations similar to those in which the data were derived, the impact of unavoidable transients becomes in most cases a relatively minor facet of the irradiation environment, but one that is typical of the actual history of an irradiated material. When data are derived in one reactor environment, however, but then applied to another environment where the neutron spectra and reactor environment (displacement rate and temperature history) are significantiy different, then allowance must be made 0 account for the impact of history-related pienomena.

FUTURE WORK

This effort is complete.

\section{ACKNOWLEDGMENTS}

The Darticipation of the U.S. participants was sponsored by the U.S. Cesartment of tharay under three separate contracts. The participation of the Japanese participants was soonsored h: the JapaniU.S. coilaboration between the U.S. Department of Energy and Monbusho, the Japanese 4 nist. of Education. Science and Culture. Pacific Northwest Laboratory is oderated for the U.S. COE o, Batlelle Memoriai institute under Contract DE-AC06-76RLO 1830. Oak Ridge National laboratory is onerateg for the U.S. DOE by Martin Marietta Energy Systems, Inc. Under Contract De-ACO5-840R214000.

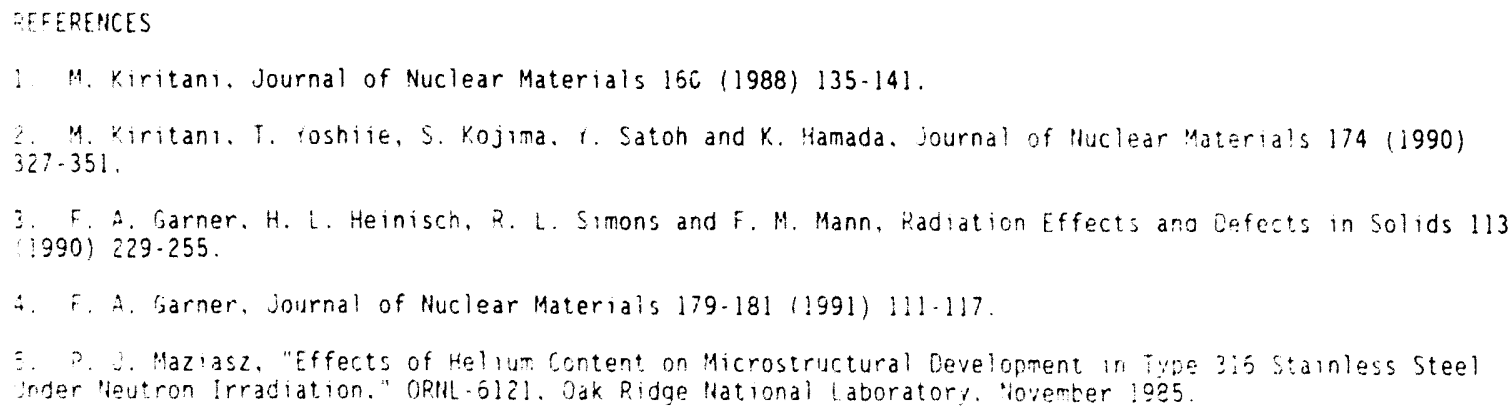


5. F. A. Garner, W. V. Cummings, J. F. Bates and E. R. Gilbert, "Densification-Induced Strains in 20\% Cold-Worked 316 Stainless Steel During Neutron Irradiation," HEDL-TME 78-79, Hanford Engineering Development Laboratory, June 1978

7. R. J. Puigh, A. J. Lovell and F. A. Garner, Journal of Nuclear Materials 122-123 (1984) 242-245.

8. R. W. Clark, A. S. Kumar and F. A. Garner, Journal of Nuclear Materials 155-157 (1988) 845-849.

9. F. A. Garner, E. R. Gilbert, D. S. Gelles and J. P. Foster, pp. 698-712 in Effects of Radiation on Materials: Tenth Conference ASTM STP 725, 0. Kramer, H. R. Brager and J. S. Perrin. EdS.. American Society for Testing and Materials, 1981.

10. W.J.S. Yang and F. A. Garner, pp. 186-206 in Effects of Radiation on Materials: Eleventh Conference, 1STM STP 782, H. R. Brager and J. S. Perrin. Eds., American Society for Testing and Materials. 1982.

11. D. L. Porter, E. L. Wood and F. A. Garrer, pp. 551-559 in Effects of Radiation on "aterials: 14th International Symposium (Vol. II), ASTM STP 1046. H. H. Packan, P. E. Stoller and a. S. Kumar. Eds.. American Society for Testing and Materials. 1990.

12. N. Yoshida, Journal of lluclear Materiais 174 (1990) 270.228

13. H. Koshida, H. L. Heinisch. T. Muroga, K. Arak and M. Viritani, Journal of Muclear Materials 179-181 (1991) $1078-1082$.

14. H. L. Heinisch, Journal of Nuclear Materials 155-157 (:988) 121-129.

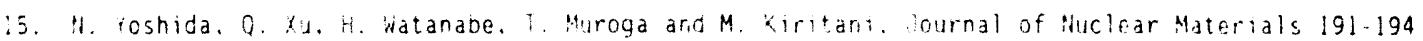
$199 ? \lcm{1114}$

16. R. J. Puigh and R. E. Schenter, pp. 759-802 in Effects of Radiation on Materials: iwelfth international Symposium, ASTM STP 370. F. A. Garner and J. S. Perrin. Eds., American society for Testing and Materials, 1985

17. F. A. Garner, A. M. Ermi. N. Sekimura, and J. 'N. Hewkirk, Dp. E-16 in Fusion reactor Materials Semiannual Progress Report DOE/ER-0313/11 (1992).

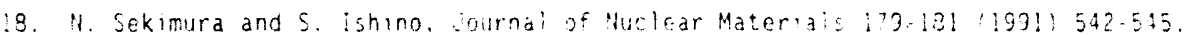

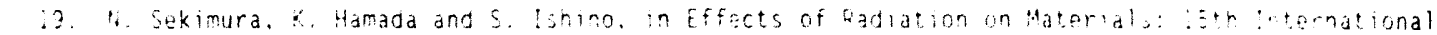

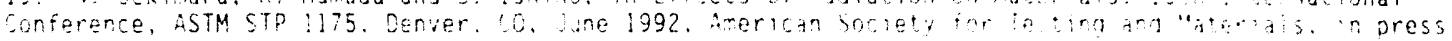

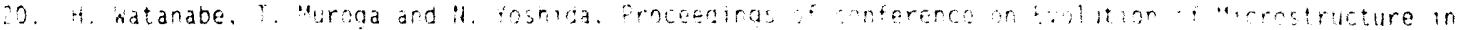

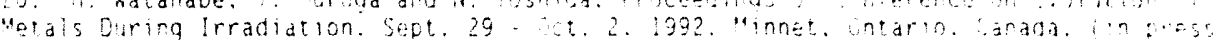

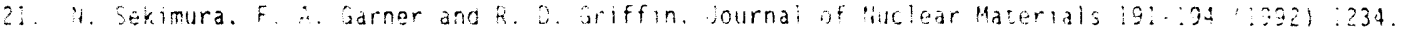

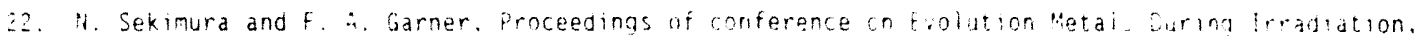
Sent. 29. Oct. 2. 992 . Minnet. Intario. Canada. (in presel.

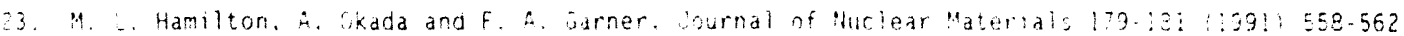

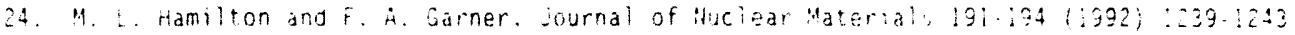

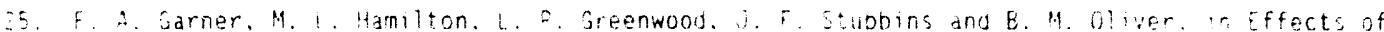

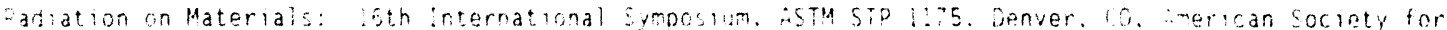
asting and Materiats. in press:

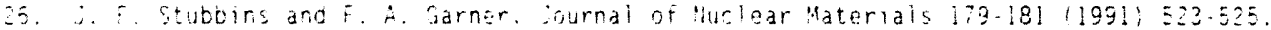

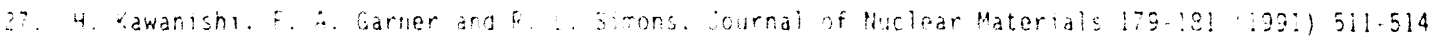

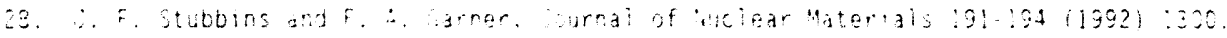

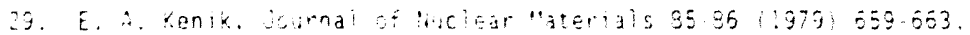

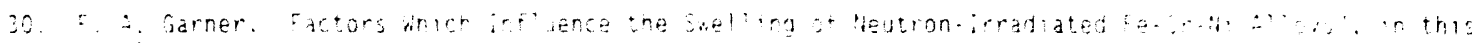
jomianual report.

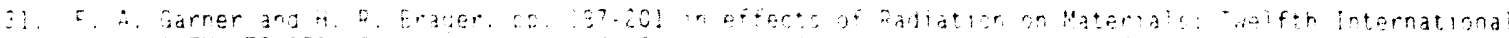

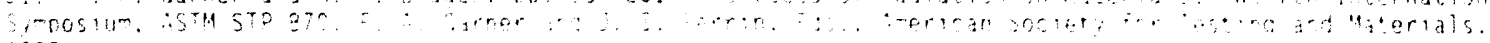

$: 2 .=A$ Garner and 4 . S. kumar, o0. 289.314 in Radiation Induced Channes in Micrastricture: 13 th international Symposium (Part I) ASM STP 955. F. A. Sarner. N. H. Packan and A. 3 . Imar. Eds., American society for iesting and Materials., 987 
NEUTRON-INDUCED SWELLING OF PURE NICKEL AND NICKEL BINARY ALLOYS - F. A. Garner (Pacific Narthwest Laboratory) ${ }^{\mathrm{a}}$

\section{OBJECTIVE}

The objective of this effort is to provide insight on the factors which control the microstructural evolution of irradiated metals.

SUMMARY

The second and last phase of the EBR-I1 AA-14 experiment confirms many of the trends observed in Phase I of the experiment. Phase I reached 12 to $14 \mathrm{dpa}$ for pure nickel and nickel-binary alloys at 425 , 500 and $600^{\circ} \mathrm{C}$. Phase II reached 31.1 to $31.8 \mathrm{dpa}$ at the same temperatures.

Annealed nickel exhibits a strongly temperature-dependent tendency toward saturation of void swelling. This tendency is reduced by cold-working and thus swelling is increased initially by cold-working, but this does not preclude attainment of saturation. Ni-5Al in the annealed condition continues to swell in the 12-31 dpa interval, but swelling is suppressed somewhat by cold-working. Aging of the cold-worked material tends to restore the swelling to levels near that of the annealed alloy. The suppression in swelling observed in $\mathrm{Ni}-5 \mathrm{Si}$ and $\mathrm{Ni}-8 \mathrm{Si}$ at $12-14 \mathrm{dpa}$ is preserved to $-31 \mathrm{dpa}$.

PROGRESS AND STATUS

\section{Introduction}

In several earlier reports, the results of Phase 1 of the AA-14 fusion materials experiment in EBR-II were presented for pure nickel (99.999\%), Ni-5Si, $\mathrm{Ni}-8 \mathrm{Si}$ and $\mathrm{Ni}-5 \mathrm{Al}$, all in atomic percent ${ }^{1.2}$. In the first phase at 12-14 dpa, pure nickel tended to exhibit an eventual collapse in

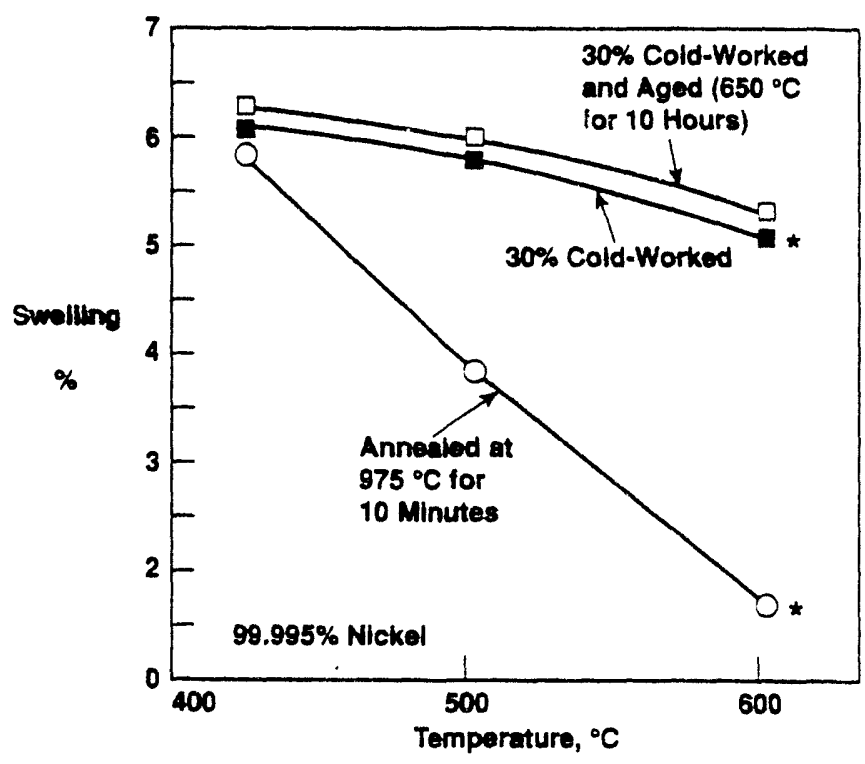
dislocation density that caused a saturation in swelling. As shown in Figure 1, the strong temperature dependence of swelling in annealed material at this dose level was not observed in cold-worked or cold-worked and aged specimens. Dislocation networks induced by cold-working resist the tendency toward collapse of the dislocation density, a process which is strongly dependent on temperature.

It was also shown that addition of 5 atomic percent of either silicon or aluminum caused substantial reductions in swelling, but increasing silicon from 5 to 8 atomic percent led to a reversal in swelling behavior, increasing it somewhat (Figures 2 and 3 ). Collapse of the dislocation population was not observed in any of the three binary alloys at any irradiation temperature ${ }^{2}$.

The second and last phase of the AA-14 experiment reached 31.1 and 31.8 dpa in EBRII and has now been examined using immersion density measurement. Whereas the phase 1 portion of the experiment involved three starting conditions for each alloy (annealed $975 . \mathrm{C} / 10 \mathrm{~min} / \mathrm{WQ}, 30 \%$ cold-worked, and $30 \%$ cold-worked and aged $650^{\circ} \mathrm{C} / 10 \mathrm{hr} / \mathrm{wQ}$ ), phase Il contained only two conditions for each

Fig. 1. Swelling gbserved for three starting states of pure nickel in Phase I (1). Data points marked with stars denote swelling at $12 \mathrm{dpa}$. All other data measured at $14 \mathrm{dpa}$. alloy. The cold-worked and aged condition of pure nickel and the cold-worked condition of the binary alloys were not included in the phase II irradiation experiment.

${ }^{ \pm}$Pacific Northwest Laboratory is operated for the U.S. Department of Energy by Battelle Memorial Institute under Contract OE-ACO6-76RLO 1830. 


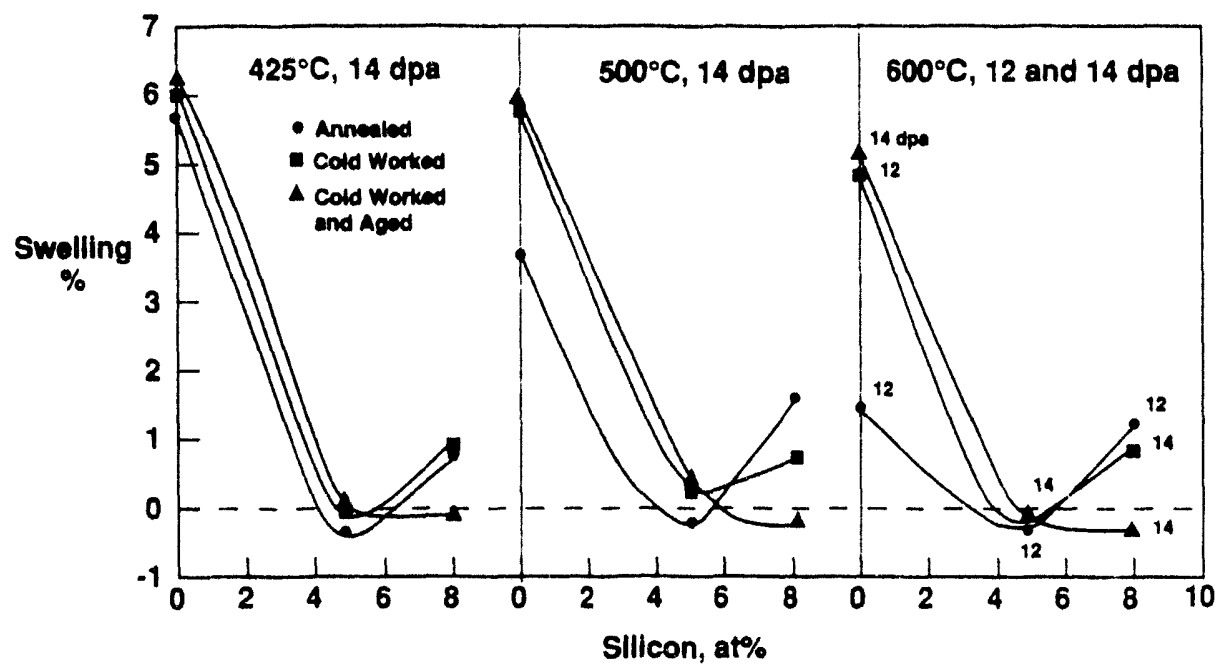

Fig. 2. The influence of aluminum, thermomechanical starting condition, and irradiation temperature on the swelling of nickel at 12 - 14 dpa in Phase I.

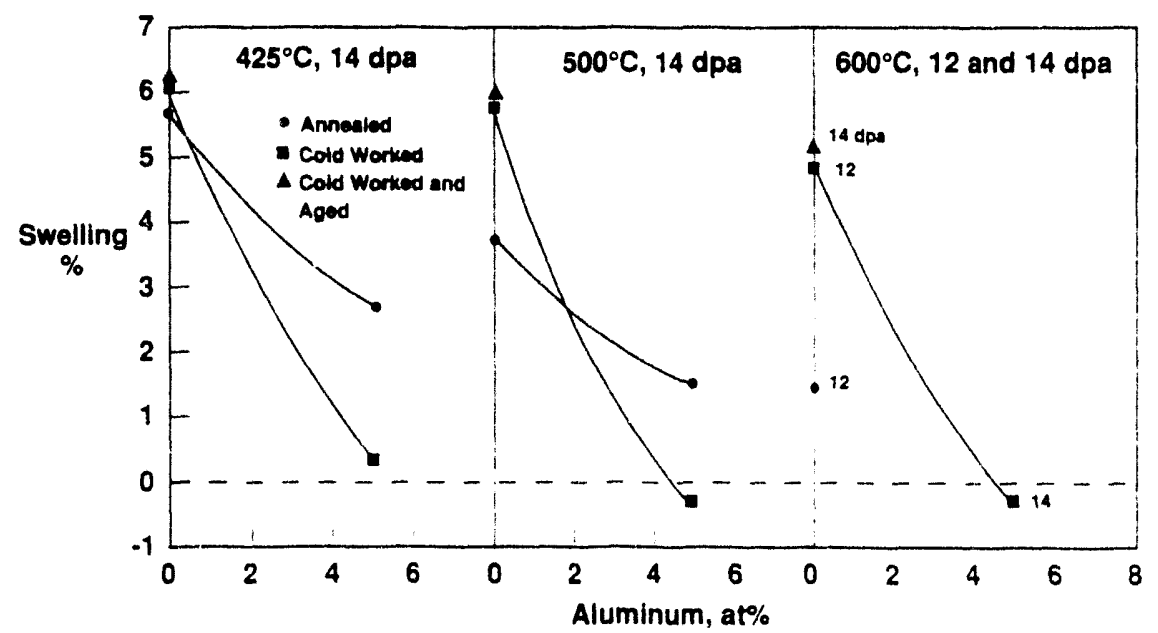

Fig. 3. The influence of silicon level, thermomechanical starting condition, and irradiation temperature on the swelling of $\mathrm{Ni}-\mathrm{Si}$ alloys at $12 \cdot 14$ dpa in Phase $\mathrm{I}$.

\section{Experimenta! Details}

The specimens were irradiated in the form of $3 \mathrm{~mm}$ diameter microscopy disks of $-0.25 \mathrm{~mm}$ thickness and were in contact with the reactor sodium coolant at temperatures of 425,500 and $600^{\circ} \mathrm{C}$ in Phase 1 . During Phase ?. however. the $500^{\circ} \mathrm{C}$ specimens were irradiated at $550^{\circ} \mathrm{C}$. No changes in temperature occurred for the 425 and $600^{\circ} \mathrm{C}$ specimens. Post-irradiation changes in density were determined using an automated immersion density technique known to be accurate to $\pm 0.16 \%$ swelling.

\section{Restilts and Discussion}

The density change data for both phase 1 and phase 11 are listed in Table 1 . Figure 4 shows that the welling of annealed nickel indeed appears to saturate at $600^{\circ} \mathrm{C}$ and that the tendency toward saturation is folayed by cold-working, especially at higher irradiation lemperatures. At the iower irradiation amperatures there is almost no effect of cold-working, however 
Table 1. Swelling Observed in Phases 1 and 11 of the AA-14 Experiment

\begin{tabular}{|c|c|c|c|c|c|}
\hline Allor & $\begin{array}{l}\text { TEMPERATURE } \\
\text { ' } \mathrm{C}\end{array}$ & $\begin{array}{c}\text { DOSE } \\
\text { dpa }\end{array}$ & $S A^{\prime}$ & $\begin{array}{l}\text { SWELLING } \\
\text { CW }^{\prime}\end{array}$ & $E W A^{\prime}$ \\
\hline $\mathrm{Ni}$ & 425 & 140 & 5.70 & 6.01 & 620 \\
\hline $\mathrm{Ni}$ & 425 & 31.1 & 748 & 914 & - \\
\hline$N$ & 500 & 140 & 3.3 & 5.68 & 583 \\
\hline $\mathrm{Ni}$ & $500-550$ & 31.8 & 6.30 & $=$ & $\ldots$ \\
\hline $\mathrm{Ni}$ & 600 & $120-14.0$ & $130^{\circ *}$ & $476^{\circ "}$ & 500 \\
\hline $\mathrm{Ni}$ & 600 & 31.8 & 2.24 & 743 & $\ldots$ \\
\hline Ni. $5 \mathrm{~N}$ & 425 & 140 & 2.88 & 0.21 & $\ldots$ \\
\hline $\mathrm{N}_{\mathrm{N}} .5 \mathrm{AN}$ & 425 & 31.1 & 692 & $=$ & 503 \\
\hline Ni.SN & 500 & 14.0 & 148 & 0.36 & $\ldots$. \\
\hline $\mathrm{Ni}-5 \mathrm{~N}$ & $500-550$ & 31.8 & 413 & - & 405 \\
\hline Ni.5N & 600 & 14.0 & $=$ & 0.39 & - \\
\hline Ni.5A & 600 & 31.8 & 0.86 & $=$ & 030 \\
\hline N..5S & 425 & 140 & .0 .40 & .0 .11 & 206 \\
\hline $\mathrm{Ni}-5 \mathrm{Si}$ & 425 & 31.1 & 0.50 & $=$ & 028 \\
\hline $\mathrm{Ni} .5 \mathrm{Si}$ & 500 & 140 & -041 & 0.12 & 010 \\
\hline $\mathrm{Ni.5 \textrm {Si }}$ & $500-550$ & 31.8 & -0.21 & $\ldots$ & 142 \\
\hline Ni.5Si & 600 & $: 20140$ & $0.22^{\circ}$ & $\ldots$. & 012 \\
\hline Ni.5S & 500 & 31 & 006 & $\ldots$ & $\therefore 15$ \\
\hline Ni.8Si & 425 & 140 & 087 & 084 & $; \infty 6$ \\
\hline $\mathrm{NiBSi}$ & 425 & 31. & - & $\ldots$ & 213 \\
\hline $\mathrm{Ni}-6 \mathrm{Si}$ & 500 & 140 & 123 & 078 & 012 \\
\hline $\mathrm{Ni}-8 \mathrm{Si}$ & $500-550$ & 318 & $=$ & $\cdots$ & $25:$ \\
\hline$N_{1}-8 S_{1}$ & $\epsilon \infty$ & $120-140$ & $113^{* *}$ & 200 & 37 \\
\hline
\end{tabular}

1 SA. CW. CWA = olution annealed. cold worked, and cold worked and i. eded. respectively.

As shown in Figure 5. Ni-5Al swells less than pure nickel but continues to swell in the 12 to 31 dpa interval without hint of saturation. The behavior observed vs. temperature and opa level in this rather limited experiment is consistent with the behavior observed in a more comprehensive experiment on $\mathrm{Ni}-\mathrm{Al}$ alloys. Whereas cold-working suppresses the swelling of $\mathrm{Ni}-5 \mathrm{Al}$ somewhat, aging at $650^{\circ} \mathrm{C}$ restores the swelling to levels close to those observed in annealed specimens.

The addition of $5 \%$ silicon to nickel is more effective in reducing swelling than is $5 \%$ aluminum, but unlike the effect of aluminum, the swelling suppression by silicon appears to be maintained in the $12-31$ dpa interval at all three irradiation temperatures. While the specimen matrix is rather sparce for Ni-8Si, it appears that swelling in general is larger than for $\mathrm{Ni}-5 \mathrm{Si}$. This was the behavior observed in phase 1 , and it appears that swelling of $\mathrm{Ni}-8 \mathrm{Si}$ increases slowly with increasing neutron exposure in the $12-31$ dpa intervai. 


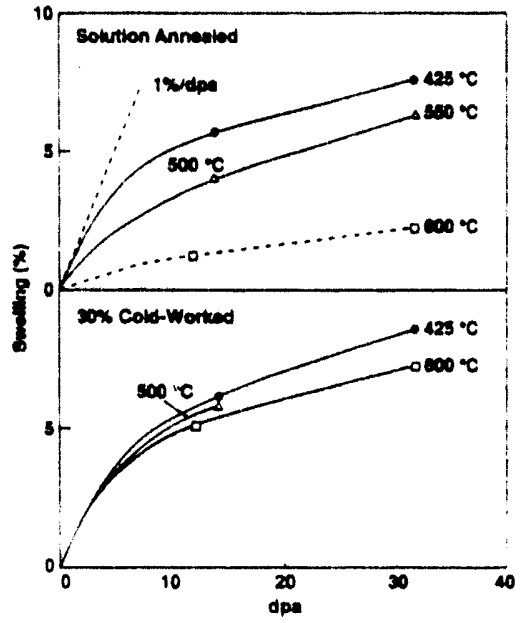

Fig. 4. Influence of displacement level, temperature and cold-work on the tendency toward saturation in pure nickel.

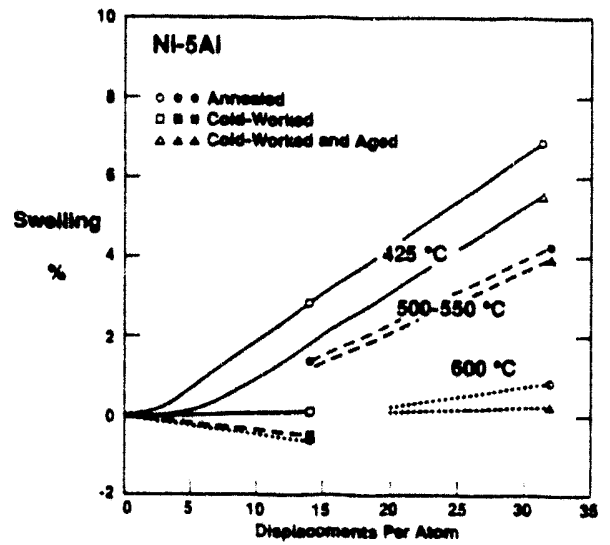

Fig. 5. Swelling of $\mathrm{Ni}-5 \mathrm{Al}$ in phases 1 arid $1 \mathrm{I}$.

\section{Expected Achievements In the Next Reporting Period}

The microstructural origins of the observed changes in density will be examined in a joint study with $\mathrm{S}$. Ohnuki of Hokkaido University.

\section{REFERENCES}

1. J. F. Stubbins and F. A. Garner. "Swelling and Microstructure of High Furity licke! Irradiated with Fast Neutrons in EBR-1I". J. Nucl. Mater. 191-194(1992) 1295-1299.

?. H. Takahashi and F. A. Garner, "Microstructural Evolution of Neutron-Irradiated Ni-ji and Ni-Al 41'ays", J. Hucl. Mater. 195(1992) 1-10.

3. M. A. Mitchell and F. A. Garner, "leutron-Induced Swelling of Binary Mi-Al Alloys'. S. Vucl. Mater. 187(1992) $102-108$ 
DEFECT PRODUCTION IN IRRADIATED METALS - H. L. Heinisch (Pacific Northwest Laboratory ${ }^{\mathrm{a}}$ )

\section{OBJECTIVE}

The objective of this work is to determine the spectral dependence of defect production and microstructure evolution under neutron irradiation.

\section{SUMMARY}

Our knowledge of the processes involved in creating defects during cascade-producing irradiations is reviewed. Molecular dynamics simulations within the past few years have led to an understanding of the creation and survival of point defects in the critical first picoseconds of the cascade process, through the quenching of the thermal spike. The concept that "freely migrating defects" arise only from isolated Frenkel pairs produced in a cascade is critically discussed.

\section{PROGRESS AND STATUS}

\section{Introduction}

Any models or theories that describe the effects of radiation daunage on a material should have as their basis a quantitative description of the production of the defects that cause microstructural changes. When a single radiation event occurs, a distribution of single point defects and clusters of point defects is produced in the local region where the displacement energy was deposited. This distribution evolves with time and can interact in various ways with the existing microstructure or with defects produced elsewhere in the material. In general, two types of defects are produced: relatively mobile defects and relatively immobile defects. The mobile defects are single point defects and small clusters. They can interact among themselves, annihilating or clustering, interact with immobile clusters formed in the same event, or migrate throughout the material until they interact with the existing microstructure or defects from other events. The immobile clusters can collapse to dislocation loops, becoming part of the dislocation structure of the material. Immobile clusters are sinks for mobile defects, or, depending on the temperature, they can contribute to the mobile defect population through thermal decomposition. Evidence also exists that small, glissile self-interstitial loops can form under danage conditions, gliding in one dimension'.

The production rate of the mobile or "freely migrating defects" is not a directly measurable quantity. It must be inferred from measurements of the observable effects produced by the freely migrating defects, as interpreted through some model that relates defect production to changes in observable properties. Thus, one must have a clear idea of the processes and mechanısms involved in order to extract the correct quantitative information from the analysis of the experiments. In particular, it is necessary to start with the correct definition of "freely migrating defects" as a function of the irradiation parameters (time, temperature, flux and material properties). It is helpful to review the defect production process.

'Pacific Northwest Laboratory is operated for the U.S. Department of Energy by Battelle Memorial Institute under Contract DE-AC06-76RLO 1830. 


\section{Defect Production}

In the first step, the irradiating particles impart their energy to the atoms of the material. The response of the material to irradiating particles can be described in terms of a primary recoil atom spectrum, as long as the primary recoils are sufficiently separated in space or time from each other (an exception, for example, is when heavy ions deposit energy with much higher density than can be achieved by recoil atoms of the material--in essence, the cascades originate simultaneously from nearly adjacent lattice sites and overlap). Daunage by neutrons and many ions (especially self-ions) can be addressed in terms of energetic recoil atoms.

The dissipation of recoil energy occurs in four definable phases relevant to the production and disposition of lattice defects: the collisional phase, the thermal spike phase, the quenching phase and the annealing phase.

\section{Collisional Phase}

In the collisional phase a primary recoil atom initiates a cascade of displacive collisions that continues until no atom contains enough energy to create further displacements. The creation of displaced atoms at this stage is conceptually similar to the Kinchin-Pease model for the creation of displated atoms that forms the basis for calculations of "displacements per atom" (dpa), a commonly used exposure paraneter. The "modified Kinchin-Pease" expression of Norgett. Robinson and Torrens" is the recognized standard for dpa calculations, viz.

$$
n(T)=0.8 T / 2 E_{d},
$$

where $T$ is the recoil daunage energy, $E_{d}$ is the displacement energy and the factor (). 8 is the "displacement efficiency factor," (the displacement efficiency factor is a correction to the original hardsphere scattering model assumed by Kinchin and Pease that accounts for somewhat fewer displacements obtained when using more realistic scattering potentials. It is descriptive of the collisional phase and does not include any information on subsequent behavior of displaced atoms, such as recombination. This should not be confused or combined with other defect production efficiency factors.) A ballistic effect that occurs during the collisional phase is the replacement collision sequence (RCS), which can result in extended vacancy-self-interstitial atom separations. Molecular dynamics (MD) simulations of energetic collision cascades show that the collisional phase lasts up to a few times $10^{-1.3}$ s, depending on the recoil energy.

\section{Thermal Spike Phase}

During the collisional phase, the thermal spike phase is also beginning, as the energy in the cascade is shared aunong many atoms through lower energy collisions in a localized region of high energy density. Molecular dynamics simulations show that, at recoil energies above a few $\mathrm{keV}$, a molten zone is created that exhibits liquid-like properties". Outside the molten zone are displaced atoms, mostly at the end of RCSs. The RCSs propagate supersonically and, therefore, are at the periphery of the cascade region before the molten zone fully develops, which takes about $1 \mathrm{ps}^{7}$. During the thermal spike phase, the identity of defects within the molten zone is largely lost, hut the defects outside the molten zone (mostly displaced atoms at the ends of RCSs) retain their identity. The displaced atoms become self-interstitial atoms (SIA). Molecular dynamics simulations indicatte that elastic interactions lead to clustering of SIAs outside the molten zone 


\section{Quenching Phase}

The quenching phase begins as the spike energy is dissipated to the rest of the material. During this time the molten zone returns to a condensed state containing a distribution of vacincies within it. MD simulations have even shown the formation of small vacancy loops during quenching. The thermal spike forms and is quenched within a few picoseconds, depending on the cascade energy and energy transport properties of the material. In general, after quenching, the vacancy-type defects tend to occupy the center of the defect configuration and are somewhat more closely spaced than the surrounding interstitial-type defects.

\section{Annealing Phase}

After the quenching phase, further rearrangement and interaction of the remaining defects take place by normal, thermally-activated diffusion of mobile defects (single point defects, small clusters, and, depending on the temperature, mobile defects resulting from dissolution of clusters). During this annealing phase, some of the mobile defects escape annihilation or clustering within the cascade region, becoming the "freely migrating defects" that can migrate away from the cascade region and interact with other elements of the microstructure.

Computer simulations of the annealing phase in $\mathrm{Cu}$ cascades (allowing no cluster dissolution) showed that at least $10 \%$ of the SIAs remaining after the quenching phase escaped the cascade region ${ }^{10}$, even when the simulation was performed using extreme clustering of SIAs during the quenching phase. The SIAs escape because they tend to lie at the periphery of the cascade defect distribution. A sinaller fraction of vacancies escape because their relatively closer proximity near the center of the cascade defect distribution leads to greater probability of clustering among themselves.

\section{Cascade Energy Dependence}

The creation and disposition of defects during all the phases of cascade development depend on the cascade energy, material parameters and the temperature. At any energy, the initial arrangement of defects produced (during the collisional phase) is determined largely by ballistic processes such as RCSs. The self-interstitial atoms tend to be at the periphery of the cascade defect distribution at all energies, and some fraction of the mobile SIAs will always tend to escape. At very low energies, up to several hundred $\mathrm{eV}$, where only a few defects pairs are produced, most of the surviving defects will be free to migrate from the cascade site. With increasing cascade energy, the surface-to-volume ratio of the defect distribution decreases, and a decreasing fraction of SIAs will escape rather than cluster or annihilate, tending toward a constant value at the threshold energy for formation of subcascades.

A minimum cascade energy is required for formation of a thermal spike. They do not form in cascades with energies less than about $1 \mathrm{kev}$ in $\mathrm{Cu}$ (reduced energy 0.003$)^{9}$. When a spike occurs, SIAs within the molten zone disappear, and during quenching, vacancies are formed, equal in number to the displaced atoms remaining outside the molten zone. With increasing energy the molten zones become larger, so they quench more slowly. Thus, vacancy clustering is more likely in higher energy cascades because the vacancies have a longer time to interact. However, even the largest molten zones quench within a few tens of lattice vibrations, so formation of large clusters or collapse to loops is not issured. The maximum melt zone size is achieved at energies where subcascades form.

\section{Material Properties}

The physical properties of a material can affect the amount and type of defect production in cascades. Molecular dynamics simulations comparing cascades in $\mathrm{Cu}$ and $\mathrm{Ni}$, which have significantly different melting points", have shown that the slower quenching in $\mathrm{Cu}$ leads to greater clustering of vacancies 
and greater chances for collapse to loops than in Ni. Contributions of electron-phonon coupling, which do not appear to be significant in $\mathrm{Cu}$, may be important in other materials?.

\section{Effects of Temperature}

Higher temperatures may result in somewhat shorter RCSs during the collisional phase and in somewhat larger molten zones during the thermal spike phase. Since only the SIAs outside the molten zone survive, the net result could be a decrease in total defect production at higher temperatures. Higher temperatures also mean slower quenching, which increases the opportunities for clustering of vacancies. At temperatures where vacancy clusters are thermally unstable, (small) vacancy clusters will not readily form during the quenching and annealing stages. Instead, mobile vacancies will diffuse from the center of the cascade. Some will annihilate at the surrounding interstitial clusters, and some will escape the cascade. Results of a simple diffusion model ${ }^{12}$ show that a significant fraction of vacancies can escape from a cascade in this way.

\section{Freely Migrating Defects}

In a letter to the editor of the Journal of Nuclear Materials Naundorf suggests that the origin of freely migrating defects in ion and neutron irradiated metals is free single Frenkel pairs produced hy "low recoil energies transferred by the primary collisions." ${ }^{13}$ As evidence for this assertion, a simple calculation was performed in which the number of single Frenkel pairs produced was found to be consistent with the very low efficiencies of free defect production extracted from diffusion experiments ${ }^{14-17}$. The calculation was performed using a Kinchin-Pease displacement model including an exponential distribution of separations between primary collisions. It was assumed that a free Frenkel pair was produced if the energy transfer to the atoms was less than 2.5 times the displacement energy (to create just one Frenkel pair) and if the distance between two consecutive collisions was larger than the spontaneous recombination volume (so the Frenkel pairs would geither recombine nor cluster). Calculations were made for the same systems on which diffusion experiments have been performed, and the calculated fractions of freely migrating defects were compared with the experimental values, showing the same trend as the experiments.

The calculations are essentially an analytical approximation describing the collisional phase of a cascade. The actual spatial distribution of the collisions is not represented. The thermal spike, quenching and annealing phases are completely ignored. The four-phase description of defect production in cascades outlined above is well-supported by hundreds of MD cascade simulations, as well as hinary collision studies and annealing simulations. It is clear that Naundorf's calculation is not relevant to the production of defects in cascades.

The diffusion experiments to which the Naundorf calculations are compared are good experiments carefully performed. Unfortunately, the interpretation of their results has not been done in light of our knowledge of defect production in cascades. It would be interesting to reinterpret the results of these valuable experiments using a more physically-based description of the defect production.

\section{REFERENCES}

1. H. Trinkaus, B.N. Singh and A.J.E. Foreman, Phil. Mag., in press.

2. G.H. Kinchin and R.S. Pease, Rep. Prog. Phys., 18 (1955) 1.

3. M.J. Norgett, M.T. Robinson and I.M. Torrens, Nucl. Eng. Design 33 (1975) 51). 
4. M.T. Robinson, Proc. Int. Conf. on Irradiation-induced Voids in Metals, Albany, N.Y.. June 9-11, 1971397.

5. H.L. Heinisch and B.N. Singh. J. Nucl. Mater. 191-194 (1992) 1083.

6. T. Diaz de la Rubia, R. S. Averback. R. Benedek and W. E. King, Phys. Rev. Lell. 59 (1987) 19.31).

7. R. S. Averback. T. Diaz de la Rubia and R. Benedek, Nucl. Inst. Meth. B33 (1988) 693.

8. T. Diaz de la Rubia and M.W. Guinan. Mat. Sci. Forum $97-99$ (1992) 23.

9. T. Diaz de la Rubia and W.J. Phythian, J. Nucl. Mater. 191-194 (1992) 108.

10. H.L. Heinisch, J. Nucl. Mater. 117 (1983) 46.

11. T. Diaz de la Rubia, R. S. Averback. H. Hsieh and R. Benedek, J. Mater. Res. 4 (1989) 579.

12. B.N. Singh and A.J.E. Foreman, J. Nucl. Mater. in press.

13. V. Naundorf, J. Nucl. Mater. 182 (1991) 254.

14. L.E. Rehn and P. Okamoto, Mat. Sci. Forum 15-18 (1987) 985.

15. A. Mueller, V. Naundorf and M-P. Macht, J. Appl. Phys. 64 (1988) 3445.

16. R.A. Erck and L.E. Rehn, J. Nucl. Mater. 168 (1989) 208.

17. M-P. Macht, R. Willecke and V. Naundorf, Nucl. Instr. and Meth. B43 (1989) 507. 


\section{MOLECULAR DYNAMICS CALCULATIONS OF DEFECT ENERGETICS IN $\beta$ - $\mathrm{SiC}^{*}$-- Hanchen Huang, Anter El-Azab, and Nasr Ghoniem (Mechanical, Aerospace and Nuclear Engineering Department,University of Califomia, Los Angeles, CA 90024-1597, USA)}

\section{OBJECTIVE}

The objective of the present work is to establish a data base for defect formation and migration energies in SiC. Experimental and theoretical studies of microstructure evolution will rely on this data base.

\section{SUMMARY}

The Molecular Dynamics (MD) method is used to calculate defect energetics in $\beta$ - silicon carbide. Many-body interaction effects in this covalent material are accounted for by using a hybrid of two-body and three-body potentials. Calculated bulk propertics of $\beta-\mathrm{SiC}$ based on this potential are in agreement with experimental data to within $17 \%$. A micro-crystal is constructed to represent the computational cell and external forces are applied to the micro-crystal so that it behaves as a part of an infinite medium. The potential energy for the unperturbed computational cell is first calculated. The cell is then set at a defect configuration and relaxed, and the potential energy of the relaxed cell is calculated. The difference between the potential energy of the unperturbed cell and that of the defect-containing cell is used to calculate the formation and binding energies of point defects, defect clusters and heliumvacancy clusters in $\mathrm{SiC}$.

\section{PPROGRESS AND STATUS}

\section{Introduction}

Defect energetics in covalent materials have not yet been studied by the Molecular Dynamics (MD) simulation technique. Several approximate calculations were performed for vacancy formation

\footnotetext{
* Work supported by the Office of Fusion Energy, US DOE under grant DE-FG03-91ER54115
} 
energies[1-6] in germanium, diamond, silicon, and silicon-carbide. These studies can be classified into two categories. The first one[1,2,3] employed a Morse-type potential and made several approximations about the relaxation of atoms neighboring a vacancy. The shortcomings of this approach are: (1) it does not fully relax the defected lattice, and (2) it does not consider surface distortion associated with forming a vacancy. The second approach $[4,5,6]$ considered the electronic structure of a defected lattice and omitted lattice relaxation. Since a defected lattice does relax, this approach shouldn't be able to give reasonable results. Surprisingly, results of both approaches are in good agreement with experimental data.

In our numerical simulations, an empirically-calibrated potential function for $\mathrm{Si}$ and $\mathrm{SiC}[8]$ is used. Many-body effects are taken into account by employing a phenomenological three-body potential. The bulk and cluster properties calculated using this potential function agree with experimental data to within $17 \%$. An important process to consider is surface distortion of the crystal when a vacancy or a vacancy cluster is formed. When an atom is put on a surface of a crystal, some bonds will be formed. Meanwhile, there will also be surface distortion. This process is demonstrated in figures (1) and (2).

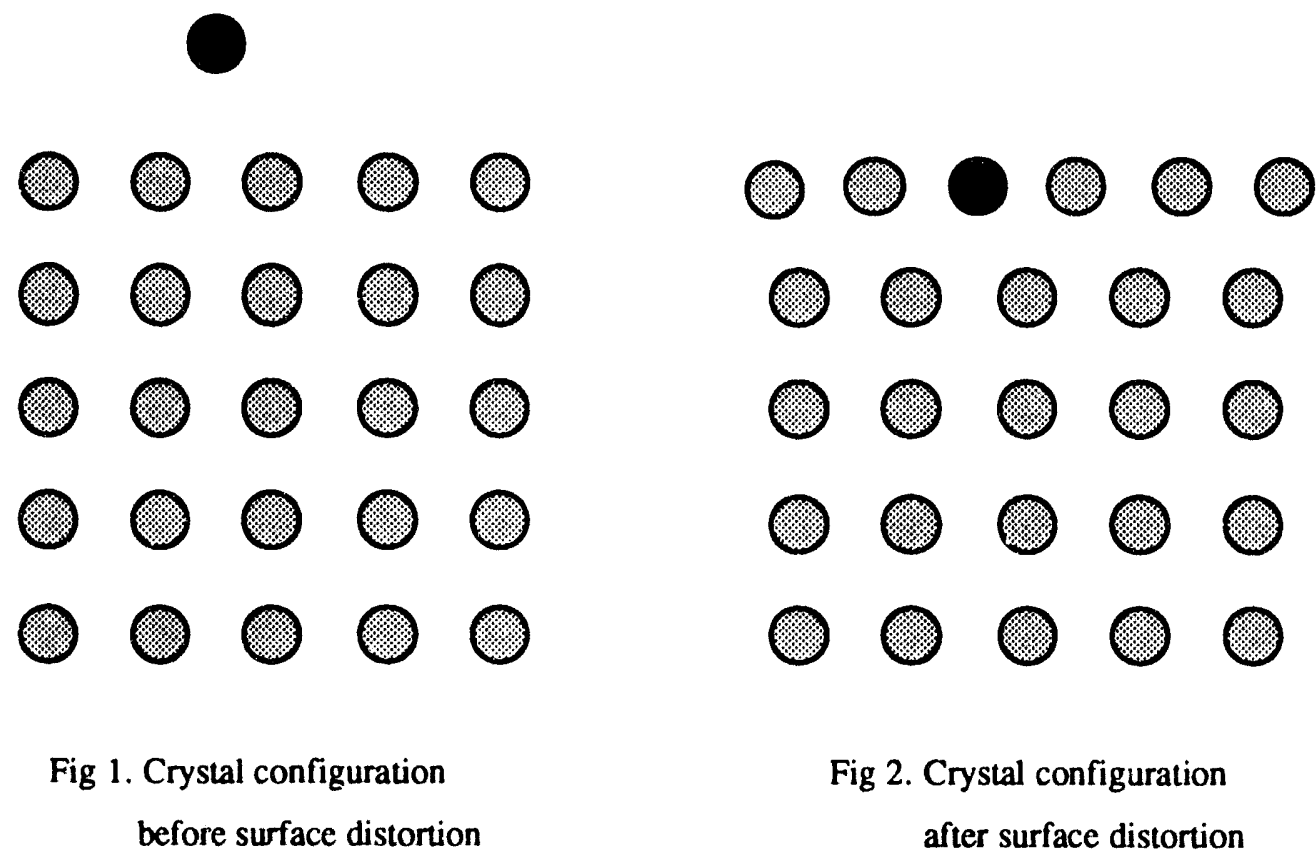

\section{Simulation}

The Molecular Dynamics simulation method is well established. Several numerical algorithms have been used to solve Newtonian mechanics equations. Calibrating interatomic potential 
functions and constructing a representative computational cell are generally the two main considerations when the technique is applied to a class of problems.

\section{Newtonian Mechanics}

According to Newtonian mechanics, a particle of given initial position and velocity can be tracked if the potential or force acting on it is known. In solid crystal, an empirical potential form describing interactions of lattice atoms is required for solution of the equations of motion. Theoretically speaking, one can track all lattice atoms in a solid crystal. In practice, however, this is not feasible and a cutoff distance for atom interactions is always used. The coupled equations of motion for an atom $\mathrm{i}$ are given by:

$\frac{\mathrm{dr}}{\mathrm{dt}}=\overrightarrow{\mathrm{v}}_{\mathrm{i}}$

$\frac{\mathrm{d} \overrightarrow{\mathrm{v}}_{\mathrm{i}}}{\mathrm{dt}}=\frac{\overrightarrow{\mathrm{F}}_{\mathrm{i}}\left(\overrightarrow{\mathrm{r}}_{1}, \overrightarrow{\mathrm{r}}_{2}, \ldots \ldots, \overrightarrow{\mathrm{r}}_{\mathrm{n}}\right)}{\mathrm{m}_{\mathrm{i}}} \quad \mathrm{i}=1,2, \ldots \ldots, \mathrm{n}$

with $\overrightarrow{\mathrm{r}}_{\mathrm{i}}(0)$ and $\overrightarrow{\mathrm{v}}_{\mathrm{i}}(0)$ given.

For a conservative for ce, $\overrightarrow{\mathrm{F}}_{\mathrm{i}}\left(\overrightarrow{\mathrm{r}}_{1}, \overrightarrow{\mathrm{r}}_{2}, \ldots \ldots, \overrightarrow{\mathrm{r}}_{\mathrm{n}}\right)=-\vec{\nabla} \Phi_{\mathrm{i}}\left(\overrightarrow{\mathrm{r}}_{1}, \overrightarrow{\mathrm{r}}_{2}, \ldots \ldots, \overrightarrow{\mathrm{r}}_{\mathrm{n}}\right)$. For boundary atoms, additional forces, $\mu \frac{d \vec{r}_{i}}{d t}$, will also be included. Here, $\vec{r}_{i}$ and $\vec{v}_{i}$ are space and velocity coordinate vectors of the $\mathrm{i}$-th atom, and $\Phi_{i}\left(\vec{r}_{1}, \vec{r}_{2}, \ldots \ldots, \vec{r}_{n}\right)$ is the potential energy of the $\mathrm{i}$-th particle.

\section{Interatomic Potentials in Silicon Carbide}

Two-body potentials have been widely used for metals[9]. When one considers a covalent material (e.g. $\mathrm{SiC}$ ) short range interactions become important. A many-body potential appropriate for this purpose has been developed by Born and Opperheimer[7], and the potential is given in the form:

$$
\begin{aligned}
\Phi_{i}\left(\vec{r}_{1}, \vec{r}_{2}, \ldots \ldots, \vec{r}_{n}\right)= & \frac{1}{2 !} \sum_{i \neq j} V^{(2)}\left(\vec{r}_{i j}\right)+\frac{1}{3 !} \sum_{j \neq i} \sum_{k \neq j \neq i} V^{(3)}\left(\vec{r}_{i j}, \vec{r}_{i k}, \vec{r}_{j k}\right) \\
& +\ldots \ldots+\frac{1}{n !} \sum_{i \neq \ldots \neq n} \ldots V^{(n)}\left(\vec{r}_{i j}, \ldots, \vec{r}_{i n}, \ldots\right)
\end{aligned}
$$


To make this many-body potential usable in practice, Pearson et al[8] truncated the expansion up to the three-body level. For $\mathrm{SiC}$, they combined Lennard-Jones two-body potential[9] and Axilrod-Teller three body potential[10] in the form:

$$
\begin{aligned}
& V^{(2)}\left(\vec{r}_{i j}\right)=\frac{\varepsilon}{m-n}\left[n\left(\frac{R_{o}}{r_{i j}}\right)^{m}-m\left(\frac{R_{o}}{r_{i j}}\right)^{n}\right] \\
& V^{(3)}\left(\vec{r}_{i j}, \vec{r}_{i k}, \vec{r}_{j k}\right)=Z\left[\frac{1+3 \cos \theta_{i j} \cos \theta_{i k} \cos \theta_{j k}}{\left(r_{i j} r_{i k} r_{j k}\right)^{3}}\right]
\end{aligned}
$$

Where the energy parameters $(\varepsilon, Z)$ and the two-body structure parameters $\left(m, n, R_{0}\right)$ were determined to give the best fit to experimental data for bulk solid and atomic clusters (e.g. bonding energies and bond length). For $\mathrm{SiC}$, Pearson et al give[8]:

$(\mathrm{m}, \mathrm{n})$ value:

$\varepsilon$ value $(\mathrm{eV}): \quad(\mathrm{Si}-\mathrm{Si})=2.817, \quad(\mathrm{Si}-\mathrm{C})=3.895, \quad(\mathrm{C}-\mathrm{C})=5.437$

$\mathrm{R}_{\mathrm{O}} \operatorname{value}(\AA): \quad(\mathrm{Si}-\mathrm{Si})=2.2951,(\mathrm{Si}-\mathrm{C})=1.7400,(\mathrm{C}-\mathrm{C})=1.4806$

$\mathrm{Z}$ value $(\mathrm{eV} / \AA):(\mathrm{Si}-\mathrm{Si}-\mathrm{Si})=3484.0,(\mathrm{Si}-\mathrm{Si}-\mathrm{C})=698.2,(\mathrm{Si}-\mathrm{C}-\mathrm{C})=261.8,(\mathrm{C}-\mathrm{C}-\mathrm{C})=167.3$

\section{Interatomic Potentials in He-C and He-Si Systems}

Interaction between closed shell atoms is dominated by Van der Waals mechanism. Using a perturbation method, Slater et al[11] calculated the interatomic potential between two helium atoms. Their calculated result of polarizability is close to that measured experimentally, and their potential function is given by:

$$
\mathrm{V}_{\mathrm{He}-\mathrm{He}}=-\frac{0.91}{\mathrm{r}^{6}} \mathrm{eV}
$$

It is also shown by Slater et al[11] that the potential is proportional to $\alpha_{1}^{3 / 4} \alpha_{2}^{3 / 4}$, where $\alpha$ denotes the polarizability, while the subscripts represent interacting particles. The polarizability data for silicon or carbon atoms is not available. Since the electronic structure of carbon is intermediate between helium and neon, while that of silicon is intermediate between neon and argon, as a first order approximation, the polarizability of carbon is taken as an average for that for helium and neon. Likewise, the polarizability of silicon is taken as an average for that for neon and argon. The polarizabilities for silicon and carbon can therefore be written as:

$$
\alpha_{\mathrm{Si}} \approx \frac{1}{2}\left(\alpha_{\mathrm{Ne}}+\alpha_{\mathrm{Ar}}\right)
$$


$\alpha_{\mathrm{C}} \approx \frac{1}{2}\left(\alpha_{\mathrm{He}}+\alpha_{\mathrm{Ne}}\right)$

According to Slater et al[11], $\alpha_{\mathrm{He}}, \alpha_{\mathrm{Ne}}$, and $\alpha_{\mathrm{Ar}}$ are $0.39 \times 10^{-24} \mathrm{~cm}^{-3}, 1.65 \times 10^{-24} \mathrm{~cm}^{-3}$, and $2.50 \times 10^{-24} \mathrm{~cm}^{-3}$, respectively. Interatomic potentials between helium and carbon and that between helium and silicon can then be derived from the helium-helium interatomic potential. They can be expressed as:

$\begin{aligned} V_{\mathrm{He}-\mathrm{C}} & =\left(\frac{\alpha_{\mathrm{C}}}{\alpha_{\mathrm{He}}}\right)^{3 / 4} \mathrm{~V}_{\mathrm{He}-\mathrm{He}} \\ \mathrm{V}_{\mathrm{He}-\mathrm{Si}} & =\left(\frac{\alpha_{\mathrm{Si}}}{\alpha_{\mathrm{He}}}\right)^{3 / 4} \mathrm{~V}_{\mathrm{He}-\mathrm{He}}\end{aligned}$

Using Lennard-Jones potential to account for the intrinsic repulsive interaction, we can write the total interatomic potential between helium and carbon or that between helium and silicon as:

$V=\frac{\varepsilon}{6}\left(6 \frac{r_{0}^{12}}{r^{12}}-12 \frac{r_{0}^{6}}{r^{6}}\right)$

Where $r_{0}$ is equilibrium interatomic distance, which is approximated as the sum of atomic radius of the interacting atoms. When bonds are formed, the atomic radii of helium, carbon, and silicon are $0.93 \AA$, $0.77 \AA$, and $1.11 \AA$, respectively[12]. On this basis, $\varepsilon$ is calculated to be $2.07 \times 10^{-2} \mathrm{eV}$ and $2.46 \times 10^{-2}$ $\mathrm{eV}$ for helium-silicon and helium-carbon interaction, respectively.

\section{Construction of a Computational Cell}

A computational cell is surrounded by boundary atoms, whose thickness is larger than effective range of interactions in the crystal. The boundary consists of a hybrid of fixed and flexible atoms. Due to the cutoff of interatomic interactions, a net force on an atom in a perfect crystal is not zero. External forces are applied to the lattice atoms to balance these forces. A vacancy is created by moving an inner lattice atom to the surface of the crystal. A vacancy cluster is created by moving several neighboring atoms to surfaces of the crystal. These atoms are located far away from each other on surfaces, so that mutal interactions do not take place. An antisite defect is formed by replacing a silicon (or carbon) atom by a carbon (or silicon) atom. A cavity consisting of a vacancy and a helium atom is formed by: (1) creating a vacancy, and (2) filling the vacancy by a helium atom. In each case, the defected lattice is relaxed to its equilibrium state. 


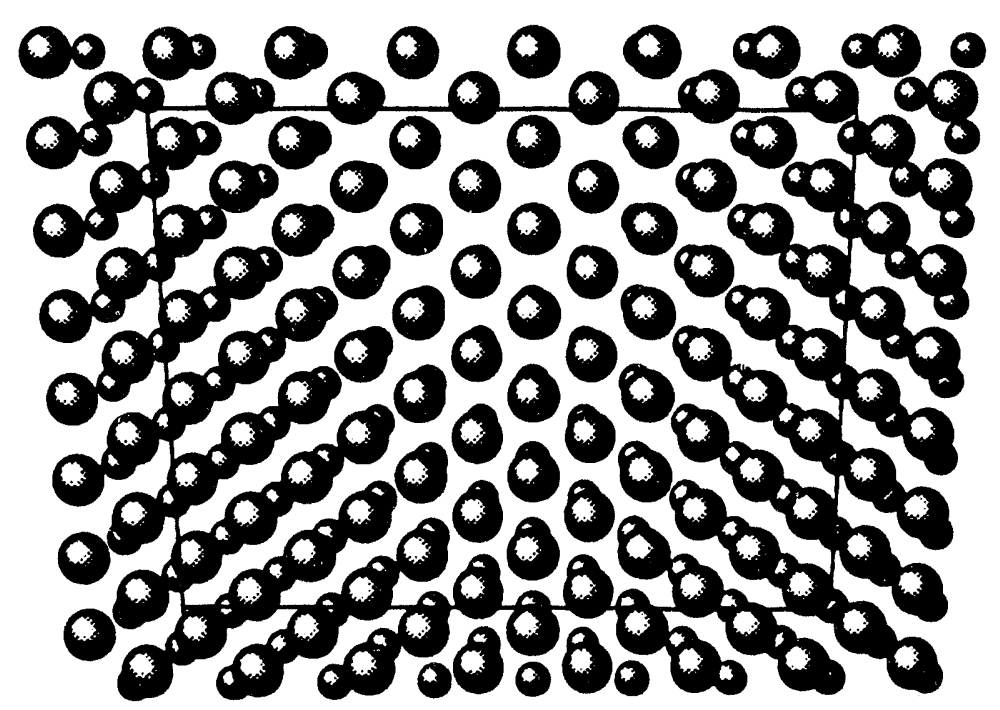

Fig 3. View of the computational cell from (100) direction. The larger spheres represent silicon atoms, while the smaller ones represent carbon atoms. Boundary atoms and inner atoms are separated by solid lines.

A computer code for solving these coupled equations was developed at UCLA[13]. The standard Leap-frog numerical method was used in solving the coupled differential equations. In the simulation process, a velocity component is quenched to zero whenever it is in the opposite direction to the corresponding acceleration component. Figure (3) shows a typical computational cell for $\mathrm{SiC}$.

\section{Defect Energetics}

A self-diffusion process is controlled by its activation energy. If vacancy diffusion is the operating mechanism, the activation energy can be divided into: (1) vacancy formation energy, and (2) atom migration energy.

\section{Defect Formation Energies}

The vacancy formation energy consists of several parts. In covalent materials, several bonds are broken when an atom is moved away from its lattice position. The potential energy of the crystal increases by $\Delta E$. Relaxation of surrounding atoms decreases the potential energy of the cell by $E_{\text {rel }}^{\prime}$. 
The relaxation of lattice atoms surrounding a silicon single vacancy is shown in figure (4). Relaxation of nearest neighbors to a silicon vacancy and and those to a carbon vacancy are compared in figure (5)

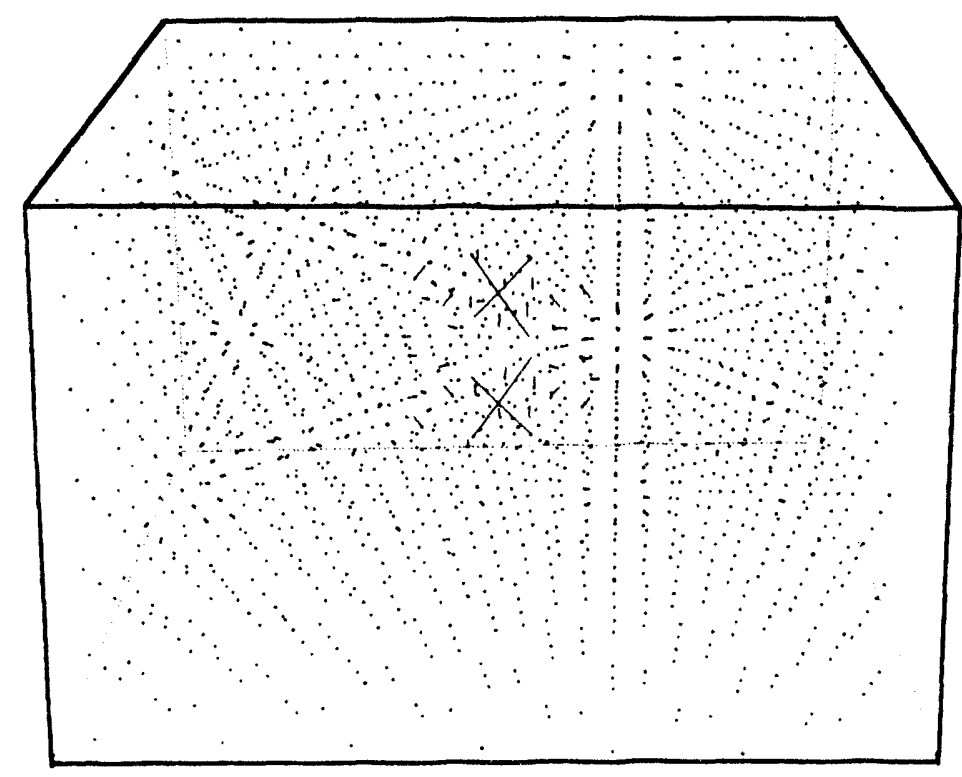

Fig 4. Relaxation of lattice atoms around a silicon vacancy. Length of the lines corresponds to magnitude of the relaxation.

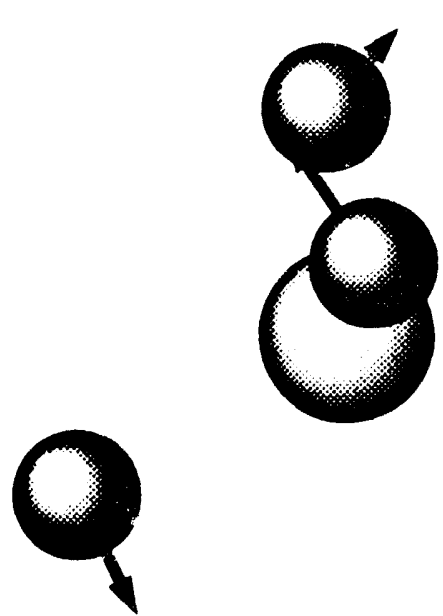

(a)
)

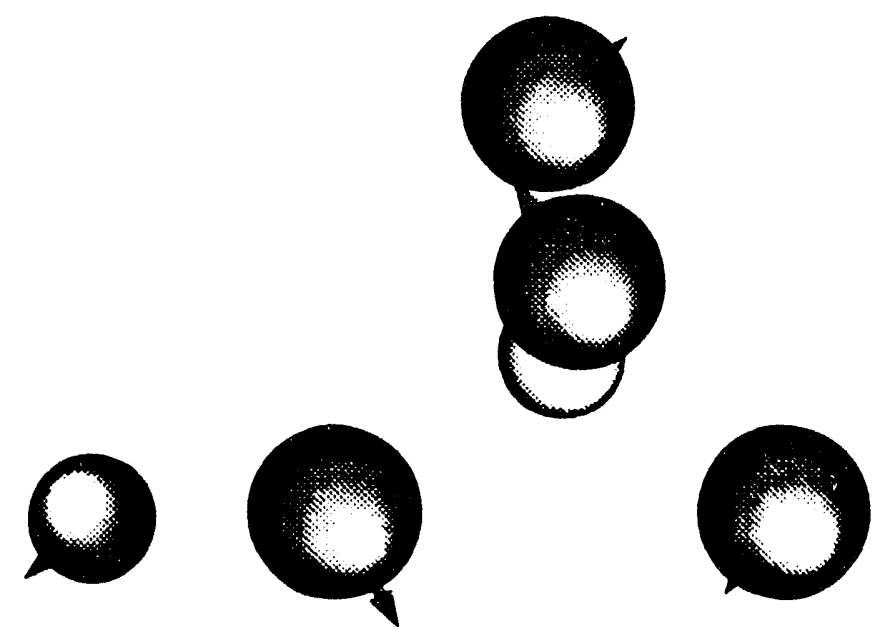

(b)

Fig 5. Relaxation of the nearest neighbors: (a) around a silicon vacancy, (b) around a carbon vacancy. The larger spheres are silicon atoms and the smaller ones are carbon aroms. 
When an atom is placed on a surface of the crystal, half of the bond energy, $\frac{1}{2} \beta D$, is restored. Meanwhile, distortion of the surface near this atom increases the potential energy of the cell by $\frac{1}{2} \mathrm{E}_{\mathrm{rel}}$. The formation energy of a single vacancy is therefore given by:

$E_{v}^{f}(1)=\Delta E-E_{r e l}^{\prime}-\frac{1}{2} \beta D+\frac{1}{2} E_{r e l}$

Similarly, the formation energy of a vacancy cluster is given by:

$E_{v}^{f}(n)=\Delta E-E_{r e l}^{\prime}-\sum_{j=1}^{n}\left(\frac{1}{2} \beta D-\frac{1}{2} E_{r e l}\right)$

When a lattice atom (say $\mathrm{Si}$ in $\mathrm{SiC}$ ) is replaced by an atom of the other type (say $\mathrm{C}$ ), potential energy of the crystal increases by $\Delta E$. Relaxation of the surrounding atoms decreases the potential energy of the crystal by $E_{\text {rel }}^{\prime}$. Formation energy of an antisite defect is given by:

$\mathrm{E}_{\mathrm{a}}^{\mathrm{f}}=\Delta \mathrm{E}-\mathrm{E}_{\mathrm{rel}}^{\mathrm{r}}$

Where $\beta$ is coordination number of the crystal, $D$ is bonding energy, $\beta D$ equals $\Delta E$ in forming a single vacancy, $E_{r e l}$ is the relaxation energy of lattice atoms surrounding a single vacancy, and $E_{\text {rel }}^{\prime}$ is the relaxation energy of lattice atoms surrounding the given defect. The formation energy of a gas filled vacancy is calculated in the same way as for a single vacancy. The only difference is that a helium atom is placed at the vacant lattice point before the crystal is relaxed.

Binding energies of a vacancy in a vacancy cluster of $n$ vacancies can be calculated by: $E_{v}^{b}=E_{v}^{f}(n)-E_{. .}^{f}(n-1)$

Where the cluster of (n-1) vacancies has one less vacancy ( $\mathrm{Si}$ or $\mathrm{C}$ depending on which vacancy type is being considered) than the cluster of $n$ vacancies.

\section{Defect Migration Energies}

Self-atom migration energy can be deduced from thermal diffusion data if the atom migrates through vacancies. The migration energy is the difference between the thermal activation energy and the vacancy formation energy. For $\mathrm{SiC}$, the thermal diffusion data has been documented by Ghoshtagore et al[14], Hong et al[15,16] and Hon et al[17,18]. Experimental data and theoretical simulation results will be combined to give the defect migration energies. The thermal diffusion data for $\beta$-SiC, given by 
Hon et al $[17,18]$, are listed in table 1. For comparison, thermal diffusion data for $\alpha-\mathrm{SiC}$, given by Hong et al[15,16], are appended to table 1.

A vacancy diffusion mechanism is strongly suggested by the experimental data[14-18]. It is found that acceptor dopants always occupy Si-sites[19,20]. Hong et al[15,16] found that $n$-doping increases Si diffusivity and decreases $\mathrm{C}$ diffusivity. These results imply that $\mathrm{Si}$ atom diffuses through $\mathrm{Si}$ vacancies while $C$ atom diffuses through $C$ vacancies. Based on these experimental evidences, we can divide the measured activation energy of $\mathrm{Si}$ into two parts. The first is the formation energy of the $\mathrm{Si}$ vacancy, and the second is the migration energy of the Si atom. Similar arguments apply to $\mathrm{C}$.

\section{TABLE 1: Diffusion Data for Point Defects in SiC}

\begin{tabular}{|c|c|c|c|c|c|}
\hline Sample & $\begin{array}{c}\text { Diffusion } \\
\text { ALom }\end{array}$ & T-Range(K) & $\mathrm{D}_{0}\left(\mathrm{~cm}^{2} / \mathrm{s}\right)$ & $\mathrm{Q}(\mathrm{eV})$ & Ref \\
\hline \multirow{2}{*}{$\beta-\mathrm{SiC}$} & $\mathrm{C}$ & $2128-2384$ & $2.6 \times 10^{8}$ & 8.7 & 15 \\
\cline { 2 - 6 } & $\mathrm{Si}$ & $2283-2547$ & $8.4 \times 10^{7}$ & 9.5 & 16 \\
\hline \multirow{2}{*}{$\alpha-\mathrm{SiC}$} & $\mathrm{C}$ & $2123-2453$ & $8.6 \times 10^{5}$ & 7.4 & 13 \\
\cline { 2 - 6 } & $\mathrm{Si}$ & $2273-2563$ & $5.9 \times 10^{2}$ & 7.2 & 14 \\
\hline
\end{tabular}

\section{$\underline{\text { Results and Conclusions }}$}

The energy increase due to atom displacement, $\Delta \mathrm{E}-\mathrm{E}_{\text {rel }}^{\prime}$ is first calculated. Then, energy changes due to surface restoration and surface distortion are derived from bond energies and the energy of relaxation around a vacancy, respectively. With this procedure, the formation energies of several types of defects are deduced. Binding energies of vacancy clusters, antisite defects, and gas filled vacancies are also calculated. Migration energies of single vacancies are obtained by combining the theoretical vacancy formation energies and the experimental thermal activation energies. The results are shown in table 2. From these calculated results, several salient conclusions can be drawn: 
TABLE 2: Calculated Results for Defect Energetics in $\beta$-SiC

\begin{tabular}{|c|c|c|c|c|c|c|}
\hline Defect Sample & $\begin{array}{c}\Delta E_{-}-E_{\text {rel }}^{\prime} \\
(e V)\end{array}$ & \begin{tabular}{|c|} 
Surface \\
Restoration \\
$(\mathrm{eV})$
\end{tabular} & $\begin{array}{c}\text { Surface } \\
\text { Distortion } \\
(\mathrm{eV})\end{array}$ & $\begin{array}{l}\text { Formation } \\
\text { Energy }(\mathrm{eV})\end{array}$ & $\begin{array}{c}\text { Binding } \\
\text { Energy (eV) }\end{array}$ & $\begin{array}{c}\text { Migration } \\
\text { Energy (eV) }\end{array}$ \\
\hline He-filled Si & 6.57 & 5.64 & 2.30 & 3.23 & -0.11 & - \\
\hline He-filled C & 9.88 & 5.35 & 0.30 & 4.83 & -0.23 & - \\
\hline Antisite-Si & -3.75 & $\mathrm{~N} / \mathrm{A}$ & N/A & -3.75 & N/A & - \\
\hline Antisite-C & 6.18 & N/A & N/A & 6.18 & $\mathrm{~N} / \mathrm{A}$ & - \\
\hline Si-vacancy & 6.68 & 5.64 & 2.30 & 3.34 & N/A & 2.52 \\
\hline C-vacancy & 10.11 & 5.35 & 0.30 & 5.06 & N/A & 6.16 \\
\hline SiC-divacancy & 16.28 & 10.99 & 2.60 & 7.89 & -0.51 & \\
\hline $\mathrm{Si}_{2} \mathrm{C}$-trivacancy & 23.99 & 16.63 & 4.90 & 12.26 & +1.03 for $\mathrm{Si}$ & - \\
\hline $\mathrm{SiC}_{2}$-trivacancy & 25.99 & 16.34 & 2.90 & 12.55 & -0.40 for $C$ & \\
\hline $\mathrm{Si}_{3} \mathrm{C}$-tetravacancy & 31.58 & 22.27 & 7.20 & 16.51 & +0.91 for $\mathrm{Si}$ & - \\
\hline $\mathrm{SiC}_{3}$-tetravacancy & 35.82 & 21.69 & 3.20 & 17.33 & -0.28 for $C$ & 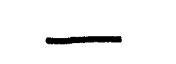 \\
\hline $\mathrm{Si}_{2} \mathrm{C}_{2}$-tetravacancy & 35.02 & 21.98 & 5.20 & 18.24 & $\begin{array}{l}+2.35 \text { for } \mathrm{Si} \\
+0.92 \text { for } \mathrm{C}\end{array}$ & \\
\hline
\end{tabular}

(1) The surface distortion energy is found to have an important contribution to defect energetics calculation.

(2) A silicon atom can be spontaneously replaced by a carbon atom from the energy point of view. This means that more carbon atoms may be present in non-stoichiometric cases.

(3) Atoms surrounding a silicon vacancy undergo substantial relaxation while atoms surrounding a carbon vacancy do not relax as much. This is due to the size asymmetry of silicon and carbon atoms 
(4) A divacancy is thermodynamically stable against single vacancies. A divacancy is always composed of one silicon vacancy and one carbon vacancy because the nearest neighbors are always of different types.

(5) Vacancy clusters of up to 4 vacancies prefer absorbing a carbon vacancy to a silicon vacancy in forming larger vacancy clusters.

(6) Helium-filled vacancies are more stable as compared to unoccupied vacancies. The effect of helium in stabilizing vacancies is therefore important.

\section{FUTURE WORK}

Defect energetics established in this work will be included in a comprehensive microstructure evolution model of $\mathrm{SiC}$ under neutron irradiation.

\section{ACKNOWLEDGMENT}

Special thanks are directed to Mr. Ed Aguilar for his assistance in typing the manuscript. Support of the Office of Fusion Energy, through the DOE-grant DE-FG03-91ER54115 with UCLA, is greatly acknowledged.

\section{REFERENCES}

1 R. Swalin, J. Phys. Chem. Solids 18(1960)290

2 A. Scholz, Phys. Status Solidi 3(1063)43

3 A. Scholz and A. Seeger, Phys. Status Solidi 3(1963)1480

4 C. Hwang and L. Watt, Phys. Rev. 171(1965)958

$5 \quad$ K. Bennemann, Phys. Rev. 137A(1965)1497

6 J. Bernholc, S. Kajhara, C. Wang, and A. Antonelli, Mater. Sci. Engr. B11(1992)265

7 J. Lennard-Jones, Interatomic Forces, Special Publication No. VIII, Indian Association for the Cultivation of Science,Calcutta, India, 1939

8 E. Perason, T. Takai, T. Halicioglu and W. Tiller, J. Crystal growth 70(1984)33

9 G. Maitland et al, Intermolecular Forces, Oxford, 1981, Appendix 1. 
10 B. Axilrod and E. Teller, J. Chem. Phys. 54(1971)2129

11 J. Slater and J. Kirwood, Phys. Rev. 37(1931)690

12 Table of Periodic Properties of the Elements, Sargent-Welch Scientific Company, USA, 1992

13 P. Chou and N. Ghoniem, Phys. Rev. B43(1991)2490

14 R. Ghoshtagore and R. Coble, Phys. Rev. 143(1966)623

15 J. Hong and R. Davis, J. Am. Ceram. Soc. 63(1980)546

16 J. Hong, R. Davis and D. Newbury, J. Mater. Sci. 16(1981)2485

17 M. Hon and R. Davis, J. Mater. Sci. 14(1979)2411

18 M. Hon and R. Davis, J. Mater. Sci. 15(1980)2073

19 W. Choyke and L. Patrick, Phys. Rev. B2(1970)4959

20 Y. Vodakov and E. Mokhov, Silicon Carbide-1973, ed by R. Marshall, J. Faust Jr, and C. Ryan, University of Southern California Press, 1974, p508 


\subsection{DEVELOPMENT OF STRUCTURAL ALLOYS}

\subsection{Ferritic Stainless Steels}


EFFECTS OF HYDROGEN AND LOADING MODE ON THE FRACTURE TOUGHNESS OF A REDUCED ACTIVATION FERRITIC STAINLESS

STEEL - H. Li (Washington State University), R. H. Jones (Pacific Northwest Laboratory ${ }^{3}$ ), J, P. Hirth (Washington State University). and D. S. Gelles (Pacific Northwest Laboratory)

\section{OBJECTIVE}

The purpose of this effort is to investigate the effects of hydrogen and loading mode on the fracture toughness of a reduced activation ferritic stainless steel (F-82H).

SUMMARY

The full spectrum of fracture toughness $(\mathrm{J}$ integrals), including pure mode 1 , different nixed mode lill and pure mode III, will be examined for a ferritic/martensitic stainless steel with $0.1 \mathrm{C}-8 \mathrm{Cr}-2 \mathrm{~W}-2.2 \mathrm{~V}$ -

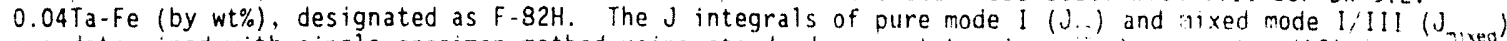
are determined with single specimen method using standard compact tension specimens a.lo rodified compact tension specimens, respectively. The pure mode III integral is measured with multiple specimen method using "triple-pantleg" specimens. Effects of hydrogen on the $J$ integrals of pure mode I and mixed mode l/III are also going to be studied. $9 \mathrm{ppm} \mathrm{H}$ (about 500 appm) is pre-charged into specimens cathodically. The details of experimental procedure were described in this report. The preliminary results showed that addition of mode III stress (shear stress) to mode I loading had a significant negative effect on the fracture toughness of $\mathrm{F}-82 \mathrm{H}$. The complete results, analys is and conclusion will be reported in next report. The results would be important to fusion reactor design.

PROGRESS AND STATUS

\section{Introduction}

Since the late 1970s, ferritic/martensitic $\mathrm{Cr}$-Mo steels have been considered alternate candidate structural materials to austenitic stainless steels for first wall and blanket structure applications. Irradiation studies $(1,2)$ in fast reactors showed these steels are superior to austenitic steels in several aspects, such as swelling resistance, higher thermal conductivity and lower thermal expansion. and compatibility with potential breeder and coolant materials. Investigation indicates that ferritic stcels are crrroded by liquid lithium and $\mathrm{Pb}-\mathrm{Li}$ eutectic at the rates of 5 to 10 times siower than austenitic stainless scels. By replacement of molybdenum in conventional Cr-Mo steels with vanadium and/or tungs:en. reducedactivation ferritic steels have been developed since the mid 1980s. Among them martensitic steels with $7.9 \% \mathrm{Cr}$ have been favored over $12 \% \mathrm{Cr}$ steels, becauce it is difficult to eliminate 6. ferrite in a $12 \% \mathrm{Cr}$ steel without increasing carbon or manganese fo "ite stabilization. Delta-ferrete can lower toughness, and manganese promotes chi-phase $p$. iduring irradiation. which can cause embrittlement. As a potential material used for blanket. fracture tougnness is an important mechanical property. However, there is litti. oughness data, especially $j$ ntemral. on either unirradiated or irradiated conditions. Critic. of $\mathrm{J}$ integral can be used as an angineering estimate of fracture toughness near the initiatabl, slow stable crack growth of a are-existing crack in netallic materials.

iraditionally, mode I fracture has been u:ed to study elastic-plastic fracture mechanics. However. in recent years, mixed mode fracture has become the focus of many studies because many ooserved faliures include shear components $(3-11)$. Fracture characteristics have been found to differ. depenoing on niciostructure, strength, and toughness level of materials. In low toughness high-strength ailoys, such as $0.29 \mathrm{C}, 0.83 \mathrm{Cu}$ steel and $1.25 \mathrm{C}$ bainitic steels $(9.11)$. mode 111 additions to mode i ioading had ittle or no affect on the overall value of $J$, the mode 1 component $J$ integral for mixed mode cack initiation. and tended to increase $J_{.:}$, the total $J$ integral for mixed mode crack initiation. in the tounher materials. such as 3.5NiCrMoV stëel. A710A and a high purity rotor steel (HPRS) (3.11), which fallod primarily by a -icrovoid nucleation and growth mechanism. mode 111 additions lowered the j vaiues considerably from their pure mode I values. The J. values passed through a minimum at a position petween oure moce 1 and cure mode $l 11$ on aplot of $J$. vs crack inclination angle. It was also found that introducing hydrogen tu a tough material. such as HPRS. further lowered the total, I integral (see Figure l) even tnough hydrogen showed little effect on the elongation of tension specimen.

2acific Northwest Laboratory is operated for the U.S. Jepartment of Energy by Bat:el: lemorial instiote under Contract DE-ACO6-76RLO 1830. 
A steel with $0.1 \mathrm{C}-8 \mathrm{Cr}-2 \mathrm{~W}-0.2 \mathrm{~V}-0.04 \mathrm{Ta}$ (designated as $\mathrm{F}-82 \mathrm{H}$ ) has been developed as a reduced activation ferritic/martensitic steel by Japanese scientists. $\mathrm{F}-82 \mathrm{H}$ has been considered as one of the candidates for first wall material of a fusion reactor. Preliminary $J$ integral data (12) obtained from three point bending specimens showed that $F-82 \mathrm{H}$ is a very tough steel. It is possible that introduction of mode III component to pure mode I loading would also lower the total $\mathrm{J}$ integral of $\mathrm{F}$ $82 \mathrm{H}$ as in the case of HPRS. Furthermore, it is well known that the next generation of fusion reactors will produce hydrogen during operation. Hence, investigation of combined effects of mixed mode loading and hydrogen on fracture toughness of F. $82 \mathrm{H}$ is critical for the steel to be used as first wall material.

\section{Material and Experimental Methods}

\section{Material}

$\mathrm{F}-82 \mathrm{H}$ plate used in this study was supplied by Nippon Kokan Steel Company (NKK) in Japan. The chemical composition of the plate is in Table 1 .

Specimens used in this study were heat-treated with the procedure of $1000 \cdot \mathrm{C} / 20$ hours/air ccoling, $1100 \cdot \mathrm{C} / 7$ minutes/air cooling, and $700^{\circ} \mathrm{C} / 2$ hours/air cooling. The microstructure was tempered martensite. Average intersection distance of grains was $25 \mu \mathrm{m}$ (ASTM $\$ 7.5$ ).

Table 1 Chemical Comoosition of F-82H Meat No 3033 ). Wh Pet

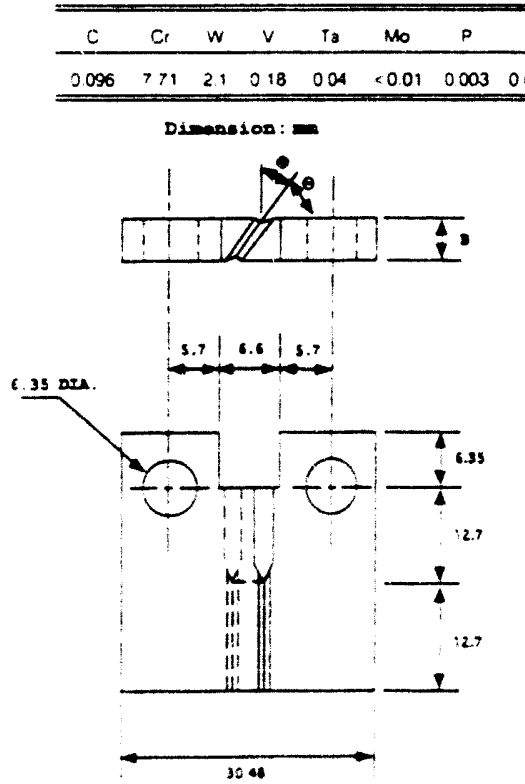

I.t. : Vodified compact tension specimen feometry used in Mode $I$ and combined

inear mode
that the $\delta$ increased w th $\delta$ in a linear node $(3.5)$. Hence, 5 s were caiculated approximateiy ficm $\delta$.

in electric discharge machine (EOM) was used to make a cut with small racius (radius $=0.051$ mm) soproxinately $\vdots .3 \mathrm{~mm}$ iong as a cuostitute of pre-fatigued-crack. The pre-fatiaue-crack tended to grow out of original crack piane in mixed-mode specimens while the fire EDM cut was found identical to a pre-

fat:qued-crack (5). The EOM cuts were made after final heat-treatment and specimens with cuts were heated $\therefore$ about $100^{\circ} \mathrm{C}$ for 24 hours in a acuum oven (io $\mathrm{Pa}$ to outgas cossible hydrogen introduced by eom

modified compart terision specimens to be used for mixed-mode $1 / 111$ testing is schenatically shown in Figure changing the crack slant angie $\$$. O gegree represents the pure mode I loading, the geometry of the 0 degree specimen becomes the standard compact tension specimen as seecified in ASTM standard E813-89. As the crack inclination angle (\$)

increases, the contribution of mode III component increases.

The crack inclination angles to be used in this study were 0 10, $20,30,45.55 \mathrm{agr} .5$ Side grooves of $20 \%$ reduction of These side grooves can increase the irlaxiality at the edges of the growing crack and constrain the advancing crack in the riginal crack plane. The calculation of $J$ intearal in mixed. -ode 1.111 involves the measurements of both vertical isolacement ( 8 ) and horizortal disoiacement (f) of load soints. Knife eoges were secured to the front face of the specimen. A standard Clip CCD (Crack Opening vistance) gage was positioned on the knife edges. The load ine $\delta$ s were calculated from front faces $s$ with the method proposed by saxena and Hudak ir a d 
cutting (14). The single specimen technique was used in this study. Crack length and crack extension were calculated from compliances following the procedure described in E813-89 and Ref. 13 .

\section{ii. Tests with "Triple-Pantleg" Specimens}

Specimen geometry for pure mode $111 \mathrm{~J}$ integral were depicted in Figure 3 , which looks like "triple. pantleg" (5). Side grooves of $40 \%$ reduction of the total thickness were made in order to guarantee crack propagation before general yielding in the cantilever beam arms of the specimen. The outer two legs of the specimen were bolted to a U-shaped base through the $6.36 \mathrm{~mm}$ holes. Load was applied to the central leg in a direction normal to the plane of the drawing. The incorporation of two cracks in the specimen leads to a symmetric loading arrangement minimizing the out-of-plane bending $(6)$. Two $1.3 \mathrm{~mm}$ EOM cuts were also made as the substitutes of fatigue cracks. Indirect crack length monitoring techniques such as the electrical potential drop method or unloading compliance are affected by the contact of the asperities on the two specimen surfaces during pure Mode III deformation. Hence, a multiple specimen technique was adopted and the crack lengths were measured after breaking open the specimens.

iii. Charging of Hydrogen

Hydrogen was introduced by cathodic charging at a current density of $80 \mathrm{~A} / \mathrm{m}^{2}$ in a solution of $1 \mathrm{~N} \mathrm{H}, \mathrm{SO}_{4}$ with $200 \mathrm{mg} / \mathrm{L}$ of $\mathrm{As}_{2} \mathrm{O}_{3}$ added to the solution as a hydrogen recombination poison. All specimens were ground to 600-grit before cathodic charging. Samples were nickel-plated immediately following hydrogen charging. The goal hydrogen content was 9 ppm. The length of charging time to achieve $9 \mathrm{ppm} H$ was determined experimentally by charging several small samples of $5 \times 5 \times 2.5 \mathrm{~mm}^{3}$ for different lengths of time and measuring total hydrogen quantitatively with LECO Hydrogen Determinator (Model RH-1SP) using inert gas fusion technique. The time needed to charge real specimens was calculated by the means of diffusion

equations described in Ref. 15. Effects of hydrogen on fracture toughness were only carried out on pure mode I and mixed I/III specimens with $0,15,25,35,45$, and 55 deg.

\section{DATA ANALYSIS}

$\therefore$ Mode 1 and Mixed Mode $1 / 111 \mathrm{~J}$ Integral

The mode $1 \mathrm{~J}$ integral was calculated from the area under the load-displacement curve by means of E. $[1](16)$.

$$
J=\frac{2}{B b_{j}} \int_{0}^{1} P d V
$$

where: $B=$ specimen thickness

$0 .=$ the initial uncracked ligament, $W \cdot a_{-}$

$\omega=$ specimen width.

$a=$ the original crack length.

The physical crack length a was calculated using the unloading compliance technique outlined in ASTM standara E8:3-89 and Ref. 13. The mode 1 and mode 111 components of mixed mode $J$, designated as $J$. and $J$... respectively were calculated by the procedure proposed by Hirth et al (6). The resolved Mode $I$ and Mode 111 loads and displacements were first calculated in the way as shown schematically in Figure 4 and then used to calculate $J$ and $J$ by means of Eq. (1). The subscripts $i$ and $i$ ii are used to emphasize that these are not standard values. However. in the case of $\phi=0$ deg. J becomes the plain strain mode I ialue of $\mathrm{J}$.. Equations [2a] and [2b] show the calculations of $\mathrm{J}$ and $\mathrm{J}$,.., respective 

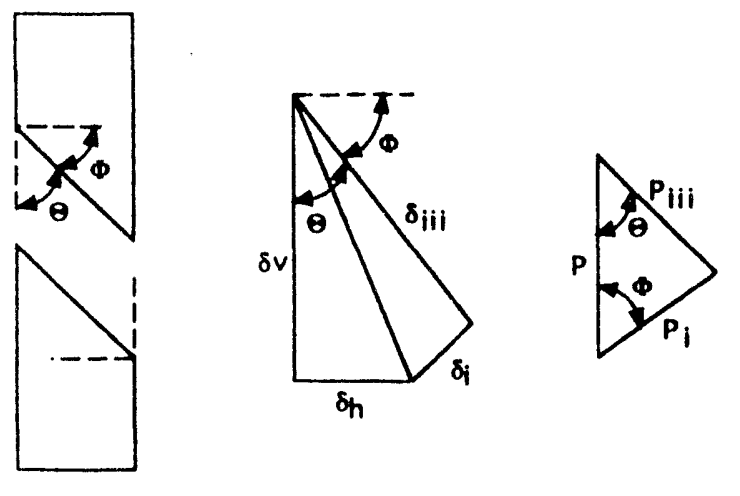

$$
\begin{aligned}
& \delta_{i}=\delta_{h} \cos \phi-\delta_{h} \sin \phi \\
& \delta_{i i i}=\delta_{V} \sin \phi+\delta_{h} \cos \phi
\end{aligned}
$$

$$
\begin{gathered}
J_{i}=\frac{2}{B_{\text {net }} b_{0}} \int_{0}^{\delta_{1}} P_{i} d V_{i} \\
J_{i i j}=\frac{2}{B_{\text {net }} b_{0}} \int_{0}^{B_{w}} P_{i i j} d V_{i i i}
\end{gathered}
$$

Here, $B_{\text {t }}$ is the net crack front width excluding the $10 \%$ side grooves on each side. Eq. [3] gives $B_{\text {net }}$ in terms of the overall specimen thickness $B$.

$$
B_{\text {met }}=\frac{0.8 B}{\cos \Phi}
$$

The standard ASTM E813 has two versions, E813-81 and E813-89. There are some differences between the two versions regarding construction of $\mathrm{J}-1 \mathrm{a}$ curves and determination of critical $J$ values. Because previous studies of mixed mode I/III J integral were guided by E813-81, critical $J$ values will be calculated with the two versions in this study so that a comparison could be made.

In ASTM E813-81, a $J$ vs $\Delta$ a curve, al so referred to as a $J-R$ curve is first generated. Figure 5 shows

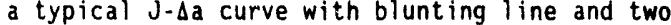

exclusion lines. In the case of pure Mode $1 \mathrm{~J}$

Fig. 4. Resolution of applied load and measured displacements into mode I and mode III components. integral, the slope of the blunting line is $J_{l} / \Delta a=2 \sigma_{f}$, where $\sigma_{f}=\left(\sigma_{y}+\sigma_{f y}\right) / 2$. The exclusion lines between the two exclusion lines are used for the best line fitting. The intersection points between the best straight line and the blunting line and the two exclusion lines define the values of $J_{1}$ and $J_{\text {,exc }}$, respectively. The mixed mode data are analyzed similarly. The blunting line slope $m$. of mode I component is calculated as J $\Delta a=2 \sigma$ s same as pure mode I. The blunting kne slope $m_{11}$ of mode 111 component is given by " $\mathrm{J}_{i,} / \Delta \mathrm{a}=2 \tau_{f}$, whare $\tau_{c}=(\sigma+\sigma) / 4$. "The total mixed mode blunting line slope in terms of $m$ and $m_{1,}$ is given by Eq. [4].

$$
m_{i ! u t}=\frac{m_{i} \cos \Phi+m_{t i i} \sin \Phi}{\sin \Phi+\cos \Phi}
$$

This mixed mode blunting line can not be used to evaluate the values of $\mathrm{J}$. and $J$ separately, because the

initiation values of $\Delta a$ and $d a_{\text {...., might }}$ be different, which would not be sensible for a real crack. Hence, $J$. (total J) vs $\Delta a$ is plotted first.

Mixed mode blunting line and exclusion

ines in this plot are used to evaluate

3. arid J. and corresponding values of $\Delta a$ and $\Delta a$. Vertical lines corresponding to the $\Delta a$. and $\Delta a$ arc are crawn in the $J,-R$ and $J .,-R$ plots, which act as blunting and exclusion lines, respectively. The intersections of these vertical lines with J-Aa curves define the respective mode I and mode III component $\checkmark$ initiation and exclusion values. This procedure is illustrated schematically in figure 6 . The same procedure is also utilized to modify ASTM E813-89. Due to the large amount of calculation, a computer 
program was written with QBasic to calculate the compliances, crack length, $J$ integrals, best $\mathrm{J}-\Delta a$ data curve fitting and critical $J$ values.

\section{i i. Mode III J Integral}

Due to two cracks in the "triple-pantleg" specimen, Eq. [1] is divided by a factor of 2 , hence $J_{111}$ was calculated by $\mathrm{Ea}$. [6].

$$
J_{m}=\frac{1}{B_{\text {nem }} b_{0}} \int_{0}^{\sigma_{\pi}} P_{m I} d V_{I I I}
$$

Here, $B=0.60 B$ due to the $20 \%$ side grooves on each side. The procedure to determine critical $\mathrm{J}$ values is the same as that described in the last section. The slope of the blunting line is $\mathrm{J}_{\mathrm{H}} / \Delta \mathrm{a}=2 \tau_{\mathrm{f}} \mathrm{l}$, where $\tau_{\mathrm{f}}=$ $\left(\sigma_{y}+\sigma_{x+3}\right) / 4$.

\section{Preliminary Results}

Preliminary tests with 10 and $30 \mathrm{deg}$. modified compact tension specimens showed that the addition of mode III loading (shear stress) to mode I loading had a

significant negative effect on fracture toughness of $\mathrm{F}-82 \mathrm{H}$ steel. These preliminary results appear to be similar to those observed for the HPRS as shown in Figure 1. The complete results, analysis and conclusion will be reported in the next Semiannual Report.

\section{References}

1. David S. Gelles, "Effects of Irradiation on Low Activation Ferritic Alloys: A Review, "Reduced Activation Materials for Fusion Reactors, R. L. Xlueh, D. S. Gelles, M. Okada, and N. H. Packan, Eds., American Society for Testing and Materials, Philadelphia, 1990 pp. $113-129$

2. R. L. Klueh, K. Ehrlich, Kernforschungszentrum Karlsruhe, and F. Abe, "Ferritic/Martensitic Steels: Promises and Problems", Fusion Reactor Materials Semiannual Progress Report For The Period Ending March 31, 1992, pp. 131-141.

3. M. T. Miglin, I.-H. Lin, J. P. Hirth, and A. R. Rosenfield, Fracture Mechanics: 14th Symp. - -Vol. II

Testing and Applications, ASTM STP 791, J.C. Lewis and G. Sines, Eds., ASTM, Philadelphia, PA, 1983, Pp.
1I-353-11-369.

4. M. T. Miglin, J. P. Hirth and A. R. Rosenfield, Res Mechanica, 11 (1984), pp. 85-95.

5. J. G. Schroth, J. P. Hirth, R.G. Hoagland, and A. R. Rosenfield, Met. Trans. A, 18A (1987), pp. 1061-

E. M. Manoharan, J. P. Hirth, and A. F Gsenfield, J. of Testing and Evaluation, JTEVA, 18 (1990), No.2, pp. $106-114$.

7. S. Raghavachary. A. R. Rosenfield, and J. P. Hirth, Met. Trans. A, 21A (1990), pp. $2539-45$.

8. J. A. Gordon, J. P. Hirth, A. M. Kumar, and N. R. Moody, Jr., Met. Trans. A, 23A (1991), pp. 1013M. Manoharan, S. Raghavachary, J. P. Hirth, and A. R. Rosenfield, J. of Eng. Materials and Technology,
iil (1989), October, pp. $440-442$.

10. A. M. Kumar and J. P. Hirth, Scripta MetalluRgicA. et MATERIALIA, 25 (1991), pp. 985-90.

11. M. Manoharan, Scripta Metallufgica, et Materialia, 26 (1992), pp. 1187 - 1192. 
12. Yoshiro Kuriki, Akihide Yoshitake, and Manabu Tamura, "Fracture Toughness Test Results of Low

Activation Ferritic Steel for First Wall Material (F-82H)", NKK Steel Research Center, Japan, April, 1989.

13. Ashok Saxena and S. J. Hudak, Jr, Int. Journ. of Fracture, 14 (1978), pp. 453-468.

14. T. Foecke, P. G. Marsh, N. R. Moody, and W. W. Gerberich, Scripta METALluRgiCA. et. MATERIALIA, 28 (1993), pp. 77-80.

15. P. G. Shewmon, Diffusion in Solids, Chapter 1, McGraw-Hill Book Company, 1963.

16. J. R. Rice, P. C. Paris, and J. G. Merkle, ASTM STP 536, ASTM, Philadelphia, PA, 1973, pp. $231-235$. 
IRRADIATION CREEP AND SWELLING OF THE FUSION HEATS OF HT9 AND 9Cr-1Mo TO 208 DPA AT $-400^{\circ} \mathrm{C}$. - F.A. Garner (Pacific Northwest Laboratory ${ }^{\mathrm{a}}$ ), M.B. Toloczko (University of California at Santa Barbara) and C.R. Eiholzer (Westinghouse Hanford Company)

\section{OBJECTIVE.}

The objective of this effort is to determine the factors which control the response of structural alloys to radiation and applied stress.

\section{SUMMARY}

The irradiation creep behavior of the fusion heats of HTg and $9 \mathrm{Cr}-1$ Mo at $\sim 400^{\circ} \mathrm{C}$ has been measured to exposures as large as $208 \mathrm{dpa}$. HT9 is somewhat nonlinear in its response to hoop stress level in the range $0-200 \mathrm{MPa}$, but $9 \mathrm{Cr}$-1Mo exhibits only slightly greater than linear behavior with stress level. The strain data of both alloys appear to include some contributions from precipitate-related density changes. Swelling may have occurred in $9 \mathrm{Cr}-1 \mathrm{Mo}$.

\section{PROGRESS AND STATUS}

\section{Introduction}

Helium pressurized creep tubes constructed from the fusion heats of the ferritic martensitic alloys HTS and $9 \mathrm{Cr}$ 1Mo (fusion heats $9607 R 2$ and 30176 ) have completed their irradiation in FFTF at a nominal temperature of $-400^{\circ} \mathrm{C}$. The composition and heat treatment of these alloys is listed in Table 1 . These $2.24 \mathrm{~cm}$ long tubes were

Table 1 Composition of Alloys in Weight Percent

\begin{tabular}{|c|c|c|c|c|c|c|c|c|c|c|c|c|c|}
\hline & $\underline{c}$ & $\underline{\text { Si }}$ & $\underline{M n}$ & $\underline{-}$ & $\underline{\mathbf{S}}$ & $\mathrm{Cr}$ & Mo & N. & $\underline{y}$ & $\underline{w}$ & $N$ & $\underline{\mathbf{A}}$ & II \\
\hline HTQ & 0.20 & 0.17 & 0.57 & 0.016 & 0.003 & 121 & 1.04 & 0.51 & 0.28 & 045 & 0027 & 0006 & $0 \infty 1$ \\
\hline Cr- 1 Mo & 008 & 0.11 & 037 & 0.010 & 0.003 & 8.61 & 089 & 009 & 021 & $.00:$ & 0055 & 0.007 & $\infty 04$ \\
\hline
\end{tabular}

periodically discharged from reactor and measurements made of their diameter prior to reinsertic into reactor. (1) The tubes were inserted in all MOTA vehicles from MOTA-1B through MOTA-1G and then cont inued into MOTA-2B. Both alloys were irradiated at hoop stress levels of $0,60,100$, and $140 \mathrm{MPa}$, and $\mathrm{HT}$ T was also irradiated at $200 \mathrm{MPa}$. Irradiation temperatures varied somewhat from one MOTA to the next, but during any one irradiation interval, the temperature was actively controlled within $\pm 5^{\circ} \mathrm{C}$ of the nominal temperature. Table 2 presents the detaled temperature history

Tabie 2. Irradiation Mistory of Piessurized Tubes

\begin{tabular}{|c|c|}
\hline MOTA & TEMPERATURE.C \\
\hline $1 B$ & 407 \\
\hline $1 C$ & 425 \\
\hline $1 D$ & 406 \\
\hline $1 E$ & 403 \\
\hline IF & 406 \\
\hline $1 G$ & 420 \\
\hline $2 B$ & 433 \\
\hline
\end{tabular}
of these tubes. These tubes reached exposure dpa levels as large as 208 dpa. The strains of these tubes were last reported at $-150 \mathrm{dpa}$. (2)

\section{Results and Discussion}

Figure 1 presents the total diametral strain and midwall creep strain for HTS, and Figure 2 presents the strains for $9 \mathrm{Cr}-1$ Mo. The midwall creep strain is calculated assuming that the strain at zero stress is isotropic and unaffected by stress. Since the strain at zero stress saturates with increasing exposure. it is pussible that it arises from precipitation-related changes in density rather than void swelling. In this case, the strain may not be isotropically distributed, however.

The strains observed in $9 \mathrm{C} r-1$ Mo exhibit more complexity, especially at higher fluence. Since such complexity was not observed in HTg, it is assumed that the origin of the complexity is related to a material difference from HT9, rather than some artifact of reactor history. Note that the strain at zero stress for $9 \mathrm{Cr}$-1Mo is larger than that of HTg with less tendency toward saturation, and therefore may include some contribution from void swelling.

APacific Northwest Laboratory is operated for the U.S. Department of Energy by Battelle Memorial Institute under Contract DE-ACO6-76RLO 1830. 

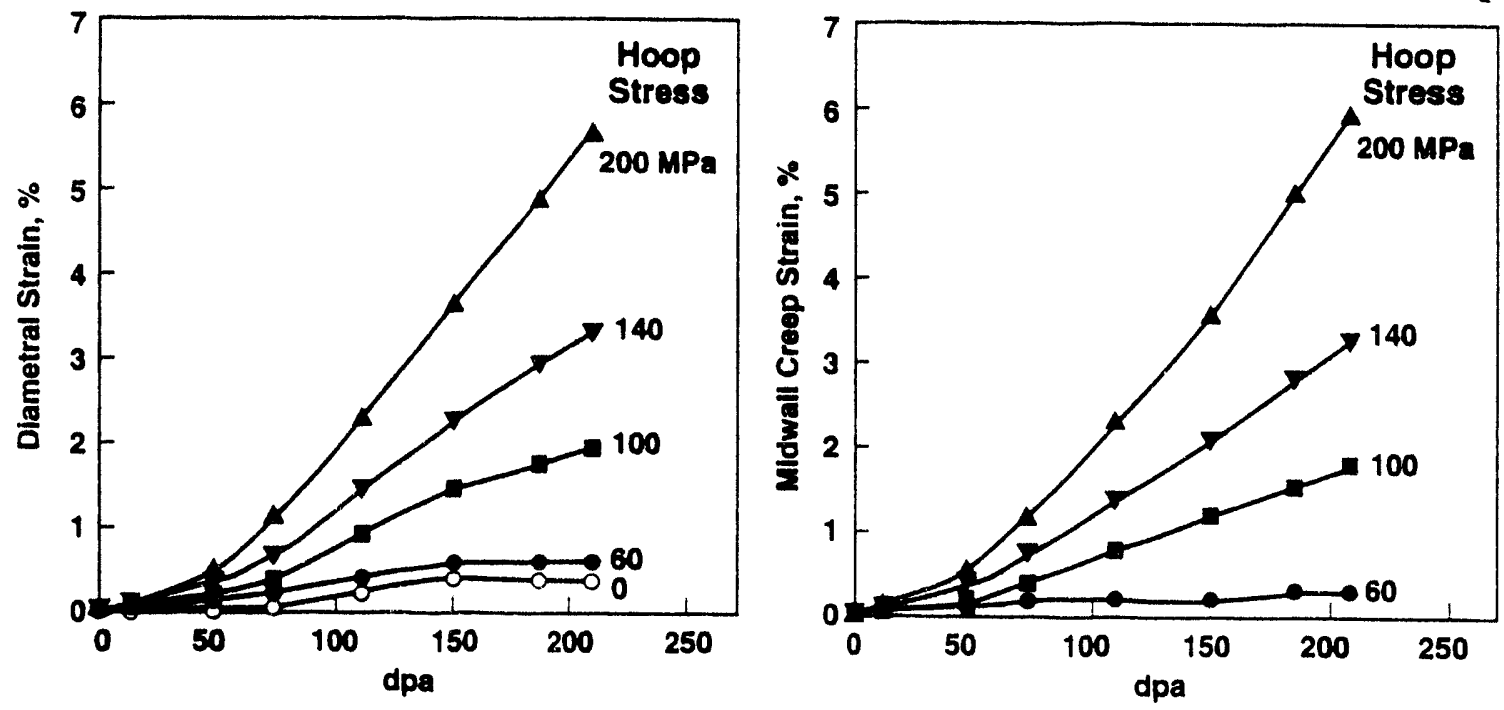

Fig. 1. Total diametral strains and midwall creep strains for HT9.
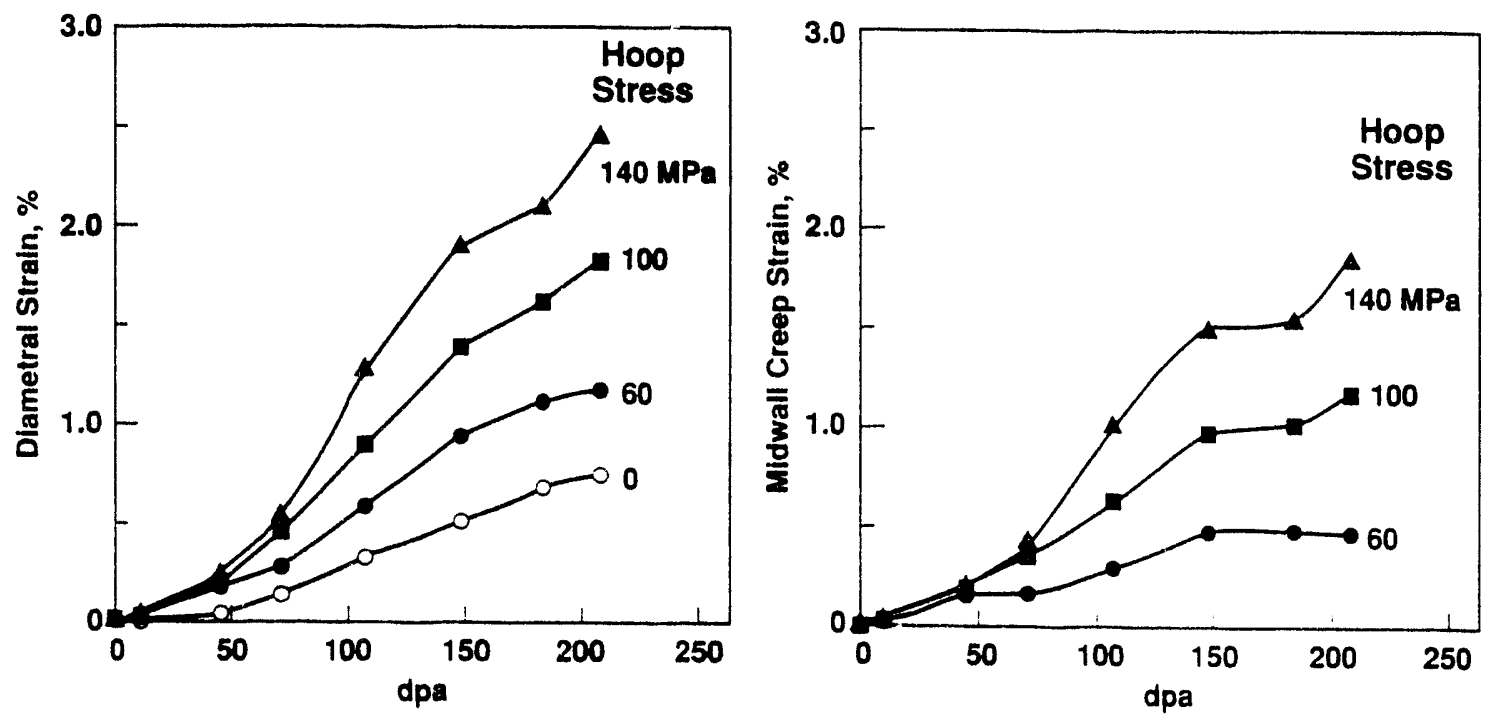

Fig. 2. Totai dimetral strains and midwall creep strains for ar. illo.

When the midwall creep strains are normalized to their respective hoop stresses. of HT9 to stress is characterized by a stress exponent somewhat greater than 1.0 ias shrwn in Fiqure 3 ). The

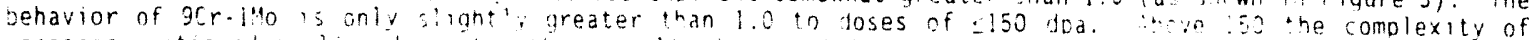
response mentioned earlier dominates the normalized conep behavior of gCr-l ho as inow in Figure 4. 


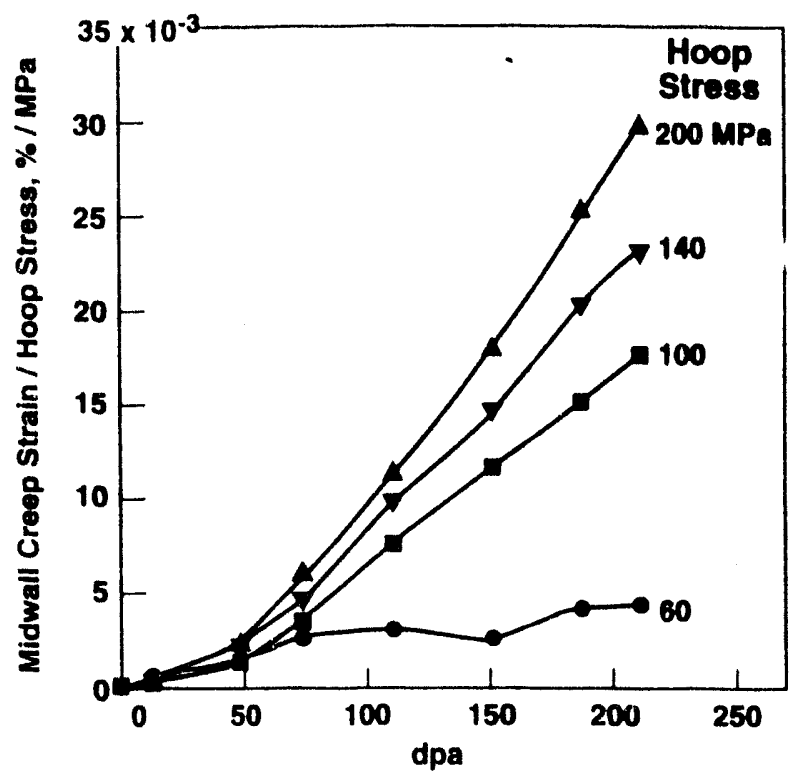

Fig. Stress-normalized midwall creep strains for HT9

Expected Achievements in the Next Reporting Period

The pressurized tubes will be cut to produce open tubes and the density of these will be measured. Microscopy examination will also proceed.

REFERENCE

1. E.R. Gilbert and B.A. Chin, in Effects of Radiation on Materials: Tenth Conference, ASTM STP 725, 1981, pp. $665-679$.

2. F.A. Garner and R.J. Puigh, J. Nucl. Mater., 199-181 (1991) 577-580.

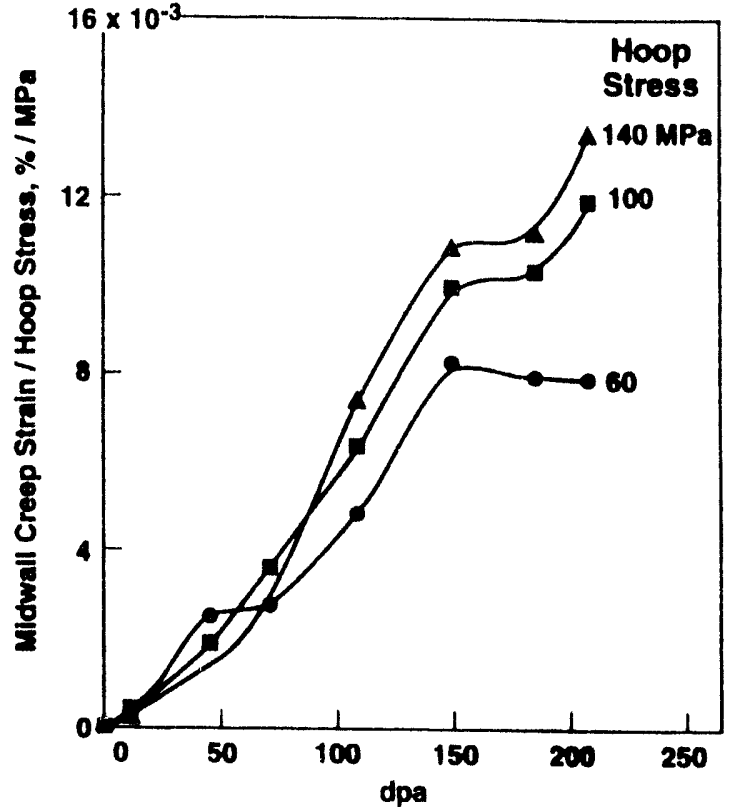

Fig. 4. Stress-normalized midwall creep strains for $9 \mathrm{Cr}-1 \mathrm{Mo}$. 
EFFECT OF VANADIUM AND TITANIUIM ON MECHANICAL PROPER'TIES OF LOW-CHROMIUM, REDUCED-ACTIVATION FERRITIC STEELS -- R. L. Kluch and D. J. Alexander

\section{OBJECTIVE}

The goal of this study is the development of a low-chromium reduced-activation ferritic steel.

\section{SUMMARY}

Tensile and Charpy impact tests were made on three normalized-and-tempered $21 / 4 \mathrm{Cr}-2 \mathrm{WV}(0.1 \% \mathrm{C})$ steels with $0.1,0.25$, and $0.5 \% \mathrm{~V}$ (all concentrations are in weight percent). Increasing vanadium from 0.1 to $0.25 \%$ increased the yield stress up to twenty percent. A higher ductile-brittle transition temperature (DBTT) accompanied the higher strength of the $0.25 \% \mathrm{~V}$ steel when both were tempered at $700^{\circ} \mathrm{C}$. Tempering at $750^{\circ} \mathrm{C}$ gave similar DBTTs. Increasing vanadium from 0.25 to $0.5 \%$ caused a slight increase in strength with a large decrease in toughness. Thus, a balance between strength and impact toughness is achieved with an intermediate vanadium concentration. Addition of $0.02 \%$ Ti to $21 / 4 \mathrm{Cr}-0.25 \mathrm{~V}, 21 / 4 \mathrm{Cr}-2 \mathrm{~W}$, and $21 / 4 \mathrm{Cr}-2 \mathrm{~W}-0.25 \mathrm{~V}(0.1 \% \mathrm{C})$ steels caused a yield stress decrease of 10 to $30 \%$, which was attributed to the effect of titanium on the MC precipitate distribution. The strength loss was accompanied by an increase in impact toughness, which may also have been affected by a decrease in prior austenite grain size. Furthermore, there was little difference in the DBTT of the Ti-modified steels tempered at 700 or $750^{\circ} \mathrm{C}$. If it were possible to use a Ti-modified steel tempered at $700^{\circ} \mathrm{C}$, this might offset the strength advantage of steels without titanium, which have to be tempered at the higher temperature.

\section{PROGRESS AND STATUS}

\section{Introduction}

Much of the effort to develop reduced-activation ferritic steels has been concentrated on Cr-W-V steels with 8-10\% $\mathrm{Cr}$ [1-3]. Low-chromium steels have advantages as structural materials [1], and preliminary work indicated that these steels can have strengths as good or better than the higher chromium steels [4]. The strength of a $2.25 \mathrm{Cr}-2 \mathrm{~W}-0.25 \mathrm{~V}-0.1 \mathrm{C}$ ( $(2 \mathrm{1} / 4 \mathrm{Cr}-2 \mathrm{WV})$ steel (all concentrations are in wt. \%) exceeded that for $9 \mathrm{Cr}-2 \mathrm{~W}-0.25 \mathrm{~V}-0.07 \mathrm{Ta}-0.1 \mathrm{C}(9 \mathrm{Cr}-2 \mathrm{WVTa})$ steel, the strongest $9 \mathrm{Cr}$ reduced-activation steel tested. However, the Charpy impact toughness of the $21 / 4 \mathrm{Cr}-2 \mathrm{WV}$ steel was inferior to that of the 9Cr-2WVTa. Because toughness decreases during neutron irradiation, it would be necessary to improve this property for a low-chromium steel before it could be considered for fusion applications.

Reduced-activation steels cannot contain molybdenum and niobium, two alloying elements in conventional steels of interest for fusion $(21 / 4 \mathrm{Cr}-1 \mathrm{Mo}$, $9 \mathrm{Cr}-1 \mathrm{MoVNb}$, and $12 \mathrm{Cr}-1 \mathrm{MoVW})$. Tungsten is considered a replacement for molybdenum, and titanium and tantalum have been considered possible replacements for niobium [1]. A series of low-chromium stecls was examined previously [4-6]. These included: $21 / 4 \mathrm{CrV}, 21 / 4 \mathrm{Cr}-1 \mathrm{WV}, 21 / 4 \mathrm{Cr}-2 \mathrm{~W}$, and $21 / 4 \mathrm{Cr}-2 \mathrm{WV}$ steels, where the vanadium concentration was constant at $0.25 \%$ and all steels contained $0.1 \% \mathrm{C}$.

Work is in progress to develop reduced-activation low-Cr steels. As part of that work compositional variations were examined in an effort to obtain an optimum composition. In this report, 2.25Cr steels are examined to determine the effect of vanadium on strength and impact toughness. Another series of steels were examined to determine how sinall anc unts of titanium affect properties. Impact toughness was evaluated from the ductile-britte transition !emperature (DBTT) and upper shelf energy (USE) in a Charpy test. 


\section{Experimental Procedure}

Experimental alloys were obtained in the form of 600-g vacuum arc-melted button heats. As starting stock for the present studies, material from the original four low-chromium heats were used [4]. These were electroslag-remelted heats prepared by Combustion Engineering, Inc. (CE), Chattanooga, Tennessee. In addition to nominal compositions of $\mathrm{Cr}, \mathrm{W}$, and $\mathrm{V}$, concentrations of elements normally found in steels, such as $\mathrm{Mn}, \mathrm{P}, \mathrm{Si}$, etc., were adjusted to levels typical of commercial practice. Details on chemical composition, microstructure, and mechanical properties of the original heats have been published [4-6].

For the steels with varying vanadium content, heats containing $0.1,0.25$, and $0.5 \% \mathrm{~V}$ were obtained by adding vanadium to the $21 / 4 \mathrm{Cr}$ - $2 \mathrm{~W}$ heat from ( The $0.02 \% \mathrm{Ti}$ additions were made to the $21 / 4 \mathrm{CrV}$, $21 / 4 \mathrm{Cr}-2 \mathrm{WV}$ (both with $0.25 \% \mathrm{~V}$ ), and $21 / 4 \mathrm{Cr}-2 \mathrm{~W}$ heats to obtain $21 / 4 \mathrm{CrVTi}, 21 / 4 \mathrm{Cr}-2 \mathrm{WTi}$, and $21 / 4 \mathrm{Cr}-2 \mathrm{WVTi}$, respectively. The original CE heats contained $0.1 \% \mathrm{C}$. Alloys were cast into ingots with a rectangular cross section of $12.7 \mathrm{~mm}$ by $25.4 \mathrm{~mm}$ and $152 \mathrm{~mm}$ in length. The ingots were hot rolled at $700^{\circ} \mathrm{C}$ to approximately $6.4 \mathrm{~mm}$. Half of this plate was cold rolled to $0.76-\mathrm{mm}$-thick sheet, with an intermediate $700^{\circ} \mathrm{C}$ anneal. Chemical compositions are given in Table 1.

Tensile specimens with a reduced gage section of $20.3-\mathrm{mm}$ long by $1.52-\mathrm{mm}$ wide by $0.76-\mathrm{mm}$ thick were machined from the $0.76-\mathrm{mm}$ sheet with gage lengths parallel to the rolling direction. One-third size Charpy specimens measuring 3.3 by 3.3 by $25.4 \mathrm{~mm}$ with a $0.51-\mathrm{mm}$-deep $30^{\circ} \mathrm{V}$-notch and a $0.05-$ to 0.08 -mm-root radius were machined from the $6.4-\mathrm{mm}$ plate. Specimens were taken along the rolling direction with the notch running transverse to the rolling direction (L-T orientation).

Specimens were tested in the normalized-and-tempered condition. Normalizing of all but the $21 / 4 \mathrm{Cr}-2 \mathrm{~W}$ steel involved austenitizing $0.5 \mathrm{~h}$ at $1050^{\circ} \mathrm{C}$ in a helium atmosphere and then rapidly cooling in flowing helium. The $21 / 4 \mathrm{Cr}-2 \mathrm{~W}$ was austenitized $0.5 \mathrm{~h}$ at $900^{\circ} \mathrm{C}$. Two tempering conditions were tested: $1 \mathrm{~h}$ at $700^{\circ} \mathrm{C}$ and $1 \mathrm{~h}$ at $750^{\circ} \mathrm{C}$. Heat treaunents were carried out on machined tensile specimens, and the 6.4-mm plate was heat treated before the Charpy specimens were machined from it.

Tensile tests were made in vacuum from room temperature to $600^{\circ} \mathrm{C}$ on a $44-\mathrm{kN}$-capacity Instron universal testing machine at a nominal strain rate of $4.2 \times 10^{-4} / \mathrm{s}$. Charpy tests were carried out in a pendulum-type impact machine specially modified to accommodate subsize specimens. Details on the test machine and test procedure have been published [7].

Results and Discussion

This report will concentrate on the effect of the alloying additions on mechanical properties.

Microstructures will be described only briefly and will be presented in more detail in a future report.

Vanadium variations

Increasing vanadium concentration had two effects on the tempered bainite microstructure of the steels with $0.1,0.25$, and $0.5 \%$ V. First, prior austenite grain size decreased with increasing vanadium concentration. ASTM grain size numbers were estimated at 3,4 , and 5 for the steels with $0.1,0.25$, and $0.5 \% \mathrm{~V}$, respectively. The second effect involved the fine precipitates that formed in the steels. With increasing vanadium, the number density of fine precipitates increased and the size decreased. The greatest change occurred between 0.1 and $0.25 \% \mathrm{~V}$, with less change between 0.25 and $0.5 \% \mathrm{~V}$. These fine precipitates were mainly $\mathrm{V}_{4} \mathrm{C}_{3}$, but the steels also contained coarser $\mathrm{M}_{3} \mathrm{C}$ and $\mathrm{M}_{7} \mathrm{C}_{3}$ precipitates [5].

Tensile data plotted as a function of test temperature are shown in Figs. 1 and 2. The relative behavior is similar for specimens tempered at either 700 or $750^{\circ} \mathrm{C}$, al though there is a decrease in strength with increasing tempering temperature. Yield stress [Fig. 1(a)] and ultimate tensile strength [Fig. 1(b)] increase with increasing vanadium concentration. The greatest strength difference occurred between 0.1 and $0.25 \%$ $\mathrm{V}$, with much less change between 0.25 and $0.5 \% \mathrm{~V}$. This observation is probably associated with the observation that a larger change in precipitate number density occurred between the 0.1 and $0.25 \% \mathrm{~V}$ steels than the change between 0.25 and $0.5 \% \mathrm{~V}$. The 0.25 and $0.5 \% \mathrm{~V}$ steels are considerably stronger than the $0.1 \% \mathrm{~V}$ steel, again a reflection of the microstructure. 
Total elongation [Fig. 2(a)] and uniform elongation [Fig. 2(b)] behavior is essentially inverse to the yield stress behavior, in that the strongest steel has the lowest elongation and vice versa. There is much less difference between the behavior after tempering at 700 and $750^{\circ} \mathrm{C}$ than there was for the yield stress and ultimate tensile strength. The ductility data show more scatter than the strength data. No explanation is available for the large drop in total elongation for the $0.1 \% \mathrm{~V}$ steel tempered at $750^{\circ} \mathrm{C}$ and tested at $600^{\circ} \mathrm{C}$ [Fig. 2(a)]. The relative behavior of the uniform elongation [Fig. 2(b)] with test temperature was similar to the total elongation.

Charpy impact behavior is affected by vanadium composition (Fig. 3). For a given tempering temperature, the DBTT increased with increasing vanadium [Fig 3(a)]. Relatively low values were obtained for the $0.1 \% \mathrm{~V}$ steel for both tempering conditions, as was true for the $0.25 \% \mathrm{~V}$ steel tempered at $750^{\circ} \mathrm{C}$. The steel with $0.5 \% \mathrm{~V}$ had a negative DBTT only after the $750^{\circ} \mathrm{C}$ temper, and then the value was less than half that of the other two steels tempered at this temperature.

As opposed to the large effect of vanadium on DB'TT, only a minimal effect was observed for the USE, with essentially no difference for the three steels after the $750^{\circ} \mathrm{C}$ temper [Fig 3(b)]. After the $700^{\circ} \mathrm{C}$ anneal, a small decrease occurred between the steel with 0.1 and $0.25 \% \mathrm{~V}$, with little difference between the $0.25 \%$ and $0.5 \% \mathrm{~V}$ steels.

The observations on the DBTT reflect the strength differences of the three steels. Observations on USE are probably a consequence of the ductile fracture process, which must be similar for the three steels. Fracture on the upper shelf is generally determined by the nucleation of voids at precipitate or inclusion particles, and a similar USE implies that similar microstructural features nucleate the fracture in the three steels.

These results indicate that for an optimization of the strength and impact toughness of a $2.25 \% \mathrm{Cr}$ steel with $2 \% \mathrm{~W}$, vanadium should be limited to about $0.25 \%$. Increasing the vanadium concentration from 0.25 to $0.5 \%$ results in only a minimal increase in strength at the cost of substantially raising the DBTr.

Titanium additions

The $0.02 \%$ Ti additions were made to $21 / 4 \mathrm{Cr}-0.25 \mathrm{~V}(21 / 4 \mathrm{CrV}), 21 / 4 \mathrm{Cr}-2 \mathrm{~W}$, and $21 / 4 \mathrm{Cr}-2 \mathrm{~W}-0.25 \mathrm{~V}$ $(21 / 4 \mathrm{Cr}-2 \mathrm{WV})$ steels, which were previously tested and examined [4-6]. The microstructures of the test specimens were tempered bainite. Addition of titumium caused a decruase in the prior austenite grain size of the two steels with vanadium, and a decrease in the number density of precipitates relative to all three steels without titanium. Estimated ASTM grain size numbers changed from approximately 4 to 7 for the $21 / 4 \mathrm{CrV}$ and $21 / 4 \mathrm{CrVTi}$, from 4 to 8 for $21 / 4 \mathrm{Cr}-2 \mathrm{WV}$ and $21 / 4 \mathrm{Cr}-2 \mathrm{WVTi}$; a grain size number of 10 was estimated for both $21 / 4 \mathrm{Cr}-2 \mathrm{~W}$ and $21 / 4 \mathrm{Cr}-2 \mathrm{WTi}$.

Steels with vanadium and no titanium contained a tine distribution of vanadium-rich $M C\left(V_{4} C_{3}\right)$ in addition to $\mathrm{M}_{3} \mathrm{C}$ and $\mathrm{M}_{7} \mathrm{C}_{3}$; the $21 / 4 \mathrm{Cr}-2 \mathrm{~W}$ also contained some $\mathrm{M}_{23} \mathrm{C}_{6}$ [5]. Although TEM analysis has not been completed on the steels with titanium, they are expected to contain some MC rich in titanium, in addition to vanadium-rich MC, along with the other carbides observed in the steels without titanium.

It is suggested that not all of the titanium-rich MC dissolved during the austenitization treatment. This would limit the grain growth and result in a smaller prior austenite grain size. The reduction in the number density of precipitates of the steels containing titanium could be caused by undissolved titaniumrich carbides acting as nuclei for the vanadium-rich MC that formed during tempering. The limited number of these pre-existing nuclei reduced the number of precipitates that formed.

Addition of $0.02 \%$ Ti to the Cr-W.V steels affected the tensile behavior (Figs. 4-7). It caused a marked decrease in the yield stress and ultimate tensile strength of all three steels, as shown in Figs. 4 and 6 for the steels tempered at 700 and $750^{\circ} \mathrm{C}$, respectively. The magnitude of the yield strength decrease [Figs. 4(a) and 6(a)] depended on the strength of the steel without the tianium. The $21 / 4 \mathrm{Cr}-2 \mathrm{WV}$ steel was the strongest steel, and it showed the largest decrease. Smaller changes occurred for the other two steels. These observations reflect the observations on the reduction in the precipitate number density caused by 
the titanium. Ultimate tensile strength behavior [Figs. 4(b) and $6(\mathrm{~b})$ ] was similar to the yield stress behavior.

A slight increase in total and uniform elongation (Figs. 5 and 7) accompanied the strength decrease caused by the titanium addition, although there was considerable scatter in the data. Ductility increased with decreasing strenguh, and the steels tempered at $750^{\circ} \mathrm{C}$. had a higher ductility than those tempered at $700^{\circ} \mathrm{C}$.

Titanium had a large effect on the DBTT of the steels that contained vanadium--the $21 / 4 \mathrm{CrV}$ and $21 / 4 \mathrm{Cr}$ $2 W V$ steels [Fig. 8(a)]. It had relatively little effect on the $21 / 4 \mathrm{Cr}-2 \mathrm{~W}$ steel, which had the lowest DBTT prior to the titanium addition. These observations must be attributed to the change in grain size, in addition to the reduction in strength caused by the titanium addition. The addition of titanium to $21 / 4 \mathrm{Cr}$ $2 \mathrm{~W}$ did not cause a large change in prior austenite grain size, and thus did not cause a noticeable change in DBTT. There was no effect on the prior austenite grain size of the $21 / 4 \mathrm{Cr}-2 \mathrm{~W}$ because it was austenitized at $900^{\circ} \mathrm{C}$ without titanium and at $1050^{\circ} \mathrm{C}$ when titanium was present. A higher austenitizing temperature was used for the $21 / 4 \mathrm{CrV}, 21 / 4 \mathrm{Cr}-2 \mathrm{WV}$, and the steels with titanium in order to ensure the dissolution of the V-rich and Ti-rich carbides.

Note that whereas there is no effect of tempering temperature on the $21 / 4 \mathrm{CrV}$, there is a significant difference for the $21 / 4 \mathrm{Cr}-2 \mathrm{WV}$. The change for this latter steel probably reflects the reduction of the dispersion strengthening effect because of the larger precipitate particles formed by tempering at $750^{\circ} \mathrm{C}$. (The higher number density of samaller precipitate particles in the $21 / 4 \mathrm{Cr}-2 \mathrm{WV}$ makes this steel much stronger than the $21 / 4 \mathrm{CrV}$, which contains a lower density of larger particles.) When titanium is added to this steel, the difference in DBTT for the 700 and $750^{\circ} \mathrm{C}$ tempering temperatures, is reduced significantly.

There was relatively little difference in the USE of the steels with and without titanium, regardless of the tempering temperature [Fig. 8(b)]. In fact, there was little difference between the different steels. Only the $21 / 4 \mathrm{Cr}-2 \mathrm{WV}$ steel showed some variation, but it was relatively minor compared to the differences noted for the DBTT. Again, this must reflect a similarity in the ductile fracture hehavior of these steels, as suggested above for the steels with different vanadium compositions.

These results indicate that titanium might be used to improve impact toughness. Such improvement is desirable, since the DBTT is increased by irradiation. However, this improvement comes at the expense of strength. The effect on strength may be alleviated somewhat by austenitizing at a higher temperature than the $1050^{\circ} \mathrm{C}$ used in this experiment. This would cause more titanium carbide to dissolve, although it would also increase the prior austenite grain size. Therefore, the best austenitization temperature would have to be determined, because if the temperature was too high, the large prior austenite grain size would negate the positive effect of titanium.

\section{SUMMARY AND CONCLUSION}

As part of the effort to develop low-chromium, reduced-activation ferritic steels for fusion reactors, a series of $21 / 4 \mathrm{Cr}$ steels was tested to deternine the effect of vanadium and titanium on tensile and Charpy impact properties. The steels were tested after normalizing and tempering at 700 and $750^{\circ} \mathrm{C}$. The first part of the study examined the effect of adding $0.1,0.25$, and $0.5 \%$ V 10 a $21 / 4 C r-2 \mathrm{~W}$ steel. Increasing the vanadium from 0.1 to $0.25 \%$ caused a large strength increase. Little further increase occurring when vanadium was increased from 0.25 to $0.5 \%$. The DBTT in the Charpy impact tests increased with vanadium, with the largest increase for steels tempered at $700^{\circ} \mathrm{C}$; the DBTT of the $0.5 \% \mathrm{~V}$ steel was above room temperature. After tempering at $750^{\circ} \mathrm{C}$, there was less difference between the steels with 0.1 and $0.25 \% \mathrm{~V}$ with a greater difference between the 0.25 and $0.5 \% \mathrm{~V}$ steels. Based on these observations, it was concluded that for optimum strength and impact toughness, a $21 / 4 \mathrm{Cr}-2 \mathrm{WV}$ steel should contain about $0.25 \% \mathrm{~V}$. A $0.02 \%$ Ti addition to $21 / 4 \mathrm{CrV}, 21 / 4 \mathrm{Cr}-2 \mathrm{~W}$, and $21 / 4 \mathrm{Cr}-2 \mathrm{WV}$ steels caused a strength decrease, but it improved the Charpy impact behavior. An improved DBTT would be desirable, since the DBTT increases during irradiation. It may be possible to maintain the improved DBTT and improve the strength by increasing the austenitizing temperature. 


\section{REFERENCES}

[1] R. L. Klueh and E. E. Bloom, Nucl. Eng. Design/Fusion, 2 (1985) 383.

[2] M. Tamura, H. Hayakawa, M. Tanimura, A Hishinuma, and T. Kondo, J. Nucl. Mater., 141-143 (1986) 1067.

[3] D. Dulieu, K. W. Tupholme, and G. J. Butterworth, J. Nucl. Mater., 141-143 (1986) 1097.

[4] R. L. Klueh, Met. Trans. 20A (1989) p. 463.

[5] R. L. Klueh and P. J. Maziasz, Met. Trans. 20A (1989) 373.

[6] R. L. Klueh and W. R. Corwin, J. Materials Eng. 11 (1989) 169.

[7] D. J. Alexander, R. K. Nanstad, W. R. Corwin, and J. T. Hutton, Applications of Automation Technology to Fatigue and Fracture Testing, ASTM STP 1092, A. A. Braun, N. E. Ashbaugh, and F. M. Smith, Eds. (American Society for Testing and Materials, Philadelphia, 1990) p. 83 
Table 1. Chemical composition (wt \%) of experimental alloys

\begin{tabular}{|c|c|c|c|c|c|c|}
\hline Element & $0.1 \mathrm{~V}$ & $\begin{array}{c}1 / 4 \mathrm{Cr}-2 \\
\text { with } \\
0.25 \mathrm{~V}\end{array}$ & $0.5 \mathrm{~V}$ & $21 / 4 \mathrm{CrVTi}$ & $21 / 4 C r-2 W T i$ & $21 / 4 C r-2 W V T i$ \\
\hline$C$ & 0.097 & 0.10 & 0.099 & 0.10 & 0.10 & 0.11 \\
\hline $\mathrm{Mn}$ & 0.35 & 0.35 & 0.36 & 0.37 & 0.35 & 0.39 \\
\hline $\mathrm{P}$ & 0.016 & 0.016 & 0.016 & 0.016 & 0.017 & 0.018 \\
\hline$S$ & 0.006 & 0.006 & 0.006 & 0.007 & 0.003 & 0.003 \\
\hline $\mathrm{Si}$ & 0.12 & 0.12 & 0.12 & 0.14 & 0.15 & 0.16 \\
\hline $\mathrm{Ni}$ & 0.01 & 0.01 & $<0.1$ & 0.01 & 0.01 & 0.01 \\
\hline $\mathrm{Cr}$ & 2.40 & 2.40 & 2.45 & 2.37 & 2.47 & 2.44 \\
\hline Mo & $<.01$ & $<.01$ & $<.01$ & $<.01$ & $<.01$ & $<.01$ \\
\hline $\mathrm{V}$ & 0.10 & 0.25 & 0.49 & 0.25 & 0.009 & 0.23 \\
\hline $\mathrm{Cb}$ & $<.01$ & $<.01$ & $<.01$ & $<.01$ & $<.01$ & $<.01$ \\
\hline $\mathrm{Ti}$ & $<.01$ & $<.01$ & $<.01$ & 0.024 & 0.024 & 0.020 \\
\hline $\mathrm{Co}$ & 0.008 & 0.008 & 0.008 & 0.007 & 0.009 & 0.009 \\
\hline $\mathrm{Cu}$ & 0.03 & 0.03 & 0.03 & 0.03 & 0.03 & 0.03 \\
\hline $\mathrm{Al}$ & 0.009 & 0.009 & 0.009 & 0.005 & 0.013 & 0.013 \\
\hline B & 0.001 & 0.001 & 0.001 & $<.001$ & 0.002 & 0.002 \\
\hline W & 2.10 & 2.11 & 2.08 & 0.01 & 1.90 & 1.90 \\
\hline As & 0.024 & 0.025 & 0.026 & & & \\
\hline $\mathrm{Sn}$ & 0.002 & 0.002 & 0.002 & & & \\
\hline $\mathrm{Zr}$ & $<.001$ & $<.001$ & 0.013 & & & \\
\hline
\end{tabular}



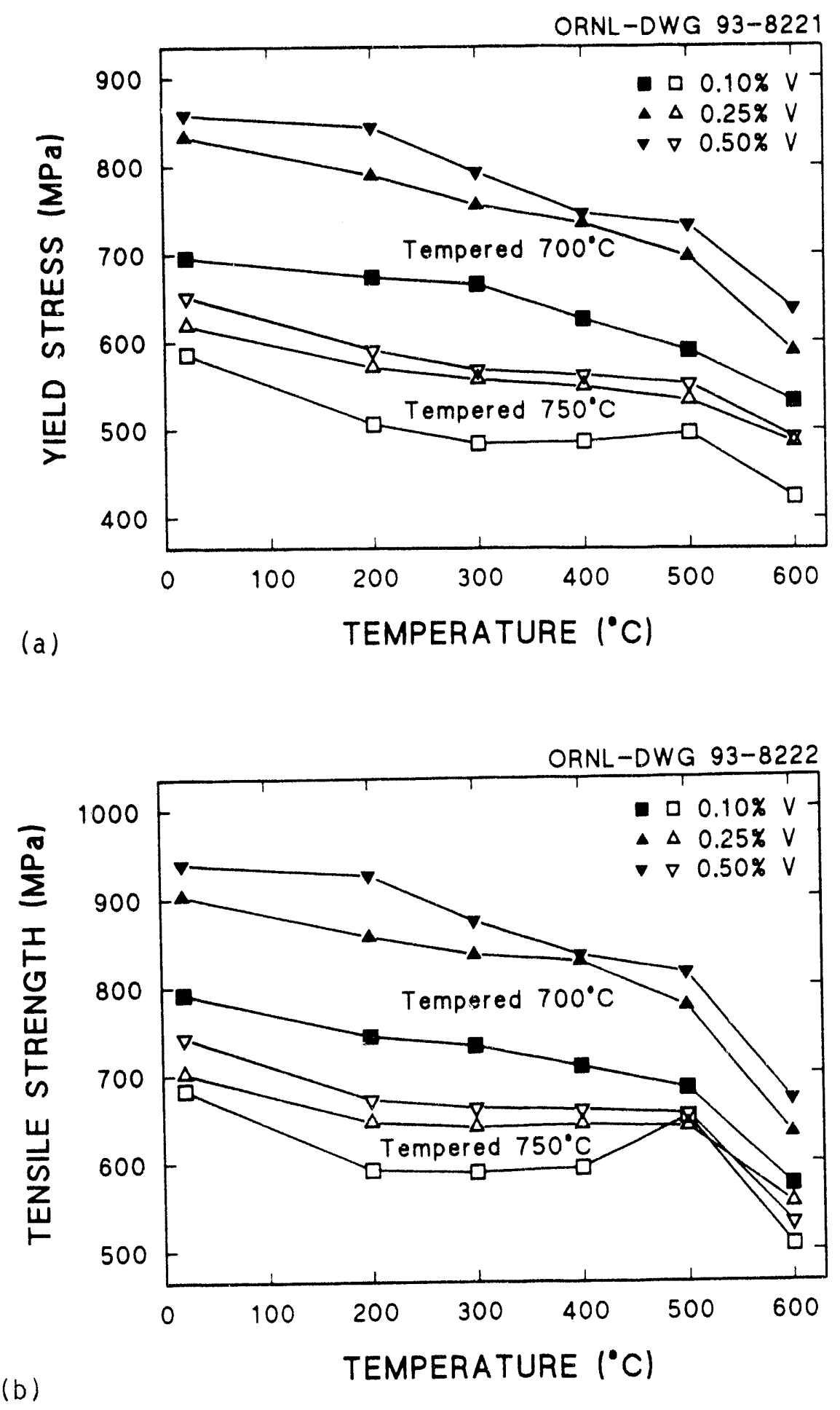

Fig. 1. a) Yield stress and (b) ultimate tensile strength as a function of test temperature of the steels with varying vanadium concentration. 

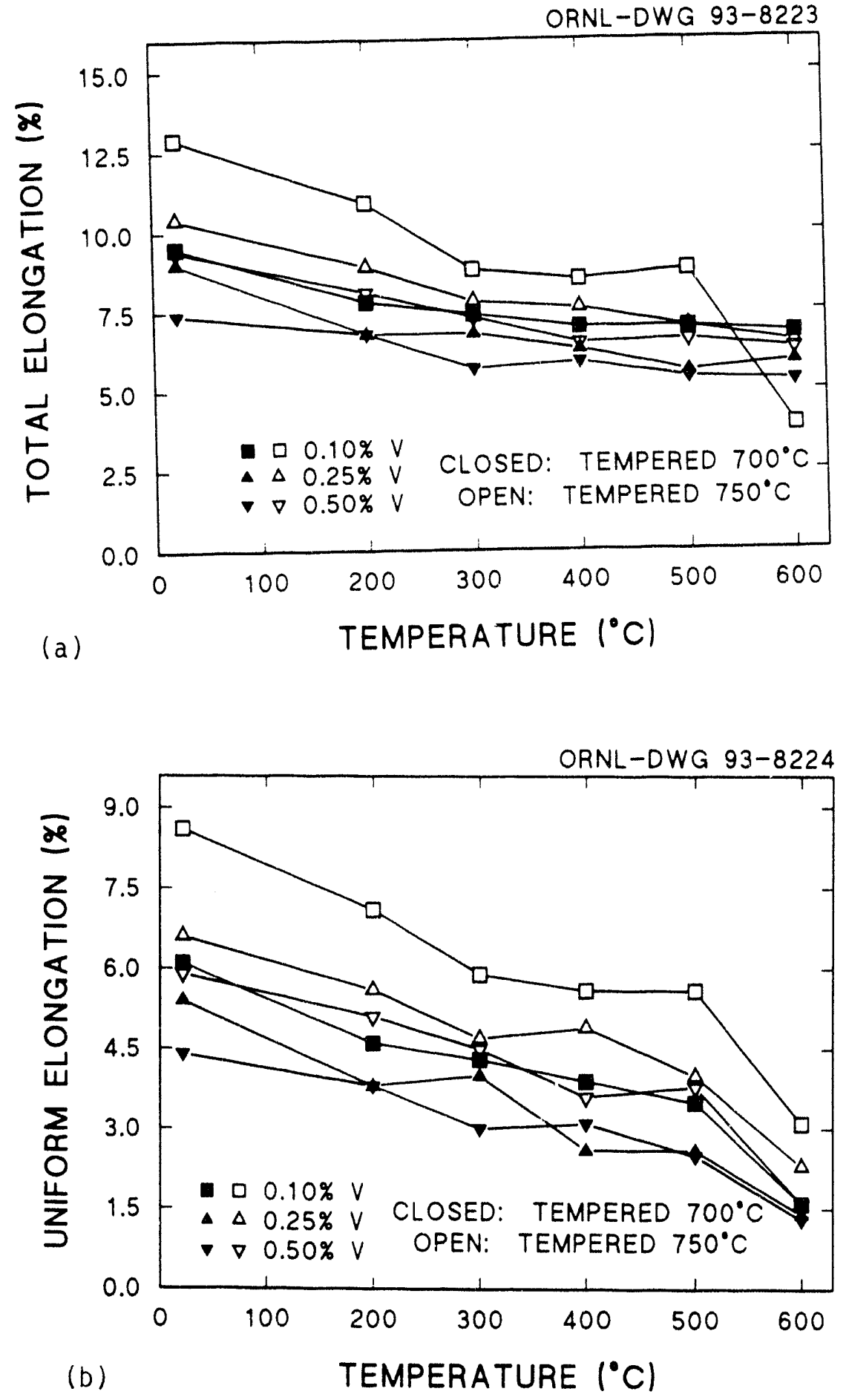

Fig. 2. (a) Total and (b) uniform elongation as a function of test temperature of the steels with varying vanadium concentration. 

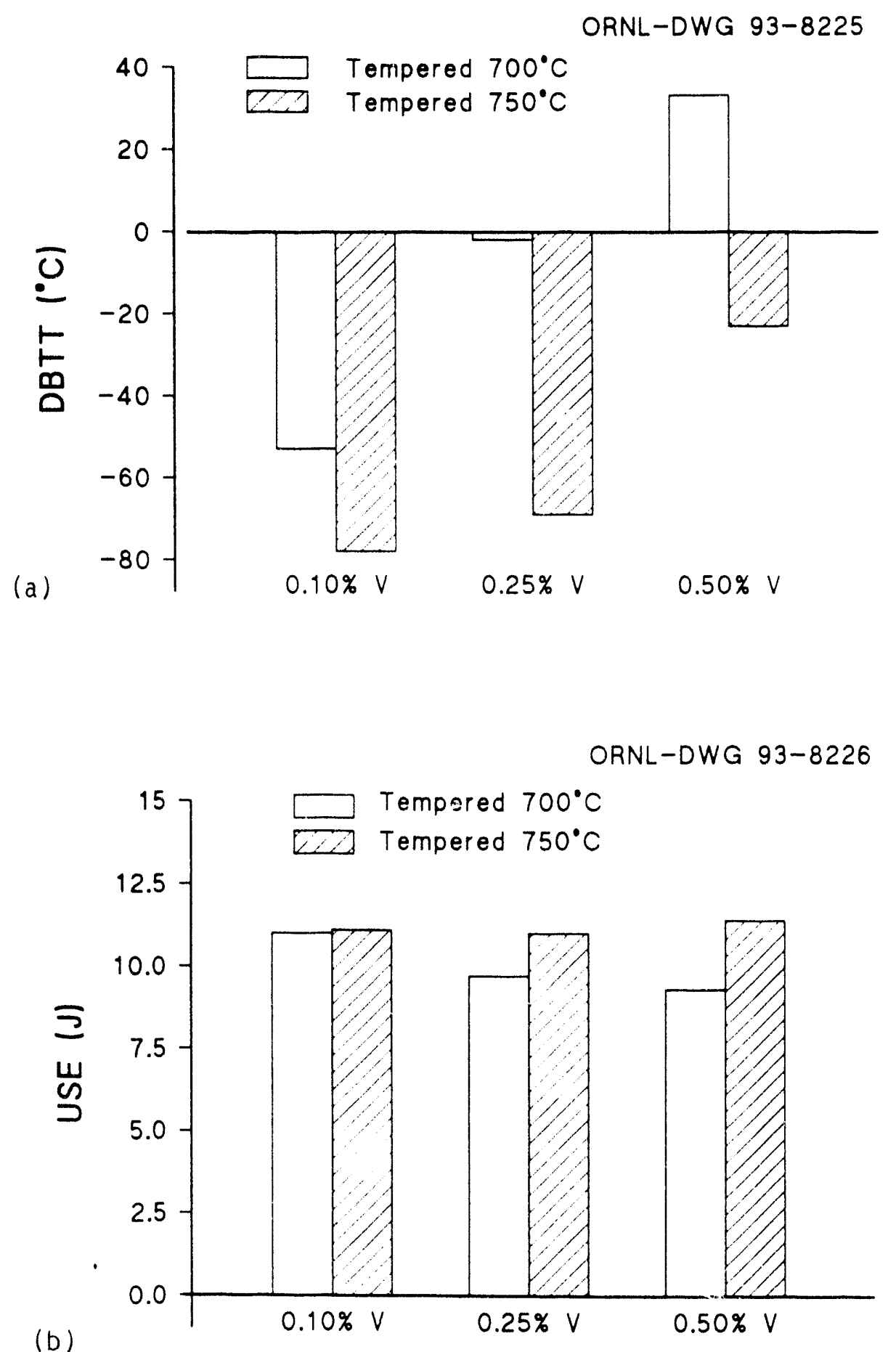

Fig. 3. (a) Ductile-brittle transition temperature and (b) upper shelf energy for the three steels with varying vanadium concentration. 

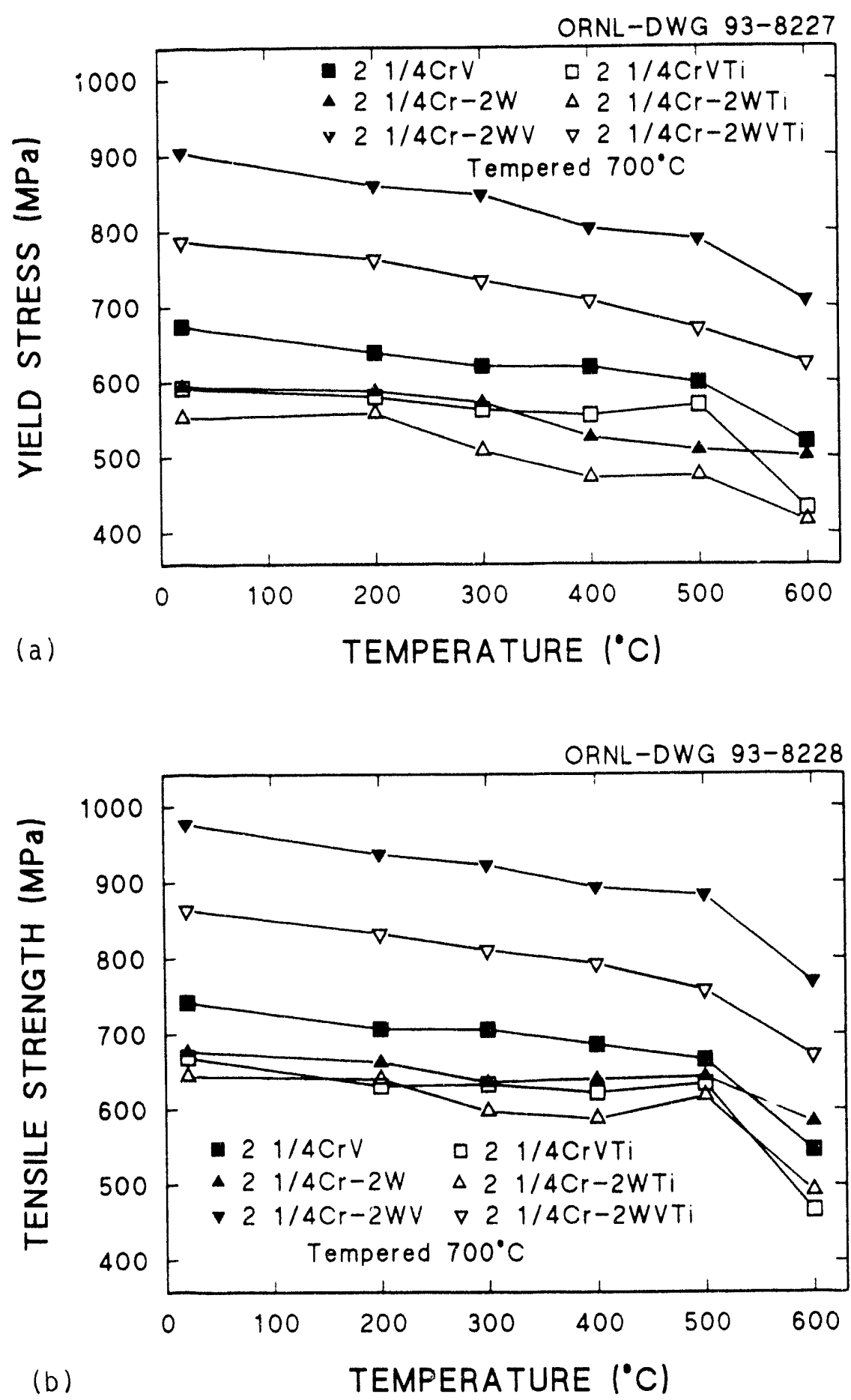

Fig. 4. (a) Yield stress and (b) ultimate tensile strength as a function of test temperature of the $21 / 4 \mathrm{CrV}, 21 / 4 \mathrm{Cr}-2 \mathrm{~W}$, and $21 / 4 \mathrm{Cr}-2 \mathrm{WV}$ steels with and without an addition of $0.02 \% \mathrm{Ti}$ after normalizing and then tempering $1 \mathrm{~h}$ at $700^{\circ} \mathrm{C}$. 

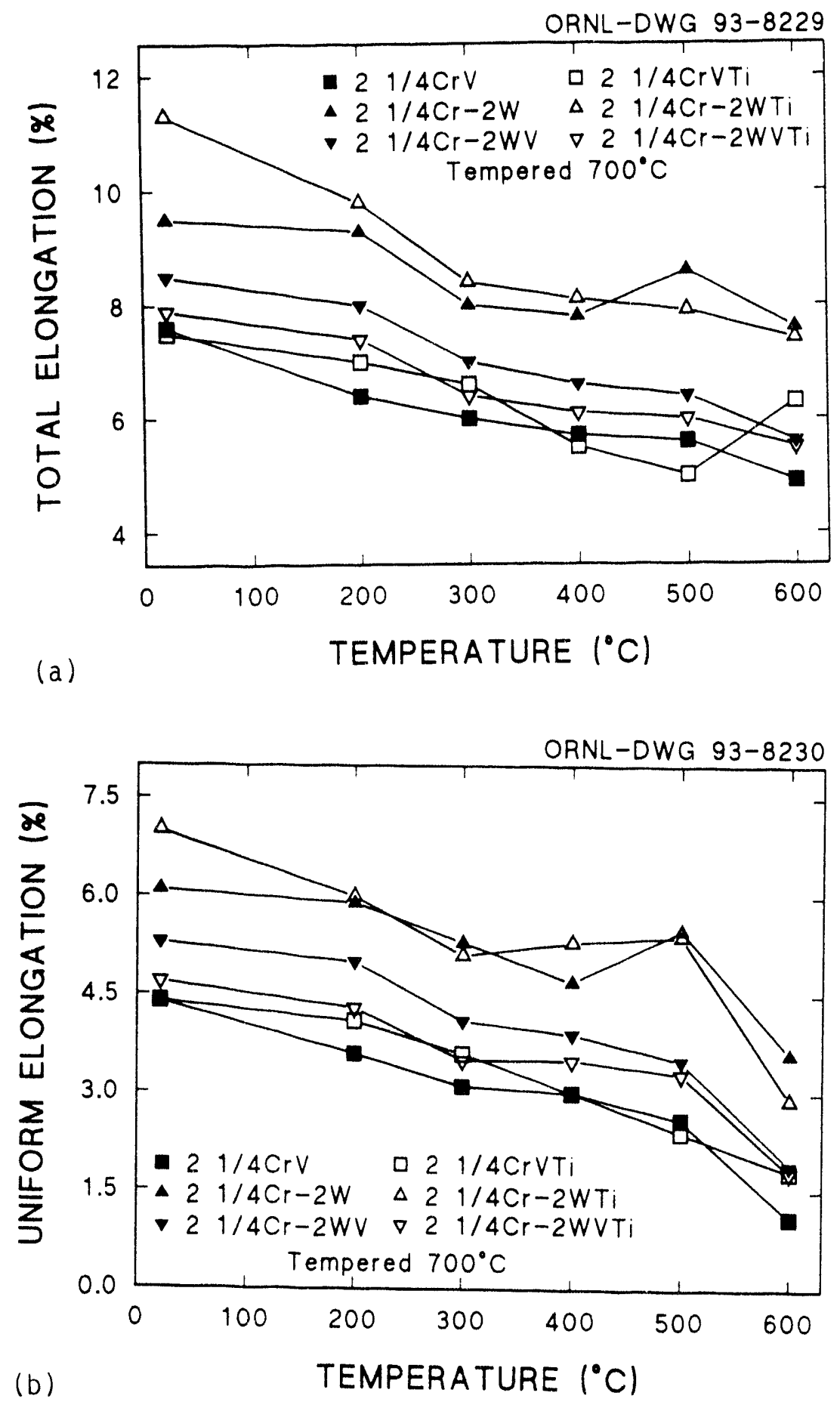

Fig. 5. (a) Total and (b) unifornı elongation as a function of test temperature of the $21 / 4 \mathrm{CrV}, 21 / 4 \mathrm{Cr}-2 \mathrm{~W}$, and $21 / 4 \mathrm{Cr}-2 \mathrm{WV}$ steels with and without an addition of $0.02 \% \mathrm{Ti}$ after normalizing and then tempering $1 \mathrm{~h}$ at $700^{\circ} \mathrm{C}$. 

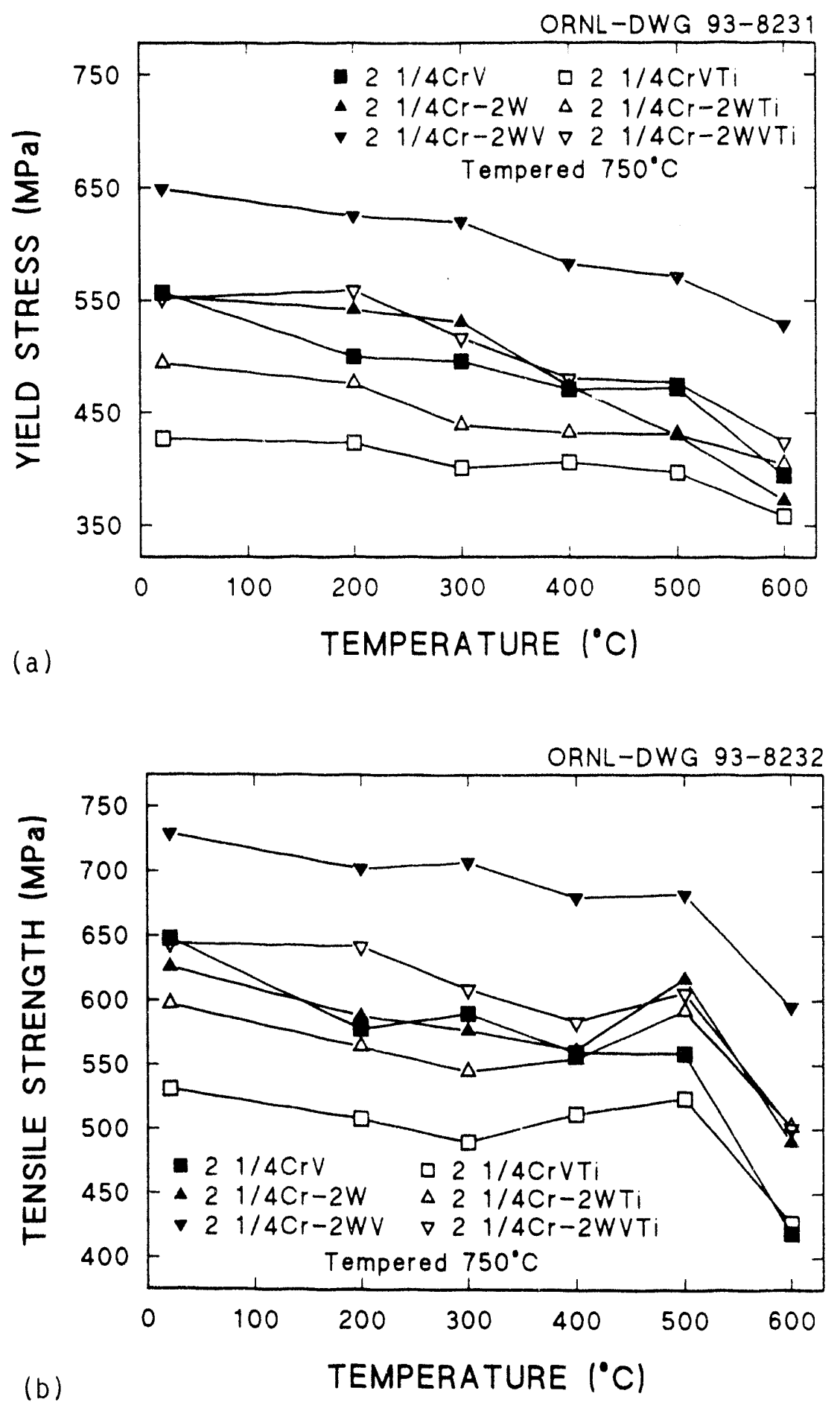

Fig. 6 (a) Yield stress and (b) ultimate tensile strength as a function of test temperature of the $21 / 4 \mathrm{CrV}, 21 / 4 \mathrm{Cr}-2 \mathrm{~W}$, and $21 / 4 \mathrm{Cr}-2 \mathrm{WV}$ steels with and without an addition of $0.02 \% \mathrm{Ti}$ after normalizing and then tempering $1 \mathrm{~h}$ at $750^{\circ} \mathrm{C}$. 

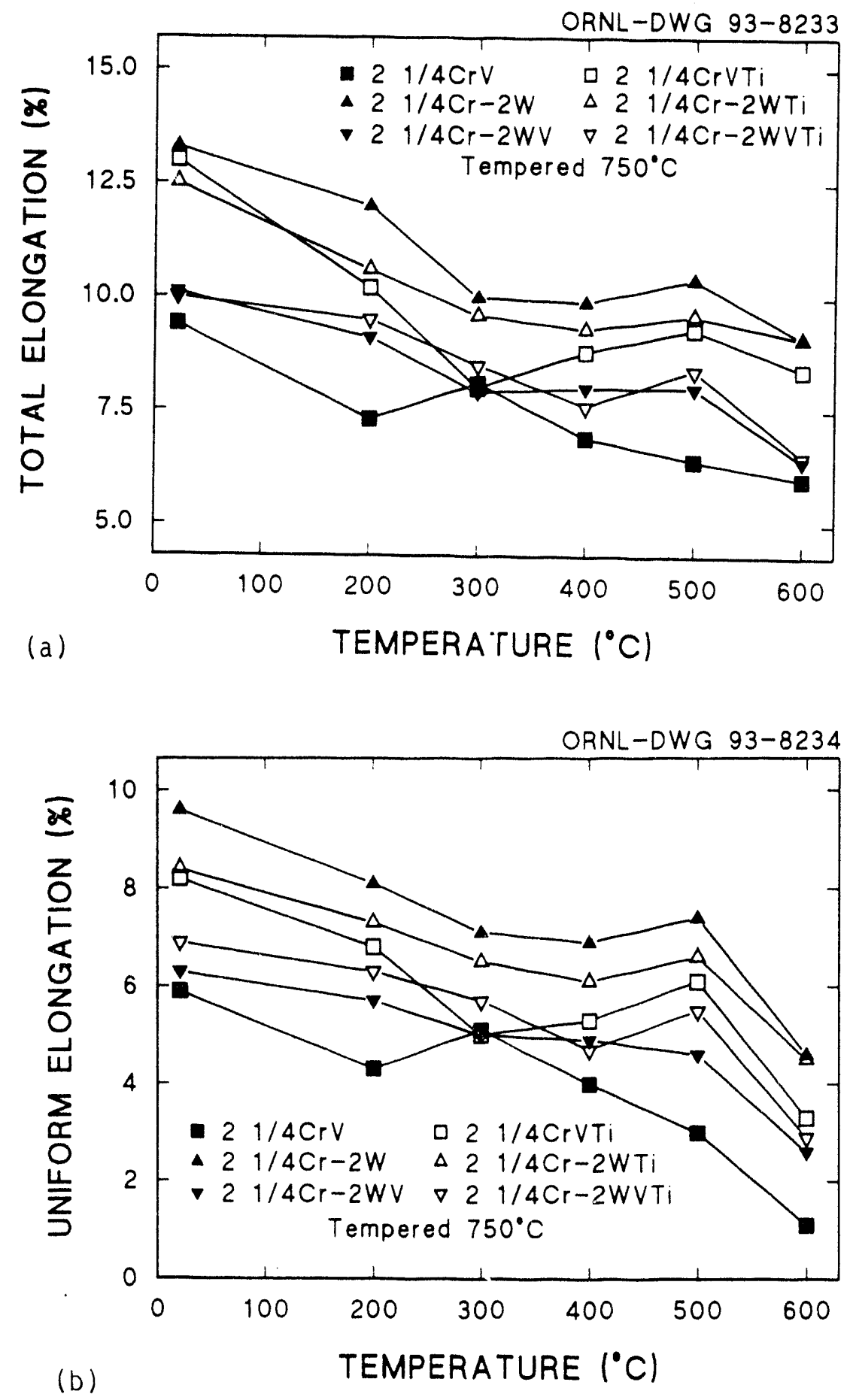

Fig. 7. (a) Total and (b) uniform elongation as a function of test temperature of the $21 / 4 \mathrm{CrV}, 21 / 4 \mathrm{Cr}-2 \mathrm{~W}$, and $21 / 4 \mathrm{Cr}-2 \mathrm{WV}$ steels with and without an addition of $0.02 \% \mathrm{Ti}$ after normalizing and then tempering $1 \mathrm{~h}$ at $750^{\circ} \mathrm{C}$. 

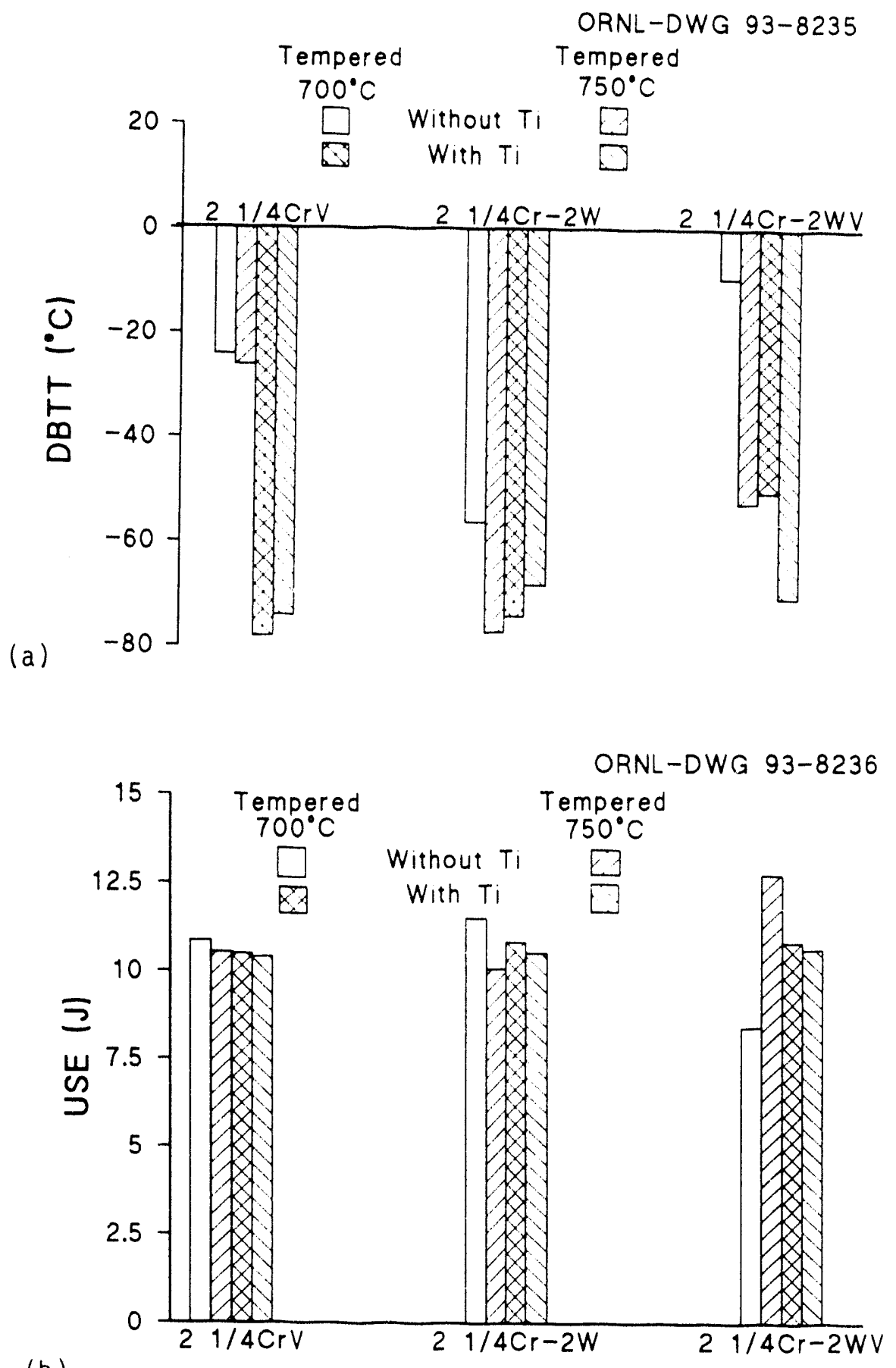

(b)

Fig. 8. (a) Ductile-brittle transition temperature and (b) upper shelf energy of the $21 / 4 \mathrm{CrV}, 21 / 4 \mathrm{Cr}-2 \mathrm{~W}$, and $21 / 4 \mathrm{Cr}-2 \mathrm{WV}$ steels with and without an addition of $0.02 \% \mathrm{Ti}$ after normalizing and then tempering $1 \mathrm{~h}$ at $700^{\circ} \mathrm{C}$ and $1 \mathrm{~h}$ at $750^{\circ} \mathrm{C}$. 


\subsection{Austenitic Stainless Steels}


STRESS-MODIFIED WELDING PROCESS FOR HELIUM-BEARING TYPE 316 STAINLESS STEELS - C. A. Wang and B. A. Chin (Auburn University), and M. L. Grossbeck (Oak Ridge National Laboratory)

\section{OBJECTIVE}

The objective of this work is to evaluate the new technique for the welding of heliumbearing materials.

\section{SUMMARY}

Experiments have shown that Type 316 stainless steel is susceptible to heat-affected-zone (HAZ) cracking upon cooling when welded using the gas tungsten arc (GTA) process under lateral constraint. The cracking has been hypothesized to be caused by stress-assisted helium bubble growth and rupture at grain boundaries. This study utilized an experimental welding setup which enabled different compressive stresses to be applied to the plates during welding. Autogenous GTA welds were produced in Type 316 stainless steel doped with 256 appm helium. The application of a compressive stress, $55 \mathrm{MPa}$, during welding suppressed the previously observed catastrophic cracking. Detailed examinations conducted after welding showed a dramatic change in helium bubble morphology. Grain boundary bubble growth along directions parallel to the weld was suppressed. The results suggest that stress-modified welding techniques may be used to suppress or eliminate helium-induced cracking during joining of irradiated materials.

\section{PROGRESS AND STATUS}

\section{$\underline{\text { Introduction }}$}

Large amounts of helium will be generated within many materials from transmutation reactions as a consequence of neutron bombardment of structural components in a fusion reactor[1-3]. Due to its inert nature and extremely low solubility in metals, helium will diffuse and agglomerate to form bubbles after being trapped at point defect aggregates, dislocations, and grain boundaries. Such bubbles have been shown to degrade materials properties [3-12]. Investigations have also shown that helium bubbles grow rapidly along grain boundaries that are subjected to a tensile stress at high temperature [9-15]. Both high stress and high temperature are typically encountered following conventional gas tungsten arc (GTA) welding upon cooling. Shrinkage-induced tensile stresses are produced due to the volume contraction of the weld upon solidification and subsequent thermal contraction during cooling. Intergranular heat-affectedzone (HAZ) cracking following GTA welding with lateral constraint was observed by Lin et al. in Type 316 stainless steel with helium concentrations greater than 2.5 appm [9-12]. HAZ cracking was found to occur at the grain boundaries parallel to the welding direction, approximately 2 to 3 grain diameters (grain size was about $70 \mu \mathrm{m}$ ) from the fusion boundary. Centerline interdendritic fractures in the fusion zone have also been observed in GTA welds of Type 316 stainless steels containing more than $100 \mathrm{appm}$ helium. These severe failures are attributed to the growth of helium bubbles at both HAZ grain boundaries and weld dendrite boundaries.

The objective of the present study was to investigate techniques which might be used to eliminate heat-affected-zone cracking in helium-containing steels subjected to GTA welding. These techniques need to be identified to enable repair and maintenance of the first wall of a fusion reactor. This work investigated the weldability of helium-bearing austenitic Type 316 
stainless steel under controlled stress conditions during welding. Modification of the stress field was accomplished by the application of a compressive stress perpendicular to the weld direction during welding.

\section{Experimental Procedure}

The material investigated in this study was $0.76 \mathrm{~mm}$ thick austenitic Type 316 stainless steel sheet. Following a solution anneal at $1050^{\circ} \mathrm{C}$ for one hour, the avcrage grain size was about $70 \mu \mathrm{m}$. Helium was implanted into the steel using tritium doping and decay'. The steel was exposed to tritium gas at $125 \mathrm{MPa}$ at $300^{\circ} \mathrm{C}$ for 30 days. The dissolved tritium was then allowed to decay to helium at $-40^{\circ} \mathrm{C}$ for six months. The excess tritium was then pumped off under a vacuum $\left(10^{-3} \mathrm{~Pa}\right)$ at $400^{\circ} \mathrm{C}$ to prevent further helium generation. This doping process introduced $256 \mathrm{appm}$ helium into the stecl. The pump-off treatment resulted in the formation of stable helium bubbles about $4.5 \times 10^{20} / \mathrm{m}^{3}$ in density and approximately $1.7 \mathrm{~nm}$ in diameter in the matrix while a density of $8.8 \times 10^{14} / \mathrm{m}^{2}$ and $2.0 \mathrm{~nm}$ diameter bubbles were observed on the grain boundaries.

Autogenous single pass GTA welds were produced under laterally constrained conditions. The edges of the plates parallel to the weld direction were securely fastened to the welding stage to simulate the restraints encountered in practical weld repair and maintenance of structural components. Welding was performed at $10 \mathrm{~V}$-de, $24 \mathrm{~A}$ at a torch travel speed of $3.6 \mathrm{~mm} / \mathrm{s} \mathrm{under}$ a protective argon atmosphere. The resulting heat input was $66.7 \mathrm{~J} / \mathrm{mm}$, which produced a full penetration weld approximatcly $3 \mathrm{~mm}$ wide.

A theoretical model has been proposed by Lin et al. to describe the helium bubble growth during GTA welding of helium containing materials [9-12]. The model indicates that the growth of grain boundary helium bubbles should be significantly altered by a change in the stress state during cooling of the weld. To investigate this hypothesis, a weld plate fixture system was constructed to apply a controlled compressive stress (55 MPa, i.e., 25\% of the yicld stress) perpendicular to the weld path (Figure 1).

The compressive stress is produced by applying a constant compressive strain perpendicular to the weld direction from the edges of weld plates. Both optical microscopy and scanning electron microscopy (SEM) were used to examine the integrity of the weld and the surrounding heat-affected zone. Transmission electron microscope (TEM) specimens were prepared from the fusion zone/heat-affected-zone interface for both standard (control welds) and stress-modified welds for further examination.

\section{Results and Discussion}

According to the proposed model, most of the grain boundary helium bubble growth which occurs during welding is stress-assisted [9-12]. The growth of grain boundary bubbles in the HAZ can be divided into three regimes. In regime I, the heat-up regime before the material reaches its melting temperature, compressive stresses are introduced normal to the welding direction due to thermal expansion of the plates. Although grain boundary helium bubbles can grow by thermal vacancy absorption in this regime, the compressive stress tends to retard the bubble growth. Consequently, it was assumed that there is no bubble growth in this heat-up

'The tritium doping was performed at Sandia National Laboratory, Livermore, CA. 


\section{Torch}

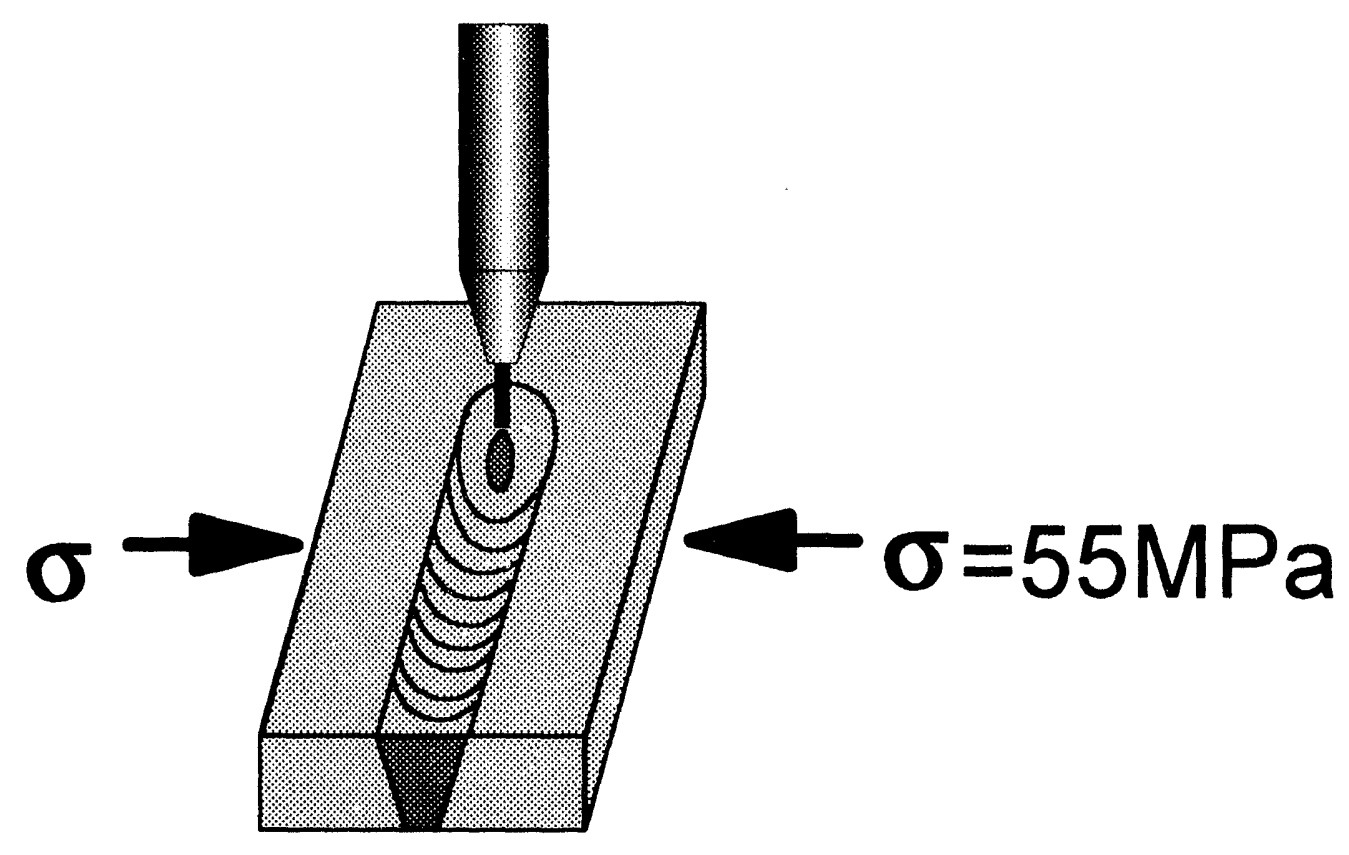

FIG. 1--Schematic of applied compressive stress during welding.

period. In regime II, where the torch passes through, the material reaches the melting tempcrature and a stress-free state is obtained in the melted region. Therefore, the stress is assumed to be zero in areas adjacent to the melted region. The bubbles grow mainly by vacancy absorption during this stage due to the high vacancy concentration and diffusivity at that temperature. The grain boundary bubble growth in this regime is derived based on the theory of helium bubble growth in the matrix by vacancy absorption presented by Greenwood and Speight [16]. The final bubble radius, $R$, was expressed by Lin et al $[9,10,12]$ as

$$
\mathrm{R}^{3}-\mathrm{R}_{\mathrm{i}}^{3}=38_{\mathrm{gb}} \Omega \mathrm{D}_{\mathrm{gb}} \mathrm{C}_{\mathrm{v}} \Delta \mathrm{t} / 2
$$

where

$$
\begin{array}{ll}
\mathrm{R} & =\text { bubble radius, } \mathrm{m}, \\
\mathrm{R}_{\mathrm{i}} & \text { = bubble radius at regime } \mathrm{I}, \mathrm{m}, \\
\delta_{\mathrm{gb}} & =\text { grain boundary thickness, } \mathrm{m}, \\
\Omega & =\text { atomic volume, } \mathrm{m}^{3}, \\
\mathrm{D}_{\mathrm{gb}} & =\text { grain boundary vacancy diffusivity, } \mathrm{m}^{2} / \mathrm{s}, \\
\mathrm{C}_{\mathrm{v}} & =\text { equilibrium vacancy concentration, } \mathrm{m}^{-3}, \text { and } \\
\Delta \mathrm{t} & =\text { elapsed time in regime } \mathrm{II}, \mathrm{s} .
\end{array}
$$

Finally, in regime III, the stress state becomes tensile at grain boundaries parallel to the welding direction due to weld solidification and cooling. Stress-assisted bubble growth dominates, and most of the grain boundary bubble growth during welding occurs in this regime. The bubble 
growth at grain boundaries in this regime can be expressed by the following equation, which is based on Hull and Rimmer's models [17,18]:

$$
\Delta R=2 \pi \delta_{g b} \Omega D_{g b}(t) \sigma(t) \Delta t /\left\{R(t)^{2} k T(t) \log (a / R(t)-0.75)\right\}
$$

where

$$
\begin{array}{ll}
\mathbf{k} & =\text { Boltzmann's constant, } \mathrm{J} / \mathrm{K}, \\
\mathbf{a} & =\text { average bubble spacing, } \mathrm{m}, \\
\Delta R & =\text { amount of bubble growth, } \mathrm{m}, \\
\mathrm{T}(\mathrm{t}) & =\text { temperature at time } \mathrm{t}, \mathrm{K} \\
\sigma(\mathrm{t}) & =\text { thermal stress at time } \mathrm{t}, \mathrm{Pa}, \\
\mathrm{R}(\mathrm{t}) & =\text { bubble radius at time } \mathrm{t}, \mathrm{m}, \text { and } \\
\mathrm{D}_{\mathrm{gb}}(\mathrm{t}) & =\text { grain boundary vacancy diffusivity at time } \mathrm{t}, \mathrm{m}^{2} / \mathrm{s} .
\end{array}
$$

It should be emphasized that this model is not meant to predict the resulting stress state of the weld but rather to give physical insight into what may be occurring during the weld process.

Results of grain boundary bubble growth calculations for the final stage are shown in Figure 2. In this study, grain boundary thickness is assumed to be $8 \AA$. The average bubble spacing on grain boundaries was assumed to be $1 \mu \mathrm{m}$ from examination of the HAZ fracture surfaces which were decorated with uniformly distributed dimples about $1 \mu \mathrm{m}$ in diameter. The initial bubble radius at regime III, i.e., final radius at regime II, was $0.049 \mu \mathrm{m}$ after calculations according to equation (1).

In the standard weld, curve A, HAZ cracking occurs approximately 2 seconds after the onset of Regime III, where bubbles reach $1 \mu \mathrm{m}$. This is consistent with the results of videotaping during welding, which showed cracks that initiate 1 to 2.2 seconds after passage of the weld pool. When a compressive stress is applied during welding, bubble growth is retarded, and bubble size may never reach the critical size which leads to cracking (curves $B, C$ and $D$ ). Bubble growth was also retarded when the bubble surface tension is greater than thermal tensile stresses (where $8(t)$ became negative in equation (2), i.e., in compressive state), as indicated at the beginning region of Figure 2.

Figure 3 shows the results of macroscopic examination of weld integrity. Continuous through-thickness heat-affected zone cracking was observed in standard welds of Type 316 stainless steel containing 256 appm helium. Further examination also rcvealed that the crack was completely intergranular. The crack ran parallel to the welding direction and was within 2 to 3 grain diameters of the fusion zone/heat-affected-zone interface. Helium bubbles had migrated and grown rapidly at grain boundaries under the combined actions of high temperature and internal tensile stress, which occurred during the welding process. Grain boundary strength decreases as the grain boundary helium bubbles grow and the area fraction of bubbles increases. Rupture occurs as the cohesive strength of the grain boundaries, reduced by the growing bubbles, can no longer bear the shrinkage-induced internal tensile stress during cooling.

Results from stress-modified GTA welds reveal no visible cracks in the heat-affected zone, as shown in Figure 3b. A compressive stress of $55 \mathrm{MPa}$, about $25 \%$ of the room temperature yield stress of Type 316 stainless steel, was applied in these experiments, as measured by strain gauges attached to the weld plates. This result is consistent with the conclusion from Lin's study that high temperature alone is not sufficient to cause significant grain boundary helium bubble growth and HAZ cracking. The combination of both high temperature and high tensile shrinkage stress are required for intergranular HAZ cracking [9-12]. 
ORNL-DWG 93-1655

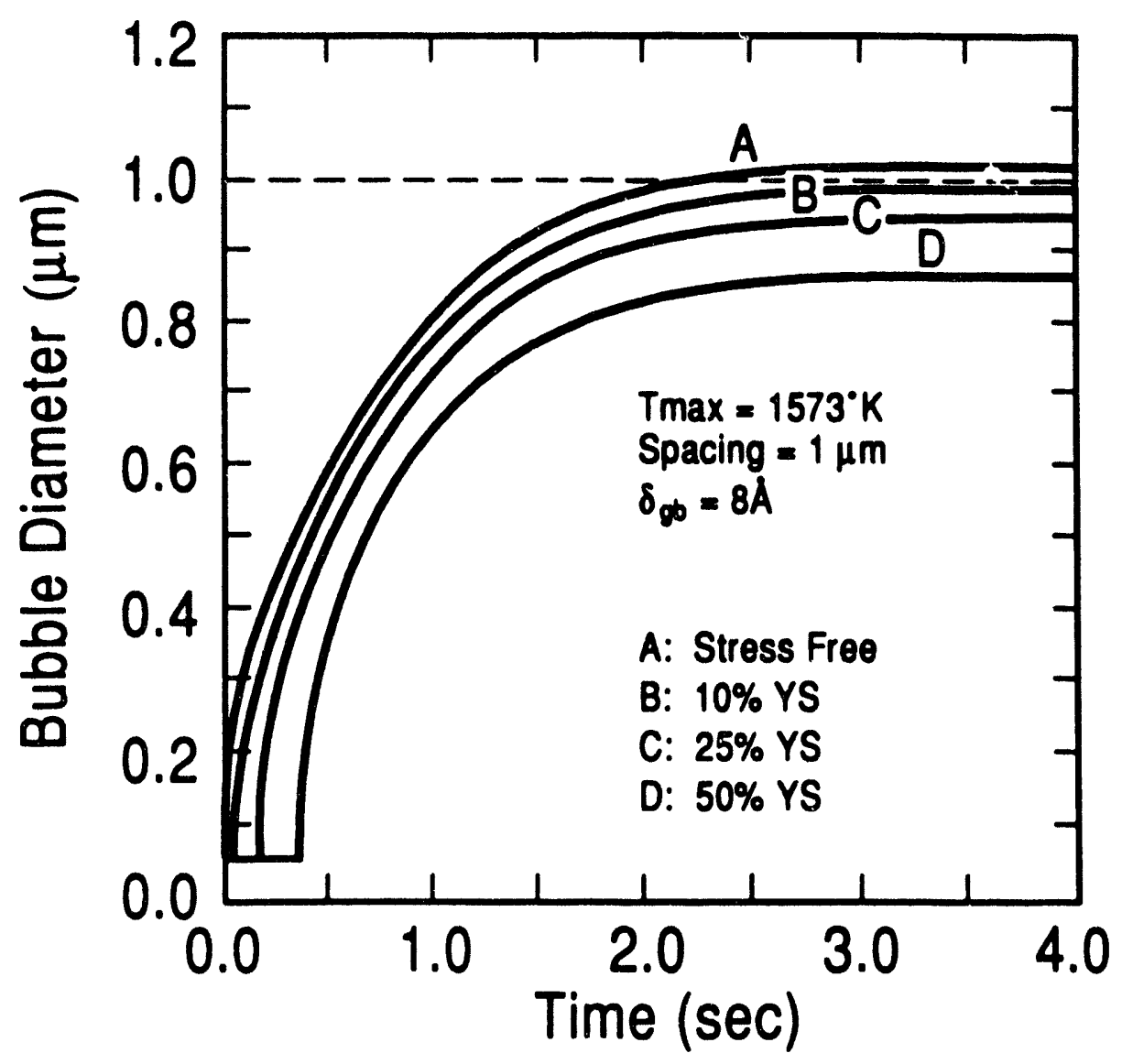

FIG. 2--The predicted grain boundary bubble size in Regime III. In a standard weld without external applied stress, curve A, bubbles reach critical size, dotted line, at about 2 seconds after the onset of Regime III, while bubble growth is retarded by the application of a compressive stress (indicated as a percentage of the yield strength) during welding, curves B, C and D.

Further examinations on TEM disks, prepared from the fusion zone/heat-affected-zone boundary, were conducted using scanning electron microscopy following jet thinning. The results are shown in Figures 4 for both standard and stress-modified welds. Welding directions are indicated by the large arrows. In the standard GTA weld, as shown in Figure 4a, severe perforation and cracking are observed with cracks tending to align parallel to the welding direction. On the other hand, parallel cracking associated with grain boundary helium bubble growth has been effectively suppressed by the application of a compressive stress in the stressmodified GTA welding process, as shown in Figure $4 \mathrm{~b}$. In addition, the bubble growth has been altered such that larger bubbles grow predominantly along grain boundaries perpendicular to the weld direction, whereas previously they occ.nrred principally on grain boundaries parallel to the weld. It should be pointed out that jet polishing during TEM specimen preparation attacks the grain boundaries and enlarges grain boundary holes. Therefore, the grain boundary bubble sizes indicated in Figures 4 are exaggerated as compared to the as-welded material. Figure $4 \mathrm{c}$ and $4 \mathrm{~d}$ are magnified views of the circled areas in Figure $4 \mathrm{a}$ and $4 \mathrm{~b}$ respectively. Results of TEM examinations are not available at this time, and will be presented in the future. 

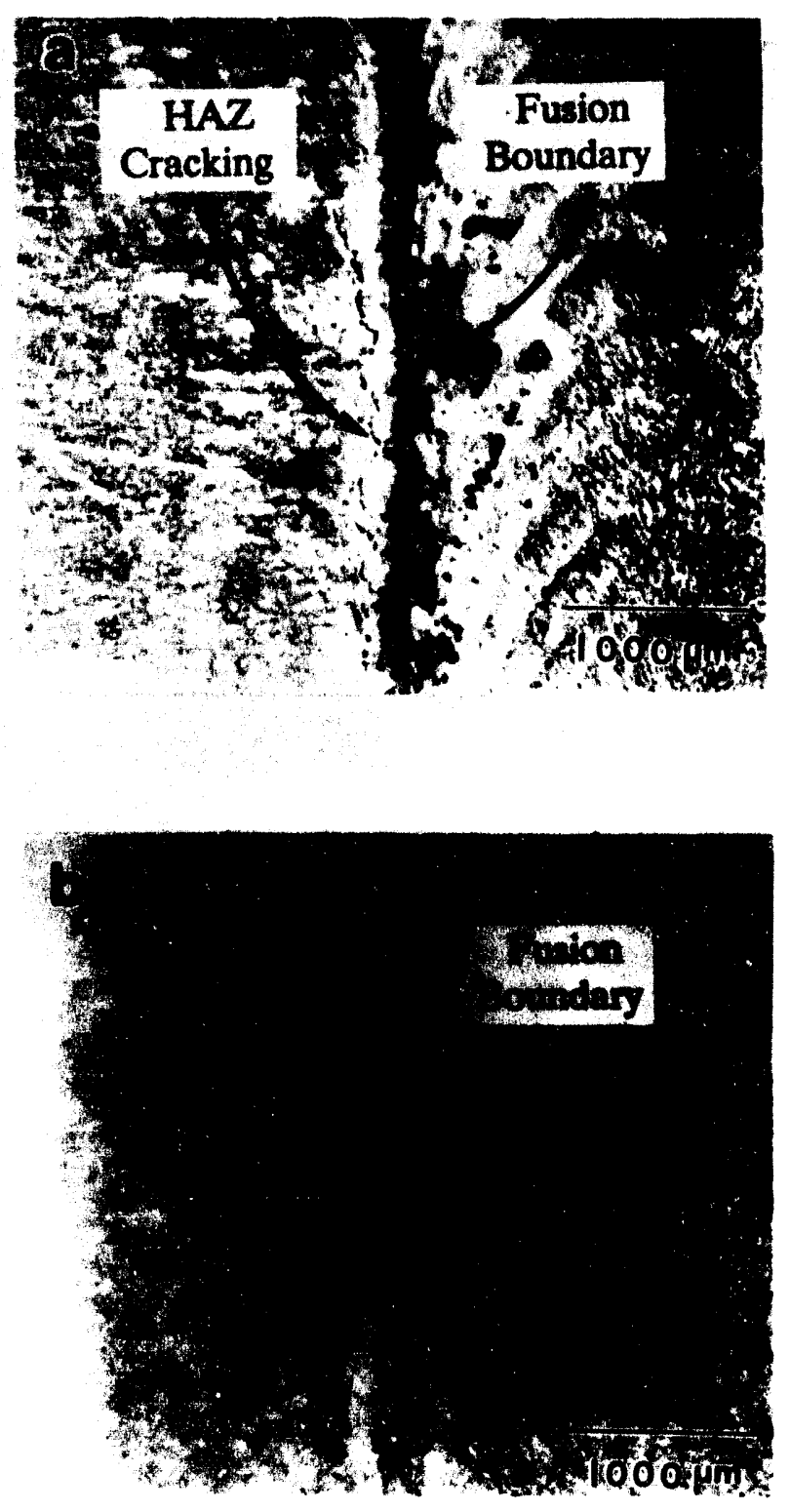

FIG. 3--Comparison of as-welded heat-affected zones in Type 316 stainless steel containing 256 appm helium: (a) continuous through-thickness intergranular HAZ cracking in standard weld; (b) no visible HAZ cracking in stress-modified weld.

During weld solidification and cooling, the principal shrinkage-induced internal tensile stress is perpendicular to the welding direction. The stress level is enhanced by the lateral constraints as in the repair welding of structural ccmponents. This stress causes the helium bubbles to grow rapidly at the grain boundaries at high temperatures, preferentially along grain boundaries aligned perpendicular to the stress (parallel to the weld). Since the shrinkage-induced tensile stress is altered by applying an initial compressive stress perpendicular to the welding 

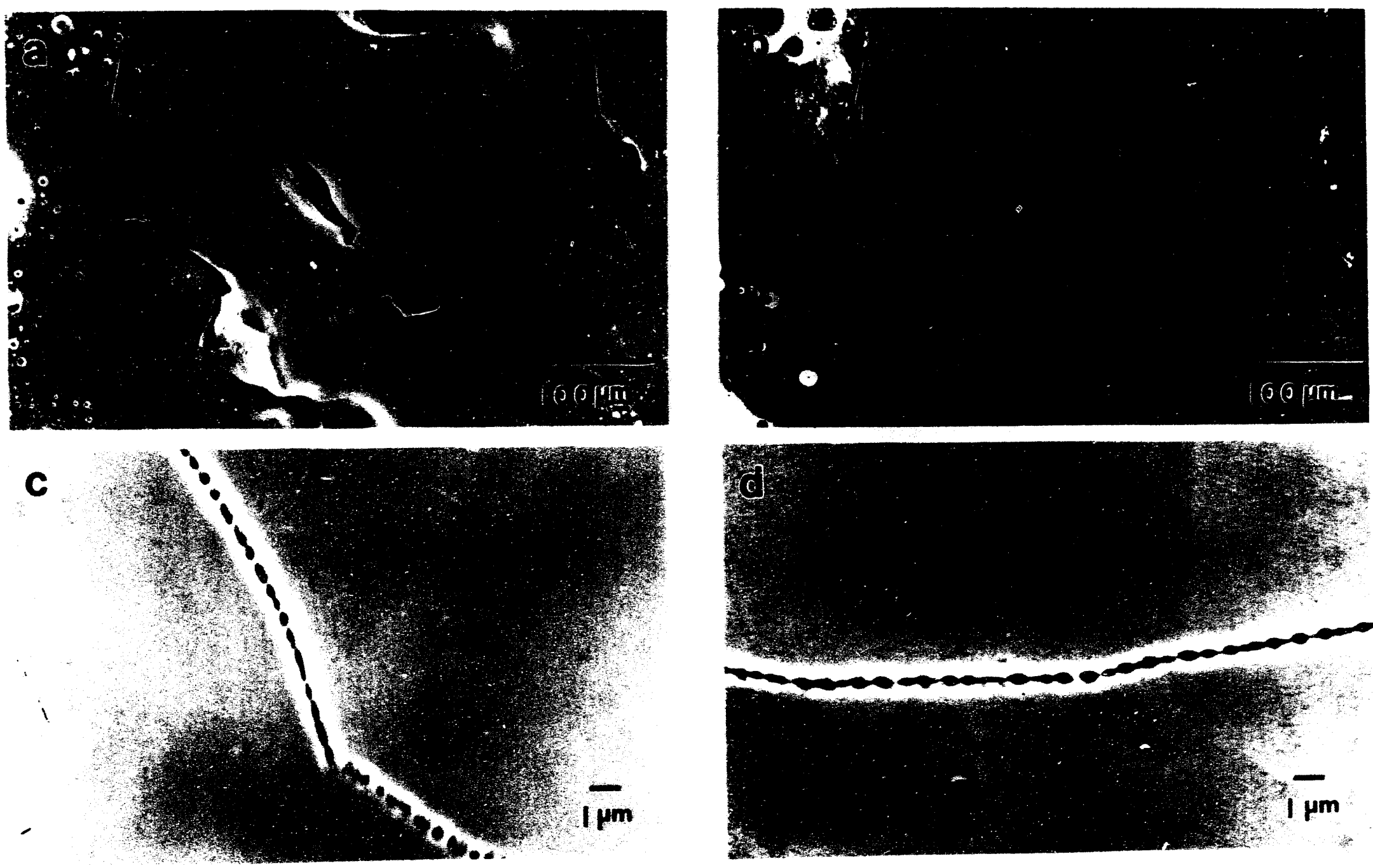

FIG. 4--SEM photographs of the jet-polished TEM dises from (a) standard GTA weld; (b) stress-modified GTA weld. Arrows indicate the welding direction. Note that the applied compressive stress in $3 b$ effectively suppressed grain boundary cracking associated with bubble growth and favored bubble growth on grain boundaries perpendicular to the weld. (c) and (d) are magnified views of the circled areas in (a) and (b) respectively. 
direction, the helium bubble growth process is retarded along grain boundaries parallel to the weld; therefore, HAZ cracking is less likely to occur. However, a small number of helium bubbles still grow preferentially along the direction perpendicular to the weld. This may be due to the internal tensile stresses generated by bulk body constraint of the stecl along the weld direction during cooling.

\section{Conclusions}

The following conclusions can be drawn from this study:

1. Severe intergranular heat-affected-zone cracking during welding of helium-bearing Type 316 stainless steel is caused by the grain boundary helium bubble growth.

2. Grain boundary helium bubble growth is enhanced by the combined action of high temperaturc and shrinkage-induced tensile stress generated during the welding process.

3. Sound autogenous GTA welds can be produced in helium-bearing Type 316 stainless steel by the application of a compressive stress to alter grain boundary bubble growth kinetics.

The results of this study suggest that the stress-modified welding process can effectively suppress the helium bubble growth and may be applied to eliminate the severe HAZ cracking which occurs during GTA repair welding of irradiated materials.

\section{$\underline{\text { References }}$}

1. R. W. Conn, "Tokamak Reactors and Structural Materials", Journal of Nuclear Materials, 85\&86(1979)9-16.

2. E. E. Bloom, "Mechanical Properties of Materials in Fusion Reactor First-Wall and Blanket Systems", Journal of Nuclear Materials, 85\&86(1979)795-804.

3. M. M. Hall, Jr., A. G. Hins, J. R. Summers, and D. E. Walker, "Fusion Welding of Irradiated AISI 304L Stainless Steel Tubing", Weldment:Physical Metallurgy and Failure Phenomena, Proceedings of the Fifth Bolton Landing Conference, August 1978, pp. 365-378.

4. J. P. Maloney, D. Baker, W. A. Day, W. G. Fraser, H.R. Huxford, K. E. Kehr, W. R. Kennedy, J. B. McClain, D. H. McKenney, C. A. Meyer, R. F. Mittelberg and J. E. Walls, "Repair of a Nuclear Reactor Vessel", DP-1199, E. I. du Pont de Nemours \& Co., Savannah River Laboratory, Aiken, SC, June 1969.

5. S. D. Atkin, "Weld Bend Tests on Irraciated, $20 \%$ Cold-Work 316 Stainless Steel", Fusion Reactor Materials, ADIP Semiannual Progress Report, Sept. 30, 1981, DOE/ER-0045/7, pp. 110-117, U.S. DOE, Office of Fusion Energy.

6. W. K. Kanne, C. L. Angerman and B. J. Eberhard, "Weldability of Tritium-Charged 304L Stainless Steel", DP-1740, E. I. du Pont de Nemours \& Co., Savannah River Laboratory, Aiken, SC, February 1987.

7. W. R. Kanne, "Helium Embrittlement Cracking During Patch Welding in Savannah River C reactor," DPMS-8940, E. I. Dupont Co., Savannah River Laboratory, Aiken, SC, 1989. 
8. A. K. Birchenall, "Helium Induced Weld Cracking in Irradiated 304 Stainless Steel," DPMS-8941, E. I. Dupont Co., Savannah River Laboratory, Aiken, SC, 1989.

9. H. T. Lin, M. L. Grossbeck and B. A. Chin, "Cavity Microstructure and Kinetics During Gas Tungsten Arc Welding of Helium Containing Stainless Stecl," Metallurgical Transactions A, V21A, September 1990, pp.2585-2596.

10. H. T. Lin, Ph.D. Dissertation, Auburn University, 1989.

11. H. T. Lin, S. H. Goods, M. L. Grossbeck, and B. A. Chin, "Helium-Induced Degradation in the Weldability of an Austenitic Stainless Steel", Elfect of Radiation on Materials, 14th International Symposium, Volume I, ASTM STP 1064, N. H. Packan, R. E. Stoller, and A. S. Kumar, Eds., American Society for Testing and Materials, Philadelphia, 1989, pp. 301-314.

12. H. T. Lin, "Simulation of the Welding of Irradiated Materials", ORNL/TM-11158, Oak Ridge National Laboratory, Oak Ridge, TN, 1989.

13. D. Hull and D. E. Rimmer, "The Growth of Grain-Boundary Voids Under Stress," Philosophical Magazine, 4(1959)673-687.

14. M. V. Speight and J. E. Harris, "The Kinetics of Stress-Induced Growth of Grain-Boundary Voids," Metal Science Journal, Vol.1, 1967, pp.83-85.

15. H. Trinkaus, "Stress Induced Drift Diffusion in Grain Boundaries - Application to Creep and to the Growth of Grain boundary Voids." Berichte der Bundes Gesellschaft fur Physikalische Chemic, 82(1978)249-253.

16. G. W. Greenwood and M. V. Speight, "An Analysis of the Diffusion of Fissile Gas Bubbles and its Effect on the Behaviour of Reactor Fucls," Journal of Nuclear Materials, 10(1963)140-144.

17. D. Hull and D. E. Rimmer, "The Growth of Grain-Boundary Voids Under Stress," Philosophical Magazine, 4(1959)673. 587.

18. J. Weertman, "Hull-Rimmer Grain Boundary Void Growth Theory - A Correction," Scripta Metallurgica, Vol. 7, 1973, pp. 1129-1130. 
RELATIONSHIP BETWEEN SWELLING AND IRRADIATION CREEP IN COLD WORKED PCA STAINLESS STEEL TO 178 DPA AT $~ 400^{\circ} \mathrm{C}$ $M$. B. Toloczko (University of California at Santa Barbara) and F. A. Garner (Pacific Northwest Laboratory ${ }^{d}$ ).

\section{OBJECTIVE}

The objective of this effort is to determine the factors which control the response of structural alloys to radiation and applied stress.

\section{SUMMARY}

At $178 \mathrm{dpa}$ and $4000^{\circ} \mathrm{C}$. the irradiation creep behavior of $20 \%$ cold worked PCA has becore dominated by the creep 1isappearance phenomenon. The total diametral deformation rate has reached the iimiting value of $0.33 \% / \mathrm{dpa}$ at the three highest stress levels. The stress-enhancement of swelling tends to camouflage the onset of creep disappearance, however.

\section{PROGRESS ATO STATUS}

\section{Introduction}

Uelium pressurized tubes constructed from the fusion heat $k 280$ of the austenitic Prime Candidate Alloy (PCA) in the $20 \%$ cold worked condition have completed their irradiation in FFTF/MOTA at a nominai temperature of $-400^{\circ} \mathrm{C}$. These $2.24 \mathrm{~cm}$ long tubes were periodically discharged from reactor and measurements made of the ir diameter prior to reinsertion into reactor. These tubes were inserted in all MoTA vehicles from MOTA-1A through MOTA-1G and then cont inued into MOTA-2B. The tubes were pressurized to hoop stress levels of 0 , 30, $50,100,140$ and $200 \mathrm{MPa}$. Irradiation temperatures varied somewhat from one MOTA to the next. but during any one irradiation interval. the temperature was actively controlled within \pm 5 of the nominal temperature. Table 1 presents the detalled temperature history of these tubes, which reached dpa levels as large as $-178 \mathrm{dpa}$. The strains of these tubes were last reported for MOTA-1F at $\sim 119$ dpa.

Table 1 Irradiation History of Pressurized Tubes

\begin{tabular}{|c|c|}
\hline MOTA & Iemperature \\
\hline $1 A$ & 405 \\
\hline $1 B$ & 401 \\
\hline $1 C$ & 396 \\
\hline 10 & 386 \\
\hline $1 E$ & 384 \\
\hline $1 F$ & 386 \\
\hline 16 & 390 \\
\hline $2 B$ & 433 \\
\hline
\end{tabular}

\section{asults and Discissinn}

$\therefore$ gure 1 shows the total drametrai strains measured in each of the tubes, reaching ievels as large as $25 \% \Delta 0 / 0$ -1 thout failure. Hote that the tubes at the three highest stress levels have developed the 0.33\% dpa maximum dianetral deformation rate often observed in pressurized tubes at sufficient? nigh enough neut ron exposures."

Thus. the creep rate becomes unresponsive to significant increases in stress level. Egen though a volumetric Weiting level of $-21 \%$ was attained in the absence of stress. the stress free sweliing rate at $0.46 \% / d p a$ is :11) far from its maximum possible rate of $-1^{0}:$ dpa, as shown in figure 2 . Since stress normally accelerates inn onset of swelling, it is excected that the stress-affected swelling rates are probably larger.

Pacitic Horthwest aboratory is operated for the U.S. Department of Ererar hi Battelle Memorial incitute under Contract DE-ACOS- ZORLLO 1330. 
:f we assume, however, that stress does not affact swelling, we can calculate the creep coefficient associated with the $B+D S$ creep model, where $B$ is the $c r$ sep compliance and $D$ is the creep-swelling coupling coefficient, -elating the creep rate $\dot{\varepsilon} / \sigma$ to the swelling rate $\dot{S}$. Table 2 shows that for each tube. $B-2 \times 10^{-6} \mathrm{MPa}^{-1} \mathrm{dpa}$ and $0-0.6 \times 10^{\circ} \mathrm{MPa} ;$, in agreement with the re:ults of earlier studies. " The attainment of the $-0.33 \% / \mathrm{dpa}$ diametral deformation rate signals, however, that stress enhancement of swelling has indeed occurred, and the creep disappearance phenomenon is dominatirg the experiment.

Table 2. Creep coefficients derived over the interval of

0 to $178 \mathrm{dpa}$, assuming that stress does not affect swelling.

\begin{tabular}{|c|c|c|}
\hline $\begin{array}{c}\text { Stress Level } \\
M P^{2}\end{array}$ & \begin{tabular}{c} 
MPa \\
\hline 30
\end{tabular} & $M^{B}{ }^{B} \mathrm{dpa}$ \\
\hline 60 & $0.58 \times 10^{-2}$ & $1.7 \times 10^{-5}$ \\
\hline 100 & $0.53 \times 10^{-6}$ & $2.0 \times 10^{-6}$ \\
\hline 140 & $0.57 \times 10^{-2}$ & $2.2 \times 10^{-6}$ \\
\hline 200 & $0.54 \times 10^{-2}$ & $2.3 \times 10^{-6}$ \\
\hline
\end{tabular}

In the absence of swelling measurements on stressed tubes, an estimate of the effect of stress on swelling can be made, providing that the analysis proceeds at a dpa level where the creep disappearance phenomenon has not yet become totally dominant. This appears to be the case at the end of MOTA-1G at -153 dpa. Assuming that the creep strain must be linearly proportional to stress, an estimate of the stress-affected swelling can be calculated, as shown in Figure 3. This estimate implies that the swelling at $200 \mathrm{MPa}$ and 178 dpa may be twice as large as that at zero stress.

Such large swelling levels will also cause a decrease in the gas pressure and thereby the stress level in the tube wall, but the correction to the midwall creep strains are not very large, as shown in figure 4 . The creep coefficients derived from both the stress-insensitive and stress-affected swelling assumptions are shown in Figure 5. It is clear that the influence of stress on swelling camouflages the onset of the creep disappearance phenomenon. These calculations are based on the entire data set, however. Thus, the values shown in figure 5 are average coefficients, taken over the entire neriod where the creep disappearance phenomenon evolves from a minimal to a near-dominant influence.

If we calculate $D_{y}$, the creep-swelling coefficient for each of the last three $i$ radiation segments, using the iverage creep and swelling rates for each segment, the decrease in the D copificient becomes more pronounced as the swelling rate increases and the creep disappearance phenomenor. also increases. The progressive nfluence of this process is clearly shown in Figure 6.

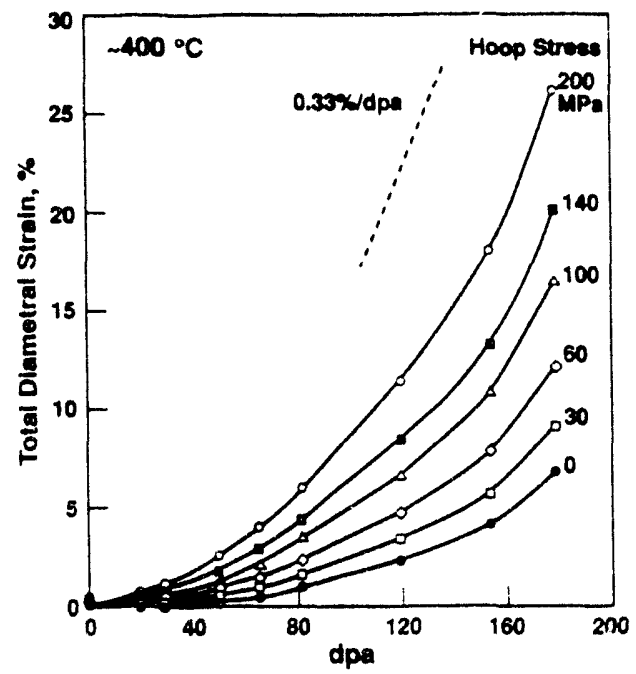

$=$ 1. Total diametral strains observed in PCA tubes at $-400^{\circ} \mathrm{C}$ and 0 to $178 \mathrm{dpa}$. 


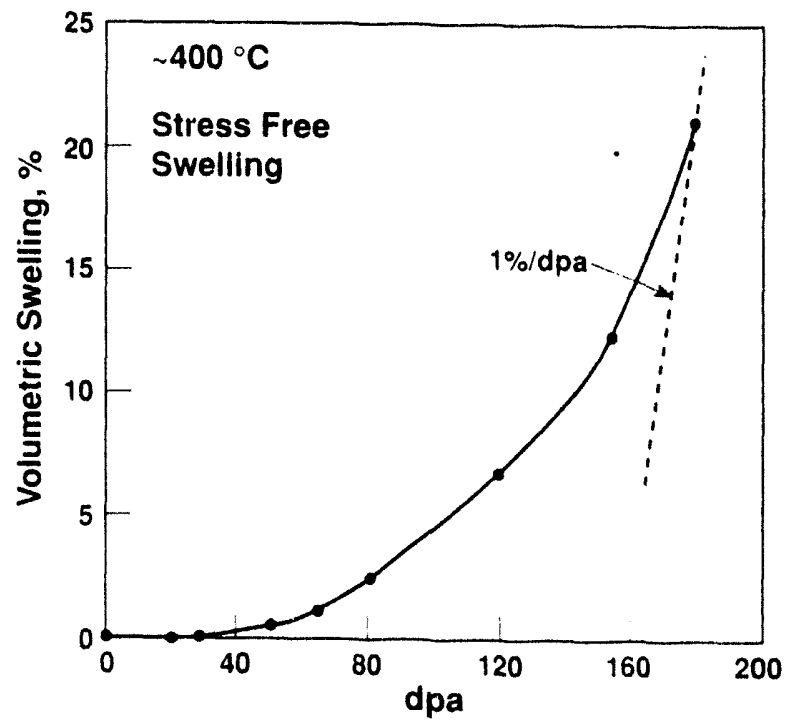

Fig. 2 Stress-free volumetric swelling, reaching a swelling rate of $0.46 \% /$ dpa at 179 doa.

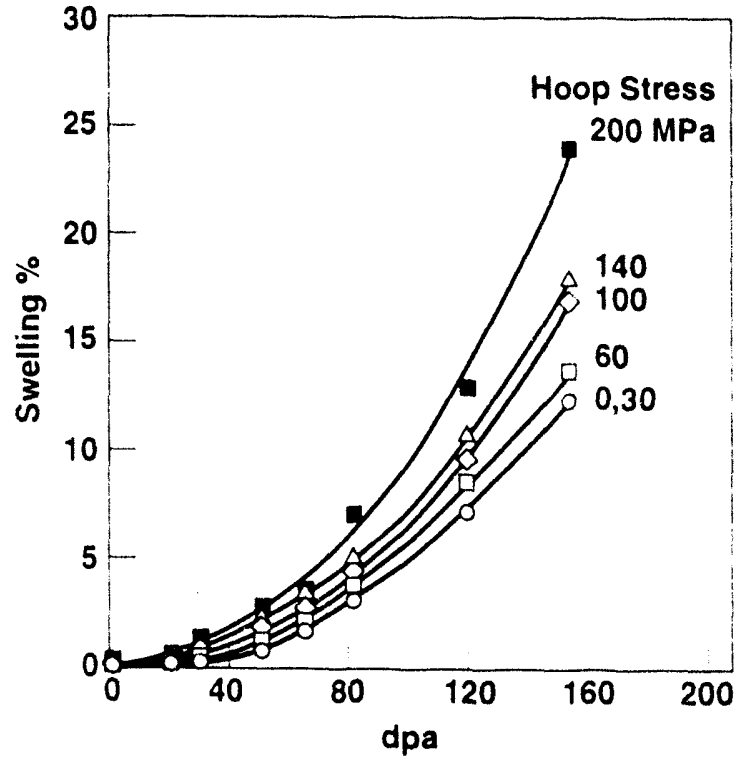

$\therefore$ a alculated astimate of stress.affected sweling benavior using data to 150 dod. assuming that creep rans rist te prooortional to stress. 


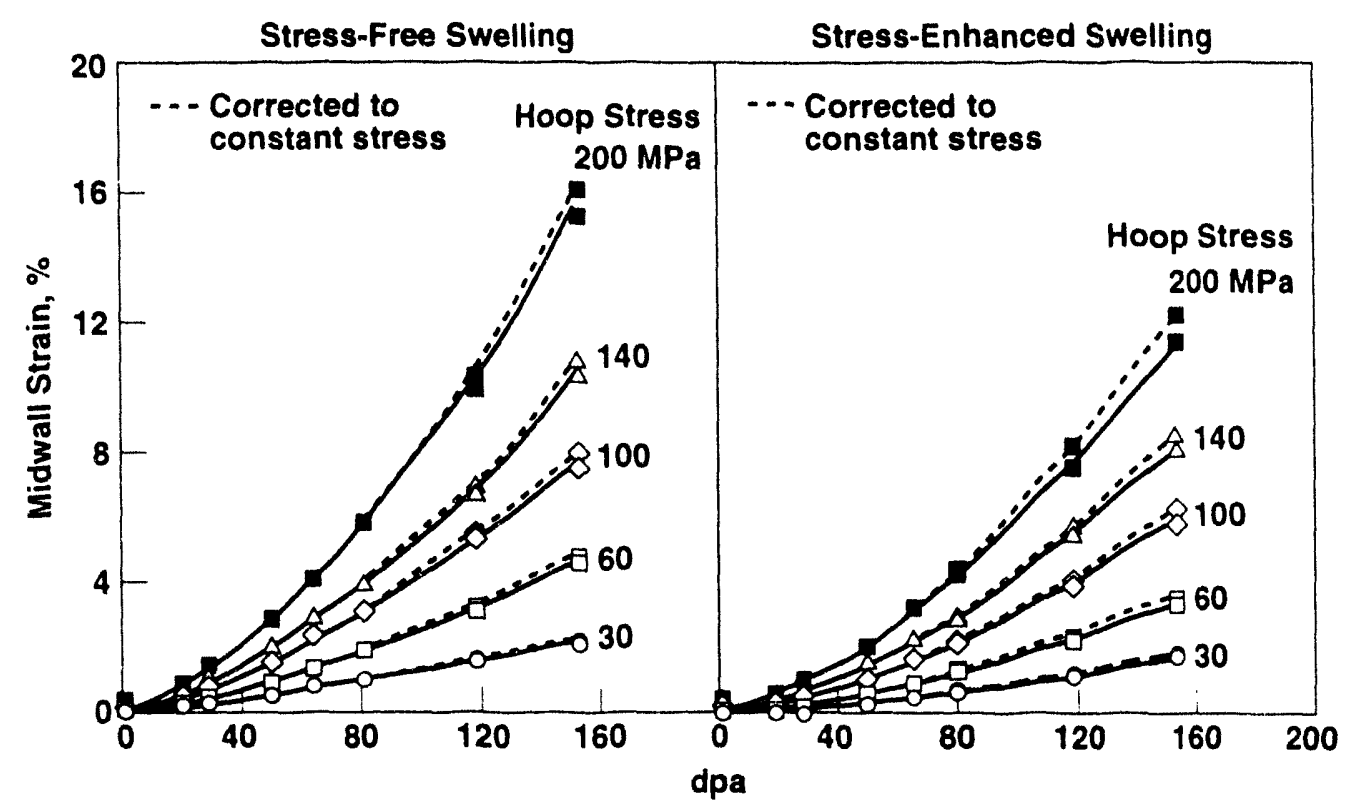

Fig. 4 Midwall creep strains calculated for both the stress-insensitive and stress-affected swelling cases. Large levels of swelling also decrease the stress level in the tube wall and a correction to constant stress must be made.
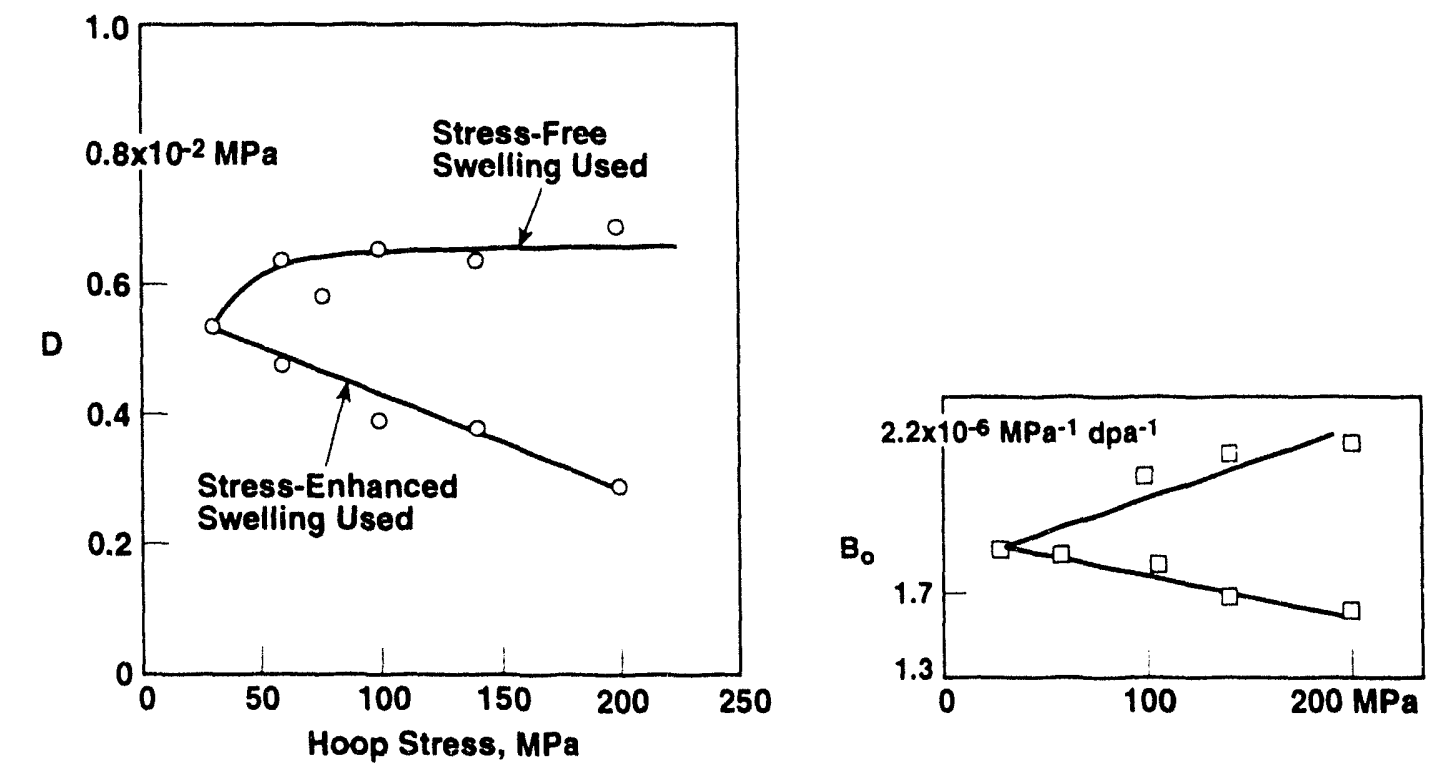

$\therefore$ ig. 5 Average creep coefficients derived from the full irradiation sequence. 

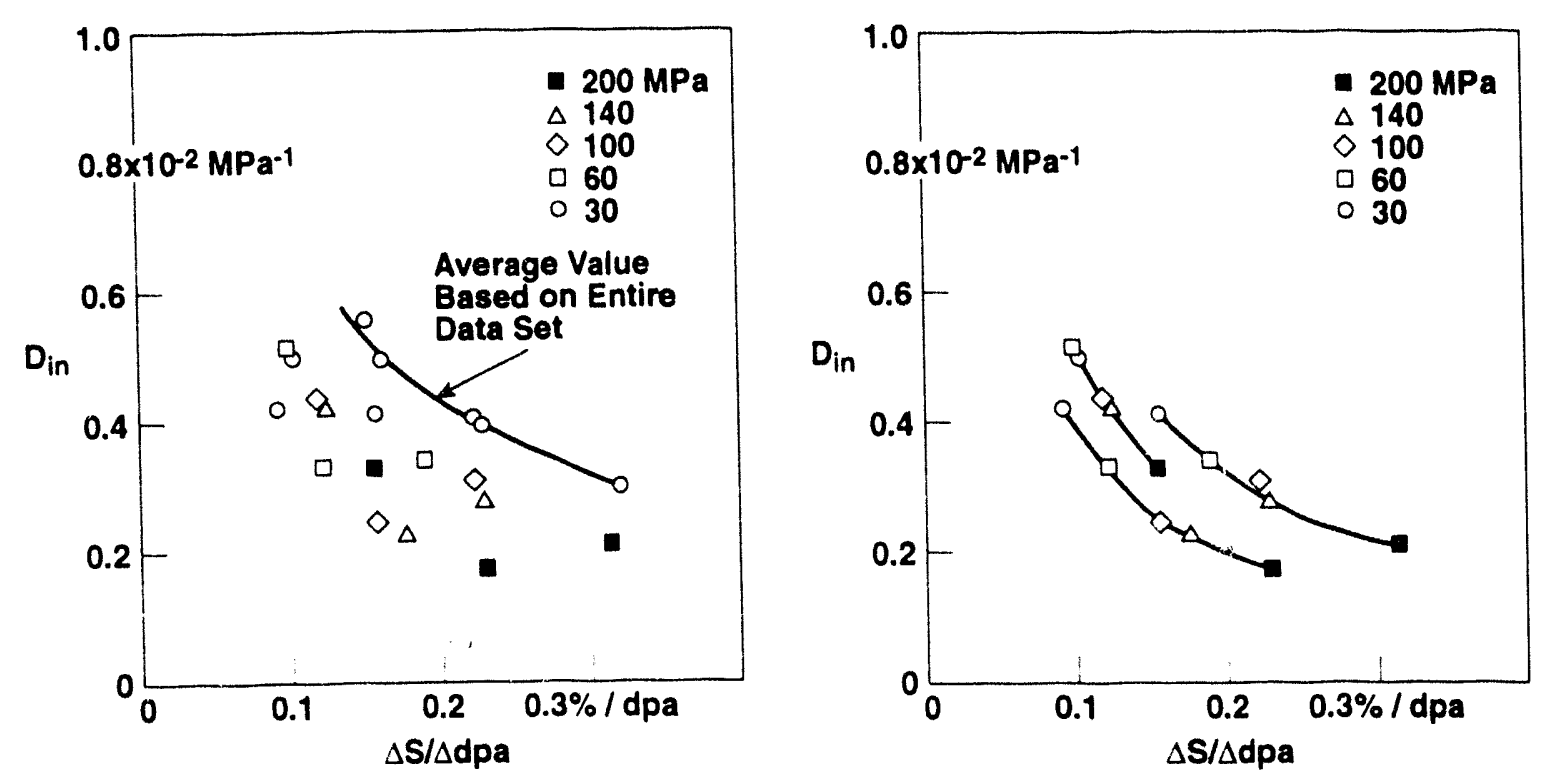

Fig. 6 a) Comparison of creep-swelling coupling coefficient derived from the full irradiation sequence Fig. 6 a) Comparison of creep-swelling coupling coefficient der for the last three irradiation segments in MOTAs IF, 1G, and with the incremental coefficients derived for each of the last three trat data are plotted against the average

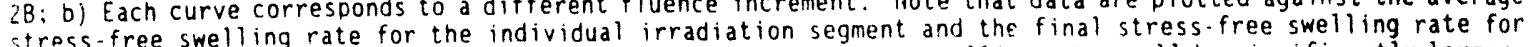

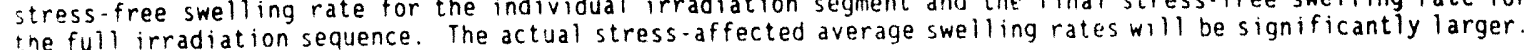

\section{Fiture Work}

This effort will continue. with primary emphasis on determining the true stress-affected swelling behavior. This will be done by sectioning the tubes and measuring the actual density changes. Ihe creep analysis will then be updated.

\section{REFERENCES}

E. P. Gilbert and B. A. Chin, in Effects of Radiation on Materials: ienth Conference. ASTMA STP 725. 1981, pp. 665-679.

M. B. Toloczko. F. A. Garner, and C. R. Eiholzer, J. Nucl. Mater. 191-194 (1992) 803-807.

D. L. Porter and F. A. Garner, J. Nucl. Mater. 59 (1988) $14-121$.

F. G. Garner and M. B. Toloczko, in: Fusion Reactor Materials Semiannual Frogress Report DOE/ER-0313/12 1992) pD. 145-147.

F.A. Garner. M. B. Toloczko and R. J. Puigh, ibid. Fp. 148-162.

$F$. A. Garner and D. L. Porter. He Nuci. Mater. 155.157 (1988) 1006-1013.

F. Porter 6. 0. Huaman. ano F. A. Garner, J. Nucl. Mater. 179-13! (1991) $581-584$.

- Porter. A Garner. J. Mucl. Mater 191-194 (1992) 1309-1312.

2. Woo. F. A. Garner. and R. A. Holt, in: Effects of Radiation on Materials, isth international imposium. ASTM STP 1175, 1993 (in press). 
Density Changes Observed in Pure Molybdenum and Mo-4lRe After Irradiation in FFTF, MOTA. F. A. Garner and L. R. Greenwood, (Pacific Northwest Laboratory)

\section{OBJECTIVE}

The objective of this effort is to provide data on the performance during irradiation of candidate materials for fusion reactor application.

SUMMARY

Pure molybdenum and Mo.4lwt\% Re, in both the $20 \%$ cold-worked and aged and the annealed and aged conditions, were irradiated in FFTF/MOTA to exposures as high as 111 dpa. Pure molybdenum appears to approach a saturation swelling level that is independent of the starting state. cold-worked and aged molybdenum initially swells at a higher rate than that of solution-annealed and aged molybdenum and overshoots the saturation level at lower irradiation temperatures. This requires that part of the accumulated swelling be removed to approach saturation, probably by void shrinkage. The alloy Mo-4lRe exhibits a more complex behavior with the annealed and aged condition initially swelling faster, but eventually the density change of both conditions begins to turn downward and tends toward densification. The role of solid transmutation to Tc. Re. and 0 s is thought to be very important in the irradiation behavior of these two metals. Calculations of transmutant generation are provided for FFTF, HFIR and STARFIRE spectra.

\section{PROGKESS AND STATUS}

\section{Introduction}

Molybdenum and molybdenum-rhenium alloys are being considered as possible candidates for fusion reactor application. ". Pure molybdenum and Mo-4lwt\% Re were irradiated in MOTA-IB, IC, $1 D$, and $I E$ at five target temperatures between 420 and $722^{\circ} \mathrm{C}$. With peak exposures on the order of 60 dpa (steel) at most temperatures and $-100 \mathrm{dpa}$ at $420^{\circ} \mathrm{C}$. 3 The specimens were in the form of $3 \mathrm{~mm}$ diameter microscopy disks. Both materials were irradiated in two starting conditions: solution annealed for $1 \mathrm{hr}$ at $760^{\circ} \mathrm{C}$ followed by aging at $320^{\circ} \mathrm{C}$ for 2 hrs, and $20 \%$ cold worked followed by the same aging treatment. Irradiation proceeded in weeper packets so that the specimens were in contact with the sodium coolant of the reactor.

Although the irradiation in MOTA proceeded largely under active temperature Control $\left( \pm 5^{\circ} \mathrm{C}\right)$ in $M 0 T A^{\prime} S 1 B$, $1 C$, and $I E$, there was a short ( -50 minutes) temperature excursion in MOTA-10 during FFTF Cycle 7 . referred to as an overtemperature event. This event compromised the integrity of many of the pressurized tube experiments in MOTA 10. Therefore, a decision was made to run the MOTA in the helium-purged mode for the remainder of FFTF cycles 7 and 8 while a series of reactivity feedback tests were conducted. The majority of the MoTA canisters thereafter operated at variable but lower-than-target temperatures until the end of FFTF cycle 3 . Isothermal irradiation was reestablished in MOTA $I E$, but only the $420^{\circ} \mathrm{C}$ specimens were included in that irradiation segment. A summary of the target conditions for these specimens is shown in Table 1

\section{Results}

Density measurements were performed using an immersion technique whose accuracy has been established to be $+0.15 \%$ swelling. The displacement levels quoted are those for stainless steel. Detajled calculations for molybdenum have not yet been run, but should be on the order of $-80 \%$ of those of steel. No guidance is available to calculate dpa levels for $10-41 \mathrm{Re}$.

The density change data are presented in Table 2 and represent the average values for two identical specimens. Figure 1 shows that the cold-worked and aged condition of pure molybdenum swelled $-1 \%$ or rore at $420^{\circ} \mathrm{C}$ during the first irradiation segment and then declined thereafter. The annealed and aged conditian appeared to densify. aithough the reasons for such densification are hard to identify. in the annealed and aged state at $420^{\circ} \mathrm{C}$, Mo-4lRe appears to swell initially and then decline in swelling. The cold-worked and aged condition appears to be swelling between 50 and $100 \mathrm{dpa}$.

Figure 2 shows that the cold-worked and aged condition of pure molybdenum always swells at a faster rate :nitially than the annealed and aged condition, but the swelling of the two conditions appears to be converging by the end of MOTA-10. This convergence requires that the cold-worked and aged specimen must decline in swelling at the 471 and $596^{\circ} \mathrm{C}$ target temperatures. Note also in Figure 2 that three of the four specimen groups are converging to the same level $(-2 \%)$

Figure 3 shows that at three of four irradiation temperatures, the annealed and aged condition of Mo-4lRe swelled more than the cold-worked and aged condition, in agreement with the behaviur observed at $420^{\circ} \mathrm{C}$ in

:Pacific Northwest Laboratory is operated for the U.S. Department of Energy by Battelle Hemorial Institute under Contract DE-ACO6-76RLO 1830 
Figure 1. The most surprising aspect of the data in Figure 3, however, is that the initial swelling appears to be followed by a decline in swelling, in several cases reaching a net densification.

Table 1

Irradiation Conditions for Molybdenum and Mo-4lRe Specimens Examined in This study

\begin{tabular}{|c|c|c|c|c|c|c|c|c|c|c|}
\hline & & MOTA-1B & & MOTA.IC & & MOTA.10 & & MOTA-IE & & \\
\hline Packel & Contents & Temperature. ${ }^{\circ} \mathrm{C}$ & $d p^{|0|}$ & Temperalure, ${ }^{\circ} \mathrm{C}$ & dpa & Temperalure, ${ }^{\circ} \mathrm{C}$ & $\mathrm{dpa}$ & Temperalure, ${ }^{\circ} \mathrm{C}$ & dpa & Total dpa \\
\hline $\begin{array}{l}\text { MAEZ } \\
\text { NAEZ } \\
\text { N6EZ } \\
\text { MGEZ } \\
\text { PAEZ }\end{array}$ & $\begin{array}{l}A \\
\hat{A} \\
B \\
B \\
A \\
\end{array}$ & $\begin{array}{l}431 \\
431 \\
431 \\
431 \\
431 \\
\end{array}$ & $\begin{array}{l}15.0 \\
15.0 \\
14.1 \\
14.5 \\
15.0 \\
\end{array}$ & $\begin{array}{l}420 \\
120 \\
120 \\
420 \\
\end{array}$ & $\begin{array}{l}35.3 \\
33.1 \\
33.9 \\
35.3 \\
\end{array}$ & $\begin{array}{c}\cdots \\
\cdots \\
404 \\
404 \\
\end{array}$ & $\begin{array}{c} \\
\cdots \\
24.5 \\
25.5 \\
\end{array}$ & $\begin{array}{c}\cdots \\
\cdots \\
414 \\
414 \\
\end{array}$ & $\begin{array}{c}\cdots \\
\therefore \\
32.8 \\
35.0 \\
\end{array}$ & $\begin{array}{r}15.0 \\
50.3 \\
47.2 \\
105.7 \\
110.8 \\
\end{array}$ \\
\hline $\begin{array}{l}\text { MAE I } \\
\text { NAE I } \\
\text { NGE I } \\
\text { P6E I } \\
\text { PAE I }\end{array}$ & $\begin{array}{l}A \\
A \\
B \\
B \\
A\end{array}$ & $\begin{array}{l}471 \\
471 \\
471 \\
471 \\
471 \\
\end{array}$ & $\begin{array}{l}11.4 \\
11.4 \\
9.6 \\
8.7 \\
11.4 \\
\end{array}$ & $\begin{array}{l}470 \\
470 \\
470 \\
470 \\
\end{array}$ & $\begin{array}{l}26.8 \\
22.6 \\
20.3 \\
26.8 \\
\end{array}$ & $\begin{array}{l}\therefore \\
470 \\
470 \\
\end{array}$ & $\begin{array}{c}\because \\
\because \\
14.7 \\
19.4 \\
\end{array}$ & $\begin{array}{l}\cdots \\
\therefore \\
\therefore \\
\therefore\end{array}$ & $\begin{array}{l}\cdots \\
\cdots \\
\cdots \\
\cdots\end{array}$ & $\begin{array}{l}11.4 \\
38.2 \\
32.2 \\
43.7 \\
57.6 \\
\end{array}$ \\
\hline $\begin{array}{l}\text { MAE7 } \\
\text { NAE7 } \\
\text { N6E7 } \\
\text { PAE7 } \\
\text { RAE7 }\end{array}$ & $\begin{array}{l}A \\
A \\
A \\
B \\
A \\
A\end{array}$ & $\begin{array}{l}569 \\
569 \\
569 \\
569 \\
569 \\
\end{array}$ & $\begin{array}{l}11.5 \\
11.5 \\
12.2 \\
11.5 \\
11.5 \\
\end{array}$ & $\begin{array}{l}550 \\
550 \\
550 \\
550 \\
\end{array}$ & $\begin{array}{l}27.0 \\
28.6 \\
27.0 \\
27.0 \\
\end{array}$ & $\begin{array}{c}\cdots \\
\cdots \\
549 \\
549 \\
\end{array}$ & $\begin{array}{c} \\
\cdots \\
19.6 \\
19.6 \\
\end{array}$ & $\begin{array}{l}\cdots \\
\cdots \\
\cdots \\
\end{array}$ & $\begin{array}{l}\cdots \\
\cdots \\
\cdots \\
\cdots\end{array}$ & $\begin{array}{l}11.5 \\
38.5 \\
40.8 \\
58.1 \\
58.1 \\
\end{array}$ \\
\hline $\begin{array}{l}\text { MAE5 } \\
\text { NAE5 } \\
\text { N6E5 } \\
\text { R6E5 } \\
\text { PAE5 } \\
\end{array}$ & $\begin{array}{l}A \\
A \\
B \\
B \\
A\end{array}$ & $\begin{array}{l}645 \\
545 \\
645 \\
645 \\
645 \\
\end{array}$ & $\begin{array}{l}11.5 \\
11.5 \\
12.2 \\
12.7 \\
11.5\end{array}$ & $\begin{array}{l}0 \\
652 \\
652 \\
652 \\
652\end{array}$ & $\begin{array}{c}27.0 \\
28.6 \\
30.8 \\
27.0 \\
\end{array}$ & $\begin{array}{l}\cdots \\
\cdots \\
650 \\
650 \\
\end{array}$ & $\begin{array}{c}\cdots \\
\cdots \\
22.3 \\
19.6 \\
\end{array}$ & $\begin{array}{l}- \\
\cdots \\
\cdots \\
\end{array}$ & $\begin{array}{l}\cdots \\
\therefore \\
\therefore \\
\therefore\end{array}$ & $\begin{array}{l}11.5 \\
38.5 \\
40.8 \\
65.8 \\
58.1\end{array}$ \\
\hline $\begin{array}{l}\text { MAE6 } \\
\text { NAE } 6 \\
\text { NEE } 6 \\
\text { MEE } 6 \\
\text { PAE6 }\end{array}$ & $\begin{array}{l}A \\
A \\
B \\
B \\
A\end{array}$ & $\begin{array}{l}722 \\
722 \\
722 \\
722 \\
722\end{array}$ & $\begin{array}{l}11.5 \\
11.5 \\
12.2 \\
12.2 \\
11.5\end{array}$ & $\begin{array}{l}730 \\
730 \\
730 \\
730 \\
\end{array}$ & $\begin{array}{r}27.0 \\
28.6 \\
28.6 \\
27.0\end{array}$ & $\begin{array}{l}\cdots \\
\therefore \\
730 \\
730 \\
\end{array}$ & $\begin{array}{c}\cdots \\
\therefore \\
20.7 \\
19.6\end{array}$ & $\begin{array}{l}\cdots \\
\cdots \\
\cdots \\
\cdots\end{array}$ & $\begin{array}{l}\cdots \\
\cdots \\
\cdots \\
\cdots\end{array}$ & $\begin{array}{l}11.5 \\
38.5 \\
40.8 \\
61.5 \\
58.1\end{array}$ \\
\hline
\end{tabular}

(a) Group A contains cold-worked and aged Mo only. Group B contains Mo-4lRe (both annealed and aged as wel

(b) dpa values calculated for stainless steel.

Table 2a

Density Changes $\left(\cdot \Delta p / p_{0}\right)$ Measured in Irradiated Pure Molybdenum

\begin{tabular}{|c|c|c|c|c|c|}
\hline \multicolumn{3}{|c|}{ Annealed and Aged } & \multicolumn{3}{|c|}{ Cold-Worked and Aged } \\
\hline Temperature ${ }^{\circ} \mathrm{C}$ & Dose doa & $-\Delta \rho / \rho_{0}$ & Temperature't & Dose dpa & $-\Delta p / p$ \\
\hline $\begin{array}{l}420 \\
420\end{array}$ & $\begin{array}{r}47.2 \\
105.7\end{array}$ & $\begin{array}{l}-0.15 \\
-0.36\end{array}$ & $\begin{array}{l}420 \\
420 \\
420 \\
\end{array}$ & $\begin{array}{r}15.0 \\
50.3 \\
110.8 \\
\end{array}$ & $\begin{array}{l}0.96 \\
0.28 \\
0.05 \\
\end{array}$ \\
\hline $\begin{array}{l}471 \\
471\end{array}$ & $\begin{array}{l}32.2 \\
43.7\end{array}$ & $\left\{\begin{array}{l}.79 \\
1.82\end{array}\right.$ & $\begin{array}{l}471 \\
471 \\
471 \\
\end{array}$ & $\begin{array}{r}11.4 \\
38.2 \\
57.6 \\
\end{array}$ & $\begin{array}{l}1.10 \\
3.41 \\
1.68 \\
\end{array}$ \\
\hline $\begin{array}{l}569 \\
569\end{array}$ & $\begin{array}{l}40.8 \\
53.9\end{array}$ & $\begin{array}{l}1.18 \\
3.10\end{array}$ & $\begin{array}{r}569 \\
569 \\
569 \\
\end{array}$ & $\begin{array}{r}11.5 \\
38.5 \\
58.1 \\
\end{array}$ & $\begin{array}{l}1.93 \\
3.32 \\
3.02 \\
\end{array}$ \\
\hline $\begin{array}{l}645 \\
645\end{array}$ & $\begin{array}{l}40.8 \\
55.8\end{array}$ & $\begin{array}{l}1.02 \\
2.07\end{array}$ & $\begin{array}{l}645 \\
645 \\
645 \\
\end{array}$ & $\begin{array}{l}11.5 \\
38.5 \\
58.1 \\
\end{array}$ & $\begin{array}{r}1.57 \\
1.89 \\
1.83 \\
\end{array}$ \\
\hline $\begin{array}{l}730 \\
730\end{array}$ & $\begin{array}{l}40.8 \\
51.5\end{array}$ & $\begin{array}{l}0.98 \\
1.68\end{array}$ & $\begin{array}{l}730 \\
730 \\
730 \\
\end{array}$ & $\begin{array}{r}11.5 \\
38.5 \\
58.1 \\
\end{array}$ & $\begin{array}{l}1.56 \\
1.98 \\
191 \\
\end{array}$ \\
\hline
\end{tabular}

Table $2 b$

Donsity Chancles $\left(. \Delta \rho_{0}\right)$ Heasured in Irradiated Mo-4lRe

\begin{tabular}{|c|c|c|c|}
\hline & & \multicolumn{2}{|c|}{ Densily Change, } \\
\hline Iemperature $\mathrm{C}$ & Cose dpa & Annealed and Aged & Cold-worked and Aged \\
\hline $\begin{array}{l}420 \\
420\end{array}$ & $\begin{array}{r}47.2 \\
105.7\end{array}$ & $\begin{array}{l}0.33 \\
0.11\end{array}$ & $\begin{array}{r}-0.08 \\
0.28\end{array}$ \\
\hline $\begin{array}{l}471 \\
471\end{array}$ & $\begin{array}{r}32.2 \\
43.7 \\
\end{array}$ & $\begin{array}{r}2.26 \\
-0.28 \\
\end{array}$ & $\begin{array}{r}0.06 \\
-0.25 \\
\end{array}$ \\
\hline $\begin{array}{l}569 \\
569 \\
\end{array}$ & $\begin{array}{l}40.8 \\
63.9 \\
\end{array}$ & $\begin{array}{l}0.72 \\
0.52 \\
\end{array}$ & $\begin{array}{l}1.14 \\
0.12 \\
\end{array}$ \\
\hline $\begin{array}{l}545 \\
645 \\
\end{array}$ & $\begin{array}{l}40.8 \\
65.8\end{array}$ & $\begin{array}{l}0.66 \\
1.41\end{array}$ & $\begin{array}{l}0.04 \\
0.15\end{array}$ \\
\hline $\begin{array}{l}130 \\
730\end{array}$ & $\begin{array}{l}40.8 \\
61.5\end{array}$ & $\begin{array}{r}1.45 \\
0.07\end{array}$ & $\begin{array}{r}0.47 \\
-0.49 \\
\end{array}$ \\
\hline
\end{tabular}




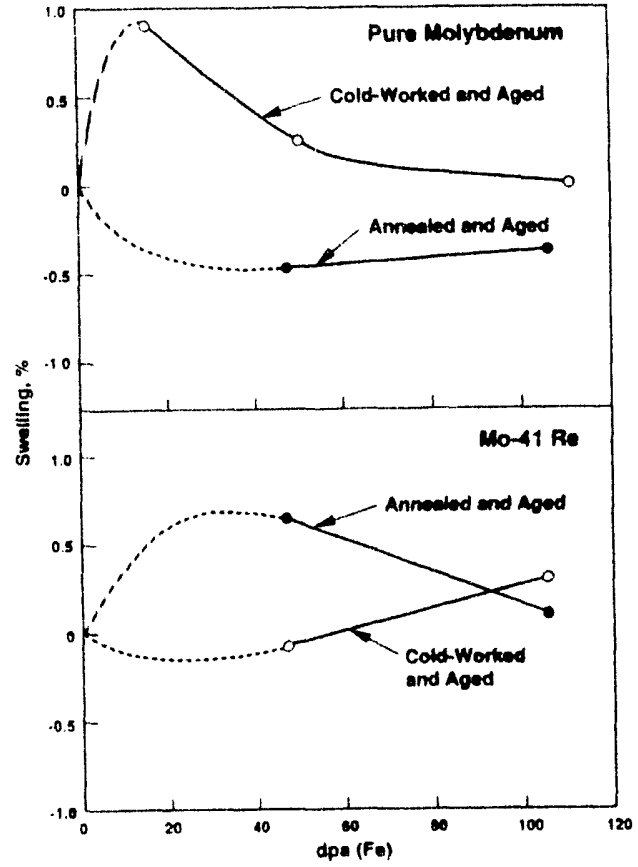

Fig. 1. Swelling $\left(-\Delta \rho / \rho_{-}\right)$of pure Mo and Mo-4lRe after irradiation in FFTF MOTA at a target temperature of $420^{\circ} \mathrm{C}$

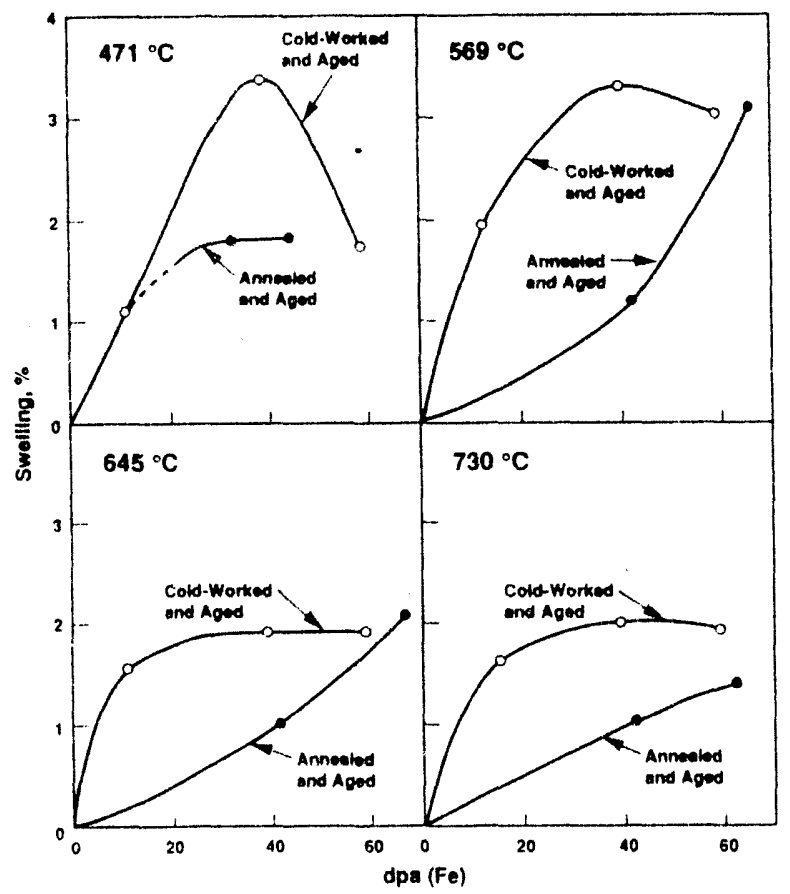

Fin 2 Swelling $(-\Delta 0)$ of pure tho at tarqet temperatures atwen 47 and $720 \%$

\section{Discussion}

From density change measurements aione, it is imossible to determine for Mo-4lRe whether the observed changes are due solely or in part to lattice parameter changes accompanying precipitation. Chi-phase precipitates are known to develop in ion-irradiated Mo-Re alloys, even though the equilibrium phase diagram would not predict the formation of this phase. ${ }^{-3}$ The densification of annealed and aged pure molybdenum at $420^{\circ} \mathrm{C}$ is al so difficult to explain. Since technicium formation by transmutation was invoked previously to explain void shrinkage in molybdenum, calculations were performed to assess the level of solid transmutants produced in these two alloys. Since the alloys are also being irradiated in thermal reactors in other laboratories. calculations were performed both for FFTF and HFIR to assess the range of possible transmutation in these materials. The STARFIRE spectrum was used to assess the transmutation produced in a typical fusion spectrum.

\section{Calculation of Transmutation Products}

The calculations required several steps including the determination of the principal nuclear reactions and subsequent decays, extraction of nuclear cross sections from ENDF/B-V or VI, addition of these new cross sections to existing PNL libraries, spectral averaging of each cross section using the STAY'SL computer code. and numerical calculations for different irradiation times. In most cases, the accuracy is estimated at 10 to $20 \%$ due both to uncertainties in the adjusted neutron spectra and in the evaluated ieutron activation cross sections. In the majority of cases. Econd-order transmutation of the primary reaction oroducts into secondary products was neglected. This is generally a cood assumption, inless either the primary transmulation is quite high (above $1 \%$ ) and/or the product has a very hion tansmutation rate.

The results are is isted in Tabie 3. Results for FFTf are given at 30.60 , and $100 \mathrm{dpa}$ (iron) at midplane. correspondira to full-power-day irradiations of 244. 188. and 813 FPD at 291 MW: total neutron fluences are 1.02, 2.04 and $3.40 \times 10$ n.cm. Galcalations are also provided for the midplane of the FFTF below. core canister $1-50.3 \mathrm{~cm}$ for the same irradiation times, corresconding to fe dpa values of 4.4.8.7. and 14.5 and total fluences

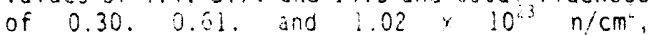
respectively. These fFif conditions correspond to the new core configuration used for fusion experiments, such as MOTA-1F, $1 G, 2 \mathrm{~A}$, and $2 \mathrm{~B}$.

Calculations for HFIR are shown at midplane of the Peripheral Target Position (PTP) for 1 full power year at $85 \mathrm{MW}$, corresponaing to $27 \mathrm{dpa}$ in iron and a fast fluence of $3.6 \times 10^{22} \mathrm{n} / \mathrm{cm}^{2}$. This reflects LFIR operating conditions employed since the reactor was restarted in 1990. 


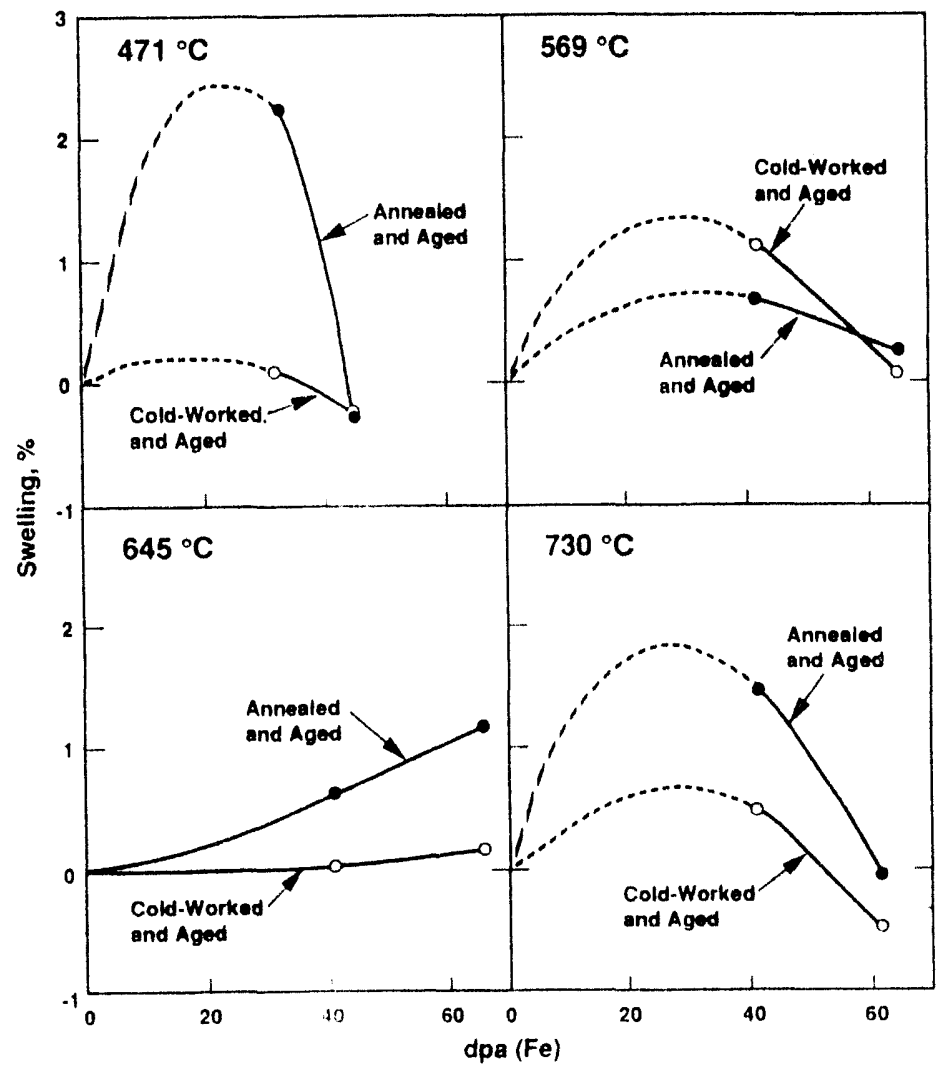

=3. 3. Swelling (-AD.0.) of to-4lRe at fonneratures metween a: and $730 \%$.

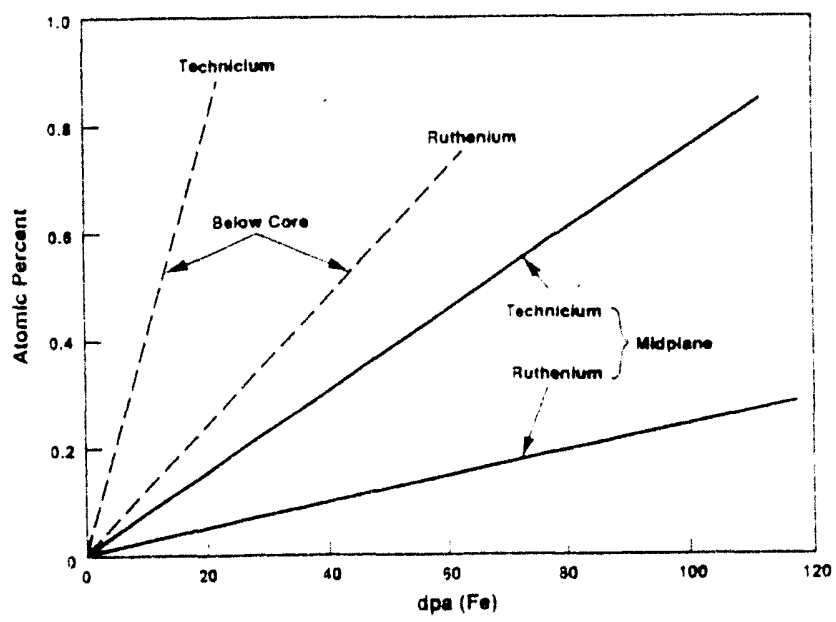

The principal transmutation reactions for Mo are the $(n, y)$ capture reactions on Mo-98 to Mo$99\left(2.7\right.$ d) to $99-T_{c}(200,000 \mathrm{y})$ and on Mo-100 to Mo-101 (15 m) to Ru-101. Capture reactions on the other isotopes lead to other stable Mo isotopes. Weaker reactions considered include $(n, p)$ and $(n, \alpha)$. Many of the $(n, p)$ reactions :roduce short-lived products which decay back to other Mo isotopes. However, the nuclear reactions Ho- 94 (n.p) Nb-94 $(20,000$ y) and $\mathrm{Mo}-92$ ( $n, p) \mathrm{Nb}-92$ (10 d) which decays to $2 r .92$ must be considered. The $(n, \alpha)$ reactions to $\mathrm{Zr}$ were included for all of the Mo isotopes except that Mo-92 produces $2 r-89(3.3 \mathrm{~d})$ which decays to $Y-89$, and Mo-98 and Mo100 have products which decay back to other Mo isotopes. Hence, nine reactions were used in the transmutation calculations. Some of these transmutation products may be further transmuted: in general this is not important except for isotopes that have significant capture gamma cross sections. For Mo, the only significant second order transmutation is ic.99. Which in turn will partially transmute to all-100 in HFiR.

Soth Fe-135 and ka-187 have large $n . \because)$ reaction ates leading to inificant *ansmutation in both

HR ard fif both reactions qat in 0 were turther reactions ad in! iner stable o iolopes $\therefore 1$ if the (n.p) eacions ad :a short-lived :ungsten isotopes which decay back -a a the n.al reactions produce sral? amounts of $W-182$ and $n-184$.

- cure 4 nows that the technicium and runchlum levels generated in fFT are not negligible. aspeciail in below core rrajia: in. Whether oncentrat uns ${ }^{*}$ this magnitude an account iar the rensification of moluaenum acserued at $420^{\circ} \mathrm{C}$ ras not, be ven established. iable : nilcaies that the transmutation ra:e will be higher in HFll. sDeciali: for ruthenium. agure 5 cnows tnat inenium wil? - ransmute to asmium vary strongly - $n$ FFTF ath the rate increasing harply below and near the edges of the crore in IIfIR. however. chenium will aimost completely *ansmuteo to osmiam at a moderate doa leve: a nown in figure 5. 
Table 3

Transmutation in FFT and HFIR

(Values are ilisted in at\%, unless noted as appmi)

\begin{tabular}{|c|c|c|c|c|c|c|c|}
\hline \multirow[b]{2}{*}{ Iransmutant } & \multicolumn{3}{|c|}{ FFTF Midplane } & \multicolumn{3}{|c|}{ FFT Below Core } & \multirow{2}{*}{ HFIR Middane* } \\
\hline & 244 & 488 & 833 & 244 & 488 & 833 & \\
\hline $\begin{array}{l}\text { Fluence, } \\
\text { doa. Fe }\end{array}$ & $\begin{array}{l}1.0 \\
30 \\
\end{array}$ & $\begin{array}{l}2 . ! \\
50 \\
\end{array}$ & $\begin{array}{l}3.4 \\
100 \\
\end{array}$ & $\begin{array}{l}0.30 \\
4.4 \\
\end{array}$ & $\begin{array}{l}0.61 \\
3.7 \\
\end{array}$ & $\begin{array}{l}1.02 \\
14.5 \\
\end{array}$ & $\begin{array}{r}3.6 \\
27.0 \\
\end{array}$ \\
\hline$\frac{\text { Molundenum: }}{\text { Tc-99 }}$ & 0.24 & 0.45 & 0.76 & 0.17 & 0.35 & 0.62 & 0.49 \\
\hline Ru & 0.07 & 0.14 & 0.24 & 0.05 & 0.10 & 0.17 & 0.64 \\
\hline :ib-94 avom: & 0.02 & 0.04 & 0.07 & 0.001 & 0.002 & 0.003 & 0.11 \\
\hline Ir appm: & 2.0 & 4.0 & 6.8 & 0.08 & 0.16 & 0.27 & 9.1 \\
\hline$\frac{\text { 2henium: }}{\text { OS }}$ & 10.1 & 19.2 & 29.9 & 17.7 & 32.1 & 47.3 & $99.5+$ \\
\hline W appm: & 0.4 & 0.8 & 1.4 & 0.02 & 0.04 & 0.08 & 0.33 \\
\hline
\end{tabular}

- Self-shieldina has rot been incarporated in these calculations.

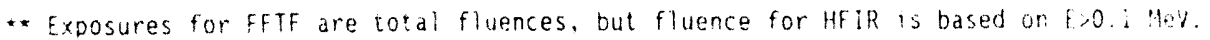

- Intial rate for transmuting Re to Os in HFIR is $2.1 \%$ per day.

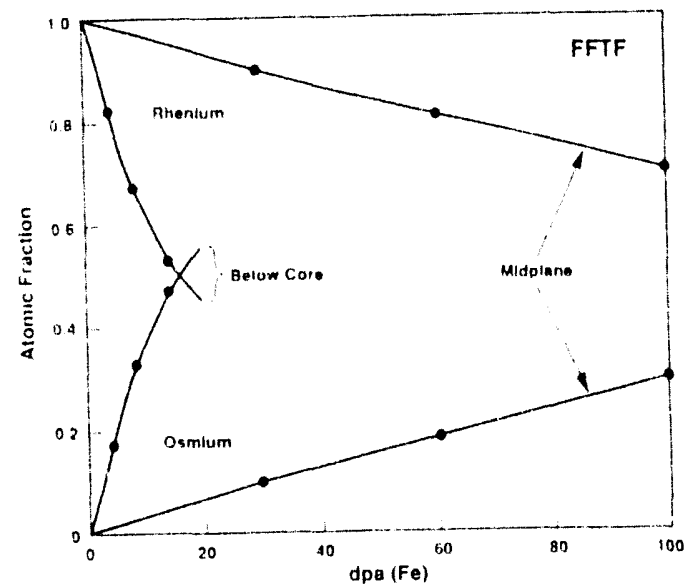

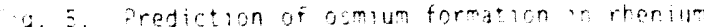
iring irratiation in if if

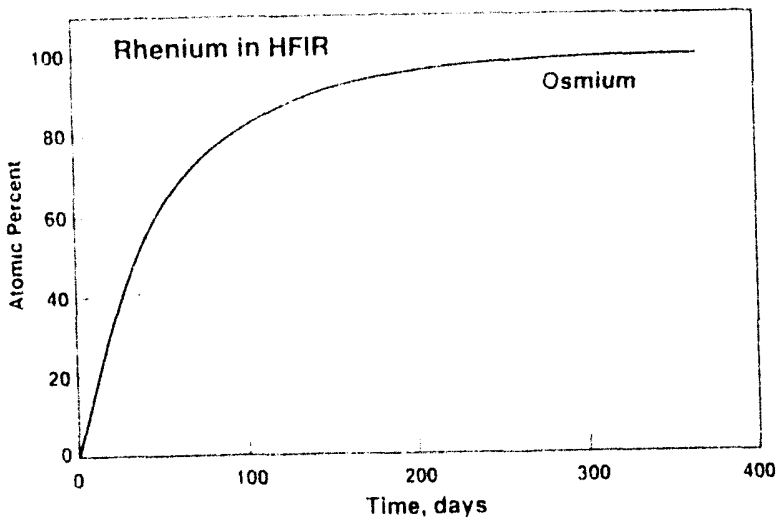

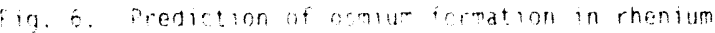
during irradiation in it? 
It is safe to say that the Mo-4lRe specimens irradiated in FFTF are now Mo-Re-Os-TC-2e alloys of varying composition, depending on their location in the FFTF core and the total exposure. Microscopy and EDX analysis are necessary to determine the composition of these alloys and the role of transmutation and precipitation in determining the density changes induced by radiation. It is also slispected that large levels of osmium may change the formation rate of chi phase.

Recent Russian studies showed that Mo-Re alloys irradiated in SM-2 (similar to HFIR in spectrum) lost. 20 to $30 \%$ of their electrical conductivity and much of their fracture resistance at relatively low exposures $(-5 \times$ $10^{\circ} \mathrm{n} \mathrm{cm}^{-}$). Based on the preceding calculations. osmium formation was probably the major cause of the conductivity degradation, but the loss of fracture resistance may be due to both precinitation and osmium formation.

:t appears that transmutation will also be important in fusion spectra at levels intermediate to that in fFTF and HFIR. This is demonstrated in Figures 7 and 8 for the STARFIRE spectra.

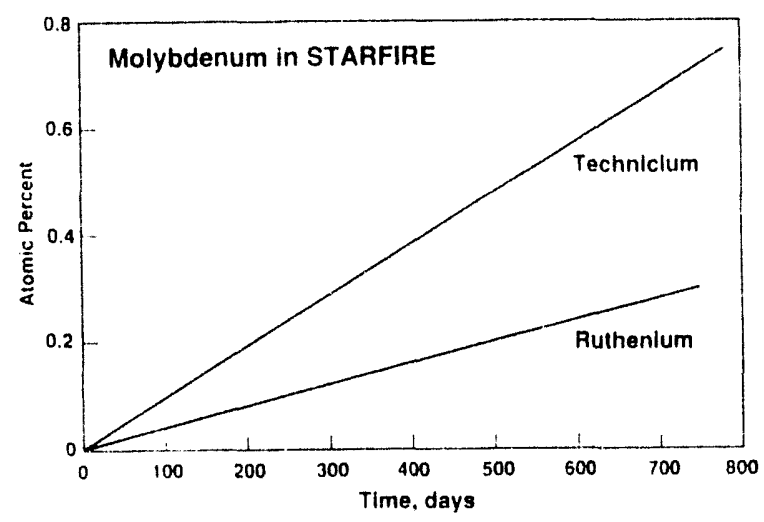

-ig. ?. Prediction of transmutation in pure $\rightarrow$ ibdenum in STARFIRE.

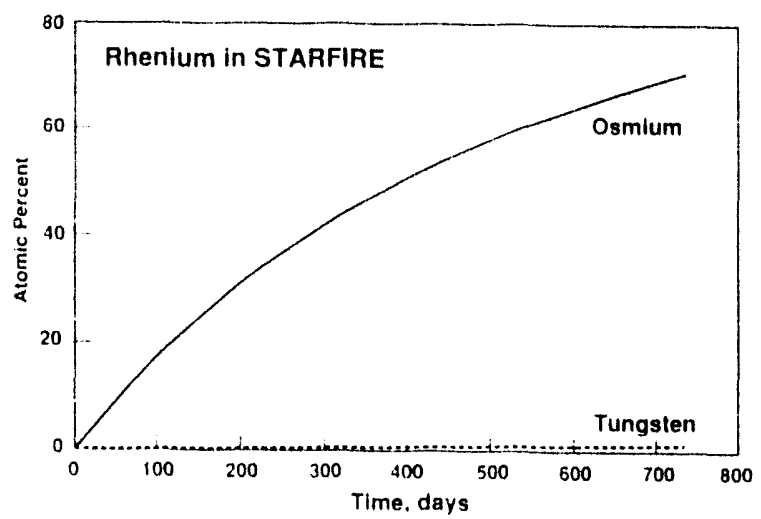

= 9. 3. Prediction of tranc-utation in oure rhenium II STARFIRE

ZUTURE WORK

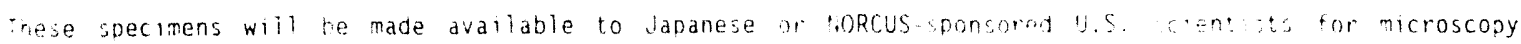
$\therefore$ amination.

\section{DEERENCES}

S. A. Fabritsiev et al. Bilucl. Mater. $191 \cdot 194(1992) 425-429$

$\therefore \quad \therefore \%$ corynin et al. J. Nuc: Mater., 191-194 1!992; $421-425$.

$\therefore \quad \therefore$ Garner, "FFTF,MOTA irradiation of Refractory Alloys Under consideration as Plasma facing Components." ¿sion Feactor Materials Semiannual Progress Report. DOE ER-0313/9 (1991) . op. $159-1 \%$.

$\therefore$ A. A. Erck and L. E. Fehn, Phil. Mag. A. 62. (1990) 29.51 .

5. A. Erck and L. E. Fehn, B. Hucl. Mater., 158 (1989) 203.219.

$\therefore \quad$ P. A. Erck, C. M. Wayman. and L. E. Rehn, in Radiation-Induced Changes in Microstructure: 13th anternational Symposium (Part 1). ASTM STP 955. F. A. Garner. N. H. Packan and A. S. Kumar. Eds.. American cotety for Testing and Materials. Philadelphia. :987. pp. 721-729.

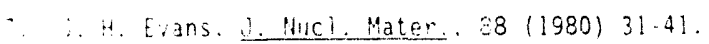


Irradiation Creep of Russian Federation Pressurized Tubes in NOTA-26. F. A. Garner. Pacific Northwest Laboratory), C. R. Eiholzer, (Westinghouse Hanford Company), E. V. Demina and L. I. Ivanov. (Baikov Institute)

\section{OBJECTIVE}

The objective of this effort is to provide irradiation creep data on a reduced activation austenitic allay supplied by the Baikov Institute.

SUMMARY

Irradiation has been completed in MOTA-28 for creep tubes constructed from a candidate reduced activation austenitic alloy supplied by the Baikov Institute in Moscow. The total strains are strongly dependent on irradiation temperature in the range $425-600^{\circ} \mathrm{C}$, but are not completely linear with stress level.

PROGRESS AND STATUS

\section{Introduction}

In a previous report the first details of a joint US/RF (Russian Federation) irradiation study were presented. This effort involved the irradiation of two groups of reduced activation austenitic alloys in FFTF using the MOTA-2B irradiation vehicle. One of these material groups was supplied by the Baikov Institute as tubing in the annealed condition for fabrication into pressurized creep tubes. Table 1 nrovides the composition of these tubes. The tubing dimensions are $4.57 \mathrm{~mm}(0.180 \mathrm{~m}) 00$ and $0.2 \mathrm{~mm}(0.008$ in) wall thickness. End caps for these tubes were of standard WHC design and were fabricated from the U.S. D9 variant of AISI 316 stainless steel, the composition of which is provided in table 2.

Table 1.

Chemical Composition of Austenitic Steel 10KhI2G20V. Heat 394. Fubing

\begin{tabular}{|c|c|c|c|c|c|c|c|c|}
\hline Eiement & Fe & Cr & Mn & $W$ & $S i$ & $C$ & $P$ \\
\hline wt $\%$ & Bal & 13.0 & 19.0 & 1.0 & 0.32 & 0.09 & 0.024 & 0.012 \\
\hline
\end{tabular}

Table 2 .

Nominal Chemical Composition of 09 , (lieat 2956) fod Used for End saps

\begin{tabular}{|c|c|c|c|c|c|c|c|c|}
\hline Element & $\mathrm{Fe}$ & $\mathrm{Ni}$ & $\mathrm{Cr}$ & $\mathrm{Hn}$ & $\%$ & $\mathrm{Si}$ & $\mathrm{H}$ & $\mathrm{H}$ \\
\hline wt $\%$ & $\mathrm{Bal}$ & 15.64 & 14.03 & 2.19 & 1.45 & 1.05 & 0.25 \\
\hline
\end{tabular}

\begin{tabular}{|c|c|c|c|c|c|c|c|c|}
\hline Element & $C$ & V & Al & $P$ & $i a$ & 80 & 5 & $N$ \\
\hline wt $\%$ & 0.046 & 0.04 & 0.04 & 0.012 & 0.01 & 0.03 & 0.001 & 0.009 \\
\hline
\end{tabular}

\section{Experimental Details}

The components were ultrasonically cleaned in acetone for 5 min. and then in alcono: fal 5 min. Tie components were air dried. The cleaned components wor handled with white gioves.

A laser engraver was used to put 10 numbers on set of top and tottom end caps. ihe : characteristic letters followed by a two number sequence starting with 00. Tha characteristic letters for the Russian Federation pressurized tubes are FG. Hentification codes used were FGoj througn FG35.

The end caps were electron beam weided to the gage sections. Before welding the test apecimens, qualification welds were inade to determine if the welding parameters were correct for the material. ihe qualification procedure consisted of making six welds which had the same joint and materials that would be welded on the test specimens. The qualification welds were leak checked and then metaliographicaliy examined for penetration. The required penetration is $85 \%$ of the wall thickness. All production welds were made to this procedure.

Pacific Northwest Laboratory is operated for the U.S. Department of Energy by Battelle Memorial Institute under Contract DE-ACO6-76RLO 1830 
The actron heam production welds were inspected before the specimens were accented for further rabrication steps. A visual inspection was then made on all the production welds. $\therefore l 1$ ine weids passed - he inspection. Two production specimens from each production lot were sacrificed ts determine if the weld anetration for the lot was correct. These specimens had the beginning or ending lot production welds made in them. The weids were then metallographically examined. The tubes were electron beam welded in two ts. The sacrificial specimens from each lot showed the correct penetration. both lots of specimens were ircepted for further fabrication steps.

tho jesired hoop stresses and corresponding fill pressures were determined before tre specimens were filled with gas. The destred hoop stresses were based on the ultimate tensile strength of mo material, creep outavior of similar material, and the irradiation history of the material. The tensi e data provided by he bakov Institute showed that the material behaved similarly to solution annealed 310 stainless steel. tro final desired hoop stresses were based on the limited creep data on solution annealed 316 ss. Fhe test atrix is given in Table 3 .

Table 3.

lest Matrix for Pressurized Tubes

\begin{tabular}{|c|c|c|c|c|c|}
\hline \multirow{2}{*}{ Temperature } & \multicolumn{5}{|c|}{ Stress (MPa) } \\
\hline & 0 & 30 & 60 & $\therefore 22$ & 140 \\
\hline $\begin{array}{l}420 \\
520 \\
500\end{array}$ & $\begin{array}{l}x \\
x \\
x\end{array}$ & $\begin{array}{l}x \\
x \\
y\end{array}$ & $\begin{array}{l}x \\
x \\
x\end{array}$ & t & $\begin{array}{l}x \\
x \\
x\end{array}$ \\
\hline
\end{tabular}

The FILPRES computer program was used to determine the gas fill pressures. This prooram uses elastic sess.strain relationships for cylindrical tubes to calculate fill pressures for the specimens to achieve the desired stress at temperature. The code also incorporates the effects of wall thickness. material ape. fill gas. test temperature. and desired hoop stress. The fill pressures were tased on the thick wall auation for hoop stress. austenitic materials, helium fill gas. helium compressibrl. vequations, and the atrix awon in Table 3 . Table 4 presents the 111 pressures that were selected

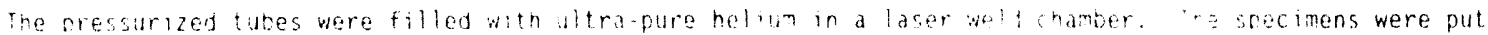

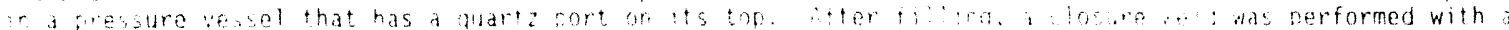

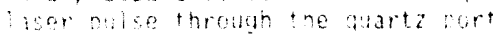

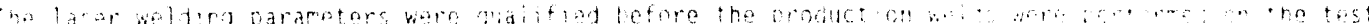

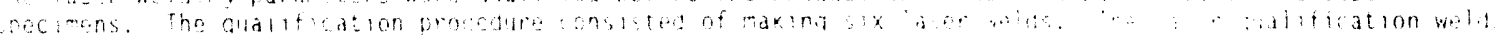

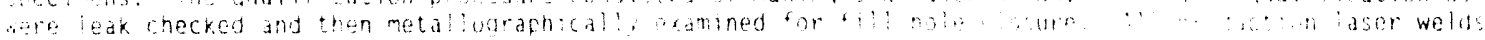

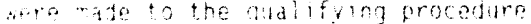

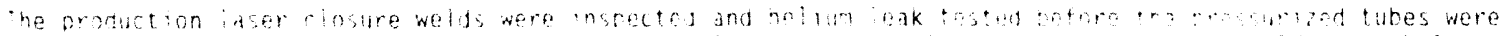

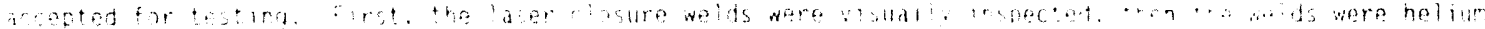

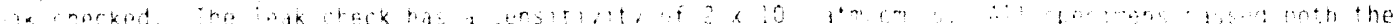

wection and liak tas

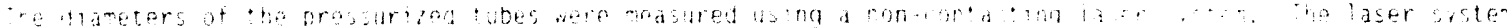

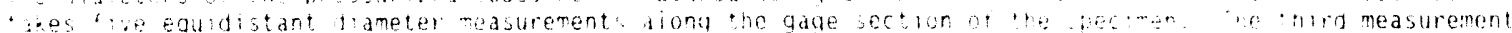

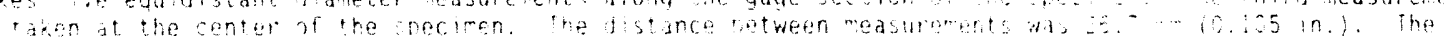

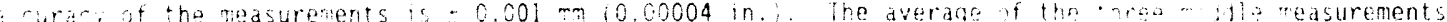

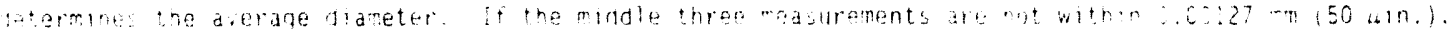

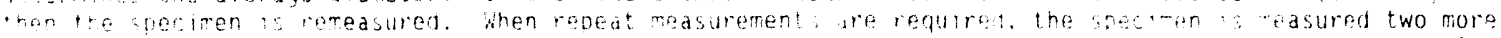

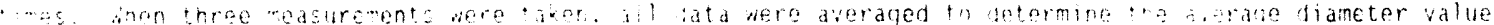

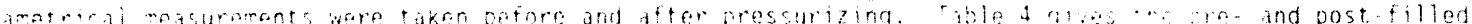

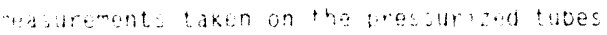

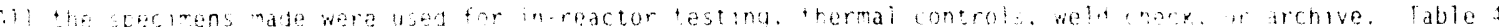

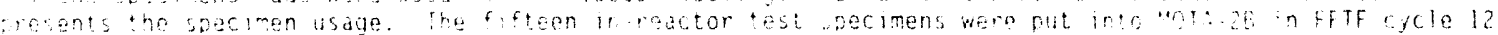

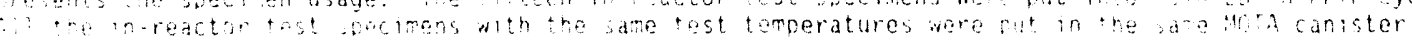

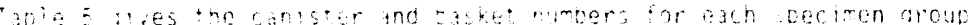


iable 4.

Summary of Fabrication Data

\begin{tabular}{|c|c|c|c|c|c|c|}
\hline 10 & $\begin{array}{l}\text { lloop } \\
\text { Stress } \\
\text { (MPa) }\end{array}$ & $\begin{array}{l}\text { lest } \\
\text { Temp. } \\
\left({ }^{\circ} \mathrm{C}\right)\end{array}$ & $\begin{array}{c}1111 \\
\text { Pressure } \\
\text { (psig) }\end{array}$ & $\begin{array}{l}\text { Average } \\
\text { Pre-fill } \\
\text { Diameter } \\
\text { (in.) }\end{array}$ & $\begin{array}{l}\text { Average } \\
\text { Post-fill } \\
\text { Diameler } \\
\text { (ln.) }\end{array}$ & $\begin{array}{c}\text { Specimen } \\
\text { Usage }\end{array}$ \\
\hline $\mathrm{rg}, 00$ & NA & HN & in & NA & NA & $\begin{array}{l}\text { Check EB } \\
\text { weld lot }\end{array}$ \\
\hline$f(60)$ & HA & Nn & in & in & Hn & $\begin{array}{l}\text { Check IB } \\
\text { weld lot }\end{array}$ \\
\hline $\mathrm{FGO2}$ & 0 & 420 & $9.7 \star$ & .18004 & .18005 & Reactor \\
\hline $\mathrm{fGO}_{\mathrm{C}}$ & 0 & 420 & $9.7^{\star}$ & .18019 & .18027 & Thermal \\
\hline FGO1 & 30 & 420 & 181 & .18060 & .18061 & Reactor \\
\hline rG,05 & 30 & 420 & 182 & .18014 & .18021 & Thermal \\
\hline $\mathrm{rC}_{0} 06$ & 60 & 120 & 369 & $.1799 !$ & .17994 & Reactor \\
\hline 1607 & 60 & 420 & 369 & .18017 & .18025 & Thermal \\
\hline rG08 & 100 & 420 & 620 & .17961 & 17965 & Reactor \\
\hline $\mathrm{rCO} 09$ & 100 & 420 & 620 & .18022 & .18034 & Thermal \\
\hline 1610 & 140 & 420 & 873 & .18034 & .18038 & Reactor \\
\hline 1611 & 140 & 420 & 873 & .18038 & .18050 & Thermal \\
\hline 10,12 & 0 & 520 & $8.6^{\star}$ & .18022 & .18023 & Reactor \\
\hline 1613 & 0 & 520 & $8.6^{\star}$ & .18001 & .18014 & Ihermal \\
\hline$f G / 4$ & 30 & 520 & 158 & .18030 & .18031 & Reactor \\
\hline 1015 & 30 & 520 & 158 & .18003 & .18010 & lhermal \\
\hline$r(i) 6$ & 60 & 520 & 323 & .18020 & .18019 & Reactor \\
\hline 10,17 & $1^{60}$ & 520 & 323 & .17998 & .18007 & Ihermal \\
\hline 1618 & 100 & 520 & 544 & .18013 & .18015 & Reactor \\
\hline$F G 19$ & 100 & 520 & 514 & .17981 & .17998 & Thermal \\
\hline $16: 20$ & 140 & 520 & 166 & .18011 & .18020 & Reactor \\
\hline$r(; 2)$ & 110 & 570 & 767 & .18001 & .18012 & Thermal \\
\hline 1622 & 0 & 600 & $7.8^{4}$ & 11996 & .17991 & Reactor \\
\hline 1623 & 0 & 600 & $1.8 *$ & .18034 & .18043 & |hermal \\
\hline 1624 & $m$ & in & $11 n$ & IIn & IIn & $\begin{array}{l}\text { Check IB } \\
\text { weld lot }\end{array}$ \\
\hline $11 ; 25$ & in & $m$ & in & in & 111 & $\begin{array}{l}\text { lheck to } \\
\text { weld lot }\end{array}$ \\
\hline$\Gamma(1,26$ & 30 & 600 & 143 & .11994 & .17996 & Reactor \\
\hline 10,27 & 30 & 600 & 143 & .17986 & $.1 / 996$ & Thermal \\
\hline$\Gamma G 28$ & 60 & 600 & 294 & .18002 & .18004 & Reactor \\
\hline 10,29 & 60 & 600 & 294 & .18020 & .18033 & lherinal \\
\hline$f G 30$ & 100 & 600 & 496 & .18023 & .18025 & Reactor \\
\hline$F G 31$ & 100 & 600 & 491 & .18030 & .18045 & Ihermal \\
\hline 1632 & 140 & 600 & 699 & .17969 & . 17974 & Reactor \\
\hline FG33 & 140 & 600 & 699 & .18040 & .18059 & Ihermal \\
\hline 1634 & $\mathrm{Mn}$ & 111 & $\mathrm{MA}$ & .18005 & $11 n$ & Archive \\
\hline 1635 & in & III & IM & .18023 & HA & Archive \\
\hline
\end{tabular}

* These are psla values. Iow or negatlve pressures $c$ an only be acheived using lisia gage.

Table 5

Location of Pressurized Tubes in MOTA-2B

\begin{tabular}{|c|c|}
\hline Pressurized Tube & MoTA-20 \\
Test Temperature (C) & Canister llo. basket \\
\hline 420 & 48.2 \\
520 & $2 F-3$ \\
600 & $4 F-4$ \\
\hline
\end{tabular}

10TE: The specimens designated for $420^{\circ} \%$. were placed in $3425 \%$ canister.

The hoop stress should not differ significantly for the 5 c difference. 
The tubes were mantained close to their target temperatures throughout the irradiat on sequence, as shown in Table 6, reaching fluences between 5.3 and $5.8 \times 10^{i 2} \mathrm{n} / \mathrm{cm}^{2}$ (E> $0.111 \mathrm{MeV}$ ). After discharge from MOTA. 23. the diameters of the tubes were again measured. A11 specimens were observed $: 0=2$ in good shape with no obvious failures.

iable 6.

Average Test Temperatures

\begin{tabular}{|c|c|c|c|c|c|}
\hline Canister & $\begin{array}{c}\text { Canister } \\
\text { Type } \\
\end{array}$ & $\begin{array}{l}\text { Target Test } \\
\text { Temp. }(C) \\
\end{array}$ & $\begin{array}{c}\text { Maximum lest } \\
\text { Temp. (C) }\end{array}$ & $\begin{array}{c}\text { Average Tost } \\
\text { Tero. }\end{array}$ & $\begin{array}{l}\text { Time at } \\
\text { Average Test } \\
\text { Temp. (Days) }\end{array}$ \\
\hline $\begin{array}{l}2 F \\
48 \\
4 F\end{array}$ & $\begin{array}{l}\text { Gas-Gapped } \\
\text { Weeper } \\
\text { Gas-Gapped }\end{array}$ & $\begin{array}{l}520 \\
425 \\
600 \\
\end{array}$ & $\begin{array}{l}533 \\
434 \\
614\end{array}$ & $\begin{array}{l}519 \\
428 \\
599\end{array}$ & $\begin{array}{l}200.4 \\
199.3 \\
200.3\end{array}$ \\
\hline
\end{tabular}

Results and Discussion

Table 7 presents the average diametral strains measured for the fifteen irradiated tunes. The amount of diametral strain $\Delta D / D$ was determined by

$$
\frac{\Delta D}{D}(\delta)=100\left(\left(D_{n}-D_{n}\right) / D_{p}\right)
$$

where $D_{m}$ is the current diameter and $D_{p}$ is the post-filled diameter.

Table 7

MOTA-2B In-Reactor Creep Data

\begin{tabular}{|c|c|c|c|c|c|c|c|c|c|}
\hline $\begin{array}{c}\text { Specimen } \\
10\end{array}$ & $\begin{array}{l}\text { Hoop } \\
\text { Stress } \\
\text { (MPa) }\end{array}$ & $\begin{array}{l}\text { Average } \\
\text { Test } \\
\text { Temp. } \\
\text { (C) }\end{array}$ & Basket & $\begin{array}{c}\text { MOTA-2B } \\
\text { Fluence } \\
10^{22} \mathrm{n} / \mathrm{cm}^{-} \\
E>0.111 \mathrm{MeV}\end{array}$ & $\begin{array}{c}\text { Average } \\
\text { Postfilled } \\
\text { Diameter } \\
\text { (mm) }\end{array}$ & $\begin{array}{l}\text { Average } \\
\text { Final } \\
\text { Diameter } \\
\text { (mm) }\end{array}$ & $\begin{array}{c}\text { Total } \\
\text { Diametral } \\
\text { Strain }(:)\end{array}$ & $\begin{array}{c}\text { creep } \\
\text { strain* } \%\end{array}$ & $\begin{array}{c}\text { Stress } \\
\text { Normalized } \\
\text { Creep } \\
\text { Strain* } \\
\% / M P a\end{array}$ \\
\hline $\begin{array}{l}F G 02 \\
F G 04 \\
F G 06 \\
F G 08 \\
F G 10\end{array}$ & $\begin{array}{r}0 \\
30 \\
60 \\
100 \\
140\end{array}$ & 428 & $4 B-2$ & 5.3 & $\begin{array}{l}4.57327 \\
4.58749 \\
4.57048 \\
4.56311 \\
4.58155\end{array}$ & $\begin{array}{l}4.57683 \\
4.59638 \\
4.58368 \\
4.57733 \\
4.59638\end{array}$ & $\begin{array}{l}0.38 \\
0.19 \\
0.29 \\
0.31 \\
0.32\end{array}$ & $\begin{array}{l}0.11 \\
0.11 \\
0.21 \\
0.23 \\
0.24\end{array}$ & $\begin{array}{l}3.7 \times 10 \\
3.5 \times 10 \\
2.3 \times 10 \\
1.7 \times 10\end{array}$ \\
\hline $\begin{array}{l}F G 12 \\
F G 14 \\
F G 16 \\
F G 18 \\
F G 20\end{array}$ & $\begin{array}{r}0 \\
30 \\
60 \\
100 \\
140\end{array}$ & 519 & $2 F-3$ & 5.8 & $\begin{array}{l}4.57794 \\
4.57962 \\
4.57683 \\
4.57581 \\
4.57708\end{array}$ & $\begin{array}{l}4.59486 \\
4.59943 \\
4.60299 \\
4.61416 \\
4.63220\end{array}$ & $\begin{array}{l}0.37 \\
0.43 \\
0.57 \\
0.34 \\
1.20\end{array}$ & $\begin{array}{l}0 . \\
0.06 \\
0.20 \\
0.47 \\
0.83\end{array}$ & $\begin{array}{l}2.0 \times 10 \\
3.3 \times 10 \\
4.7 \times 10 \\
5.9 \times 10\end{array}$ \\
\hline $\begin{array}{l}F G 22 \\
F G 26 \\
F G 28 \\
F G 30 \\
F G 32\end{array}$ & $\begin{array}{r}0 \\
30 \\
60 \\
100 \\
140\end{array}$ & 599 & $4 F-4$ & 5.4 & $\begin{array}{l}4.57124 \\
4.57098 \\
4.57302 \\
4.57835 \\
4.55540\end{array}$ & $\begin{array}{l}4.57810 \\
4.59435 \\
4.63626 \\
4.68935 \\
4.70103\end{array}$ & $\begin{array}{l}0.15 \\
0.51 \\
1.32 \\
2.42 \\
? .9 ?\end{array}$ & $\begin{array}{r}-. \\
? .35 \\
\therefore .23 \\
2.27 \\
? .32\end{array}$ & $\begin{array}{l}1.2 \times 10 \\
2.1 \times 10 \\
2.3 \times 10 \\
2.0 \times 10\end{array}$ \\
\hline
\end{tabular}

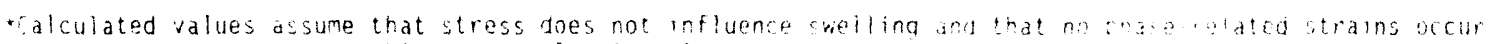
rese assumptions are probably not completeiy idid.

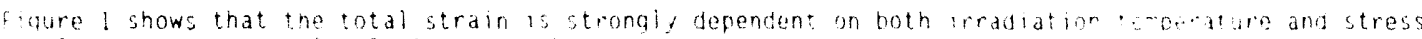

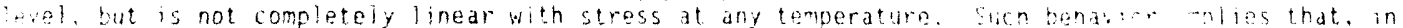
dat tion to irradiation creep. pnase-rolated density chances and stress-enhancer a ina are probably

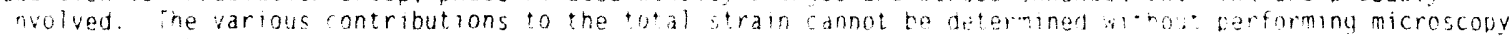
and density change measurements. 


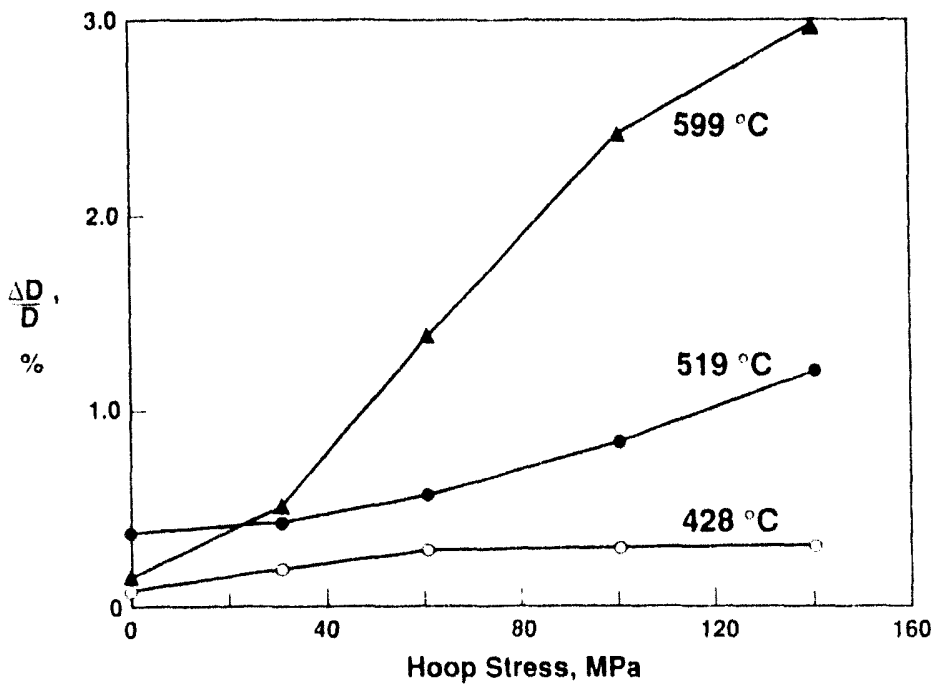

Figure 1 . Diameter changes observed in pressurized tubes after irradiation $n: 40 T A 26$.

FUTURE WORK

These tubes will be examined by a Russian Federation assignee at Oak Ridge lationai Laboratory. Since the MOTA irradiation will not be continues, these tubes may be sacrificed for density measurements. Thermal control studies have not been initiated and may be abandoned.

PEFERENCES

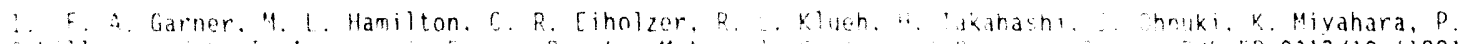

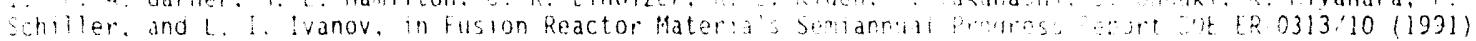
sp. $109 \cdot 112$ 
Density Measurements Performed on Ispra Second Generation AMCR Alloys Irradiated in MOTA-2A - F. A. Garner, (Pacific Northwest Laboratory) d, P. Sihiller, (Ispra Establishment), and H. Takahashi, (Hokkaido

University)

\section{OBJECTIVE}

The objective of this effort is to provide information on the radiation response of reduced activation alloys considered for fusion application.

SUMMARY

Density change measurements have been completed on the Ispra second generation AMCR alloys irradiated in MOTA-2A. The various compositional modifications induce a wide variation of swelling behavior in the range $423.600^{\circ} \mathrm{C}$ at $32-36 \mathrm{dpa}$.

PROGRESS AND STATUS

\section{Introduction}

in the early FFTF irradiation studies on commercial Fe-Cr-Mn alloys it was shown that the AMCR alloy supplied by Creusot-Marrel ( $\mathrm{Fe}-10 \mathrm{Cr}-18 \mathrm{Mn}-0.7 \mathrm{Ni}-0.6 \mathrm{Si}-0.06 \mathrm{~N}-0.2 \mathrm{C}$ ) exhibited somewhat better performance than the other alloys investigated. Researchers at the Ispra Establishment have developed a series of lower activation variations on this steel ${ }^{2}$ which was inserted for irradiation in MOTA-2A during FFTF cycle 11 and 12 at 420,520 , and $600^{\circ} \mathrm{C}$. (See Table 1 for the composition of these steels). Cycle 11 has been completed and density measurements performed.

Table 1

Composition (wt\%) of ISPRA Second Generation AMCR Alloys

\begin{tabular}{|c|c|c|c|c|c|c|c|c|c|}
\hline Alloy & $C r$ & $M n$ & $N i$ & $M_{0}$ & $C$ & $N$ & $S i$ & $S$ & $P$ \\
\hline ISPRA-A & 12.5 & 10.5 & 2 & $<0.1$ & 0.10 & $<0.05$ & 0.5 & $<0.01$ & $<0.02$ \\
\hline ISPRA-B & 12.5 & 10.5 & $<0.25$ & $<0.1$ & 0.30 & $<0.05$ & 0.5 & $<0.01$ & $<0.02$ \\
\hline ISPRA-C & 12.5 & 17.5 & 2 & $<0.1$ & 0.10 & $<0.05$ & 0.5 & $<0.01$ & $<0.02$ \\
\hline ISPRA-D & 10.0 & 17.5 & $<0.25$ & $<0.1$ & 0.30 & $<0.05$ & 0.5 & 0.01 & $<0.02$ \\
\hline ISPRA-E & 17.0 & 10.5 & 2 & $<0.1$ & 0.10 & $<0.05$ & 0.5 & 0.01 & $<0.02$ \\
\hline
\end{tabular}

\begin{tabular}{|c|c|c|c|c|c|c|c|c|}
\hline$c u$ & $A 1$ & $N b$ & $V$ & $W$ & $T a$ & $\rho b$ & 0 & $B$ \\
\hline 0.1 & 0.05 & $<0.001$ & 0.75 & 1.4 & 00.005 & 0.001 & 0.1 & $<0.005$ \\
\hline 0.1 & $<0.05$ & 0.001 & 0.75 & 1.4 & $<0.005$ & 0.001 & 0.1 & $<0.005$ \\
\hline 0.1 & $<0.05$ & $<0.001$ & 0.1 & 2.0 & 00.005 & 0.001 & 0.1 & $<0.005$ \\
\hline 0.1 & 0.05 & $<0.001$ & $<0.1$ & 2.0 & $<0.005$ & 0.001 & 0.1 & $<0.005$ \\
\hline 0.1 & 0.05 & $<0.001$ & 0.75 & 2.0 & 0.005 & 0.001 & 0.1 & $<0.005$ \\
\hline
\end{tabular}

Uesults

Table 2 presents the results of the density measurements, and demonstrates that a large variation in welling benavior occurs. Hote that the AMCP steel used in the previous Us stidia: was also included in MOIA $2 \hat{A}$ and $2 B$ for comparison with the behavior of the rew Ispra alloys.

Pacific Northwest Laboratory is operated for the U.S. Department of Energy by Battelle Memorial institute under Contract DE-ACO6-76RLO 1830. 
Table 2

Swelling (\%) of FeCrMn lspra Alloys and AMCR in MOTA-2A'

\begin{tabular}{|c|c|c|c|c|}
\cline { 2 - 5 } \multicolumn{1}{c|}{} & $\begin{array}{c}\text { Original } \\
\text { Density }(\mathrm{g} \mathrm{cm})\end{array}$ & $\begin{array}{c}423^{\circ} \mathrm{C} \\
36.1 \mathrm{dpa}\end{array}$ & $\begin{array}{c}520^{\circ} \mathrm{C} \\
36.3 \mathrm{dpa}\end{array}$ & $\begin{array}{c}600^{\circ} \mathrm{C} \\
32.3 \mathrm{dpa}^{* *}\end{array}$ \\
\hline ISPRA-A & 7.94768 & 0.96 & $1.23 / 0.28$ & 0.15 \\
\hline ISPRA-B & 7.94965 & 0.30 & 0.07 & 0.99 \\
\hline ISPRA-C & 7.98265 & 1.49 & 3.97 & 1.96 \\
\hline ISPRA-D & 7.97152 & 0.28 & 0.58 & 0.72 \\
\hline ISPRA-E & 7.85483 & 0.52 & 4.08 & 0.58 \\
\hline AMCR & 7.86452 & 0.96 & 0.71 & 1.19 \\
\hline
\end{tabular}

* Unless two values are given, the swelling quoted is the average of two separate specimens that exhibited nearly identical densities.

$\star \star$ Corresponding to neutron exposures of $8.53,8.58$ and $7.64 \times 10^{\circ *} \mathrm{n} \mathrm{cm}^{*}(E>0.1 \mathrm{MeV})$ at 423,520 , and $600^{\circ} \mathrm{C}$, respectively.

\section{FUTURE WORK}

The specimens from MOTA-2A have been shipped to Hokkaido University for microscopy examination. A second discharge of this experiment from MOTA-2B has been completed and density measurements will be measured.

\section{REFERENCES}

1. F. A. Garner and J. M. McCarthy in "Reduced Activation Materials for Fusion Reactors, " ASTM STP 1047. American Society for Testing and Materials, Philadelphia (1990) pp. 19-29.

2. G. Piatti, D. Boerman and J. Heritier. Fusion Technology 1988. Proceedings of 15 th Symposium on Fusion Technology (1989), pp. $983-990$. 
THERMAL STABILITY OF MANGANESL-SIABILITEDS STAINIIESS STELISS -- R. L. Klueh and E. A. Kenik

\section{OBJECTIVE}

Induced radioactivity in the first-wall and blanket-structure materials of fusion reactors will make these components highly radioactive after their service lifetime, leading to difficult radioactive wastemanagement problems. One way to minimize the disposal problem is to use structural materials in which radioactive isotopes induced by irradiation decay quickly to levels that allow simplified disposal techniques. We have assessed the feasibility of developing such austenitic stainless steels.

\section{SUMMARY}

Previous work on a series of experimental high-manganese reduced-activation austenitic stainless steels demonstrated that they had improved tensile properties relative to type 316 stainless steel in both the annealed and $20 \%$ cold-worked conditions. Steels were tested with an Fc-20Mn-12C.r-0.25C (in weight percent) base composition, to which various combinations of 'Ti, W, V, P, and B were added. Tensile tests have now been completed on these steels after thermal aging at $600^{\circ} \mathrm{C}$. Thermal stability varied with composition, but the alloys were as stable or more stable than rype 316 stainless steel. The strength of the annealed steds increased slightly after aging $10.5000 \mathrm{~h}$, while a strength decrease occurred for the cold worked steel. In both conditions, a steel containing a combination of all the alloying elements was most stable and had the best strength after thermad aging $500(\mathrm{~h}) \mathrm{h}$ at $600^{\circ} \mathrm{C}$. Despite having much higher strength than 316 stainless sleel alter aging, the ductility of the strongest experimental alloy was still as good as that of 316 stainless steel.

\section{PROGRESS AND STATUS}

\section{Introduction}

Conventional structurad adloys used for components of a fusion reactor will become highly radioactive during the service lifetime, making the disposad of the components a difficult nuclear waste problem. This has led to a proposal to develop reduced-activation alloys [1]. Such alloys would contain only elements in which the induced radioactivity would decaly much more rapidly than in conventional alloys. Common alloying elements that must be eliminated from reduced-activalton alloys include $\mathrm{Ni}, \mathrm{Mo}, \mathrm{Cu}$, $\mathrm{Nb}$, and $\mathrm{N}$.

Nickel-stabilized austenitic stainless steels have long been considered potential structural alloys for fusion reactors. Therefore, a reduced-activation austenitic stainless stecl substitute was sought. There have been several programs to develop such a steel [2-6], including a progran at Oak Ridge National Laboratory (ORNL) $[4,8,9]$.

The ORNL program sought to develop reduced-activation or fast induced-radioactivity decay (FIRD) austenitic stainless steels using manganese as a replacement for nickel. It wats recognized that this could prove difticult, beciuse minganese is not as strong an austenite stabilizer as nickel and because the metallurgical effects of nickel and manganese in the alloy may not otherwise be expuivalent [4]. The first step was the determination of a "modified Schaefler diagram" for high-manganese alloys [8]. This diagram differed significantly from the standard Schaefler diagran determined for high-nickel steels with small amounts of inanganese. The inodified diagran was used to pick a composition range where stable austenite, high-manganese $\mathrm{Fe}-\mathrm{Mn}-\mathrm{Cr}-\mathrm{C}$. alloys should be obtained. 
Based on the original work [8], a nominal Fe-20Mn-12(r-0.25C. steel was chosen as a base composition. This composition was then alloyed for strength and iradiation resistance by adding various combinations of $\mathrm{Ti}, \mathrm{W}, \mathrm{V}, \mathrm{P}$, and $\mathrm{B}$. Seven Fe-Cr-Mn-C. steels with various combinations of Ti, W, V, B, and P were examined and shown to have strength and ductility ats g(x)d or better than type 316 stainless steel [9].

After the program began, the high-manganese stecls were concluded to pose potential safety problems in a fusion reactor first wall, and they no longer have a high priority in the U. S. fusion program.

Although the development program has been discontinued, knowledge obtained in the program could be of interest for the fusion program in the future and for other applications. For the record, therefore, we intend to publish the information obtained. In this paper, microstructural observations and tensile property determinations were made on the seven solute-modified alloys after thermally aging for $5000 \mathrm{~h}$ at $600^{\circ} \mathrm{C}$.

\section{Experimental Procedure}

Seven experimental alloys, including the base composition, were obtained in the form of 600 -g vacuum arc-melted button heats. Table 1 lists alloy compositions and designations. By making elemental additions to the base composition (designated MnCrC), alloys were obtained with titanium (MnCrCTi), lungsten (MnCrCW), a combination of titanium and tungsten (MnCrCTiW), and combinations of these elements with V, B, and P (MnC.CliBP, MnCrCTivBP, and MnCrCTiWVBP). Nominal levels of Ti, $W, V, B$, and $P$ of $0.1,1,0.1,0.005$, and 0.03 weight pereent, respectively, were sought. Actual compositions are given in Table 1.

Alloys were cast into ingots with a reclangulat cross section ol $12.7 \mathrm{~mm}$ by $2.5 .4 \mathrm{~mm}$ and $152 \mathrm{~mm}$ in length. The ingots were hot rolled at $1050^{\circ} \mathrm{C}$ 10 a thickness of approximatcly $6.4 \mathrm{~mm}$. After homogenizing for $5 \mathrm{~h}$ at $1200^{\circ} \mathrm{C}$, the sleel was cold rolled in five stages 10 0.76-mm-thick sheet. Between each stage, the steel was annealed $1 \mathrm{~h}$ at $1150^{\circ} \mathrm{C}$. The sheet was finished in the $20 \%$ coldworked condition.

Tensile specimens with gage lengths parallel to the rolling direction and a reduced gage section 20.3-mm long by $1.52-\mathrm{mm}$ wide by $0.76-\mathrm{mm}$ thick were thermally aged. They were aged for $500,1000,2500$, and $5000 \mathrm{~h}$ at $600^{\circ} \mathrm{C}$ in the $20 \%$ cold-worked condition and after a solution anneal of $1 \mathrm{~h}$ at $1050^{\circ} \mathrm{C}$. Tests were at $600^{\circ} \mathrm{C}$ in vacuum on a $120-\mathrm{kN}$-capacity Instron universal testing machine at a crosshead speed of $8.5 \mathrm{~mm} / \mathrm{s}$ (a nominal strain rate of $4.2 \times 10^{-4} / \mathrm{s}$ ).

Microstructures were exanined by optical and transmission electun microscopy. Analytical electron microscopy was performed on foils and on carbon exuaction replicas in Philips EM 400T/FEG and CM30 microscopes equipped with EDAX $9100 / 70$ or 9900 energy dispersive $x$-ray analyzers, respectively. Some information on the composition of precipitates observed after aging $5000 \mathrm{~h}$ at $600{ }^{\circ} \mathrm{C}$ was previously published [10]

\section{RESULTS AND DISCUSSION}

\section{Microstructures}

The microstructures of the unaged stecls were previously presented [9]. Adelition of the alloying elements to the MnCrC base composition affected the grain size and the amount of precipitate present. All of the steels with titanium had an estimated ASTM grain size number 8 , compared 10.3 for MnC $\mathrm{rC}$ and 4 for MnCrCW. The annealed 316 SS had ASTM grain size 4 [9].

After the $1050^{\circ} \mathrm{C}$ anneal, no precipitate was detected in $\mathrm{MnCrC}$ and $\mathrm{MnCrCW}$--the stecls without titanium [9]. Steels with titanium contained $\mathrm{MC}$ precipitates after annealing at $1050^{\circ} \mathrm{C}$ [9]. The MnCrCTiVBP and MnCrCTiWVBP also contained $\mathrm{M}_{23} \mathrm{C}_{6}$. Most of the MC occurred in the matrix, although some grain boundary MC was detected in the MnCrCTiBP, MnCrCTiVBP, and 
Table 1. Fe-Cr-Mn Alloys Tested

\begin{tabular}{lcccccccc}
\hline \multirow{2}{*}{ Alloy } & \multicolumn{7}{c}{ Composition, wt\% } \\
\cline { 2 - 8 } \multicolumn{1}{c}{ Designation } & $\mathrm{Cr}$ & $\mathrm{Mn}$ & $\mathrm{C}$ & $\mathrm{Ti}$ & $\mathrm{W}$ & $\mathrm{V}$ & $\mathrm{P}$ & $\mathrm{B}$ \\
\hline $\mathrm{MnCrC}$ & 11.83 & 20.51 & 0.24 & & & 0.01 & 0.003 \\
$\mathrm{MnCrCTi}$ & 11.73 & 20.50 & 0.25 & 0.11 & 0.09 & 0.01 & 0.003 \\
$\mathrm{MnCrCW}$ & 11.80 & 20.46 & 0.23 & & 0.83 & 0.01 & 0.004 \\
$\mathrm{MnCrCTiW}$ & 11.71 & 21.13 & 0.25 & 0.12 & 0.77 & 0.01 & 0.003 \\
$\mathrm{MnCrCTiBP}$ & 11.85 & 20.50 & 0.24 & 0.10 & & 0.01 & 0.034 & 0.005 \\
MnCrCTiVBP & 11.84 & 20.82 & 0.22 & 0.10 & & 0.10 & 0.033 & 0.005 \\
MnCrCTiWVBP & 11.70 & 20.39 & 0.25 & 0.10 & 1.08 & 0.10 & 0.027 & 0.005 \\
\hline
\end{tabular}

Balance iron 
MnCrCTiWVBP. Grain boundary precipitates in the latter two steels were mainly $\mathrm{M}_{23} \mathrm{C}_{6}$. The coldworked steels also contained precipitates that remained from intermediate anneals at $1150^{\circ} \mathrm{C}$ during deformation [9].

Thermal aging resulted in more precipitate formation. Optical microscopy (Fig 1) indicated that precipitation in the solution-annealed steels occurred primarily on grain boundaries [Fig. 1(a)]. For the cold-worked steels, considerable precipitation appeared to occur in the matrix on slip bands, although grain boundary precipitation was also observed [Fig. 1(b)].

Specimens aged $5000 \mathrm{~h}$ were examined by electron microscopy. Solution-annealed steels were characterized by extensive grain boundary precipitation, as seen in Fig. 2 for the replica from $\mathrm{MnCrCW}$. Little matrix precipitation occurred in steels without titanium. Although the grain boundary precipitate for this steel was $\mathrm{M}_{23} \mathrm{C}_{6}$, steels with titanium also contained coarse TiC, which may not have completely dissolved during the anneal at $1050^{\circ} \mathrm{C}$. Figure 3 shows grain boundary and matrix precipitation in MnCrCTi; matrix precipitation was primarily MC. When vanadium was added (MnCrCTiVBP), there was a slight increase in MC precipitate. (Fig. 4), compared to alloys without vanadium. The most intergranular precipitation was observed for MnCrCTiWVBP, which, as discussed below, was the strongest steel and showed the greatest resistance to thermal aging.

Matrix precipitation was often observed to lie in parallel straight lines (Fig. 4). This was also observed after the $1050^{\circ} \mathrm{C}$ anneal before aging and was attributed to grain boundary migration during annealing [9]. Examination of micrographs of the aged steel indicates that lines of precipitate within a given grain often cross and are at angles to the grain boundaries, suggesting that precipitation may be occurring on preferential crystallographic planes.

Some $\mathrm{M}_{23} \mathrm{C}_{6}$ was found in the matrix after aging, and it often appeared to contain large amounts of titanium (up to 10\%) [10]. However, on closer examination it was found that this $\mathrm{M}_{23} \mathrm{C}_{6}$ had formed on Ti-rich MC particles, resulting in a Ti-rich core with an outer shell that contained fittle titanium [Fig. 5(a)]. It was concluded that pre-existing TiC particles (those not completely dissolved during the solution anneal) served as heterogeneous nucleation sites for the $\mathrm{M}_{23} \mathrm{C}_{6}$ [10]. Another example of this phenomenon is seen in Fig. 5(b). Here, a coating of $\mathrm{M}_{23} \mathrm{C}_{6}$ has formed on the TiC and then smaller $\mathrm{M}_{23} \mathrm{C}_{6}$ particles nucleated on, or near to, or grew out of this precipitate. From an examination of the replica, it is not clear whether the precinitates are attached to the $\mathrm{M}_{23} \mathrm{C}_{6}$ that coats the $\mathrm{TiC}$.

Examination of foil specimens of the annealed material indicated that TiC particles often are surrounded by dislocations, and the $\mathrm{M}_{23} \mathrm{C}_{6}$ particles could have nucleated on them, in addition to coating the TiC particles.

Cold-worked specimens showed extensive precipitation in both the grain boundaries and matrix, as shown for the MnCrCTiVBP in Fig. 6. Much of the matrix precipitate appeared to be aligned along crystallographic planes, as seen in the optical microstructures (Fig 1). Just as for the annealed steels, precipitates consisted of $\mathrm{M}_{23} \mathrm{C}_{6}$ and $\mathrm{MC}$, the latter appearing in the steels that contained titanium. No Laves phase was found in either the annealed or cold-worked steels after thermal aging.

Tensile hehavior

Figures 6 through 9 show the tensile behavior of the unaged and aged solution-annealed (Figs. 6 and 7) and cold-worked (Figs. 8 and 9) steels. Yield stress and total elongation data are shown for the seven different steels as a function of aging time, along with data for type 316 stainless steel (316 SS), which was tested in the same condition as the high-manganese steels.

The yield stress of all the solution-annealed steels was higher after aging $5000 \mathrm{~h}$ than in the unaged condition [Fig. 6(a)]. All of the steels were stronger than type 316 SS. The manganese steels fell into two categories: those with and those without titanium. Those with titanium were considerably stronger than those without, which included the base composition and the composition with just tungsten added. These latter two steels were only slightly stronger than 316 SS. The five steels with titanium were considerably stronger.

Although lungsten by itself had little effect on the yield stress of the solution-annealed base composition, tungsten in combination with the other alloying elements was effective in strengthening the steels. The MnCrCTiWVBP steel, which contains tungsten in combination with all the other 

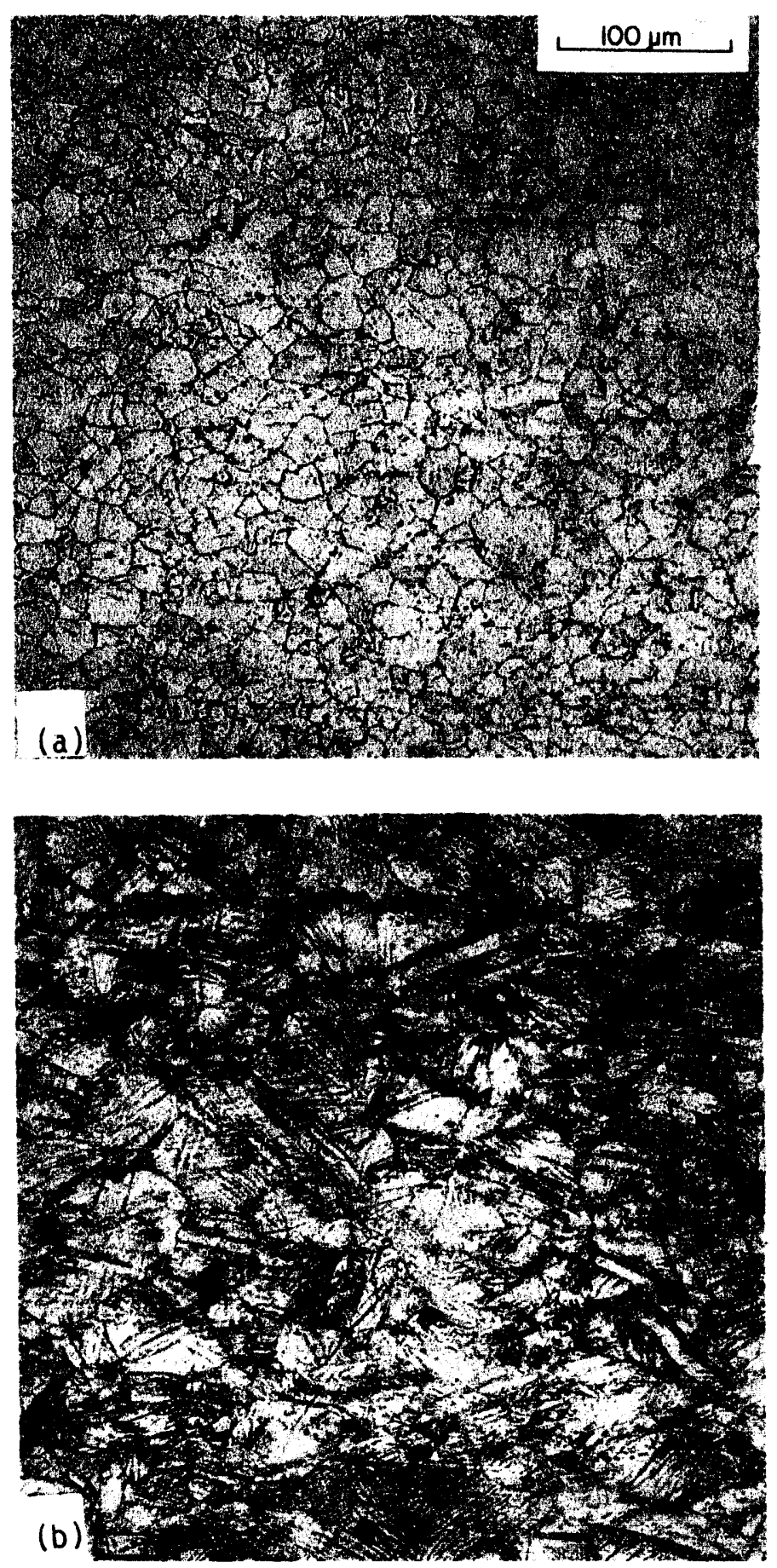

Fig. 1. Optical microstructure of the MnCrCTi alloy in the (a) annealed and (b) cold-worked conditions after thermally aging $5000 \mathrm{~h}$ at $600^{\circ} \mathrm{C}$. 


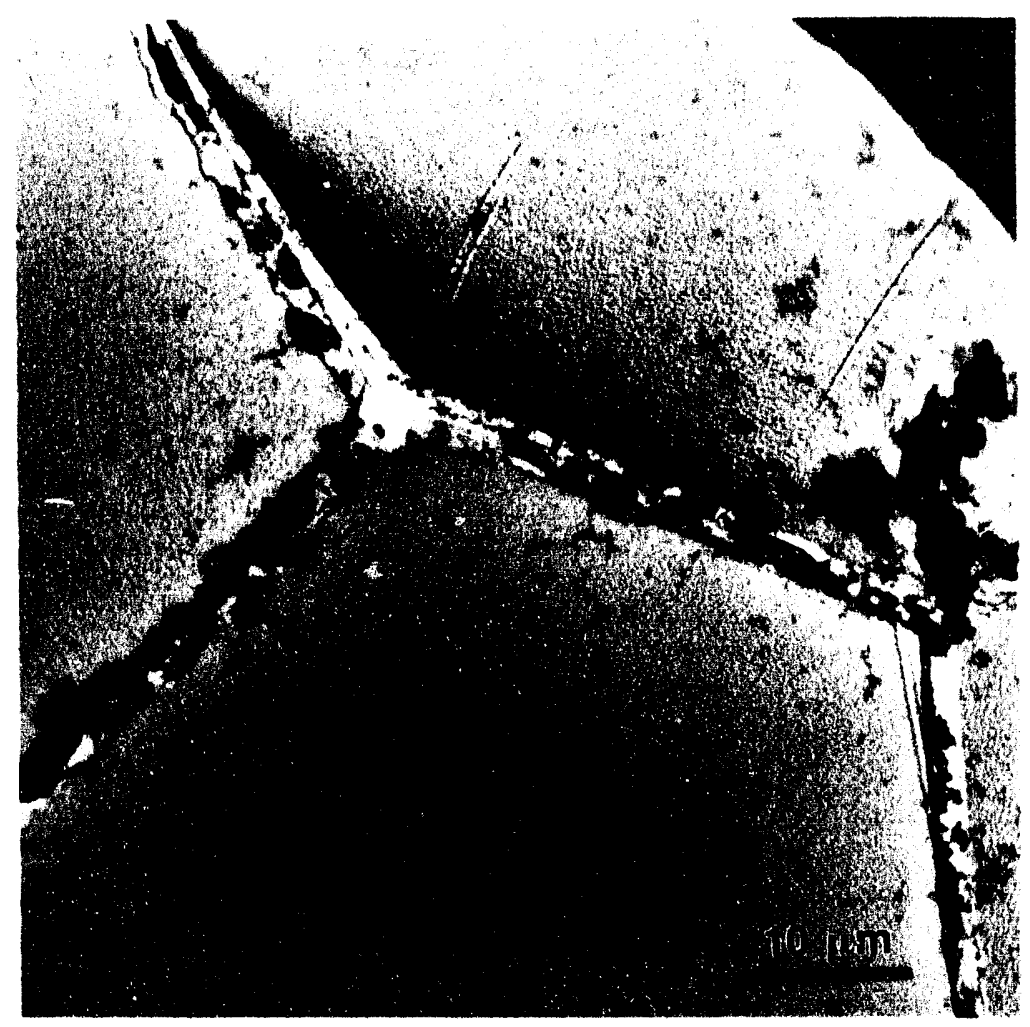

Fig. 2. Extraction replica of the annealed $\mathrm{MnCrCW}$ alloy after thermally aging $5000 \mathrm{~h}$ at $600^{\circ} \mathrm{C}$.

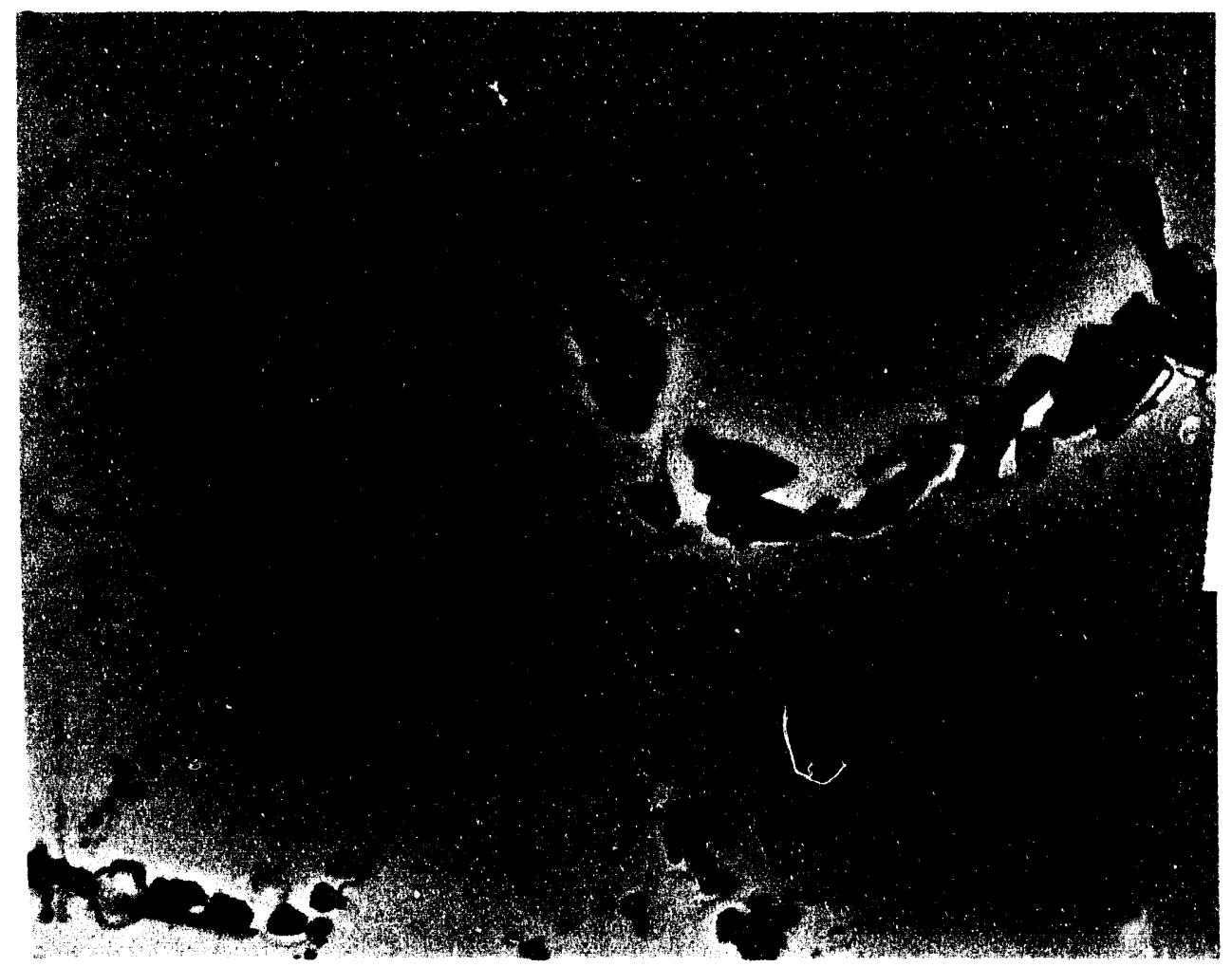

Fig. 3. Extraction replica of the annealed $\mathrm{MnCrCTi}$ alloy after thermally aging $5000 \mathrm{~h}$ at $600^{\circ} \mathrm{C}$. 


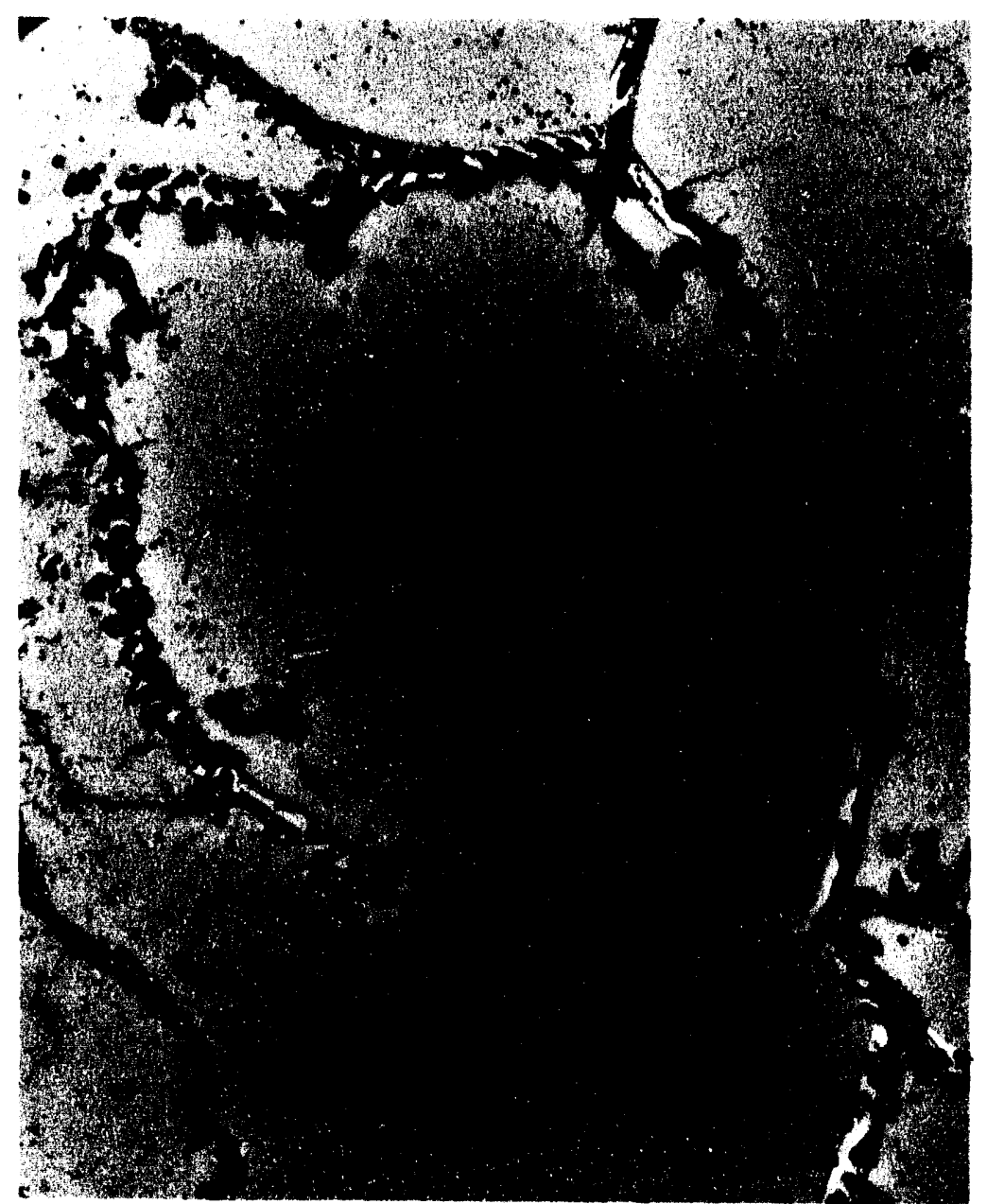

Fig. 4. Extraction replica of the annealed MnCrCTiVBP alloy after thermally aging $5000 \mathrm{~h}$ at $600^{\circ} \mathrm{C}$. 

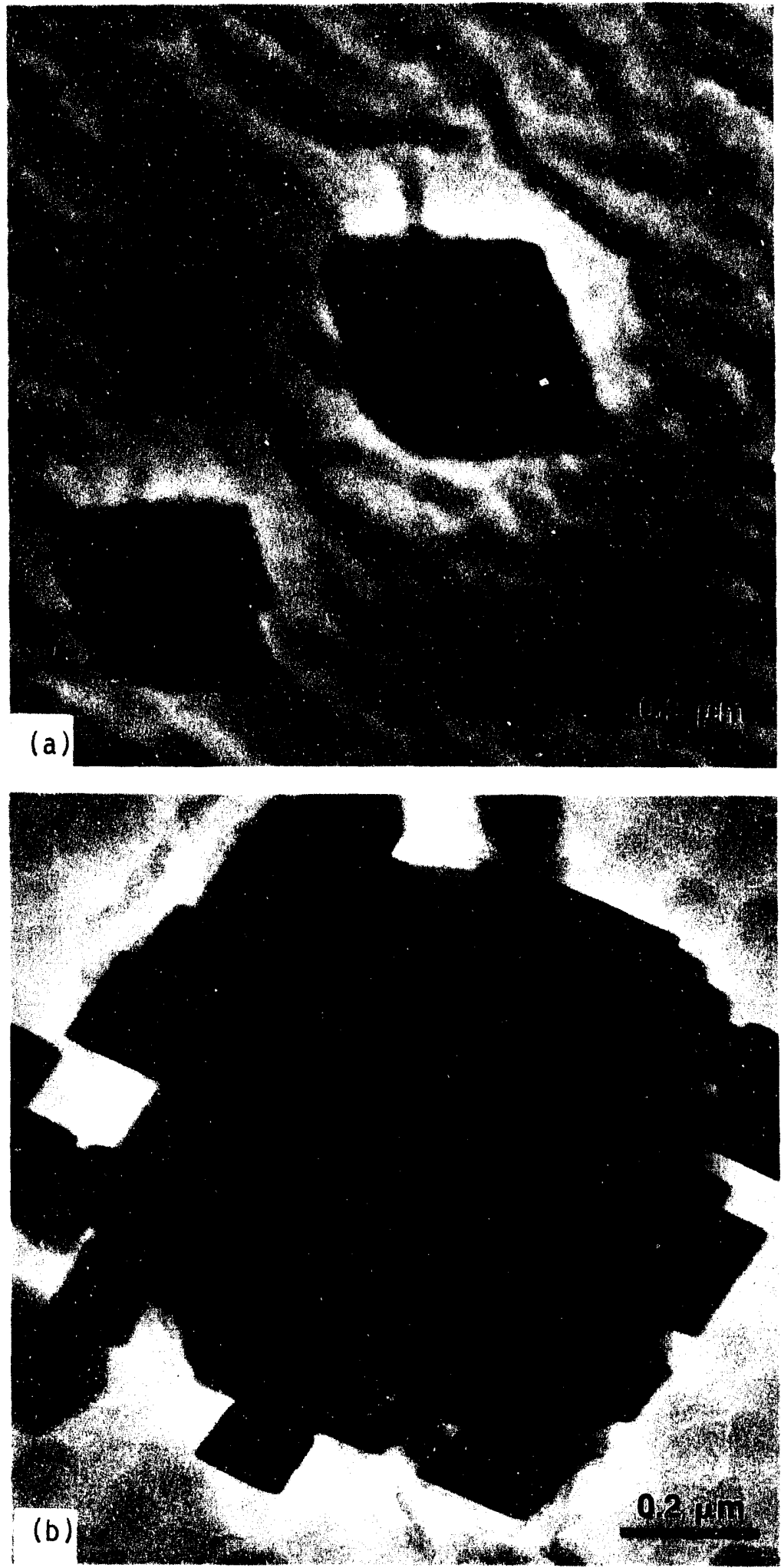

Fig. 5. Extraction replicas from annealed MnCrCTiVBP alloy after thermally aging $5000 \mathrm{~h}$ at $600^{\circ} \mathrm{C}$. (a) $\mathrm{M}_{23} \mathrm{C}_{6}$ precipitate coating on a TiC particle, and (b) a coated particle surrounded by other $\mathrm{M}_{23} \mathrm{C}_{6}$ precipitate particles. 


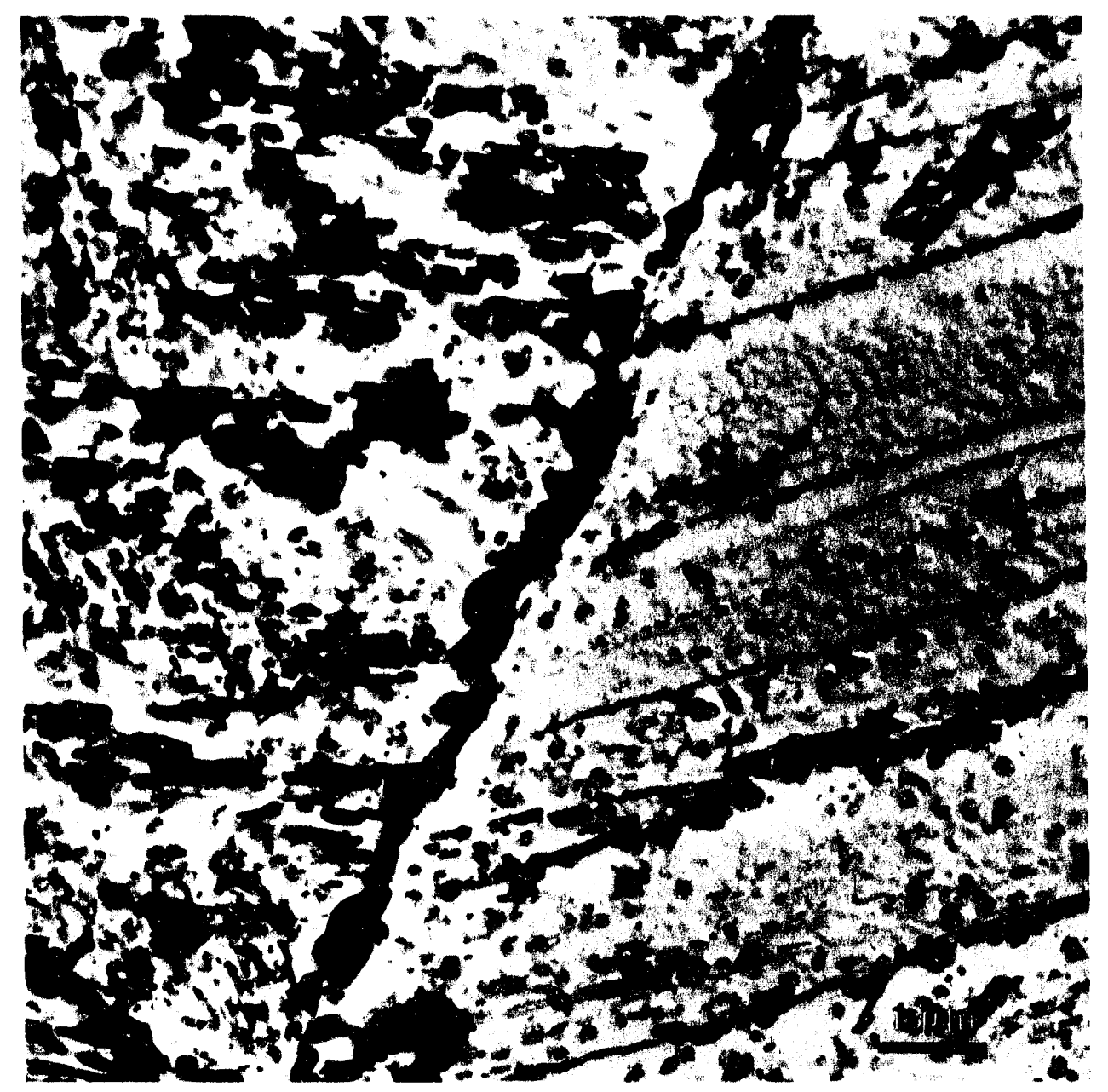

Fig. 6. Extraction replica of the cold-worked MnCrCTiVBP alloy after thermally aging $5000 \mathrm{~h}$ at $600^{\circ} \mathrm{C}$. 


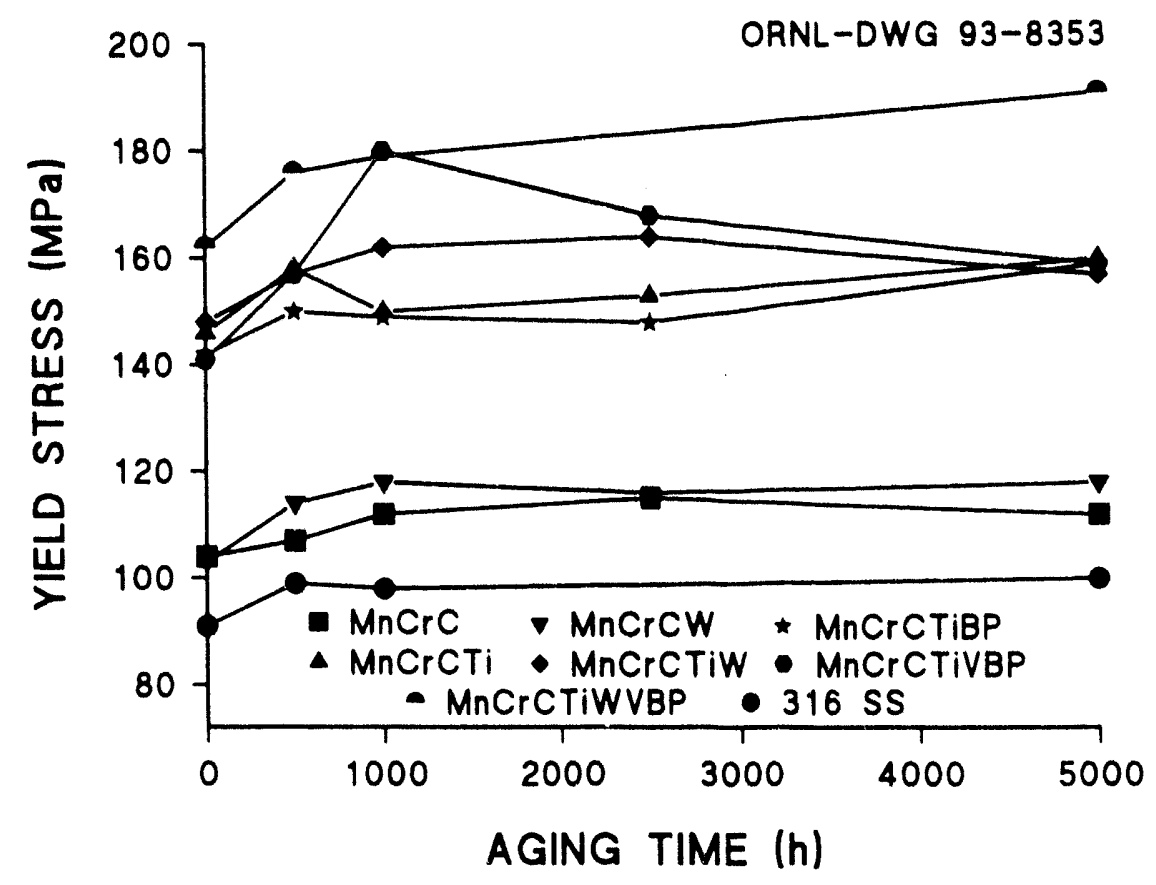

(a)

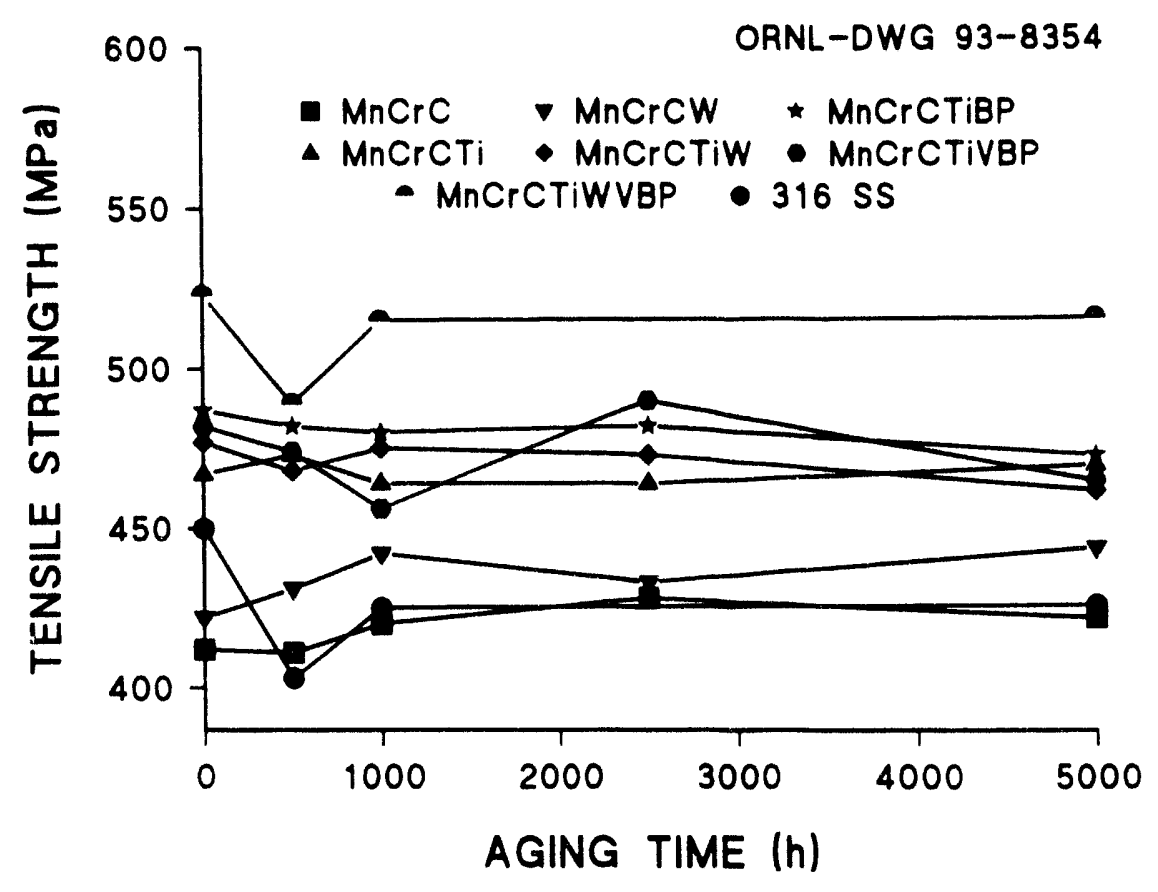

(b)

Fig. 7. (a) Yield stress and (b) ultimate tensile strength as a function of aging time for annealed highmanganese steels and type 316 stainless steel. 


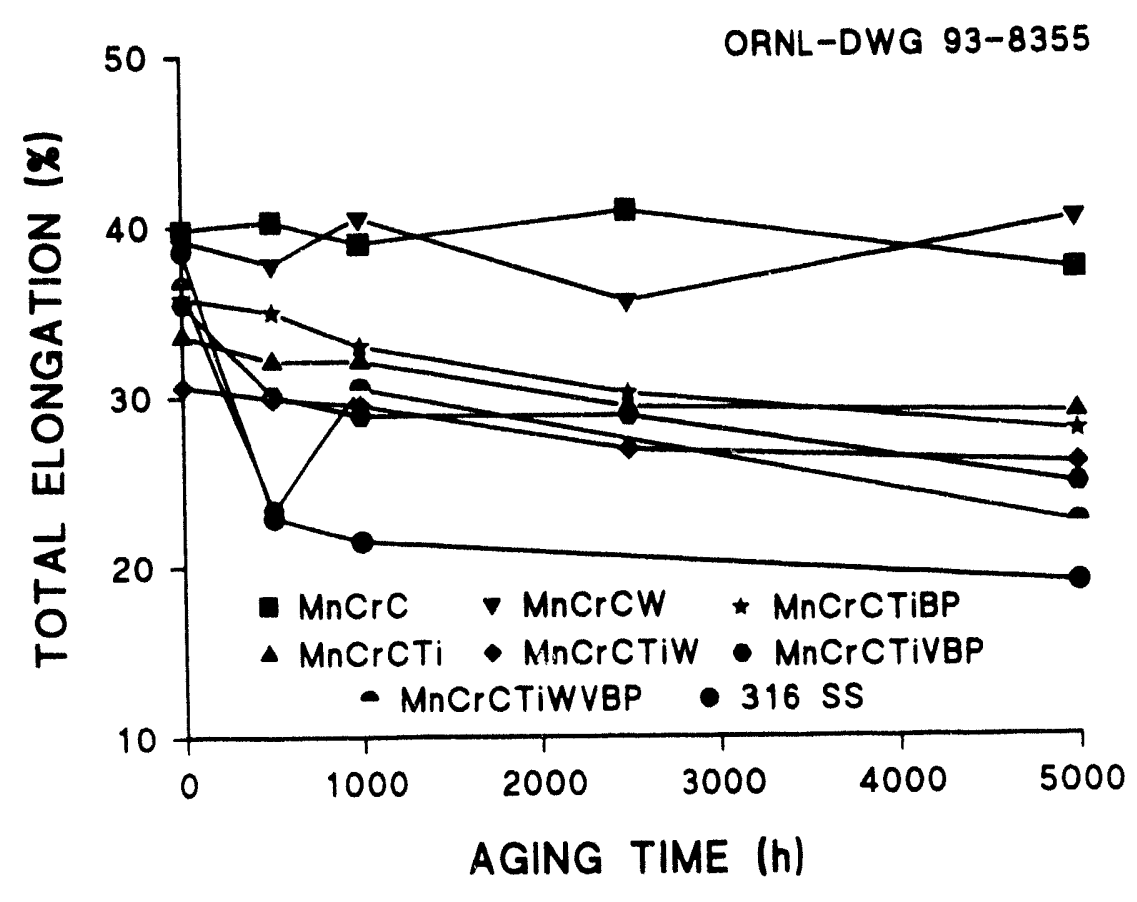

(a)

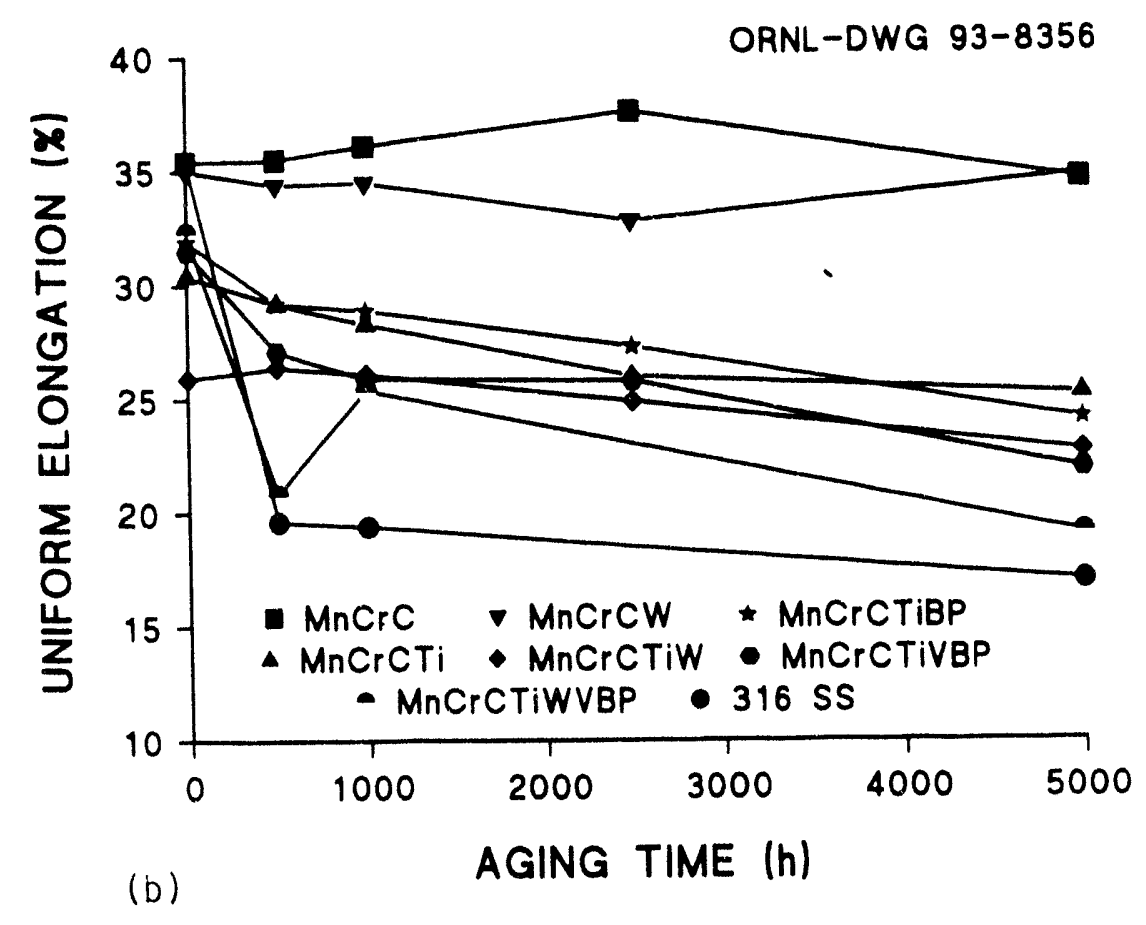

Fig. 8. (a) Total elongation and (b) uniform elongation as a function of aging time for annealed highmanganese steels and type 316 stainless steel. 

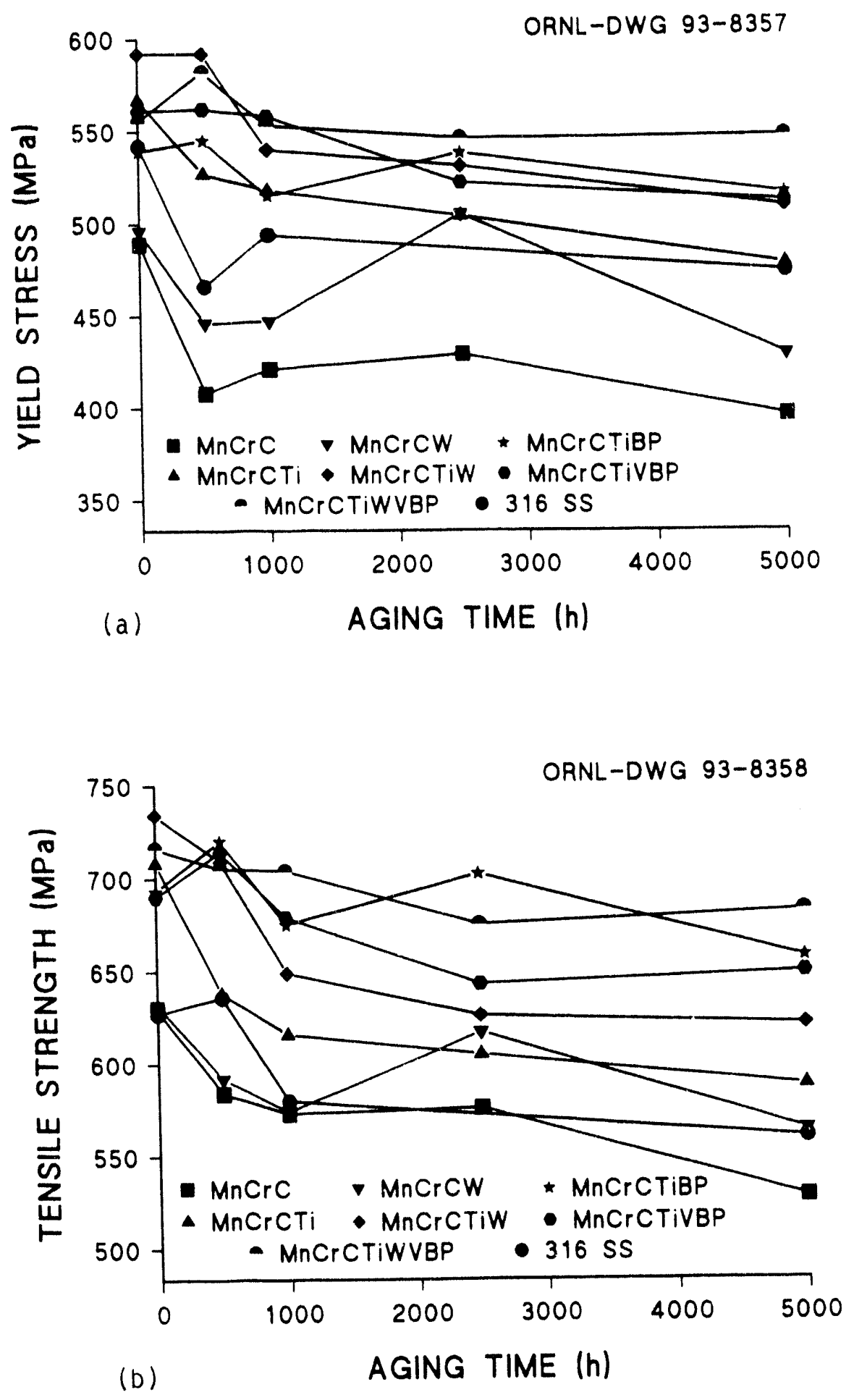

Fig. 9. (a) Yield stress and (b) ultimate tensile strength as a function of aging time for cold-worked highmanganese steels and type 316 stainless steel. 

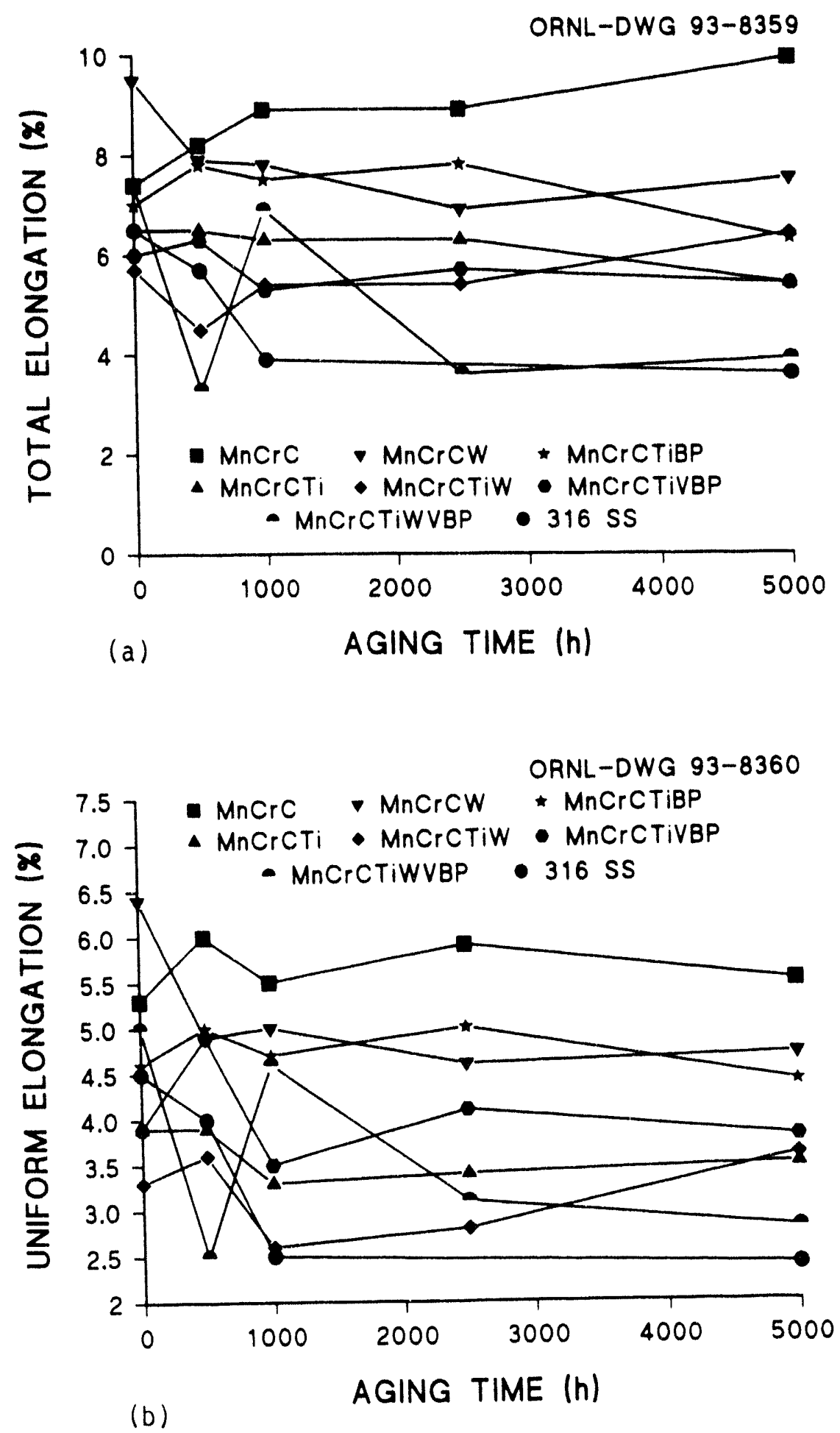

Fig. 10. (a) Total elongation and (b) uniform elongation as a lunction of aging time for cold-worked high-manganese steels and type 316 stainless steel. 
selected elements, is the strongest alloy in the unaged condition and after aging $5000 \mathrm{~h}$ at 600$)^{\circ} \mathrm{C}$. After the $5000 \mathrm{~h}$ age, this steel is substantially stronger than the other four titanium-containing steels, which have similar strengths.

Ultimate tensile strength behavior of the solution annealed steels was relatively similar to that for the yield stress [Fig. 6(b)], although it did not show the kind of strength increase observed for yield stress. In most cases, there was little change in strength between the annealed steel and the one aned $5000 \mathrm{~h}$. The differences between the manganese steels and the 316 SS were also not as large as they were for the yield stress.

The ductility of the solution-annealed steels, as measured by uniform [Fig. 7(a)] and total [Fig. 7(b)] elongation, indicated that the strongest manganese steels had the lowest ductility in both the unaged and aged conditions. Relative trends in uniform and tolal elongation were similar. The MnCrCTiWVBP, which was the strongest high-manganese steel, had the lowest ductility, while the $\mathrm{MnCrC}$ and MnCrCW, the weakest of these steels, had the highest ductility. The ductilities of the other five highmanganese steels fell between those extremes, similar to the observations on the yield stress. However, the ductilities of all the manganese-stahilized steels exceeded that for 316 SS, even though the 316 SS was the weakest steel.

Thermal aging of the cold-worked steels $10.500(0)$ h caused a decrease in the yield stress [T. ultimate lensile stress $\mid 1$ igg. $8(\mathrm{~b})]$ of all steels. Steels without titanium were again the weakest, and in this condition were weaker than $316 \mathrm{SS}$. The other tive high-manganese sleels were stronger than the 316 SS. Although the MnCrCliW sted was the strongest cold-worked steel in the unaged condition, the MnCrCTiWVBP was strongest after the $5000 \mathrm{~h}$ age, just as it was in the solution-annealed condition. The reason for dhis was that the MnCrCTiWVBP showed litte strength decrease after $5000 \mathrm{~h}$ at $6000^{\circ} \mathrm{C}$ :

Total [Fig. 9(a)] and uniform [Fig. 9(b)] elongations of the cold-worked steels reflected the strength behavior, with the strongest steels having the lowest ductility and vice versa. The MnCrCTiWVBP steel had the lowest ductility of the manganese-stabilized steels after the $50(0)$ h age. IIowever, the ductility was comparable to that of $316 \mathrm{SS}$, even though the $316 \mathrm{SS}$ had a substantially lower strength.

The results indicate that the high-manganese stecls are quite resistant to thermal aging at $600^{\circ} \mathrm{C}$. This is especially true for the MnCreTiWVBP in touth the annealed and cold-worked condition.

\section{SUMMARY AND CONCLUSIONS}

Thermal aging studies were conducted on a series of experimental, high-manganese austenitic stainless steels. An Fe-20Mn-12Cr-0.25C base composition was used, to which various combinations of titanium, tungsten, vanadium, boron, and phosphorus were added for improved strength. Aging was at $600^{\circ} \mathrm{C}$ to $5000 \mathrm{~h}$ on the steels in the solution-annealed and $20 \%$ cold-worked conditions. Results were compared with type 316 SS.

The yield stress of all the high-manganese steels in the solution-annealed condition increased with thermal aging, and the strength of the steels before and after aging exceeded that for 316 SS. Despite the greater surength, the tolat elongalion of the manganese steels also exceeded that for 316 SS. Coldworked steels showed a decrease with aging time at $600^{\circ} \mathrm{C}$. All but two of the experimental cold-worked steels had yield stresses that exceeded that for 316 SS. The ductility of all of the cold-worked highmanganese steels wass as goxd or better than that for $316 \mathrm{SS}$.

In both the solution-annealed and cold-worked conditions, an Fe-20Mn-12Cr- $0.25 \mathrm{C}-1 \mathrm{~W}-0.03 \mathrm{P}-0.005 \mathrm{~B}$ steel was most stable. It showed the most increase in strength in the solution-annealed condition and the smallest loss of strength in the cold-worked condition. The maintenance of strength was accompanied by excellent ductility. 


\section{REFERENCES}

1. R. W. Conn et al., Banel Beport on Low Activation Materials for Fusion Anplications, UCL.A Report PPG 728, University of California at Los Angeles, June 1983.

2. E. Ruedl, D. Rickerhy, and T. Sasaki, Eusion Technology, Vol. 2, p. 1029, Pergamon Press, London, 1984.

3. E. Ruedl and T. Sasaki, Jourmal of Nuclear Materials, Vol. 122 \& 123, 1984, pp. 794-798.

4. R. L. Klueh and E. E. Bloom, Optimizing Materials for Nuclear Applications, F. A. Garner, D. S. Gelles, and F. W. Wiffen, Eds., The Metallurgical Society, Inc., Warrendale, Pennsylvania, 1985, pp. 73-8.5.

5. H. R. Brager, F. A. Ganner, D. S. Cielles, and M. L. Humilton, Lourmal of Nuclear Materials, Vol. $133 \& 134,1985, \mathrm{pp} .90 \%-911$.

6. A. H. Bott, F. B. Pickering, and (i. J. Butterworth, Journal of Nuclear Materials, Vol. 141-143, 1986, pp. 1088-1096.

7. M. Tamura, H. Hayakawa, M. Tanimura, A. Ilishinuma, and T. Kondo, Loumal of Nuclear Malteriads, Vol.141-143, 1986, pp. 1067-1073.

8. R. L. Klueh, P. J. Maziats, and E. A. Lee, Mater Sci. Eing, Vol. 102, pp. 115-124.

9. R. L. Klueh and P. J. Maziasz, Maler. Sci. Eng, vol. A127 (1990) pp. 17-31.

10. E. A. Kenik, P. J. Maziasz, and R. L. Kluch, Proceedings of the 47in Annual Meeting of the Electron Microscopy Society of America, Ed., G. W. Bailey (San Francisco, 1989) pp. 284-285. 
COMPARISON OF MICROSTRUCTURAL. EVOLUTION IN REACTOR-IRRADIATED AUSTENITIC STAINLESS STEELS WITH AND WITHOUT SPECTRALLY TAILORING -- S. Jitsukawa, T. Sawai, K. Shiba, S. Hamada and A. Hishinuma (Japan Atomic Energy Research Institute)

\section{OBJECTIVE}

The objective of this work is to evaluate the microstructural data so far obtained through the USJapan collaborative program using HFIR and ORR and examine the effect of spactrally tailoring conducted in ORR experiment by comparing the microstructural evolution in the same set of austenitic stainless steels irradiated in HFIR and ORR.

\section{SUMMARY}

The effects of He/dpa ratio on swelling behavior were examined on three austenitic stainless steels. Materials were solution-annealed JPCA and two low carbon containing alloys ( $\mathrm{C}$ and $\mathrm{K}$ ) modified with titanium and niobium. These steels were neutron-irradiated in ORR and HFIR with and without spectrally tailoring, respectively. Achieved damage level was $7.4 \mathrm{dpa}$ in ORR irradiation with average He/dpa of about $21 \mathrm{appm} / \mathrm{dpa}$. In case of HFIR irradiation, they were $33 \mathrm{dpa}$ and $76 \mathrm{appm} / \mathrm{dpa}$, respectively. Alloy to alloy variation and temperature dependence of swelling behavior are far more distinctively detected in ORR irradiation than in HFIR irradiation, in spite of the lower damage level of ORR irradiation. In the case of ORR-irradiation, JPCA exhibited small swelling values of $<0.01$ and $0.03 \%$ at 603 and $673 \mathrm{~K}$, respectively, while a low carbon alloy $\mathrm{K}$ showed relatively larger swelling; $0.2 \%$ at $603 \mathrm{~K}$ and $0.6 \%$ at $673 \mathrm{~K}$. Swelling of JPCA and $\mathrm{K}$ irradiated in HFIR were almost same values of $0.2 \%$ at temperatures of 573 and $673 \mathrm{~K}$. Number densities of cavities in HFIR-irradiated alloys were larger than those observed in ORR by one to two orders. On the other hand, number densities and sizes of dislocation loops produced by ORR irradiation were two to five times as large as those by HFIR irradiation. These facts suggest that in ORR condition with closer He/dpa to that of fusion, mutual annihilation rate of point defects was reduced and then bias driven cavity growth might be enhanced compared with HFIR condition.

\section{PROGRESS AND STATUS}

\section{Introduction}

Materials for the first wall of blanket structures of a fusion reactor will be exposed to high-energy fusion neutrons with $14 \mathrm{MeV}$ peak. Main damages induced in materials irradiated by the fusion neutrons, consist of displacement damage and generation of transmutans. To evaluate the irradiation effects of fusion neutrons on material behavior, fission reactors have been often used, because we have no high energy neutron sources for irradiation experiments. However, there are big differences between fusion and fission neutron damages in terms of primary knock-on energies and gaseous and solid transmutants by transmutation reactions that strongly depend on neutron energy. Among such differences, the ratio of $\mathrm{He}$ in appm and displacement damage production rates (He/dpa ratio) has been demonstrated to affect strongly the microstructural evolution in austenitic alloys and then it has been considered as the most important factor for evaluating the differences[1].

For evaluation of the He/dpa effects on fusion materials, a spectrally tailored irradiation in the Oak Ridge Research Reactor (ORR) by the U.S.-Japan Collaborative Experiment on Fusion Materials was planned and has been conducted to accomplish typical He/dpa ratio of fusion neutron environment for austenitic alloys [2]. This study is a continuation of the previous ORR works $[3,4]$ and to understand the the 
effects of He/dpa ratio on microstructural development including the compositional effects, three kinds of austenitic steels were irradiated by spectrally tailored ORR capsules and discussed compared with the results by irradiated in the High Flux Isotope Reactor (HFIR) producing larger amount of He.

\section{Experimental procedure}

Specimens used were Japanese Prime Candidate Alloy (JPCA), a titanium and niobium modified lowcarbon alloy ( $\mathrm{K}$ alloy) and a titanium -modified low-carbon alloy ( $\mathrm{C}$ alloy) in solution annealed condition. Nominal chemical compositions of alloys are shown in table 1. Transmission electron microscope (TEM) specimens of those were irradiated in the ORR-MFE-7J capsule at temperatures of 603 and $673 \mathrm{~K}$ with fluxes of approximately $2 \times 10^{18} \mathrm{n} / \mathrm{m}^{2} \mathrm{~s}$ for both thermal and fast $(E>0.1 \mathrm{MeV})$ neutrons to a damage level of 7.4 dpa with a He concentration of about 155 appm (for JPCA) $[5]$ and JPCA and $\mathrm{K}$ were irradiated in HFIR target capsules with fluxes of $1.4 \times 10^{19} \mathrm{n} / \mathrm{m}^{2} \mathrm{~s}$ of fast and $2.8 \times 10^{19} \mathrm{n} / \mathrm{m}^{2} \mathrm{~s}$ of thermal to a damage level of $33 \mathrm{dpa}$ with He concentration of about $2500 \mathrm{appm} / 6 \mid$. After the irradiation, specimens were perforated in a Tenupol twin jet electro-polishing unit for transmission electron microscopy. A JEM2000FX TEM operated at $200 \mathrm{keV}$ was used for microstructural observation at the areas with thickness of ranging from 100 to $200 \mathrm{~nm}$. Foil thickness was evaluated jy improved contamination spot separation (CSS) method $[7,8\}$ for ORR data. Some of the HFIR data already published $|6,9|$, where CSS error lead to overestimation of thickness and, therefore, underestimation of volume concentration of microstructural features, were up-dated. Detailed experimental procedure are shown elsewhere[6,8].

Table 1 Chemical compositions of used materials

\begin{tabular}{ccccccccccccc}
\hline & $\mathrm{C}$ & $\mathrm{Si}$ & $\mathrm{Mn}$ & $\mathrm{P}$ & $\mathrm{S}$ & $\mathrm{Ni}$ & $\mathrm{Cr}$ & $\mathrm{Mo}$ & $\mathrm{Nb}$ & $\mathrm{Ti}$ & $\mathrm{B}$ & $\mathrm{N}$ \\
\hline JPCA & 0.06 & 0.50 & 1.77 & 0.027 & 0.005 & 15.6 & 14.2 & 2.3 & - & 0.24 & .0031 & .0039 \\
$\mathrm{C}$ & 0.02 & 0.51 & 1.56 & 0.017 & 0.007 & 15.6 & 15.4 & 2.4 & 0.08 & 0.25 & - & .0018 \\
$\mathrm{~K}$ & 0.02 & 0.48 & 1.46 & 0.015 & 0.005 & 17.6 & 18.0 & 2.6 & - & 0.29 & - & .004 \\
\hline
\end{tabular}

\section{Results}

Microstructure of JPCA, K and C alloys irradiated in a spectrally tailored MFE-7J capsule of the ORR, and those of JPCA and K alloy irradiated in the JP- 1 and 3 capsules of the HFIR are shown in Fig. 1. Cavities formed by HFIR irradiation were finer than those produced during ORR irradiation.

Figures 2 (a) to (c) show cavity microstructural components in alloys irradiated in ORR at 603 and $673 \mathrm{~K}$ and irradiated in HFIR at 573 and $673 \mathrm{~K}$. Average cavity diameters $\left(\mathrm{d}_{\mathrm{c}}\right)$ were about $6 \mathrm{~nm}$ for $\mathrm{K}$ and $\mathrm{C}$ alloys ORR-irradiated at 603 and $673 \mathrm{~K}$. The values were greater than that of JPCA irradiated in the ORR, and also of JPCA and K alloy irradiated in HFIR. Average cavity diameter of $3.5 \mathrm{~nm}$ formed during HFIR irradiation were almost constant for both JPCA and K alloy at temperatures of 573 and $673 \mathrm{~K}$. It should be noted that the average cavity diameter is usually affected by tiny but many bubbles and that the difference of bias-driven voids growth would be much more than the difference of average cavity size. The ratio of $d_{c}$ at lower and higher irradiation temperatures was highest in ORR-irradiated JPCA than other materials or irradiation conditions. 

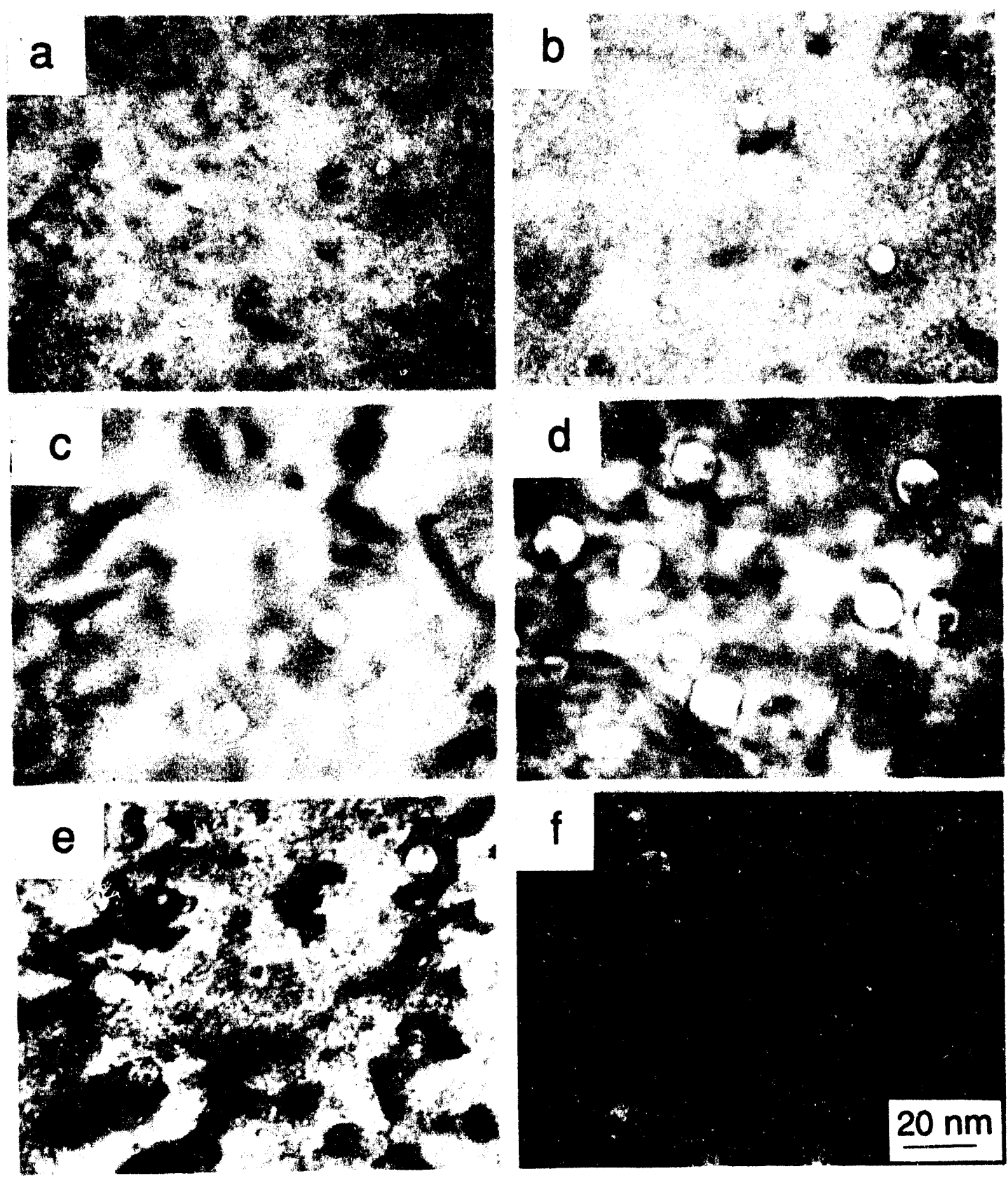

Fig. 1 Microstructure of ORR-irradiated JPCA(a, b), K(c, d) C(e,f) alloys and HFIR-irradiated $\mathrm{JPCA}(\mathrm{g}, \mathrm{h}), \mathrm{K}(\mathrm{i}, \mathrm{j})$ alloys. Irradiation temperature are $603 \mathrm{~K}$ for $\mathrm{a}, \mathrm{c}, \mathrm{e}, 673 \mathrm{~K}$ for b, d, f, h, j and 573K for $g$,i. 

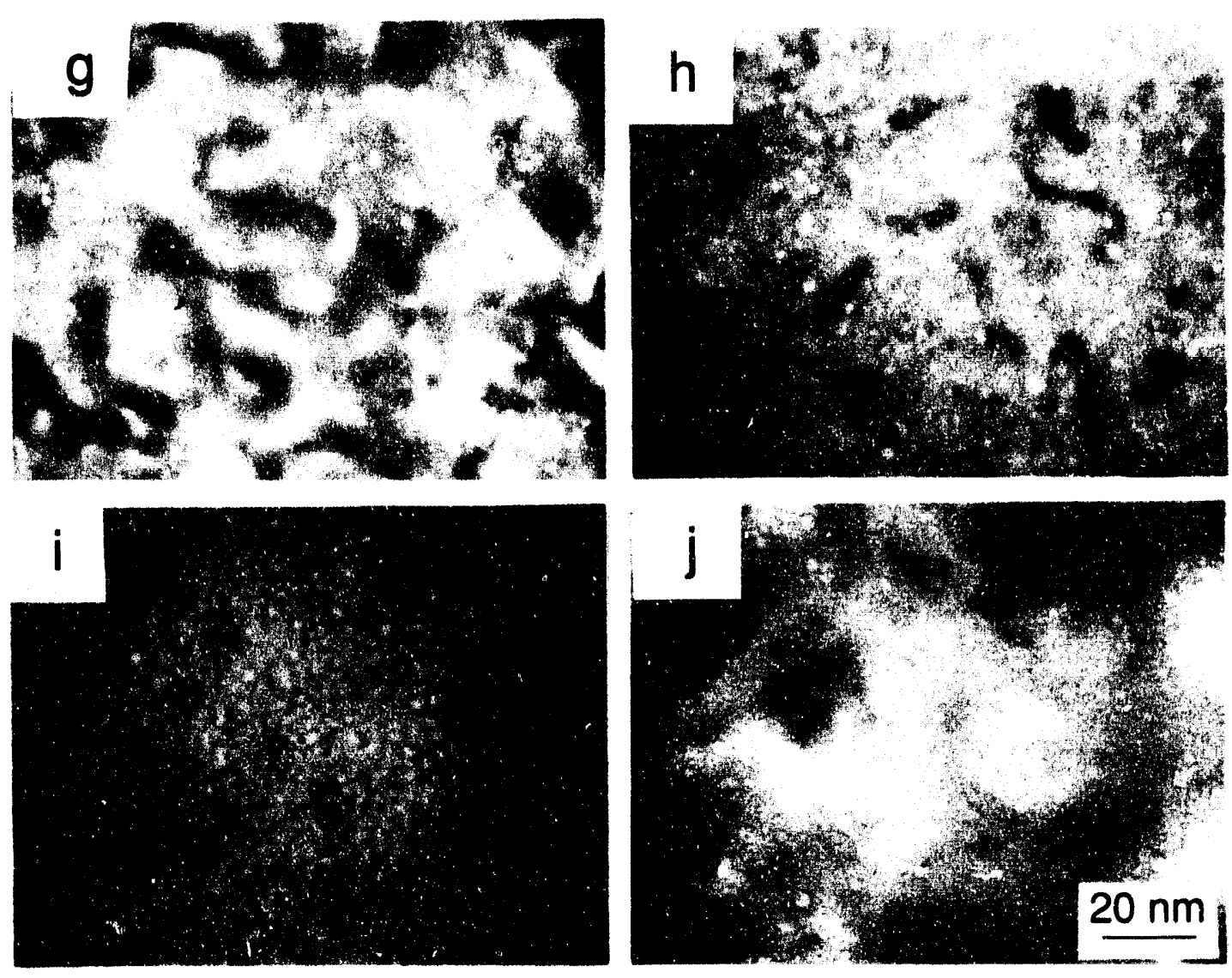

Fig. 1

(continued)

Number densities of cavities $\left(\mathrm{N}_{\mathrm{c}}\right)$ in the alloys irradiated in the HFIR were one to two orders higher than those produced by ORR irradiation. In ORR, JPCA exhibited higher $\mathrm{N}_{c}$ value of $4 \times 10^{22} / \mathrm{m}^{3}$ at a lower temperature of $603 \mathrm{~K}$ compared with other alloys. At high temperature $673 \mathrm{~K}$, however, the values were of about $1 \times 10^{22} / \mathrm{m}^{3}$ for all the alloys. On the other hand, HFIR irradiated JPCA and K alloy showed almost same $N_{c}$ of $4 \times 10^{23} / \mathrm{m}^{3}$ at $573 \mathrm{~K}$, and also same $N_{c}$ of $2 \times 10^{23} / \mathrm{m}^{3}$ for both alloys at $673 \mathrm{~K}$. Marked difference in $\mathrm{N}_{\mathrm{c}}$ between both alloys was only observed in ORR irradiation at lower temperature $603 \mathrm{~K}$.

Swelling for ORR irradiated $\mathrm{K}$ and $\mathrm{C}$ alloys were relatively large at higher temperature $673 \mathrm{~K}$. K alloy exhibited swelling value of $0.7 \%$ at temperatures of $673 \mathrm{~K}$ while JPCA exhibited much smaller values $(<0.04 \%)$. HFIR irradiation caused almost constant swelling of about $0.2 \%$ for both JPCA and $\mathrm{K}$ alloy at $573 \mathrm{~K}$. At higher temperature, swelling shows slight increase for $\mathrm{K}$ alloy and effectively no change for JPCA. Temperature dependence and alloy to alloy variations of swelling were larger for ORR irradiated specimens. 
Figures 2 (d) and (e) show average diameters $\left(D_{1}\right)$ and number densities $\left(N_{1}\right)$ of dislocation loops. Both $D_{1}$ and $N_{1}$ of ORR irradiated JPCA, $K$ and $C$ alloys tended to be larger than those of HFIR irradiated JPCA. Line dislocations were merely observed in these specimens. Microstructural parameters for precipitates were not quantitatively analyzed yet, however MC precipitations were observed for all the specimens examined. MC precipitates formed during irradiation in $\mathrm{K}$ and $\mathrm{C}$ alloys were rather coarser than those in JPCA after irradiation in the ORR.

Fig.2 Microstructural data of cavities ( $a, b$ and $c)$ and dislocation loops (d and $e$ ) in ORR- and HFIR irradiated JPCA, $\mathrm{K}$ and $\mathrm{C}$ alloys.

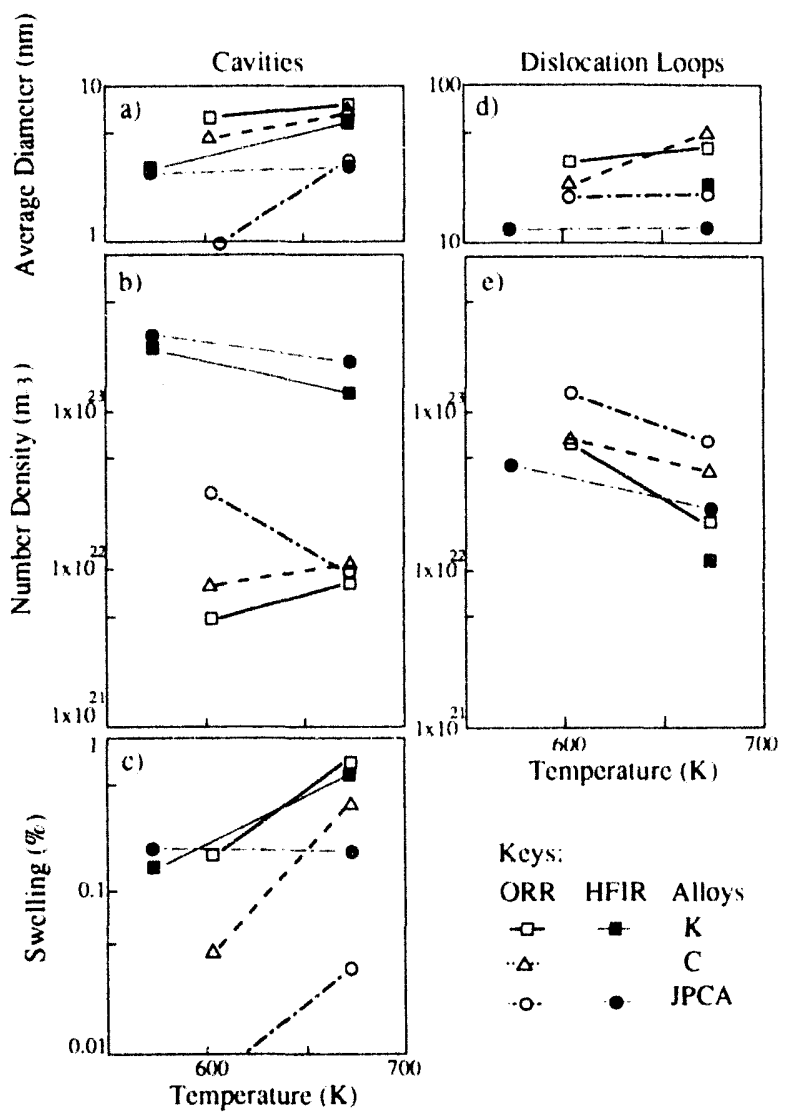

\section{Discussion}

\section{4.l. Effect of Heldpa on microstructural evolution}

Number densities of cavities found in ORR irradiated alloys were smaller than those by HFIR irradiation one to two order. On the other hand, number density of loops in ORR irradiated JPCA was five to ten times larger than that formed during irradiation in the HFIR. Displacement damage level of $7.4 \mathrm{dpa}$ by the ORR was about one fourth of that produced by the HFIR. Both $N_{c}$ and $N_{1}$ are reported to saturate

with dose up to about $10 \mathrm{dpa}$ at temperatures $673 \mathrm{~K}$ or below during EBR-11] 10] and HFIR |11] irradiations producing lower and higher He levels comparing with levels by ORR spectrally tailored irradiation at a damage level of $7.4 \mathrm{dpa}$ in the alloys. Therefore, it seems unlikely that the differences in number densities resulted from smaller damage level by the ORR.

Irradiation by HFIR producing higher levels of He formed cavities with much larger number density. Larger cavity number density is thought to increase mutual recombination of radiation produced vacancies and interstitials at cavity surfaces, and reduce point defect fluxes to dislocations $[12 \mid$. This leads to reduce excess vacancy concentration which resulted from dislocation bias for interstitials, and retards bias-driven cavity growth. Sink strength of cavities and dislocation loops for vacancies are calculated using equations,

$$
\begin{aligned}
& S_{1}=2 \pi \rho_{d} / n\left(\left(2 \rho_{d}\right)^{-1 / 2} / 4 b\right), \\
& S_{c}=2 \pi d_{c} N_{c}\left(1+\left(S_{c}+S_{1}\right)^{1 / 2} d_{c} / 2\right)
\end{aligned}
$$


where these equations, $S_{1}$ and $S_{c}$ are sink strengths of loops and cavities; $\rho_{d}$ and $b$ are dislocation density $\left(=\pi D_{1} N_{1}\right)$ and Burgers vector of dislocation. Because more than half population of dislocation loops were faulted loops, $b$ was chosen to be Burgers vector of Frank loop. Bias factor of dislocation loops for interstitials only slightly affects sink strengths (less than about $10 \%$ ), therefore only $\mathrm{S}_{c}$ and $\mathrm{S}_{1}$ for vacancies were calculated. Calculation was carried out using microstructural data given in Fig. 2. Estimated partitioning of radiation induced point defects between dislocation loops and cavities at $673 \mathrm{~K}$ are shown in Fig. 3. Sink strength of precipitates and grain boundaries were also calculated, however the values were negligibly small: smaller by one to two order than $S_{1}$ and $S_{c}$. Figure 3 shows that dislocation is the main sink in ORR irradiation for both JPCA and $\mathrm{K}$ alloys, while cavity component become larger than dislocation component in HFIR irradiation for both alloys. Cavity component would be still larger in case of HFIR irradiation if tiny bubbles under TEM resolution are considered. Difference of dislocation sink strength between JPCA and $\mathrm{K}$ in ORR irradiation can be attributed to the difference of their swelling resistance, or suppression of loop growth by MC precipitate was more successful in JPCA than K|13|. On the ther hand, suppression of loop growth by tiny but many bubbles is equally dominant in HFIR irradiation for both alloys and thus slight difference of dislocation sink strength between both alloys is resulted. These suggest that bias-driven cavity growth was suppressed by stronger cavity sink strength during irradiation in the HFIR, while dislocation loops acted as a major sink producing excess vacancies caused by bias for interstitials. This also agrees the result that $d_{1} s$ in ORR irradiated alloys were larger than those in HFIR irradiated alloys.

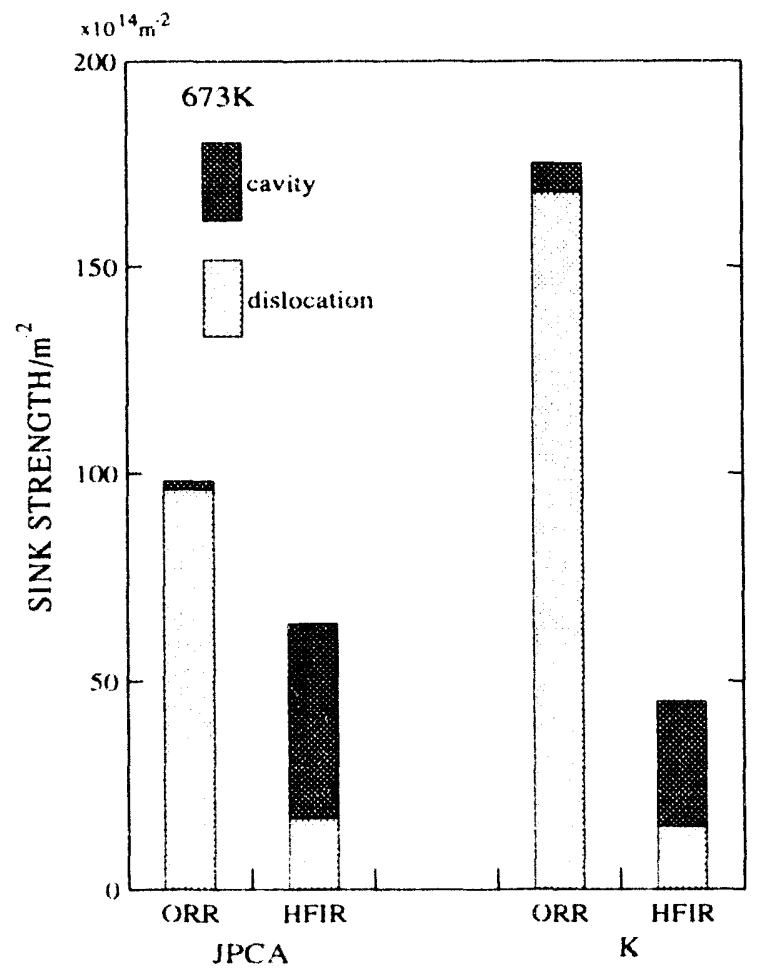

Fig. 3 Comparison of cavity and dislocation sink strength in HFIR- or ORR-irradiated JPCA and $\mathrm{K}$ alloy.

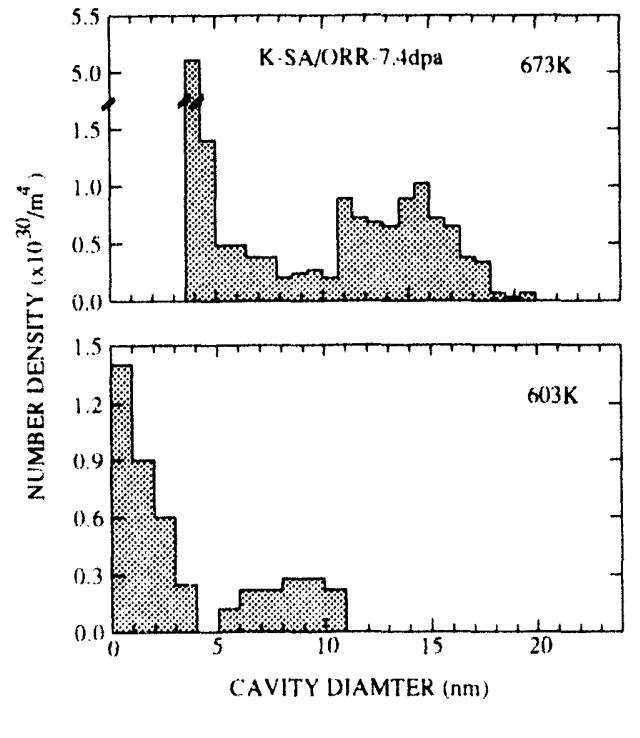

Fig. 4 Cavity size distribution in $\mathrm{K}$ alloy irradiated in ORR at $603 \mathrm{~K}$ and $673 \mathrm{~K}$. 
Bimodal cavity size distribution shown in Fig. 4(a) indicates that bias-driven cavity growth (BDG) occurred in $\mathrm{K}$ alloy during ORR irradiation at $673 \mathrm{~K}$. Cavity size distribution even a low temperature of $603 \mathrm{~K}$ (Fig. 4(b)) is rather wide, and this may indicate BDG mechanism operated during irradiation $\mid 14,15]$. On the other hand, cavities in HFIR irradiated $\mathrm{K}$ alloy to 33 dpa were reported to be equilibrium bubbles; bimodal size distributions were observed in K alloy and JPC.A only at 773 and $873 \mathrm{~K}$. These facts may indicate that spectrally tailored irradiation in the ORR extended temperature regime of BDG to lower temperatures comparing with irradiation in the HFIR.

\subsection{Alloy dependence of swelling by irradiation in the ORR}

It has been indicated in many researches that MC precipitation during irradiation is effective to suppress swelling in titanium (Ti) and niobium $(\mathrm{Nb})$ containing austenitic steels $[16,17,18]$. Swelling values of two low carbon alloys ( $\mathrm{K}$ and $\mathrm{C}$ alloys) by irradiation in the ORR were much larger than that found in JPCA. JPCA containing larger amount of carbon should have higher tendency of MC forming during irradiation; finer but smaller total volume of MC were observed in JPCA comparing with MC in $\mathrm{K}$ and $\mathrm{C}$ alloys after irradiation at $673 \mathrm{~K}$. It has been reported that $\mathrm{MC}$ in HFIR and He-ion irradiated austenitic alloys suppressed cavity migration to retard cavity coalescence and reduced swelling[19,20]. If the MC effects for swelling supression were mainly preventing the cavity coalescence, this mechanism would be more effective in HFIR irradiation where higher number density of caivies were formed. The fact that alloy dependence of swelling was large for ORR irradiation than for HFIR irradiation suggests MC precipitations and alloying elements $(\mathrm{Ti}, \mathrm{Nb}$ and $\mathrm{C}$ ) might reduce dislocation bias and point defect migration to enhance mutual annihilation.

\section{$\underline{\text { 5. Conclusions }}$}

1. Swelling in ORR irradiated two low $C$ alloys were much larger than those found in JPCA and HFIR irradiated JPCA and low C alloy.

2. ORR irradiation exhibited larger alloy dependence of swelling comparing with HFIR irradiation.

3. Number density of cavities in ORR irradiated alloys were smaller than those in HFIR irradiated same alloys by one to two order.

4. Calculations of sink strengths revealed that fraction of radiation induced point defects absorbed by dislocations (mostly, dislocation loops) was larger during ORR spectrally tailored irradiation comparing with HFIR irradiation.

5. MC precipitations and alloying elements might reduce dislocation bias and point defect migration to suppress swelling during ORR spectrally tailored irradiation by enhancing mutual annihilation of radiation induced point defects.

\section{REFERENCES}

(1) R. E. Stoller, P. J. Maziasz, A. F. Rowcliffe and M. P. Tanaka, J. Nucl. Mater. 155-157(1988)1328.

[2] J. L. Scott, L. K. Mansur, M. L. Grossbeck, E. H. Lee, K. Farrell, L. L. Horton, A. F. Rowcliffe and M. P. Tanaka, "DESCRIPTION OF THE U.S./JAPAN SPECTRAL TAILORING EXPERIMENT IN ORR," p.12 in ADIP Semiannu. Prog. Rep., Mar. 31, 1985, DOE/ERER0045/14, U.S. DOE, Office of Fusion Energy.

[3] T. Sawai , P. J. Maziasz, and A. Hishinuma, J. Nucl. Mater. 179-181(1991)519.

14] T. Sawai, P. J. Maziasz, H. Kanazaswa and A. Hishinuma, J. Nucl. Mater. 191-194(1992) p.712

[5] L. R. Greenwood, "NEUTRON DOSIMETRY AND DAMAGE CALCULATIONS FOR THE ORR-MFE 7J EXPERIMENT," p.23 in FRM Semiannu. Prog. Rep., Mar. 31, 1989, DOE/ER- 
0313/6, USDOE, Office of Fusion Energy.

[6] M. P. Tanaka, P..J. Maziasz, A. Hishinuma and S. Hamada, J. Nucl. Mater. 141-143(1986) 943.

[7] T. Sawai and M. Suzuki, Script. Met. 24(1990)2047.

[8] T. Sawai, M. Suzuki, P. J. Maziasz and A. Hishinuma, J. Nucl. Mater. 187(1992)146.

[9] M. P. Tanaka, S. Hamada, A. Hishinuma and P. J. Maziasz, J. Nucl. Mater. 155-157(1988) p.801.

[10] H. R. Brager and J. L. Straalsund, J. Nucl. Mater. 46(1973)p. 134

[11] P. J. Maziasz, "Effects of Helium Content on Microstructural Development in Type 316 Stainless Steel Under Neutron Irradiation," ORNL-6121, ORNL.

112] R. E. Stoller and G. R. Odette, "The Effect of Helium on Swelling in Stainless Steel: Influence of Cavity Density and Morphology," p.275 in Effect of Radiation on Materials: 11 th Conf. ASTM STP 782, ed., H. R. Brager and J. S. Perrin, American Society for Testing Materials, Philadelphia, 1982.

[13] S. Jitsukawa, to be published.

[14] A. Hishinuma and L. K. Mansur, J. Nucl. Mater. 118(1983)91.

[15] L. K. Mansur, E. H. Lee, P. J. Maziasz and A. F. Rowcliffe, J. Nucl. Mater. 141-143(1986)633.

[16] M. J. Makin, J. Nucl. Mater. 107(1982)133.

[17] T. M. Williams, J. M. Titchmarch and D. R. Arkell, J. Nucl. Mater. 107(1982)222.

[18] A. F. Rowcliffe, G. J. C. Carpenter, H. F. Merrick and R. B. Nicholson, "An Electron Microscope Investigation of High-Temperature Embrittlement of Irradiated Stainless Steel," p.161, in The Effects of Radiation on Structural Metals: ASTM STP 426. American Society for Testing Materials, Philadelphia, 1967.

[19] P. J. Maziasz, pp.477 in Phase Stability During Irradiation, TMS-AIME, The Metallurgical Society of AIME, New York, 1981.

[20] S. Jitsukawa, K. Hojo and A. Hishinuma, J. Nucl. Mater. 179-181(1991)538. 
MICROSTRUCTURES OF A WELDED JOINT USING AN IRRADIATED WRAPPER TUBE-S. Hamada, K. Watanabe, A. Hishinuma, I. Takahashi and T. Kikuchi (Japan Atomic Energy Research Institute)

\section{OBJECTIVE}

The objective of this work is to clarify the effect of the helium bubbles evolution on the fracture mechanism in welded joints using an irradiated wrapper tube.

\section{SUMMARY}

The behavior of helium in welded joint fabricated using tungsten inert gas (TIG) welding process for a type 316 stainless steel wrapper tube irradiated in a fast reactor was investigated. The wrapper tube was irradiated to $(1.5-4.2) \times 10^{26} \mathrm{n} / \mathrm{m}^{2}$ (helium level of 3 to $9 \mathrm{appm}$ ) at $395-410^{\circ} \mathrm{C}$. All welded joints fractured in the heat-affected zone (HAZ). The microstructures of each portion of the base metal, the HAZ and the fusion zone in a welded joint were examined through a transmission electron microscope. Small helium bubbles were observed in number density of $2 \times 10^{20} \mathrm{~m}^{-3}$ in the matrix and rarely found on the grain boundaries of the base metal. In the HAZ, small and large helium bubbles mixed and lined up along the grain boundaries. In particular, some of them elongated along the grain boundary. In the matrix of the fusion zone, delta-ferrite phases and unresolved carbides were scattered. Large cavities were attached to these precipitates and also occurred along grain boundaries. These results suggest that the failure in the HAZ of welded joints is attributed to the preferential growth and coalescence of helium bubbles in the grain boundaries of the HAZ caused by weld heat input and stress during welding.

\section{PROGRESS AND STATUS}

\section{Introduction}

The reactor components, such as the reactor vessel and interiors of fission reactors and the first wall and blanket structures in fusion reactors, are exposed to the severe environment of displacement damage and helium produced by nuclear transmutation reactions with energetic neutrons. The long term exposure of materials under such environments will gradually deteriorate their mechanical properties and corrosion resistance, which play a decisive role in the life time of components of nuclear reactors. The repair and replacement of some parts of degraded reactor components will therefore eventually be required. Such repair will require the use of conventional welding techniques. Neutron irradiated steels contain entrapped helium, which forms bubbles at elevated temperatures. Helium bubbles grow and coalesce rapidly along grain boundaries under tensile stresses $1-4$, which weaken the grain boundaries. This situation is typically found in welding processes which produce both internal stress and elevated temperature.

In order to simulate this situation, tungsten inert gas (TIG) welding has been performed for type 316 stainless steel contained helium using tritium doping and decay 5-8. The helium-doped materials containing levels greater than $2.5 \mathrm{appm}$ induced intergranular cracking in the HAZs during welding $5-7$. Helium introduced through this method tends to precipitate preferentially to form belium bubbles on grain boundaries before welding. In this study, it was tried to evaluate helium effects on the fusion welding using neutron irradiated stainless steel instead of belium-doped materials.

\section{Experimental Procedure}

The material employed in this study was $10 \%$ cold worked type 316 stainless steel, which was used as a wrapper tube with $1.9 \mathrm{~mm}$ in thickness in the MK-I core of the JOYO fast breeder reactor of Power Reactor and Nuclear Fuel development corporation in Japan. the chemical composition of this alloy is shown in 
Table 1. The wrapper tube was irradiated to a fluence of $1.5-4.2 \times 10^{26} \mathrm{n} / \mathrm{m}^{2}$ (helium level of 3-9 appm) in the temperature range of $395-410^{\circ} \mathrm{C}$. Rectangular sheets $70 \mathrm{~mm}$ long and $40 \mathrm{~mm}$ wide were cut out of each of the faces of the hexagonal wrapper tube following irradiation.

Table 1. Chemical Composition used in the Present Experiment (wt \%).

\begin{tabular}{|cccccccccccccccc|}
\hline $\mathrm{C}$ & $\mathrm{Si}$ & $\mathrm{Mn}$ & $\mathrm{P}$ & $\mathrm{S}$ & $\mathrm{N}$ & $\mathrm{Cr}$ & $\mathrm{Mo}_{0}$ & $C_{0}$ & $B$ & $N$ & $N$ & $A s$ & $C_{u}$ & $N b+T a$ & $V$ \\
\hline 0.05 & 0.48 & 1.72 & 0.024 & 0.006 & 13.60 & 16.80 & 2.18 & 0.31 & 0.0001 & 0.0254 & 0.0100 & 0.0040 & 0.2500 & 0.0040 & 0.0037 \\
\hline
\end{tabular}

Butt-joint welds with full penetration were made using the single path Tungsten Inert Gas (TIG) welding process at $12 \mathrm{~V}$-ac, $25 \mathrm{~A}$ at a travel speed of $3.6 \mathrm{~mm} / \mathrm{s}$. During welding, filler wire was automatically supplied. Welding for an unirradiated wrapper tube also was performed under similar conditions as an irradiated wrapper tube. After welding, grinding of the portion of convex bead was made by a grinder wheal. A sheet of $30 \mathrm{~mm} \times 20 \mathrm{~mm}$ including a bead in the middle portion was cut from a rectangular sheet described above. The $5 \mathrm{~mm}$ square sheets for transmission electron microscope (TEM) were cut from each location corresponding to HAZ, fusion zone and base metal in the sheet of $30 \mathrm{~mm} \times 20 \mathrm{~mm}$ as shown in Fig. 1. Subsequently these were thinned from $1.9 \mathrm{~mm}$ to $0.2 \mathrm{~mm}$ thick by mechanical polishing with emery papers. The discs were manufactured to about $3 \mathrm{~mm}$ in diameter by cutting the corners of $5 \mathrm{~mm}$ square sheets with a nipper. Samples were subsequently electropolished to perforation in a Struers Tenupol twin jet using a 5\% perchloric acid $\left(\mathrm{HClO}_{4}\right)$ and $95 \%$ acetic acid $\left(\mathrm{CH}_{3} \mathrm{COOH}\right)$ electrolyte at $15^{\circ} \mathrm{C}$ using 150 $\mathrm{mA}$ and $70 \mathrm{~V}$ - dc. The polishing tasks for TEM discs were performed in a glove box. Thin foils were examined using $\mathrm{H} 800 \mathrm{TEM}$ operated at $200 \mathrm{kV}$.

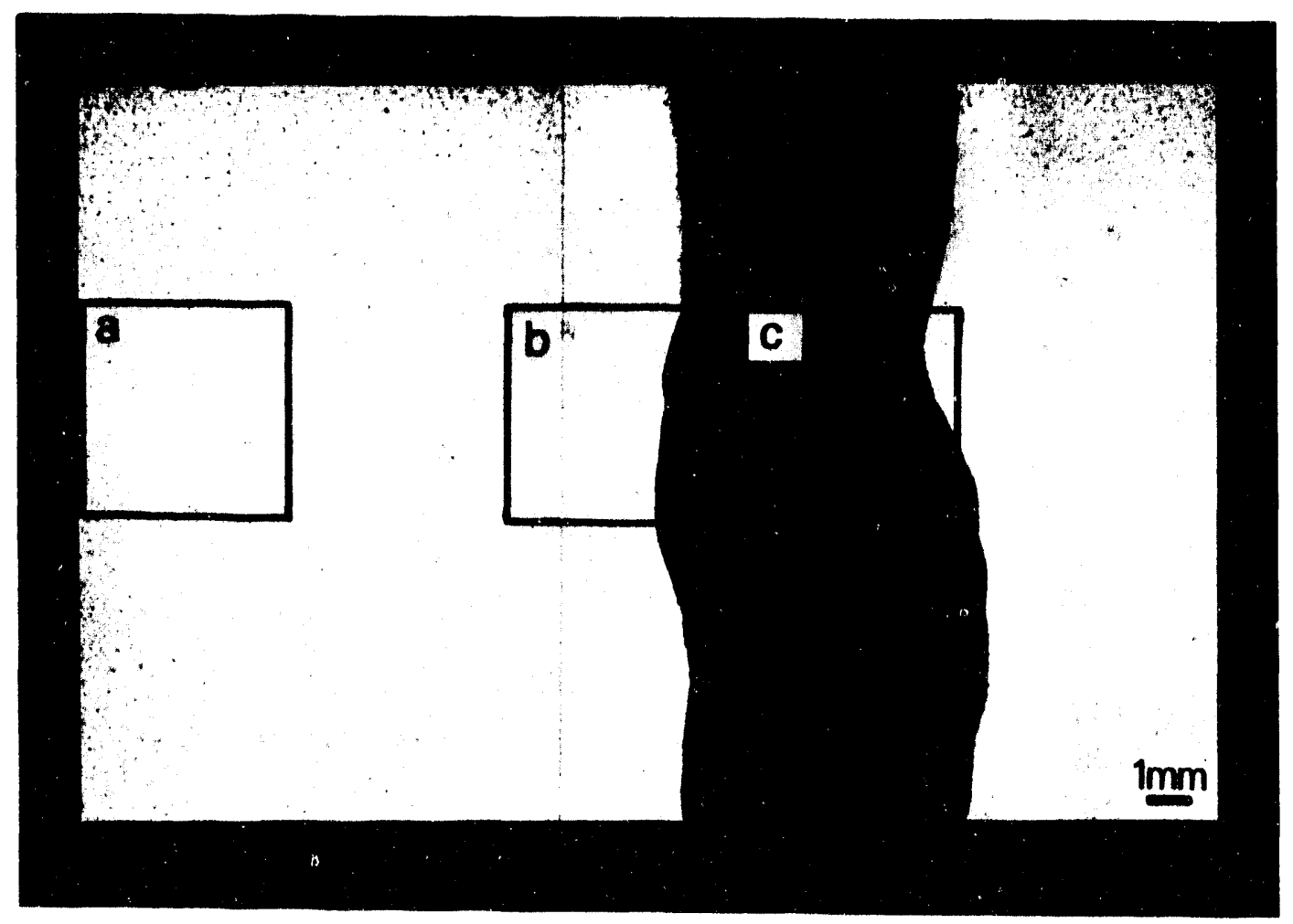

Fig. 1. Micrograph of a TIG welded joint and areas cut from it for TEM samples: (a) base metal; (b) heataffected zone and (c) fusion zone. 


\section{Results}

No cracks were found in the fusion zone and the HAZ of as-welded joints. Tensile tests for base metals and welded joints of both un- and irradiated materials were carried out at room temperature, 400,500 , and $600^{\circ} \mathrm{C}$. Figure 2 shows the location of fractures. All irradiated welded joints fractured in the fusion zone, while ones fractured in the HAZ of each tensile test temperature. The failure position was adjacent to the fusion line. Figure 3 shows an optical micrograph at high magnification of the fractures portion on the HAZ of a sample tensile-tested at $500^{\circ} \mathrm{C}$. Many intergranular cracks occurred in the HAZ. They were often found to be located on the grain boundaries parallel to an applied stress. There were no cracks in the fusion zone.

Figure 4 shows microstructures of the base metal in a welded joint. Small helium bubbles were uniformly scattered in density of $2 \times 10^{20} \mathrm{~m}^{-3}$ in a matrix. The size distribution of helium bubbles was a relatively narrow range of 3 to $15 \mathrm{~nm}$ diameter. The average diameter of them was about $8 \mathrm{~nm}$. A few small helium bubbles also were sometimes found on the grain boundaries. Furthermore, dislocation loops in the range of $10-100 \mathrm{~nm}$ in diameter were observed in density of $3.3 \times 10^{21} \mathrm{~m}^{-3}$. Helium bubble evolution between the base metal and the HAZ indicated a big difference. Figure 5 shows microstructures found in the HAZ. Helium bubbles in the HAZ were greater than those in the base metal as a whole. Helium bubbles of 10 to $70 \mathrm{~nm}$ diameter slightly un-uniformly distributed in the matrix, that is, most of them attached on dislocation lines and/or at the adjacency of dislocation lines, which has grown from dislocation loops as seen in the matrix of the base metal (Fig. 5a). In the grain boundaries, small (several tens $\mathrm{nm}$ ) and large (100 - 400nm) helium bubbles mixed and lined up along the grain boundaries (Fig. 5b). Some of them elongated aiong a grain boundary and a typical example is shown in Fig. $5 \mathrm{c}$. The maximum size of elongated helium bubbles observed in this experiment was about $600 \mathrm{~nm}$. High heat input through only a single pass in welding may not produce such big elongated helium bubbles on a grain boundary. The effect of stress including compression and tensile in addition to the thermal effect may enhance the formation of elongated helium bubbles. Dislocation network, developed from dislocation loops subjected to heat input in weiding. No dislocation loops were found in the matrix of the $\mathrm{HAZ}$ at a distance of $1 \mathrm{~mm}$ from the fusion line (Fig. 5d).

Delta-ferrite phases of several microns, unresolved carbides (200-300 nm diameter) were scattered in a matrix of the fusion zone. The huge cavities attached to delta-ferrite phases and unresolved carbides (Fig. 6a) are penetration holes formed at the position of each initial helium bubble during electro-polishing. The sizes of initial helium bubbles presented in the fusion zone would be smaller than those of holes observed after electro-polishing. A fairly high density of dislocation network induced during cooling process after fusion was observed in the matrix. Hugh holes as described above were also found on the grain boundaries as shown in Fig. $6 b$.

\section{Discussion}

The optical micrographs shown in Fig. 3 reveal intergranular failure of the HAZ only in welded joints of an irradiated wrapper tube. In order to understand the mechanism of fracture in the HAZ, it is important to know the behavior of helium bubbles in the grain boundaries and their effect on the strength of grain boundaries.

Two main factors are considered to influence the behavior of helium bubbles; one is temperature through weld heat input, the other is thermal stress induced during welding. The temperature of the position of a TEM disc cut from the HAZ for TEM observation was evaluated by calculation. Figure 7 shows the temperature profile as a function of a distance from the fusion line in the HAZ of type 316 stainless steel measured and calculated by $\mathrm{Lin} 7$. His data was available to the present study because of similar welding conditions and materials. The data suggest the temperature of the position of the observed HAZ to be about $1100^{\circ} \mathrm{C}$. Such elevated temperature promotes the growth and coalescence of helium bubbles in the grain boundaries. The temperature, therefore, of the failure position in the HAZ (a distance of 0.1 to $0.5 \mathrm{~mm}$ from a fusion line) was estimated to be in the range of temperature of 1200 to $1300^{\circ} \mathrm{C}$. This temperature range will provide more rapid growth and coalescence of helium bubbles in the grain boundaries. Above such temperatures, migration of belium atoms to free surfaces will suppress the growth and coalescence of belium bubbles in the boundaries, although this is necessary to clarify in the future. 


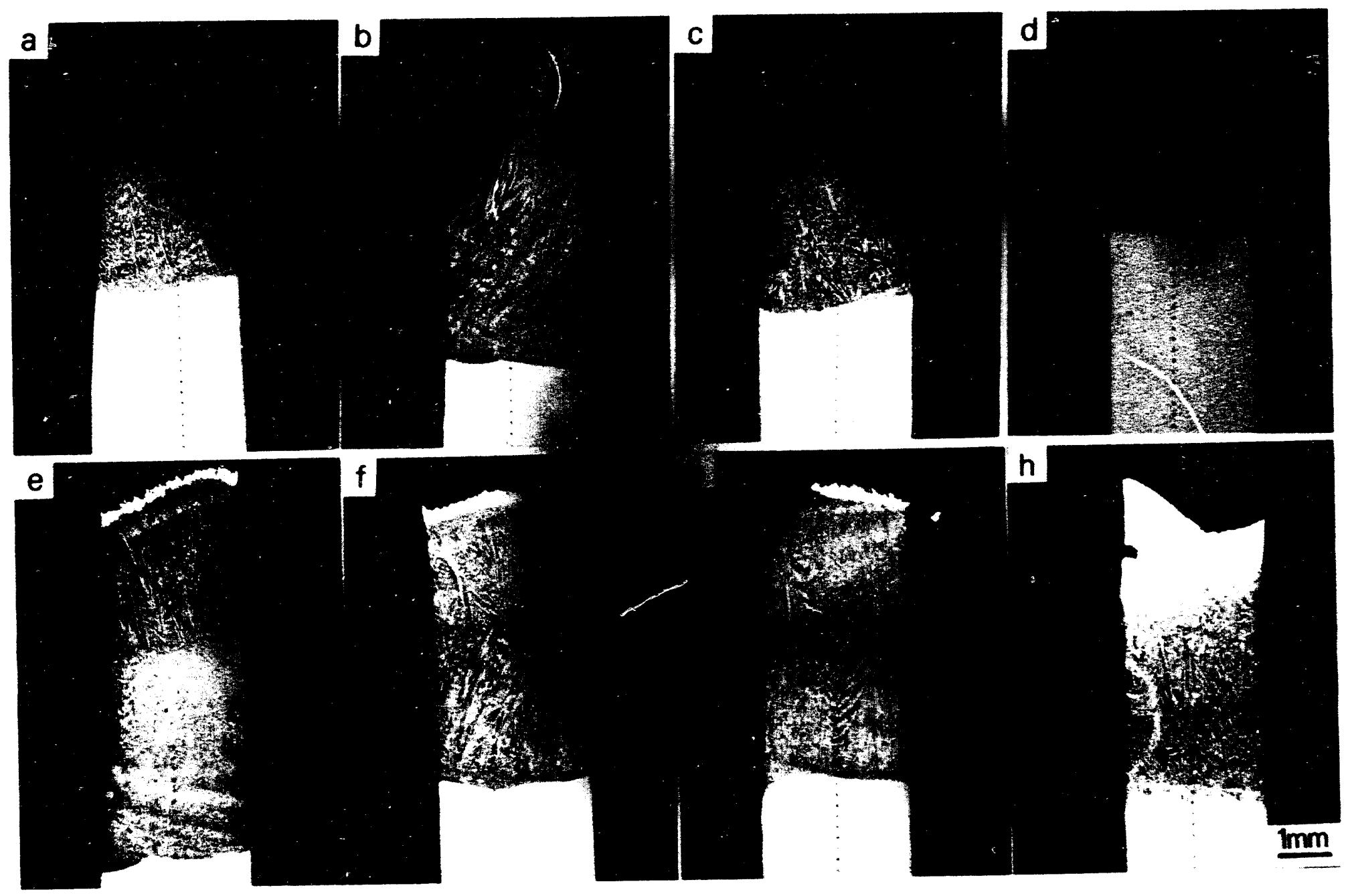

Fig. 2. Optical metallographies of samples fractured during tensile testing under each temperature: (a) and (e) room temperature; (b) and (f) $400^{\circ} \mathrm{C}$; (c) and (g) $500^{\circ} \mathrm{C}$; (d) and (b) $600^{\circ} \mathrm{C}$. Upper and lower row show un- and irradiated welded joints, respectively. 


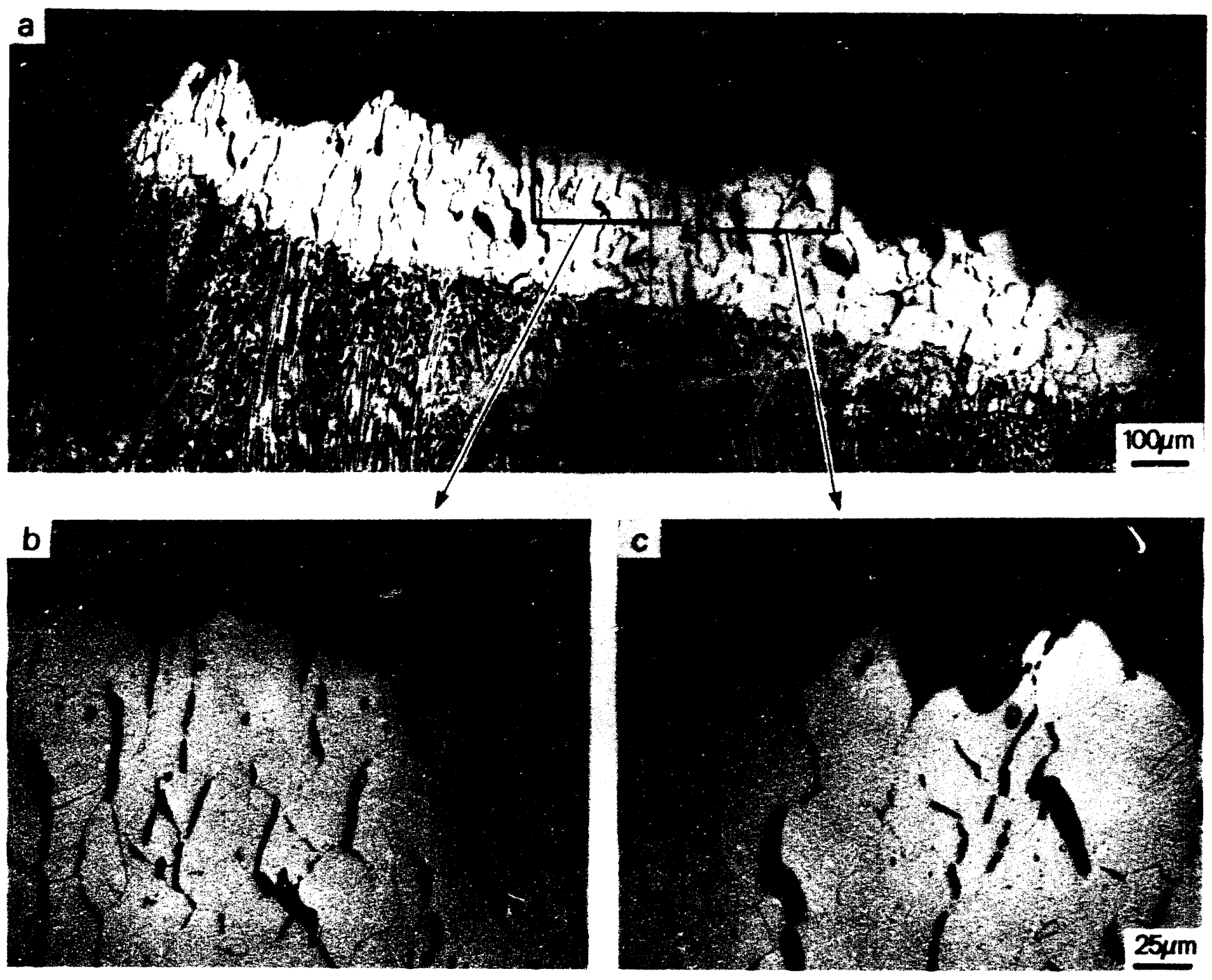

Fig. 3. Micrographs of mtergranular cracks observed in the heat-affected zone fractured during tensile testing at $500^{\circ} \mathrm{C}$ : (a) low magnification, (b) and (c) high magnification. 


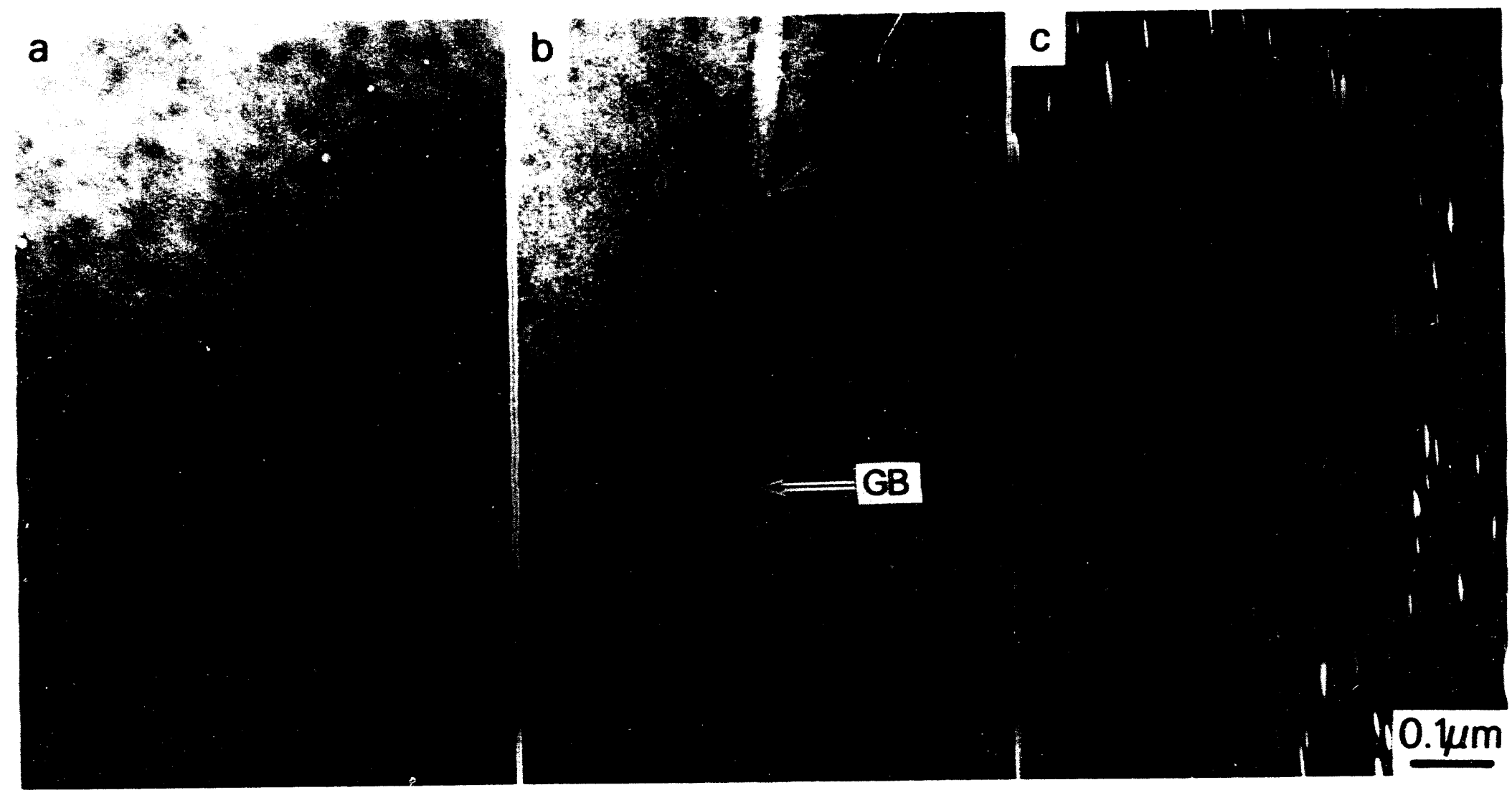

Fig. 4. Microstructures observed in a base metal: (a) helium bubbles in a matrix; (b) helium bubbles in a grain boundary; and (c) dislocation loops (dark field). 

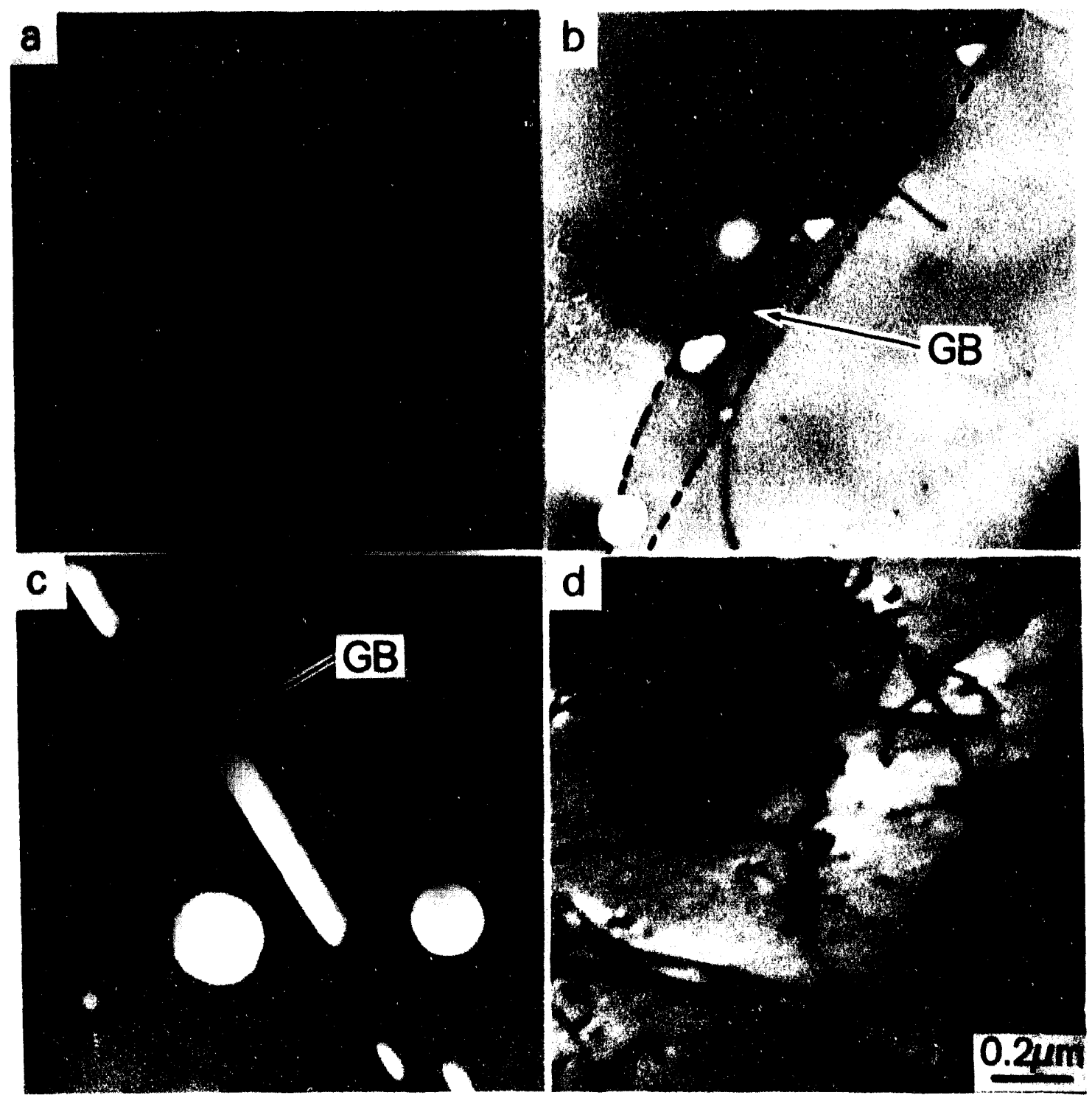

Fig. 5. Microstructures observed in the heat-affected zone: (a) belium bubbles in a matrix; (b) big helium bubbles in a grain boundary; (c) elongated helium bubbles in a grain boundary. 


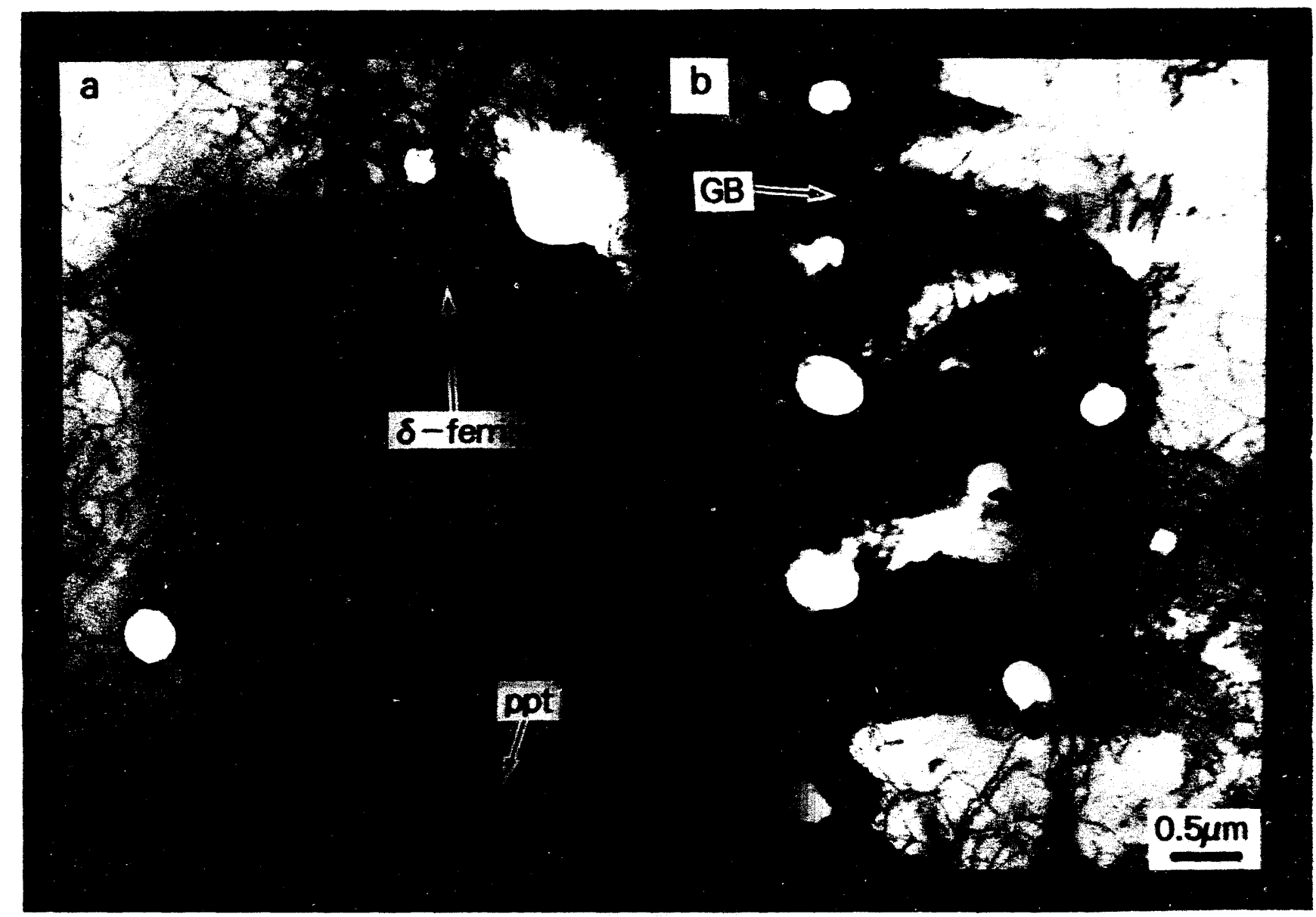

Fig. 6. Microstructures found in the fusion zone: (a) cavities attached to a delta-ferrite phase and an unsolved carbide; (b) cavities precipitated in the grain boundaries. 


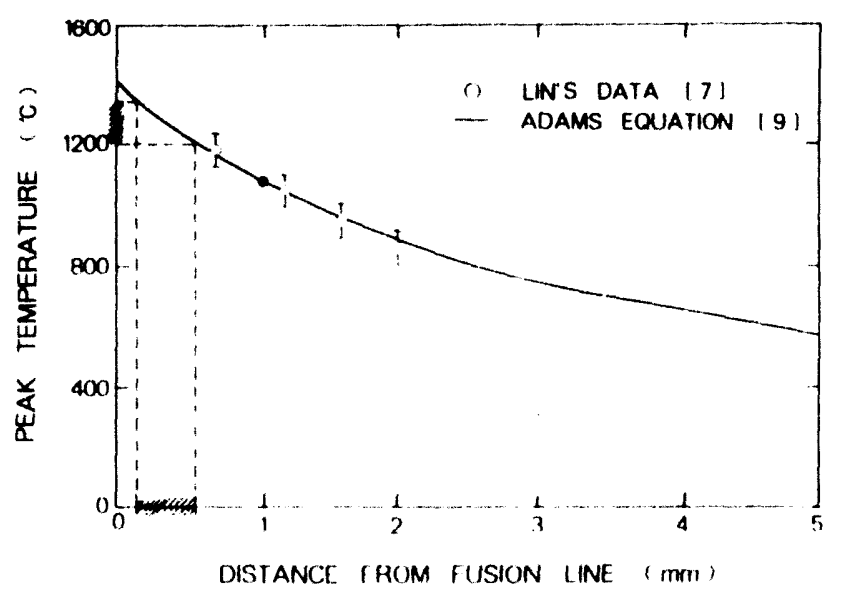

Fig. 7. Temperature-position profile in the heat-affected zone as a function of a distance from the fusion line of type 316 stainless steel. A filled circle means the position of the HAZ observed in this study. Two shaded areas show the fractured position and the corresponding temperature.

Secondly, helium bubbles have been observed to grow and coalesce rapidly along grain boundaries subjected to a tensile stress $1-4,8$. Under the fully constrained conditions of butt-TIG welding, restrained stresses of compression and tension take place during welding and they remain in a welded joint after welding. In particular, considerably large tensile stress remains in a central region including HAZ and fusion zone under the constrained condition of welding after cooling. The un-constrained condition decreases the tensile stress in a central region and spreads the lower tensile stress to a normal direction to a welding bead direction. Tensile stress is evaluated to be somewhat uniform in entire HAZ 10 . The effect of tensile stress on growth and coalescence of helium bubbles in the grain boundaries does not depend on the positions in the HAZ in this study.

Simultaneous effects of both elevated temperatures and stress may enhance the growth and coalescence of helium bubbles in the grain boundaries. In particular, the temperature effect would be larger than the stress effect on the behavior of helium bubbles in the grain boundaries. As a result, intergranular fracture occurs in the region of the HAZ adjacent to the fusion line, in which the largest effect on growth and coalescence of helium bubbles in the grain boundaries would develop.

\section{SUMMARY AND CONCLUSION}

The behavior of helium bubbles in welded joints fabricated using a TIG welding process for a type 316 stainless steel wrapper tube actually employed in the fast reactor JOYO was investigated. The wrapper tube was irradiated to $(1.5-4.2) \times 10^{26} \mathrm{n} / \mathrm{m} 2$ at $395-410^{\circ} \mathrm{C}$. Most of the welded joints fractured intergranularly in the heat-affected zone adjacent to the fusion line. The cause is atuributed to the growth and coalescence of helium bubbles due to elevated temperature and tensile stress induced by the welding heat input in this
region.

\section{FUTURE WORK} The examination of weldability for a wrapper tube irradiated to higher damage levels will be performed in
the future. 


\section{REFERENCES}

1. D. Hull and D. E. Rimmer, Philo. Mag 4 (1959) 673.

2. M. V. Speight and J. E. Harris, Meal Sci.J. 1 (1967) 83.

3. H. Trinkaus, Ber. Bunsenges. Phys Chem 82 (1978) 249.

4. H. Ullmaier, Nucl. Fusion, 24 (1984) 1039.

5. H. T. Lin, M. L. Grossbeck, and B. A. Chin, Metall. Trans. A21 (1990) 2585

6. H. T. Lin, S. H. Goods, M. L. Grossbeck, and B. A. Chin, Effects of Irradiation on Materials: Fourteenth Conference, Vol. I, ASTM-STP 1064, N. H. Packan, R. E. Stoller, and A. S. Kummer, Eds., American Society for Testing Materials, Philadelphia, 1989, p. 301.

7. H. T. Lin, Simulation of the Welding of Imadialed Materials, ORNL/TM-11158, Oak Ridge National Laboratory, 1989.

8. C. A. Wang, H. T. Lin, M. L. Grossbeck, and B. A. Chin, LNucl Mater. $191-194$ (1992) 696.

9. C. M. Adams, Jr., Weld. J. 37 (1958) 210.

10. K. Satoh, Y. Mukai and M. Toyoda, Welding Engineering Rikohgakusha, 1985, Tokyo (in Japanese). 


\begin{abstract}
DOSE DEPENDENCE OF THE MICROSTRUCTURAL EVOLUTION IN NEUTRON-IRRADIATED AUSTENITIC STAINLESS STEEL .- S.J. Zinkle, P.J. Maziasz and R.E. Stoller (Oak Ridge National Laboratory)
\end{abstract}

\title{
OBJECTIVE
}

The objective of this work is to examine the duration of the microstructural transient regime in neutron irradiated austenitic stainless steels

\section{SUMMARY}

Microstructural data on the evolution of the dislocation loop, cavity, and precipitate populations in neutron-irradiated austenitic stainless steels are reviewed in order to estimate the displacement damage levels needed to achieve the "steady state" condition. The microstructural data can be conveniently divided into two temperature regimes. In the low temperature regime (below about $300^{\circ} \mathrm{C}$ ) the microstructure of austenitic stainless steels is dominated by "black spot" defect clusters and faulted interstitial dislocation loops. The dose needed to approach saturation of the loop and defect cluster densities is generally on the order of 1 displacement per atom (dpa) in this regine. In the high temperature regime $\left(-300\right.$ to $\left.700^{\circ} \mathrm{C}\right)$, cavities, precipitates, loops and network dislocations are all produced during irradiation; doses in excess of 10 dpa are generally required to approach a "steady state" microstructural condition. Due to complex interactions between the various microstructural components that form during irradiation, a secondary transient regime is typically observed in commercial stainless steels during irradiation at elevated temperatures. This slowly evolving secondary transient may extend to damage levels in excess of 50 dpa in typical 300 -series stainless steels, and to $>100 \mathrm{dpa}$ in radiation-resistant developmental steels. The detailed evolution of any given microstructural component in the high-temperature regime is sensitive to slight variations in numerous experimental variables, including heat-to-heat composition changes and neutron spectrum.

\section{Introduction}

Austenitic stainless steels have been the subject of numerous investigations on radiation effects. Most of these studies have been driven by technological applications, ranging from light water and fast breeder fission reactors to fusion reactor first-wall structures. It is well established that the microstructural response of austenitic stainless steels to neutron irradiation is sensitive to heat-to-heat compositional variations (e.g., $\mathbf{N}$-lot vs DO heats of type 316 stainless steel in the US breeder reactor program) [1-3]. This inherent sensitivity to slight compositional changes has made it difficult to systematically sort out "generic" effects associated with irradiation spectrum, damage rate, or He/dpa variations, since many studies were performed using different heats of otherwise similar material.

There are three major categories of transient behavior that can be identified in irradiated metals: Point defect (vacancy and interstitial) supersaturation; microscopic nucleation of defect aggregates such as dislocation loops, voids and precipitates; and macroscopic changes such as void swelling and mechanical property transients. Previous reviews of neutron irradiation effects in austenitic stainless steel have concentrated on the cavity swelling and precipitate evolution associated with high-dose ( $>10 \mathrm{dpa}$ ) neutron irradiation [2-9]. The transient behavior of point defects is addressed in a companion paper in these proceedings [10], and reviews on the transient swelling [5,11] and mechanical property [12] behavior of neutron-irradiated stainiess steel are also available. The focus of the present paper is to critically review the microstructural response of stainless steel to neutron imadiation at low to moderate doses, where the microstructure evolves rapidly. The bulk of the analysis will be restricted to relatively simple $\mathrm{Fe}-\mathrm{Cr}-\mathrm{Ni}$ ternary austenitic alloys or 300 series stainless steels in order to establish the intrinsic behavior of "pure" 
austenitic stainless steels to neutron irradiation. Unfortunately, the lack of low-fluence data on a standardized heat of steel makes it difficult to rigorously define the extent of the transient regime for microstructural evolution. This paper incorporates data from a range of steel compositions, and therefore is only strictly relevant for examining qualitative rather than quantitative trends. Three microstructural categories will be examined: (1) dislocation loops and network dislocations, (2) cavities, and (3) precipitates.

The specific goals of this review are to establish the temperature dependence of the "steady state" microstructural components, to determine the neutron damage level required to attain these "steady-state" densities, and to examine the influence of controlled solute additions on the duration of transient regimes prior to "steady-state". It should be recognized that the individual microstructural components listed above interact with each other as they evolve. Thus, although a given microstructural component (e.g., dislocation loop density) may approach an apparent "saturation" density at low fluence, its value may be subsequently affected by changes in another component of the microstructure [11]. Hence, it will be seen that the term "steady state" is in general only an approximation for the overall microstructural response of austenitic steels irradiated to high fluences.

Table 1 lists the alloy compositional ranges for several different austenitic stainless steels that have been the subject of numerous published radiation effects studies. These steels can be categorized as either conventional low-carbon steels (AISI 304 and 316) or Ti- or Nb-stabilized steels (DIN 1.4970, FV548, D9I, and PCA). Macroscopic swelling due to void formation and growth can have profound implications on the allowable operating lifetime of austenitic steel components irradiated at temperatures $2400^{\circ} \mathrm{C}$. The dose-dependent behavior of macroscopic swelling includes an initial low-swelling transient regime followed by a linear high swelling rate regime. Therefore, the philosophy of most materials programs engaged in developing swelling-resistant structural alloys has been to manipulate metallurgical variables such as thermomechanical condition and alloy composition to extend the low-swelling transient regime to the highesi doses possible [3]. Alloy modifications with specific solute additions, like titanium, have generally been quite successful in improving void swelling resistance for fast breeder reactor applications [13-18]. The best swelling-resistant steels invoke additional microstructural refinements that produce finely dispersed precipitates and dislocations which can remain stable up to high damage levels. These radiation-resistant microstructures are not permanent or true "steady-state" microstructures, however, and they eventually become unstable at some higher dose.

Table 1. Chemical composition (wt \%) of austenitic stainless steels (balance Fe)

\begin{tabular}{|c|c|c|c|c|c|c|c|}
\hline Alloy & $\mathrm{Cr}$ & $\mathrm{Ni}$ & $\mathrm{Mn}$ & $\mathrm{Si}$ & C & Mo & $\mathrm{Ti}$ \\
\hline AISI 304 & $18-20$ & $8-12$ & $<2.0$ & $<1.0$ & $<0.08$ & - & - \\
\hline AISI 316 & $16-18$ & $10-14$ & $<2.0$ & $<1.0$ & $<0.08$ & $2-3$ & - \\
\hline FV $548^{a}$ & $16-17$ & $11-12$ & $0.75-1.25$ & $<0.6$ & $0.06-0.09$ & $1-1.75$ & $<0.05$ \\
\hline DIN $1.4970^{b}$ & 15 & 15 & 1.5 & 0.4 & 0.1 & 1.2 & 0.5 \\
\hline$P C A^{c}$ & 14 & 16.2 & 1.8 & 0.4 & 0.05 & 2.3 & 0.24 \\
\hline D9 ${ }^{d}$ & 13.5 & 15.5 & 2 & 0.4 & 0.04 & $1.8 \cdot 2.2$ & 0.25 \\
\hline $\begin{array}{l}\text { aNb-stabilized } \\
\text { bTi-stabilized } \\
\text { cU.s. Fusion n } \\
\text { dAlloy develo }\end{array}$ & $\begin{array}{l}\text { l, also } \\
\text { l, also } \\
\text { ial Pro } \\
\text { for U. }\end{array}$ & $\begin{array}{l}\text { ns }< \\
\text { as } 0 . \\
\text { s Pri } \\
\text { der }\end{array}$ & Progra & $3 \mathrm{~B}$ & $\begin{array}{l}0.01 \mathrm{P} \\
5 \mathrm{~V}, 0.00\end{array}$ & $06 \mathrm{I}$ & $.04 \mathrm{P}$ \\
\hline
\end{tabular}




\section{Classification of Temperature Regimes}

As shown in Fig. 1, the microstructural data obtained on neutron-irradiated austenitic stainless steels at temperatures above $50^{\circ} \mathrm{C}$ can be conveniently classified into three broad temperature regimes. This temperature classification parallels the conventions established from numerous isochronal annealing studies performed on pure metals $[19,20]$. The "low-temperature" regime extends from the onset of vacancy motion (annealing Stage III) up to temperatures where vacancy clusters created in the displacement cascade become thermally unstable (annealing Stage V). For neutron irradiated austenitic stainless steel, this low temperature regime covers the temperature range from about $50^{\circ} \mathrm{C}$ to about $300^{\circ} \mathrm{C}$ [21]. It should be recognized that since the mobility and thermal stability of defects depends on the length of observation (i.e. irradiation time), the actual temperatures associated with observable monovacancy migration and vacancy cluster evaporation for a given damage dose will be somewhat dependent on the irradiation time and hence damage rate. The temperature range between vacancy migration (Stage III) and vacancy cluster evaporation (Stage V) for ion-irradiation conditions, which are typically performed at high damage rates, would therefore lie at correspondingly higher temperatures relative to neutron irradiation conditions.

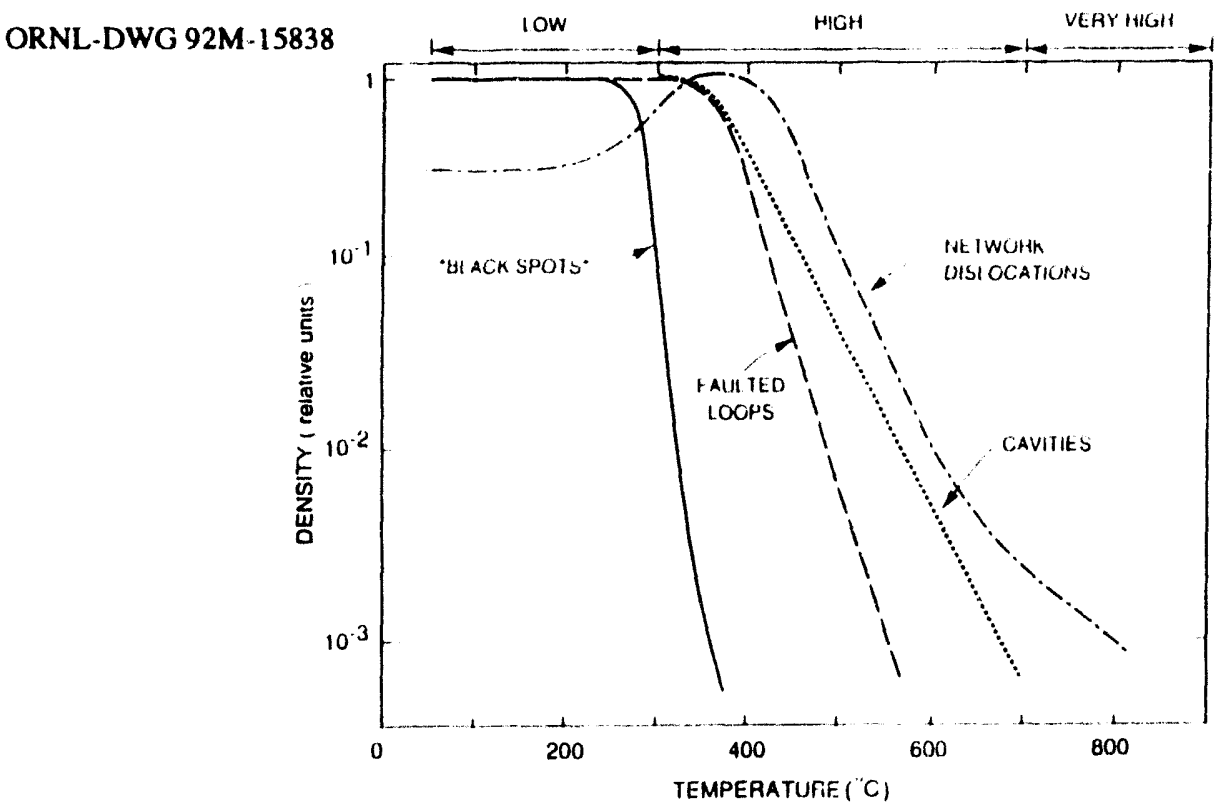

Fig. 1. Temperature dependence of the experimentally observed "saturation" densities of the various microstructural components in neutron-irradiated austenitic stainless steel (see Sections 3-5 for details). The microstructural data can be grouped into "low temperature", "high temperature" and "very high temperature" regimes.

The typical microstructural features observed in the "low-temperature" regime are small defect clusters ("black spots"), faulted dislocation loops, and network dislocations [6,22]. The observable densities of "black spots", faulted loops and network dislocations are nearly independent of irradiation temperature in the low-temperature regime (Fig. 1); as described later, the "black spot" density begins to decrease at temperatures above abos! $250^{\circ} \mathrm{C}$ and there are indications [22] that the network dislocation density may simultaneously increase slightly. Radiation-produced cavities and precipitates are generally not observed in the low-temperature regime. The degree of radiation-induced solute segregation (RIS) is minimal due to the limited point defect mobility and the high sink strengths associated with the high density of small defect clusters that are formed at low doses. The microstructure is relatively insensitive to variations in the damage rate or He/dpa ratio in this temperature regime, and reaches a "saturation" level at relatively low doses. 
The "high-temperature" regime extends from the onset of thermally-induced vacancy emission from vacancy clusters (annealing Stage V) up to temperatures at which interstitial clusters become thermally unstable. For typical neutron irradiation conditions, this regime covers the temperature range from about $300^{\circ} \mathrm{C}$ to about $700^{\circ} \mathrm{C}$. The microstructural evolution during irradiation in the high temperature regime is complex, and consists of cavities (helium bubbles and/or voids), dislocation loops and network dislocations, and various types of precipitates [6,9]. The "saturation" densities of helium bubbles, voids, dislocation loops, and network dislocations all decrease with increasing temperature in this regime (Fig. 1). There is some evidence [22] that the network dislocation density may reach a local maximum at a temperature near $350^{\circ} \mathrm{C}$, but additional high-dose studies are needed to confirm this possibility. High doses ( $>10 \mathrm{dpa}$ ) are often required to reach a "steady-statc" defect microstructure in the high temperature regime, due to extensive interactions between the individual microstructural components. The density of small "black-spot" defect clusters is negligible in this temperature regime. Radiation-induced solute segregation effects can be very significant in the "high-temperature" regime. The specific details of the microstructural evolution are sensitive to numerous parameters including damage rate, alloy composition, and He/dpa ratio.

In the "very high-temperature" regime, which corresponds to temperatures above about $700^{\circ} \mathrm{C}$, all radiation-induced defect clusters except gas-pressurized bubbles are thermally unstable. Hence, the microstructure in this temperature regime is essentially identical to that found in unirradiated steels aged at the same temperature. There are no significant concentrations of dislocation loops or radiation-produced voids, and the precipitate and network dislocation behavior is equivalent to that observed thermally. Helium bubble formation can still occur in this temperature regime, but its behavior is determined primarily by the thermal equilibrium vacancy concentration and He concentration.

\section{Dislocation Loops and Network Dislocations}

\subsection{Dislocation Loops}

Figure 2 presents the temperature dependence of the faulted dislocation loop density that is formed during high-dose neutron irradiation of Type 316 austenitic stainless steel [22-31]. Essentially all of the

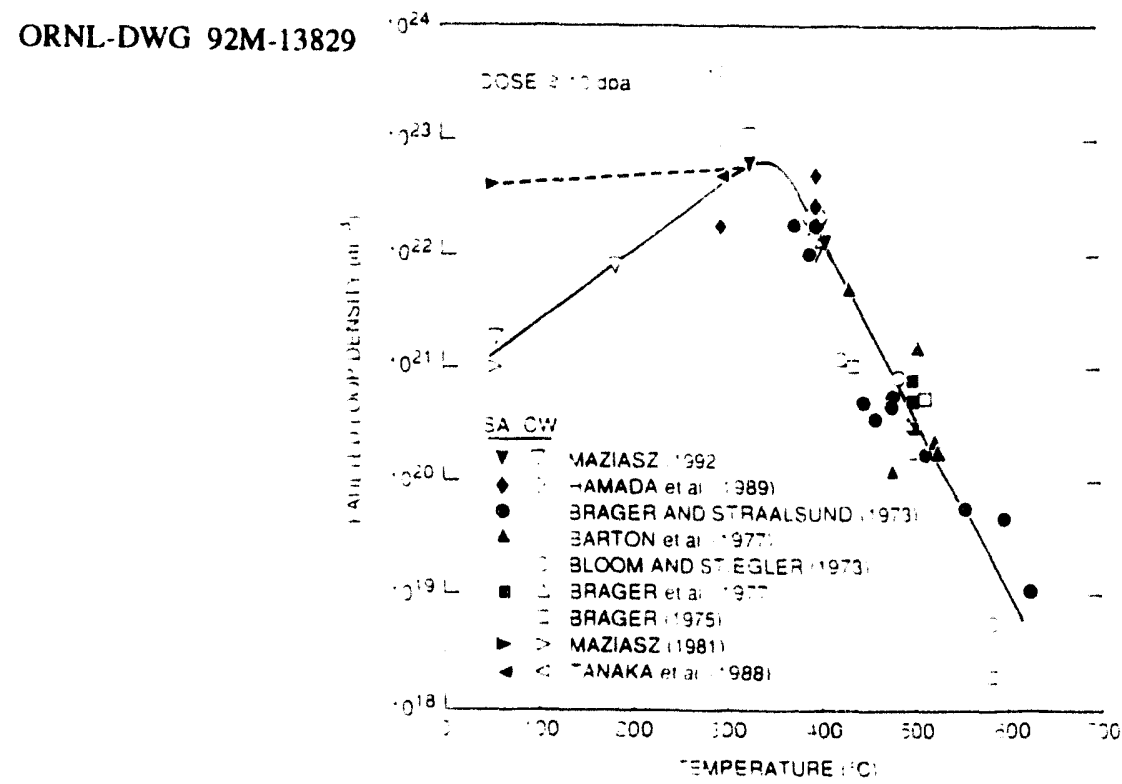

Fig. 2. Effect of irradiation temperature on the faulted dislocation loop density in neutron-irradiated austenitic stainless steel [22-31]. 
faulted loops formed during neutron irradiation in austenitic steels that are larger than $10 \mathrm{~nm}$ in diameter have been identified as interstitial in nature, lying on (111) planes with Burgers vectors of the type $b=a_{0} / 3<111>[23,32-34]$. A fairly sharp transition in the loop density occurs between the "low temperature" and the "high temperature" regime. The loop density decreases rapidly with increasing temperature above $350^{\circ} \mathrm{C}$, and for damage levels $>5$ to 10 dpa there is no significant difference between solution annealed (SA) and $20 \%$ cold-worked (CW) material. There can be a substantial difference between the dislocation evolution in SA and CW steels at low doses (<10 dpa) in the "high temperature" regime, but there is little systematic data to quantify this behavior.

The dislocation loop and "black spot" defect cluster densities are very high at low temperatures $\left(<300^{\circ} \mathrm{C}\right)$, which causes a high sink strength for point defects. Furthermore, the low point defect mobilities at these temperatures can extend the transient period for the evolution of the loops and network dislocations before reaching a "steady state" microstructure. The available data suggest that the observable faulted loop density in the low-temperature regime is lower for cold-worked alloys than for solution annealed material for damage levels up to about $10 \mathrm{dpa}$ (Fig. 2). Since the development of observable faulted loops in coldworked alloys first requires a significant reduction of the initially high network dislocation density to take place, it is possible that the cold-worked material does not reach its "steady-state" loop density even after 10 dpa at these temperatures. A systematic study of the same heat of solution annealed and cold-worked steel irradiated over a wide range of doses in this low-temperature regime is needed to evaluate this possibility.

Figure 3 shows a typical microstructure produced in austenitic stainless steel by neutron irradiation in the low-temperature regime [35]. The dominant microstructural feature is a high density of small "black spot" defect clusters. The average size of the small defect clusters is about $2 \mathrm{~nm}[22,28,34-36]$. Numerous studies performed on $\mathrm{Fe}-\mathrm{Cr}-\mathrm{Ni}$ alloys and pure face-centered cubic (FCC) metals indicate that much of the "black spot" cluster density is created directly in the displacement cascade during the cascade quench $[33,36,37]$. The total density of the small defect clusters in austenitic steel is comparable to the densities observed in pure FCC metals of similar mass, such as $\mathrm{Ni}$ or $\mathrm{Cu}$. However, it is interesting to note that the fraction of defect clusters that are resolvable as stacking fault tetrahedra in stainless steel is $<1 \%$ [34-36], which is much less than the corresponding fraction of 25 to $50 \%$ observed in $\mathrm{Ni}$ or Cu following irradiation at comparable conditions [38]. This suggests that the solutes in stainless steel somehow modify the cascade quench behavior and inhibit SFT formation in the displacement cascade.

OHAL PHOTC $17-93$

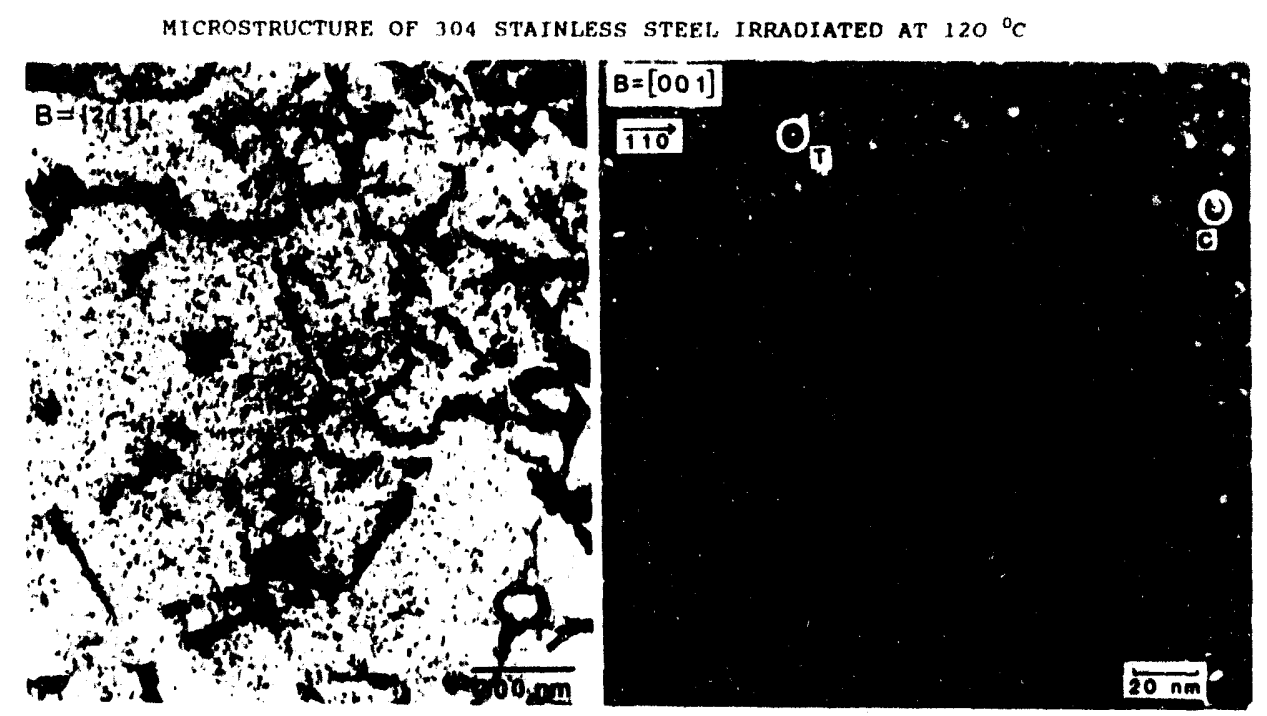

Fig. 3. Microstructure of $304 \mathrm{~L}$ stainless steel after fission neutron irradiation at $120^{\circ} \mathrm{C}$ to $\sim 0.5 \mathrm{dpa}$ [35]. 
Due to a lack of neutron irradiation studies on stainless steel in the low temperature regime, the dose dependence of the small defect clusters, network dislocations and faulted dislocation loops is not well established. The available data $[22,28,34,36]$ suggest that the "saturation" density of black spot damage may be greater than $10^{24} / \mathrm{m}^{3}$, and that this density is attained after doses of about $0.1 \mathrm{dpa}$. Mechanical property measurements made on Type 304 and 316 stainless steel following fission neutron irradiation at temperatures less than $100^{\circ} \mathrm{C}$ also suggest that defect cluster saturation occurs at damage levels $<0.1 \mathrm{dpa}$ [39]. The dose dependence for the accumulation of defect clusters during neutron irradiation at low temperatures is apparently sublinear from 0.002 to $0.03 \mathrm{dpa}$ [36], which is an indication of interaction between displacement cascades and surrounding defect clusters even at these low doses. The density of resolvable faulted loops increases with increasing temperature between 50 and $300^{\circ} \mathrm{C}$ [22]. Although conventional theoretical models predict that the as cold-worked network dislocation structure should be relatively stable at low temperatures [11], some experimental results suggest that significant dislocation recovery can occur at low doses for irradiation temperatures below $300^{\circ} \mathrm{C}$ [22]. Additional data in this temperature regime on both solution annealed and cold worked material are needed in order to better define the "inherent" material response.

In the high-temperature regime $\left(300\right.$ to $\left.700^{\circ} \mathrm{C}\right)$, faulted (Frank) interstitial loops are formed at low dose and approach a maximum density after a damage level of a few dpa. Figure 4 shows a typical example of the dose dependence of the faulted loop density for solution annealed stainless steel irradiated at temperatures near $400^{\circ} \mathrm{C}[22,23,30,31,40-44]$. The loop density reaches an apparent saturation level after about $3 \mathrm{dpa}$, and this density is then maintained up to much higher doses. The loop densities in simple austenitic steels are similar for both mixed-spectrum and fast reactor fission-neutron irradiations. The exact saturation values attained during irradiation depend on experimental conditions such as alloy composition and dose rate [40]. The sensitivity of the loop density to experimental conditions increases with increasing irradiation temperature [9].

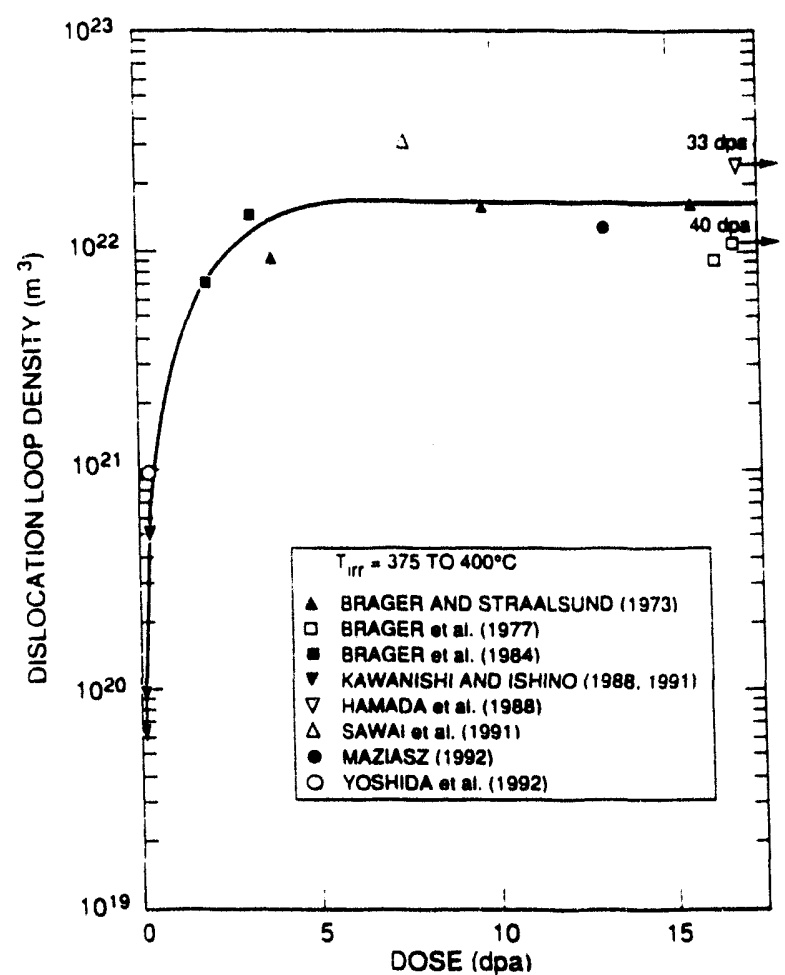

ORNL-DWG 92M-13863R

Fig. 4. Evolution of the faulted dislocation loop density in austenitic stainless steel irradiated with fission neutrons at 375 to $400^{\circ} \mathrm{C}[22,23,30,31,40-44]$. 
At higher irradiation temperatures $\left(2450^{\circ} \mathrm{C}\right.$ ), the loop density has been observed to reach a maximum value after low doses, and then begins to decrease with increasing fluence $[6,30,31,45]$. Frank loops which have grown beyond a diameter of 50 to $100 \mathrm{~nm}$ tend to unfault to form the lower-energy perfect loop configuration with $b=a_{0} / 2<110>$ Burgers vectors. The unfaulting reaction is usually triggered by physical impingement of adjoining Frank loops as a result of loop growth $[31,33]$. While Frank loops are sessile, the perfect loops formed by the unfaulting process are glissile and can glide to interact and form network dislocations. The maximum in the faulted loop density at moderate doses during elevated temperature neutron irradiation may be attributed to a sink competition effect due to interaction between different radiation-produced microstructural components. Radiation-produced precipitation, along with the dislocation network created by the growth and unfaulting of dislocation loops generated earlier in the irradiation, produces new point defect sinks in the lattice that compete with the loops for the available interstitials. Hence, once the initial population of loops grows to a size where significant overlapping and associated unfaulting occurs, a new population of loops cannot be nucleated in sufficient density to replace them. Additional mechanisms may also contribute. For example, radiation induced solute segregation (RIS) could modify the chemical composition of the matrix in a manner that inhibited the formation of new loops (see Section 5).

\subsection{Total Dislocation Density}

The total dislocation density (loop plus network) observed in solution-annealed (SA) type 316 stainless steels after irradiation to high damage levels is plotted in Fig. 5 as a function of irradiation temperature $[22,45]$. At temperatures below about $400^{\circ} \mathrm{C}$, the total dislocation density is dominated by faulted loops $[22,23,27,45]$. As the irradiation temperature increases above about $350^{\circ} \mathrm{C}$, the total dislocation density decreases rapidly with increasing temperature and the relative contribution from faulted loops becomes progressively smaller. The total dislocation density is dominated by the network dislocation component at irradiation temperatures above about $500^{\circ} \mathrm{C}[22,23,27,45,46]$. The temperaturedependent transition from a loop-dominated dislocation microstructure to a network-dominated dislocation microstructure depends synergistically upon several parameters, including alloy composition, irradiation spectrum and dose. Due to the decrease in the faulted loop density with increasing dose at elevated temperatures, the transition temperature between a loop-dominant and a network-dominant microstructure shifts to lower temperatures as the dose increases.

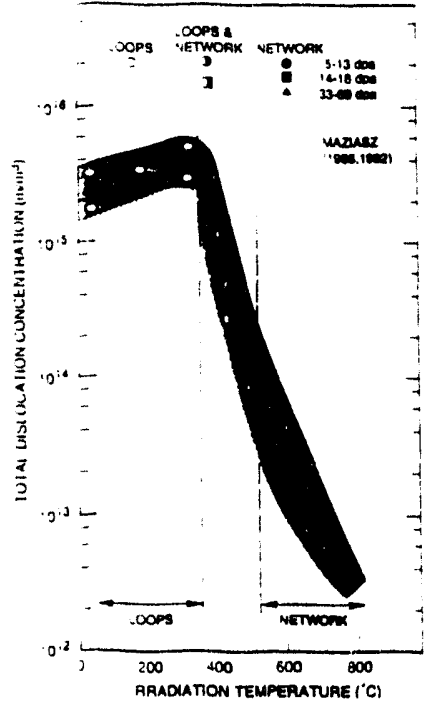

ORNL-DWG 92M-15862

Fig. 5. Temperature dependence of the total dislocation density in solution annealed 316 stainless steel irradiated in the HFIR mixed spectrum and EBR-Il fast fission reactors [22,45]. The Figure also includes recent unpublished data by Maziasz on specimens irradiated to $34 \mathrm{dpa}$ at 300 to $600^{\circ} \mathrm{C}$ in HFIR. 
Figure 6 shows the dose dependence of the total dislocation density observed in stainless steel irradiated at about $400^{\circ} \mathrm{C}[22,23,40-42]$. The damage level needed for the total dislocation density to approach a "steady-state" value is $10 \mathrm{dpa}$ or more, which is significantly higher than the dose needed to achieve the "steady state" loxp density at that temperature (Fig. 4). This difference in doses to achieve the two different "steady-state" conditions is due to the fact that the total dislocation densitydepends on the product of the loop density and the loop size along with the network dislocation density. The network dislocation density in tum depends on loop growth and unfaulting to achieve its "steady-state" value. Therefore, significant growth of dislocation loops must occur after loop nucleation saturates in order for the total dislocation density to achieve its "steady-state" value.

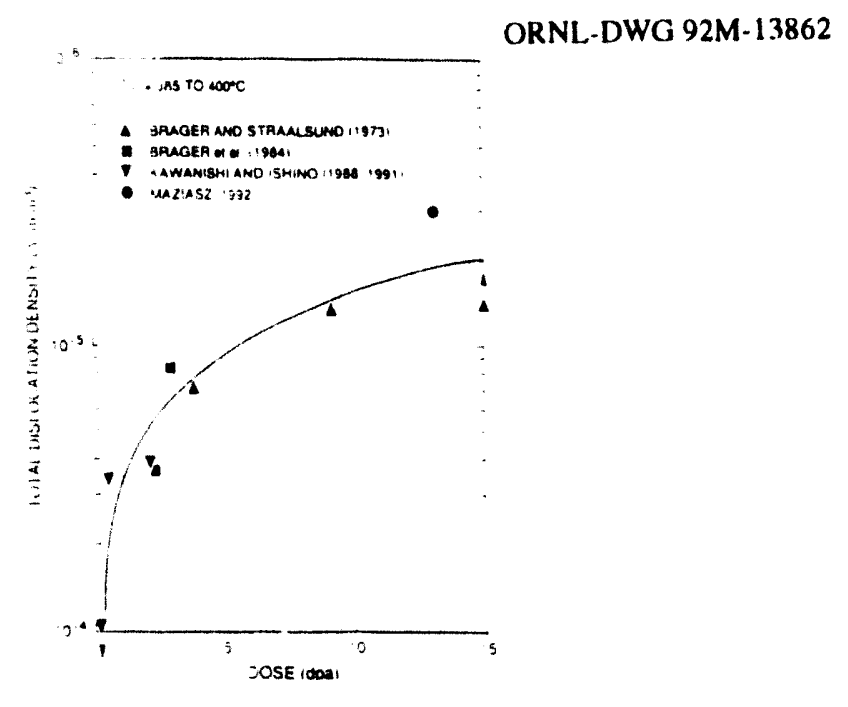

Fig. 6. Effect of neutron irradiation on the total dislocation density in solution annealed austenitic stainless steel irradiated near $400^{\circ} \mathrm{C} \cdot[22,23,40-42]$.

Figure 7 summarizes the evolution of the total dislocation density in SA 316 stainless steel irradiated at three different temperatures within the "high-temperature" regime $[23,31,40-42,45]$. An initial transient associated with the rapid buildup of dislocation density is completed within about 10 dpa at all temperatures. A secondary microstructural transient subsequently occurs in specimens irradiated at the higher temperature end of this regime. The total dislocation density can either increase or decrease slightly in this secondary transient regime, depending on temperature and steel heat chemistry. This is a reflection of the dynamic balance between the process of loop nucleation, growth, and unfaulting to create network dislocations, and the process of radiation-assisted recovery to remove network dislocations. The particular total dislocation density achieved depends on the details of the other microstructural components created during irradiation (in particular precipitates and cavities), and hence is very sensitive to alloy composition and neutron spectrum [45].

Irradiation of cold-worked stainless steel causes the network dislocation density to initially decrease rapidly below its preirradiation value. Figure 8 shows an example of the evolution of the loop and network compenents of the total dislocation density obtained from a recent spectrally-tailored irradiation experiment on 20\%CW PCA stainless steel conducted at fusion-relevant damage rates and He/dpa levels [22]. The network dislocation density decreased by one order of magnitude after irradiation to 7.4 dpa at 330 and $400^{\circ} \mathrm{C}$, then increased with further irradiation due to the formation of additional network dislocations from loops that had grown and unfaulted. The corresponding changes in the total dislocation density were less dramatic than the changes in network component alone. The lack of data at doses less than 7 upa under similar, fusion-relevant irradiation conditions raises an important question, namely - how rapidly does such 


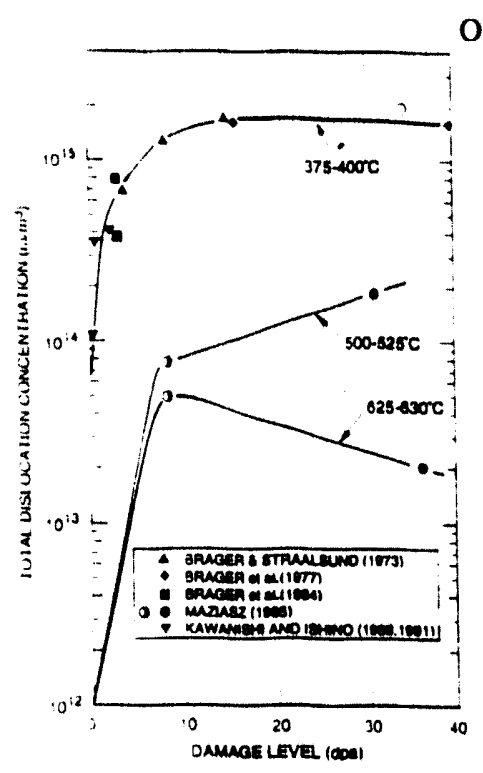

Fig. 7. Evolution of the total dislocation density in neutron irradiated solution annealed austenitic stainless steel $[23,31,40-42,45]$. The filled symbols denote loop-dominant dislocation microstructures, whereas the half-filled symbols refer to microstructures containing comparable dislocation line densities from loops and network dislocations.

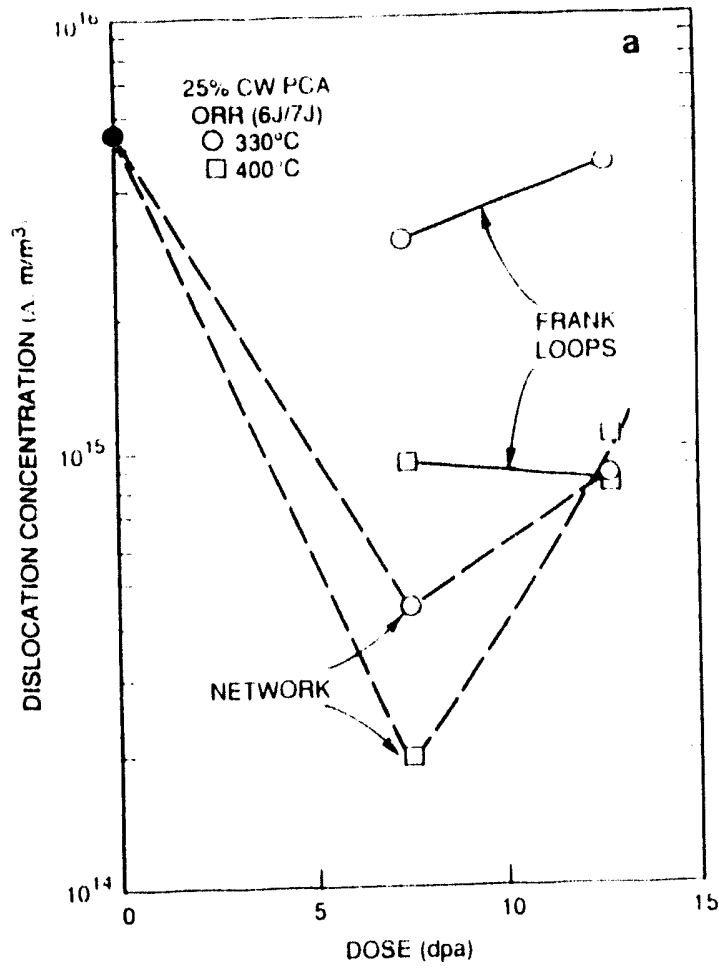

ORNL-DWG 92M-13860/ORNL-DWG 91M-6422R2

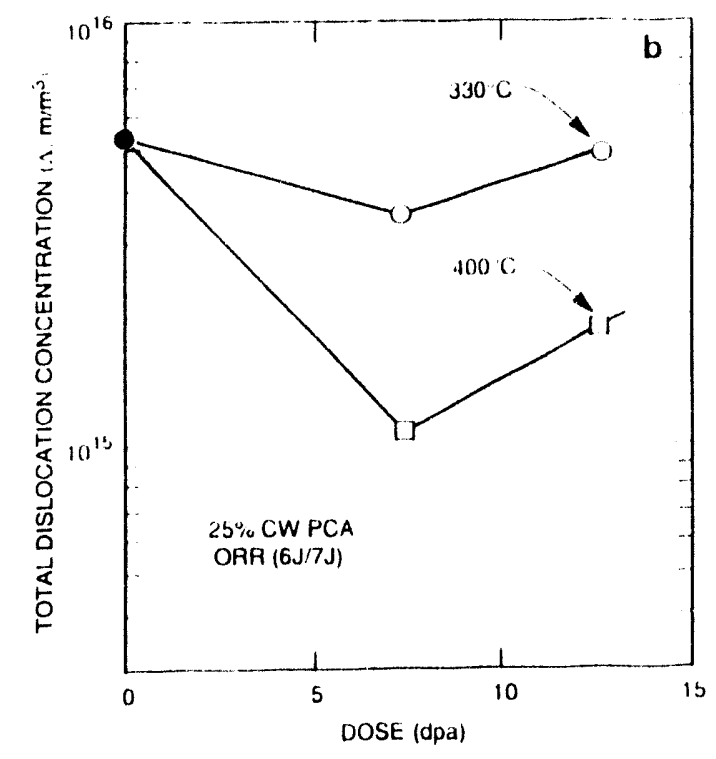

Fig. 8. Effect of ORR fission neutron irradiation at 330 and $400^{\circ} \mathrm{C}$ on the evolution of the a) network dislocation and faulted loop density and b) total dislocation density in cold worked PCA austenitic steel [22]. 
network dislocation recovery occur during the initial stages of the irradiation? It is possible that the combination of a rapid recovery of the cold-worked dislocation density during irradiation and the delayed nucleation of faulted loops in cold-worked material could create a low-dose regine where both the dislocation network and the loop densities are low? Such dislocation behavior could produce a transient radiation-induced softening in cold-worked steel prior to the radiation-induced hardening traditionally seen at higher doses. The possibility of unanticipated transient softening in cold-worked steel would be of obvious importance for fusion structural engineering designs. Further studies are needed at dumage levels between 0.1 and 10 dpa to clearly establish the microstructural evolution in cold-worked austenitic stainless steels.

Irradiation of cold-worked type 316 stainless steel in the HFIR mixed-spectrum reactor at elevated temperatures [45] resulted in a slower recovery of the network dislocation density than was observed in the spectrally-tailored ORR irradiations of cold-worked PCA stainless steel at temperatures $\leq 400^{\circ} \mathrm{C}$ [22] (only a factor of three decrease after $8 \mathrm{dpa}$ at $425-450^{\circ} \mathrm{C}$ ). Unfortunately, there are too many experimental differences between these two studies (damage rate, irradiation temperature, PCA vs. 316SS, He/dpa ratio) to draw any firm conclusions regarding the controlling mechanism for the kinetics of the recovery of the $\mathrm{CW}$ network dislocation structure. The physical mechanisms responsible for the evolution of the dislocation microstructure in both simple and complex alloys must be better understood before engineering designs for fusion reactors can be finalized.

Figure 9 compares the evolution of the total dislocation density of SA and $25 \%$ CW stainless steels irradiated near $400^{\circ} \mathrm{C}$ [22,23,40-42]. The total dislocation densities of both SA and $25 \% \mathrm{CW}$ materials approach a common value of 1 to $2 \times 10^{15} / \mathrm{m}^{2}$ after a damage level of about 5 dpa. Similar conclusions regarding the common saturation value of the total dislocation density have also been obtained from TEM observations of SA and $20 \% \mathrm{CW} 316$ irradiated in a fast reactor [31]. A common dislocation saturation density in SA and $20 \% \mathrm{CW}$ stecls has also been inferred from analyses of tensile data $[47,48]$ obtained at temperatures above $300^{\circ} \mathrm{C}$, although the dose required to reach saturation of mechanical properties was often greater than 20 dpa [48]. On the other hand, recent tensile results on SA and CW stainless steel irradiated at $250^{\circ} \mathrm{C}$ (i.e., near the upper limit of the "low-temperature" regime) showed that the $\mathrm{SA}$ and $\mathrm{CW}$ materials saturated at different strength levels [49]. Once again, more experimental studies are needed to complete our understanding of the microstructural evolution at low temperatures.

Figure 10 summarizes the temperature dependence of the various individual microstructural components that make up the total dislocation concentration in PCA steel irradiated to $7.4 \mathrm{dpa}$ at a fusionrelevant damage rate and Ho/dpa ratio [22]. The irradiated network dislocation density is approximately onetenth of the preirradiated $25 \%$ cold-worked value even for an irradiation temperature as low as $60^{\circ} \mathrm{C}$. The total dislocation density in the "low temperature" regime is dominated by the dislocation line-length contribution from "black spot" defect clusters, whose size and density are nearly independent of irradiation temperature up to $20^{\circ} \mathrm{C}$. The resolvable Frank loop concentration increases with increasing irradiation temperature in the "low-temperature" regime. This causes the Frank loops to dominate the total dislocation density at irradiation temperatures near $300^{\circ} \mathrm{C}$, which corresponds to the transition from the "lowtemperature" to the "high-ltinperature" regime. The rapid decrease of the Frank loop density at temperatures above $300^{\circ} \mathrm{C}$ eventually leads to a transition from a loop-dominant to a network-dominant dislocation structure at temperatures above $400^{\circ} \mathrm{C}$ for a damage level of $13 \mathrm{dpa}$ [22]. The large amount of dislocation network recovery at low temperatures, and the temperature dependence of the network dislocation density may both be related to an extended point defect transient which was invoked to explain the high levels of creep at $60^{\circ} \mathrm{C}$ in pressurized-tube specimens of $25 \% \mathrm{CW}$ PCA steel irradiated in this experiment [50].

\section{Cavity Evolution}

Pronounced cavity (He bubble and void) formation generally occurs in steels irradiated in the "hightemperature" regime $\left(300\right.$ to $\left.700^{\circ} \mathrm{C}\right)$. Figure 11 summarizes the temperature-dependent cavity densities 


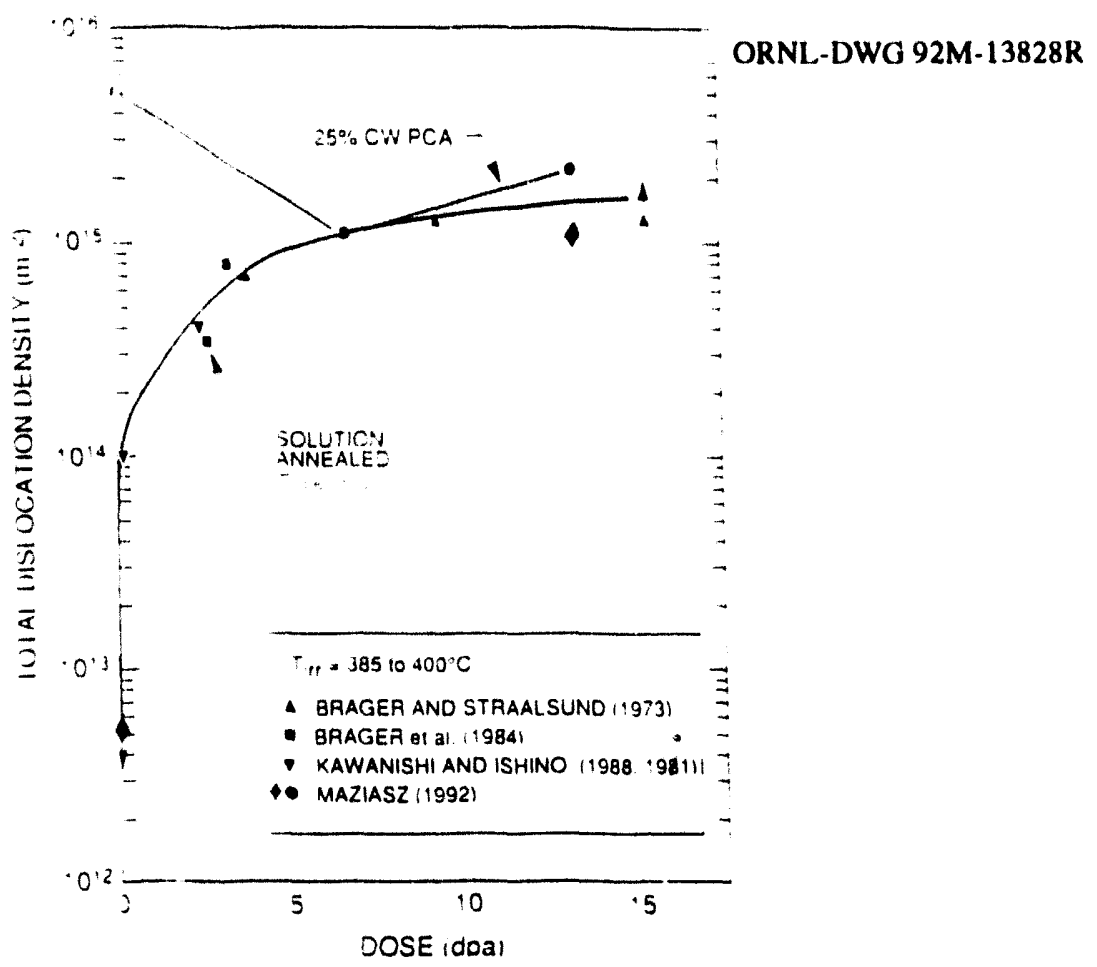

Fig. 9. Comparison of the total dislocation density in solution annealed 316 and cold worked PCA austenitic steel after fission neutron irradiation near $400^{\circ} \mathrm{C}$ [22,23,40-42].

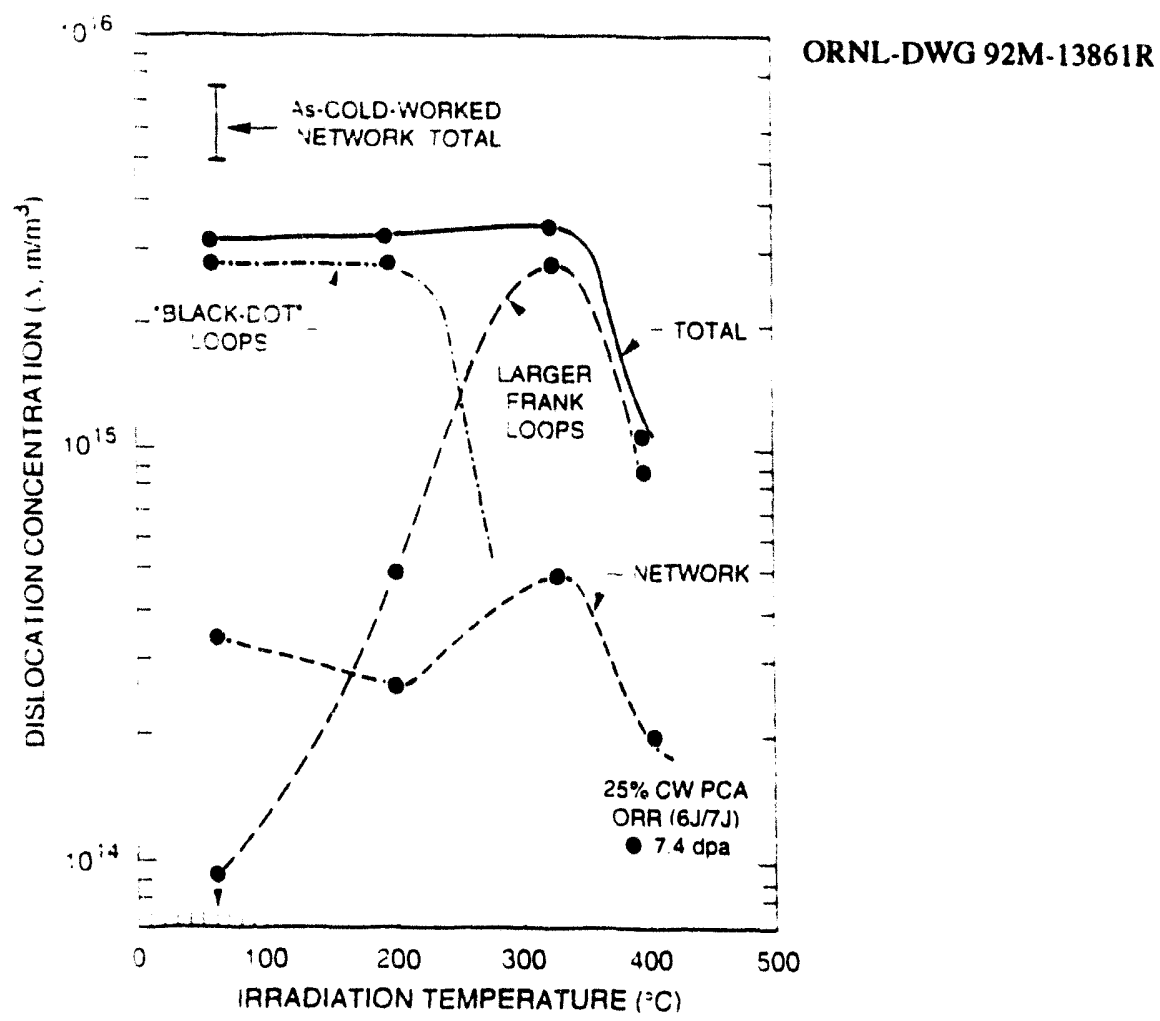

Fig. 10. Effect of irradiation temperature on the various components of the total dislocation density in neutron-irradiated cold worked PCA austenitic steel [22]. 
observed in neutron-irradiated stainless steel $(22,23,30,35,45,51,52]$. A bimodal distribution of cavities, consisting of voids and small helium bubbles, is often observed at temperatures between 400 and $650^{\circ} \mathrm{C}$. The precise temperature range where helium bubbles and voids coexist is strongly dependent on the experimental conditions such as He/dpa ratio, dannage rate and alloy composition. The bubble and void density both decrease rapidly with increasing temperature for irradiations above $400^{\circ} \mathrm{C}$. Void formation has been observed in neutron-irradiated austenitic steel at temperatures as low as $325^{\circ} \mathrm{C}$. [53] and as high as $730^{\circ} \mathrm{C}[6,23,51]$. The regime where significant void swelling occurs ranges from about 370 to $700^{\circ} \mathrm{C}$. At low temperatures $\left(<300^{\circ} \mathrm{C}\right)$, the high sink density associated with thernally stable defect clusters (Figs 1 and 2) increases the recombination of point defects at sinks, which suppresses the vacancy supersaturation and thereby inhibits cavity nucleation and growth. At high temperatures, thermal vacancy emission from cavity embryos limits the nucleation of voids, and low sink densities cause an increase in the matrix recombination of point defects.

The "saturation" void density and post-transient swelling rate of austenitic steels in the temperature range of 400 to $650^{\circ} \mathrm{C}$ is relatively insensitive to irradiation spectrum and cold work level [2,51,54-56]. The primary effect of cold-work is to cause an extension of the low-swelling transient regime by delaying void nucleation. Cold-work generally suppresses the cavity density observed during the low-swelling ransient in steels irradiated in fast reactors (low He/dpa ratio), whereas it generally causes an increase in the cavity density in alloys irradiated in mixed spectrum reactors (high $\mathrm{He} / \mathrm{dpa}$ ratio). The higher dislocation density in cold-worked material can enhance helium bubble formation by providing heterogeneous nucleation sites as well as fast paths for helium diffusion. As discussed later, solutes such as titanium, silicon or phosphorus can stabilize the dislocation structure against radiation-induced recovery, and will thereby affect bubble and void nucleation.

Helium bubble formation has routinely been observed after mixed-spectrum (high He/dpa ratio) neutron irradiation at temperatures from $300^{\circ} \mathrm{C}$ to greater than $850^{\circ} \mathrm{C},[6,22,23,30]$. There has been at least one reported observation of small He bubbles after irradiation at a temperature as low as $120^{\circ} \mathrm{C}$ [35]. Since vacancies in austenitic steels are mobile at temperatures above about $50^{\circ} \mathrm{C}$ [21], the formation of observable He bubbles is possible in the "low temperature" regime $\left(50\right.$ to $\left.300^{\circ} \mathrm{C}\right)$. However, the high sink densities associated with the thermally stable "black-spot" defect clusters created in the displacement cascade suppress the vacancy supersaturation and thereby inhibit bubble nucleation and growth. In addition, most of the vacancies that survive the displacement cascade quench will be contained in sessile vacancy clusters which are thermally stable up to about $367^{\circ} \mathrm{C}$. Hence, only a small fraction of the surviving vacancies are capable of free migration to form He bubbles in this temperature regime.

The He bubble density is typically an order of magnitude higher than the void density at a given irradiation temperature (Fig. 11). The precise bubble density for any given case depends strongly on the details of the irradiation conditions (He/dpa ratio and total dose) as well as metallurgical factors, and tends to be highest when no voids form. The He bubble density observed after irradiation in a mixed-spectrum reactor at low temperatures $\left(5400^{\circ} \mathrm{C}\right)$ is typically in excess of $10^{23} / \mathrm{m}^{3}[22,30,57]$. These very high bubble densities are nearly comparable to the "black-spot" defect cluster saturation densities obtained after irradiation at lower temperatures (Section 3). At the intermediate helium generation rates characteristic of D'T-fusion reactors (10-20 appm He/dpa), helium has recently been shown to lead to "unprecedented" high cavity densities in isotopic tailored steel specimens irradiated in a fast reactor [58]. However, it should be noted that these high cavity densities are comparable to those that have been commonly observed in numerous mixed-spectrum (high He/dpa) reactor irradiations $[6,8,9,11,22,30]$.

As shown in Fig. 12, the void density in simple austenitic steels like SA type 316 or an Fe-Cr-Ni ternary alloy can reach a saturation value at doses of less than 0.5 dpa during irradiation near $400^{\circ} \mathrm{C}$ $[23,41,42,45,59-61]$. There is some evidence that higher doses of 15 to 20 upa are required to achieve the saturation void density at higher temperatures [6], but further work is needed to clarify this issue. At 


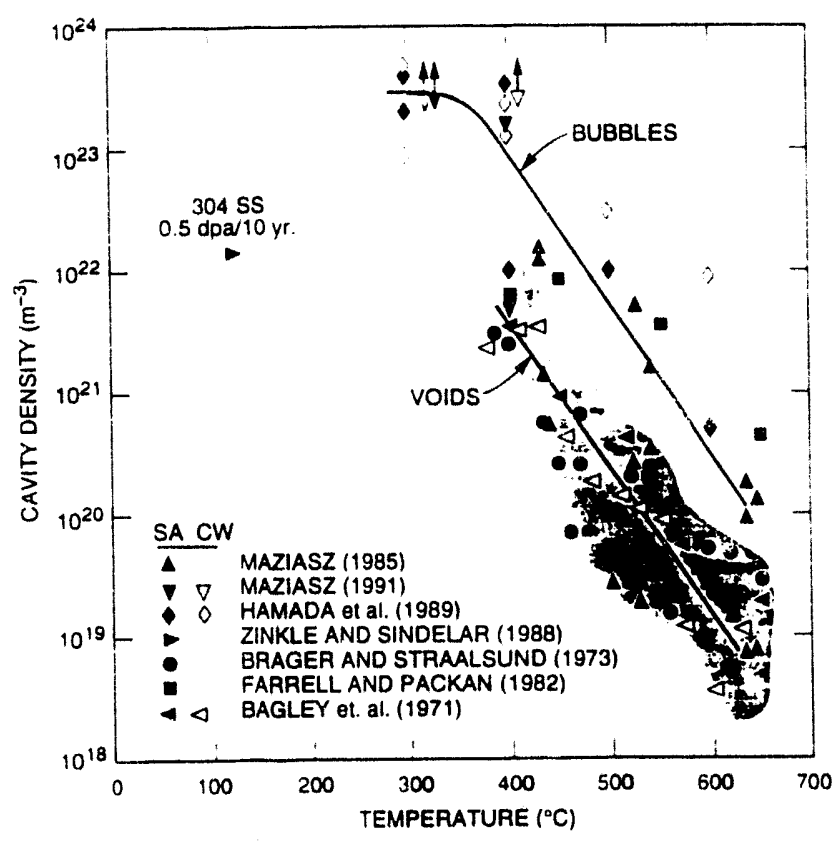

ORNL-DWG 92M-13830 R

Fig. 11. Effect of neutron irradiation temperature on the cavity density observed in austenitic stainless steel $[22,23,30,35,45,51,52]$.

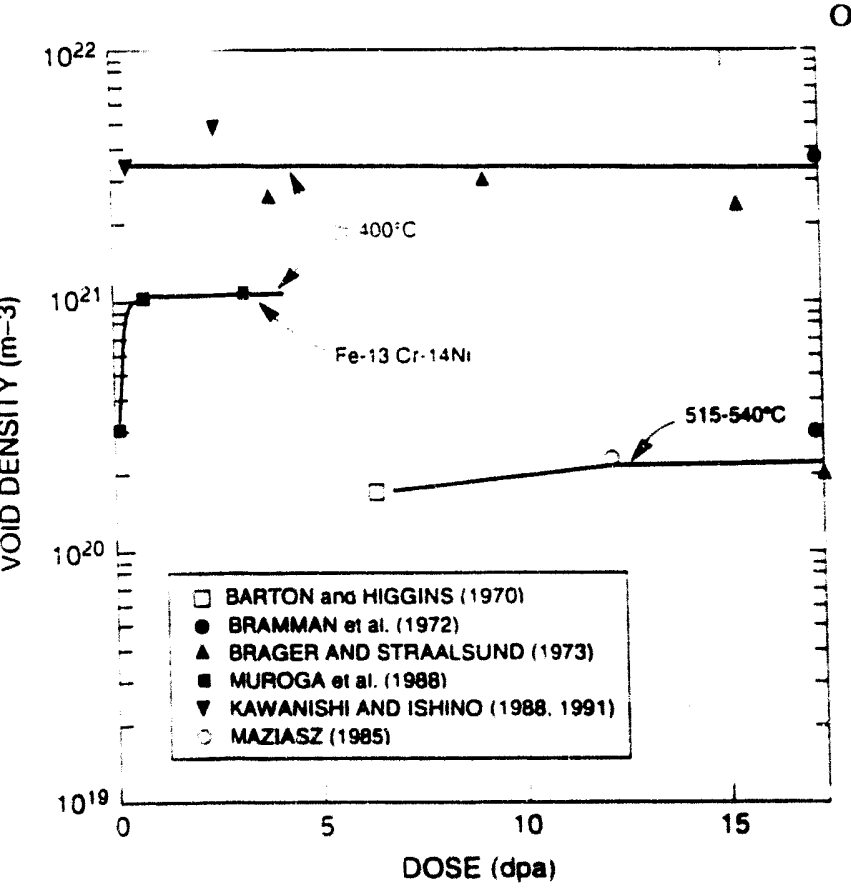

Fig. 12. Dose dependence of the void density in neutron-irradiated solution annealed austenitic steel $[23,41,42,45,59-61]$. 
temperatures of $500-650^{\circ} \mathrm{C}$, void formation in SA 316 and other steels usually requires higher doses to saturate than for simple ternary alloys, largely because void formation is coupled to RIS and the formation of microstructural features such as Frank loops and precipitates (see Section 5). While there is good evidence for the "saturation" void density remaining constunt to about $70 \mathrm{dpa}$ in SA 316 irradiated in fast reactors at $450-550^{\circ} \mathrm{C}$, there is also some data suggesting that void densities can decline somewhat with fluence at 30-70 dpa at 600 to $670^{\circ} \mathrm{C}$. [45]. Void coalescence due to growth and impingement could cause such an effect [62]. In high-swelling ternary alloys, the void density has been observed to decline slightly during fast reactor irradiation at doses $>10$ dpa for irradiation temperatures as low as $510^{\circ} \mathrm{C}[63]$.

The addition of certain solutes such as $\mathrm{C}, \mathrm{P}, \mathrm{Si}$, or Ti can extend the transient regime for cavity nucleation in austenitic steels by a considerable amount, particularly in cold-worked alloys

$[1,3,9,13,41,61,64-69]$. The magnitude of the solute influence on enhancing or inhibiting void swelling depends on the solute concentration, with the strongest influence typically occurring at intermediate concentrations on the order of $0.1 \mathrm{wt} . \%[65,66]$. Figure 13 shows the effect of titanium additions on the cavity density in two austenitic steels irradiated near $400^{\circ} \mathrm{C}$.al either a fast (JOYO) or a mixed-spectrum (HFIR) reactor $[61,64]$. In the Fe-Cr-Ni ternary irradiated in a fast reactor (low He/dpa ratio), the addition of $0.12 \mathrm{wt} . \%$ Ti increased the transient void nucleation regime from about $0.5 \mathrm{dpa}$ to $3 \mathrm{dpa}$ or higher. The addition of $0.23 \mathrm{wt}$ \% Ti to 20\% CW 316 stainless steel caused extensive refinement of the He bubbles produced during irradiation in a mixed-spectrum reactor (high He/dpa ratio). The density of observable bubbles had not yet reached saturation after $13 \mathrm{dpa}$, and none of the bubbles had converted to voids. Similar dose-dependent behavior for the bubble evolution has also been observed in $25 \% \mathrm{CW}$ Ti-modified PCA steel irradiated in spectrally-tailored experiments at $400^{\circ} \mathrm{C} 107.4$ and 13 dpa [70]. The detectable bubble concentration in that case increased by about a factor of ten to reach $>2.5 \times 10^{23} / \mathrm{m}^{3}$ at 13 dpa without evidence of saturation. Alloying elements like titanium and phosphorus can have indirect effects on void formation and growth when they are in solid-solution, and can also directly affect helium hubble nucleation in steels by causing the formation of fine $\mathrm{MC}$ or $\mathrm{M}_{2} \mathrm{P}$ precipitates.

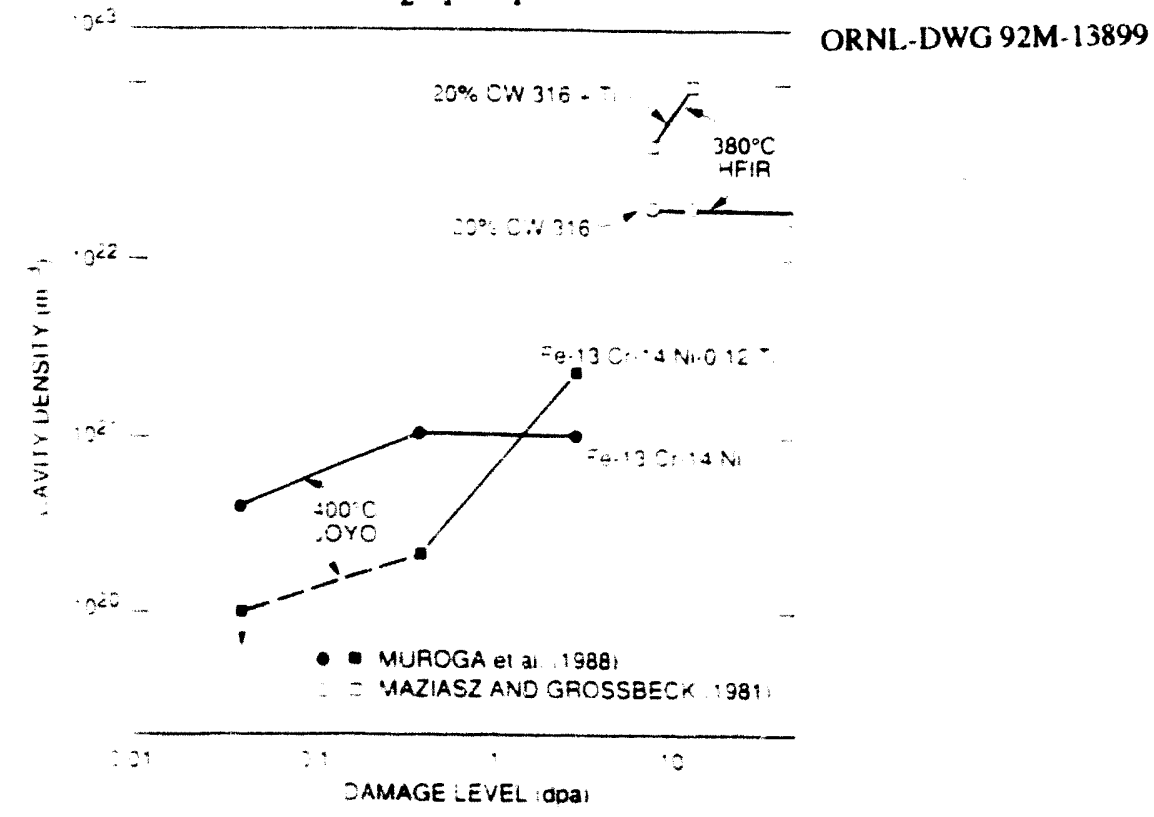

Fig. 13. Effect of Ti additions on extending the transient regime for cavity nucleation in austenitic stainless steels irradiated in a fast neutron [61] and inixed spectrum [64] fission reactor.

The transition in the mactoscopic void swelling behavior from a low-swelling regime to a linear high-swelling regime is direculy related to the microscopic void nucleation. However, the duration of the low-swelling transient regime is typically much greater than the dose required for the "steady-state" cavity 
density to evolve. Whereas the cavity density in an alloy such as Type 316 steel typically reaches its "saturation" level within a few dpa, the swelling transient can extend to doses in excess of $10 \mathrm{dpa}$. The difference in the duration of the cavity nucleation and void swelling transients is due to the dose needed to convert gas-stabilized bubbles to bias-driven voids [71,72]. Cavities below a certain critical size are unstable because they emit vacancies faster than they absorb vacancies; such cavities require an internal gas pressure to exist, and therefore only grow as bubbles driven by gas absorption (and at high densities, coalescence). When a cavity reaches a critical size, vacancy absorption overcomes emission and the cavity can grow without further need of additional gas absorption. The macroscopic void swelling transient is largely determined by the time required for the bubbles to reach the critical size and convert to voids. Since cavity nucleation necessarily precedes the conversion of bubbles to voids, the cavity nucleation transient regime is always somewhat shorter than the void swelling transient.

Figure 14 summarizes the dose-dependent void swelling behavior of several different types of austenitic stainless steels $[3,4]$. In high-purity ternary alloys, the swelling transient may last only a few dpa, whereas in fast-breeder reactor irradiated SA 316 that period is about $30 \mathrm{dpa}$, and in $20 \%$ CW 316 can be about $50 \mathrm{dpa}$. Studies in which the transient regime for macroscopic swelling during neutron irradiation of advanced austenitic steels extends to damage levels of 70 dpa or more correlate with similar extensions of the "incubation" dose for microscopic void formation $[8,69,73-76]$. Such prolonged transients in advanced steels are always related to delayed void formation (bubble to void conversion) as opposed to delayed void growth.

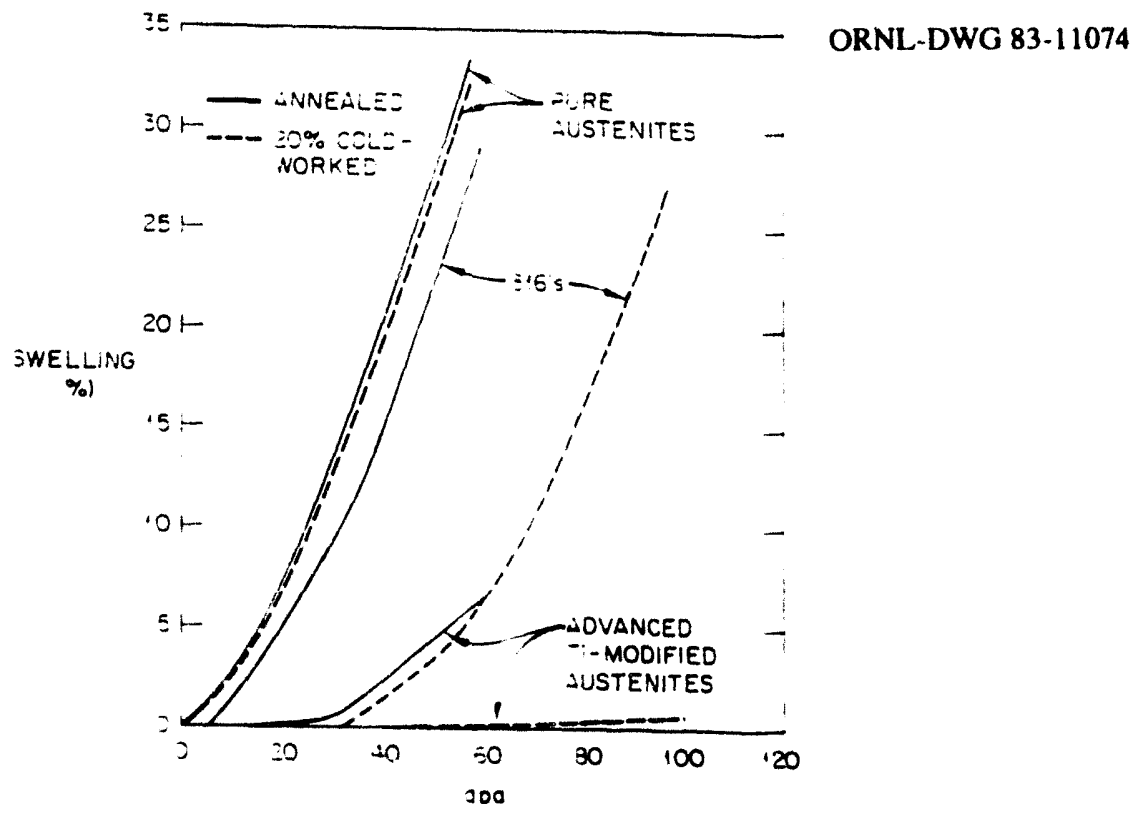

Fig. 14. Trend lines for swelling of austenitic steels irradiated in the EBR-II fast reactor at temperatures of 500 to $650^{\circ} \mathrm{C}[3,4]$.

Only small dimensional changes can be tolerated in most reactor structural components. Posttransient swelling rates in austenitic steels are typically from $0.4 \%$ to $1 \%$ per dpa for irradiation temperatures between 400 and $600^{\circ} \mathrm{C}[56,67,77]$. Therefore, the most realistic engineering goal for changing materials behavior in an irradiation environment is to extend the low-swelling transient period. The scientific apprcach to development of swelling-resistant alloys has been to control microstructural development during irradiation in order to delay void formation as long as possible. Several factors can 
influence the duration of the void swelling "incubation" period. One major factor is the amount of gas available to promote bubble formation and growth. Reaching the critical cavity size for void formation is equivalent to the bubble obtaining a critical number of gas atoms $[71,72]$. Both residual gases $(O)$ and gases generated by transmutation reactions $(\mathrm{H}, \mathrm{He}$ ) can play a role. The simplest effect of adding some of the solutes commonly found in steels $(\mathrm{C}, \mathrm{Si}$, Ti are all potent deoxidizers) is to react with residual oxygen and remove it from the alloy system [78], so that void nucleation now must depend on the transmutation-

generated gas buildup during irradiation to stabilize bubble nuclei. In commercial steels, residual gases can play a significant role in the low-dose cavity behavior, whereas at higher doses transmutant gases increasingly influence bubble formation, growth, and conversion to voids. Helium has generally been shown to be the most important gaseous transmulant [71]. The dose to obtain the critical number of gas atoms to induce conversion of bubbles to voids for a fixed bubble density is inversely proportional to the helium generation rate. In addition, helium has a strong direct influence on the evolution of bubble density, with many experimental observations supporting a roughly square-root dependence of the bubble density on the helium generation rate [79]. This has been shown to lead to void swelling behavior which is not a simple, monotonic function of the helium generation rate $[8,80]$.

\section{Precipitation and Solute Segregation}

Several different precipitate phases normally form in type 316 austenitic steels during thermal aging at 550 to $900^{\circ} \mathrm{C}$ in the absence of irradiation $[6,15,81-83]$. These phases include carbides such as $\mathrm{M}_{23} \mathrm{C}_{6}$ and $\mathrm{M}_{6} \mathrm{C}$ (and $\mathrm{MC}$ if Ti or $\mathrm{Nb}$ are present) and intermetallic phases such as Laves, sigma and chi. If type 316 steel is appropriately modified, phosphides $\left(\mathrm{M}_{2} \mathrm{P}\right.$ or $\left.\mathrm{M}_{3} \mathrm{P}\right)$ or $\mathrm{G}$-phase $\left(\mathrm{M}_{6} \mathrm{Ni}_{16} \mathrm{Si}_{7}\right)$ silicides can also precipitate during aging. The main feature of neutron irradiation is to introduce new or composition-modified phases which are not observed during thermal aging. Radiation-induced solutesegregation and radiation-affected precipitation in austenitic steels are complex topics that have been the subject of numerous conferences and review articles [6,7,9,15,81-83]. For this paper, we will merely present a brief overview of the salient fealures of precipitation that enable us to discuss the overall microstructural evolution. The reader will find more detailed information on precipitation behavior in neutron-irradiated steels in the papers cited above.

Figure 15 shows the experimental dose and temperature regimes in which precipitation has been observed in SA type 316 austenitic steel following fast reactor irradiation [6]. The detailed phase evolution in austenitic steel is sensitive to several factors, including metallurgical variables such as alloy composition and irradiation parameters such as spectral or danage-rate effects [7]. Despite such differences, precipitation generally occurs only in the temperature range of about $30010800^{\circ} \mathrm{C}$ for both mixed-spectrum and fast reactor irradiations $[6,7]$. Significant anounts of precipitation typically does not begin to occur until doses on the order of 1 to $10 \mathrm{dpa}$. In some cases, the formation of certain phases peculiar to the irradiation environment (silicides like $\gamma$ - $\mathrm{Ni}_{3} \mathrm{Si}$ or G-phase) can be delayed until doses in excess of $50 \mathrm{dpa}$ are achieved [6,7]. In other cases, some radiation-induced phases (fine $\gamma^{\prime}$ or $\mathrm{M}_{2} \mathrm{P} / \mathrm{M}_{3} \mathrm{P}$ phosphide needles) form in the high-temperature regime after only a few dpa and then dissolve at higher doses of $20 \mathrm{to} 40 \mathrm{dpa}$. It is therefore difficult to categorize transient and "steady-state" regimes for radiation-produced precipitation. Indeed, the concept of a "steady-state" precipitate microstructure may not be appropriate until doses in excess of $50 \mathrm{dpa}$. The extended transient asscciated with the formation of radiation-produced precipitation can have a profound impact on the other microstructural components, such as Frank loop formation and the total dislocation density.

The formation of precipitates in steels is controlled by solute segregation, which can be substantially modified during irradiation as a result of preferential solute-defect coupling $[6,7,9]$. Therefore, RIS and the associated precipitation are sensitive to any thing that modifies point-defect behavior [84-87]. Solute segregation creates spatially localized variations in the alloy composition; initially RIS effects occur 


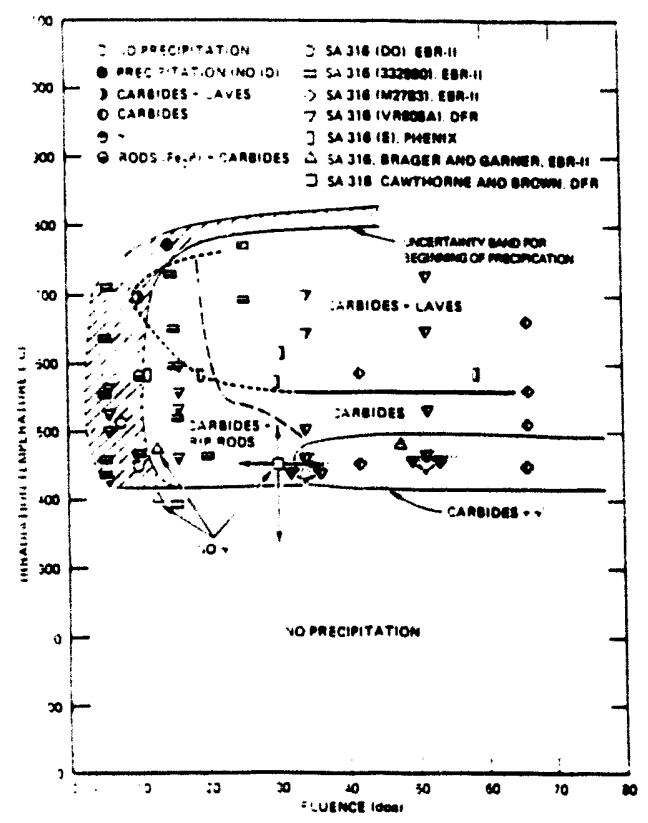

ORNL-DWG 83-14875R

Fig. 15. Temperature and dose regimes where precipitation is observed in solution annealed Type 316 stainless steel irradiated in fast neutron fission reactors [6].

only at sinks such as Frank loops and voids, but at high doses RIS eventually also affects the matrix between the various microstructural features [88-90]. This creates the possibility of triggering precipitation of phases in these segregated volumes that would not normally be seen during aging in alloys of the original bulk composition.

The general effect of RIS in austenitic alloys is to cause the buildup of undersized solutes such as $\mathrm{Ni}, \mathrm{Si}$, and to a lesser extent, $\mathrm{P}$ at sinks, mainly by the interstitial drag mechanism. Since the interstitialsolute complexes are generally highly mobile, this segregation mechanism usually dominates at lower temperatures and doses. RIS typically also causes depletion of oversized (fast-diffusing) substitutional elements like $\mathrm{Cr}$ and $\mathrm{Mo}$ at sinks during irradiation, mainly due to the inverse-Kirkendall vacancy diffusion mechanism. These effects are usually more prominent at higher temperatures and doses due to the relatively sluggish vacancy diffusivities. Nickel is a slow-diffusing solute in steel, so it is enriched at sinks via both the inverse-Kirkendall mechanism and the interstitial drag mechanism. The buildup of $\mathrm{Ni}$ at sinks is a characteristic feature of $\mathrm{R}$ - over a wide range of dose and temperature. Conversely, while silicon is enriched at sinks via the the drag mechanism, it is a fast-diffusing substitutional solute and can be depleted via the inverse-Kirkendall mechanism. Figure 16 shows an example of the net effects of RIS described above ( $\mathrm{Si}$ and Ni enrichment, $\mathrm{Cr}$ depletion) that occurred at a large Frank loop in neutron-irradiated austenitic steel [88]. Manganese is an example of an alloying element whose RIS behavior depends on alloy composition. In type 316 steel with a small amount of $\mathrm{Mn}(2 \mathrm{wt} \%)$, little effect of RIS is found, whereas in a Mn-stabilized steel (Russian EP-838, 13.5 wt \%), Mn was depleted at sinks instead of $\mathrm{Cr}$ due to its faster substitutional diffusivity [88]. While it is simple to say that RIS is the dominant mechanism affecting radiation-produced precipitation, it can be seen that the detailed RIS behavior of the various solute elements in each particular heat of steel is complicated.

The precipitates that form in austenitic steels during irradiation can be classified into three general groups, as outlined in Table $2[9,83]$. The first precipitate category includes radiation-enhanced and -retarded thermal phases. These precipitates are normally found to have the same phase composition after thermal 
RAS TO FAULTED DISLOCATION LOOPS IN NHSTABILZED USPCA FFTF, 15 dpa, $520^{\circ} \mathrm{C}$

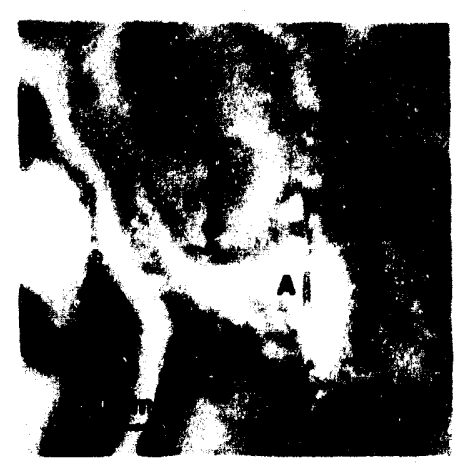

A
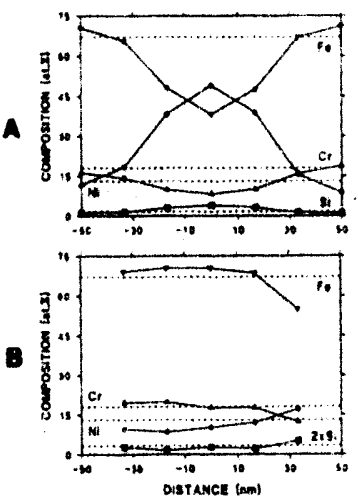

Fig. 16. (a) Nearly edge-on dislocation loops (A,B) in solution annealed PCA steel irradiated in the FFTF fast fission reactor to $15 \mathrm{dpa}$ at $520^{\circ} \mathrm{C}$. (b) RIS profiles at loop A, which has a diameter of $\sim 100 \mathrm{~nm}$. (c) RIS profiles at loop B, which has a diameter of $\sim 50 \mathrm{~nm}$. Dashed lines indicate the composition levels in the unperturbed matrix [88].

aging or neutron irradiation, but their relative abundances are different in the two environments. Radiationenhanced precipitation refers to an enhancement in the kinetics or nucleation level of a thermal precipitate phase, or to the formation of the phase at a lower temperature during reactor irradiation compared to thermal aging of the same steel. Conversely, radiation-retarded precipitation refers to phase formation which is less abundant or shifted to higher temperatures in the presence of irradiation. Radiation-enhanced and -retarded phases are thermally stable and do not disappear or change chemical composition during postirradiation annealing at the irradiation temperature [91]. The particular thermal phases enhanced or retarded during irradiation depend on the level of RIS during irradiation. When RIS is at a high level (e.g., SA 316, fastreactor irradiation), $\mathrm{M}_{6} \mathrm{C}$ and Laves formation is enhanced during irradiation, while $\mathrm{M}_{23} \mathrm{C}_{6}$ (and in Timodified steels, MC) formation is retarded during irradiation. At a lower level of RIS (e.g., CW 316, mixed-spectrum reactor irradiation) a phase like $\mathrm{M}_{23} \mathrm{C}_{6}$ that was retarded in the previous case can now be enhanced during irradiation. Another group of precipitates are the irradiation-modified thermal phases, such as $\mathrm{M}_{6} \mathrm{C}$ and Laves. These phases have the same crystal structure (and often same morphology) as the corresponding phases formed during aging, but their phase composition is different during irradiation. Generally the compositional differences reflect the effects of $\mathrm{RIS}$ (more $\mathrm{Ni}$ and $\mathrm{Si}$, less $\mathrm{Cr}$ and $\mathrm{Mo}$ ) balanced against the inherent compositional flexibility of the thermal phase. The third group of precipitates are radiation-induced phases. Such phases are unique to the irradiation environment, and would not form in that particular heat of steel during aging at any temperature. These phases are thermally unstable and dissolve during postirradiation annealing at the irradiation temperature [91]. The formation of radiation-induced precipitates is caused by RIS creating a localized compositional modification around a sink that is sufficient to induce precipitation of a new phase. 
Table 2. Classes of radiation-produced precipitate phases in 300-series austenitic stainless steels

\begin{tabular}{|l|c|c|}
\hline \multicolumn{1}{|c|}{$\begin{array}{c}\text { Radiation-enhanced, } \\
\text {-retarded phases }\end{array}$} & Radiation-modified phases & Radiation-induced phases \\
\hline $\mathrm{M}_{6} \mathrm{C}$, Laves, $\mathrm{M}_{23} \mathrm{C}_{6}$, & $\mathrm{M}_{6} \mathrm{C}$, Laves, $\mathrm{M}_{2} \mathrm{P}$ & $\mathrm{M}_{6} \mathrm{Ni}_{16} \mathrm{Si}_{7}(\mathrm{G})$, \\
$\mathrm{MC}, \sigma, \chi$ & & $\mathrm{Ni}_{3} \mathrm{Si}\left(\gamma^{\prime}\right)$, \\
& & $\mathrm{MP}, \mathrm{M}_{2} \mathrm{P}, \mathrm{M}_{3} \mathrm{P}$ \\
\hline
\end{tabular}

Figure 17 shows the fluence-dependent nickel content of Laves precipitates in SA and 20\%CW type 316 steel irradiated at 500 to $550^{\circ} \mathrm{C}$ in fast and mixed-spectrum reactors $[9,45,92,93]$. Similar fluencedependent compositional changes have been observed for other precipitates, such as the radiation-enhanced MC phase [94]. During thermal aging, the Ni content of the Laves phase is characteristically low (5 to $8 \mathrm{wt} \%$ ) in both SA and $20 \% \mathrm{CW}$ material. The nickel content of radiation-produced Laves is direculy related to the degree of compositional modification caused by RIS. When RIS is intense (e.g., when voids are forming easily during irradiation, SA 316 in HFIR or 20\%CW 316 in EBR-II), the Ni-content of the Laves phase increases significantly with dose, and does not appear to have stabilized even after doses in excess of $50 \mathrm{dpa}$ (Fig. 17a and 17b). Conversely, when RIS is low or suppressed (e.g., when a high density of bubbles form and do not convert to voids, 20\%CW 316 in HFIR), the Laves Ni-content remains low and does not change during extended irradiation (Fig. 17b). When type 316 stainless steel is aged to produce thermal precipitation prior to irradiation, these precipitates consistently dissolve rapidly before the appropriate radiation-produced phases form [95]. The detailed behavior of radiation-produced precipitation in steels is very sensitive to irradiation parameters (temperature, He/dpa ratio, damage rate) and metallurgical variables (heat-to-heat compositional variations, pretreatment).

ORNL-DWG $₫ 3-15910 / O R N L-D W G$ 82-13222
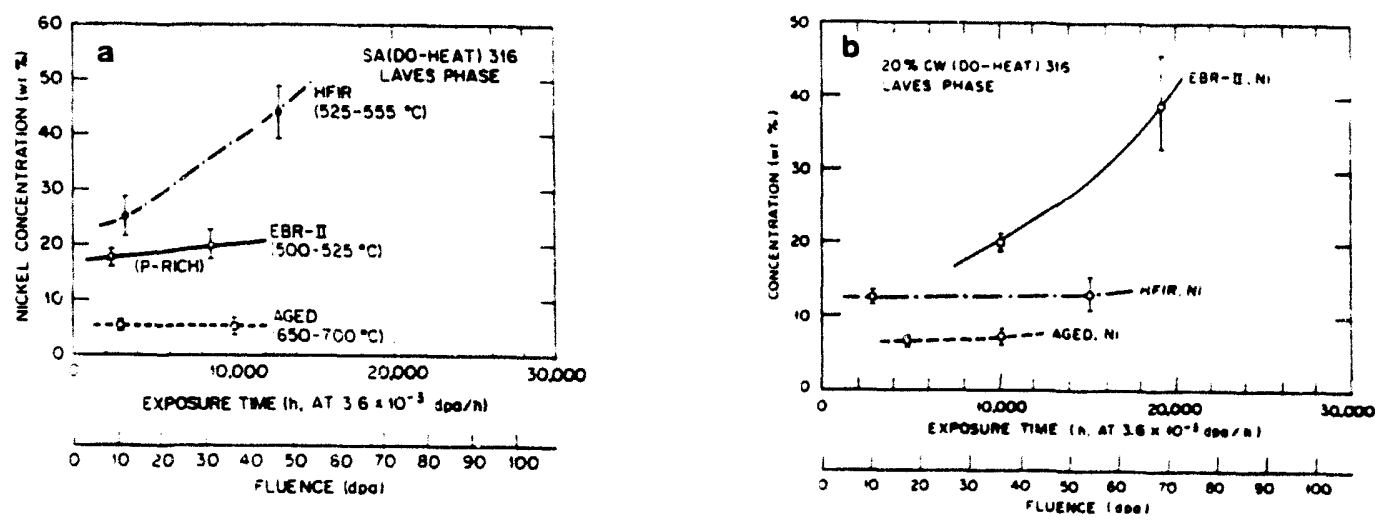

Fig. 17. Energy dispersive $x$-ray spectroscopy measurements of the Ni concentration of individual Laves phase particles on extraction replicas from a) SA 316 ars b) CW 316 after thermal aging or neutron irradiation in a fast neutron (EBR-II) or mixed spectrum (HFIR) fission reactor [45]. 
The presence of radiation-modified or -induced phases during irradiation at temperatures of 450 to $600^{\circ} \mathrm{C}$ is generally a sign of poor radiation resistance. These precipitates are indicators that significant solute segregation has taken place during the irradiation, which implies that a high level of solute-coupled point defect fluxes were present. Since high point defect fluxes generally accelerate deleterious radiationinduced processes such as void swelling, the presence of high levels of RIS (directly visible in the form of radiation-induced or-modified precipitates) is an indication of a microstructure with poor radiation stability. Conversely, the presence of thermally stable precipitates (radiation-enhanced or -retarded) is an indicator of a radiation-resistant microstructure. As discussed below, the fine radiation-induced $\mathrm{M}_{2} \mathrm{P}$ precipitates in phosphorus-modified steels are a notable exception to this general rule.

Precipitates can directly affect partitioning of defect fluxes when the matrix-precipitate interfaces act as sinks for point defects. Relatively high precipitate densities are required for such precipitate sink-strength effects to be significant in irradiated materials. Due to their small size and high density, the radiationinduced $\mathrm{M}_{2} \mathrm{P}$ precipitates that forn in phosphorus-modified steels effectively disperse He atoms and promote point defect recombination. Since the $\mathrm{M}_{2} \mathrm{P}$ precipitates are resistant to coarsening up to high doses [96], this produces a swelling-resistant microstructure. The $\gamma$ radiation-induced precipitates also initially aci to suppress void swelling due to their high density (high sink strength). However, $\gamma^{\prime}$ coarsens rapidly during irradiation at temperatures $2500^{\circ} \mathrm{C}[96]$. This reduces the $\gamma$ sink strength to a level where it is not effective in dispersing He atoms or promoting point defect recombination, producing poor swelling resistance. Most of the radiation-induced and -modified phases in austenitic steels (Table 2) have undersized volumetric misfit strains relative to the lattice. Such misfit-strain effects lead to a further enhancement of void swelling because interstitials will be preferentially attracted to the precipitate-matrix interface, creating a precipitatebased interstitial bias component that complements the more familiar dislocation bias. Another way in which certain precipitates directly enhance void formation and growth is when coarse precipitate particles are attached to voids of comparable size $[92,96]$. Generally, such behavior is observed for radiation-induced or -modified $\mathrm{G}$, Laves and $\mathrm{M}_{6} \mathrm{C}$ phases $[92,96,97]$, which is an indication of strongly coupled RIS and vacancy fluxes. Since RIS is normally strong to large voids, it is logical that the formation of phases that require RIS would occur at void sites. Moreover, the formation and growth of such RIS-compatable precipitates at voids then directly enhances void growth by mechanisms that involve the precipitate as a vacancy collector for the void $[92,96,98]$.

Precipitate formation is just one of the microstructural factors that contribute to the extension of the low-swelling transient regime in type 316 steel relative to simple tenary alloys. However, precipitation is the dominant microstructural feature responsible for extension of the low-swelling transient to doses in excess of $80 \mathrm{dpa}$ in swelling-resistant advanced steels. In this case, the combination of alloy compositional modification (Ti, C., Si, P additions) and pretreatment condition (20-25\% CW) causes fine precipitation of radiation-enhanced thermal phases (MC and/or FeTiP needles) instead of the radiationaffected RIS-compatable phases generally associated with voids. These special carbides and phosphides contain titanium (and $\mathrm{Mo}, \mathrm{V}$ and $\mathrm{Nb}$ in some cases), and generally contain little or no nickel and silicon. By contrast, the radiation-induced or -modified phases $\left(\mathrm{G}, \gamma^{\prime}, \mathrm{M}_{6} \mathrm{C}\right.$ and Laves) have nickel and silicon as their main constituents.

The fine stable thermal phases that form in advanced steels during irradiation at 400 to $600^{\circ} \mathrm{C}$ impart void formation resistance through several mechanisms, which include: (a) interfacial helium trapping, often resulting in finer and more profuse helium bubble nucleation than would occur without the precipitates $[96,99,100]$, (b) increased sink strength, which promotes point defect recombination at the precipitate/matrix interface [96], and (c) precipitate pinning of dislocations to hinder climb associated with excess interstitial absorption [96]. Such void-resistant microstructures establish themselves quickly during irradiation and then remain relatively unchanged for long periods of time $[9,69,73-76,93]$. However, they represent a transient rather than a "steady state" microstructure during irradiation. Indeed, as voids finally begin to form at higher doses, the fine thermal precipitates begin to dissolve $[69,73-76,94,101]$. This 
eventually produces a transition from the low-swelling to the high-swelling rate regime. A key point is that very dramatic changes occur in the microstructure before macroscopic swelling changes are observed. Fast reactor irradiation data from both the French $20-25 \% \mathrm{CW}$ 15-15Ti steel modified with $\mathrm{B}+\mathrm{P}$ and the Japanese PNC316 steel modified with $\mathrm{T} i+\mathrm{P}+\mathrm{B}$ indicate that the extension of the low-swelling transient to beyond $80 \mathrm{dpa}$ depends on the existence of fine dispersions of MC or FeTiP precipitates and their resistance to dissolution [69,73-76]. The French data in particular indicates that such microstructures may be stable to more than $150 \mathrm{dpa}[75]$.

\section{Discussion}

There is no simple relation that connects the neutron displacement damage level directly to the establishment of a "steady-state" or saturation microstructure in austenitic stainless steel. Although the concept of a "steady-state" microstructure may be viable in the low-temperature irradiation regime, that concept loses meaning for many of the microstructural components in certain types of austenitic steels at higher irradiation temperatures. The duration of the macroscopic low.swelling transient regime is the result of a complex microstructural evolution, which in turn depends (synergistically) on many other irradiation parameters and metallurgical variables, not just dose.

In the "low temperature" regime $\left(<300^{\circ} \mathrm{C}\right)$, the high sink density associated with thermally stable vacancy clusters produced in the displacement cascades suppresses the concentration of freely-migrating point-defects and inhibits their long-range migration. Hence, the length of the microstructural transient at these temperatures is largely controlled by the dose needed to induce significant physical cascade overlap (i.e., $\sim 0.1 \mathrm{dpa}$ ). However, despite the high density of sinks, the low point defect mobilities associated with this temperature regime can lead to extended transients in the point defect concentrations $[10,50]$. For irradiation temperatures below about $150^{\circ} \mathrm{C}$, the time required for the point defect concentrations to reach steady state can exceed the duration of typical reactor irradiation experiments. For example, the calculated point defect transient lasts about six years at $100^{\circ} \mathrm{C}$ [50]. The interstitial concentrations would be much higher and the corresponding vacancy concentration much lower than their steady state values during this transient. Since microstructural evolution is generally driven by the difference in the point defect fluxes, the use of theoretical models which assume steady state point defect concentrations can lead to significant errors in predicting microstructural evolution at low temperatures. The significant dislocation recovery shown at low temperatures in Fig. 10 and the surprisingly large amount of creep observed in steel irradiated at $<150^{\circ} \mathrm{C}[50]$ are examples of the potential impact of the extended point defect transient. Hence, the relationship between point-defect behavior and microstructural evolution is complex, even at low irradiation temperatures.

The evolution of the dislocation loop and cavity densities in simple $\mathrm{Fe}-\mathrm{Cr}-\mathrm{Ni}$ ternaries during irradiation in the "high-temperature" regime $\left(300\right.$ to $\left.700^{\circ} \mathrm{C}\right)$ can be described by a relatively rapid initial microstructural transient that is completed within damage levels of about 0.5 to $5 \mathrm{dpa}$. This initial transient is subsequently followed by a secondary microstructural transient that can extend to doses in excess of $50 \mathrm{dpa}$, due to interaction between the various microstructural components. The initial microstructural transient regime for the total dislocation density (loops plus network) generally requires doses in excess of $10 \mathrm{dpa}$ and is controlled primarily by the process of loop growth and unfaulting. Since solute segregation to dislocation loops can be pronounced (Fig. 16) [88], the duration of the transient regime for the total dislocation density may be influenced by RIS. The evolution of bubbles and voids in the high-temperature regime is controlled by RIS-modifed accumulation of helium atoms and vacancies. Microcompositional studies $[102,103]$ have found that substantial RIS of rickel is detectable around tiny helium bubbles and small voids. Other studies have shown thick $(20-40 \mathrm{~nm})$ RIS zones around larger voids [6,9], so that RIS is involved in all stages of void evolution. Under certain conditions at 400 to $550^{\circ} \mathrm{C}$, the initially homogeneous austenite matrix can break up into a heterogeneous mixture of austenite (the $\mathrm{Ni}$-rich regions 
around sinks) and $\alpha$-ferrite at doses in excess of 30 dpa $[7,90,104,105]$. This may represent the true "steady state" microstructure during irradiation (and corresponds with swelling saturation), but is technologically uninteresting since it only occurs after a large amount of void swelling and is a highly embrittled mechanical condition.

Clearly the most difficult phenomena to classify in terms of a "steady state" microstructure is radiation-produced precipitation. In most steels, the precipitate behavior falls somewhere between the extremes of highly RIS-affected phase formation and radiation-enhanced thermal phase formation with relatively weak RIS effects. Because both of these precipitate classes require sustained solute segregation and point defect fluxes to form and remain stable, this component of the evolving microstructure usually lags behind the others during irradiation. Since the stability of fine radiation-induced precipitates is dependent on the same mechanisms that caused them to form, subtle changes in the global microstructure, point defect fluxes, or RIS generally affects the precipitate structure more than the void or dislocation network structures. The transient for precipitate formation in relatively simple alloys like type 316 is generally greater than 10 dpa.

In advanced swelling-resistant steels, fine dispersions of thermal phases that are not compatible with RIS (e.g., MC) develop rapidly during irradiation and remain stable up to high doses ( $>50 \mathrm{dpa}$ ). This dense precipitate microstructure promotes uniform dispersal of helium atoms and forces virtually all of the freely migrating defects to recombine at sinks, which depresses the vacancy supersaturation and thereby inhibits cavity nucleation. The finely dispersed sinks also dilute RIS to the point that it is not significant. The extended period during which this nearly-thennal microstructure exists is not a true "steady state", because when point defect concentrations eventually move toward "steady state" values and RIS begins to develop, the "thermal" precipitates dissolve and the microstructure enters a new transient that evolves toward a strongly radiation-affected microstructure of voids, dislocations and radiation-modified or -induced precipitates.

The complexities in the microstructural evolution of austenitic steels in the transient regime may be contrasted with the relatively straightforward behavior of pure metals [38]. The irradiation dose needed for void and dislocation loop nucleation to be completed in Ni during neutron irradiation at elevated temperature is only about $1 \mathrm{dpa}$, and compared to austenitic steel the length of the transient is relatively insensitive to neutron spectrum differences. This comparison highlights the importance of solutes and precipitates on the extension of the transient regime. The situation for steel becomes increasingly complex as additional solutes are added to the base ternary composition. The strong synergistic effects between the various alloying elements, and interactions between the various components of the microstructure cause an extension of the microstructural transients and the macroscopic low-swelling regime to very high doses in technologically relevant steels. Mechanistically, macroscopic low swelling behavior is only possible when the microstructure inhibits the normally efficient biased partitioning of vacancies and interstitials to sinks and instead promotes point defect recombination during irradiation.

\section{Conclusions}

The damage level needed to achieve a "steady state" microstructural condition in neutron-irradiated austenitic stainless steel varies from less than 0.1 dpa to greater than 50 dpa, dependling on the irradiation conditions and the specific microstructural component being investigated. The evolution of most of the microstructural components $\mathrm{c}$ an be characterized by a relatively rapid initial transient regime lasting for a damage level of about $1 \mathrm{dpa}$, Collowed by a slowly evolving secondary transient regime. Due to interactions between the various microstructural components which evolve at different rates, the overall microstructure $\because$ ically remains in this secondary transient regime up to very high damage levels ( $>50 \mathrm{dpa}$ ). In some (but 
not all) cases, steady state approximations may be invoked for the purposes of irradiation effects modeling in this secondary transient regime.

Despite the hundreds of neutron irradiation studies performed on austenitic stainless steels over the past 25 years, it is apparent that further irradiation experiments are needed due to a lack of systematic data at low temperatures $\left(<350^{\circ} \mathrm{C}\right)$ and low doses $(<10 \mathrm{dpa})$. Data are needed on both complex and simple model alloys to further our understanding of the microstructural evolution. For fusion reactor applications, singlevariable experiments at fusion-relevant He/dpa ratios (utilizing spectral tailoring or isotopic tailoring techniques) are needed to investigate the important experimental parameters and controlling mechanisms associated with the transient regime.

Acknowledgments

This work was sponsored by the Office of Fusion Energy and the Office of Basic Energy Sciences, U.S. Department of Energy, under contract DE-AC05-84OR21400 with Martin Marietta Energy Systems, Inc.

\section{References}

[1] P.J. Maziasz and D.N. Braski, J. Nucl. Mater. 122\&123 (1984) 311.

[2] H.R. Brager and F.A. Garner, J. Nucl. Mater. $108 \& 109$ (1982) 347.

[3] P.J. Maziasz, J. Nucl. Mater. 122\&123 (1984) 472.

[4] H.R. Brager and F.A. Garner, J. Nucl. Mater. 117 (1983) 159.

[5] F.A. Garner and H.R. Brager, in Effects of Radiation on Materials, Vol. I, ASTM STP 870, Eds. F.A. Garner and J.S. Perrin (ASTM, Philadelphia, 1985) p. 187.

[6] P.J. Maziasz and C.J. McHargue, Intern. Mater. Rev. 32 (1987) 190.

[7] P.J. Maziasz, J. Nucl. Mater. 169 (1989) 95.

[8] R.E. Stoller, J. Nucl. Mater. 174 (1990) 289.

[9] P.J. Maziasz, J. Nucl. Mater. 205 (1993), in press.

[10] L.K. Mansur, J. Nucl. Mater., in press.

[11] R.E. Stoller and G.R. Odette, in Radiation-Induced Changes in Microstructure (Part I), ASTM STP 955, Eds. F.A. Garner, N.H. Packan and A.S. Kumar (ASTM, Philadelphia, 1987) p. 371.

[12] G.E. Lucas, J. Nucl. Mater., in press.

[13] J.I. Bramman, K.Q. Bagley, C. Cawthorne, E.J. Fulton and W.D.J. Sinclair, in Voids Formed by Irradiation of Reactor Materials, Eds. S.F. Pugh, M.H. Loretto and D.I.R. Norris (BNES, 1971) p. 27.

[14] H.J. Bergmann, W. Dietz and D. Haas, J.Nucl. Mater. 65 (1974) 210.

[15] D.R. Harries, in Mechanical Behaviour and Nuclear Applications of Stainless Steel at Elevated Temperatures (The Metals Society, London, 1982) p. 1.

[16] B.A. Chin, R.J. Neuhold and J.L. Straalsund, Nucl. Tech. 57 (1982) 426.

[17] J.L. Seran et al., in Effects of Radiation on Materials, Vol. I, ASTM STP 870, Eds. F.A. Gamer and J.S. Perrin (ASTM, Philadelphia, 1985) p. 233.

[18] P.J. Maziasz and T.K. Roche, J. Nucl. Mater. 103\&104 (1981) 797.

[19] J.W. Corbett, Electron Radiation Damage in Semiconductors and Metals, Solid State Physics Suppl. 7 (Academic Press, New York, 1966).

[20] W. Schilling, P. Ehrhart and K. Sonnenberg, in Fundamental Aspects of Radiation Damage in Metals, Vol. 1, Eds. M.T. Robinson and F.W. Young, Jr., CONF-751006-P1, (NTIS, Springfield, VA, 1975) p. 470.

[21] C. Dimitrov, A. Benkaddour, O. Dimitrov, C. Corbel and P. Moser, Mater. Sci. Forum 15-18 (1987) 1275.

[22] P.J. Maziasz, J. Nucl. Mater. 191-194 (1992) 701.

[23] H.R. Brager and J.L. Straalsund, J. Nucl. Mater. 46 (1973) 134. 
[24] E.E. Bloom and J.O. Stiegler, in Effects of Radiation on Substructure and Mechanical Properties of Metals and Alloys, ASTM STP 529 (ASTM, Philadelphia, 1973) p. 360.

[25] H.R. Brager, J. Nucl. Mater. 57 (1975) 103.

[26] H.R. Brager, F.A. Garner and G.L. Guthrie, J. Nucl. Mater. 66 (1977) 301.

[27] P.J. Barton, B.L. Eyre and D.A. Stow, J. Nucl. Mater. 67 (1977) 181.

[28] P.J. Maziasz, Trans. ANS 39 (1981) 433.

[29] M.P. Tanaka, S. Hamada, A. Hishinuma, and P.J. Maziasz, J. Nucl. Mater. 155-157 (1988) 801.

[30] S. Hamada, M. Suzuki, P.J. Maziasz, A. Hishinuma and M.P. Tanaka, in Effects of Radiation on Materials, ASTM STP 1046, Vol. I, Eds. N.H. Packan, R.E. Stoller and A.S. Kumar (ASTM, Philadelphia, 1989) p. 172.

[31] H.R. Brager, F.A. Garner, E.R. Gilbert, J.E. Flinn and W.G. Wolfer, in Radiation Effects in Breeder Reactor Structural Materials, Eds. M.L. Bleiberg and J.W. Bennett (TMS-AIME, New York, 1977) p. 727.

[32] H.R. Brager, E.R. Gilbert and J.L. Straalsund, Rad. Effects 21 (1974) 37.

[33] B.L. Eyre, in Fundamental Aspects of Radiation Damage in Metals, Vol. 2, Eds. M.T. Robinson and F.W. Young, Jr. CONF-751006-P2 (NTIS, Springfield, VA, 1975) p. 729.

[34] T. Muroga, Y. Miyamoto, H. Watanabe and N. Yoshida, J. Nucl. Mater. 155-157 (1988) 810.

[35] S.J. Zinkle and R.L. Sindelar, J. Nucl. Mater. 155-157 (1988) 1196.

[36] N. Yoshida, J. Nucl. Mater. 174 (1990) 220.

[37] T.M. Robinson and M.L. Jenkins, Phil. Mag. A 34 (1981) 999.

[38] B.N. Singh and S.J. Zinkle, in press, J. Nucl. Mater.

[39] H.R. Higgy and F.H. Hammad, J. Nucl. Mater. 55 (1975) 177.

[40] H.R. Brager, L.D. Blackburn and D.L. Greenslade, J. Nucl. Mater. 122\&123 (1984) 332.

[41] H. Kawanishi and S. Ishino, J. Nucl. Mater. 155-157 (1988) 806.

[42] H. Kawanishi and S. Ishino, J. Nucl. Mater. 179-181 (1991) 534.

[43] T. Sawai, P.J. Maziasz and A. Hishinuma, J. Nucl. Mater. 179-181 (1991) 519.

[44] N. Yoshida, Q. Xu, H. Watanabe, T. Muroga and M. Kiritani, J. Nucl. Mater. 191-194 (1992) 1114.

[45] P.J. Maziasz, Effects of He Content on Microstructural Development in Type 316 Stainless Steel under Neutron Irradiation, ORNL-6121 (Oak Ridge, TN, 1985).

[46] J.I. Bramman, C. Brown, C. Cawthorne, E.J. Fulton and G.A.B. Linekar, in The Physics of Irradiation Produced Voids, UKAEA Report AERE-R7934, Ed. R.S. Nelson (Harwell, UK, 1975) p. 71 .

[47] G.D. Johnson, F.A. Garner, H.R. Brager and R.L. Fish, in Effects of Radiation on Materials, ASTM STP 725, Eds. D. Kramer, H.R. Brager and J.S. Perrin (ASTM, Philadelphia, 1981) p. 393.; F.A. Garner, M.L. Hamilton, N.F. Panayotou and G.D. Johnson, J. Nucl. Mater. 103\&104 (1981) 803.

[48] M.L. Grossbeck, K. Ehrlich and C. Wassilew, J. Nucl. Mater. 174 (1990) 264.

[49] J.D. Elen and P. Fenici, J. Nucl. Mater. 191-194 (1992) 766.

[50] R.E. Stoller, M.L. Grossbeck and L.K. Mansur, in Effects of Radiation on Materials, ASTM STP 1125, Eds. R.E. Stoller, A.S. Kumar and D.S. Gelles (ASTM, Philadelphia, 1992) p. 517.

[51] K.Q. Bagley, J.I. Bramman and C. Cawthorne, in Voids Formed by Irradiation of Reactor Materials, Eds. S.F. Pugh, M.H. Loretto and D.I.R. Norris (BNES, 1971) p. 1.

[52] K. Farrell and N.H. Packan, in Effects of Radiation on Materials, ASTM STP 782, Eds. H.R. Brager and J.S. Perrin (ASTM, Philadelphia, 1982) p. 953.

[53] C. Brown, J.K. Butler and E.J. Fulton, in Irradiation Behavior of Metallic Materials for Fast Reactor Core Components, Eds. J. Poirier and J.M. DuPouy (CEA, Gif-Sur-Yvette, France, 1979) p. 129.

[54] W.K. Appleby and U.E. Wolff, in Effects of Radiation on Substructure and Mechanical Properties of Metals and Alloys, ASTM STP 529 (ASTM, Philadelphia, 1973) p. 122.

[55] H.R. Brager and F.A. Garner, J. Nucl. Mater. 103\& 104 (1981) 993.

[56] F.A. Garner, J. Nucl. Mater. 122\&123(1984) 459.

[57] F.A. Garner, J. Nucl. Mater. 174 (1990) 229.

[58] N. Sekimura, F.A. Garner and R.D. Griffin, J. Nucl. Mater. 191-194 (1992) 1234. 
[59] P.J. Barton and P.R.B Higgins, in Irradiation Effects on Structural Alloys for Nuclear Reactor Applications, ASTM STP 484 (ASTM, Philadelphia, 1970) p. 362.

[60] J.I. Bramman, K.Q. Bagley, C. Cawthorne and J.E. Fulton, in Radiation-Induced Voids in Metals, Eds. J.W. Corbett and L.C. Ianniello, CONF-710601 (NTIS, Spring field, VA, 1972) p. 125.

[61] T. Muroga, K. Araki, Y. Miyamoto and N.Yoshida, J. Nucl. Mater. 155-157 (1988) 1118.

[62] L.K. Mansur, Nucl. Tech. 40 (1978) 5.

[63] T. Muroga, F.A. Garner and S. Ohnuki, J. Nucl. Mater. 179-181 (1991) 546.

[64] P.J. Maziasz and M.L. Grossbeck, in Alloy Development for Irradiation Performance Semiann. Progress Report, DOE/ER-0045/7 (Sept. 1981) p. 28.

[65] F.A. Garner and A.S. Kumar, in Radiation-Induced Changes in Microstructure (Part I), ASTM STP 955, Eds. F.A. Garner, N.H. Packan and A.S. Kumar, (ASTM, Philadelphia, 1987) p. 289.

[66] N. Sekimura, F.A. Garner and J.W. Newkirk, J. Nucl, Mater. 191-194 (1992) 1244.

[67] F.A. Garner and H.R. Brager, J. Nucl. Mater. 155-157 (1988) 833.

[68] E.H. Lee and N.H. Packan, in Effects of Radiation on Materials, Vol. I, ASTM STP 1046, Eds. N.H. Packan, R.E. Stoller and A.S. Kumar (ASTM, Philadelphia, 1989) p. 133.

[69] M. Itoh, S. Onose and S. Yuhara, in Radiation-Induced Changes in Microstructure (Part I), ASTM STP 955, Eds. F.A. Garner, N.H. Packan and A.S. Kumar (ASTM, Philadeiphia, 1987) p. 114.

[70] P.J. Maziasz, in Fusion Reacior Materials Semiann. Progress Report, DOE/ER-0313/10, (July 1991) p. 99.

[71] R.E. Stoller and G.R. Odette, in Radiation-Induced Changes in Microstructure (Part I), Eds. F.A. Garner, N.H. Packan and A.S. Kumar, ASTM STP 955 (ASTM, Philadelphia, 1987) p. 358.

[72] L.K. Mansur and W.A. Coghlan, J. Nucl. Mater. 119 (1983) 1.

[73] P. Dubuisson, A. Maillard, C. Delalande, D. Gilbon and J.L. Seran, in Effects of Radiation on Materials, ASTM STP 1125, Eds. R.E. Stoller, A.S. Kumar and D.S. Gelles (ASTM, Philadelphia, PA, 1992) p. 995.

[74] J.L. Seran, et al., ibid, p. 1209.

[75] A. Maillard, H. Touron, J.L. Seran and A. Chalony, in Effects of Radiation on Materials, ASTM STP 1175, eds. A.S. Kumar, D.S. Gelles and R.K. Nanstad (ASTM, Philadelphia, PA, 1993) in press.

[76] I. Shibahara, Sukai, S. Onose, and S. Shikakura, "Irradiation Perfornance of Modified 316 Stainless Steel for Monjuo Fuel," J. Nucl. Mater. in press.

[77] R.E. Stoller, in Fusion Reactor Materials Semiann. Progress Report, DOE/ER-0313/1 (1987) p. 171.

[78] S.J. Zinkle and E.H. Lee, Met. Trans. A 21 (1990) 1037.

[79] G.R. Odette, P.J. Maziasz and J.A. Spitznagel, J. Nucl. Mater. 103\&104 (1981) 1289.

[80] R.E. Stoller and G.R. Odette, in Effects of Radiation on Materials, ASTM STP 782, Eds.

H.R. Brager and J.S. Perrin (ASTM, Philadelphia, 1982) p. 275.

[81] T.M. Williams, in Effects of Radiation of Materials, ASTM STP 782, Eds. H.R. Brager and J.S. Perrin (ASTM, Philadelphia, 1982) p. 166.

[82] W.J.S. Yang, in Radiation-Induced Changes in Microstructure, ASTM STP 955, Eds. F.A. Garner, N.H. Packan and A.S. Kumar (ASTM, Philadelphia, 1887) p. 628.

[83] E.H. Lee, P.J. Maziasz and A.F. Rowcliffe, in Phase Stability During Irradiation, Eds. J.R. Holland, L.K. Mansur and D.I. Potter (TMS-AIME, Warrendale, PA, 1981) p. 191.

[84] P.R. Okamoto and H. Wiedersich, J. Nucl. Mater. 53 (1974) 336.

[85] R.A. Johnson and N.Q. Lam, Phys. Rev. B, 13 (1976) 4364.

[86] R.A. Johnson and N.Q. Lam, J. Nucl. Mater. 69\&70 (1978) 424.

[87] H. Weidersicil, P.R. Okamoto and N.Q. Lam, J. Nucl. Mater. 83 (1979) 98.

[88] E.A. Kenik and K. Hojou, J. Nucl. Mater. 191-194 (1992) 1331.

[89] E.A. Kenik, J. Nucl. Mater. 187 (1992) 239.

[90] D.L. Porter and E.L. Wood, J. Nucl. Mater. 83 (1979) 90.

[91] P. Wilkes, J. Nucl. Mater. 83 (1979) 166. 
[92] D.F. Pedraza and P.J. Maziasz, in Radiation-Induced Changes in Microstructure (Part I), ASTM S'TP 955, Eds. F.A. Garner, N.H. Packan and A.S. Kumar (ASTM, Philadelphia, 1987) p. 161.

[93] P.J. Maziasz, in Proc. Symp. MiCon 86: Optimization of Processing, Properties and Service Performance Through Microstructural Control, ASIM STP 979, Eds. B.L. Bramfitt, R.C. Benn, C.R. Brinkman and G.F. Vander Voort (ASTM, Philadelphia, PA, 1988) p. 116.

[94] M. Suzuki, S. Hamada, P.J. Maziasz, S. Jitsukawa and A. Hishinuma, J. Nucl. Mater. 191-194 (1992) 1351.

[95] D.L. Porter, J. Nucl. Mater. 92 (1980) 155.

[96] E.H. Lee and L.K. Mansur, Met. Trans A 23 (1992) 1977.

[97] A.S. Bakai, et al., J. Nucl. Mater. 185 (1991) 260.

[98] L.K. Mansur, Phil. Mag. A 44 (1981) 867.

[99] P.J. Maziasz, Scripta Met. 14 (1980) 1251.

[100] W. Kesternich, Rad. Eff. 78 (1983) 261.

[101] E.H. Lee, N.H. Packan and L.K. Mansur, J. Nucl. Mater. 117 (1983) 123.

[102] C.M. Shepherd and S.M. Murphy, J. Nucl. Mater. 172 (1990) 143.

[103] C.M. Shepherd, J. Nucl. Mater. 175 (1990) 170.

[104] D.L. Porter, J. Nucl. Mater. 79 (1979) 787.

[105] H.R. Brager and F.A. Garner, in Phase Stability During Irradiation, Eds. J.R. Holland, L.K. Mansur and D.I. Potter (TMS-AIME, Warrendale, PA, 1981) p. 219 
FRACTURE TOUGHNESS OF IRRADIATED CANDIDATE MATERIALS FOR ITER FIRST WALL/BLANKET STRUCTURES: PRELIMINARY RESULTS - D. J. Alexander, J. E. Pawel, M. L. Grossbeck, and A. F. Rowcliffe (Oak Ridge National Laboratory)

\section{OBJECTIVE}

The purpose of this work is 10 determine the effect of irradiation at low temperatures (less than $300^{\circ} \mathrm{C}$ ) to damage levels of about $3 \mathrm{dpa}$ on the mechanical properties, in particular the fracture toughness, of candidate materials for the International Thermonuclear Experimental Reactor (ITER) first wall/blanket structures.

\section{SUMMARY}

Candidate materials for first wall/ $t$ 'anket structures in ITER have been irradiated to damage levels of about 3 dpa at temperatures of either 60 or $250^{\circ} \mathrm{C}$. Preliminary results 1 ave been obtained for several of these materials irradiated at $60^{\circ} \mathrm{C}$. The results show that irradiation at this temperature reduces the fracture toughness of austenitic stainless steels, but the toughness remains quite high. The unloading compliance technique developed for the subsize disk compact specimens works quite well, particularly for materials with lower toughness. Specimens of materials with very high toughness deform excessively, and this results in experimental difficulties.

\section{PROGRESS AND STATUS}

\section{$\underline{\text { Introduction }}$}

Work is under way at Oak Ridge National Laboratory (ORNL) to evaluate the fracture toughness of candidate materials for first wall/blanket structure applications in the ITER. A variety of austenitic stainless steels are being examined, as well as several additional materials. These materials have been irradiated in the High Flux Isotope Reactor (HFIR) at ORNL. To date, three capsules have been designed, fabricated, and irradiated to dose levels of approximately 3 dpa. These capsules were designed for irradiation temperatures of either 60 to $125^{\circ} \mathrm{C}$ (capsules HFIR-JP-18 and -19) or 250 to $300^{\circ} \mathrm{C}$ (HFIR-JP-17) [1-3]. All of the capsules have been successfully irradiated in HFIR, and two of the capsules (JP-18 and -19) have been disassembled. Work has begun on testing the fracture toughness specimens from these capsules, and some preliminary results are reported here.

\section{Experimenial Procedure}

Several variants of type 316 austenitic stainless steel are being considered for structural applications in ITER. These include American and Japanese type 316 steels (designated US316 and J316, respectively), a European type 316L steel (EC316L), and the JPCA alloy. Some ferritic stecls were also included in this experiment, including HT-9 and F82H. Specimens were fabricated from material in several different conditions, including annealed or cold worked, as well as weldments.

In order to utilize the HFIR target region for the irradiations, the specimen size was severely limited. Therefore, a small disk compact specimen $12.5 \mathrm{~mm}$ in diameter was selected for the fracture toughness experiments. Techniques were developed for generating the J-integral-resistance (J-R) curve using either unloading compliance (UC) or dc-potential drop (PD) to monitor crack extension [4,5]. Initial trials showed that either method could be used to develop useful fracture toughness data from these 
small specimens [4-6]. As a result of the success of the laboratory trials, it was decided to use the unloading compliance technique for testing the irradiated specimens.

The disk compact specimens [designated $\mathrm{DC}(\mathrm{T})$ ] were $12.5 \mathrm{~mm}$ in diameter by $4.63 \mathrm{~mm}$ thick. All specimens were fabricated from the middle of the thickness of the parent plates of material, with the nuch oriented so that crack growth would occur parallel to the rolling direction (T-L orientation). The specimens were fatigue precracked at room temperature and side grooved $10 \%$ of their thickness on each side, prior to irradiation. Filler pieces were inserted in the loading holes and in the notches to reduce disturbances in the flow of cooling water over the specimens in the capsule and to improve the uniformity of heat transfer across the specimens.

Capsules JP-18 and 19 completed their irradiation in October 1991 [3], and have been disassembled. Capsule JP-17 completed its irradiation in February 1992 [3] and is awaiting disassembly. After the disassembly, the inserts in the individual specimens were pushed out of the loading holes using an arbor press and punch. The filler in the notch was removed with the aid of a hammer and a thinned screwdriver blade.

Tests were conducted in general accordance with American Society for Testing and Materials standards E 813-89, Standard Test Method for $\mathrm{J}_{\mathrm{lc}}$, A Measure of Fracture Toughness, and E 1152-87, Standard Test Method for Determining J-R Curves. The specimens were tested with a computer-controlled testing and data acquisition system [7]. Tests in the laboratory used an $89-\mathrm{kN}$ capacity servohydraulic test machine. In the hot cell, a $445-\mathrm{kN}$ servohydraulic testing machine with an ultraprecision $22-\mathrm{kN}$ load cell was used. All tests were run in strain control. The displacements were measured with an "outboard" clip gage that seated in grooves machined on the outer edge of the specimen along the load line $[4,5]$. This arrangement provided very good load-displacement and UC results. Test temperatures were maintained within $\pm 2^{\circ} \mathrm{C}$ of the desired temperature with a split-box furnace that enclosed the specimen and the grips during the test. Temperature was monitored throughout the testing with a thermocouple that was held in contact with the specimen by a springloaded clip. Since tensile tests for materials irradiated under these conditions have not yet been conducted, estimated values of the yield and ultimate tensile strengths and Young's moduli were used in the calculations for the J-R curves. These estimated values are given in Table 1.

After testing, the specimens were heat tinted by placing them on a hot plate and heating them until a noticeable color change had occurred. The specimens were cooled in liquid nitrogen and then broken open. The initial and final crack lengths for the unirradiated specimens were measured with the use of an optical measuring microscope. For the irradiated specimens, photographs of the fracture surfaces were fastened to a digitizing tablet to measure the crack lengths.

\section{Results and Discussion}

Six different materials were tested in the laboratory to establish baseline fracture toughness propertics for the unirradiated materials. These include EC316L annealed, JPCA annealed, JPCA cold worked (15\%), J316 annealed, US316 cold worked, and HT-9. The EC316L and JPCA annealed material was tested at 22,100 , and $200^{\circ} \mathrm{C}$; the remaining tests were conducted at $22^{\circ} \mathrm{C}$. EC316L and JPCA annealed irradiated specimens were tested in the hot cell at 25,100 , and $200^{\circ} \mathrm{C}$.

Materials with very high toughness and low yield strength, such as the annealed austenitic stainless steels, proved to be more difficult to test than material with lower toughness such at HT-9. The soft, tough materials showed enormous crack-tip blunting before stable crack growth began. This resulted 
Table 1. Estimated tensile properties

\begin{tabular}{|c|c|c|c|c|c|}
\hline \multirow{2}{*}{ Alloy } & \multirow{2}{*}{ Condition } & \multirow{2}{*}{$\begin{array}{l}\text { Temperature } \\
\left({ }^{\circ} \mathrm{C}\right)\end{array}$} & \multicolumn{2}{|c|}{$\begin{array}{l}\text { Strength } \\
(\mathrm{MPa})\end{array}$} & \multirow{2}{*}{$\begin{array}{c}\text { Young's } \\
\text { modulus } \\
(\mathrm{GPa})\end{array}$} \\
\hline & & & Yield & $\begin{array}{l}\text { Ultimate } \\
\text { tensile }\end{array}$ & \\
\hline EC316L annealed & Unirradiated & $\begin{array}{r}22 \\
100 \\
200\end{array}$ & $\begin{array}{l}275 \\
225 \\
186\end{array}$ & $\begin{array}{l}582 \\
504 \\
441\end{array}$ & $\begin{array}{l}193 \\
186 \\
179\end{array}$ \\
\hline EC316L annealed & Irradiated & $\begin{array}{r}22 \\
100 \\
200\end{array}$ & $\begin{array}{l}425 \\
375 \\
325\end{array}$ & $\begin{array}{l}650 \\
600 \\
550\end{array}$ & $\begin{array}{l}193 \\
186 \\
179\end{array}$ \\
\hline JPCA annealed & Unirradiated & $\begin{array}{r}22 \\
100 \\
200\end{array}$ & $\begin{array}{l}250 \\
230 \\
210\end{array}$ & $\begin{array}{l}580 \\
520 \\
460\end{array}$ & $\begin{array}{l}193 \\
186 \\
179\end{array}$ \\
\hline JPCA annealed & Irradiated & $\begin{array}{r}22 \\
100 \\
200\end{array}$ & $\begin{array}{l}410 \\
390 \\
370\end{array}$ & $\begin{array}{l}630 \\
570 \\
510\end{array}$ & $\begin{array}{l}193 \\
186 \\
179\end{array}$ \\
\hline JPCA cold worked & Unirradiated & 22 & 671 & 710 & 193 \\
\hline US316 cold worked & Unirradiated & 22 & 725 & 785 & 193 \\
\hline J316 annealed & Unirradiated & 22 & 295 & 570 & 193 \\
\hline HT-9 & Unirradiated & 22 & 650 & 800 & 207 \\
\hline
\end{tabular}

in gross changes in the specimen geometry (see Fig. 1), and so the crack length predictions were not very accurate. The J-R curve is much steeper than the calculated blunting line. In these cases, the data were used to calculate a blunting line. A straight line was fit by eye through the initial portion of the data points, and a second line was drawn parallel to the first but offset by an amount corresponding to a crack extension of $0.2 \mathrm{~mm}$ (see Fig. 2). The candidate toughness value $J_{Q}$ was then determined from the intersection of the data with this offset line. Materials with lower toughness, such as the cold-worked austenitic stainless steels, behaved in a much more conventional manner. For these materials, the data followed the calculated blunting line quite closely, so no additional construction was required. These specimens also showed very good agreement between the measured and predicted final crack lengths.

The results of the testing are given in Table 2 and the various J-R curves are shown in Figs. 3 to 7 . These curves show that the toughness of the austenitic steels is very high. In most cases, the toughness decreases slightly as the temperature increases, but remains very high. The EC316L annealed steel shows a slight decrease in toughness after irradiation. The JPCA annealed material responds much more to irradiation, with a much greater decrease in toughness than the EC316L steel showed. Even in this case, the toughness is still quite high, as Table 2 shows. The other materials also have high toughness values, with the exception of the cold-worked US316 steel. This material has by far the lowest toughness of all the materials tested. 

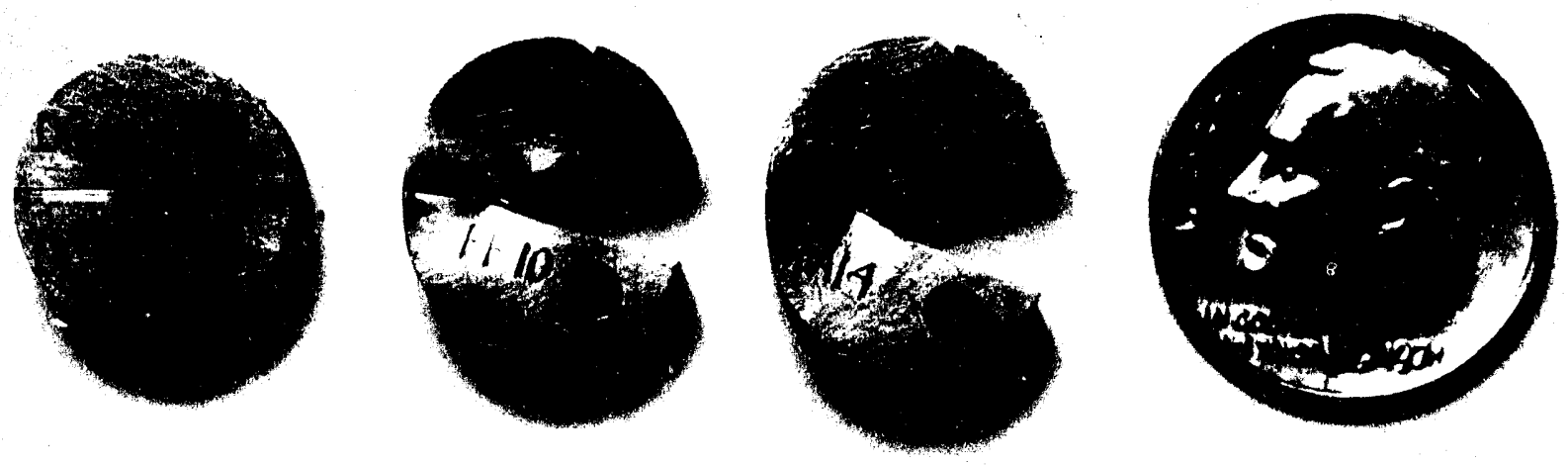

Fig. 1. An example of the gross changes in geometry that resulted when testing the annealed austenitic stainless steel specimens.

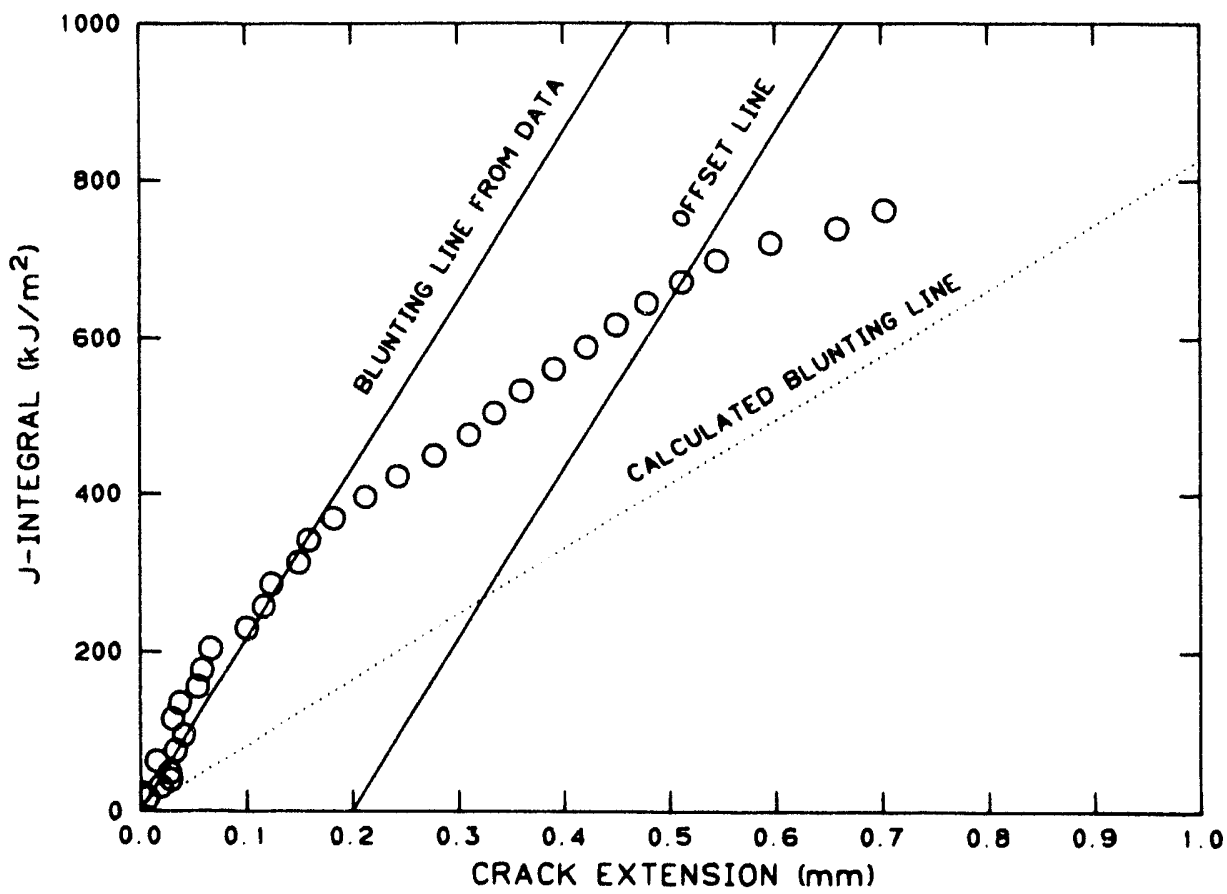

Fig. 2. Typical example of a J-R curve that is much steeper than the calculated blinting line. A straight line was fit by eye through the initial portion of the data, and an offset line was used to determine $\mathrm{J}_{\mathrm{Q}}$. 


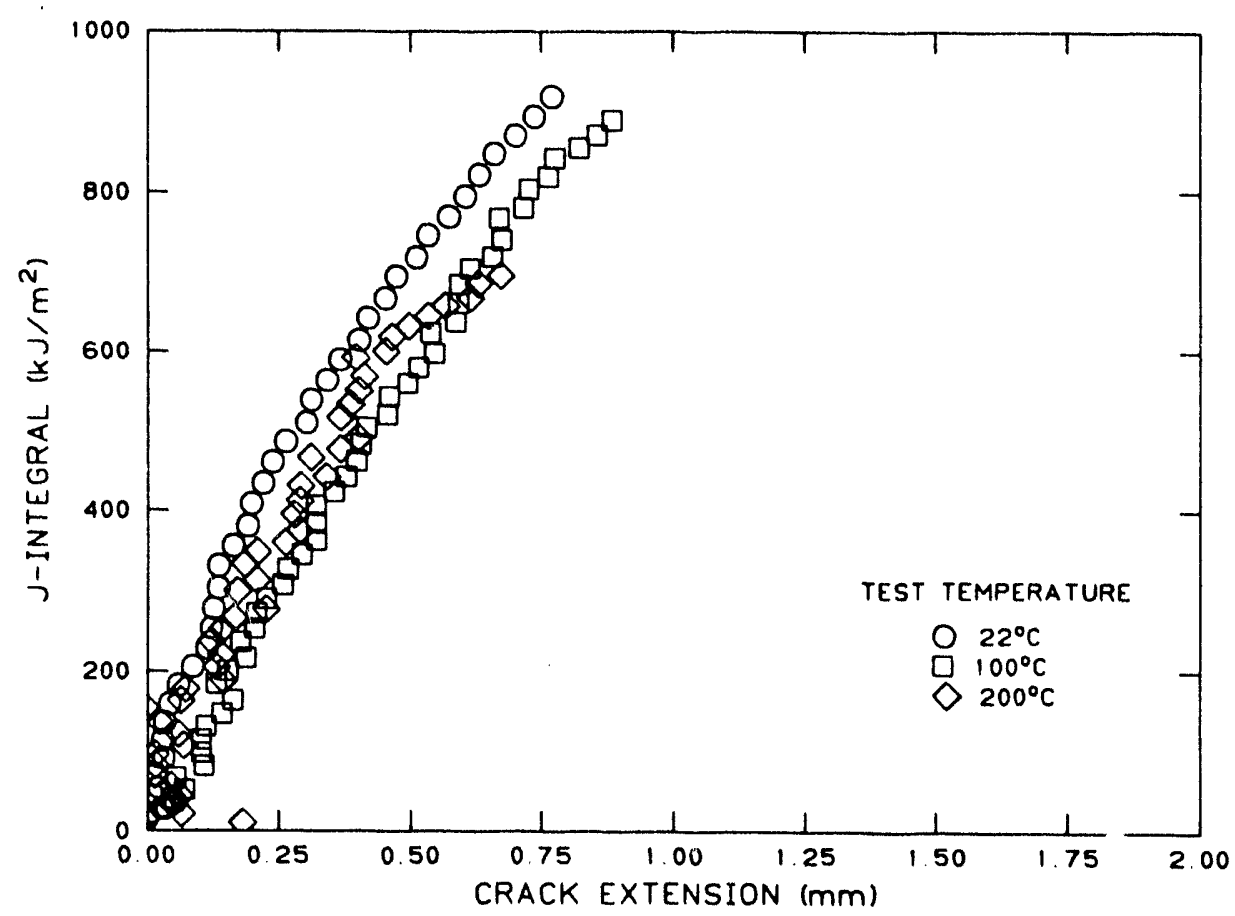

Fig. 3. J-R curves for unirradiated EC316L steel.

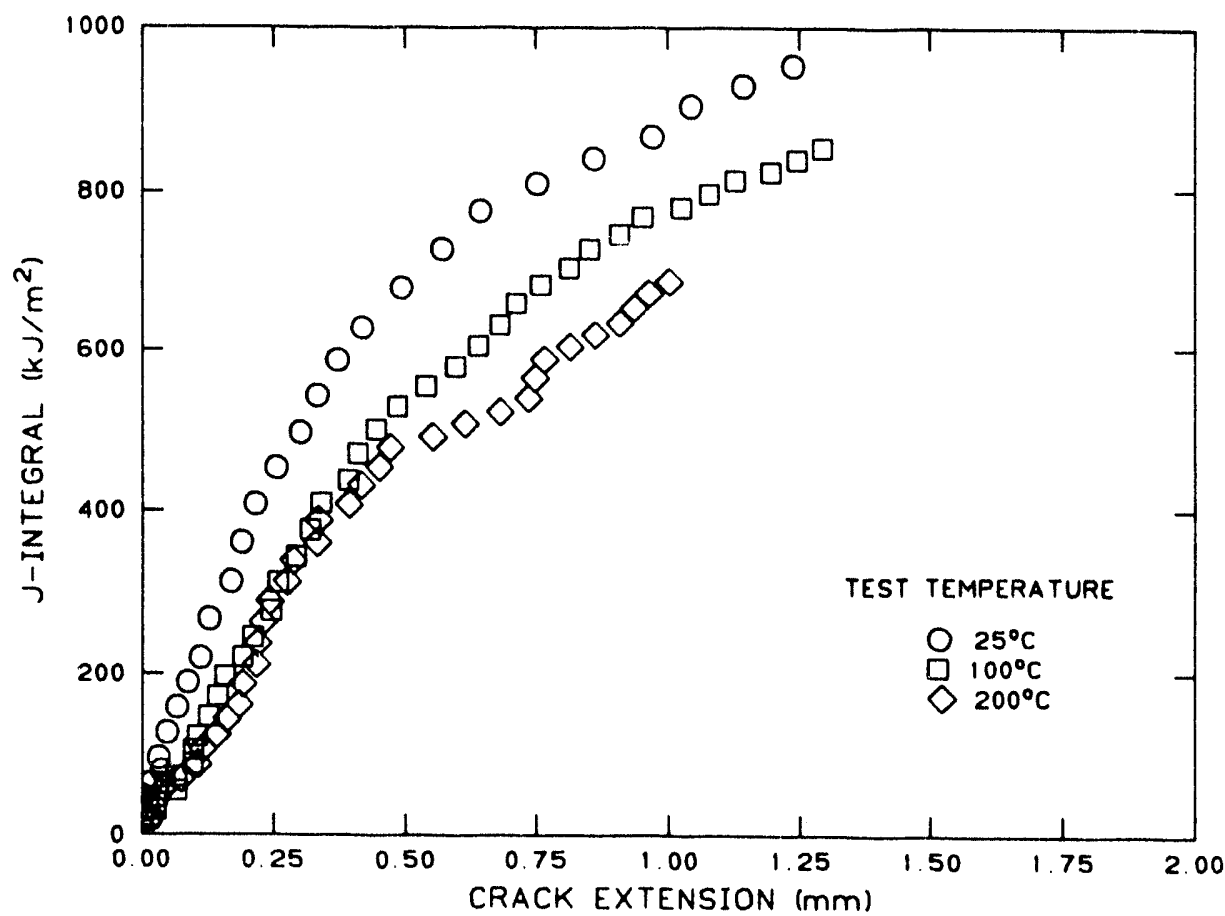

Fig. 4. J-R curves for EC316L sted irradiated to 3 dpa at 60 to $125^{\circ} \mathrm{C}$. 


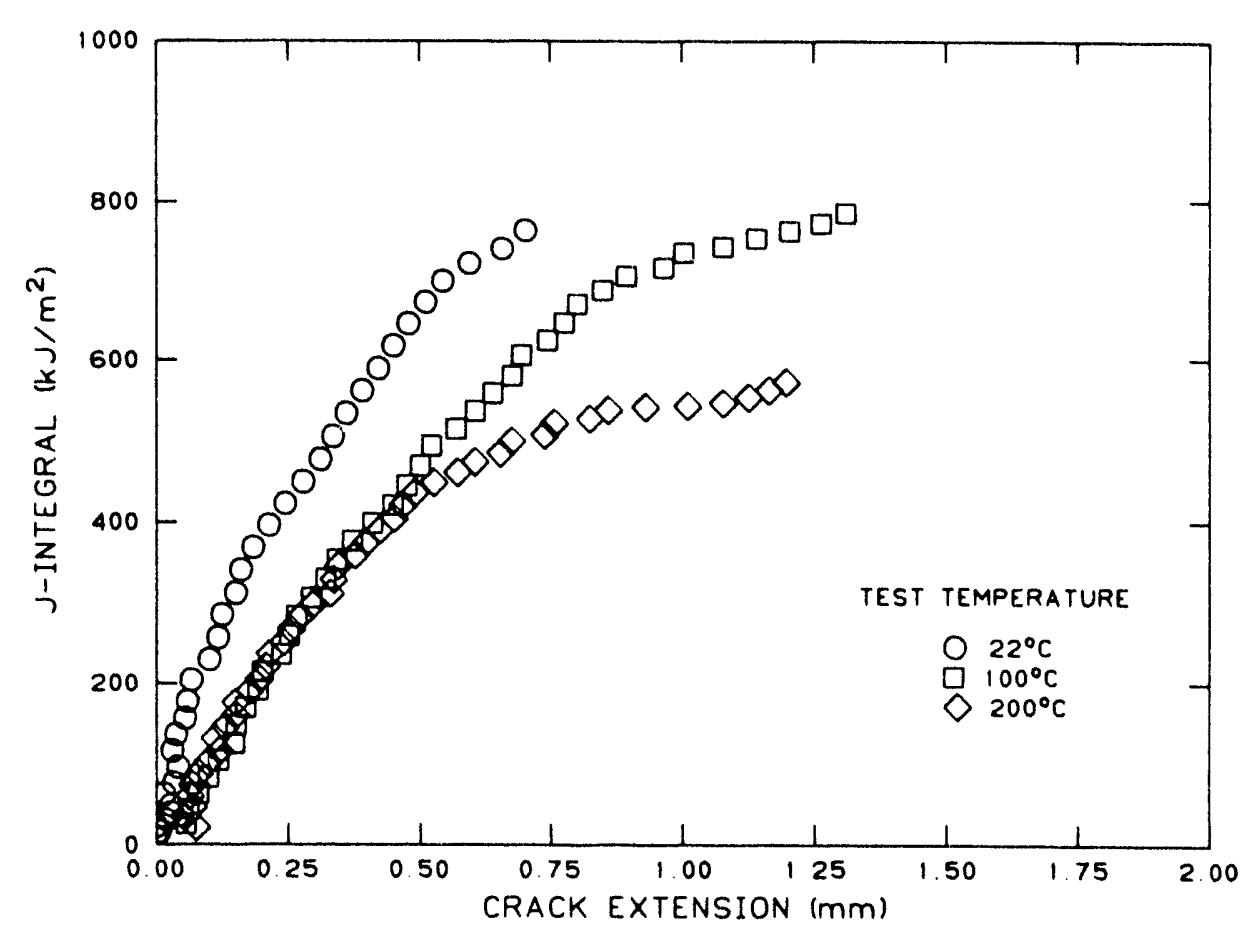

Fig. 5. J-R curves for unirradiated JPCA annealed stecl.

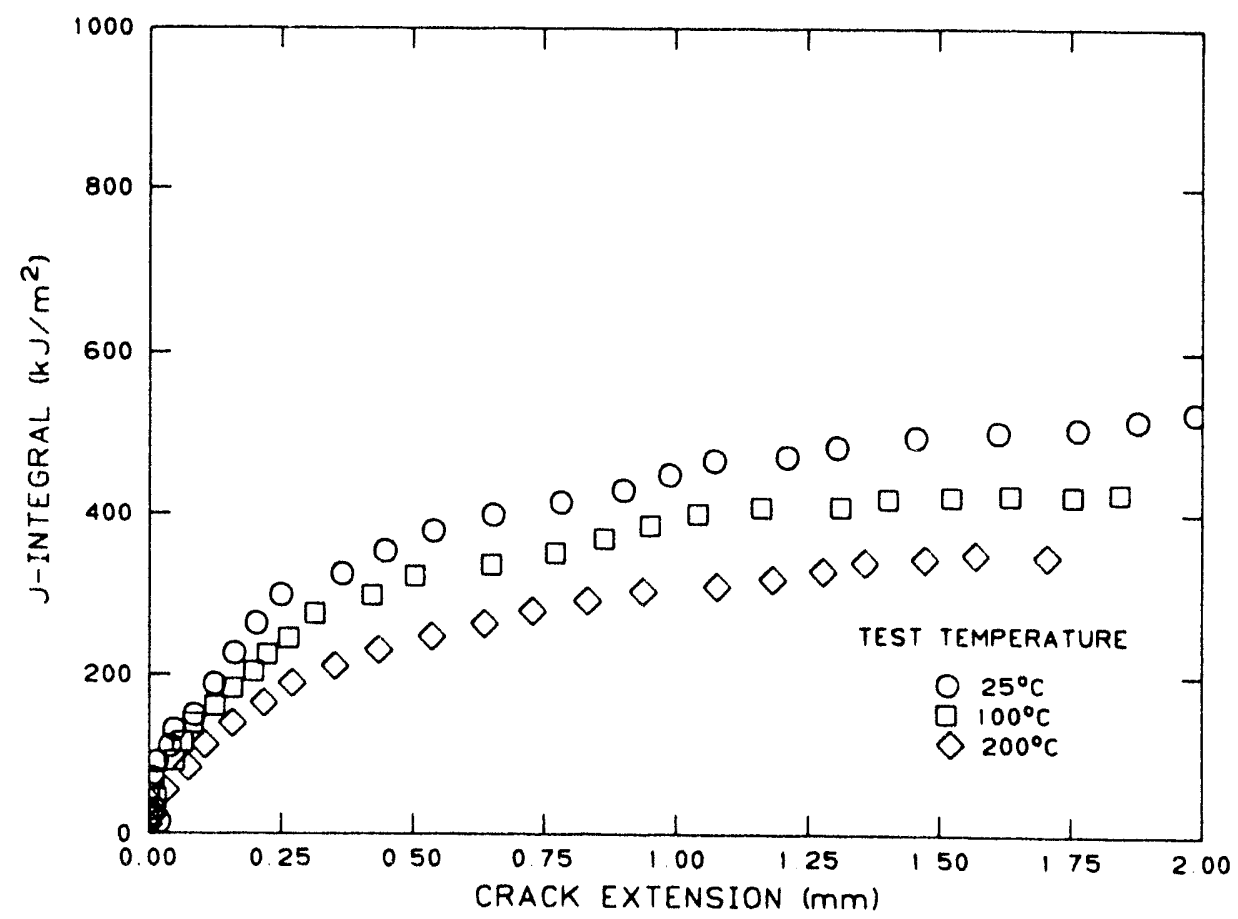

Fig. 6. J-R curves for irradiated JPCA annealed steel irradiated to 3 dpa at 60 to $125^{\circ} \mathrm{C}$. 


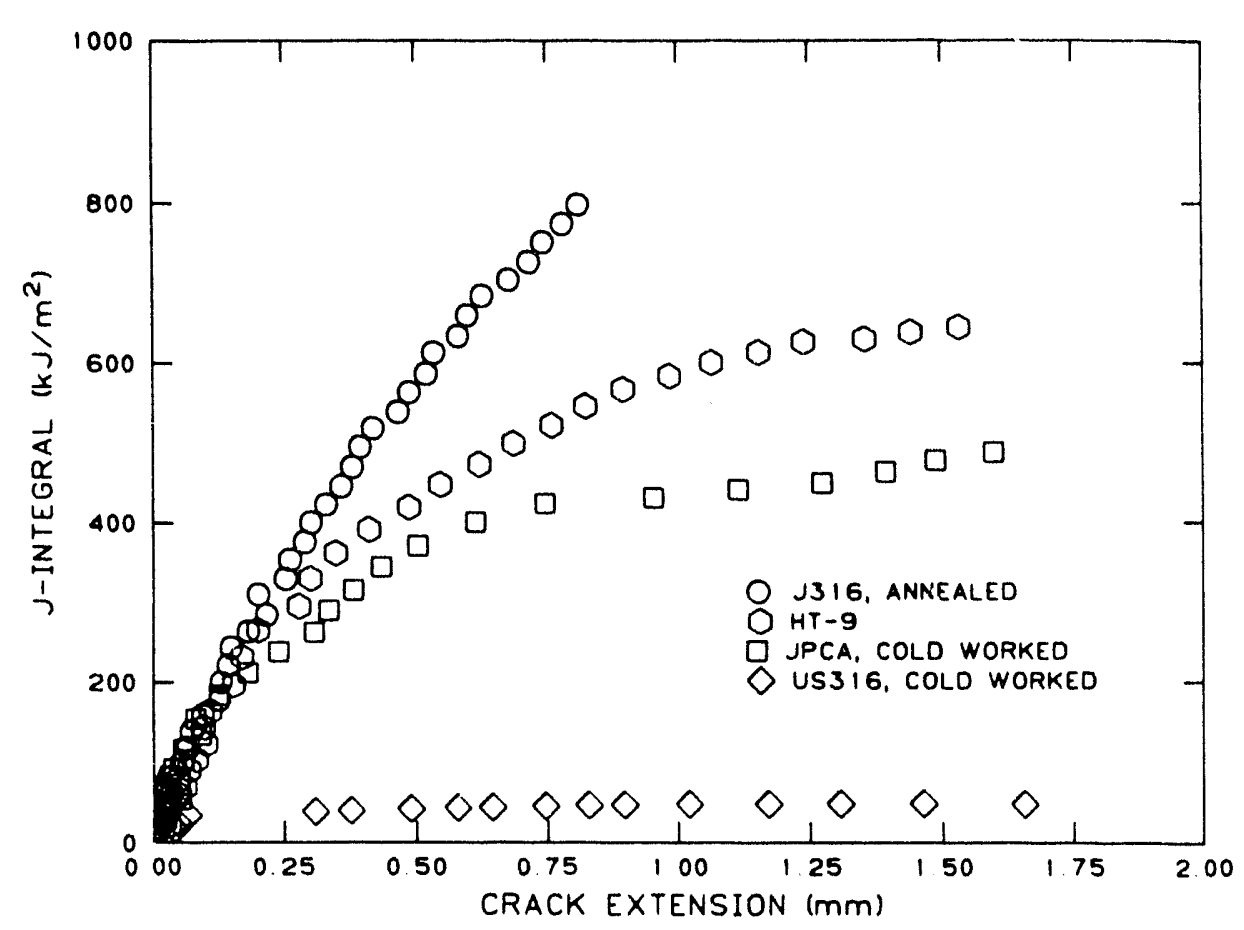

Fig. 7. J-R curves for the remaining unirradiated materials.

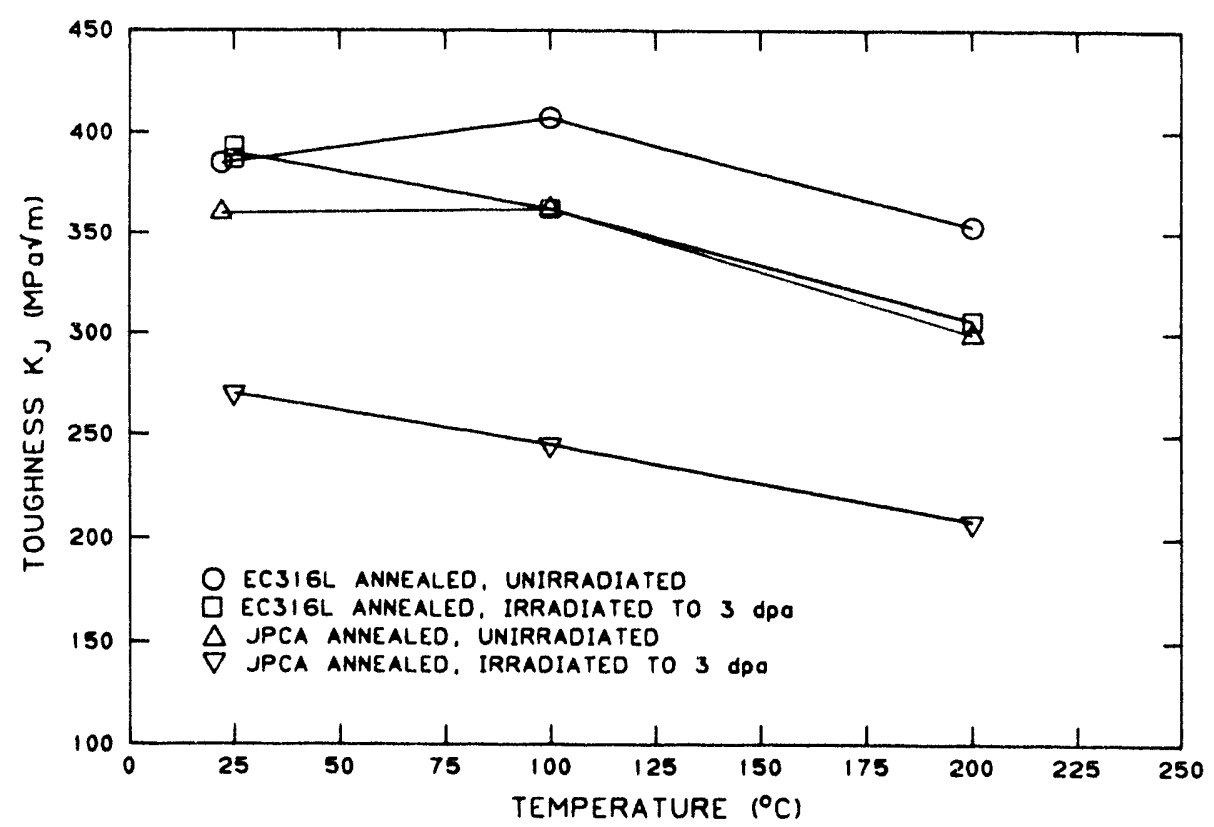

Fig. 8. Fracture toughness values for EC316L and JPCA annealed steels as a function of temperature, showing the effects of irradiation and test temperature. 
Table 2. Fracture toughness values

\begin{tabular}{|c|c|c|c|c|c|}
\hline Material & Condition & Specimen & $\begin{array}{c}\text { Temperature } \\
\left({ }^{\circ} \mathrm{C}\right)\end{array}$ & $\underset{\left(\mathrm{kJ} / \mathrm{m}^{2}\right)}{\mathrm{J}_{\mathrm{Q}}}$ & $\begin{array}{c}\mathrm{K}_{\mathrm{J}} \\
(\mathrm{MPa} \mathrm{V})\end{array}$ \\
\hline EC316L annealed & Unirradiated & $\begin{array}{c}\text { FA14 } \\
\text { FA22 } \\
\text { FA5 }\end{array}$ & $\begin{array}{r}22 \\
100 \\
200\end{array}$ & $\begin{array}{l}769 \\
889 \\
696\end{array}$ & $\begin{array}{l}385 \\
407 \\
353\end{array}$ \\
\hline EC316L annealed & Irradiated & $\begin{array}{c}\text { FA16 } \\
\text { FA3 } \\
\text { FA6 } \\
\text { FA17 }\end{array}$ & $\begin{array}{r}25 \\
25 \\
100 \\
200\end{array}$ & $\begin{array}{l}775 \\
802 \\
703 \\
521\end{array}$ & $\begin{array}{l}387 \\
393 \\
362 \\
306\end{array}$ \\
\hline JPCA annealed & Unirradiated & $\begin{array}{l}\text { FF10 } \\
\text { FF13 } \\
\text { FF20 }\end{array}$ & $\begin{array}{r}25 \\
100 \\
200\end{array}$ & $\begin{array}{l}672 \\
705 \\
499\end{array}$ & $\begin{array}{l}360 \\
362 \\
299\end{array}$ \\
\hline JPCA annealed & Irradiated & $\begin{array}{c}\text { FF5 } \\
\text { FF16 } \\
\text { FF2 }\end{array}$ & $\begin{array}{r}22 \\
100 \\
200\end{array}$ & $\begin{array}{l}379 \\
323 \\
242\end{array}$ & $\begin{array}{l}270 \\
245 \\
208\end{array}$ \\
\hline J316 annealed & Unirradiated & FCS & 22 & 798 & 393 \\
\hline JPCA cold worked & Unirradiated & FE6 & 22 & 356 & 262 \\
\hline US316 cold worked & Unirradiated & FL13 & 22 & 37 & 85 \\
\hline HT-9 & Unirradiated & FH11 & 22 & 447 & 304 \\
\hline
\end{tabular}

The effects of test temperature and irradiation are summarized in Fig. 8 for the EC316L annealed and JPCA annealed materials irradiated at $6010125^{\circ} \mathrm{C}$. The EC316L material has a higher toughness than the JPCA material. Both show a tendency for lower toughness as the test temperature is increased. The JPCA alloy shows a much greater decrease in toughness following irradiation than the EC316L material. However, even in the worst case, the toughness is still quite high.

\section{CONCLUSIONS}

Useful fracture toughness data can be generated using the unloading compliance technique and the small disk compact specimens. Specimens of several austenitic stainless steels have been irradiated in HFIR to about 3 dpa at 60 to $125^{\circ} \mathrm{C}$. Preliminary results have shown that the toughness of the annealed EC316L and JPCA austenitic stainless steels is quite high. The JPCA alloy shows a greater response to irradiation, with a more significant decrease in the toughness after irradiation. The effect of irradiation is most noticeable at higher test temperaiures $\left(200^{\circ} \mathrm{C}\right)$. However, even in this case the toughness is still high.

\section{FUTURE WORK}

Additional specimens will be tested in both the irradiated and unirradiated conditions. The third capsule (JP-17) that was irradiated at higher temperature $\left(250\right.$ to $\left.300^{\circ} \mathrm{C}\right)$ will be disassembled, and these specimens will be tested as well. Tensile tests will be conducted to provide actual values for the 
yield and ultimate tensile strengths after irradiation. These values will be used to revise the fracture toughness analyses of all of the fracture toughness tests.

\section{ACKNOWLEDGMENTS}

The fracture toughness testing was performed by R. L. Swain. We would like to thank F. M. Haggag and R. L. Klueh for their helpful reviews of the manuscript, which was prepared by J. L. Bishop.

\section{REFERENCES}

1. A. W. Longest, D. W. Heatherly, K. R. Thoms, and J. E. Corum, "Design and Fabrication of HFIR-MFE-JP Target Irradiation Capsules," Fusion Reactor Materials Semiannual Progress Report for Period Ending March 31, 1991, DOE/ER-0313/10, 1991, p. 3.

2. A. W. Longest, D. W. Heatherly, J. E. Wolfe, K. R. Thoms, and J. E. Corum, "Fabrication and Irradiation of HFIR-MFE-JP-17, -18, and -19 Target Irradiation Capsules," Fusion Reactor Materials Semiannual Progress Report for Period Ending September 30, 1991, DOE/ER-0313/11, 1992 , p. 30.

3. A. W. Longest, D. W. Heatherly, K. R. Thoms, and J. E. Corum, "Fabrication and Irradiation of HFIR-MFE-JP-17, -18, and -19 Target Irradiation Capsules," Fusion Reactor Materials Semiannual Progress Report for Period Ending March 31, 1992, DOE/ER-0313/12, 1992, p. 24.

4. D. J. Alexander, "Fracture Toughness Measurements with Subsize Disk Compact Specimens, Fusion Reactor Materials Semiannual Progress Report for Period Ending March 31, 1992, DOE/ER-0313/12, 1992, p. 35.

5. D. J. Alexander, "Fracture Toughness Measurements with Subsize Disk Compact Specimens," in ASTM Symposium on Small Specimen Test Techniques and Their Application to Nuclear Reactor Vessel Thermal Annealing and Plant Life Extension," to be published by American Society for Testing and Materials, Philadelphia, 1993.

6. C. Elliot, M. Enmark, G. E. Lucas, and G. R. Odette, "Development of Disc Compact Specimens and Test Techniques for HFIR Irradiations," Fusion Reactor Materials Semiannual Progress Report for Period Ending September 30, 1990, DOE/ER-0313/9, 1991, p. 7.

7. R. K. Nanstad, D. J. Alexander, R. L Swain, J. T. Hutton, and D. L. Thomas, "A Computer-Controlled Automated Test System for Fatigue and Fracture Testing," in Applications of Automation Technology to Fatigue and Fracture Testing, ASTM STP 1092, A. A. Braun, N. E. Ashbaugh, and F. M. Smith, eds., Amcrican Society for Testing and Materials, Philadelphia, 1990, p. 7. 
6.3 Refractory Metal Alloys 
Density Changes Induced by Neutron Irradiation in Dynamically Compacted Tungsten and Fit. F. A. Garner. (Pacific Northwest Laboratory) and J. Megusar. (Massachusetts Institute of Technology)

\section{OBJECTIVE}

The objective of this effort is to determine the potential of rapid solidification and dynamic compaction as tools for improving the performance of candidate fusion materials.

SUMMARY

Dynamically compacted tungsten with a starting density of $95.3 \%$ of the theoretical value densified 2 to $3 \%$ when irradiated in FFTF/MOTA-2A at three temperatures between 423 and $600^{\circ} \mathrm{C}$ and displacement levels corresponding to 32 to 36 dpa in stainless steel. Rapidly solidified and dynamically compacted PCA with high levels of titanium and carbon were also irradiated at these conditions. The density changes were small enough to determine that significant swelling had not occurred but, microscony is necessary to determine whether void growth occurred in addition to precipitate-related strains.

PROGRESS AND STATUS

\section{introduction}

Papid solidification and dynamic compaction have been proposed as methods to produce ailoys for use in fusion environments." 2 One such material. a titanium-modified austenitic stainless stesl designated PCA, was irradiated earlier in EBR-II to $15 \mathrm{dpa}$ in the rarge 395 to $550^{\circ} \mathrm{C}$. A total absence of swelling was observed in this alloy, although some swelling was observed in fully annealed speciners that were also irradiated.

Both the as-produced and fully annealed material were also irradiated in M0TA-2A and M0TA-2B at 423 , 520 and $600^{\circ} \mathrm{C}$. Density measurements have now been performed on the MOTA-2A specimens. Dynamically compacted tungsten was also included in the same packets. This material might serve as an armor material for the first wall or divertor.

\section{Experimental Procedure}

The titanium-modified austenitic stainless steel (PCA) was provided by the 0ak Ridge National Laboratory, with the following composition (in wt\%): 16.59 nickel: 14.27 chromium: i.96 molybdenum: 0.32 titanium: 1.62 ranganese: 0.53 silicon: 0.046 carbon; 0.008 nitrogen: 0.04 cobalt: 0.014 phospnorus: 2.002 sulfur: and balance iron. Additional carbon and titanium were added in a remelt followed by raic solidification and dynamic compaction. This material contained approximately triple the nominal arounts of carbon and titanium (that is. 0.17 wt\% carbon and 0.92 wt\% titanium) originally in PCA. Rapic so idification was performed in a roller quenching apparatus, with an estimated cooling rate of $10 \%=$

Oynamic compaction was performed at the Institut Cerac. Ecublens. Switzerland. aasidi solidified foils were ctit into pieces with a length to thickness ratio of 30 to ! or less and were compacted with the gun speed at $1200 \mathrm{~m} / \mathrm{s}$. The diameter of the compacted material was $5 \mathrm{~cm}$, and the height was 1 cm. Compaction was achieved with a shock wave that was produced by impact of the projectile on the ocuder. Calculations showed the following relation between the shock speed, particle velocity, and tre internal energy. Steel powder of $-50 \%$ loose density and compacted to a shock pressure of $5 \mathrm{GPa}$ gave 3 snock 1 iocity of $1600 \mathrm{~m} / \mathrm{s}$. a particle velocity of $800 \mathrm{~m} / \mathrm{s}$, and an internal energy change of $3 \times 10 \mathrm{~J} / \mathrm{kg}$. This ciergy change corresponds to a temperature rise of $600 \mathrm{~K}$, and if the energy is considered to be ceposited predominantly at the powder particle surface, the value of $2 \times 10^{\circ} \mathrm{J} / \mathrm{m}^{2}$ for energy density is ceduces.

Some of this material was subsequently annealed $8 \mathrm{~h}$ at $650 \%$. resulting in a homogeneous precipitation of coherent $T i C$ precipitates approximately $5 \mathrm{~nm}$ in size. Some recovery of dislocation structure probably took lace during annealing, as evidenced by a large drop in the knoop microhardness. Soth the as-produced and annealed conditions were irradiated in MOTA-2A and MOTA-2B along with dynamicaliy compacted tungsten. The latter was produced at Lawrence Livermore National Laboratory. Density changes were determined by an immersion density technique determined to be accurate to $\pm 0.15 \%$ swelling.

Eesults

Table l presents the density change data for the specimens discharged from MOTA-2A. : is obvious that the (1)namically compacted tungsten is densifying on the order of 2 to $3 \%$. The preirradiation density of 18.49 $\mathrm{cm}$ is $95.3 \%$ of the textbook value of $19.3 \mathrm{~g} \mathrm{~cm}$. Therefore, during irradiation the compacted tungsten is

Pacific Horthwest Laboratory is operated for the U.S. Department of Energy Dy Battelle Menorial institute under contract DE-ACO6-75RLO 1330. 
3pproaching, but has not yet reached. the theoretical density. Some portion of the cansification may aiso -esult from transmutation of tungsten to rhenium and osmium.

The density changes for PCA in both starting conditions are snall enough to preclude drawing conclusions concerning the onset of sweiling. Both positive and negative changes were observed. indicating that orecipitation-related chages in lattice parameter are occuring.

Table 1

Swelling in Percent from Dynamically Compacted Specimens in MOTA.2A*

\begin{tabular}{|c|c|c|c|}
\hline & Pre-1rradiation Density & $423^{\circ} \mathrm{C} .36 .1 \mathrm{dpa}$ & $520 \cdot \mathrm{C}, 36.3 \mathrm{dpa}$ \\
\hline$W^{* \star}$ & 18.4098 & -2.23 & $-2.05,-3.19$ \\
\hline PCA & 7.8677 & -0.29 & $32.3 \mathrm{dpa}$ \\
\hline PCA-Annealed & 7.9083 & +0.51 & +0.28 \\
\hline
\end{tabular}

Unless two values are given, the swelling is the average of two separate specimens which agreed within $=0.2 \%$

*dpa for $W$ is less than that of steei. Uut has not ret poen calculated.

SUTURE WORK

Denslty changes will be determinod for the second discharge of the arperimert (rofa-zel. ticroscopy and ED analyses will also be cerionmed.

DETERENCES

․ J. J. Grant, 0. K. Marling, G. Kohse, A. Megusar. and T. Ege. J. Nucl. Mater. 141-143 (1986) 427.

2. D. Imeson et al. three sucessive papers in J. Hucl. Mater. 122 \& 123 (1984) 266-271:272-277; $278-283$.

3. J. Megusar, in Effects of Fadiation on Materials: 14 th International Srmposium. inlume 1 , ASTM STP 046, H. H. Packan R. E. Stoller, and A. S. Kumar. Eds., American Society for lesting and Materials, philadelphia, 1389. pp. :85-192.

4. A. A. Carner and L. R. Sreenwood, in this Semiannual Report. 
Density Changes Observed in Nb-1Zr After Irradiation in FFTF-MOTA. F.A. Garner (Pacific Northwest Laboratoryz).

\section{OBJECTIVE}

The objective of this effort is to provide data on the irradiation behavior of $\mathrm{Nb}-1 \mathrm{Zr}$, an alloy proposed for potential application to ITER and possibly other long-range fusion goals.

\section{SUMMARY}

Nb- $1 \mathrm{Zr}$ has been proposed for potential application to ITER. Whereas previous irradiation studies on Nb-iZr were focused on the annealed condition, this study involved a comparative irradiation of both the annealed and aged, and the cold-worked and aged conditions. Based on measurements of density change, the cold-worked and aged condition appears to first undergo a phase-related dilation prior to the onset of void swelling, while the annealed condition densifies prior to swelling and in some cases does not swell at all.

\section{PROGRESS AND STATUS}

\section{Introduction}

The commercial alloy $\mathrm{Nb}-1 \mathrm{Zr}$ is currently being considered as a candidate for high heat flux service in the ITER divertor. This alloy was therefore irradiated in MOTA 1B, IC, ID, and IE at five target temperatures between 420 and $722^{\circ} \mathrm{C}$, with peak exposures on the order of $60 \mathrm{dpa}$ (steel) at most temperatures and to $\sim 100$ dpa at $420^{\circ} \mathrm{C}$. (1) Most previous studies focused only on the annealed condition.(2-4)

The specimens were in the form of $3 \mathrm{~mm}$ diameter microscopy disks in two starting conditions. The first condition was solution annealed for $1 \mathrm{hr}$ at $760^{\circ} \mathrm{C}$ and then aged for $2 \mathrm{hrs}$, at $320^{\circ} \mathrm{C}$. The second was $20 \%$ cold. worked following the $760^{\circ} \mathrm{C}, 1 \mathrm{hr}$ annealing, and then aged at $320^{\circ} \mathrm{C}$ for 2 hrs. Irradiation proceeded in weeper packets, and thus the specimens were in contact with the sodium coolant of the reactor. Table 1 lists the irradiation conditions.

Table 1

Irradiation Conditions for Nb-IZr Specimens Examined in This Study

\begin{tabular}{|c|c|c|c|c|c|c|c|c|c|c|}
\hline \multirow[b]{2}{*}{ Packet } & \multirow[b]{2}{*}{ Contents ${ }^{1 / 1}$} & \multicolumn{2}{|l|}{ MOTA.1B } & \multicolumn{2}{|l|}{ MOTA-1C } & \multicolumn{2}{|l|}{ MOTA.10 } & \multicolumn{2}{|l|}{ MOTA-1E } & \multirow[b]{2}{*}{ Total dpa } \\
\hline & & Temperature. ${ }^{\circ} \mathrm{C}$ & dpa 101 & Temperature. ${ }^{\circ} \mathrm{C}$ & dpa & Temperature, ${ }^{\circ} \mathrm{C}$ & $\mathrm{dpa}$ & Temperature. ${ }^{\circ} \mathrm{Cl}$ & dpa & \\
\hline $\begin{array}{l}\text { MAEZ } \\
\text { NAEZ } \\
\text { NGEZ } \\
\text { MGEZ } \\
\dot{i} . Z\end{array}$ & $\begin{array}{l}A \\
A \\
B \\
B \\
A\end{array}$ & $\begin{array}{l}431 \\
431 \\
431 \\
431 \\
431\end{array}$ & $\begin{array}{l}15.0 \\
15.0 \\
14.1 \\
14.5 \\
15.0\end{array}$ & $\begin{array}{l}\therefore \\
420 \\
420 \\
420 \\
420\end{array}$ & $\begin{array}{l}35.3 \\
35.1 \\
33.9 \\
35.3\end{array}$ & $\begin{array}{c}\cdots \\
\cdots \\
404 \\
404\end{array}$ & $\begin{array}{c}\cdots \\
\cdots \\
24.5 \\
25.5\end{array}$ & $\begin{array}{c}\cdots \\
\cdots \\
\cdots \\
114 \\
414\end{array}$ & $\begin{array}{c}\cdots \\
\cdots \\
\cdots \\
32.8 \\
35.0\end{array}$ & $\begin{array}{r}15.0 \\
50.3 \\
47.2 \\
105.7 \\
110.8\end{array}$ \\
\hline $\begin{array}{l}\text { MAE I } \\
\text { NAE I } \\
\text { N6E I } \\
\text { P6E I } \\
\text { PAE I }\end{array}$ & $\begin{array}{l}A \\
A \\
B \\
B \\
A\end{array}$ & $\begin{array}{l}471 \\
471 \\
471 \\
471 \\
471 \\
\end{array}$ & $\begin{array}{c}11.4 \\
11.4 \\
9.6 \\
8.7 \\
11.4\end{array}$ & $\begin{array}{c} \\
470 \\
470 \\
470 \\
470\end{array}$ & $\begin{array}{c}-- \\
26.8 \\
22.6 \\
20.3 \\
26.8\end{array}$ & $\begin{array}{c} \\
\therefore \\
\cdots \\
470 \\
470\end{array}$ & $\begin{array}{c}\cdots \\
\cdots \\
14.7 \\
19.4\end{array}$ & $\begin{array}{l}\cdots \\
\cdots \\
\cdots \\
\cdots\end{array}$ & $\begin{array}{l}\cdots \\
\cdots \\
\cdots \\
\cdots \\
\cdots\end{array}$ & $\begin{array}{l}11.4 \\
38.2 \\
32.2 \\
43.7 \\
57.6\end{array}$ \\
\hline $\begin{array}{l}\text { MAE7 } \\
\text { NAE7 } \\
\text { N6E7 } \\
\text { PAE7 } \\
\text { RAE7 }\end{array}$ & $\begin{array}{l}A \\
A \\
B \\
A \\
A\end{array}$ & $\begin{array}{l}569 \\
569 \\
569 \\
569 \\
569 \\
\end{array}$ & $\begin{array}{l}11.5 \\
11.5 \\
12.2 \\
11.5 \\
11.5\end{array}$ & $\begin{array}{c}- \\
550 \\
550 \\
550 \\
550\end{array}$ & $\begin{array}{l}27.0 \\
28.6 \\
27.0 \\
27.0\end{array}$ & $\begin{array}{c}\cdots \\
\cdots \\
549 \\
549\end{array}$ & $\begin{array}{c}\cdots \\
\ldots \\
19.5 \\
19.6\end{array}$ & $\begin{array}{l}\cdots \\
\cdots \\
\cdots \\
\cdots\end{array}$ & $\begin{array}{l}\cdots \\
\cdots \\
\cdots \\
\cdots\end{array}$ & $\begin{array}{l}11.5 \\
38.5 \\
40.8 \\
58.1 \\
58.1\end{array}$ \\
\hline $\begin{array}{l}\text { MAES } \\
\text { NAE5 } \\
\text { N6E5 } \\
\text { R6E5 } \\
\text { PAE5 }\end{array}$ & $\begin{array}{l}A \\
A \\
B \\
B \\
A\end{array}$ & $\begin{array}{l}645 \\
645 \\
645 \\
645 \\
645\end{array}$ & $\begin{array}{l}11.5 \\
11.5 \\
12.2 \\
12.7 \\
11.5\end{array}$ & $\begin{array}{l}-0 \\
652 \\
652 \\
652 \\
652\end{array}$ & $\begin{array}{c}\cdots \\
27.0 \\
28.6 \\
30.8 \\
27.0\end{array}$ & $\begin{array}{c}\cdots \\
\cdots \\
\cdots \\
650 \\
650\end{array}$ & $\begin{array}{c}\cdots \\
\cdots \\
22.3 \\
19.6\end{array}$ & $\begin{array}{l}\cdots \\
\cdots \\
\cdots \\
\cdots\end{array}$ & $\begin{array}{l}\cdots \\
\cdots \\
\cdots \\
\cdots\end{array}$ & $\begin{array}{l}11.5 \\
38.5 \\
40.8 \\
65.8 \\
58.1\end{array}$ \\
\hline $\begin{array}{l}\text { MAE6 } \\
\text { NAE6 } \\
\text { N6E6 } \\
\text { M6E6 } \\
\text { PAE6 }\end{array}$ & $\begin{array}{l}A \\
A \\
B \\
B \\
A\end{array}$ & $\begin{array}{l}722 \\
722 \\
722 \\
722 \\
722 \\
\end{array}$ & $\begin{array}{l}11.5 \\
11.5 \\
12.2 \\
12.2 \\
11.5\end{array}$ & $\begin{array}{l}\cdots \\
730 \\
730 \\
730 \\
730\end{array}$ & $\begin{array}{c}-- \\
27.0 \\
28.6 \\
28.6 \\
27.0\end{array}$ & $\begin{array}{c}\cdots \\
\cdots \\
\cdots \\
730 \\
730\end{array}$ & $\begin{array}{c}\cdots \\
\cdots \\
20.7 \\
19.6\end{array}$ & $\begin{array}{l}\cdots \\
\cdots \\
\cdots \\
\cdots\end{array}$ & $\begin{array}{l}\cdots \\
\cdots \\
\cdots \\
\cdots\end{array}$ & $\begin{array}{l}11.5 \\
38.5 \\
40.8 \\
61.5 \\
58.1\end{array}$ \\
\hline
\end{tabular}

(a) Group A contains cold-worked and aged specimens only. Group B contains annealed and aged specimens.

(b) dpa values calculated for stainless steel in early FFTF core configurations.

Pacific Northwest Laboratory is operated for the U.S. Department of Energy by Battelle Memorial Institute under Contract DE-ACO6-76RLO 1830. 
Although irradiation in MOTA proceeded largely under active temperature contro? $(=5 \mathrm{C})$ in MOTA'S $1 \mathrm{~B}, 1 \mathrm{C}$ and $1 \mathrm{E}$, there was a short ( -50 minutes) temperature excursion in MOTA 10 during FFTF cycle 7 , referred to as an over-temperature event. The event compromised the integrity of many of the other experiments in MOTA ID. Therefore, a programmatic decision was made to run MOTA 10 in the hel ium-purged mode for the remainder of FFTF cycles 7 and 8 while a series of reactor feedback tests were conducted. The majority of the MOTA canisters therefore operated at variable but lower than target temperatures until the end of FFTF cycle 8 . Isothermal irradiation was reestablished in MOTA $1 E$, but only the $420^{\circ} \mathrm{C}$ specimens were included in that irradiation segment.

Density measurements were performed using an immersion density technique whose accuracy has been established to be $\pm 0.15 \%$ swelling. The displacement levels (NRT) quoted are those calculated for stainless steel. Detailed calculations for $\mathrm{Nb}-12 \mathrm{r}$ have not yet been performed but should be on the order of $114 \%$ of those of steel. (5)

\section{Results and Discussion}

Figure 1 presents the results of density measurements performed on the Nb-12r specimens. It is obvious that some phase-related dilation of the alloy matrix probably occurs in the cold-worked alloy early in the irradiation, producing a density decrease of $0.5 \pm 0.1 \%$. This conclusion is drawn from the relative temperature independence of the density change. This change may actually include contributions from void swelling, however, a possibility that will be examined by microscopy. The swelling behavior thereafter appears to be rather complex, both with irradiation temperature and increasing neutron exposure. In general, however, there is a tendency at the higher temperatures for swelling to continue. There are indications of shrinkage at 420 and $569^{\circ} \mathrm{C}$

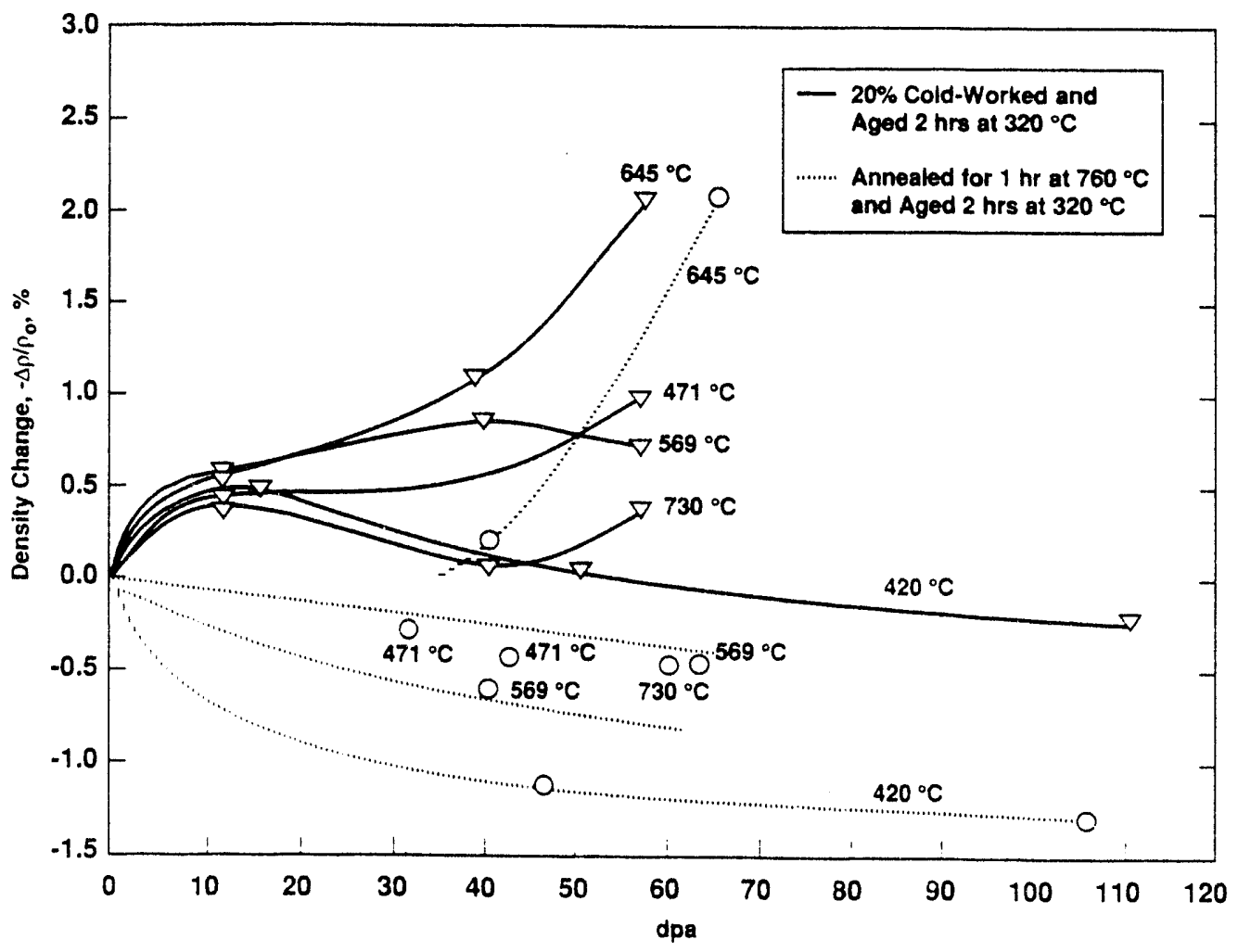

Fig. 1. Density changes observed in Mb-1Zr after irradiation in FFTF-MOTA.

The annealed and aged condition. with one exception, appears to densify, probably as a result of some precipitation reaction. The exception is significant in that the behavior at $645^{\circ} \mathrm{C}$ parallels that of the coldworked and aged condition at this temperature. with the offset between the behavior of the two conditions consistent with their respective differences in phase-related density changes. 
of particular interest is the parallel behavior of both starting conditions observed at $420 \mathrm{C}$, leading to densification. It is obvious that two or more processes are competing to produce the observed changes in density and that the starting state affects at least one of these processes. It is surmised that the primary difference between the two starting states resides in the distribution of grain sizes. In companion studies conducted on molybdenum in this same irradiation series, small grain sizes produced by an identical heat treatment have been found to cause earlier and, therefore, larger swelling, similar to that observed in Nb$\operatorname{lir} .(5)$

FUTURE WORK

These specimens will be examined by microscopy in a collaboration with H. Watanabe of Kiushu University.

\section{References}

1. F. A. Garner. "FFTF/MOTA Irradiation of Refractory Alloys Under Consideration as Plasma Facing components." in Fusion Reactor Materials Semiannual Progress Report, D0E/ER-0313-3 (1990) pP. $169-171$.

2. R. W. Powell, D. T. Peterson, M. K. Zimmershied. and J. F. Bates, J. Mucl. Mater.. 1033104 (1981) 969.974.

3. S. S. Gelles, J. Hucl. Hater., $122 \$ 123$ (1984) 207-213.

4. 4. Jang and J. Hoteff. in Proc. Conf. on Radiation Effects and Tritium Technology for Fusion Reactors, Voi. I. CONF-750989 (1975) op. I-106 to 1-121.

5. F. A. Garner and L. R. Greenwood. Fusion Reactor Materials Semiannual Progress Renort. D0E/ER-0313/l2 (1992) op. $54-58$.

j. F. A. Garner and L. R. Greenwood, "Density Changes Observed in Pure Molybdenum and Mo-4lRe After irradiation in FFTF-MOTA", in this semiannual report. 


\section{ASSESSMENT OF NIOBIUM-BASE ALLOYS FOR STRUCTURAL APPLICATIONS IN THE ITER DIVERTOR* - I. M. Purdy (Argonne National Laboratory)}

\section{OBJECTIVE}

Niobium-base alloys are under consideration as candidate materials for the divertor structure of the International Thermonuclear Experimental Reactor (ITER). Criteria for suitability of the alloys include resistance to aqueous corrosion, crosion/corrosion, fatigue, stress corrosion cracking, hydrogen embrittlement, and radiation-induced embrittlement. Because high thermal fluxes are predicted, thermal conductivity, thermal expansion, and heat capacity are important propertics. Corrosion resistance, mechanical propertics, and physical characteristics are being investigated to identify the most promising $\mathrm{Nb}$-base alloys.

\section{SUMMARY}

The corrosion and embritlement of pure $\mathrm{Nb}, \mathrm{Nb}-1 \mathrm{Zr}, \mathrm{Nb}-5 \mathrm{Mo}-1 \mathrm{Zr}$, and $\mathrm{Nb}-5 \mathrm{~V}-1.25 \mathrm{Zr}$ (alloy elements in wt.\%) were cvaluated in high-purity (HP) deoxygenated water at $300^{\circ} \mathrm{C}$ for up to 120 days. One heat of the $\mathrm{Nb}-5 \mathrm{~V}-1.25 \mathrm{Zr}$ alloy ("O $\mathrm{O}$ " lot) exhibited both a modest corrosion rate and good resistance to embrittlement relative to other $\mathrm{Nb}$-base alloys. At present, $\mathrm{Nb}-5 \mathrm{~V}-1.25 \mathrm{Zr}$ is the most promising $\mathrm{Nb}$-base alloy on the basis ol both corrosion and embrittlement characteristics in HP deoxygenated water at $3000^{\circ} \mathrm{C}$.

\section{PROGRESS AND STATUS}

In previous work, ${ }^{1-3}$ the corrosion behavior of $\mathrm{Nb}$-base alloys $(\mathrm{Nb}-2.5 \mathrm{~V}, \mathrm{Nb}-2.5 \mathrm{Ta}, \mathrm{Nb}-2.5 \mathrm{~W}$, $\mathrm{Nb}-2.5 \mathrm{Zr}, \mathrm{Nb}-2.5 \mathrm{Hf}, \mathrm{Nb}-2.5 \mathrm{Mo}, \mathrm{Nb}-2.5 \mathrm{Fe}$, and several ternary alloys, namely, $\mathrm{Nb}-2.5 \mathrm{Ti}-2.5 \mathrm{Ta}$, $\mathrm{Nb}-2.5 \mathrm{Mo}-2.5 \mathrm{Ti}$, and $\mathrm{Nb}-2.5 \mathrm{Mo}-2.5 \mathrm{Hl}$ ) was investigated in $\mathrm{HP}$ deoxygenated water at $300^{\circ} \mathrm{C}$. Although the weight-gain corrosion rates were not excessive and only a fraction $(<20 \%)$ of the hydrogen that was liberated by the overall corrosion reaction was absorbed by the alloys, most of the alloys were deemed to be brittle, i.e., fracture occurred during a $90^{\circ}$ bend test. Microstructural characteristics of the corrosion-product layers were examined by optical and scanning electron microscopy (SEM). ${ }^{2}$ These cvaluations revealed numerous cracks and spalling of the oxide layers, which is characteristic of nonprotective film formation. Some crack surfaces in the alloys were covered by corrosion product, indicating that the cracks formed during exposure to high-temperature water. The results suggest that $\mathrm{Nb}$ alloys with higher concentrations of alloying elements (namely, $\mathrm{V}, \mathrm{Mo}$, and $\mathrm{Zr}$ ) are required to improve the protective nature of the corrosion-product layers and to decrease hydrogen uptake and embrittlement. During this reporting period, pure $\mathrm{Nb}, \mathrm{Nb}-1 \mathrm{Zr}, \mathrm{Nb}-5 \mathrm{Mo}-1 \mathrm{Zr}$, and $\mathrm{Nb}-5 \mathrm{~V}-1.25 \mathrm{Zr}$ were exposed to $\mathrm{HP}$ deoxygenated water at $300^{\circ} \mathrm{C}$ for up to 120 days. The corrosion behavior and degree of embrittlement of these alloys has been assessed and compared with earlier results.

\section{Experimental Procedures}

Thin sheets of pure $\mathrm{Nb}$ and $\mathrm{Nb}$-base alloys were sheared to approximate dimensions of $8 \times 20 \mathrm{~mm}$. The Nb-5V-1.25Zr alloy, formerly designated "Cb 753" by Haynes, was obtained from two different lots; hence the " $\mathrm{N}$ " and "O" designations in Table 1. Thickness of the $\mathrm{Nb}$ and "O" lot sheet was $0.5 \mathrm{~mm}$; that of the other materials was $0.8 \mathrm{~mm}$. The materials designated " $\mathrm{O}$ " and " $\mathrm{N}$ " differ mainly in the impurity content; the levels in the " $\mathrm{N}$ " material are higher by a factor of $\approx 2$.

\footnotetext{
* Work supported by the U.S. Department of Energy, under Contract W-31-109-Eng-38.
} 
Table 1. Composition of niobium and niobium-base alloys

\begin{tabular}{|c|c|c|c|c|c|c|c|c|c|c|c|}
\hline \multirow[t]{2}{*}{ Alloy ${ }^{a}$} & \multicolumn{3}{|c|}{ wt. $\%$} & \multicolumn{8}{|c|}{$\mathrm{ppm}$} \\
\hline & Mo & V & $7 r$ & 0 & $\mathbf{N}$ & $\mathrm{C}$ & $\mathrm{H}$ & $\mathrm{Si}$ & $\mathrm{Al}$ & $\mathrm{Fe}$ & $\mathrm{Cr}$ \\
\hline $\mathrm{Nb}$ & 0.01 & $<0.01$ & $<0.01$ & 5700 & 1700 & 130 & 2.9 & $<100$ & 50 & $<50$ & $<20$ \\
\hline $\mathrm{Nb}-17 \pi$ & $<0.01$ & $<0.01$ & 0.82 & 153 & 57 & 70 & 4.0 & $<100$ & 65 & $<50$ & $<20$ \\
\hline $\mathrm{Nb}-5 \mathrm{Mo}-1 \mathrm{Zr}$ & 4.86 & $<0.01$ & 0.81 & 186 & 56 & 70 & 8.5 & $<100$ & 70 & $<50$ & $<20$ \\
\hline $\mathrm{Nb}-5 \mathrm{~V}-1.25 \mathrm{Zr}(\mathrm{N})$ & $<0.01$ & 5.76 & 1.11 & 720 & 75 & 300 & 10.3 & 150 & 155 & 100 & 150 \\
\hline $\mathrm{Nb}-5 \mathrm{~V}-1.25 \mathrm{Zr}(\mathrm{O})$ & $<0.01$ & 5.69 & 0.84 & 310 & 95 & 130 & 4.1 & 260 & 65 & 35 & 25 \\
\hline
\end{tabular}

${ }^{\mathrm{a} C o n c e n t r a t i o n s}$ of $\mathrm{Hf}, \mathrm{W}, \mathrm{Ta}$, and $\mathrm{Ti}$ are $\leq 100 \mathrm{ppm} ; \mathrm{Mn}, \mathrm{Cu}$, and $\mathrm{Ni} \leq 50 \mathrm{ppm}$; and $\mathrm{Mg} \leq 5 \mathrm{ppm}$.

The surface arca of each specimen was deiermined by an image analysis technique, using Image ${ }^{\mathrm{TM}}$ software. ${ }^{4}$ The specimens were annealed in vacuo at $1000^{\circ} \mathrm{C}$ for $2 \mathrm{~h}$. Prior to testing, the samples were cleaned with methanol and dried. Corrosion exposures were conducted in a refreshed autoclave system at $300^{\circ} \mathrm{C}\left( \pm 2^{\circ} \mathrm{C}\right)$ and $1400 \mathrm{psi}$. Water flow rate through the system was $\approx 0.07 \mathrm{~cm}^{3} \cdot \mathrm{s}^{-1}$. The dissolvedoxygen concentration of the inlet water was maintained at $<12 \mathrm{ppb}$ and was monitored with an Orbisphere oxygen meter. The 120-day immersion test was interrupted at approximately 30,60 , and 90 days for removal of specimens. Weight changes of the specimens were determined to $\pm 0.001 \mathrm{mg}$ with a Mettler microbalance. A mechanical-bend test was used to screen the samples for ductility in order to evaluate embrittlement.

\section{$\underline{\text { Results and Analysis }}$}

The weight-change data from the tests are shown in Table 2. Nearly all of the alloys showed consisteni weight gains, although the pure $\mathrm{Nb}$ specimen lost weight during the last 30-day exposure. Corrosion rates of the alloys followed power-law kinetics, as shown in Fig. 1. The weight-gain vs. time data for $\mathrm{Nb}-\mathrm{Zr}, \mathrm{Nb}-5 \mathrm{Mo}-1 \mathrm{Zr}$, and $\mathrm{Nb}-5 \mathrm{~V}-1.25 \mathrm{Zr}$ alloys exhibit $\iota^{0.68}, \iota^{0.58}$, and $=\mathrm{l}^{0.35}$ kinetics, respectively. Corrosion behavior of the two heats of the Nb-5V-1.25Zr alloy was quite similar and showed significantly slower weight gain than did the other materials.

Table 2. Weight change per unit are $a\left(g \cdot m^{-2}\right)$ with exposure time

\begin{tabular}{crrccc}
\hline Time $(\mathrm{h})$ & $\mathrm{Nb}$ & $\mathrm{Nb}-1 \mathrm{Zr}$ & $\mathrm{Nb}-5 \mathrm{Mo}-1 \mathrm{Zr}$ & $\mathrm{Nb}-5 \mathrm{~V}-1.25 \mathrm{Zr}(\mathrm{N})$ & $\mathrm{Nb}-5 \mathrm{~V}-1.25 \mathrm{Zr}(\mathrm{O})$ \\
\hline 768 & 17.74 & 15.83 & 3.865 & 2.928 & 2.290 \\
1564 & 36.75 & 25.97 & 6.697 & 3.869 & 3.435 \\
2287 & 39.66 & 33.38 & 7.594 & 4.552 & 3.257 \\
3052 & 37.24 & 40.46 & 8.639 & 4.588 & 3.981 \\
\hline
\end{tabular}

Ductility after each exposure period was assessed by a simplified bend test on a scale of 1 to 6 , as devised by Hull et al. ${ }^{1}$ Material response when the specimens were bent at ambient temperature was categorized according to the fracture index (FI) explaincd in Table 3. 


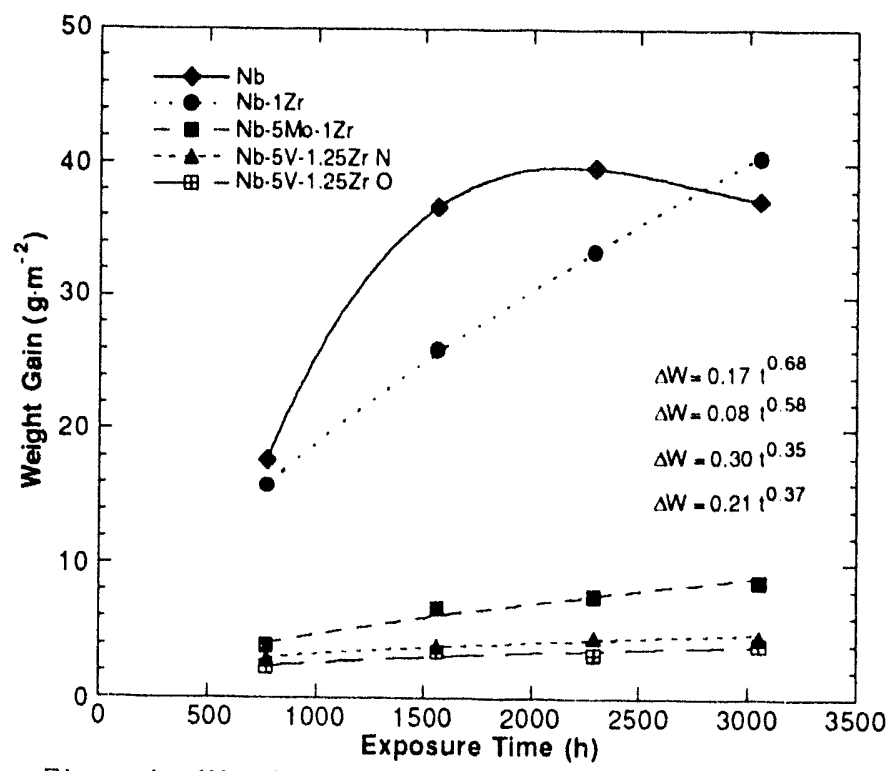

Figure 1. Weight gain vs. time for $\mathrm{Nb}$ and $\mathrm{Nb}$-base alloys exposed to IIP deoxygenated water at $300^{\circ} \mathrm{C}$

Although both heats of the Nb-5V-1.25Zr alloy showed very similar corrosion behavior, the "N" lot became progressively more brittle with increasing exposure time compared with the other metals that were tested, including pure $\mathrm{Nb}$ (Table 3). In terms of ductility evaluated by this test, $\mathrm{Nb}-5 \mathrm{~V}-1.25 \mathrm{Zr}$ ("O" $\mathrm{O}$ " showed the least embrittlement. During the bend tests, it was observed that the oxide scale readily flaked from the bend region of the $\mathrm{Nb}$ and $\mathrm{Nb}-1 \mathrm{Zr}$ specimens.

Table 3. Fracture susceptibility of $\mathrm{Nb}$ and $\mathrm{Nb}$-alloy specimens versus exposure time

\begin{tabular}{|c|c|c|c|c|}
\hline \multirow[b]{2}{*}{ Mctal } & \multicolumn{4}{|c|}{$\begin{array}{c}\text { Fracture Index a after Exposure } \\
\text { (days) }\end{array}$} \\
\hline & 30 & 60 & 90 & 120 \\
\hline $\mathrm{Nb}$ & 2 & 4 & 4 & 5 \\
\hline $\mathrm{Nb}-1 \mathrm{Zr}$ & 2 & 2 & 3 & 3 \\
\hline $\mathrm{Nb}-5 \mathrm{Mo}-1 \mathrm{Zr}$ & 3 & 4 & 4 & 5 \\
\hline $\mathrm{Nb}-5 \mathrm{~V}-1.25 \mathrm{Zr}(\mathrm{O})$ & 2 & 2 & 2 & 2 \\
\hline $\mathrm{Nb}-5 \mathrm{~V}-1.25 \mathrm{Zr}(\mathrm{N})$ & 2 & 4 & 5 & 5 \\
\hline \multicolumn{5}{|c|}{$\begin{array}{l}\text { Fracture susceptibility was categorized according to the following } \\
\text { fracture index (FI): an FI of } 6 \text { indicales breakage before bending } \\
\text { began; an FI of } 5 \text { denotes fracture at a } 90^{\circ} \text { bend; an FI of } 4 \text {, fracture } \\
\text { occurs after a } 180^{\circ} \text { bend; an FI of } 3 \text {, the specimen fractures only } \\
\text { after unbending of a fold; an FI of } 2 \text {, no fracture even on unbending } \\
\text { of a fold; and an FI of } 1 \text {, no fracture or surface cracking of the oxide } \\
\text { scale that formed during exposure. }\end{array}$} \\
\hline
\end{tabular}


The corrosion and embrittlement characteristics of the ternary alloys determined from this and a previous experiment ${ }^{1}$ after 120 days at $300^{\circ} \mathrm{C}$ are shown in Figs. 2 and 3 . The corrosion weight gains for the $\mathrm{Nb}-5 \mathrm{Mo}-1 \mathrm{Zr}$ and $\mathrm{Nb}-2.5 \mathrm{Ti}-2.5 \mathrm{Ta}$ alloy from the previous experiment ${ }^{1}$ are similar, namely, $\approx 8-10 \mathrm{~g} \cdot \mathrm{m}^{-2}$, whereas the values for the other alloys are lower by a factor of 2 . However, the fracture index of one heat (lot "O") of the Nb-5V-2.5Zr alloy (Fig. 3) indicates less embrittlement, as determined from room-temperature bend tests, than any of the $\mathrm{Nb}$-base alloys evaluated thus far. Metallographic and SEM analyses and hardness profiles will be obtained to rationalize differences in the cmbrittlement characteristics of the two heats of the Nb-5V-2.5Zr alloy.

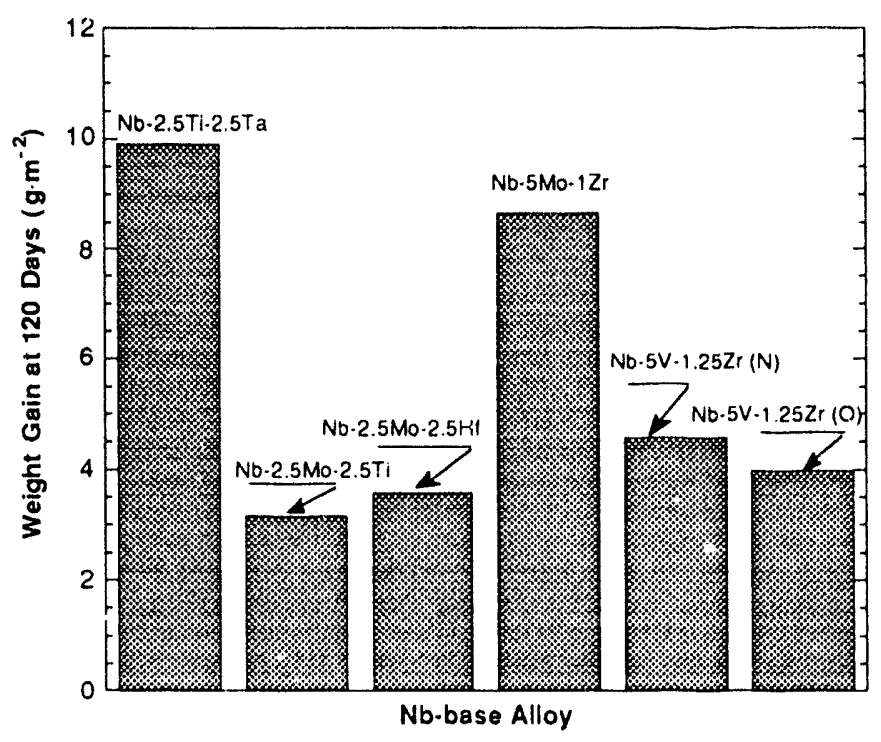

Figure 2. Weight gains for $\mathrm{Nb}$-base alloys after exposure to IIP deoxygenaled water for 120 days at $300^{\circ} \mathrm{C}$

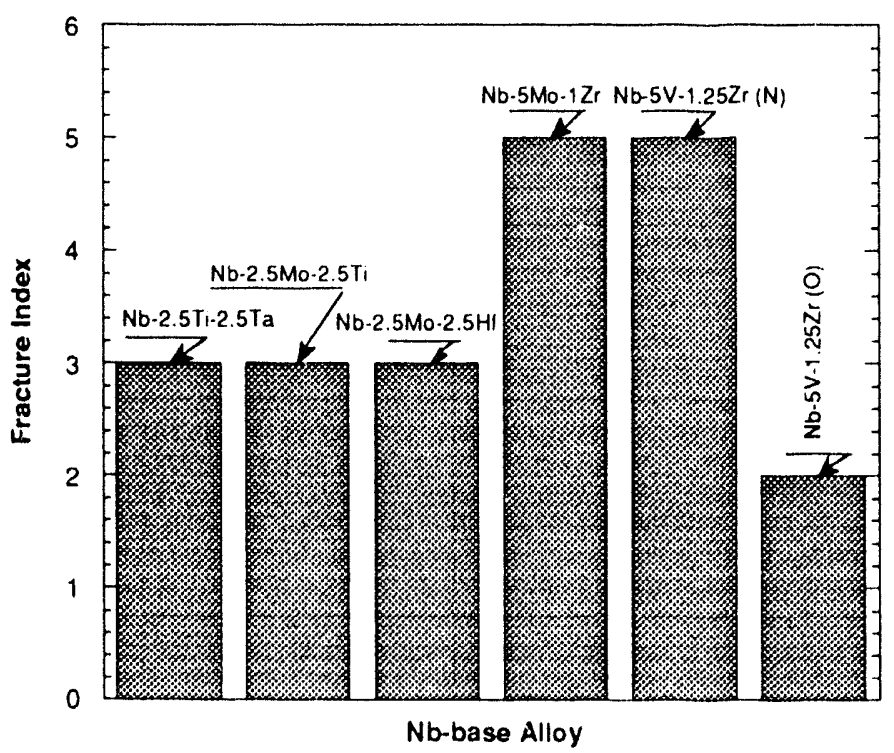

Figure 3. Fracture index for $\mathrm{Nb}$-base alloys after exposure to IIP deoxygenated water for 120 days at $300^{\circ} \mathrm{C}$ 


\section{CONCLUSIONS}

Experience has shown that alloys with high $\mathrm{W}(\approx 10 \mathrm{wt} . \%)$ and $\mathrm{Mo}(\approx 5 \mathrm{wt} . \%)$ contents are difficult to fabricate and weld, and that a high Ta content reduces the irradiation resistance of the material. ${ }^{3}$ Our results have shown that (a) $\mathrm{V}$ additions lower the corrosion rate and (b) $\mathrm{Hf}$ and $\mathrm{Zr}$ additions lower both the $\mathrm{H}$ concentrations and the percentage of corrosion-product $\mathrm{H}$ that is absorbed by $\mathrm{Nb}$-base alloys ${ }^{3}$ (compared to $\mathrm{Nb}-\mathrm{V}$ alloys). Further, $\mathrm{Nb}-5 \mathrm{~V}-1.25 \mathrm{Zr}$ shows the greatest promise in terms of resistance to both corrosion and embrittement for ITER divertor applications.

\section{FUTURE WORK}

The next series of corrosion tests on two heats of the $\mathrm{Nb}-5 \mathrm{~V}-1,25 \mathrm{Zr}$ alloy will be conducted at a somewhat lower temperature to determine the temperature dependence of the corrosion rate and the degree of embrittlement. A detailed microstructural evaluation of the corrosion films on specimens from the present test will be conducted to quantify differences in the embrittement characteristies of the two lots of the alloy.

\section{REFERENCES}

1. A. B. Hull, B. A. Loomis, and L. J. Nowicki, Preliminary Assessment of Aqueous Corrosion of Niobium Alloys for Structural Applications in the ITER Divertor, Fusion Reactor Materials Semiannual Report for Period Ending March 31, 1991, DOE/ER-(1313/10, Oak Ridge National Laboratory, p. 248.

2. J. A. Todd and 1. M. Purdy, Preliminary Assessment of Condidale Niobium Alloys for the Divertor Structures, Fusion Reactor Materials Semiannal Repont for Perind Ending Sept 30, 1992, DOE/ER0313/13, Oak Ridge National Laboralory, p. 203.

3. D. T. Peterson, A. B. Hull, and B. A. Loumis, Ilydrogen Embritlement of Niohium-Base Alloys for Application in the TIER Divertor. Fusion Reactor Materials Semiannual Report for Period Ending Sept 30, 1992, DOE/ER-(1313/13, Oak Ridge National Laboratory, p. 182.

4. W. Rasband, Image, Public Demain Program for the Matintosh Computer, distributed by Twilight Clone BBS, Silver Spring, MD, 199(). 


\section{MICROSTRUCTURAL EVOLUTION INDUCED BY BORON TRANSMUTATION IN NEUTRON- IRRADIATED VANADIUM-BASE ALLOYS* -- H. M Chung (Argonne National Laboratory).}

\section{OBJECTIVE}

The objective of this work is to characterize the microstructural evolution induced by transmutation of ${ }^{10} \mathrm{~B}$ in neutron-irradiated vanadium-base alloys, and thereby to provide a better understanding of the boron-doping technique that is used to simulate the effect of helium generation under fusion reactor conditions.

\section{SUMMARY}

Microstructural evolution associated with transmutation of ${ }^{10} \mathrm{~B}$ to helium and lithium has been characterized to provide a better understanding of the boron-doping technique, a technique frequently used to simulate the effect of helium generation under fusion reactor conditions. Transmission electron microscopy (TEM) was used to examine specimens of V-20Ti alloy after irradiation at $600^{\circ} \mathrm{C}$ to $\approx 44-80 \mathrm{dpa}$ in the Fast Flux Test Facility (FFTF). In the earlier stage of irradiation to low fluence, concentric shells of He-damage and $\mathrm{Li}$-damage zones are produced around $\mathrm{a} \mathrm{V}_{3} \mathrm{~B}_{2}$ precipitate or a ${ }^{10} \mathrm{~B}$-rich cluster. On further irradiation, helium atoms diffuse away from the damage shell either to be dissolved in the matrix or to form microcavities, leaving a shell rich in $\mathrm{Li}$, defect clusters, and dislocations. Oxygen atoms in solid solution migrate toward the $\mathrm{Li}$-rich shells, and $\gamma-\mathrm{LiV}_{2} \mathrm{O}_{5}$ shells precipitate subsequently. In view of this behavior, neither boron nor $\mathrm{Li}$ produced from the transmutation is likely to result in a detrimental weakening of grain boundaries.

\section{INTRODUCTION}

Vanadium-base alloys are considered promising candidate structural materials for a fusion reactor first wall because they offer the important advantages of inherently low irradiation-induced activity, good mechanical properties, good compatibility with lithium, high thermal conductivity, and good resistance to irradiation damage. One of the properties of the vanadium-base alloys that is not well understood yet is the effect of simultaneous generation of helium and neutron damage under conditions relevant to fusion-reactor operation (i.e., at a ratio $\approx 5 \mathrm{appm} \mathrm{He/dpa).}{ }^{1-15}$ Several methods have treen utilized in the past to simulate the effect of helium generation in ncutron-irradiated vanadium-base alloys, i.e., the "tritium-trick" technique, ${ }^{1-5}$ cyclotron-injection of helium, 6-9,12 boron-doping technique, ${ }^{10-13}$ and dynamic helium charging experiment. ${ }^{14-15}$

The ${ }^{10} \mathrm{~B}$-doping method is a convenient technique in that it requires a relatively simple procedure to prepare specimens. Furthermore, based on results of tensile tests reported in the literature, ${ }^{12}$ no detrimental side effect seems to be associated with this technique in contrast to the "tritium-trick" method in which a damaging effect of charged hydrogen (tritium) or the unrealistically high initial helium content is suspected to weaken grain boundaries in some alloys. The boron-doping technique utilizes the large thermal-neutron cross section $(\approx 3840$ barn $)$ of the ${ }^{10} \mathrm{~B}(n, \alpha)^{7} \mathrm{Li}$ reaction. By adjusting the level of doped ${ }^{10} \mathrm{~B}$, the method can be tailored to suit the characteristic neutron spectrum of a fission reactor. However, to assess the viability of the technique and to understand the effect of the Li by-product on swelling and mechanical properties, it is necessary to understand the behavior of $\mathrm{B}$ and $\mathrm{Li}$ during irradiation. For this

\footnotetext{
* Work supported by the Office of Fusion Energy, U.S. Departunent of Energy, under Contract W-31-109-Eng-38.
} 
purpose, microstructural evolution associated with transmutation of ${ }^{10} \mathrm{~B}$ has been characterized in specimens of a vanadium-base alloy that were irradiated to high fluence in the Fast Flux Test Facility (FFTF).

\section{MATERIALS AND PROCEDURES}

TEM examination was conducted on disk specimens from a V-20Ti alloy irradiated in the FFTF. The chemical composition of the alloy is given in Table 1. The content of boron, apparently dissolved in the alloy as an impurity, was not known prior to irradiation. The disks were irradiated at $600^{\circ} \mathrm{C}$ to neutron fluences $(E>0.1 \mathrm{McV})$ of $7.8 \times 10^{22} \mathrm{n} \cdot \mathrm{cm}^{-2}(\approx 44 \mathrm{dpa})$ and $1.33 \times 10^{23} \mathrm{n} \cdot \mathrm{cm}^{-2}(\approx 80 \mathrm{dpa})$. They were sealed in $\mathrm{Li}^{7}$-filled TZM capsules during irradiation to prevent contamination with $\mathrm{O}, \mathrm{N}$, and $\mathrm{C}$ impurities dissolved in the sodium coolant of the FFTF. The irradiated specimens were jet-thinned for TEM in a solution of $15 \%$ sulfuric acid- $72 \%$ methanol- $13 \%$ butyl cellosolve maintained at $-5^{\circ} \mathrm{C}$. TEM was conducted with a JEOL $100 \mathrm{CX}$-II scanning transmission electron microscope operating at $100 \mathrm{keV}$.

Table 1. Composition of V-18Ti alloy irradiated in the FFTF and analyzed to characterize boron-transmutation. induced microstructural evolution

\begin{tabular}{|c|c|c|c|c|c|}
\hline \multirow[b]{2}{*}{ Alloy ID } & \multirow{2}{*}{$\begin{array}{c}\text { Nominal } \\
\text { Composition } \\
(w t \%)\end{array}$} & \multicolumn{4}{|c|}{ Impurity Concentration (wopm) } \\
\hline & & 0 & $N$ & $C$ & $\mathrm{Si}$ \\
\hline BL. 1.5 & $V-17.7 T i$ & 830 & 160 & 380 & 480 \\
\hline
\end{tabular}

\section{RESULTS AND DISCUSSION}

The irradiated V-20Ti alloy specimens exhibited a hitherto unknown peculiar microstructural feature. As an example, charactoristic TEM microstructures observed in specimens irradiated to $=44$ and $\approx 80$ dpa are shown in bright-and dark-field morphology, respectively, in Figs. IA and IB. Both micrographs show characteristic circular shells in dark contrast. The norphology of the shells in Fig. IA is strikingly similar to those of the cylindrical damage shells reported by Rau and Ladd 16 for neutron-irradiated unalloyed vanadium doped with $<10 \mathrm{wppm}$ boron. In that study, the specimens were irradiated at $=70^{\circ} \mathrm{C}$ to a relatively low fast-neutron fluence of $5.4 \times 10^{19} \mathrm{n} \cdot \mathrm{cm}^{-2}(\mathrm{E}>1 \mathrm{MeV})$ and a thermal-neutron fluence of $3.5 \times 10^{20} \mathrm{n} \cdot \mathrm{cm}^{-2}$ in the Oak Ridge Reactor (ORR). Two concentric shells, surrounding rod-like precipitates of $\mathrm{V}_{3} \mathrm{~B}_{2}$, were produced by recoil $\mathrm{Li}$ and $\mathrm{He}$ atoms during transmutation of ${ }^{10} \mathrm{~B}$. On further annealing of the irradiated specimens at $\geq 6.50)^{\circ} \mathrm{C}$, the defect clusters that made up the damage shells were removed and replaced by dislocation tangles. At the same time, blocky precipitates $\approx 100 \mathrm{~nm}$ in size emerged in the inner Li-damage shells. Although they were not positively identified, the blocky precipitates were believed to be an Li-rich vanadium compound.

In the study of Kawanishi et al., ${ }^{13} \mathrm{~V}$-20Ti specimens doped with $120 \mathrm{wppm}{ }^{10} \mathrm{~B}$ were examined after irradiation at $520^{\circ} \mathrm{C}$ to 42 dpa in FFTF. Halo images due to high-density microcavities $=5()-200 \mathrm{~nm}$ in size were observed roughly within the range of recoil $\mathrm{Li}\left(\mathrm{i} . \mathrm{e} .,=1200 \mathrm{~nm}\right.$ ) from $\mathrm{V}_{3} \mathrm{~B}_{2}$ particles. Infrequently, unidentified particles believed to be lithium precipitates were observed in the vicinity of the halo. Such particles were absent in specimens irradiated at 365 and $406^{\circ} \mathrm{C}$. However, in the absence of a dark-field image produced from a reciprocal lattice spot of the particles, the nature of such precipitates is not clear. For instance, the precipitates could be confused with $\mathrm{Ti}_{5} \mathrm{Si}_{3}$ particles that are commonly observed in irradiated vanadium alloys containing Ti. 17,18 

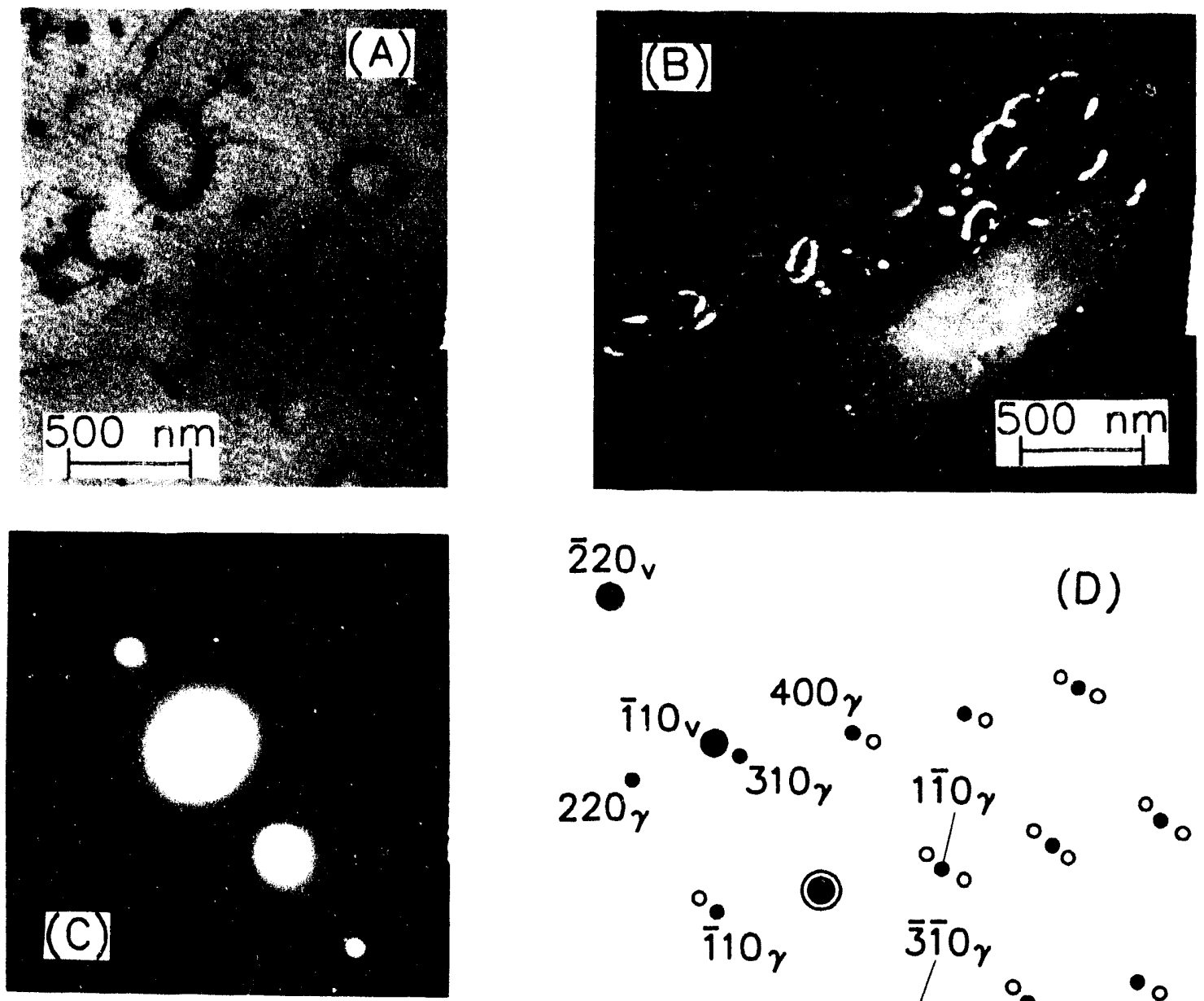

(D)
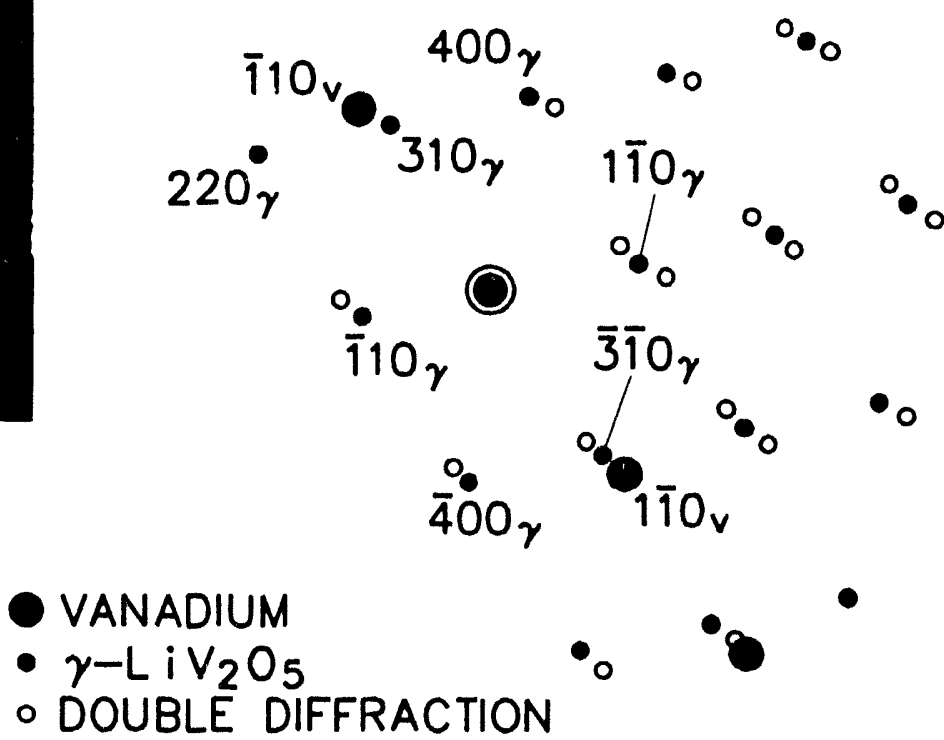

Figure 1. Shell-shaped $\gamma-\mathrm{LiV}_{2} \mathrm{O}_{5}$ precipitates observed in $\mathrm{V}$-20Ti specimens after irradiation at $600^{\circ} \mathrm{C}$ (A) to $\approx 44 \mathrm{dpa}$ (bright-field) and (B) to $\approx 80 \mathrm{dpa}$ (dark-field); (C) SAD pattern of (B) and (D) indexed pattern of $(C)$ showing reflections from $\mathrm{\gamma LiV}_{2} \mathrm{O}_{5}$ and double-diffraction spots

The shell-shaped and nearby globular features observed in Figs. 1A and 1B indicate a secondary precipitation that occurred in association with the damage zones reported by Rau and Ladd. 16 To identify positively the nature of the precipitates, SAD and dark-field-imaging analyses were conducted. The result showed that the precipitates are $\gamma-\mathrm{LiV}_{2} \mathrm{O}_{5}$ phase. Examples of observed and indexed SAD patterns are given, respectively, in Figs. 1C and 1D. The dark-field image of Fig. 1B was produced from the (400) reflection of $\gamma-\mathrm{LiV}_{2} \mathrm{O}_{5}$ in Fig. ID. 

ct al. ${ }^{19}$ as:

Stoichiometry and crystallographic structures of $\mathrm{Li}_{\mathrm{x}} \mathrm{V}_{2} \mathrm{O}_{5}$ phases have been reported by Hagenmuller

$$
\begin{aligned}
& \alpha-\mathrm{Li}_{\mathrm{x}} \mathrm{V}_{2} \mathrm{O}_{5}, 0<\mathrm{x} \leq 0.13 \text {, orthorhombic } \\
& (\mathrm{a}=1.1460 \mathrm{~nm}, \mathrm{~b}=0.3554 \mathrm{~nm}, \mathrm{c}=0.4368 \mathrm{~nm}) \\
& \beta-\mathrm{Li}_{\mathrm{x}} \mathrm{V}_{2} \mathrm{O}_{5}, 0.22 \leq \mathrm{x} \leq 0.62, \text { monoclinic } \\
& \left(\mathrm{a}=1.003 \mathrm{~nm}, \mathrm{~b}=0.360 \mathrm{~nm}, \mathrm{c}=1.538 \mathrm{~nm}, \mathrm{~b}=110^{\circ} 40^{\prime}\right) \\
& \gamma-\mathrm{Li}_{\mathrm{x}} \mathrm{V}_{2} \mathrm{O}_{5}, 0.88 \leq \mathrm{x} \leq 1, \text { orthorhombic } \\
& (\mathrm{a}=0.9702 \mathrm{~nm}, \mathrm{~b}=0.3607 \mathrm{~nm}, \mathrm{c}=1.0664 \mathrm{~nm})
\end{aligned}
$$

Lattice spacings of the $\alpha-\mathrm{Li}_{\mathrm{x}} \mathrm{V}_{2} \mathrm{O}_{5}$ and $\gamma-\mathrm{Li}_{\mathrm{x}} \mathrm{V}_{2} \mathrm{O}_{5}$ phases calculated on the basis of these structures are tabulated in Table 2. The SAD patterns could be indexed only on the basis of the structure of $\gamma-\mathrm{Li}_{\mathrm{x}} \mathrm{V}_{2} \mathrm{O}_{5}$. The measured lattice spacings of the (110), (310), and (400) reflections in Fig. ID are, respectively, $0.337,0.242$, and $0.243 \mathrm{~nm}$, which agree well with the calculated values given in Table 2 . Interplanar angles measured for $(1 \overline{1} 0) /(400),(\overline{1} 10) /(310),(400) /(310),(\overline{1} 10) /(220)$, and $(1 \overline{1} 0) / 510)$ reflections were, respertively, $69.6,68.5,42.2,41.0$, and $41.5^{\circ}$. These values also agree well with the respective calculated values, i.e., $69.66,68.59,42.23,40.82$, and $41.37^{\circ}$.

Based on the result of present study and information reported by Rau and Ladd, ${ }^{16}$ the behavior of $B$ and $\mathrm{Li}$ can be summarized by the schematic illustration in Fig. 2 . According to the phase diagram reported in the literature, ${ }^{20}$ there is no solubility between vanadium and lithium in the solid or liquid state. Therefore, virtually all $\mathrm{Li}$ atoms produced from the transmutation are expected to present themselves in $\mathrm{Li}_{\mathrm{x}} \mathrm{V}_{2} \mathrm{O}_{5}$ precipitates. Consequently, grain-boundary segregation of $\mathrm{Li}$ is not likely to occur. The precipitation of the Li-rich compound could be strongly influenced by the $\mathrm{O}$ level in the alloy, as well as by irradiation temperature, because a sufficient number of $\mathrm{O}$ atoms are needed to form the $\mathrm{Li}_{\mathbf{x}} \mathrm{V}_{2} \mathrm{O}_{5}$ phase. Solubility of $B$ in vanadium-base alloys is also very low, although the solubility limit is not well known yet and values as low as $10 \mathrm{wppm}^{16}$ and as high as $140 \mathrm{wppm}^{13}$ have been mentioned for the temperature range of present interest. Boron atoms seem to be distributed more or less uniformly either in solid solution or in small $V_{3} B_{2}$ precipitates, and no evidence of grain-boundary segregation of $B$ has been reported. This behavior of $\mathrm{Li}$ and $\mathrm{B}$, therefore, seems to strongly support the viability of the ${ }^{10} \mathrm{~B}$-doping technique.

\section{CONCLUSIONS}

1. Microstructural evolution associated with transmutation of ${ }^{10} \mathrm{~B}$ to helium and lithium has been characterized to provide a better understanding of the boron-doping technique, a technique frequently used to simulate the effect of helium generation under fusion reactor conditions. In the earlier stage of irradiation to low fluence, concentric shells of He-damage and Li-damage zones are produced around a $\mathrm{V}_{3} \mathrm{~B}_{2}$ precipitate or a ${ }^{10} \mathrm{~B}$-rich cluster. On further irradiation, helium atoms diffuse away from the damage shell either to be dissolved in the mairix or to form microcavities, leaving a shell rich in $\mathrm{Li}$, defect clusters, and dislocations. Oxygen atoms in solid solution migrate toward the Li-rich shells, and $\gamma-\mathrm{LiV}_{2} \mathrm{O}_{5}$ shells precipitate subsequently.

2. Grain-boundary segregation of $\mathrm{B}$ or $\mathrm{Li}$ is not expected to occur either during fabrication or irradiation. This behavior of $\mathrm{Li}$ and $\mathrm{B}$, therefore, strongly supports the viability of the ${ }^{10} \mathrm{~B}$-doping technique. 
Table 2. Calculated reciprocal lattice spacing (in unit of $0.1 \mathrm{~nm}$ ) of $\alpha-L i_{x} V_{2} O_{5}{ }^{a}$ and $\gamma-L i_{x} V_{2} O_{5} b$

\begin{tabular}{|c|c|c|c|c|c|}
\hline (hkl) & $\alpha-\mathrm{Li}_{\mathrm{x}} \mathrm{V}_{2} \mathrm{OS}$ & $\gamma-\mathrm{Li}_{\mathrm{x}} \mathrm{V}_{2} \mathrm{O}_{5}$ & (hkl) & $\alpha-\mathrm{Li}_{\mathrm{x}} \mathrm{V}_{2} \mathrm{O}_{5}$ & $\gamma-\mathrm{Li}_{x} \mathrm{~V}_{2} \mathrm{O}_{5}$ \\
\hline 100 & 11.46 & 9.70 & 130 & 1.18 & 1.19 \\
\hline 010 & 3.55 & 3.61 & 103 & 1.44 & 3.33 \\
\hline 001 & 4.37 & 10.66 & 013 & 1.35 & 2.53 \\
\hline 110 & 3.39 & 3.38 & 311 & 2.24 & 2.34 \\
\hline 011 & 2.76 & 3.41 & 113 & 1.34 & 2.45 \\
\hline 101 & 4.08 & 7.17 & 131 & 1.14 & 1.18 \\
\hline 200 & 5.73 & 4.85 & 222 & 1.34 & 1.61 \\
\hline 020 & 1.78 & 1.80 & 320 & 1.61 & 1.57 \\
\hline 002 & 2.18 & 5.33 & 302 & 1.90 & 2.76 \\
\hline 201 & 3.47 & 4.41 & 203 & 1.41 & 2.86 \\
\hline 021 & 1.65 & 1.78 & 230 & 1.16 & 1.17 \\
\hline 120 & 1.76 & 1.77 & 032 & 1.04 & 1.17 \\
\hline 102 & 2.14 & 4.67 & 023 & 1.71 & 1.61 \\
\hline 012 & 1.86 & 2.98 & 321 & 1.51 & 1.56 \\
\hline 210 & 3.02 & 2.89 & 312 & 1.67 & 2.19 \\
\hline 220 & 1.70 & 1.69 & 231 & 1.12 & 1.16 \\
\hline 022 & 1.38 & 1.71 & 213 & 1.31 & 2.24 \\
\hline 202 & 2.04 & 3.59 & 123 & 1.12 & 1.59 \\
\hline 111 & 2.68 & 3.22 & 132 & 1.04 & 1.16 \\
\hline 112 & 1.83 & 2.85 & 322 & 1.30 & 1.51 \\
\hline 121 & 1.63 & 1.75 & 232 & 1.02 & 1.14 \\
\hline 211 & 2.48 & 2.79 & 223 & 1.10 & 1.53 \\
\hline 221 & 1.58 & 1.67 & 400 & 2.87 & 2.42 \\
\hline 212 & 1.77 & 2.54 & 040 & 0.89 & 0.90 \\
\hline 211 & 1.37 & 1.68 & 004 & 1.09 & 2.66 \\
\hline 300 & 3.82 & 3.23 & 401 & 2.40 & 2.36 \\
\hline 030 & 1.18 & 1.20 & 410 & 2.23 & 2.01 \\
\hline 003 & 1.45 & 3.55 & 140 & 0.88 & 0.89 \\
\hline 301 & 2.87 & 3.09 & 104 & 1.09 & 2.57 \\
\hline 031 & 1.14 & 1.19 & 014 & 1.04 & 2.14 \\
\hline 310 & 2.60 & 2.40 & 041 & 0.87 & 0.90 \\
\hline
\end{tabular}

${ }^{a}$ Orthorhombic, $a=1.1460 \mathrm{~nm}, \mathrm{~b}=0.3554 \mathrm{~nm}$, and $\mathrm{c}=0.4368 \mathrm{~nm}$, $0<\mathrm{x} \leq 0.13$.

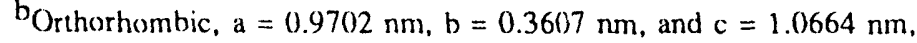
$0.88 \leq \mathrm{x} \leq 1$. 
(A)

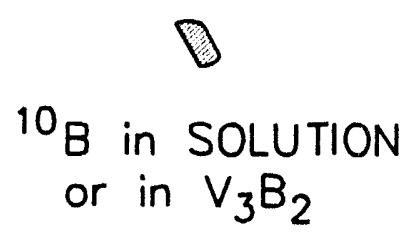

(C)

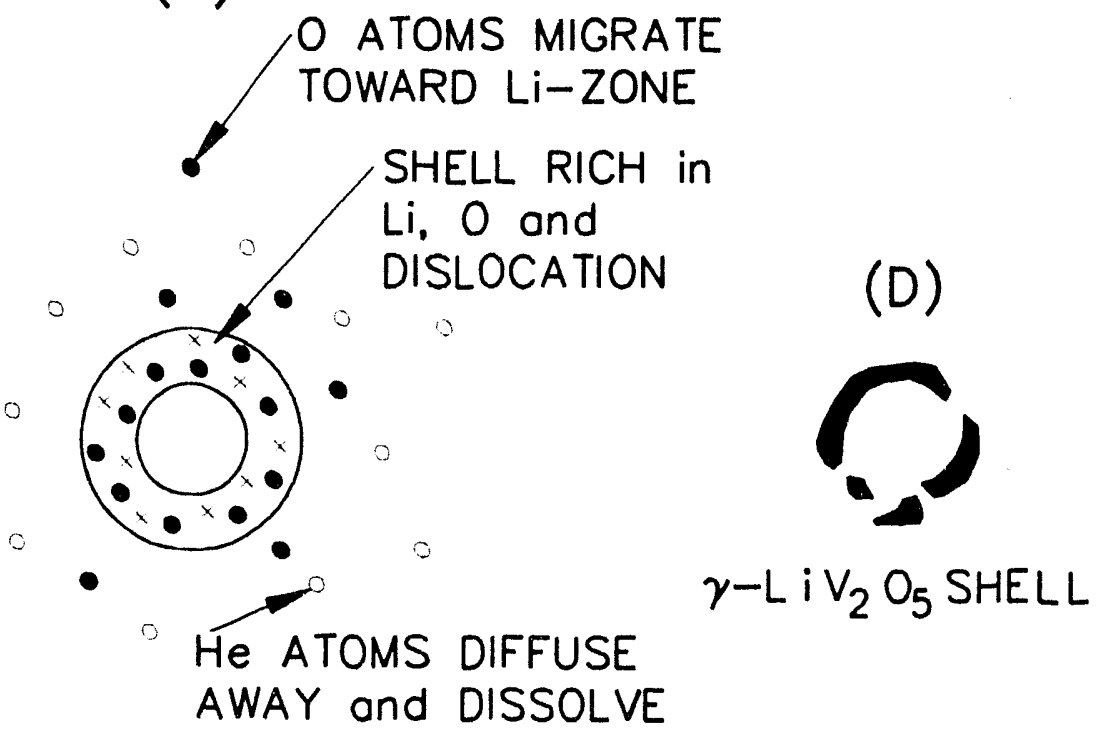

Figure 2. Schematic illustration of microstructural evolution associated with transmutation of ${ }^{10} B$ in neutron-irradiated vanadium-base alloys

\section{FUTURE WORK}

Behavior of Li produced from transmutation of ${ }^{10} \mathrm{~B}$ will be examined in similar specimens irradiated at 420 and $520^{\circ} \mathrm{C}$.

\section{REFERENCES}

1. D. N. Braski, in Influence of Radiation on Material Propertics, ASTM-STP 956 (1986) pp. 271-290.

2. D. N. Braski, J. Nucl. Mater. 141-143 (1986) 1125.

3. D. N. Braski, in Reduced Aclivation Materials for Fusion Reactors, ASTM-STP 1047 (1988) pp. 161-178.

4. H. Matsui, M. Tanaka, M. Yamamoto, and M. Tada, J. Nucl. Mater. 191-194 (1992) 919. 
5. M. Satou, K. Abe, and H. Matsui, J. Nucl. Mater. 191-194 (1992) 938.

6. W. van Witzenburg, A. Mastenbrock, and J. D. Ellen, J. Nucl. Mater. 103-104 (1981) 1187.

7. M. P. Tanaka, E. E. Bloom, and J. A. Horak, J. Nucl. Mater. 114 (1981) 895.

8. M. L. Grossbeck and J. A. Horak, in Influence of Radiation on Material Properties, ASTM-STP 956 (1986) 291.

9. J. M. Vitek, D. N. Braski, and J. A. Horak, J. Nucl. Mater. 141-143 (1986) 982.

10. L. L. Horton and K. Farrell, J. Nucl. Mater. 122-123 (1984) 687.

11. H. Kawanishi and S. Ishino, in Reduced Activation Materials for Fusion Reactors, ASTM-STP 1047 (1988) pp. 179-189.

12. W. van Witzenburg and E. de Vries, in Effects of Radiation on Materials, ASTM-STP 1125 (1990).

13. H. Kawanishi, Y. Arai, and S. Ishino, J. Nucl. Mater. 191-194 (1992) 933.

14. D. L. Smith, H. Matsui, L. R. Greenwood, and B. A. Loomis, J. Nucl. Mater. 155-157 (1988) 1359.

15. D. L. Smith, B. A. Loomis, H. Matsui, M. L. Hamilton, K. L. Pearce, J. P. Kopasz, C. E. Johnson, R. G. Clemmer, and L. R. Greenwood, in Fusion Reactor Materials, Semiannual, Prog. Rep. DOE/ER-0313/10, Oak Ridge National Laboratory, Oak Ridge, TN (1991) 159.

16. R. C. Rau and R. L. Ladd, J. Applicd. Phys. 40 (1969) 2899.

17. H. M. Chung and D. L. Smith, J. Nucl. Mater. 191-194 (1992) 942.

18. H. M. Chung, B. A. Loomis, and D. L. Smith, in Effects of Radiation on Materials: 16th International Symposium, ASTM STP 1175, A. S. Kumar, D. S. Gelles, R. K. Nanstad, and T. A. Little, eds., American Society for Testing and Materials, Philadelphia, 1993.

19. P. Hagenmuiler, J. Galy, M. Pouchard, and A. Casalot, Mat. Res. Bulletin 1 (1966) 45.

20. T. B. Massalski, J. L. Murray, L. H. Benett, and H. Baker (Eds.), Binary Alloy Phase Diagrams, American Society for Metals, Metals Park, OH, 1986. 
STATUS OF THE DYNAMIC HELIUM CHARGING EXPERIMENT (DHCE) ${ }^{*}-$ H. Tsai, H. M. Chung, B. A. Loomis, D. L. Smith (Argonne National Laboratory), H. Matsui (Tohoku University), M. L. Hamilton, L. R. Greenwood, and R. Ermi (Pacific Northwest Laboratory)

\section{OBJECTIVE}

The objective of this experiment is to investigate the effects of concurrent helium production and fast-neutron irradiation on the physical and mechanical properties of vanadium-base alloys. To isolate the helium effects, sibling samples were irradiated under comparable fast-neutron conditions but without helium production.

\section{SUMMARY}

Irradiation of the seven DHCE capsules was completed in the Materials Open Test Assembly (MOTA)-2B at the end of Cycle 12B in the Fast Flux Test Facility (FFTF). The accrued exposure was 203.3 effective full-power days (EFPDs), vis-a-vis the target exposure of 300 EFPDs. Peak damage in the samples was $\approx 29$ displacement per atom (dpa). All seven capsules have been discharged from the FFTF and are being shipped to Argonne National Laboratory (ANL), where the samples will be retrieved from the capsules and distributed to the experimenters, including Monbusho of Japan, for examination and testing. A substantial effort is underway at ANL to retrieve the samples from the highly tritiated capsules.

\section{PROGRESS AND STATUS}

\section{Introduction}

Helium generation by $(n, a)$ reactions in vanadium-based structural materials in fusion reactors may affect the physical and mechanical properties of the materials. To study these effects, it is important that the prototypical rates of helium generation be achieved in specimens during irradiation testing. Because of the fission neutron spectrum in the FFTF, the rate of hclium production in vanadium is normally low (about $0.02 \mathrm{appm} / \mathrm{dpa}$ ). The production rate in fusion reactors, on the other hand, is much higher ( $\approx 5 \mathrm{appm} / \mathrm{dpa}$ ), due to the higher-energy $14-\mathrm{McV}$ fusion neutrons. The objective of the DHCE in the FFTF is to enhance helium production by in-situ decay of tritium, which is generated in the capsule lithium bond and subsequently diffuses into the vanadium-alloy samples. Detailed descriptions of the DHCE capsules can be found in Refs. 1 and 2.

\section{Test Matrix}

Seven capsules containing a large number of tensile samples and transmission electron microscope (TEM) disks were built and irradiated. The test matrix is shown in Table 1. A detailed listing of specimens is provided in Ref. 1. To ensure that helium generation starts immediately after the reactor startup, each capsule was precharged with a controlled amount of tritium contained in a tritiated vanadium foil. The ${ }^{6} \mathrm{Li}$ content in the lithium bond in each capsule was adjusted to maintain a near-constant rate of tritium influx into the samples during the irradiation.

\footnotetext{
*Work supported by the Office of Fusion Energy, U.S. Department of Energy, under Contract W-31-109-Eng-38.
} 
Irradiation History

The DHCE was designed for a cumulative exposure of 300 EFPDs, in three 100-EFPD cycles. However, because of the halt of FFTF operation, the irradiation was terminated after two cycles, 12A and 12B, for a total exposure of 203.3 EFPDs. Two of the capsules, 4D1 and 4D2, located at Level 4 in the FFTF/MOTA, attained an estimated peak fluence of $\approx 5.3 \times 10^{22} \mathrm{n} / \mathrm{cm}^{2}$ and a damage of $\approx 29$ dpa in vanadium. The other five capsules $(5 \mathrm{C} 1,5 \mathrm{C} 2,5 \mathrm{D} 1,5 \mathrm{E} 1$, and $5 \mathrm{E} 2)$ were located in Level 5 and attained estimated fluence and damage of $\approx 2.9 \times 10^{22} \mathrm{n} / \mathrm{cm}^{2}$ and $\approx 15 \mathrm{dpa}$, respectively.

Table 1. MOTA-2B DHCE test matrix

\begin{tabular}{|c|c|c|c|c|c|c|c|c|}
\hline \multirow[b]{3}{*}{ Capsule } & \multirow{3}{*}{$\begin{array}{l}\text { Irradiation } \\
\text { Temperalure } \\
\text { (ㄷ) }\end{array}$} & \multirow{3}{*}{$\begin{array}{l}\text { Initial } \\
\text { Tritium } \\
\text { (Ci) }\end{array}$} & \multirow{3}{*}{$\begin{array}{c}{ }^{6} \mathrm{Lja} \\
\text { Fraction } \\
(\%)\end{array}$} & \multicolumn{4}{|c|}{$\begin{array}{l}\text { Total } \\
\text { Number of Specimens }\end{array}$} & \multirow{3}{*}{$\begin{array}{c}\text { Total } \\
\text { Specimer } \\
\text { Mass (g) }\end{array}$} \\
\hline & & & & \multicolumn{2}{|c|}{ Japan } & \multicolumn{2}{|r|}{ U.S. } & \\
\hline & & & & $\mathrm{TS}(\mathrm{S})$ & D3 & SS3 & TEM & \\
\hline 4D1 & 425 & 99 & 5.0 & 24 & 94 & 8 & 45 & 5.86 \\
\hline 4D2 & 425 & 70 & 4.5 & 16 & 96 & 8 & 44 & 5.38 \\
\hline $5 \mathrm{E} 2$ & 425 & 26 & 1.0 & 16 & 100 & 8 & 42 & 5.38 \\
\hline SD1 & 500 & 74 & 6.5 & 23 & 94 & 8 & 42 & 5.77 \\
\hline $5 \mathrm{E} 1$ & 500 & 57 & 1.0 & 24 & 102 & 8 & 43 & 5.82 \\
\hline $5 \mathrm{Cl}$ & 600 & 16 & 8.0 & 24 & 93 & 8 & 45 & 5.82 \\
\hline $5 \mathrm{C} 2$ & 600 & 18 & 8.0 & 24 & 108 & 8 & 45 & 5.95 \\
\hline
\end{tabular}

${ }^{\text {a Atomic ratio of }}{ }^{6} \mathrm{Li}$ to total lithium.

$\mathrm{b}_{\mathrm{TS}}(\mathrm{S})$ and SS3 are tensile specimens; D3 and TEM are TEM disks.

${ }^{c}$ Does not include tritiated vanadium foil.

Because of the uncertainties in the FFTF schedule, the DHCE capsules were not immediately discharged after Cycle 12B (March 1992). In the interim holding period, additional helium was generated in the samples due to the continued tritium diffusion and decay. As a result, the actual He/dpa ratios will be greater than those for the end-of-irradiation conditions listed in Table 2. The difference, however, is expected to be limited because of a lower distribution coefficient of tritium at the holding temperature $\left(\approx 200^{\circ} \mathrm{C}\right)$. A lower tritium concentration in vanadium at $200^{\circ} \mathrm{C}$ results in a lower helium production rate than at the higher test temperatures. The actual Hc/dpa ratios in the samples will be determined with helium assays when the samples are retrieved from the capsules.

\section{Status}

All seven DHCE capsules have been successfully removed from the MOTA-2B vehicle. The capsules are being shipped from Pacific Northwest Laboratory (PNL) to ANL for disassembly. To date, a shipment of three capsules has been completed. At ANL, the capsules will be opened to retrieve the samples for postirradiation examination and testing. The Monbusho samples in the capsules will be clearied and returned to Japan.

Considerable design and engineering effort is being applied toward the disassembly of the DHCE capsules. The principal challenge is to safely retrieve and dispose of the tritium in the capsules. To ensure 
Table 2. Preliminary calculated conditions for DHCE irradiation (203.3 EFPDS)

\begin{tabular}{cccccc}
\hline Capsule & $\begin{array}{c}\text { Irradiation } \\
\text { Temp. }\left({ }^{\circ} \mathrm{C}\right)\end{array}$ & $\begin{array}{c}\text { Plenum } \\
\text { Vol. }(\mathrm{mL})\end{array}$ & $\begin{array}{c}\text { Fast Fluence } \\
\left(10^{22} \mathrm{n} / \mathrm{cm}^{2}\right)\end{array}$ & $\begin{array}{c}\text { Damage } \\
(\mathrm{dpa})\end{array}$ & $\begin{array}{c}\text { He(appm)/dpa a } \\
\text { End of lrr. (3/92) }\end{array}$ \\
\hline $4 \mathrm{D} 1$ & 425 & 2.85 & 5.3 & 29 & $3.8-23.2$ \\
$4 \mathrm{D} 2$ & 425 & 2.93 & 5.3 & 29 & $2.8-17.4$ \\
$5 \mathrm{E} 2$ & 425 & 3.11 & 2.9 & 15 & $2.1-12.5$ \\
$5 \mathrm{D} 1$ & 500 & 2.53 & 2.9 & 15 & $4.4-29.0$ \\
$5 \mathrm{E} 1$ & 500 & 2.49 & 2.9 & 15 & $3.1-20.2$ \\
$5 \mathrm{C} 1$ & 600 & 2.77 & 2.9 & 15 & $1.1-6.7$ \\
$5 \mathrm{C} 2$ & 600 & 2.47 & 2.9 & 15 & $1.1-6.8$ \\
\hline
\end{tabular}

a The first numbers assume $\mathrm{Ka}$, the equilibrium ratio of tritium in vanadium alloy to that in the lithium bond, to be 0.073 . The second numbers assume Ka to be 0.73 . The two numbers cover the estimated possible range.

compliance with regulations, all of the high-risk operations will be completed remotely in enclosed systems inside the hot cells. In an enclosed chamber, the capsule plenum will be punctured to trap the cover gas, which may contain tritium. The lithium in the capsule will be dissolved with liquid ammonia in a second enclosed chamber. The released gascous ammonia will be condensed in cold traps maintained at liquid nitrogen temperature, and the released tritium will be collected in chemical getters. After retrieval, the samples will be annealed at $400^{\circ} \mathrm{C}$ in high vacuum for $\approx 1 \mathrm{~h}$ to remove the residual tritium in the materials.

It is expected that the disassembly of DHCE capsules will commence in the summer of 1993.

\section{REFERENCES}

1. D. L. Smith et al., "Status of the Dynamic Helium Charging Experiment (DHCE) in FFTF/MOTA," Fusion Reactor Materials Scmiannual Progress Report DOE/ER-0313/10, March 31, 1991, pp. 159-163.

2. L. R. Greenwood, "Revised Calculations for the Dynamic Helium Charging Experiment in FFTF/MOTA 2B," Fusion Reactor Materials Semiannual Progress Report DOE/ER-0313/10, March 31, 1991, pp. 156-158. 
THERMAL CREEP BEHAVIOR OF V-5Cr-5Ti AND V-10Cr-5Ti ALLOYS* -- H. M Chung, B. A. Loomis, L. J. Nowicki, and D. L. Smith (Argonne National Laboratory)

\section{OBJECTIVE}

The objective of this work is to determine the thermal creep behavior of several promising $\mathrm{V}$-Cr-Ti alloys, and thereby identify an alloy that exhibits an optimal combination of creep strength, tensile properties, fracture toughness, corrosion resistance, fabricability, and weldability for use as a structural material in a magnetic fusion reactor.

\section{SUMMARY}

The thermal creep rates and stress-rupture life of $\mathrm{V}-5 \mathrm{Cr}-5 \mathrm{Ti}$ and $\mathrm{V}-10 \mathrm{Cr}-5 \mathrm{Ti}$ alloys were determined at $600^{\circ} \mathrm{C}$ and the impurity composition and microstructural characteristics of creep-tested specimens were analyzed and correlated with the measured creep properties. The results of these tests show that V-5Cr-5Ti, which contains impurity compositions typical of a commercial vanadium-base alloy, exhibits creep strength substantially superior to that of V-20Ti, HT-9, or Type 316 stainless steel. The V-10Cr-5Ti alloy exhibits creep strength somewhat higher than that of $\mathrm{V}-5 \mathrm{Cr}-5 \mathrm{Ti}$.

\section{INTRODUCTION}

Vanadium-base alloys are considered promising candidate structural materials for a fusion reactor first wall because they offer the important advantages of inherently low irradiation-induced activity, good mechanical properties, good compatibility with lithium, high thermal conductivity, and good resistance to irradiation damage. As part of a program to screen candidate alloys and develop an optimal alloy, extensive investigations have been conducted on the swelling behavior, tensile properties, impact toughness, and microstructural evolution of $\mathrm{V}, \mathrm{V}-\mathrm{Ti}, \mathrm{V}-\mathrm{Cr}, \mathrm{V}-\mathrm{Cr}-\mathrm{Ti}$, and $\mathrm{V}-\mathrm{Ti}-\mathrm{Si}$ alloys after irradiation by fast neutrons at 420,520 , and $600^{\circ} \mathrm{C}$. From these investigations, $\mathrm{V}-\mathrm{Cr}$ - $\mathrm{Ti}$ alloys containing 5-7 wt.\% Cr, 3-5 at.\% Ti, $500-1000$ wt. ppm Si, and $<1000$ wt. ppm $\mathrm{O}+\mathrm{N}+\mathrm{C}$ were identified as desirable alloys that exhibit superior resistance to swelling, embrittlement, and hydrogen-induced effects during irradiation in lithium. ${ }^{1-4}$ As a result, recent attention has focused primarily on the ternary alloys V-5Cr-5Ti, V-5Cr-3Ti, and V-7Cr-5Ti. For these alloys, however, no data base has been reported on thermal or irradiation creep, and a favorable creep behavior commensurate with the superior resistance of the alloys to swelling and embrittlement has not been demonstrated. In the work reported here, the thermal creep behavior of a V-5Cr-5Ti alloy was investigated at $600^{\circ} \mathrm{C}$. The creep of $\mathrm{V}-10 \mathrm{Cr}-5 \mathrm{Ti}$ was also investigated to provide information on the effect of increased $\mathrm{Cr}$ content. Preliminary results of the creep tests have been described in a previous report. ${ }^{5}$

\section{MATERIALS AND PROCEDURES}

Details of experimental procedures have been reported elsewhere. ${ }^{5}$ The chemical composition of the two alloys is given in Table 1. The 0.635 - $\mathrm{mm}$-thick tensile specimens were recrystallized prior to the creep test by annealing at $1125^{\circ} \mathrm{C}$ for $1 \mathrm{~h}$ in a vacuum of $2 \times 10-5 \mathrm{~Pa}$. The creep tests were conducted in an ion-pumped system in which vacuum was typically maintained at $2 \times 10^{-6} \mathrm{~Pa}$ during testing at $600^{\circ} \mathrm{C}$. The specimen was wrapped with a $\mathrm{Ti}$ or $\mathrm{Ta}$ foil to reduce contamination with impurities during testing. The elongation of a specimen was determined with a linear variable differential transformer (LVDT) with digitized output. The concentration of interstitial impurities (i.e., O, N, and C) and hardness (VHN) of

\footnotetext{
*Work supported by the Office of Fusion Energy, U.S. Department of Energy, under Contract W-31-109-Eng-38.
} 
specimens were measured after testing. The phase and dislocation structures of the specimens were examined by transmission electron microscopy (TEM) before and after the creep test. In addition to the normal constant-load stress-to-rupture tests, applied stress was increased stepwise in some tests to measure a set of steady-state (minimum) creep rates corresponding to each stress level. An example of this kind of testing is shown in Fig. 1.

Table 1. Chemical composition of V-5Cr-5Ti and V-10Cr-5Ti alloys ${ }^{a}$

\begin{tabular}{ccccccccc}
\hline & & \multicolumn{5}{c}{ Composition (wt.\% or wt. ppm) } \\
\cline { 3 - 8 } Material & ANL ID & Cr & Ti & Si & O & C & N \\
\hline V-5Cr-5Ti & BL-47 & $4.1 \%$ & $4.3 \%$ & 870 & 350 & 200 & 220 \\
V-10Cr-5Ti & BL-43 & $9.2 \%$ & $4.9 \%$ & 340 & 230 & 100 & 31 \\
\hline
\end{tabular}

${ }^{\mathrm{a}}$ Annealed at $1125^{\circ} \mathrm{C}$ for $1 \mathrm{~h}$.

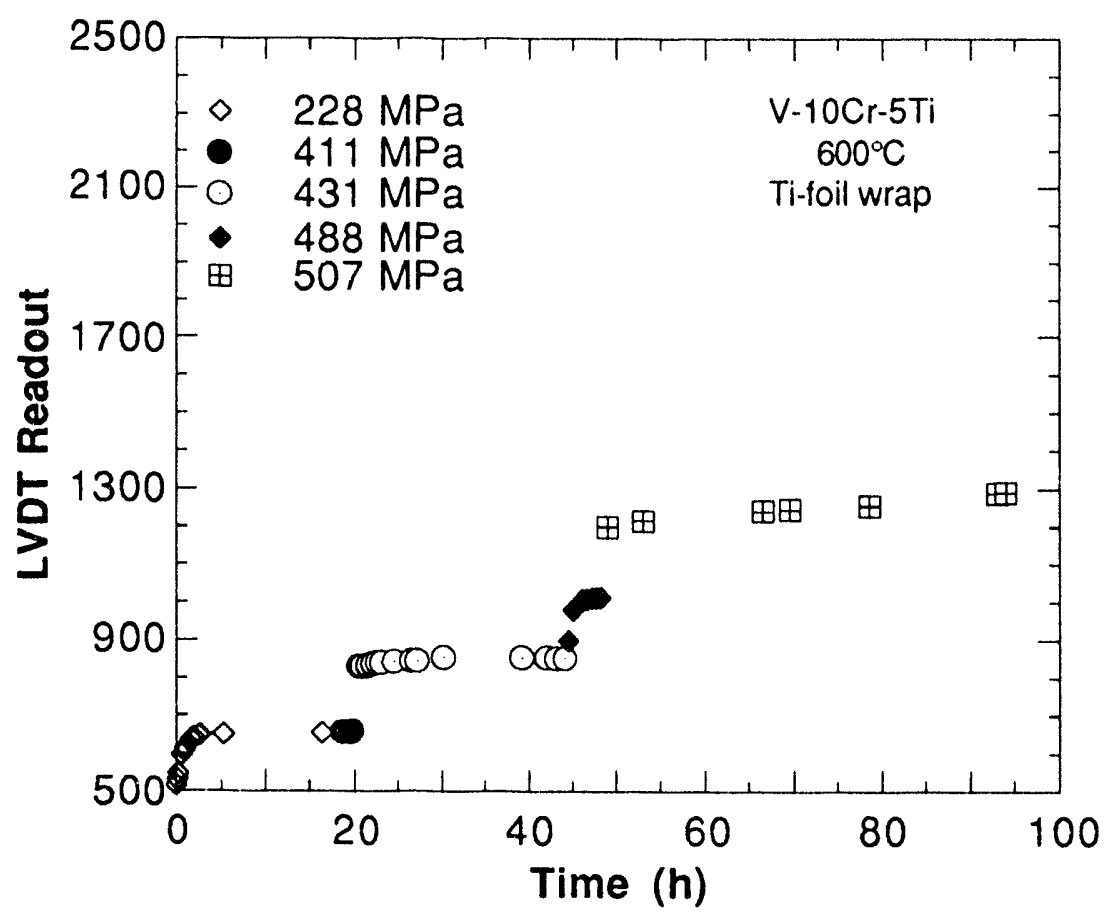

Figure 1. Elongation (LVDT readout) vs. time for V-10Cr-5Ti under stepwise increase in loading at $600^{\circ} \mathrm{C}$, used to measure steady-state creep rates

\section{RESULTS AND DISCUSSION}

\section{Stress-Rupture Life and Creep Rate}

The stress-to-rupture time of $\mathrm{V}-5 \mathrm{Cr}-5 \mathrm{Ti}$ and $\mathrm{V}-10 \mathrm{Cr}-5 \mathrm{Ti}$ is given in Fig. 2. The figure shows that the creep strength of the $\mathrm{V}-10 \mathrm{Cr}-5 \mathrm{Ti}$ alloy is significantly higher $(\approx 100 \mathrm{MPa})$ than that of $\mathrm{V}-5 \mathrm{Cr}-5 \mathrm{Ti}$. This finding is consistent with the higher ultimate tensile strength (UTS) of $\mathrm{V}-10 \mathrm{Cr}-5 \mathrm{Ti}$, i.e., $\approx 512 \mathrm{vs}$. 
$\approx 434 \mathrm{MPa} .{ }^{6}$ At $600^{\circ} \mathrm{C}$, the stress-to-rupture time of the two alloys is extremely sensitive to applied stress. For example, an increase in rupture time of more than two orders of magnitude was observed for $\mathrm{V}-5 \mathrm{Cr}-5 \mathrm{Ti}$ when applied stress was decreased only $\approx 5 \%$. In previous investigations of creep properties of $\mathrm{V}-13 \mathrm{Cr}-3 \mathrm{Ti}$, $\mathrm{V}-15 \mathrm{Cr}-3 \mathrm{Ti}, \mathrm{V}-15 \mathrm{Cr}-5 \mathrm{Ti}$, and Vanstar alloys at $\geq 650^{\circ} \mathrm{C}$, a similar trend was observed. ${ }^{7-9}$ Because of the high creep strength, determination of stress-rupture life of $\mathrm{V}-5 \mathrm{Cr}-5 \mathrm{Ti}$ at $600^{\circ} \mathrm{C}$ for stress $\leq 350 \mathrm{MPa}$ is estimated to take impractically long test times ( $\geq 3$ years).

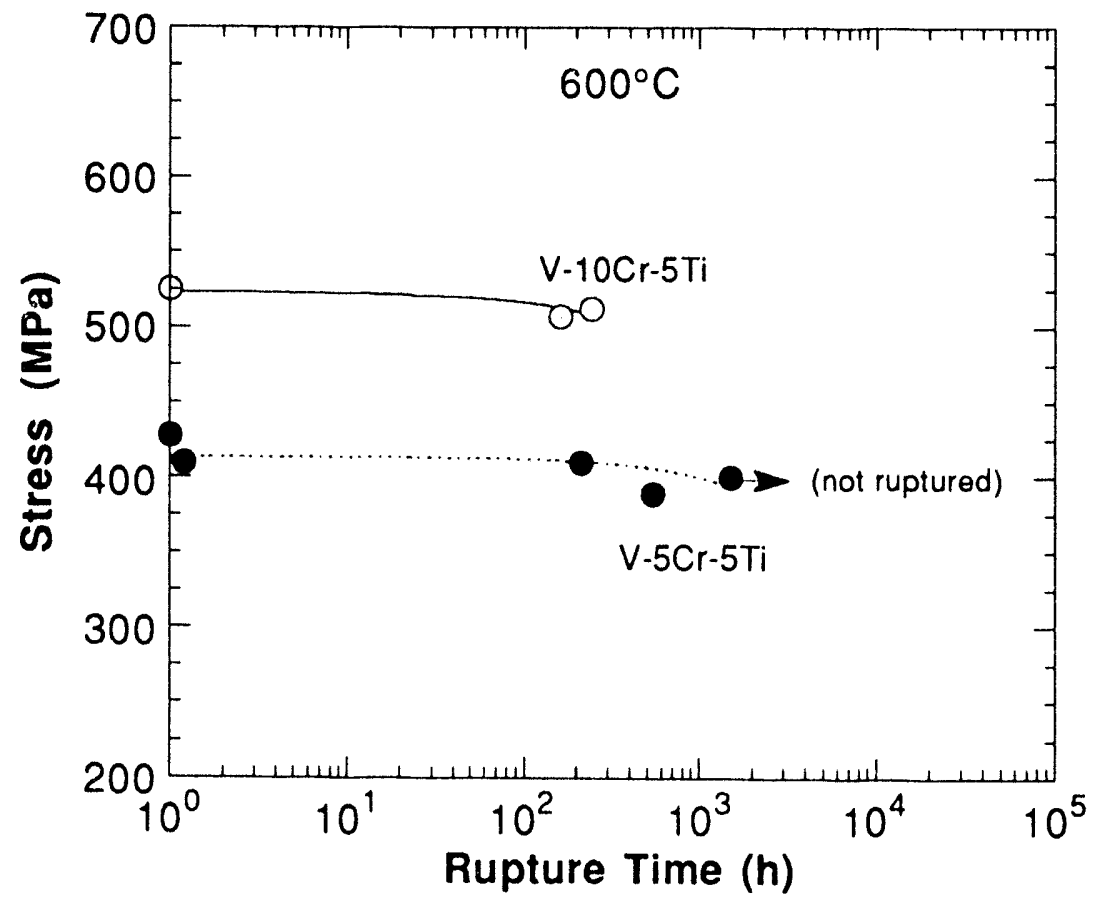

Figure 2. Stress-to-rupture time for V-10Cr-5Ti and V-5Cr-5Ti at $600^{\circ} \mathrm{C}$

In Fig. 3, steady-state (minimum) creep rates of $\mathrm{V}-5 \mathrm{Cr}-5 \mathrm{Ti}$ and $\mathrm{V}-10 \mathrm{Cr}-5 \mathrm{Ti}$ alloys are shown as a function of applied stress. In the stress range between $\approx 300$ and $\approx 420 \mathrm{MPa}$, the steady-state creep rate of $\mathrm{V}-5 \mathrm{Cr}-5 \mathrm{Ti}$ at $600^{\circ} \mathrm{C}$ was between $\approx 10^{-3}$ and $5 \times 10^{-2} \% / \mathrm{h}$; for a comparable stress level, the creep rate of $\mathrm{V}-10 \mathrm{Cr}-5 \mathrm{Ti}$ was $\approx 7-8$ times lower.

In Fig. 4, the creep strengths of V-15Cr-5Ti, V-10Cr-5Ti, and V-5Cr-5Ti are given. Although data for $\mathrm{V}-15 \mathrm{Cr}-5 \mathrm{Ti}$ were obtained at temperatures higher than $600^{\circ} \mathrm{C},{ }^{9}$ the creep strengths can be compared from a plot of the Larsen-Miller parameter, which is defined by the equation

$$
\mathrm{P}=\mathrm{T}(20+\log \mathrm{t}),
$$

where creep temperature $\mathrm{T}$ is in $\mathrm{K}$ and rupture time $\mathrm{t}$ is in hours. The $\mathrm{V}-15 \mathrm{Cr}-5 \mathrm{Ti}$ specimens tested by Bajaji and Gold ${ }^{9}$ contained 200-1400 wppm O, $500 \mathrm{wppm} \mathrm{N}$, and $170 \mathrm{wppm} \mathrm{C.} \mathrm{By} \mathrm{comparison,} \mathrm{the}$ impurity content measured in the creep-tested specimens of $\mathrm{V}-10 \mathrm{Cr}-5 \mathrm{Ti}$ and $\mathrm{V}-5 \mathrm{Cr}-5 \mathrm{Ti}$ in the present investigation were significantly lower; i.e., O, 370-770 wppm, N, 99-200 wppm, and C, 252-270 wppm (see Table 2). Within the uncertainties associated with the variations in impurity content, the results indicate that the creep strengths of $\mathrm{V}-15 \mathrm{Cr}-5 \mathrm{Ti}$ and $\mathrm{V}-10 \mathrm{Cr}-5 \mathrm{Ti}$ are similar. The UTS of the present $\mathrm{V}-10 \mathrm{Cr}-5 \mathrm{Ti}(541 \mathrm{MPa})$ and that of a V-15Cr-5Ti alloy containing $400 \mathrm{wppm} \mathrm{O}, 490 \mathrm{wppm} \mathrm{N}$, and 280 wppm $\mathrm{C}$ was found to be similar (555 MPa). Therefore, it is not surprising that the creep strengths of the V-10Cr-5Ti and V-15Cr-5Ti shown in Fig. 3 are similar. 


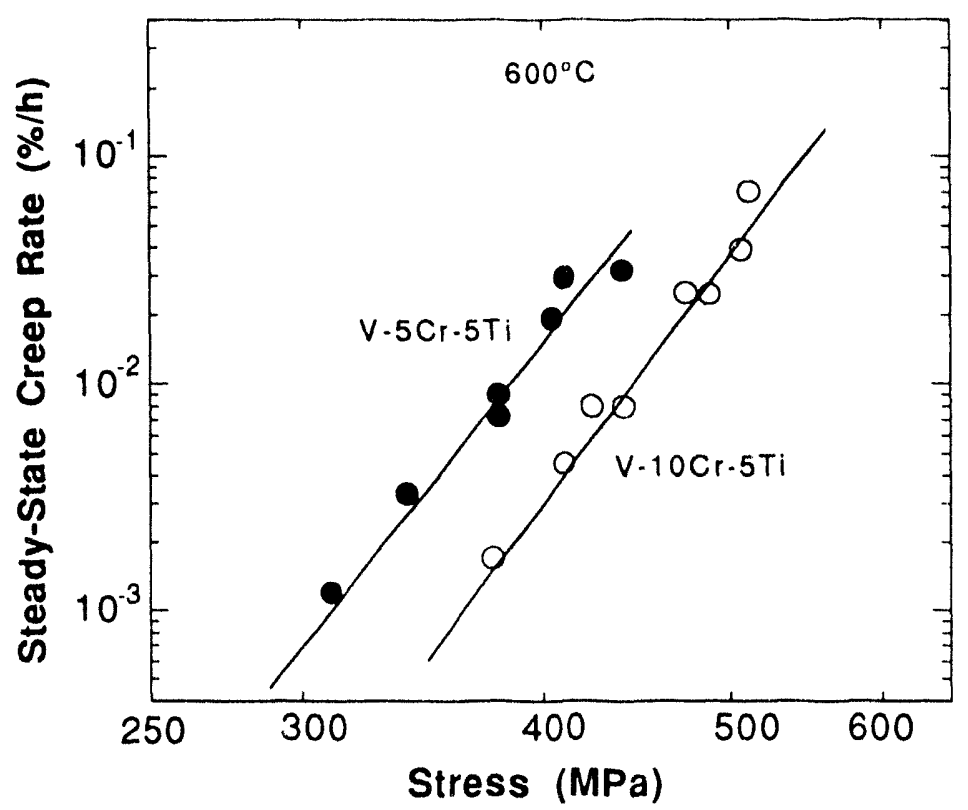

Figure 3. Steady-state creep rate vs. stress for $\mathrm{V}-10 \mathrm{Cr}$-5Ti and V-5Cr-5Ti al $600^{\circ} \mathrm{C}$

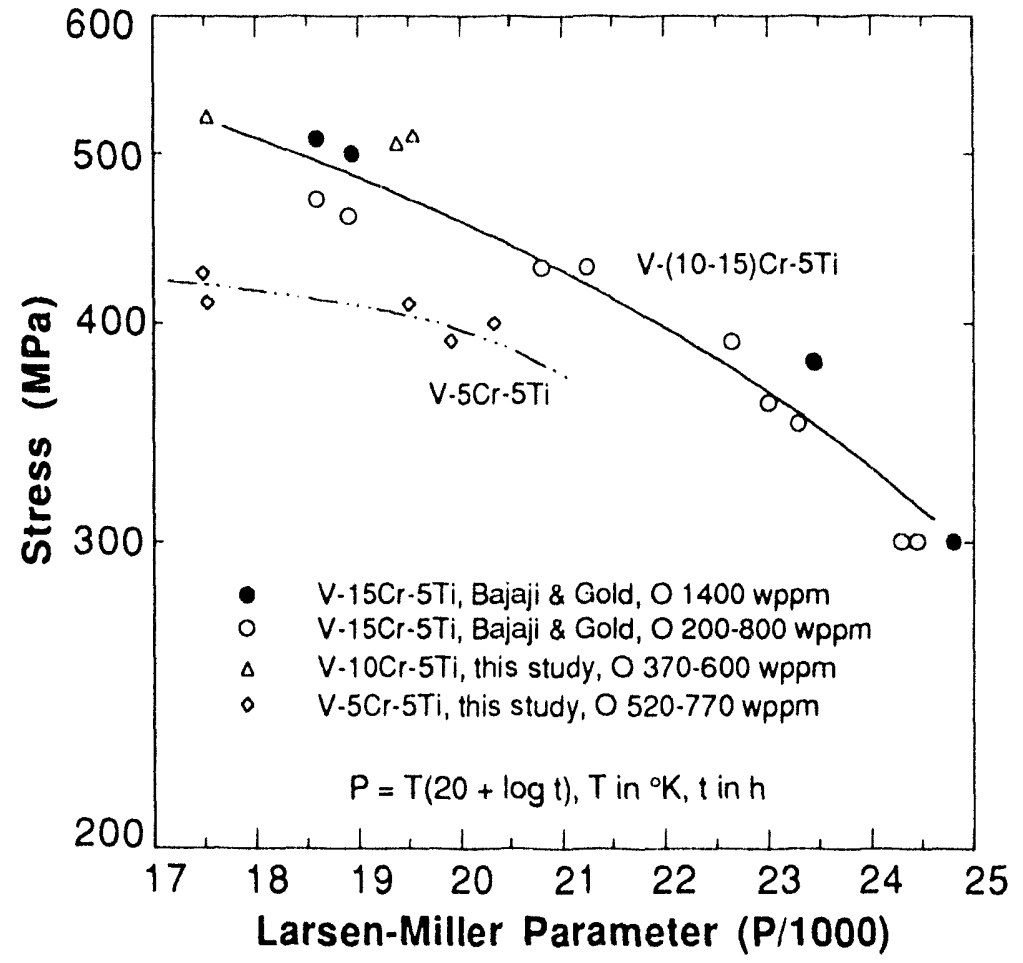

Figure 4. Larsen-Miller plots for V-15Cr-5Ti, V-10Cr-5Ti, and $\mathrm{V}-5 \mathrm{Cr}-\mathrm{STi}$ 
Table 2. Impurity content of creep specimens from $V-5 C r-5 T i a_{\text {and }} V-10 C r-5 T i b$ after testing at $600^{\circ} \mathrm{C}$

\begin{tabular}{|c|c|c|c|c|c|c|c|}
\hline \multirow[b]{2}{*}{ Material } & \multirow[b]{2}{*}{ Specimen IN } & \multirow{2}{*}{$\begin{array}{l}\text { Stress } \\
(\mathrm{MPa})\end{array}$} & \multirow{2}{*}{$\begin{array}{c}\text { Time to } \\
\text { Rupture } \\
\text { (h) }\end{array}$} & \multicolumn{4}{|c|}{ Composition (wt. ppm) } \\
\hline & & & & Wrap & $\mathrm{O}$ & C & $\mathbf{N}$ \\
\hline $\mathrm{V}-5 \mathrm{Cr}-5 \mathrm{Ti}$ & $B L-47 A$ & 420 & 1 & none & 560 & 252 & 160 \\
\hline $\mathrm{V}-5 \mathrm{Cr}-5 \mathrm{Ti}$ & BL-47C & 408 & 1.1 & $\mathrm{Ta}$ & 520 & 261 & 200 \\
\hline $\mathrm{V}-5 \mathrm{Cr}-5 \mathrm{Ti}$ & BL-47E & 387 & 541 & $\mathrm{Ta}$ & 770 & - & 200 \\
\hline $\mathrm{V}-5 \mathrm{Cr}-5 \mathrm{Ti}$ & $\mathrm{BL}-47 \mathrm{~F}$ & 410 & 213 & $\mathrm{Ta}$ & 520 & 270 & 190 \\
\hline $\mathrm{V}-10 \mathrm{Cr}-5 \mathrm{Ti}$ & $B L-43 A$ & 512 & 243 & none & 600 & - & 120 \\
\hline $\mathrm{V}-10 \mathrm{Cr}-57 \mathrm{i}$ & $B L-43 B$ & 507 & 162 & $\mathrm{Ti}$ & 370 & - & 99 \\
\hline
\end{tabular}

\section{Impurity Content and Microstructure}

The creep of unalloyed vanadium is known to be sensitive to impurities (in particular dissolved 0 ), although the creep of $\mathrm{V}-15 \mathrm{Cr}-5 \mathrm{Ti}, \mathrm{V}-20 \mathrm{Ti}$, and Vanstar-7 (V-9Cr-3Fe-1.3Zr-0.05C) appears to be less sensitive to $O$ contamination (see Fig. 4). ${ }^{7-9}$ In view of this, it was considered necessary to characterize the specimen impurity content, hardness, phase distribution, and other undesirable microstructural changes associated with the creep test to qualify the data obtained in this study.

The results obtained from analysis for $\mathrm{O}, \mathrm{N}$, and $\mathrm{C}$ concentrations are summarized in Table 2. Compared with the impurity content of the as-annealed specimens before the test (Table 1), $\mathrm{N}$ content in V-5Cr-5Ti decreased to some extent (from 220 to $160-190 \mathrm{wppm}$ ) and $\mathrm{C}$ content increased modestly (from 200 to $250-270 \mathrm{wppm})$. Nitrogen content in V-10Cr-5Ti increased from 31 to $\approx 100 \mathrm{wppm}$. However, the $O$ content of both alloys increased significantly after testing (from 230-350 wppm to 370-770 wppm). The increase in $\mathrm{O}$ content was more pronounced in specimens tested without a wrap or with a Ta-foil wrap. For a specimen with a $\mathrm{Ti}$ wrap, the increase in $\mathrm{O}$ content was minimal (e.g., from 230 to 370 wppm). The more pronounced $O$ contamination in the Ta-wrapped specimens is probably associated with the volatility of tantalum oxide. Because of the smaller contamination when Ti foil was used, all subsequent tests are being conducted with a $\mathrm{Ti}$ wrap. Despite the increase in $\mathrm{O}$ and $\mathrm{C}$, the impurity content of the two alloys is still comparable to that typical of a commercial vanadium-base alloy.

To detect any undesirable phase structure that might have been produced during testing, TEM specimens excised from near the gage section were examined. The results are shown in Fig. 5. A comparison of Figs. 5A and 5B shows that the phase structure of $\mathrm{V}-5 \mathrm{Cr}-5 \mathrm{Ti}$ did not change appreciably during testing at $600^{\circ} \mathrm{C}$ for $541 \mathrm{~h}$. That is, the size and distribution of the Ti(O,N,C) precipitates, normally observed in these alloys after fabrication, ${ }^{3}$ were similar before and after testing, and no new types of precipitates were produced. 

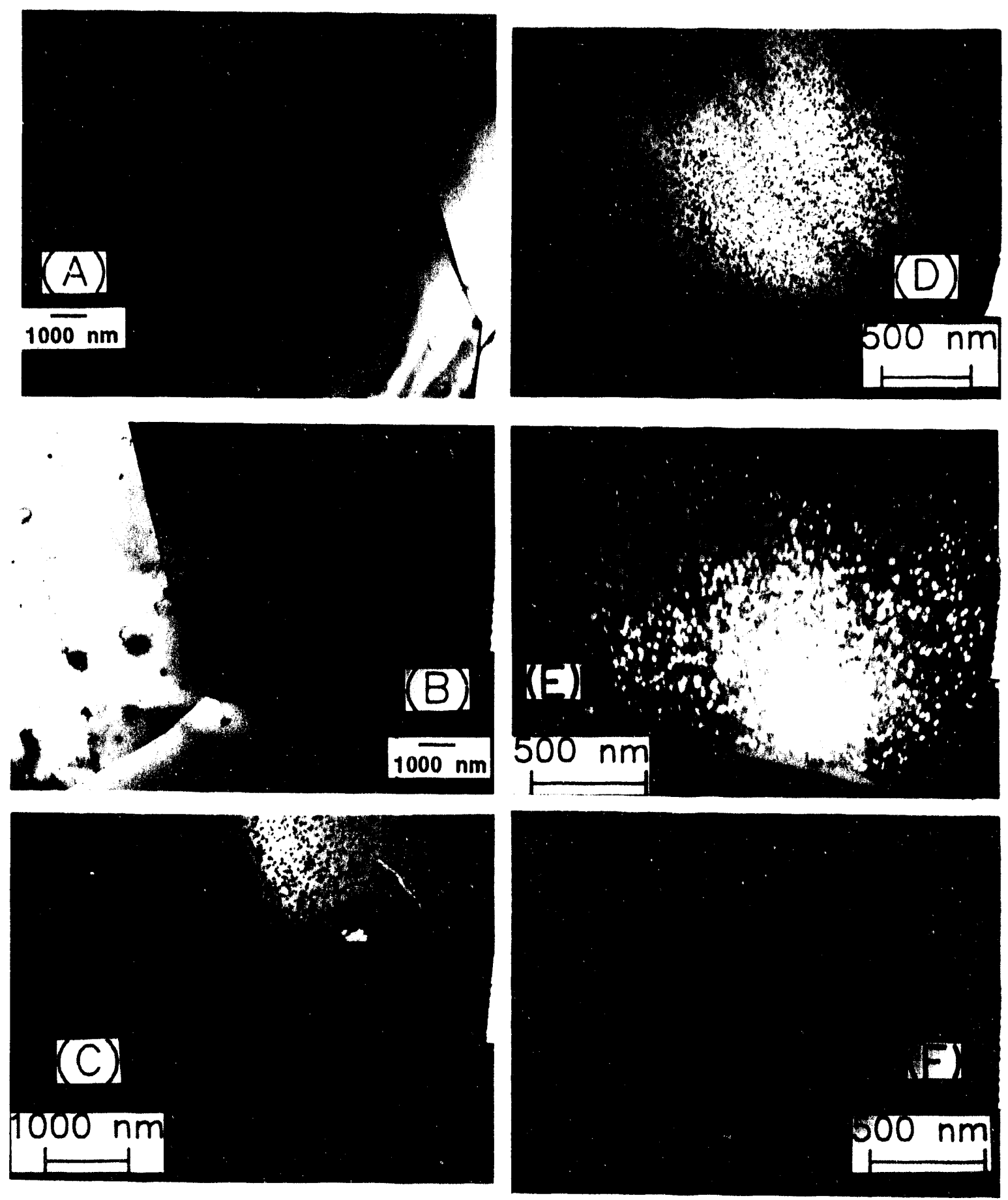

Figure 5. Phase structure of $\mathrm{V}-5 \mathrm{Cr}-5 \mathrm{Ti}(\mathrm{A})$ before and $(B)$ after creep test at $600^{\circ} \mathrm{C}$ for $541 \mathrm{~h}$; $(C)$ dislocation loops in the specimen shown in $(B)$, and $(D)$ in V-10Cr-5Ti after test at $600^{\circ} \mathrm{C}$ for $216 \mathrm{~h} ;(E)$ dark-field image of loop distribution of $(C)$; and $(F)$ brightfield image of dislocations and dislocation loops of $(C)$ 
However, dislocation loops were observed in high density in creep-tested specimens of both $\mathrm{V}-5 \mathrm{Cr}$ 5Ti and $\mathrm{V}-10 \mathrm{Cr}-5 \mathrm{Ti}$ (Figs. 5C and 5D, respectively). From bright-field imaging alone, the dislocation loops ( $\leq 100 \mathrm{~nm}$ in size) can be mistakenly confused with small precipitates. However, results of selectedarea diffraction and dark-field imaging showed that they are indeed dislocation loops. Line dislocations were also observed frequently in conjunction with loops (Fig. 5E). A major difference in the microstructural aspect of creep-tested $\mathrm{V}-5 \mathrm{Cr}-5 \mathrm{Ti}$ and $\mathrm{V}-10 \mathrm{Cr}$-5Ti specimens was the distribution of dislocation loops. In $\mathrm{V}-10 \mathrm{Cr}-5 \mathrm{Ti}$, loop distribution was more or less uniform within a grain. In contrast, size and density of the loops were higher near a grain boundary in $\mathrm{V}-5 \mathrm{Cr}-5 \mathrm{Ti}$. This can be seen by comparing the two bright-field images of Figs. 5C and 5D. The dark-ficld image shown in Fig. 5F reveals more clearly a dense loop distribution of $\mathrm{V}-5 \mathrm{Cr}-5 \mathrm{Ti}$ in the vicinity of a grain boundary.

Hardness profiles were measured across the specimen thickness (nominal thickness $0.635 \mathrm{~mm}$ ) after the creep test. An example of typical hardness profiles is given in Fig. 6, which was determined for a $\mathrm{V}$-10Cr-5Ti specimen that ruptured after $162 \mathrm{~h}$. Except for narrow regions $\leq 0.01 \mathrm{~mm}$ underneath the free surfaces, a more or less uniform hardness of $\approx 205 \mathrm{VHN}$ was observed, a slight increase from the original hardness of $=192 \mathrm{VHN}$. The hardness increase is attributed not only to the effect of the increase in O content (i.e., from 230 to $370 \mathrm{wppm}$ ) but also to the effect of the high-density dislocation loops.

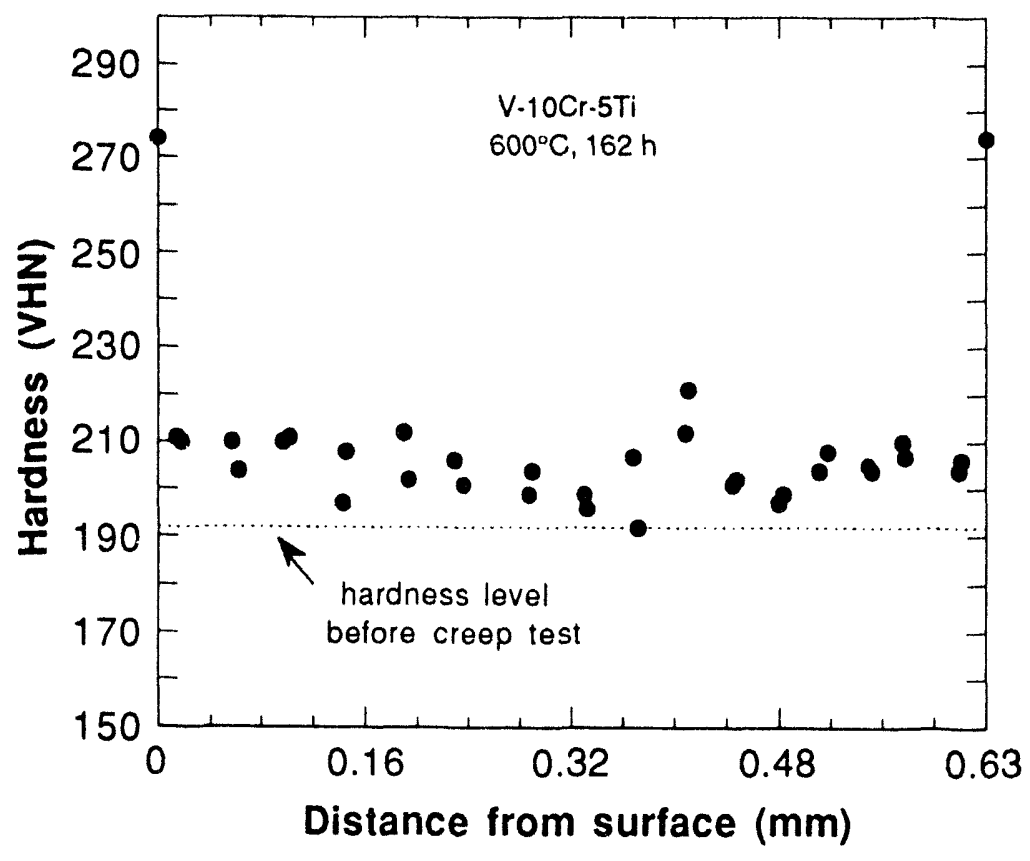

Figure 6. Vickers hardness profile across wall thickness of $V$-10Cr-5Ti after creep test at $600^{\circ} \mathrm{C}$ for $162 \mathrm{~h}$

In summary, no unusual features were observed that indicate an unacceptable effect of the environment of the creep test at $600^{\circ} \mathrm{C}$. Impurity content and phase structure of the test specimens were similar to those of typical commercial alloys.

\section{Comparison with Other Materials}

In Fig. 7, the creep property of $\mathrm{V}-5 \mathrm{Cr}-5 \mathrm{Ti}$ and ferritic and austenitic steels is shown in Larsen-Miller plots. From the figure, it is obvious that the creep strength of the alloy is substantially superior to that of 
HT-9, Type 316 stainless steel, and V-20Ti. In particular, this difference in creep strength is more pronounced when Larsen-Miller parameters are higher, i.e., at higher temperatures or longer times.

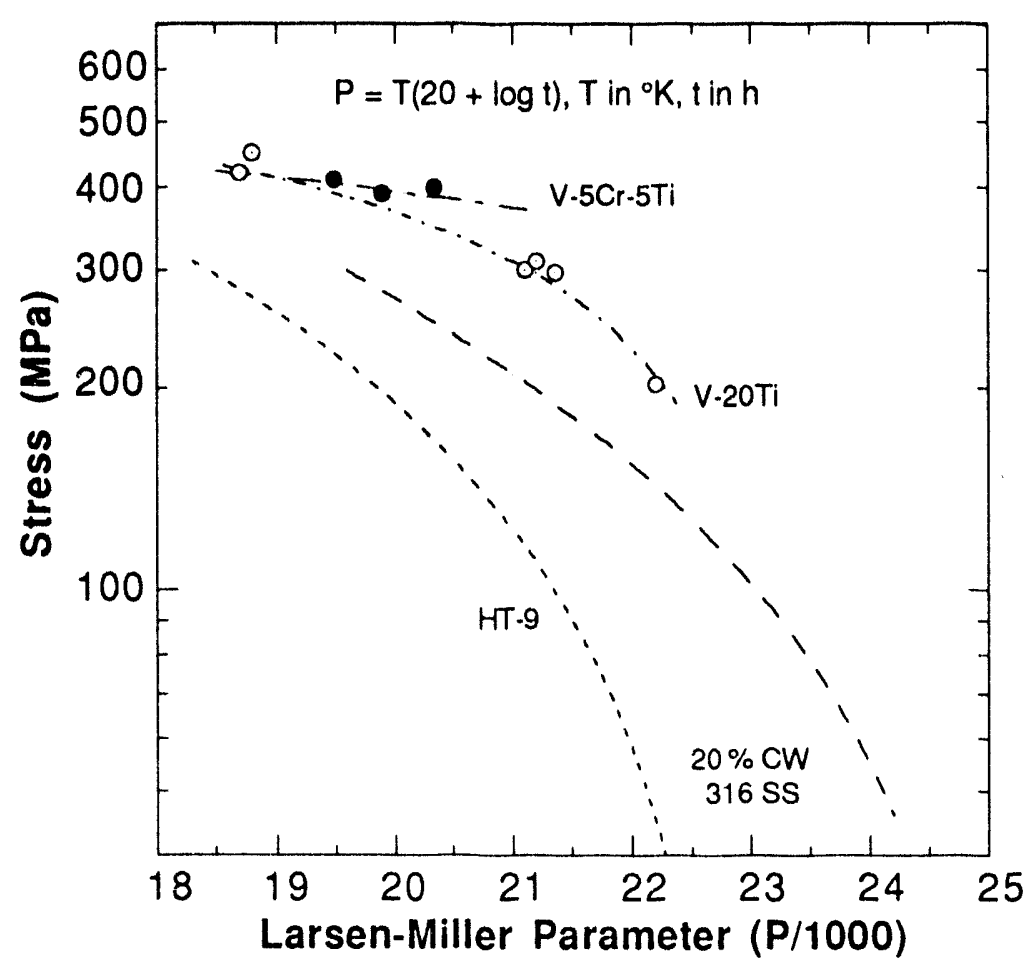

Figure 7. Larsen-Miller plots of creep strength of V-5Cr-5Ti and ferritic and austenitic steels

It has been reported that creep strength of binary V-Ti and ternary $\mathrm{V}-15 \mathrm{Cr}$ - Ti and $\mathrm{V}-3 \mathrm{Cr}$ - Ti alloys is maximum for 3 wt. $\% \mathrm{Ti}^{7}, 8$ Titanium content greater or less than $\approx 3 \mathrm{wt} . \%$ resulted in significantly decreased creep strength. Based on this observation, the creep strength of $\mathrm{V}-5 \mathrm{Cr}-3 \mathrm{Ti}$ is expected to be substantially higher than that of $\mathrm{V}-5 \mathrm{Cr}-5 \mathrm{Ti}$. Increasing the $\mathrm{Cr}$ content to $7 \mathrm{wt} . \%$ is also expected to improve the creep strength of $\mathrm{V}-5 \mathrm{Cr}-5 \mathrm{Ti}$. However, selection of optimal content of $\mathrm{Cr}(5-7 \mathrm{wt} . \%)$ and $\mathrm{Ti}(3-5 \mathrm{wt} . \%)$ must be tied closely to other important considerations, in particular, to the effects of neutron damage and helium generation on embrittlement and fracture toughness.

\section{CONCLUSIONS}

1. Stress-rupture life and steady-state creep rate of $\mathrm{V}-5 \mathrm{Cr}-5 \mathrm{Ti}$ and $\mathrm{V}-10 \mathrm{Cr}-5 \mathrm{Ti}$ have been determined at $600^{\circ} \mathrm{C}$. Results of characterization of impurity contamination, hardness, phase structure, and dislocation and loop structures in the creep-tested specimens showed no unusual features that indicate an unacceptable effect of the environment on the measured creep rates. Impurity content of the tested specimens was comparable to that of a typical commercial vanadium-base alloy.

2. V-5Cr-5Ti exhibits a creep strength that is substantially superior to that of Type 316 stainless steel, HT-9, or V-20Ti, in particular, at higher Larsen-Miller parameters, i.e., at higher temperatures and/or longer service times. 
3. Creep strength of $\mathrm{V}-10 \mathrm{Cr}-5 \mathrm{Ti}$ is similar to that of $\mathrm{V}-15 \mathrm{Cr}-5 \mathrm{Ti}$ and several times higher than that of $\mathrm{V}-5 \mathrm{Cr}-5 \mathrm{Ti}$. However, if a creep strength higher than that of $\mathrm{V}-5 \mathrm{Cr}-5 \mathrm{Ti}$ is required, $\mathrm{V}-5 \mathrm{Cr}-3 \mathrm{Ti}$ or $\mathrm{V}-7 \mathrm{Cr}-5 \mathrm{Ti}$ appears to be a more attractive alternative than $\mathrm{V}-10 \mathrm{Cr}-5 \mathrm{Ti}$ from the point of view of irradiation-induced embrittlement.

\section{FUTURE WORK}

Stress-rupture tests on $\mathrm{V}-5 \mathrm{Cr}-5 \mathrm{Ti}$ and $\mathrm{V}-10 \mathrm{Cr}-5 \mathrm{Ti}$ will be extended to $650^{\circ} \mathrm{C}$ to obtain a larger number of data in a reasonable time period. Creep tests will be conducted on $\mathrm{V}-5 \mathrm{Cr}-3 \mathrm{Ti}, \mathrm{V}-7 \mathrm{Cr}-5 \mathrm{Ti}$, and V-3Ti-0.1Si alloys at 600 and $650^{\circ} \mathrm{C}$, and an alloy that exhibits optimal creep properties will be identified.

\section{REFERENCES}

1. B. A. Loomis, A. B. Hull, and D. L. Smith, "Evaluation of Low-Activation Vanadium Alloys for Use as Structural Material in Fusion Reactors," J. Nucl. Mater., 179-181 (1991) 148-154.

2. B. A. Loomis and D. L. Smith, 'Vanadium Alloys for Structural Applications in Fusion Systems: A Review of Mechanical and Physical Properties," J. Nucl. Mater., 191-194 (1992) 84-91.

3. H. M. Chung and D. L. Smith, "Correlation of Microstructure and Tensile and Swelling Behavior of Neutron-Irradiated Vanadium Alloys," J. Nucl. Matcr. 191-194 (1992) 942-947.

4. H. M. Chung, B. A. Loomis, and D. L. Smith, "Irradiation-Induced Precipitation in Vanadium-Base Alloys Containing Titanium," Effects of Radiation on Matcrials: 16th International Symposium, ASTM STP 1175, A. S. Kumar, D. S. Gelles, R. K. Nanstad, and T. A. Little, eds., American Society for Testing and Materials, Philadclphia, 1993.

5. B. A. Loomis, L. J. Nowicki, and D. L. Smith, "Creep of V-5Cr-5Ti and V-10Cr-5Ti Alloys at $600^{\circ} \mathrm{C}$," in Fusion Reactor Materials, Semiannual Progress Report for Period Ending September 30, 1992, DOE/ER-0313/13, U.S. Department of Energy, Office of Fusion Energy, in press.

6. B. A. Loomis, L. J. Nowicki, and D. L. Smith, "Tensile Properties of Vanadium and Vanadium-Base Alloys," in Fusion Reactor Materials, Scmiannual Progress Report for Period Ending March 31, 1991, DOE/ER-0313/10, U.S. Department of Energy, Office of Fusion Energy, July 1991, pp. 145-155.

7. M. Schirra, "Das Zeitstandfestigkeits und Kriechverhalten von Vanad-Basis Legierungen," KfK-2440, April 1977, Karlsruhe Nuclear Research Center, Germany.

8. D. Harrod and R. Gold,"Mechanical Properties of Vanadium and Vanadium Base Alloys," Int. Met. Rev. 25 (1980) 163-221.

9. R. Bajaji and R. E. Gold, in Alloy Development for Irradiation Performance Semiannual Progress Report, DOE/ER(0045/10, Oak Ridge National Laboratory, Oak Ridge, TN, 1983, p. 74. 
DUCTILE-BRITTLE TRANSITION TEMPERATURES OF UNIRRADIATED VANADIUM ALLOYS, BASED ON CHARPY-IMPACT TESTING* - B. A. Loomis, L. J. Nowicki, J. Gazda, and D. L. Smith (Argonne National Laboratory).

\section{OBJECTIVE}

The objective of this research is to determine the composition of a vanadium-base alloy with the optimal combination of mechanical properties, corrosion resistance, fabricability, and weldability for use as a structural material in the environment of a magnetic fusion reactor.

\section{SUMMARY}

Ductile-brittle transition temperatures (DB'TTs) were determined hy Charpy-impact tests for dehydrogenated and hydrogenated V-3Ti, $\mathrm{V}-5 \mathrm{Cr}-3 \mathrm{Ti}$, and $\mathrm{V}-5 \mathrm{Cr}-5 \mathrm{Ti}$ alloys. These DBTT data complement the data previously obtained by Loomis et al. ${ }^{1.3}$ on Charpy-impact testing of unalloyed V, V-1Ti, V$3 \mathrm{Ti}-1 \mathrm{Si}, \mathrm{V}-5 \mathrm{Ti}, \mathrm{V}-10 \mathrm{Ti}, \mathrm{V}-18 \mathrm{Ti}, \mathrm{V}-4 \mathrm{Cr}-4 \mathrm{Ti}, \mathrm{V}-8 \mathrm{Cr}-6 \mathrm{Ti}, \mathrm{V}-9 \mathrm{Cr}-5 \mathrm{Ti}, \mathrm{V}-10 \mathrm{Cr}-9 \mathrm{Ti}, \mathrm{V}-14 \mathrm{Cr}-5 \mathrm{Ti}, \mathrm{V}-15 \mathrm{Cr}-$ $5 \mathrm{Ti}, \mathrm{V}-7 \mathrm{Cr}-15 \mathrm{Ti}$, and Vanstar-7 alloys. The results show that $\mathrm{V}$ alloys with Ti additions $(0-18 \mathrm{wt} . \%)$ have a minimum DBTT $\left(-250^{\circ} \mathrm{C}\right)$ in an alloy containing $3-5 \mathrm{wt} . \% \mathrm{Ti}$, that addition of 4 to $15 \mathrm{wt} . \%$ $\mathrm{Cr}$ to $\mathrm{V}-(4-6) \mathrm{Ti}$ alloy results in a substantial increase $\left(25-215^{\circ} \mathrm{C}\right)$ of the DBTT, and that 0.5 and 1.0 wt.\% Si additions to V-3Ti alloy result in a significant increase $\left(-100^{\circ} \mathrm{C}\right)$ in DBTT. In addition, the results show that the presence of $4(0)-1200$ appm $H$ in unalloyed $V$ and $V$-base alloys causes a significant increase $\left(-100^{\circ} \mathrm{C}\right)$ in DBTT. The results of these studies lead us to recommend the V-5Cr-5Ti alloy containing $-400 \mathrm{ppm} \mathrm{O},-200 \mathrm{ppm} \mathrm{N},-200 \mathrm{ppm} \mathrm{C}$, and $-900 \mathrm{ppm}$ Si for use as structural material in a fusion reactor.

\section{PROGRESS AND STATUS}

\section{Introduction}

The V-15Cr-5Ti alloy has been considered to be a reference alloy for the evaluation of vanadiumbase alloys as structural matcrial for a fusion reactor, based on this alloy's generally attractive mechanical, corrosion, and irradiation performance. However, recent data obtained from Charpyimpact tests and tensile tests on this alloy with and without neutron irradiation show that this alloy may be unacceptable as structural material for a fusion reactor because of its high DBTT $\left(>250^{\circ} \mathrm{C}\right) .^{1.5}$ Loomis et al. have shown from Charpy-impact tests on unirradiated and irradiated vanadium alloys that a vanadium-base alloy containing $\mathrm{Cr}$ and/or $\mathrm{Ti}$ and $\mathrm{Si}$ alloying additions and intended for use as a structural material in a fusion reactor should contain 3-9 wt.\% total alloying addition for maximum resistance to hydrogen- and/or irradiation-induced embrittlement..$^{2.3}$ In this report, we present data on the DBTTs for $\mathrm{V}-3 \mathrm{Ti}, \mathrm{V}-5 \mathrm{Cr}-3 \mathrm{Ti}$, and $\mathrm{V}-5 \mathrm{Cr}-5 \mathrm{Ti}$ alloys that tend to confirm the requirement of 3-9 wt.\% combined $\mathrm{Cr}$ and/or Ti alloying addition to vanadium for a minimum DBTT. We also include DBTT data for unirradiated V and V-base alloys previously presented in Refs. 1-3.

\section{Materials and Procedures}

Vanadium-base alloys with the nominal compositions of V-3Ti, V-5Cr-3Ti, and V-5Cr-5Ti were obtained in sheet form with a $50 \%$ thickness reduction, i.e., cold work, resulting in a nominal thickness of $3.8 \mathrm{~mm}$. The compositions of these materials and previously tested vanadium alloys

*Work supported by the Office of Fusion Energy, U.S. Department of Energy, under Contract W31-109-Eng-38. 
are listed in Table $1 .^{1.3}$

Table 1. Compositions of $\mathrm{V}$ and $\mathrm{V}$ alloys.

\begin{tabular}{|c|c|c|c|c|c|c|c|c|}
\hline \multirow[t]{2}{*}{$\begin{array}{l}\text { Nominal } \\
\text { Composition }\end{array}$} & \multirow[t]{2}{*}{$\begin{array}{l}\text { ANL } \\
\text { I.D. }\end{array}$} & \multicolumn{3}{|c|}{$\begin{array}{l}\text { Concentration } \\
\text { (wt.\%) }\end{array}$} & \multicolumn{4}{|c|}{$\begin{array}{c}\text { Concentration } \\
\text { (ppm) }\end{array}$} \\
\hline & & $\mathrm{Cr}$ & $\mathrm{Ti}$ & $\mathrm{Fe}$ & $O$ & $\mathrm{~N}$ & $\mathrm{C}$ & $\mathbf{S i}$ \\
\hline V & BL 51 & - & - & - & 570 & 49 & 56 & 370 \\
\hline $\mathrm{V}-1 \mathrm{Ti}$ & BL 50 & - & 1.0 & - & 230 & 130 & 235 & 1050 \\
\hline $\mathrm{V}-3 \mathrm{Ti}$ & BL 62 & - & 3.1 & - & 320 & 86 & 109 & 660 \\
\hline V-3Ti-0.5Si & BL 42 & - & 3.1 & 0.02 & 580 & 190 & 140 & 5400 \\
\hline V-3Ti-1Si & BL 45 & - & 2.5 & 0.01 & 345 & 125 & 90 & 9900 \\
\hline$V-5 T i$ & BL 46 & - & 4.6 & - & 300 & 53 & 85 & 160 \\
\hline V-10Ti & BL 12 & - & 9.8 & 0.63 & 1670 & 390 & 450 & 245 \\
\hline V-18Ti & BL 15 & - & 17.7 & 0.04 & 830 & 160 & 380 & 480 \\
\hline $\mathrm{V}-5 \mathrm{Cr}-3 \mathrm{Ti}$ & BL 54 & 5.1 & 3.0 & - & 480 & 82 & 133 & 655 \\
\hline $\mathrm{V}-4 \mathrm{Cr}-4 \mathrm{Ti}$ & BL 47 & 4.1 & 4.3 & - & 350 & 220 & 200 & 870 \\
\hline $\mathrm{V}-5 \mathrm{Cr}-5 \mathrm{Ti}$ & BL 63 & 4.6 & 5.1 & - & 440 & 28 & 73 & 310 \\
\hline $\mathrm{V}-8 \mathrm{Cr}-6 \mathrm{Ti}$ & BL 49 & 7.9 & 5.7 & - & 400 & 150 & 127 & 360 \\
\hline V-9Cr-5Ti & BL 43 & 9.2 & 4.9 & 0.02 & 230 & 31 & 100 & 340 \\
\hline $\mathrm{V}-14 \mathrm{Cr}-5 \mathrm{Ti}$ & BL 24 & 13.5 & 5.2 & 0.05 & 1190 & 360 & 500 & 390 \\
\hline $\mathrm{V}-15 \mathrm{Cr}-5 \mathrm{Ti}$ & BL 41 & 14.5 & 5.0 & 0.02 & 330 & 96 & 120 & 400 \\
\hline V-10Cr-9Ti & BL 44 & 9.9 & 9.2 & 0.04 & 300 & 87 & 150 & 270 \\
\hline $\mathrm{V}-7 \mathrm{Cr}-15 \mathrm{Ti}$ & BL 10 & 7.2 & 14.5 & 0.09 & 1110 & 250 & 400 & 400 \\
\hline Vanstar- $7^{a}$ & BL 28 & 9.7 & - & 3.50 & 280 & 520 & 640 & - \\
\hline
\end{tabular}

aAloy contains $1.3 \% \mathrm{Zr}$.

Miniature Charpy-impact specimens were prepared for a determination of the temperature dependence of fracture behavior in the dehydrogenated and hydrogenated V-base alloys. The Charpytest specimens had overall dimensions of $3.30 \times 3.30 \times 25.4 \mathrm{~mm}$ and a notch depth of $0.61 \mathrm{~mm}$. Specimens were prepared with the notch orientation perpendicular to the rolling direction maintained during thickness reduction. Dehydrogenated Charpy-test specimens in the fully recrystallized condition werc prepared from the 50\% cold-worked materials by annealing for $1 \mathrm{~h}$ in a vacuum of $2 \times 10^{-5} \mathrm{~Pa}$.

The V-3Ti alloy specimens were annealed at $1050^{\circ} \mathrm{C}$, and the V-5Cr-3Ti and V-5Cr-5Ti alloy specimens were annealed at $1125^{\circ} \mathrm{C}$. In the case of the previously tested alloy specimens, the V-Cr-Ti specimens and the Vanstar-7 specimens were annealed at $1125^{\circ} \mathrm{C}$. The V-18Ti and V-3Ti-Si alloy specimens were annealed at 1100 and $1050^{\circ} \mathrm{C}$, respectively. These annealing conditions for the coldworked materials resulted in average recrystallized grain diameters in the range of $0.02-0.04 \mathrm{~mm}$. Hydrogen was introduced into Charpy-test specimens of the alloys by annealing the cold-worked specimens at the previously mentioned temperatures in argon-filled quartz tubes for $1 \mathrm{~h}$ and subsequently quenching the tubes and their contents, without rupture, in water. The hydrogen concentration in the specimens was adjusted by surface-finishing the specimens prior to the anneal. ${ }^{6}$

The hydrogen concentration in the Charpy-test specimens was determined from the total partial pressure of hydrogen that was evolved on heating a specimen at $15^{\circ} \mathrm{C} / \mathrm{min}$ from $25^{\circ} \mathrm{C}$ to $1000^{\circ} \mathrm{C}$. This procedure is discussed in Ref. 6. In the case of the Charpy specimens annealed in vacuum (i.e., dehydrogenated), the hydrogen concentration was determined to be $<30 \mathrm{appm}$. The hydrogen concentration in specimens annealed in quartz tubes (i.e., hydrogenated) ranged from 400 to $1200 \mathrm{appm}$. 
The Charpy-impact tests were performed with an instrumented Dynatup Drop-Weight Impact Test machine. Impact velocity and load for these tests were $2.56 \mathrm{~m} / \mathrm{sec}$ and $14.995 \mathrm{~kg}$, respectively. Energy absorption was determined from applied load-time data that were acquired during impact. These data were analyzed and plotted with a GRC Model 730-I data acquisition and analysis system. The specimen temperature at the instant of impact was determined from a thermocouple that was spot-welded near the notch. Specimen temperatures during the Charpy tests were limited to -190 to $250^{\circ} \mathrm{C}$. A curve for the energy absorbed during impact versus test temperature for $\mathrm{V}$ and $\mathrm{V}$-base alloy specimens was fitted with a hyperbolic tangent equation to determine the curve inflection point; this curve point was used to define the DBTT. The DBTTs of the V-1Ti, V-3Ti, V-5Ti, V-10Ti, V-4Cr-4Ti, and V$5 \mathrm{Cr}-5 \mathrm{Ti}$ alloys were $<-190^{\circ} \mathrm{C}$ since the alloy specimens on impact bent to an angle of $85^{\circ}$ without complete fracture at temperatures $z-190^{\circ} \mathrm{C}$; and the DBTTs of these alloys were estimated from the temperature dependence of energy absorption during impact for test temperatures $z-190^{\circ} \mathrm{C}$.

The microstructures of annealed Charpy specimens, the appearance of fracture surfaces of tested specimens, and the temperature dependence of energy absorbed during the impact tests on some of the V-base alloys are described in Refs. 1 and 2.

\section{Experimental Results}

The DBTTs for dehydrogenated (<30 appm $\mathrm{H}$ ) and hydrogenated $(400-1200 \mathrm{appm} \mathrm{H}) \mathrm{V}$ and V-base alloys are presented in Table 2 .

\section{Dependence of DBTT on Ti concentration}

The DBTT dependence of dehydrogenated (i.e., $<30$ appm H) and hydrogenated (i.e., 400-1200 appm $\mathrm{H}) \mathrm{V}$-Ti alloys on Ti concentration is shown in Fig. 1. The DBTT of unalloyed $\mathrm{V}\left(-150^{\circ} \mathrm{C}\right.$ for dehydrogenated $\mathrm{V}$ and $-10^{\circ} \mathrm{C}$ for hydrogenated $\mathrm{V}$ ) decreases as the Ti concentration increases to 3-5 wt.\%, to yield the alloys with the minimum DBTTs, i.e., $\sim-250^{\circ} \mathrm{C}$ for dehydrogenated alloy and $-160^{\circ} \mathrm{C}$ for hydrogenated alloy. DBTTs for V-Ti alloys (dehydrogenated and hydrogenated) increase as $\mathrm{Ti}$ concentration increases from -5 to $-18 \mathrm{wt} . \%$. The DBTT values of the dehydrogenated and hydrogenated $\mathrm{V}-18 \mathrm{Ti}$ alloy were $-40^{\circ} \mathrm{C}$ and $55^{\circ} \mathrm{C}$, respectively.

As shown in Fig. 1, the presence of $400-1200$ appm H in binary V-(0-18)Ti alloys causes a significant DBTT increase $\left(60-200^{\circ} \mathrm{C}\right)$ in the dehydrogenated alloys. The differences between the DBTTs of dehydrogenated and hydrogenated unalloyed $\mathrm{V}$ and binary $\mathrm{V}$-Ti alloys suggest that V-Ti alloys containing $s 5 \mathrm{wt} . \% \mathrm{Ti}$ may be more susceptible to hydrogen embrittlement (see Fig. 1).

\section{Dependence of DBTT on Cr concentration}

The DBTT dependence of dehydrogenated and hydrogenated $\mathrm{V}-\mathrm{Cr}-(4-6) \mathrm{Ti}$ alloys on $\mathrm{Cr}$ concentration is shown in Fig. 2. The DBTTs of dehydrogenated and hydrogenated V-(4-6)Ti alloys, e.g., $\sim-250^{\circ} \mathrm{C}$ and $-160^{\circ} \mathrm{C}$, respectively, for $\mathrm{V}-5 \mathrm{Ti}$ (BL 46), increase as the $\mathrm{Cr}$ concentration in these alloys rises to at least $15 \mathrm{wt} \%$. DBTT values of the dehydrogenated and hydrogenated $\mathrm{V}-15 \mathrm{Cr}-5 \mathrm{Ti}$ alloy (BL 41) were $-10^{\circ} \mathrm{C}$ and $135^{\circ} \mathrm{C}$, respectively. The presence of $400-1200 \mathrm{appm} \mathrm{H}$ in $\mathrm{V}-\mathrm{Cr}-(4-6) \mathrm{Ti}$ alloys causes a significant DBTT increase $\left(60-145^{\circ} \mathrm{C}\right)$ in the dehydrogenated alloy (Fig. 2). The V-Cr-(4-6)Ti alloys containing $<10 \mathrm{wt} . \% \mathrm{Cr}$ may be less susceptible to hydrogen embrittlement.

\section{Dependence of DBTT on combined $\mathrm{Cr}$ and Ti concentration}

The DBTT dependence of $\mathrm{V}$ and $\mathrm{V}$-base alloys on combined $\mathrm{Cr}$ and $\mathrm{Ti}$ concentration is shown 
Table 2. DBTTs of V and V-base alloys.

\begin{tabular}{|c|c|c|c|}
\hline $\begin{array}{l}\text { Nominal } \\
\text { Composition }\end{array}$ & $\begin{array}{l}\text { ANL } \\
\text { I.D. }\end{array}$ & $\begin{array}{l}\text { Hydrogen } \\
\text { (appm) }\end{array}$ & $\begin{array}{l}\text { DBTT } \\
\left({ }^{\circ} \mathrm{C}\right)\end{array}$ \\
\hline V & BL 51 & $<30$ & -150 \\
\hline$n$ & " & 700 & -10 \\
\hline V-1Ti & BL 50 & $<30$ & $-225^{a}$ \\
\hline$n$ & $n$ & 650 & -25 \\
\hline $\mathrm{V}-3 \mathrm{Ti}$ & BL 62 & $<30$ & $-255^{a}$ \\
\hline$n$ & $n$ & 600 & -175 \\
\hline V-3Ti-0.5Si & BL 42 & $<30$ & -150 \\
\hline$n$ & $n$ & 520 & -125 \\
\hline$n$ & $n$ & 970 & -170 \\
\hline V-3Ti-1Si & BL 45 & $<30$ & -165 \\
\hline$n$ & $n$ & 990 & -30 \\
\hline $\mathrm{V}-5 \mathrm{Ti}$ & BL 46 & $<30$ & $-250^{a}$ \\
\hline$n$ & & 860 & -160 \\
\hline $\mathrm{V}-10 \mathrm{Ti}$ & BL 12 & $<30$ & $-190^{a}$ \\
\hline$"$ & & 600 & -130 \\
\hline $\mathrm{V}-18 \mathrm{Ti}$ & BL 15 & $<30$ & -40 \\
\hline$n$ & " & 580 & +55 \\
\hline $\mathrm{V}-5 \mathrm{Cr}-3 \mathrm{Ti}$ & BL 54 & $<30$ & $-85^{b}$ \\
\hline$n$ & $n$ & 600 & $+65^{b}$ \\
\hline V-4Cr-4Ti & BL 47 & $<30$ & $-225^{a}$ \\
\hline " & & 1200 & -125 \\
\hline V-5Cr-5Ti & ${ }_{n}$ BL 63 & $\begin{array}{l}<30 \\
600\end{array}$ & $\begin{array}{l}-190^{\mathrm{a}} \\
-110^{-1}\end{array}$ \\
\hline $\mathrm{V}-8 \mathrm{Cr}-6 \mathrm{Ti}$ & BL 49 & $<30$ & -85 \\
\hline " & $n$ & 600 & -5 \\
\hline V-9Cr-5Ti & BL 43 & $<30$ & -60 \\
\hline$"$ & $n$ & 670 & +50 \\
\hline $\mathrm{V}-14 \mathrm{Cr}-5 \mathrm{Ti}$ & BL 24 & $<30$ & -10 \\
\hline$"$ & $n$ & 590 & +130 \\
\hline $\mathrm{V}-15 \mathrm{Cr}-5 \mathrm{Ti}$ & BL 41 & $<30$ & -10 \\
\hline$n$ & $n$ & 620 & +135 \\
\hline V-10Cr-9Ti & BL 44 & $<30$ & +10 \\
\hline$n$ & $n$ & 1180 & +155 \\
\hline $\mathrm{V}-7 \mathrm{Cr}-15 \mathrm{Ti}$ & BL 10 & $<30$ & +25 \\
\hline " & $n$ & 400 & +250 \\
\hline Vanstar-7 & BL 28 & $<30$ & -65 \\
\hline$n$ & n & 500 & -25 \\
\hline
\end{tabular}

${ }^{a}$ Lowest test temperature was $-190^{\circ} \mathrm{C}$. DBTT was estimated from the temperature dependence of energy absorption for test temperatures above $-190^{\circ} \mathrm{C}$.

${ }^{b} \mathrm{DBTT}$ was anomalously high due to presence of 6-16 $\mu \mathrm{m}$ diameter precipitates on grain boundaries.

in Fig. 3. (Note that the combined $\mathrm{Cr}$ and Ti concentration is $\mathrm{C}_{\mathrm{Cr}}+\left(\mathrm{C}_{\mathrm{Tr}}\right)^{0.95}$. For the Vanstar-7 alloy, the $\mathrm{Fe}$ and $\mathrm{Zr}$ concentrations are treated as $\mathrm{Cr}$ and $\mathrm{Ti}$ concentrations, respectively. The DBTT dependence on combined $\mathrm{Cr}$ and Ti concentration (Fig. 3) is similar to the DBTT dependence on Ti concentration shown in Fig. 1, i.e., the minimum DBTT for dehydrogenated and hydrogenated V-base 


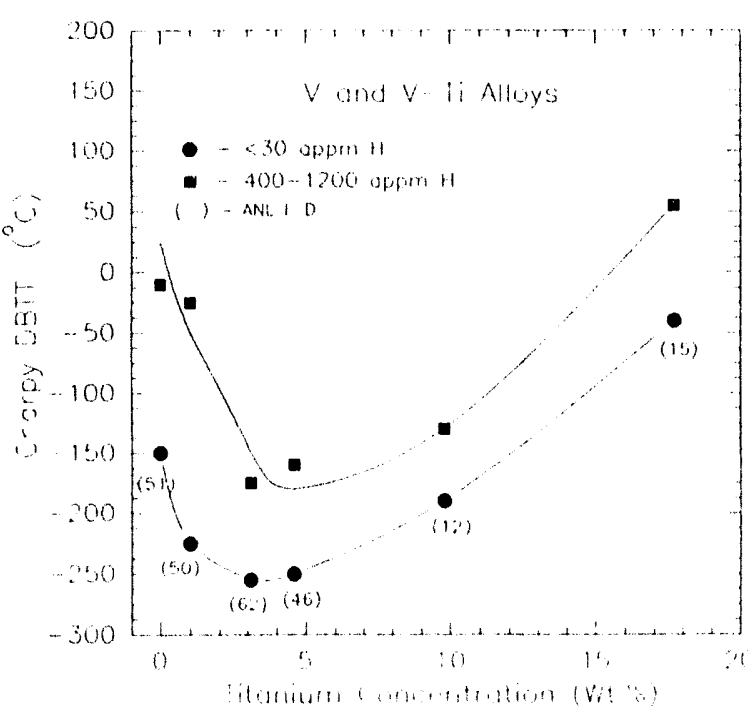

Fig. 1. V and V-Ti alloy dependence of DBTT on Ti concentration.

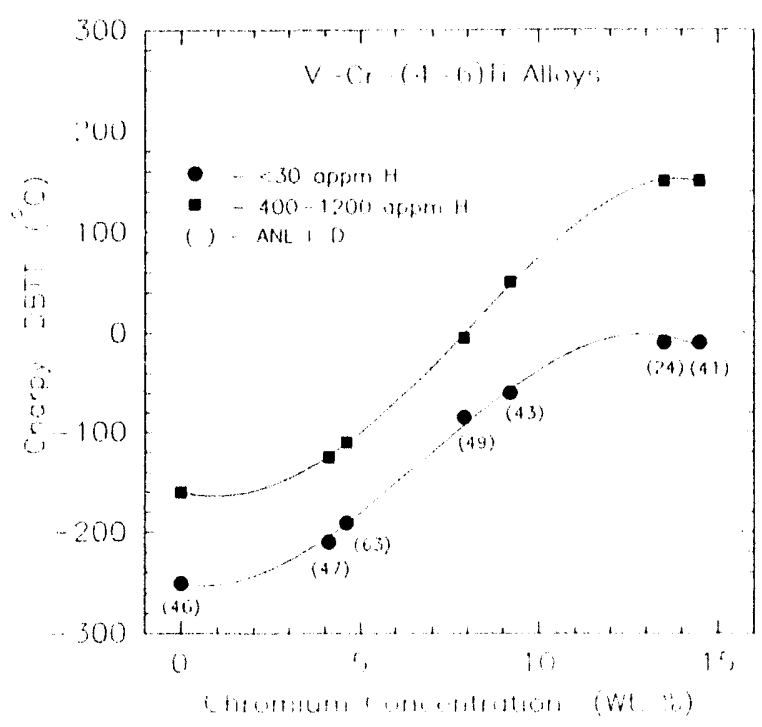

Fig. 2. V-Cr-(4-6)Ti alloy dependence of DBTT on $\mathrm{Cr}$ concentration.

alloys is seen when the combined $\mathrm{Cr}$ and $\mathrm{Ti}$ concentration is $-5 \mathrm{wt} \%$. The differences between DBTTs of dehydrogenated and hydrogenated unalloyed V and V-base alloys show that V-base alloys containing $<15$ wt.\% combined $\mathrm{Cr}$ and Ti concentration are less susceptible to hydrogen embrittlement (Fig. 3).

The DBTT data in Table 2 for the dehydrogenated and hydrogenated V-5Cr-3Ti alloy (BL 54) are not shown in Fig. 3, since these DBTTs are believed to be anomalously high $\left(100-200^{\circ} \mathrm{C}\right)$ and do not conform with the general trend for dependence of the DBTT of V-base alloys on combined $\mathrm{Cr}$ and Ti concentration. The surfaces of fractured Charpy specimens of the $\mathrm{V}-5 \mathrm{Cr}-3 \mathrm{Ti}$ alloy were examined

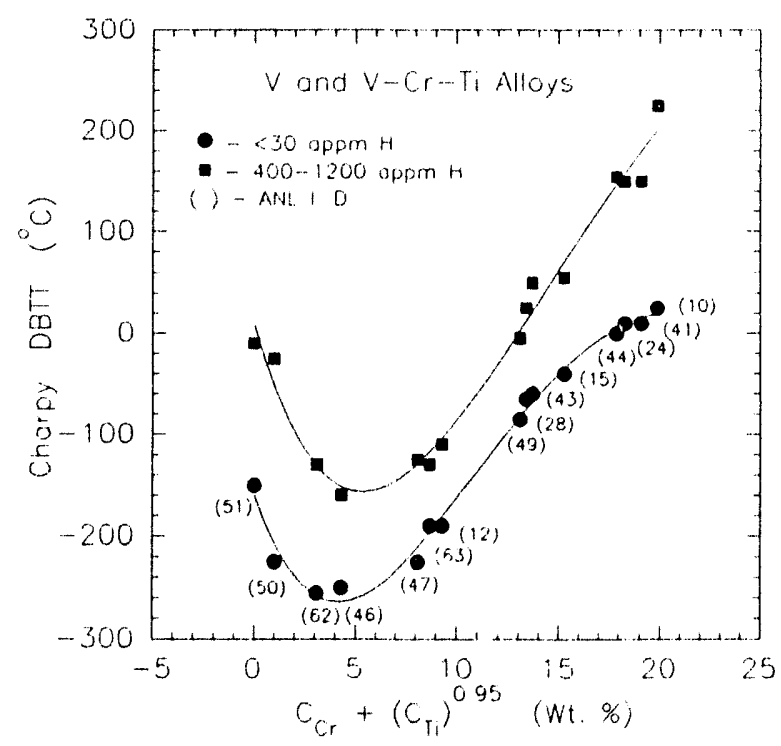

Fig. 3. $\mathrm{V}$ and $\mathrm{V}$-base alloy dependence of DBTT on combined $\mathrm{Cr}$ and $\mathrm{Ti}$ concentration. by observation with a JEOL JSM-50 scanning electron microscope (SEM). These observations showed the presence of precipitates with 6-16 $\mu \mathrm{m}$ diameter on grain boundaries (Fig. 4). These precipitates were non-uniformly distributed in the fracture surface with the highest number density of precipitates in some areas being $-300 / \mathrm{mm}^{2}$ (c.g., see Fig. 4). The average grain size appeared to be significantly larger in areas of high precipitate number density. Precipitates with similar appearance and diameter $(6-16 \mu \mathrm{m})$ were also observed in the fracture surface of the V-3Ti alloy (BL 62), but the precipitates were uniformly distributed with a number density of $-50 / \mathrm{mm}^{2}$ (e.g., see Fig. 5). Analyses of the precipitates in the V-5Cr-3Ti and V-3Ti alloys using x-ray energy dispersive spectroscopy (EDX) showed that the precipitates were a vanadium compound containing $\mathrm{K}, \mathrm{Na}, \mathrm{Cl}, \mathrm{C}$, and $\mathrm{O}$. It should be noted that these precipitates did not contain Ti.

Precipitates with this composition, i.c., $\mathrm{V}(\mathrm{K}, \mathrm{Na}$, $\mathrm{Cl}, \mathrm{C}, \mathrm{O}$ ) were not observed in the other alloys. 


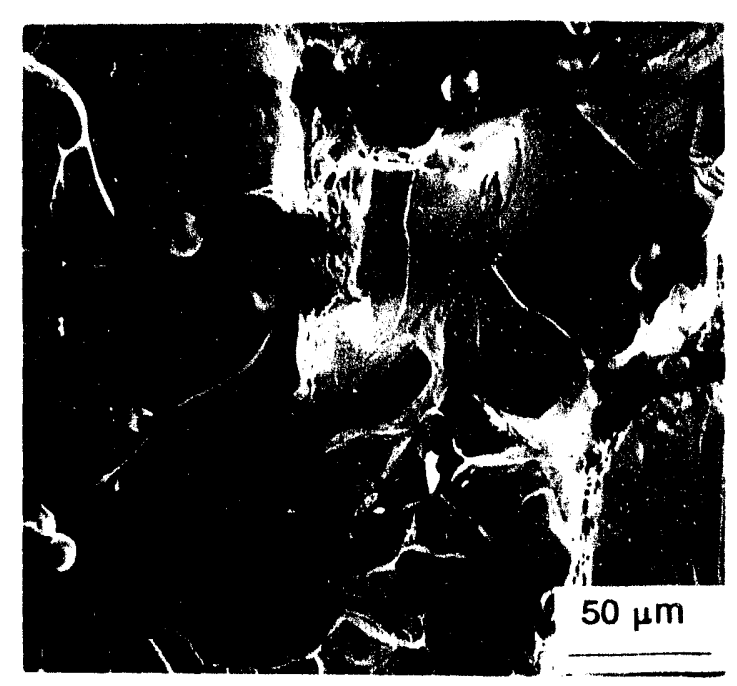

Fig. 4. Fracture surface of V-5Cr-3Ti alloy.

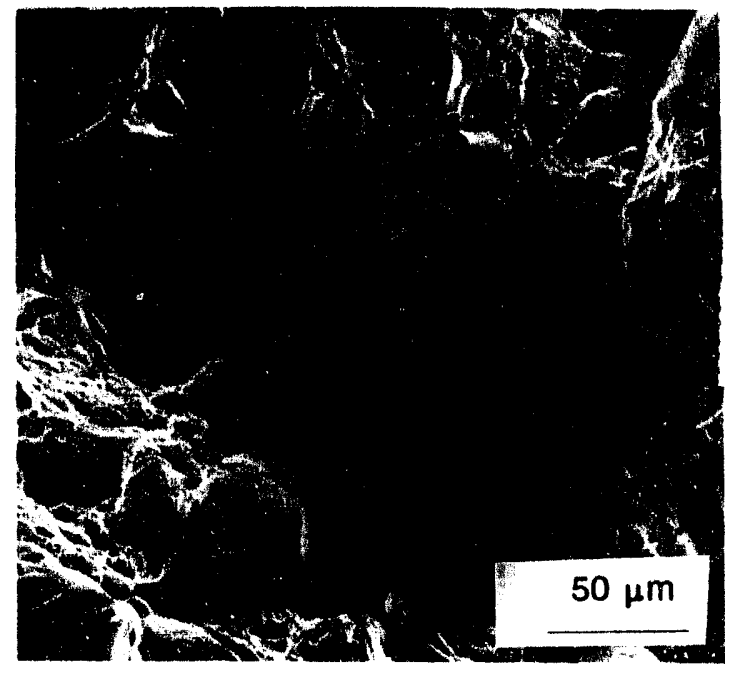

Fig. 5. Fracture surface of V-3Ti alloy.

\section{Dependence of DBTT on Si concentration}

The DBTTs for V-3Ti (BL 62), V-3Ti-0.5Si (BL 42), and V-3Ti-1Si (BL 45) alloys are presented in Table 2 and in Fig. 6 . These results suggest that the addition of $5400-9900 \mathrm{ppm}$ Si to V-3Ti alloy results in $-100^{\circ} \mathrm{C}$ increase of DBTT in the dehydrogenated V-3Ti alloy. Hydrogenation (520-990 appm) of V-3Ti and V-3Ti-(0.5-1)Si alloys caused a $25-135^{\circ} \mathrm{C}$ increase of DBTT. The experimental results suggest that the presence of $>0.5 \mathrm{wt} . \%$

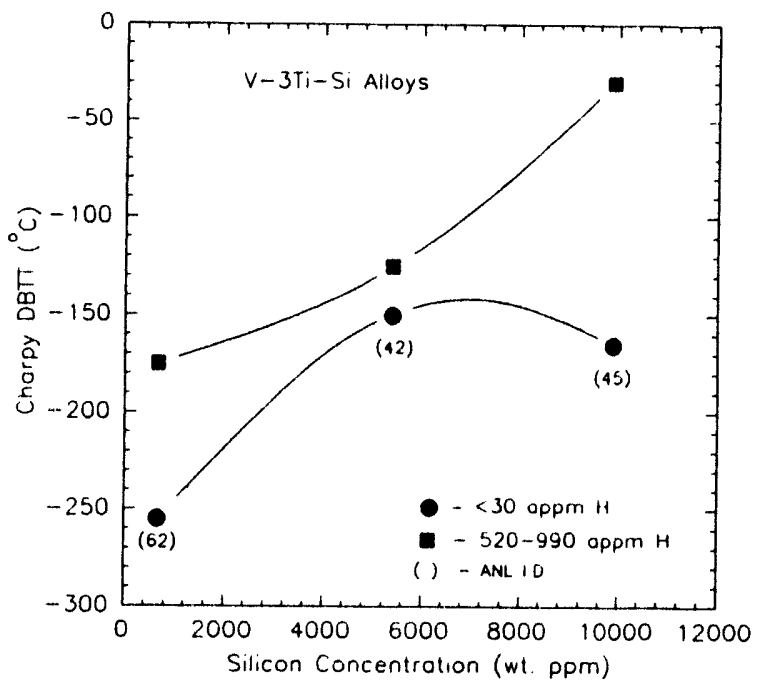

Fig. 6. V-3Ti alloy dependence of DBTT on Si concentration. $\mathrm{Si}$ in V-3Ti alloy causes this alloy to be more susceptible to embrittlement by hydrogen.

The effect of Si concentration on the DBTT of $\mathrm{V}$-Cr-Ti alloys has not been extensively investigated. However, comparison of the DBTT for the $\mathrm{V}-4 \mathrm{Cr}-4 \mathrm{Ti}$ alloy $\left(-225^{\circ} \mathrm{C}\right)$ containing 870 ppm Si and the V-5Cr-5Ti alloy $\left(-190^{\circ} \mathrm{C}\right)$ containing $310 \mathrm{ppm} \mathrm{Si}$ suggests that the difference in DBTT for these alloys is principally due to the higher $\mathrm{Cr}$ and $\mathrm{Ti}$ concentration, rather than the lower Si concentration, in the V-5Cr-5Ti alloy. With the exception of the V-3Ti-0.5Si (BL 42) and V-3Ti-1Si (BL 45) alloys, the Si concentration in the V-Ti and V-Cr-Ti alloys in Table 1 is in the range of 160 to $1050 \mathrm{ppm}$ with the average Si concentration being $460 \mathrm{ppm}$. There was no significant effect of $\mathrm{Si}$ concentration on the DBTT (Table 1 and Figs. 1-3) of these alloys that could be attributed to variations of Si concentration in the range of $160-1050 \mathrm{ppm}$.

\section{Dependence of DBTT on $\mathrm{O}, \mathrm{N}$, and $\mathrm{C}$ concentration}

The $\mathrm{O}, \mathrm{N}$, and $\mathrm{C}$ concentrations in the V.Ti and V.Cr.Ti alloys in Tuble 1 are in the ranges of 230-1670, 28-390, and 73-500 ppm, respectively. There was no significant effect on the DBTT (Table 
2 and Figs. 1-3) of these alloys that could be attributed to these ranges of $\mathrm{O}, \mathrm{N}$, and $\mathrm{C}$ concentration.

\section{DISCUSSION OF RESULTS}

The results of this experimental study on V-Cr-Ti alloys utilizing Charpy-impact loading show that the DBTT of these alloys is lowest $\left(\sim-250^{\circ} \mathrm{C}\right)$ when the combined $\mathrm{Cr}$ and Ti concentration in the alloy is $-5 \mathrm{wt} . \%$. Also, the DBTT of hydrogenated (400-1200 appm) V-Cr-Ti alloys is lowest $\left(-160^{\circ} \mathrm{C}\right)$ when the the combined $\mathrm{Cr}$ and $\mathrm{Ti}$ concentration in the alloys is $-5 \mathrm{wt} . \%$.

A comprehensive analytical electron microscopy study of precipitates in the microstructures of unalloyed vanadium and $\mathrm{V}-1,3,5,10$, and $18 \mathrm{wt} . \% \mathrm{Ti}$ alloys (Table 1) by Gazda has shown that (a) the unalloyed V and V-Ti alloys with $\leq 3 \mathrm{wt} . \%$ Ti contain VC precipitates with BCC structure and additional $\mathrm{Ti}(\mathrm{CNO})$ precipitates with unidentified structure that are coherent with the matrix, (b) the most common precipitates in all of the alloys containing $\mathrm{Ti}$ are $\mathrm{Ti}\left(\mathrm{C}_{1 \cdot-\mathrm{x} y \mathrm{x}} \mathrm{N}_{\mathrm{x}} \mathrm{O}_{\mathrm{y}}\right)$ precipitates with FCC $\mathrm{NaCl}$ structure that are noncoherent with the matrix, (c) all of the precipitates in alloys with $>3 \mathrm{wt} . \%$ $\mathrm{Ti}$ are noncoherent with the matrix, (d) the number density of all precipitates in these materials is maximum in the V-3Ti alloy, and (e) the size of precipitates in these materials is the minimum for alloys with $1-3 \mathrm{wt} . \% \mathrm{Ti}^{8}$ In comparison with the DBTTs for $\mathrm{V}-\mathrm{Ti}$ alloys, we note that the tensile properties of $\mathrm{V}-(0-18) \mathrm{Ti}$ alloys at $600^{\circ} \mathrm{C}$ are also significantly altered when the Ti concentration is -5 wt.\% (see Figs. 7 and 15 in Ref. 7).

The dependence of DBTT for V-Ti alloys on Ti concentration (Fig. 1) is similar to the dependence of DBTT for V-Cr-Ti alloys on combined $\mathrm{Cr}$ and $\mathrm{Ti}$ concentration (Fig. 3). This similarity suggests that the minimum DBTT at $\sim 5$ wt.\% alloy concentration on Charpy-impact loading of V-Ti alloys, as well as $\mathrm{V}-\mathrm{Ti}$ alloys with $\mathrm{Cr}$ additions, is due to the complex combination of $\mathrm{Cr}$ and $\mathrm{Ti}$ solidsolution strengthening effects and coherent and noncoherent precipitate-strengthening effects. The maximum number density and minimum size of precipitates in V-Ti alloys with $-3 \mathrm{wt}$.\% $\mathrm{Ti}$ are considered to be a manifestation of coherency and noncoherency of the precipitates.

The anomalously high $\left(100-200^{\circ} \mathrm{C}\right) \mathrm{DBTT}$ for the $\mathrm{V}-5 \mathrm{Cr}-3 \mathrm{Ti}$ alloy is attributed primarily to the high number density of large $\mathrm{V}(\mathrm{K}, \mathrm{Na}, \mathrm{Cl}, \mathrm{C}, \mathrm{O})$ precipitates on the grain boundaries in this material. Although these precipitates were present in the V-3Ti alloy, their number density was relatively low and the precipitates were uniformly distributed which resulted in a minor effect on the DBTT. These precipitates may have been the result of use of Ti that contained a relatively high $\mathrm{Na}, \mathrm{K}$, and $\mathrm{Cl}$ concentration in the alloy preparation. ${ }^{9}$

The objective of this experimental program is to determine the composition of a vanadium-base alloy with the optimal combination of mechanical properties, corrosion resistance, fabricability, and weldability for use as a structural material in the environment of a fusion reactor. The following experimental results are considered in the selection of the optimal composition of the vanadium-base alloy. (1) The DBTT of a vanadium-base alloy can be expected to increase substantially $\left(100-200^{\circ} \mathrm{C}\right.$, 41-44 dpa at $420^{\circ} \mathrm{C}$ ) on neutron irradiation. ${ }^{2}$ (2) The swelling of V-Cr-Ti alloys on neutron irradiation is significantly reduced $\left(<1 \%\right.$ swelling, $36 \mathrm{dpa}$ at $420^{\circ} \mathrm{C}$ ) by the presence of $25 \mathrm{wt} . \% \mathrm{Ti}$ in the alloy. ${ }^{10}$ (3) The long-term creep strength of V-Ti alloys is significantly increased by the addition of $\mathrm{Cr}^{11}$ (4) The tensile properties of $\mathrm{V}-(0-15) \mathrm{Cr}-5 \mathrm{Ti}$ alloys with a tungsten/inert-gas weld zone are comparable to tensile properties of recrystallized alloys without a weld zone, but $\mathrm{V}-(0-15) \mathrm{Cr}-5 \mathrm{Ti}$ alloys with $\mathrm{Cr}$ concentrations $>5 \mathrm{wt} . \%$ have significantly reduced fracture toughness. ${ }^{12}$ These experimental results, together with the experimental results presented in this report, lead us to select the $\mathrm{V}-5 \mathrm{Cr}-5 \mathrm{Ti}$ alloy containing $\sim 400 \mathrm{ppm} \mathrm{O,} \sim 200 \mathrm{ppm} \mathrm{N}, \sim 200 \mathrm{ppm} \mathrm{C}$, and $\sim 900 \mathrm{ppm} \mathrm{Si}$ for use as a structural material in a fusion reactor. 


\section{CONCLUSIONS}

1. The V-5Cr-5Ti alloy containing $-400 \mathrm{ppm} \mathrm{O,}-200 \mathrm{ppm} \mathrm{N},-200 \mathrm{ppm} \mathrm{C}$, and $-900 \mathrm{ppm} \mathrm{Si} \mathrm{is}$ recommended for use as a structural material in a fusion reactor.

\section{FUTURE WORK}

The effect of neutron irradiation on the DBTT of V-3Ti-1Si, V-5Ti, and V-5Cr-5Ti alloys will be determined, and this will complement the DBTT data in Ref. 2 for irradiated V-base alloys.

\section{REFERENCES}

1. B. A. Loomis, B. J. Kestel, B. D. Edwards, and D. L. Smith, "Temperature Dependence of the Fracture Behavior and the DBTT for Dehydrogenated and Hydrogenated Vanadium-Base Alloys," in: Fusion Reactor Materials, Semiannual Progress Report for Period Ending September 30, 1988, DOE/ER-0313/5, U.S. Department of Energy, Office of Fusion Energy, pp. 242-255.

2. B. A. Loomis, and D. L. Smith, "Response of Unirradiated and Neutron-Irradiated Vanadium Alloys to Charpy-Impact Loading," J. Nucl. Mater., 179-181, Part A (1991), pp. 783-786.

3. B. A. Loomis, L. J. Nowicki, and D. L. Smith, "The Effect of Hydrogen, Chromium, Titanium, and Silicon on the Ductile-Brittle Transition Temperature of Vanadium and Vanadium-Base Alloys," in: Fusion Reactor Materials, Semiannual Progress Report for Period Ending September 30, 1991, DOE/ER-0313/11, U.S. Department of Energy, Office of Fusion Energy, pp. 227-232.

4. N. S. Cannon, M. L. Hamilton, A. M. Ermi, D. S. Gelles, and W. L. Hu, "Influence of Neutron Irradiation on the Charpy Impact Properties of V-15Cr-5Ti," in: Fusion Reactor Materials, Semiannual Progress Report for Period Ending September 30, 1987, DOE/ER-0313/3, U.S. Department of Energy, Office of Fusion Energy, pp. 239-245.

5. D. N. Braski, "The Tensile Properties of Several Vanadium Alloys after Irradiation to 90 DPA in FFTF, ${ }^{n}$ in: Fusion Reactor Materials, Semiannual Progress Report for Period Ending September 30, 1987, DOE/ER-0313/3, U.S. Department of Energy, Office of Fusion Energy, pp. 235-238.

6. B. A. Loomis, A. B. Hull, O. K. Chopra, and D. L. Smith, "Hydrogen Concentration Distribution in Vanadium-Base Alloys after Surface Preparation and Exposure to Liquid Lithium," in: Fusion Reactor Materials, Semiannual Progress Report for Period Ending March 31, 1988, DOE/ER0313/4, U.S. Department of Energy, Office of Fusion Energy, pp. 160-167.

7. B. A. Loomis, L. J. Nowicki, and D. L. Smith, "Tensile Properties of Vanadium and VanadiumBase Alloys," in: Fusion Reactor Materials, Semiannual Progress Report for Period Ending March 31, 1991, DOE-ER/0313/10, U.S. Department of Energy, Office of Fusion Energy, pp. 145-155.

8. J. Gazda, "Analytical Electron Microscopy Study of Vanadium and Vanadium-Base Alloys," University of Illinois at Chicago, 1993 (unpublished thesis for Master of Science in Metallurgy).

9. Communication from J. R. Peterson, Teledyne Wah Chang Albany, Albany, Oregon.

10. B. A. Loomis, D. L. Smith, and F. A. Garner, "Swelling of Neutron-Irradiated Vanadium Alloys," J. Nucl. Mater., 179-181, Part A (1991), pp. 771-774.

11. B. A. Loomis, L. J. Nowicki, and D. L. Smith, "Creep of V-5Cr-5Ti and V-10Cr-5Ti Alloys at $600^{\circ} \mathrm{C}$," in: Fusion Reactor Materials, Semiannual Progress Report for Period Ending September 30, 1991, DOE/ER-0313/13, U.S. Department of Energy, Office of Fusion Energy.

12. B. A. Loomis, C. F. Konicek, L. J. Nowicki, and D. L. Smith, "Tensile Properties of VanadiumBase Alloys with a Tungsten/Inert-Gas Weld Zone," in: Fusion Reactor Materials, Semiannual Progress Report for Period Ending March 31, 1992, DOE-ER/0313/12, U.S. Department of Energy, Office of Fusion Energy. 
6.4 Copper Alloys 
STATUS OF FATIGUE STUDies ON IRRADIATED COPPER ALlOYS - F. A. Garner and M. L. Ham I ton (Pacific Northwest Laboratory ), J. F. Stubbins and A. Singhal (University of $l l l$ inois) and B. N. Sinch (Riso National Laboratory)

\section{OBJECTIVE}

The objective of this effort is to provide fatigue life data for application of irradiated copper alloys to fusion high heat flux needs.

\section{SUMMARY}

Irradiation continues in the EBR-II and DR-3 reactors of pure copper and GI idCOD CUAI25 in the form of subsize tensile fatigue specimens. The first phase of the EBR-II irradiation sequence has been completed. A size effects experiment conducted on unirradiated CuAl25 fatigue specimens is nearing completion. Eariy results on the fatigue behavior of subsize specimens are presented in this report.

\section{PROGRESS AND STATUS}

\section{Introduction}

Pure copper and GIidCop CUA125 are currently being considered as high heat flux structural components for the ITER divertor plate assembly. Data are required on the radiation performance of these materials and a variety of studies are in progress to provide data on void swelling, tensile properties and electrical conductivity.

One of the most important properties for high heat flux applications, however, is the low cycle fatigue behavior, which is used to assess the mechanical strain contribution of thermal cycling on component lifetimes. A joint U.S./E.C. research program involving neutron irradiation of pure copper and GlidCop CuAl25 in the form of low cycle fatigue specimens is now in progress. The participants are the Riso Naticnal Laboratory in Denmark, Pacific Northwest Laboratory and the University of Illinois. The program is directed toward serving the goals of both the ITER (International Thermonuclear Experimental Reactor) and NET (Next European Torus) programs. The full program was described in an earlier report."

\section{Specimen Description}

The specimens employed are not full-size tensile fatigue specimens as defined by ASTM standards but are typical of those employed in many fatique studies. As shown in Figure 1 the specimens are 6 mm in maximum diameter by $50 \mathrm{~mm}$ long, with the gauge section $7 \mathrm{~mm}$ in length and $3.1 \mathrm{~mm}$ in diameter. The pure copper specimens were cut from OFHC copper and then fully annealed, while the CuAl25 specimens were cut from the as-wrought condition as supplied to Ris National Laboratory by SCM Metals Products. All specimens were prepared at Ris to preserve uniformity between the various tests.

\section{Status of Neutron Irradiation Experiments}

The first discharge from EBR-II of the COBRA :A subassembly has been accomplished after two reactor cycles. Fatigue specimens irradiated in COBRA $1 \mathrm{~A}$ at $-400^{\circ} \mathrm{C}$ are expected to be delivered to Pacific Northwest

Laboratory in the second half of CY1993. The

second set of specimens will continue irradiation in COBRA IA to a higher but yet unspecified exposure level.

The lower exposure experiment currently being conducted in the DR-3 reactor at the RIS Laboratory at 40 , 100. 250,350 and $450^{\circ} \mathrm{C}$ to $\sim 0.4 \mathrm{dpa}$ is nearing completion. Only the $450^{\circ} \mathrm{C}$ sequence remains to be irradiated. Fatique testing of these specimens is scheduled to begin toward the end of CY 1993.

'Pacific Northwest Laboratory is operated for the U.S. Department of Energy by Battelle Memorial institute under Constract DE-AC06-76RLO 1830. 


\section{Size Effects Comparison}

Subsize specimens of GlidCop CuAl25 in the as-received condition have been tested to establish the fatigue durability of this alloy at room temperature. The tests were conducted as strain-controlled, fully-

reversed cyclic fatigue to failure experiments. Testing of full size specimens is now in progress. The results of the subsize tests are shown in Figure 2 and will be used to establish the influence of specimen

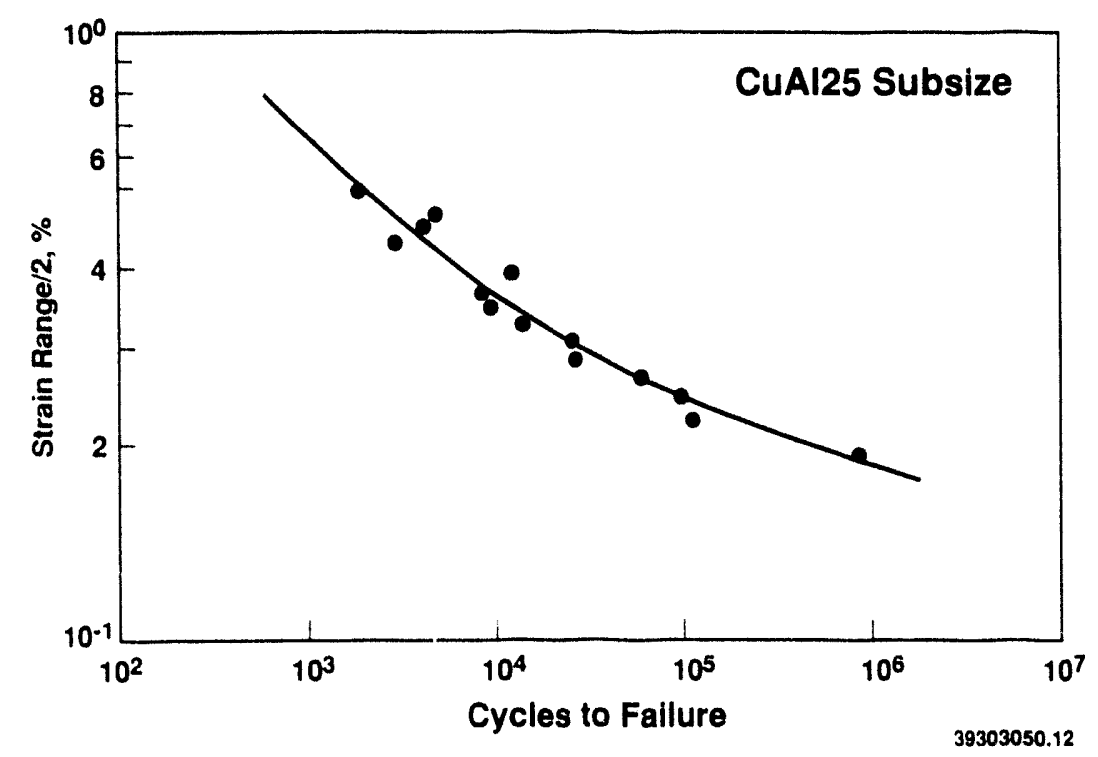
size on fatigue durability, as well as to establish a baseline for the fatigue properties of irradiated subsize specimens. The present data show no fatigue limit at least up to $10^{6}$ cycles.

\section{Future Work}

Testing of full size specimens of CUAI25 will continue. A similar set of tests will then proceed on pure copper.

\section{Reference}

1. F. A. Garner, B. N. Singh and J. F. Stubbins, "Status of Low Cycle Fatigue Studies on Irradiated Copper", Fusion Reactor Materials

Semiannual Progress Report DOE/ER-0313/13 (1993) pD.

265-266.

Fig. 2. Low cycle fatigue data obtained on subsize CuAl25 specimens tested at room temperature.

2. F. A. Garner and M. L. Hamilton, "COBRA 1A

Experiment in EBR-II", lbid, pp. 255-257. 
The Response of Dispersion-Strengthened Copper Alloys To High Fluence Neutron Irradiation at $415^{\circ} \mathrm{C}-\mathrm{D}$. $J$. Edwards, J. W. Newkirk, (U. of MO-Rolla). F. A. Garner, M. L. Hamilton, (Pacific Northwest Laboratory) A. Hadkarni, and P. Samal, (SCM Metal Products)

\section{OBJECTIVE}

The objective of this effort is to supply irradiation data on copper alloys selected as candidates for high heat flux applications in fusion reactors.

\section{SUMMARY}

Various oxide-dispersion-strengthened copper alloys have been irradiated to 150 dpa at $415^{\circ} \mathrm{C}$ in the Fast Flux Test Facility (FFTF). The $\mathrm{Al}_{2} \mathrm{O}_{3}$-strengthened $\mathrm{GlidCop}{ }^{\text {TM }}$ alloys, followed closely by a $\mathrm{HfO}_{2}$-strengthened alloy, displayed the best swelling resistance, electrical conductivity, and tensile properties. The conductivity of the $\mathrm{HFO}_{2}$-strengthened alloy reached a plateau at the higher levels of irradiation, instead of exhibiting the steady decrease in conductivity observed in the other alloys. A high initial oxygen content resulted in significantly higher swelling for a series of castable oxide-dispersion-strengthened alloys. while a $\mathrm{Cr}_{2} \mathrm{O}_{3}$-strengthened alloy showed poor resistance to radiation.

\section{PROGRESS ANO STATUS}

\section{Introduction}

One of the most crucial components of the International Thermonuclear Experimental Reactor (ITER) is the divertor plate assembly, which will be subjected to a high heat flux ( $\left.25 \mathrm{MW} / \mathrm{m}^{2}\right)$ from the charged particles and thermal energy that escape the plasma, and to radiation damage from the $14 \mathrm{MeV}$ neutrons and charged particles [1-5]. As a consequence of this severe irradiation environment, the divertor plate assembly must utilize structural materials that can maintain high strength and high thermal conductivity throughout its. lifetime.

The high thermal conductivity requirement leads to the consideration of pure copper and its alloys. Pure copper, however, is not generally considered a structural material due to its iow strength and low softening temperature. In addition, irradiation experiments [6-11] in the Fast Flux Test Facility (FFTF) have demonstrated that pure copper has little resistance to void swelling, which dramatically decreases the slectrical conductivity. The thermal conductivity w1ll also decrease since the two conductivities are directly proportional to each other. The FFTF experiments also revealed that oxide-dispersion-strengthened (OOS) Copper alloys demonstrated the most promising behavior after irradiation to $\cdots 100$ dpa, exhibiting excellent swelling resistance and good retention of electrical conductivity and strength. Transmutation of the copper produced enough nickel and zinc to lower the conductivity, an effect which becomes more noticeable as the fluence increases $[12,13]$.

on the basis of electrical conductivity and yield strength, the GlidCop" alloys are considered a prime candidate material for current divertor plate designs, possibly being used for the neat sink and perhaps the tubing that carries the coolant. Typical designs, shown in fig. 1, call either for carbon fiber composite (CFC) tiles to be brazed onto the plasma-facing surface of the copper heat sink. or for the divertor block to be made entirely of CFC with a metal coolant tube. possibly fabricated from dispersionstrengthened copper. The tiles act as an armor to prevent the thermal erosion of the copper and thus reduce the contamination of the plasma by high 2 elements, and also allow higher temperatures to be obtained at the divertor surface without melting the copper $[2,5]$. Some of the problems assuciated with using copper alloys for the divertor include brazing difficulties due to mismatches in the thermal expansion coefficients of the copper and CFC's, and melting of the conper during a ioss of cooling accident (î).

in this report the resuits of density measurements, tensile tests, fractography, and electrical conductivity measurements (used to estimate thermal conductivity) are presented for various dispersion. trengthened copper alloys irradiated to 104 and $150 \mathrm{dpa}$ at $415^{\circ} \mathrm{C}$ in FFTf. Al though these displacement inels are considerably higher than anticipated for ITER applications $(-10 \mathrm{dpa})$, understanding the irradiation effects on the materials at these high displacement levels may be useful for commercial reactor applications.

Experimental Results

The copper alloys irradiated in FFTF are listed in Table 1 along with their compositions and thermomechanical treatments. Although the three alloy classes are all dispersion-strengthened systems,

'Pacific Northwest Laboratory is operated for the U.S. Department of Energy by Battelle Memorial institute under Contract DE-ACO6-76RLO 1830. 


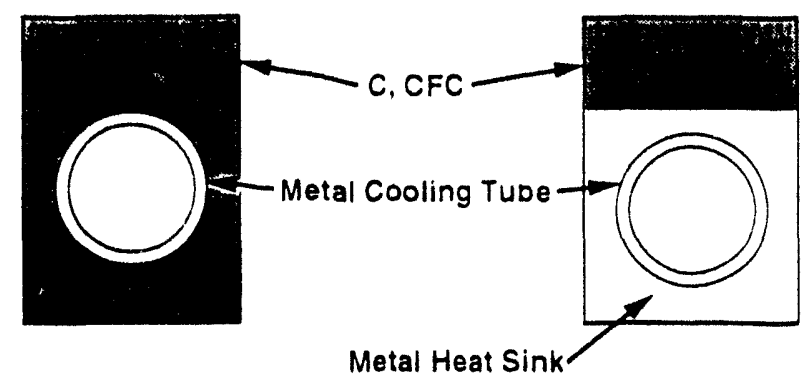

Monoblock Type

Heat Sink Type

Fig. 1. Two possible designs for the ITER divertor block assembly utilizing dispersion-strengthened copper alloys [ref. 1].

each class was produced by a different method. The GlidCop "alloys are produced by SCM Metal Products using an internal oxidation technique [14]. which yields a very fine, uniform dispersion of A1,0, particles, imparting high strength and yet allowing good electrical conductivity. The CuAlls alloy contains $\leq 200 \mathrm{ppm}$ boron. which was used as a deoxidant.

Table 1 - -ODS Copper alloys Irradiated in FFTF at $\sim 415 \mathrm{C}$

\begin{tabular}{|c|c|c|}
\hline ALLOY & COMPOSITION (WT\%) & THERMO - MECHANICAL PROCESSING \\
\hline \multicolumn{3}{|c|}{ GlidCop " Alloys } \\
\hline $\begin{array}{l}\text { CuAl15+ } \\
\text { boron }\end{array}$ & $\begin{array}{l}0.15 \% \mathrm{Al} \text { as } \mathrm{Al} \mathrm{O}_{3} \\
<200 \mathrm{ppm} \text { residuat boron }\end{array}$ & $\begin{array}{l}\text { Annealed, } 900^{\circ} \mathrm{C} / 0.5 \mathrm{hr} / \\
\text { air cooled }(A C)\end{array}$ \\
\hline CUAI20 & $0.20 \%$ Al as Al. 0 & $20 \%$ coid worked $(\mathrm{CH})$ \\
\hline CuA125 & $0.25 \%$ Al as Al. & $50 \% \mathrm{CW}$ \\
\hline $\begin{array}{l}\text { CUAI } 25 \\
\text { WELD }\end{array}$ & Same, laser welded & $50 \% \mathrm{CW}$ \\
\hline \multicolumn{3}{|c|}{ Mechanically Alloyed Copper " } \\
\hline $\mathrm{Cu}-\mathrm{HFO}=$ & $1.1 \% \mathrm{Hf}$ as HFO. & $20 \% \mathrm{CW}, 450 \% 0.5 \mathrm{hr}, \mathrm{AC}$ \\
\hline $\mathrm{Cu}-\mathrm{Cr}_{2} \mathrm{O}_{3}$ & $3.5 \% \mathrm{Cr}$ as $\mathrm{Cr}_{2} \mathrm{O}_{3}$ & $20 \% \mathrm{CW} .450 \cdot \mathrm{C}=0.5 \mathrm{hr} A \mathrm{AC}$ \\
\hline \multicolumn{3}{|c|}{ Castable Copper Alloys ${ }^{\cdots}$} \\
\hline ODS-1 & $0.25 \% \mathrm{Mg} .1 \%$ Al 0 & $40 \% \mathrm{CW}$ \\
\hline $\begin{array}{l}\text { OOS } 1 \\
\text { WELD }\end{array}$ & Same, laser welded & $40 \% \mathrm{CW}$ \\
\hline $005 \cdot 2$ & $0.25 \% \mathrm{Mg}, 1 \%$ Al. 0 & $40 \% \mathrm{CW}$ \\
\hline ODS-3 & $0.50 \% \mathrm{Mg}, 1 \% \mathrm{zrO}$ & $40 \% \mathrm{CW}$ \\
\hline $005-4$ & $0.50 \% \mathrm{Mg}, 1 \%$ al. 0 & $40 \% \mathrm{CW}$ \\
\hline
\end{tabular}


The second class of alloys studied were two mecnanically alloyed copper alloys incoidorating either $\mathrm{Cr}_{\mathrm{O}} \mathrm{O}_{3}$ or HfO. as the strengthening particles. Dr. N. Grant at the Massachusetts Institute of Technology suppilad these alloys. The alloys were produced using powder metallurgy techniques involving the mixing of pure copper powder and the metal oxide powder and then extruding the final powder at 700 \% 15 ing a $16: 1$ extrusion ratio.

The third class of alloys represented an attempt by Technical Research Associates, inc. to produce a castable, oxide-dispersion-strengthened alloy. As will be shown later. this effort proved unsuccessful for an unexpected reason. The alloy was produced by adding oxide particles (coated with copper by a proprietary chemical coprecipitation method) to a melt of magnesium-bearing oxygen-free high conductivity (OFHC) copper, and then casting the melt. The ODS-1 and ODS-2 alloys have the same composition but were produced from different melts. The ODS-3 and ODS-4 alloys contain more magnesium than the two previous alloys. but the OOS-3 alloy uses $2 \mathrm{rO}$, as the oxide dispersion instead of the Al.0, used in the other three a) loys.

Both transmission electron microscopy (TEM) disks and miniature tensile specimens [15, 16] were punched from sheet stock of the various materials; only TEM disks were punched from the 00S-2 stock. Tensile specimens of CUAI25 and ODS-1 were also fabricated from strips of $0.25 \mathrm{~mm}$ thick sheet that had been cut and then joined together by laser welding. The tensile specimens were punched from the welded sheet so that the weld was centered in the gage length. TEM disks were also punched from the weld regions.

Density measurements were obtained at room temperature from TEM disks, using an immersion density technique accurate to $\pm 0.16 \%$ density change. Electrical conductivity measurements were made at room temperature on both miniature tensile specimens and TEM disks using a four-point probe. DC potential drop method described by Anderson and coworkers [9]. The dimensions of the miniature tensile specimens art given in Fig. 2. Conductivity measurements on both types of specimens were in good agreement with eacn other. Tensile tests were performed after the conductivity measurements were completed, using a miniature tensile testing apparatus developed specifically for this specimen geometry $[15,16]$. Tensile tests were performed at room temperature with a free-running crosshead speed of 0.0025 $\pi m s^{*}$, which yields an initial strain rate of $4.8 \times 10^{-4}$ $s^{*}$

Fracture surfaces were examined in both a JEOL 840 scanning electron microscope and a JEOL JSM $35 C$. oxidation of the surfaces can occur quickly and obscure details at magnifications higher than $1000 x$, so specimens were loaded into one of the microscopes immediately after being tested.

Results

\section{Castable ODS Alloys}

Swelling data for the castable ODS alloys are presented in Fig. 3 along with data on pure copper for comparison. As a group, all four alloys exhibit poor swelling resistance, roughly paralleling the swelling behavior of pure copper, although significant differences are apparent for the various ODS alloys. The ODS-4 alloy exhibits considerably less swelling than pure copper and the other three alloys, however. The swelling resistance of the ZrO,-strengthened OOS-3 alloy is the lowest.

Laser welding obviously has an additional detrimental

effect on the swelling of the ODS-1 alloy because the welded 0OS-1 material disolars the nost swelling, areater than that of pure copper.

Figure 4 shows that the electrical conductivity of the castable ODS alloys lies within a common band that steadily decreases with increasing irradiation. Notice that the conductivity for the oos-3 alloy lies near the bottom of the band, which is not unexpected since it exhibits the greatest swelling of the four alloys.

Conductivity for the laser welded ODS-1 alloy was not otcained because of surface irregularities caused by the weld zone develoning considerably more swelling than that of the surrounding unwelded material. As a result. the probes could not make proper contact with the surface of the specimen, and no reliable reading could be obtained.

The ultimate tensile and yield strengths of the castable ODS alloys are presented in Fig. 5 , and show that both measures of strength decrease dramatically after exposure to $50 \mathrm{dpa}$. The yield strengths of the ODS-1 and $005-4$ alloys decrease $50 \%$ or more after irradiation to $50 \mathrm{dpa}$, and then appear to level out. The data for the DOS-3 alloy, which are avallable only at " and 150 dpa. show that the strength of the ODS-3 alloy matches closely the strength of the ODS-1 and Ci, A alloys. The welded ODS-1 sDecimens irradiated to 104 
dpa and to $150 \mathrm{dpa}$ both failed before reaching $0.2 \%$ strain. The specimen irradiated to 104 dpa failed in two different locations within the gage length, while the specimen irradiated to $150 \mathrm{dpa}$ failed in the welded region of the gage length.

\section{Mechanically Alloyed $\mathrm{Cu}-\mathrm{Cr}_{2} \underline{0}_{3}$ and $\mathrm{Cu}-\mathrm{HFO}_{2}$}

The two mechanically alloyed copper alloys exhibited different behavior, demonstrating the importance of the stability of the oxide used for the dispersion strengthening. Fig. 6 shows the swelling behavior of the $\mathrm{Cu}-\mathrm{Cr}_{2} \mathrm{O}_{3}$ and the $\mathrm{Cu}-\mathrm{HfO}_{2}$ alloys, and clearly shows that a large difference exists. The $\mathrm{Cu}-\mathrm{HfO}_{2}$ alloy appears to swell slightly, although no voids were found in the specimens irradiated to $50 \mathrm{dpa}$.

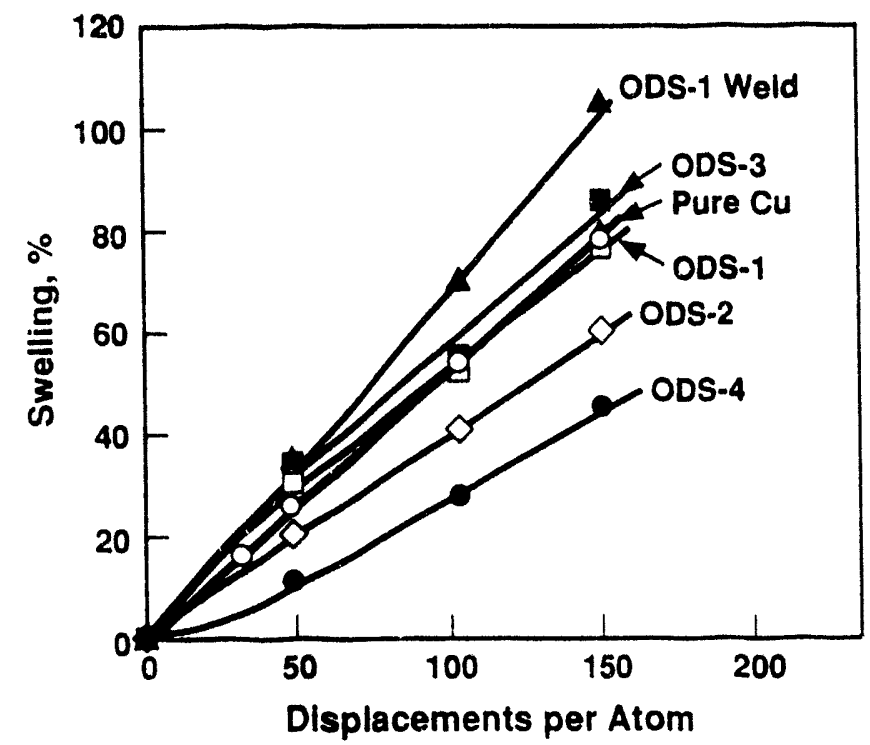

Fig. 3. Swelling of the castable OOS alloys irradiated to 150 dpa in FFTF at $415 \mathrm{C}$. Swelling data for pure copper are also presented for comparison.

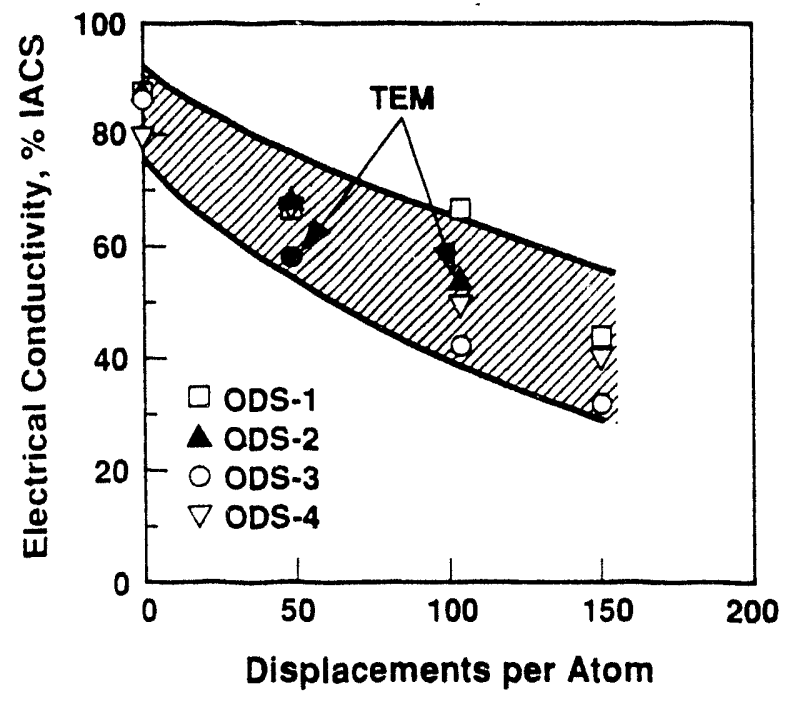

ing. 4 . Electrical conductivity behavior of the castable ODS alloys after irradiation to 150 dpa at $415^{\circ} \mathrm{C}$ 


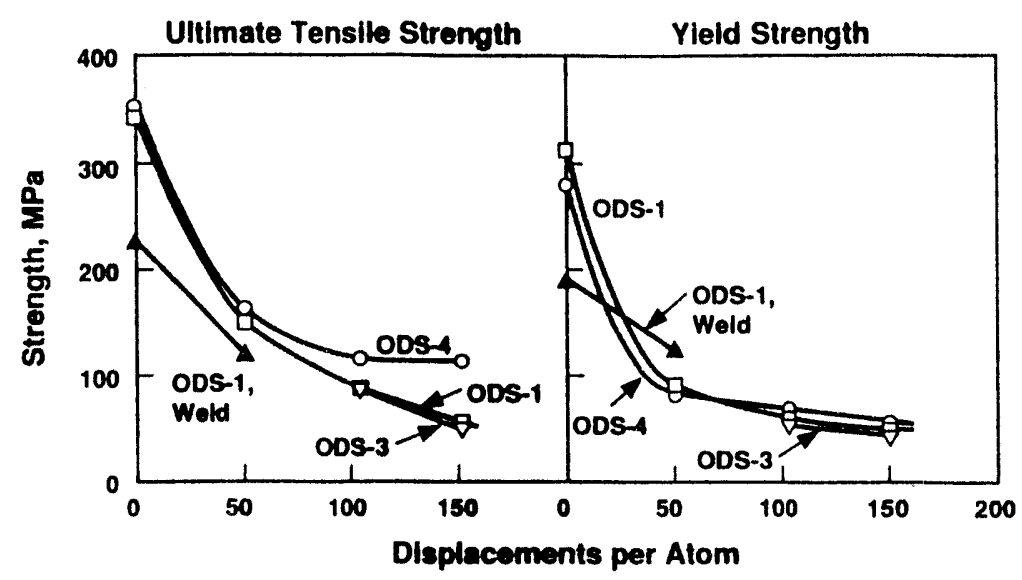

Fig. 5. Ultimate tensile and yield strength of the castable ODS alloys irradiated to 150 dpa in FFTF at $415^{\circ} \mathrm{C}$.

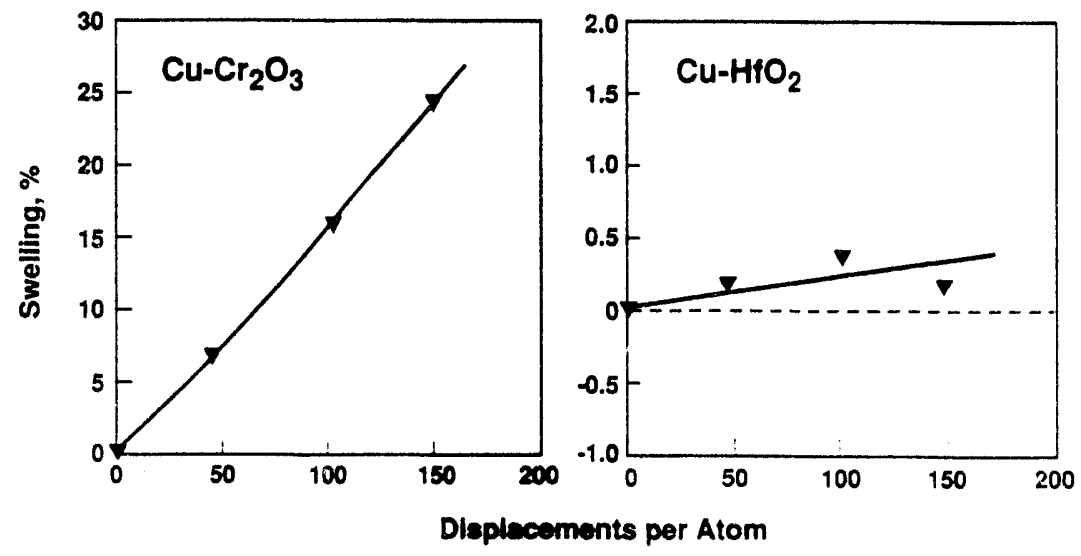

Fig. 6. Swelling behavior of the mechanically alloyed $\mathrm{Cu}-\mathrm{Cr}, \mathrm{O}$, and $\mathrm{Cu}-\mathrm{HfO}$, alloys irradiated to $150 \mathrm{dpa}$ in FFTF at $415^{\circ} \mathrm{C}$.

The electrical conductivity of the two alloys, shown in Fig. 7 , further demonstrates the difference between the two alloys. The conductivity of the Cu-HfO, alloy shows an unusual plateau behavior not seen in any of the other alloys. As expected, the conductivity of the Cu-Cr,0. alloy continuousiy decreases as expected in response to swelling and transmutation.

The strength behavior of the two alloys is shown in Fig. 8 . The strength of the Cu-bifo, alloy initially jecreases but then reaches a minimum value and maintains that level throughout the rest of the irradiation. in comparison. the strength of the $\mathrm{Cu}-\mathrm{Cr}_{2} \mathrm{O}_{2}$ alloy is lower in the unirradiated condition, and decreases steadily throughout the irradiation. Tensile curves are presented later in the report (Fig. 14) comparing the behavior of the $\mathrm{Cu}-\mathrm{Cr}_{2} \mathrm{O}_{3}$ alloy with that of the CuAl25 alloy. Fracture surfaces for the $\mathrm{Cu}-\mathrm{Cr}_{2} \mathrm{O}_{3}$ alloy are shown in Fig. 9, and reveal that the failure mode involved microvoid coalescence.

GlidCop" Alloys

The GlidCOp" alloys showed the best overall swelling resistance of any of the three classes of oxide. dispersion-strengthened alloys investigated in this study. As shown in Fig. 10. the CuAl20 and CuAl25 alloys actually densify at the higher dpa levels, in contrast to the CuAl15 which swells throughout the irradiation. Swelling data for the laser-welded CuAl25 are quite variable, ranging from $19 \%$ to $43 \%$ at $104 \mathrm{apa}$, and $8 \%$ to $20 \%$ at $150 \mathrm{dpa}$. This variability probably reflects a considerable heterogeneity in the welded zone and surrounding region. 


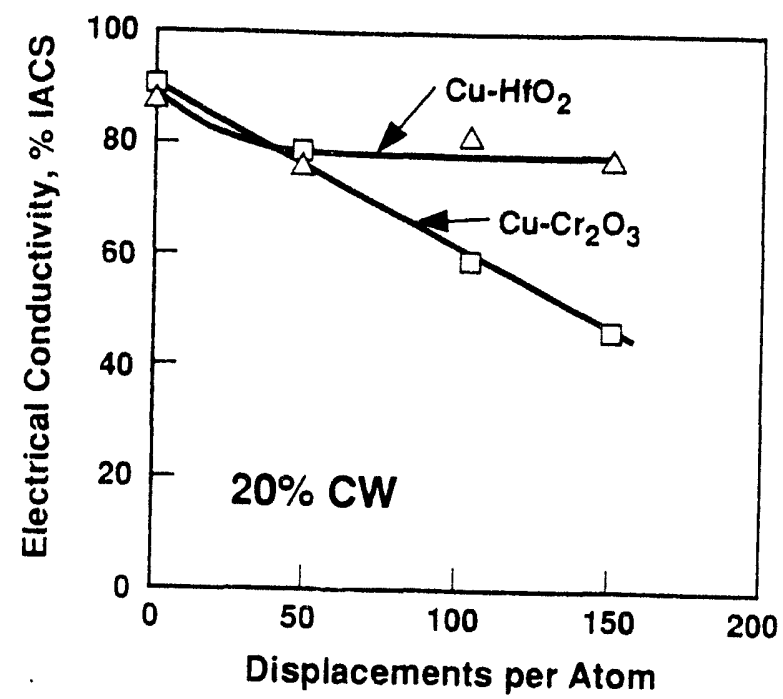

Fig. 7. Electrical conductivity of the mechanically alloyed $\mathrm{Cu}-\mathrm{Cr}, \mathrm{O}$, and $\mathrm{Cu}-\mathrm{HfO}$. alinys irradiated to 150 ipa in FFTF at $415: \mathrm{C}$.

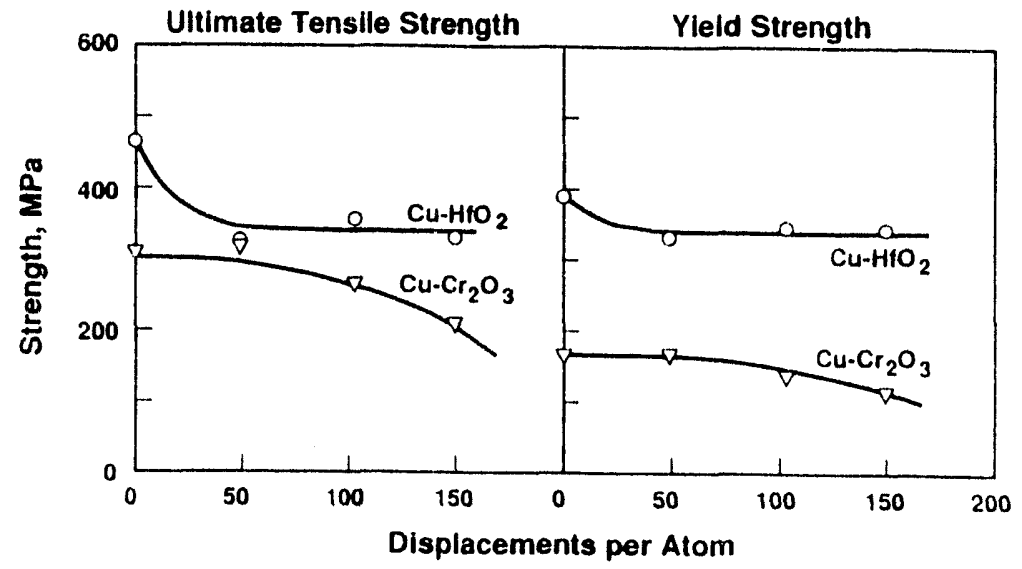

Fig. 8. Ultimate tensile and yield strength of the mechanically a:loved :u-r.o ano caito alloys irradiated to 150 dpa in FFTF at $415^{\circ} \mathrm{C}$.

Fig. 1! demonstrates that the electrical conductivity of the varicus biarop " as axniblts essentially the same behavior despite the differing levels of cold work and $\$ 1.0$ content. is a ing with increasing iradiation exposure. lote that laser welding lowers the conductivity coth before arjafter irradiation.

The ultimate tensile and yieid strength of the $\mathrm{alidCop}$ "4 alloys are shown in fig. $\vdots 2$. As observed in CuifO. the CuAl20 and CuAl25 snow the same behavior. i.e. their strength decreases so-ownat and then levels out: The strength of the GlidCop alloys, however, is higher than that of the Ca-Hfo. alloy both before and after irradiation, demonstrating that the only advantage to using the Cu-HfO instead of the GlidCop alloys is its surprising electrical conductivity behavior. The effect of laser welding on the strength of the CuAl25 is more dramatic compared to the castable ODS-1 alloy, primarily because of the higher initial trength of the GlidCop alloys. The fracture surfaces for the CuAl25 alloy are shown in Fig. 13, -evealing the failure mode as transgranular failure by microvoid coalescence. i comparison of the tensile urves for the CuAl25 alloy and the Cu-C.r.O. ailoy is fresented in Fig. 14. demonstrating the dramatic fifferences in tensile tehavior both before and after irradiation. most notably :n the degree of strain iardening. total elongation. arid reduction in area. 

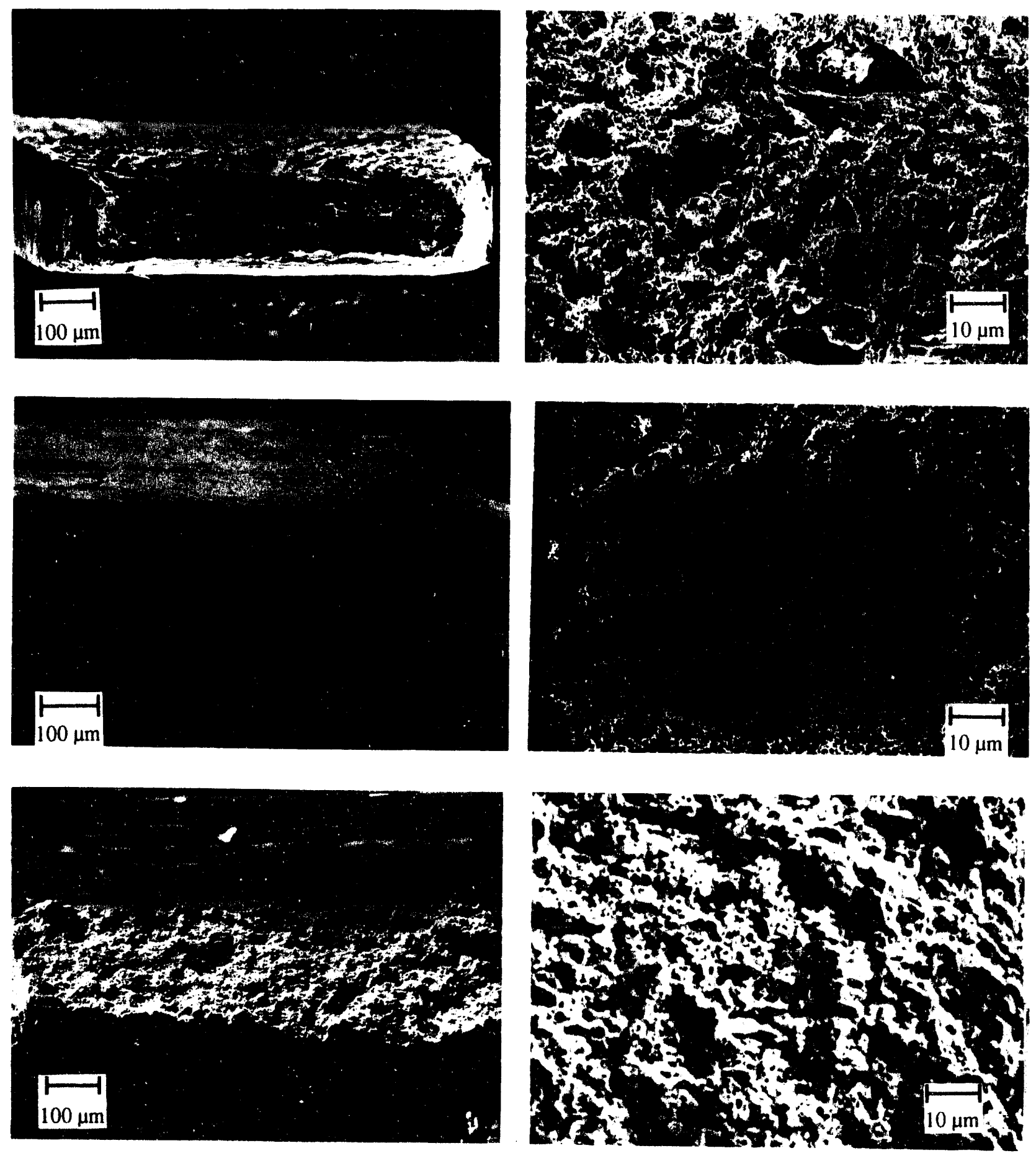

Fig. 9. Fracture surfaces of the $\mathrm{Cu}-\mathrm{C}, \mathrm{O}$, alloy in the unirradiated condition (top), after irradiation to $50 \mathrm{dpa}$ (middle) and after $150 \mathrm{dpa}$ (bottom). The entire fracture surface is shown on the left, and a higher magnification is shown on the right. 


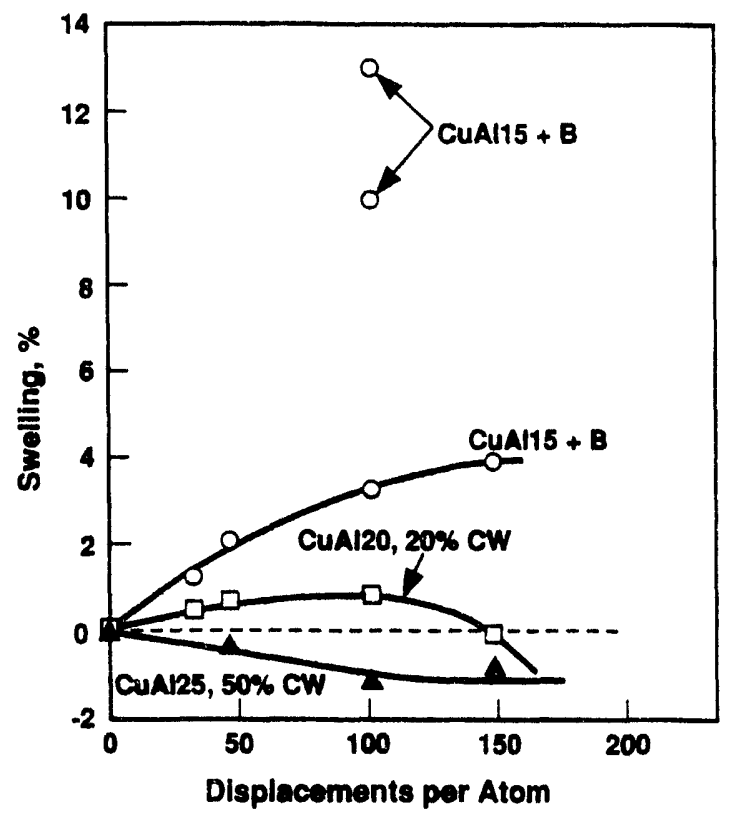

Fig. 10. Swelling behavior of the GlidCop ${ }^{T H}$ alloys irradiated to 150 dpa in FFTF at $415^{\circ} \mathrm{C}$.

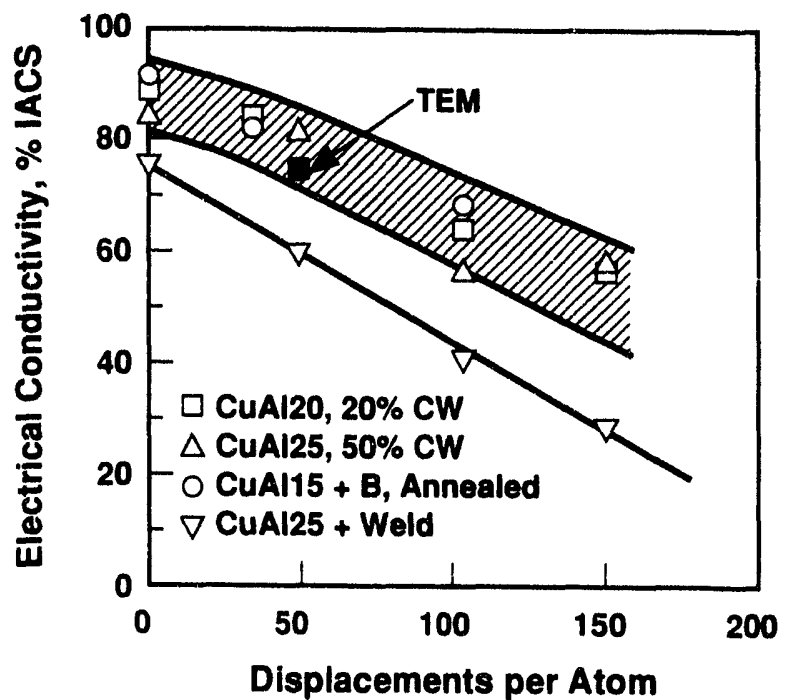

Fig. 11. Electrical conductivity of the GlidCop ${ }^{4}$ alloys irradiated to 150 dpa in FFTF at $415^{\circ} \mathrm{C}$.

\section{DISCUSSION}

The results of this study showed that the GlidCop ${ }^{-M}$ alloys exhibit the best overall retention of strength, electrical conductivity, and swelling resistance, followed closely by the $\mathrm{Cu}-\mathrm{HfO}$ alloy which actually demoristrates the best electrical conductivity behavior for very high fluence applications. The castable ODS alloys as a group have proven undesirable due to lack of swelling resistance, a problem also encountered with the $\mathrm{Cu}-\mathrm{Cr}_{2} \mathrm{O}_{3}$ alloy. The overall retention of electrical conductivity and strength relates directly to the resistance of the alloy to swelling, allowing the alloys studied to be divided into two groups based solely on swelling resistance. The castable ODS alloys, the laser-welded specimens, and the $\mathrm{Cu}-\mathrm{Cr}_{2} \mathrm{O}$ alloy form one group, whose lack of swelling resistance is comparable to that of pure copper, whereas the GlidCop alloys and the $\mathrm{Cu}-\mathrm{HfO}_{2}$ alloy demonstrate excellent swelling resistance. 


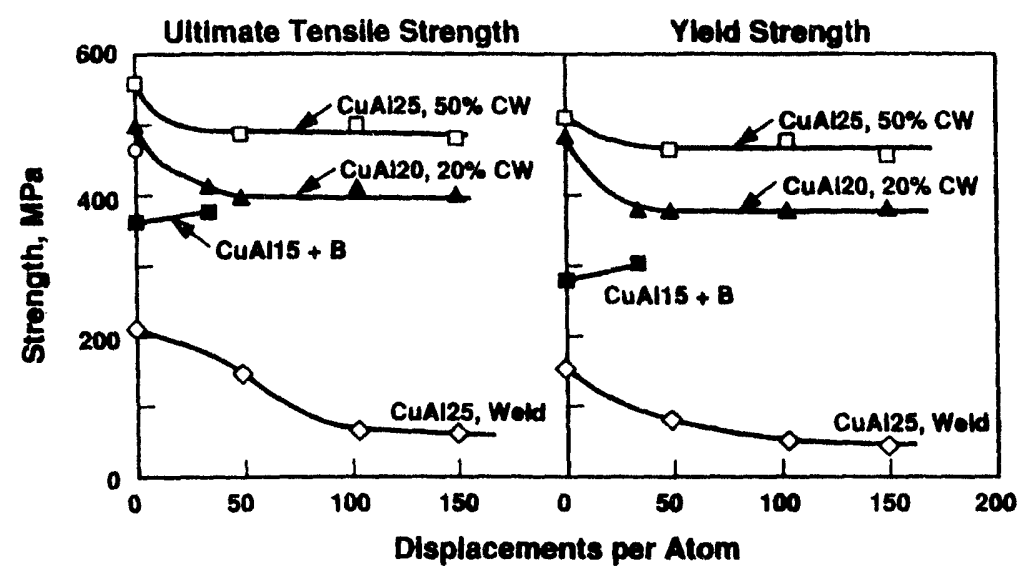

Fig. 12. Uitimate tensile and yield strength of the GlidCop ${ }^{T M}$ alloys irradiated to 150 dpa in FFTF at $415^{\circ} \mathrm{C}$.

In this study swelling was found to occur whenever the oxide djspersion was altered by either irradiation In this study swelling was found to occur whenever the oxide dispersion and castable ODS) laser welding has been or laser welding. In two separate classes of alloys (GlidCops and castable obs) shown to lead to a significant oxyen into Al $\mathrm{O}_{3}$ dispersion in the weld zone is thought to have occurred and ol colling of copper in two separate studies. Garner solution. Both elements have been found to enhance the swe pure copper, presumably due to the aluminum in et al. $[6,7]$ showed that a Cu-5Al alloy swelled more than pure copper, presumably due to the aluminum in solution. Zinkle and Lee [17] have shown significant enhancement of swelling under ion bombardment due to solution. small concentrations of oxygen in solution. The voids, making them more stable than dislocation loops and formation by reducing the surface tension of the voids, making them more stable than dion of electrolytic tough pitch copper $[18-20]$ demonstrated a swelling rate of $-2.5 \%$ per dpa.

Laser welding of the CuAl25 provides a measure of just how detrimental the dissolution of the oxide can be to the electrical conductivity. Butterworth [21] reports that aluminum in solution increases the to the electrical conductivity

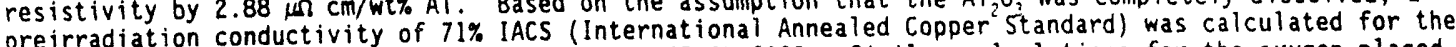
preirradiation conductivity of $71 \%$ IACS (International Annealed Copper standard) was cal cions for the oxygen placed in CuA125 alloy compared to the measured value of $75.8 \%$ IACS. Similar calculations for the oxygen placed in solution lowers the preirradiation conductivity by an additional $3 \%$ IACS for a total reduction to $68 \%$ IACS. The fact that the measured conductivity is somewhat higher than the calculated value suggests that most but not all of the oxide was dissolved by the laser welding process.

The poor performance of the castable OOS alloys in almost every respect provides additional information on The poor performance of dissolved oxygen. The alloys apparently picked up considerable oxygen during the

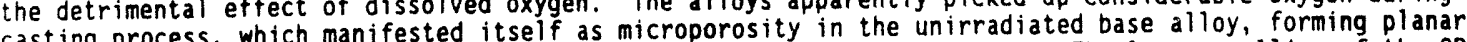
casting process, which manifested itself as microporosity in the un 22,23$]$. The lower swelling of the ODS-4 arrays of bubbles along the rolling direction of the rolled sheet $[22,23]$. The lower swelling of the oDs-4 al loy may be due to the higher amount of magnesium added to promote the distribution of the oxide during alloy may be due to the higher amount of magnesium added to promote the disto casting. The ODS-3 alloy contains the same amount of magnesim as the ODS-4 allo irradiation as the Al, $0_{3}$. The swelling of the OOS-3 alloy suggests that the $\mathrm{ZrO}_{2}$ may not be as stable under irradiation as the Al ${ }_{3}{ }^{\circ}$ The poor strength of the castable ODS alloys is due in part to poor thermal stability, as demonstrated by these
alloys in ageing studies [23]. This instability in conjunction with the large swelling results in very poor tensile properties.

Another mechanism whereby oxygen and aluminum may be introduced into solution is recoil resolution of the oxide particles. Spitznagel and coworkers suggested this mechanism as a possible explanation for the dissolution and amorphization of the AI, 0 , particles observed in an ion-irradiated CuAl60 GlidCop ${ }^{M}$ alloy [24]. Anderson and coworkers suggested that recoil resolution accounted for the apparent decrease in [24]. Anderson and Coworkers suggested that recoll alloys irradiated to 50 dpa [23]. The intensity of the particle number density in the CuAl oxide diffraction rings in electron diffraction patterns decreased with increasing irradiat to the conclusion that the number density of the particles was smaller, and that radiation damage in the particles perhaps altered the oxide dispersion. The densification of the CuAl25 after irradiation in this study supports the supposition that the oxide is being dissolved, and its constituents placed in solutid The relatively low swelling of the CuAl25 and the CuAl20 indicates that if the Al ${ }_{3}$ ofispersion indeed

undergoes recoil resolution, then the oxygen and aluminum must be recombining on a smalte
effect on swelling is being counteracted somehow by the operation of another mechanism. 

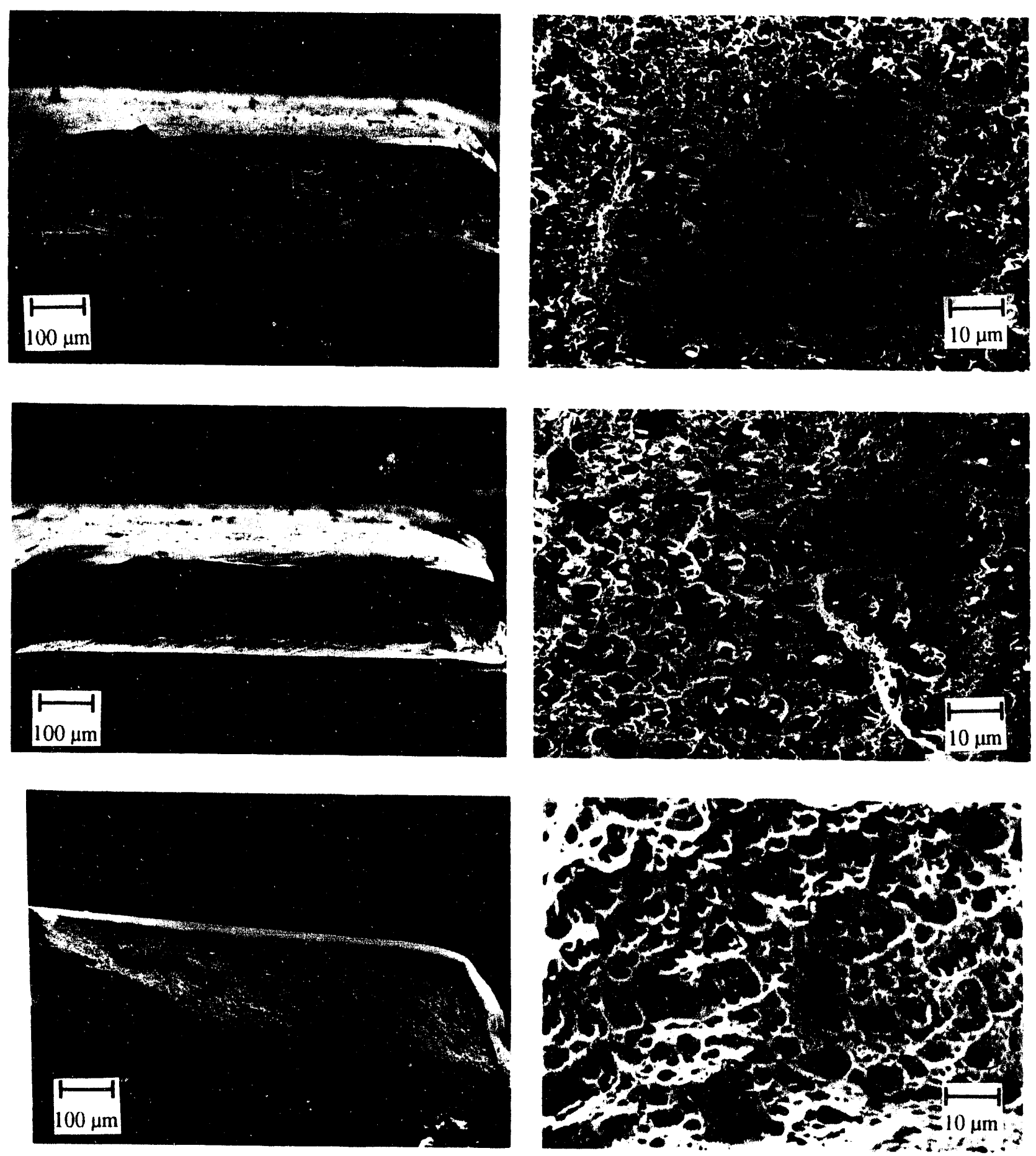

Fig. 13. Fracture surfaces of the CuAl25 alloy in the unirradiated condition (a), fracture surfaces of the CuAl25 alloy (b) after irradiation to $50 \mathrm{dpa}$, and (c) after irradiation to $150 \mathrm{dpa}$. 


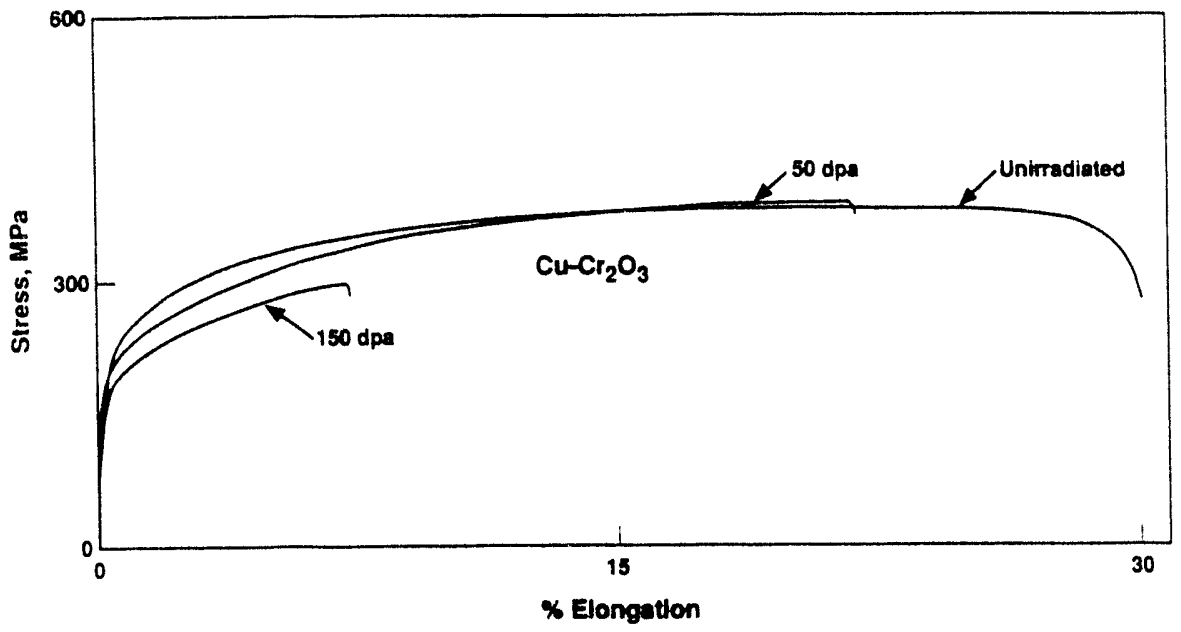

Fig. 14. Tensile curves of the CuAl25 alloy and the $\mathrm{Cu}-\mathrm{Cr}_{2} \mathrm{O} 3$ alloy, showing the effect of neutron irradiation and the importance of the type of dispersion.

It may well be that the aluminum and oxygen are being reprecipitated to form smaller oxide particles. Wanderka et al. [25] presented strong evidence that in CuAl25 irradiated to $30 \mathrm{dpa}$ at $293 \mathrm{~K}$ by $300 \mathrm{keV}$ copper ions, Al, 0 , particles smaller than $10 \mathrm{~nm}$ were not stable under irradiation, and that larger particles fragmented to form smaller particles. The results of their work may not be directly comparable to the present work because their study was conducted at room temperature, whereas the specimens in FFTF were irradiated to much larger fluences and at -0.5 of the melting temperature allowing for a stronger role of diffusion in reforming the particles.

The results of the ion irradiation study lend some credibility to the idea of recoil resolution and reprecipitation of precipitates, particularly when the irradiation temperature is fairly high and takes place over a period of several years. A recent study by Zinkle and coworkers [26] showed a $20 \%$ decrease in average particle size $(10 \mathrm{~nm}$ to $8 \mathrm{~nm})$ for the same CuAl25 alloy examined in this study after irradiation by $750 \mathrm{MeV}$ protons at $470 \mathrm{~K}$ to $2 \mathrm{dpa}$. It is unclear whether a steady-state particle distribution had been obtained at this low dpa level [26]. Thus it is possible that irradiation to higher displacement levels may result in a greater change in particle-size distribution.

Although no microscopy results are yet available in this study to directly answer the question of recoil resolution. the tensile test results of the CuAl25 and $\mathrm{Cu}-\mathrm{Cr}_{2} \mathrm{O}_{3}$ provide additional evidence that the oxide dispersion was altered by the neutron irradiation. Fig. 13 shows the fracture surfaces from the CuAl25 miniature tensile specimens in the unirradiated condition, and irradiated to 50 and $150 \mathrm{dpa}$. The mode of failure throughout the entire series was microvoid coalescence, accompanied by a small amount of reduction in area in the irradiated specimens. Note that oxide particles are easily visible in the dimples of the unirradiated specimen's fracture surface. They are fewer in number in the specimen irradiated to 50 dpa, however, and completely absent in the $150 \mathrm{dpa}$ specimen. Whether the oxide particles have been completely dissolved or simply redistributed into very small particles that cannot be easily imaged is not apparent from the SEM micrographs. Transmission electron microscopy is in progress to answer this question.

The tensile behavior of the CUA125, CuAl20, and CU-HfO suggests that some form of dispersoid still exists at $104-150$ dpa because their high strength is maintained. The decrease in the ultinate tensile strength (UTS) and yield strength of all three alloys is attributed to recovery and recrystallization, which reduces the initial dislocation density resulting from the pre-irradiation cold work. The apparent increase in strength of the CuAlls alloy might be a result of void strengthening, but at this point this suggestion is just speculative. The tensile curve for the CuAi25 alloy is shown in fig. 14. and demonstrates the behavior that is representative of the CUAl20 and $\mathrm{CU}-\mathrm{HfO}$ alloys as well. Of great interest is the fact that after irradiation the amount of strain hardening falls essentially to zero. with a slight drop in strength after yielding, reminiscent of a yield drop phenomenon. The tensile curve for the unirradiated CuAi 25 alloy is characteristic of a material in the $50 \%$ cold-worked state, displaying only a 1 imited ability to strain harden due to the high dislocation density already present from the $50 \%$ cold work. The lack of any significant strain hardening in the irradiated specimens suggests that the dislocations are shearing through the particles, not bypassing them through the Orowan mechanism. Such behavior has been observed before in precipitation strengthened Al-Cu alloys [27] aged to form coherent Guiner-Preston (GP) zones. In this case the dislocations were able to cut through the GP zones, but only at a significantly higher stress than required for easy glide in either pure aluminum or solution strengthened aluminum. After irradiation, the decreasing intensity of the oxide diffraction ring, the prominent lack of particles 
on the $150 \mathrm{dpa}$ specimen's fracture surface, and the tensile behavior of the CuAl25 all point to redistribution of the oxide to smaller particle sizes. Microscopy is in process to determine if this is actually the case, however.

The decrease in strength of the CuAl20 alloy is due to complete recrystallization after 50 dpa [23]. Anderson et al. reported that the CuAl25 alloy still retained some of its prior cold worked structure even after irradiation to $50 \mathrm{dpa}$, most likely due to the higher Al.0, content. The unexpected high swelling values noted for the CuAl15 at 104 dpa represent an unexplained breakdown in the swelling resistance. perhaps due to inhomogeneous distribution of the boron and/or the Al.0. The CuAl25 and CuAl20 both exhibited a reasonable amount of reduction of area even after irradiation to 150 dpa. The total elongation increased significantly after irradiation to 50 dpa, most likely due to recovery and recrystallization of the cold work induced dislocation structure. Following further irradiation to 150 dpa, however, the total elongation decreased from $-12 \%$ to $-5 \%$. The reason for this decrease in total elongation without swelling remains to be determined. The steady decrease in conductivity is easier to explain and is attributed to the formation of transmutation products, mainly nickel and $z$ inc $[12,13]$.

The strength behavior of the $\mathrm{Cu}-\mathrm{HfO}_{2}$ alloy following irradiation parallels that of the GlidCops ${ }^{\circ}$, presumably for the same reasons. The alloy was reported to be completely recovered and recrystailized after irradiation to $50 \mathrm{dpa}$ [23], with the hafnia being redistributed to form smaller polygonal particles. The retention of room-temperature strength after irradiation suggests that the oxide dispersion still exists in some form to strengthen the alloy, just as in the GlidCops ${ }^{4}$. Also, the total elongation increased from $8.7 \%$ to $20.5 \%$ after irradiation to $50 \mathrm{dpa}$, and then remained constant through irradiation to $150 \mathrm{dpa}$. The reason for this behavior is not immediately obvious. The surprising electrical conductivity behavior of the $\mathrm{Cu}-\mathrm{HFO}_{2}$ alloy is probably caused by the transmutants and hafnia being redistributed or interacting in some manner that keeps the individual elements out of solution. One unfortunate drawback to using the Cu-HiO, alloy is the longer-lived radioactivity from "Hf, making it somewhat less desirable for use as a structural material.

The strength of the $\mathrm{Cu}-\mathrm{Cr}, \mathrm{O}$, alloy, shown in $\mathrm{Fig}$. 8, remains roughly the same after irradiation to 50 dpa, then decreases with further irradiation. One possible explanation for the strength retention lies in the redistribution of the $\mathrm{Cr}_{2} \mathrm{O}_{3}$ particles into smaller particles. The increased degree of orowan strengthening possibly compensates for the expected strength decrease due to complete recrystallization. The tensile curves shown in $\mathrm{Fig}$. 14 for the $\mathrm{Cr}, 0$, alloy differ drastically from the curves of the CuAl25 alloy, showing a steady decrease in total elongation and a considerable decrease in the reduction of area.

The fracture surface of the unirradiated specimen shown in fig. 9 contains large inclusions embedded in the surface, apparently introduced at some stage in the production of the powders. These large inclusions are no longer present at 150 dpa, presumably because they were dissolved durinti the iradiation. The fracture surface at 150 dpa clearly demonstrates the effect of the loss of the recuction in area, and the resultant inability to sustain even a small amount of localized deformation. The subseguent droo in strength after irradiation to 104 and 150 dpa suggests that the oxide dispersion mav nave coarsened curing irradiation. but microscopy is needed to check this possibility. Though a gradual decrease in strength occurs, there remains a moderate amount of strain hardening. suggesting that there is still a small degree of Orowan strengthening occurring from the redistributed oxide. The higher swelling of this alioy compared to the C.U-HFO. and the GlidCops could be the result of oxygen being placed into solution by irradiation.

\footnotetext{
ONCLUSIONS

Fradiation of the several different oxide-dispersion-strengthener a iloys at $415 \mathrm{C}$ to 104 and 150 dpa rovealed that the Al.O.-strengthened GiddCop alloys offered the best overall resistance to irradiation. $A$ cu-Hfo. alloy also stowed some potential despite having a higher level of longer-lived radioactivity. 1? though pure copper becomes nighly radioactive due to the formation of ico. Goth the Glidcops and the "u-Hfo. alloy exhibit similar tensile behavior, particularly with respect to the iack of strain hardening iter irradiation. Despite the apparent alteration of the oxide disoersion. the inree alloys still

antain a large fraction of their strength after exposure to hign fluences. ihe retention of electrical conduct vity after irradiation of the Gi idcop alioys and the Cu-HfO alloy was cery good. particularly in moarison to the other alloys studied. The formation of transmutation froducts $(1 / 1$ ind $2 n$ ) is believed to e primarlly responsible for the observed decrease in conductivity in the two GlidCop alioys. An ineraction between the hafnium and the transmutation products may have removed scme of the transmutation roducts from solution. thus leading to the unusual conductivity behavior of the cu-tfo. alloy. This aroposal has not yet been confirmed experimentally.

The castable ODS alloys exhibited poor swelling resistance, which had a very adverse effect on their isctrical conductivity and mechanical properties. The high swelling that developed in the irradiated oos a loys appears to be the result of oxygen contamination introduced during the casting process. The welling appeared to dominate the mechanical property behavior of the castable oDs alloys. overshadowing " ossible effect that the iarious compositional variations of the alloys mignt have nad in determining - ina strength behavior.
} 
The Cu-Cr.0, alloy exhibited relatively poor swelling resistance compared to that of the GildCops and the Cu-HFO, alloy, possibly due to the dissolution of the $\mathrm{Cr} . \mathrm{O}$. which may have placed oxygen into solution. As observed in the castable ODS alloys, void swelling was primarily responsible for the coor alectrical conductivity and strength of the Cu-Cr, 0 , alloy.

FUTURE WORK

Microscopy will be completed on the CuH.O and GlidCop alloys.

\section{REFERENCES}

1. Conn, R.W., Chuyanov, V.A., Inoue, N., and Sweetman. D.R., Scientific American, April 1992, p. 103.

2. Vieider, G., Cardella, A., Akiba, M., Matera, R., and Watson, R., Fusion Engineering and Design, Vol. 16. 1991, pp. 23-34

3. Zolti, E., Fusion Engineering and Design, Vol, 16, 1991, pp. 163-17i.

4. Munz, D. and Diegele, E., Fusion Engineering and Design, Vol. 16, 1991, pp. 45-57.

5. Akiba, M., Bolt, H., Watson, R., and Kneringer, G., and Linke, J., Fusion Engineering and Design, Vol. 10,1991 , pp. 111-125.

5. Garner. F. A., Brager, H. R.. and Anderson. K. R., Journal of Nuclear Materials, Vol. 179-181, 1991, p. 250 .

7. Garner, F. A. and Anderson, K. R., Fusion Reactor Materials Semiannual Progress Peport DOE/ER-0313/7, 1989 , p. 220.

8. Brager, H. R., Journal Nuclear Materials 141-143, 1986, p. 79, 163.

9. Anderson, K. R., Garner, F. A., Hamilton, M. L.. and Stubbins, J. F. Fusion Reactor Materials Semiannual Progress Report DOE/ER 0313/6, 1989, p. 357

10. Garner, F. A., Anderson, K. R., and Shikama. T., Fusion Reactor Materials Semiannual Progress Report. DOE/ER-0313/9, 1990, p. 199.

11. Shikama, T., Garner, F. A., Hamilton, M. L, and Anderson, R. R.. Proceedings of the i5th international Symposium on Effects of Radiation on Materials, ASTM STP $1125, R$. E. Stoller. A. S. Kumar and D. S. Gelles, Eds., American Society for Testing and Materials. Philadelphia, 1992. pp. 846-853.

12. Carner, F. A., Heinisch, H. L.. Simons, F. L., and Mann. F. M. . Radiation Effecte ard Defects in solids, 1990 , p. 229.

13. Garner, F. A., Hamilton, M. L., Edwards, D. J., Newkirk, J. W. Stubbins, J. F.. and Mitchell, M. A., this conference.

14. GlidCop, SCM Metal Products, Inc., 11000 Cedar Ave., Cleveland. Ohio, 44106, USA. 1988.

15. Panayotou, N. F., Atkin, S. D., Puigh, R. J., and Chin. B. A., ASTM STP 888, 1986. p. 201.

16. Garner, F. A., Hamilton. M. L.. Meinisch, H. L.. and Kumar, A. S.. Proceedings of ASTM International Symposium on Small Test Techniques and Their Applications to Pressure Vessel Annealing and Plant Life Extension, liew Orleans, Louisiana, January 29-30. 1992, (in press).

17. Zinkle, S. J., and Lee. E. H., Metallurgical Transactions, Vol. 21A, May 1990, p. 103?.

18. Ames, M., Kohse, G., Lee, T. S., Grant. N. J.. and Harling, O. K., Journal of Nuc iear Materials, Vol. $141 \cdot 143,1986, \mathrm{pp} .174-178$

19. Lee, T. S., Hobbs, L. W., Kohse, G.. Ames. H., Harling. O. K.. and Grant. II. U.. journal of Nuclear Materials, Vol. 141-143,1986, pp. 179-183.

20. Harling, O. K., Grant, N. J., Kohse, G., Ames, G., Lee, T. S., and Hobbs, L. W., Journal of Materials Research, Vol. 2, 1987, pp. 568-579.

21. Butterworth, G. J., Journal of Puclear Materials, Vo1. 135, 1985, p. 160.

22. Anderson, K. R. Doctoral Thes1s. University of Ill inois at Urbana-Champargn. 1990. 
23. Anderson, K. R., Garner, F. A.. Hamilton, M. L., and Stubbins, J. F., Proceedings of 15th

International Symposium of Effects of Radiation on Materials. ASTM STP 1125, R. E. Stoller. A. S. Kumar and 0. S. Gelles, Eds., American Society for Testing and Materials, Philadelphia, 1992. pp. 854-874.

24. Spitznage1, J. A., Doyle, N. J., Choyke, W. J., Greggi Jr., J. G., McGruer, J. H.. and Davis, J. W., Huclear Instruction and Methods in Physics Research, Vol. B16, 1986, p. 279.

25. Wanderka, N., Yuan, Y., Jiao, L., Wahi, R. P., and Wollenberger, H., Proceedings of the 5th International Conference of Fusion Reactor Materials, held in Florida. Hov. 1991, in press.

25. Zinkle, S. J., Horsewell, A., Singh, B. N.. and Sommer, W. F.. this conference.

27. Greetham, G., and Honeycomb, R. W. K., Institute of Metals Journal, Vol, 89. 1950-1961, p. 13. 
Neutron-Induced Swelling Observed in Copper Alloys Irradiated in MOTA's 2A and 2B. F. A. Garner (Pacific Northwest Laboratory) ${ }^{a}, 0$. J. Edwards (University of Missouri Rolla), 8. N. Singh, (Riso National

Laboratory) and $H$. Watanabe (Kyushu University)

\section{OBJECTIVE}

The objective of this effort is to provide data on the response of copper alloys being considered for application in fusion reactors.

SUMMARY

Density measurements have been completed on copper alloys irradiated in MOTA $2 \mathrm{~A}$ and MOTA $2 B$ at (375. $C$, $12.7 \mathrm{dpa}$ and $21.2 \mathrm{dpa})$ and $\left(423^{\circ} \mathrm{C}, 48.0\right.$ and $\left.95.4 \mathrm{dpa}\right)$. While most of the density changes observed are consistent with those of earlier studies, there were several surprises. Addition of $5 \% \mathrm{Ni}$ appears to accelerate the swelling rate initially at $423^{\circ} \mathrm{C}$, but depresses swelling at $375^{\circ} \mathrm{C}$. The suppressing action of cold work on swelling of Cu-5Ni is relatively small, and Cu-5Mn resists swelling very strongly in both the annealed and cold-worked conditions.

\section{PROGRESS AND STATUS}

\section{Introduction}

In an earlier report (1) the status of on-going copper irradiation experiments was reviewed. One of the experimerits discussed was a two-part FFTF irradiation sequence conducted in MOTA $2 A$ and MOTA $2 B$ at target temperatures of 373 and $418^{\circ} \mathrm{C}$. Gamma heating ratses the temperatures to 375 and $423^{\circ} \mathrm{C}$. Both segments of this irradiation sequence have now been completed and measurements were made of the densities of the various specimens.

\section{Results}

Each part of the irradiation sequence consisted of two TEM packets. The first MOTA 2A packet (OEO1) operated at $375 \pm 5^{\circ} \mathrm{C}$ and reached $2.61 \times 10^{22} \mathrm{n} \mathrm{cm}^{-2}$ (E>0.1MeV) which is $12.7 \mathrm{dpa}$ (1.333 $\times 9.5 \mathrm{dpa}$ for stainless steel) for copper. The second packet $(0 E 02)$ operated at $423 \pm 5^{\circ} \mathrm{C}, \mathrm{reaching} 8.53 \times 10^{22} \mathrm{n} / \mathrm{cm}^{2}$ (E>0.1MeV), which is 48.0 dpa for copper (36.0 for stainless steel). The comparable copper dpa values for the MOTA $2 B$ packets (OEO3 and OEO4) were 21.2 and $95.4 \mathrm{dpa}$, respectively.

The swelling values calculated from the density changes observed in both irradiation segments of this experiment are listed in Table 1.

Table 1. Swelling of Copper Alloys from MOTA $2 A$

\begin{tabular}{|c|c|c|c|c|c|c|}
\hline \multirow{3}{*}{ Alloy } & \multirow{3}{*}{ Condition } & \multirow{3}{*}{$\begin{array}{l}\text { Specimen } \\
\text { Engraving } \\
\text { Code }\end{array}$} & \multicolumn{4}{|c|}{ Swelling, \% } \\
\hline & & & \multicolumn{2}{|c|}{$375^{\circ} \mathrm{C}$} & \multicolumn{2}{|c|}{$423^{\circ} \mathrm{C}$} \\
\hline & & & $12.7 \mathrm{dpa}$ & $21.2 \mathrm{dpa}$ & $48.0 \mathrm{dpa}$ & $95.4 \mathrm{dpa}$ \\
\hline Marz Cu & Annealed & 1 & 4.7 & 7.0 & $\begin{array}{c}24.4 \\
(21.6) *\end{array}$ & $\begin{array}{c}45.4 \\
(43.5)\end{array}$ \\
\hline $\mathrm{Cu}-5 \mathrm{Ni}$ & Annealed & 2 & 0.91 & 1.63 & 30.1 & $\begin{array}{c}50.3 \\
(46.6)\end{array}$ \\
\hline $\mathrm{Cu}-5 \mathrm{Ni}$ & $40 \% \mathrm{CW}$ & 3 & 0.37 & 0.85 & 22.1 & $\begin{array}{c}35.9 \\
(38.8) \\
\end{array}$ \\
\hline $\mathrm{Cu}-5 \mathrm{Mn}$ & Annealed & 4 & 0.004 & 1.40 & -0.04 & 2.4 \\
\hline $\mathrm{Cu}-5 \mathrm{Mn}$ & $40 \% \mathrm{CW}$ & 5 & -0.03 & 0.72 & 0.13 & 2.0 \\
\hline
\end{tabular}

Three specimens were measured, one at $21.6 \%$ and two at $24.4 \%$. Any measurements without a separate value in parentheses represent the average of 3 identical specimens whose swelling values agreed within the convergence criterium used, i.e. $\pm 0.16 \%$.

${ }^{3}$ Pacific Northwest Laboratory is operated for the U.S. Department of Energy by Battelle Memorial Institute under Contract DE-ACO6-76RLO 1830. 


\section{Discussion}

If we assume that the 375 and $423^{\circ} \mathrm{C}$

swelling data for annealed pure copper are independent of temperature, as shown in Figure la, the swelling appears to be consistent with the $-0.5 \% / \mathrm{dpa}$

swelling rate usually observed for pure copper at $-400^{\circ} \mathrm{C}$ (2) An incubation period of $\leq 6$ dpa is

associated with this assumed behavior, however. Table $i$ and Figure 18 show that nickel's influence on swelling of copper is rather variable,

however, increasing swelling at $423^{\circ} \mathrm{C}$ and decreasing it at

$375^{\circ} \mathrm{C}$, al though the variability may reflect the impact of

the order of magnitude difference in displacement rate associated with these two irradiation temperatures. Cold work appears to suppress swelling temporarily in both Cu-5Ni and Cu-5Mn. The suppressant effect of manganese on swelling persists to very high fluence. Swelling of Cu-5Mn appears to begin sooner at $375^{\circ} \mathrm{C}$ than at $423^{\circ} \mathrm{C}$, however.

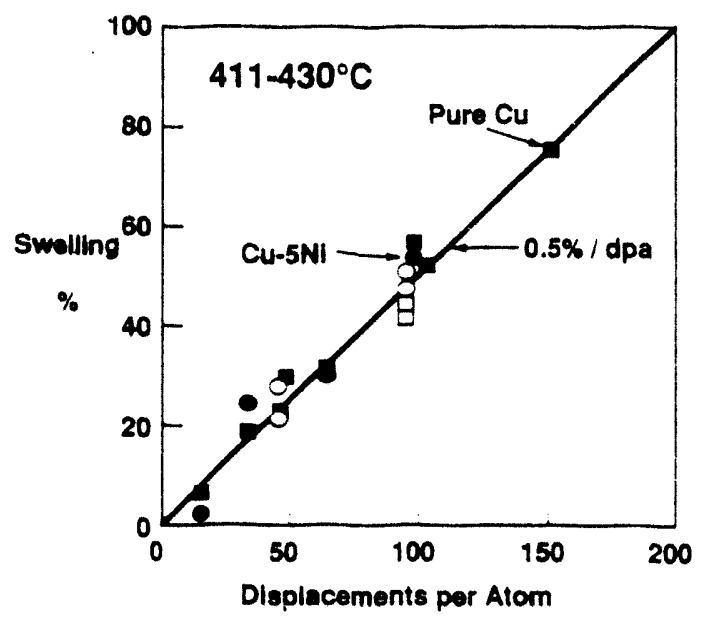

F:a. 2 Comparison of data from MOTA $2 A$ and $2 B$ with data from earlier experiments in FFTF

lesignated Ceneration 1 and Generation 2.
Since these comparisons are based on side-by-side irradiations, it is felt that the conclusions drawn in the preceding paragraph are relatively valid. It is expected, however, that the onset of swelling in simple copper alloys is somewhat sensitive to a variety of environmental history variables. The range of data scatter shown in Figure 2 tends to obscure somewhat the effects of second order variables such as solute composition, displacement rate ald temperature history.

FUTURE WORK

Microscopy on these alloys will proceed. The electrical conductivity of each alloy will also ve measured.

\section{REFERENCES}

1. F. A. Garner, M. L. Hamilton, D. J. Edwards, B. N. Singh, J. F. Stubbins, $T$. Shikama, S. J. Zinkle and $P$. Samal. Fusion Reactor Materials Semiannual Progress Report DOE/ER-0313:10 (1991) op. :86-191. 
IRRADIATION OF COPPER ALLOYS IN THE SM-3 REACTOR - - S.J. Zinkle (ORNL), F.A. Garner (PNL), V.R. Barabash (D.V. Efremov), S.A. Fabritsiev (D.V. Efremov) and A.S. Pokrovsky (SRIAR)

\section{OBJECTTVE}

This report summarizes the experimental matrix of copper specimens which have been prepared for irradiation in the SM-3 reactor.

\section{SUMMARY}

A total of 74 alloys of varying composition and thermomechanical condition have been prepared for a joint US-Russia irradiation experiment in the SM-3 reactor in Dimitrovgrad, Russia. The alloys will be irradiated in the form of TEM disks and sheet tensile specimens at temperatures of about 120,250, and $340^{\circ} \mathrm{C}$ for one 45 -day cycle in the core and Channel 2 irradiation positions. This will produce damage levels of about 7 and $1 \mathrm{dpa}$, respectively. Cadmium shielding will be used in the Channel 2 position to shield the thermal neutrons and thereby reduce the amount of solid transmutation products in copper.

\section{INTRODUCTION}

Accurate predictions of material lifetimes in a fusion reactor depend on irradiation data generated in fission reactors at fusion-relevant conditions. Although mixed spectrum fission reactors can achieve low irradiation temperatures that are of interest for near-term fusion reactors, the associated high thermal neutron fluxes induce large amounts of solid transmutation products in copper. These solid transmutation products cause a large decrease in the electrical and thermal conductivity of copper alloys. In addition, the amount of helium generated in a fission neutron spectrum is about an order of magnitude less than that produced in a fusion reactor. Helium production may have a strong influence on the resistance of copper alloys to swelling and high-temperature irradiation embrittlement.

In order to provide a closer simulation of the fusion neutron irradiation behavior of copper alloys, a spectrally tailored experiment has been designed for the SM-3 mixed spectrum reactor. A cadmium sheet of 2-mm thickness will be used in the Channel 2 irradiation position to screen out the thermal neutrons. Specimens will also be irradiated without $\mathrm{Cd}$ shielding in the reactor core. Specimens will be irradiated with and without boron doping in order to study the effects of helium generation.

\section{IRRADIATION CONDITIONS AND SPECIMEN MATRIX}

The SM-3 reactor has recently been restarted after being shut down for about 2 years in order to replace the reactor core. The water-cooled SM-3 reactor operates at a power level of $100 \mathrm{MW}_{\text {th }}$ and has a core height of about $40 \mathrm{~cm}$. The present irradiation experiment will utilize space in the core and Channel 2 irradiation positions. Detailed characterization of the neutron spectrum for the new reactor core is still in progress. 
Preliminary calculations of the neutron spectrum are summarized in Table 1 along with a general description of the core and Channel 2 irradiation positions. Irradiation for one 45-day cycle in the core and Channel 2 positions will produce approximately $7 \mathrm{dpa}$ and $1 \mathrm{dpa}$, respectively in copper.

Table 1. Characteristics of Irradiation Positions in the SM-3 reactor.

\begin{tabular}{|c|c|c|}
\hline & Core & Channel 2 \\
\hline $\begin{array}{l}\text { Neutron Flux }\left(\mathrm{n} / \mathrm{cm}^{2}-\mathrm{s}\right) \\
\qquad \begin{aligned} \mathrm{E} & >1 \mathrm{MeV} \\
\mathrm{E} & >0.1 \mathrm{MeV} \\
\mathrm{E} & <0.68 \mathrm{eV}\end{aligned}\end{array}$ & $\begin{array}{l}\sim 1 \times 10^{15} \\
\sim 2 \times 10^{15} \\
\sim 2 \times 10^{14}\end{array}$ & $\begin{array}{l}\sim 2 \times 10^{14} \\
-3 \times 10^{14} \\
\sim 1 \times 10^{15}\end{array}$ \\
\hline Irradiation Cycle (days) & 45 & 45 \\
\hline Fluence $\left(\mathrm{n} / \mathrm{cm}^{2}, \mathrm{E}>0.1 \mathrm{MeV}\right)$ & $\sim 8 \times 10^{21}$ & $-1 \times 10^{21}$ \\
\hline Channel Diameter $(\mathrm{cm})$ & 1.0 & 6.0 \\
\hline Capsule Length $(\mathrm{cm})$ & 35 & 35 \\
\hline Coolant temperature $\left({ }^{\circ} \mathrm{C}\right)$ & 70 & 70 \\
\hline
\end{tabular}

Three types of specimen geometries will be irradiated: Transmission electron microscopy (TEM) disks ( $3 \mathrm{~mm}$ dia $x \sim 0.25 \mathrm{~mm}$ thickness), and two types of sheet tensile specimens, "large tensile specimens" (LTS) and "small tensile specimens" (STS). The geometries for the LTS and STS specimens are shown in Fig. 1. The thickness of the STS specimens was increased to $1 \mathrm{~mm}$ in some cases such as annealed copper in order to ensure a minimum of 4 grains across the gage thickness. In addition to tensile properties, the electrical conductivity can be measured on either type of sheet tensile specimen.
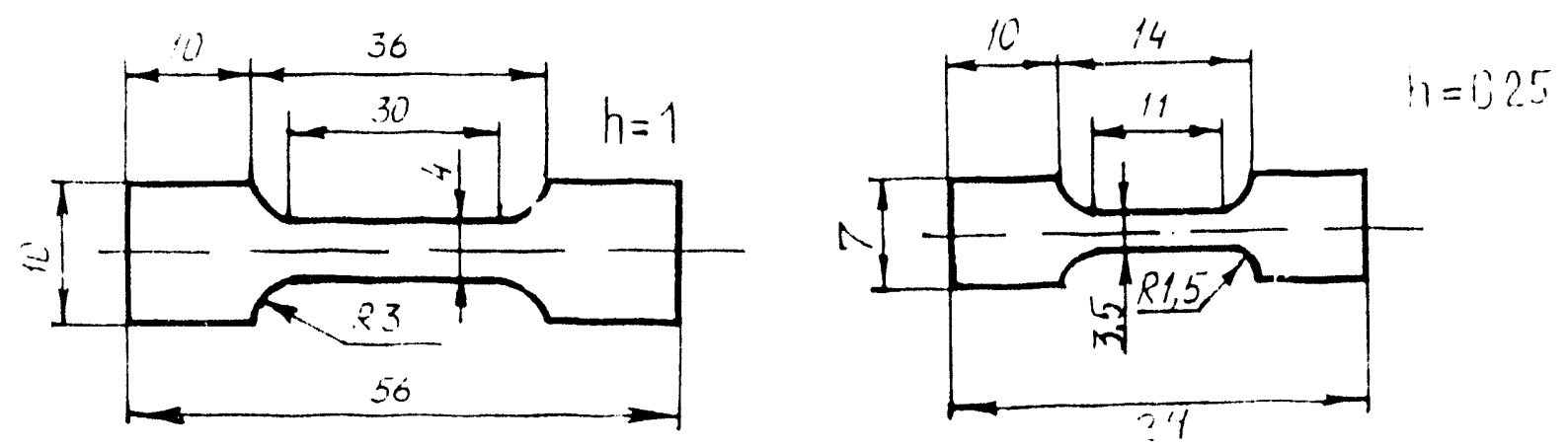

Fig 1. Types of samples being used for irradiation in the channel 2 (dimensions in $\mathrm{mm}$ )

A total of 3 capsules will be irradiated in the core positions for one cycle (45 days) to produce a damage level of about $7 \mathrm{dpa}$. The design temperatures for these 3 capsules are 100 to $120^{\circ} \mathrm{C}, 240$ to $260^{\circ} \mathrm{C}$, and 330 to $350^{\circ} \mathrm{C}$. A total of 2 capsules will be irradiated in the Channel 2 positions to produce a damage level of about $1 \mathrm{dpa}$. These capsules are designed to be irradiated at 120 to $140^{\circ} \mathrm{C}$ and 240 to $260^{\circ} \mathrm{C}$. 
Approximately half of the length of the Channel 2 capsules will be surrounded with a $2 \mathrm{~mm}$ Cd shield to eliminate the thermal neutrons. All of the US-supplied specimens irradiated in the Channel 2 positions will be located in the Cd-shielded region of the capsules.

Tables 2 and 3 summarize the specimen matrix supplied by the US for the core and Channel 2 irradiation capsules, respectively. The US specimen matrix has a strong emphasis on two grades of oxide dispersion strengthened copper, GlidCop Al15 and A125. The GlidCop A125 specimens were supplied by B.N. Singh of Risø National Laboratory in Denmark as part of a collaborative investigation. The experimental matrix will allow the effects of cold work and He generation (from ${ }^{10} \mathrm{~B}(n, \alpha)$ reactions) to be independently studied. High-purity copper in various thermomechanical conditions (with and without $B$ ) has been included for comparison with the dispersion strengthened copper. The remainder of the specimen matrix is restricted to TEM disks. It includes some binary alloys, precipitation-strengthened $\mathrm{Cu}-\mathrm{Cr}-\mathrm{Zr}$, and several different types of dispersion strengthened copper which will be compared with the GlidCop alloys. A prototypic heat of $\mathrm{Cu}-\mathrm{Al}_{2} \mathrm{O}_{3}$ and several $\mathrm{Cu}-\mathrm{W}$ and $\mathrm{Cu}-\mathrm{Mn}$ alloys were supplied by T. Shikama, I. Smid, and Y. Shimomura, respectively as part of a collaborative study.

Table 2. Summary of US specimens in the core positions of the SM-3 reactor.

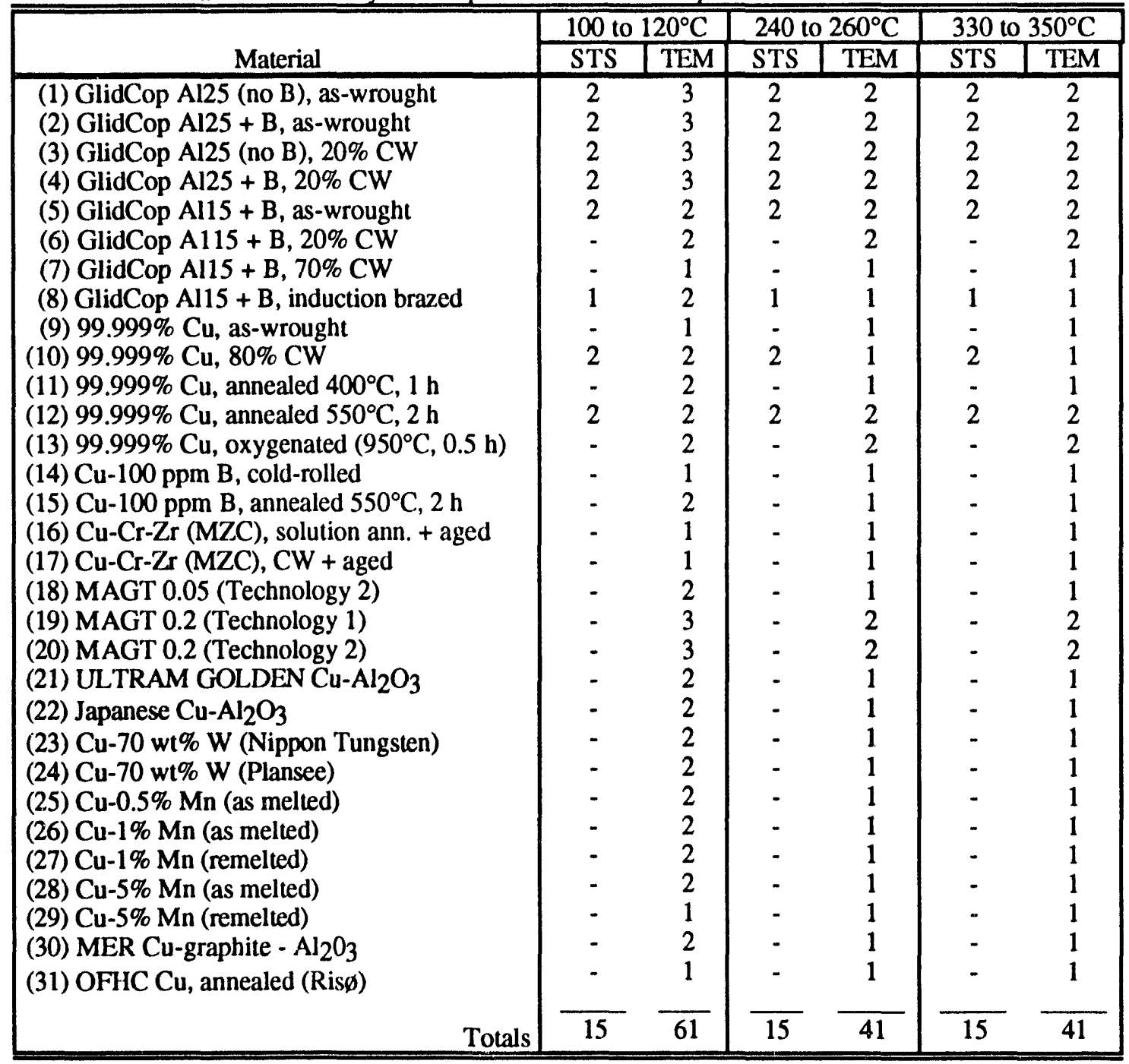


Table 3. Summary of US specimens in the Channel 2 position of the SM-3 reactor.

\begin{tabular}{|c|c|c|c|c|c|c|}
\hline \multirow[b]{2}{*}{ Material } & \multicolumn{3}{|c|}{$\begin{array}{c}\text { Channel } 2 \\
\left(120 \text { io } 140^{\circ} \mathrm{C}\right)\end{array}$} & \multicolumn{3}{|c|}{$\begin{array}{c}\text { Channel } 2 \\
\left(240 \text { to } 260^{\circ} \mathrm{C}\right)\end{array}$} \\
\hline & $\overline{\text { LTS }}$ & STS & TEM & LTS & STS & TEM \\
\hline 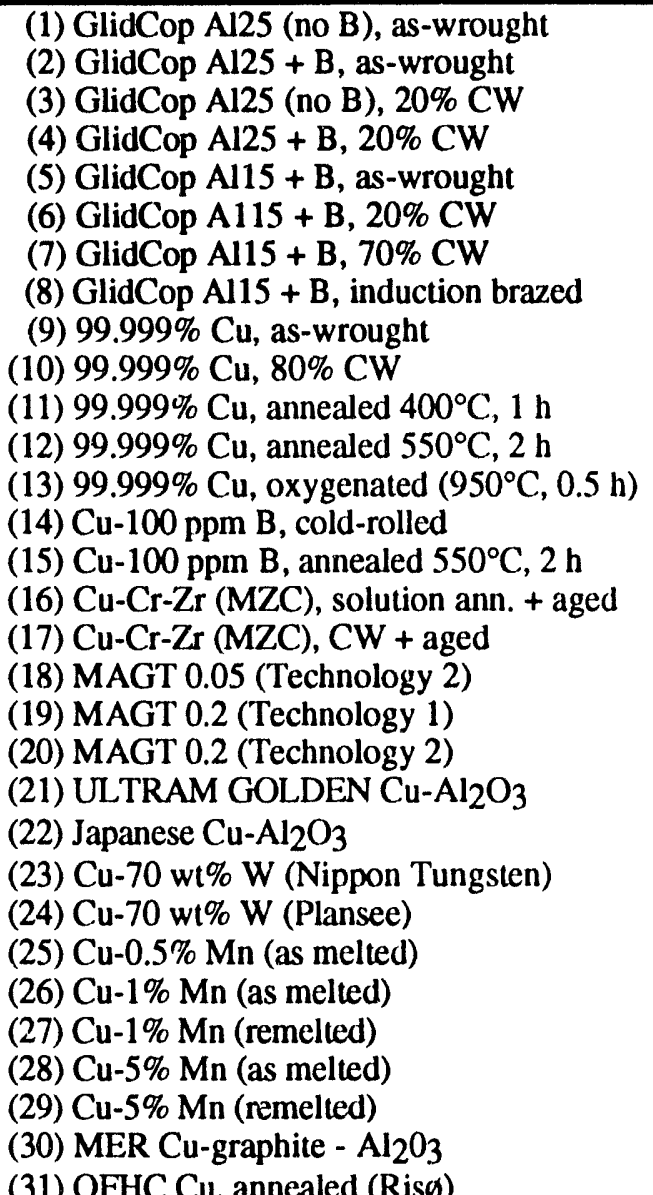 & $\begin{array}{l}3 \\
3 \\
3 \\
3 \\
2 \\
1 \\
5 \\
3 \\
3 \\
- \\
3 \\
- \\
- \\
- \\
- \\
- \\
- \\
- \\
- \\
- \\
- \\
- \\
- \\
- \\
- \\
- \\
-\end{array}$ & $\begin{array}{l}3 \\
3 \\
3 \\
3 \\
3 \\
- \\
2 \\
2 \\
- \\
3 \\
3 \\
3 \\
3 \\
- \\
- \\
- \\
- \\
- \\
- \\
- \\
- \\
- \\
- \\
- \\
- \\
- \\
- \\
- \\
- \\
- \\
-\end{array}$ & $\begin{array}{l}3 \\
3 \\
3 \\
3 \\
3 \\
3 \\
2 \\
2 \\
2 \\
2 \\
3 \\
3 \\
3 \\
3 \\
2 \\
1 \\
2 \\
2 \\
2 \\
2 \\
3 \\
3 \\
3 \\
3 \\
3 \\
2 \\
2\end{array}$ & $\begin{array}{l}3 \\
3 \\
3 \\
3 \\
2 \\
1 \\
- \\
3 \\
3 \\
- \\
- \\
3 \\
- \\
- \\
- \\
- \\
- \\
- \\
- \\
- \\
- \\
- \\
- \\
- \\
- \\
- \\
- \\
-\end{array}$ & $\begin{array}{l}3 \\
3 \\
3 \\
3 \\
3 \\
- \\
2 \\
2 \\
- \\
3 \\
3 \\
3 \\
3 \\
- \\
- \\
- \\
- \\
- \\
- \\
- \\
- \\
- \\
- \\
- \\
- \\
- \\
-\end{array}$ & $\begin{array}{l}3 \\
3 \\
3 \\
3 \\
3 \\
3 \\
2 \\
2 \\
2 \\
3 \\
3 \\
3 \\
2 \\
1 \\
2 \\
2 \\
2 \\
3 \\
3 \\
3 \\
3 \\
2 \\
2 \\
2 \\
2 \\
2 \\
2 \\
2 \\
2 \\
3 \\
2\end{array}$ \\
\hline Totals & 24 & 31 & 75 & 24 & 33 & 75 \\
\hline
\end{tabular}

Table 4 summarizes the Russian specimens included in the SM-3 irradiation capsules. The Russian matuix includes specimens prepared by alternative techniques such as electron beam evaporation and condensation.

\section{FUTURE WORK}

The SM-3 irradiation is scheduled to begin in June 1993. Postirradiation testing of the mechanical and electrical properties of the specimens will be performed in Russia. The US TEM specimens will be shipped to the US for density measurements and microstructural analysis. Several $\mathrm{Cu}$-B specimens will be analyzed for He content in the US and Russia as part of a round robin study. 
Table 4. List of RF samples to be irradiated in the core and Channel 2 positions in SM-3.

\begin{tabular}{|c|c|c|c|}
\hline $\begin{array}{l}\text { 1. Pure } \mathrm{Cu}(1) \text {, annealed } 550^{\circ} \mathrm{C}, 1 \mathrm{~h} \\
\text { 2. Pure } \mathrm{Cu}(1), 70 \% \mathrm{CW}\end{array}$ & $\begin{array}{l}\text { LTS } \\
\text { LTS }\end{array}$ & $\begin{array}{l}\text { STS* } \\
\text { STS }\end{array}$ & $\begin{array}{l}\text { TEM } \\
\text { TEM }\end{array}$ \\
\hline $\begin{array}{l}\text { 3. Pure } \mathrm{Cu} \text {, annealed } 550^{\circ} \mathrm{C}, 1 \mathrm{~h} \\
\text { 4. Pure } \mathrm{Cu}(3)+\mathrm{H}, 70 \% \mathrm{CW} \\
\text { 5. Pure } \mathrm{Cu}(3)+\mathrm{H} \text {, annealed } 550^{\circ} \mathrm{C}, \mathrm{lh} \\
\text { 6. Pure } \mathrm{Cu}(2), 70 \% \mathrm{CW}\end{array}$ & LTS & STS $^{*}$ & $\begin{array}{l}\text { TEM } \\
\text { TEM } \\
\text { TEM } \\
\text { TEM }\end{array}$ \\
\hline $\begin{array}{l}\text { 7. } \mathrm{Cu}-70 \mathrm{ppm} \mathrm{B} \text {, annealed } 550^{\circ} \mathrm{C}, 1 \mathrm{~h} \\
\text { 8. } \mathrm{Cu}-70 \mathrm{ppm} \mathrm{B}, 70 \% \mathrm{CW}\end{array}$ & LTS & $\begin{array}{l}\text { STS* } \\
\text { STS }\end{array}$ & $\begin{array}{l}\text { TEM } \\
\text { TEM }\end{array}$ \\
\hline 9. $\mathrm{Cu}-300 \mathrm{ppm} \mathrm{B}$, annealed $550^{\circ} \mathrm{C}, 1 \mathrm{~h}$ & LTS & STS $^{*}$ & TEM \\
\hline 10. $\mathrm{Cu}-300 \mathrm{ppm} \mathrm{B}, 70 \% \mathrm{CW}$ & & STS & TEM \\
\hline 11. Cu-90 ppm B (e-beam), $70 \% \mathrm{CW}$ & & STS & TEM \\
\hline 12. $\mathrm{Cu}-90 \mathrm{ppm} \mathrm{B}$ (e-beam), ann. $550^{\circ} \mathrm{C}, 1 \mathrm{~h}$ & & STS & TEM \\
\hline 13. Cu-Mo (e-beam), $70 \% \mathrm{CW}$ & & STS & TEM \\
\hline 14. $\mathrm{Cu}-\mathrm{Mo}$ (e-beam), annealed $550^{\circ} \mathrm{C}, 1 \mathrm{~h}$ & & STS & TEM \\
\hline 15. Cu-Mo-B (e-beam), 70\% CW & & STS & TEM \\
\hline 16. $\mathrm{Cu}-\mathrm{Mo}-\mathrm{B}$ (e-beam), annealed $550^{\circ} \mathrm{C}$, lh & & STS & TEM \\
\hline 17. MAGT 0.2 , as-wrought & LTS & STS & TEM \\
\hline 18. MAGT 0.2 , annealed $550^{\circ} \mathrm{C}, 1 \mathrm{~h}$ & LTS & STS & TEM \\
\hline 19. MAGT 0.2 , annealed $950^{\circ} \mathrm{C}, 1 \mathrm{~h}$ & & STS & TEM \\
\hline 20. MAGT 0.05 , as-wrought & LTS & STS & TEM \\
\hline 21. MAGT 0.05 , annealed $550^{\circ} \mathrm{C}, 1 \mathrm{~h}$ & & STS & TEM \\
\hline 22. $\mathrm{Cu}-70 \mathrm{ppm} \mathrm{B}$, annealed $950^{\circ} \mathrm{C}, \mathrm{lh}$ & & STS & TEM \\
\hline 23. $\mathrm{Cu}-300 \mathrm{ppm} \mathrm{B}$, annealed $950^{\circ} \mathrm{C}, 1 \mathrm{~h}$ & & STS & TEM \\
\hline 24. $\mathrm{Cu}-90 \mathrm{ppm} \mathrm{B}$ (e-beam), ann. $950^{\circ} \mathrm{C}, 1 \mathrm{~h}$ & & STS & TEM \\
\hline 25. $\mathrm{Cu}-\mathrm{Be}$, aged & LTS & STS & TEM \\
\hline 26. Cu-Mo (type 3, e-beam), as wrought & & STS & TEM \\
\hline 27. Cu-Mo (type 9, e-beam), as wrought & & STS & TEM \\
\hline 28. Cu-Mo (type 11, e-beam), as wrought & & STS & TEM \\
\hline 29. $\mathrm{Cu}-\mathrm{Cr}$, annealed $550^{\circ} \mathrm{C}, 1 \mathrm{~h}$ & & STS & TEM \\
\hline 30. $\mathrm{Cu}-\mathrm{Zr}$, annealed $550^{\circ} \mathrm{C}, 1 \mathrm{~h}$ & & STS & TEM \\
\hline 31. $\mathrm{Cu}-\mathrm{Al}$, annealed $550^{\circ} \mathrm{C}, 1 \mathrm{~h}$ & & STS & TEM \\
\hline 32. $\mathrm{Cu}-\mathrm{Cr}-\mathrm{Zr}$, aged & LTS & STS & TEM \\
\hline 33. $\mathrm{Cu}-\mathrm{Cr}-\mathrm{Zr}$, annealed $550^{\circ} \mathrm{C}, 1 \mathrm{~h}$ & & STS & TEM \\
\hline 34. $\mathrm{Cu}-\mathrm{Cr}-\mathrm{Zr}-\mathrm{Mg}$, aged & & STS & TEM \\
\hline 35. $\mathrm{Cu}-\mathrm{Cr}-\mathrm{Zr}-\mathrm{Mg}$, annealed $550^{\circ} \mathrm{C}, 1 \mathrm{~h}$ & & STS & TEM \\
\hline 36. $\mathrm{Cu}-\mathrm{NbC}$ (e-beam), as wrought & & STS & TEM \\
\hline 37. $\mathrm{Cu}-\mathrm{Al}_{2} \mathrm{O}_{3}$ (e-beam), as wrought & & STS & TEM \\
\hline 38. Stainless steel, annealed $550^{\circ} \mathrm{C}, 1 \mathrm{~h}$ & & STS & TEM \\
\hline 39. Stainless steel $+\mathrm{ZrB} 2$, ann. $950^{\circ} \mathrm{C}, 1 \mathrm{~h}$ & & STS & TEM \\
\hline 40. High nickel alloy, annealed $950^{\circ} \mathrm{C}, 1 \mathrm{~h}$ & & STS & TEM \\
\hline 41. High nickel alloy $(\mathrm{PH})$, aged & & & TEM \\
\hline 42. MAGT $0.2+\mathrm{H}$, as wrought & LTS & STS & TEM \\
\hline 43. MAGT $0.2+\mathrm{H}$, annealed $550^{\circ} \mathrm{C}$, 1h & & STS & TEM \\
\hline
\end{tabular}

${ }^{*} \mathrm{~S}$ TS thickness $=1 \mathrm{~mm}$ 
EFFECT OF ION IRRADIATION ON THE STRUCTURAL STABILITY OF DISPERSIONSTRENGTHENED COPPER ALLOYS ${ }^{*--S}$. J. Zinkle, ${ }^{1}$ E. V. Nesterova, ${ }^{2}$ V. R. Barabash, ${ }^{3}$ V. V. Rybin, ${ }^{2}$ and A. V. Naberenkov 3

${ }_{1}$ Oak Ridge National Laboratory, P.O. Box 2008, Oak Ridge, TN 37831-6376, USA

${ }^{2}$ Central Research Institute for Structural Materials "Prometey," 193167 St. Petersburg, Russia

${ }^{3}$ D. V. Efremov Scientific Research Institute of Electrophysical Apparatus, 189631 St. Petersburg, Russia

\section{OBJECTIVE}

To investigate the effect of high dose ion irradiation on the microstructure of Russian and American dispersion strengthened copper alloys.

\section{SUMMARY}

Transmission electron microscopy was used to compare the microstructure and particle distributions of two commercial oxide dispersion-strengthened copper alloys, GlidCop Al25 and MAGT 0.2. Measurements were made on specimens in their as-wrought condition, after thermal annealing for $1 \mathrm{~h}$ at $900^{\circ} \mathrm{C}$, and after 3 $\mathrm{MeV} \mathrm{Ar}{ }^{+}$ion irradiation at 180 and $350^{\circ} \mathrm{C}$ to damage levels of 20 to 30 displacements per atom (dpa). All of the annealed and ion-irradiated specimens were found to be resistant to recrystallization. In addition, void formation was not observed in any of the irradiated specimens. The GlidCop oxide particle geometry was transformed from triangular platelets to circular disks by the ion irradiation. The MAGT particle geometry consisted of circular disks and spheres before and after irradiation. The oxide particle edge length in the unirradiated GlidCop alloy was about $10 \mathrm{~nm}$, whereas the mean diameter of the particles in the unirradiated MAGT alloy was about $6 \mathrm{~nm}$. After irradiation, the mean particle diameter in both the MAGT and GlidCop alloys was about $6 \mathrm{~nm}$.

\section{PROGRESS AND STATUS}

Introduction

Dispersion-strengthened copper alloys are being considered as a high heat flux structural material in fusion reactors due to their combination of high thermal conductivity with high mechanical strength. Unlike precipitation strengthened alloys, oxide dispersion strengthened copper is not susceptible to precipitate overaging and softening after high temperature annealing. This feature is important because high temperature braze cycles will likely be needed for joining high heat flux components. Recent ion $[1,2]$ and fission neutron [3-5] studies have found that dispersion strengthened copper containing a high density of small $\mathrm{Al}_{2} \mathrm{O}_{3}$ particles is very resistant to radiation-induced softening and void swelling. One important issue that has not yet been completely resolved is the stability of these small oxide particles against ballistic dissolution during irradiation to high doses. Spitznagel et al. [1] reported evidence of particle fragmentation in oxide dispersion-strengthened copper after ion irradiation to $10 \mathrm{dpa}$ at $25010350^{\circ} \mathrm{C}$, but did not quantify the fraction of affected particles. Two recent studies $[6,7]$ have found that energetic particle irradiation to damage levels of 2 to 3 dpa may cause a modest decrease in the size and density of $\mathrm{Al}_{2} \mathrm{O}_{3}$ particles in a dispersion-strengthened copper.

*Research sponsored in part by the Office of Fusion Energy, U.S. Department of Energy, under contract DE-AC05-840R21400 with Martin Marietta Energy Systems, Inc. 
The purpose of the present study was to compare the effect of high-dose ion irradiation on the microstructure and particle size of two commercial oxide dispersion-strengthened alloys produced in Russia and the United States. These two alloys have slightly different particle geometries and sizes in the as-fabricated condition due to differences in the manufacturing processes. The microstructural response of the two alloys to high temperature thermal annealing and high-dose ion irradiation was investigated by transmission electron microscopy (TEM).

\section{Experimental Procedure}

The two alloys for this study were MAGT 0.2, produced by "Spetssplav," Moscow, Russia, and GlidCop Al25, produced by SCM Metal Products, Inc., Research Triangle Park, North Carolina, USA. The MAGT alloy contained $0.17 \mathrm{wt} \% \mathrm{Al}, 0.05 \mathrm{wt} \% \mathrm{Hf}$, and $0.09 \mathrm{wt} \% \mathrm{Ti}$ in the form of oxide particles, and the GlidCop alloy contained $0.25 \mathrm{wt} \% \mathrm{Al}$ in the form of $\mathrm{Al}_{2} \mathrm{O}_{3}$. Proprietary powder metallurgy and internal oxidation techniques were used to produce a uniform dispersion of small oxide particles in the alloys. The GlidCop alloy used in this study was cold worked $50 \%$ after fabrication.

Several specimens of each alloy were vacuum annealed at $900^{\circ} \mathrm{C}$ for $1 \mathrm{~h}$. Some of the annealed and asreceived specimens were subsequently irradiated with $3 \mathrm{MeV} \mathrm{Ar}^{+}$ions at the $\mathrm{D}$. V. Efremov Institute to damage levels of 20 to 30 displacements per atom (dpa) at temperatures of 180 and $350^{\circ} \mathrm{C}$. These calculated damage levels refer to a depth of $0.2 \mathrm{~mm}$, which was the depth chosen for TEM observations in this study. The corresponding damage rate at this depth was between 2 and $4 \times 10^{-3} \mathrm{dpa} / \mathrm{s}$. The as-received, annealed, and irradiated specimens were electrochemically thinned near room temperature and examined in a Philips EM400 electron microscope at CRISM Prometey. The TEM specimens were initially electropolished with an applied potential of $25 \mathrm{~V}$ in a solution containing $133 \mathrm{ml} \mathrm{CH} 3 \mathrm{COOH}, 40 \mathrm{ml} \mathrm{H} \mathrm{H}_{2} \mathrm{O}$ and $25 \mathrm{~g} \mathrm{CrO}$. The final electropolishing solution contained $440 \mathrm{ml} \mathrm{H}_{3} \mathrm{PO}_{4}$ and $60 \mathrm{~g} \mathrm{CrO} 3$.

The techniques used to examine the particle distribution in the alloys have been described previously [7]. Briefly, the analysis used weak-beam dark field micrographs taken on [002] copper matrix diffraction spots and centered dark field imaging using reflections from the $\{440\}$ diffraction ring of the cubic $\mathrm{Al}_{2} \mathrm{O}_{3}$ particles. Carbon extraction replicas were prepared from unirradiated specimens by electropolishing at $-30^{\circ} \mathrm{C}$ in a solution of $33 \% \mathrm{HNO}_{3} / 67 \% \mathrm{CH}_{3} \mathrm{OH}$ with an applied potential of $5 \mathrm{~V}$, evaporating a carbon film, and etching in a solution of $10 \% \mathrm{HCI}$ in methanol. The chemical composition of individual particles in the extraction replicas was analyzed by energy dispersive X-ray spectroscopy (EDS) using a Philips 400T electron microscope equipped with a field emission gun at ORNL.

\section{Besults}

Both alloys initially contained a high density of dislocations $\left(>10^{14} / \mathrm{m}^{2}\right)$ due to their as-wrought coldworked condition. Details of the dislocation and subgrain structure of the two alloys before and after thermal annealing or ion irradiation are described elsewhere [8]. The total particle density observed in both the unirradiated MAGT and GlidCop alloys was about $4.5 \times 10^{22} / \mathrm{m}^{3}$. This included a low density $(<1 \times$ $10^{21} / \mathrm{m}^{3}$ ) of large particles with sizes $\geq 100 \mathrm{~nm}$. It was observed that the particle size in the two alloys was unaffected by annealing at $900^{\circ} \mathrm{C}$. Figure 1 compares the microstructure of the MAGT and GlidCop alloys after annealing at $900^{\circ} \mathrm{C}$ for $1 \mathrm{~h}$.

Most of the oxide particles in the GlidCor "lloy were found to be triangular platelets (Fig. 1), with an average edge length of about $10 \mathrm{~nm}$. The aspect ratio of the particles (edge length to thickness) in the GlidCop alloy was between 2 and 6 , in agreement with previous measurements on $\mathrm{Cu}-\mathrm{Al}_{2} \mathrm{O}_{3}$ alloys $[7,9$, 10]. About 80 to $90 \%$ of the oxide particles in the MAGT alloy were spherical in shape, and the rest of the particles were in the form of circular disks. The average particle diameter in the MAGT alloy was $6 \mathrm{~nm}$. As discussed elsewhere [10], the round particle shape in the MAGT alloy is due to the addition of Ti and Hf, which also acts to refine the particle size. Figure 2 shows the chemical composition of two small particles 
extracted from the as-wrought MAGT alloy. Whereas the GlidCop alloy contained only aluminum oxide particles, the MAGT alloy contained Al-, Ti-, and Hf-oxide particles, and mixed Al- and Ti-oxide particles of varying composition. For example, the Ti/Al atomic ratio for the particle in Fig. 2a was 0.21 .
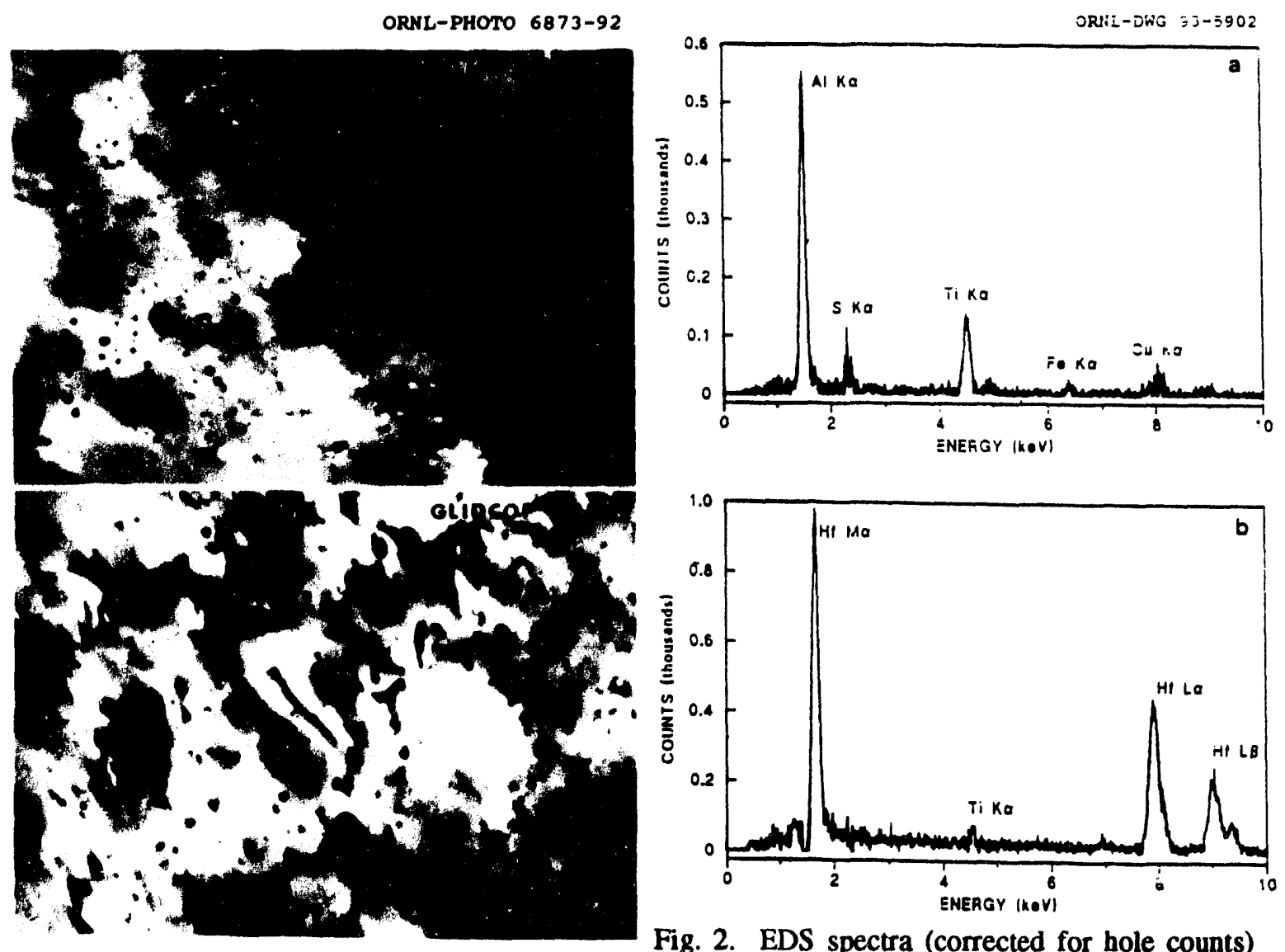

Fig. 2. EDS spectra (corrected for hole counts) obtained on two individual small oxide particles

Fig. 1. Comparison of the oxide particle dispersions in MAGT 0.2 and GlidCop A125 copper alloys after annealing at $900^{\circ} \mathrm{C}$ for $1 \mathrm{~h}$. extracted from the as-wrought MAGT 0.2 alloy. The sulfur peak visible in Fig. $2 a$ is a contaminant present in the evaporated carbon.

Figure 3 compares the measured particle size distributions in the as-received $M_{1} A G T$ and GlidCop alloys. A precise measurement of the particle size and density was hampered by heterogeneous variations of the particle distribution within the alloys. The dispersion strengthened alloys exhibited good resistance to recrystallization during annealing at $900^{\circ} \mathrm{C}(0.87 \mathrm{TM})$ for $1 \mathrm{~h}$. Several isolated regions in the MAGT 0.2 alloy recrystallized after this annealing treatment, whereas the GlidCop Al25 alloy remained in its nonrecrystallized state. The slightly superior resistance to recrystallization of GlidCop Al25 compared MAGT 0.2 may be attributable to the larger average particle size in the GlidCop alloy $(10 \mathrm{~nm}$ vs. $6 \mathrm{~nm})$. As shown in Fig. 4, recrystallization in the MAGT alloy occurred heterogeneously in regions where the localized particle size was only about $4 \mathrm{~nm}$. Recrystallization did not occur in the remaining volume of the MAGT alloy, where the mean particle diameter was about $6 \mathrm{~nm}$. Vickers microhardness measurements for the annealed MAGT and GlidCop specimens were both comparable, which indicates that the limited recrystallized volume in the MAGT alloy did not seriously degrade its mechanical strength. The as-received and annealed microhardness for MAGT 0.2 was 167 and 145 VHN, respectively. The corresponding microhardness measured for the as-received and annealed GlidCop alloy was 137 and 134 VHN, respectively. 


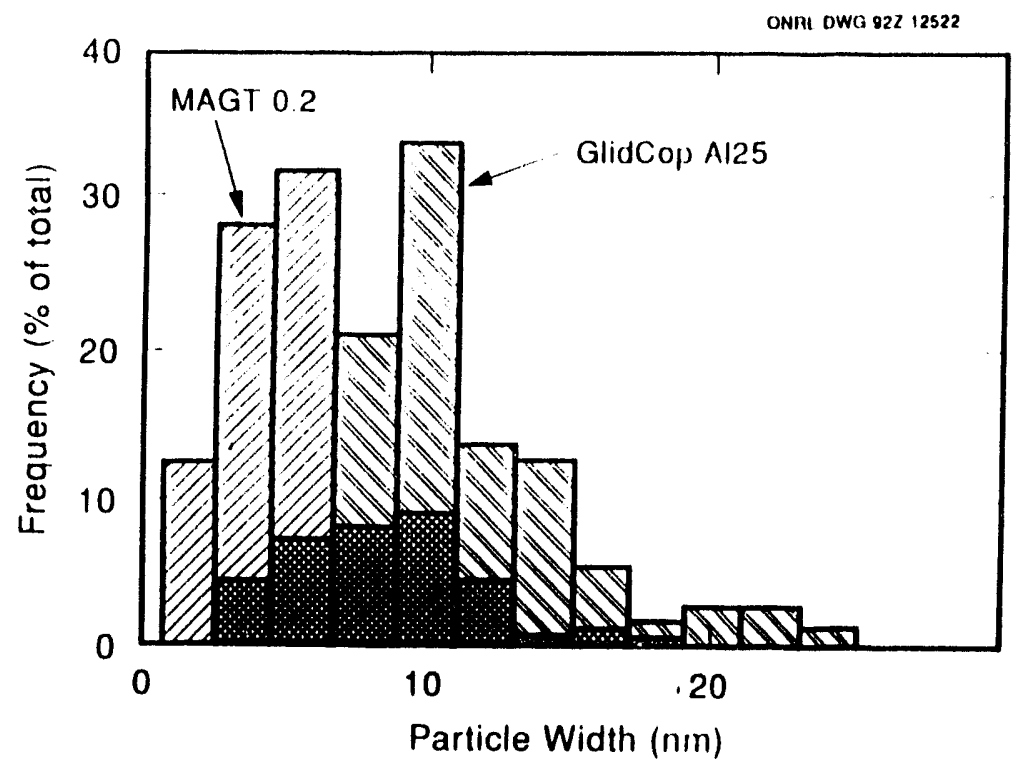

Fig. 3. Size distribution of oxide particles in the as-wrought MAGT 0.2 and $50 \%$ cold-worked GlidCop A125 copper alloys.

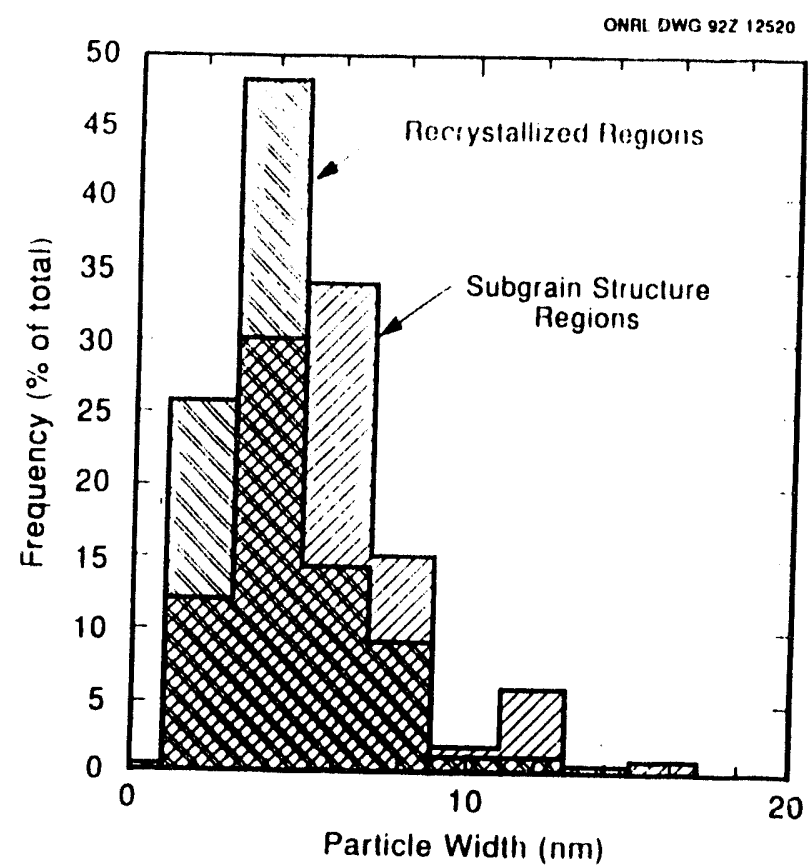

Fig. 4. Comparison of the oxide particle size distribution in recrystallized and nonrecrystallized regions of a MAGT 0.2 specimen that was annealed at $900^{\circ} \mathrm{C}$ for $1 \mathrm{~h}$.

The general microstructure of the irradiated alloys was similar to their unirradiated state. The main effect of irradiation on the dislocation and subgrain structure was to induce dislocation recovery, which produced welldefined subgrains with a reduced dislocation density [8]. Cavity formation was not observed in either alloy 
for any of the irradiation conditions of this study. Figure 5 shows the microstructure of the GlidCop alloy after irradiation to $30 \mathrm{dpa}$ at $180^{\circ} \mathrm{C}$. A high density $\left(5 \times 10^{23} / \mathrm{m}^{3}\right)$ of defect clusters was created in the MAGT and GlidCop alloys as a result of this irradiation condition, with a mean size of $2 \mathrm{~nm}$. Figure 6 shows the measured defect cluster size distribution in the GlidCop alloy irradiated at $180^{\circ} \mathrm{C}$. About $80 \%$ of the defect clusters were identified as stacking fault tetrahedra (SFT) (visible as triangular-shaped defects in the lower photo in Fig. 5). Irradiation at a temperature of $350^{\circ} \mathrm{C}$ produced a much lower defect cluster density of about $7 \times 10^{21} / \mathrm{m}^{3}$ in both the MAGT and GlidCop alloys, with essentially all of the clusters in the form of SFT.

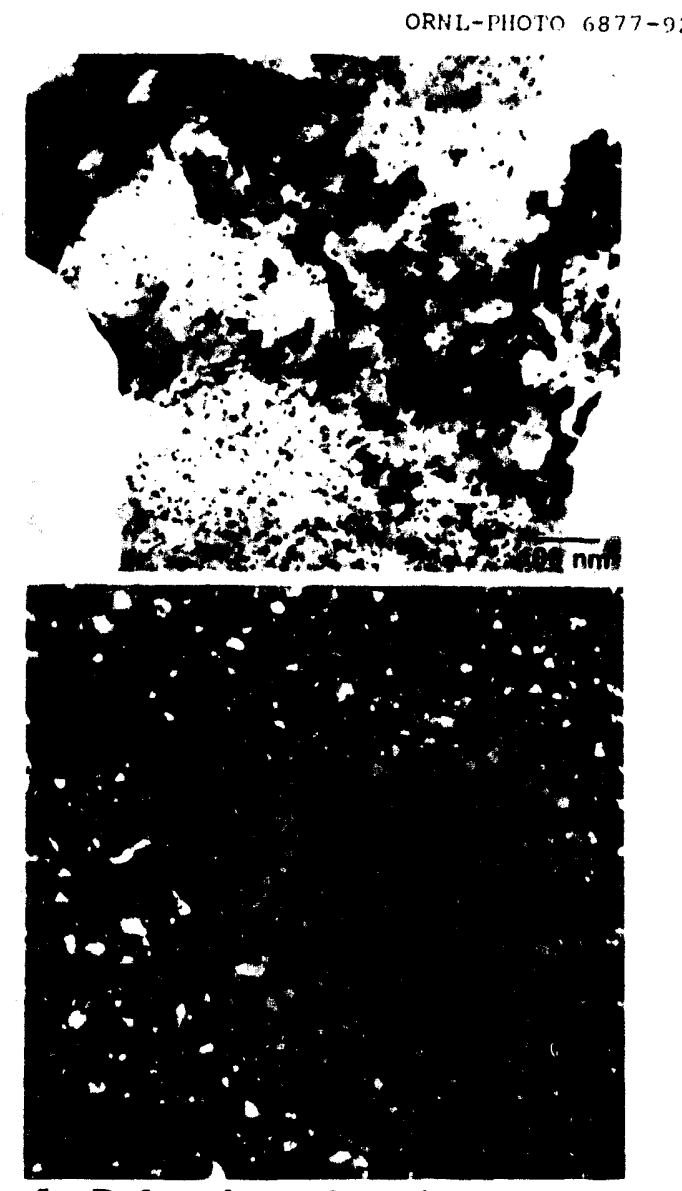

Fig. 5. Defect cluster formation in $50 \%$ coldworked GlidCop Al25 that was irradiated with 3 $\mathrm{MeV} \mathrm{Ar}^{+}$ions to a damage level of $30 \mathrm{dpa}$ at $180^{\circ} \mathrm{C}$. Both micrographs were taken at a beam direction near $\langle 110\rangle$ and a diffraction vector of $<002>$. The bottom photograph is a $(\mathrm{g}, 3 \mathrm{~g})$ weak beam micrograph showing triangular-shaped stacking fault tetrahedra.
Following ion irradiation to damage levels greater than $20 \mathrm{dpa}$, the geometry of the oxide particles in the GlidCop alloy was transformed from predominantly triangular platelets to nearly circular platelets. This gradual change in particle geometry was apparently due to selective ballistic dissolution of the corners of the initially triangular oxide particles in GlidCop. The circular disk and spherical geometries of the MAGT alloy oxide particles was not changed even after high-dose irradiation. Figures 7 and 8 show the typical particle morphology in GlidCop Al25 following irradiation to 30 dpa at $180^{\circ} \mathrm{C}$. The aspect ratio (diameter/thickness) of the oxide particles was about three in the irradiated GlidCop specimens, which is comparable to the unirradiated value of two to six. The small arrow in Fig. 8 points to an oxide particle that is close to an edge-on orientation. Measurements on particles in this orientation were used to determine the aspect ratio.

There was occasional evidence for complete ballistic fracturing of a small fraction of the oxide particles in the MAGT and GlidCop alloys after high dose irradiation. Figure 9 shows a fractured $\mathrm{Al}_{2} \mathrm{O}_{3}$ particle in a GlidCop Al25 specimen that was irradiated to $30 \mathrm{dpa}$. The percentage of fractured particles observed in the irradiated specimens was only about $1 \%$ of the total particles, and we cannot exclude the possibility that these particles may have been fractured as a result of mechanical processing (cold rolling) prior to the irradiation.

Figure 10 compares the measured particle size distribution in nonirradiated and irradiated GlidCop Al25. These size distributions include measurements made on both as-received and annealed specimens. Irradiation to $30 \mathrm{dpa}$ at $180^{\circ} \mathrm{C}$ caused a shift in the GlidCop particle distribution to smaller sizes. The most probable edge length of the predominantly triangular platelets present in nonirradiated GlidCop Al25 was $10 \mathrm{~nm}$. After irradiation, the most probable diameter of the predominantly circular platelets was $6 \mathrm{~nm}$. The corresponding mean particle sizes before and after irradiation were $10.5 \mathrm{~nm}$ and $7.1 \mathrm{~nm}$, respectively. 


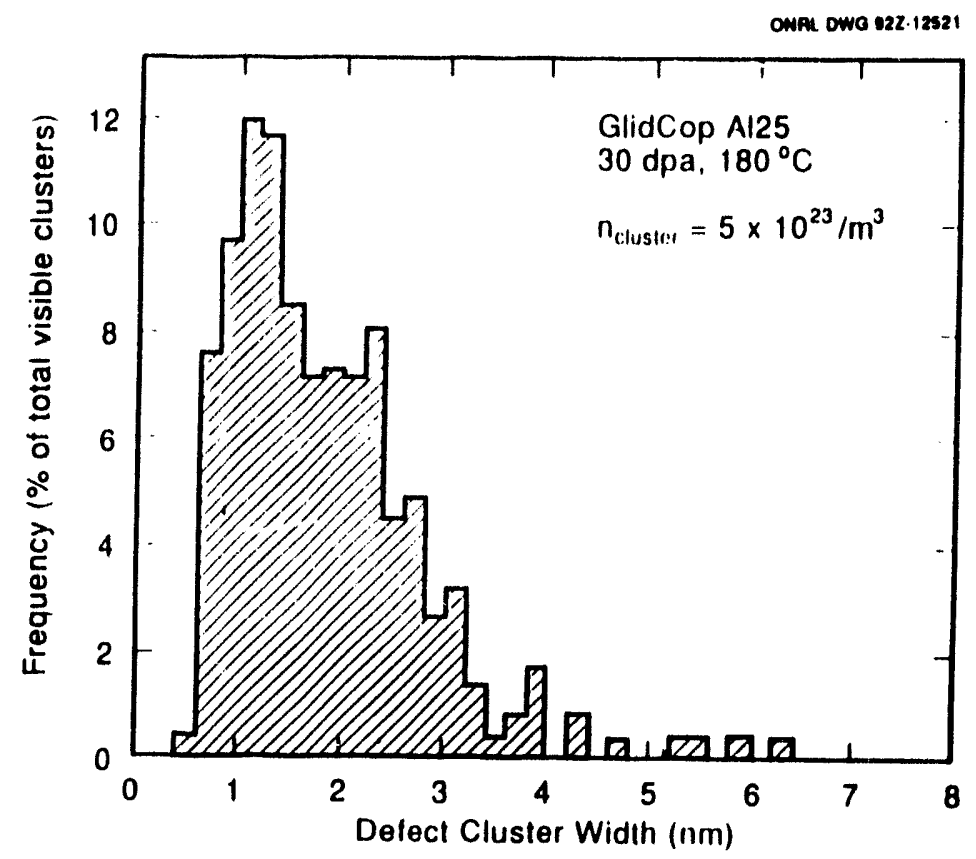

Fig. C. Size distribution of radiation-induced defect clusters in 50\% cold-worked GlidCop A125 after 3 $\mathrm{MeV} \mathrm{Ar}^{+}$ion irradiation to $30 \mathrm{dpa}$ at $180^{\circ} \mathrm{C}$.

ORNL-H11OTO $6878-92$

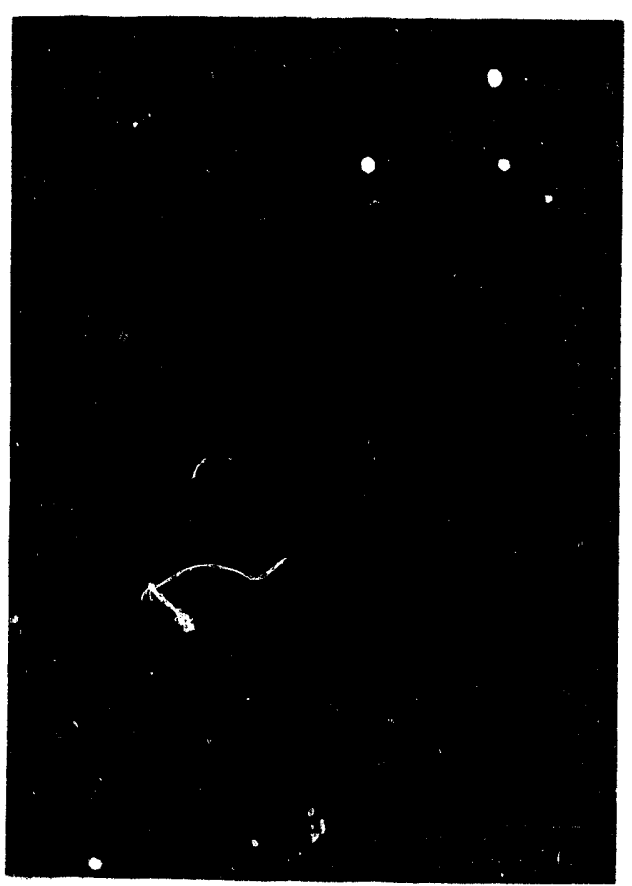

Fig. 7. Centered dark-field image of the $\mathrm{Al}_{2} \mathrm{O}_{3}$ particle morphology in annealed GlidCop A125 after $3 \mathrm{MeV} \mathrm{Ar}^{+}$ion irradiation to $30 \mathrm{dpa}$ at $180^{\circ} \mathrm{C}$. 


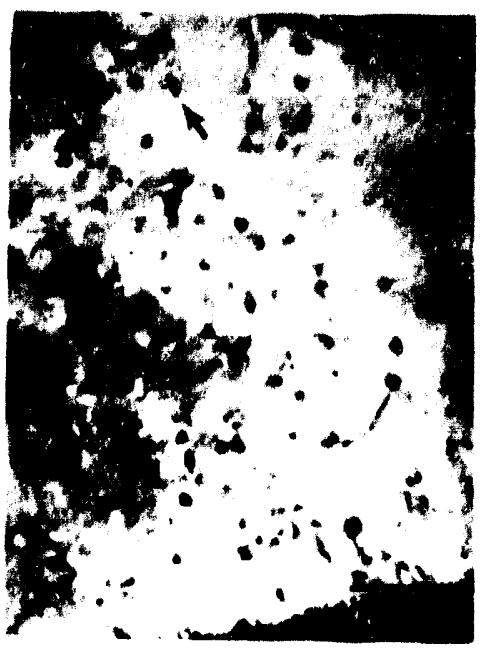

Fig. 8. $\mathrm{Al}_{2} \mathrm{O}_{3}$ particle morphology in a GlidCop Al25 specimen that was annealed at $900^{\circ} \mathrm{C}$ for $1 \mathrm{~h}$ and then irradiated with $3 \mathrm{MeV} \mathrm{Ar}^{+}$ions to $30 \mathrm{dpa}$ at $180^{\circ} \mathrm{C}$. The arrow points to a particle that is close to an edge-on orientation.

Fig. 9. Centered dark-field image of a fractured $\mathrm{Al}_{2} \mathrm{O}_{3}$ particle in a $50 \%$ cold-worked GlidCop Al25 specimen that was irradiated to $30 \mathrm{dpa}$ at $180^{\circ} \mathrm{C}$.

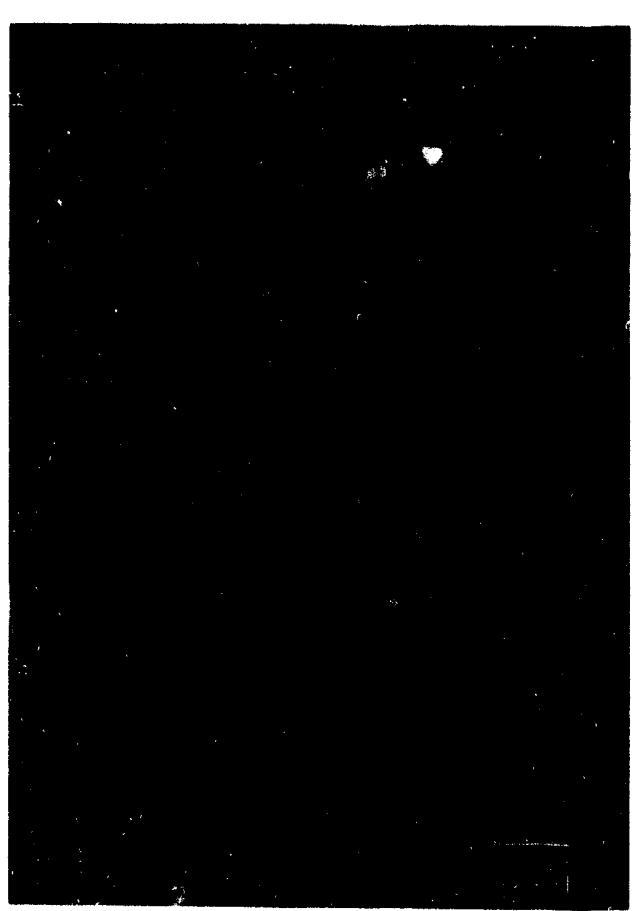


ONAL DWO 92212511

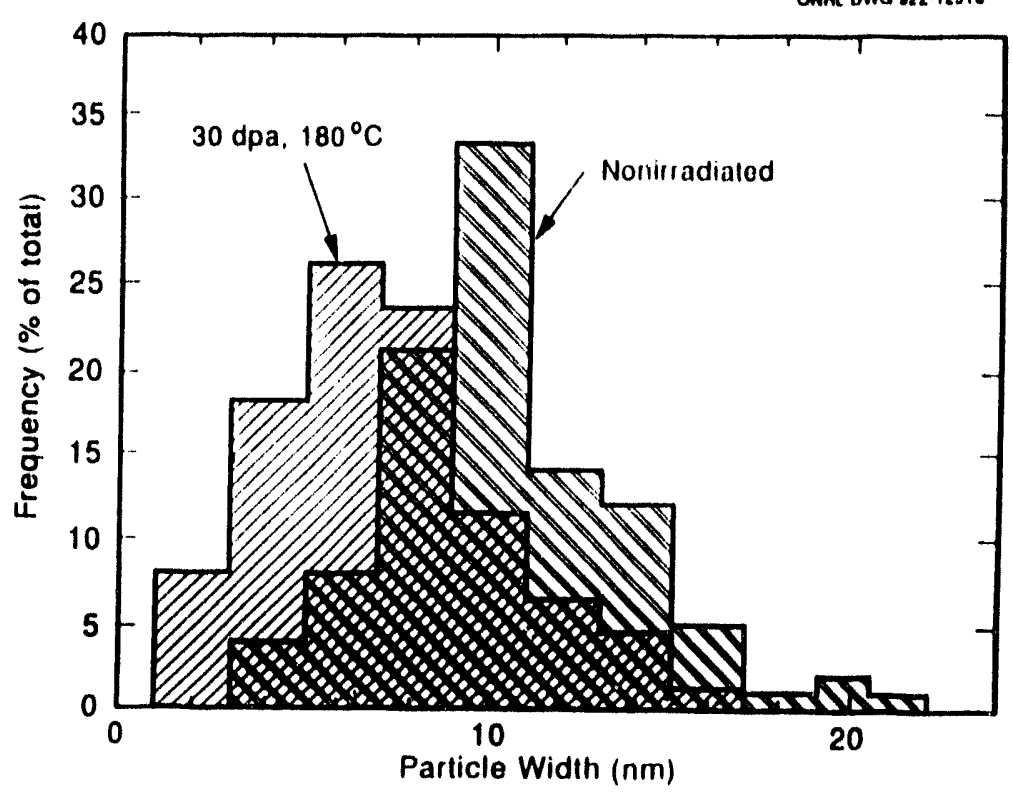

Fig. 10. Size distribution of $\mathrm{Al}_{2} \mathrm{O}_{3}$ particles in GlidCop $\mathrm{Al} 25$ before and after ion irradiation to 30 dpa at $180^{\circ} \mathrm{C}$.

ORHL-PHOTO 6879-92
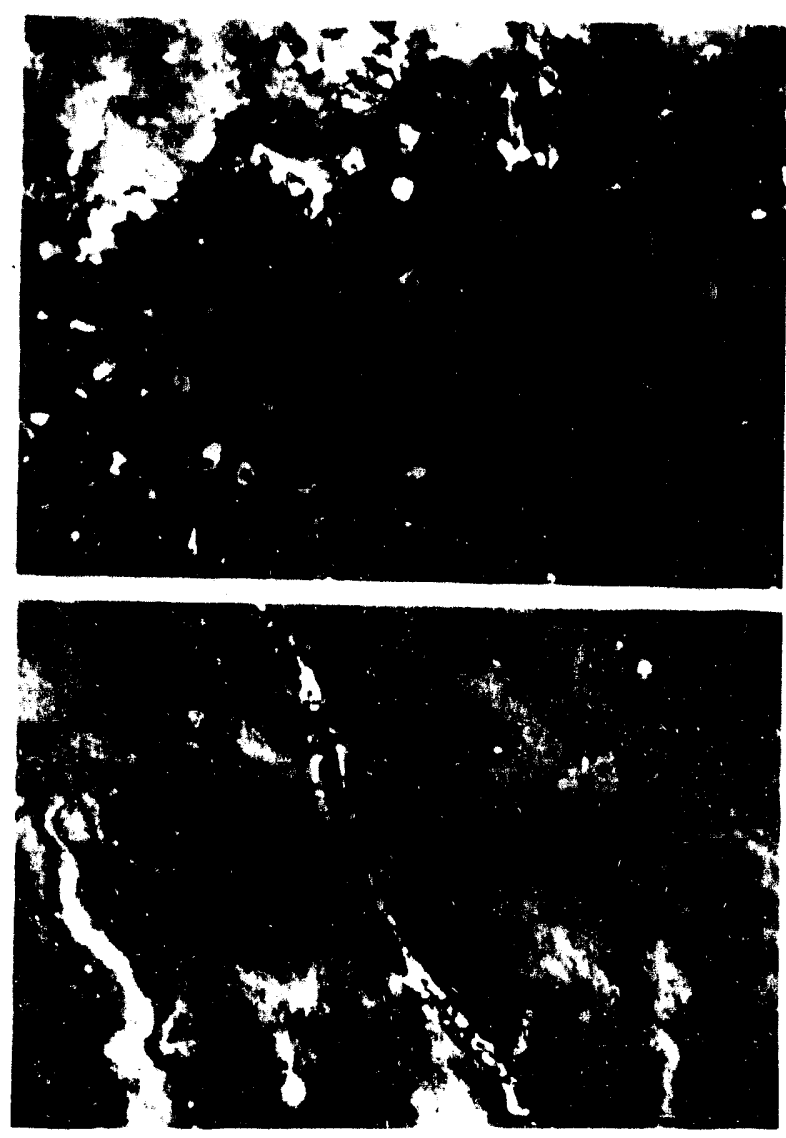

Irradiation of GlidCop at a higher temperature and lower dose caused a somewhat smaller shift in the particle distribution. The most probable and mean particle sizes in GlidCop after irradiation to $20 \mathrm{dpa}$ at $350^{\circ} \mathrm{C}$ were about $8 \mathrm{~nm}$ and 8.4 $\mathrm{nm}$, respectively.

The average particle density in GlidCop A125 was about $4.5 \times 10^{22} / \mathrm{m}^{3}$ before irradiation, with some regions containing particle densities as high as $8 \times 10^{22} / \mathrm{m}^{3}$ or as low as $2 \times 10^{22} / \mathrm{m}^{3}$. The measured oxide particle density in the GlidCop alloy after irradiation ranged between $1.3 \times 10^{22} / \mathrm{m}^{3}$ and $8.6 \times 10^{22} / \mathrm{m}^{3}$. Figure 11 shows an example of the large variability observed in the particle size and density for different regions in an irradiated GlidCop specimen.

As shown in Figure 12, the particle size distribution in the MAGT 0.2 alloy was essentially unaffected by irradiation to damage levels in excess of $20 \mathrm{dpa}$. The particle size and density in the MAGT alloy also exhibited significant ( $50 \%)$ region-toregion variations, in a manner similar to that observed in the GlidCop specimens. Due to these heterogeneous variations in the particle size and density, it was not possible to quantitatively determine if the average particle density in the MAGT 0.2 alloy was altered by irradiation. However, in qualitative terms, the density - was similar in the nonirradiated and irradiated specimens.

Fig. 11. Centered dark field micrographs showing the variability of the $\mathrm{Al}_{2} \mathrm{O}_{3}$ particle sizes in different regions of a GlidCop Al25 specimen that was annealed at $900^{\circ} \mathrm{C}$ and then irradiated to $30 \mathrm{dpa}$ at $180^{\circ} \mathrm{C}$. 


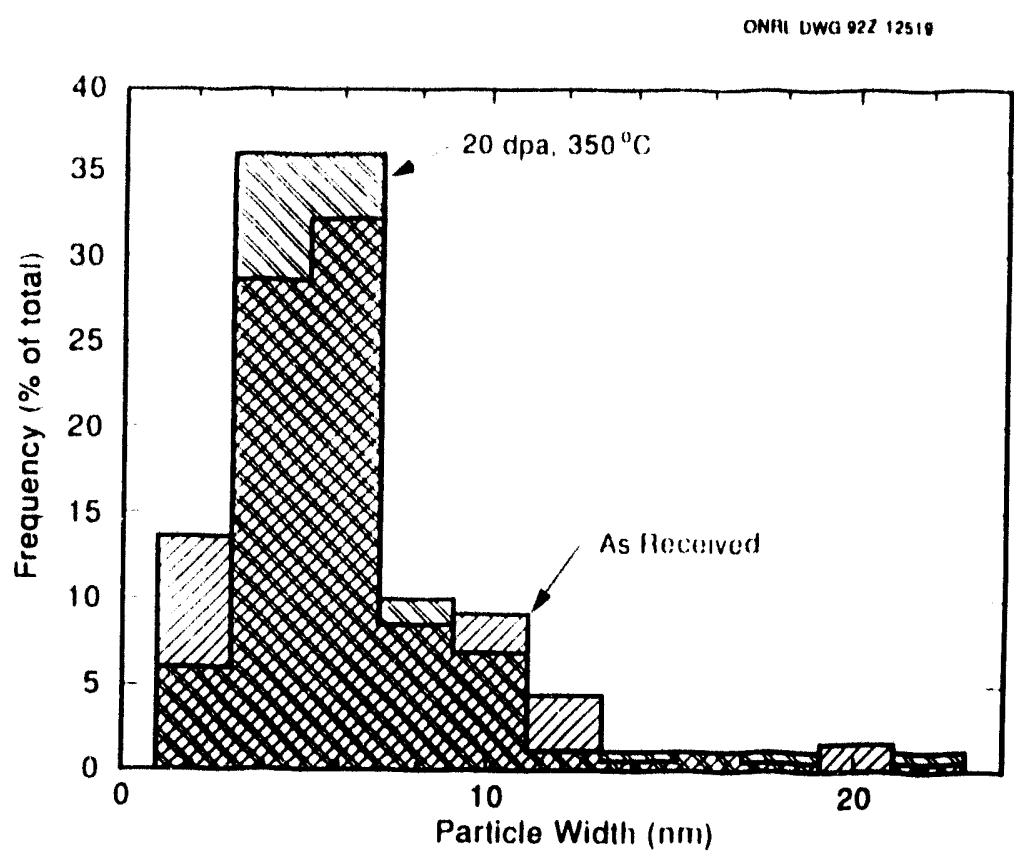

Fig. 12. Size distribution of oxide particles in aswrought MAGT 0.2 before and after ion irradiation.

\section{DISCUSSION}

Several different types of oxide particles were observed in the GlidCop and MAGT alloys. Thermal annealing and ion irradiation did not produce any measurable compositional or phase changes in the oxide particles. The large particles $(d>100 \mathrm{~nm})$ in both the MAGT and GlidCop alloys were identified as thombohedral a - $\mathrm{Al}_{2} \mathrm{O}_{3}$, which is the stable phase for $\mathrm{Al}_{2} \mathrm{O}_{3}$ [11]. Electron diffraction analysis of the small (d $\leq 20 \mathrm{~nm})$ particles in the GlidCop alloy indicated that it was a cubic phase with a lattice parameter of about $0.795 \mathrm{~nm}$. As discussed by Emst et al. [9], these small $\mathrm{Al}_{2} \mathrm{O}_{3}$ particles are most likely $h c-\mathrm{Al}_{2} \mathrm{O}_{3}$. The $\mathrm{h} \phi$ cubic spinel phase has essentially the same lattice parameter as the $\mathrm{g}-\mathrm{Ai}_{2} \mathrm{O}_{3}$ spinel transitional phase $(0.790$ to $0.797 \mathrm{~nm})[9,11]$, and can be considered to be a disordered form of $\mathrm{g}-\mathrm{Al}_{2} \mathrm{O}_{3}$ due to slightly different coordination of the ions on the Al sublattice [9]. Characterization of the small particles in the MAGT 0.2 alloy was somewhat more complicated due to the presence of $\mathrm{TiO}_{2}$ and $\mathrm{HfO}_{2}$ particles in addition to $\mathrm{Al}_{2} \mathrm{O}_{3}$. In addition, EDS (Fig. 2a) indicated that at least some of the small Al-rich particles in MAGT 0.2 also contained Ti. Daneliya and Teplitskiy [10] reported that the mixed $\mathrm{Al}$ - and Ti-oxide particles in an alloy similar to MAGT 0.2 consisted of a cubic $\mathrm{Al}_{2} \mathrm{O}_{3}$ core and a Ti-rich shell. The structure of these mixed oxide particles was not investigated in the present study.

The particle size distributions summarized in Figures 10 and 12 indicate that the most probable oxide particle size after high dose irradiation with $3 \mathrm{MeV} \mathrm{Ar}^{+}$ions is between 5 and $6 \mathrm{~nm}$ for both the MAGT 0.2 and GlidCop A125 alloys. Since the mean particle diameter in nonirradiated MAGT 0.2 was $6 \mathrm{~nm}$ (Fig. 3), ion irradiation to $30 \mathrm{dpa}$ did not have a large effect on the particle distribution. On the other hand, the particle size in GlidCop was reduced by about $40 \%$ (from $10 \mathrm{~nm}$ to $6 \mathrm{~nm}$ ) as a result of the ion irradiation. This size reduction was accomplished primarily through the dissolution of the corners of the triangularshaped oxide platelets in GlidCop, which caused the particle geometry to transform into nearly circular disks after high-dose irradiation (Figs. 7 and 8). From simple geometric considerations, the largest circle that can be inscribed inside of an equilateral triangle of edge length $L$ is $D=L / 3=0.58 \mathrm{~L}$. This suggests that the observed $40 \%$ reduction in the GlidCop particle size can be directly accounted for by selective ballistic dissolution of the corners of the initially triangular particles. The oxide particles in MAGT 0.2 were initially in the form of spheres and circular disks, and their geometry was not changed during irradiation.

Previous microstructural studies of irradiated GlidCop alloys have not reported evidence for a transformation in the oxide particle geometry from triangular plateiets to circular disks $[1,3,6,7]$. However, the dose for one of these studies [7] was only $2 \mathrm{dpa}$, and the high dose studies $[1,3,6]$ apparently did not examine the morphology of the small $(<10 \mathrm{~nm})$ particles but instead concentrated on the larger $(>10 \mathrm{~nm})$ oxide particles, 
which may be less susceptible to ballistic dissolution effects. Spitznagel and coworkers [1] reported that some of the $\mathrm{Al}_{2} \mathrm{O}_{3}$ particles were fractured by ballistic dissolution following high dose (>10 dpa) ion irradiation, but the fraction of affected particles was not reported.

Since the oxide particles in MAGT 0.2 are relatively unaffected by high-dose ion irradiation, this suggests that the radiation stability and tensile properties should not be greatly changed after irradiation. Barabash and coworkers [2] have observed that the yield strength of MAGT 0.2 measured at $400^{\circ} \mathrm{C}$ was essentially unchanged after fast neutron irradiation at $400^{\circ} \mathrm{C}$ to a dose of about $7 \mathrm{dpa}$. High-dose neutron irradiation studies performed on GlidCop Al 25 have found that its room temperature yield strength decreased by about $10 \%$ after irradiation at 415 to $430^{\circ} \mathrm{C}$ to a damage level of $16 \mathrm{dpa}$, and then remained constant during further irradiation up to damage levels of $150 \mathrm{dpa}[5,12]$. This strength decrease after neutron irradiation to $16 \mathrm{dpa}$ may be due to a slight decrease in the mean size of the $\mathrm{Al}_{2} \mathrm{O}_{3}$ particles associated with ballistic dissolution, in a manner similar to our observations on ion-irradiated GlidCop (Fig. 10). If the strength decrease in neutron-irradiated GlidCop is due to a decrease in the oxide-dispersion size, then the strength decrease measured at elevated temperatures $\left(\right.$ e.g., $400^{\circ} \mathrm{C}$ ) would be proportionately greater, due to the increased importance of thermally activated bypassing of the oxide particles by dislocations for small particle sizes. Tensile tests performed at the irradiation temperature are needed to quantitatively evaluate the strength decrease in GlidCop alloys associated with neutron irradiation at elevated temperatures.

\section{CONCLUSIONS}

Microstructural examination of two commercial oxide dispersion-strengthened copper alloys after thermal annealing and ion irradiation revealed the following features:

1. MAGT 0.2 and GlidCop A125 are both resistant to microstructural changes during annealing at high temperature and high-dose ion irradiation. GlidCop Al25 is slightly more resistant to recrystallization than MAGT 0.2 during thermal annealing, apparently because of its slightly larger initial oxide particle size $(10 \mathrm{~nm}$ vs. $6 \mathrm{~nm})$.

2. The most probable particle size in GlidCop Al25 was reduced from $10 \mathrm{~nm}$ to $6 \mathrm{~nm}$ after $3 \mathrm{MeV} \mathrm{Ar}^{+}$ ion irradiation to damage levels greater than $20 \mathrm{dpa}$, and the oxide particle morphology changed from triangular platelets to circular disks. In contrast, the particle size in MAGT 0.2 was nearly unaffected by high-dose ion irradiation with a constant diameter near $6 \mathrm{~nm}$. Radiation-induced changes in the particle density in the MAGT and GlidCop alloys were insignificant compared to grain-to-grain variations in the particle density ( $-50 \%$ variation) in the as-wrought material. The similarity of the particle size, density, and morphology in the MAGT and GlidCop alloys after high dose ion irradiation suggests that both alloys will exhibit similar mechanical properties after irradiation.

\section{ACKNOWLEDGEMENTS}

The authors thank F. A. Garner (Battelle Pacific Northwest Laboratory) for supplying the GlidCop A125 foil used for this study, and N. D. Evans for performing the EDS measurements.

\section{REFERENCES}

1. J. A. Spitznagel, N. J. Doyle, W. J. Choyke, J. G. Greggi, J. N. McGruer, and J. W. Davis, Nucl. Instr. Methods B 16 (1986) 279. 
2. V. R. Barabash, A. A. Gervash, A. V. Naberenkov, E. V. Nesterova, and S. A. Fabritsiev, Mat. Sci. Forum 97.99 (1992) 483.

3. R. J. Livak, T. G. Zocco, and L. W. Hobbs, J. Nucl. Mater. 144 (1987) 121.

4. I. V. Gorynin, S. A. Fabritsiev, V. V. Rybin, V. A. Kasakov, A. S. Pokrovskii, V. R. Barabash, and Y. G. Prokofiev, J. Nucl. Mater. 191-194 (1992) 401.

5. D. J. Edwards, K. R. Anderson, F. A. Garner, M. L. Hamilton, J. F. Stubbins, and A. S. Kumar, J. Nucl. Mater. 191-194 (1992) 416.

6. N. Wanderka, Y. Yuan, L. Jiao, R. P. Wahi, and H. Wollenberger, J. Nucl. Mater. 191-194 (1992) 1356.

7. S. J. Zinkle, A. Horsewell, B. N. Singh, and W. F. Sommer, J. Nucl. Mater. 195 (1992) 11

8. E. V. Nesterova, V. V. Rybin, S. J. Zinkle, V. R. Barabash, and A. V. Naberenkov, 2nd Conf. on the Effect of Irradiation on the Materials of Fusion Reactors, September 22-24, 1992, St. Petersburg, Russia, to be published in Plasma Devices and Operations (in press).

9. F. Ernst, P. Pirouz, and A. H. Heuer, Phil. Mag. A 63 (1991) 259.

10. Ye. P. Daneliya and M. D. Teplitskiy, Phys. Met. Metallogr. (Fiz. Metal. Metalloved.) 52, No. 4 (1981) 104.

11. K. Wefers and C. Misra, Oxides and Hydroxides of Aluminum, Alcoa Laboratories Technical Paper No. 19, revised (Alcoa Laboratories, 1987).

12. H. R. Brager, H. L. Heinisch, and F. A. Garner, J. Nucl. Mater. 133-134 (1985) 676. 
6.5 Environmental Effects in Structural Materials 


\section{MASS TRANSFER IN LITHIUM/STAINLESS STEEL TEST LOOP* \\ P. R. Luebbers and O. K. Chopra (Argonne National Laboratory)}

\section{OBJECTIVE}

The objective of this program is to investigate the influence of a lithium environment on compatibility, corrosion, and mechanical properties of candidate vanadium alloys for first wall/blanket systems in fusion reactors.

\section{SUMMARY}

The plugged pipe removed from the cold-trap purification loop of the forced-circulation lithium system was examined to study mass transfer/deposition bchavior and to establish the cause of plugging. Several intermetallic compounds were identified in residue collected from the plugged cold-trap pipe. Plugging was caused by deposition of calcium/zinc/nickel crystals in the pipe sections within the pump coil and flow-meter magnet. Addition of calcium as a getter to reduce the concentration of nitrogen in the lithium leads to formation of $(\mathrm{Ca}, \mathrm{Zn}) \mathrm{Ni} 5$ crystals and subsequent plugging of the cold-trap loop. Deposits of manganese/iron/nickel globules and manganese/zinc/nickel dendrites, as well as $\mathrm{Li}_{9} \mathrm{CrN}_{5}$ and possibly $\mathrm{Ca}_{3} \mathrm{~N}_{2}$, were also identified in the residue. These phases may have reduced flow through the cold-trap loop but were not abundant enough to plug the loop. The results indicate that the use of a dissolved getter, such as calcium, to reduce nitrogen content in an austenitic stainless steel loop may not be effective. Elements in the lithium from structural alloys (c.g., due to corrosion) and those added (e.g., calcium) to reduce the concentration of nonmetallic impurities (e.g., nitrogen) play an important role in the mass transfer/deposition behavior in circulating lithium systems.

\section{PROGRESS AND STATUS}

Compatibility of structural materials with liquid metals has a major influence on material selection and operating limitations for liquid-mctal blankets. Corrosion in the form of uniform or selective dissolution, intergranular attack, and transfer of interstitial elements to and from the liquid metal can reduce the effective section thickness of structural components. Radioactive mass transfer/deposition of corrosion products may cause severe flow restrictions and excessive accumulation of radioactive material in unshielded regions. Corrosion/dissolution can reduce mechanical integrity, and mass transfer/deposition phenomena can increase pumping-power requirements, decrease cnergy conversion efficiency, and complicate system maintenance.

Mass transfer/deposition occurs in nonisothermal systems because of temperature and concentration gradients. Alloy elements dissolve in the hot regions of a liquid-metal loop because their concentrations in the liquid metal are lower than their solubilities, and they deposit in cold regions of the loop where their concentrations in the liquid metal are greater than their solubility limits. Severity of the corrosion and mass transfer varies with different combinations of containment material and liquid metal and depends on many variables. These include the liquid metal and its purity (i.e., concentrations of nitrogen, carbon, oxygen, etc.); composition and microstructure of the containment material; time and temperature of exposure; and system parameters such as flow velocity (including magnetohydrodynamic effects), $\Delta \mathrm{T}$ (difference of temperature across the circulating system), surface area and temperature profile of the system, and material

\footnotetext{
* Work supported by Office of Fusion Energy, U.S. Department of Energy, under Contract W-31-109-Eng-38.
} 
combination (i.e., bimetallic or monometallic system). Several studies have been conducted to evaluate the influence of different material and system parameters on corrosion behavior of candidate structural materials in lithium. ${ }^{1,2}$ Most studies have been conducted in circulating lithium systems such as thermal-convection or forced-circulation loops.

The present investigation was undertaken in an attempt to better understand the process of mass transfer/deposition in circulating lithium systems. Since 1981, corrosion/compatibility studies at Argonne National Laboratory have been conducted in a test facility consisting of a forced-circulation lithium loop and an MTS servohydraulic fatigue machine for performing mechanical tests in the liquid metal environment. A schematic diagram of the lithium loop is shown in Fig. 1. The lithium system, which is constructed of Type 304 stainless steel, consists of a primary loop with three test vessels and a secondary coldtrap purification loop. The quantity of lithium in the loop is $\approx 20 \mathrm{~L}$ which is circulated at $\approx 16 \mathrm{~cm}^{3} / \mathrm{s}$ in the primary loop. The concentration of interstitial elements in the lithium is controlled by maintaining the cold-trap temperature at $200-220^{\circ} \mathrm{C}$. In addition, the nitrogen level in the lithium is reduced to levels of $<100$ wppm by hot-trapping with Ti foils and by dissolved getters such as calcium. Nitrogen content is reduced by formation of $\mathrm{TiN}$ or $\mathrm{Ca}_{3} \mathrm{~N}_{2}$, which are more stable than $\mathrm{Li}_{3} \mathrm{~N}$. In the latter case, $\mathrm{Ca}_{3} \mathrm{~N}_{2}$ is trapped in cooler regions of the loop, e.g., the cold trap.

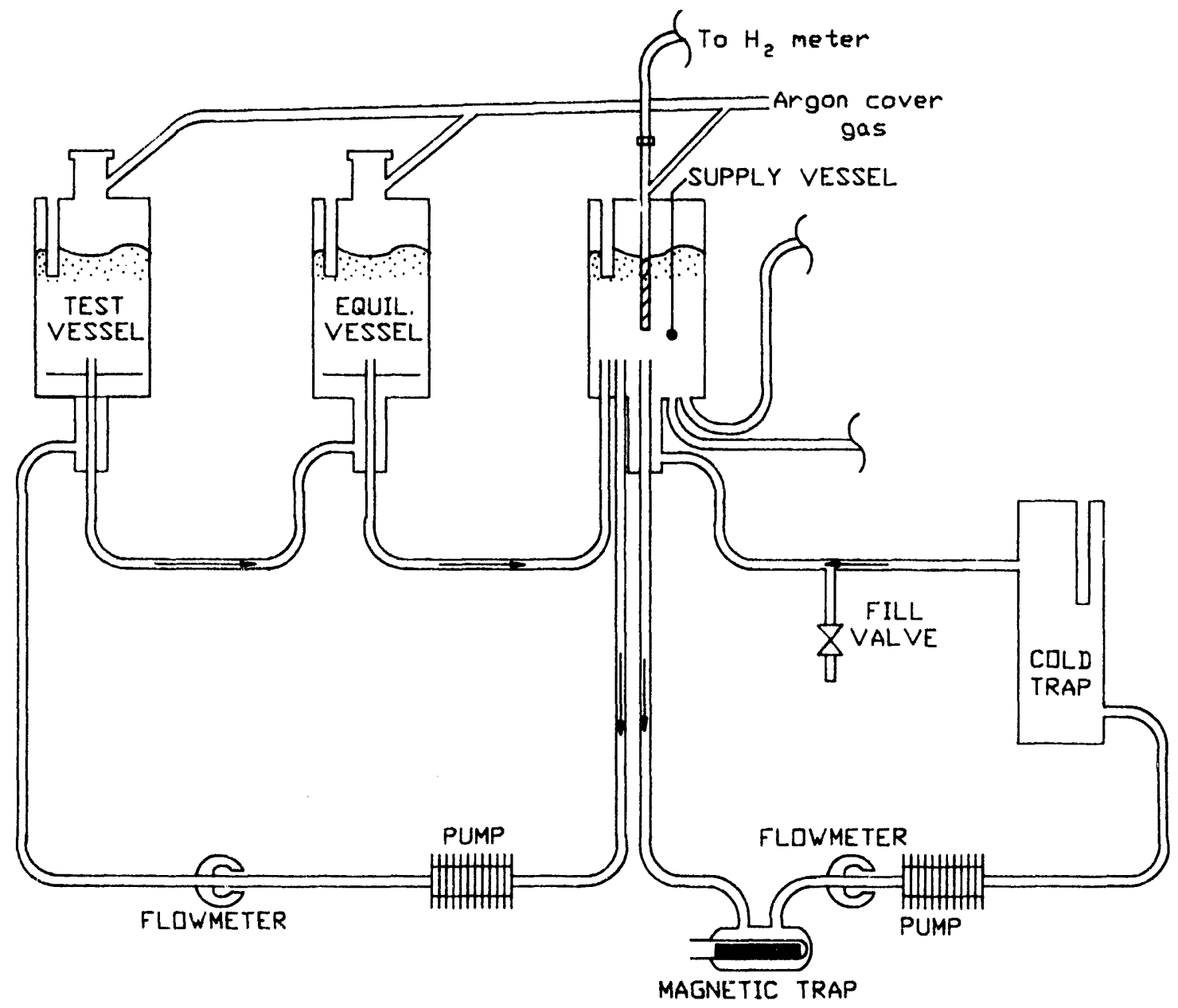

Figure 1. Schematic diagram of the lithium loop 
During the initial six months of operation, the lithium system was shut down several times because of plugging of the flow meter and pump section of the cold-trap loop. Nitrogen concentration in the lithium during these carly phases of operation increased to $\approx 1200 \mathrm{wppm}$ due to contamination from the fixture used for performing mechanical tests. Examination of the plugged pipe sections indicated an accumulation of $\mathrm{MnNi}$ and $\mathrm{MnNi} 3$ compounds, which are paramagnetic below $360^{\circ} \mathrm{C}$, inside the pipe sections within the pump coil and flow-meter magnct. ${ }^{3}$ Particles of pure iron and iron/nickel compounds were also detected in metalis residue collected from the plugged sections. Chromium was present as a ternary nitride $\left(\mathrm{Lig}_{9} \mathrm{CrN}_{5}\right)$ that decomposed into ammonia and lithium chromate when the lithium was dissolved in a solution of methyl alcohol and water. Subsequently, a magnetic trap (Fig. 1) was installed upstream of the flow meter and pump section of the cold-trap loop. The lithium loop has operated with few interruptions for $\approx 10 \mathrm{yr}$ after installation of the magnetic trap.

At present, the lithium loop is being used to study the stability of various nitride and oxide coatings on vanadium-base alloys. Nitrogen content in the lithium has occasionally increased to $>1000 \mathrm{wppm}$; consequently, calcium was added as dissolved getter to reduce the nitrogen concentration. The cold-trap loop plugged up within $24 \mathrm{~h}$ of the calcium addition. The magnetic trap, flow meter, and pump section of the cold-trap loop were removed for examination, and the results are presented in this report.

\section{Results and Analysis}

The plugged pipe removed from the cold-trap loop was cleaned by dissolving the lithium in a solution of methyl alcohol and water. The solution and residue collected from different sections of the pipe were examined to study mass transfer/deposition behavior and to establish the cause of plugging.

Cleaning solutions from those sections of pipes not within the pump coil or flow meter magnet, were relatively clean. Solutions collected after dissolving lithium from the center of these pipes had a milky-white appearance and were free of particulates. Solutions collected after cleaning the surfaces of these sections turned muddy gray or yellow and contained particulates. Cleaning solutions from inside the pipe sections within the pump coil or flow meter magnet formed a dark yellow or green sludge. A strong odor of ammonia was detected while cleaning these sections. Spectrographic analysis of the yellow/green solutions indicated a high concentration of chromium and small amounts of iron and calcium. These results indicate the presence of $\mathrm{Li}_{9} \mathrm{CrN}_{5}$ and possibly $\mathrm{Ca}_{3} \mathrm{~N}_{2}$, both of which decompose in alcohol or water.

Several intermetallic compounds were identified in the residue of the cleaning solutions. Sludge collected from inside the pipe sections within the pump coil or flow meter magnet consists primarily of large rectangular plates of a calcium/zinc/nickel compound (Fig. 2)." Energy-dispersive X-ray (EDAX) analyses indicate that the crystals are most likely $(\mathrm{Ca}, \mathrm{Zn}) \mathrm{Ni}$. The surface morphology of the particles varies from a perfectly smooth surface to an etched and pitted appearance, depending on the composition. Other major constituents in the sludge were long dendritic crystals of a manganese/zinc/ nickel compound and small globular particles of a manganese/iron/nickel compound (shown in Fig. 3). The latter is most likely the cubic ( $\mathrm{Mn}, \mathrm{Fe}) \mathrm{Ni}_{3}$ phase that had been identificd earlier in the particulate collected from plugged sections of the cold-trap loop. ${ }^{3}$

\footnotetext{
* The source of zinc in the lithium is a Korloy $(\mathrm{Zn}-11 \mathrm{Al})$ clamp that accidentally fell into the test vessel of the loop.
} 

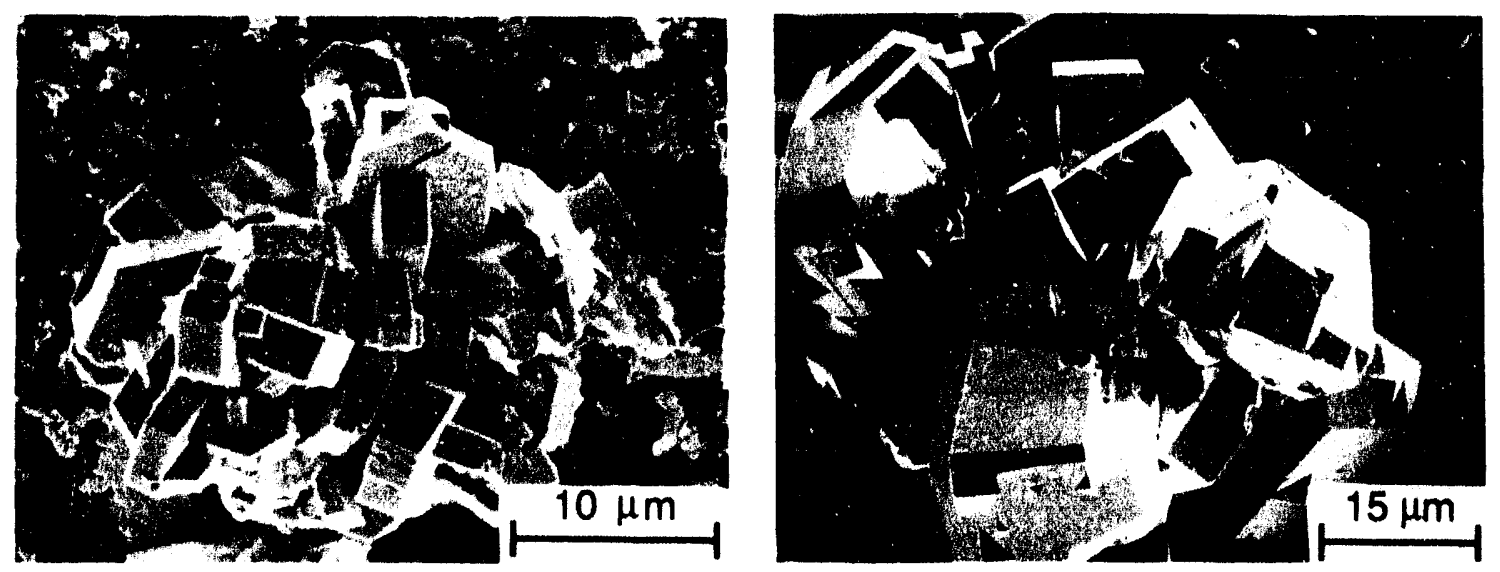

Figure 2. Photomicrographs of calcium/zinc/nickel compound collected from plugged flow meter and pump sections of cold-trap pipe
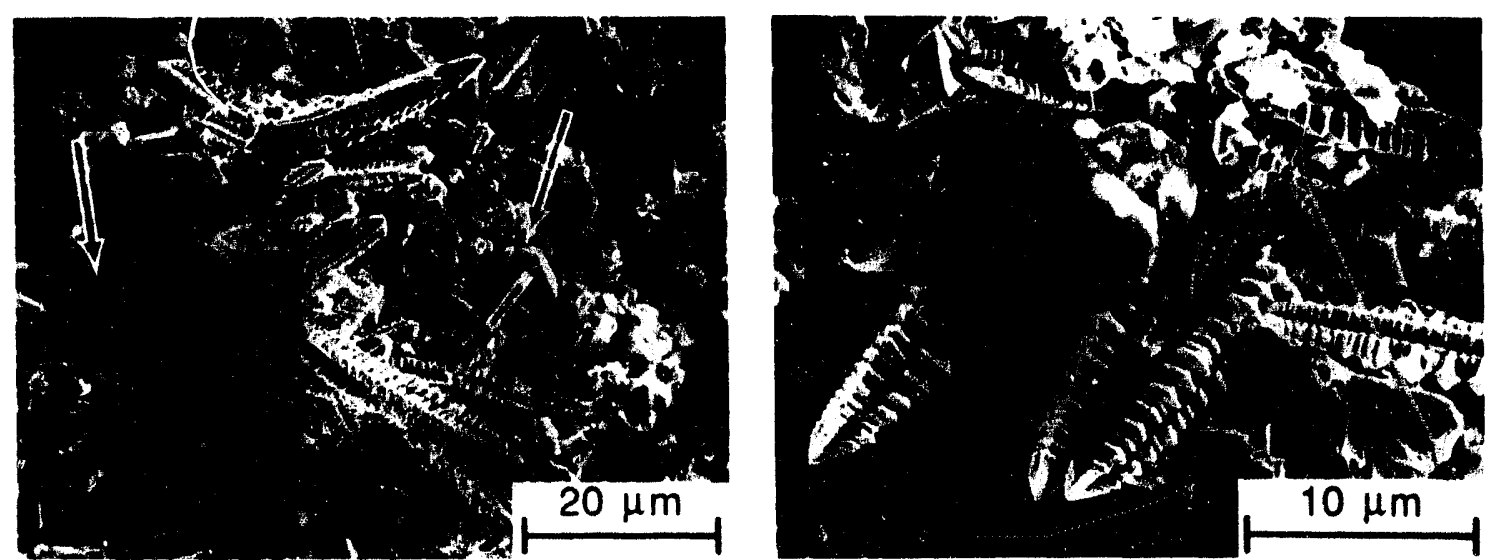

Figure 3. Photomicrographs of metallic residue collected from plugged flow meter and pump sections of cold-trap pipe. Phases at the left are $(a)(\mathrm{Ca}, \mathrm{Zn}) \mathrm{Nis}$ and $(b)(\mathrm{Mn}, \mathrm{Fe}) \mathrm{Ni}$.

Large pieces of what appear to be broken ferrite layers were also detected in the residue. Austenitic stainless steels exposed to lithium develop a ry pornus ferrite layer because of preferential dissolution of nickel and, to some extent, chromium from rite layer from the loop material. ecl. The large metallic chunks are most likely spalled fer-

A photomicrograph of the surface of the pipe section within the flow-meter magnet is shown in Fig. 4. The surface has the etched appearance typical of austenitic stainless steels exposed to lithium and is covered with globular deposits that are enriched in nickel and manganese. EDAX analyses indicate that the deposits are globular particles of the manganese/iron/nickel compound shown in Fig. 3. The pipe surfaces do not show preferential dissolution of nickel or chromium from the steel; the composition of the pipe surface is the same as that of the base metal. 


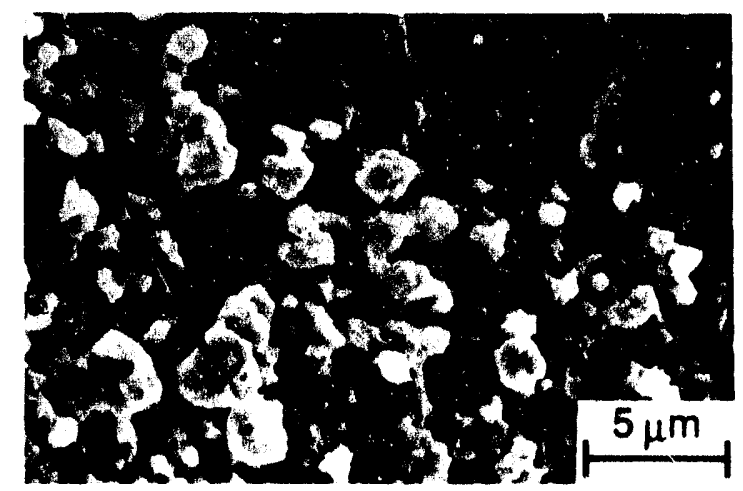

Figure 4.

Surface of pipe section within flow meter magnet. Region (a) is pipe surface; Region (b) and (c) are globular particles of manganesel iron/nickel compound shown in Fig. 3.

\section{CONCLUSIONS}

Metallographic examination of the cold-trap pipe indicates that plugging was caused by trapping of calcium/zinc/nickel crystals within the pump coil and flow-meter magnet sections of the pipe. The addition of dissolved calcium to reduce the nitrogen in the lithium leads to formation of $(\mathrm{Ca}, \mathrm{Zn}) \mathrm{Ni}_{5}$ crystals and subsequent plugging of the cold-trap loop. Deposits of manganese/iron/nickel globules and manganese/zinc/nickel dendrites, as well as $\mathrm{Li}_{9} \mathrm{CrN}_{5}$ and possibly $\mathrm{Ca}_{3} \mathrm{~N}_{2}$, were already present in the pipe sections prior to the calcium addition. These other phases may have reduced the flow through the cold-trap loop but were not abundant enough to plug the loop.

The results indicate that the use of a dissolved getter, such as calcium, to reduce the nitrogen content in an austenitic stainless steel loop may not be effective. The calcium may react with dissolved nickel in the lithium to form a calcium/nickel compound rather than $\mathrm{Ca}_{3} \mathrm{~N}_{2}$. Elements in lithium from structural alloys (e.g., due to corrosion) and those added (e.g., calcium) to reduce the concentration of nonmetallic impurities (e.g., nitrogen) play an important role in the mass transfer/deposition behavior of circulating lithium systems.

\section{FUTURE WORK}

The contents of the magnetic trap removed from the cold-trap loop will be examined. X-ray diffraction and microprobe analyses will be used to identify the various phases.

\section{REFERENCES}

1. O. K. Chopra, D. L. Smith, P. F. Tortorelli, J. H. DeVan, and D. K. Sze, Liquid-Metal Corrosion, Fusion Technol., 8, 1956-1969 (1985).

2. O. K. Chopra and P. F. Tortorelli, Compatibility of Materials for Use in Liquid-Metal Blankets of Fusion Reactors, J. Nucl. Mater., 122 \& 123, 1201-1212 (1984).

3. O. K. Chopra and D. L. Smith, Corrosion of Ferrous Alloys in a Flowing Lithium Environment, J. Nucl. Mater., 133 \& 134, 861-866 (1985). 
COMPATIBILITY OF CANDIDATE STRUCTURAL MATERIALS WITH STATIC GALLIUM*

P. R. Lucbbers, W. F. Michaud, and O. K. Chopra (Argonne National Laboratory)

\section{OBJECTIVE}

Gallium has been considered as a possible heat transport liquid in the International Thermonuclear Experimental Reactor (ITER). Gallium is attractive for such applications because the temperature range over which it remains liquid is wider than that of any other metal, i.e., from near room temperature $\left(30^{\circ} \mathrm{C}\right)$ to $2300^{\circ} \mathrm{C}$, and because it has good thermal conductivity and very low vapor pressure at high temperatures. However, gallium has high chemical reactivity with most metals. The objective of this study is to investigate the compatibility of gallium with candidate structural materials for ITER first-wall/blanket systems.

\section{SUMMARY}

Scoping tests were conducted on compatibility of gallium with candidate structural materials, e.g., Type $316 \mathrm{SS}$, Inconel 625, and $\mathrm{Nb}-5 \mathrm{Mo}-1 \mathrm{Zr}$ alloy, as well as Armco iron, Nickel 270, and pure chromium. Type 316 stainless steel is least resistant and $\mathrm{Nb}-5 \mathrm{Mo-1} \mathrm{Zr}$ alloy is most resistant to corrosicn in static gallium. At $400^{\circ} \mathrm{C}$, corrosion rates are $\approx 4.0,0.5$, and $0.03 \mathrm{~mm} / \mathrm{y}$ for Type $316 \mathrm{SS}$, Inconel 62.5 , and $\mathrm{Nb}-5 \mathrm{Mo}-1 \mathrm{Zr}$ alloy, respectively. The pure metals react rapidly with gallium. In contrast to findings in earlier studies, pure iron shows greater corrosion than does nickel. The corrosion rates at $400^{\circ} \mathrm{C}$ are $\geq 90$ and $17 \mathrm{~mm} / \mathrm{y}$, respectively, for Armco iron and Nickel 270. The results indicate that at temperatures up to $400^{\circ} \mathrm{C}$, corrosion occurs primarily by dissolution accompanied by formation of metal/gallium intermetallic compounds.

\section{PROGRESS AND STATUS}

Gallium has a high affinity for most engineering metals and alloys. Pure metals such as aluminum, zinc, and tin disintegrate in liquid gallium at $30^{\circ} \mathrm{C}$. The refractory metals and ceramics show the greatest stability in gallium. Gallium can be contained successfully in beryllium, tantalum, stabilized $2 \mathrm{rO}_{2}$, or Pyrex glass at temperatures up to $450^{\circ} \mathrm{C}$; in tungsten, rhenium, or graphite at temperatures up to $800^{\circ} \mathrm{C}$; and in refractory oxides (such as sintercd $\mathrm{BeO}$ or $\mathrm{Al}_{2} \mathrm{O}_{3}$ ) and vitreous quartz at $1000^{\circ} \mathrm{C}$ or higher. ${ }^{1-3}$

Corrosion occurs primarily by dissolution due to solubility of metals in gallium which results in metal recession and weight loss, and at higher temperatures also by diffusion into the metal, which leads to formation of surface scale and weight gain. For most metals, dissolution is accompanied by formation of metal/gallium intermetallic compounds from the saturated solution. The solubility and corrosion of pure metals in gallium have been investigated. ${ }^{4-8}$ Figure 1 shows solubility of pure metals in gallium at 200$700^{\circ} \mathrm{C}$. Unlike alkali metals, where solubility represents a saturated solution in equilibrium with pure metal, solubility in gallium is based on a saturated solution in equilibrium with an intermetallic compound. For most engineering metals, the intermetallic compound is of the form $\mathrm{MGa}_{3}$ or MGa4. Solubility data at a given temperature, e.g., $400^{\circ} \mathrm{C}$, show a periodicity with atomic number similar to that observed in other low-melting metals, e.g., mercury, indium, tin, lead, bismuth, lithium, sodium, or potassium. Although the absolute value of solubility may vary for the various liquid metals, in all cases a minimum in solubility is observed for beryllium, boron, vanadium, niobium, molybdenum, tantalum, tungsten, rhenium, and osmium. ${ }^{8}$

\footnotetext{
* Work supported by Office of Fusion Energy, U.S. Department of Energy, under Contract W-31-109-Eng-38.
} 


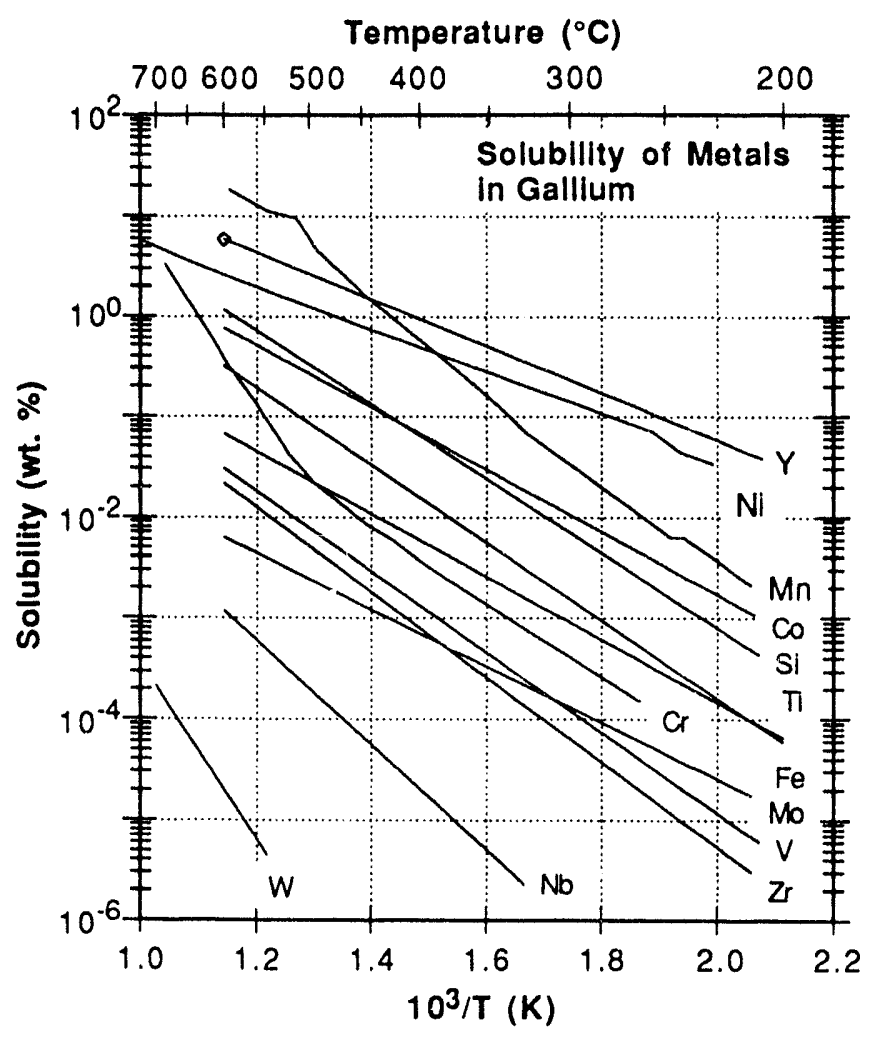

Figure 1. Solubility of pure metals in gallium at $200-700^{\circ} \mathrm{C}$

Corrosion data correlate well with solubility, i.e., metals with high solubility show poor corrosion resistance. At $400^{\circ} \mathrm{C}$, both solubility and corrosion of nickel in gallium are more than one order of magnitude greater than for iron. ${ }^{7,9}$ Various high-alloy ferritic and martensitic steels and austenitic stainless steels (SSs) show fair resistance to corrosion in gallium at temperatures up to $400^{\circ} \mathrm{C}$, i.e., a corrosion rate of $\leq 1 \mathrm{~mm} / \mathrm{y} .{ }^{9}$ In general, corrosion rates of high-alloy steels decrease with increasing chromium content, while changes in nickel content have little or no effect on corrosion. Additions of aluminum to nickelchromium stecls increase corrosion rates, and titanium additions decrease corrosion rates in gallium. ${ }^{9}$ This report presents results of scoping tests on compatibility of gallium with candidate structural materials for ITER first-wall/blanket systems, e.g., Type $316 \mathrm{SS}$, Inconel 625, and $\mathrm{Nb}-5 \mathrm{Mo}-1 \mathrm{Zr}$ alloy. Armco iron, Nickel 270 , and pure chromium were also included in the study as reference materials.

\section{Experimental Procedures}

Corrosion tests were conducted in alumina capsules $(\approx 11-\mathrm{mm}$ inner diameter and $254-\mathrm{mm}$ length) with a threaded metal fitting at the top end for sealing. The capsules were filled with $\approx 11 \mathrm{~cm}^{3}(\approx 65 \mathrm{~g})$ of gallium, capped, and sealed in a high-purity argon environment. The capsules were baked for $24 \mathrm{~h}$ at $425^{\circ} \mathrm{C}$ prior to the tests. Each capsule contained a single test specimen. An alumina rod $(6.5-\mathrm{mm}$ diameter and $150-\mathrm{mm}$ length) was placed in each capsulc to ensure that the corrosion coupon would remain immersed in gallium and to keep the specimen in place when the capsules were inverted during cooling. Corrosion coupons $(\approx 10 \times 20 \times 0.4-1.1 \mathrm{~mm})$ were prepared from Type $316 \mathrm{SS}$, Inconel $625, \mathrm{Nb}-5 \mathrm{Mo}-1 \mathrm{Zr}$ alloy, Nickel 270, Armco iron, and pure chromium. The coupons were bent into a $U$ shape to study the effect of cold work. Dimensions and weights of the specimens were recorded after degreasing and cleaning. 
Corrosion tests were conducted at 300 and $400^{\circ} \mathrm{C}$ for times up to $3,000 \mathrm{~h}$. In addition, the Type 316 SS specimens were also exposed at $200^{\circ} \mathrm{C}$ for up to $3,000 \mathrm{~h}$. After testing, the capsules were inverted and the gallium drained from the specimens to prevent possible deposition of corrosion products on the specimen surface during cooling. Corrosion coupons were washed in a warm solution of soap and water to remove gallium. If needed, a rubber scrubber was used to scrape any gallium adhering to the surface. Specimen weight and dimensions were recorded after rinsing and drying. All specimens were examined metallographically to determine metal loss and thickness of the reaction layer. A schematic representation of the corrosion behavior is shown in Fig. 2. Metal loss for each surface was determined from the initial thickness of the corrosion coupon and sound metal remaining after the test.

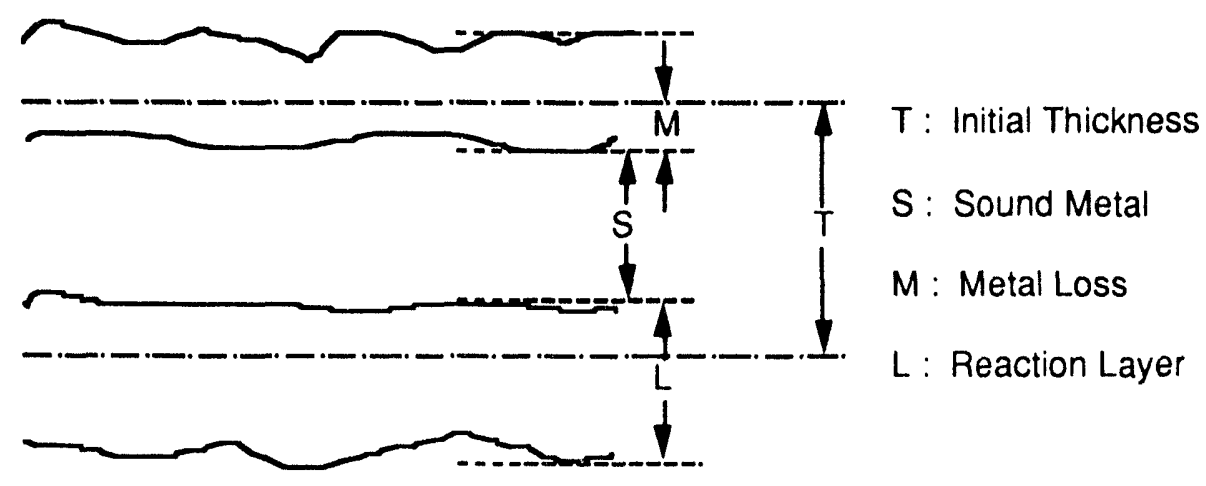

Figure 4 . Schematic diagram showing typical measurements to determine corrosion behavior of materials

\section{Results and Analysis}

The corrosion test results for the various materials are given in Table 1. Nearly all corrcsion coupons gained weight after exposurc; only the $\mathrm{Nb}-5 \mathrm{Mo}-1 \mathrm{Zr}$ alloy exposed at $400^{\circ} \mathrm{C}$ for 300 and $1,076 \mathrm{~h}$ lost weight. The pure metals react rapidly with gallium at $400^{\circ} \mathrm{C}$. An $\approx 0.5-\mathrm{mm}$-thick iron specimen reacted completely within $24 \mathrm{~h}$, and $\approx 0.3$-mm-thick chromium specimen disintegrated within $100 \mathrm{~h}$. In contrast to earlier results, ${ }^{9}$ pure iron shows higher corrosion than nickel. The corrosion rates at $400^{\circ} \mathrm{C}$ were estimated as $\geq 10$ and $2 \mu \mathrm{m} / \mathrm{h}$ for Armco iron and Nickel 270, respectively. A corrosion rate for chromium cannot be estimated accuratcly because the chromium coupon was exposed only for $100 \mathrm{~h}$ (the $100-\mathrm{h}$ result yielded a rate of $\geq 1.5 \mu \mathrm{m} / \mathrm{h}$ ).

Armco iron shows significant corrosion even at $300^{\circ} \mathrm{C}$; photomicrographs of the specimen exposed to gallium for $300 \mathrm{~h}$ at $300^{\circ} \mathrm{C}$ are shown in Fig. 3. The specimen develops a very porous and thick reaction layer that $\mathrm{X}$-ray diffraction analysis reveals to be $\mathrm{FeGa}_{3}$, with gallium metal present in the pores. A similar corrosion behavior is observed for Nickcl 270; the reaction layer contains $\mathrm{Ni}_{2} \mathrm{Ga}_{3}$ and some $\mathrm{NiGa}_{4}$ in the region in contact with gallium. Most likely, the latter formed during cooling. Metallographic examination of the reaction layers indicates that at the test temperatures, corrosion of nickel, chromium, and iron occurs entirely by dissolution accompanied by formation of mctal/gallium intermetallic compounds from the saturated solution of gallium. Corrosion or dissolution can occur only with the growth of intermetallic compounds. The growth of these compounds may control the overall rate of corrosion of most metals and alloys. For nickel and iron, the reaction proceeds at the metal surface and an adherent but extremely porous reaction layer grows outward into the melt. The process continues as long as gallium can reach the reaction zone. 
Table 1. Corrosion bchavior of matcrials exposed with gallium in scaled alumina capsules

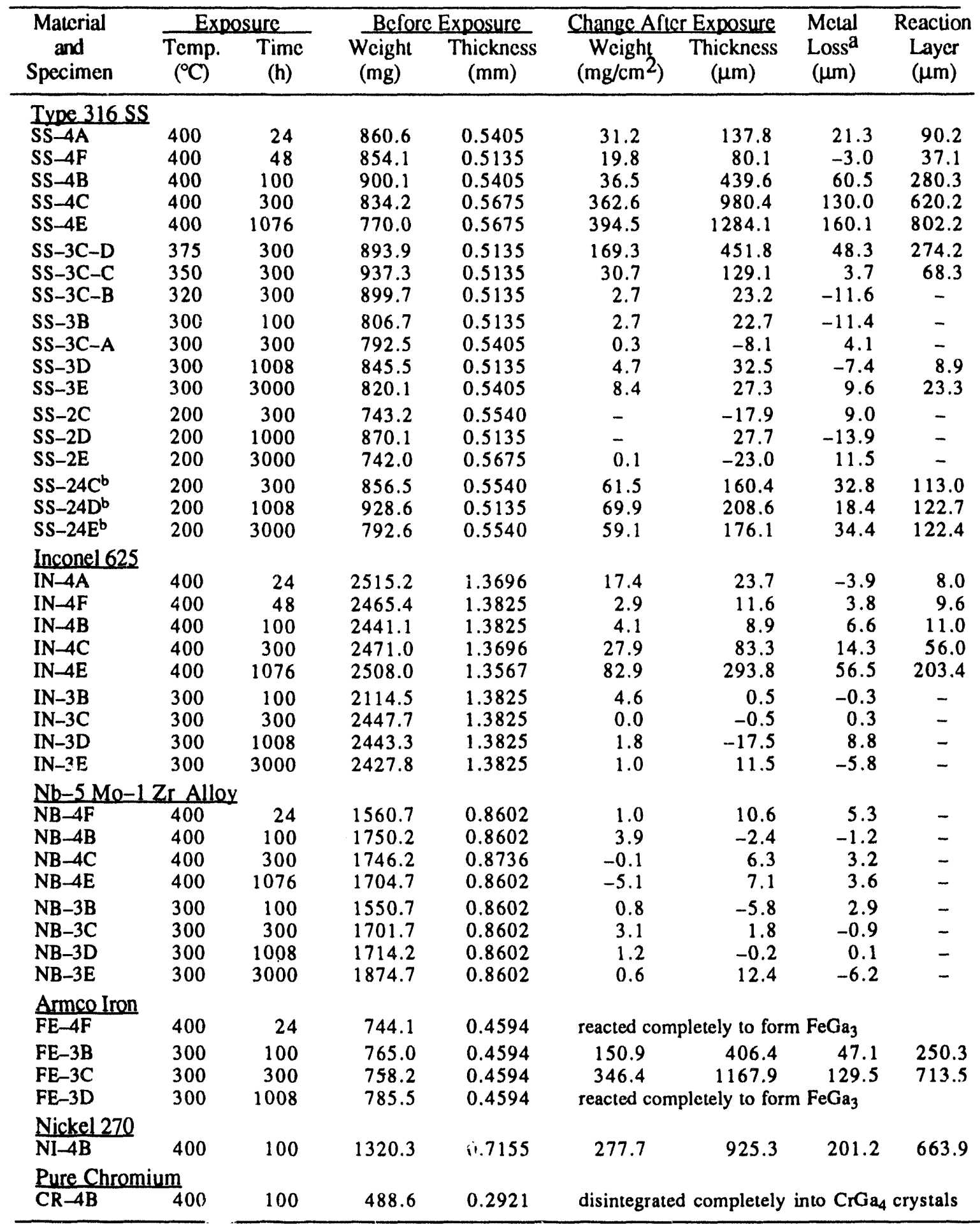

a Negative value represeit an increase in thickness. Accuracy of measurements $\pm 10 \mu \mathrm{m}$.

b Specimens exposed at $400^{\circ} \mathrm{C}$ for $24 \mathrm{~h}$ to ensure complete wetting prior to the exposure at $200^{\circ} \mathrm{C}$. 


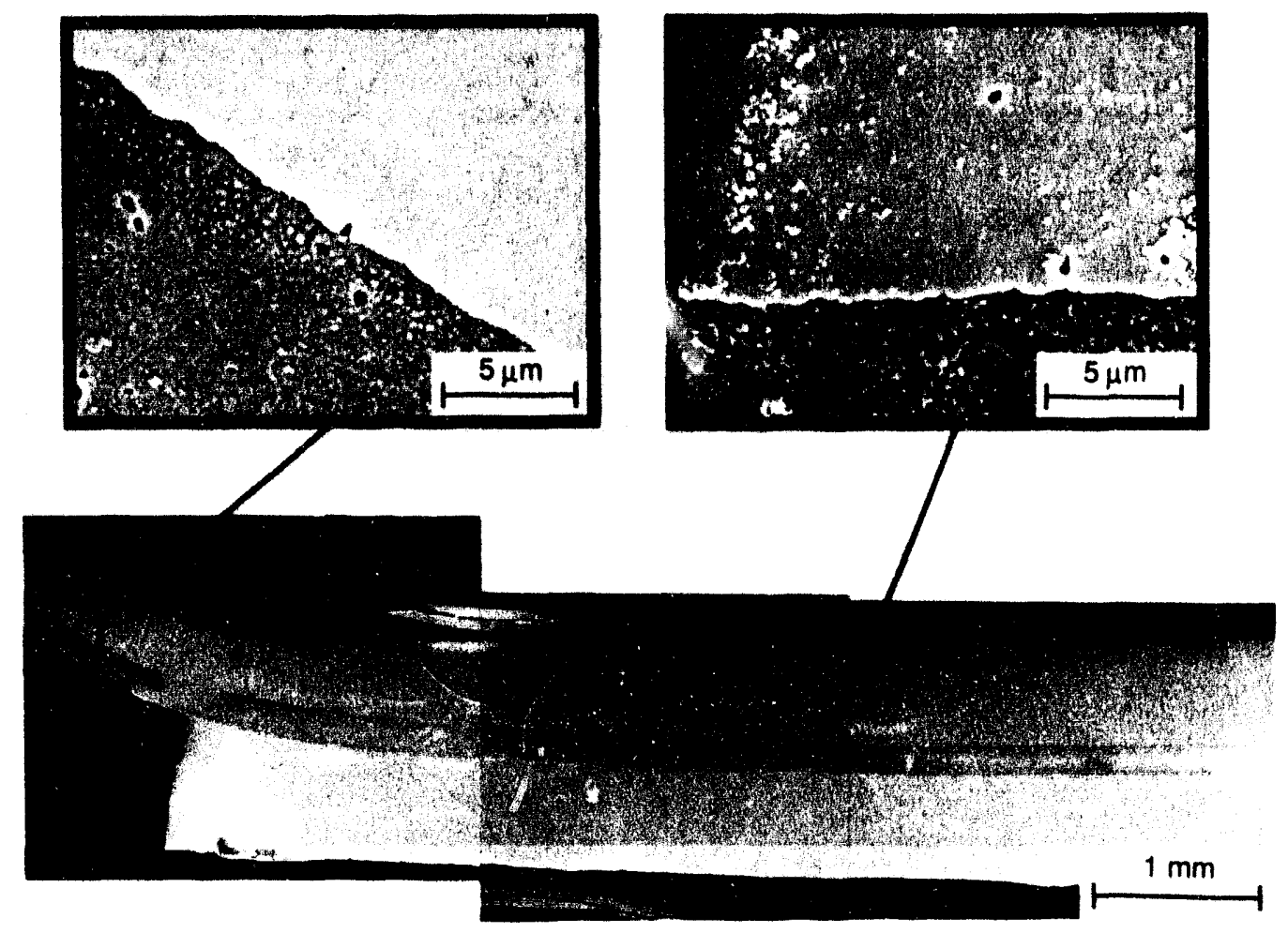

Figure 3. Cross section of Armco iron exposed to gallium at $300^{\circ} \mathrm{C}$ for $300 \mathrm{~h}$

A somewhat different behavior is observed for chromium metal: the specimen disintegrated into small crystals. The crystals were identified as $\mathrm{CrGa}_{4}$ by $\mathrm{X}$-ray diffraction analyses. This indicates that the mechanism for corrosion of chromium is basically the same as that for nickel or iron, with the only difference that the $\mathrm{CrGa}_{4}$ phase in equilibrium with the saturated solution of gallium does not adhere to the metal surface.

Type $316 \mathrm{SS}$ and Inconel 625 specimens show significant corrosion at $400^{\circ} \mathrm{C}$ and little or no corrosion at $300^{\circ} \mathrm{C}$. Once again, the iron-base Type $316 \mathrm{SS}$ shows greater corrosion than did the nickel-base Inconel 625 alloy. At $400^{\circ} \mathrm{C}$, the corrosion rate of Type $316 \mathrm{SS}$ is nearly one order of magnitude greater than that of Inconel 625 . The $\mathrm{Nb}-5 \mathrm{Mo}-1 \mathrm{Zr}$ alloy showed no measurable corrosion at 300 or $400^{\circ} \mathrm{C}$. Metal loss for the various alloys and pure metals exposed to gallium at $300^{\circ} \mathrm{C}$ and $400^{\circ} \mathrm{C}$ is plotted as a function of time in Fig. 4. Only approximate values of corrosion rates could be obtained for the various alloys exposed at $300^{\circ} \mathrm{C}$; long-term corrosion data are needed for accurate estimates of corrosion rates.

In most cases, metal loss increases linearly with time, and the corrosion rates may be represented by a single value. Corrosion rates for Type $316 \mathrm{SS}$ exposed at $400^{\circ} \mathrm{C}$, however, decrease with time. This behavior may be attributed to changes in the experimental conditions within the capsule. As discussed above, corrosion may slow or stop completely when the intermetallic compounds form. This may happen in several ways because of the limited quantity of gallium used in the experiments and also because of space restrictions. For example, corrosion on the inner surface of the U-shaped coupon will stop when the space between the two sides of the specimen fills with reaction layer. This behavior was observed for the Type 316 specimen exposed at $400^{\circ} \mathrm{C}$ for $1076 \mathrm{~h}$. Consequently, only values of metal loss up to $300 \mathrm{~h}$ were used to determine the corrosion rate of Type $316 \mathrm{SS}$ at $400^{\circ} \mathrm{C}$. Short-term corrosion tests $(300 \mathrm{~h})$ were 

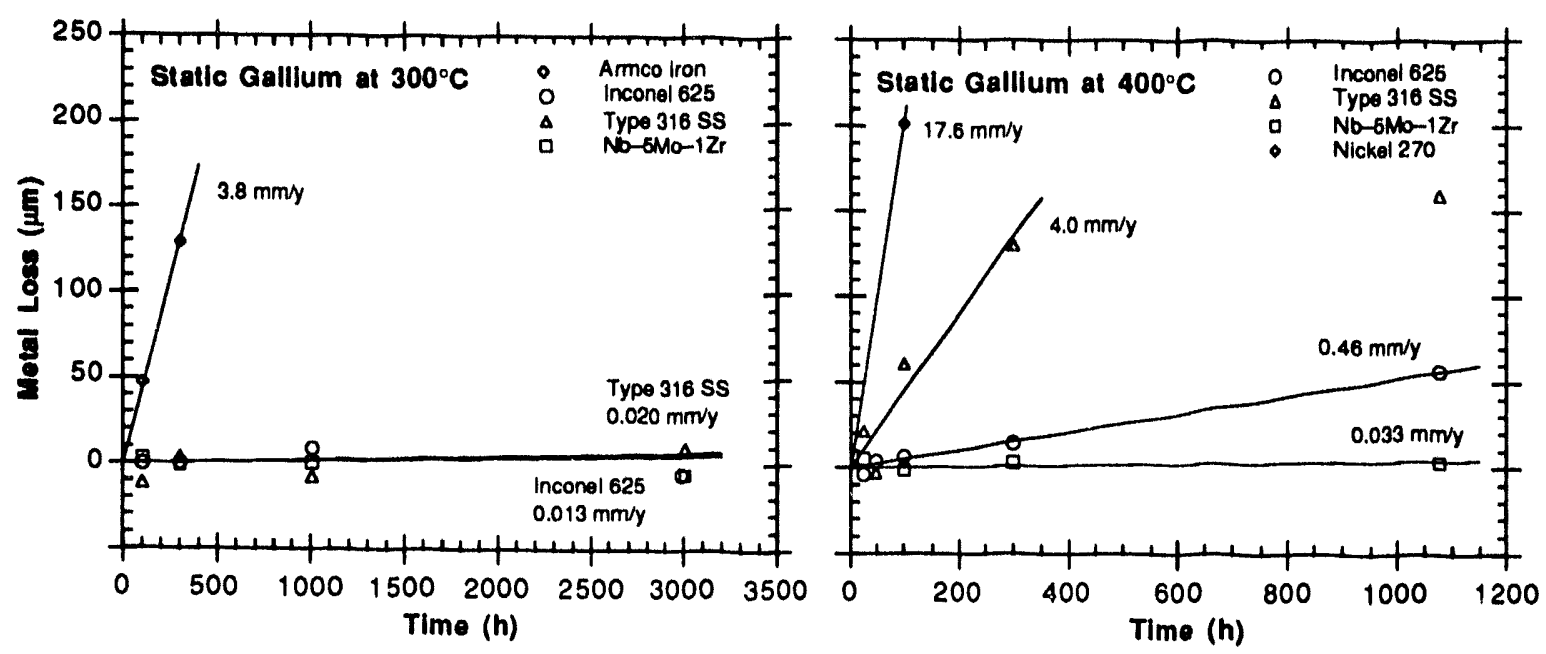

Figure 4. Metal loss for candidate structural alloys and pure metals exposed to gallium at 300 and $400^{\circ} \mathrm{C}$

conducted at 375,350 , and $320^{\circ} \mathrm{C}$ to better establish the temperature dependence of the corrosion rate of Type 316 SS. The results show excellent agreement with $300-\mathrm{h}$ tests at 400 and $300^{\circ} \mathrm{C}$.

Photomicrographs of cross sections of Type $316 \mathrm{SS}$, Inconel 625 , and $\mathrm{Nb}-5 \mathrm{Mo}-1 \mathrm{Zr}$ alloy exposed to gallium at $400^{\circ} \mathrm{C}$ are shown in Figs. 5-7. Type $316 \mathrm{SS}$ and Inconel 625 develop a thick and porous reaction layer similar to those of pure iron or nickel specimens. The $\mathrm{Nb}-5 \mathrm{Mo}-1 \mathrm{Zr}$ alloy shows little or no reaction with gallium. The reaction layer on Type $316 \mathrm{SS}$ consists primarily of $\mathrm{FeGa3}_{3}$ and gallium and also some $\mathrm{CrGa}_{4}$ in the region next to the steel surface; nickel-gallium compounds were not detected. The reaction layer on Inconel 625 contains $\mathrm{CrGa}_{4}$ and gallium across the entire thickness, and also $\mathrm{Ni}_{2} \mathrm{Ga}_{3}$ in the region next to the steel surface. The overall corrosion rate of these alloys is most likely controlled by the rate of formation of these compounds. Corrosion rates of the alloys are lower than those of pure metals because of differences in the morphology of reaction layer and/or differences in the rate of formation of these multicomponent compounds. Microprobe and X-ray diffraction analyses of the specimens are in progress to establish the mechanism of corrosion.

The results also indicate that cold work has no effect on corrosion of Type 316 SS and Inconel 625. However, cold-worked (i.e., bent) regions of $\mathrm{Nb}-5 \mathrm{Mo}-1 \mathrm{Zr}$ alloy show some corrosive attack at $400^{\circ} \mathrm{C}$ (Fig. 7). Entire grains seem to have broken from the surface. These are the only specimens that showed weight loss after exposure. Metallographic examination of the specimens indicate that weight loss is due to corrosive attack in cold-worked regions of the specimen.

An Arrhenius plot of the corrosion rates of various metals and alloys is shown in Fig. 8. In all cases, linear metal-loss behavior was assumed to determine the corrosion rates. These values may represent a conservative estimate of corrosion. Results for high-alloy steels Kh18N9T (Fe-18 Cr-9 Ni-0.6 Ti) and

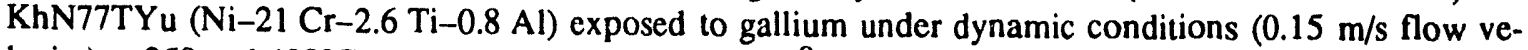
locity) at 250 and $400^{\circ} \mathrm{C}$ are also included in the figure. ${ }^{9}$ Corrosion rates of Inconel 625 and Type $316 \mathrm{SS}$ at $400^{\circ} \mathrm{C}$ are comparable to those of $\mathrm{Kh} 18 \mathrm{~N} 9 \mathrm{~T}$ and $\mathrm{KhN} 77 \mathrm{TYu}$ but show lower values at $250^{\circ} \mathrm{C}$. The differences are most likely due to velocity effects. 


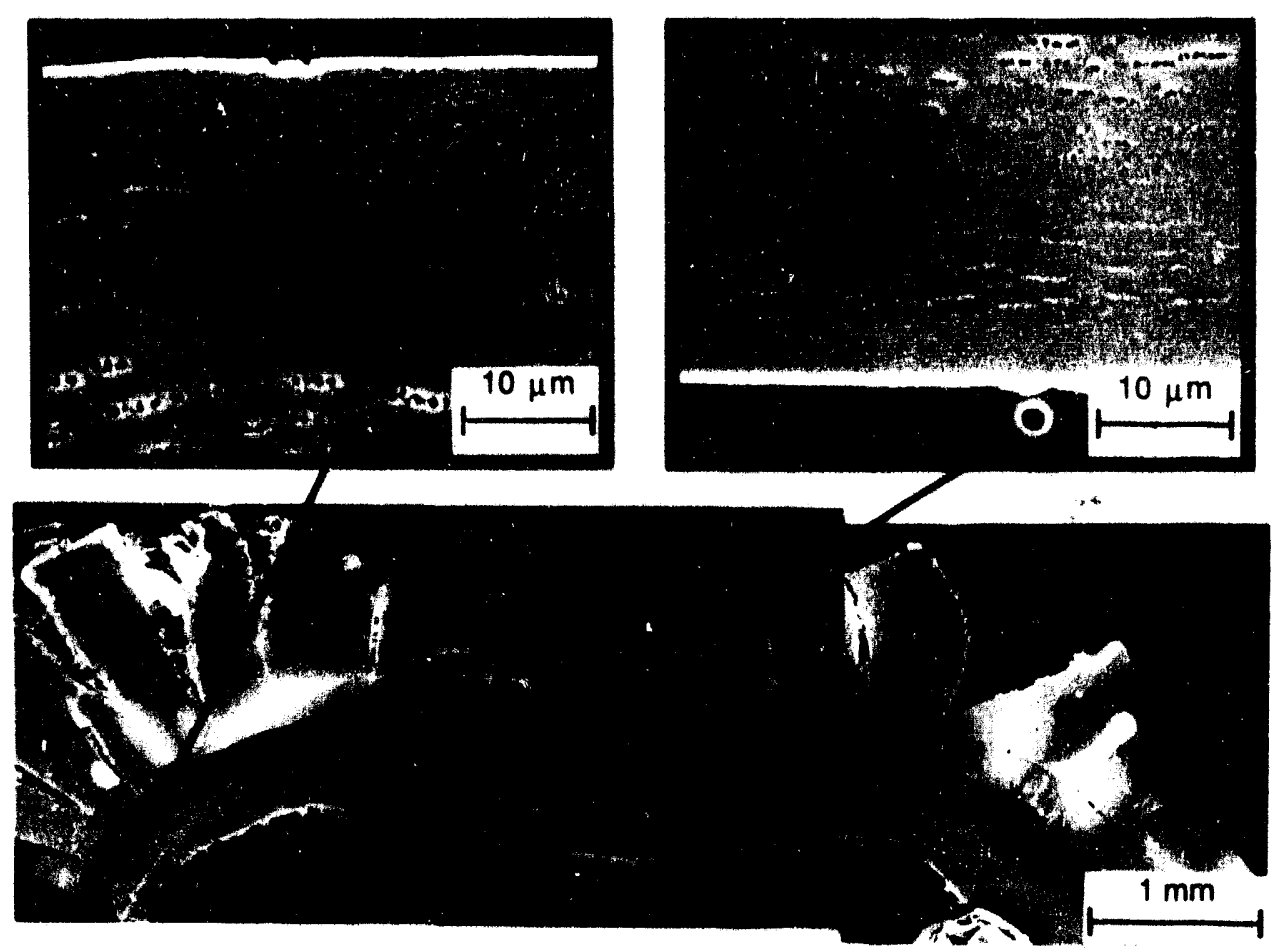

Figure 5. Cross section of Type 316 stainless steel exposed to gallium at $400^{\circ} \mathrm{C}$ for $300 \mathrm{~h}$
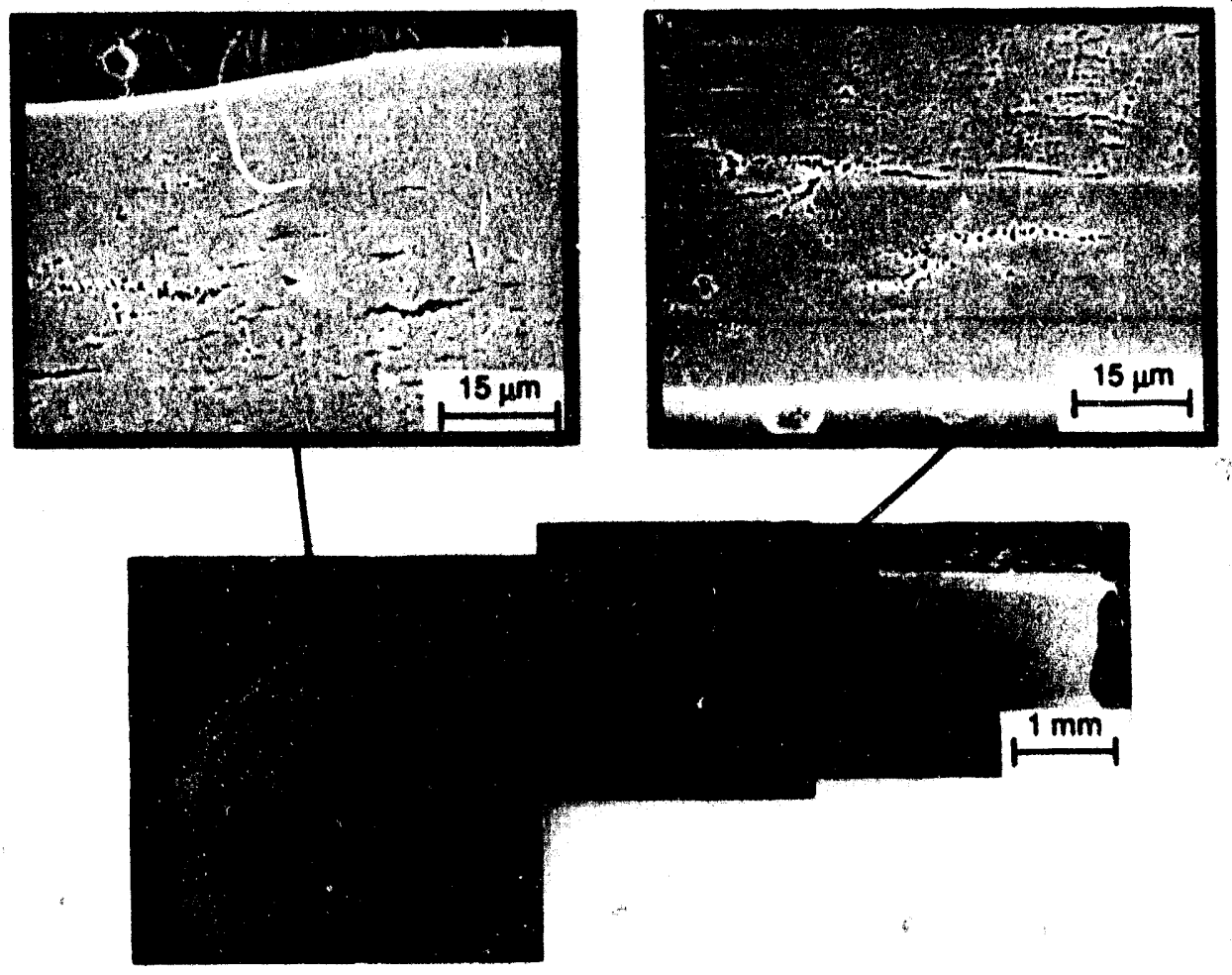

Figure 6. Cross section of Inconel 625 exposed to gallium at $400^{\circ} \mathrm{C}$ for $1076 \mathrm{~h}$ 


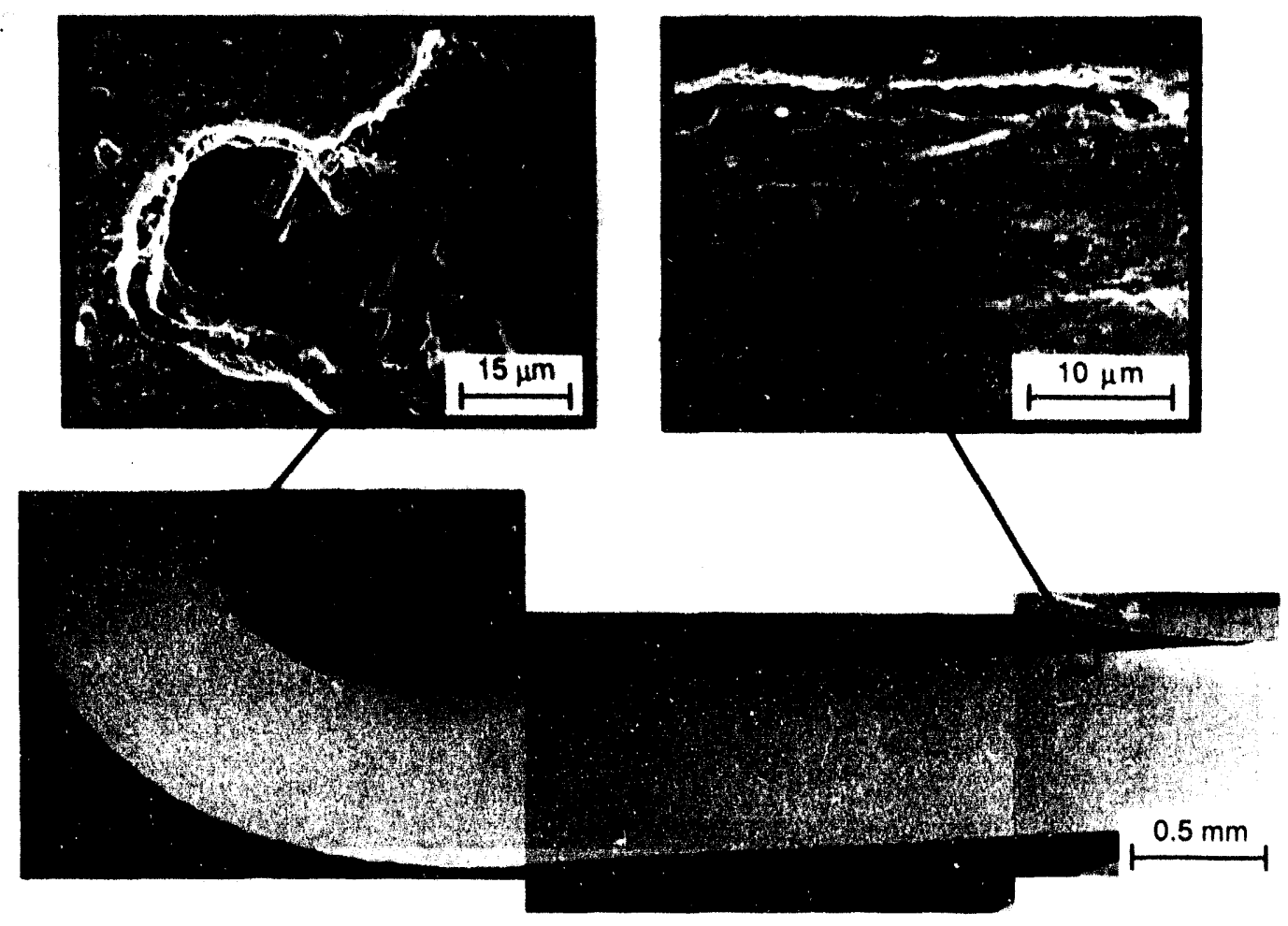

Figure 7. Cross section of $\mathrm{Nb}-5 \mathrm{Mo}-1 \mathrm{Zr}$ alloy exposed to gallium at $400^{\circ} \mathrm{C}$ for $1076 \mathrm{~h}$

Figure 8 can be used to establish the maximum temperature limit for gallium/structural alloy systems. A maximum corrosion rate is first defined on the basis of either the allowable change in section thickness of the component or allowable mass transfer in the liquid metal system. The maximum operating temperature corresponding to the maximum corrosion rate is then obtained from Fig. 8 for a specific alloy/gallium system. For example, the maximum surface temperature of a Type 316 SS component must be $<350^{\circ} \mathrm{C}$ to keep the corrosion rates below $250 \mu \mathrm{m} / \mathrm{y}$. The niobium alloy can operate at higher temperatures for the same corrosion criterion. It should be noted that Fig. 8 does not include the effects of system variables such as velocity and $\Delta \mathrm{T}$ on corrosion mass transfer.

\section{CONCLUSIONS}

Scoping tests have been conducted on the compatibility of gallium with candidate structural materials, e.g., Type $316 \mathrm{SS}$, Inconel 625 , and $\mathrm{Nb}-5 \mathrm{Mo}-1 \mathrm{Zr}$ alloy, as well as Armco iron, Nickel 270, and pure chromium. The pure metals react rapidly with gallium. In contrast to earlier studies, pure iron shows greater corrosion than does nickel. The corrosion rates for Armco iron and Nickel 270 at $400^{\circ} \mathrm{C}$ are $\geq 90$ and $17 \mathrm{~mm} / \mathrm{y}$, respectively. The results indicate that at 'cmperatures up to $400^{\circ} \mathrm{C}$, corrosion occurs primarily by dissolution accompanied by formation of metal/gallium intermetallic compounds. The growth of intermetallic compounds may control the overall rate of corrosion. Corrosion of iron-base Type 316 SS is greater than that of nickel-base Inconel 625 . The $\mathrm{Nb}-5 \mathrm{Mo-1} \mathrm{Zr}$ alloy is most resistant to corrosion in static gallium. At $400^{\circ} \mathrm{C}$, corrosion rates are $\approx 4.0,0.5$, and $0.03 \mathrm{~mm} / \mathrm{y}$ for Type $316 \mathrm{SS}$, Inconel 625 , and $\mathrm{Nb}-5 \mathrm{Mo}-1 \mathrm{Zr}$ alloy, respectively. 


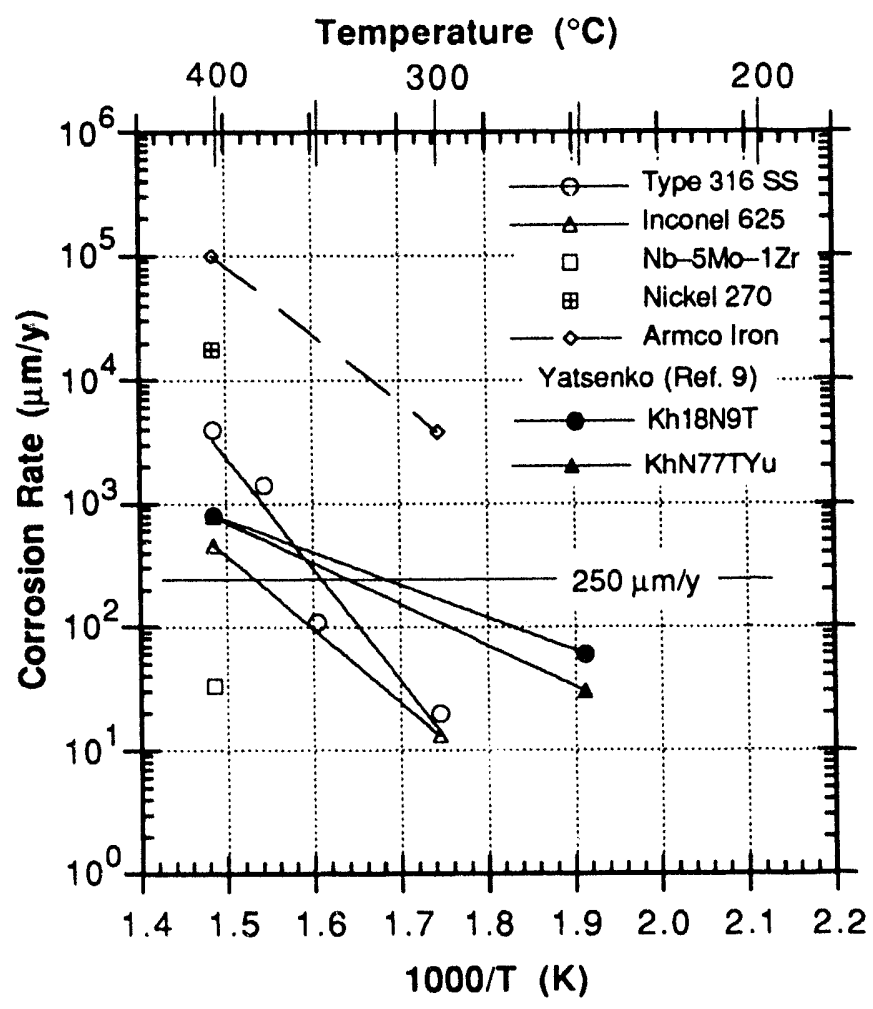

Figure 8. Corrosion rates of candidate alloys and pure metals in ga:lium

\section{FUTURE WORK}

Compatibility tests are in progress on preoxidized Type 316 SS specimens. Tests are also planned in an oxidizing environment to study the stability of oxide coatings in gallium.

\section{ACKNOWLEDGMENTS}

The autiors thank C. Reed and P. Dombrowski for experimental contributions, B. Tani for performing $\mathrm{X}$-ray diffraction analyses, and T. F. Kassner for helpful discussions.

\section{REFERENCES}

1. W. D. Wilkinson, Effects of Gallium on Materials at Elevated Temperatures, Argonne National Laboratory Report ANL-5027 (August 1953).

2. W. D. Wilkinson, Effects of Gallium on Materials at Elevated Temperatures Supplementary Report, Argonne National Laboratory Report ANL-4582 (August 1953).

3. L. R. Kelman, W. D. Wilkinson, and F. L. Yaggee, Resistance of Materials to Attack by Liquid Metals, Argonne National Laboratory Report ANL-4417 (July 1950). 
4. S. P. Yatsenko and Y. A. Anikin, Solubility of Metals of the Fifth Period in Liquid Gallium, Sov. Mat. Sci., 6, 333-337 (1970).

5. S. P. Yatsenko and Y. A. Anikin, Solubility of Group IV Metals in Liquid Gallium, Russ. Metall., 4, 118-123(1970).

6. S. P. Yatsenko, L. N. Rykova, Y. A. Anikin, and E. N. Dieva, The Corrosion of Group VIII Metals in Liquid Gallium, Sov. Mat. Sci., 8, 310-313 (1972).

7. S. P. Yatsenko, Correlation of Physical Properties of Pure Solid Metals with Their Resistance to Corrosion by Liquid B Metal, Russ. J. Phy. Chem., 45, (8), 1095-1098 (1971).

8. C. Guminski, Solubility of Metals in Liquid Low-Melting Metals, Z. Metallkd., 81, (2), 105-110 (1990).

9. S. P. Yatsenko, Gallium Interaction With Metals, Nauka, Moscow (1974). 
AQUEOUS STRESS CORROSION OF CANDIDATE AUSTENITIC STEELS FOR ITER STRUCTURAL APPLICATIONS* - W. K. Soppet, D. M. French, and T. F. Kassner (Argonne National Laboratory)

\section{OBJECTIVE}

Austenitic stainless steels are being considered as a structural material for first-wall/blanket systems in the International Thermonuclear Experimental Reactor (ITER). ${ }^{1}$ Information on stress corrosion cracking (SCC) susceptibility of several candidate stainless steels under ITER-relevant conditions will help to identify an optimal combination of structural material, coolant chemistry, and operational conditions for ongoing ITER design work. The objective of this task is to provide baseline information on SCC susceptibility of candidate stainless steels in oxygenated water that simulates many important parameters anticipated in ITER first-wall/blanket systems. SCC tests will also be conducted under off-normal water chemistry conditions and at higher temperatures to establish the performance limits of the materials.

\section{SUMMARY}

Susceptibility of crevice-weldment specimens of Types $316 \mathrm{~L}$ and $316 \mathrm{NG}$ stainless steel (SS) to SCC was investigated in slow-strain-rate-tensile (SSRT) tests in water that simulates important parameters anticipated in first-wall/blanket systems. The SSRT tests were performed in oxygenated water containing $0.06-10 \mathrm{ppm}$ chloride at temperatures of 95 to $225^{\circ} \mathrm{C}$ to establish the effects of water purity and temperature on SCC resistance. These steels, including weldments, exhibit good resistance to SCC under crevice conditions at temperatures of $<150^{\circ} \mathrm{C}$ in water containing $\leq 0.1 \mathrm{ppm}$ chloride. It appears that Type 316 NG SS is somewhat more resistant to SCC than Type $316 \mathrm{~L} \mathrm{SS}$ at temperatures $>150^{\circ} \mathrm{C}$ in oxygenated water containing $0.1-10 \mathrm{ppm}$ chloride. Most specimens fractured in the base metal, and several others fractured in the heat-affected zone (HAZ) of the weld, but none failed in the weld metal.

\section{PROGRESS AND STATUS}

The research and development needs ${ }^{2}$ of the ITER with respect to aqueous corrosion include establishing a reliable data base on reference materials (viz., Types $316,316 \mathrm{~L}$, and $316 \mathrm{NG}$ SS in the solution-annealed, cold-worked, and welded conditions). A nominal ITER water chemistry would most likely be high-purity water containing stable radiolysis/clectrolysis products, e.g., dissolved $\mathrm{O}_{2}, \mathrm{H}_{2} \mathrm{O}_{2}$, and $\mathrm{H}_{2}$ at ppm levels, and ionic species at ppb levels, namely, soluble corrosion products and impurities in the makeup water and from release by ion-exchange resins in water purification systems. Higher concentrations of ionic impurities (e.g., $\mathrm{Cl}^{-}, \mathrm{SO}_{4}^{2-}, \mathrm{H}^{+}, \mathrm{ctc}$.) in the coolant may be present during offnormal operating and extended lay-up conditions of the system.

Previous work ${ }^{3,4}$ focused on developing criteria to define the simulated ITER water chemistry and establishing experimental methods for SSRT tests on noncrevice and crevice specimens. Results from experiments to evaluate SCC susceptibility from SSRT tests on Types 316NG, 316, and 304 SS have been reported previously. ${ }^{5-10}$ No indication of SCC was observed in tests on noncrevice specimens of Type $316 \mathrm{NG} \mathrm{SS}{ }^{8}$ in oxygenated water containing $0.1-1.0 \mathrm{ppm} \mathrm{SO}_{4}^{2-}$ at temperatures of 95 and $150^{\circ} \mathrm{C}$ and a strain rate of $3 \times 10^{-7} \mathrm{~s}^{-1}$. Crevice specimens were also resistant to SCC in oxygenated water containing $0.1 \mathrm{ppm} \mathrm{SO} \mathrm{SO}_{4}^{2-}$ at temperatures $\leq 150^{\circ} \mathrm{C}^{9}$ Predominantly ductile fracture (with a minor amount of transgranular cracking, TGSCC) was observed in crevice specimens of Type 316NG SS at higher temperatures. Intergranular failure occurred in Type 304 SS crevice specimens heat treated to yield sensitization values of 2 and $20 \mathrm{C} \cdot \mathrm{cm}^{-2}$ by electrochemical potentiokinetic reactivation. ${ }^{8,9}$ Initial tests on

\footnotetext{
* Work supported by the U.S. Department of Energy, under Contract W-31-109-Eng-38.
} 
temperatures. Intergranular failure occurred in Type 304 SS crevice specimens heat treated to yield sensitization values of 2 and $20 \mathrm{C} \cdot \mathrm{cm}^{-2}$ by electrochemical potentiokinetic reactivation. ${ }^{8,9}$ Initial tests on weldment specimens of Type 316L SS with matching filler metal, under crevice conditions in oxygenated water containing $0.06-6.0 \mathrm{ppm}$ chloride at $150-225^{\circ} \mathrm{C}$, revealed that most specimens fractured in the base metal and that several others fractured in the HAZ of the weld, but that none failed in the weld metal. ${ }^{10}$ In this report, results from SSRT tests at 95 and $225^{\circ} \mathrm{C}$ on crevice-weldment specimens of Type 316NG SS in air and in water containing $\mathrm{O}_{2}, \mathrm{H}_{2} \mathrm{O}_{2}$, and $\mathrm{Cl}^{-}$are compared with similar data on weldment specimens of Type 316L SS.

\section{Experimental Procedures}

Cylindrical tensile specimens with a $6.35 \mathrm{~mm}$ diameter and a $36.0 \mathrm{~mm}$ gage length were fabricated from Types $316 \mathrm{NG}$ and $316 \mathrm{~L}$ SS. The chemical composition of the materials used in these experiments is given in Table 1. The experimental methods have been described in previous papers. ${ }^{6,8-10}$ Creviceweldment specimens were created by drilling three small-diameter $(\approx 0.8-0.9 \mathrm{~mm})$ through holes in the gage section of the specimens, i.e., in the base metal, the HAZ of the weld (edge of the hole $\approx 1-2 \mathrm{~mm}$ from the fusion line), and in the weld metal, and placing austenitic SS pins in the holes to form tight crevices (Fig. 1). The location of the hole in the HAZ was selected on the basis of experimental measurements and model predictions of variations in degree of sensitization across this region in welds of 24-in.-diameter Type 304 and 316 SS pipe. ${ }^{11}$ This location corresponds to maximum sensitization (i.c., Cr depletion and carbide precipitation at grain boundaries). Although sensitization does not occur in low-C grades of Types $316 \mathrm{NG}$ and 316L SS, this location may be synonymous with other thermal segregation processes involving alloying elements and impurities in the stecl. The wn.ldment specimens were tested in the as-received condition without any heat treatment. Tests were carried to failure at strain rates of $1 \times 10^{-5} \mathrm{~s}^{-1}$ in air and $3 \times 10^{-7} \mathrm{~s}^{-1}$ in water in small-diameter autoclaves with a once-through water system.

Water chemistry was established by bubbling a 20\% $\mathrm{O}_{2}-80 \% \mathrm{~N}_{2}$ gas mixture through deoxygenated/deionized feedwater (conductivity $<0.2 \mu \mathrm{S} \cdot \mathrm{cm}^{-1}$ ) contained in a 130-liter SS tank to produce a dissolved-oxygen concentration of $\approx 8.0 \mathrm{ppm} . \mathrm{H}_{2} \mathrm{O}_{2}(5.0$ to $8.0 \mathrm{ppm})$ and $\mathrm{NaCl}\left(0.06\right.$ to $\left.10.0 \mathrm{ppm} \mathrm{\textrm {Cl } ^ { - }}\right)$ were added to the feedwater before sparging with the gas mixture to ensure adequate mixing. An external $0.1 \mathrm{M} \mathrm{KCl} / \mathrm{AgCl} / \mathrm{Ag}$ reference electrode, a thermocouple, and $\mathrm{Pt}$ and Type $304 \mathrm{SS}$ electrodes were located at the autoclave outlet to establish redox and open-circuit potential, respectively. The electrochemical potentials measured during the experiments were converted to the standard hydrogen electrode (SHE) scale by using thermocell and liquid-junction potentials. ${ }^{12}$

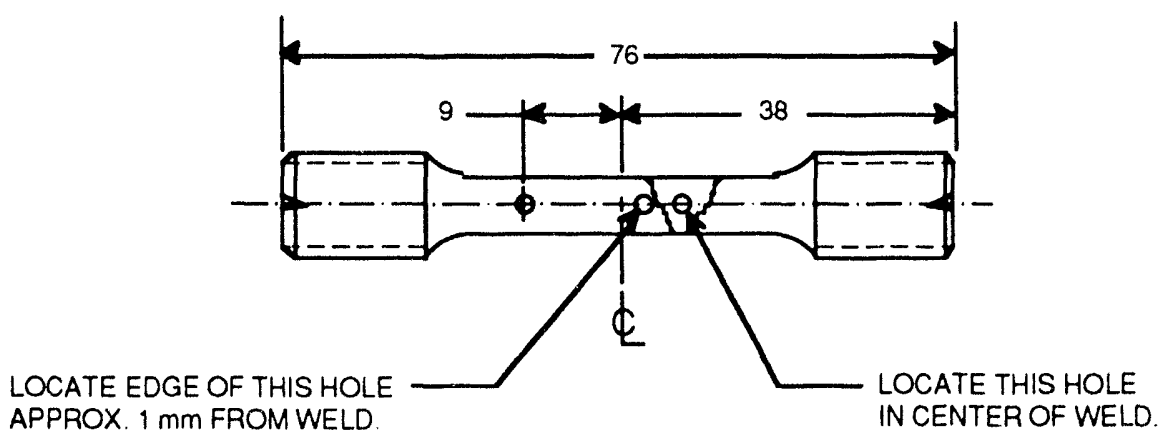

Figure 1. Weld specimen fabricated from gas-metal-arc--welded plate of Type 316L SS with matching filler metal. Crevices were formed by inserting tight-fitting SS pins into the holes. 
The tests provide information on time-to-failure, total strain, maximum stress, and appearance of fracture surfaces. The load applied to cach specimen was recorded continuously as a function of time, and an engineering-stress-versus-strain curve was produced for each specimen. Total elongation and reduction in area were determined from measurements on the fractured specimens. The fracture surfaces were examined by both optical microscopy and scanning electron microscopy (SEM) to determine the fractions of reduced cross-sectional arcas with ductile, transgranular, and intergranular morphologics. ${ }^{13}$

\section{Results and Analysis}

Cracking susceptibility can be assessed from various parameters. Total clongation, reduction in area, and maximum stress are often used, as are fracture surface morphology and maximum crack length (either on the fracture surface or on the sectioned surface after test interruption). Because of the high SCC resistance of Type $316 \mathrm{NG}$ SS relative to that of sensitized Type 304 SS, it is difficult to quantify SCC behavior of Type 316 NG SS in terms of crack growth rate ${ }^{14}$ from SSRT test results. An alternative, cmployed here, is evaluation of SCC susceptibility in terms of the ratio of the strain at failure ( $e_{e n v} / e_{a i r}$ ) from companion tests on identical specimens in water and in air. Values of the strain ratio $<1 .()$ indicate environmentally assisted cracking.

Results of SSRT tests at temperatures of $6010289^{\circ} \mathrm{C}$ on crevice and noncrevice specimens of Types 316 NG and 304 SS were presented previously. 6,8-10) The SSRT results in Tables 2 and 3 were sblained from the enginecring-stress (based on a cross-sectional area without subtracting the area associated with the hole) versus enginecring-strain curves in air and water on identical specimens. Although the air tests were performed at a higher strain rate (e.g., $1 \times 10^{-5} s^{-1}$ ), the yicld and ultimate strengths, total clongation, reduction in area, and fracture morphology can be compared in the two environments to assess SCC susceptibility. Because the tests were performed at two strain rates, time-to-failure is not a useful parameter. Total clongation at failure appears to be the most promising measure of SCC susceptibility. Consequently, the data in Tables 2 and 3 were analyzed on the basis of a strain-ratio parameter, namely, $\mathrm{S}_{\mathrm{r}}=\mathrm{e}_{\mathrm{env}} / \mathrm{e}_{\mathrm{air}}$ at failure for identical specimen geometries. The strain ratios as a function of temperature and chloride concentration in oxygenaled water are given in Tables 4 and 5 for Types $310 \mathrm{~L}$ and 316 NG SS, respectively.

It is well known that chloride concentration in oxygenated water significantly affects SCC and pitting of austenitic stainless steels. ${ }^{15-21}$ Most available SCC data pertain to standard-grade steels (e.g., Types 316 and 304 in the sensitized and solution-annealed conditions) under noncrevice conditions. As temperature and chloride and/or dissolved-oxygen concentration in the water increase, these steels become susceptible to SCC, particularly in the :ensitized condition. Types $316 \mathrm{~L}$ and $316 \mathrm{NG} \mathrm{SS}$, both with low C content and the latter with a controlled $\mathrm{N}$ contemt (0.06-0.10\%), are expected to be more resistant to SCC in oxygenated water containing low levels of chloride.

The effects of chloride concentration and temperature on the strain ratio at failure from SSRT tests on crevice-weldment specimens of Types 316L and 316NG SS are shown in Figs. 2 and 3. The results indicate that low-C-content Types $316 \mathrm{~L}$ and 316 NG SS are susceptible to TGSCC under crevice conditions in high-temperature oxygenated water containing chloride at low concentrations $(<10 \mathrm{ppm})$. The curves in Fig. 2 indicate that as the temperature increases (from $9510225^{\circ} \mathrm{C}$ ), the critical chloride concentration in water for the onset of SCC (a strain rattio of $<1.0$ ) is $<\left(0.1 \mathrm{ppm}\right.$. The actual values at temperatures $>150^{\circ} \mathrm{C}$ for Type 316L SS can only be approximaled from the results in Fig. 2. However, for chloride concentrations $>0.6 \mathrm{ppm}$ in the bulk water, $\mathrm{SCC}$ is significant, as indicated by values of the strain ratio hetween $\approx 0.3$ and 0.7 . The curves for Type $316 \mathrm{NG}$ SS at 95 and $225^{\circ} \mathrm{C}$ reveal that this material is somewhat more resistant to $\mathrm{SCC}$, c.g., at $225^{\circ} \mathrm{C}$, the strain ratios are between $=0.9$ and 0.6 , in contrast to between $\approx 0.5$ and 0.3 for Type $316 \mathrm{~L}$ SS. Strain ratios for Type $316 \mathrm{NG}$ SS were $\approx 1 .()$ at $95^{\circ} \mathrm{C}$, which is indicative of no SCC in these environments. Figure 3 also illustrates the marked effect of temperature on SCC of the stecls. 
Table 1. Composition of austenitic stainless steels (wt.\%)

\begin{tabular}{lcccccccccccc}
\hline Alloy & Heat No. & $\mathrm{Cr}$ & $\mathrm{Ni}$ & $\mathrm{Mo}$ & $\mathrm{Mn}$ & $\mathrm{Si}$ & $\mathrm{Cu}$ & $\mathrm{N}$ & $\mathrm{C}$ & $\mathrm{P}$ & $\mathrm{S}$ & $\mathrm{Fe}$ \\
\hline 316NG & NDE-28 & 17.79 & 13.58 & 2.59 & 1.77 & 0.52 & 0.10 & 0.110 & 0.014 & 0.020 & 0.002 & $\mathrm{Bal}$ \\
$316 \mathrm{~L}$ & 16650 & 16.50 & 10.39 & 2.09 & 1.78 & 0.43 & 0.19 & 0.054 & 0.018 & 0.026 & 0.013 & $\mathrm{Bal}$ \\
$316 \mathrm{~L}^{\mathrm{a}}$ & $4 \mathrm{H} 3367$ & 18.69 & 12.29 & $\mathrm{~b}$ & 1.98 & 0.63 & 0.25 & $\mathrm{~b}$ & 0.018 & 0.023 & 0.018 & $\mathrm{Bal}$ \\
\hline
\end{tabular}

Type 316L SS filler metal for weld specimens of Heat 16650.

bNot analyzed.

Table 2. SCC susceptibility of Type 316NG SS crevice-weldment specimens ${ }^{a}$ strained to failure

\begin{tabular}{|c|c|c|c|c|c|c|c|c|c|c|c|c|c|c|c|c|c|}
\hline \multirow[b]{3}{*}{$\begin{array}{l}\text { Test } \\
\text { No. }\end{array}$} & \multirow[b]{3}{*}{$\begin{array}{c}\text { Heat } \\
\text { No. }\end{array}$} & \multirow[b]{3}{*}{$\begin{array}{c}\text { Temp. } \\
\left({ }^{\circ} \mathrm{C}\right)\end{array}$} & \multirow{3}{*}{$\begin{array}{l}\text { Strain } \\
\text { Rate } \\
\left(\mathrm{s}^{-1}\right)\end{array}$} & \multirow{2}{*}{\multicolumn{5}{|c|}{ Feed water Chemistryb }} & \multicolumn{7}{|c|}{ SSRT Parameters } & & \\
\hline & & & & & & & & & Fail. & Yield & Max. & Total & Reduct. & Falure & & \multicolumn{2}{|c|}{ Potentials } \\
\hline & & & & $\begin{array}{l}\mathrm{H}_{2} \mathrm{O}_{2} \\
(\mathrm{ppm})\end{array}$ & $\begin{array}{c}\mathrm{O}_{2} \\
(\mathrm{ppm})\end{array}$ & $\begin{array}{c}\mathrm{Cl} \\
\mathrm{pm})\end{array}$ & $\begin{array}{c}\text { Cond. } \\
\left(\mu \mathrm{S} \cdot \mathrm{cm}^{-1}\right)\end{array}$ & $\begin{array}{l}\mathrm{pH} \text { at } \\
25^{\circ} \mathrm{C}\end{array}$ & $\begin{array}{l}\text { Time } \\
\text { (h) }\end{array}$ & $\begin{array}{l}\text { Suress } \\
(\mathrm{MPa})\end{array}$ & $\begin{array}{l}\text { Stress } \\
(\mathrm{MPa})\end{array}$ & $\begin{array}{l}\text { Elong. } \\
(\%)\end{array}$ & $\begin{array}{l}\text { in Area } \\
(\%)\end{array}$ & Region $c$ & $\begin{array}{l}\text { Fracture } \\
\text { Morphology }\end{array}$ & $\begin{array}{l}304 \mathrm{SS} \\
\quad \mathrm{mV}[\mathrm{SHI} \\
\end{array}$ & $\begin{array}{l}\mathrm{Pl} \\
\mathrm{E}] \mathrm{l}\end{array}$ \\
\hline 100 & NDE 28 & 95 & $1 \times 10^{-5}$ & 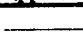 & $-a$ & test & -2 & & 5.0 & 339 & 567 & 18.1 & 72 & B & $1.0 \mathrm{D}$ & - & - \\
\hline 101 & NDE 28 & 95 & $3 \times 10^{-7}$ & 5.0 & 8.0 & 0.1 & 1.4 & 6.2 & 162 & 329 & 563 & 16.8 & 72 & B & $1.0 \mathrm{D}$ & 433 & 396 \\
\hline 102 & NDE 28 & 95 & $3 \times 10^{7}$ & 5.0 & 8.5 & 1.0 & 4.2 & 6.3 & 172 & 348 & 570 & 18.3 & 69 & B & $1.0 \mathrm{D}^{\mathrm{d}}$ & 443 & 389 \\
\hline 103 & NDE 28 & 95 & $3 \times 10^{-7}$ & 5.0 & 8.0 & 10.0 & 34.5 & 6.5 & 171 & 327 & 568 & 18.1 & 54 & HAZ & $0.7 \mathrm{D}, 0.3 \mathrm{~T}$ & 414 & 389 \\
\hline 104 & NDE 28 & 225 & $3 \times 10^{-7}$ & 5.5 & 8.0 & 0.1 & 0.9 & 6.2 & 139 & 260 & 497 & 14.9 & 63 & B & $1.0 \mathrm{D}$ & 290 & 305 \\
\hline 105 & NDE 28 & 225 & $3 \times 10^{-7}$ & 6.0 & 8.0 & 1.0 & 4.0 & 6.3 & 101 & 266 & 458 & 11.6 & 55 & B & $0.7 \mathrm{D}, 0.3 \mathrm{~T}$ & 295 & 320 \\
\hline 106 & NDE 28 & 225 & $3 \times 10^{-7}$ & 6.0 & 8.0 & 10.0 & 35.9 & 6.2 & 68 & 296 & 411 & 10.0 & 44 & B & $0.5 \mathrm{D}, 0.5 \mathrm{~T}$ & 273 & 325 \\
\hline
\end{tabular}

${ }^{a}$ Crevice SSRT specimen from a gas-metal-arc weldment of Type 316NG SS 28-in--diameter pipe (Heat No. NDE 28).

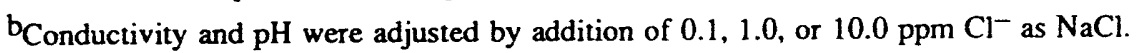

'Specimen failed in the base metal (B), in the heat affected zone (HAZ), or in the weld (W).

d Specimen failed in the base metal but a crack was present in the HAZ. 
Table 3. SCC susceptibility of Type 316 crevice-weldment specimens $^{a}$ strained to failure

\begin{tabular}{|c|c|c|c|c|c|c|c|c|c|c|c|c|c|c|c|c|c|}
\hline \multirow[b]{3}{*}{$\begin{array}{l}\text { Test } \\
\text { No. }\end{array}$} & \multirow[b]{3}{*}{$\begin{array}{c}\text { Heat } \\
\text { No. }\end{array}$} & \multirow[b]{3}{*}{$\begin{array}{l}\text { Temp. } \\
\left({ }^{\circ} \mathrm{C}\right)\end{array}$} & \multirow{3}{*}{$\begin{array}{l}\text { Strain } \\
\text { Rate } \\
\left(\mathrm{s}^{-1}\right)\end{array}$} & \multirow{2}{*}{\multicolumn{5}{|c|}{ Foedwater Chemistryb }} & \multicolumn{7}{|c|}{ SSRT Parameters } & & \\
\hline & & & & & & & & & Fail & & & & & Faikre & & \multicolumn{2}{|c|}{ Potentials } \\
\hline & & & & $\begin{array}{l}\mathrm{H}_{2} \mathrm{O}_{2} \\
(\mathrm{ppm})\end{array}$ & $\begin{array}{c}\mathrm{O}_{2} \\
\text { (pom) }\end{array}$ & $\begin{array}{c}\mathrm{Cl} \\
(\mathrm{ppm})\end{array}$ & $\begin{array}{c}\text { Cond. } \\
\left(\mu \mathrm{S} \cdot \mathrm{cm}^{-1}\right)\end{array}$ & $\begin{array}{l}\text { pll at } \\
25^{\circ} \mathrm{C} \\
\end{array}$ & $\begin{array}{l}\text { Time } \\
\text { (h) }\end{array}$ & $\begin{array}{l}\text { Stress } \\
\left(\mathrm{MP}_{2}\right)\end{array}$ & $\begin{array}{l}\text { Stress } \\
\left(\mathrm{MPa}^{2}\right) \\
\end{array}$ & $\begin{array}{c}\text { Elong. } \\
(\%)\end{array}$ & $\begin{array}{c}\text { in Area } \\
(\%)\end{array}$ & Region $^{c}$ & $\begin{array}{l}\text { Fracture } \\
\text { Morphology }\end{array}$ & $\begin{array}{c}304 \mathrm{SS} \\
(\mathrm{mV}[\mathrm{SH} \\
\end{array}$ & $\begin{array}{c}\mathrm{P}_{1} \\
\mathrm{El}]\end{array}$ \\
\hline 80 & 16650 & 150 & $1 \times 10^{-5}$ & 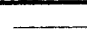 & ai & test - & $\ldots$ & & 4.4 & 296 & 497 & 15.7 & 66 & B & $1.0 \mathrm{D}$ & $\cdots$ & - \\
\hline 82 & 16650 & 150 & $3 \times 10^{-7}$ & 7.0 & 8.0 & 0.06 & 1.5 & 6.01 & 152 & 281 & 498 & 16.2 & 65 & B & $0.9 \mathrm{D}, 0.1 \mathrm{~T}$ & 359 & 331 \\
\hline 87 & 16650 & 150 & $3 \times 10^{-7}$ & 7.0 & 8.0 & 0.6 & 3.4 & 6.06 & 97 & 280 & 439 & 10.6 & 61 & B & $0.8 \mathrm{D}, 0.2 \mathrm{~T}$ & 359 & 367 \\
\hline 83 & 16650 & 150 & $3 \times 10^{-7}$ & 7.0 & 8.0 & 6.0 & 23.0 & 5.95 & 96 & 291 & 456 & 10.4 & 52 & HAZ & $0.8 \mathrm{D}, 0.2 \mathrm{~T}$ & - & -- \\
\hline 84 & 16650 & 175 & $1 \times 10^{-5}$ & 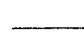 & - ai & test -... & $\ldots$ & & 4.5 & 292 & 493 & 16.1 & 67 & B & $1.0 \mathrm{D}$ & $-\cdots$ & $\ldots$ \\
\hline 86 & 16650 & 175 & $3 \times 10^{-7}$ & 8.0 & 8.0 & 0.06 & 2.1 & 6.05 & 141 & 279 & 494 & 14.3 & 66 & B & $0.9 \mathrm{D}, 0.1 \mathrm{~T}$ & 333 & 349 \\
\hline 85 & 16650 & 175 & $3 \times 10^{-7}$ & 6.0 & 8.0 & 0.6 & 3.6 & 5.80 & 89 & 281 & 434 & 9.2 & 52 & B & $0.8 \mathrm{D}, 0.2 \mathrm{~T}$ & 346 & 384 \\
\hline 88 & 16650 & 200 & $1 \times 10^{-5}$ & _ & & test & $\ldots$ & & 4.4 & 279 & 485 & 16.1 & 65 & B & $1.0 \mathrm{D}$ & $\cdots$ & - \\
\hline 90 & 16650 & 200 & $3 \times 10^{-7}$ & 8.0 & 8.0 & 0.06 & 2.0 & 6.17 & $>80$ & 276 & $>431$ & $>6$ & d & $\mathrm{d}$ & - & 246 & 246 \\
\hline 89 & 16650 & 200 & $3 \times 10^{-7}$ & 7.0 & 8.0 & 0.6 & 3.6 & 5.60 & 70 & 275 & 402 & 7.5 & 53 & B & $0.8 \mathrm{D}, 0.2 \mathrm{~T}$ & 280 & 287 \\
\hline 91 & 16650 & 200 & $3 \times 10^{-7}$ & 8.0 & 8.0 & 6.0 & 21.6 & 6.02 & 61 & 247 & 338 & 6.6 & 39 & ILAZ & $0.9 \mathrm{D}, 0.1 \mathrm{~T}$ & 295 & 346 \\
\hline 92 & 16650 & 225 & $1 \times 10^{-5}$ & - & -- ai & test - & $\ldots$ & & 4.6 & 284 & 486 & 16.7 & 68 & B & $1.0 \mathrm{D}$ & - & - \\
\hline 94 & 16650 & 225 & $3 \times 10^{-7}$ & 8.0 & 9.0 & 0.06 & 1.8 & 5.92 & 89 & 262 & 429 & 9.5 & 61 & B & $0.7 \mathrm{D}, 0.3 \mathrm{~T}$ & 284 & 307 \\
\hline 93 & 16650 & 225 & $3 \times 10^{-7}$ & 8.0 & 8.0 & 0.6 & 4.0 & 5.86 & 58 & 270 & 388 & 5.9 & 54 & B & $0.6 \mathrm{D}, 0.4 \mathrm{~T}$ & e & 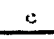 \\
\hline
\end{tabular}

${ }^{a}$ Crevice SSRT specimen from a gas-metal-arc weldment of Type 316L SS plate (Heat No. 16650) and filler metal (Heat No. 4H3367).

${ }^{b}$ Conductivity and $\mathrm{pH}$ were adjusted by addition of $0.06,0.6$, or $6.0 \mathrm{ppm} \mathrm{Cl}^{-}$as $\mathrm{NaCl}$.

${ }^{c}$ Specimen failed in the base metal (B), in the heat affected zone (HAZ), or in the weld (W).

${ }^{\mathrm{d}}$ Specimen did not fracture; test was terminated because of an equipment problem.

Reference electrode failed: no values were measured. 
Table 4. Influence of temperature on SCC susceptibility of Type 316L SS crevice-weldment specimens $s^{a}$ in oxygenated water containing various chloride concentrations, based on strain ratio $\left(\varepsilon_{\text {env }} / \varepsilon_{\text {air }}\right)$ at failure

\begin{tabular}{lccccccc}
\hline $\begin{array}{l}\text { Test } \\
\text { No. }\end{array}$ & $\begin{array}{c}\text { Temp. } \\
\left({ }^{\circ} \mathrm{C}\right)\end{array}$ & $\begin{array}{c}\mathrm{Cl}^{-} \\
(\mathrm{ppm})\end{array}$ & $\begin{array}{c}\text { Strain } \\
\text { Ratio }\end{array}$ & $\begin{array}{c}\text { Test } \\
\text { No. }\end{array}$ & $\begin{array}{c}\text { Temp. } \\
\left({ }^{\circ} \mathrm{C}\right)\end{array}$ & $\begin{array}{c}\mathrm{Cl}^{-} \\
(\mathrm{ppm})\end{array}$ & $\begin{array}{c}\text { Strain } \\
\text { Ratio }\end{array}$ \\
\hline $82 / 80$ & 150 & 0.06 & 1.03 & $90 / 88$ & 200 & 0.06 & $>0.4$ \\
$87 / 80$ & 150 & 0.6 & 0.68 & $89 / 88$ & 200 & 0.6 & 0.47 \\
$83 / 80$ & 150 & 6.0 & 0.66 & $91 / 88$ & 200 & 6.0 & 0.41 \\
$86 / 84$ & 175 & 0.06 & 0.89 & $94 / 92$ & 225 & 0.06 & 0.57 \\
$85 / 84$ & 175 & 0.6 & 0.57 & $93 / 92$ & 225 & 0.6 & 0.35 \\
\hline
\end{tabular}

${ }^{\mathrm{a} C r e v i c e ~ S S R T ~ s p e c i m e n s ~ f r o m ~ a ~ g a s-m e t a l-a r e ~ w e l d m e n t ~ o f ~ T y p e ~} 316 \mathrm{~L}$ SS plate (Heat No. 16650) and filler metal (Heat No. 4H3367).

Table 5. Influence of temperature on SCC susceptibility of Type 316NG SS crevice-weldment specimens in oxygenated water containing various chloride concentrations, based on strain ratio $\left(\varepsilon_{\text {env }} / \varepsilon_{\text {air }}\right)$ at failure

\begin{tabular}{lccccccc}
\hline $\begin{array}{l}\text { Test } \\
\text { No. }\end{array}$ & $\begin{array}{c}\text { Temp. } \\
\left({ }^{\circ} \mathrm{C}\right)\end{array}$ & $\begin{array}{c}\mathrm{Cr} \\
(\mathrm{ppm})\end{array}$ & $\begin{array}{c}\text { Strain } \\
\text { Ratio }\end{array}$ & $\begin{array}{c}\text { Test } \\
\text { No. }\end{array}$ & $\begin{array}{c}\text { Temp. } \\
\left({ }^{\circ} \mathrm{C}\right)\end{array}$ & $\begin{array}{c}\mathrm{Cr} \\
(\mathrm{ppm})\end{array}$ & $\begin{array}{c}\text { Strain } \\
\text { Ratio }\end{array}$ \\
\hline $101 / 100$ & 95 & 0.1 & 0.93 & $104 / 92$ & 225 & 0.1 & 0.89 \\
$102 / 100$ & 95 & 1.0 & 1.01 & $105 / 92$ & 225 & 1.0 & 0.70 \\
$103 / 100$ & 95 & 10.0 & 1.00 & $106 / 92$ & 225 & 10.0 & 0.60 \\
\hline
\end{tabular}

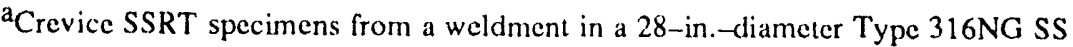
pipe (Heat No. NDE 28).
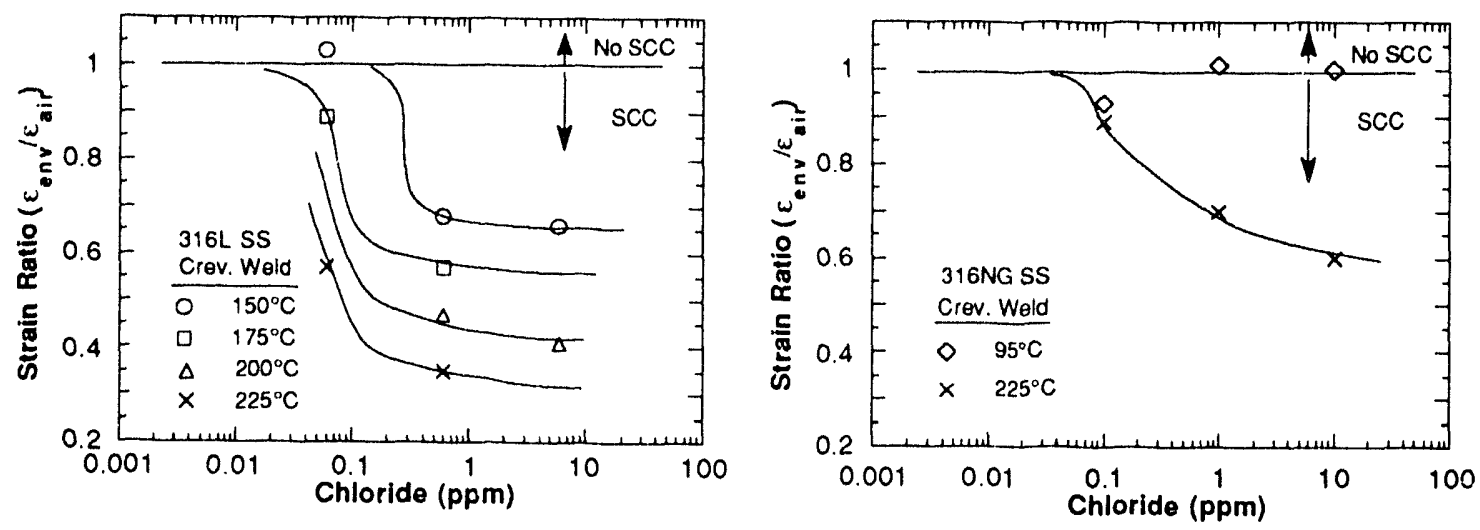

Figure 2. Strain ratio at failure vs. chloride concentration in oxyginn: d water at several temperatures for SSRT crevice-weldment specimens of Type $316 \mathrm{~L}$ SS and Type $316 N G$ SS 

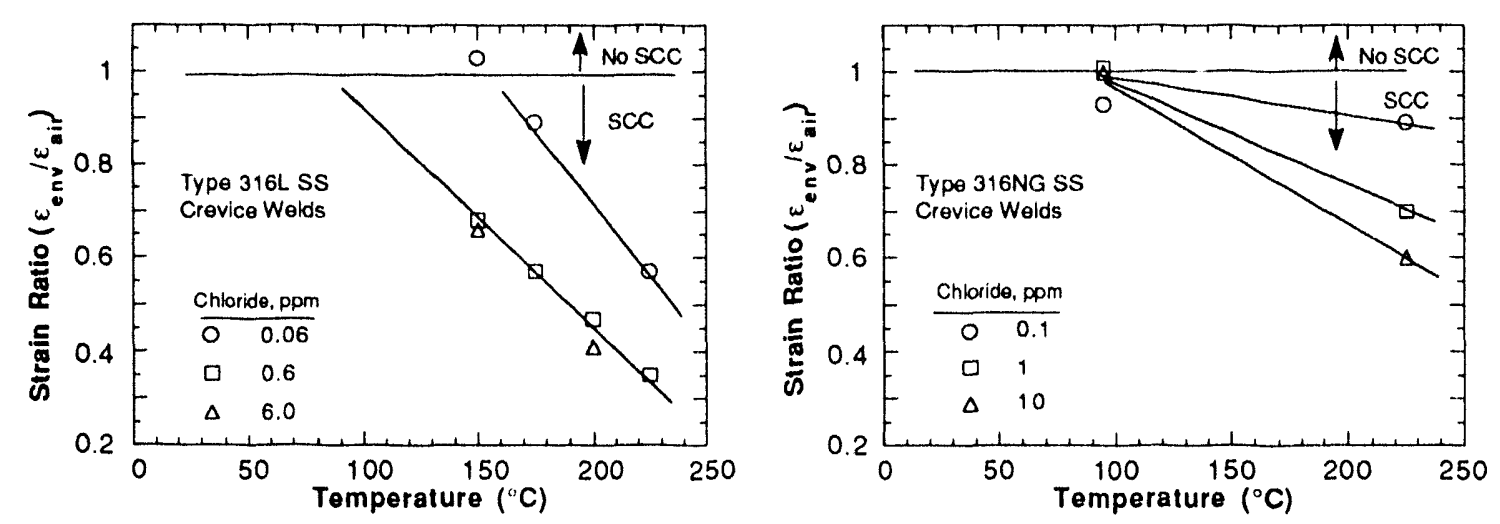

Figure 3. Strain ratio at failure vs. temperature for SSRT crevice-weldment specimens of Types $316 \mathrm{~L}$ and $316 \mathrm{NG}$ SS in oxygenated water containing $0.06-10$ ppm chloride

As indicated in Tables 2 and 3, most of the specimens failed in the base metal and three specimens failed in the HAZ of the weld, but no failures occurred in the weld metal. Fracture surfaces of the specimens have been examined by SEM to determine the mode of cracking and to establish whether the cracks initiated in the crevice as expected. Photomicrographs showed that the extent of TGSCC increased with temperature at a constant chloride level in the water and with chloride concentration at a constant temperature.

\section{CONCLUSIONS}

Types $316 \mathrm{~L}$ and $316 \mathrm{NG}$ SS crevice-weldment specimens exhibit good resistance to SCC in SSRT tests in oxygenated water containing $\leq 0.1 \mathrm{ppm} \mathrm{Cl}^{-}$at temperatures $\leq 150^{\circ} \mathrm{C}$. This environment is representative of a nominal coolant chemistry for an ITER first wall/blanket system, except for short-lived radical species from radiolysis of water. Most of the Types 316L and 316NG SS crevice-weldment specimens fractured in the base metal rather than in the HAZ of the weld or in the weld metal. From the present results, it appears that the purity of bulk coolant water (c.g., $\mathrm{Cl}^{-}$and $\mathrm{SO}_{4}^{2-}$ concentrations) will have to be maintained to a high standard to mitigate SCC of low-C grades of austenitic SSs, particularly at temperatures of $>150^{\circ} \mathrm{C}$. Present guidelines for the design and operation of water purification systems for light-water-cooled fission reactors can be employed to ensure that impurity levels in an ITER coolant are maintained at levels that will limit corrosion and SCC of system materials.

\section{FUTURE WORK}

Additional SSRT tests will be conducted on crevice-weldment specimens of Type 316NG SS in water containing dissolved $\mathrm{O}_{2}, \mathrm{H}_{2} \mathrm{O}_{2}$, and $\mathrm{Cl}^{-}$to define the critical chloride concentration in oxygenated water that is required for the onset of SCC. These data, when coupled with tic present results, will be used to determine the regime of temperature and chloride concentration at which these materials are resistant to SCC under crevice conditions, and thereby establish the margin of performance of the material under offnormal or poor lay-up water chemistry conditions at temperatures of 95 to $225^{\circ} \mathrm{C}$.

\section{REFERENCES}

1. R. W. Conn, V. A. Chuyanov, N. Inoue, and D. R. Swectman, The International Thermonuclear Experimental Reactor, Scientific American, 226 (4) 1992. 
2. D. L. Smith, Aqueous Corrosion Task for ITER R\&D, U.S. Coordination Mecting, Argonne National Laboratory, August 6, 1990.

3. H. G. Khalak, Computer Simulation of Water Coolant Chemistry in a Fusion Reactor, Proc. 3rd National Conf. on Undergraduate Research, April 27-29, 1989, University of North Carolina, Asheville, p. 287.

4. H. Khalak, A. B. Hull, and T. F. Kassner, Aqueous Stress Corrosion of Austenitic Steels, 6th Fusion Reactor Materials Semiannual Progress Report for Period Ending March 31, 1989, DOE/ER-0313/6, Oak Ridge National Laboratory, p. 379.

5. A. Patel, A. B. Hull, and T. F. Kassner, Aqueous Stress Corrosion of Structural Materials, 7th Fusion Reactor Materials Semiannual Progress Report for Period Ending September 30, 1989, DOE/ER-0313/7, Oak Ridge National Laboratory, p. 250.

6. A. B. Hull, M. R. Fox, J. W. Pascoe, and T. F. Kassner, Environmental Effects on Aqueous Stress Corrosion of Candidate Austenitic Steels for ITER Structural Applications, 9th Fusion Reactor Materials Semiannual Progress Report for Period Ending September 30, 1990, DOE/ER-0313/9, Oak Ridge National Laboratory, p. 228.

7. A. B. Hull and T. F. Kassner, Aqueous Stress Corrosion of Candidate Austenitic Steels for ITER Structural Applications, 10th Fusion Reactor Matcrials Semiannual Progress Report for Period Ending March 31, 1991, DOE/ER-0313/10, Oak Ridge National Laboratory, p. 241.

8. M. R. Fox, A. B. Hull, and T. F. Kassner, Stress Corrosion Cracking of Candidate Structural Materials under Simulated First-Wall/Aqueous Coolant Environments, Fusion Technol., 19, 1619-1628 (1991).

9. A. B. Hull, P. R. Luebbers, M. R. Fox, W. K. Soppel, and T. F. Kassner, Aqueous Stress Corrosion of Candidate Austenitic Steels for ITER Structural Applications, 12th Fusion Reactor Materials Semiannual Progress Report for Period Ending March 31, 1992, DOE/ER-0313/12, Oak Ridge National Laboratory, p. 225.

10. D. M. French, W. K. Soppet, and T. F. Kassner, Aqueous Stress Corrosion of Candidate Austenitic Steels for ITER Structural Applications, 13th Fusion Reactor Materials Semiannual Progress Report for Period Ending September 30, 1992, DOE/ER-0313/13, Oak Ridge National Laboratory, p. 276.

11. S. M. Bruemmer, L. A. Charlot, and D. G. Atteridge, Sensitization Development in Austenitic Stainless Steel-Measurement and Prediction of Thermomechanical History Effects, Corrosion 44, 427-442 (1988).

12. D. D. Macdonald, A. C. Scott, and P. Wentrcek, External Reference Electrodes for Use in High Temperature Aqueous Systems, J. Elcctrochem. Soc., 126, 908-911 (1979).

13. H. D. Solomon, Transgranular, Granulated, and Intergranular Stress Corrosion Cracking in AISI 304 SS, Corrosion 40, 493-506 (1984).

14. W. E. Ruther, W. K. Soppet, and T. F. Kassner, Effect of Temperature and lonic Impurities at Very Low Concentrations on Stress Corrosion Cracking of AISI 304 Stainless Steel, Corrosion 44, 791-799 (1988).

15. B. M. Gordon, The Effect of Chloride and Oxygen on the Stress Corrosion Cracking of Stainless Steels: Review of Literalure, Matcrials Pcrformance 19 (4), 29-37 (1980).

16. P. L. Andresen and D. J. Duquette, The Effects of Dissolved Oxygen, Chloride Ion, and Applied Potential on the SCC Behavior of Type 304 Stainless Steel in $290^{\circ} \mathrm{C}$ Water, Corrosion 36, $409-415$ (1980). 
17. J. Congleton, H. C. Shih, T. Shoji, and R. N. Parkins, The Stress Corrosion Cracking of Type 316 Stainless Steel in Oxygenated and Chlorinated High Temperature Water, Corrosion Science 25. 769-788 (1985).

18. W. M. M. Huijbregts, Oxygen and Corrosion Potential Effects on Chloride Stress Corrosion Cracking, Corrosion 42, 456-462 (1986).

19. J.-H. Wang, C. C. Su, and Z. Szklarska-Smialowska, Effects of $\mathrm{Cl}^{-}$Concentration and Temperature on Pitting of AISI 304 Stainless Steel, Corrosion 44, 732-737 (1988).

20. H. K. Juang and C. Altstetter, Effect of pH and Chloride Contents on Stress Corrosion Cracking of Austenitic Stainless Steels at Room Temperature, Corrosion 46, 881-887 (1990).

21. H. M. G. Sncts and W. F. L. Bogacrts, SCC Analysis of Austenitic Stainless Steels in Chloride Bearing Water by Neural Network Techniques, Corrosion 48, 618-623 (1992). 


\section{FORMATION OF ELECTRICALLY INSULATING COATINGS ON ALUMINIDED VANADIUM- BASE ALLOYS IN LIQUID LITHIUM ${ }^{*}$ - J.-H. Park and G. Dragel (Argonne National Laboratory)}

\section{OBJECTIVE}

The magnetohydrodynamic (MHD) force and its subsequent influence on thermal hydraulics are major concerns in the design of liquid-metal blankets for magnetic fusion reactors (MFRs). The objective of this study is to develop in-situ stable electrically insulating coatings at the liquid-metal/structural-material interface to prevent adverse MHD-generated currents from passing through the structural walls. ${ }^{1-3}$

\section{SUMMARY}

Aluminide coatings were produced on vanadium and vanadium-base alloys 4,5 by exposure of the materials to liquid lithium that contained 3-5 at.\% dissolved aluminum in sealed capsules at temperatures between 775 and $880^{\circ} \mathrm{C}$. Reaction of the aluminide layer with dissolved nitrogen in liquid lithium provides a means of developing an in-situ electrical insulator coating on the surface of the alloys. The electrical resistivity of AIN coatings on aluminided V and and V-20 wt.\% Ti was determined in-situ.

\section{INTRODUCTION}

Corrosion resistance of structural materials, and the MHD force and its subsequent influence on thermal hydraulics, are major concerns in the design of liquid-metal cooling systems. ${ }^{1-3}$ The objective of this study is to develop in-situ electrically insulating coatings at the liquid-metal/structural-material interface. The electrically insulating coatings should be capable of forming on various shapes such as the inside of tubes or on irregular shapes during operational conditions to prevent adverse MHD-generated currents from passing through the structural walls. The coatings could also improve general corrosion resistance and act as a diffusion barrier for hydrogen isotopes, viz., deuterium and tritium. Aluminide coatings on vanadium and vanadium-base alloys can react with nitrogen in lithium to form a thin electrically insulating AIN film.

\section{COATING METHODS}

Nitride coatings (e.g., AIN, TiN, etc.) on aluminide layers and Ti can be produced in an $\mathrm{Li}+\mathrm{Li}_{3} \mathrm{~N}$ mixture, based on thermodynamic considerations ${ }^{6}$ and the $\mathrm{Li}_{-}-\mathrm{Li}_{3} \mathrm{~N}$ phase diagram. The melting points of $\mathrm{Li}$ and $\mathrm{Li}_{3} \mathrm{~N}$ are 180.6 and $815^{\circ} \mathrm{C}$, respectively. The liquidus temperature increases monotonically as the nitrogen concentration increases. ${ }^{7}$ However, an $\mathrm{Li}_{-} \mathrm{Li}_{3} \mathrm{~N}$ mixture at a given temperature provides a means of establishing a fixed nitrogen partial pressure that corresponds to the thermodynamic equilibrium for the two-phase mixture.

\section{EXPERIMENTAL PROCEDURE}

A nitride coating ( $\mathrm{TiN}$ ) on $\mathrm{Ti}$ was produced in an $\mathrm{Li}-\mathrm{Li}_{3} \mathrm{~N}$ mixture at temperatures betwean 200 and $807^{\circ} \mathrm{C}$. Aluminized $\mathrm{V}$ and $\mathrm{V}-20 \% \mathrm{Ti}$ capsules from previous experiments were filled with liquid $\mathrm{Li}$ that was enriched in $\mathrm{Al}$ and $\mathrm{N}$ by adding $\mathrm{Al}$ powder and $\mathrm{Li} 3 \mathrm{~N}$. The capsules were heated to $700-850^{\circ} \mathrm{C}$ for $24-72 \mathrm{~h}$.

\footnotetext{
* Work supported by the U.S. Department of Energy under Contract W-31-109-Eng-38.
} 
The $\mathrm{Al}$ powder and Li3 $\mathrm{N}$ facilitated the formation of $\mathrm{AIN}$ on the aluminide surface layer on the capsules. Electrical resistivity of layers that formed was monitored as a function of time during the exposure.

\section{RESULT AND DISCUSSION}

Figure 1a is an SEM micrograph of a TiN layer on the surface of a Ti tube (1/4-in. outer diameter) that formed in liquid $\mathrm{Li}$ containing $\mathrm{Li}_{3} \mathrm{~N}$. The TiN surface was bright in appearance after rinsing with water. EDS analyses were performed to determine the $\mathrm{N}$ concentration after exposure to $\mathrm{Li}^{*}$ Figure $\mathrm{lb}$ shows that a significant amount of $\mathrm{N}$ was detected in samples exposed to $\mathrm{Li}$ at tcmperatures $\geq 600^{\circ} \mathrm{C}$.
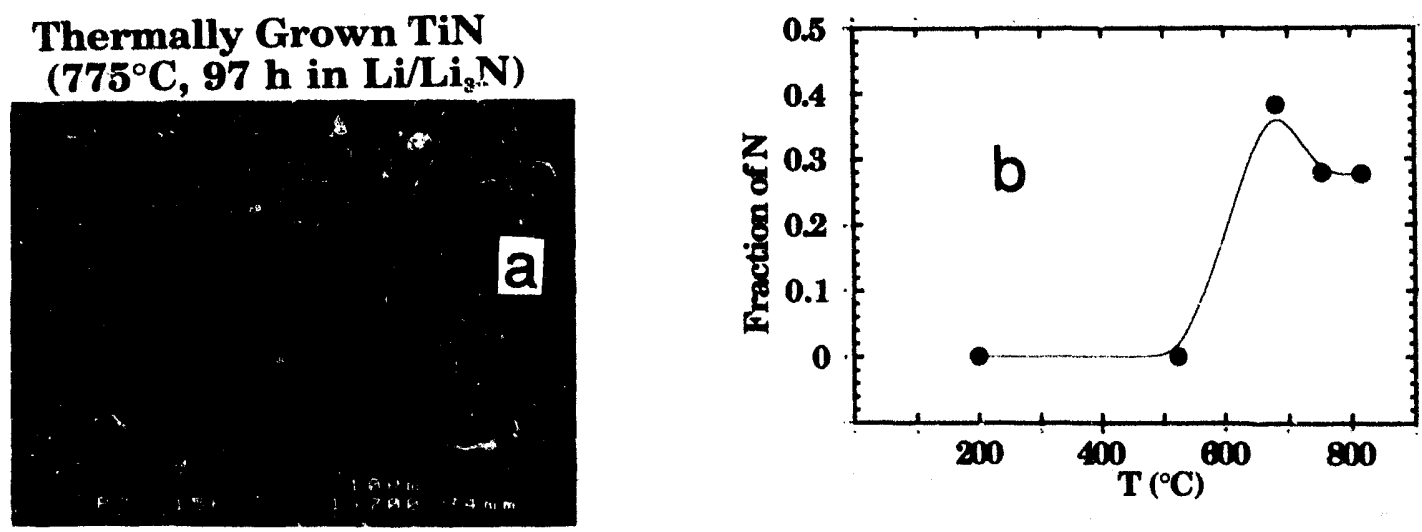

Figure 1. (a) SEM photograph of surface of thermally grown layer of TiN on Ti in liquid lithium containing $N$, and (b) $N$ content of surface layers as a function of exposure temperature

To determine the in-situ electrical conductivity of nitride layers, an aluminide coating was applied to the inside surface of V and V-20\%Ti capsules, as described previously. The aluminide layer was then nitrided in an $\mathrm{Li}-\mathrm{Li}_{3} \mathrm{~N}$ mixture in a system that also allowed measurement of electrical conductivity during formation of the AIN layer. Electrical resistance was determined from the slopes of potential drop vs. current curves when the current through the coating layers was passed in the positive and negative directions (Fig. 2). Because of the open-circuit potential across the coating layer (without supplying current), the ohmic resistance across the coating layer was determined by Ohm's law, i.e., $R(\Omega)=[\partial \mathrm{E}($ Volt $) / \partial \mathrm{i}($ Amp $)]$.

Results of in-situ electrical conductivity measurements are shown in Fig. 2, and the dependence of the ohmic resistance on temperature over the duration of the experiment is shown in Fig. 3. The coating area (surface of the tube in contact with liquid $\mathrm{Li}$ ) was $20 \mathrm{~cm}^{2}$. If we assume that the thickness of the AlN film is $\approx 1 \mathrm{~mm}$, the electrical conductivity at $700^{\circ} \mathrm{C}$ is consistent with literature values. ${ }^{8}$ However, thermal cycling tends to decrease the resistivity, as shown in Fig. 3 for the second cycle. Ohmic resistance dropped from $\approx 1.5$ to $0.43 \Omega$ and remained constant after the temperature was increased to $800^{\circ} \mathrm{C}$, where we expected that the reaction between the aluminide layer and $\mathrm{N}$ would proceed at a higher rate and thereby show an increase in resistance over the previous value of $\approx 1.5 \Omega$. This trend, if it had occurred, would indicate that nitriding of spalled regions or defects (e.g., cracks or open boundaries) in the film occurs rapidly. However, an ohmic resistance of $\approx 0.4 \Omega$ may be adequate for an insulator coating in MFR applications.

- Because the positions of the $T(1)$ and $N(k)$ peaks are very close to one another, the $N$ concentration was determined by subtraction of the TI(l) peak area from the EDS spectrum of TIN. 

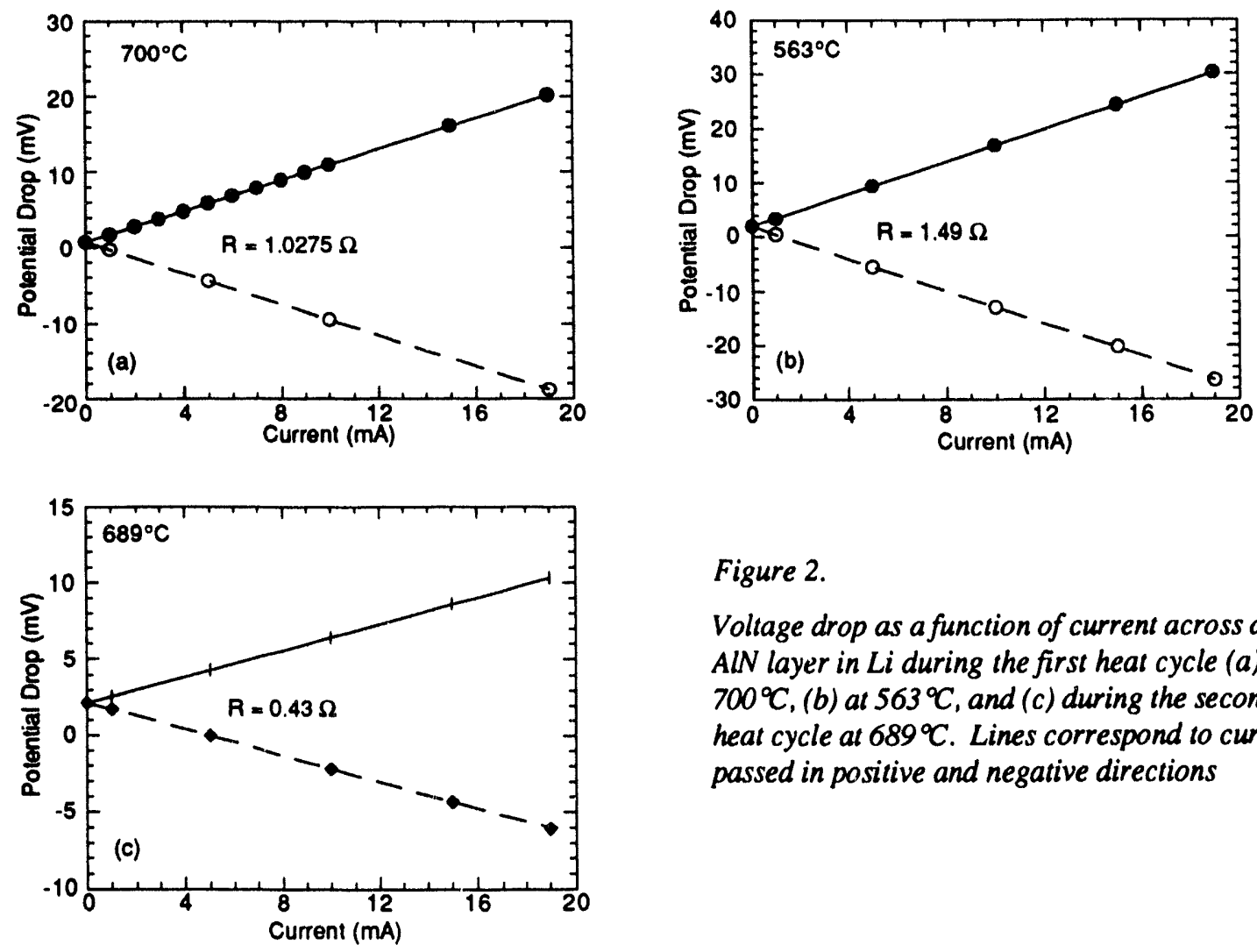

Figure 2.

Voltage drop as a function of current across an AlN layer in Li during the first heat cycle (a) at $700^{\circ} \mathrm{C},(\mathrm{b})$ at $563^{\circ} \mathrm{C}$, and (c) during the second heat cycle at $689^{\circ} \mathrm{C}$. Lines correspond to current passed in positive and negative directions

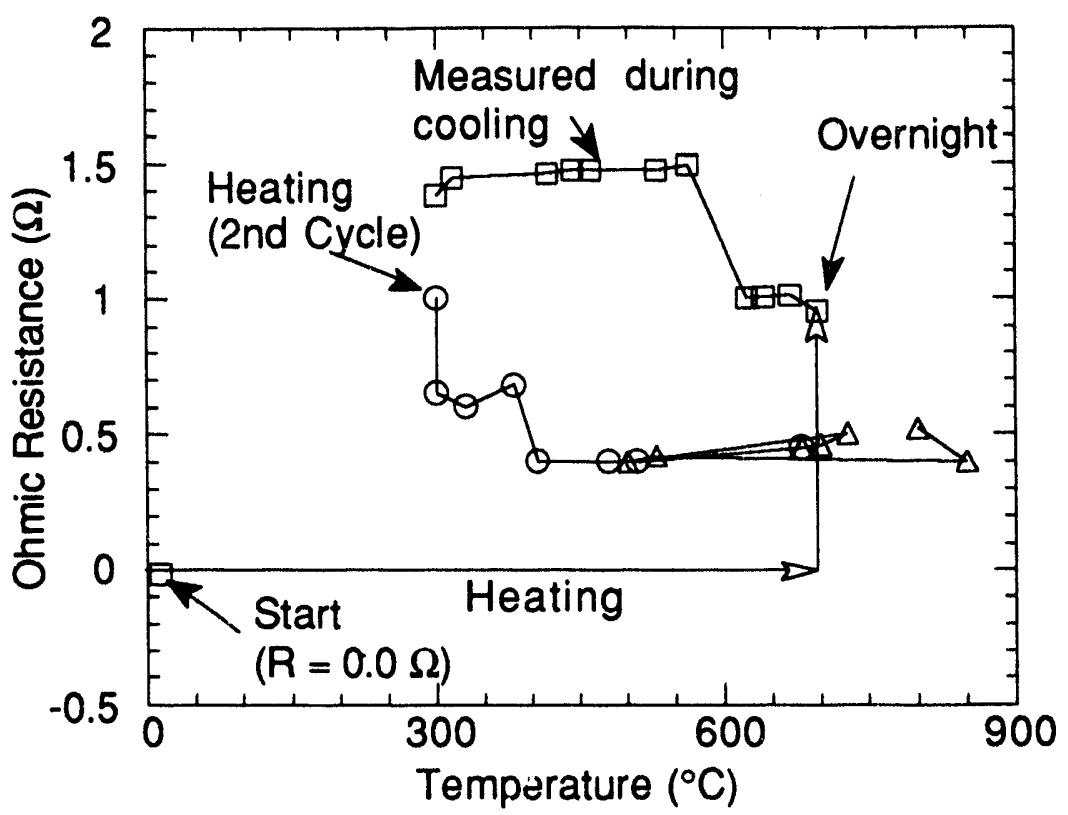

Figure 3. Ohmic resistance vs. temperature during heating cycles 
Figure 4 shows SEM micrographs of an AlN film and a spalled area on an aluminided surface of $\mathrm{V}-20 \% \mathrm{Ti}$, along with e.ectron-energy-dispersive-spectroscopy (EDS) spectra from the two regions. The EDS results indicate a relatively high concentration of $\mathrm{Al}, \mathrm{N}$, and $\mathrm{O}$ in the coating compared to the spalled area. Electrical resistivity of the AIN film was measured at room temperature after the cell was dissembled. The ohmic resistance was $>10^{12} \Omega$, which indicates that it is a good electrical insulator.
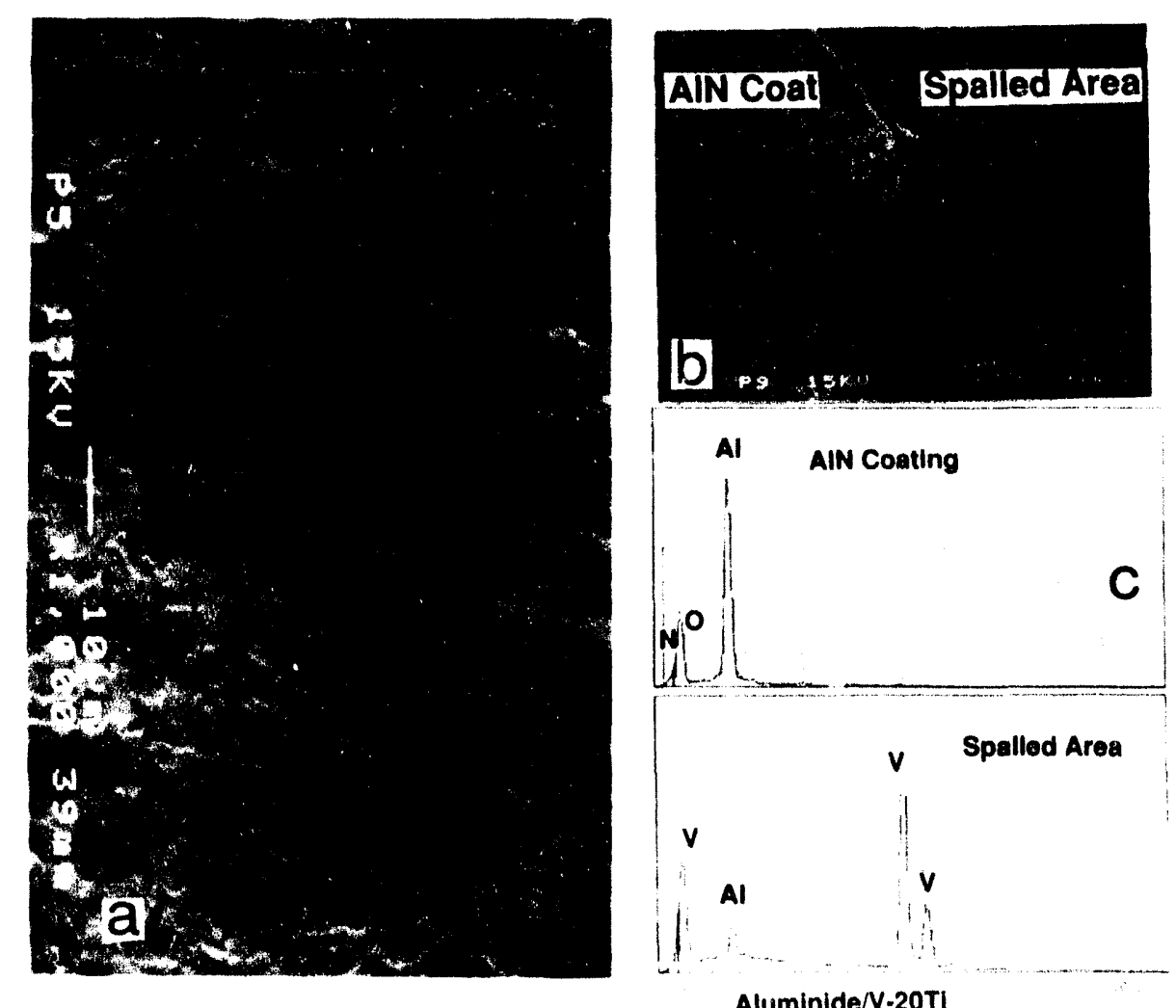

Figure 4. (a) SEM micrograph of surface of AIN on aluminide layer on V-20\%Ti, (b) AlN and spalled area of coating, and (c) EDS spectra from AlN layer and spalled area in $(b)$

To rationalize the present conductivity measurements, the thermodynamic stability of several simple oxides and nitrides has been considered. Figure 5a shows calculated equilibrium partial pressures of $\mathrm{O}_{2}$ and $\mathrm{N}_{2}$ in the $\mathrm{Li}-\mathrm{Al}-\mathrm{Y}$ system as a function of temperature, ${ }^{9}$ and Fig. $5 \mathrm{~b}$ shows a schematic thermochemical diagram for the M-N-O system, where $\mathrm{M}$ denotes $\mathrm{Al}, \mathrm{Li}$, and $\mathrm{Y}$. In these experiments, it is difficult to exclude interactions with the gas-phase environment, especially $\mathrm{O}_{2}$ contamination. When $\mathrm{O}_{2}$ interacts with liquid $\mathrm{Li}$ and the $\mathrm{O}$ solubility limit is exceeded, $\mathrm{Li}_{2} \mathrm{O}$ will form. Because $\mathrm{Li}_{2} \mathrm{O}$ is the most stable oxide in the $\mathrm{Li}-\mathrm{Al}-\mathrm{O}$ system, it is not likely that $\mathrm{Al}_{2} \mathrm{O}_{3}$ will form. Similarly, an AlN layer is not likely to react with dissolved oxygen in $\mathrm{Li}$ to form $\mathrm{Al}_{2} \mathrm{O}_{3}$ because the latter is not stable in $\mathrm{O}$-saturated $\mathrm{Li}$. Consequently, AlN can be a stable phase in liquid $\mathrm{Li}$ with a relatively high $\mathrm{N}_{2}$ partial pressure. Figure $5 \mathrm{a}$ indicates that the stability of AIN is greater than that of $\mathrm{Li}_{3} \mathrm{~N}$ over a wide temperature range. 

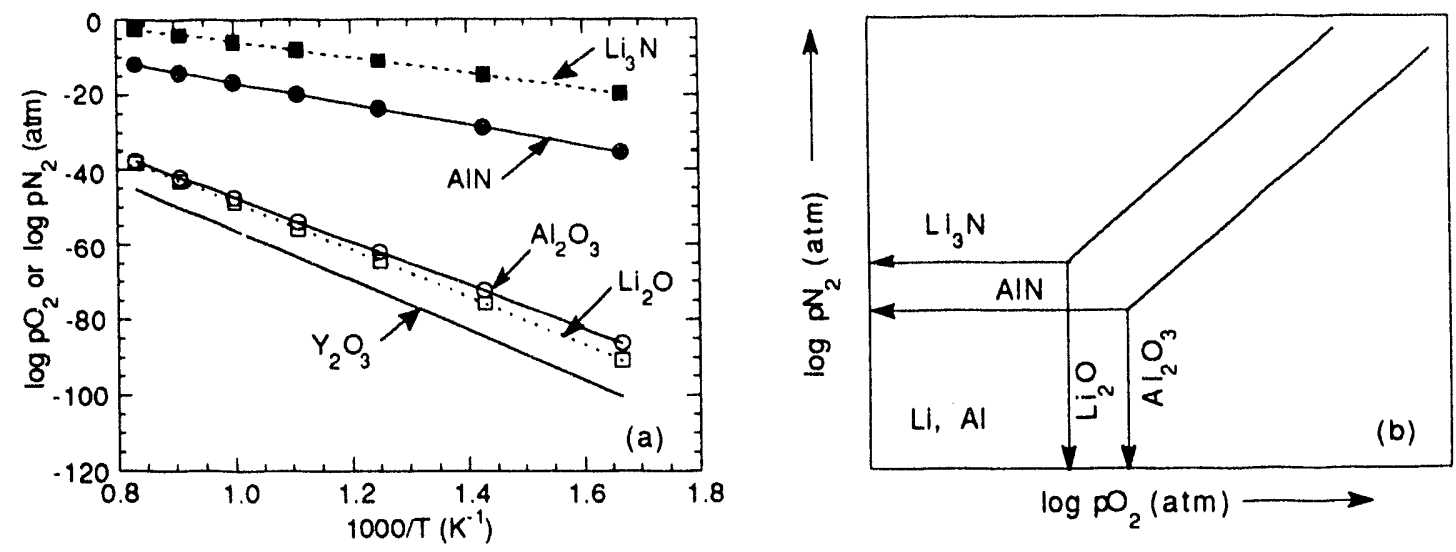

Figure 5. (a) Calculated equilibrium partial pressures of $\mathrm{O}_{2}$ and $\mathrm{N}_{2}$ in Li-Al-Y system and (b) schematic thermochemical diagram for $M-N-O$ system, where $M$ represents $A l$ or $L i$

Formation of an AIN film on an aluminide layer follows the reaction

$$
\mathrm{Li}_{3} \mathrm{~N}+\mathrm{Al}=3 \mathrm{Li}+\mathrm{AlN}
$$

where the free-energy change, $\Delta \mathrm{G}$, is $-25 \mathrm{kcal} / \mathrm{molc}$ at $500^{\circ} \mathrm{C}$. If the AIN film cracks or spalls, the reaction (Eq. 1) should take place and repair the film, provided that $\mathrm{N}$ is present in $\mathrm{Li}$ and the Al activity in the alloy is sufficient for spontaneous reaction to occur. The main requirement is that the $\mathrm{N}$ level in $\mathrm{Li}$ be high enough. If this is not the case, we must also consider the possibility of dissolution of the AIN film based on the solubilitics of $\mathrm{Al}$ and $\mathrm{N}$ in liquid $\mathrm{Li}$, i.e.,

$$
A I N=\underline{A l}+\underline{N}(\text { in Li) }
$$

The $\Delta \mathrm{G}$ for this reaction is $+3 . .2 \mathrm{kcal} / \mathrm{molc}$; therefore, the equilibrium constant $\mathrm{K}$ for the reaction at $500^{\circ} \mathrm{C}$ is

$$
\mathrm{K}=2 \times 10^{-9}=\mathrm{a}_{\underline{A l}} \underline{\mathrm{a}} \underline{\mathrm{N}},
$$

when the activities for $\mathrm{Li}$ and AIN are assumed to be unity. The typical impurity level for $\mathrm{N}$ in $\mathrm{Li}$ is $\approx 50-200 \mathrm{ppm}$. Therefore, the Al concentration in Li must be in the range of $40-10 \mathrm{ppm}$ at $500^{\circ} \mathrm{C}$ to maintain the AIN layer. In capsulc experiments, it is relatively casy to meet these critcria for the formation and long-term stability of the AIN phase. In a forced-circulation loop under heat transfer conditions, the effect of the temperature gradient throughout the system on the concentrations of $\mathrm{Al}$ and $\mathrm{N}$ in Li must be considered so that the AIN film can be maintained at all temperature regions over long periods of time. This will be explored in future work after additional information on the stability and resistivity of insulator coatings is obtained in capsule tests. Subsequently, the results will be applied to an MFR system.

\section{CONCLUSIONS}

Surface modification via high-temperature liquid-phase deposition can provide intermetallic aluminide coatings on $\mathrm{V}$-base alloys. This process is facilitated in liquid $\mathrm{Li}$ because surface contamination by $\mathrm{O}_{2}$ or oxide films is virtually eliminated, and the process to produce homogeneous coatings on various surface shapes can be controlled by exposure time, temperature, and composition of the liquid metal. Conversion of aluminide layers to an electrically insulating coating (e.g., an AIN film) in liquid Li was demonstrated. 


\section{FUTURE STUDIES}

Results of mechanical-property ${ }^{10}$ and irradiation-damage ${ }^{11,12}$ studies indicate that $\mathrm{V}-5 \% \mathrm{Cr}-5 \% \mathrm{Ti}$ is the most promising V-base alloy for MFR applications. Consequently, the insulator development study will focus on the $\mathrm{V}-5 \% \mathrm{Cr}-5 \% \mathrm{Ti}$ alloy.

\section{REFERENCES}

1. C. C. Baker et al., Tokamak Power System Studies FY 1985, Argonne National Laboratory Report ANL/FPP-85-2 (December 1985).

2. Y. Y. Liu and D. L. Smith, Ceramic Electrical Insulators for Liquid Metal Blankets, J. Nucl. Mater., 141-143, 38 (1986).

3. T. Kammash, Fusion Reactor Physics, Chapter 15, Ann Arbor Science Pub. Inc., Ann Arbor, MI (1975) pp. 405-439.

4. J.-H. Park and G. Dragel, Development of In-Situ-Formed Electrical Insulator Coalings on HighTemperature Alloys in Lithium, Fusion Reactor Materials Semiannual Progress Report for the Period Ending September 30, 1992.

5. J.-H. Park and G. Dragel, Development of Aluminide Coatings on Vanadium-Base Alloys in Liquid Lithium, Fusion Reactor Matcrials Scmiannual Progress Report for the Period Ending March 31, 1993.

6. L. S. Darken and R. W. Gurry, Physical Chemistry of Metals, McGraw-Hill, New York (1953).

7. M. Hansen, Constitution of Binary Alloys, McGraw-Hill, New York (1958).

8. S. F. Palguev, R. P. Lesunova, and L. S. Karenina, Solid State Ionics 20, 255-258 (1986).

9. F. A. Shunk, Constitution of Binary Alloys, Second Supplement, McGraw-Hill, New York (1969).

10. R. F. Mattas, B. A. Loomis, and D. L. Smith, Vanadium Alloys for Fusion Reactor Applications, JOM, 44(8), 26 (1992).

11. H. M. Chung, L. J. Nowicki, and D. L. Smith, Effect of Impurities and Doping Elements on Phase Structure of Vanadium-based Alloys Containing Titanium, Fusion Reactor Materials Semiannual Progress Report for the Pcriod Ending Scptember 30, 1991, DOE/ER-(3313/11, Oak Ridge National Laboratory, Oak Ridge, TN, pp. 215-226.

12. M. Satou and H. M. Chung, Effect of Impurities and Doping Elements on Phase Structure of Vanadium-based Alloys Containing Titanium, Fusion Reactor Materials Semiannual Progress Report for the Period Ending September 30, 1992, DOE/ER-()313/13, Oak Ridge National Laboratory, Oak Ridge, TN. 
CORROSION FATIGUE OF CANDIDATE AUSTENITIC STEELS FOR ITER STRUCTURAL APPLICATIONS* - W. E. Ruther and T. F. Kassner (Argonne National Laboratory)

\section{OBJECTIVE}

Austenitic stainless steels are being considered as a structural matcrial for first-wall/blanket systems in the International Thermonuclear Experimental Reactor (ITER). ${ }^{1}$ Information on the corrosion fatigue properties of candidate stainless steels under ITER-relevant conditions will help to identify an optimal combination of structural material, coolant chemistry, and opcrational conditions for ongoing ITER design work. The objective of this task is to provide bascline information on corrosion fatigue of candidate stainless stecls in oxygenated water that simulates many important parameters anticipated in ITER firstwall/blanket systems. Tests will also be conducted under off-normal water chemistry conditions and over a range of temperatures to establish the performance limits of the materials.

\section{SUMMARY}

Crack-growth-rate (CGR) tests were performed on 1-in.-thick (1T) compact-tension (CT) specimens of Types $316 \mathrm{NG}$ and $316 \mathrm{~L}$ stainless stecl (SS) in oxygenated water containing 0-5 ppm $\mathrm{Cl}^{-}$at 150,185 , and $225^{\circ} \mathrm{C}$. The results obtained under cyclic loading conditions at stress intensity factors of $\approx 27$ to $39 \mathrm{MPa} \cdot \mathrm{m}^{1 / 2}$ indicate that environmental enhancement of the rates increases with $\mathrm{Cl}^{-}$concentrations $>0.1 \mathrm{ppm}$ at $150^{\circ} \mathrm{C}$ in comparison with calculated rates in air under the specific loading conditions. In contrast, at the higher temperatures the CGRs were not affected by $\mathrm{Cl}^{-}$in oxygenated water but were greater than the predicted rates in air by one order of magnitude.

\section{PROGRESS AND STATUS}

Research and development needs ${ }^{2}$ of the ITER with respect to aqueous corrosion include establishing a reliable data base on reference matcrials, viz., Types $316,316 \mathrm{~L}$, and $316 \mathrm{NG}$ SS in the solution-annealed, cold-worked, and welded conditions. A nominal ITER water chemistry would most likely be high-purity (HP) water (a) containing stable radiolysis/clectrolysis products, e.g., dissolved $\mathrm{O}_{2}, \mathrm{H}_{2} \mathrm{O}_{2}$, and $\mathrm{H}_{2}$ at ppm levels, and (b) ionic species at ppb levels, namely, soluble corrosion products and impurities in the makeup water and from release by ion-exchange resins in water purification systems. Higher concentrations of ionic impurities (e.g., $\mathrm{Cl}^{-}, \mathrm{SO}_{4}^{2-}, \mathrm{H}^{+}$, ctc.) in the coolant may be present during off-normal operating and extended lay-up conditions of the system.

Although the nominal ITER coolant operating temperature in an initial design was $\approx 60^{\circ} \mathrm{C}$, periodic increases to $150^{\circ} \mathrm{C}$ and above were envisaged. Mechanical loads and temperature gradients across the firstwall structure will produce both static and cyclic stresses, which when coupled with residual tensile stresses associated with welds, can exceed the yield strength of the material. Tensile stresses that exceed the yield stress under ITER cyclic operation $\left(\approx 10^{4}\right.$ cycles) are conducive to crack propagation under corrosion fatigue conditions.

Previous work focused on susceptibility of Types 316NG, 316L, and 304 SS to stress corrosion cracking (SCC) by slow-strain-rate-tensile (SSRT) tests. ${ }^{3-7}$ No indication of SCC was observed in tests $^{3}$ on noncrevice specimens of Type $316 \mathrm{NG} \mathrm{SS}$ in oxygenated water containing $0.1-1.0 \mathrm{ppm} \mathrm{SO}_{4}^{2-}$ at temperatures of 95 and $150^{\circ} \mathrm{C}$ and a strain rate of $3 \times 10^{-7} \mathrm{~s}^{-1}$. Crevice specimens were also resistant to SCC in oxygenated water containing $0.1 \mathrm{ppm} \mathrm{SO}_{4}^{2-}$ at $\leq 150^{\circ} \mathrm{C}^{3-5}$ Predominantly ductile fracture (a minor amount of transgranular cracking, or TGSCC) was observed in crevice specimens of Type 316NG SS

\footnotetext{
* Work supported by the U.S. Department of Energy, under Contract W-31-109-Eng-38.
} 
at higher temperatures. Intergranular failure occurred in crevice specimens of sensitized Type 304 SS.6,7 Results described in this report are from corrosion fatigue tests in water containing dissolved oxygen and $\mathrm{Cl}^{-}$at 150,185 , and $225^{\circ} \mathrm{C}$ on fracture-mechanics specimens fabricated from Type $316 \mathrm{~L}$ and two heats of Type 316NG SS.

\section{Experimental Procedures}

A large autoclave $(\approx 6 \mathrm{~L}$ ) equipped with an MTS hydraulic test system was used for fracturemechanics CGR tests on 1-in.-thick compact-tension (1TCT) specimens. The apparatus had a calibrated load cell and a crack-length monitoring system for in-situ measurement of the crack length of each specimen during the test. Crack lengths were determined by a DC potential-drop method, which can resolve length changes of $0.025 \mathrm{~mm}$. Standard 1TCT specimens (ASTM E-399) of the same heats of stcel used in the SSRT tests, ${ }^{3-7}$ viz., two specimens of Type 316NG and one specimen of Type 316L SS, all with machined side grooves, were loaded in series. All specimens were solution-annealed for $0.5 \mathrm{~h}$ and then heat treated at $650^{\circ} \mathrm{C}$ for $24 \mathrm{~h}$, which simulates the material condition of a heat-affected zone in a typical weld. The composition of the steels is given in Table 1.

Table 1. Composition of Types $316 N G$ and $316 L$ stainless steels (wt.\%)

\begin{tabular}{llccccccccccc}
\hline Alloy & Heat No. & $\mathrm{Cr}$ & $\mathrm{Ni}$ & $\mathrm{Mo}$ & $\mathrm{Mn}$ & $\mathrm{Si}$ & $\mathrm{Cu}$ & $\mathrm{N}$ & $\mathrm{C}$ & $\mathrm{P}$ & $\mathrm{S}$ & $\mathrm{Fe}$ \\
\hline $316 \mathrm{NG}$ & $\mathrm{D} 440104$ & 17.91 & 13.25 & 2.48 & 1.75 & 0.49 & 0.01 & 0.098 & 0.015 & 0.011 & 0.002 & Bal \\
$316 \mathrm{NG}$ & 13198 & 16.51 & 10.70 & 2.08 & 1.63 & 0.64 & 0.20 & 0.085 & 0.021 & 0.022 & 0.017 & Bal \\
$316 \mathrm{~L}$ & 16650 & 16.50 & 10.39 & 2.09 & 1.78 & 0.43 & 0.19 & 0.054 & 0.018 & 0.026 & 0.013 & Bal \\
\hline
\end{tabular}

The specimens were fatigue-precracked in air at room temperature to introduce a sharp starter crack. The tests were then conducted in water under a low-frequency cyclic-loading with a positive sawtooth waveform at a frequency of $0.09 \mathrm{~Hz}$, an $\mathrm{R}$ retio of 0.7 (where $\mathrm{R}$ is the ratio of the minimum load to the maximum load of $21.24 \mathrm{kN}$ ), and maximum stress intensity values, $K_{\max }$, ranging from $\approx 27$ to $39 \mathrm{MPa} \cdot \mathrm{m}^{1 / 2}$. Stress intensity values were computed with the expression in ASTM Standard E-399, together with compensation for the side grooves in the specimens. The electrochemical potential (ECP) of Type 304 SS and a platinum electrode was also monitored during the CGR tests, and optical and scanning electron microscopes were used to evaluate the fracture surface of the specimens and measure the final crack length.

Water chemistry was established by bubbling a $20 \% \quad \mathrm{O}_{2}-80 \% \quad \mathrm{~N}_{2}$ gas mixture through deoxygenated/deionized feedwater (conductivity $<0.1 \mu \mathrm{S} \cdot \mathrm{cm}^{-1}$ ) contained in a 130-L SS tank to produce a dissolved-oxygen concentration of $\approx 8.0 \mathrm{ppm}$. $\mathrm{NaCl}\left(0\right.$ to $\left.5.0 \mathrm{ppm} \mathrm{Cl}{ }^{-}\right)$was added to the feedwater before sparging with the gas mixture to ensure adequate mixing. Influent and effluent water chemistry was monitored $(\mathrm{pH}$, conductivity, and concentration of dissolved oxygen), and an electrochemical measurement system with an $0.1 \mathrm{M} \mathrm{KCl} / \mathrm{AgCl} / \mathrm{Ag}$ external reference electrode for redox and corrosion potential measurements was located at the autoclave outlet. The measured ECP values were converted to the standard hydrogen electrode (SHE) scale by using thermocell and liquid-junction potentials. ${ }^{8}$ The dissolved-oxygen concentrations in the feed-and effluent water were measured with an Orbisphere oxygen meter. 
$\underline{\text { Results }}$

CGR tests have been completed on one set of three 1TCT specimens of Types $316 \mathrm{NG}$ and 316L SS at 150,185 and $225^{\circ} \mathrm{C}$. The tests were conducted under low-frequency cyclic loading with a positive sawtooth waveform (rise time of $10 \mathrm{~s}$ and fall time of $1 \mathrm{~s}$ ) at a load ratio $\left(R=K_{\min } / K_{\max }\right)$ of 0.7 . The water chemistry, loading conditions, and results of the CGR tests are given in Table 2. The CGRs encompass the range of $\approx 3 \times 10^{-10}$ to $1 \times 10^{-8} \mathrm{~m} \cdot \mathrm{s}^{-1}$ for the various test conditions. Figure 1 shows the dependence of the CGRs on $\mathrm{Cl}^{-}$concentration at 150 and $225^{\circ} \mathrm{C}$. At $150^{\circ} \mathrm{C}$, the CGRs increase with $\mathrm{Cl}^{-}$ concentration $>0.1 \mathrm{ppm}$ in the oxygenated water; at $225^{\circ} \mathrm{C}$ the rates are quite high and are not dependent on either alloy composition or $\mathrm{Cl}^{-}$concentration in watcr.

The dependence of the CGRs on temperature is shown in Fig. 2. The results indicate that rates increase more slowly as the temperature increases, and in water containing $5 \mathrm{ppm} \mathrm{Cl}^{-}$, a broad maximum occurs at temperatures of $\approx 170-210^{\circ} \mathrm{C}$. SSRT data by Ruther et al. ${ }^{9}$ and Ford ${ }^{10}$ suggest that environmentally assisted CGRs of austenitic SSs peak at $\approx 200-225^{\circ} \mathrm{C}$ and that in HP water (conductivity $<0.2 \mu \mathrm{S} \cdot \mathrm{cm}^{-1}$ ), CGRs decrease at both higher and lower temperatures. In tests by Ruther et al. ${ }^{9}$ at higher impurity levels (conductivity $>0.9 \mu \mathrm{S} \cdot \mathrm{cm}^{-1}$ ), no decrease was observed at higher temperatures. Because the tests were performed only with $\mathrm{H}_{2} \mathrm{SO}_{4}$ additions, it is not known whether this effect was associated with specific chemical species or depends only on the overall impurity (conductivity) level. In fracturemechanics CGR tests at $\mathrm{R}=0.95$, Ruther et al..$^{9}$ confirmed that in $\mathrm{HP}$ water, CGRs at $320^{\circ} \mathrm{C}$ were much lower than at $288^{\circ} \mathrm{C}$. Andresen ${ }^{*}$ found that CGRs in fracture-mechanics tests are typically $10-20$ times higher at $200^{\circ} \mathrm{C}$ than at $288^{\circ} \mathrm{C}$. His data also suggest a sharp drop in CGRs at temperatures of $>300^{\circ} \mathrm{C}$ in HP water. At the end of the tests, the specimens were sectioned for metallographic examination. The crack paths and fracture surface morphologies of the specimens indicate a predominantly transgranular mode.

\section{Analysis}

Most of the available data on corrosion fatigue of piping and pressure vessel stecls in aqueous environments have been developed in support of light-water-reactor (LWR) technology in the United States and abroad. Because Section XI of the ASME Code currently provides only an in-air design curve, corrosion fatigue data in simulated boiling-water-reactor (BWR) environments, obtained at Argonne National Laboratory (ANL) and from the literature, have been analyzed to develop corrosion fatigue curves for SSs in aqueous environments. ${ }^{11}$ The approach is basically an update of the work of Gilman et al., ${ }^{12}$ incorporating additional data that are now available. The modified equations from Section XI of the ASME Code for fatigue crack growth of Type $304 \mathrm{SS}$ in air (ASME air curve) and crack growth curves in $289^{\circ} \mathrm{C}$ water ${ }^{11}$ form a useful basis of comparison for our current results under specific loading conditions at lower temperatures.

The CGR, $\dot{a}$, in the environment is written as a superposition of a term representing the

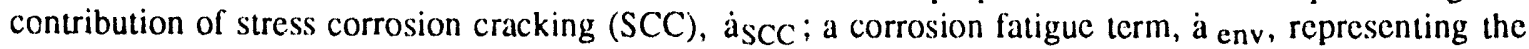
additional CGR under cyclic loading due to the environment; and a mechanical fatigue term $\dot{a}_{\text {air }}$, representing the fatigue crack growth in air:

$$
\dot{a}=\dot{a}_{\text {SCC }}+\dot{a}_{\text {env }}+\dot{a}_{\text {air }} \text {. }
$$

\footnotetext{
* Private communication, Peter Andresen, General Electric Corporate R \& D Center, to W. J. Shack, Argonne National Laboratory, May 1991.
} 
Table 2. Crack growth results for ausienitic SS specimens ${ }^{a}$ under cyclic loading in oxygenated water at 150,185 , and $225^{\circ} \mathrm{C}$

\begin{tabular}{|c|c|c|c|c|c|c|c|c|c|c|c|c|c|c|c|c|}
\hline \multirow{3}{*}{$\begin{array}{l}\text { Test } \\
\text { No. }\end{array}$} & \multirow{3}{*}{$\begin{array}{c}\text { Test } \\
\text { Time. } \\
\text { h }\end{array}$} & \multirow[b]{3}{*}{$\begin{array}{l}\text { Temp.. } \\
\quad{ }^{\circ}\end{array}$} & \multicolumn{3}{|c|}{ Water Chemistry } & \multicolumn{2}{|c|}{$\begin{array}{l}\text { Electrode } \\
\text { Potential }\end{array}$} & \multicolumn{3}{|c|}{$\begin{array}{c}\text { Loading } \\
\text { Conditions }\end{array}$} & \multicolumn{6}{|c|}{ Crack Growth Parameters for Several Heats of Type 316NG SS } \\
\hline & & & \multirow{2}{*}{$\begin{array}{c}\text { Oxygen } \\
\text { Conc.. } \\
\text { ppm }\end{array}$} & \multirow{2}{*}{$\begin{array}{c}\mathrm{Cr} \\
\text { Conc.. } \\
\text { ppm }\end{array}$} & \multirow{2}{*}{$\begin{array}{l}\text { Cond. } \\
\text { at } 25^{\circ} \mathrm{C} \text {. } \\
\mu \mathrm{S} \cdot \mathrm{cm}^{-1}\end{array}$} & \multirow[b]{2}{*}{$\begin{array}{c}304 \mathrm{SS} \\
\mathrm{mV}(\mathrm{SHE})\end{array}$} & \multirow[b]{2}{*}{$\begin{array}{c}\mathrm{Pt} \\
\mathrm{mV}(\mathrm{SHE})\end{array}$} & \multirow{2}{*}{$\begin{array}{c}\text { Rise } \\
\text { Time. } \\
s\end{array}$} & \multirow[b]{2}{*}{$\begin{array}{c}\text { Freq.. } \\
\mathrm{Hz}\end{array}$} & \multirow{2}{*}{$\begin{array}{l}\text { Load } \\
\text { Ratio }\end{array}$} & \multicolumn{2}{|c|}{ Heat No. 13198} & \multicolumn{2}{|c|}{ Heat No. 440104} & \multicolumn{2}{|c|}{ Heat No. 16650} \\
\hline & & & & & & & & & & & $\begin{array}{c}\mathrm{K}_{\max } \mathrm{e}^{\mathrm{C}} \\
\mathrm{MPa} \cdot \mathrm{m}^{1 / 2}\end{array}$ & $\begin{array}{l}\text { Growth Rate. } \\
10^{-10} \mathrm{~m} \cdot \mathrm{s}^{-1}\end{array}$ & $\begin{array}{c}\mathrm{K}_{\max }{ }^{\mathrm{C}} \\
\mathrm{MPa} \cdot \mathrm{m}^{1 / 2}\end{array}$ & $\begin{array}{l}\text { Growth Rate. } \\
10^{-10} \mathrm{~ms}^{-1}\end{array}$ & $\begin{array}{c}K_{\max }{ }^{\mathrm{e}} . \\
\mathrm{MPa} \cdot \mathrm{m}^{1 / 2}\end{array}$ & $\begin{array}{l}\text { Growth Rate. } \\
10^{-10} \mathrm{~m} \cdot \mathrm{s}^{-1}\end{array}$ \\
\hline 4 & 188 & 150 & 8.9 & 0 & 0.09 & -1 & -1 & 10 & 0.09 & 0.7 & 27.4 & $\overline{2.7}$ & 27.1 & 2.5 & 27.3 & 2.8 \\
\hline 5 & 120 & 150 & 9.3 & 0.1 & 0.47 & $-f$ & $f$ & 10 & 0.09 & 0.7 & 27.6 & 3.2 & 27.3 & 2.5 & 27.5 & 3.3 \\
\hline 6 & 140 & 150 & 8.9 & 1.0 & 3.67 & -1 & $-f$ & 10 & 0.09 & 0.7 & 28.3 & 7.5 & 27.6 & 2.4 & 28.3 & 8.9 \\
\hline 7 & 120 & 150 & 7.8 & 5.0 & 17.4 & $-f$ & $f$ & 10 & 0.09 & 0.7 & 29.5 & 17.2 & 28.1 & 7.5 & 29.7 & 18.1 \\
\hline 8 & 28 & 225 & 8.1 & 5.0 & 17.4 & $-f$ & 1 & 10 & 0.09 & 0.7 & 30.3 & 50.1 & 28.9 & 54.5 & 31.3 & 69.5 \\
\hline 9 & 28 & 225 & 8.9 & 1.0 & 3.67 & $-f$ & \lrcorner & 10 & 0.09 & 0.7 & 31.0 & 39.1 & 29.8 & 46.8 & 32.7 & 65.3 \\
\hline 10 & 24 & 225 & 8.1 & 0.1 & 0.47 & 220 & 350 & 10 & 0.09 & 0.7 & 320 & 56.1 & 30.8 & 63.4 & 34.1 & 76.3 \\
\hline 11 & 24 & 225 & 9.3 & 0 & 0.10 & 210 & 370 & 10 & 0.09 & 0.7 & 33.1 & 59.4 & 32.2 & 73.0 & 36.4 & 97.1 \\
\hline 12 & 29 & 185 & 8.7 & 0 & 0.10 & 252 & 337 & 10 & 0.09 & 0.7 & 34.1 & 38.6 & 33.1 & 42.3 & 36.7 & 8.6 \\
\hline 13 & 24 & 185 & 8.6 & 5.0 & 17.4 & 265 & 390 & 10 & 0.09 & 0.7 & 35.6 & 82.2 & 34.1 & 54.5 & 38.9 & 105.0 \\
\hline
\end{tabular}

${ }^{a}$ Compact tension specimens (1TCT) of Type 316NG SS (Heat No. 13198; Specimen No. 4), (Heat No. 440104; Specimen No. 3), and Type 316L SS

(Heat No. 16650; Specimen No. 11) received the following heat treatment: solution-anneal at $1050^{\circ} \mathrm{C}$ for $0.5 \mathrm{~h}$ followed by $650^{\circ} \mathrm{C}$ for $24 \mathrm{~h}$.

b Electrochemical potential of Type 304 SS and platinum at the test temperature corrected to the standard hydrogen electrode (SHE).

c Rise time, frequency, and load ratio for the positive sawtooth waveform.

$\mathrm{d}$ After the chloride concentration in water was either increased or decreased, the system operated for $\approx 48 \mathrm{~h}$ before load cycling began.

e Stress intensity, $K_{\max }$, values at the end of the time period.

$\mathrm{f}$ Electrodes were shorted internally; problem was correcied at the beginning of Test No. 10. 

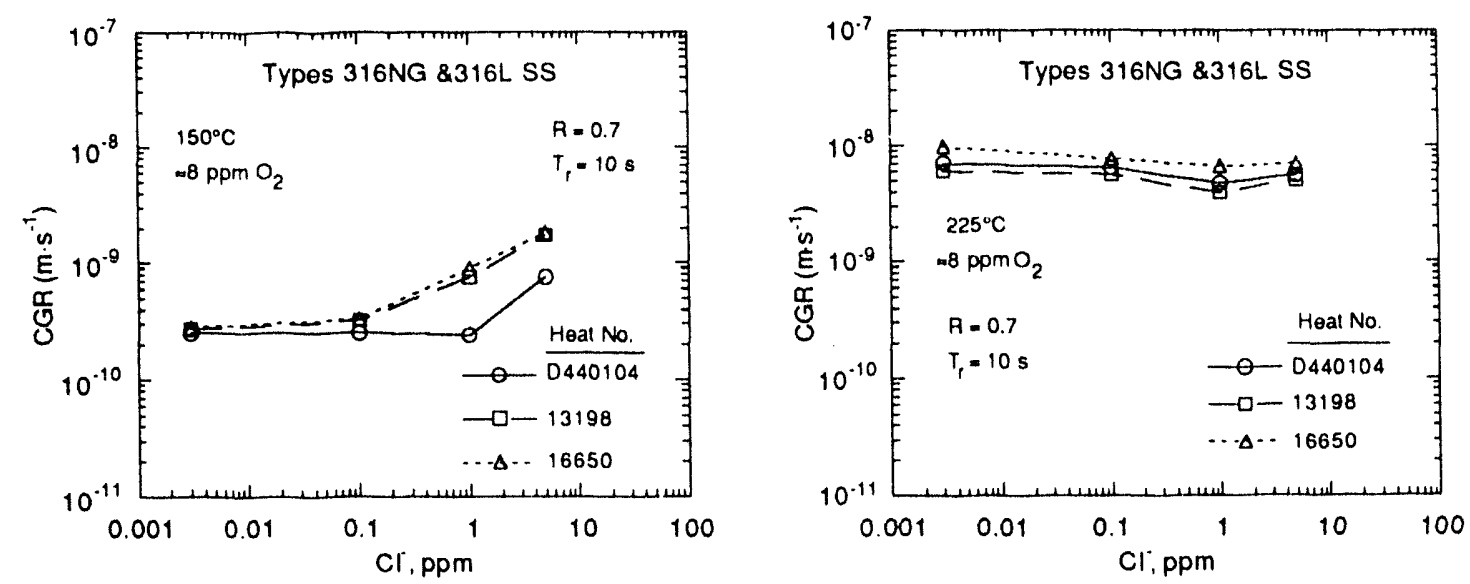

Figure 1. Dependence of crack growth rates of Types $316 \mathrm{NG}$ and $316 \mathrm{~L}$ SS on $\mathrm{Cl}^{-}$concentration in oxygenated water at 150 and $225^{\circ} \mathrm{C}$ during high-R, low-frequency loading
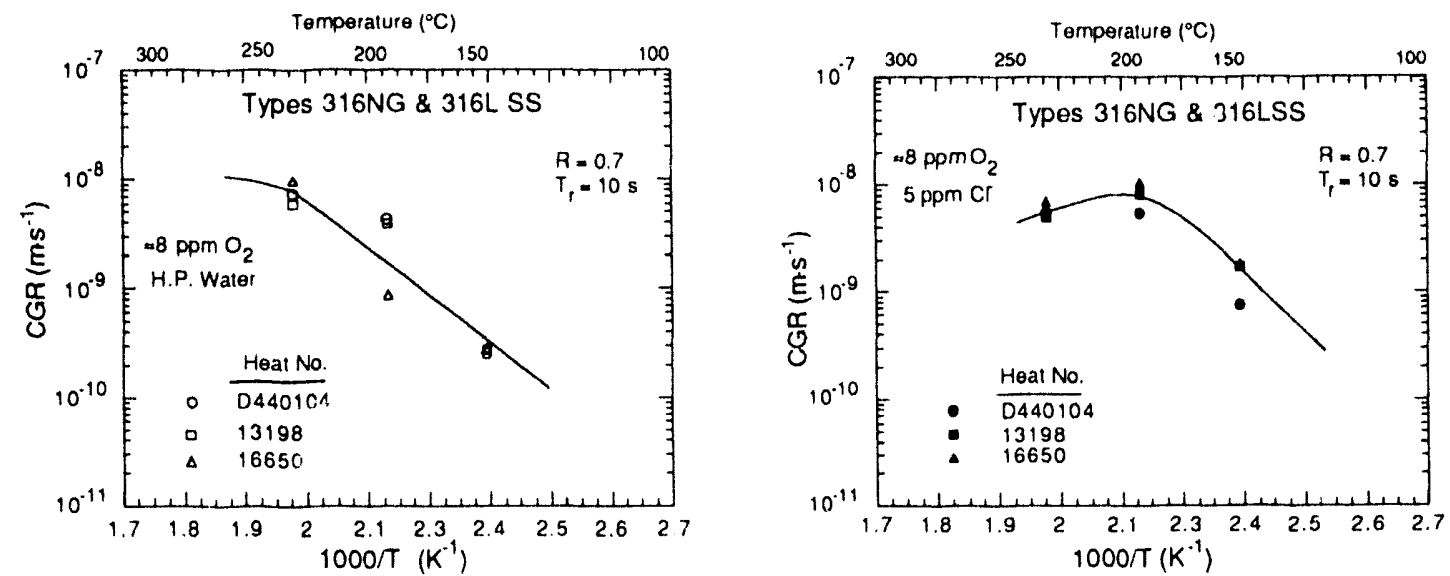

Figure 2. Dependence of crack growth rates of Types $316 N G$ and $316 L$ SS on reciprocal temperature during high- $R$, low-frequency loading in $H P$ oxygenated water and oxygenated water containing $5 \mathrm{ppm} \mathrm{Cl}^{-}$

For the SCC term, the correlation given in the U.S. Nuclear Regulatory Commission Report NUREG0313, Rev. 2, January 1988, is used for water chemistries with $8 \mathrm{ppm}$ dissolved oxygen:

$$
\dot{a}_{S C C}=2.1 \times 10^{-13} \mathrm{~K}^{2.161}\left(\mathrm{~m} \cdot \mathrm{s}^{-1}\right) .
$$

The air term is given by the current ASME Section XI correlation at $288^{\circ} \mathrm{C}$, based on the work of James and Jones: 13

$$
\begin{array}{rlrl}
\dot{\mathrm{a}}_{\text {air }} & =3.43 \times 10^{-12} \mathrm{~S}(\mathrm{R}) \Delta \mathrm{K}^{3.3} / \mathrm{T}_{\mathrm{R}} & \left(\mathrm{m} \cdot \mathrm{s}^{-1}\right) \\
\mathrm{S}(\mathrm{R}) & =1+1.18 \mathrm{R} & \mathrm{R} \leq 0.8 \\
& =-43.35+57.97 \mathrm{R} & \mathrm{R}>0.8
\end{array}
$$


where $T_{R}$ is the rise time of the loading waveform. Following Shoji et al. ${ }^{14}$ and Gilman et al., ${ }^{12}$ the corrosion fatigue term is assumed to be related to $\dot{a}_{\text {air }}$ through a power law,

$$
\dot{\mathrm{a}}_{\mathrm{cnv}}=\mathbf{A} \dot{\mathrm{a}}_{\mathrm{air}}^{\mathrm{m}} .
$$

The values of the coefficient $A$ and the exponent $m$ for water with $8 \mathrm{ppm}$ dissolved oxygen at $288^{\circ} \mathrm{C}$, obtained by an empirical power-law curve fit to the existing data for $\mathrm{R}<0.9$ (where cyclic loading dominates and the stress corrosion term in the superposition model Eq. 1, can be ignored), are

$$
\begin{aligned}
& A=1.5 \times 10^{-4} \\
& m=0.5,
\end{aligned}
$$

for CGRs in $\mathrm{m} \cdot \mathrm{s}^{-1}$ and $\mathrm{K}$ in MPa $\mathrm{m}^{1 / 2}$.

The available experimental data for sensitized Type 304 SS in water with $8 \mathrm{ppm}$ dissolved oxygen at $288^{\circ} \mathrm{C}$ are compared in Fig. 3 with correlations based on Eys. 1-5. In most cases, the correlations were intended to be conservative but not necessarily upper bounds for all the data. The data from the ANL tests in simulated BWR environments are summarized in Ref. 15. The other data were obtained from the literature (Refs. 16-22). Although it is clear that nonsensitized steels such as Types $316 \mathrm{NG}, \mathrm{CF}-3 \mathrm{M}$, and solution-annealed 304 SS are much more resistant to SCC initiation, they show comparable environmentally enhanced CGRs under cyclic loading.

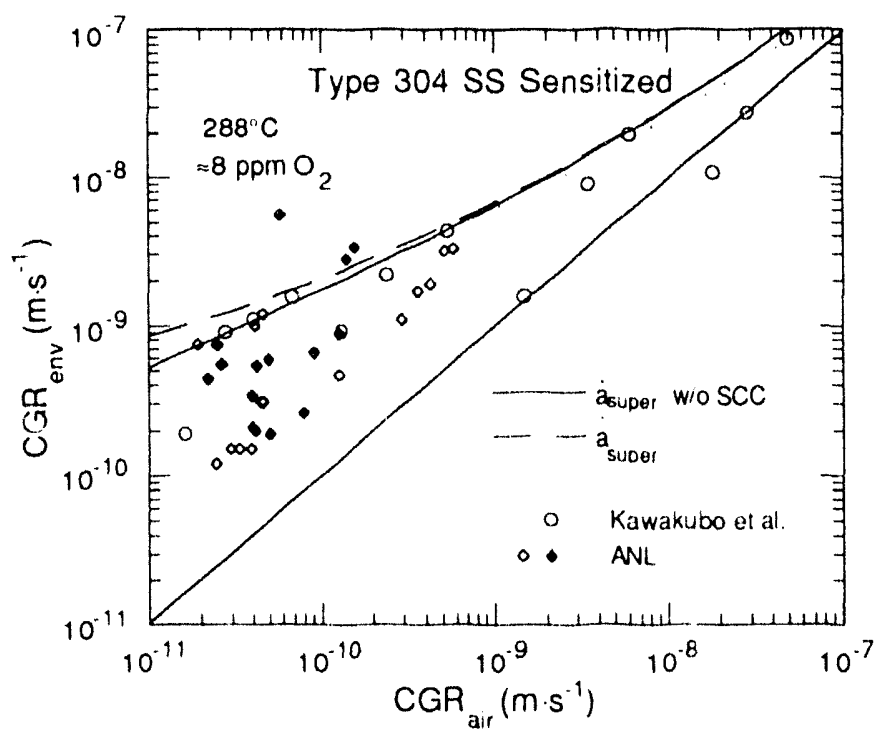

Figure 3. Corrosion fatigue data for sensitized Type 304 SS in water containing $8 \mathrm{ppm}$ dissolved oxygen at $288^{\circ} \mathrm{C}$ compared with models. Diagonal line corresponds to crack growth in air.

The correlations (Eqs. 1-5) and data (Fig. 3) are based on tests at $288^{\circ} \mathrm{C}$; relatively few data are available in the literature on corrosion fatigue CGRs at other temperatures. The CGRs in Table 2 were compared with those predicted by the modified ASME Section XI fatigue crack growth correlation for Type $304 \mathrm{SS}$ in air (Eq. 3) under the loading conditions in the different tests. The results are plotted in 
Figs. 4-6. Almost all of the data points in Fig. 4 and 5 fall above the diagonal line, i.c., the experimental CGR values in water are higher than the Code predictions in air by factors of $\approx 5$ to 10 . Under these loading conditions, the erivironmental contribution to crack growth is significant. The results at $150^{\circ} \mathrm{C}$ (Fig. 6) indicate that CGRs in water containing 1.0 and $0 \mathrm{ppm} \mathrm{Cl}^{-}$are either consistent with or lower than the Code predictions (diagonal line), respectively, which implies that crack growth is dominated by mechanical fatigue. In oxygenated water containing $5 \mathrm{ppm} \mathrm{Cl}^{-}$at $150^{\circ} \mathrm{C}$, the environmental enhancement compared to air is small (greater by a factor of $\approx 2$ ). Because the Code curve is drawn at a $95 \%$ confidence level, it is not surprising that in the absence of environmental effects, the Code predictions are somewhat conservative.

Although the present data (Figs. 4-6) are probably inadequate to completcly quantify the effects of temperature on CGRs in water, the correlations ${ }^{11}$ based on data at $288^{\circ} \mathrm{C}$ are consistent with results at 185 and $225^{\circ} \mathrm{C}$, but are conservative for temperatures $\leq 150^{\circ} \mathrm{C}$.

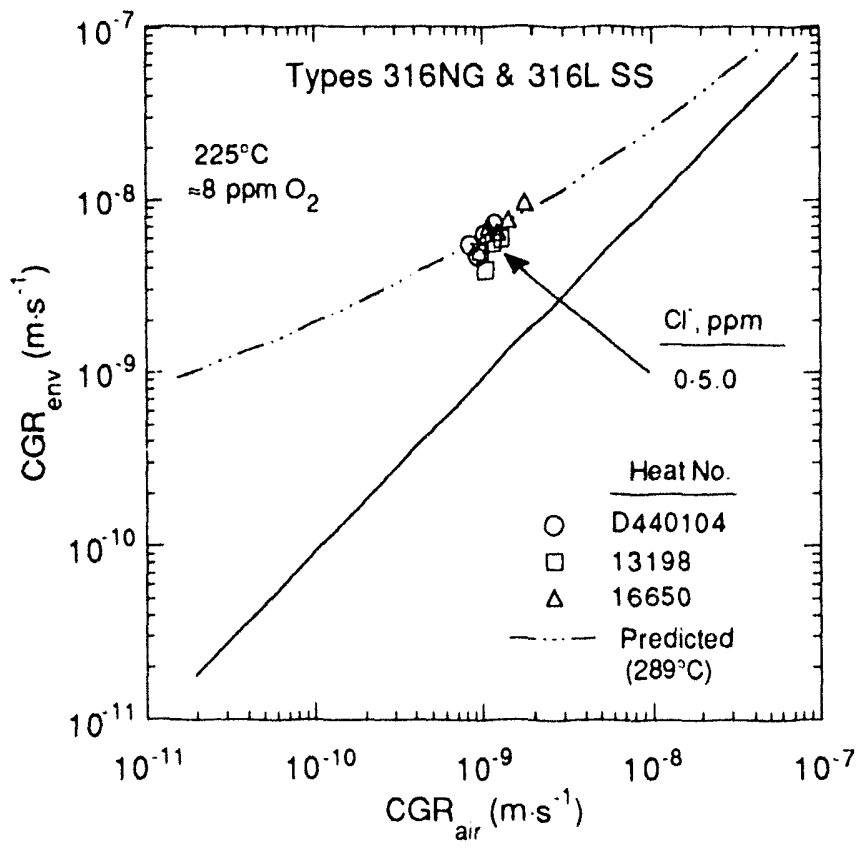

Figure 4. Corrosion fatigue data at $225^{\circ} \mathrm{C}$ in water containing

$8 \mathrm{ppm}$ dissolved oxygen and $0-5 \mathrm{ppm} \mathrm{Cl}$ compared with model. Diagonal line corresponds to crack growth in air.

\section{CONCLUSIONS}

CGR tests were performed on a set of three 1TCT specimens of Types 316NG and 316L SS in oxygenated water containing $0-5 \mathrm{ppm} \mathrm{Cl}-$ at 150,185 , and $225^{\circ} \mathrm{C}$. The results obtained at 225 and $185^{\circ} \mathrm{C}$ at and $\mathrm{R}$ value of 0.7 , a frequency of $0.09 \mathrm{~Hz}$, and stress intensity factors of $\approx 27$ to $39 \mathrm{MPa} \cdot \mathrm{m}^{1 / 2}$ indicate environmental enhancement relative to calculated rates in air under the specific cyclic loading conditions. In contrast, the data obtained at $150^{\circ} \mathrm{C}$ were consistent with the predicted rates in air, particularly at lower $\mathrm{Cl}^{-}$ concentrations (i.e., $<1 \mathrm{ppm}$ ). Predictions of a model (developed at $\mathrm{ANL}^{11}$ ) for corrosion fatigue of austenitic SSs in aqueous environments at $288^{\circ} \mathrm{C}$ are consistent with data obtained at 185 and $225^{\circ} \mathrm{C}$ in this study. The model must be modified to accurately predict CGRs at temperatures $<170^{\circ} \mathrm{C}$. 


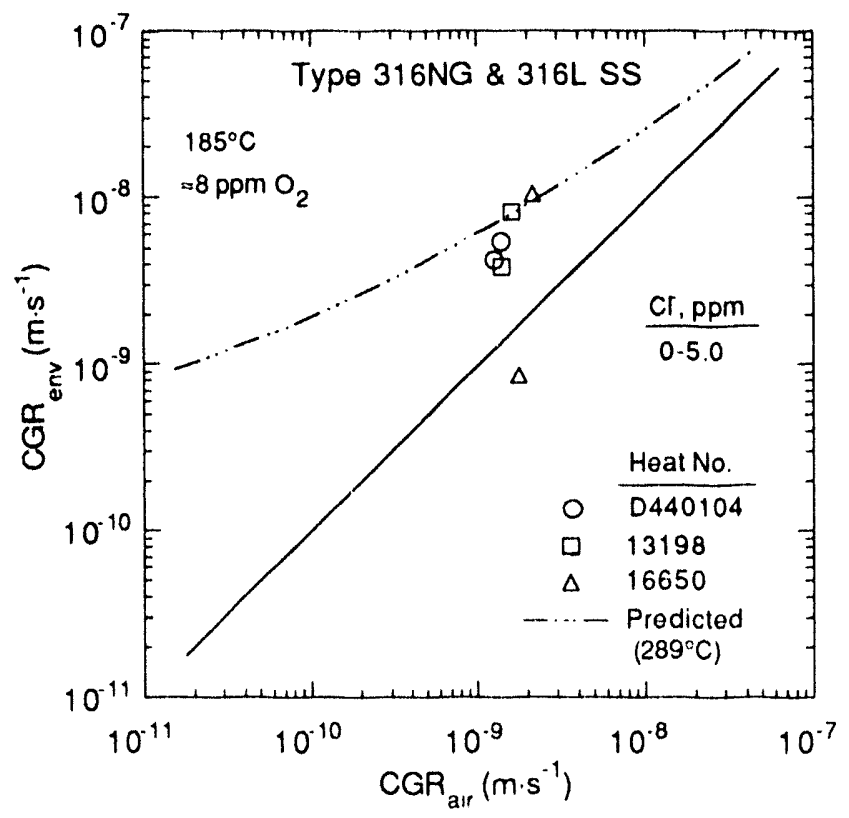

Figure 5. Corrosion fatigue data at $185^{\circ} \mathrm{C}$ in water containing $8 \mathrm{ppm}$ dissolved oxygen and 0-5 ppm Ct compared with model. Diagonal line corresponds to crack growth in air.

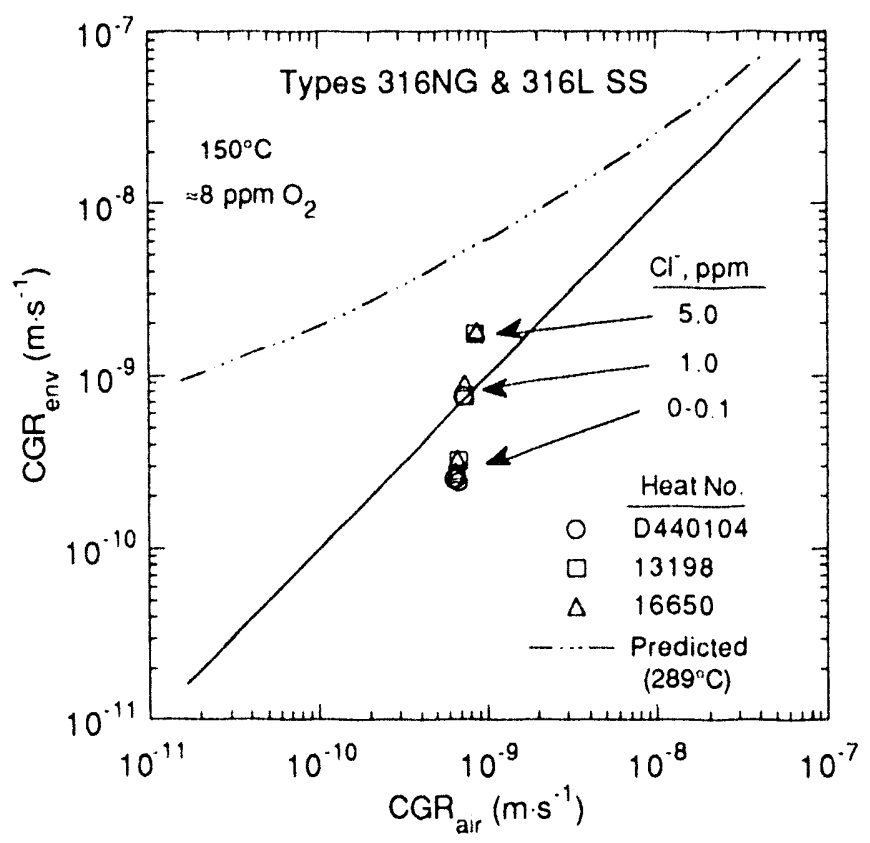

Figure 6. Corrosion fatigue data at $150^{\circ} \mathrm{C}$ in water containing $8 \mathrm{ppm}$ dissolved oxygen and 0-5 ppm Ct compared with model. Diagonal line corresponds to crack growth in air. 


\section{FUTURE WORK}

Crack growth rate tests will be conducted on another set of 1TCT specimens from several heats of Type 316NG SS in simulated ITER water chemistries under cyclic loading conditions. The tests will be performed at higher load ratios and lower frequencies that are more typical of reactor loading conditions. The influence of temperature on CGRs will also be investigated. This information will supplement the existing data base developed for BWRs, as well as the ASME Boiler and Pressure Vessel Code, ASTM Standards, and other consensus codes and standards. The tests will provide a technical basis for selection of appropriate crack growth curves for design and analysis, and will confirm that the chances of service-induced cracking of a candidate material for ITER first-wall/blanket systems are small.

\section{REFERENCES}

1. R. W. Conn, V. A. Chuyanov, N. Inoue, and D. R. Swectman, The International Thermonuclear Experimental Reactor, Scientific Amcrican, 226 (4) 1992.

2. D. L. Smith, Aqueous Corrosion Task for ITER R\&D, U.S. Coordination Mecting, Argonne National Laboratory, August 6, 1990.

3. A. B. Hull, M. R. Fox, J. W. Pascoe, and T. F. Kassncr, Environmental Effects on Aqueous Stress Corrosion of Candidate Austenitic Steels for ITER Structural Applications, 9th Fusion Reactor Materials Semiannual Progress Report for Period Ending September 30, 1990, DOE/ER-0313/9, Oak Ridge National Laboratory, p. 228.

4. A. B. Hull and T. F. Kassner, Aqueous Stress Corrosion of Candidate Austenitic Steels for ITER Structural Applications, 10th Fusion Reactor Materials Scmiannual Progress Report for Period Ending March 31, 1991, DOE/ER-0313/10, Oak Ridge National Laboratory, p. 241.

5. M. R. Fox, A. B. Hull, and T. F. Kassner, Stress Corrosion Cracking of Candidate Structural Materials under Simulated First-Wall/Aqueous Coolant Environments, Fusion Technol., 19, 1619-1628 (1991).

6. A. B. Hull, P. R. Luebbers, M. R. Fox, W. K. Soppet, and T. F. Kassner, Aqueous Stress Corrosion of Candidate Austenitic Steels for ITER Structural Applications, 12th Fusion Reactor Materials Semiannual Progress Report for Period Ending March 31, 1992, DOE/ER-0313/12, Oak Ridge National Laboratory, p. 225.

7. D. M. French, W. K. Soppet, and T. F. Kassner, Aqucous Stress Corrosion of Candidate Austenitic Steels for ITER Structural Applications, 13th Fusion Reactor Matcrials Semiannual Progress Report for Period Ending September 30, 1992, DOE/ER-0313/13, Oak Ridgc National Laboratory.

8. D. D. Macdonald, A. C. Scolt, and P. Wentrcck, External Reference Electrodes for Use in High Temperature Aqueous Systems, J. Electrochem. Soc., 126, 908-911 (1979).

9. W. E. Ruther, W. K. Soppet, and T. F. Kassner, in Environmentally Assisted Cracking in Light Water Reactor: Annual Report, October 1983-September 1984, NUREG/CR-4287, ANL-85-33, pp. 93-113 (June 1985).

10. F. P. Ford, A Mechanism of Environmentally-Controlled Crack Growth of Structural Steels in High-Temperature Water. Proc. IAEA Specialists' Meeting on Subcritical Crack Growth, NUREG/CP-()44 Vol. 2, MEA-2014 Vol. 2 (May 1983). 
11. W. J. Shack, in Environmentally Assisted Cracking in Light Water Reactors Semiannual Report, October 1990-March 1991, NUREG/CR-4667 Vol. 12, ANL-91/24, pp. 31-37 (August 1991).

12. J. D. Gilman, R. Rungta, P. Hinds, and H. Mindlan, Corrosion-Fatigue Crack Growth Rates in Austenitic Stainless Steels in Light Water Reactor Environments, Int. J. Pressure Vessel Piping 31, 55-68 (1988).

13. L. A. James and D. P. Jones, Fatigue Crack Growth Correlation for Austenitic Stainless Steels in Air, Proc. Conf. on Predictive Capabilities in Environmentally-Assisted Cracking, R. Rungta, ed., PVP Vol. 99, American Society of Mechanical Engineers. NY, pp. $363-414$ (1985).

14. T. Shoji, H. Takahashi, M. Suzuki, and T. Kondo, A New Parameter for Characterizing Corrosion Fatigue Crack Growth, J. Eng. Mater. Technol. 103, 298-304 (1981).

15. W. E. Ruther, W. J. Shack, T. F. Kassner, and W. K. Soppet, in Environmentally Assisted Cracking in Light Water Reactors Semiannual Report, April-September 1988, NUREG/CR-4667 Vol. 7, ANL-89/40, pp. 3-14 (March 1990).

16. L. G. Ljungberg, D. Cubicciotti, and M. Trolle, The Effect of Sulfate on Environmental Cracking in Boiling Water Reactors under Constant Load or Fatigue, Corrosion 46, 641-652 (1990).

17. L. G. Ljungticrg, D. Cubicciotti, and M. Trolle, Effect of Water Impurities in BWRs on Environmental Crack Growth under Realistic Load Conditions, Proc. 4th Int. Symp. Environmental Degradation of Materials in Nuclear Power Systems-Water Reactors, National Association of Corrosion Enginecrs, Houston, pp. 4-59 to 4-74 (1990).

18. L. G. Ljıngberg, D. Cubicciouti, and M. Trolle, Effect of Water Impurities in BWRs on Environmental Crack Growth in Type 304 Stainless Steel, NUREG/CP-0112 Vol. 2, ANL-90/22 Vol. 2, pp. 57-64 (August 1990).

19. J. Alexander et al., Alternative Alloys for BWR Pipe Applications, EPRI NP-2671-LD, pp. 5-17 to 5-32, Electric Power Research Institute, Palo Alto, CA (October 1982).

20. C. W. Jewett and A. E. Pickett, The Benefil of Hydrogen Addition to the Boiling Water Reactor Environment on Stress Corrosion Crack Initiation and Growth in Type 304 Stainless Steel, J. Eng. Mater. Technol. 108, 10-19 (1986).

21. P. L. Andresen, Effects of Stress Intensity, $R$ Value, and Environmental Impurities in $288^{\circ} \mathrm{C}$ Water on Crack Growtk Rate in Type 304 SS CT Specimens, Corrosion 88, Paper No. 11, St. Louis, MO (March 1988).

22. T. Kawakubo, M. Hishida, K. Amano, and M. Katsuta, Crack Growth Behavior of Type 304 Stainless Steel in Oxygenated $290^{\circ} \mathrm{C}$ Pure Water under Low Frequency Cyclic Loading, Corrosion 36, 638-647 (1980). 


\section{DEVELOPMENT OF ALUMINIDE COATINGS ON VANADIUM-BASE ALLOYS \\ IN LIQUID LITHIUM* — J.-H. Park and G. Dragel (Argonne National Laboratory)}

\section{OBJECTIVE}

The corrosion resistance of structural materials and the magnetohydrodynamic (MHD) force and its subsequent influence on thermal hydraulics and corrosion are major concerns in the design of liquid-metal blankets for magnetic fusion reactors (MFRs). The objective of this study is to develop in-situ stable coatings at the liquid-metal/structural-material interface, with emphasis on coatings that can be converted to an electrically insulating film to prevent adverse MHD-generated currents from passing through the structural walls. ${ }^{1-3}$

\section{SUMMARY}

Aluminide coatings were produced on vanadium and vanadium-base alloys ${ }^{4}$ by exposure of the materials to liquid lithium that contained 3-5 at.\% dissolved aluminum in sealed $\mathrm{V}$ and $\mathrm{V}-20 \mathrm{wt} . \% \mathrm{Ti}$ capsules at temperatures between 775 and $880^{\circ} \mathrm{C}$. After each test, the capsules were opened and the samples were examined by optical microscopy and scanning electron microscopy (SEM), and analyzed by electronenergy-dispersive spectroscopy (EDS) and X-ray diffraction. Hardness of the coating layers and bulk alloys was determined by microindentation techniques. The nature of the coatings, i.e., surface coverage, thickness, and composition, varied with exposure time and temperature, solute concentration in lithium, and alloy composition. Solute elements that yielded adherent coatings on various substrates can provide a means of developing in-situ electrical insulator coatings by reaction of the reactive layers with dissolved nitrogen in liquid lithium.

\section{INTRODUCTION}

The corrosion resistance of structural materials and the MHD force and its subsequent influence on thermal hydraulics are major concerns in the design of liquid-metal cooling systems. ${ }^{1-3}$ This study focuses on the development of in-situ stable corrosion-resistant coatings at the liquid-metal/structural-material interface. The coatings should be capable of (a) forming on various shapes such as the inside of tubes or on irregular shapes during operational conditions, (b) improving general corrosion resistance, and (c) acting as a diffusion barrier for hydrogen isotopes, viz., deuterium and tritium.

\section{COATING METHODS}

Aluminide coatings that form on structural alloys during exposure to liquid $\mathrm{Li}$ that contain dissolved Al suggest a means for producing stable electrical insulator layers, such as AIN, by subsequent nitridation of the intermetallic layer in the liquid-metal environment. ${ }^{4}$ The formation of several aluminides $\left(\mathrm{V}_{\mathrm{x}} \mathrm{Al}_{\mathrm{y}}\right)$ that contain $>40-50$ at. \% of $\mathrm{Al}$ on $\mathrm{V}$-base alloys can be predicted from the $\mathrm{V}$-Al phase diagram. ${ }^{5}$ The Al$\mathrm{Li}$ phase diagram ${ }^{5,6}$ indicates that $\mathrm{Al}$ is soluble in liquid $\mathrm{Li}$, whereas $\mathrm{V}$ is not soluble in $\mathrm{Li}^{7}{ }^{7}$ These phase relations make up the underlying basis for the formation of aluminide coatings on $\mathrm{V}$ and its alloys in liquid $\mathrm{Li}$. Aluminide coatings were produced on $\mathrm{V}$ and $\mathrm{V}$-base alloys by exposure of the materials to liquid $\mathrm{Li}$ that contained 3-5 at.\% Al in sealed $\mathrm{V}$ and $\mathrm{V}-20 \% \mathrm{Ti}$ capsules. ${ }^{4}$ The nature of aluminide coatings formed on $\mathrm{V}, \mathrm{Ti}$, and $\mathrm{V}$-base alloys containing $\mathrm{Ti}$ and $\mathrm{Cr}$ at $775-880^{\circ} \mathrm{C}$ is described in this report.

"Work supported by the U.S. Department of Energy under Contract W-31-109-Eng-38. 


\section{EXPERIMENTAL, PROCEDURE}

Aluminide coatings were produced on $\mathrm{V}, \mathrm{Ti}$, and several $\mathrm{V}$-base alloys ( $\mathrm{V}-5 \% \mathrm{Ti}, \mathrm{V}-20 \% \mathrm{Ti}, \mathrm{V}-5 \% \mathrm{Cr}$ $5 \% \mathrm{Ti}$, and $\mathrm{V}-15 \% \mathrm{Cr}-5 \% \mathrm{Ti}$ ) by exposure of the materials to liquid $\mathrm{Li}$ containing $\mathrm{Al}$ at temperatures of 775 , 800,860 , and $880^{\circ} \mathrm{C}$. The specimens and liquid $\mathrm{Li}$ were contained in $\mathrm{V}-20 \% \mathrm{Ti}$ and $\mathrm{V}$ capsules that were placed in a larger stainless stecl container. An argon cover gas $(99.999 \%$ pure) was maintained in the system to prevent oxidation of the $\mathrm{V}$ capsules and the $\mathrm{Li}$. The whole assembly was placed in a vertical furnace. At the end of the test, the capsules were cut open above the Li level to remove the samples. The capsules were placed in a beaker of water to dissolve the small volume of $\mathrm{Li}$ and the samples were removed and cleaned ultrasonically in acetone and ethanol and dried in air. The samples were examined by optical microscopy and SEM, and analyzed by EDS and X-ray diffraction. Hardness of the coating layers and bulk alloys was determined by Vickers indentation measurements with a Leitz microhardness tester.

\section{RESULT AND DISCUSSION}

The effects of exposure time, temperature, environment above the $\mathrm{Li}$, and capsule material ( $\mathrm{V}$ and $\mathrm{V}-20 \% \mathrm{Ti}$ ) on the formation of aluminide coatings were explored. Degree of surface coverage and thickness of the layers varied considerably, depending on exposure time and temperature. At temperatures and exposure times of $<800^{\circ} \mathrm{C}$ and $<90 \mathrm{~h}$, respectively, the aluminide layers were not uniform. Figure 1 shows the microstructures of aluminide coatings formed at $775^{\circ} \mathrm{C}$ for $87 \mathrm{~h}$ and $880^{\circ} \mathrm{C}$ for $48 \mathrm{~h}$. At the lower temperature, small grains on the surface began to connect with neighboring grains by a grain-growth mechanism. At the higher temperature, the microstructure reveals that grain size is larger by at least one order of magnitude. Dependence of Al concentration at the coating surface on temperature is shown for several samples in Fig. 2. The EDS analysis of the coating surface was obtained over a region of $1,000 \times 1,000 \mu \mathrm{m}$.

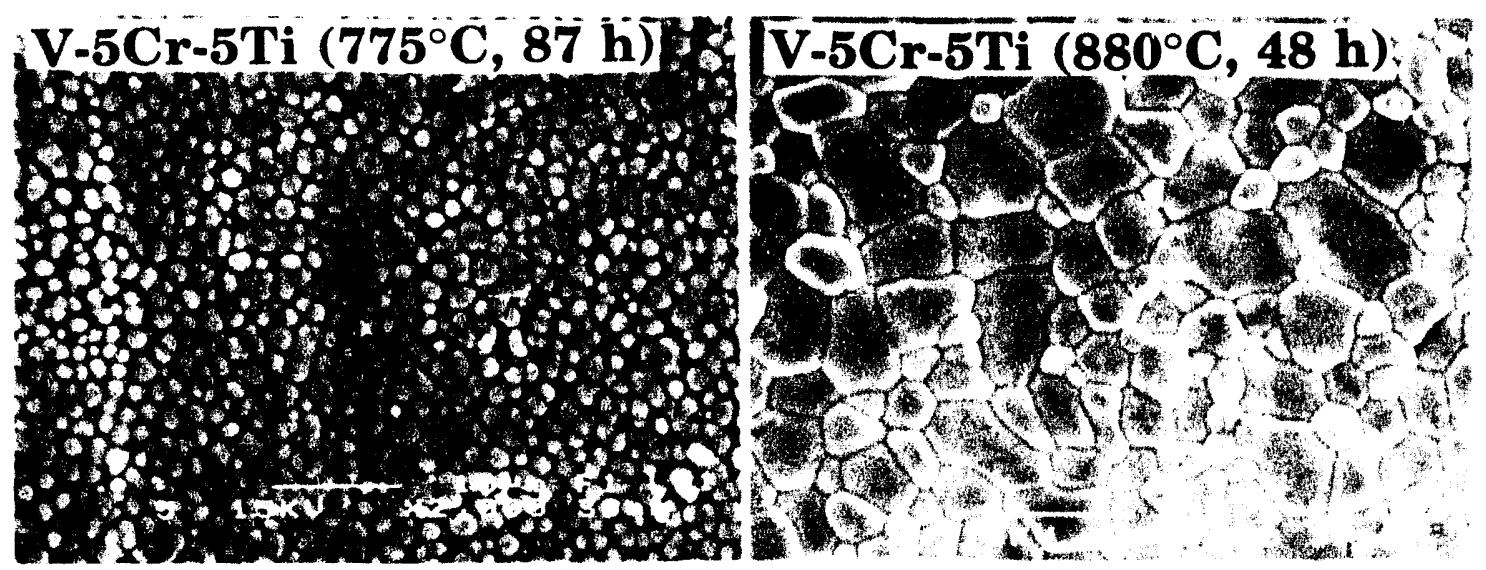

Figure l. Typical aluminide surface formed on V-5\%Cr-5\%Ti at 775 and $880^{\circ} \mathrm{C}$

A typical cross section of an aluminide coating layer is shown in Fig. 3. Based on these SEM photographs, the surface region is virtually defect-free, but an array of small defects is present beneath the compact layer. These defects may be clustered near a dislocation zone that is depleted in $\mathrm{Al}$ and rich in $\mathrm{Li}$ because of fast diffusion of $\mathrm{Li}$ via dislocations. Composition-vs.-depth profiles for the $\mathrm{V}$ and $\mathrm{V}-20 \% \mathrm{Ti}$ specimens are shown in Fig. 4. The depth of $\mathrm{Al}$ interdiffusion in $\mathrm{V}-20 \% \mathrm{Ti}$ is $\approx 3-4$ times greater than in pure $\mathrm{V}$ at $860^{\circ} \mathrm{C}$, which suggests a higher mobility of $\mathrm{Al}$ in $\mathrm{V}-20 \%$ Ti than in $\mathrm{V}$. 


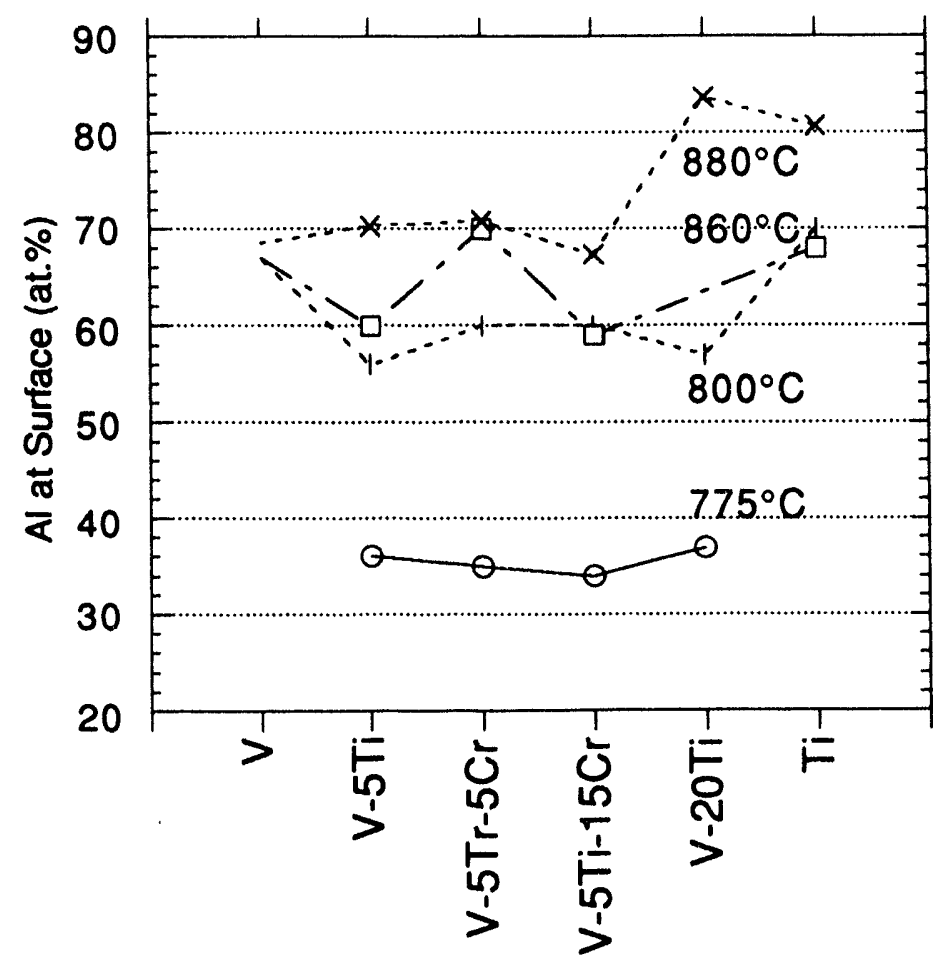

Figure 2. Aluminum content of aluminized surfaces formed on several $V$-base alloys and Ti at several temperatures between 775 and $880^{\circ} \mathrm{C}$

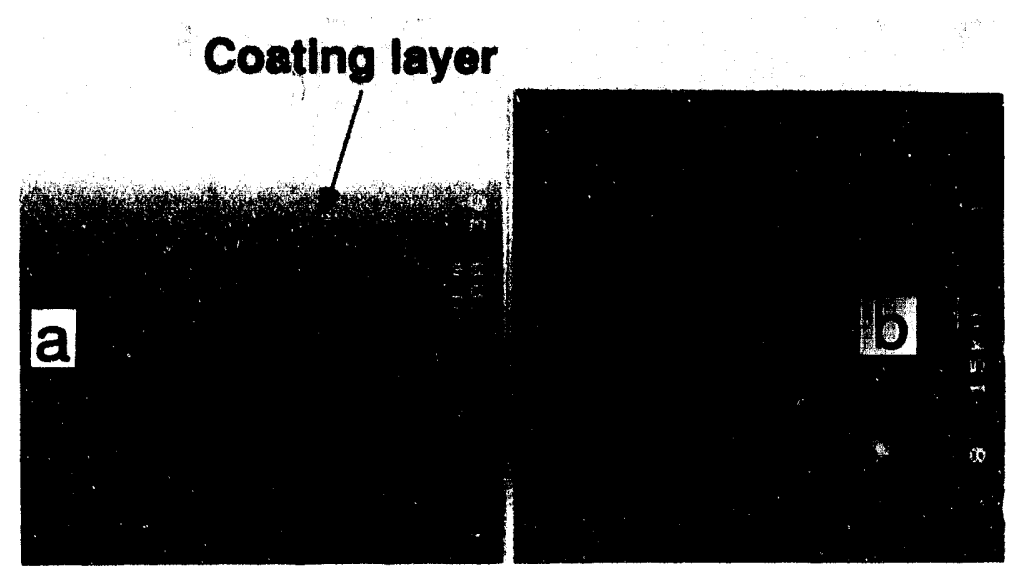

Figure 3. SEM photographs of a cross section of an aluminide layer on a V-20\%Ti alloy specimen: (a) bright field and (b) back-scatter electron image 

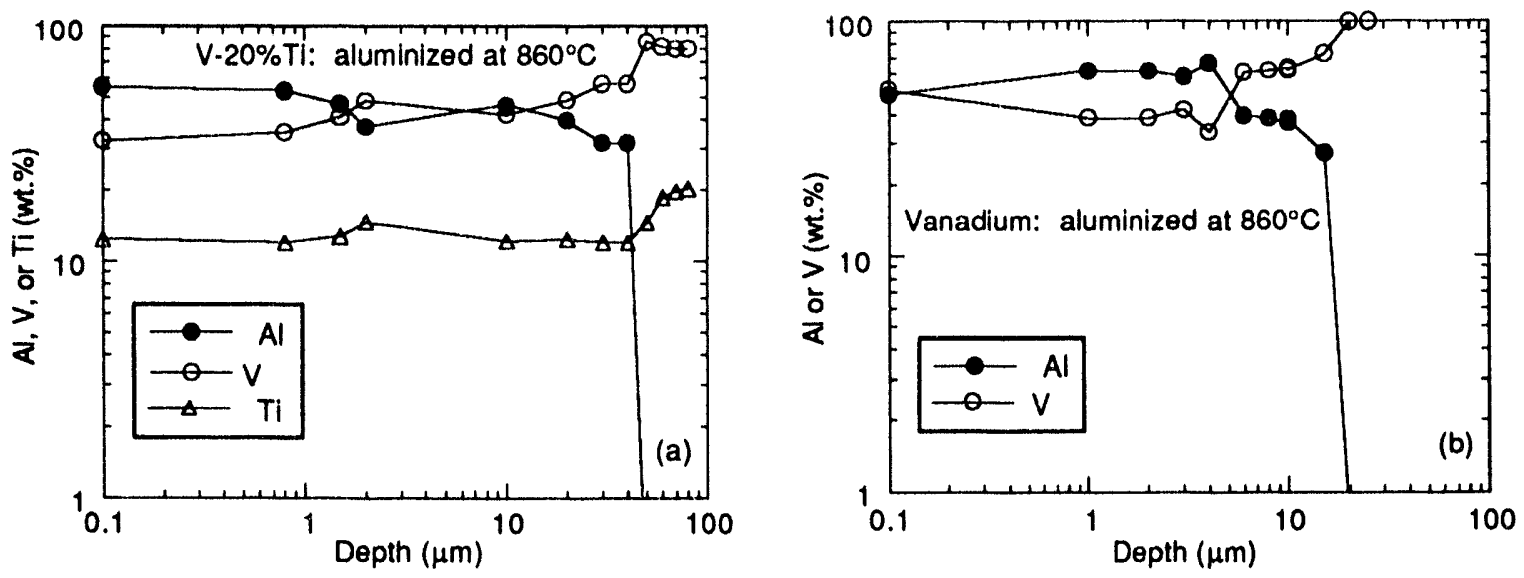

Figure 4. Chemical composition as a function of depth for aluminide layers on (a) V-20\%Ti and (b) V

Vickers hardness measurements of the aluminide layers and the underlying V and V-20\%Ti alloy were conducted at 25- and 50-g loads. The aluminide layers were harder than either V or V-20\% Ti, which can be attributed to interstitial $\mathrm{Al}$ atoms in the cubic lattice of $\mathrm{V}$. Because the distribution on nonmetallic elements $(\mathrm{O}, \mathrm{N}, \mathrm{C}, \mathrm{H})$ between $\mathrm{V}$-base alloys and $\mathrm{Li}$ favors the $\mathrm{Li}$, the alloys tend to become depleted in these constituents during exposure to high-temperature $\mathrm{Li}$. Consequently, the hardness increase is most likely caused by diffusion of $\mathrm{Al}$ into $\mathrm{V}$ and $\mathrm{V}-20 \% \mathrm{Ti}$. Our experience indicates that $\mathrm{V}$ becomes more ductile after exposure to liquid $\mathrm{Li}$.

Figure 5 illustrates the high degree of coverage of an aluminide layer on a welc joint between a $\mathrm{V}-20 \% \mathrm{Ti}$ tube and a V disk, as well as in the crevice region where fusion did not occur. Figure 5a shows a cross section of the capsule containing the weld zone; it reveals shallow penetration and a crevice between the tube and the disc. Figure $5 \mathrm{~b}$ shows this region in higher magnification. The aluminide coating is not only present on the surface of the tube and the face of the disk, but also penetrates the 1- $\mu \mathrm{m}$ space between the V-20\% Ti tube and V disk. The thickness of the coating in this region is similar to that on the inner surface of the tube and the disk exposed to liquid Li. Figure $5 \mathrm{c}$ shows that the gap region between tube and the edge of the disk (denoted by the arrow in Fig. 5a) has also been coated. The coating behavior suggests that bulk diffusion is the main piocess.

\section{CONCLUSIONS}

Surface modification via high-temperature liquid-phase deposition can provide intermetallic aluminide coatings on various alloys, namely, V, V-5\%Ti, V-20\% Ti, V-5\%Cr-5\%Ti, V-15\%Cr-5\% Ti, and Ti. This process is facilitated in liquid $\mathrm{Li}$ because surface contamination by $\mathrm{O}_{2}$ or oxide films is virtually eliminated and the process to produce homogeneous coatings on various surface shapes can be controlled by exposure time, temperature, and composition of the liquid metal. Coating integrity does not appear to be sensitive to defects (e.g., open pores, fissures, or microcracks) present in the alloy substrate. Conversion of aluminide layers to an electrical insulator coating (e.g., an AIN film) in liquid $\mathrm{Li}$ is being investigated.

\section{FUTURE STUDIES}

Results of mechanical-property ${ }^{8}$ and irradiation-damage ${ }^{9,10}$ studies indicate that $\mathrm{V}-5 \% \mathrm{Cr}-5 \% \mathrm{Ti}$ is the most promising V-base alloy for MFR applications. Consequently, the coating development study will focus on the $\mathrm{V}-5 \% \mathrm{Cr}-5 \% \mathrm{Ti}$ alloy. 

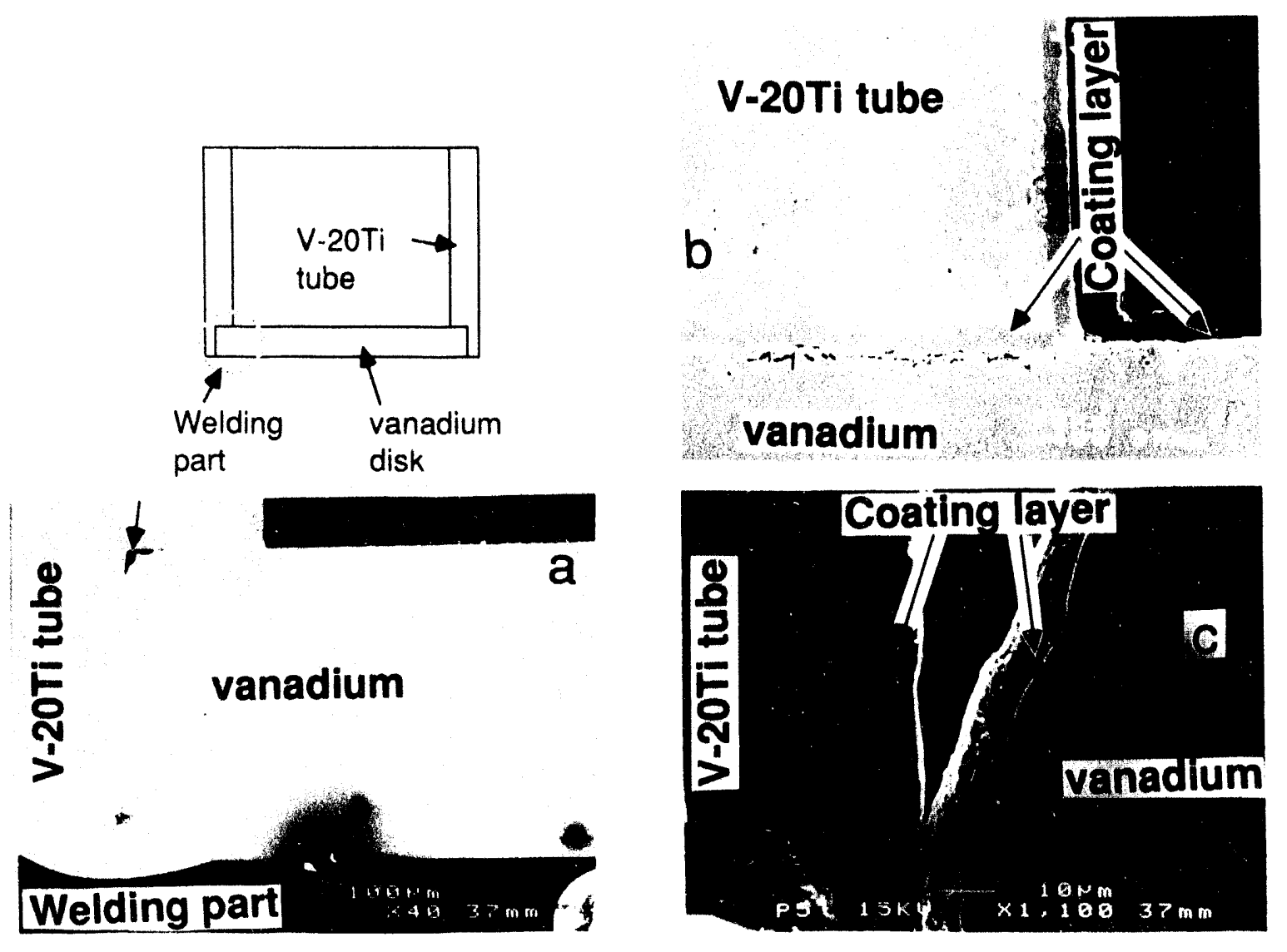

Figure 5. (a) Cross section of weld zone between V-20\%Ti tube and V disk, (b) aluminide coating on surface of tube and disk and in crevice region between tube and disk, and $(c)$ coating of gap region between tube and disk, denoted be arrow in (a)

\section{REFERENCES}

1. C. C. Baker et al., Tokamak Power System Studies FY 1985, Argonne National Laboratory Report ANL/FPP-85-2 (December 1985).

2. Y. Y. Liu and D. L. Smith, Ceramic Electrical Insulators for Liquid Metal Blankets, J. Nucl. Mater., 141-143, 38 (1986).

3. T. Kammash, Fusion Reactor Physics, Chapter 15, Ann Arbor Science Pub. Inc., Ann Arbor, MI (1975) pp. 405-439.

4. J.-H. Park and G. Dragel, Development of In-Situ-Formed Electrical Insulator Coatings on HighTemperature Alloys in Lithium, Fusion Reactor Materials Semiannual Progress Report for the Period Ending September 30, 1992.

5. M. Hansen, Constitution of Binary Alloys, McGraw-Hill, New York (1958).

6. F. A. Shunk, Constitution of Binary Alloys, Second Supplement, McGraw-Hill, New York (1969). 
7. J. F. Smith, ed., Phase Diagrams of Binary Vanadium Alloys, ASM International, Metals Park, $\mathrm{OH}$ (1989).

8. R. F. Mattas, B. A. Loomis, and D. L. Smith, Vanadium Alloys for Fusion Reactor Applications, JOM, 44(8), 26 (1992).

9. H. M. Chung, L. J. Nowicki, and D. L. Smith, Effect of Impurities and Doping Elements on Phase Structure of Vanadium-based Alloys Containing Titanium. Fusion Reactor Matcrials Scmiannual Prugress Report for the Pcriod Ending September 30, 1991, DOE/ER-0313/11, Oak Ridge National Laboratory, Oak Ridge, TN, pp. 215-226.

10. M. Satou and H. M. Chung, Effect of Impurities and Doping Elements on Phase Structure of Vanadium-based Alloys Containing Titanium. Fusion Reactor Matcrials Semiannual Progress Report for the Period Ending September 30, 1992. 
7.0 SOLID BREEDING MATERIALS AND BERYLLIUM

No contributions. 
413

8.0 CERAMICS 
CERAMICS RADIATION EFFECTS ISSUES FOR ITER--S. J. Zinkle (Oak Ridge National Laboratory)

\section{OBJECTIVE}

To review the key radiation effects issues associated with the use of ceramic insulators in near-term fusion reactors.

\section{SUMMARY}

The key radiation effects issues associated with the successful operation of ceramic materials in components of the planned International Thermonuclear Experimental Reactor (ITER) are discussed. Radiation-induced volume changes and degradation of the mechanical properties should not be a serious issue for the fluences planned for ITER. On the other hand, radiation-induced electrical degradation effects may severely limit the allowable exposure of ceramic insulators. Degradation of the loss tangent and thermal conductivity may also restrict the location of some components such as ICRH feedthrough insulators to positions far away from the first wall. In-situ measurements suggest that the degradation of physical properties in ceramics during irradiation is greater than that measured in postirradiation tests. Additional in-situ data during neutron irradiation are needed before engineering designs for ITER can be finalized.

\section{INTRODUCTION}

Ceramic insulators are integral parts of numerous components essential for the heating, control, and diagnostic measurement of fusion plasmas. The proposed International Thermonuclear Experimental Reactor (ITER) will be the first fusion plasma machine to receive significant amounts of radiation damage due to the anticipated extended periods of operation with a deuterium-tritium fuel mixture, which generates $14 \mathrm{MeV}$ neutrons and intense ionizing radiation fields. As shown schematically in Figure 1, the anticipated radiation fields to be experienced by ceramic components in ITER range from ionizing and displacement damage fluxes of $<1 \mathrm{~Gy} / \mathrm{s}$ and $<10^{-10} \mathrm{dpa} / \mathrm{s}$ at the neutral beam insulators located several meters outside of the vacuum vessel to $\sim 10^{4} \mathrm{~Gy} / \mathrm{s}$ and $\sim 10^{-6} \mathrm{dpa} / \mathrm{s}$ for diagnostic component insulators located near the first wall (Clinard 1979, Scott et al. 1985, Zinkle and Hodgson 1992). Most of these ceramic insulators will have moderate electric fields (10 to $1000 \mathrm{~V} / \mathrm{mm}$ ) applied during their operation. In addition to maintaining adequate dimensional stability and mechanical properties through their design lifetime, ceramic insulators must also maintan acceptable physical properties during irradiation. The physical properties of greatest interest for fusion applications are electrical conductivity (dc and ac), dielectric loss tangent at frequencies from $50 \mathrm{MHz}$ to $200 \mathrm{GHz}$, and thermal conductivity.

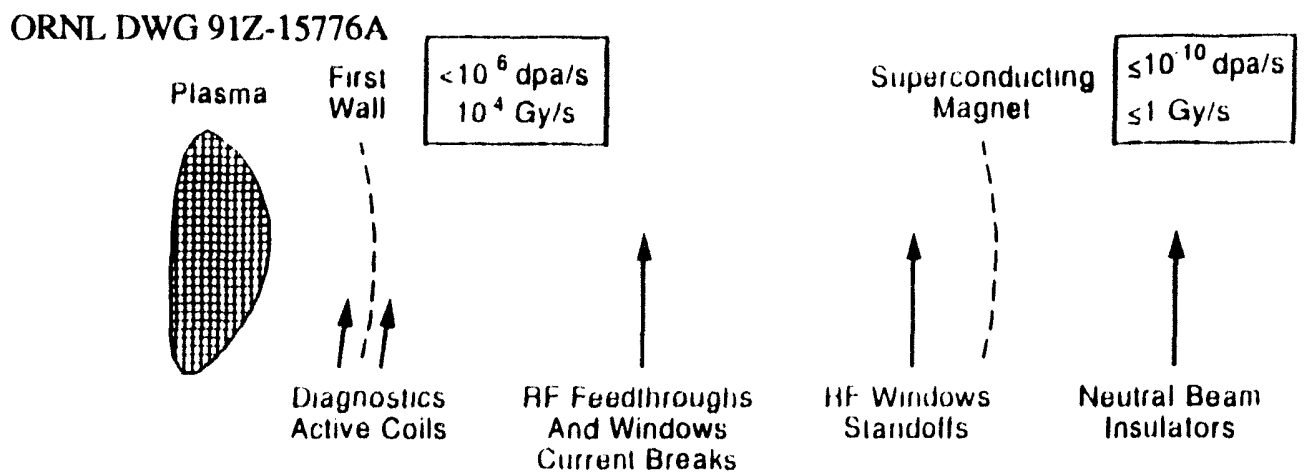

Fig. 1. Range of ionizing and displacive radiation fluxes anticipated for ceramic components in ITTER. 
As discussed by Zinkle and Hodgson (1992), radiation-induced swelling and mechanical property degradation of ceramics typically become significant after damage levels greater than 1 dpa. This damage level is in excess of the anticipated lifetime dose of many of the ceramic components in I'TER. Unfortunately, recent data suggests that significant degradation in the physical properties of ceramic insulators may occur during irradiation to doses much less than 1 dpa. A particularly important point regarding the experimental measurement of the physical properties of ceramics is that the value measured during irradiation can be significantly different from the postirradiation value (Zinkle and Hodgson 1992). This highlights the importance of obtaining data in-situ during irradiation, since the anticipated physical property changes that occur during operation are the relevant parameters for fusion design purposes. Unfortunately, with the exception of measurements of the transient radiation-induced electrical conductivity in ceramics (with little or no displacement damage), there has been only a handful of in-situ physical property measurements obtained on ceramics during irradiation. In the following sections, the available data on in-situ measurements of changes in the electrical conductivity, loss tangent, and thermal conductivity are summarized.

\section{ELECTRICAL CONDUCTIVITY}

Ionizing radiation excites bound electrons from the valence band of insulators into the conduction band. The resultant free electron-hole pairs are very mobile and can produce a large enhancement in the electrical conductivity of insulators. The elecurical conductivity during irradiation is given by:

$$
\sigma=\sigma_{o}+K R^{\delta}
$$

where $s_{0}$ is the conductivity in the absence of a radiation field (base conductivity), and the second term represents the radiation-induced conductivity (RIC) where $\mathrm{R}$ is the ionizing dose rate and $\mathrm{K}$ and $\mathrm{d}$ are constants which depend on material and irradiation conditions (Rose 1955, van Lint et al. 1957, 1980, Pells $1991 \mathrm{~b})$. It is generally observed that the RIC is proportional to the ionizing radiation flux $(d=1)$, although the specific relation between RIC and flux depends on the details of electron-hole trapping and recombination (and hence on experimental variables such as temperature and impurity content). Most studies have found that the RIC is only weakly dependent on irradiation temperature (Zinkle and Hodgson 1992). Figure 2 summarizes some RIC data that has been obtained on high-purity oxide insulators during irradiation near room temperature (van Lint et al. 1968, Klaffky et al. 1980, Pells 1986, 1991b, Hodgson and Clement 1986). The room temperature conductivity in the absence of radiation was $<10^{-12} / \mathrm{W}-\mathrm{m}$ in

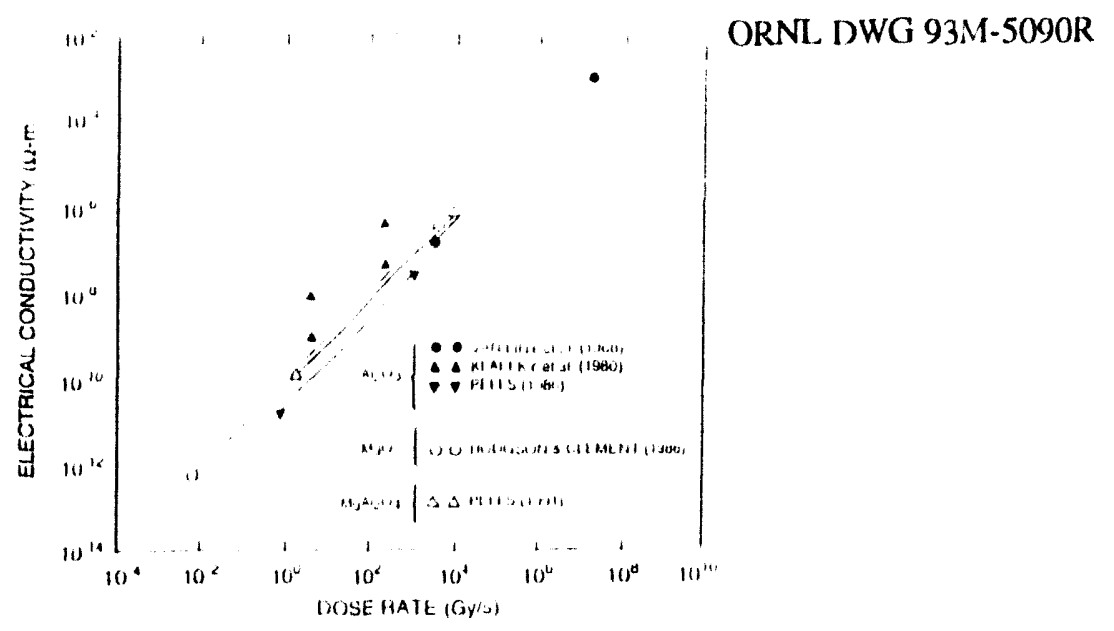

Fig. 2. Radiation induced conductivity of pure oxide ceramics measured during irradiation near room temperature. 
these materials. The RIC for the three oxides shown in Fig. 2 is directly proportional to the ionizing dose rate over a wide range ( 10 orders of magnitude) of flux. Since the maximum ionizing dose rate associated with a fusion reactor is $\sim 10^{4} \mathrm{~Gy} / \mathrm{s}$, Fig. 2 indicates that the associated maximum RIC expected in pure ceramic oxides in fusion reactor components would be $\sim 10^{-6} / \mathrm{W}-\mathrm{m}$. Although this conductivity is a significant increase compared to the nonirradiated room temperature value of $<10^{-12} / \mathrm{W}-\mathrm{m}$, it is too low to be of concern for fusion reactor insulator applications. The maximum conductivity allowable in fusion insulators ranges from $\sim 10^{-4}$ to $1 / \mathrm{W}-\mathrm{m}$, depending on the application. Hence, based on prompt RIC measurements alone, one would anticipate that ceramic insulators should operate satisfactorily in a fusion irradiation environment.

Recent in-situ studies have determined that there is an additional, potentially more serious, degradation of the electrical resistivity of ceramic insulators that only occurs when displacement damage and an electric field are simultaneously present (along with ionizing radiation) during the irradiation (Ivanov et al. 1981, Hodgson 1989, 1991, 1992a, 1992b, Pells 1991a, Shikama et al. 1992). Figure 3 shows the dosedependent electrical conductivity of $\mathrm{Al}_{2} \mathrm{O}_{3}$ measured in-situ during $1.8 \mathrm{MeV}$ electron irradiation at $450^{\circ} \mathrm{C}$. with an applied electric field of $130 \mathrm{~V} / \mathrm{mm}$ (Hodgson 1989). The conductivity rapidly increased to a plateau regime at the beginning of the irradiation due to ionization-induced RIC effects. However, accumulated displacement damage in the presence of an applied electric field eventually caused the conductivity to increase above this plateau level. Hodgson $(1989,1991,1992 \mathrm{a}, 1992 \mathrm{~b})$ has shown that the conductivity increase associated with accumulated displacement damage represents a permanent degradation in the base conductivity $s_{0}$ (Eq. 1) of the ceramic. As shown in Fig. 3, the base conductivity measured in the absence of radiation $\left(\mathrm{s}_{\mathrm{o}}\right)$ steadily increases with increasing dose and can become much larger than the RIC component. Of particular importance is that, unlike RIC, this radiation induced electrical degradation (RIED) represents a permanent degradation of the electrical conductivity and cannot be recovered by thermal annealing (Pells 1991a). Permanent degradation in the electrical conductivity of $\mathrm{Al}_{2} \mathrm{O}_{3}$ and $\mathrm{MgAl}_{2} \mathrm{O}_{4}$ above $10^{-4} / \mathrm{W}-\mathrm{m}$ has been observed by Pells (1991a) after light ion irradiation.

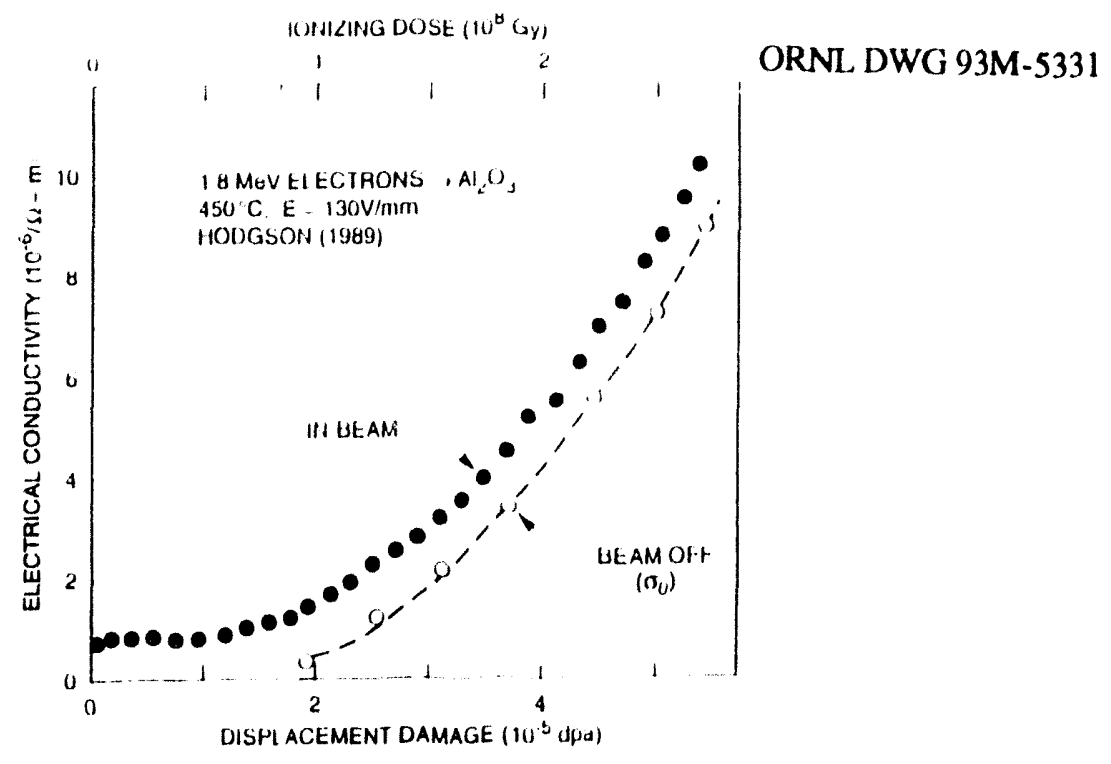

Fig. 3. Fluence-dependent behavior of the electrical conductivity of $\mathrm{Al}_{2} \mathrm{O}_{3}$ measured in-silu by Hodgson (1989) during $1.8 \mathrm{MeV}$ electron irradiation at $450^{\circ} \mathrm{C}$ with an applied dc electric field of $130 \mathrm{~V} / \mathrm{mm}$. The ionizing dose rate was $2800 \mathrm{~Gy} / \mathrm{s}$.

Complete quantification of the magnitude of RIED is hampered by a lack of data on the influence of electric field strength, temperature, and irradiation spectrum. In the absence of an applied electric field, permanent electrical degradation apparently does not occur in irradiated ceramics. Instead, several studies have shown that ceramics often become better insulators after irradiation if an electric field is not applied during the irradiation (Thatcher et al. 1964, Klaffky 1980, Zinkle and Hodgson 1992). As summarized by 
Zinkle and Hodgson (1992), significant pernanent electrical degradation can occur if an electric field $\geq 10$ $\mathrm{V} / \mathrm{mm}$ is applied during the irradiation, and the degradation process is accelerated if the electric field is greater than $\sim 60 \mathrm{~V} / \mathrm{mm}$. The degradation occurs for both dc and ac fields, up to at least $126 \mathrm{MHz}$ (Hodgson 1992a). The electrical degradation process is apparently maximized at temperatures between 300 and $600^{\circ} \mathrm{C}$ (Zinkle and Hodgson 1992, Pells 1992a). This temperature dependence is consistent with suggestions (Hodgson 1991) that the RIED may be associated with the formation of metallic precipitates (colloids).

There are several indications that irradiation spectrum may have a significant influence on the kinetics of RIED. In particular, there is considerable evidence that the electrical degradation process is accelerated in radiation environments with a high ratio of ionizing to displacive radiation. Figure 4 compares the results of several recent $\mathrm{RIED}$ studies on $\mathrm{Al}_{2} \mathrm{O}_{3}$ that have been performed at temperatures of 450 to $530^{\circ} \mathrm{C}$ using

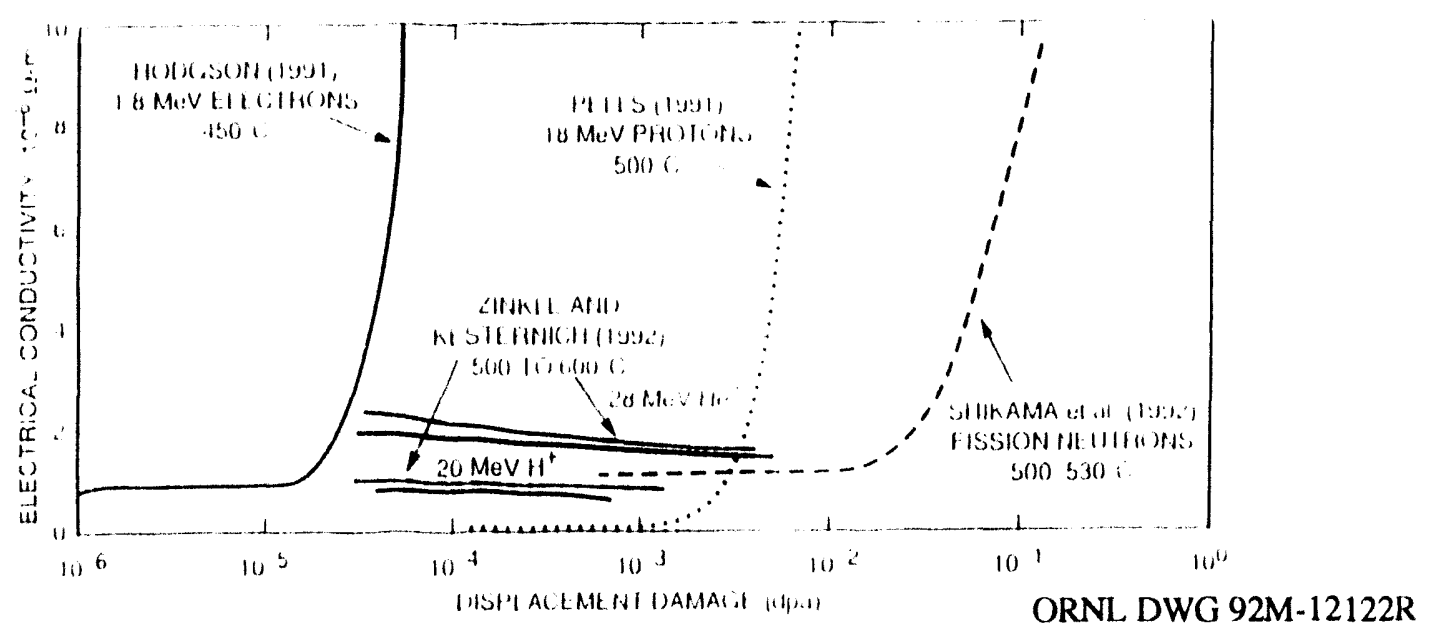

Fig. 4. Effect of extended irradiation in different radiation fields on the electrical conductivity of $\mathrm{Al}_{2} \mathrm{O}_{3}$. The electric fields present during irradiation ranged from $130 \mathrm{~V} / \mathrm{mm}$ (Hodgson 1991) to $500 \mathrm{~V} / \mathrm{mm}$ (Pells 1991a and Shikama et al. 1992). The figure includes unpublished data by Zinkle and Kesternich obtained with an applied electric field of $500 \mathrm{~V} / \mathrm{mm}$.

electron, light ion, and fission reactor irradiation sources (Hodgson 1991, Pells 1991a, Shikama et al. 1992). It can be seen that the dose required to initiate significant permanent electrical degradation $(>1 \mathrm{x}$ $10^{-5} / \mathrm{W}-\mathrm{m}$ ) is $<10^{-4}$ dpa for electron irradiation, whereas $>0.1 \mathrm{dpa}$ is required to induce a similar amount of degradation during fission neutron irradiation. The accelerated degradation process found in highly ionizing environments such as electron irradiation may be due to the phenomenon of ionization-enhanced diffusion (Zinkle 1993). For ITER design applications, the fission neutron data shown in Fig. 4 is the closest match to the anticipated ionizing and displacement damage radiation fields in a fusion reactor first wall or blanket. However, additional data are needed over a wide range of temperature and dose in order to better assess the potential problems associated with RIED in ceramic insulators. In particular, extended in-situ neutron irradiation data are needed to determine if the RIED process causes the conductivity to significantlyexceed $10^{-4} / \mathrm{W}-\mathrm{m}$ (the maximum allowable conductivity for some fusion insulator applications).

Due to the inherent difficulties associated with obtaining in-situ electrical conductivity data, there are only a few published studies that have monitored the performance of ceramic insulators during neutron irradiation with an applied electric field. As summarized by Thatcher et al. (1964), no permanent degradation was observed in ceramic insulators or capacitors after fission reactor irradiation at temperatures of $250^{\circ} \mathrm{C}$ to damage levels of about $2 \times 10^{-3}$ dpa. In addition, little or no degradation occurred in $\mathrm{Al}_{2} \mathrm{O}_{3}$ or $\mathrm{Y}_{2} \mathrm{O}_{3}$ for neutron doses of 0.01 to $0.1 \mathrm{dpa}$ at temperatures of 700 to $1100^{\circ} \mathrm{C}$ with an applied field of $\sim 40 \mathrm{~V} / \mathrm{mm}$ (Grossman and Kaznoff 1966, Ranken and Veca 1988, Ranken 1991). Considering these data and other published RIED fission neutron studies (Gus\&kov and Sachkov 1959, 
Ivanov et al. 1981, Shikama 1992), it appears that RIED should not be a serious ITER design concern for damage levels less than $10^{-3}$ to $0.1 \mathrm{dpa}$, depending on the particular ceramic and irradiation temperature. Further study is clearly needed to improve the data base for ITER ceramic insulator engineering designs.

\section{DIELECTRIC PROPERTIES AT RADIO FREQUENCIES}

The power absorbed by a low-loss dielectric from an incident electromagnetic wave is given by

$$
P=\omega \varepsilon^{\prime} \tan \delta E^{2}
$$

where $w$ is the angular frequency of the ac electric field with root mean square amplitude $E$, ef is the dielectric permittivity, and tan $d$ is the loss tangent (Kingery et al. 1976). For ITER applications, the dielectric loss factor, ed tan d, should be less than $10^{-2}$ for ion cyclotron $(-100 \mathrm{MHz})$ heating applications and less than about $10^{-5}$ for electron cyclotron $(-100 \mathrm{GHz})$ heating applications to avoid excessive heating in the dielectric. The dielectric permittivity of most ceramic insulators is approximately $10 \mathrm{e}_{0}$ over a wide range of temperature and frequency, where $e_{0}$ is the permittivity of free space. The value of tan $d$ for lowloss dielectrics is dependent on temperature and frequency (Heidinger 1991). Typical unirradiated loss tangent values for a low-loss dielectric such as single crystal alumina at a frequency of $100 \mathrm{MHz}$ are $\sim 10^{-4}$ at room temperature and $\sim 10^{-6}$ at $77 \mathrm{~K}$.

Radiation-induced changes in the dielectric properties occur mainly in the loss tangent; most studies have found that the dielectric constant remains within 5\% of its nonirradiated value (Zinkle and Hodgson 1992). The radiation-induced changes in the loss tangent can be described by two main components (Kingery et al. 1976, Pells and Hill 1986):

$$
\tan \delta=\frac{\sigma}{\varepsilon^{\prime} \omega}+\frac{\chi^{\prime \prime} \varepsilon_{o}}{\varepsilon^{\prime}}
$$

The first term represents electrical conductivity (s) joule heating losses associated with RIC and RIED. The second term represents polarization losses associated with the accumulation of displacement damage in the form of point defects or defect, clusters, where $c \leq$ is the imaginary part of the electric susceptibility. From Eq. (3) the loss tangent increase at a frequency of $100 \mathrm{MHz}$ associated with RIC or RIED during irradiation is simply:

$$
(\Delta \tan \delta)_{\theta} \cong 18 \sigma
$$

where $s$ is measured in units of $(\mathrm{W}-\mathrm{m})^{-1}$ and assuming a typical dielectric constant of $e \not / \mathrm{e}_{\mathrm{o}}=10$. It can be seen from Eq. (4) that an electrical conductivity of $\sim 5 \times 10^{-5} / \mathrm{W}-\mathrm{m}$ in the dielectric produces an unacceptable loss tangent increase of $10^{-3}$ in ceramic components at frequencies relevant for ion cyclotron heating $(100 \mathrm{MHz})$. Similarly, an unacceptable loss tangent increase of $10^{-6}$ also occurs at electron cyclotron heating frequencies $(\sim 100 \mathrm{GHz})$ for a ceramic electrical conductivity of $\sim 5 \times 10^{-5} / \mathrm{W}-\mathrm{m}$. Hence, considerations of RIC and RIED are even more important for dielectrics in radio frequency heating components than for dc fusion insulator applications.

Postirradiation measurements have generally found that neutron doses in excess of $0.1 \mathrm{dpa}$ are required to increase the room temperature loss tangent of low-loss ceramics to $10^{-3}$ (Heidinger 1991, Zinkle and Hodgson 1992). However, it should be recognized that these postirradiation measurements did not detect the electrical conductivity contribution associated with RIC or RIED (Eq. 4), since an electric field was not applied during the irradiation. In-situ measurements during extended irradiation with an applied electric field must be performed to assess the magnitude of this component of the loss tangent degradation. In addition, Buckley and Agnew (1988) have shown that a significant amount of the loss tangent increase 
that is present immediately after irradiation is recovered by annealing at room temperature for several hours. Postirradiation measurements on neutron irradiated ceramic specimens are typically not performed until weeks or months after the end of the irradiation. Hence, much of the displacement-induced loss tangent degradation may have recovered prior to the measurements.

Figure 5 shows the loss tangent at $100 \mathrm{MHz}$ measured in-situ for six different ceramic insulators during pulsed fission neutron irradiation at room temperature (Stoller et al. 1992, Goulding et al. 1993). A large transient increase in the loss tangent was observed in all six materials during the $\sim 30$ ms pulse length, and the loss tangent rapidly recovered to near the unirradiated value after the pulse. The in-situ loss tangent increases during the irradiation pulse were correlated with the ionizing radiation flux, and it was determined by $\mathrm{Pb}$ shielding experiments that the transient loss tangent increases were due to RIC effects, as described by Eq. (4). There was no correlation between the preirradiation (or post-irradiation) loss tangent and the loss tangent measured during the irradiation pulse, which underscores the importance of in-situ measurements for ITER design purposes. In a separate study, in-situ measurements made at higher frequencies (1. to $10 \mathrm{GHz}$ ) did not record any significant increase in the loss tangent of several ceramics

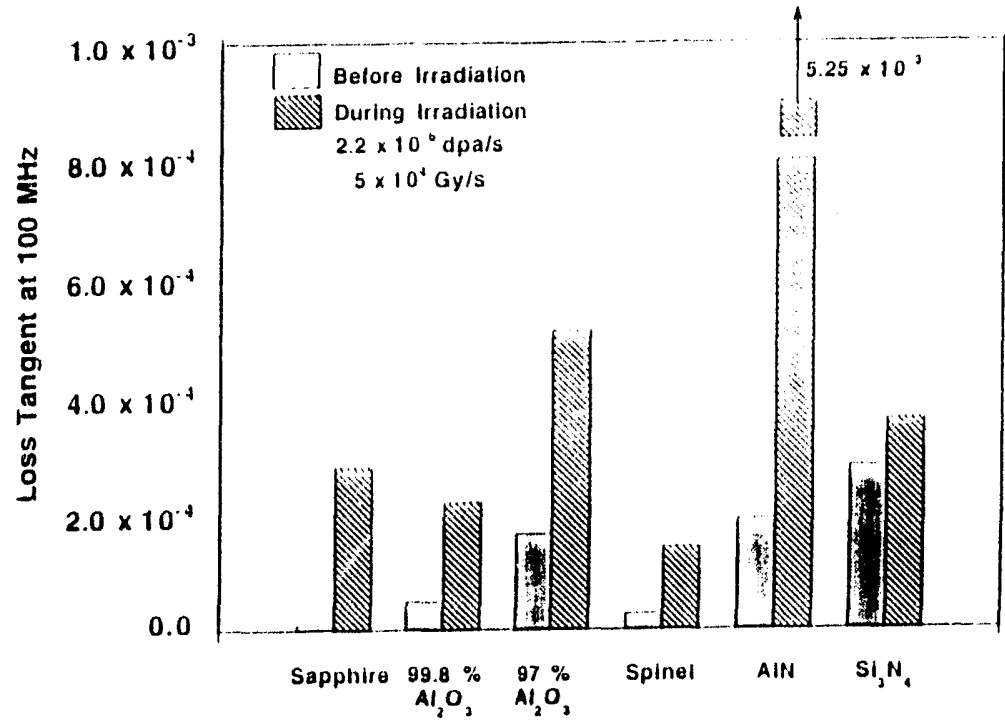

ORNL DWG 93-11628

Fig. 5. Loss tangent of ceramic insulators measured in-situ before and during pulsed fission neutron irradiation at room temperature (Goulding et al. 1993).

during pulsed neutron irradiation above their nonirradiated room temperature values of $\sim 10^{-4}$ (Edelson et al. 1969). The expected contribution of ionization-induced electrical conductivity (RIC) to the loss tangent at these higher frequencies is small $\left(\sim 10^{-5}\right)$ compared to the room temperature polarization losses (Eq. 3). However, prompt RIC effects could still be significant at these frequencies, since the maximum loss tangent that could be tolerated in a high power plasma heating system operating at 1 to $10 \mathrm{GHz}$ (lower hybrid regime) would be $-10^{-5}$, which corresponds to an RIC of $5 \times 10^{-5} / \mathrm{W}-\mathrm{m}$.

There is only one known in-situ study that examined the effect of extended irradiation on the loss tangent. Buckley and Agnew (1991) found that the dielectric loss factor (eftan d) of $\mathrm{Al}_{2} \mathrm{O}_{3}$ increased above an unacceptable level of $10^{-2}$ at $60 \mathrm{MHz}$ during room temperature proton irradiation after a displacement dose of only $\sim 10^{-3} \mathrm{dpa}$. An rf electric field of $\sim 10 \mathrm{~V} / \mathrm{mm}$ was applied during the irradiation. In view of the apparent strong influence of irradiation spectrum on the RIED measurements (Fig. 4), it appears essential for ITER design purposes that extended in-situ neutron irradiation experiments must be performed to confirm if a similar rapid degradation of the loss tangent occurs during neutron irradiation with a fusion-relevant applied rf field. 


\section{THERMAL CONDUCTIVITY}

A high thermal conductivity is desirable to minimize thermal stresses that could lead to mechanical failure of ceramic components such as if windows and insulating feedthroughs. Postirradiation measurements have found that the room temperature thermal conductivity of ceramics is reduced to 10 to $50 \%$ of the unirradiated value after neutron irradiation to doses of $\sim 0.1 \mathrm{dpa}$, and that further irradiation produces an apparent saturation in the conductivity degradation (Wullaert et al. 1964, Wilks 1968, Sandakov et al. 1984, Rohde and Schuiz 1990, Heidinger 1991, Yano and Iseki 1991). The rate of degradation of the thermal conductivity for ceramics irradiated or measured at cryogenic temperatures is proportionally much greater (Berman et al. 1955, McDonald 1963, Pryor et al. 1964, Salce and de Goer 1988).

These postirradiation results must be considered lower limits to the amount of thermal conductivity degradation that would occur during irradiation, since substantial annealing of point defects and small point defect clusters may occur at room temperature during the time interval between the end of the irradiation and the start of the postirradiation measurements (typically several months). The limited amount of published in-situ thermal conductivity data indicates that post-irradiation annealing at room temperature may induce a significant $(>30 \%)$ recovery of the thermal conductivity degradation in some cases (McDonald 1963, Keilholtz et al. 1964, Davis 1966). Postirradiation annealing effects become insignificant for ceramics irradiated at temperatures well above room temperature.

In contrast to the electrical conductivity and loss tangent behavior, there does not appear to be any prompt degradation in the thermal conductivity of ceramics associated with ionizing radiation; no instantaneous changes in the thermal conductivity occurred during low flux $\left(\sim 1 \mathrm{~Gy} / \mathrm{s}, \sim 10^{-10} \mathrm{dpa} / \mathrm{s}\right)$ fission reactor irradiations as the neutron source was turned on and off (McDonald 1963, Davis 1966). Figure 6 shows the calculated degradation in the thermal conductivity of $\mathrm{Al}_{2} \mathrm{O}_{3}$ at $400 \mathrm{~K}$ due to increased phonon-electron scattering associated with RIC (White 1993). It can be seen that RIC values as high as $10^{-2} / \mathrm{W}-\mathrm{m}$ produce a negligible $(<0.1 \%)$ degradation in the thermal conductivity.

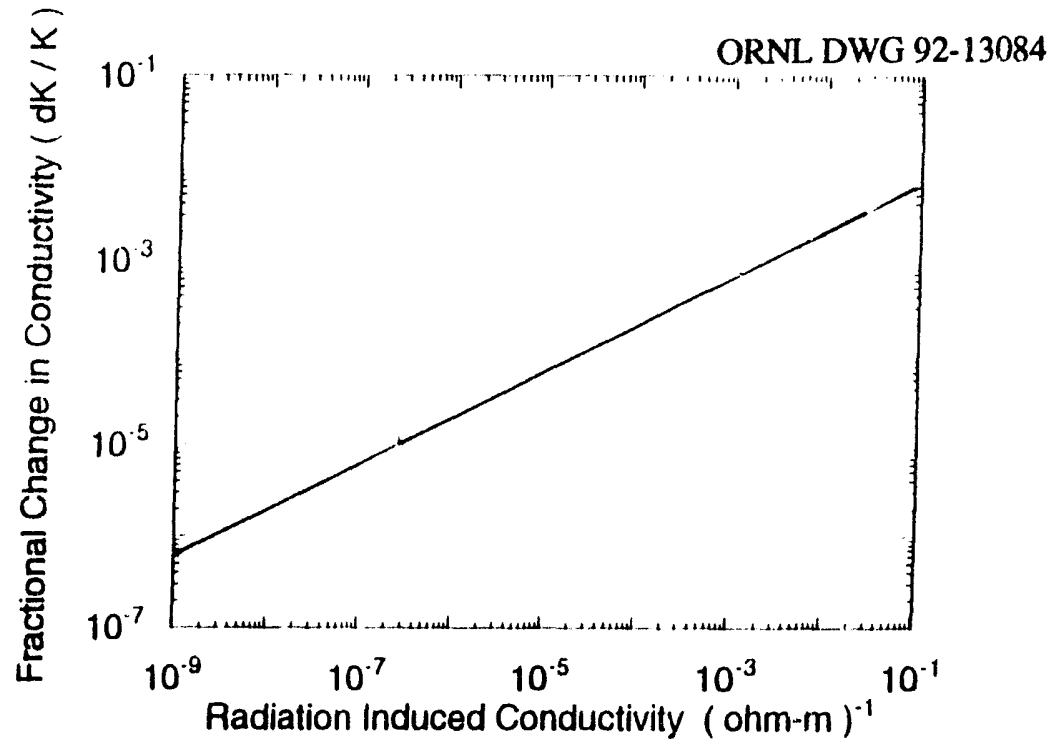

Fig. 6. Calculated fractional decrease in the thermal conductivity of $\mathrm{Al}_{2} \mathrm{O}_{3}$ due to radiation induced electrical conductivity (electron-phonon scattering) at $400 \mathrm{~K}$.

Point defects and small defect clusters are effective phonon scatterers, and hence can cause large degradations in the thermal conductivity of ceramics (Klemens et al. 1976, White 1993). Calculations by White (1993) indicate that a point defect concentration of 1 at. \% can produce $-40 \%$ degradation in the thermal conductivity of $\mathrm{Al}_{2} \mathrm{O}_{3}$ at $400 \mathrm{~K}$. Such point defect concentrations have been indirectly observed from lattice parameter and density measurements on ceramics after neutron irradiation near room temperature to damage levels of about $0.1 \mathrm{dpa}$ (Wullaert et al. 1964, Thorne et al. 1967, Wilks 1968, 
Palentine 1980). Since point defects can recombine or coalesce during postirradiation annealing at room temperature, there is a strong need for in-situ thermal conductivity measurements to assess the amount of degradation that occurs during irradiation.

In-situ measurements are generally not needed for high temperature $\left(>400^{\circ} \mathrm{C}\right)$ applications, since significant defect annealing will occur during the irradiation and subsequent postirradiation annealing at room temperature would be insignificant. However, it should be recognized that the amount at thermal conductivity degradation that occurs as the result of high-temperature irradiation (measured in-situ or postirradiation) will generally depend on the irradiation flux, due to defect annealing that occurs during the irradiation (Keilholtz et al. 1964). Hence, application of postirradiation thermal conductivity data must take into consideration the irradiation flux along with the accumulated amount of displacement damage.

A final concern is the possibility that different radiation-induced defect microstructures may develop in ceramics irradiated under fusion-relevant electric fields and mechanical stresses. In particular, the possible formation of colloids (metallic precipitates) in ceramics irradiated in the presence of an electric field would introduce an additional component to the thermal conductivity degradation since these colloids would be effective phonon scatterers (Klemens et al. 1976, White 1993).

\section{DISCUSSION AND CONCLUSIONS}

Due to their relative ease and lower cost, postirradiation measurements have been used almost exclusively over in-situ measurements in radiation effects studies on materials. Although a large amount of postirradiation physical property data has been accumulated on ceranic insulators, this data pool is not directly relevant for ITER design purposes since it is generally an improper measurement of the in-situ degradation. There are two reasons why in-situ measurements are needed for an accurate assessment of the potential performance of ceramic components in a radiation environment. First, in-situ measurements can detect transient property changes that occur during irradiation that either vanish quickly (e.g., RIC) or gradually recover (e.g., point defect annealing) after irradiation, and hence would not be fully detected in postirradiation measurements. Second, the recent discovery of new radiation-induced phenomena such as RIED demonstrates that the microstructural development during irradiation will, in general, depend strongly on the electro-mechanical environment in addition to the irradiation spectrum. This consideration requires that irradiations be performed with applied electric fields and mechanical stresses that are comparable to the intended fusion component operating condition. For example, the possibility that applied mechanical loads during irradiation might accelerate the mechanical property degradation of ceramics beyond that observed in conventional post- irradiation tests (due to radiation-enhanced crack initiation or stress corrosion cracking) should be investigated.

It appears at the present time that the useful lifetime of ceramic insulators in fusion reactor components will be controlled by deterioration in their physical properties (e.g., electrical conductivity or loss tangent) rather than by structural degradation (e.g., swelling or flexure streng(h). Unacceptable degradation in the physical properties of ceramic insulators may occur after damage levels as low as $10^{-3} \mathrm{dpa}$, depending on temperature, radiation spectrum, dose rate, and the electro-mechanical environment. This corresponds to less than one hour of full power operation in the first wall region of ITER.

In-situ studies at ITER-relevant radiation fluxes (ionizing and displacive) are urgently needed before the ITER engineering designs can be finalized. RIED effects associated with microstructural changes during irradiation with an applied electric field may cause unacceptable degradation in both the electrical resistivity and rf loss tangent of ceramic insulators at very low doses. There is some encouraging evidence from the limited number of published in-situ studies that operation of ceramic components at low $\left(<200^{\circ} \mathrm{C}\right)$ or very high $\left(>700^{\circ} \mathrm{C}\right)$ temperatures may suppress the development of RIED. A comparison of in-situ data obtained from various irradiation sources suggests that highly ionizing radiation sources such as electrons or light ions produce an acceleration of the RIED process compared to neutron irradiation results (Fig. 4). However, in recognition of the present lack of comprehensive in-situ neutron irradiation 
studies, the electron and ion irradiation results should be considered to be more appropriate for ITER design purposes than conventional postirradiation data obtained on neutron irradiated specimens.

\section{ACKNOWLEDGMENTS}

This work was supported by the Office of Fusion Energy, U.S. Department of Energy, under contract DEAC05-84OR21400 with Martin Marietta Energy Systems, Inc.

\section{REFERENCES}

Berman, R., Foster, E. L. and Rosenberg, H. M. (1955) in Report of the Bristol Conf. on Defects in Crystalline Solids, The Physical Society, London, p. 321.

Buckley, S. N. and Agnew, P. (1988) J. Nuclear Mater. 155-157, 361.

Buckley, S. N. and Agnew, P. (1991) in Microwave Processing of Materials I, W. B. Snyder et al., eds, MRS Symp. Proc. Vol. 189, Materials Research Soc., Pittsburgh, p. 503.

Clinard, F. W., Jr. (1979) J. Nucl. Mater. 85-86, 393.

Davis, M. V. (1966) in Proc. Conf. on Nuclear Applications of Nonfissionable Ceramics, A. Boltax and J. H. Handwerk, eds, American Nucl. Soc., Hinsdale, IL, p. 229.

Edelson, D., Jaeger, R. E., and Williams, J. C. (1969) J. Amer. Ceram. Soc. 52, 359.

Goulding, R. H., Rasmussen, D. A., Stoller, R. E., and Zinkle, S. J. (1993), "Transient Effects of Ionizing and Displacive Radiation on the Dielectric Properties of Ceramic Insulators," submitted to Phys. Rev. B.

Grossman, L. N. and Kaznoff, A. I. (1955) in Proc. Conf. on Nuclear Applications of Nonfissionable Ceramics, A. Boltax and J. H. Handwerk, eds, American Nucl. Soc., Hinsdale, IL, p. 421.

Guskov, Yu. K. and Sachkov, V. F. (1959), Sov. J. Atomic Energy (Atomnaya Energ.) 6, 204.

Heidinger, R. (1991), J. Nucl. Mater. 179-181, 64.

Hodgson, E. R. (1989), Crys. Latt. Def. Amorphous Mater. 18, 169.

Hodgson, E. R. (1991), J. Nucl. Mater. 179-181, 383.

Hodgson, E. R. (1992a), Nucl. Instr. Methods B 65, 298.

Hodgson, E. R. (1992b), J. Nucl. Mater. 191-194, 552.

Hodgson, E. R. and Clement, S. (1985), Rad. Effects 97, 251.

Ivanov, V. M., Kalinin, G. M., Kuzovitkin, V. F., Sklizkov, S. P., Markina, N. V., Sarksyan, V. V., and Skobeleva, V. A. (1981), Inorganic Materials (Izv. Akad. Nauk SSSR, Neorgan. Mater.) 17, 1203.

Kingery, W. D., Bowen, H. K., and Uhlmann, D. R. (1976), Introduction to Ceramics, 2nd Ed., Wiley and Sons, New York, p. 913. 
Klaffky, R. W. (1980) in Special Purpose Materials Annual Progress Report, DOE/ER-0048/1, U.S. Dept. of Energy, Washington, D.C., p. 19.

Klaffky, R. W., Rose, B. H., Goland, A. N., and Dienes, G. J. (1980), Phys. Rev. B 21, 3610.

Klemens, P. G., Hurley, G. F., and Clinard, F. W. (1976), in Proc. 2nd Topical Mtg. on the Technology of Controlled Nuclear Fusion, G. L. Kulcinski and N. M. Burleigh, eds, CONF760935, pp. 957-964.

McDonald, D. L. (1963), Appl. Phys. Lett. 2, 175.

Palentine, J. E. (1980), J. Nucl. Mater 92, 43.

Pells, G. P. (1986), Rad. Effects 97, 199.

Pells, G. P. (1991a), J. Nucl. Mater 184, 177.

Pells, G. P. (1991b), J. Nucl. Mater 184, 183.

Pells, G. P. and Hill, G. J. (1985), J. Nucl. Mater. 141-143, 375.

Pryor, A. W., Tainsh, R. J., and White, G. K. (1964), J. Nucl. Mater. 14, 208.

Ranken, W. A. (1991) in Proc. DOE Workshop on Electrical Breakdown of Insulating Ceramics in a High Radiation Field, CONF-9105175, National Technical Inform. Serv., Springfield, VA, p. 433.

Ranken, W. A. and Veca, A. R. (1988) in Space Nuclear Power Systems, M.S. El-Genk and M. D. Hoover, eds, Orbit Book Co., Malabar, FL, p. 329.

Rohde, M. and Schulz, B. (1990), J. Nucl. Mater. 173, 289.

Rose, A. (1955), Phys. Rev. 97, 1538.

Salce, B. and deGoer, A. M. (1988) in Proc. Conf. Digest of the Int. Conf. on Defects in Insulating Materials, Parma, p. 499.

Sandakov, V. S., Kostyukov, N. S., and Dubinin, G. V. (1984), Irradiation Effects on the Ceramics Thermal Stress Resistance, Research Inst. Atomic Reactors Report, RIAR-8 (620), Dimitrovgrad.

Scott, J. L., Clinard, F. W., Jr., and Wiffen, F. W. (1985), J. Nucl. Mater. 133 \& 134, 156.

Shikama, T., Narui, M., Endo, Y., Sagawa, T., and Kayano, H. (1992), J. Nucl. Mater. 191-194, 575.

Stoller, R. E., Goulding, R. H., and Zinkle, S. J. (1992), J. Nucl. Mater. 191-194, 602.

Thatcher, R. K., et al. (1964), The Effects of Nuclear Radiation on Electronic Components, Including Semiconductors, Battelle Memorial Institute Report REIC-36, Battelle Columbus Lab., Columbus, OH.

Thorne, R. P., Howard, V. C., and Hope, B. (1967), Proc. Brit. Ceram. Soc. 7, 449.

van Lint, V.A.J., Flanagan, T. M., Leadon, R. E., Nabor, J. A., and Rogers, V. C. (1980), Mechanisms of Radiation Effects in Electronic Materials, Vol. 1, Wiley and Sons, New York.

van Lint, V.A.J., Harrity, J. W., and Flanagan, T. M. (1968), IEEE Trans. on Nucl. Sci., NS-15, No. 6, 194. 
White, D. P. (1993), J. Applied Phys. 73, 2254.

Wilks, R. S. (1968), J. Nucl. Mater. 26, 137.

Wullaert, R. A., Burian, R. J., Melehan, J. B., Kangilaski, M., and Gates, J. E. (1964) in Effects of Radiation on Materials and Components, J. F. Kircher and R E Bowman, eds, Reinhold Publ. Corp., New York, pp. 277-401.

Yano, T. and Iseki, T. (1991), J. Nucl. Mater., 179-181, 387.

Zinkle, S. J. (1993), "Effect of Irradiation Spectrum on the Microstructural Evolution in Oxide Ceramics," this semiannual (DOE/ER-0313/14).

Zinkle, S. J. and Hodgson, E. R. (1992), J. Nucl. Mater. 191-194, 58. 
EFFECT OF IRRADIATION SPECTRUM ON THE MICROSTRUCTURAL EVOLUTION IN OXIDE CERAMICS -- S.J. Zinkle (Oak Ridge National Laboratory)

\section{OBJECTIVE}

To summarize recent microstructural evidence for ionization enhanced diffusion obtained on ion-irradiated oxide ceramics.

\section{SUMMARY}

Cross section transmission electron microscopy was utilized to examine the radiation-induced microstructural changes in oxide ceramics after irradiation with a wide variety of ion beams. The microstructure showed a strong dependence on ion mass and energy. The microstructural results have been correlated with the calculated depth-dependent partitioning between ionization and displacement damage. This correlation indicates that defect clusters do not form in $\mathrm{MgAl}_{2} \mathrm{O}_{4}$ if the ratio of energy deposited into electronic ionization to atomic displacements is greater than about 10 . The corresponding ratio needed to suppress defect cluster formation in $\mathrm{MgO}$ and $\mathrm{Al}_{2} \mathrm{O}_{3}$ is 500 to 1000 . Additional microstructural evidence obtained on the ion irradiated ceramic specimens suggests that the physical mechanism responsible for the lack of defect clusters in highly ionizing radiation environments is associated with ionization-enhanced diffusion (IED), which promotes annihilation of the point defects created by displacement damage during the irradiation. The most important parameter for IED is the ratio of ionizing to displacive radiation, since this is roughly proportional to the amount of ionization per dpa. However, the absolute magnitude of the ionizing radiation flux is also important.

\section{INTRODUCTION}

In a previous report [1], microstructural evidence was presented which showed that irradiation of oxide ceramics such as $\mathrm{Al}_{2} \mathrm{O}_{3}$ and $\mathrm{MgAl}_{2} \mathrm{O}_{4}$ with light ions caused a suppression in the nucleation of dislocation loops compared to heavy ion or neutron irradiation. It was proposed that the suppression in dislocation loop formation was associated with the high proportion of energy lost to electronic ionization events compared to displacement damage events during light ion irradiation. In the present report, additional microstructural evidence is presented which indicates that the suppression in dislocation loop nucleation is due to enhanced point defect diffusion (as opposed to a modification in the production of point defects).

\section{EXPERIMENTAL PROCEDURE}

Polycrystalline blocks of $\mathrm{Al}_{2} \mathrm{O}_{3}$ (GE Lucalox or Wesgo Al995), $\mathrm{MgO}$ (Ube) and $\mathrm{MgAl}_{2} \mathrm{O}_{4}$ (Ceredyne) were sliced into foils of $0.5 \mathrm{~mm}$ thickness, and 3-mm-diameter TEM disks were cut from the foils. The disks were mechanically polished with $0.5 \mu \mathrm{m}$ diamond paste, and then bombarded in a $3 \times 3$ array at room temperature or $650^{\circ} \mathrm{C}$ in the triple ion beam accelerator facility [2] at Oak Ridge National Laboratory.

Table 1 lists the ion beam conditions which have been studied to date. The TRIM-90 [3] computer code was used to calculate the depth-dependent ionizing and displacive radiation doses for an $\mathrm{Al}_{2} \mathrm{O}_{3}$ target. $\mathrm{A}$ threshold displacement energy of $40 \mathrm{eV}$ was used to calculate the displacements per atom (dpa) in $\mathrm{Al}_{2} \mathrm{O}_{3}$. 
This displacement energy is intermediate between the measured [4] threshold displacement energics of $24 \mathrm{eV}$ and $78 \mathrm{eV}$ for the $\mathrm{Al}$ and $\mathrm{O}$ sublattices, respectively. The near-surface $(0.5 \mu \mathrm{m}$ depth) ionizing radiation dose rate ranged from 0.1 to $10 \mathrm{MGy} / \mathrm{s}$, whereas the ionizing to displacive absorbed dose (IDAD) ratio

Table 1. Summary of Ion Beam Conditions

\begin{tabular}{|c|c|c|c|c|c|c|c|}
\hline Ion Beam & $\begin{array}{l}\text { Temp } \\
{ }^{\circ} \mathrm{C}\end{array}$ & $\begin{array}{l}\text { Flux } \\
\left(10^{\left.16 / \mathrm{m}^{2}-\mathrm{s}\right)}\right.\end{array}$ & $\begin{array}{l}\text { Fluence } \\
\left(10^{20} / \mathrm{m}^{2}\right)\end{array}$ & $\begin{array}{l}\text { Dose at } 0.5 \mu \mathrm{m} \\
\text { depth (dna) }\end{array}$ & $\begin{array}{l}\text { Peak } \\
\text { dose (dpa) }\end{array}$ & $\begin{array}{l}\text { MGy/s } \\
\text { @ } 0.5 \mu \mathrm{m}\end{array}$ & $\begin{array}{l}\text { IDAD } \\
@ 0.5 \mu \mathrm{m}\end{array}$ \\
\hline $1 \mathrm{MeV} \mathrm{H}^{+}$ & $\begin{array}{l}650 \\
650 \\
650 \\
650\end{array}$ & $\begin{array}{l}60 \\
60 \\
6 \\
8\end{array}$ & $\begin{array}{l}170 \\
20 \\
15 \\
3\end{array}$ & $\begin{array}{l}0.09 \\
0.01 \\
0.008 \\
0.002\end{array}$ & $\begin{array}{l}3.2 \\
0.4 \\
0.3 \\
0.06\end{array}$ & $\begin{array}{l}3 \\
3 \\
0.3 \\
0.4\end{array}$ & $\begin{array}{l}2000 \\
2000 \\
2000 \\
2000\end{array}$ \\
\hline $1 \mathrm{MeV} \mathrm{He}^{+}$ & $\begin{array}{l}650 \\
650 \\
650 \\
650\end{array}$ & $\begin{array}{l}40 \\
40 \\
4 \\
4\end{array}$ & $\begin{array}{l}100 \\
10 \\
10 \\
1\end{array}$ & $\begin{array}{l}1 \\
0.1 \\
0.1 \\
0.01\end{array}$ & $\begin{array}{l}21 \\
2.1 \\
2.1 \\
0.2\end{array}$ & $\begin{array}{l}10 \\
10 \\
1 \\
1\end{array}$ & $\begin{array}{l}800 \\
800 \\
800 \\
800\end{array}$ \\
\hline $3 \mathrm{MeV} \mathrm{C}^{+}$ & $\begin{array}{l}25 \\
25 \\
650 \\
650 \\
650\end{array}$ & $\begin{array}{l}1.5 \\
1.5 \\
0.8 \\
0.2 \\
0.2\end{array}$ & $\begin{array}{l}4 \\
0.4 \\
0.5 \\
0.3 \\
0.04\end{array}$ & $\begin{array}{l}0.3 \\
0.03 \\
0.03 \\
0.02 \\
0.003\end{array}$ & $\begin{array}{l}5 \\
0.5 \\
0.6 \\
0.4 \\
0.05\end{array}$ & $\begin{array}{l}1 \\
1 \\
0.7 \\
0.1 \\
0.1\end{array}$ & $\begin{array}{l}250 \\
250 \\
250 \\
250 \\
250\end{array}$ \\
\hline $2.4 \mathrm{MeV} \mathrm{Mg}^{+}$ & $\begin{array}{l}25 \\
25 \\
650\end{array}$ & $\begin{array}{l}20 \\
15 \\
15\end{array}$ & $\begin{array}{l}22 \\
14 \\
14\end{array}$ & $\begin{array}{l}14 \\
10 \\
10\end{array}$ & $\begin{array}{l}54 \\
40 \\
40\end{array}$ & $\begin{array}{l}14 \\
10 \\
10\end{array}$ & $\begin{array}{l}20 \\
20 \\
20\end{array}$ \\
\hline $2 \mathrm{MeV} \mathrm{Al}^{+}$ & $\begin{array}{l}25 \\
25 \\
650 \\
650 \\
650\end{array}$ & $\begin{array}{l}11 \\
11 \\
11 \\
11 \\
11\end{array}$ & $\begin{array}{l}30 \\
12 \\
40 \\
15 \\
5\end{array}$ & $\begin{array}{l}30 \\
10 \\
30 \\
14 \\
4\end{array}$ & $\begin{array}{l}90 \\
35 \\
100 \\
45 \\
14\end{array}$ & $\begin{array}{l}7 \\
7 \\
7 \\
7 \\
7\end{array}$ & $\begin{array}{l}13 \\
13 \\
13 \\
13 \\
13\end{array}$ \\
\hline $4 \mathrm{MeV} \mathrm{Zr}^{3+}$ & $\begin{array}{l}25 \\
25 \\
25 \\
650 \\
650\end{array}$ & $\begin{array}{l}0.3 \\
0.2 \\
0.2 \\
0.2 \\
0.2\end{array}$ & $\begin{array}{l}2.2 \\
0.3 \\
0.1 \\
0.2 \\
0.02\end{array}$ & $\begin{array}{l}20 \\
3 \\
1 \\
2 \\
0.2\end{array}$ & $\begin{array}{l}34 \\
5 \\
1.5 \\
3 \\
0.3\end{array}$ & $\begin{array}{l}0.3 \\
0.2 \\
0.2 \\
0.2 \\
0.2\end{array}$ & $\begin{array}{l}2.4 \\
2.4 \\
2.4 \\
2.4 \\
2.4\end{array}$ \\
\hline
\end{tabular}

ranged from 2.4 to 2000. Figure 1 shows the calculated depth-dependent IDAD ratios for several of the ion beams used in this study. The IDAD ratio for ion irradiations is simply obtained from the depth-dependent ratio of the electronic stopping power to the nuclear stopping power.

Some of the $\mathrm{C}^{+}$ion irradiated specimens were coated with a thin layer of conductive carbon prior to irradiation to ensure that specimen charging did not occur. The microstructure of these carbon-coated specimens was found to be identical to that of uncoated specimens following irradiation. 


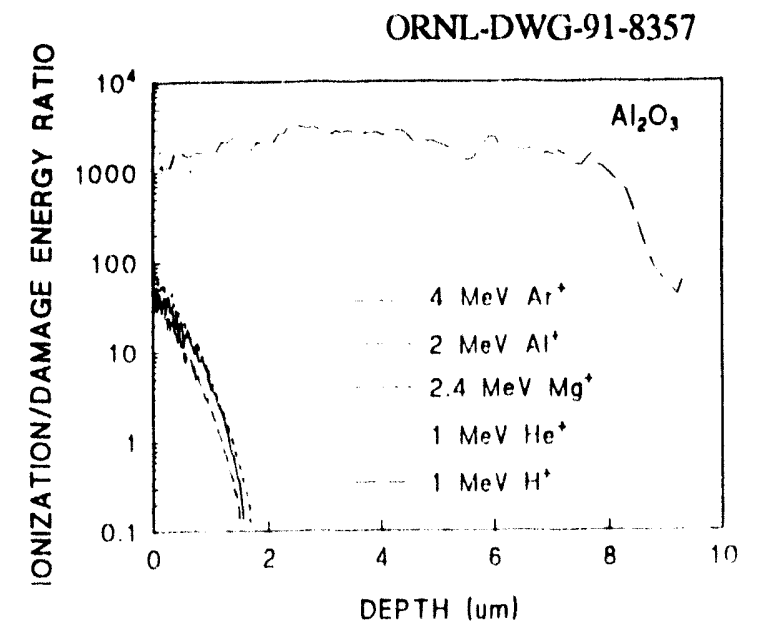

Fig. 1. Depth dependent ratio of ionizing to displacive absorbed dose (IDAD) for various ions incident in $\mathrm{Al}_{2} \mathrm{O}_{3}$.
Cross section transmission electron microscopy (TEM) specimens were prepared using techniques that are described elsewhere [5]. The microstructure of the cross section specimens was examined with a Philips CM12 electron microscope, operating at 120 $\mathrm{keV}$.

\section{RESULTS}

The dominant microstructural feature associated with ion irradiation of the three oxide ceramics was the formation of nterstitial dislocation loops. The size and density of the loops was dependent on the damage level and irradiation spectrum (IDAD ratio). For a given dose, the size of theloops increased and the density of the loops decreased with increasing IDAD ratio. Most of the spectrum-dependent changes occurred near a sharp threshold IDAD value. The threshold IDAD ratio was about 10 for $\mathrm{MgAl}_{2} \mathrm{O}_{4}$, and 500 to 1000 for $\mathrm{MgO}$ and $\mathrm{Al}_{2} \mathrm{O}_{3}$.

\section{Threshold Dose for Dislocation Loop Formation}

Figure 2 shows the typical microstructure for $\mathrm{MgAl}_{2} \mathrm{O}_{4}$ irradiated with $4 \mathrm{MeV} \mathrm{Zr}^{+}$ions, which have a low IDAD ratio. A very high density of small dislocation loops were uniformly distributed throughout the irradiation region. Microstructural analysis of spinel specimens irradiated with $\mathrm{Zr}^{+}$ions at low doses, and analysis of spinel specimens irradiated with $4 \mathrm{MeV} \mathrm{Ar}{ }^{+}$ions [6] indicates that the threshold dose for observable dislocation loop formation in $\mathrm{MgAl}_{2} \mathrm{O}_{4}$ is $\leq 0.1$ dpa. This result is in agreement with observations on spinel irradiated with $\mathrm{Xc}^{+}$ions [7] and fission neutrons [8].

Figure 3 shows the cress section microstructure of $\mathrm{Al}_{2} \mathrm{O}_{3}$ after $3 \mathrm{MeV} \mathrm{C}+$ ion irradiation to a fluence of $3 \mathrm{x}$ $10^{19} \mathrm{C}^{+} / \mathrm{m}^{2}$. This produced a displacement daunage level of about $0.4 \mathrm{dpa}$ at the damage peak $(2 \mu \mathrm{m}$ depth) and a damage level of about $0.02 \mathrm{dpa}$ at a depth of $0.5 \mu \mathrm{m}$. Small dislocation loops were observable between depths of about $0.5 \mu \mathrm{m}$ and $2 \mu \mathrm{m}$, which suggests that the threshold dose for observable dislocation loop formation in $\mathrm{Al}_{2} \mathrm{O}_{3}$ is about $0.02 \mathrm{dpa}$.

In a previous study [9], the threshold dose for dislocation loop formation in $\mathrm{MgO}$ was determined to be less than $\sim 0.1 \mathrm{dpa}$ for $2.4 \mathrm{MeV} \mathrm{Mg}$ ion irradiation.

\section{Effect of Irradiation Spectrum on Dislocation Loop Formation}

Figure 4 shows the cross section microstructure of $\mathrm{MgO}$ following $1 \mathrm{MeV} \mathrm{H}^{+}$ion irradiation to a fluence of $1.7 \times 10^{22} / \mathrm{m}^{2}$, which produced a peak damage level of about $3 \mathrm{dpa}$. A high density of dislocation loops were present near the ion implantation region $(11 \mu \mathrm{m}$ depth), where the IDAD ratio approaches unity. 


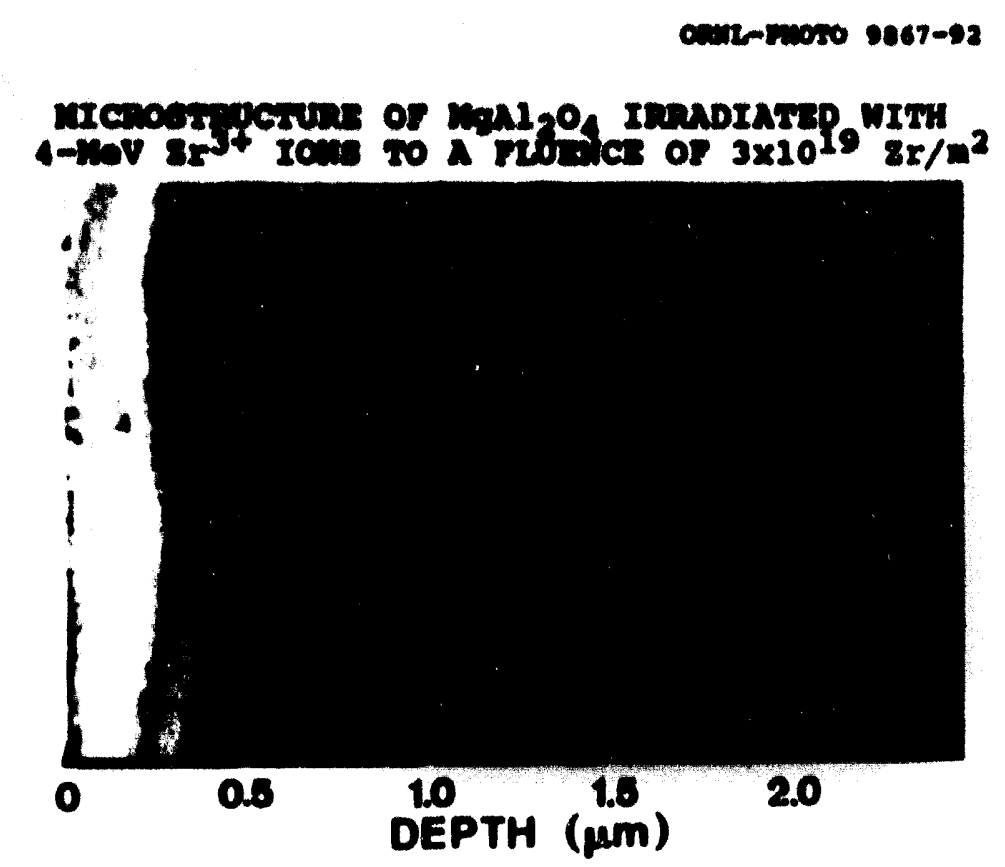

Fig. 2. Microstructure of $\mathrm{MgAl}_{2} \mathrm{O}_{4}$ after $4 \mathrm{MeV} \mathrm{Zr}^{3+}$ ion irradiation to a peak damage level of 5 dpa at $25^{\circ} \mathrm{C}$.

ORHL-PHOTO 2242-93

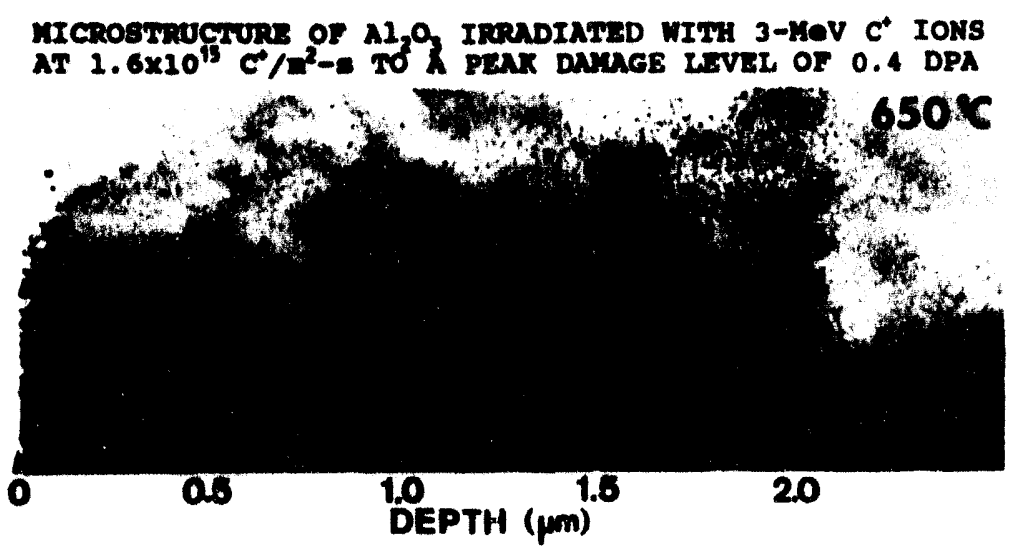

Fig. 3. Microstructure of $\mathrm{Al}_{2} \mathrm{O}_{3}$ irradiated with $3 \mathrm{MeV} \mathrm{C}^{+}$ions to a peak damage level of 0.4 dpa at $650^{\circ} \mathrm{C}$. 
Dislocation loop formation was not observed at depths up to $10 \mu \mathrm{m}$ (where the IDAD ratio is $>1000$ ), despite the fact that the calculated damage level at these depths is greater than the measured threshold dose for dislocation loop formation of $0.1 \mathrm{dpa}$.

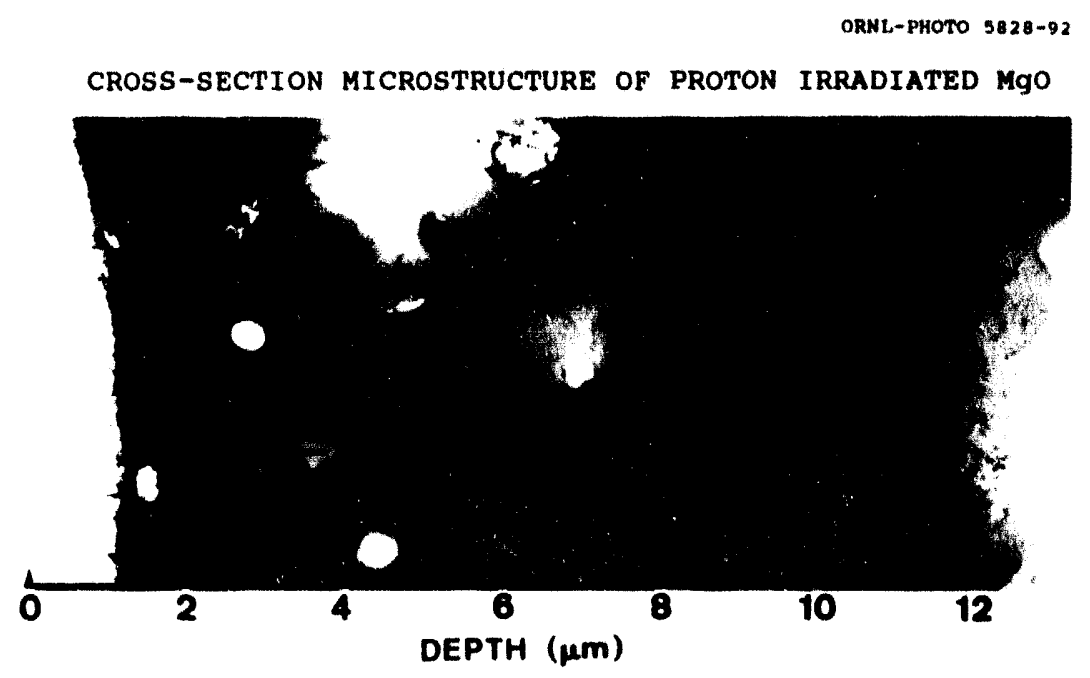

Fig. 4. Microstructure of $\mathrm{MgO}$ irradiated with $1 \mathrm{MeV} \mathrm{H}^{+}$ions to a peak damage level of $3 \mathrm{dpa}$ at $650^{\circ} \mathrm{C}$. Some sintering pores are visible in the micrograph.

Figure 5 shows the corresponding cross section microstructure of $\mathrm{MgO}$ following $1 \mathrm{MeV} \mathrm{He}{ }^{+}$ion irradiation to a fluence of $1 \times 10^{22} \mathrm{He}^{+} / \mathrm{m}^{2}$, which produced a peak damage level of about $21 \mathrm{dpa}$. Dislocation loop formation is pronounced near the ion implantation region $(2.3 \mu \mathrm{m}$ depth). A very low density of dislocation loops were observed at depths $<1.8 \mu \mathrm{m}$, where the IDAD ratio is $>500$.

Spinel has been found to be particularly sensitive to irradiation spectrum variations. For example, Shaibani $[10,11]$ was unable to observe any dislocation loop formation in stoichiometric spinel during $1 \mathrm{MeV}$ electron irradiation (IDAD ratio $~ 10,000$ ) up to very high damage levels. Stoichiometric spinel did not form any observable defect clusters after $3 \mathrm{MeV}$ proton irradiation (IDAD ratio $\sim 2500$ ) at $600^{\circ} \mathrm{C}$ to a damage level of $0.1 \mathrm{dpa}$ [12]. We have previously reported that dislocation loop formation in ion irradiated spinel is suppressed if the IDAD ratio is greater than $\sim 10$ [1]. Figure 6 shows the cross section microstructure of spinel irradiated with $2 \mathrm{MeV} \mathrm{Al}^{+}$ions to a fluence of $1.5 \times 10^{21} \mathrm{Al}^{+} / \mathrm{m}^{2}$, which produced a displacement damage level of about $14 \mathrm{dpa}$ at a depth of $0.5 \mu \mathrm{m}$. Dislocation loops did not form in the near-surface region, and a defect-free region was also observed surrounding an internal defect sink. Large defect-free regions have also been observed adjacent to grain boundaries in $\mathrm{Al}^{+}$-irradiated spinel [13]. These microstructural observations suggest that ionizing radiation is somehow effective in enhancing point defect diffusion in spinel. 


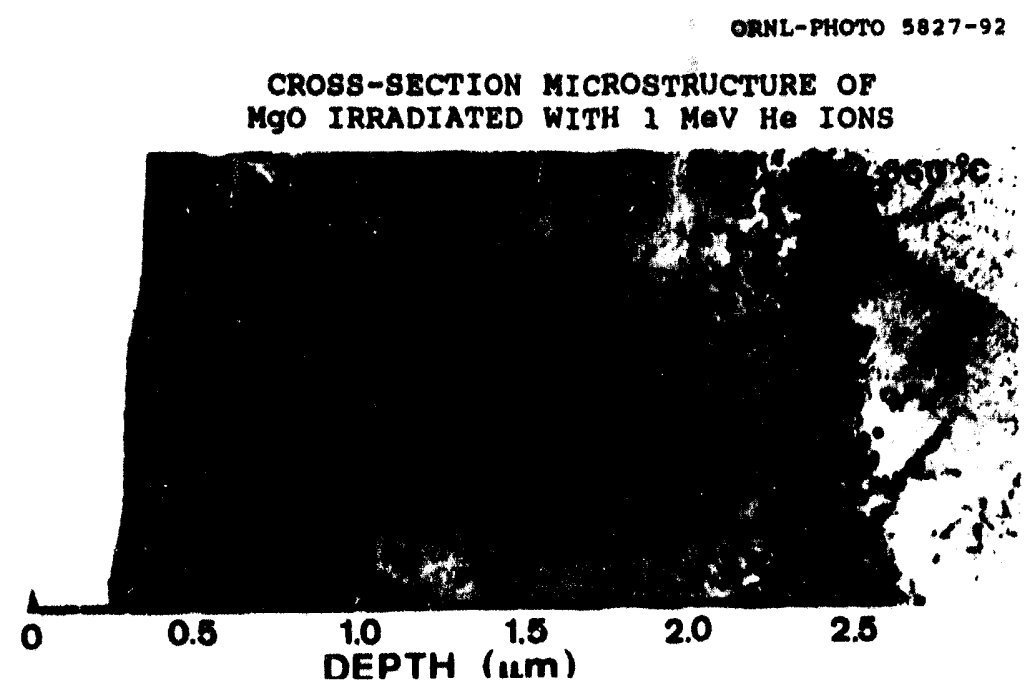

Fig. 5. Microstructure of $\mathrm{MgO}$ irradiated with $1 \mathrm{MeV} \mathrm{He}^{+}$ions to a peak damage level of $21 \mathrm{dpa}$ at $650^{\circ} \mathrm{C}$.

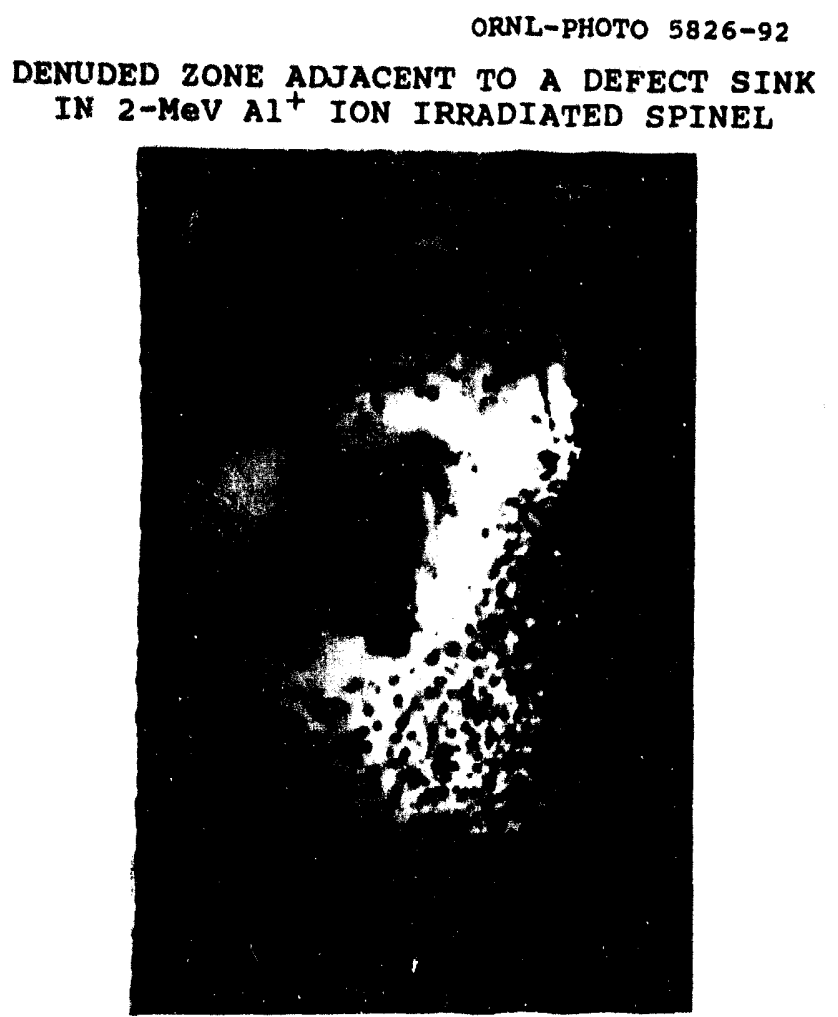

Fig. 6. Defect-free zones adjacent to the surface and an internal defect sink in $\mathrm{MgAl}_{2} \mathrm{O}_{4}$ irradiated with 2 $\mathrm{MeV} \mathrm{Al}{ }^{+}$ions to a fluence of $1.5 \times 10^{21} \mathrm{Al}^{+} / \mathrm{m}^{2}$ at $650^{\circ} \mathrm{C}$. 
ORNL-PHOTO $5821-92$

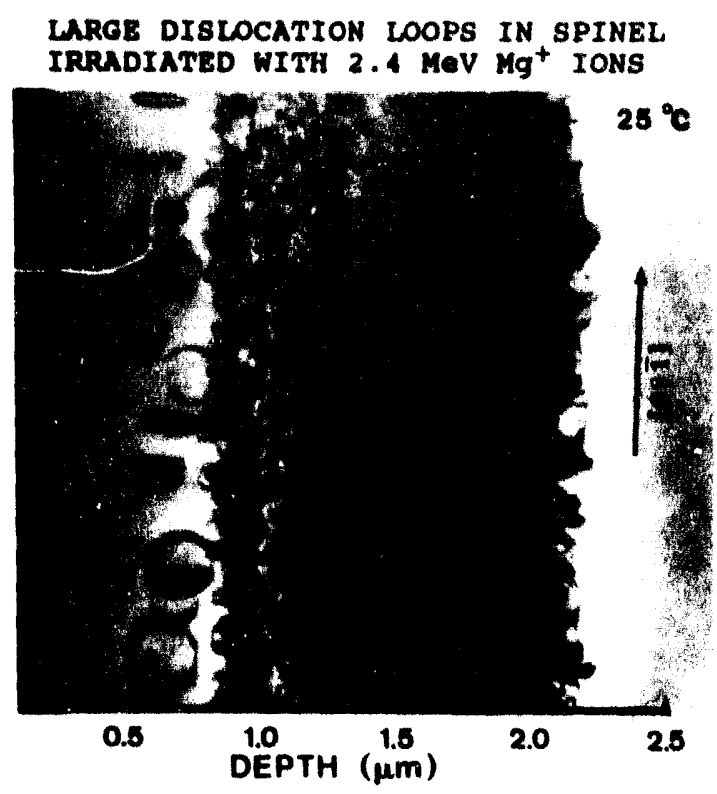

Fig. 7. Microstructure of $\mathrm{MgAl}_{2} \mathrm{O}_{4}$ irradiated with $2.4 \mathrm{MeV} \mathrm{Mg}{ }^{+}$ions to a peak damage level of $54 \mathrm{dpa}$ at $25^{\circ} \mathrm{C}$.
Figure 7 shows the cross-section microstructure of spinel irradiated at room temperature with $2.4 \mathrm{McV} \mathrm{Mg}^{+}$ions to a tluence of $2.2 \times 10^{21} \mathrm{Mg}^{+} / \mathrm{m}^{2}$ (peak damage level of $54 \mathrm{dpa}$ ). An abrupt transition in the microstructure occurs at a depth of about 0.8 $\mu \mathrm{m}$ (corresponding to an IDAD ratio of about 10). A very low density of large (250 nm diameter) interstitial dislocation loops lying on $\{110\}$ planes are present in the nearsurface region. The presence of such a low density of large dislocation loops implies that the point defect diffusivity must have been very high in this region. The loop size rapidly decreases and the loop density rapidly increases at depths greater than $0.8 \mu \mathrm{m}$, which implies that the point defect diffusivity is much lower in this region compared to near the surface.

Further evidence of enhanced point defect diffusion in $\mathrm{MgAl}_{2} \mathrm{O}_{4}$ during light ion irradiation is obtained from an examination of the grain boundaries. As shown in Fig. 8, irradiation with $2.4 \mathrm{MeV} \mathrm{Mg}^{+}$ions at room temperature produced substantial subsurface grain boundary cavitation. This implies that irradiation enhances not only interstitial diffusivities but also vacancy diffusivities.

ORWL-PTOTO 5822-9

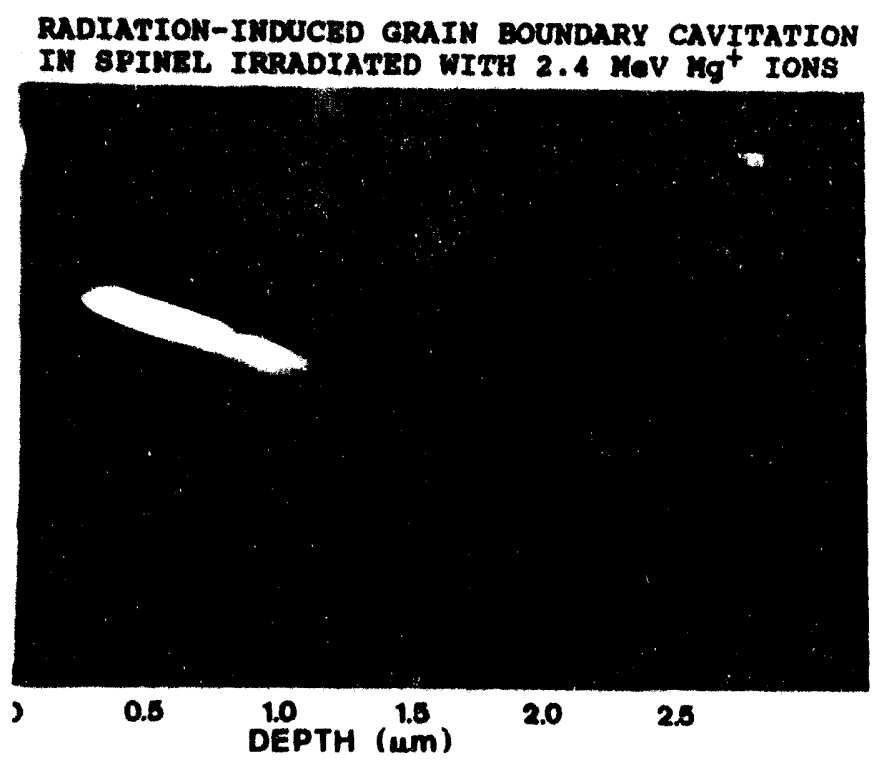

Fig. 8. Radiation-induced grain boundary cavitation in $\mathrm{MgAl}_{2} \mathrm{O}_{4}$ irradiated with $2.4 \mathrm{MeV} \mathrm{Mg}^{+}$ ions to a peak damage level of $54 \mathrm{dpa}$ at $25^{\circ} \mathrm{C}$. 
Effect of Jonizing Radiation Flux on Dislocation Loop Eormation

A limited study of flux effects for a fixed ion mass and energy has been completed to date. The microstructural results indicate that the absolute magnitude of the ionizing flux can influence the size and density of dislocation loops. Figure 9 compares the cross section microstructure of 2 spinel specimens that were irradiated to comparable damage levels with $3 \mathrm{MeV} \mathrm{C}^{+}$ions at two different fluxes. Due to the high initial IDAD ratio of $3 \mathrm{MeV} \mathrm{C}^{+}$ions, dislocation loop formation only occurred near the ion implanted region $(2.2 \mu \mathrm{m}$ depth) where the IDAD ratio approached a value of 10 . The dislocation loops in the "high flux" specimen were larger and of lower density compared to the "low flux" specimen. This implies that the point defect diffusivity was enhanced for the "high flux" irradiation condition.

Figure 10 compares the microstructure in $\mathrm{Al}_{2} \mathrm{O}_{3}$ following $1 \mathrm{MeV} \mathrm{H}^{+}$ion irradiation at two different fluxes. As noted previously [1], dislocation loops were not observed at intermediate depths in the "high flux" specimen $\left(-3 \times 10^{6} \mathrm{~Gy} / \mathrm{s}\right.$ at a depth of $\left.0.5 \mu \mathrm{m}\right)$. However, irradiation at an order of magnitude lower flux $\left(0.3 \times 10^{6} \mathrm{~Gy} / \mathrm{s}\right.$ at a depth of $\left.0.5 \mu \mathrm{m}\right)$ produced some observable dislocation loops despite the fact that the total accumulated dose was only $0.01 \mathrm{dpa}$, which was one-tenth of the "high flux" specimen. This observation is consistent with the proposed interpretation that high fluxes of ionizing radiation cause an enhancement in the point defect diffusivities.

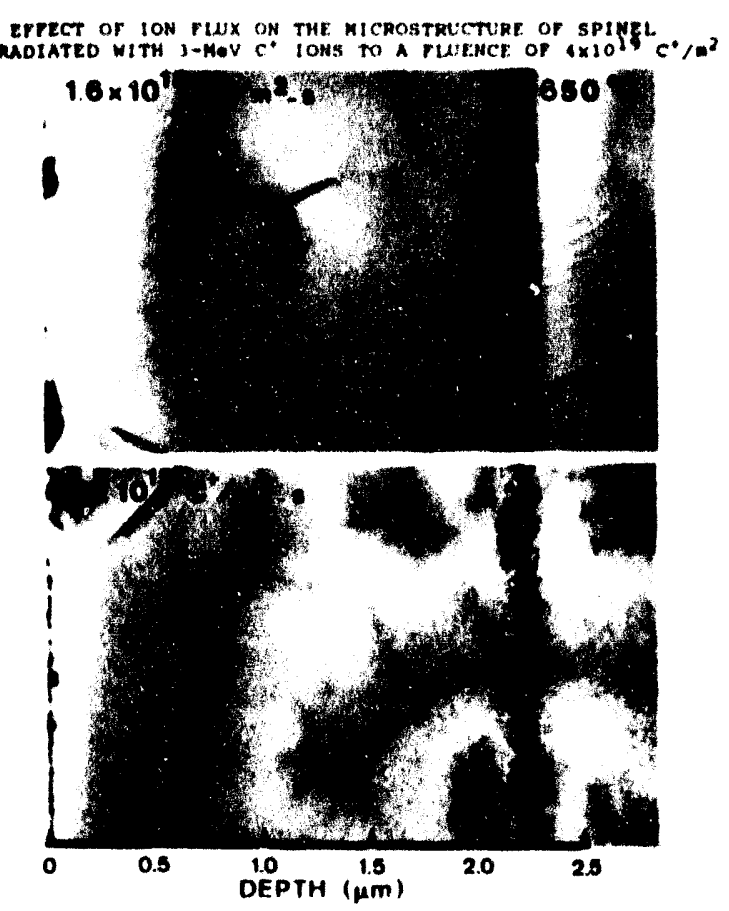

Fig. 9. Effect of ion flux on the microstructure of $\mathrm{MgAl}_{2} \mathrm{O}_{4}$ irradiated with $3 \mathrm{MeV} \mathrm{C}{ }^{+}$ions to a peak damage level of about $0.5 \mathrm{dpa}$ at $650^{\circ} \mathrm{C}$.
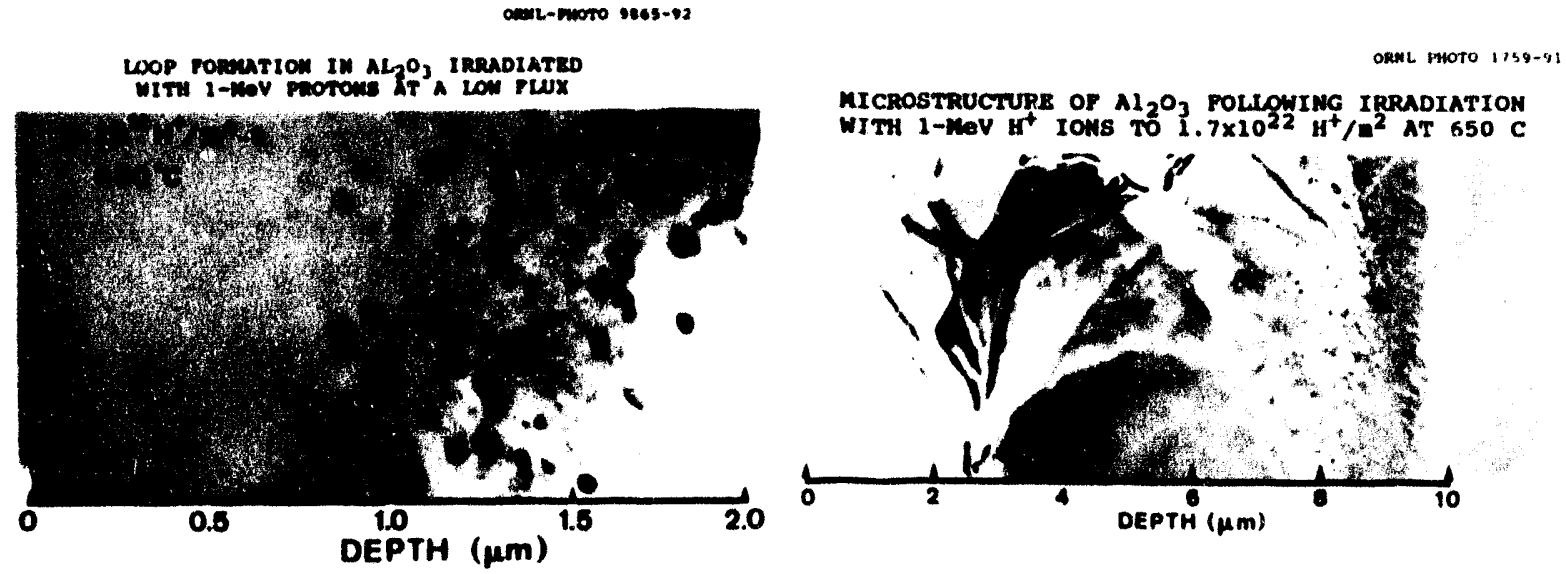

Fig. 10. Comparison of the microstructure of $\mathrm{Al}_{2} \mathrm{O}_{3}$ irradiated at two different fluxes with $1 \mathrm{MeV}$ protons at $650^{\circ} \mathrm{C}$. (a) $6 \times 10^{17} \mathrm{H}^{+} / \mathrm{m}^{2}$-s, (b) $6 \times 10^{16} \mathrm{H}^{+} / \mathrm{m}^{2}$-s. 


\section{DISCUSSION}

The suppression of dislocation loop formation in oxide ceramics irradiated with light ions (high IDAD ratio) could in principle be due to two different effects; either a decrease in the defect production rate or an increase in the amount of point defect diffusion. It appears unlikely that the defect production rate was significantly reduced for the light ion irradiation case, since defect clusters were observed in $\mathrm{Al}_{2} \mathrm{O}_{3}$ irradiated with a low flux of protons after a dose of only $-0.01 \mathrm{dpa}$ (Fig. 10). In addition, considerable growth occured in the few dislocation loops that were nucleated in regions with high IDAD ratios (e.g., Fig. 7). This suggests that the suppressed dislocation loop density is not associated with a reduction in defect production. Defect production measurements by Luera [14] on $\mathrm{Al}_{2} \mathrm{O}_{3}$ irradiated with low energy ions indicate that protons actually have a higher defect production rate (relative to the calculated displacement damage rate) than heavier ions such as $\mathrm{N}^{+}$or $\mathrm{Xe}^{++}$. Buckley and Shaibani [11] observed that the lack of defect clusters in spinel irradiated with $1 \mathrm{MeV}$ electrons (IDAD ratio 10,000 ) was due to difficulties in loop nucleation rather than point defect production--preexisting dislocations climbed readily during electron irradiation, which is evidence for a significant concentration of point defects.

Several previous studies have found that the radiation-induced changes in oxide ceramics are dependent on the irradiation spectrum. The most extensive study to date on spectrum effects was performed by Eernisse, Arnold and coworkers on $\mathrm{SiO}_{2}$ and $\mathrm{Al}_{2} \mathrm{O}_{3}$ [15-17]. Light ions such as $\mathrm{H}^{+}$and $\mathrm{He}^{+}$(which have a high IDAD ratio) produced less volume swelling per dpa in $\mathrm{Al}_{2} \mathrm{O}_{3}$ compared to heavier ions. In addition, the volume expansion induced by the heavy ion irradiation could be relieved by subsequent electron or $\mathrm{H}^{+}$ion irradiation. Walker [18] reported similar annealing of volumetric swelling for $\mathrm{BeO}$ that was irradiated with fission neutrons and subsequently irradiated with $1 \mathrm{MeV}$ electrons. Irradiation of $\mathrm{BeO}$ with electrons alone did not produce any significant change in the lattice parameter. It was suggested that electron irradiation enhanced the mobility of point defects, which led to enhanced point defect recombination.

There is relatively little published information on radiation enhanced diffusion in ceramics $[19,20]$. Bourgoin and Corbett [19] have summarized a variety of physical mechanisms which could produce enhanced diffusion in semiconductors and insulators. Of direct interest is the phenomenon of ionization enhanced diffusion (IED). They discussed several mechanisms which could produce IED, including (1) reduced point defect migration energies due to an ionization-induced change in the charge state of the migrating defect, (2) Electro-striction enhanced diffusion, in which the presence of electrons and holes in the conduction or valence bands results in a change of the lattice constant, (3) the Bourgoin saddle point jump mechanism, and (4) multiple ionization of anions which would give an anion defect enough energy to cause migration. Irradiation studies performed on metals have determined that moderate levels of ionizing radiation promotes recombination of point defects [19,21-23].

Another ionization mechanism which would produce enhanced diffusion in insulators is defect creation by self trapped excitons $[19,24]$. This mechanism is important in alkalai halides and in other insulators such as $\mathrm{SiO}_{2}$, but has not been found to produce significant amounts of displacement damage in $\mathrm{MgO}$ or $\mathrm{Al}_{2} \mathrm{O}_{3}$ [24-26].

Supporting evidence for ionization enhanced diffusion of point defects in irradiated oxide ceramics can be found in published studies of cavity formation. Resolvable cavities were present in $\mathrm{Al}_{2} \mathrm{O}_{3}$ after triple beam irradiation at room temperature with $2 \mathrm{MeV} \mathrm{Al}+1.44 \mathrm{MeV} \mathrm{O}^{+}$and $200-400 \mathrm{keV} \mathrm{He}^{+}$ions (combined IDAD ratio $\sim 100$ ) [27]. Cavity formation is generally not observed in neutron-irradiated $\mathrm{Al}_{2} \mathrm{O}_{3}$ unless the irradiation temperature is well above room temperature. The presence of resolvable cavities at room temperature in the light ion irradiated specimens may be due to IED. 


\section{CONCLUSIONS}

The microstructural changes in oxide ceramics induced by ion irradiation are dependent on the mass and energy of the incident ion. The microstructural evidence suggests that ionization enhanced diffusion (IED) promotes long range diffusion and recombination of point defects. The results are most closely correlated with the ratio of ionizing to displacive absorbed dose (IDAD). The absolute magnitude of the ionizing radiation flux is also an important parameter.

\section{ACKNOWLEDGEMENTS}

Most of the ion irradiations were performed by S.W. Cook. The cross section TEM specimens were prepared by A.M. Williams, J.W. Jones and J.M. Cole. A portion of the microscopy on the $\mathrm{C}^{+}$ion irradiated $\mathrm{Al}_{2} \mathrm{O}_{3}$ specimens was performed by Y. Katano (JAERI).

\section{FUTURE WORK}

Specimens of $\mathrm{Al}_{2} \mathrm{O}_{3}, \mathrm{MgAl}_{2} \mathrm{O}_{4}$, and $\mathrm{Si}_{3} \mathrm{~N}_{4}$ will be irradiated with varying dual-beam fluxes of $4 \mathrm{MeV}$ $\mathrm{Fe}^{++}$and $1 \mathrm{MeV} \mathrm{He}{ }^{+}$ions in order to further investigate the importance of the IDAD ratio, ionizing flux, and irradiation spectrum on microstructural evolution in insulating ceramics.

\section{REFERENCES}

1. S.J. Zinkle, Fusion Reactor Materials Semiann. Prog. Report for Period Ending March 31, 1991, DOE/ER-0313/10.

2. M.B. Lewis, W.R. Allen, R.A. Buhl, N.H. Packan, S.W. Cook, and L.K. Mansur, Nucl. Instr. Meth. B 43 (1989) 243.

3. J.F. Ziegler, J.P. Biersak, and U.L. Littmark, The Stopping and Range of lons in Solids (Pergamon Press, New York, 1985).

4. P. Agnew, Phil. Mag. A 65 (1992) 355.

5. S.J. Zinkle, C.P. Haltom, L.C. Jenkins, and C.K.H. DuBose, J. Electron Microscopy Techn. 19 (1991) 452.

6. R. Yamada, S.J. Zinkle, and G.P. Pells, J. Nucl. Mater., submitted (1993).

7. H. Abe, C. Kinoshita, and K. Nakai, J. Nucl. Mater. 179-181 (1991) 917.

8. K. Nakai, K. Fukumoto, and C. Kinoshita, J. Nucl. Mater. $191-194$ (1992) 630.

9. S.J. Zinkle, in Structure-Property Relationships in Surface-Modified Ceramics, Eds. C.J. McHargue et al. (Kluwer Academic Publ., 1989) p. 219.

10. S.J. Shaibani, D. Phil. Thesis, Univ. Oxford, Oxford, UK, 1986. 
11. S.N. Buckley and S.J. Shaibani, Phil. Mag. Lett. 55 (1987) 15.

12. P.A. Knight, D. Phil. Thesis, Univ, Oxford, Oxford, UK, 1989.

13. S.J. Zinkle, in Effects of Radiation on Materials, ASTM STP 1125, Eds. R.E. Stoller, A.S. Kumar and D.S. Gelles (ASTM, Philadelphia, 1992) p. 749.

14. T.F. Luera, J. Appl. Phys. 51 (1980) 5792.

15. E.P. EerNisse, J. Appl. Phys. 45 (1974) 167.

16. G.W. Arnold, G.B. Krefft and C.B. Norris, Appl. Phys. Lett. 25 (1974) 540.

17. G.B. Krefft and E.P. EerNisse, J. Appl. Phys. 49 (1978) 2725.

18. D.G. Walker, J. Nucl. Mater. 14 (1964) 195.

19. J.C. Bourgoin and J.W. Corbelt, Rad. Effects 36 (1978) 157.

20. Hj. Matzke, Rad. Effects 64 (1982) 3.

21. A. Dunlop and D. Lesueur, Rad. Effects 117 (1991) 91.

22. A. Iwase, T. Iwata, S. Sasaki and T. Nihara, J. Phys. Soc. Jpn. 59 (1990) 1451.

23. I.P. Chernov et al., Rad. Effects 97 (1986) 155.

24. N. Itoh, Rad. Effects 110 (1989) 19.

25. C. Itoh, K. Tanimura, and N. Itoh, J. Phys. C 19 (1986) 6887.

26. F. Jollet, J.P. Duraud and C. Noguera, Rad. Effects 110 (1989) 185.

27. S.J. Zinkle and S. Kojima, J. Nucl. Mater. 179-181 (1991) 395. 
ELECTRICAL CONDUCTIVITY OF CERAMIC INSULATORS DURING EXTENDED ION IRRADIATION WITH AN APPLIED ELECTRIC FIELD .- S.J. Zinkle (ORNL) and W. Kesternich (Forschungszentrum Juelich)

\section{OBJECTIVE}

The objective of this study is to examine whether ceramic insulators suffer radiation-induced electrical degradation (RIED) during irradiation with an applied electric field.

\section{SUMMARY}

The initial results are presented from a cyclotron ion irradiation program investigating radiation-induced conductivity (RIC) and radiation-induced electrical degradation (RIED) of ceramic insulators. Polycrystalline specimens of $\mathrm{Al}_{2} \mathrm{O}_{3}, \mathrm{MgAl}_{2} \mathrm{O}_{4}, \mathrm{AlN}$ and $\mathrm{Si}_{3} \mathrm{~N}_{4}$ were irradiated with either $28 \mathrm{MeV} \mathrm{He}^{++}$or $20 \mathrm{MeV} \mathrm{H}^{+}$ ions at temperatures between 150 and $600^{\circ} \mathrm{C}$ with an applied de electric field of 100 to $500 \mathrm{~V} / \mathrm{mm}$. A large prompt increase in the electrical conductivity was observed in all of the specimens during irradiation. However, there was no evidence for permanent electrical degradation in any of the specimens for damage levels up to about $5 \times 10^{-3}$ displacements per atom.

\section{INTRODUCTION}

Insulating ceramics are essential for the successful operation of numerous components in a fusion reactor, including radiofrequency heating systems, the breeding blanket and first wall (as a current break), and numerous diagnostic systems [1-3]. It has long been known that the electrical properties of insulating materials are dramatically altered by energetic radiation, due to the excitation of valence electrons into the conduction band [4-7]. The high mobility and capture cross sections of electrons and holes in the conduction band generally results in recombination of the electron-hole pairs within $\left\langle 10^{-9} \mathrm{~s}\right.$ [7]. Hence, the magnitude of this radiation-induced conductivity (RIC) can only be determined by in-situ experiments conducted while the specimen is being irradiated. It has generally been observed that the electrical conductivity of the ceramic reverts to a value very near its preirradiation value immediately after the irradiation source is turned off $[7,8]$. One notable exception is the class of alkali halides, which can suffer permanent displacement damage associated with ionizing radiation alone [9].

Most studies have found that the increase in the electrical conductivity of insulating materials during irradiation is nearly proportional to the ionizing radiation dose rate $[6,7,10-14]$ :

$$
\sigma=\sigma_{0}+K R^{\delta}
$$

where $\sigma_{0}$ is the conductivity in the absence of radiation, $R$ is the ionizing radiation dose rate, $K$ is a proportionality constant, and $\delta$ is the dose rate exponent, which is on the order of 1.0.

According to fusion design studies, the maximum conductivity that is allowable in ceramic insulators during operation is between $10^{-4} \mathrm{~S} / \mathrm{m}$ and $1 \mathrm{~S} / \mathrm{m}$, depending on the particular application [1]. Fortunately, the prompt RIC associated with fusion-relevant ionizing radiation levels ( 1 to $10^{4} \mathrm{~Gy} / \mathrm{s}$ ) is generally less 
than $10^{-6} \mathrm{~S} / \mathrm{m}$ in oxide ceramic insulators. Figure 1 shows the measured RIC in several oxide ceramic insulators as a function of ionizing dose rate [10-14]. It can be seen that the RIC is proportional to the ionizing dose rate over a very wide range of ionizing dose rates (10 orders of magnitude). Whereas the prompt RIC can be very significant at fusion-relevant ionizing dose rates compared to the typical nonirradiated room temperature conductivities of $10^{-12} \mathrm{~S} / \mathrm{m}$, the conductivity is still well below the practical upper limit for fusion insulator applications of $10^{-4}$ to $1 \mathrm{~S} / \mathrm{m}$.

OHNI DWC : $33 \mathrm{M} 5090 \mathrm{H}$

RADIATION - INDUCED CONDUCTIVITY IN OXIDE CERAMICS IRRADIATED NEAR ROOM TEMPERATURE

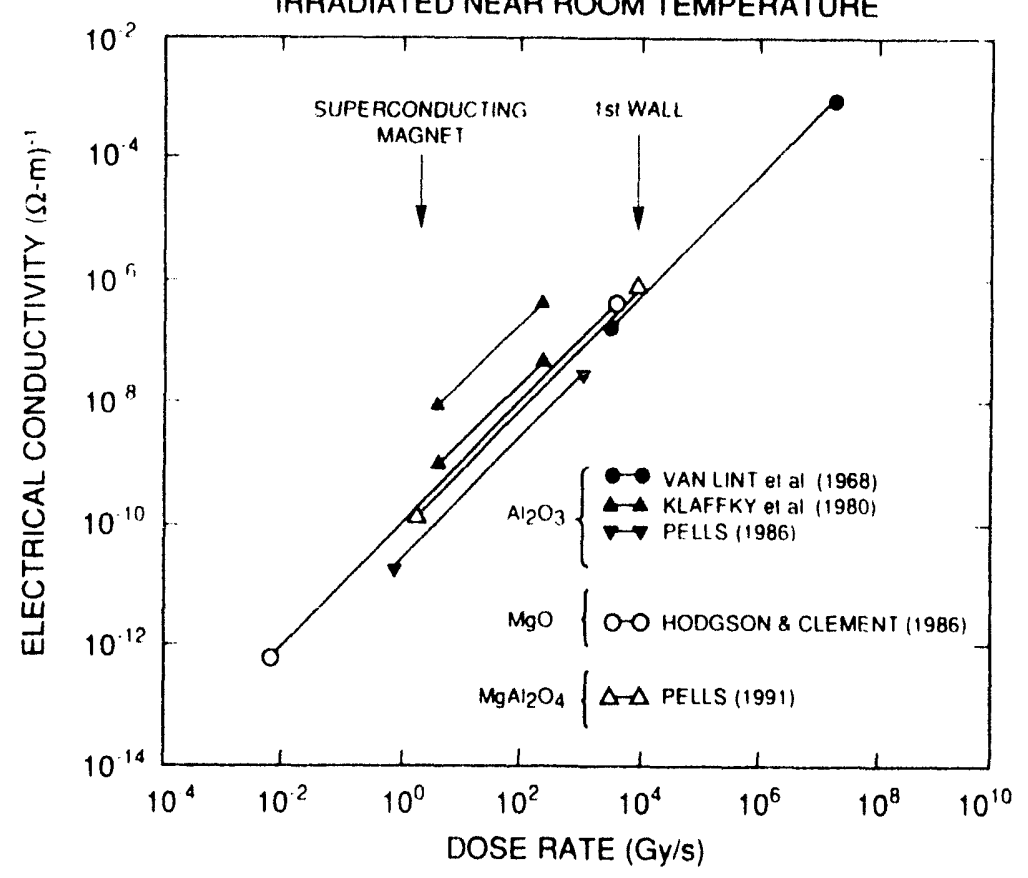

Fig. 1. Effect of ionizing dose rate on the electrical conductivity of oxide ceramics irradiated near room temperature [10-14].

Recently, several studies have found that severe permanent increases in the electrical conductivity of ceramic insulators may occur during extended irradiation if an electric field is applied during the irradiation [15-22]. Most of the data available on this new phenomenon are due to Hodgson [16-18,22], who used electron irradiation to show that radiation-induced electrical degradation (RIED) did not occur unless the radiation produced atomic displacements in addition to the ever-present ionizing radiation component. Hodgson also demonstrated that application of an electric field during the irradiation was necessary to produce RIED, and that the degradation stopped as soon as the electric field was turned off. On the other hand, irradiation without an applied electric field typically causes a slight improvement in the electrical resistivity of ceramics, due to an increase in the trap concentration associated with displacement damage $[1,8,23]$. RIED has been observed to occur for electric fields as small as $\sim 20 \mathrm{~V} / \mathrm{mm} \mathrm{[18].} \mathrm{This} \mathrm{phenomenon} \mathrm{is} \mathrm{a} \mathrm{more}$ serious technological issue than the well-known RIC because the observed electrical degradation is permanent [16,17] (i.e., it is retained even after the specimen is removed from the radiation field). In addition, the degradation apparently cannot be removed by thermal annealing [19]. The magnitude of the 
permanent RIED observed to date has exceeded $10^{-4} \mathrm{~S} / \mathrm{m}[19,21]$. Permanent increases in the electrical conductivity of $\mathrm{Al}_{2} \mathrm{O}_{3}$ and $\mathrm{MgAl}_{2} \mathrm{O}_{4}$ above $10^{-5} \mathrm{~S} / \mathrm{m}$ have been observed after exposure to damage levels of 0.001 to $0.1 \mathrm{dpa}$, and there is no definitive evidence of any saturation in the RIED [16-20]. There is limited evidence that the electrical degradation is maximized at irradiation temperatures near $450^{\circ} \mathrm{C}$, with relatively little degradation occurring at temperatures $\leq 200^{\circ} \mathrm{C}$ or $\geq 650^{\circ} \mathrm{C}[1,18,19]$.

Observations of RIED reported to date have been limited to 3 oxide ceramics, $\mathrm{Al}_{2} \mathrm{O}_{3}, \mathrm{MgO}$, and $\mathrm{MgAl}_{2} \mathrm{O}_{4}$ [15-22]. The microstructural alteration responsible for the large permanent increase in the electrical conductivity has not yet been identified, although there are several indications that it may be due to the formation of metallic precipitates (colloids). The evidence in support of colloid formation includes optical observation of large opaque features [22], reduction of the activation energy for conduction to values coparable to metals $[1,19]$, and the temperature dependence of the RIED process $[1,19]$.

The present study was initiated in order to generate additional data on this intriguing physical process, and to determine by postirradiation analytical electron microscopy whether colloid formation had occurred. Since materials with ionic bonding are generally thought to be more susceptible to colloid formation [9], two types of nitride ceramics with predominantly covalent bonds were included in the experimental matrix in order to assess the importance of bond type on RIED susceptibility.

\section{EXPERIMENTAL PROCEDURE}

Four commercial polycrystalline ceramics were used for this study: $\mathrm{Al}_{2} \mathrm{O}_{3}$ (Wesgo AL-995), $\mathrm{MgAl}_{2} \mathrm{O}_{4}$ (Ceredyne), AlN (Cercom), and $\mathrm{Si}_{3} \mathrm{~N}_{4}$ (Kyocera SN733). Wafers of thickness $0.25 \mathrm{~mm}$ were cut from the bulk material using a low-speed diamond saw, and disks of $3 \mathrm{~mm}$ diameter were ultrasonically cut from the wafers. The 3-mm diameter disks were mounted on a steel stub with a low-melting wax and were precision ground on a diamond wheel to a final thickness of 0.15 to $0.16 \mathrm{~mm}$ with the aid of a commercial precision grinding tool. The final $15 \mu \mathrm{m}$ of material was removed in 3 passes of $5 \mu \mathrm{m}$ each.

Disks of the four ceramic materials were brazed to a nickel substrate. Pure nickel was chosen as the substrate material due to its relatively high thermal and electrical conductivity and also because its coefficient of thermal expansion was comparable to that of the four ceramics (which thereby minimized temperature-induced stresses on the thin ceramic disks). Attempts to diffusion bond the ceramic disks to a $\mathrm{Ni}$ substrate using a thin $(10 \mu \mathrm{m}) \mathrm{Au}$ foil produced poor adhesion for the $\mathrm{AlN}$ and $\mathrm{Si}_{3} \mathrm{~N}_{4}$ specimens. Satisfactory adhesion of all 4 ceramic TEM disks was achieved by brazing the specimens onto a 5-mm thick Ni base using a $60 \mu \mathrm{m}$ thick Ag-19.5\% Cu-5\%In-3\% Ti brazing foil. The braze cycle consisted of heating slowly to $820^{\circ} \mathrm{C}$, holding at temperature for 20 minutes, then heating at $5^{\circ} \mathrm{C}$ per minute up to $920^{\circ} \mathrm{C}$, holding for 5 minutes, then cooling at 10 to $20^{\circ} \mathrm{C}$ per minute to room temperature. The ceramic disks were precisely aligned on the $\mathrm{Ni}$ substrate during the brazing process with the aid of a ceramic alignment fixture. The brazed surface of the ceramic disks served as the back (ground) electrode, and ensured that there was good thermal contact between the ceramic disks and the Ni substrate. This latter feature was important because the specimen thermocouple was located in the Ni substrate approximately $2.5 \mathrm{~mm}$ beneath the specimens, and the high beam currents utilized in our irradiations would have produced an unacceptable temperature gradient between the specimens and the thermocouple if there was poor thermal contact. The specimen temperatures given in this paper have been corrected for the temperature gradient between the thermocouple and the specimens $\left(<50^{\circ} \mathrm{C}\right.$ for the highest flux irradiations).

The center and guard ring electrodes were attatched to the top of the brazed ceramic disks by sputter deposition. Sputter-deposited platinum did not have good adhesion to spinel or the nitride ceramics. Good 
adhesion of the electrodes to all of the specimens was obtained by first depositing $0.3 \mu \mathrm{m} \mathrm{Ti}$ and then $3 \mu \mathrm{m}$ $\mathrm{Pt}$ using a 2-source vacuum sputter deposition system. The guard ring geometry was produced by attatching with silver paint a small steel ring of inner and outer dianeter $1.6 \mathrm{~mm}$ and $2.0 \mathrm{~mm}$, respectively, to the top surface of each ceramic disk prior to the sputter deposition. The steel ring was removed from the specimens after the Pt deposition by soaking in acetone, and the excess silver paint was removed by rubbing with a cotton tip applicator. Figure 2 shows the final geometry of the guarded specimens. The specimen geometry was in conformance with the applicable ASTM standards on 3-terminal volume resistivity measurements [28]. The resistance between the guard ring and the $\mathrm{Ni}$ base was typically very low $(\sim 1 \Omega)$ after the brazing and electrode deposition processes due to the presence of a thin film of metallic impurities on the ceramic disk surfaces. This metallic film around the edges of the disks was removed by a small dental abrasive drill. The resistance between the center and guard-ring electrodes and the guard-ring and base electrodes was $>20 \mathrm{M} \Omega$ after this cleaning procedure.

\section{CERAMIC SPECIMEN GEOMETRY FOR IN-SITU ELECTRICAL CONDUCTIVITY TESTS}

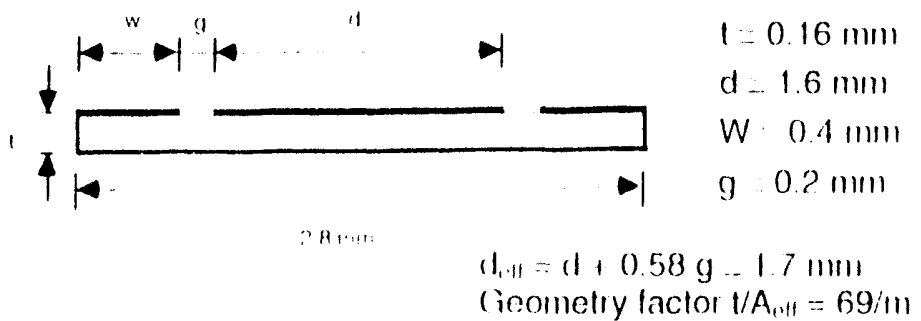

\begin{tabular}{|c|c|}
\hline ASTM Standard " & P'resent design \\
\hline$W=21$ & $W \cdot 2.51$ \\
\hline $1=41$ & (1) 191 \\
\hline 91 & $1.25 t$ \\
\hline
\end{tabular}

- D257-78 (reapproved 1983) Standard Test Melliods for D-C Resislance or Conductance of Insulating Materials

0150-87 Standard Test Mellods for A-C Loss Characteristics and

Permittivity (Dielectric Conslant) of Solid Electrical Insulating Materials

Fig. 2 Specimen and electrode geometry used for the in-situ electrical conductivity measurements.

Figure 3 shows schematically how the electrical leads were attached to the center and guard ring surfaces. Initial attempts to attach $100 \mu \mathrm{m}$ diameter $\mathrm{Pt}$ wires to the electrode surfaces with a parallel-electrode spot welding machine produced mixed results. Excellent wire adhesion was generally obtained for the $\mathrm{Al}_{2} \mathrm{O}_{3}$ specimens, but $\mathrm{Pt}$ wires could not be welded to the $\mathrm{Si}_{3} \mathrm{~N}_{4}$ specimens. In addition, attempts to ultasonically bond thin $\mathrm{Pt}$ wires to the $\mathrm{Pt}$ electrodes were also unsuccessful. Satisfactory results were obtained by employing a spring-loaded tungsten wire contact system. The signal from the center electrode of each specimen was protected against leakage currents to ground by incorporating a guarded pedestal configuration for the W spring supports, as shown in Fig. 3. 


\section{Specimen Configuration for RIED Experiment}

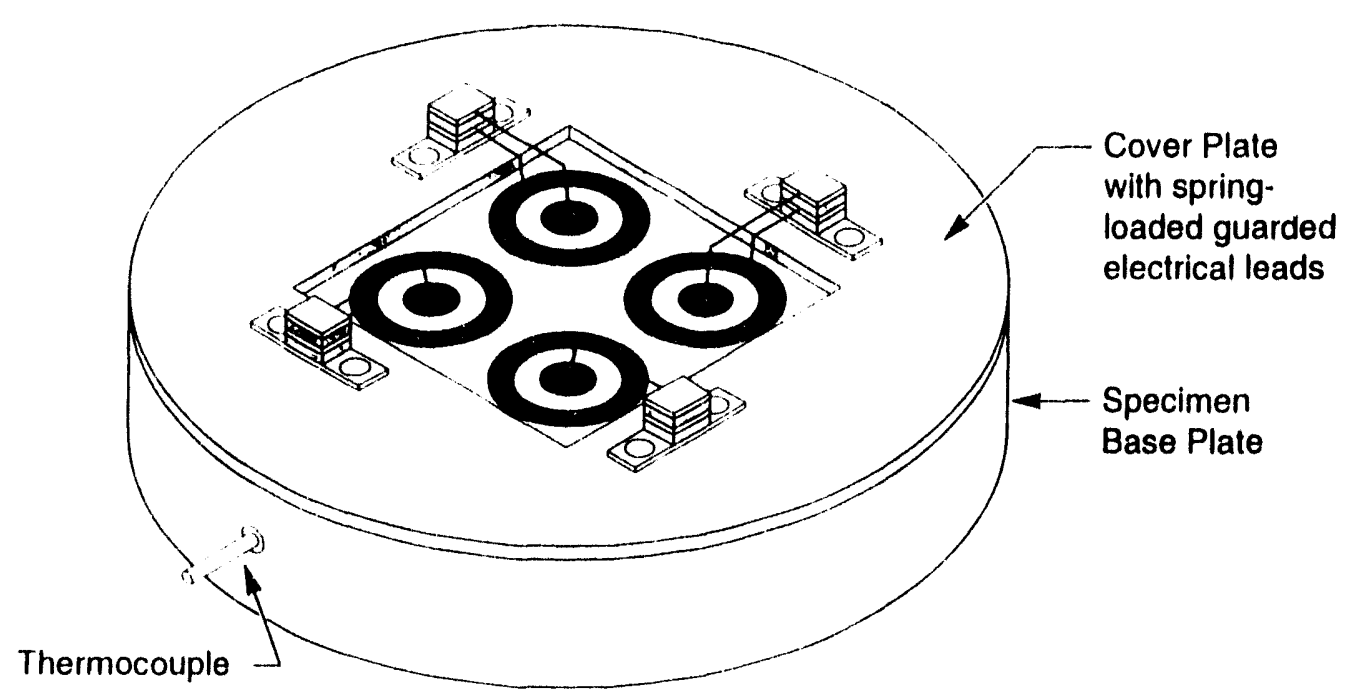

Fig. 3. Specimen configuration for the cyclotron insitu conductivity measurements showing the springloaded W wire contacts and the guarded wire support pedestals.

The irradiations were performed using either $20 \mathrm{MeV} \mathrm{H}^{+}$ions or $28 \mathrm{MeV} \mathrm{He} \mathrm{He}^{++}$ions at the Forschungszentrum Juelich compact cyclotron. The range of these ions in $\mathrm{Al}_{2} \mathrm{O}_{3}$ of ideal density is 0.21 $\mathrm{mm}$ and $1.3 \mathrm{~mm}$, respectively, according to a TRIM-90 [24] calculation. The calculated displacement damage and ionizing dose rates at a depth of $0.08 \mathrm{~mm}$ for a beam current of $1 \mathrm{~A} / \mathrm{m}^{2}$ incident on an $\mathrm{Al}_{2} \mathrm{O}_{3}$ target are $1.21 \times 10^{-6} \mathrm{dpa} / \mathrm{s}$ and $2.2 \times 10^{6} \mathrm{~Gy} / \mathrm{s}$ for $20 \mathrm{MeV} \mathrm{H}^{+}$ions, and $6.7 \times 10^{-6} \mathrm{dpa} / \mathrm{s}$ and $1.2 \times 10^{7}$ $\mathrm{Gy} / \mathrm{s}$ for $28 \mathrm{MeV} \mathrm{He}{ }^{++}$ions. Typical fluxes maintained during the irradiation were 0.05 to $0.1 \mathrm{~A} / \mathrm{m}^{2}$. The TRIM calculations were performed using a binding energy of $2 \mathrm{eV}$ and the measured $[24,25]$ threshold displacement energies for $\mathrm{Al}_{2} \mathrm{O}_{3}$ of $20 \mathrm{eV}$ and $78 \mathrm{eV}$ for the aluminum and oxygen sublattices, respectively. Identical results for the nuclear and electronic stopping powers were obtained from TRIM calculations performed with a threshold displacement energy of $40 \mathrm{eV}$ for both sublatices. The conversion from damage energy (nuclear stopping power) to NRT dpa [27] assumed an average displacement energy of $40 \mathrm{eV}$. Figure 4 shows the calculated displacement damage and ionizing radiation profiles for $20 \mathrm{MeV} \mathrm{H}^{+}$and $28 \mathrm{MeV}$ $\mathrm{He}^{++}$ions incident on $\mathrm{Al}_{2} \mathrm{O}_{3}$. The calculated variation in the damage rate between the front and back surfaces for an $\mathrm{Al}_{2} \mathrm{O}_{3}$ specimen of thickness $0.16 \mathrm{~mm}$ was $<5 \%$ for the $20 \mathrm{MeV}$ proton irradiations and $-50 \%$ for the $28 \mathrm{MeV} \mathrm{He}^{++}$ion irradiations.

A schematic of the target chamber used for the cyclotron irradiations is shown in Fig. 5. The target chamber was evacuated during the irradiations with a $270 \mathrm{l} / \mathrm{s}$ turbomolecular pump, which produced a base pressure of about $1 \times 10^{-5}$ torr in the chamber. The specimen temperature was controlled with a cylindrical ( $5 \mathrm{~mm}$ diam.) mineral-insulated electrical resistance heater that was controlled by the specimen thermocouple. The target chamber was electrically isolated from the cyclotron beam line and target stand by 


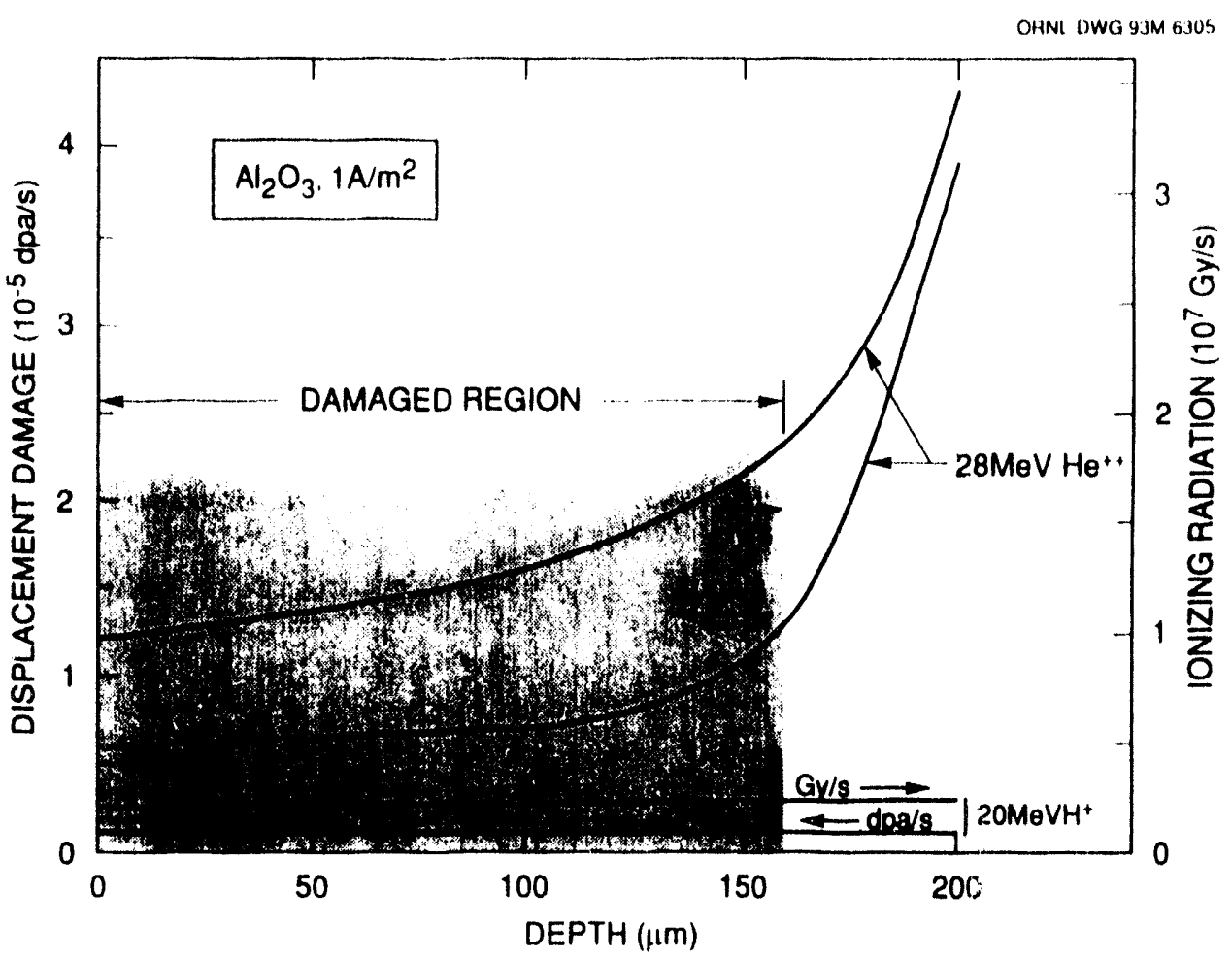

Fig. 4 Calculated [24] displacement damage and ionizing radiation profiles for ion-irradiated $\mathrm{Al}_{2} \mathrm{O}_{3}$.

OANL.DWG 92M-14971

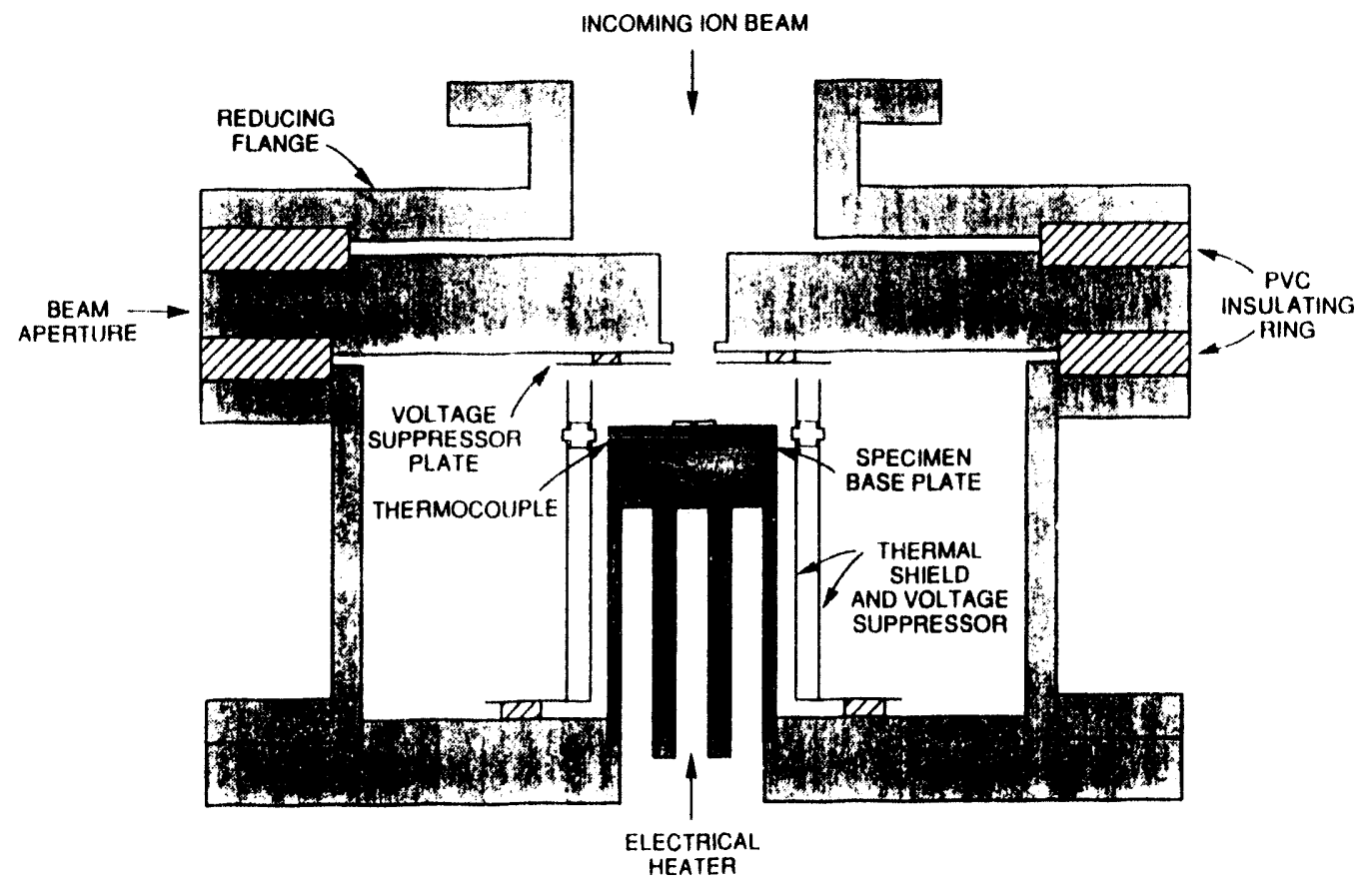

Fig. 5 Schematic of the target chamber used for the in-situ electrical conductivity measurements. 
polyvinyl chloride insulation. A set of electrically isolated concentric cylindrical steel sheets surrounding the specimen pedestal served as both a heat shield and to suppress the emission of secondary electrons during the irradiation. The suppressor voltage was set at the same (negative) value as the voltage applied to the specimens during the irradiation. This feature effectively guarded the specimen leads as they passed through the steel heat shields inside of Macor ceramic-insulated feedthoughs. Floating coaxial vacuum feedthroughs and triaxial cables were used to connect the guard and center leads from the target chamber to the experimenters area outside of the irradiation target room.

A Keithley Model 480 picoammeter was used to measure the specimen currents. A dc potential of either 15 or $75 \mathrm{~V}$ was continuously applied during the irradiation, which produced an electric field of 100 and 500 $\mathrm{V} / \mathrm{mm}$, respectively. A switching circuit was built that allowed the current through each individual center electrode or guard ring circuit to be monitored one at a time, while continuously maintaining the potential on all 8 leads. Due to the small size of the specimens used in this study, the resolution limit for electrical conductivity changes was about $5 \times 10^{-8} / \Omega-\mathrm{m}$. In addition, the spinel specimens were generally found to have anomalously high leakage currents compared to the other specimens. It is believed that the low strength of the spinel caused it to be susceptable to microcracking during the spec:men grinding on the diamond-impregnated metal platen. Improved performance has recently been observed in spinel specimens that were ground with diamond paste on a standard nylon polishing pad.

\section{RESULTS AND DISCUSSION}

Table 1 summarizes the irradiation conditions that have been studied to date on the 4 ceramic insulators. The electrical conductivity of all four ceramics was observed to increase immediately at the start of the irradiation, and then remained constant or decreased slightly as the irradiation proceeded. Typical RIC values observed during irradiation with $28 \mathrm{MeV} \mathrm{He}{ }^{++}$ions at $600^{\circ} \mathrm{C}$ at a beam current of $0.06 \mathrm{~A} / \mathrm{m}^{2}(0.7 \mathrm{MGy} / \mathrm{s})$ ranged from $1 \times 10^{-6}$ to $1 \times 10^{-5} / \Omega-\mathrm{m}$ for the different ceramics. These prompt RIC measurements were in reasonable agreement with previous measurements (Fig. 1) reported for oxide ceramics. The ion beam was turned off at regular intervals of about 2 hours during the irradiation so that the conductivity in the absence of radiation could be measured. This "beam off" conductivity did not show any significant change compared to the nonirradiated values for any of the irradiation conditions studied so far. The present results indicate that significant amounts of RIED does not occur in any of the four ceramic materials during cyclotron irradiation with light ions for displacement damage levels up to about $5 \times 10^{-3} \mathrm{dpa}$.

Figure 6 compares the results of several studies on the effect of electron, ion, or neutron irradiation at 450 to $530^{\circ} \mathrm{C}$ on the electrical conductivity of $\mathrm{Al}_{2} \mathrm{O}_{3}[1,16,17,19,20]$. Irradiation with an applied electric field eventually produces significant RIED in all three types of irradiation spectra. However, the dose required to produce a significant permanent degradation in the electrical resistivity appears to vary considerably depending on the irradiation source. In particular, irradiation sources such as electrons which produce isolated point defects (low energy primary knock-on atoms, PKAs) and have high ionizing to displacive radiation ratios appear to exhibit accelerated RIED kinetics compared to fission neutrons. A similar large dependence on irradiation spectrum is evident when the RIED results are plotted versus absorbed ionizing radiation dose (Gy). According to the results by Pells [19], significant $\mathrm{RIED}$ begins to occur in $\mathrm{Al}_{2} \mathrm{O}_{3}$ during light ion irradiation for displacement damage levels greater than about $5 \times 10^{-3} \mathrm{dpa}$.

This is equal to the maximum dose obtained in our cyclotron studies so far, and may explain why we have not yet observed measureable amounts of RIED. 
Table 1. Irradiation conditions for the in-situ electrical conductivity experiments. The beam currents were maintained at 0.06 to $0.1 \mathrm{~A} / \mathrm{m}^{2}$ for all irradiations. Two of the $28 \mathrm{MeV} \mathrm{He}+\mathrm{He}^{++}$ion irradiations were performed using multiple temperatures and/or electric fields, as indicated.

\begin{tabular}{|c|c|c|c|c|}
\hline Material & Ion & Electric Field & Temperatures & Dose \\
\hline $\mathrm{MgAl}_{2} \mathrm{O}_{4}$ & $28 \mathrm{MeV} \mathrm{He}++$ & $100 \mathrm{~V} / \mathrm{mm}$ & $\begin{array}{l}275^{\circ} \mathrm{C} \\
+150^{\circ} \mathrm{C}\end{array}$ & $\begin{array}{l}1 \times 10^{-3} \mathrm{dpa} \\
+1 \times 10^{-3} \mathrm{dpa}\end{array}$ \\
\hline $\begin{array}{l}\mathrm{MgAl}_{2} \mathrm{O}_{4}, \mathrm{Al}_{2} \mathrm{O}_{3}, \\
\mathrm{AIN}, \mathrm{Si}_{3} \mathrm{~N}_{4}\end{array}$ & $28 \mathrm{MeV} \mathrm{He}^{++}$ & $100 \mathrm{~V} / \mathrm{mm}$ & $590^{\circ} \mathrm{C}$ & $4 \times 10^{-3} \mathrm{dpa}$ \\
\hline $\begin{array}{l}\mathrm{MgAl}_{2} \mathrm{O}_{4}, \mathrm{Al}_{2} \mathrm{O}_{3} \\
\mathrm{AlN}, \mathrm{Si}_{3} \mathrm{~N}_{4}\end{array}$ & $28 \mathrm{MeV} \mathrm{He}^{++}$ & $\begin{array}{l}100 \mathrm{~V} / \mathrm{mm} \\
+500 \mathrm{~V} / \mathrm{mm} \\
+500 \mathrm{~V} / \mathrm{mm}\end{array}$ & $\begin{array}{l}500^{\circ} \mathrm{C} \\
+500^{\circ} \mathrm{C} \\
+600^{\circ} \mathrm{C}\end{array}$ & $\begin{array}{l}5 \times 10^{-3} \mathrm{dpa} \\
+1 \times 10^{-3} \mathrm{dpa} \\
+1 \times 10^{-3} \mathrm{dpa}\end{array}$ \\
\hline $\begin{array}{l}\mathrm{MgAl}_{2} \mathrm{O}_{4}, \mathrm{Al}_{2} \mathrm{O}_{3} \\
\mathrm{AIN}, \mathrm{Si}_{3} \mathrm{~N}_{4}\end{array}$ & $20 \mathrm{MeV} \mathrm{H}^{+}$ & $500 \mathrm{~V} / \mathrm{mm}$ & $500^{\circ} \mathrm{C}$ & $3 \times 10^{-3} \mathrm{dpa}$ \\
\hline
\end{tabular}

OHIII IIW (392M 1.'12:211

EFFECT OF EXTENDED IRRADIATION WITH AN APPLIED ELECTRIC FIELD ON THE CONDUCTIVITY OF $\mathrm{Al}_{2} \mathrm{O}_{3}$

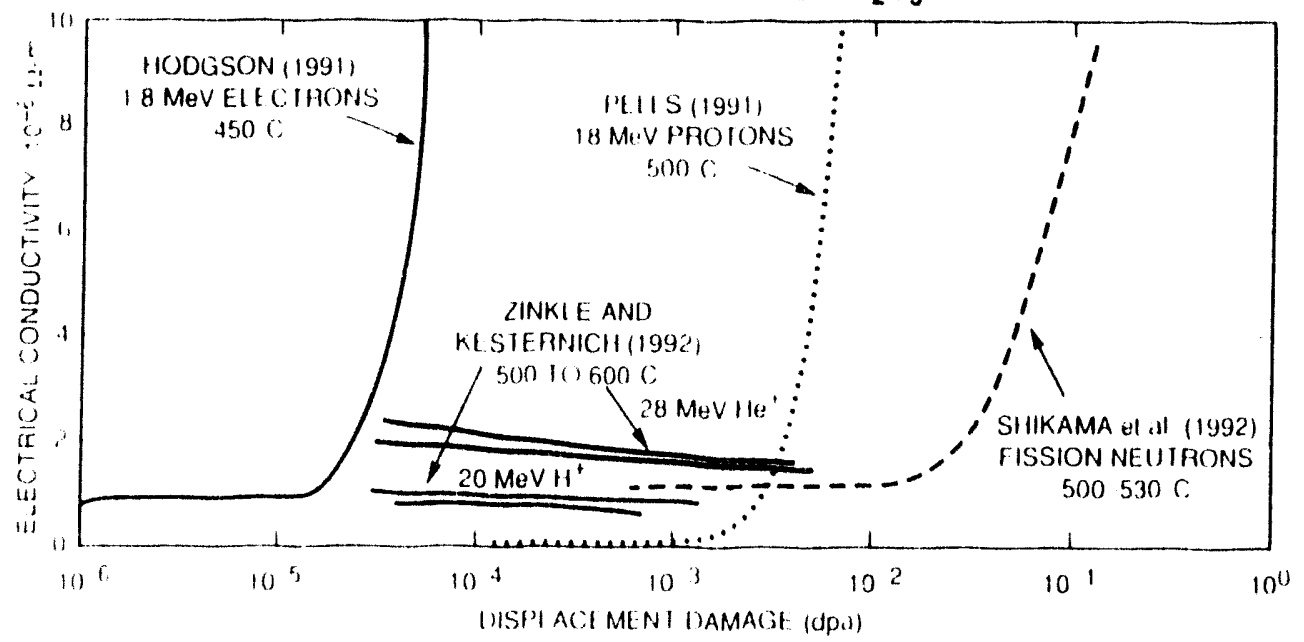

Fig. 6. Effect of extended irradiation with an applied electric field on the electrical conductivity of $\mathrm{Al}_{2} \mathrm{O}_{3}$ $[1,16,17,19,20]$. The data by Pells was obtained while the ion heam was turned off, whereas the data shown from the other studies was taken during irradiation.

Transmission electron microscopy was used to investigate the microstructure of one of the $\mathrm{MgAl}_{2} \mathrm{O}_{4}$ specimens irradiated with $28 \mathrm{MeV} \mathrm{He}^{+}$ions at $300^{\circ} \mathrm{C}$ to a damage level of about $1 \times 10^{-3} \mathrm{dpa}$. There was no 
evidence of observable ( $>2 \mathrm{~nm}$ diameter) colloids or other defect clusters. We are planning to perform higher dose irradiations at the Juelich cyclotron to further investigate the RIED behavior of ceramics. Microstructural analysis of additional ceramic specimens irradiated with $28 \mathrm{MeV} \mathrm{He}^{++}$ions to damage levels of about $5 \times 10^{-3} \mathrm{dpa}$ is in progress.

Recent microstructural observations on oxide ceramics irradiated with a wide range of different ions have found similar evidence for a strong spectral effect on the microstructural evolution [29]. A useful parameter for correlating the microstructural response with irradiation spectrum was found to be the ratio of ionizing to displacive radiation, $S_{e} / S_{d}$, where $S_{e}$ is the electronic component of the stopping power and $S_{d}$ is the nuclear (atomic displacements) component of the stopping power. The microstructural observations indicate that highly ionizing radiation environments greatly enhance defect mobilities. This ionization enhanced diffusion mechanism may explain why irradiation sources such as electrons that have high ratios of $S_{e} / S_{d}$ exhibit accelerated RIED kinetics compared to neutron irradiation sources. The ratio of $\mathrm{S}_{e} / \mathrm{S}_{d}$ in $\mathrm{Al}_{2} \mathrm{O}_{3}$ is about 10,000 for $1.8 \mathrm{MeV}$ electrons, 4000 for $20 \mathrm{MeV}$ protons, and about 100 for mixed spectrum fission neutrons [30]. The calculated ratio of $S_{\mathfrak{e}} / S_{d}$ appropriate for ceramics in a fusion reactor depends on their location. At the first wall, this ratio for $\mathrm{Al}_{2} \mathrm{O}_{3}$ is about 20. The corresponding ratio at depths further away from the plasma depends strongly on the particular choice of coolant and blanket/shielding material in a fusion reactor. Typical ratios of $S_{e} / S_{d}$ for ceramics at the superconducting magnets vary from 40 to 350 , depending on the coolant and blanket/shield material [30].

\section{ACKNOWLEDGEMENTS}

Experimental assistance for this project was provided by W. Schmitz, H. Klein and J. Deutz at Forschungszentrum Jülich.

\section{FUTURE WORK}

Specimens will be irradiated with $28 \mathrm{MeV} \mathrm{He}{ }^{++}$ions to damage levels in excess of $0.01 \mathrm{dpa}$ in an attempt to initiate RIED. This future work will be part of the thesis research of F. Scheuermann. The microstructure of the ceramic specimens will be analyzed by analytical electron microscopy to investigate the possibility of colloid formation.

\section{REFERENCES}

1. S.J. Zinkle and E.R. Hodgson, J. Nucl. Mater. $191-194$ (1992) 58.

2. F.W. Clinard, Jr., J. Nucl. Mater. 85\&86 (1979) 393.

3. J.L. Scott, F.W. Clinard, Jr. and F.W. Wiffen, J. Nucl. Mater. $133 \& 134$ (1985) 156.

4. W.C. Roentgen and A. Joffe, Ann. Physik 41 (1913) 449; 64(19^1)1.

5. R. Hofstadter, Nucleonics 4 (1949) 2.

6. A. Rose, Phys. Rev. 97 (1955) 1538. 
7. V.A.J. van Lint, T.M. Flanagan, R.E. Leadon, J.A. Nabor, and V.C. Rogers, Mechanisms of Radiation Effects in Electronic Materials, Vol. 1 (Wiley and Sons, New York, 1980).

8. E.H. Farnum, J.C. Kennedy, F.W. Clinard and H.M. Frost, J. Nucl. Mater. 191-194 (1992) 548.

9. A.E. Hughes, Rad. Effects 74 (1983) 57.

10. R.W. Klaffky, B.H. Rose, A.N. Goland and G.J. Dienes, Phys. Rev. B 21 (1980) 3610.

11. E.R. Hodgson and S. Clement, Rad. Effects 97 (1986) 251.

12. G.P. Pells, Rad. Effects 97 (1986) 199.

13. V.A.J. van Lint, J.W. Harrity and T.M. Flanagan, IEEE Trans. on Nucl. Science, Vol. NS-15, No. 6 (1968) 194

14. G.P. Pells, J. Nucl. Mater. 184 (1991) 183.

15. V.M. Ivanov, G.M. Kalinin, V.F. Kuzovitkin, S.P. Sklizkov, N.V. Markina, V.V. Sarksyan, and V.A. Skobeleva, Inorganic Mater, 17 (1981) 1203.

16. E.R. Hodgson, Cryst. Latt. Def. Amorph. Mater. 18 (1989) 169.

17. E.R. Hodgson, J. Nucl. Mater. 179-181 (1991) 383.

18. E.R. Hodgson, J. Nucl. Mater. 191-194 (1992) 552.

19. G.P. Pells, J. Nucl. Mater. 184 (1991) 177.

20. T. Shikama, M. Narui, Y. Endo, T. Sagawa, and H. Kayano, J. Nucl. Mater. 191-194 (1992) 575.

21. E.H. Farnum, private comm. (LASREF irradiation of $\mathrm{Al}_{2} \mathrm{O}_{3}$ ).

22. E.R. Hodgson, Rad. Eff. Def. Solids 119-121 (1991) 827.

23. R.W. Klaffky, in Special Purpose Materials Ann. Prog. Rep., DOE/ER-0048/1 (U.S. Dept. of Energy, Washington D.C., 1980) p. 19.

24. J.F. Ziegler, J.P. Biersack and U.L. Litunark, The Stopping and Range of lons in Solids (Pergamon Press, New York, 1985).

25. G.P. Pells and A.Y. Stathopoulos, Rad. Effects 74 (1983) 181.

26. P. Agnew, Phil. Mag. A 65 (1992) 355.

27. M.J. Norgett, M.T. Robinson and I.M. Torrens, Nucl. Eng. Des. 33 (1975) 50.

28. ASTM Standard Test Methods for DC Resistance or Conductance of Insulating Materials, D-257-91.

29. S.J. Zinkle, Fusion Reactor Materials Semiann. Prog. Rep. ending March 31, 1993, DOE/ER-0313/14.

30. S.J. Zinkle and L.R. Greenwood, Fusion Reactor Materials Semiann. Prog. Rep. ending March 31, 1993 , DOE/ER-0313/14. 
:RAOIATION OF MgAl O SPINEL IN FFTF-MOTA - F. A. Garner, and G. W. Hollenberg (Pacific Northwest inoratory)". C. A. Black and R. C. Bradt (University of Nevada-Reno)

\section{DJECTIVE}

The objective of this effort is to determine the response of $\mathrm{MgAl}_{2} \mathrm{O}_{4}$ spinel to high fluence neutron rradiation at elevated temperatures.

SJMMARY

" 9 Al 0 , spinel specimens irradiated in FFTF-MOTA at temperatures between 385 and $750 . \mathrm{C}$ to fluences ranging from 2.2 to $24.9 \times 10^{42} \mathrm{ncm}^{-2}$ (E>0.1 MeV) darken significantly, but do not develop any loss in weight or cnange in dimensions. Measurements of knoop hardness and its dependence on crystalline orientation, neutron fluence and irradiation temperature are in progress. Messurements of elastic properties are also nearing completion.

\section{STATUS AND ACCOMPLISHMENTS}

\section{introduction}

"agnesium aluminate spirel is an electrical insulator that has been considered as a potential fusion - ractor candidate material for service as dielectric windows for radio frequency heat ing systems or as insulators for magnetic coils. [1] Previous irradiation studies have shown that the dimensional stability of this material is remarkably insensitive to neutron damage at exposures up to $2 \times 10^{i i} \mathrm{n} / \mathrm{cm}^{2} .[2-5]$

Since 1985, Pacific Northwest Laboratory has been conducting a collaborative project with Professor R. C. Sradt (University of Nevada-Reno), involving irradiation in FFTF/MOTA of very high purity MgAl, $0_{4}$ spinel (see Table 1). The various irradiation sequences are now complete and analysis of the specimens is in progress.

\section{Experimental Details}

Three specimen types and two specimen geometries are empioyed in this experiment. The three types are hot pressed (HP) polycrystals at 100\% of theoretical density, (100)-oriented single crystals and (111)-oriented single crystals. Both of the latter are oriented with the specified crystalline direction in the axial or height direction of the specimen. Most of the specimens are in the form of $-0.19^{\prime \prime}(4.8 \mathrm{~mm})$ diameter cyindrical pellets. The height of the pellets varies with specimen type, as shown in $\mathrm{Fiqure} 1$. The naights were $-0.23 "(5.8 \mathrm{~mm})$ for HP, $\sim 0.17 "(4.3 \mathrm{~mm})$ for $(111)$ and $\sim 0.11 "(2.8 \mathrm{~mm})$ for $(100)$-oriented specrmens.

The other specimen geometry is in the form of $\sim 0.5^{\prime \prime}(12.7 \mathrm{~mm})$ sauare plates with thicknesses comparable to : hose of the heights of the pellet specimens. The plates were produced by diamond parallel surface irinding, and the pellets by diamond core drilling of the plate material. Laser etching was employed to ark the circumference of the pellets and the side of the squares with an individual identification code.

$\cdots$ or to irradiation the specimens were weighed and their dimensions measured to 0.0001 inches using a 2 Y 60 $\therefore$ Laser Telemetric System. Diameters of the pellets were measured using the average of three - nasurements at three orientations approximately $60^{*}$ apart on the pellets. The height of the plates was tetermined by averaging six measurements across both diagonals of the square plates. The specimens were - hen ultrasunically washed in distilled water, air dried, ultrasonically washed in ethyl alcohol and then trind in air at $200^{\circ} \mathrm{C}$ for 24 hours before being sealed in a hermetic storage container to remove adsorbed ator

- a cecimens were later removed from the storage container and placed in irradiation capsules filled with 11.um gas at $1 \mathrm{~atm}$ and room temperature. Each capsule was closed by electron beam welding under helium at then heilum leak checked. The capsules were constructed of D titanium-modified steel. Each of the - allet-containing capsules contained a molybdenum spring and five specimens; specificaily, one HP specimen ind two each of the single crystal types, as shown in figure 1.

Pacific Northwest Laboratory is operated for the U.S. Department of Energy by Battelle Memorial intitute under Contract DE-ACO6-76RLL 1830. 
Table 1 Chemical Composition* of Spinel Specimens (appm) Determined by Spectrographic Analys is

\begin{tabular}{|c|c|c|c|}
\hline & $100 * \star$ & 111 & HP \\
\hline $\mathrm{Li}$ & 0.01 & 0.1 & $>50$ \\
\hline B & 0.3 & $<0.1$ & $<0.1$ \\
\hline $\mathrm{Na}$ & 5 & 5 & 5 \\
\hline Si & 600 & 660 & 60 \\
\hline$P$ & 1 & 0.5 & 10 \\
\hline$S$ & 90 & 90 & 300 \\
\hline Cl & 10 & 10 & 10 \\
\hline$k$ & $<10$ & $<10$ & $<10$ \\
\hline $\mathrm{Ca}$ & 10 & 40 & 10 \\
\hline Sc & 10 & 10 & 30 \\
\hline $\mathrm{Ti}$ & 10 & 10 & 40 \\
\hline v & 3 & 3 & 8 \\
\hline $\mathrm{Cr}$ & 4 & 10 & 4 \\
\hline$M n$ & 5 & $<2$ & $<2$ \\
\hline $\mathrm{Fe}$ & 80 & 30 & 30 \\
\hline $\mathrm{Co}$ & 0.2 & $<0.2$ & 0.2 \\
\hline $\mathrm{Ni}$ & 1 & 1 & 1 \\
\hline $\mathrm{Cu}$ & 3 & 1 & $<0.3$ \\
\hline $\mathrm{Ga}$ & 9 & 30 & 3 \\
\hline $\mathrm{Ge}$ & 10 & 4 & $<4$ \\
\hline 40 & 7 & $\therefore 2$ & 2 \\
\hline Sn & $\measuredangle 2$ & 22 & $\therefore 2$ \\
\hline
\end{tabular}

* Najor constituents determined by stoicniometry derived from $x$ - pav gif-rac:ion to be 37.9 wt \% a luminum. $45.0 \mathrm{wt} \%$ oxygen and $17.1 \mathrm{wt} \%$ magnes ium

**Specimen type

the nominal irradiation conditions experienced by the pellets in the ffT roactor were

$205^{\circ} \mathrm{C}, 22.9$ and $24.9 \times 10^{\circ \mathrm{n}} \mathrm{n} / \mathrm{Cm}$ (E $\left.>0.1 \mathrm{MeV}\right)$.

$\therefore 05: 5.5 .3 \times 10 \mathrm{n} \mathrm{cm}$.

$50.05 .5 .: 2.7$ and $21.7 \times 10 \% \mathrm{n} \mathrm{cm}^{\circ}$.

$\therefore$ amphasis on nominal irradiation conditions reflects the fact that these specimens started irradiation - YTA.10. In which the spocimens experienced an overtemperature event in the middie of FfFF cycle 7 of - :0 -inutes duration. followed by a prolonged and variable undertemperature history in cycle 8 . Only the S.r. rradiation experienced a significant variation in temperature. however. reaching $934^{\circ} \mathrm{C}$ for 50 - nutes and then running at a range of temperatures well below $750^{\circ} \mathrm{C}$ throughout crcie 8 . For the second a thir irradiation sequences conqucted in FFTF cycles 9. 10. and 11 in MOTA-1E.: and 1G. respectively, a : omperatures were neld to $\pm 5 \cdot \mathrm{C}$ of the target temperature.

- satuare plate specimens were irradiated in larger 0-9 capsules placed in the below-rore canister at $\vdots 5:$ ? and irradiated to 1.8 .2 .2 and $4.5,10^{\circ} \mathrm{n} / \mathrm{cm} \quad(\varepsilon>0.1 \mathrm{MeV})$. The spinel specimens were placed in the disule with many other high heat flux srecimens. some of which melted and/or decomposed during

‥tilation. The $1.8 \times 10^{\circ} \mathrm{nm}$ oecimens were beiow the decomposed materials and dit not survive the wation 
After irradiation, the specimens were removed from the capsules, cleaned, and their weights and dimensions measured using the same techniques employed prior to irradiation.

\section{Resuits}

Due to their high purity, the specimens were only mildly radioactive and could be easily handled. Prior to irradiation, the single crystal specimens were transparent and the hot-pressed specimens were white. In regular light the irradiated specimens all appear to be very dark, as shown in Figure 2 , but placing them in front of a strong lamp showed that some light was transmitted, with colors ranging from yellow to dark red.

The weights of the specimens remained essentially unchanged, with all measurements ranging from 0.0 to $-0.2 \%$ loss in weight. The loss, if any, was always in the fourth significant figure and may be related either to different levels of adsorbed moisture before and after irradiation or to small chips lost during handling.

All post-irradiation measurements fell within $\pm 1 \%$ of the preirradiation measurements, with most below $\pm 0.5 \%$. Combining the point-to-point variations observed in thickness and the reproducibility of the measurements, it appears that the measured variations in preirradiation dimensions should be $\leq 1 \%$. There were no discernible trends of these small differences with respect to orientation, irradiation temperature, neutron fluence or specimen type. The obvious conclusion is that no significant irradiation-induced changes occurred in the dimensions of these specimens.

Measurements at room temperature of the orientation dependence of microhardness on the, jrradiated specimens are proceeding for comparison with measurements made earlier on unirradiated specimens. ${ }^{5}$. In the unirradiated condition, the (100) plane exhibits a maximum microhardness in the [001] direction and a minimum in the [011] direction, consistent with a primary slip system of $(111)\langle 110\rangle$. The microhardness of the (111) plane is independent of indenter orientation, also consistent with such a primary slip system. With increasing irradiation, the hardness increases somewhat and the orientation dependence tends to disappear, as the primary slip system becomes blocked.

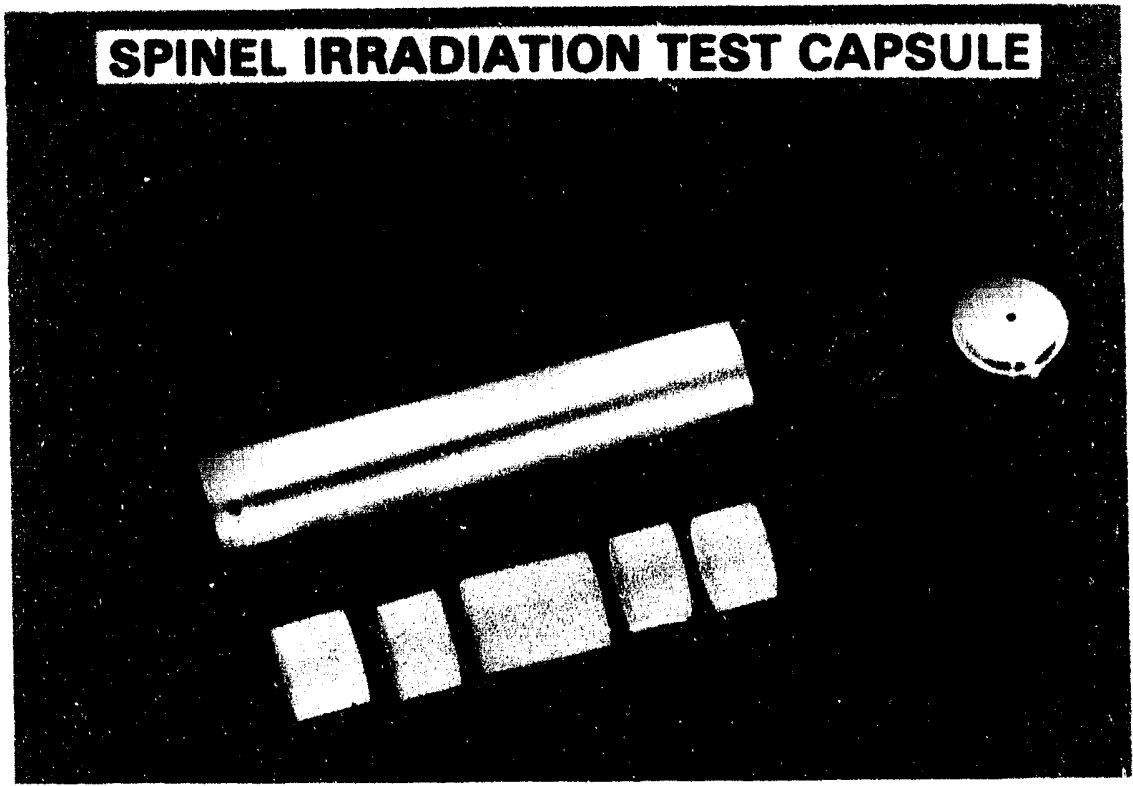

Fig. 1. Contents of typical irradiation capsule for pellet specimens. 


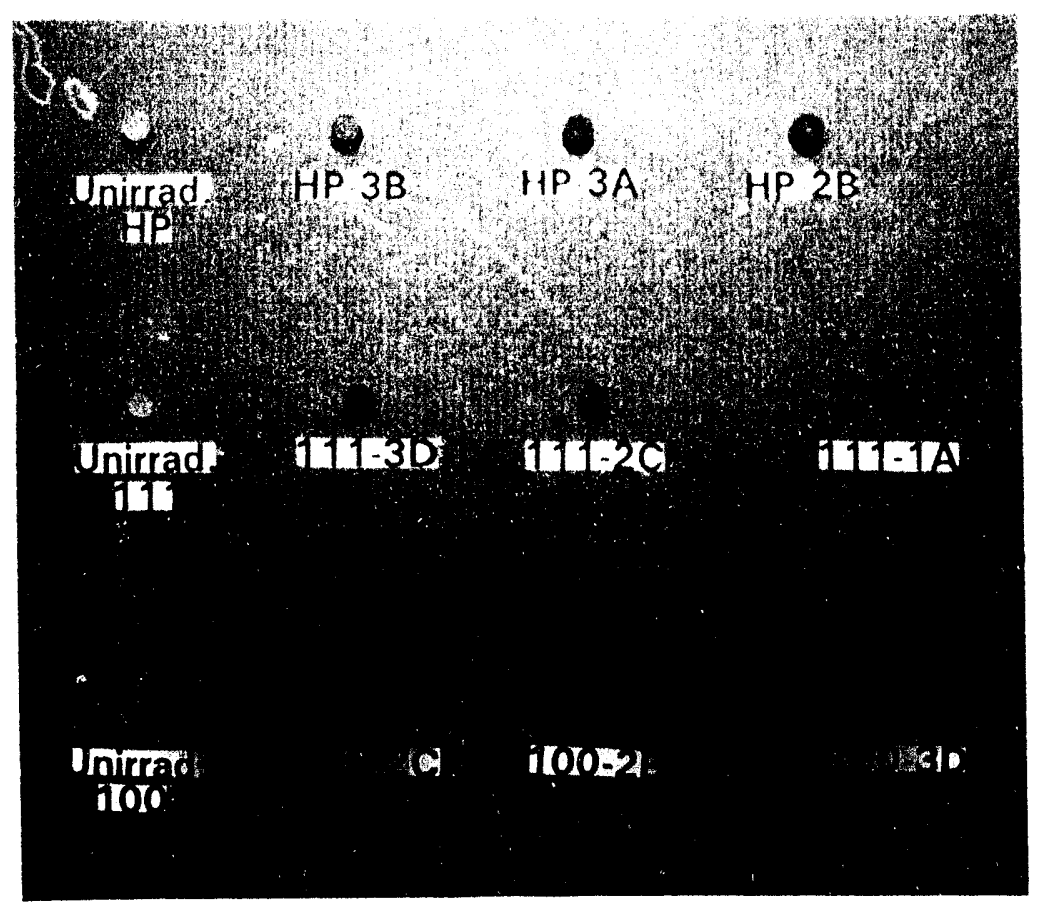

Fig. 2. Comparison of specimen appearance before and after irradiation at $750^{\circ} \mathrm{C}$. Exposure levels increase from left to right $\left(0,5.6,13.7\right.$ and $21.7 \times 10^{22} \mathrm{n} \mathrm{cm}^{2} \quad(E>0.1 \mathrm{MeV})$.

\section{Euture Efforts}

When hardness measurements are complete these specimens will be divided into a number of groups and shipped to other researchers for a variety of initially non-destructive and finally destructive measurements.

The types of examinations currently planned are as follows:

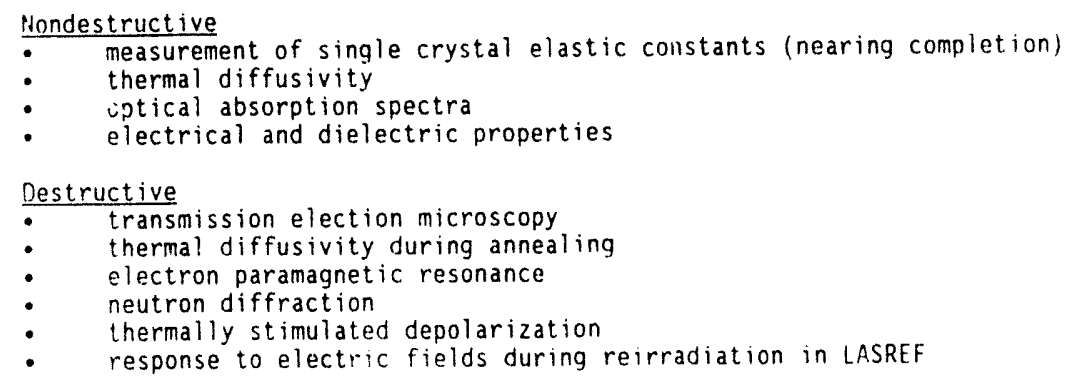

References

1) F.W. Clinard, Jr., G.F. Hurley and R.W. Klaffky, Res. Mech. 8 (1983) 207.

2) G.F. Hurley and J.M. Bunch. Am. Ceram. Soc. Bull. $59(1980) 456$

3) F.W. Clinard, Jr., G.F. Hurley and L.W. Hobbs, J. Nucl. Mater. 108-109 (1982) 655

4) Y. Fukushima, Y Yano. T. Maruyama and T. Iseki. J. Nucl. Mater. 175 (1990) 203.

5) H. Suematsu, T. Iseki, T, Yano, H. Saito, T. Suzuki and T. Mori, J. Am. Ceram. Soc. 75 (1992)

6) Y. Akimuni and R. C. Bradt, J. Am. Cer. Soc. 70 (1987) C84-C86. 
HIGH-TEMPERATURE PROPERTIES OF SIC/SIC FOR FUSION APPLICATIONS - R. H. Jones and $C$. H. Henager, Jr., (Pacific Northwest Laboratory)

DBJECTIVE

The objective of this study is to evaluate the high-temperature mechanical properties of SiC/SiC composite materials for fusion structural applications.

SUMMARY

SiC/SiC composites exhibit novel mechanical properties relative to their monolithic counterparts. The crack velocity (da/dt) versus stress intensity $(K)$ relationship for monolithic ceramics can be described by a simple power law relationship where SiC/SiC was found to exhibit a multi-stage da-dt versus $K$ relationship similar to that for stress corrosion of metals. A $K$ independent stage II was followed by a strongly $K$ dependent stage III which paralleled the monolithic behavior. Experiments to determine the threshold $K$ or stage I were not conducted; however, it is expected that they exist for these materials. There is also evidence that the fracture resistance of these materials is greater if cracks are produced by subcritical growth processes relative to machined notches. Oxygen was found to increase da/dt and decrease the $K$ for the stage II to stage III transition while cyclic loads produced little damage at low $K$ values but there was some evidence for increasing damage with increasing number of cycles and $\mathrm{K}$.

\section{PROGRESS AND STATUS}

\section{Experimental Procedures}

Composites consisting of Nicalon fiber cloth $\left(0 \% / 90^{\circ}\right)$ and $C V I \beta-S i C$ with carbon (C) interfaces were tested. The composites are 8-ply material, $4 \mathrm{~mm}$ thick, fabricated by Refractory Composites, Inc. of Whittier, CA. Interfaces of $1.0 \mu \mathrm{m} C$ were deposited on the Nicalon fibers before the $\beta-S i C$ CVI fabrication step. Singleedge-notched bend bar (SENB) specimens with dimensions of $4 \mathrm{~mm} \times 5.5 \mathrm{~mm} \times 50 \mathrm{~mm}$ were prepared. The SENB specimens were tested in 4-point bending using a fully articulated SiC bend fixture. Other test details have been discussed previously $(1,2)$.

The subcritical crack growth $(S C G)$ studies were performed using constant load tests for times up to $7 \times 10^{4}$ $s$, and using stepped load tests with load holding carried out at $1100^{\circ} \mathrm{C}$ in $\mathrm{Ar}$ and $\mathrm{Ar}$ plus varying $\mathrm{PO}_{2}$. The specimens were typically loaded at an applied stress intensity of $7-8 \mathrm{MPa}$ m to begin the test. The test continued until a load drop was observed. Specimens that were tested in Ar plus 0 . were brought up to temperature in pure Ar.

Each SCG test consisted of either a series of 1000 -s constant-load tests or a long-term hold at constant load in 4-point bending at a constant temperature. The displacement-time curves for the 1000-s exposures at constant load in Ar indicate that the specimen displacement, and thus the crack opening displacement. undergoes a transient period of displacement that is logarithmic in time and does not achieve steady-state over the $1000 \mathrm{~s}$ hold time. The slope of the displacement-time curve over the final $600 \mathrm{~s}$ of the load step, however, was fairly linear and was taken as proportional to the crack velocity for each $1000-5$ period. The longer term hold displacement-time data were fit to polynomial functions and differentiated to give as/at.

Writing $\delta=P C(\alpha)$, where $\delta$ is the displacement, $P$ is the load, $C$ is the specimen mid-boint compliance, and $a$ is equal to $a / W$ (normalized crack length) can be used to give

$$
\frac{\partial \delta}{\partial t}=\frac{\partial}{\partial t}(P C(\alpha))=P \frac{\partial C}{\partial \alpha} \frac{\partial \alpha}{\partial t}=\frac{P}{\partial} \frac{\partial C}{\partial \alpha} \frac{\partial \alpha}{\partial t}
$$

which is then used to derive the following expression for $d a / d t^{\prime} V_{c}$

$$
\frac{d a}{d t}=V_{c}=\frac{\frac{\partial \delta}{\partial t} W}{P C^{\prime}(\alpha)}
$$

where $V$ is the crack velocity and $W$ is the specimen thickness. An expression was determined for the midmint compliance of a SENB specimen in 4 -point bending and was used to calculate crack length and $C^{\prime}(\alpha)$

(2). The slope of the displacement-time curve at a given load is $\partial \delta / \partial t$.

Pacific Northwest Laboratory is operated for the U.S. Department of Energy by Battelle Memorial Institute under Contract DE-ACO6-76RLO 1830. 
Fatigue crack growth tests were performed similarly to the static load subcritical crack growth tests with the load cycled 5 or 25 times at each of the constant loads used for the static load tests. The load was held for 1000 s between each load cycle and the load ratio. $R$, was 0.1 . Tests were conducted in both $A r$ and Ar plus $2000 \mathrm{ppm} 0_{2}$. The crack velocity was determined during each of the 1000 s hold periods between load cycles and compared to the crack velocity obtained with the statically loaded samples.

\section{Experimental Results}

The data for the $C$-interface materials, when plotted as crack velocity versus applied stress intensity ( $V-K$ curves), reveal a stage-lI region where the crack velocity is essentialiy independent of the applied stress intensity (Figure 1) followed by a stage-III, or power-law crack growth region, at high stress intensities.

The power-law region exhibits a strong dependence, but the stage-11 region exhibits a weak dependence, on the applied stress intensity. The data reveal a pronounced increase in stage-11 crack velocity because of 0 in the gas. The crack velocity increases with increasing $\mathrm{O}$, content of the Ar (Figure 1). A) so. the stress intensity required for the onset of stage-III is shifted to a lower value of the applied stress intensity.

When the crack velocity is plotted as a function of time ( $V$ - $t$ curves), the effects of 0 , become more pronounced (Figure 2 ). The time-dependence of $V$ in Ar shows a decreasing velocity with time while $V$ in the varying $\mathrm{PO}_{2}$ environments show either a constant $V$ or increasing $V$. with time. The curves for 10,000- and 20,000-ppm 0 , indicate that the crack velocity increases quite rapidly and that those tests were much shorter in duration than the 5000- and 2000-ppm 0, tests.

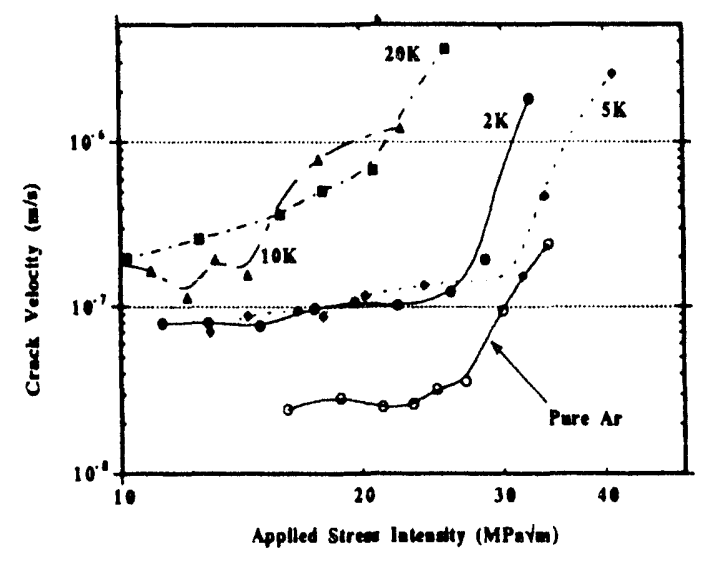

Fig. 1. V-K curves as a function of 0 , partial pressure and applied stress intensity." Curve labels indicate $\mathrm{PO}_{2}$ in units of $10^{3} \mathrm{ppm}$.

SCG data for monolithic ceramics that do not exhibit a large-scale bridging zone do not show stage-Il behavior; rather, the crack velocity is observed to be a power-law function of applied stress intensity (K.) $(3-6)$. The observed stage-II region in the present data reveals a weak dependence on $k$. This behavior suggests that SCS in CMCS is controlled by crack-bridging by the continuous f bers in the crack wake. The bridging zone screens, or shields, the crack-tip from the applied stress in:ensity. 0ver the region of increasing $k$. as a function of increasing crack length, a bridging zone is estabiished for these naterials, and it screens the crack-tip from $K$.

$A$ nearly constant crack-tip stress intensity. K. . is established as the bridging zone develops and R-curve behavior is observed. Eventually, the bridging zonesaturates and cannot continue to shield the crack-tip.

\section{Discussion and Modeling of Results}

The evidence for bridging zone domination of SCG is suggested from the experiments using Ar plus 0 . in comparison with pure Ar and also from a nicromechanical model developed to rationalize SCG in CMC materials $(1,2)$. Adding 0 , to the $1100^{\circ} \mathrm{C}$ Ar environment increases the crack velocity in the stage-II regime and shifts the stage-Il-to-stage-III transition to lower $k$. values (Figure 1). The shift to lower $k$. values for the transition to stage-III crack growth is consistent with a reduction in the closure forces imparted on the crack faces by the bridaing fibers. Scanning electron onotomicrographs (not shown here) of the CMCs ixposed to the 0 , reveal the partial removal of

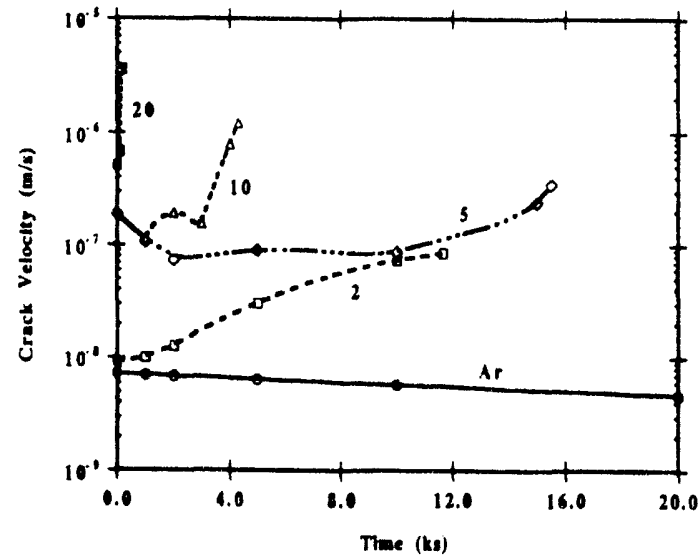

Fig. 2. Crack Velocity as a Function of Fime in Pure Ar and in Varying 0 . Partial Pressures.

the $\mathrm{C}$-interfaces due to oxidation at $1100 \mathrm{C}$. Removing this interface material roduces the shear strength of the interface, reauces the ability of the matrix to transfer load to the fibers. and reduces the s.ldging zone effectiveness. 
These effects are rationalized using a 20 -micromechanical model of a crack in a CMC material $(1,2)$. The model places a semi-infinite crack in a linear-elastic body and simulates the bridging fibers by crack closure forces placed along the crack face. The forces applied by the fibers to the crack face are calculated using an explicit frictional bridging model that calculates the fiber load transfer as a function of distance from the crack-tip. A basic result of the model is to predict crack-tip screening over a range of crack extension ( $R$-curve behavior) when high-strength fibers and weak interfaces are present $(1,2)$.

The model is used to explore the time-dependence of crack growth by allowing the crack-closure forces to undergo time-dependent relaxation. Available creep data for Nicalon fibers at $1100^{\circ} \mathrm{C}$ in pure Ar (8) were used to construct a constitutive equation for the stress-and time-dependence of creep in Nicalon fibers at $1100^{\circ} \mathrm{C}$. Based on this approach, the discrete micromechanics model is used to calculate the crack velocity using a quasi-static approach (2).

Using a definition for the stress intensity for an equilibrium bridging zone. an expression was derived for the velocity of a crack in a composite at equilibrium, which gives a quasi-static approximation to the crack velocity. For this approximation, it is assumed that the bridging zone is in equilibrium by virtue of a balance between crack advance and relaxation of bridging zone stresses. As the crack advances, it bridges additional fibers, which retards its growth. As the stresses in the bridging zone relax, the crack-tip screening is reduced, and the crack tends to advance.

The quasi-static approximation assumes that $K_{: p p}$ is a constant such that

$$
\mathrm{K}_{: i p}(a, t)=c \rightarrow a \mathrm{~K}_{i: p}=0
$$

Therefore, one can write the total differential of $k_{: . .}$as

$$
d \mathbf{K}_{t, 1 p}=\frac{\partial \mathbf{K}_{t i p}}{\partial a} d a+\frac{\partial \mathbf{K}_{t: i f}}{\partial t} d t
$$

which was used to derive an expression for crack velocity. $V_{.}$, as

$$
V_{c}=\frac{d a}{d t}=-\left|\frac{\frac{\partial K_{t i n}}{\partial t}}{\frac{\partial \mathrm{K} \cdot z}{\partial a}}\right|
$$

where the crack velocity is expressed as the ratio between the time-dependence of $k$ due to stress relaxation of bridging forces, $\mathcal{K}, / \partial t$, and the change in $k_{1}$ due to crack advance, $K_{1}$ ia. Reducing the crack-closure (fiber bridging) forces as a function of time, due to either stress relaxation in the fibers (Figure 7) or removal of the interface, allows the crack to extend during the load step. The agreement of the predicted velocities, as well as the time-dependence, suggests that fiber creep is controlling $S C G$ in the pure Ar environment at $1100^{\circ} \mathrm{C}$. Other relaxation processes, such as interface removal, would be expected to occur in 0. . This relaxation process would be faster than for fiber creep alone because the fiber/matrix interface is simultaneously being removed by oxidation. This process would reduce the fiber/matrix interfacial shear strength as a function of time. A faster stress relaxation shifts the onset of accelerated cracking (stage-III) to lower $k$ : values and increases the relative crack velocities in the stage-II region.

The crack velocity-time data in 0 . ( $F$ igure 2 ) indicates that velocities are increasing with time, which cannot be accounted for by using a logarithmic function for $k .(t)$, such as that used for fiber creep. A inearly increasing $K_{\text {.. }}(t)$ will give a constant crack velocity, while a power-law function would be required to account for increasing velocities with time. Such a result would have to come from a model of interface removal and subsequent bridging zone relaxation, which remains to be accomplished.

Fiber/matrix interfaces with improved high-temperature stability relative to $C$ are being developed by the CMC industry. Boron nitride is one such material being considered to improve the high-temperature stability. However, comparicon between SiC/SiC with BN and $C$ interfaces. Figure 1 and 3 shows little improvement. A BN interface is also not a good choice for fusion applications because of neutron activation of nitrogen and helium generation from the $B$. Carbon interfaces could have suitable long-term stability in high-purity He or liquid lithium; however, reaction with $H$ or $T$ is a major concern. The sultability of $\mathrm{SiC/SiC}$ with a carbon interface for fusion applications must be evaluated in the presence of $H$. A test in He with variable $\mathrm{H}$ partial pressures would be one method of evaluating the stability of SiC; SiC with $C$ interfaces in $H$ bearing environments. 


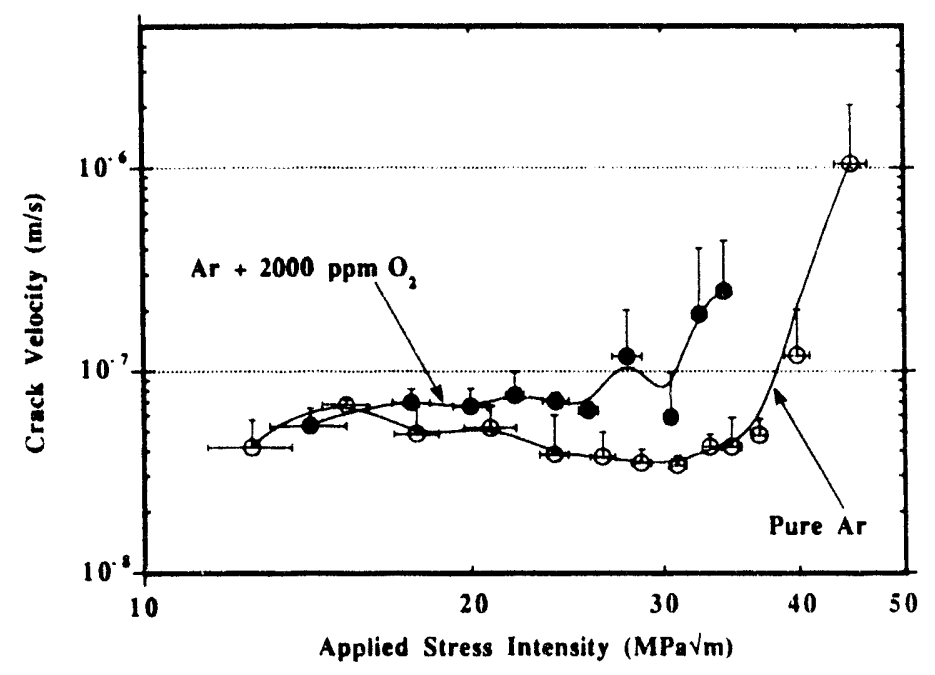

Fig. 3. Crack velocity as a function of applied stress intensity (V-K) data for BN-interface material at $1: 00^{\circ} \mathrm{C}$ in pure $\mathrm{Ar}$ and Ar plus $2000 \mathrm{ppm}$ oxygen. Data is averaged from several specimens and single-sided error bars are shown.

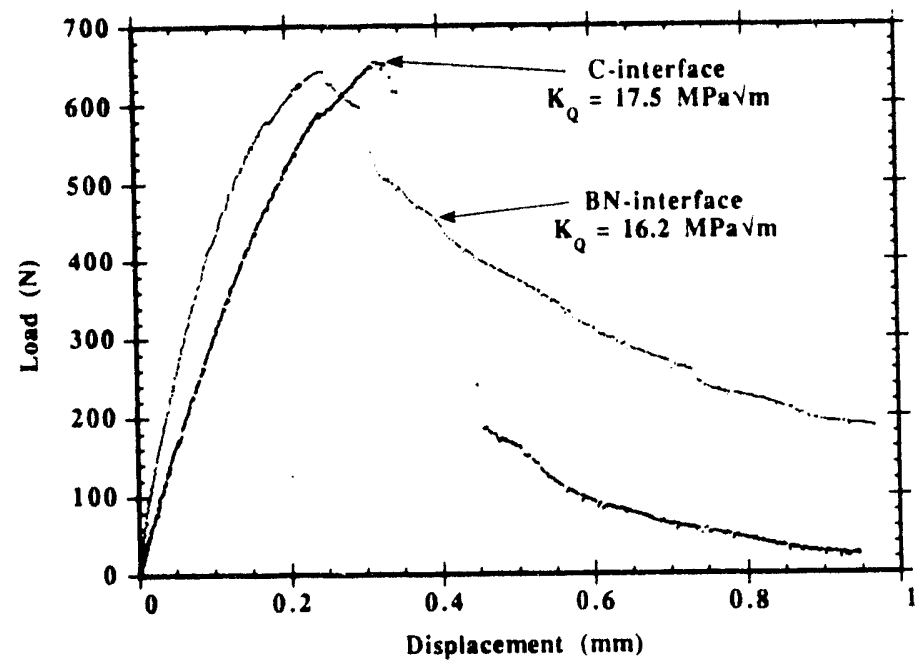

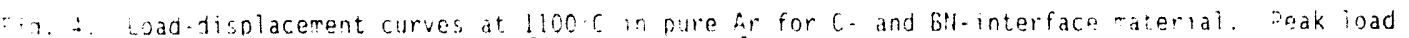

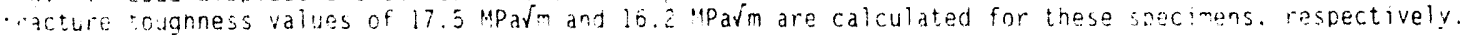


tho hign-temperature mechanical properties of sic reinforced with continuous sic c.ters axhibit novel sroperties relative to monolithic ceramics. The presence of the $k$ independent stage it is one novel aspect of the CMC material. A second is the adparent shift in $k$. for cracks produced oy subcritical growth relative to machined notches. This effect is demonstrated by comparing the transition from stage ll to stage III in Figures 1 and 3 to the fracture toughness curves shown in Figure 4 for these materials. comparison of the results in Ar show that the transition from stage II to stage III exceeds K. by a factor of almost 2 increasing from about $15 \mathrm{MPa}$ m to 27 to $30 \mathrm{MParm}$. In most materials. this transition is less than $k$. Further experimental work is in progress to verify this effect.

Further examination of the creep/fatigue data for tests conducted on Sicisic with the $C$ interface suggested that, contrary to our previous conclusion (7) that cyclic loads produced no damage. some damage may have accumulated with increasing cycles or stress-intensity. An example of this behavior is given in figure 5 where it is evident that the difference in the crack velocity following the first cycle and the tiwentiefifth cycle decreases with increasing stress intensity. Comparison of the crack velocity versus applied stress intensity for static and cyclic tests conducted in Ar. Figure 6 . may also provide evidence for fatigue damage. One cyclic test was terminated at the stage 11 to stage III transition while the second cyclic test was still in stage 11 when the test was terminated. The results srom one test suggest that crclic loads reduce the stage 11 to stage 111 transition while the other suggests no effect. Further experiments are in progress to further evaluate these effects.

\section{FIJURE DIRECTION}

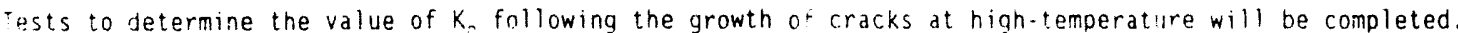
11so. further fatique tests and modeling will be completod to determine whether tension-tension cyclic stresses induce damage in these materials. The temperature dependence and oxygen reaction kinetics will be measured to determine the activation energy for crack growth and to model the environmental contribution to crack growth rates, respectively.

\section{ACKNOWLEDGEMENTS}

The assistance of $\mathrm{J}$. L. Humason in performing the crack growth experiments and Diane Forsyth for preparation of the manuscript are gratefully acknowledged. This work was supported by the office of Fusion Energy and the Office of Basic Energy Sciences of the U.S. Department of Energy under contract DE-ACO6$76 R L 01830$ with Battelle Memorial Institute which operates Pacific Northwest Laboratory for DOE.

\section{DEFERENCES}

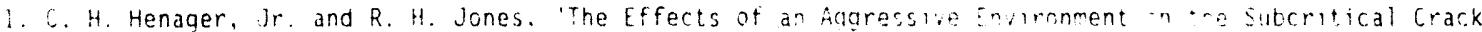

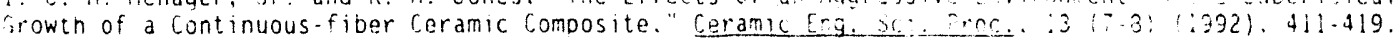

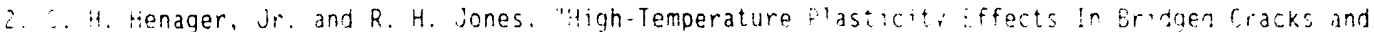
Subcriticai Crack Growtin in Ceramic Composites" (Accepted for avolication in Mater. i. and Engr.

$\therefore$ J. . Henshall. "The Mechanism and Mechanics of Subcritica" "ack Mrobation in ant-pressed Sic Above

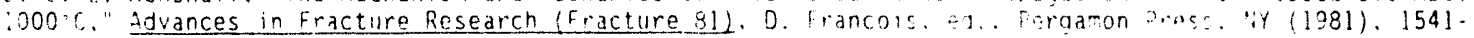
549.

4. H. Cao, B. U. Dalgleish, C. Hsueh. and A. G. Evans. "High iemerature Stress forrosion Cracking in Caramics. 3 Am. Ceram. Soc., To (1987), 257.254

5. C. H. Henayer. Jr. and R. U. Ones. Envirommental Effocts on jliw Grack Growth ir jilicon Nitride," ceramic Eng. Sci. Prnc. $9(9-10)(1988) .1525-1530$.

5. C.H. Heriager. J. and R. H. Jones. Molten Salt Corrosion of Hot-pressed Si.it. SiC.Reinforced amposites and Effects of Molten Salt Exposure on Slow Crack Growth of Hot-Pressed Si 1. ." in Corrosion and corrosive Degradation of Ceramics. Ceramic Transactions, $V .10$. R. E. Tressler and M. "illallen, eds., american Ceramics Society, Westerville. $\mathrm{OH}(1990), 197-210$.

7. R. H. Jones and C. H. Henager. Jr. "Fatique Crack Growth of Sic SiC at $1100^{\circ} \mathrm{C}^{\prime}$. In Fusion Reactor Materials Semiannual progress Report for period ending Sedember 30. 1392, D0E, ER-0313:13.

2. G. Simon and A. R. Bunsell, Ereep Eehavior and Structural Characierization at tian terderatures of

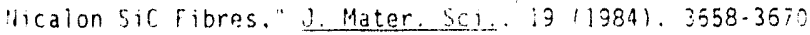



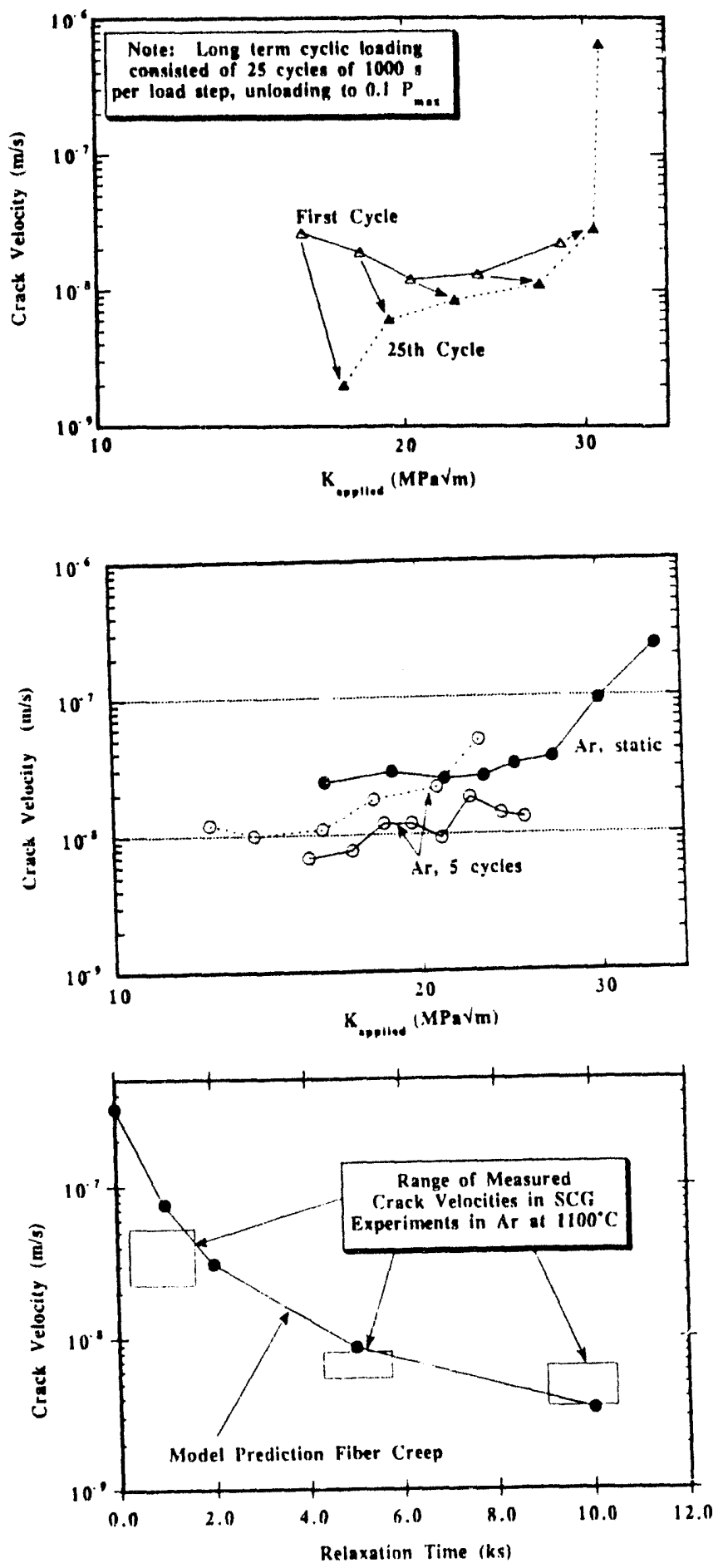

Fig. 5. Crack viocity versus stress intensity for cyclically loaded sample snowing velocity after Ist and 25 th cycle at each $k$.

Fia. b. comoarison of crack velocity. stress intens 1 .eiationships for static and colic : als

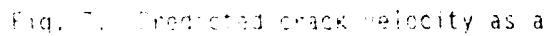
function ot …s on the iase of stress

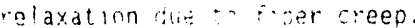


MEASUREMENT OF DC ELECTRICAL CONDUCTIVITY OF ALUMINA DURING SPALLATIONNEUTRON IRRADIATION -. E. H. Farnum, F. W. Clinard Jr., J. C. Kennedy III, W. F. Sommer and M. D. Dammeyer (Los Alamos National Laboratory)

\section{OBJECIIVE}

The objective of this experiment is to determine the extent of degradation during neutron irradiation of electrical and optical properties of candidate dielectric materials. The goals are to identify promising dielectrics for ITER and other fusion machines for diagnostic applications and establish the basis for optimization of candidate materials.

\section{SUMMARY}

An irradiation experiment was carried out during the summer of 1992 at the Los Alamos Spallation Radiation Effects Facility (LASREF). In situ measurements of electrical conductivity in alumina, sapphire and mineral-insulated electrical cables were made at $640^{\circ} \mathrm{C}, 590^{\circ} \mathrm{C}$ and $400^{\circ} \mathrm{C}$. Both $\mathrm{DC}$ and $\mathrm{AC}(100 \mathrm{~Hz}$ to $1 \mathrm{MHz})$ measurements were made to a fluence of approximately $3 \times 10^{23} \mathrm{n} / \mathrm{m}^{2}$. Optical absorption from $200 \mathrm{~nm}$ to $800 \mathrm{~nm}$ was measured in pure silica- and OH-doped silica-core optical fibers during the irradiation. A large number of passive samples were included in the irradiation, some at the furnace temperatures and some at ambient temperature. This report describes preliminary analysis of the $\mathrm{DC}$ conductivity measurements. The $\mathrm{AC}$ measurements are analyzed in the companion report. All samples are being recovered for post-irradiation examination as this report is being written in May, 1993. Final analysis of the conductivity data awaits the results of measured fluence from activation foils and will be published at ICFRM-6.

\section{PROGRESS AND STATUS}

The basic description of the experiment was reported in the last progress report (April 92 through September 92).

\section{Furnace Temperature}

Each furnace had three type $\mathrm{K}$ thermocouples. These were located near the top, center and bottom of the heated zone. The top and bottom thermocouples were located radially about half-way between the axis and wall, and the center thermocouple was located on the axis. The temperature was controlled (held at a constant set point) using the center thermocouple and the other two temperatures were recorded continuously during the experiment. Because of gamma and neutron heating, the furnace temperature profile changed slightly from the beam-on condition, in which most power was supplied by the radiation, and the beam-off condition, in which all the power was supplied by the furnace heater. Fig. 1 shows a twodimensional furnace layout with the two AC capsules on the right and the DC capsule with layered samples on the left. The temperature of the three thermocouples for each of the three furnaces, A, B and C, are plotted versus axial furnace position. This furnace temperature profile was used to obtain a better estimate of the temperature of the samples. From this, our best-estimate temperature of the three $\mathrm{DC}$ conductivity capsules when the beam was on at high power was $655^{\circ} \mathrm{C}, 615^{\circ} \mathrm{C}$ and $395^{\circ} \mathrm{C}$, all $\pm 5^{\circ} \mathrm{C}$.

The furnace temperatures were initially set $10300^{\circ} \mathrm{C}, 400^{\circ} \mathrm{C}$ and $500^{\circ} \mathrm{C}$. Early in the experiment, when the beam power was low, these temperatures were held. However, when the beam power was increased, the temperatures increased to their final values and the control points were adjusted to maintain constant temperature (within $10^{\circ} \mathrm{C}$ ) with beam on and off. The temperature history of the furnaces during the early part of the experiment is shown in Fig. 2. Only the top thermocouple for the three furnaces is plotted in this figure. The fourth plot is a thermocouple in the temperature-uncontrolled capsule containing passive samples, labeled Clinard. The temperature of this capsule is directly related to neutron flux. 

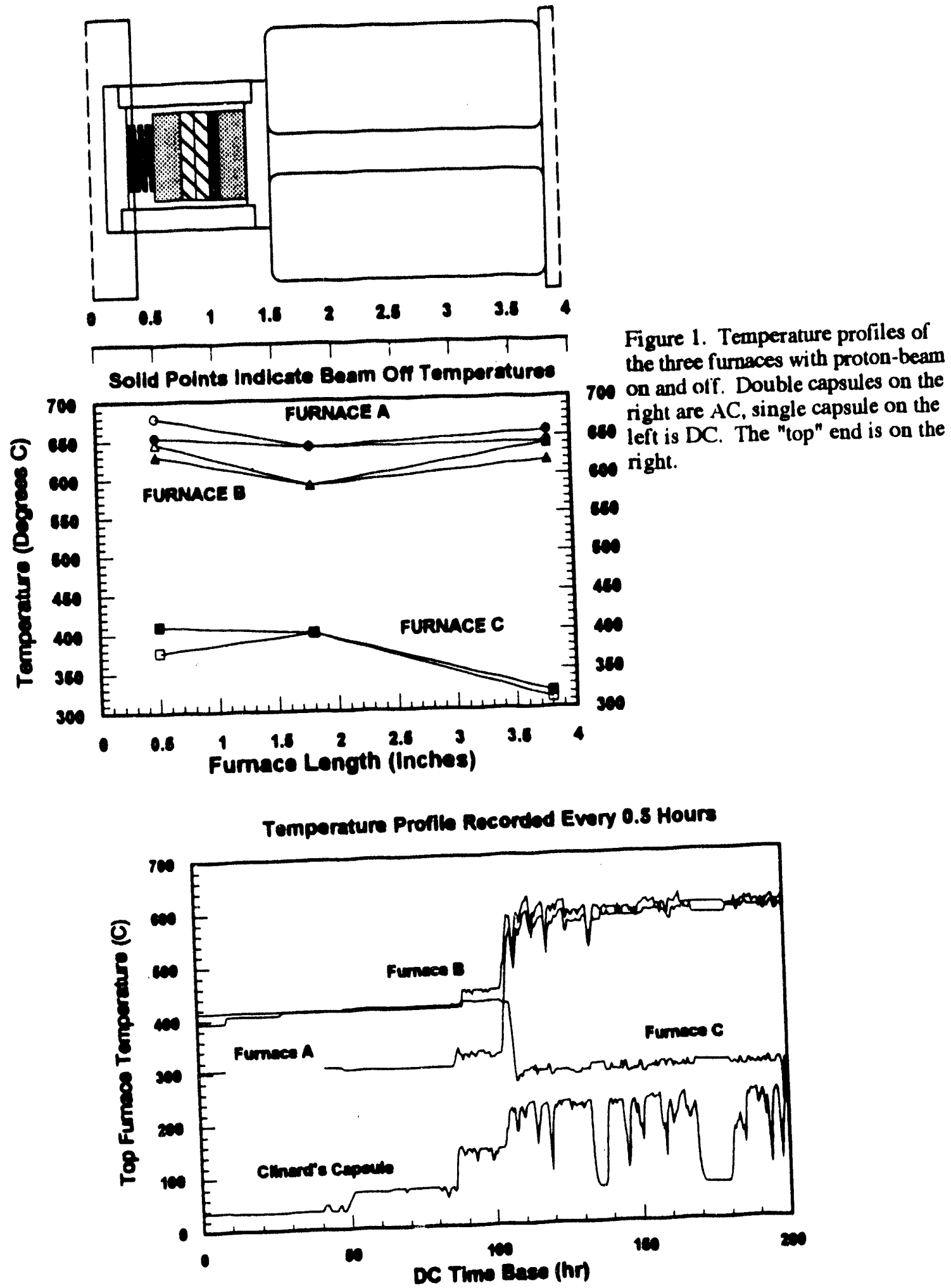

Figure 2. Temperature history of the top thermocouple in each furnace versus estimated fluence early in the experiment. 


\section{The DC electrical measurements}

Each furnace held one DC capsule that was open to the argon furnace atmosphere. Each DC capsule contained two 1-mm-thick and two 3-mm-thick, 1.9-cm-diameter alumina disks. The disks were stacked with interieaved electrodes such that disks of equal thickness were electrically parallel. An applied DC voltage of $150 \mathrm{~V}$ caused an electric field of $500 \mathrm{v} / \mathrm{cm}$ on the thick disks and $1500 \mathrm{~V} / \mathrm{cm}$ on the thin disks. This voltage was applied continuously during the experiment. The alumina disks are part of the IEA roundrobin 99.5 Wesgo alumina purchased by R. Stoller at ORNL. Each DC capsule bad four electrodes, the high-voltage input, a thin-disk output, a thick-disk output, and a "dummy" output that entered the capsule and hung down beside the samples but was not connected to any disks. The dummy electrode, placed closer to the high-voltage electrode than either of the other output electrodes, was intended to measure the maximum contribution to the sample current from gas and surface conduction. The three "output" electrodes and one MgO-insulated cable in each furmace were scanned continuously with a computercontrolled switch and pico-ammeter, and sample current, time and proton-beam current were, digitized and archived. Fig. 3 shows sample current versus estimated fluence for a sample electrode (furnace A thick samples) and a dummy electrode in the same furnace. Because of the small contribution, dummy electrode currents were not subtracted from sample currents in calculating conductivity.

During the experiment, the proton beam current was changed a number of times. This caused proportional changes in neutron flux, that in turn caused changes in the DC conductivity. The effect of these changes can be seen in Fig. 4. The DC conductivity is plotled versus estimated fluence for both proton-beam-on and beam-off condition. The flux was estimated from previous activation foil measurements and also from the temperature of the Clinard capsule as shown in Fig. 2. Using this flux data and assuming that the beam-on radiation-induced conductivity is directly proportional to the flux, we corrected the conductivity data for the flux changes by increasing the conductivity of the lower-flux regions by the ratio of maximum flux (in the fluence region between 0.5 and $1.3 \times 10^{23} \mathrm{n} / \mathrm{m}^{2}$ ) to flux in the corrected region.

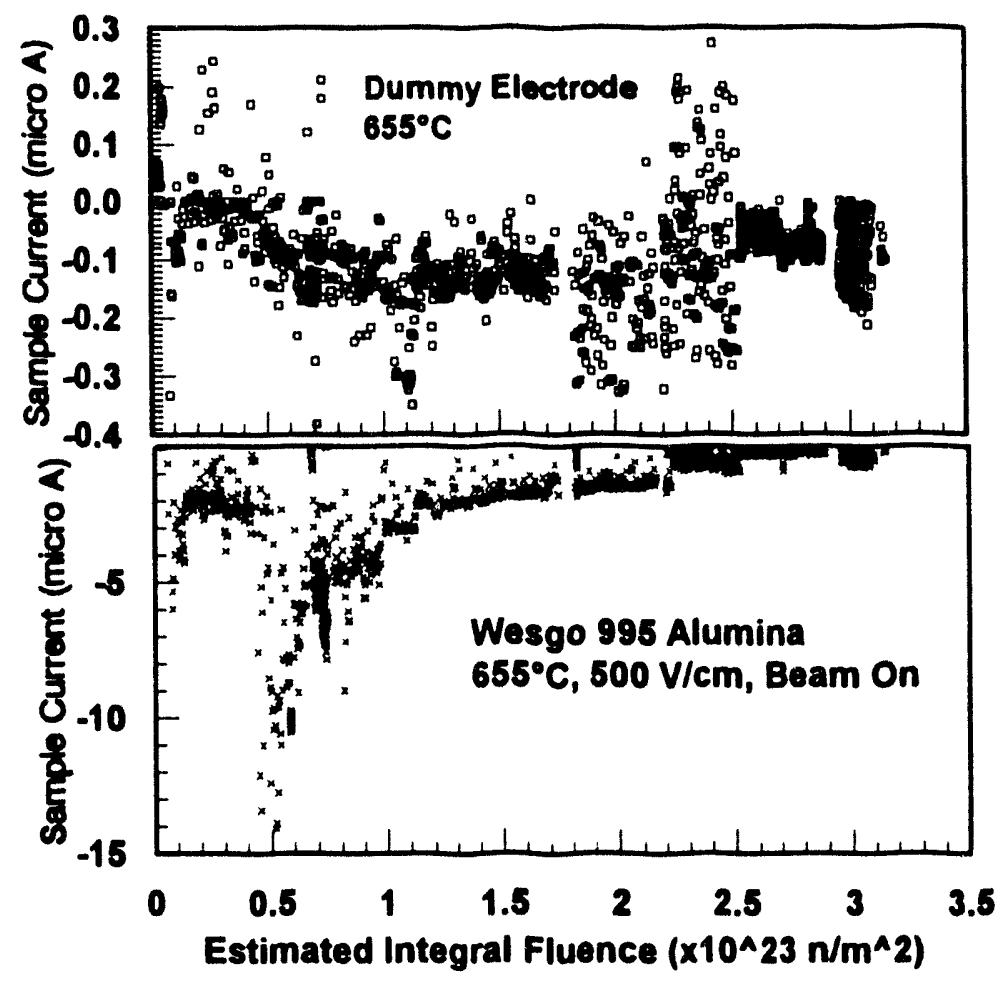

Figure 3. Comparison of the electrode current for a sample set at $655^{\circ} \mathrm{C}$ and the dummy electrode in the same furnace. 


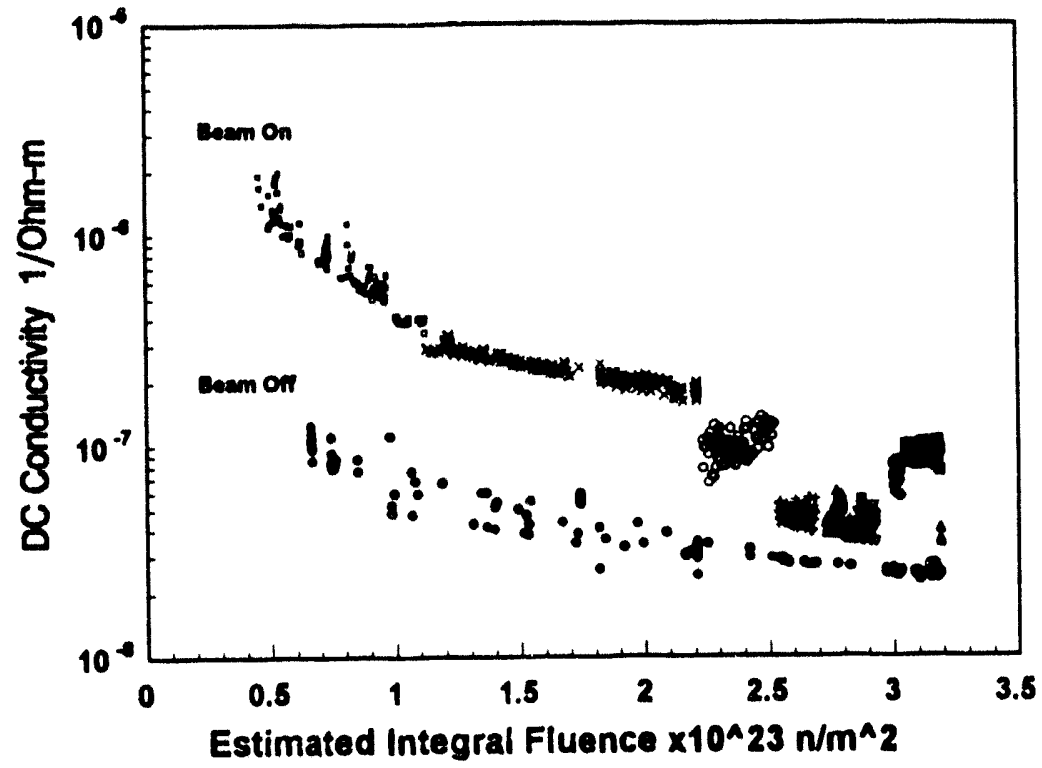

Flux 1.2E+17 (n/m^2)/s

Flux 1.0E+17 (n/m^2)s

Flux $8.3 E+16\left(n / m^{\wedge} 2\right) / s$

Flux 4.1E+16 (n/m^2)/s

Flux 3.3E+16 (n/m^2)/s

Flux 3.8E+16 (n/m^2)/s

Flux 7.1E+16 (n/m^2):

- Flux $8.8 E+16\left(n / m^{\wedge} 2\right) / s$

- Flux $3.5 E+16\left(n / m^{\wedge} 2\right) / s$

- Flux on

Figure 4. As measured conductivity in a sample set at $655^{\circ} \mathrm{C}$ versus estimated fluence without correction for flux changes.

The flux-corrected data for three sample sets are shown in Fig. 5, a,b,c. The data taken prior to stabilization of the furnace temperatures at their final value is not shown because the analysis is not yet complete. The data for the highest temperature and highest voltage samples $\left(655^{\circ} \mathrm{C}, 1500 \mathrm{~V} / \mathrm{cm}\right)$ are not presented because we presently believe that they are erroneous and are waiting for post-irradiation measurements to verify these data. The data for the lowest temperature samples are shown in Fig. 6 . At this temperature, no changes were observed in either beam-on, beam-off or long-term conductivity. Therefore, no flux correction was applied to the Fig. 6 plot. The data for both the $500 \mathrm{~V} / \mathrm{cm}$ and 1500 $\mathrm{V} / \mathrm{cm}$ sample sets were similar at the lowest temperature. The data on DC conductivity of MgO-insulated cables have not yet been analyzed.

During the experiment, when the beam was off for a substantial period, we turned off the furnace power and measured electrical conductivity vs. temperature as the samples cooled, then again as they were reheated with power on. Fig. 7 is an Arrhenius plot of the conductivity taken with beam off at an estimated fluence of $0.67 \times 10^{23} \mathrm{n} / \mathrm{m}^{2}$. Heating and cooling data were identical. The observance of two activation energies is characteristic of an irradiated material. ${ }^{1}$ 


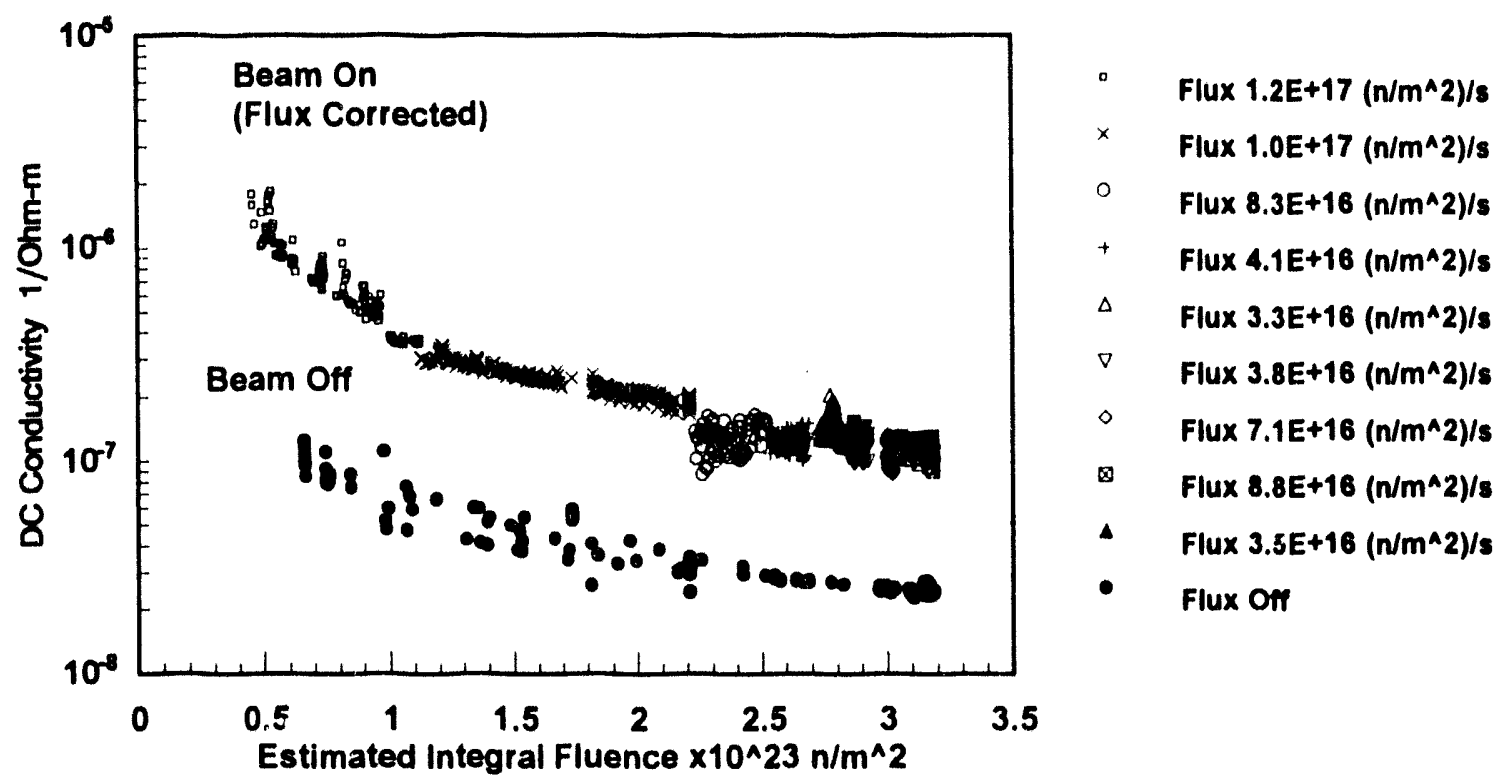

Figure 5a. Flux-corrected conductivity of the sample set at $665^{\circ} \mathrm{C}$ and $500 \mathrm{~V} / \mathrm{cm}$ versus estimated fluence. Upper curve is beam on, lower curve is beam off. Wesgo 995 Alumnia.

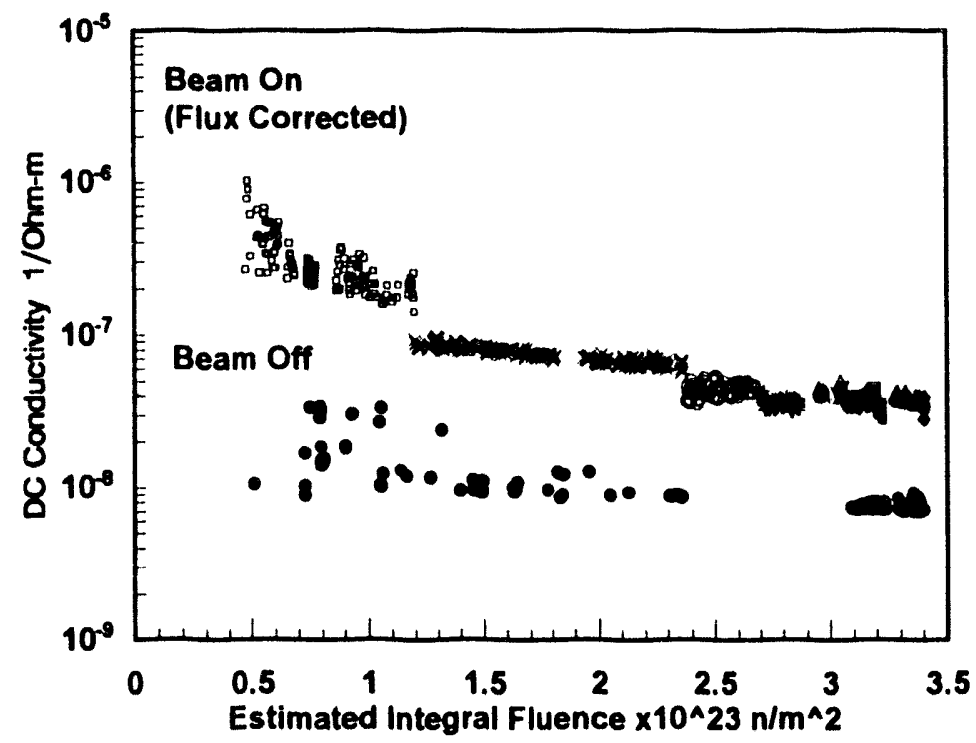

Flux $1.2 E+17\left(\mathrm{n} / \mathrm{m}^{\wedge} 2\right) / \mathrm{s}$

Flux 1.1E+17 (n/m^2)/s

Flux $8.6 E+16\left(\mathrm{n} / \mathrm{m}^{\wedge} 2\right) / \mathrm{s}$

Flux 4.2E+16 $\left(\mathrm{n} / \mathrm{m}^{\wedge} 2\right) / \mathrm{s}$

Flux $3.3 E+16\left(n / m^{\wedge} 2\right) / s$

Flux 4.0E+16 $\left(\mathrm{n} / \mathrm{m}^{\wedge} 2\right) / \mathrm{s}$

Flux $8.9 E+16\left(n / m^{\wedge} 2\right) / s$

Flux 3.4E+16 (n/m^2)/s

Flux $7.3 E+16\left(\mathrm{n} / \mathrm{m}^{\wedge} 2\right) / \mathrm{s}$

Flux $9.0 E+16\left(\mathrm{n} / \mathrm{m}^{\wedge} 2\right) / \mathrm{s}$

Flux 3.6E+16 (n/m^2)/s

Flux Off

Figure 5b. Flux-corrected conductivity of the sample set at $615^{\circ} \mathrm{C}$ and $1500 \mathrm{~V} / \mathrm{cm}$ versus estimated fluence. Upper curve is beam on, lower curve is beam off. Wesgo 995 Alumnia. 


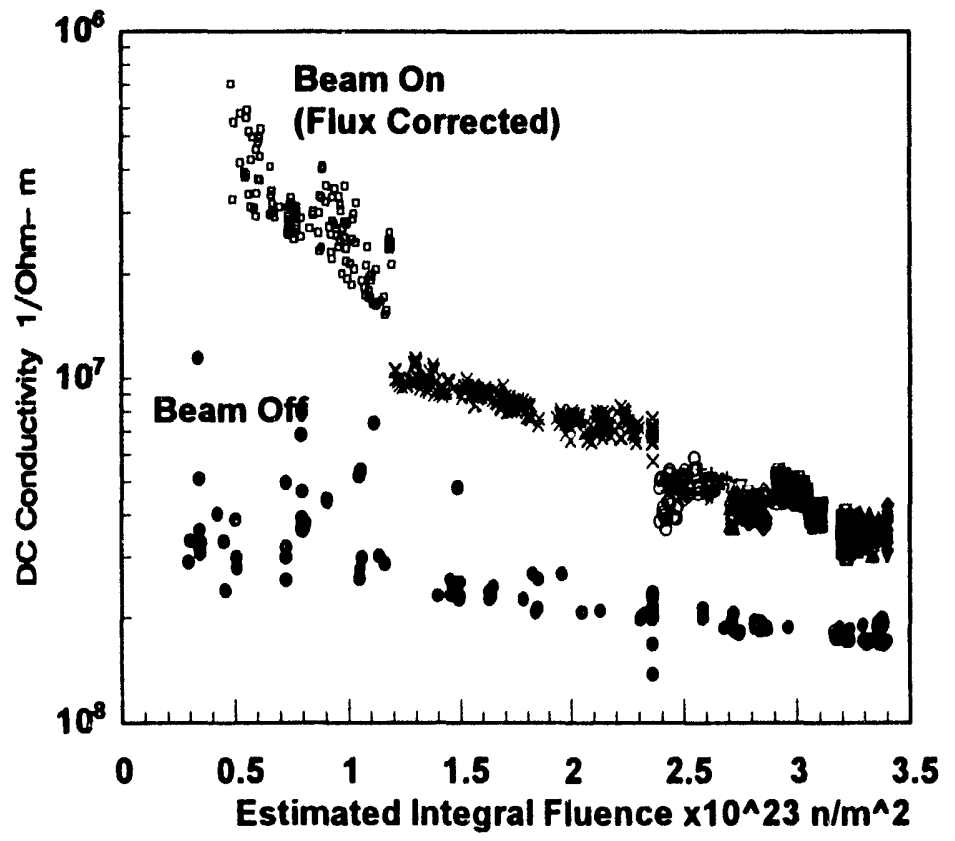

Flux 1.2e17 (n/m^2)/s

Flux $1.1 e 17\left(n / m^{\wedge} 2\right) / s$

Flux 8.6e16 (n/m^2)/s

Flux 9.0e16 (n/m^2)/s

Flux 4.2e16 (n/m^2)/s

Flux 4.0e16 $\left.\mathrm{In} / \mathrm{m}^{\wedge} 2\right) / \mathrm{s}$

Flux $4.2 \mathrm{e} 16\left(\mathrm{n} / \mathrm{m}^{\wedge} 2\right) / \mathrm{s}$

Flux 3.4e16 (n/m^2)/s

Flux $4.1 e 16\left(\mathrm{n} / \mathrm{m}^{\wedge} 2\right) / \mathrm{s}$

Flux $7.2 e 16\left(\mathrm{n} / \mathrm{m}^{\wedge} 2\right) / \mathrm{s}$

Flux $9.5 e 16\left(\mathrm{n} / \mathrm{m}^{\wedge} 2\right) / \mathrm{s}$

- Flux $7.5 e 16\left(\mathrm{n} / \mathrm{m}^{\wedge} 2\right) / \mathrm{s}$

- Flux 3.6e16 $\left(\mathrm{n} / \mathrm{m}^{\wedge} 2\right) / \mathrm{s}$

- Flux Off

Figure 5c. Flux-corrected conductivity of the sample set at $615^{\circ} \mathrm{C}$ and $500 \mathrm{~V} / \mathrm{cm}$ versus estimated fluence Upper curve is beam on, lower curve is beam off. Wesgo 995 Alumina.

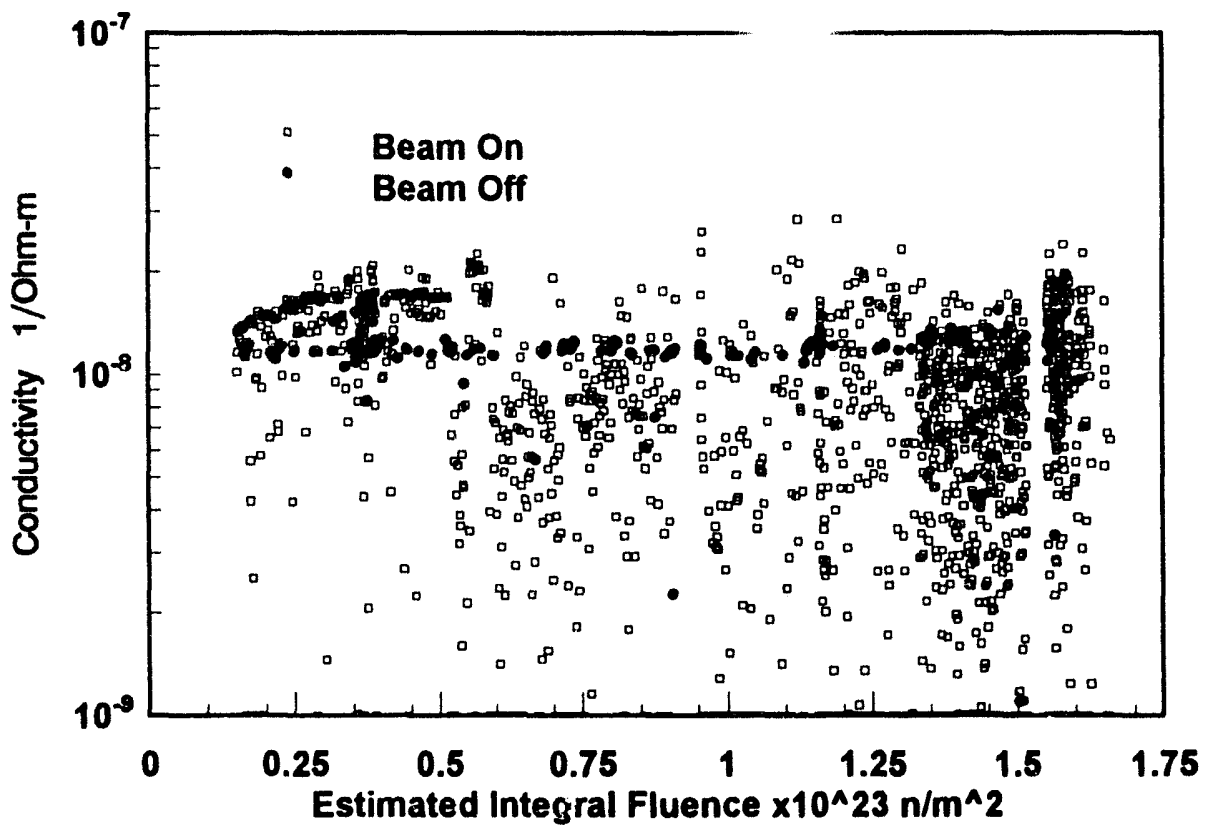

Figure 6. Conductivity of the sample set at $395^{\circ} \mathrm{C}$ and $500 \mathrm{~V} / \mathrm{cm}$ versus estimated fluence. Wesgo 995 Alumina. 


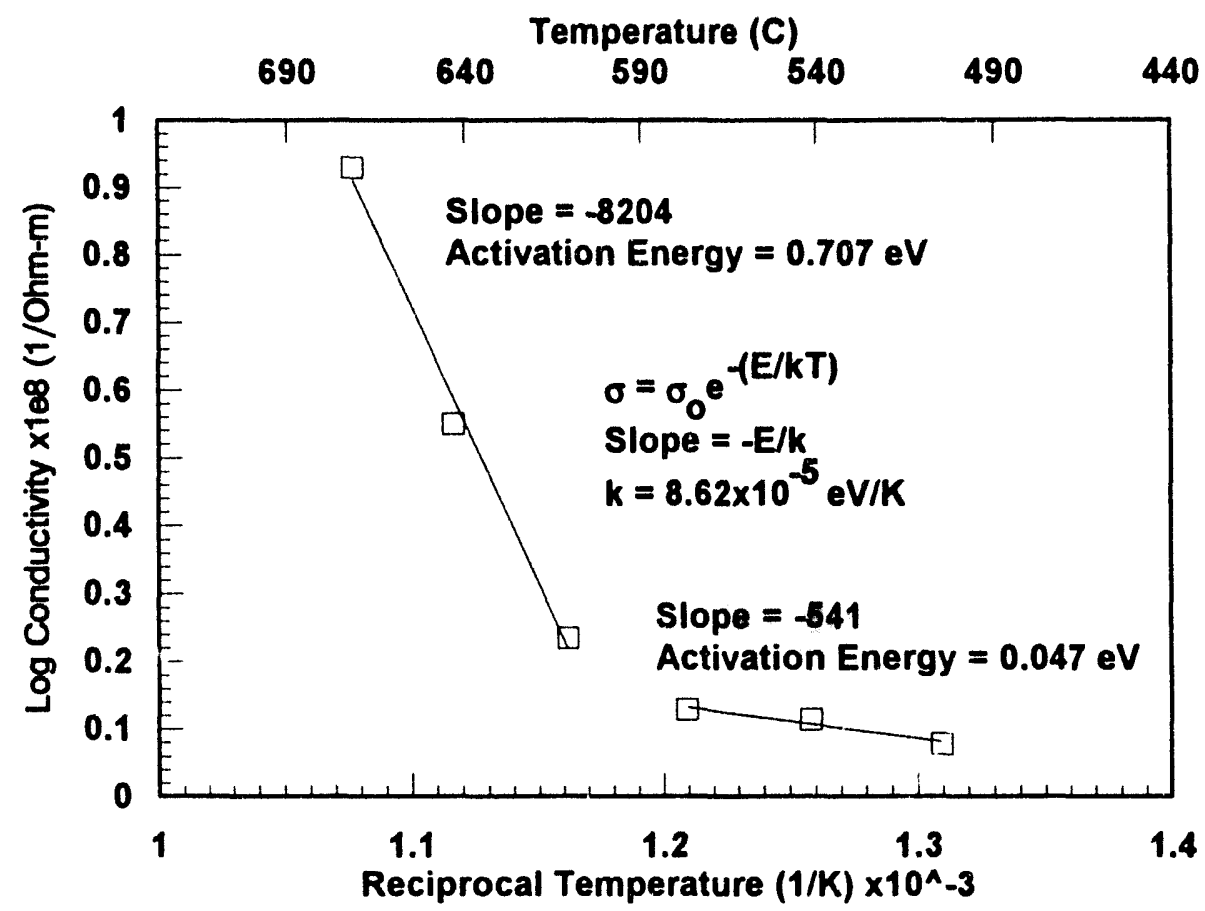

Figure 7. Logarithm of the conductivity versus reciprocal temperature for the sample set at $655^{\circ} \mathrm{C}$ and $500 \mathrm{~V} / \mathrm{cm}$. Fluence is constant at $6.65 \times 10^{23} \mathrm{n} / \mathrm{cm}^{2}$. Beam off.

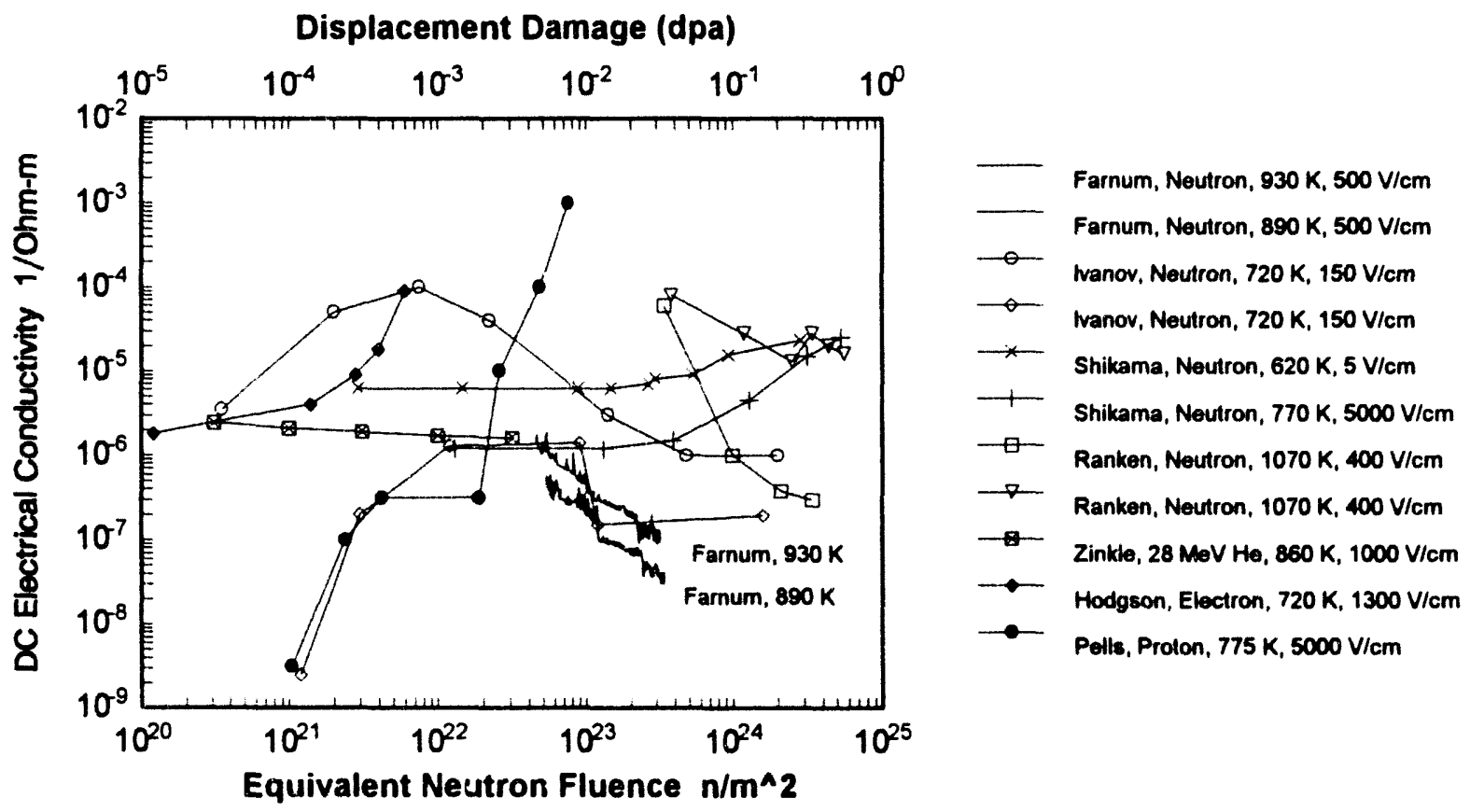

Figure 8. Compilation of data on RIED studies. Published data for electron, proton and neutron irradiation at various applied voltages and temperatures. 


\section{Summary}

The DC data for most of the LASREF in situ irradiation experiment have been analyzed. No dramatic increases in conductivity were observed to the maximum estimated flux of 0.034 displacements per atom (dpa). Data from one DC sample set and the MI cables has yet to be fully analyzed and is waiting for postirradiation measurements. The DC conductivity for two of our sample sets is compared to previous attempts to measure the RIED effect in Fig. 8. It should be noticed that no dramatic RIED effect has yet been observed with $D C$ measurements under neutron irradiation. Shikama's factor-of-three increase is, so far, the largest observed DC effect. These data would not indicate that RIED is a serious problem for fusion applications at least in the temperature, voltage, fluence ranges measured to date.

\section{FUTURE WORK}

The AC measurements we made at LASREF, described in the companion report, are dramatically different from the $D C$ data described here. We do not yet have a plausible explanation for this difference. We are in the process of recovering the insert and samples and will begin post-irradiation examination in the third quarter. Post-irradiation electrical measurements will be compared between the $\mathrm{DC}$ and $\mathrm{AC}$ samples in an attempt to understand the differences in these two experiments. We will also conduct TEM examinations of both ac and dc samples to look for the onset of colloid formation. Steve Zinkle at ORNL will collaborate in these measurements.

Many passive samples were included in the LASREF experiment. These were contributed through our collaborations with researchers world wide. We will continue these collaborations, returning samples and making some post-irradiation measurements beginning in the third quarter.

\section{References}

1. G. P. Pells et. al., "Radiation Effects in Electrically Insulating Ceramics. Harwell Report AERE R 13222, September, 1988. 
MEASUREMENT OF AC ELECTRICAL CONDUCTIVITY OF SINGLE CRYSTAL AL $2{ }_{2} \underline{0}_{3}$ DURING SPALLATION-NEUTRON IRRADIATION--, J. C. Kennedy III, E.H. Farnum, W. F. Sommer and F. W. Clinard, Jr. (Los Alamos National Laboratory)

\section{OBJECTIVE}

The objective of this experiment is to determine the extent of electrical insulating degradation in $\mathrm{Al}_{2} \mathrm{O}_{3}$, a candidate dielectric material for fusion applications, during neutron irradiation and with an applied electric field.

\section{SUMMARY}

Samples of single crystal $\mathrm{Al}_{2} \mathrm{O}_{3}$, commonly known as sapphire, and polycrystalline $\mathrm{Al}_{2} \mathrm{O}_{3}$ were irradiated with spallation neutrons at the Los Alamos Spallation Radiation Effects Facility (LASREF) under various iemperature conditions and with a continuously applied alternating electric field ${ }^{1}$. This paper describes the results of measurements on the sapphire samples. Neutron fluence and flux values are estimated values pending recovery and analysis of dosimetry packages. The conductivity increased approximately with the square root of the neutron flux at fluences less than $3 \times 10^{19} \mathrm{n} / \mathrm{m}^{2}$ and at fluxes less than $1 \times 10^{16} \mathrm{n} / \mathrm{m}^{2}$-sec. Conductivity initially decreased at low fluences with minimums near fluences of $1 \times 10^{20} \mathrm{n} / \mathrm{m}^{2}$. Incubation periods with a gradual increase in conductivity preceded the onset of an accelerated increase in conductivity beginning at fluences as low as $10^{21} \mathrm{n} / \mathrm{m}^{2}$. The increase in conductivity reached saturation levels as high as $2 \times 10^{-2}(\mathrm{ohm}-\mathrm{m})^{-1}$ at fluences as low as $2 \times 10^{22} \mathrm{n} / \mathrm{m}^{2}$. Frequency swept impedance measurements indicated a change in the electrical properties from capacitive to resistive behavior with increasing fluence.

\section{PROGRESS AND STATUS}

\section{Introduction}

The Fusion ceramics community has been concerned with the phenomenon of radiation-induced electrical degradation (RIED) in ceramic insulators ever since E.R. Hodgson ${ }^{2-3}$ observed and reported the effect in single crystal $\mathrm{Al}_{2} \mathrm{O}_{3}$ during high energy electron irradiation.

RIED has been observed 2,4 only under conditions of concurrent ionizing radiation, displacement damage, moderately elevated temperatures, and applied electric fields. Degradation has been reported 2 for single crystal $\mathrm{Al}_{2} \mathrm{O}_{3}$ under both applied $\mathrm{DC}$ and $\mathrm{AC}$ fields up to $126 \mathrm{MHz}$. There is little or no frequency dependence of degradation behavior under $\mathrm{AC}$ applied fields but the onset of degradation has been reported to be delayed and the degradation rate reduced compared to DC applied fields ${ }^{2}$.

Accelerated degradation has been observed ${ }^{2}$ at fluences as low as $10^{-5}$ displacements per atom (dpa) with applied voltages above a threshold value of about $500 \mathrm{~V} / \mathrm{cm}$ during $1.8 \mathrm{Mev}$ electron irradiation at a flux of $10^{6} \mathrm{~Gy} / \mathrm{hr}$ and a temperature of $450^{\circ} \mathrm{C}$.

Studies of proton irradiated ${ }^{4}$ polycrystalline $\mathrm{MgAl}_{2} \mathrm{O}_{4}$ and $\mathrm{Al}_{2} \mathrm{O}_{3}$ and electron irradiated ${ }^{2}$ single crystal $\mathrm{Al}_{2} \mathrm{O}_{3}$ show degradation trends consisting of an incubation period during which conductivity is slowly increasing followed by the onset of a supralinear increase in conductivity. The incubation period has been found ${ }^{2}$ to decrease with increasing dose rate and to increase with decreasing temperature.

Recently, Shikama et. al. ${ }^{5}$ observed degradation in polycrystalline $\mathrm{Al}_{2} \mathrm{O}_{3}$ after irradiation with fission reactor neutrons near $500^{\circ} \mathrm{C}$ with a $5000 \mathrm{~V} / \mathrm{cm}$ applied electric field. 


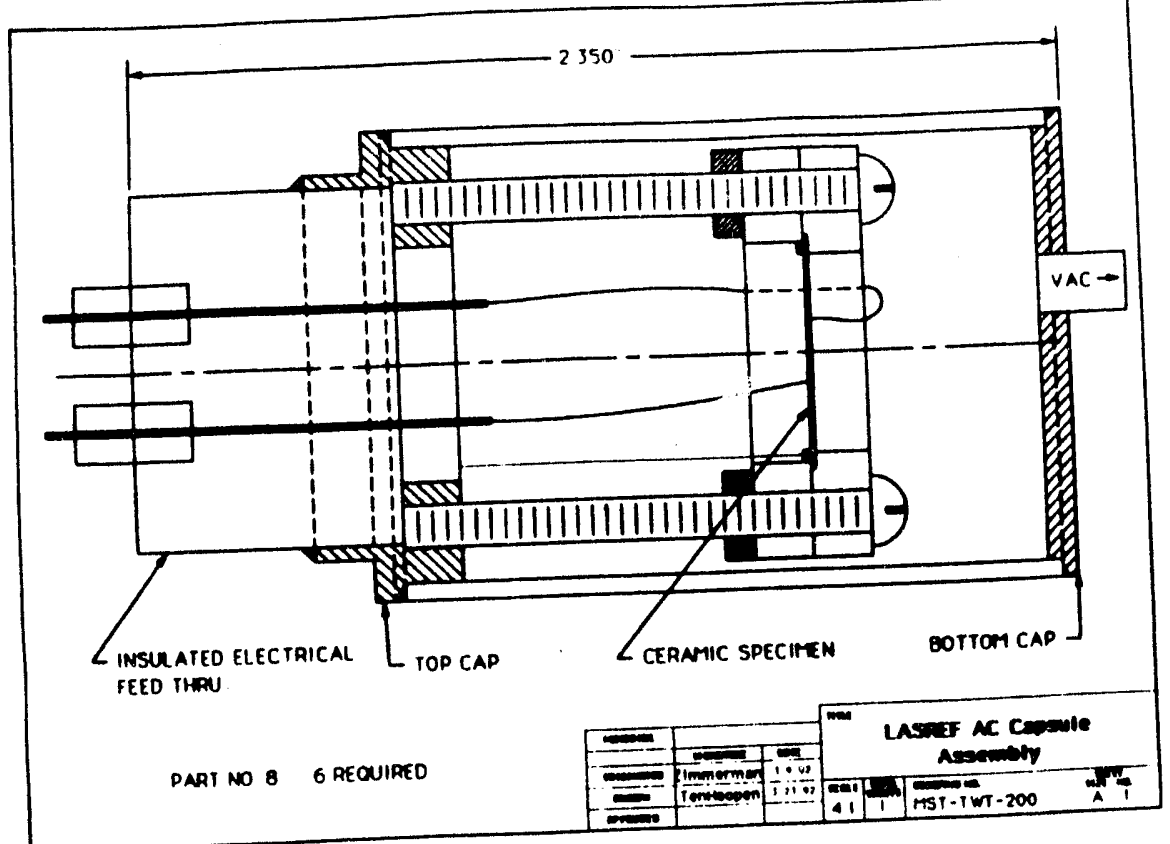

Fig. 1. Schematic diagram of AC test capsule. Guard ring electrical lead is shown in contact with the capsule body or electrical ground.

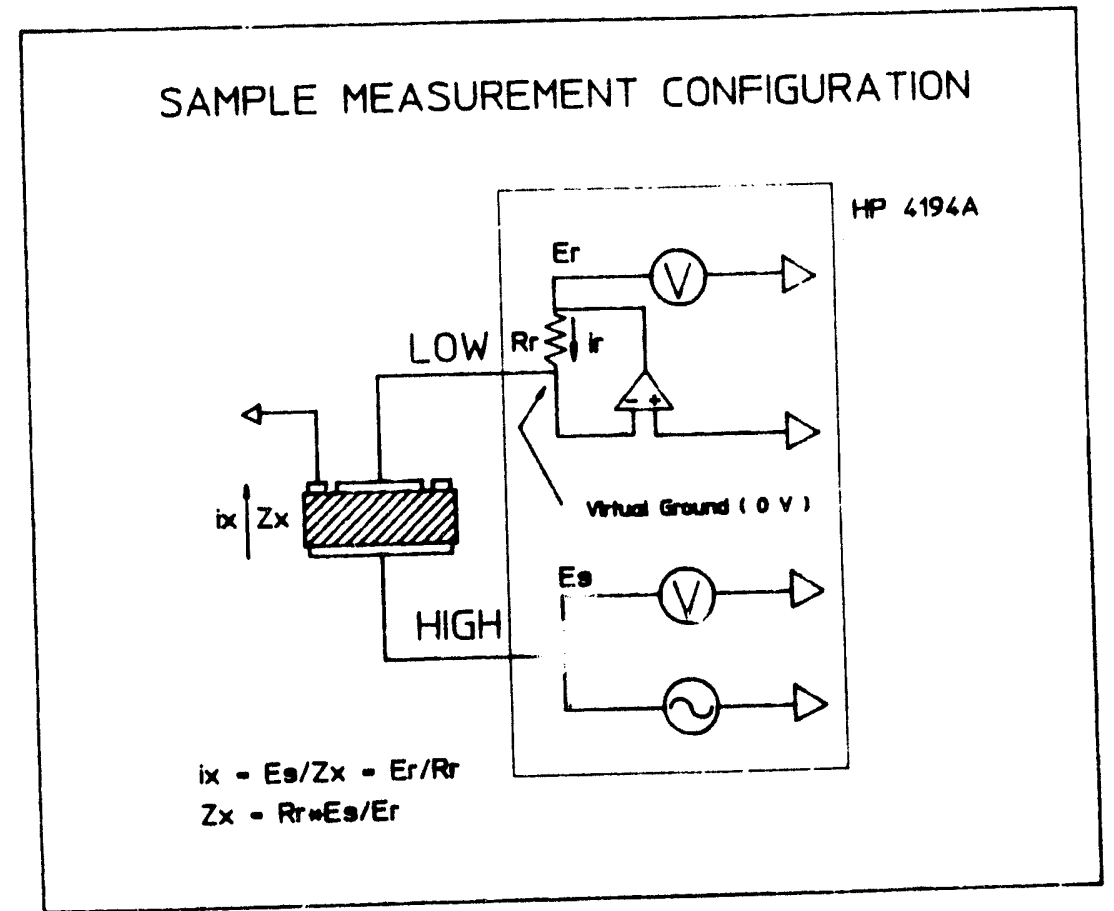

Fig 2. Wiring diagram and measurement ccnfiguration for $A C$ measureinients. The Low side is driven to 0 volts at the measuring instrument (Hir $+194 \mathrm{~A}$ Impedance Analyzer). 
A separate, but related, phenomenon is radiation induced conductivity (RIC) caused by the creation of excess charge carriers under ionizing radiation. RIC is a function of the ionization rate and the lifetime of excess charge carriers as determined by trapping and recombination processes. ${ }^{6-9}$. RIC is given by $\sigma=\sigma_{0}+K R^{\delta}$, where $\sigma_{0}$ is the conductivity in the absence of ionizing radiation and $R$ is the ionizing flux. Studies ${ }^{9-11}$ of $\mathrm{Al}_{2} \mathrm{O}_{3}$ under various types of ionizing radiation have generally reported flux-dependent $\delta$ values between 0.5 and 1.5 In addition, $\delta$ can have a complicated temperature dependence determined by the defect or doping state 10,11 .

\section{Experimental Method}

The irradiation was carried out at LASREF near the beam stop of LAMPF. LAMPF is an $800 \mathrm{MeV}$ linear proton accelerator that generally operates with an average beam current of $0.75 \mathrm{~mA}$ and a neutron flux near experimental stations of $3.8 \times 10^{17} \mathrm{n} / \mathrm{m}^{2}-\mathrm{s}-\mathrm{mA}^{12,13}$ for neutron energies greater than $0.1 \mathrm{MeV}$. Calculated ${ }^{13}$ gamma flux is approximately $1.4 \times 10^{17} / \mathrm{m}^{2}$-s-mA. The proton beam is pulsed every 8.3 $\mathrm{ms}$ with the beam on for a period of 0.5 to $0.8 \mathrm{~ms}$. Interaction of the protons with a copper beam stop produces spallation neutrons with an energy distribution corresponding to a moderated fission spectrum plus a high energy tail.

Although accurate determinations of neutron fluxes and fluences during our experiment must await recovery of dosimetry foils, it is estimated that the maximum average neutron flux $(E>0.1 \mathrm{MeV})$ at the samples ranged from $5.5 \times 10^{16}$ to $1.0 \times 10^{17} \mathrm{n} / \mathrm{m}^{2}$-sec. Total neutron fluences $(E>0.1 \mathrm{MeV})$ are estimated to range between 1.2 and $2.2 \times 10^{23} \mathrm{n} / \mathrm{m}^{2}$.

Samples were individually encapsulated in stainless steel capsules [Figure 1]. Based on measurements outside the capsules, it is estimated the single crystal sample capsules were evacuated to less than $10^{-4}$ torr. Two sample capsules, one with single crystal and one with polycrystalline $\mathrm{Al}_{2} \mathrm{O}_{3}$, were contained in each of three separately controlled and DC powered furnaces. The details of the furnace construction has been previously reported 1 . The furnaces were continuously supplied with argon at atmospheric pressure. Approximately $5 \mathrm{~m}$ of $\mathrm{MgO}$-insulated cables with stainless steel sheaths and nickel center conductors provided electrical leads from the capsules out of the high radiation area. Another $25 \mathrm{~m}$ of polymer insulated coaxial cable carried the electrical signals to the instruments.

The single crystal sample capsules had ceramic insulated electrical feed-throughs with nickel leads. Platinum leads 0.005 inches in diameter were thermosonically bonded to the sample electrodes and spotwelded to the nickel leads. The sample electrodes were sputter deposited with 100 Angstroms of titanium followed by 2500 Angstroms of platinum. A guard ring configuration as specified in ASTM Standard D150 was applied using photolithography masking techniques. Samples were single crystal $\mathrm{Al}_{2} \mathrm{O}_{3}$ supplied by Crystal Systems, Inc. with face orientation (1120). Major impurities were $8 \mathrm{ppm}$ Fe and 6 ppm Ce. Sample dimensions were $0.216 \mathrm{~mm}$ thick $\times 12.7 \mathrm{~mm}$ in diameter. The guarded electrode diameter was $7.65 \mathrm{~mm}$.

The polycrystalline samples and sample capsules were supplied by Dr. Tatsuo Shikama of Tohok" University, Japan. The capsules were similar in construction to those reported by him as a 'second subcapsule design' in a separate irradiation experiment ${ }^{14}$. The samples were manufactured by Kyocera Co. Ltd., and had nominal dimensions of $0.15 \mathrm{~mm}$ thick $\times 8 \mathrm{~mm}$ in diameter. Sample electrodes were similar to those for the single crystal samples. 

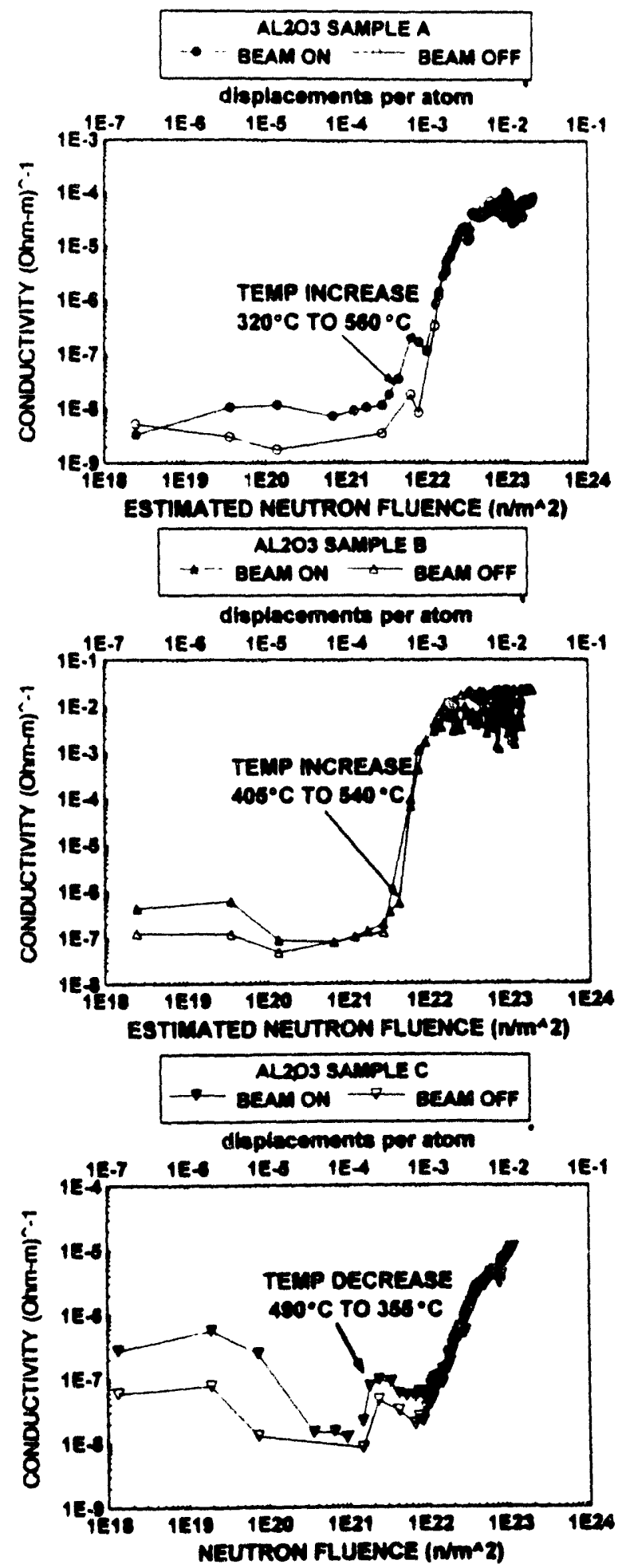

Fig's 3a-c. Averaged conductivity values measured at $100 \mathrm{~Hz}$ during spallation neutron irradiation of single crystal $\mathrm{Al}_{2} \mathrm{O}_{3}$ with a $1850 \mathrm{~V} / \mathrm{cm}$ applied $\mathrm{AC}$ electric field. Impedance measurements were made without the AC electric field applied. Results are presented with ('beam on'), and without ('beam off'), neutron flux present. 
The samples were supplied with a $10 \mathrm{kHz}$ voltage with a peak-to-peak amplitude of 80 volts. The applied electric field had a peak value of $1850 \mathrm{~V} / \mathrm{cm}$ and an rms value of $1310 \mathrm{~V} / \mathrm{cm}$. The field was continuously applied to the samples during the irradiation except for periods of 30 to 60 seconds every 1 to 2 hours to allow frequency swept impedance measurements to be made.

Electrical measurements were made with a HP 4194A impedance analyzer which uses an autobalancing bridge technique. Measurements were made over the frequency range of $100 \mathrm{~Hz}$ to $1 \mathrm{MHz}$. A three terminal configuration was used as shown in Figure 2. The impedance analyzer drives the low side of the circuit to 0 volts leaving the guard and guarded electrodes at the same potential. Measurement signal voltages are a maximum of 1 volt at high impedances with a compliance of $20 \mathrm{~mA}$. Since the source voltage applied to the sample depends only on the impedance of the sample, any leakage current on the high side has minimal effect on the accuracy of the measurement as long as the total current is within instrument specifications. Separate measurements of $\mathrm{MgO}$-insulated cables during irradiation with an applied electric field peak strength of $1750 \mathrm{~V} / \mathrm{cm}$ did not reveal any degradation in cable insulation.

\section{$\underline{\text { Results }}$}

This progress report concerns data collected from the single crystal samples. Analysis of the polycrystalline samples is not yet complete and is being done in collaboration with Dr. Tatsuo Shikama.

The irradiation initially began with Sample A (Furnace A) at $300^{\circ} \mathrm{C}$, Sample B (Furnace B) at $375^{\circ} \mathrm{C}$ and Sample $C$ (Furnace $C$ ) at $480^{\circ} \mathrm{C}$. Early in the irradiation an increase in flux-induced heating caused us to reverse the low and high temperature furnaces and to increase the controlling temperature levels. All furnaces increased in temperature at 66 hours into the irradiation coincident with a factor of two flux increase. Another factor of two flux increase and coincident temperature increase at 85 hours resulted in the changes in furnace controlling levels referred to above.

Sample A increased from $300^{\circ} \mathrm{C}$ to $320 \mathrm{C}$ at 66 hours and from $320^{\circ} \mathrm{C}$ to $560^{\circ} \mathrm{C}$ at 85 hours. Sample A averaged $580^{\circ} \mathrm{C} \pm 20^{\circ} \mathrm{C}$ over the period of rapid degradation. Sample B increased from $375^{\circ} \mathrm{C}$ to $405^{\circ} \mathrm{C}$ at 66 hours and from $405^{\circ} \mathrm{C}$ to $540^{\circ} \mathrm{C}$ at 85 hours. The temperature increase in Sample B at 85 hours, unlike Sample A, precipitated a rapid, and nearly immediate, rise in conductivity of about two orders of magnitude. Sample B averaged $550^{\circ} \mathrm{C} \pm 10 \mathrm{C}$ over the rapid degradation period. Sample $\mathrm{C}$ increased from $480^{\circ} \mathrm{C}$ to $490^{\circ} \mathrm{C}$ at 66 hours and was lowered from $490^{\circ} \mathrm{C}$ to $355^{\circ} \mathrm{C}$ at 85 hours. The temperature was thereafter increased to $380^{\circ} \mathrm{C}$ and Sample $\mathrm{C}$ averaged $380^{\circ} \mathrm{C} \pm 10^{\circ} \mathrm{C}$ over the degradation that continued throughout the irradiation cycle. The temperature profiles are further described in a companion progress report on DC conductivity measurements.

Figures 3 a-c show conductivity measured at $100 \mathrm{~Hz}$ versus estimated fluence in $\mathrm{n} / \mathrm{m}^{2}$ and dpa $\left(1 \times 10^{25}\right.$ $\mathrm{n} / \mathrm{m}^{2}$ is estimated to induce one displacement per atom ). Conductivity was calculated from the measured values of impedance modulus $|\mathrm{Z}|$ (ohms) and phase angle $\Theta$ (theta degrees). The AC conductivity is given by $\sigma=\omega k \varepsilon_{\mathrm{O}} \tan \delta$; where $\omega$ is the angular frequency, $\mathrm{k}$ is the real part of the relative dielectric constant, $\varepsilon_{\mathrm{O}}$ is the permittivity of free space and $\tan \delta$ is given by the equivalent series resistance $\operatorname{Rs}(|\mathrm{Z}| \cos \Theta)$ divided by the equivalent series reactance $X s(|Z| \sin \Theta)$. $k$ is given by $C p d / \varepsilon_{O} A$, where $C p$ is the parallel capacitance, $d$ is the sample thickness, and $A$ is the guarded electrode area. $\mathrm{Cp}$ is given by $1 / \omega \mathrm{Rp} \tan \delta$, where $\mathrm{Rp}$ is the parallel resistance. The conductivity can therefore be calculated from the expression, $\sigma=d / R p A$, where the parallel resistance, $R p$, is given by $R p=R s\left[\left(1+\tan ^{2} \delta\right) / \tan ^{2} \delta\right]$. 

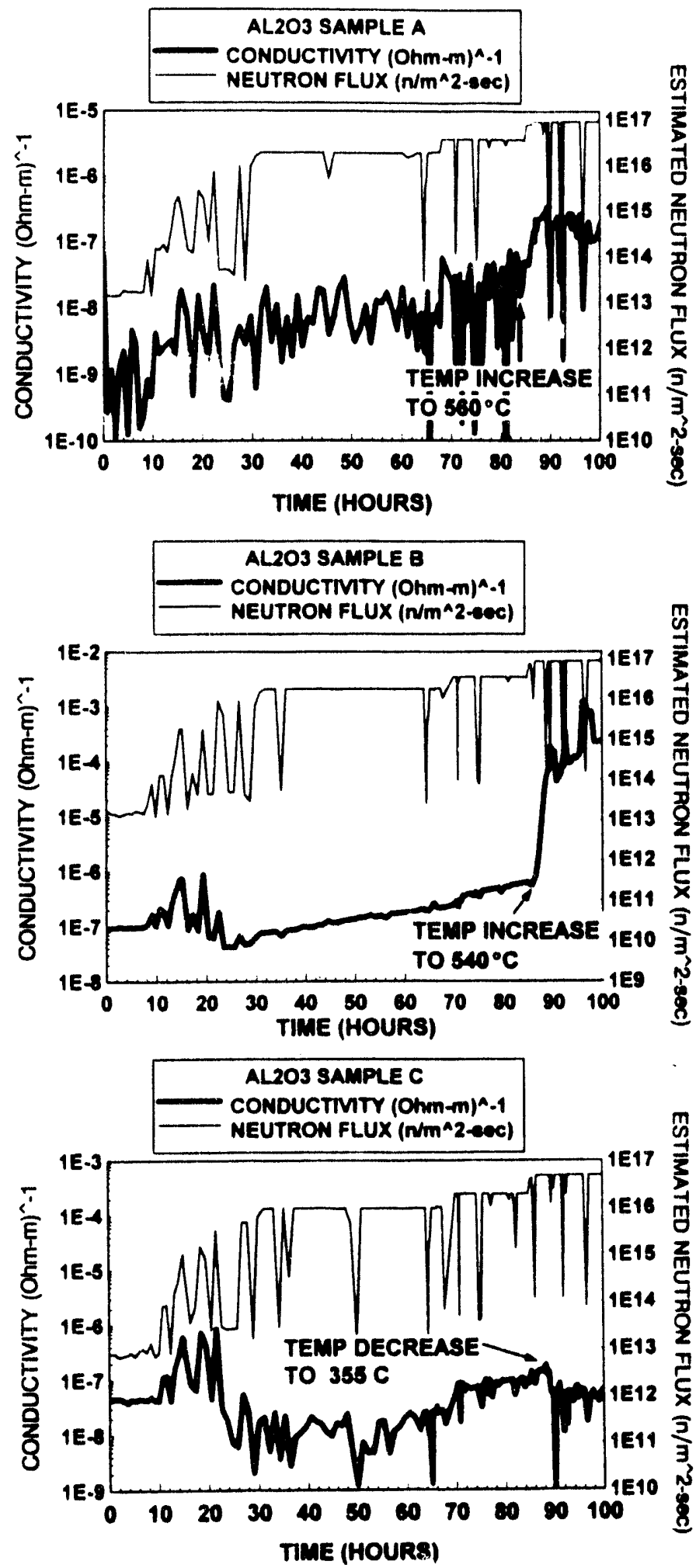

Fig's $4 a-c$. Conductivity of single crystal $\mathrm{Al}_{2} \mathrm{O}_{3}$ measured at $100 \mathrm{~Hz}$ early in the irradiation cycle. Neutron flux, in the upper part of the figure, is contrasted with conductivity, shown in the lower part of the figure. Increases in flux are seen at 66 and 85 hours. Temperature changes are indicated at 85 hours. 
Conductivity values are initially presented here at $100 \mathrm{~Hz}$ since they are they are the lowest frequency measured and are more closely comparable to DC measurements. Conductivity trends for higher frequencies are similar and will be presented in a future publication with further analysis of frequency dependent behavior.

Conductivity results presented in Figures 3 a-c represent the averages of several conductivity measurements taken over eight hour periods of irradiation. The proton beam at LAMPF was off periodically during the irradiation for periods of a few minutes to several hours. Measurements were made with the proton beam both on and off. Conductivity with the proton beam on is contrasted with beam-off values in Figures 3 a-c.

Figures 4 a-c show unaveraged conductivity measurements and estimated neutron flux. The neutron flux was calculated from beam current measurements taken before and after frequency swept impedance measurements. Early in the irradiation, increases in conductivity correspond to increases in neutron flux. Figure 5 shows conductivity as a function of neutron flux at low fluences $\left(<3 \times 10^{19} \mathrm{n} / \mathrm{m}^{2}\right)$ before any measurable change in the base conductivity. RIC increases as approximately the square root of the neutron flux.

The conductivity for all samples in Figures 3a-c shows a slight decrease in the base conductivity early in the irradiation. Decreases in radiation induced conductivity (RIC) for Samples B and C were also observed in this region. The conductivity response to flux and fluence can be seen in more detail in Figures 4 a-c. The base conductivity in all samples reaches a minimum value at about $10^{20} \mathrm{n} / \mathrm{m}^{2}$. RIC appears to decrease relative to the base conductivity in all samples before the onset of degradation.

Sample B, initially irradiated at $375^{\circ} \mathrm{C}$, shows an immediate and dramatic response with the fastest degradation rate after a temperature increase from $405^{\circ} \mathrm{C}$ to $550^{\circ} \mathrm{C}$. Sample A, initially irradiated at $300^{\circ} \mathrm{C}$, and with a large temperature increase from $320^{\circ} \mathrm{C}$ to $560^{\circ} \mathrm{C}$, shows a much slower response to temperature change and a slower degradation rate. Sample $\mathrm{C}$ initially irradiated at $480^{\circ} \mathrm{C}$ and subsequently lowered in temperature from $490^{\circ} \mathrm{C}$ to $355^{\circ} \mathrm{C}$, shows the beginning of rapid degradation which then appears to be retarded by the decrease in temperature and proceeds at a much slower rate thereafter.

Sample B reached the highest saturated conductivity with a value of $2 \times 10^{-2}(\mathrm{ohm}-\mathrm{m})^{-1}$ at a fluence near $2 \times 10^{22} \mathrm{n} / \mathrm{m}^{2}$. Sample A degraded to a saturated conductivity of about $6 \times 10^{-5}(\mathrm{ohm}-\mathrm{m})^{-1}$ at a fluence of about $5 \times 10^{22} \mathrm{n} / \mathrm{m}^{2}$. The degradation in Sample $C$ did not reach saturation, but had a conductivity of $1 \times 10^{-5}(\mathrm{ohm}-\mathrm{m})^{-1}$ at the end of the irradiation cycle at a fluence of about $1 \times 10^{23} \mathrm{n} / \mathrm{m}^{2}$. Sample B, and to a lesser extent Sample A, show very noisy signals beginning near saturation, with the 'beam-on' condition resulting in decreased conductivity (an inverse RIC).

Figures 6a-c show the measured impedance modulus and phase angle values as a function of frequency at fluences corresponding to the unirradiated condition, approximately half way (logarithmically) to saturation, and near saturation. Sample $C$, not having reached saturation, is shown at the highest fluence at the end of the irradiation cycle. Changes in the impedance behavior over the frequency spectrum indicate the general trend of a change from capacitive to resistive behavior with increasing fluence. A spike seen in some of the plots at $10 \mathrm{kHz}$ is caused by interference from the applied electric field present on the samples not being measured. 

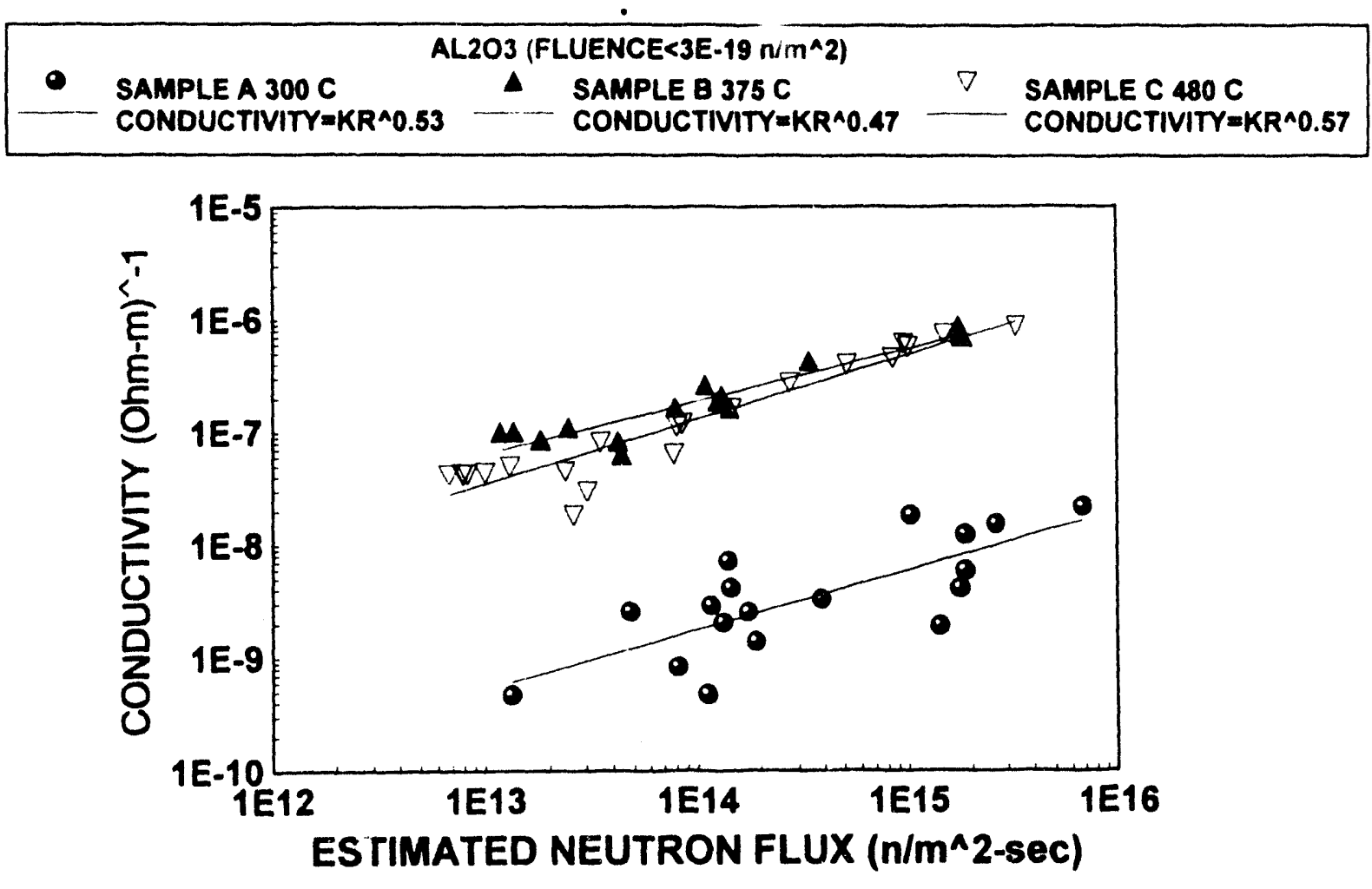

Fig. 5. Variation of radiation-induced conductivity with estimated neutron flux in single crystal $\mathrm{Al}_{2} \mathrm{O}_{3}$ at $100 \mathrm{~Hz}$ prior to any changes in the base conductivity. Data were taken at fluences $<3 \times 10^{-19} \mathrm{~nm}^{2}$. 

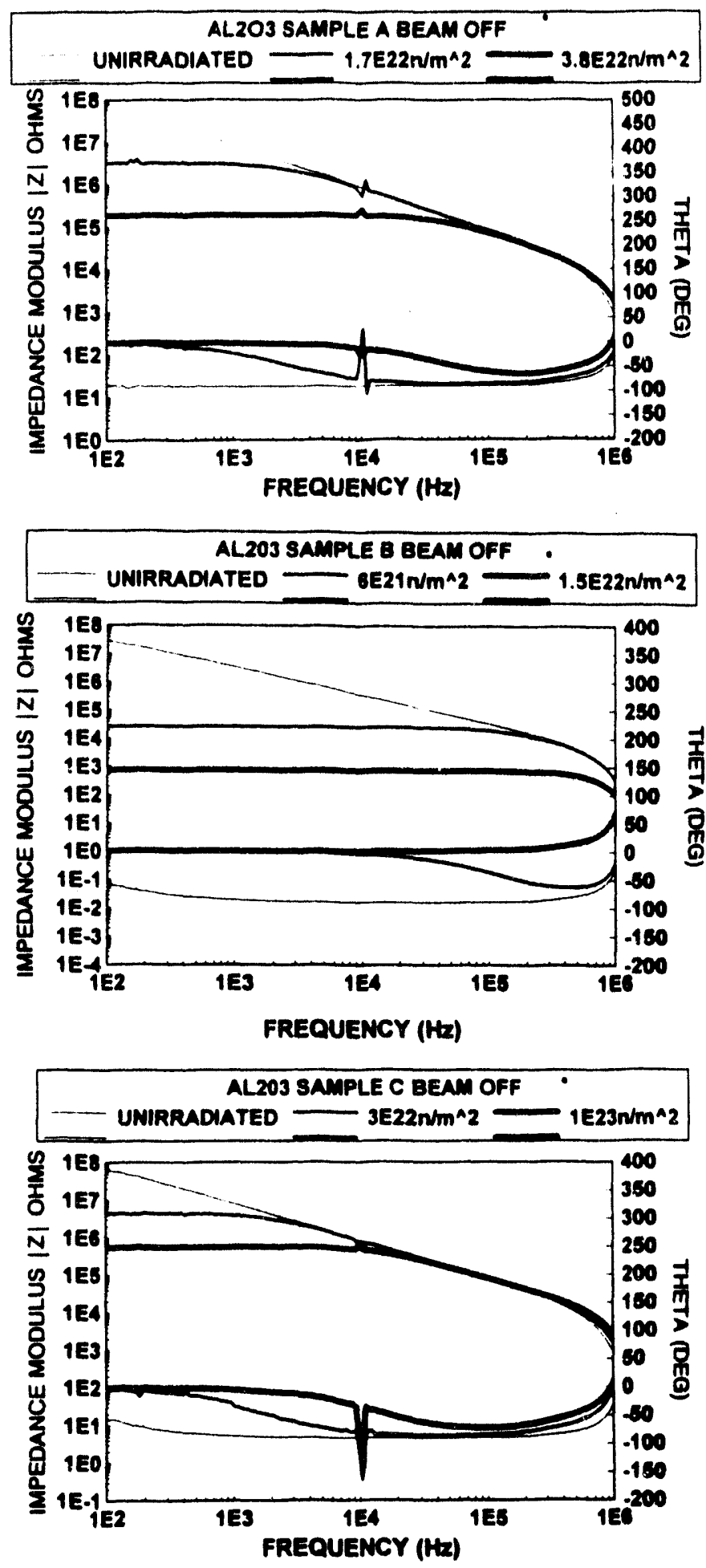

Fig's 6a-c. Impedance modulus $|\mathrm{Z}|$ (ohms) and phase angle, theta (deg), from $100 \mathrm{~Hz}$ to $1 \mathrm{MHz}$ measured in the unirradiated condition, approximately half way to conductivity saturation on a logarithmic scale, and near saturation. See Fig's 3a-c. The spike at $10^{4} \mathrm{~Hz}$ is caused by interference from the bias AC voltage. 


\section{Discussion}

The AC data reported here differ dramatically from the DC conductivity data reported in the companion progress report on polycrystalline alumina. We do not yet have a plausible explanation for these differences. The extremely rapid rise in conductivity of Sample B and very noisy signals with an unexpected response to the 'beam-on' condition beginning near saturation are reasons for further analysis. Further analysis is also needed with respect to possible synergistic effects caused by coincidental changes in flux and temperature. It is expected that some of the present uncertainties will be addressed in the near future with the recovery of dosimetry packages and post-irradiation measurements.

\section{REFERENCES}

1. E.H. Farnum, F.W. Clinard Jr., J.C. Kennedy III, and W.F. Sommer, Semiann. Prog. Rep. on Fusion Reactor Materials for the period ending September 30, 1992, in press.

2. E.R. Hodgson, Cryst. Latt. Def. and Amorph. Mater. 18 (1989) 169.

3. E.R. Hodgson, J. Nucl. Mater. 179-181 (1991) 383-386.

4. G.P. Pells, J. Nucl. Mater. 184 (1991) 177-182.

5. T. Shikama, M. Narui, Y. Endo, T. Sagawa and H. Kayano, J. Nucl. Mater. 191-194 (1992) 575.

6. A. Rose, RCA Review 12, No. 3, (1951) 363.

7. A. Rose, Concepts in Photoconductivity and Allied Problems, in: Interscience Tracts on Physics and Astronomy, No. 19 (Interscience Publishers 1963).

8. V.A.J. vanLint et. al., Mechanisms of Radiation effects in Electronic Materials, Vol. 1 (Wiley \& Sons, New York, 1980).

9. V.A.J vanLint, J.W. Harrity, and T.M. Flanagan, IEEE Trans. Nucl. Sci. NS-15, No. 6, (1968) 194.

10. R.W. Klaffky, B.H. Rose, A.N. Goland, and G.J Dienes, Phys. Rev. B 21 (1980) 3610.

11. G.P. Pells and G.J. Hill, J. Nucl. Mater. 141-143 (1986) 375.

12. D.R. Davidson, W.F. Sommer, J.N. Bradbury, R.E. Prael, and R.C. Little, J. Nucl. Mater. 122-123 (1984) 989 .

13. D.R. Davidson, PHD Dissertation, Neutron and Proton Dosimetry at the LAMPF 800-MeV Proton Accelerator, lowa State University, 1990.

14. M. Narui, T. Shikama, Y. Endo, T. Sagawa, and H. Kayono, J. Nucl. Mater. 191-194 (1992) 592. 
IRRADIATION EFFECTS IN CERAMICS: TRANSITION FROM LOW TO HIGH DOSE BEHAVIOR - F. W. Clinard, Jr. and E. H. Farnum (Los Alamos National Laboratory)

\section{OBJECTIVE}

The objective of this work is to assess the changes that occur in various types of ceramics as irradiation doses progress from low to high levels, and to interpret those changes in terms of our present understanding of damage effects [1].

\section{SUMMARY}

Ceramics subjected to irradiation show a wide variety of damage responses, depending on composition, nature of bonding, crystal structure, impurity levels, starting microstructure, number of phases, and type of bombarding particle. As doses reach high levels (a condition that varies in magnitude from one material to another) major changes in physical properties can occur, and atomic arrangements may even change from crystalline to disordered. However, some ceramics show marked resistance to damage, and some properties may improve. More work is needed to fully understand these phenomena, but it is currently possible in many cases to predict at least qualitatively both microstructural damage response and observed property changes.

\section{PROGRESS AND STATUS}

Introduction

At low damage levels, physical property changes in ceramics are for the most part small in magnitude. The primary damage state and effects of low-dose damage comprise the first topic discussed here.

As damage accumulates and larger defect aggregates are formed, major changes in physical properties (not always deleterious) can be expected. Nevertheless, in many ceramics the constituent ions are for the most part not permanently displaced, and so the damage can be characterized as isolated. High-dose isolated damage is the next topic addressed.

Ceramics with primarily covalent bonding can, at moderate damage levels (e.g., one displacement per atom) become globally disordered. This condition, which is sometimes referred to as the amorphous or metamict state, is considered next.

Engineering materials are often made up of two or more phases. Since each phase will demonstrate a characteristic response to irradiation, the combined damage state can be complex. The unusual swelling behavior of such a material is the last topic discussed.

\section{The Primary Damage State and Low-Dose Behavior}

With respect to neutron irradiation, primary damage effects are usually visualized in terms of cascade formation and post-cascade defect content. Damage cascades have been extensively studied in metals, but little work has been done on ceramics. Issues that are especially important to ceramics include:

-- The possibility of forming anti-site defe's, e.g., $\mathrm{Al}$ ions on $\mathrm{O}$ ion sites in alumina or $\mathrm{N}$ ions on $\mathrm{O}$ sites in aluminum oxynitride;

- The consequence of unequal numbers of cation and anion displacements; 
-- Amorphicity in cascades and as the permanent, bulk darnage condition;

-. Direct observation of cascades.

At low daunage levels, ceramics accommodate permanent displacement damage in the form of cation and anion vacancies and interstitials, as well as small clusters. Insight as to defect species present and their charge states can be obtained by employing various experimental techniques, among which the most commonly used is optical absorption. An example of the use of this technique is the work of Atobe et al. [2], in which various point defects and small aggregates were identified in neutron-irradiated $\mathrm{Al}_{2} \mathrm{O}_{3}$.

\section{Isolated High-Dose Damage}

Many ceramics will, after irradiation to damage levels on the order of one displacement per atom (about $1 \times 10^{25} \mathrm{n} / \mathrm{m}^{2}$ ) exhibit a population of defect aggregates such as cavities and interstitial dislocation loops. These aggregates, and other defects such as isolated vacancies, can have a profound effect on physical properties. For example, $\mathrm{Al}_{2} \mathrm{O}_{3}$ swells $4 \mathrm{vol}$. \% at $1100 \mathrm{~K}$ (Fig. 1) as a result of the formation of $9 \mathrm{~nm}$ dia. cavities [3]. Fracture toughness of this material has doubled, apparently as a result of the interaction of cracks with the cavity population [4]. Room temperature thermal diffusivity is significantly reduced, an effect attributed to phonon scattering both from the cavities and from point defects or fine aggregates too small to be detected in conventional transmission electron microscopy [5].

Figure 1 also shows swelling data for $\mathrm{MgAl}_{2} \mathrm{O}_{4}$ spinel after elevated temperature neutron irradiation [3]. It can be seen that this material is highly resistant to dimensional changes, at least in single-crystal form. The microstructure of irradiated spinel exhibits only faulted interstitial dislocation loops [3], with the absence of cavities indicating that vacancies either remain in the dispersed state or for the most part recombine with interstitials. The lack of degradation of thermal diffusivity in single-crystal spinel [5] implies that most of the point defects have in fact recombined. Measurements carried out on $\mathrm{MgAl}_{2} \mathrm{O}_{4}$ after irradiation to 680 and $815 \mathrm{~K}$ show that this material is markedly strengthened by irradiation to a fluence of $2 \times 10^{26} \mathrm{n} / \mathrm{m}^{2}[6]$. Such strengthening may result from the interaction of propagating cracks with strain fields around the interstitial loops.

Ceramics with non-cubic crystal structures are subject to anisotropic swelling, which can result in high intergranular stresses that markedly reduce mechanical properties. This effect can best be seen in the data of Hickman on the hexagonal ceramic $\mathrm{BeO}$ [7]. Here it was found that beyond a fluence of $1 \times 10^{25} \mathrm{n} / \mathrm{m}^{2}$ at $348-373 \mathrm{~K}$ the polycrystalline form of this ceramic loses more that $90 \%$ of its strength.

Electrical conductivity of insulating ceramics is usually not greatly affected by prior displacement damage. However, this property has been shown by Klaffky et al. [8] to be strongly dependent on rate of absorption of ionizing energy during irradiation, with conductivity of $\mathrm{Al}_{2} \mathrm{O}_{3}$ exhibiting increases of several orders of magnitude. A potentially more serious problem has been identified by Hodgson [9]: when deposition of ionizing energy and displacement damage occur concurrently with application of an electric field, conductivity of $\mathrm{Al}_{2} \mathrm{O}_{3}$ over time shows an additional increase beyond that caused by flux effects. This phenomenon appears to be related to microstructural changes in the material.

Of particular importance to the use of ceramics in fusion reactors is the role of transmutation products. Calculations by Rovner and Hopkins [10] indicate that after ten years at the first wall of a $2 \mathrm{MW} / \mathrm{m}^{2}$ reactor, impurity levels of gaseous and metallic transmutation products can reach concentrations on the order of 1 atomic percent. The effects of such high impurity concentrations have not been investigated, but are expected to be significant. 


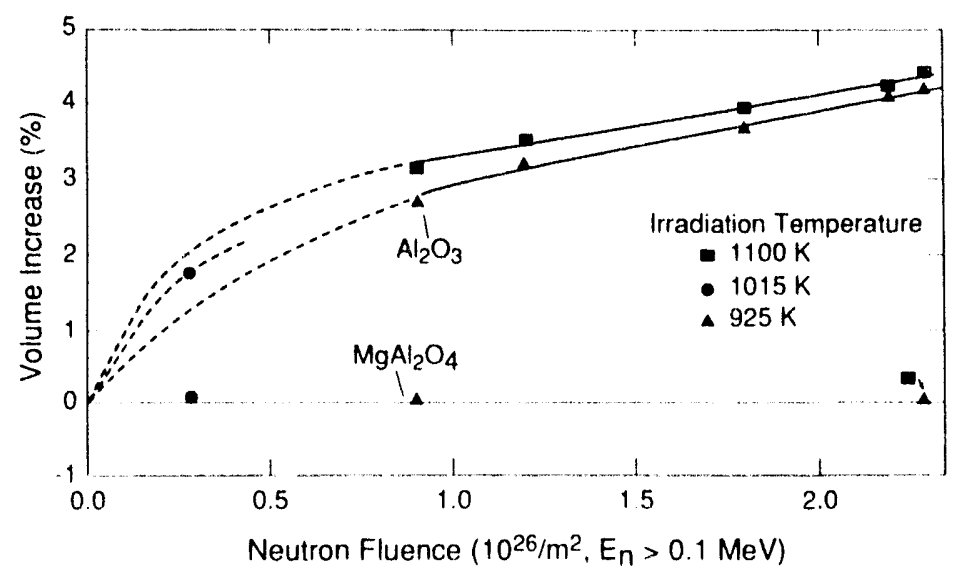

Fig. 1. Swelling of single-crystal $\mathrm{Al}_{2} \mathrm{O}_{3}$ and $\mathrm{MgNl}_{2} \mathrm{O}_{4}$ as a function of neutron fluence for three irradiation temperatures [3].

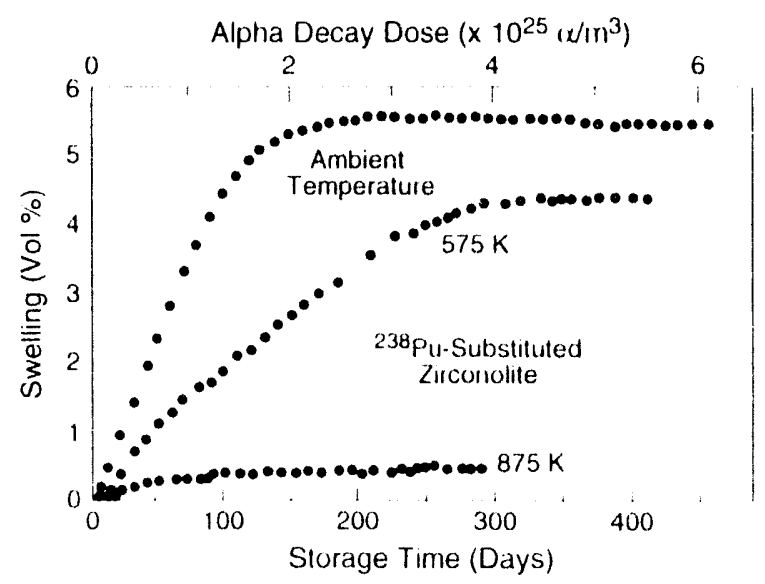

Fig. 2. Bulk swelling of $\mathrm{CaPuTi}_{2} \mathrm{O}_{7}$ as a function of temperature, damage dose, and storage time. Ambient temperature was aproximately $350 \mathrm{~K}$. [11].

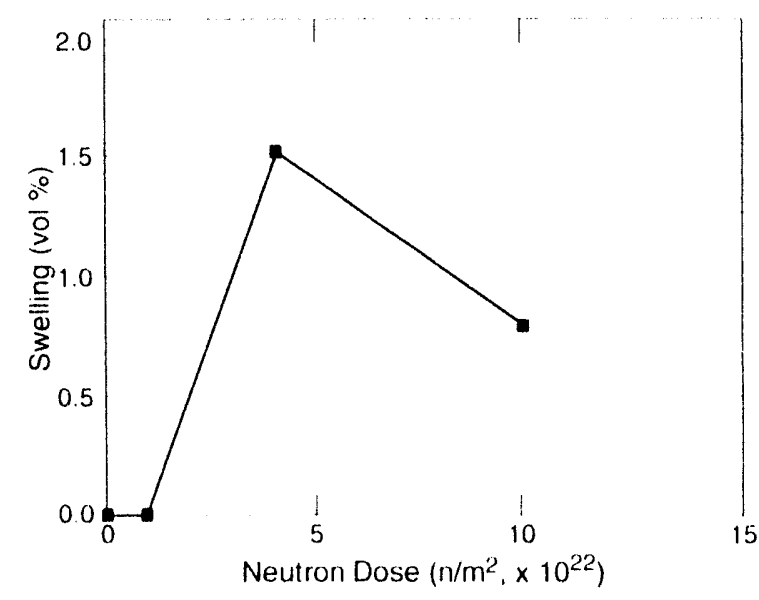

Fig. 3. Swelling of Macor at room temperature as a function of fluence of $14 \mathrm{MeV}$ neutrons [14]. 


\section{Amorphization}

Some ceramics, especially those with primarily covalent bonding, accommodate displacement damage by formation of localized microvolumes of disordered (variously referred to as amorphous, aperiodic, or metamict) material. With a sufficiently large damage dose, the ceramic can become completely amorphous.

An example of such irradiation behavior is the response of the simulated nuclear waste form $\mathrm{CaPuTi}_{2} \mathrm{O}_{7}$ to self-damage resulting from alpha decay of $238 \mathrm{Pu}$ [11]. Here, most of the damage results from recoil of the $\sim 100 \mathrm{keV}{ }^{234} \mathrm{U}$ ion. As can be seen from Fig. 2, this material exhibits significant swelling near room temperature, with saturation being reached at a damage level of about $1 \mathrm{dpa}$. If the material is held at $575 \mathrm{~K}$ during self-irradiation, a less-disordered condition is achieved and swelling is reduced. Aging at $875 \mathrm{~K}$ results in retention of the crystalline state, as damage is recovered concurrently with its formation.

With respect to fusion applications, silicate-based insulators, which are specified for use in diagnostic applications, are most likely to undergo a crystalline-to-amorphous transformation. For example, crystalline quartz $\left(\mathrm{SiO}_{2}\right)$ has been shown to convert to an amorphous condition and undergo swelling of $14 \mathrm{vol} \%$ when irradiated near room temperature to a fluence of $2 \times 10^{24} \mathrm{n} / \mathrm{m}^{2}$ [12]. Such a dose, although modest for ceramics such as $\mathrm{Al}_{2} \mathrm{O}_{3}$ and $\mathrm{MgAl}_{2} \mathrm{O}_{4}$, must be thought of as "high" for quartz.

\section{Damage Response of a Multiphase Ceramic}

Each phase of a multiphase materials system will have its own characteristic damage response under irradiation. It can be anticipated that some multiphase materials will perform less well than would each phase separately, as relative changes in some properties (e.g., density) may not easily be accommodated. An example of such a system is Macor, a machinable glass-ceramic [13]. This material consists of two silicate phases, one crystalline and one amorphous; the microstructure is made up of 1 to 10 micron platelets of crystalline mica dispersed in a borosilicate glass matrix, with each phase comprising approximately $50 \mathrm{vol} \%$ of the glass-ceramic.

Irradiation of Macor to a fluence of $1 \times 10^{23} \mathrm{n} / \mathrm{m}^{2}$ at room temperature results in the unusual swelling behavior shown in Fig. 3 [14]: after an incubation period swelling rises to $1.5 \mathrm{vol} \%$, but is then halved at a higher fluence. This behavior has been interpreted [14] by use of a model based on information in the literature on the swelling behavior of crystalline and amorphous silicates, along with the experimental data of Fig. 3. The model assumes that each phase begins to change in density after an incubation period, and swells or densifies exponentially with fluence to a steady-state value. Making use of data showing densification of amorphous $\mathrm{SiO}_{2}$ [12] and swelling of mica [15], it was possible to fit the experimental swelling curve for Macor with fair accuracy and to predict a saturation swelling value for the glass-ceramic of less than 0.5 vol \% [14]. However, it should be recognized that this reasonably good dimensional stability may, because of differential swelling, be accompanied by high internal strains, microcracking, and significant strength loss.

\section{FUTURE WORK}

Irradiation behavior of ceramics as fluence is increased from low to high doses cannot easily be generalized, because of the variety of damage responses that can occur. Future materials and reactor design studies should take into account (1) the major changes that can occur in ceramics which retain their crystallinity at high fluences, (2) the possibility that some ceramics may become amorphous under irradiation at relatively low doses, and (3) the likelihood that multiphase ceramics will suffer degradation of physical properties primarily because of differences in damage response between each phase rather than from intrinsic damage effects in the separate phases. 


\section{REFERENCES}

1. This report is an abbreviated version of a paper that will appear in the Journal of Nuclear Materials.

2. K, Atobe, N. Nishimoto and M. Nakagawa, Phys. Stat. Sol. 89 (1985) 155.

3. F. W. Clinard, Jr., L. W. Hobbs and G. F. Hurley, J. Nucl. Mater. 108\&109 (i982) 655.

4. F. W. Clinard, Jr., G. F. Hurley, R. A. Youngman and L. W. Hobbs, J. Nucl. Mater. 133\&134 (1985) 701.

5. F. W. Clinard, Jr. and L. W. Hobbs, in: Physics of Radiation Effects in Crystals, eds. R. A. Johnson and A. N. Orlov (North Holland, Amsterdam, 1986) p. 387.

6. F. W. Clinard, Jr., G. F. Hurley, L. W. Hobbs, D. L. Rohr and R. A. Youngman, J. Nucl. Mater. $122 \& 123(1984) 1386$.

7. B. S. Hickman, Radiation Effects in Beryllium and Beryllium Oxide, in: Studies in Radiation Effects, Series A, Physical and Chemical, Vol. 1, ed. G. J. Dienes (Gordon and Breach, New York, 1966) p. 72.

8. R. W Klaftky, B. H. Rose, A. N. Goland and G. J. Dienes, Phys. Rev. B21 (1980) 3610.

9. E. R Hodgson, J. Nucl. Mater. 191-194 (1992) 552.

10. L. H. Rovner and G. R. Hopkins, Nucl. Technol. 29 (1976) 274.

11. W. A. Coghlan and F. W. Clinard, Jr., J. Less-Common Metals 140 (1988) 255.

12. M. Wittels and F. A. Sherill, Phys. Rev. 93 (1954) 1117.

13. Macor is a product of Corning Glass Works, Corning, NY.

14. W. A. Coghlan and F. W. Clinard, Jr., J. Nucl. Mater. 179-181 (1991) 391.

15. C. D. Bopp, O. Sisman and R. L. Towns, The Effect of Irradiation on the Thermal Stability of Muscovite Mica, Oak Ridge National Laboratory Report ORNL-3017 (1960). 
THE EFFECT OF RADIATION INDUCED ELECTRICAL CONDUCTIVITY (RIC) ON THE THERMAL CONDUCTIVITY OF SAPPHIRE AT $77 \mathrm{~K}-$ D.P. White (Oak Ridge National Latoratory)

\section{OBJECTIVE}

This work is intended to provide information on the changes expected in the thermal conductivity of sapphire dise to the scattering of phonons by conduction band electrons, which are present due to the RIC.

\section{SUMMARY}

Microwave heating of plasmas in fusion reactors requires the development of microwave windows through which the microwaves can pass without great losses. The degradation of the thermal conductivity of alumina in a radiation enviromnent is an important consideration in reliability studies of these microwave windows. Several recent papers $\{1,2,3\}$ have adciressed this question at ligher temperatures and at low temperatures [4|. The current paper extends the low temperature calculations to determine the effect of phonon-electron scattering on the ther lal conductivity at 77 $K$ due to RIC These low temperature calculations are of interest because the successful application of high power $(>1 \mathrm{MW})$ windows for electron (ycloten heating systems in fusion reactors will most likely require cryogenic cooling to take advantage of the low loss tangent and higher thermal conductivity of candidate window materials at these temperatures.

\section{PROCIRESS AND STATUS}

\section{Introduction}

The lattice thermal conductivity is calculated using the (allaway fol formulation of the thermal conductivity integral given in Ref 4. In order to calculate the thermal conductivity using this formulation it is necessary to have functional forms for the relaxation times for the varions phonon scattering mechanisms As in Ref 4 the normal process relaxation time, the unklapp phomon relaxition time, the bondary scattering relaxation time, and the intrissic point defect scattering relaxation time used are those obtained by de Cioer |6| for a cyliudrical sapphire sampere 50 mon long and mmon in diancter ede Coor's sample 5)

In order to determine the effect of phonon-electron scattering on the thermal conductivity the phonon-electron relaxation time must be included as a resistive phonon scattering process in the Callaway formulation. The phomen-electron relaxation time may be obtained though a momentum balance argument $|3|$ and is of the form:

$$
\frac{1}{\tau_{p-\epsilon}} \frac{3 v^{2}}{\mu^{2}} \frac{\sigma}{C T}
$$

where $v$ is the phomon velocity, $\mu$ is the clectron mobility. $C$ is the phomon specific heat of those phonons which are allowed to interact with the conduction band electrons (due to encrgy and wave-vector conservation considerations), $\sigma$ is the electrical conductivity, and $T$ is the temperature. 


\section{Calculation}

The relaxation time given in Eq. 1 must be evaluated in order to use it in the thermal conductivity integral. Klaffky et. al. [7] found evidence of a temperature independent mobility for $T<300 \mathrm{~K}$, and Hughes $[8]$ reported a temperature independent mobility of $(3 \pm 1) \times 10^{-4} \mathrm{~m}^{2} / V-s$ for an undoped aluminum sample between 100 and $350 \mathrm{~K}$. In the calculations presented here it is assumed that this constant mobility holds to $77 \mathrm{~K}$.

The specific heat, $C$, of those phonons up to a cut off frequency of $\omega_{c}=\frac{2 v}{h}\left(2 m k_{B} T\right)^{1 / 2}$ is given, in the Debye approximation, by:

$$
C=9 n k_{B}\left(\frac{T}{\Theta_{D}}\right)^{3} \int_{0}^{\Theta_{c} / T} \frac{x^{4} \exp x}{(\exp x-1)^{2}} d x .
$$

In these expressions, $m$ is the electron mass, $k_{B}$ is the Boltzmann constant, $n$ is the number of unit cells per unit volune, $\Theta_{D}$ is the Debye temperature, $\Theta_{c}$ is the phonon-electron cut off temperature given by $\Theta_{c}=h \omega_{c} / k_{B}, x=h \omega / k_{B} T$, where $h$ is Plank's constant divided by $2 \pi$, and $\omega$ is the phonon angular frequency. The expression given in Eq. 2 may be evaluated by numerical integration for any particular temperature and then this value may be used in the relaxation time of Eq. 1. The value of the phonon velocity is $v=7 \times 10^{3} \mathrm{~m} / \mathrm{s}$.

It is possible to calculate the changes in the thermal conductivity due to changes in $\sigma$ by numerically evaluating the Callaway thermal conductivity integral for different values of $\sigma$ in the phonon-electron relaxation time.

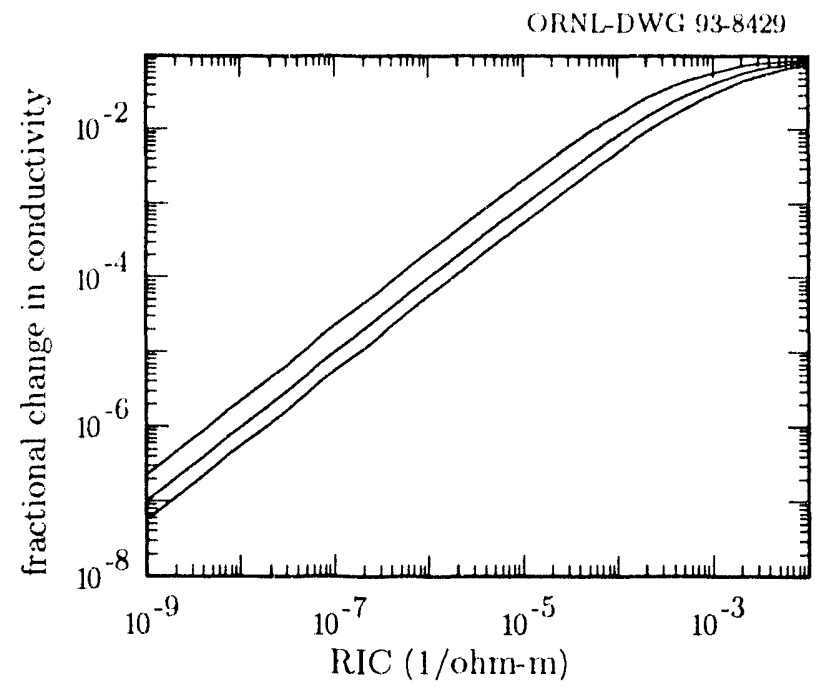

Figure 1: Fractional change in the lattice thermal conductivity versus RIC at $77 \mathrm{~K}$. Each curve corresponds to a different value of the electron mobility, covering the range of uncertainty in the mobility $(3 \pm 1) \times 10^{-4} \mathrm{~m}^{2} / \mathrm{V}-\mathrm{s}$. The upper curve corresponds to $\mu=2 \times 10^{-4} \mathrm{~m}^{2} / \mathrm{V}-\mathrm{s}$, the conter curve to $\mu=3 \times 10^{-4} \mathrm{~m}^{2} / \mathrm{V}-\mathrm{s}$, and the lower curve to $\mu=4 \times 10^{-4} \mathrm{~m}^{2} / \mathrm{V}-\mathrm{s}$. 


\section{Results of Calculations}

The results of the thermal conductivity calculations are given in Fig. 1. In this figure the fractional change in the themal conductivity versus RIC is plotted. The three different curves correspond to different values of the electron mobility, covering the range of uncertainty in the electron mobility. The upper curve corresponds to $\mu=2 \times 10^{-4} \mathrm{~m}^{2} / V-s$, the middle curve corresponds to $\mu=$ $3 \times 10^{-4} \mathrm{~m}^{2} / V-s$, and the lower curve corresponds to $\mu=4 \times 10^{-4} \mathrm{~m}^{2} / V-s$. Fom this plot it can be seen that at the highest values of the RIC plotted, the change in the thermal conductivity approaches a maximum of about $9 \%$. This value corresponds to the case of all phonons below the cut off frequency being strongly scattered, and thus is the limiting value of the reduction in the thermal conductivity which can occur at this temperature due to phonon-electron scattering.

\section{DISCUSSION AND CONCLUISIONS}

The maximum of the range of prompt RIC values in sapphire in a fusion environment is expected to be on the order of $10^{-5}(S 2-m)^{-1}$. Using this value for the RIC the corresponding range for the fractional change in the thermal conductivity is from $0.05 \%$ to $0.2 \%$ at $77 \mathrm{~K}$. It was found $[1,3]$ that at $300 \mathrm{~K}$ the expected fractional change in the conductivity at this value of the RIC was about $0.01 \%$. Thus the effect of phonon-electron scattering on the thermal conductivity is larger at low temperatures but these are very small changes in the themal conductivity and are not expected to be of importance in the design of microwave windows. Even in the extreme case of very large values of the RIC: the maximum effect the phonon-electron interaction can tave on the thermal conductivity is about $9 \%$, as pointed out in the previous section. It should also be noted that there is essentially no change in the themal conductivity due to the snall electronic component added by the RIC, as pointed out in Ref. 3.

These changes are particularly insignificant when the temperature dependence of the thernal conductivity at low temperatures is considered. In this low temperature region the thermal conductivity is strongly temperature dependent; for example, in the region aromd $77 \mathrm{~K}$ calculations show that a $1 \%$ change in the temperature leads to a $4 \%$ change in the thermal conductivity. Thus the effects of temperature fluctuations on the thermal conductivity are expected to be at least as inportant as ally effects due to phomon-electron scattering

The small changes expected in the thermal conductivity due to phonon electron scattering suggest that there is no need for in-situ themal conductivity measurements in order 10 study this effect. However this does not rule out the need for performing in-situ cryogenic themal conductivity tests in order to study the effects of thermally unstable radiation produced defects.

\section{FUTURE WORK}

It is planned to further investigate phonon-electron scattering effects in the presence of radiation induced vacancies. This will be of interest because as the point defect concentration is increased, the thernal conductivity at low temperatures is a much shallower function of temperature $[9,10]$ and it can be reduced on the order of $90 \%$ [4]. Because point defects and electrons scatter phonons on opposite ends of the phonon spectrum the phonon-electron effect may becone significant, at high point defect concentrations for these reasons. 


\section{REFERENCES}

1. D.P. White, Fusion Reactor Materials Semiann. Prog. Report DOE/ER-0313/11, 277, (1991).

2. D.P. White, Fusion Reactor Materials Semiann. Prog. Report DOE/ER-0313/12, 298, (1992).

3. D.P. White, J. Appl. Phys., 73, 2254, (1993).

4. D.P. White, Fusion Reactor Materials Semiann. Prog. Report DOE/ER-0313/13, (1992).

5. J. Callaway, Phys. Rev., 113, 1046, (1959).

6. A.M. de Goer, J. Phys. (Paris), 30, 389, (1969).

7. R.W. Klaffky, B.H. Rose, A.N. Goland, and G.J. Dienes, Phys. Rev B, 21, 3610, (1980).

8. R.C. Hughes, Phys. Rev. B, 19, 5318, (1979).

9. B. Schulz, J. Nucl. Mater., 155-157, 348, (1988).

10. M. Rohde and B. Schulz, J. Nucl. Mater., 173, 289, (1990). 
Surface Preparation Effects in Near Surface Modulus Measurement for CVD SiC M. C. Osborne (Rensselaer Polytechnic Institute), L. L. Snead (Oak Ridge National Laboratory), and D. Steiner (Rensselaer Polytechnic Institute)

\section{OBJECTIVE}

This study was perforned to deternine the variation in the measured modulus resulting from the use of various polishing grits on CVD SiC, when taking shallow indents $(20 \mathrm{~nm})$ on a SiC/Nicalon TM composite sample. When ion bombarding the $\mathrm{SiC}$ composite, the ion penetration is only a few microns. To measure the modulus as a function of the damage level, Nanoindenter ${ }^{T M}$ indents are made on the material in cross-section at various depths below the surface presented to the incoming ions. ${ }^{1,2}$ The purpose of making shallow indents is to minimize the volume sampled at a given depth, which leads to a more accurate determination of the modulus at any damage level.

\section{SUMMARY}

Surface preparation has an observable effect on the data obtained from the Nanoindenter for shallow $(20 \mathrm{~nm})$ indents on CVD SiC when polished with Syton ${ }^{\mathrm{T} M}$. This observed effect is significantly less for $1 / 2$ micron diamond polished CVD SiC and for deep $(160 \mathrm{~nm}$ ) indents. These effects were manifested by the relative variations in the experimental modulus and hardness data. An analytical analysis of the anticipated variation in the modulus and hardness is performed and shown to correlate well with the observed trends. The observed variations appear ks be the result of $\mathrm{SiC}$ material properties, as well as surface preparation, since the predicted variations are much smaller than the observed variations.

\section{PROGRESS and STATUS}

\section{$\underline{\text { Intrexluction }}$}

In the study, variations in experimental molulus and hardness data are compared to modulus and hardness variations predicted serni-theoretically considering surface roughness as the only variable. $A$ load controlled Nanoindenter is empleyed to experimentally decermine modulus and hardness values for (VD) SiC and Nieadon. Mexdulus and hardness variations are defined as relative variations given by:

$$
\begin{aligned}
& \frac{\Delta E}{E}=\frac{E_{s}-E_{C}}{E_{s}} \\
& \frac{\Delta H}{H}=\frac{H_{S}-H_{C}}{H_{S}}
\end{aligned}
$$

where ES and IS are either (1) the average modulus or hardness deternined by the Nanoindenter (experimental) or (2) a calculated modulus or hardness for a flat (smoxth) surface. $\mathrm{F}_{\mathrm{C}}$ and $\mathrm{H}_{\mathrm{C}}$ are either (1) the average plus one standard deviation of the modulus or hardness determined by the Nanoindenter (experimental) or (2) a calculated modulus or hardness for a curved (rough) surface. 
The Nanoindenter determines the sample modulus, E, by the following equation: ${ }^{3}$

$$
E=\frac{1}{2} \frac{d P}{2 d h}\left(\frac{\pi}{A\left(h_{p}\right)}\right)^{1 / 2}
$$

where $\mathrm{A}\left(\mathrm{h}_{\mathrm{p}}\right)$ is the cross-sectional area of the indenter associated with the contact area projected onto the plane of the surface. The area $\left[A\left(h_{p}\right)\right]$ is determined as a function of the plastic depth $\left(h_{p}\right)$. This contact area is calculated by the Nanoindenter software assuming ideal Berkovich indenter tip geometry. The stiffness, $\mathrm{dP} / \mathrm{dh}$, is the slope of the unloading portion of the load-displacement curve generated by a loaddisplacement experiment as shown schematically in Fig. $1{ }^{4}$ The point at which the tangent line intersects the displacement axis is the plastic depth.

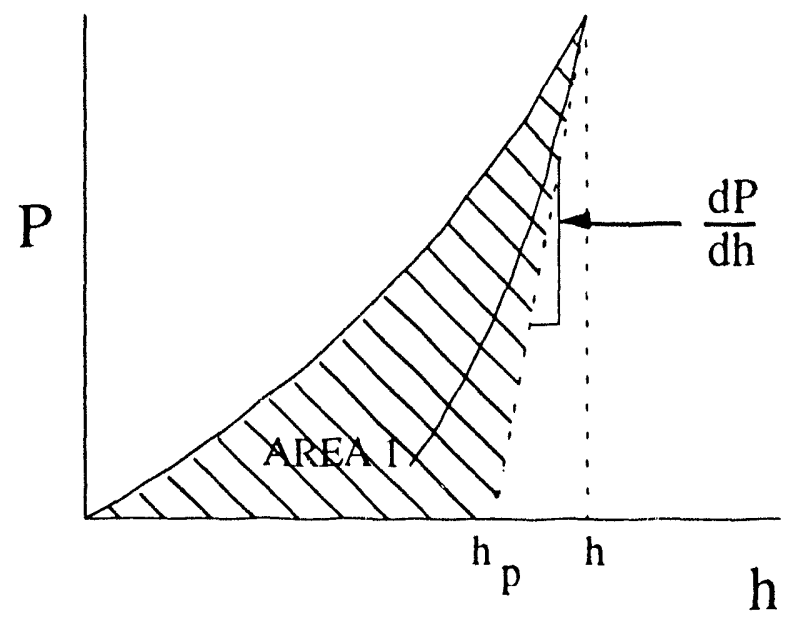

Figure 1. Indenter Load-Displacement Curve

The hardness, $\mathrm{H}$, is determined by the Nanoindenter from the following equation:

$$
H=\frac{P}{A\left(h_{p}\right)}
$$

where $P$ is the peak load.

Equations 1 through 4 are also used to predict theoretical variations in modulus and hardness for either a flat (smooth) or curved (rough) surface. The calculational approaches for obtaining $\mathrm{dP} / \mathrm{dh}, \mathrm{P}$, and $\mathrm{A}\left(\mathrm{h}_{\mathrm{p}}\right)$ are outlined below.

We first consider the evaluation of $\mathrm{dP} / \mathrm{dh}$, which can be expressed as:

$$
\frac{d P}{d h}=\frac{P}{\left(h-h_{p}\right)}
$$

where $h$ is the indenter depth. To determine $P, h$, and $h_{p}$, a knowledge of the volume of material plastically deformed by the indentation is required. For a flat surfece, this plastically deformed volume is hemispherical, with an assumed radius of about $10 \mathrm{~h}$ from the indenter tip when the indenter is at the desired depth.1,6 When the indent is made on a curved surface rather than a flat surface, a volume of material is/is not deformed by the indenter, depending on the indent location, as shown in Fig. 2. 


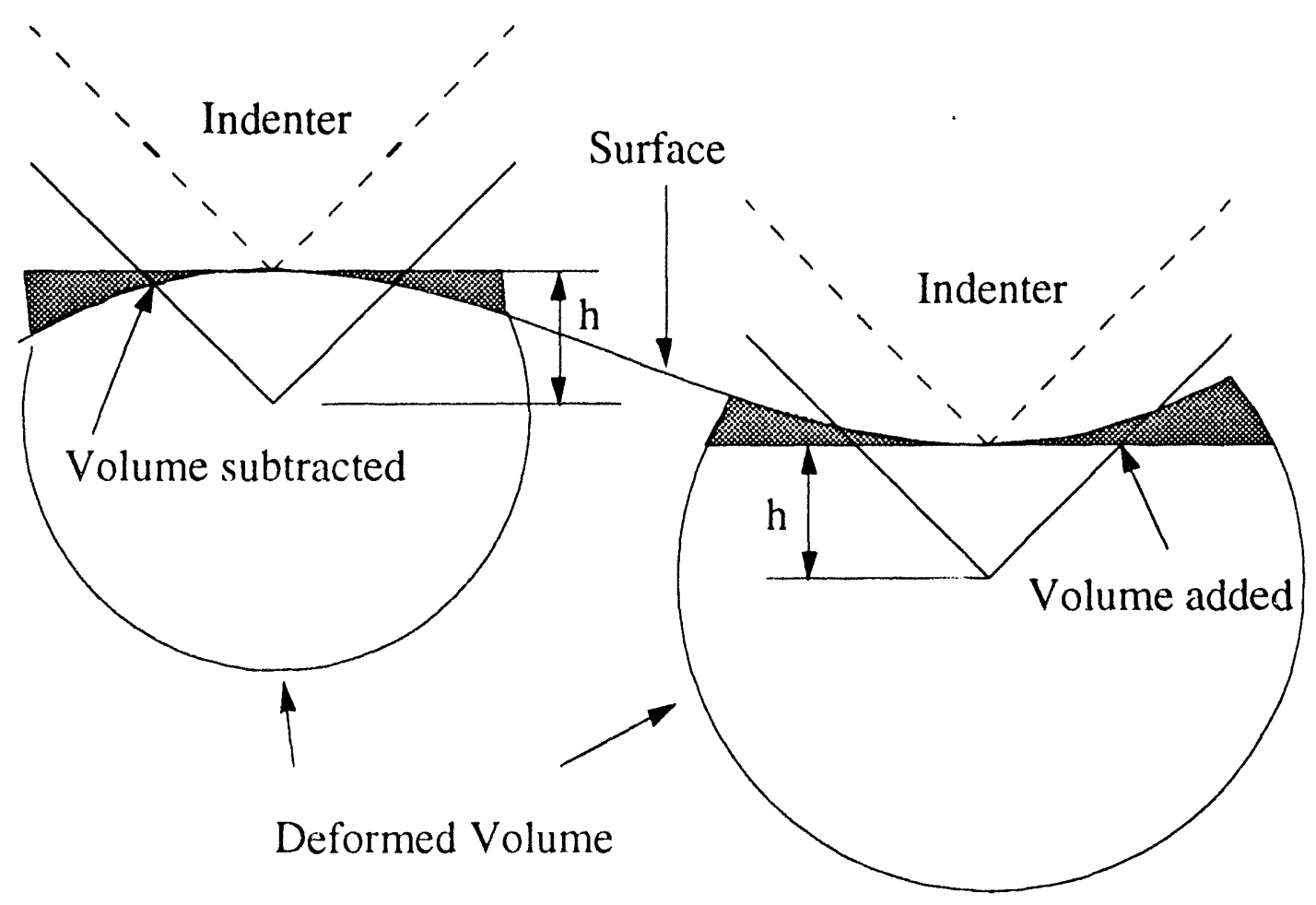

Figure 2 . Indent Cross-section Profile

Referring to Fig. 1, Area 1 represents the work done on the material due to plastic deformation and is proportional to the product of $\mathrm{P}$ and $\mathrm{h}_{\mathrm{p}}$. Assuming that the plastic strain energy per unit volume is approximately constant, since relatively little plastic deformation occurs in $\mathrm{SiC}$, the plastic work is also proportional to the volume of material plastically deformed. Therefore, the loads (P), plastic depths $\left(h_{p}\right)$, and volumes of plastically deforned material for that and curved surfaces are related as follows:

$$
\left(\frac{P h_{p}}{V_{\text {deformed }}}\right)_{\text {flat }}=\left(\frac{P h_{p}}{V_{\text {deformed }}}\right)_{\text {curved }}
$$

In the schematic of Fig. 2 (showing the cross-section of the indenter and sample) there is some volume of material that is added or subtracted depending on the indent location. The actual volume of material deformed by the indenter on a curved surface would equal the volume deformed when indenting on a flat surface plus/minus the volume between the true surface and the projected cross-section of the deformed volume onto a flat surface. Thus,

$$
V_{\text {deformed actual }}=V_{\text {deformed llat }} \pm V_{\text {surface difference }}
$$

The deformed volume for a flat surface is related to the indent depth. $h$, and can be estimated by:

$$
V_{\text {detomed flat }}=\frac{1}{2} \frac{4 \pi(10 h)^{3}}{3}+\pi(10 h)^{2} h
$$


The value $10 \mathrm{~h}$ is the assumed radial extent of the plastic deformation as measured from the indenter tip. 1,6 The volume between the true surface and the projected cross-section of the deformed volume can be calculated by assuming a surface variation function and then using integral calculus.

The plastic depth, $h_{p}$, for a flat surface is deternined by subtracting the total indentation depth, $h$, from the amount that the surface elasticly deformed. The elastic surface deformation caused some of the indenter to not contact the surface. The resulting plastic depth is deternined as follows: ${ }^{8}$

$$
h_{p}=h-h_{s}
$$

where $h_{S}$ is the elastic surface displacement due to indentation.

The elastic displacement can be intuitively derived by looking at the load displacement curve of Fig. 1. The elastic displacement, $h_{s}$, can be determined by the following:

$$
h_{s}=\varepsilon \frac{P_{\max }}{S}
$$

where $\varepsilon$ is a geometric constant to take into account indenter geometry, $P_{\max }$ is the peak load at the total displacement, and $S$ is the stiffness. Knowing that $S$ is $\mathrm{dP} / \mathrm{dh}$, and assuming reasonable values for $\varepsilon, P_{\max }$, and $E$, then $h_{p}$ for a flat surface can be calculated using Eqs. 3, 9, and 10. The calculation will involve an iterative process, since $A\left(h_{p}\right)$ is a complex function of $h_{p}$.

The calculation of the plastic depth for a rough surface is more complicated. After indentation, the indenter tip leaves an imprint whose volume is proportional to the volume of material that remains plastically deformed. This relationship is due to material conservation (continuity). A ratio relating flat to curved surfaces is given as follows:

$$
\frac{\frac{1}{3} A\left(h_{p_{c}}\right) h_{p_{c}}}{V_{\text {deformed }_{c}}}=\frac{\frac{1}{3} A\left(h_{p_{f}}\right) h_{p_{f}}}{V_{\text {deformed }}}
$$

where the subscript $c$ or $f$ denote a curved or flat surface. The plastic depth for a curved surface can be determined by an iterative process similar to the one used to calculate the plastic depth for a flat surface.

Using Eqs. 5 through $11, \Delta \mathrm{E} / \mathrm{E}$ and $\Delta \mathrm{H} / \mathrm{H}$ can be calculated by inserting the appropriate values of loads, plastic depths, indent depths, and areas into Eqs. 1 through 4 to calculate moduli and hardness for flat and curved surfaces.

\section{Experimental Setup and Results}

Small samples ( $5 \mathrm{~mm} \times 5 \mathrm{~mm}$ ) of SiC/Nicalon composite were cut from a larger piece made at the High Temperature Materials Laboratory (ORNL). Every sample was ground flat on a 6 micron diamond impregnated disk and then went through a series of polishes to get to its final state, with each polish lasting about 20 minutes. The polishes were: 6 micron diamond paste to 3 micron diamond paste to $1 / 2$ micron diamond paste to Syton. Syton is a fine $\mathrm{SiO}_{2}$ powder suspended in $\mathrm{H}_{2} \mathrm{O}$. The final sample states were either 3 micron, 1/2 micron, or Syton. A series of indents was taken on both the fiber and matrix of each sample, using a load controlled Nanoindenter, to depths of 20,40,80, and $160 \mathrm{~nm}$. Average moduli and hardness were calculated for each series of indents at depths of $20 \mathrm{~nm}$ and $160 \mathrm{~nm}$ (the extremes of the indentation experiment). Each series consisted of a 20 to 50 indent array. Curves similar to Fig. 1 were generated for each indent. There were groups of samples for each polishing grit and they are numbered sequentially. If the sample had additional indents, then each additional indent was labeled sequentially. For 
example, if the sample had been Syton polished, was the second sample of the group, and was subjected to a second set of indents on the sample, then it would be labeled Syton 2,2. Table 1 gives the results for the $20 \mathrm{~nm}$ indents and Table 2 gives the results for the $160 \mathrm{~nm}$ indents.

\begin{tabular}{|c|c|c|c|c|}
\hline $\begin{array}{c}\text { Sample } \\
\text { Syton } \\
\text { polished CVD } \\
\text { SiC }\end{array}$ & $\begin{array}{c}\text { Average } \\
\text { modulus } \\
(\text { ( } P \text { Pa) }\end{array}$ & $\begin{array}{l}\text { Relative } \\
\text { variation }\end{array}$ & Hardness & $\begin{array}{l}\text { Relative } \\
\text { variation }\end{array}$ \\
\hline $\begin{array}{l}1.1 \\
2.1 \\
2.2 \\
2.3 \\
3.1 \\
4.1\end{array}$ & $\begin{array}{l}509 \\
456 \\
478 \\
474 \\
434 \\
542\end{array}$ & $\begin{array}{l}0.0585 \\
0.0822 \\
0.1674 \\
0.160 \\
0.0624 \\
0.119\end{array}$ & $\begin{array}{l}+5.6 \\
+4.0 \\
+6.4 \\
43.7 \\
34.9 \\
55.3\end{array}$ & $\begin{array}{l}0.0877 \\
0.0977 \\
0.101 \\
0.192 \\
0.0744 \\
0.161\end{array}$ \\
\hline $\begin{array}{l}\text { Averages } \\
1 / 2 \text { micron } \\
\text { diamond polished } \\
\text { CVD SiC }\end{array}$ & 482 & 0.0916 & 45.0 & 0.119 \\
\hline $\begin{array}{l}1.1 \\
1.2 \\
2.1\end{array}$ & $\begin{array}{l}401 \\
477 \\
410\end{array}$ & $\begin{array}{l}90555 \\
0.0413 \\
0.0665\end{array}$ & $\begin{array}{r}39.7 \\
+5.6 \\
34.9\end{array}$ & $\begin{array}{l}0.0756 \\
0.0658 \\
0.0659\end{array}$ \\
\hline $\begin{array}{c}\text { Averages } \\
3 \text { micron } \\
\text { diamond polished } \\
\text { CVD SiC }\end{array}$ & 459 & 0.0544 & $\$ 0.1$ & 0.0691 \\
\hline $\begin{array}{l}1.1 \\
1.2\end{array}$ & $\begin{array}{l}473 \\
457\end{array}$ & $\begin{array}{l}0.129 \\
0.128\end{array}$ & $\begin{array}{l}+8.2 \\
+8.1\end{array}$ & $\begin{array}{l}0.158 \\
0.158\end{array}$ \\
\hline Aterages & 465 & 0.128 & $\$ 8.1$ & 0.158 \\
\hline
\end{tabular}

Table 2. Modulus and hardness for (VD SiC at an indent depth of $160 \mathrm{~nm}$

\begin{tabular}{|c|c|c|c|c|}
\hline $\begin{array}{c}\text { Sample } \\
\text { Syton } \\
\text { polished CVD } \\
\text { SiC }\end{array}$ & $\begin{array}{c}\text { Average } \\
\text { modulus } \\
\text { (CiPa! }\end{array}$ & $\begin{array}{l}\text { Relative } \\
\text { variation }\end{array}$ & Hardness & $\begin{array}{l}\text { Relative } \\
\text { variation }\end{array}$ \\
\hline $\begin{array}{l}1,1 \\
2,1 \\
2.2 \\
2.2 \\
3.1 \\
3.1 \\
4.1\end{array}$ & $\begin{array}{l}513 \\
4619 \\
474 \\
45 \\
371 \\
4 \times 1\end{array}$ & $\begin{array}{l}0.0337 \\
\text { 1) } 0356 \\
00.344 \\
0.4 .54 \\
0.0383 \\
00340\end{array}$ & $\begin{array}{l}+1.7 \\
+3.1 \\
+4.5 \\
40.9 \\
20.2 \\
+3.7\end{array}$ & $\begin{array}{l}0.0360 \\
0.0510 \\
0.0449 \\
0.0636 \\
0.0297 \\
0.0389\end{array}$ \\
\hline $\begin{array}{c}\text { Dierages } \\
1 / 2 \text { micron } \\
\text { diamond polished } \\
\text { CVD SiC: }\end{array}$ & isis & 00360 & 30.0 & 0.440 \\
\hline $\begin{array}{l}1.1 \\
1.2 \\
2.1\end{array}$ & $\begin{array}{l}+k i \\
4 i 1 \\
\vdots \vdots i)\end{array}$ & $\begin{array}{l}00170 \\
00274 \\
0251\end{array}$ & $\begin{array}{l}17.2 \\
35.9 \\
23.9\end{array}$ & $\begin{array}{l}0.0323 \\
0.0418 \\
0.0251\end{array}$ \\
\hline $\begin{array}{l}\text { lveragcs } \\
3 \text { micron } \\
\text { diamond polished } \\
\text { CVD SiC }\end{array}$ & 427 & 00232 & $: 2.3$ & 0.0331 \\
\hline $\begin{array}{l}1.1 \\
1.2\end{array}$ & $\begin{array}{l}466 \\
474\end{array}$ & $\begin{array}{l}00539 \\
0.0521\end{array}$ & $\begin{array}{l}+2.8 \\
+3.7\end{array}$ & $\begin{array}{l}0.0678 \\
\text { 1) } 0641\end{array}$ \\
\hline iverages & 470 & 1015530 & +33 & $0.06 \in 0$ \\
\hline
\end{tabular}


The Nicalon fibers were also indented. Only one sample for each polish grit was indented for the fibers. The results for Nicalon fibers are shown in Table 3.

Table 3. Modulus and hardness of Nicalon fiber, at indent denths of $20 \mathrm{~nm}$ and $160 \mathrm{~nm}$

\begin{tabular}{lcccc}
\hline \multicolumn{1}{c}{ Polish } & $\begin{array}{c}\text { Average } \\
\text { modulus (GPa) }\end{array}$ & $\begin{array}{c}\text { Relative } \\
\text { variation }\end{array}$ & Hardness & $\begin{array}{c}\text { Relative } \\
\text { variation }\end{array}$ \\
\hline indent(20 $\mathrm{nm})$ & & & & \\
Syton & 191 & 0.0445 & 20.2 & 0.0743 \\
$1 / 2$ micron & 217 & 0.106 & 25.4 & 0.177 \\
3 micron & 216 & 0.206 & 23.9 & 0.247 \\
& & & & \\
indent $(150 \mathrm{~nm})$ & & & & \\
& 176 & 0.0256 & 18.3 & 0.0273 \\
Syton & 185 & 0.0438 & 20.8 & 0.0338 \\
$1 / 2$ micron & 190 & 0.0721 & 21.7 & 0.0691 \\
3 micron & & & & \\
\hline
\end{tabular}

A 1/2 micron and a Syton sample were inspected using an atomic force microscope (AFM) to resolve the surface roughness. The surface profiles allowed the determination of the peak to valley height for the different polishes. Typical micrographs are shown in Figure 3. Figure 3a shows the surface profile of a Syton polished composite sample. It is obvious from the micrograph that the CVD SiC matrix has a rougher surface than the Nicalon fiber. Because the Syton is a very fine ( $\sim 0.05$ micron) polish of silica, preferential removal of the matrix can take place. Figure 3a shows a radial ridge typical of the radially grown CVD SiC grains. The individual grains are polished at different rates and are therefore exposed along with the growth toundaries. Figure 3b shows an AFM image of an indent taken on the Syton polished CVD SiC demonstrating that the ridge structure is on a scale which is significant as compared to the indent. Because the Nicalon fiber is made up of very fine $\mathrm{SiC}$ crystallites $(\sim 10 \mathrm{~nm})$ in an amorphous matrix of glass, no preferential polishing takes place, leaving a relatively smooth surface (Fig. 3a).

Figure 3c shows a micrograph of diamond indents taken on a 1/2 micron polished CVD surface at about half the magnification shown in $3 \mathrm{~b}$. It can be seet. from this micrograph that the diamond polish has not left behind the fine ridge structure caused by Syton polishing. This is to be expected, as the diamond polishing media is harder than the CVD SiC and is also on the order of size of the grains.

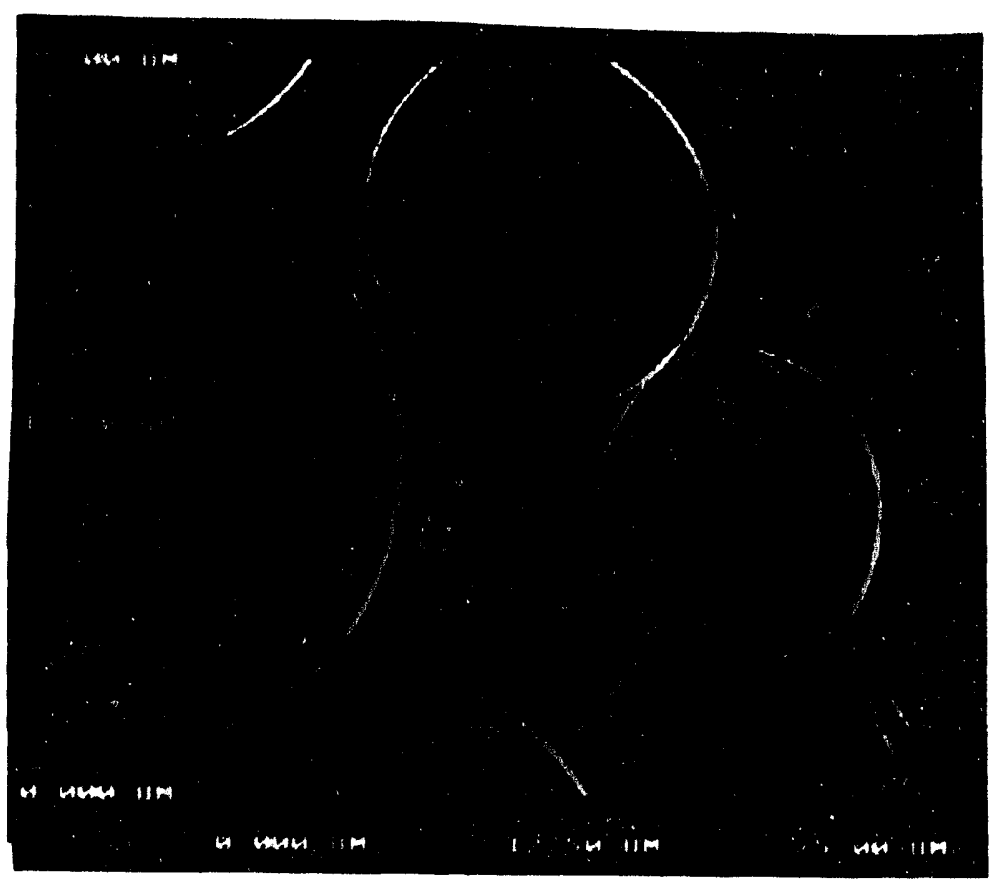



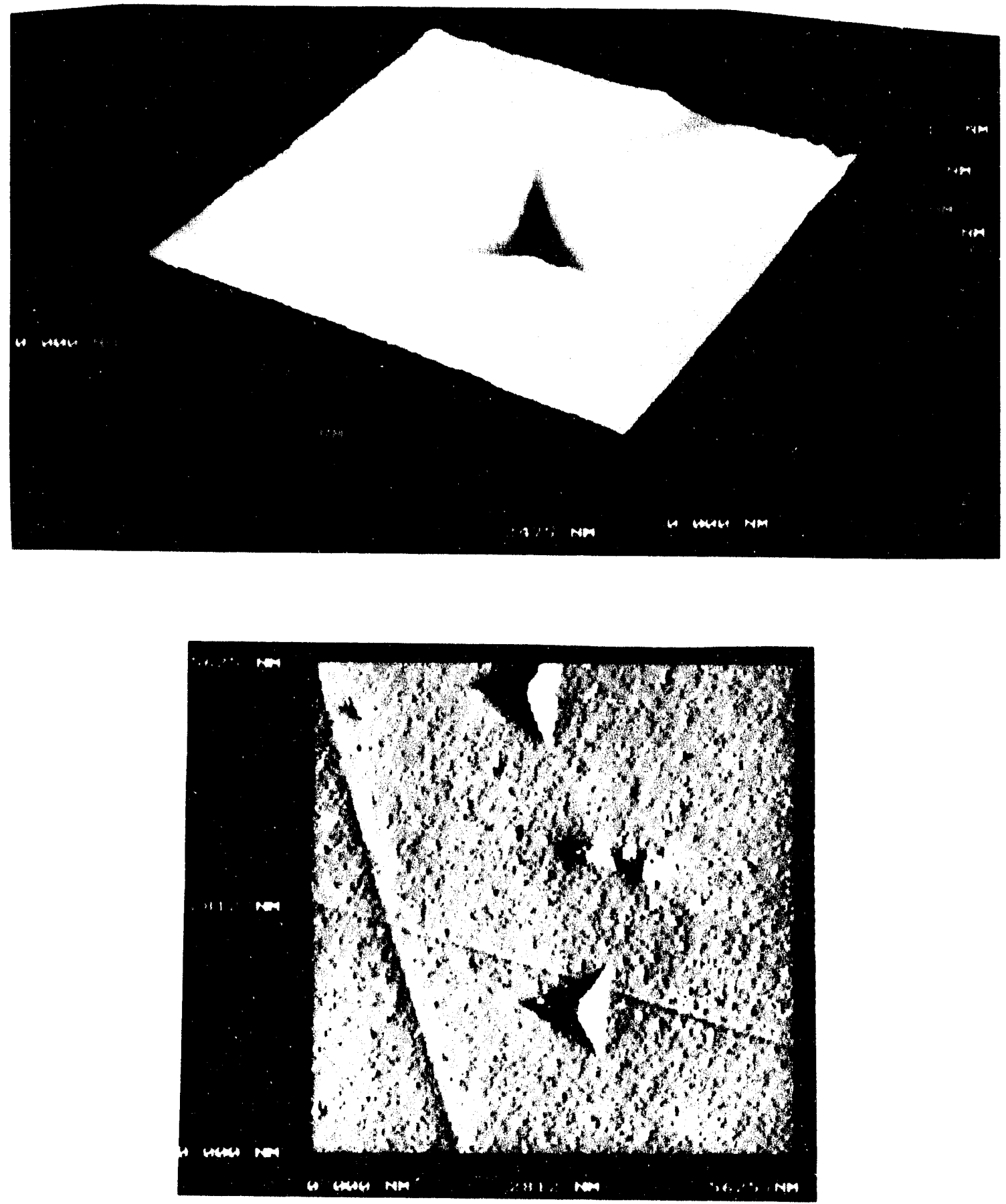

Figure 3. AFM Images on CVD SiC Matrix: (a) $1 / 2$ micron diamond polish with two indents, (b) Syton polish (c) micrograph of diamond indents taken on a $1 / 2$ micron polished CVD surface at about half the magnification shown in $3 \mathrm{~b}$. 
The AFM was able to show the surface contour of the CVD matrix for the Syton and $1 / 2$ micron polishes, as well as for the Syton polished fiber. Sample contours of each case are shown in Figure 4.

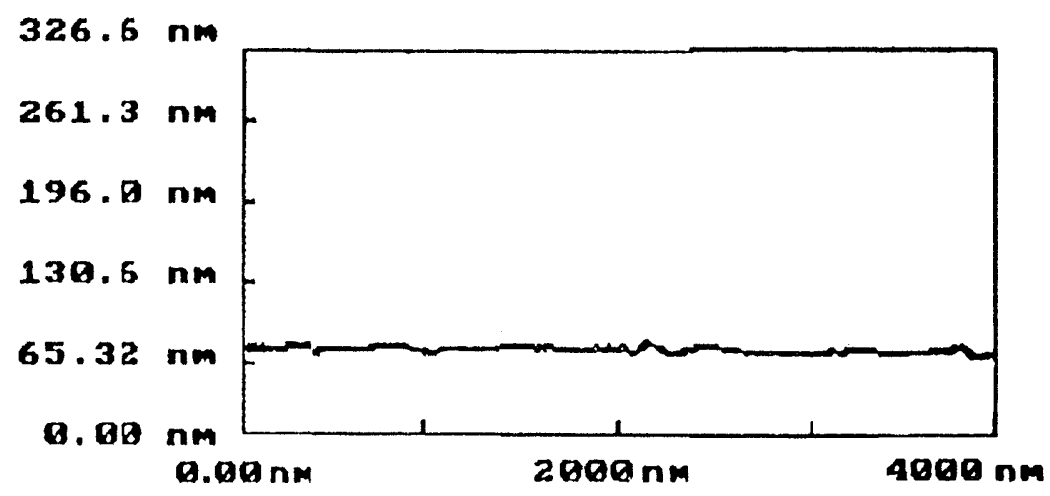

(a)

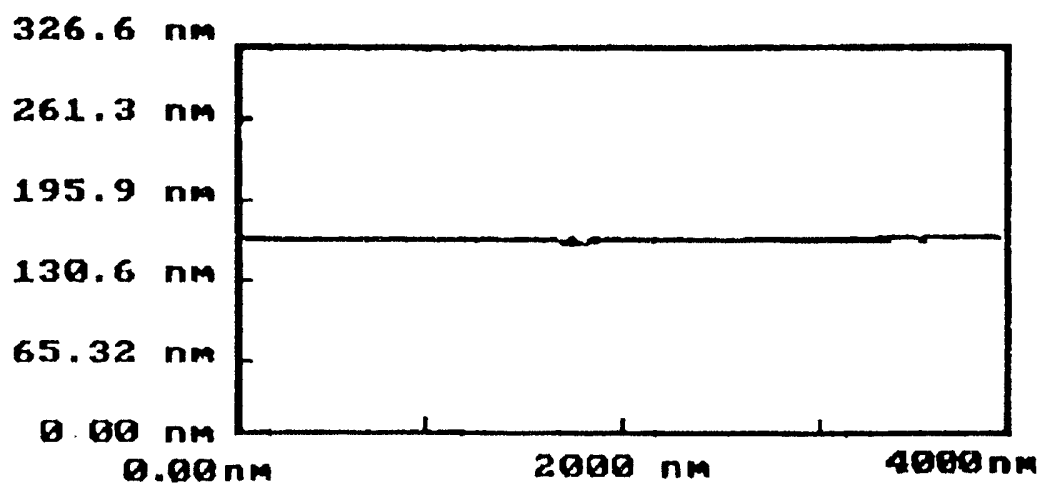

(b)

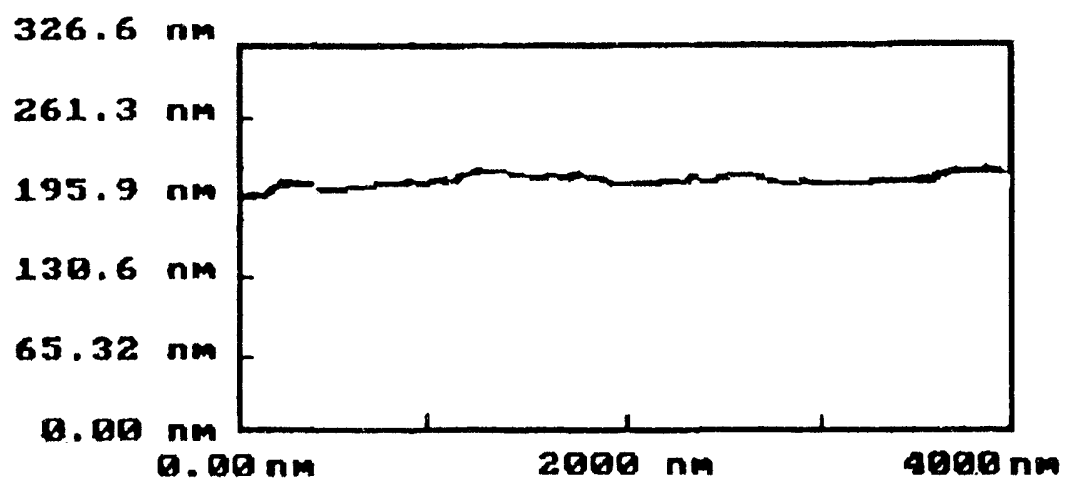

(c)

Figure 4. AFM Contours (a) 1/2 micron diamond polish on CVD SiC; (b) Syton polish on Nicalon; and (c)Syton polish on C.VD SiC. 


\section{DISCUSSION}

For the Nicalon fiber, the relative variations in modulus and hardness decrease for the finer polishes. This result was expected because the Nicalon has very small b-SiC crystals (order of a few nanometers) and has amorphous regions. ${ }^{7}$ This makes the material softer (lower in hardness and modulus than the CVD SiC) and, therefore, easily ground and polished to make the fiber approach a flat surface profile. Also, for the deeper indents ( $160 \mathrm{~nm}$ vs. $20 \mathrm{~nm})$, there is less relative variation in the modulus and hardness. This result was expected for the deeper indents because of the larger volume sampled. The small (relatively) surface variations have less of an effect for the deep indents than for the shallow indents.

As shown in Table 1, there is greater variation for the Syton polished CVD SiC than for the $1 / 2$ micron polish. This result was not expected because the finer polish should produce a flatter smoother surface, but for the CVD SiC it did not. The variation increases for the 3 micron polished samples. This result is expected because the 3 micron diamond leaves scratches on the surface that can lead to large surface variations.

As discussed earlier, the volume of material displaced varies with elevation change on the sample surface. Assuming the sample surface has a sinusoidal variation, the relative modulus and hardness variations can be estimated. For the assumed sinusoidal surface, the peak to valley height was chosen as the average height plus one standard deviation. This choice of height is expected to account for most of the height variation on the sample surface. The peak to valley average heights were calculated from contours similar to the ones shown in Figure 4. The peak to valley heights used were $20 \mathrm{~nm}$ for Syton and $5 \mathrm{~nm}$ for $1 / 2$ micron diamond polished CVD SiC. The wavelength associated with the idealized sinusoidal surface was estimated to be $300 \mathrm{~nm}$. From these values, relative moduli and hardness variations were calculated for $20 \mathrm{~nm}$ and $160 \mathrm{~nm}$ indents and are shown in Table 4 . The plastic depths for flat surfaces were calculated to be $12.29 \mathrm{~nm}$ and $123.00 \mathrm{~nm}$, respectively, using e as .75, E as $400 \mathrm{GPa}, P_{\max }$ as $.4 \mathrm{mN}$ (20 nm indents), and $15 \mathrm{mN}$ (160 nm indents).

Table 4. Analytically determined modulus and hardness variations

\begin{tabular}{|c|c|c|c|c|}
\hline \multirow[b]{2}{*}{ Polish } & \multicolumn{2}{|c|}{ Indent in peak } & \multicolumn{2}{|c|}{ Indent in valley } \\
\hline & $\Delta \mathrm{E} / \mathrm{E}$ & $\Delta \mathrm{II} / \mathrm{H}$ & $\triangle \mathrm{E} / \mathrm{E}$ & $\Delta H / H$ \\
\hline \multicolumn{5}{|l|}{ indent depth $(20 \mathrm{~nm})$} \\
\hline Syton & 0.0632 & -0.00046 & -0.0650 & 0.000577 \\
\hline $1 / 2$ micron diamond & 0.0162 & 0.00074 & -0.0163 & -0.0000753 \\
\hline \multicolumn{5}{|l|}{ indent depth ( $160 \mathrm{~nm})$} \\
\hline Syton & 0.0145 & 0.00009 & -0.0152 & 0.000037 \\
\hline $1 / 2$ micron diamond & 0.0047 & -0.00192 & -0.0038 & -0.000047 \\
\hline
\end{tabular}

The results shown in Table 4 are consistent with the data for the $20 \mathrm{~nm}$ indents, since there is a larger variation in the modulus for the Syton results than for the 1/2 micron diamond results. The calculations are also consistent with the results when comparing the $20 \mathrm{~nm}$ and $160 \mathrm{~nm}$ indents, since the variations are lower for $160 \mathrm{~nm}$ than for $20 \mathrm{~nm}$ indents.

These analytical results suggest that the surface preparation has a several percent effect on the 20 $\mathrm{nm}$ Syton polished samples, while for all the other calculated indentations, the effect was about $1.5 \%$ or less. Thus, the calculated variations in modulus for $20 \mathrm{~nm}$ indents on Syton polished CVD SiC are at least four times greater than the other calculated variations. Also, the calculated variations for the $1 / 2$ micron diamond polished and the $160 \mathrm{~nm}$ indents are much lower than their corresponding experimental values. 
Therefore, it is reasonable to assume that there are other effects causing the variations, especially in the case of the $20 \mathrm{~nm}, 1 / 2$ micron diamond polished CVD SiC.

In comparing the data of Tables 1 and 2 , the variation in modulus decreases when going from 20 $\mathrm{nm}$ and $160 \mathrm{~nm}$. This result is expected, since a larger volume of material is sampled for the $160 \mathrm{~nm}$ indents than for the $20 \mathrm{~nm}$ indents, making the effects of small volume changes on the surface insignificant. These results are consistent with Table 4.

Comparing Tables 1 and 2, the overall average moduli dropped by about 20 GPa when comparing $160 \mathrm{~nm}$ and $20 \mathrm{~nm}$ indents. This effect is also expected and discussed in Reference 5 . The overall average moduli dropped another $20 \mathrm{GPa}$ when comparing Syton and 1/2 micron diamond polishes. This observation suggests that there is also a material effect, possibly grain size (sensing only one grain for shallow indents and many grains for the deeper indents) or slight plastic deformation of the polished surface from the diamond polish affecting the indentation.

When comparing the calculated hardness variations of Table 4 , these variations are much smaller than the modulus variations and show that there is not much of a surface effect on hardness values. Any differences in the magnitude or sign of the calculated hardness variations probably arise from rounding off errors in the calculations.

The two trends discussed above were not observed for the 3 micron diamond polish. It is suggested that some other material property is coming into play. There could be some slight plastic deformation of the surface due to the 3 micron grains, or the many scratches caused by the polish might be causing an averaging of the material properties.

\section{CONCLUSIONS AND FUTURE WORK}

The surface preparation has a small effect on the CVD SiC modulus and hardness measurement. There is greater variation in the data surface profile changes due to $\mathrm{SiC}$ grain exposure by the Syton polish than in the $1 / 2$ micron polish for indents at $20 \mathrm{~nm}$. The surface variation results from the fine $\mathrm{SiO}_{2}$ particles exposing the CVD SiC grains, unlike the $1 / 2$ micron diamond polish, which removes a layer in the same plane.

The calculations confirm the trends of the experimental observations, but the calculated variations are, for most cases, smaller than the experimental variations. These calculations do not completely explain the scatter in the experimental results. Further research should examine SiC grain morphology and its effect on making shallow indents in order for this technique to be a useful tool in the measurement of CVD SiC properties after ion bombardment. Also, in future work, indentation should be performed on a known hard flat surface to detcrmine if machine noise accounts for any experimental variation.

\section{ACKNOWLEDGMENTS}

The authors would like to thank D. N. Braski for the AFM analysis and W. C. Oliver for use of the Nanoindenter.

\section{REFERENCES}

1. L. L. Snead, S. J. Zinkle, D. Steiner, "Cross Sectional Measurement of Elastic Modulus for Ion Beam Damaged Silicon Carbide," Fusion Reactor Materials, DOE/ER-0313/10, pp. 320-327 (1991).

2. S. J. Zinkle and W. C. Oliver, "Mechanical Property Measurements on Ion-Irradiated Metals," ORNL/TM-10126, (August 1986), Metals and Ceramics Division. 
3. L. L. Snead, Ph.D. Thesis, 1992, Rensselacr Polytechnic Institute, Troy, New York.

4. W. C. Oliver and G. Pharr, "An Improved Technique for Determining Hardness and Elastic Modulus Using Load and Displacement Sensing Indentation Experiments," J. Mater. Res., Vol 7 (6), (June 1992), pp. 1564-1583.

5. I. J. McColm, "Ceramic Hardness," New York (1990), Plenum Press, p 7.

6. L. E. Samuels and T. O. Mulhearn, "An Experimental Investigation of the Deformed Zone Associated with Indentation Hardness Impressions," J. Mech. and Physics of Solids, Vol. 5, pp. 125-131 (1957).

7. L. Sawyer, "Microstructure of Ceramic Fibers," Fiber Reinforced Ceramic Composites ed. K. S. Mazdiyazni, Noyes Publication, Park Ridge, NJ (1990) pp. 141-180.

8. W. C. Oliver and G. M. Pharr, "An Improved Technique For Deternining Hardness And Elastic Modulus Using Load And Displacement Sensing Indentation Experiments," J. Mater. Res, Vol. 7, pp. 1564-1583 (1992). 
MICROMECHANICS OF FIBER PULL-OUT AND CRACK BRIDGING IN SCS-6 SiC- CVD SiC COMPOSITE SYSTEM AT HIGH-TEMPERATURE ${ }^{1}$ A.El-Azab and

N.M. Ghoniem, University of California, Los Angeles

\section{OBJECTIVE}

The purpose of this work is to develop a micro mechanical model to study the process of fiber pullout and crack bridging in $\mathrm{SiC}-\mathrm{SiC}$ composites at high temperature, where fiber creep dominates the time evolution of the matrix crack mechanics. Crack growth and failure of SiC-SiC composites in fusion are determined by considerations of the micro mechanical model.

\section{SUMMARY}

A micro mechanical model is developed to study fiber pull-out and crack bridging in fiber reinforced $\mathrm{SiC}-\mathrm{SiC}$ composites with time dependent thermal creep. By analyzing the creep data for monolithic $\mathrm{CVD} \mathrm{SiC} \mathrm{(matrix)} \mathrm{and} \mathrm{the} \mathrm{SCS-6} \mathrm{SiC} \mathrm{fibers} \mathrm{in} \mathrm{the} \mathrm{temperature} \mathrm{range} 900-1250^{\circ} \mathrm{C}$, it is found that the matrix creep rates can be ignored in comparison to those of fibers. Two important relationships are obtained: (1) a time dependent relation between the pull-out stress and the relative sliding distance between the fiber and matrix for the purpose of analyzing pull-out experiments, and (2) the relation between the bridging stress and the crack opening displacement to be used in studying the mechanics and stability of matrix crack bridged by fibers at high tenmperatures. The present analysis can be also applied to Nicalon-reinforced CVD SiC matrix system since the Nicalon fibers exhibit creep characteristics similar to those of the SCS-6 fibers.

\section{PROGRESS AND STATUS}

\section{Introduction}

Ceramic matrix fiber reinforced materials have recently received significant attention because of their excellent performance at elevated temperatures, and their high strength-to-weight ratio. It has been experimentally shown that appropilate micro structural design of such materials influences their toughening and crack propagation characteristics. In this context, relevant micro mechanical modeling helps in understanding the fundamental mechanical behavior, on the one hand, and further improving the micro structural design, on the other. An important toughening mechanism in ceramic matrix composites is achieved when fibers are embedded in the matrix, leading to what is known as bridging of matrix cracks. It has been experimentally shown that such bridging can lead to impedance of propagation of matrix cracks, and thus higher loads can be withstood without catastrophic failure (MARSHALL and EVANS, 1985; LUH and EVANS, 1987; SUZUKI, SATO and SAKAI, 1992).

Several micro mechanical models have been recently developed to analyze crack bridging (GAO, MAI and COTTEREL, 1988; SHETTY, 1988; HSUEH, 1988; SIGL and EVANS, 1989; HUTCHINSON and JENSEN, 1990; LIANG and HUTCHINSON, 1993), and were coupled with push-out and pull-out experiments (MARSHALL, SHAW and MORRIS, 1992; MARSHALL, 1992; ZHOU, KIM and MAI, 1992; FU, ZHOU, CHEN, XU, HE, and LUNG 1993; JIANG and PENN, 1992). Mostly, these models are based on a composite (fiber/matrix) cylinder which represents the local mechanical response. These micro-models are then incorporated in global representations of the overall macro mechanical behavior of the composite. The relevance to crack bridging and ceramic matrix composite toughening is manifested in:

\footnotetext{
${ }^{1}$ This material is based upon work supported by the U.S. Department of Energy under award number DE-FG0391ER54115 at UCLA.
} 
1. Establishing a relationship between the bridging stress and the crack opening displacement within the bridged zone in a matrix crack so that bridged crack mechanics problems can be solved. Such a relationship is known as the traction law.

2. Studying the dependence of crack propagation on debonding and frictional pull-out of fibers (SIGL and EVANS, 1989; THOULESS and EVANS, 1988).

The development of a traction law was first considered by MARSHALL, COX and EVANS(1985) in their study of crack mechanics with fiber bridging. SIGL and EVANS(1989) and HUTCHINSON and JENSEN(1990) derived more elaborate forms of that relationship for different fiber/matrix interface conditions. NAIR, JAKUS and LARDNER(1991) developed a time dependent traction law. They considered fiber pull-out of the matrix with a viscous interface layer which softens at high temperature.

Advanced ceramic composites, such as $\mathrm{SiC}-\mathrm{SiC}$ systems, are developed for high-temperature structural applications ( e. g. in fusion reactor first walls and blankets, rocket nozzles, heat exchangers, and special aerospace components ). In these applications inelastic phenomena such as thermal creep, irradiation-induced creep and irradiation swelling are critical. For example, fiber creep within the bridged zone of a matrix crack is anticipated to relax the bridging traction and drive a time dependent evolution of the overall crack field. Linder thermal creep conditions, the relevant mechanisms become significant above a threshold temprature. Irradiation creep, however, occurs over a wide range of temperatures and is kinetically possible once the material is subjected to a combined mechanical and irradiation loading. Another example is the build-up of internal stresses by irradiation swelling. Such evolution of internal stress affects the pull-out characteristics of the fiber. This may enhance or degrade the toughness of the compusite while in service.

Regarding the $\mathrm{SiC}-\mathrm{SiC}$ composite system, creep experiments have been performed on both CVD $\mathrm{SiC}$ fibers $\left(1100-1450^{\circ} \mathrm{C}\right)$ (DICARLO, 1986) and on monolithic CVD $\mathrm{SiC}$ material $\left(1650^{\circ} \mathrm{C}\right)$ (CARTER and DAVIS, 1984) at comparable stress levels. The CVD SiC fibers are commercially known as SCS- 6 fibers. These fibers are about 140 micron in diameter and are produced by chemical vapor deposition of $\mathrm{SiC}$ on a carbon core. The creep in these fibers is explained in terms of grain boundary sliding due to free silicon. It is observed that fiber creep is anelastic or recoverable and occurs at temperatures where dislocation motion is negligible. Because of that, significant creep strains can be obtained at relatively small loads. For CVD monolithic $\mathrm{SiC}$, the creep mechanism is determined to be a dislocation mechanism which requires certair threshold stress and temperature. By analyzing the cree $\mu$ data from the last two cited references it is concluded that the creep rate of monolithic CVD-SiC is negligible compared to that of fibers up to $\sim 1500^{\circ} \mathrm{C}$.

In the present work, a model is developed to study high-temperature micro mechanics relevant to fiber pull-out and crack bridging in SCS-6 SiC - CVD SiC composites. Only thermal creep of fibers is considered. This model includes development of the relationship between the applied stress at the fiber end and the relative sliding distance between the fiber and matrix ends. This distance may then be related to the crack opening displacement, within the bridging zone in a matrix crack. Such a relationship is time-dependent since fiber creep at high-temperature drives a stress relaxation process. The relaxation modulus of SCS-6 fibers is obtained from creep compliance data by the method of Laplace transform. The elastic-viscoelastic correspondence principle is used to obtain the viscoelastic (time-dependent) solution from the elastic one. The model accounts for residual thermal mismatch stresses.

\section{Composite cylinder model : Elastic Solution}

The composite cylinder model depicted in Fig. 1 is taken to represent a composite reinforced with a volume fraction, $f=\left(R_{f} / R_{o}\right)^{2}$, of aligned continuous fibers. The analysis accounts for composite systems which have residual mismatch stresses normal to the fiber-matrix interface. A Coulomb friction type is assumed over the length of permissible relative sliding between fibers and matrix, $L_{\boldsymbol{s}}$. 


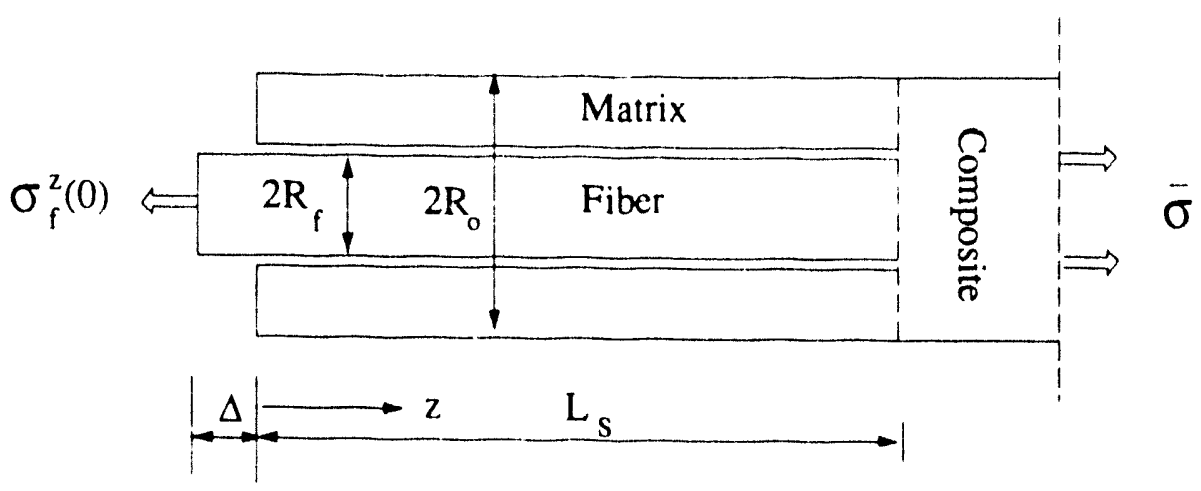

Figure 1: Composite cylinder model.

The model presented here neglects shear gradients compared with gradients in normal stresses. The outer cylinder surfaces are taken to be traction free. These approximations have been considered and justified by many authors (e. g. SIGL and EVANS, 1989; GAO, MAI and COTTERELL, 1988). In this case, the stresses in the fiber and matrix are given in terms of the interface normal stress $q$ (which is negative) by the following relations

$$
\begin{aligned}
\sigma_{r}^{f} & =q, \\
\sigma_{\theta}^{f} & =q, \\
\sigma_{r}^{m} & =\frac{q}{(1-f)}\left[\left(\frac{R_{f}}{r}\right)^{2}-f\right], \\
\sigma_{\theta}^{m} & =\frac{-q}{(1-f)}\left[\left(\frac{R_{f}}{r}\right)^{2}+f\right]
\end{aligned}
$$

where the superscripts $f$ and $m$ refer to the fiber and matrix, respectively, $r$ is the distance from the fiber center, and $R_{f}$ is the fiber radius. The elasticity solutions for this system are well developed, and the corresponding strains are given by

$$
\begin{aligned}
\epsilon_{r}^{f} & =\epsilon_{i n}^{f}+\frac{1}{E_{f}}\left[q\left(1-\nu_{f}\right)-\nu_{f} \sigma_{z}^{f}\right], \\
\epsilon_{\theta}^{f} & =\epsilon_{r}^{f} \\
\epsilon_{z}^{f} & =\epsilon_{i n}^{f}+\frac{1}{E_{f}}\left[\sigma_{z}^{f}-2 \nu_{f} q\right] \\
\epsilon_{r}^{m} & =\epsilon_{i n}^{m}+\frac{1}{E_{m}}\left(\frac{q}{(1-f)}\left[\left(\frac{R_{f}}{r}\right)^{2}\left(1+\nu_{m}\right)-f\left(1-\nu_{m}\right)\right]-\nu_{m} \sigma_{z}^{m}\right)
\end{aligned}
$$




$$
\begin{aligned}
& \epsilon_{\theta}^{m}=\epsilon_{i n}^{m}-\frac{1}{E_{m}}\left(\frac{q}{(1-f)}\left[\left(\frac{R_{f}}{r}\right)^{2}\left(1+\nu_{m}\right)+f\left(1-\nu_{m}\right)\right]-\nu_{m} \sigma_{z}^{m}\right) \\
& \epsilon_{z}^{m}=\epsilon_{i n}^{m}+\frac{1}{E_{m}}\left(\sigma_{z}^{m}+\frac{2 \nu_{m} f q}{(1-f)}\right)
\end{aligned}
$$

where $\epsilon_{i n}^{f}=\alpha_{f} \Delta T$ and $\epsilon_{i n}^{m}=\alpha_{m} \Delta T$ are thermal inelastic strain components in fibers and the matrix, respectively. Such a model was used by SIGL and EVANS(1989) for similar fiber and matrix properties. $\Delta T$ is a temperature change from the stress-free temperature. Due to the axi-symmetry of the problem, the tangential strains in fibers and matrix consist of the radial displacements $u_{r}$ divided by the radial coordinate $r$. While relative sliding in the axial direction is permissible, the continuity of the radial displacements at the fiber-matrix interface implies that

$$
\epsilon_{\theta}^{f}\left(R_{f}\right)=\epsilon_{\theta}^{m}\left(R_{f}\right)
$$

which yields

$$
\begin{aligned}
q\left(1-\nu_{f}\right)-\nu_{f} \sigma_{z}^{f} & =E_{f} \Delta \epsilon_{1 n} \\
& -\frac{E_{f}}{E_{m}}\left(\frac{q}{(1-f)}\left[\left(1+\nu_{m}\right)+f\left(1-\nu_{m}\right)\right]-\nu_{m} \sigma_{m}^{z}\right)
\end{aligned}
$$

where $\Delta c_{i n}=c_{i n}^{m}-c_{i n}^{f}$. The axial equilibrium of fibers and matrix can be described by

$$
\frac{d \sigma_{z}^{f}}{d z}=\frac{-2 \tau}{R_{f}}=-\left(\frac{1-f}{f}\right) \frac{d \sigma_{z}^{m}}{d z}
$$

where the interfacial shear stress $\tau$ is related to the interface pressure $q$ by

$$
\tau=-\mu q
$$

in which $\mu$ is the friction coefficient. Differentiating equation (4) with respect to $z$, results in a relationship between the axial gradients of $q, \sigma_{z}^{f}$ and $\sigma_{z}^{m}$. By further using equations (5) and (6), the foliowing first order differential equation is obtained for the interface pressure $q$

$$
\frac{d q_{i}}{d_{i}}=\frac{2 \mu r}{R_{j}} q
$$

where

$$
c=\frac{E_{m}(1-f) \nu_{f}-E_{f} f \nu_{m}}{E_{m}(1-f)\left(1-\nu_{f}\right)+E_{f}\left[\left(1+\nu_{m}\right)+f\left(1-\nu_{m}\right)\right]}
$$

The solution to (7) is obtained as

$$
q=q(o) \exp \left(\frac{2 \mu c}{R_{f}} z\right)
$$

where $q(o)$ is the value of $q$ at $z=0$. In the particular case $c=0, q(z)=q(0)$ which is a constant. Consequently, the axial stresses in the fiber and matrix vary linearly along the $z$ direction.

Expression for $q(0)$ in terms of $\sigma_{z}^{f}(0)$ and $\sigma_{z}^{m}(0)$ can be obtained using equation (4). The latters are given by

$$
\begin{aligned}
\sigma_{z}^{f}(0) & =\sigma_{b}+\sigma_{h}^{f} \\
\sigma_{z}^{m}(0) & =\sigma_{e}
\end{aligned}
$$


where $\sigma_{R}^{f}$ is the initial axial stress in the fiber, $\sigma_{b}$ is the externally imposed stress at the fiber end, and $\sigma_{e}$ is the external applied stress at the matrix end. The addition of $\sigma_{R}^{f}$ to $\sigma_{b}$ depends on the situation. In a pull-out experiment, where and external tensile load is applied only at the fiber end, no initial stresses are considered. In this case, $\sigma_{z}^{f}(0)=\sigma_{b}$ and $\sigma_{z}^{m}(0)=0$. In the case of crack bridging, however, an initial axial compressive stress in fibers develops such that the bridging stress at the fiber end is modified by the amount $\sigma_{R}^{f}$. On the other hand, the matrix end would still be traction free, i. e., $\sigma_{z}^{m}(0)=0$. The component $\sigma_{R}^{f}$ depends on the axial residual stresses in the fibers and matrix prior to crack initiation, $i$. e., on the initial strain mismatch. However, the formulation of $q(0)$ considers a non-zero stress at the matrix's end for a few more steps. Appendix A contains a solution for the initial axial stresses $\sigma_{R}^{f}$. Using equation (4) at $z=0$ results in the following expression for $q(0)$

$$
q(0)=\frac{a_{1} \sigma_{z}^{f}}{(0)+a_{2} \sigma_{z}^{m}(0)+a_{3} \Delta \epsilon_{i n}} a_{4}
$$

where the constants $a_{1-4}$ depend on the elastic constants of the composite system and the fiber volume fraction. These constants are given by

$$
\begin{aligned}
& a_{1}=E_{m}(1-f) \nu_{f} \\
& a_{2}=E_{f}(1-f) \nu_{m} \\
& a_{3}=E_{m}(1-f) E_{f} \\
& a_{4}=E_{m}(1-f)\left(1-\nu_{f}\right)+E_{f}\left[\left(1+\nu_{m}\right)+f\left(1-\nu_{m}\right)\right]
\end{aligned}
$$

Using equations (5), (6) and (9), expressions for the axial stresses in fiber and matrix are obtained as follows

$$
\begin{aligned}
& \sigma_{z}^{f}(z)=\sigma_{z}^{f}(0)+\frac{q(0)}{c}\left[\exp \left(\frac{2 \mu c}{R_{f}} z\right)-1\right] \\
& \sigma_{z}^{m}(z)=\sigma_{z}^{m}(0)-\left(\frac{f}{1-f}\right) \frac{q(0)}{c}\left[\exp \left(\frac{2 \mu c}{R_{f}} z\right)-1\right]
\end{aligned}
$$

In the special case of $c=0$, expression for $\sigma_{z}^{f}(z)$ and $\sigma_{z}^{m}(z)$ can be written as

$$
\begin{aligned}
& \sigma_{z}^{f}(z)=\sigma_{z}^{f}(0)+\frac{2 \mu q(o)}{R_{f}} z \\
& \sigma_{z}^{m}(z)=\sigma_{z}^{m}(0)-\left(\frac{f}{1-f}\right) \frac{2 \mu q(o)}{R_{f}} z
\end{aligned}
$$

The free end condition for the matrix, which will be considered from now and on, leads to dropping the terms containing $\sigma_{z}^{m}(0)$.

The solution given by equations (9) through (14) is valid over a certain range $z \in\left[0, L_{s}\right]$, where $L_{s}$ is the length over which relative sliding between the fiber and matrix in the axial direction is permissible. Beyond that length, axial displacements, and subsequently axial strains, in both fiber and matrix are equal (compatibility). Therefore the solution for $z \geq L_{s}$ must account for the continuity of radial and axial displacements at the fiber-matrix interface, at the same time. However, for the purpose of finding the sliding length, $L_{s}$, it is only needed to equate the expressions for the axial strains (or displacements) from equations (2) along with the use of (9) for the interface pressure $q$ and (13) or (14) for the axial stresses, at $z=L_{s}$. Implementing this procedure results in the following expression for the sliding length 


$$
\frac{L_{s}}{R_{f}}=\frac{1}{2 \mu c} \log _{e}\left[\frac{b_{4}-b_{1}+b_{2} q(0)}{\left(b_{2}-b_{3}\right) q(0)}\right]
$$

where the constants $b_{1-4}$ have the following expressions

$$
\begin{aligned}
& b_{1}=\sigma_{z}^{f}(0)-\frac{E_{f}}{E_{m}} \sigma_{z}^{m}(0) \\
& b_{2}=\left[1+\frac{f E_{f}}{(1-f) E_{m}}\right] / c \\
& b_{3}=2 \nu_{f}+\left(\frac{2 \nu_{f} f}{1-f}\right) \frac{E_{f}}{E_{m}} \\
& b_{4}=E_{f} \Delta \epsilon_{i n}
\end{aligned}
$$

SIGL and EVANS (1989) have used a different approach to determine the sliding length. They considered the global equilibrium of fiber over the sliding length such that the fiber load at its end is balanced by the resultant friction forces. Other authors (HSUEH, 1988; HSUEH, 1990), however, have used the more rigorous approach presented here to satisfy the compatibility condition in the axial direction at the end of sliding zone to determine the sliding length. The axial displacements $u_{z}^{f}(0)$ and $u_{z}^{m}(0)$ at the fiber end, $z=0$, for fiber and matrix are given in terms of the respective axial displacements at $z=L_{s}$, by the following equations

$$
\begin{aligned}
u_{z}^{f}\left(L_{s}\right)- & u_{z}^{f}(0)=\int_{0}^{L_{s}} \epsilon_{z}^{f}(z) d z=\left[\sigma_{z}^{f}(0)-\frac{q(0)}{c}\right] \frac{L_{s}}{E_{f}}+c_{i n}^{f} L_{s} \\
& +\frac{q(0) R_{f}}{2 \mu c^{2} E_{f}}\left[\exp \left(\frac{2 \mu c}{R_{f}} L_{s}\right)-1\right]-\frac{\nu_{f} q(0) R_{f}}{\mu c E_{f}}\left[\exp \left(\frac{2 \mu c}{R_{f}} L_{s}\right)-1\right] \\
u_{z}^{m}\left(L_{s}\right)- & u_{z}^{m}(0)=\int_{0}^{L_{s}} c_{z}^{m}(z) d z=\left[\sigma_{z}^{m}(0)+\frac{f q(0)}{(1-f) c}\right] \frac{L_{s}}{E_{m}} \\
& +\epsilon_{i n}^{m} L_{s}-\frac{f q(0) R_{f}}{2(1-f) \mu c^{2} E_{m}}\left[\exp \left(\frac{2 \mu c}{R_{f}} L_{s}\right)-1\right] \\
& +\frac{\nu_{m} f q(0) R_{f}}{(1-f) \mu c E_{m}}\left[\exp \left(\frac{2 \mu c}{R_{f}} L_{s}\right)-1\right]
\end{aligned}
$$

where $u_{z}^{f}\left(L_{s}\right)=u_{z}^{m_{1}}\left(L_{s}\right)$. The relative sliding distance $\Delta$ at the fiber end is then given by

$$
\begin{aligned}
\Delta & =\int_{0}^{L_{s}}\left[\epsilon_{z}^{f}-\epsilon_{z}^{m}\right] d z \\
& =u_{z}^{m}(0)-u_{z}^{f}(0)
\end{aligned}
$$

In presenting the results, the fiber volume fraction is taken to be 0.3 . The fiber and matrix properties used are those for a CVD SiC matrix with SCS- 6 fibers. These are given by: $E_{f}=420$ $\mathrm{GPa}$ (DICARLO, 1986), $E_{m}=380 \mathrm{GPa}$ (GULDEN, 1969), $\nu_{f}=0.3\left(\mathrm{HSUEH}, 1989\right.$ ), and $\nu_{m}=0.2$. The friction coefficient $\mu$ usually varies depending on the manufacturing condition of the composite as well as on the interface. A value of $\mu=0.2$ is chosen in the present work as a reference point, based on the existing literature of similar composite systems (e. g. HSEUH, 1989). However, the friction coefficient is varied to show its effect on the relative sliding between fibers and matrix when necessary. The differential thermal strain mismatch $\Delta \epsilon_{2 n}$ is taken to be $0.05 \%$. This corresponds to $\alpha_{m}-\alpha_{f}=10^{-6} \mathrm{~K}^{-1}$ and a temperature cooling of $500 \mathrm{~K}$. This choice can be justified based on 


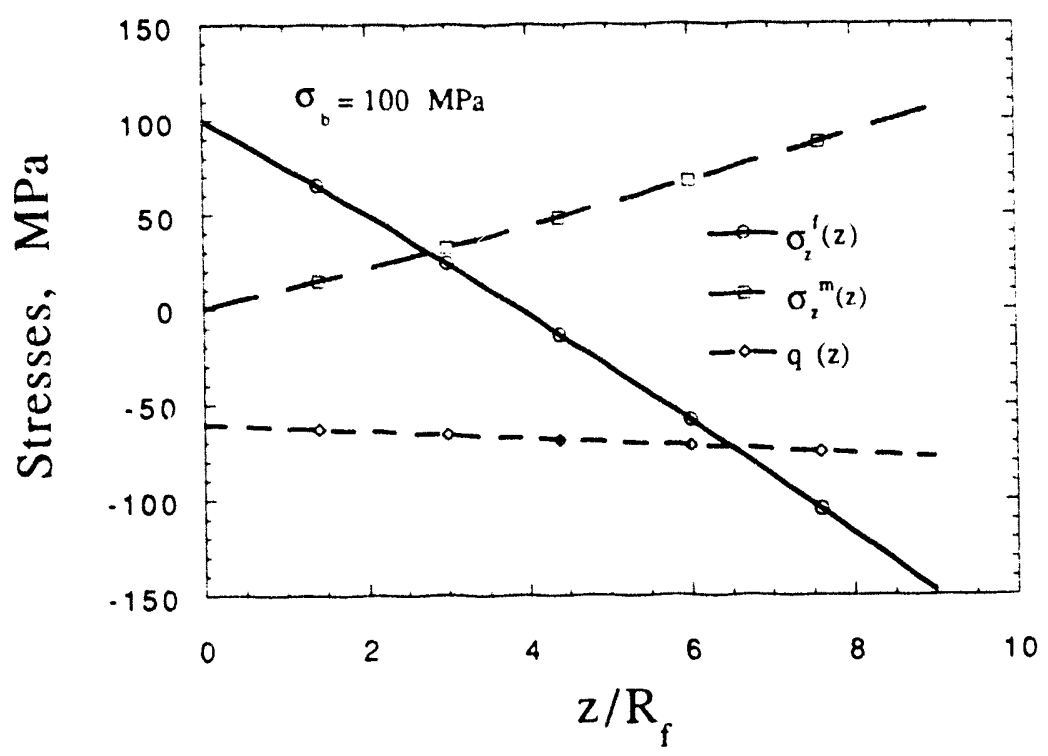

Figure 2: Axial variation of $\sigma_{z}^{f}, \sigma_{z}^{m}$ and $q(z)$.

the fact that the existing data on the coefficient of thermal expansion for CVD SiC fibers represent a wide scatter. CARROLL and DHARANI(1992) reported values of $\alpha_{f}=(2.6-3.25) \times 10^{-6} \mathrm{~K}^{-1}$, BRUN and BOROM (1989) reported values of $\alpha_{f}=(4.5-5) \times 10^{-6} \mathrm{~K}^{-1}$, which is similar to those reported by DICARLO (1986). In this case, values of the thermal strain mismatch, rather than the difference in thermal expansion coefficients and cooling temperature, are important.

In Fig.2 the axial stresses in the fiber and matrix are shown for a partial pull-out test. The results are in general agreement with the existing literature (e. g., HSUEH, 1988). The compressive fiber stress over a large part of the sliding length is caused by large values of the mismatch strain. In that particular example, the residual axial compression in the fiber, away from its end, is $\sigma_{R}^{f}=-187$ $\mathrm{MPa}$. This shows the effect of the applied stress in releasing some of that compression over $L_{s}$. Fig. 3 shows the variation of $\Delta$ with the applied stress $\sigma_{b}$ for pull-out test versus crack bridging problem. The fact that $\Delta$ is smaller in the case of bridging can be attributed to the effect of the residual compressive stress, $\sigma_{R}^{f}$, which modifies the stress at the fiber end. In Fig. $4, L_{s}$ versus $\sigma_{b}$ is shown, and the difference, again, can be interpreted the same way.

The present work is conducted to investigate the micro mechanics relevant to crack bridging and fiber pull-out in a $\mathrm{SiC}-\mathrm{SiC}$ composite system, where fibers are under thermal creep conditions. A time-dependent solution is therefore required. Before getting to that step, a summary of the creep characteristics of SCS-6 SiC fibers is given.

\section{Analysis of creep of SCS-6 SiC fibers}

As mentioned before, creep experiments on SCS-6 SiC fibers have been carried out in the temperature range $1100-1450^{\circ} \mathrm{C}$ (DICARLO, 1984; DICARLO and MORSCHER, 1991). Creep strain is observed to increase logarithmically with time, monotonically with temperature, and linearly with the applied stress. Fiber creep is found to be totally viscoelastic, which allowed a simple predictive method to be developed for describing the fiber total deformation as function of time, temperature and stress. The fiber viscoelastic behavior is explained in terms of grain boundary sliding due to free silicon. The total fiber strain $\epsilon$ is written in terms of the applied stress $\sigma_{a}$ as follows 


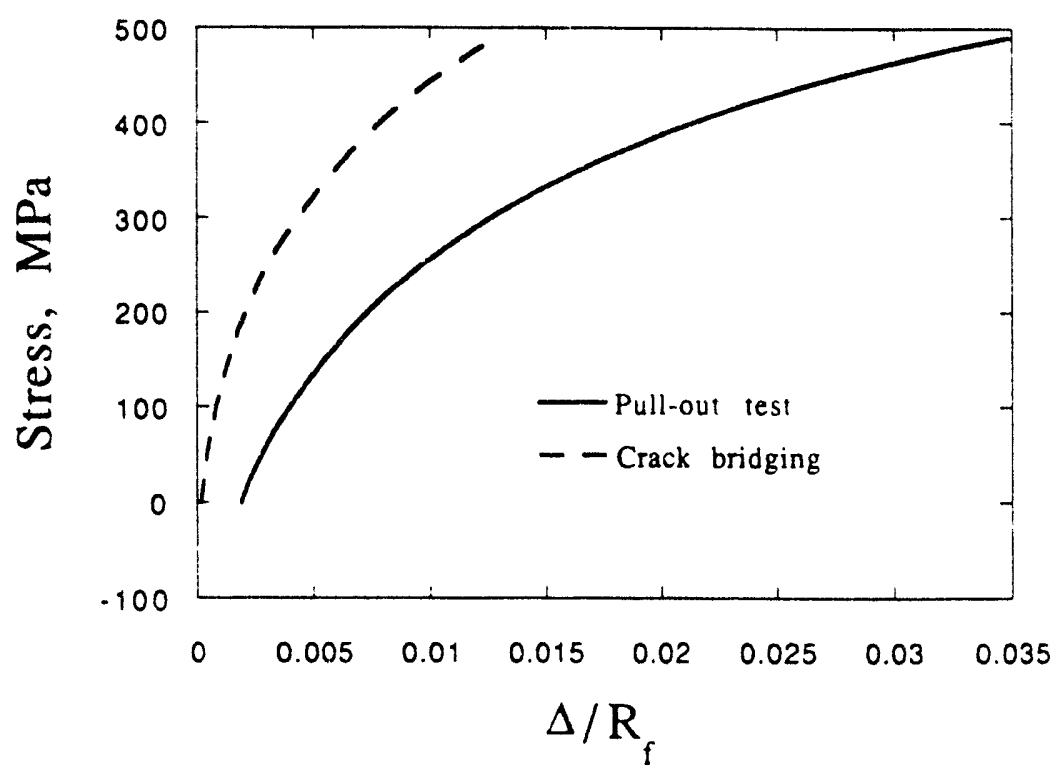

Figure 3: Variation of $\sigma_{b}$ versus $\Delta$.

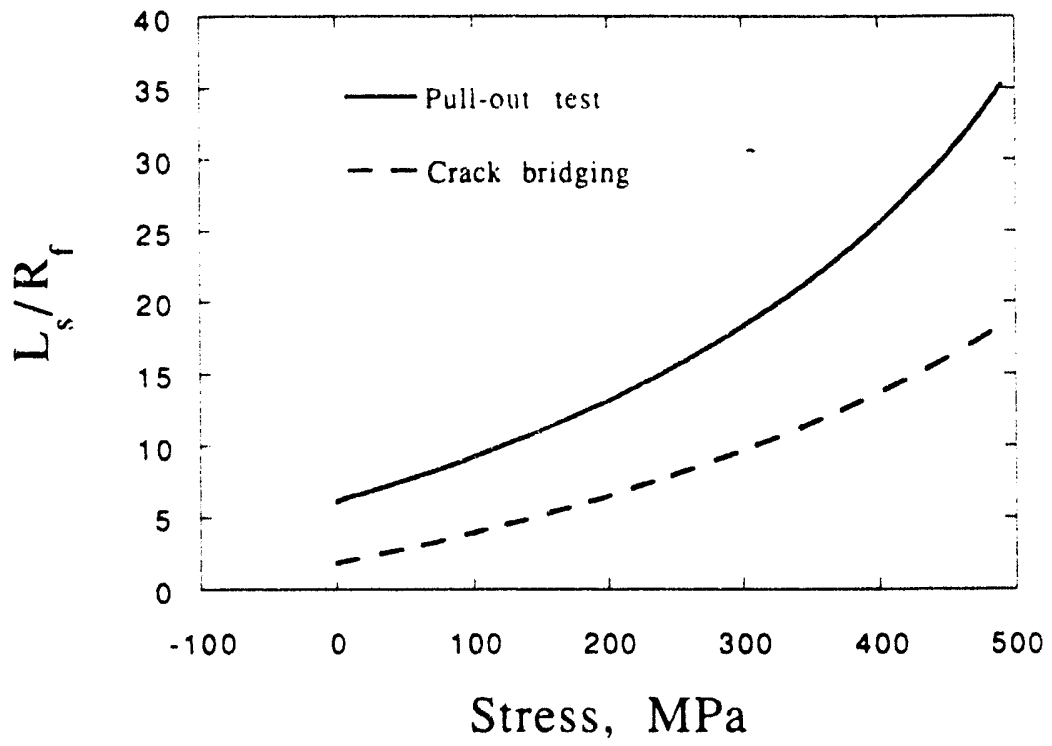

Figure 4: Varaition of $L_{s}$ versus $\sigma_{b}$. 


$$
\epsilon=\frac{\sigma_{a}}{E_{f}(0)}+J_{c}(\gamma) \sigma_{a}=J_{f}(\gamma) \sigma_{a}
$$

where the first term represents the prompt (elastic) component of the total strain, and the second term is the strain due to fiber creep. $J_{f}(\gamma)$ is the total compliance of the fiber and will be simply denoted as the creep compliance $J_{f}(t)$. The parameter $\gamma$ is written in terms of time, $t$, and the absolute temperature, $T$, as follows

$$
\gamma=\ln (t)-Q / R T=\ln (t)-57700 / T
$$

where $Q$ is the activation energy. The following empirical correlation of $J_{c}$ to time and temperature was obtained

$$
\left.J_{c}(t, T)=J_{c}\left(\gamma_{o}\right) \exp \mid-p\left(Q / R T+\gamma_{o}\right)\right] t^{p}=C(T) t^{p}
$$

where the parameters $p=0.36, \gamma_{o}=-35$ and $J_{c}\left(\gamma_{o}\right)=10^{-3}(\mathrm{GPa})^{-1}$ are measured by ritting the experimental data to formula (21). Details of this analysis are given by DICARLO and MORSCiIER (1991). In the present work we extend the analysis to obtain relaxation information from creep data.

The relaxation modulus $E_{f}(t)$ is defined by a relation similar to (19), and written as

$$
\sigma=E_{f}(t) \epsilon_{a}
$$

in which $\epsilon_{a}$ is the applied strain. The relations (19) and (22) yield the strain and stress in creep and relaxation tests, respectively. By manipulating these two relations, the relaxation modulus can be related to the one dimensional tensile creep compliance $J_{f}(t)$ by the following convolution integral (PIPKIN, 1986; GOLDEN and GRAHAM, 1988)

$$
\int_{0}^{t} E_{f}\left(t-t^{\prime}\right) J_{f}\left(t^{\prime}\right) d t^{\prime}=\int_{0}^{t} E_{f}\left(t^{\prime}\right) J_{f}\left(t-t^{\prime}\right) d t^{\prime}=t
$$

The Laplace transforms of these two functions are therefore related by

$$
\hat{E}_{f}(s) \hat{J}_{f}(s)=\frac{1}{s^{2}}
$$

which is used to obtain $E_{f}(t)$ from $J_{f}(t)$. It can be shown that the Laplace transformed compliance function is given by

$$
\hat{J}_{f}(s)=\frac{1}{s E_{f}(0)}+C(T) \frac{\Gamma(1+p)}{s^{p+1}}
$$

where $\Gamma(1+p)$ is the gamma function. The last relation yields the following expression for the Laplace transformed relaxation modulus

$$
\hat{E}_{f}(s)=\frac{E_{f}(0)}{s+C(T) E_{f}(0) \Gamma(1+p) s^{1-p}}
$$

There is no direct inversion formula for the expression (26). However, a widely used approximate inversion method, which proved to be highly accurate for the purpose of obtaining time-dependent solutions in the theory of linear viscoelasticity, is used in the present work. This formula is due to SCHAPERY(1962). The statement of that inversion formula is as follows; if $\hat{\psi}(s)$ is the Laplace transform, which is known, for the function $\psi(t)$, then the latter is approximately given by

$$
\psi(t) \simeq[s \hat{\psi}(s)]_{s=\frac{0 . s}{i}}
$$




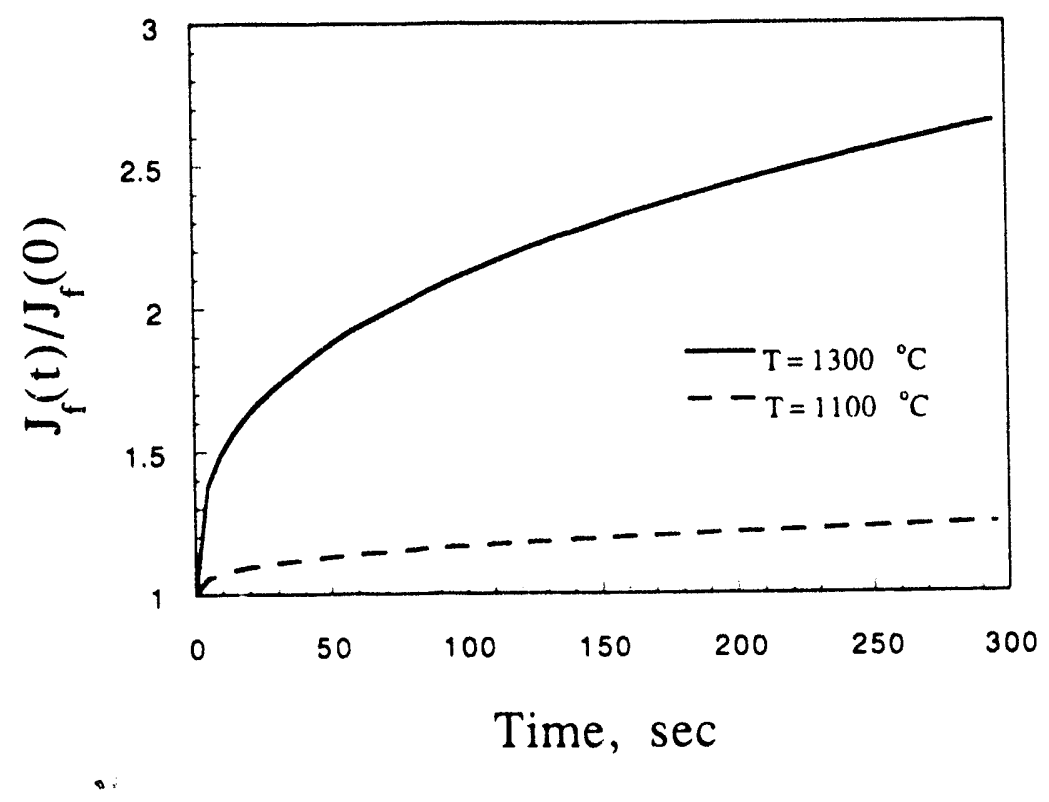

Figure 5: Creep compliance of SCS-6 fibers.

In some cases, this inversion method is found to be more accurate than other numerical techniques of inversion such as the collocation method. Besides, little computational effort is required in using this method. Details of comparison of this method with exact and collocation methods are found in ( SCHAPERY, 1962). Figs. 5 and 6 show the creep compliance and the relaxation modulus of SCS-6 fibers, where SCHAPERY's method is used to calculate the latter.

\section{Viscoelastic solution: Pull-out experiments}

The quantities $q(z), \sigma_{z}^{f}(z)$ and $\sigma_{z}^{m}(z)$ are linearly related to the applied external stress $\sigma_{b}$ and the thermal strain mismatch $\Delta \epsilon_{i n}$ through their linear dependence on $\sigma_{z}^{f}(o)$ and $q(0)$. This linearity is important in formaulating a time-dependent solution for an arbitrary time history of these externally imposed mechanical and thermal mismatch conditions. In the present work, however, we consider only the time variation of the applied stress at the fiber end and formulate an isothermal solution. Moreover, $\sigma_{z}^{m}(0)$ is taken to be zero, $i$. e., the matrix end is traction free. The solution to a step stress input is first obtained. Then, by virtue of the linearity property of $\sigma_{z}^{f}, \sigma_{z}^{m}$ and $q$ with respect to the applied stress at the fiber end, the solution corresponding to an arbitrarily time-varying stress is obtained using the convolution theory.

Let $R\left(t-t^{\prime}\right)$ be a response to a differential step input $d \sigma\left(t^{\prime}\right)$ imposed at time $t^{\prime}$. Then, the response $\mathcal{R}(t)$ due to some varying stress history $\sigma(t)$ is given by

$$
\mathcal{R}(t)=\int_{-\infty}^{t} R\left(t-t^{\prime}\right) d \sigma\left(t^{\prime}\right)
$$

Therefore it is important first to establish the response to the step input.

\section{Step input solution}

In obtaining the response to a step input, the elastic-viscoelastic correspondence principle is used. The developed elastic solution can be used to obtain the Laplace transformed viscoelastic solution by replacing the boundary conditions (externally imposed conditions, $\sigma_{z}^{f}(0)$ and $\Delta \epsilon_{\text {in }}$ ) by their 


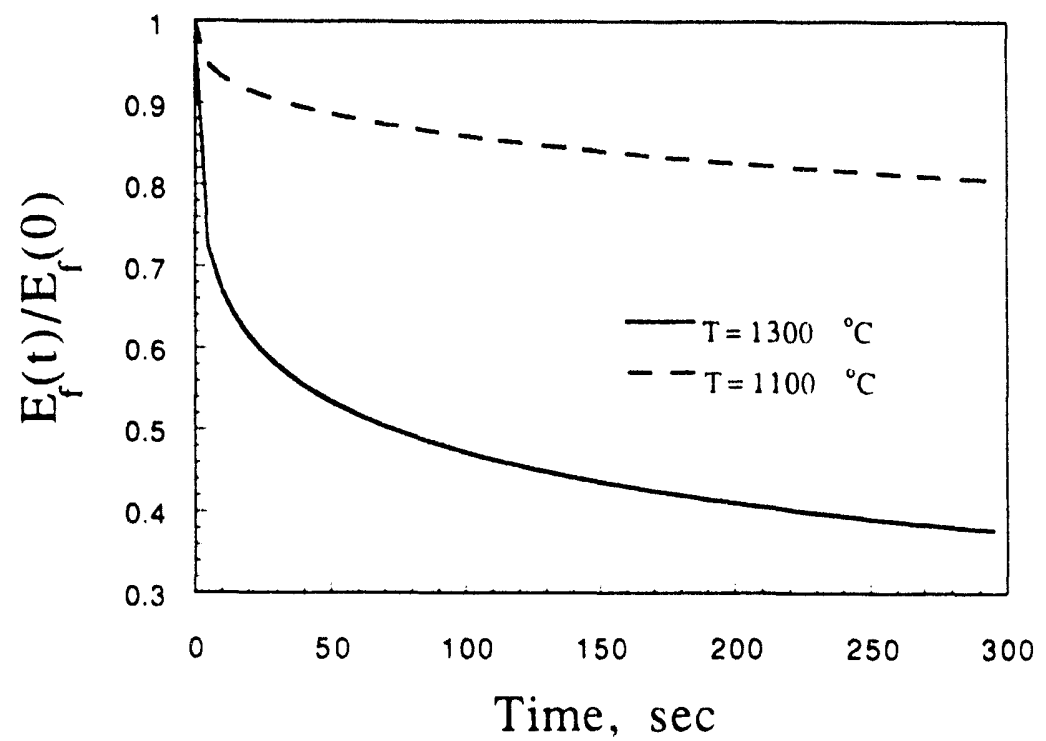

Figure 6: Relaxation modulus of SCS-6 fibers.

respective Laplace transforms in the elastic solution. Also the elastic constants are replaced by their $s$-multiplied Laplace transforms, mainly, $E_{f} \rightarrow s \hat{E}_{f}(s)$ and $\nu_{f} \rightarrow s \hat{\nu}_{f}(s)$. The quantities $a_{1-4}$ given in equation (11) contain $E_{f}$ and $\nu_{f}$. In the Laplace transformed viscoelastic solution, these quantities can be represented as functions of the Laplace parameter $s$ as $\hat{a}_{1-4}(s)$. Similarly, the constant $c$ appearing in equation(8) transforms to $\hat{c}(s)$. Having done that, the rest of the work will be just inverting the Laplace transformed viscoelastic solution to get the solution in the time domain. In performing the inversion step, Schapery's rule is used.

The following expression can be obtained for the interface pressure in the Laplace domain

$$
\hat{q}(z, s)=\hat{q}(0, s) \exp \left(\frac{2 \mu \hat{c}(s)}{R_{f}} z\right)
$$

where $\hat{q}(0, s)$ is given by

$$
\hat{q}(0, s)=\frac{\hat{a}_{1}(s) \sigma_{2}^{f}(0)+\hat{a}_{3}(s) \Delta \epsilon_{i n}}{s \hat{a}_{4}(s)}
$$

in which $\sigma_{z}^{f}(0)$ is given by equation (10) where the initial stress component $\sigma_{R}^{f}$ is not considered. By applying Schapery's method to (29) and (30), the following expression for $q(z, t)$ can be obtained

$$
q(z, t)=q(0, t) \exp \left(\frac{2 \mu c(t)}{R_{f}} z\right)
$$

where $q(0, t)$ is given by

$$
q(0, t)=\frac{a_{1}(t) \sigma_{z}^{f}(0)+a_{3}(t) \Delta \epsilon_{i n}}{a_{4}(t)}
$$

where application of Scharery's inversion method results only in replacing the constants $\hat{a}_{1-4}(s)$ and $\hat{c}(s)$, which contain $s \hat{E}_{f}(s)$ and $s \hat{\nu}_{f}$, with the time-dependent parameters $a_{1-4}(t)$ and $c(t)$. These time-dependent parameters are still given by equations (12), for $a_{1-4}$, and (8), for $c$, with replacing 
the elastic constants $E_{f}$ and $\nu_{f}$ by the time dependent relaxation modulus $E_{f}(t)$ and the timedependent poisson's ratio $\nu_{f}(t)$. A similar methodology can be implemented to obtain expressions for $\sigma_{z}^{f}(z, t)$ and $\sigma_{z}^{m}(z, l)$, which can be shown to take the form

$$
\begin{aligned}
& \sigma_{z}^{f}(z, t)=\sigma_{z}^{f}(0)+\frac{a_{1}(t) \sigma_{z}^{f}(0)+a_{3}(t) \Delta \epsilon_{i n}}{a_{4}(t) c(t)}\left[\exp \left(\frac{2 \mu c(t)}{R_{f}} z\right)-1\right] \\
& \sigma_{z}^{m}(z, t)=-\frac{a_{1}(t) \sigma_{z}^{f}(0)+a_{3}(t) \Delta \epsilon_{i n}}{a_{4}(t) c(t)} \frac{f}{(1-f)}\left[\exp \left(\frac{2 \mu c(t)}{R_{f}} z\right)-1\right]
\end{aligned}
$$

The distance $L_{s}$ can be found by numerical matching of the instantaneous axial strains in the fiber and matrix. The distance $\Delta$ is then found by integrating the differential axial strain over that distance. This is explained in the following section.

\section{Response to arbitrarily time-varying stress}

In obtaining the solution for an arbitrary applied stress, equation (28) is utilized. Since $\Delta \epsilon_{\text {in }}$ is assumed constant, the terms containing that quantity remain unchanged. Therefore, convolution integrals are considered only with terms containing $\sigma_{z}^{f}(0)$. In doing so, $\sigma_{z}^{f}(0)$ in equations (31) through $(33)$ is replaced by $d \sigma_{z}^{f}\left(0, t^{\prime}\right)$ and the integrals are carried out. The expression for the interface pressure $q(z, t)$ is written as

$$
\begin{aligned}
q(z, t)= & \frac{a_{3}(t) \Delta \epsilon_{3 n}}{a_{4}(t)} \exp \left(\frac{2 \mu c(t)}{R_{f}} z\right) \\
& +\int_{-\infty}^{t} \frac{a_{1}\left(t-t^{\prime}\right)}{a_{4}\left(t-t^{\prime}\right)} \exp \left(\frac{2 \mu c\left(t-t^{\prime}\right)}{R_{f}} z\right) d c_{z}^{f}\left(0, t^{\prime}\right)
\end{aligned}
$$

which can be rewritten as

$$
\begin{array}{r}
q(z, t)=\frac{a_{3}(t) \Delta t_{2 n}}{a_{4}(t)} \\
\exp \left(\frac{2 \mu c(t)}{R_{f}} z\right)+\frac{a_{1}(t) \sigma_{z}^{f}(0,0)}{a_{4}(t)} \exp \left(\frac{2 \mu c(t)}{R_{f}} z\right) \\
+\int_{0}^{t} \frac{a_{1}\left(t-t^{\prime}\right)}{a_{4}\left(t-t^{\prime}\right)} \exp \left(\frac{2 \mu c\left(t-t^{\prime}\right)}{R_{f}} z\right) \dot{\sigma}_{z}^{f}\left(0, t^{\prime}\right) d t^{\prime}
\end{array}
$$

The first two terms in the expression for $q(z, t)$ represent the response due to the initial application of $\sigma_{z}^{f}(0,0)$ and $\Delta \epsilon_{i n}$. It can be shown that these terms decrease in time due to the behavior of the parameters $a_{1,3,4}$ and $c$. An alternative expression for $q(z, t)$ can be written as

$$
\begin{array}{r}
q(z, t)=\frac{a_{3}(t) \Delta \epsilon_{\imath n}}{a_{4}(t)} \exp \left(\frac{2 \mu c(t)}{R_{f}} z\right)+\frac{a_{1}(0) \sigma_{z}^{f}(0, t)}{a_{4}(0)} \exp \left(\frac{2 \mu c(0)}{R_{f}} z\right) \\
+\int_{0}^{t} \sigma_{z}^{f}\left(0, t-t^{\prime}\right) \frac{d}{d t^{\prime}}\left(\frac{a_{1}\left(t^{\prime}\right)}{a_{4}\left(t^{\prime}\right)} \exp \left(\frac{2 \mu c\left(t^{\prime}\right)}{R_{f}} z\right)\right) d t^{\prime}
\end{array}
$$

In this expression, it is clear that the second term represents the prompt change in $q(z, t)$ due to varying the applied stress. However, because of the complexity of the integrand, expression (35) is easier to use for further manipulation of the equations. A similar argument can be applied to obtain expressions for the axial stresses in the fiber and matrix, which can be written as

$$
\sigma_{z}^{f}(z, t)=\frac{a_{3}(t) \Delta \epsilon_{2 n}}{a_{4}(t) c(t)}\left[\exp \left(\frac{2 \mu c(t)}{R_{f}} z\right)-1\right]
$$




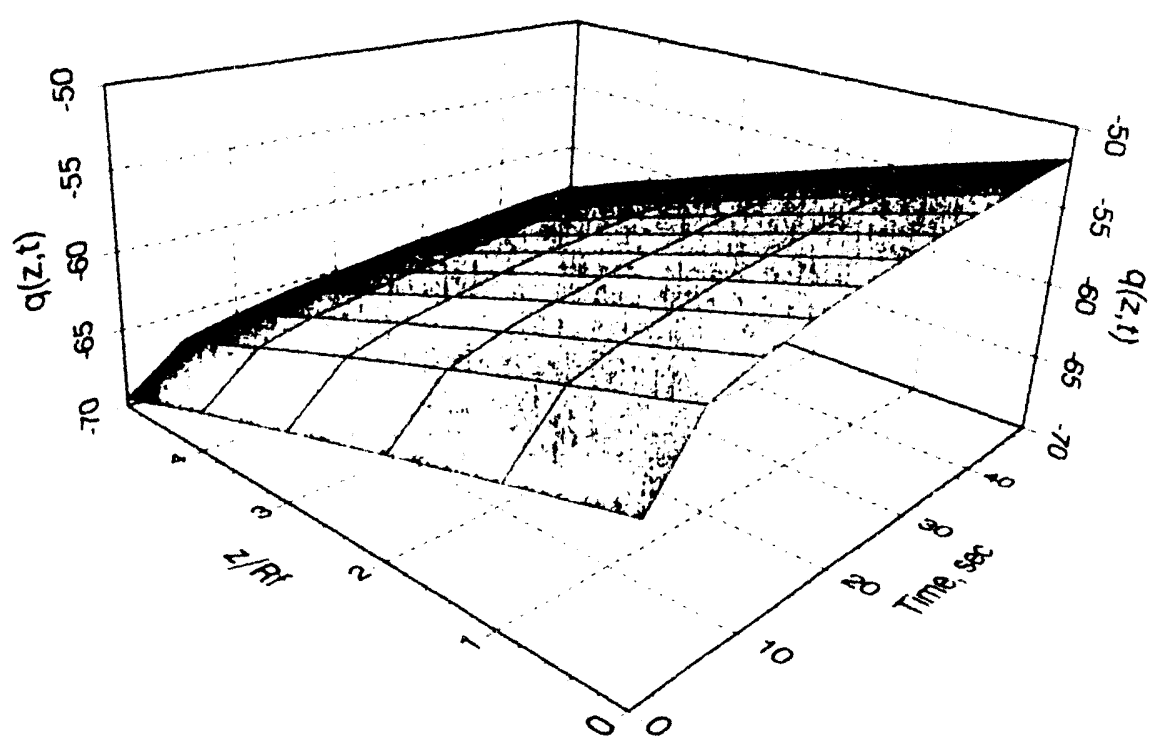

Figure 7: Relaxation of the interface pressure, $q(z, t)$.

$$
\begin{aligned}
& +\sigma_{z}^{f}(0,0)\left(1+\frac{a_{1}(t)}{a_{4}(t) c(t)}\left[\exp \left(\frac{2 \mu c(t)}{R_{f}} z\right)-1\right]\right) \\
& +\int_{0}^{t}\left(1+\frac{a_{1}\left(t-t^{\prime}\right)}{a_{4}\left(t-t^{\prime}\right) c\left(t-t^{\prime}\right)}\left[\exp \left(\frac{2 \mu c\left(t-t^{\prime}\right)}{R_{f}} z\right)-1\right]\right) \dot{\sigma}_{z}^{f}\left(o, t^{\prime}\right) d t^{\prime}
\end{aligned}
$$

and

$$
\begin{aligned}
\sigma_{z}^{m}(z, t)= & -\frac{a_{3}(t) \Delta c_{1 n}}{a_{4}(t) c(t)} \frac{f}{(1-f)}\left[\exp \left(\frac{2 \mu c(t)}{R_{f}} z\right)-1\right] \\
& -\sigma_{z}^{f}(0,0) \frac{f}{(1-f)} \frac{a_{1}(t)}{a_{4}(t) c(t)}\left[\exp \left(\frac{2 \mu c(t)}{R_{f}} z\right)-1\right] \\
& -\frac{f}{(1-f)} \int_{0}^{t} \frac{a_{1}\left(t-t^{\prime}\right)}{a_{4}\left(t-t^{\prime}\right) c\left(t-t^{\prime}\right)}\left[\exp \left(\frac{2 \mu c\left(t-t^{\prime}\right)}{R_{f}} z\right)-1\right] \dot{\sigma}_{z}^{f}\left(o, t^{\prime}\right) d t^{\prime}
\end{aligned}
$$

lution integrals in equations (35) through (38) axial stresses in the fiber/matrix system the convofiber is assumed constant (time-independent) since thered numerically. The poisson's ratio of the $\nu_{f}(t)$. According tion of time-independent of $\nu_{f}=0.35$ is used in poisson's ratio $(\nu=0.35-0.41)$ is practical intic problems, the assumpand $\sigma_{z}^{f}(z, t)$ along a portion viscoelastic analysis. Figs, 7 and 8 show In the present study a value applied at the fiber portion of the fiber. These results are calculat the time evolution of $q(z, t)$

For the purpose of finding temperature of $1200^{\circ} \mathrm{C}$. stantaneous axial strains in the fiber and matrix sliding length $L_{s}(t)$, a local matching of the inconstitutive relations are elastic, and the axial strain is written in teridered. For the matrix, the and the axial matrix stress as 


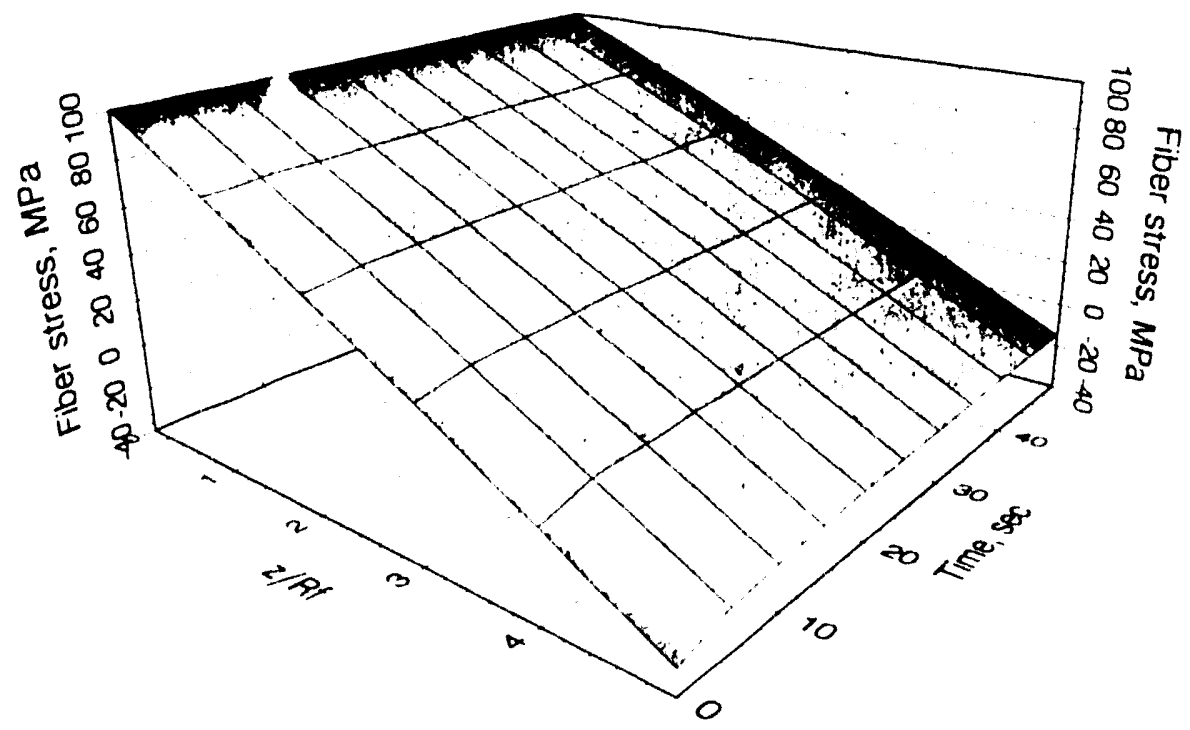

Figure s: Relaxation of the axial fiber stress, $\sigma_{z}^{f}(z, t)$

$$
c_{z}^{m}(z, t)=\epsilon_{m}^{m}+\frac{1}{E_{m}}\left(\sigma_{z}^{m}(z, t)+\frac{2 \nu_{m} f q(z, t)}{(1-f)}\right)
$$

For fibers, which behave viscoelastically the axial strain is related to the interface pressure and the: axial stress by

$$
\begin{aligned}
\left.\epsilon_{z}^{f}: z, t\right)= & f_{i r}+\frac{\sigma_{z}^{f}\left(z, t,-2 \nu_{f} q^{\prime} z, t\right.}{E_{f}(0)} \\
& +\int_{t}^{l}\left(\sigma_{z}^{f}\left(z, t-t^{\prime}-2 \nu_{f} q z \cdot t-t^{\prime}\right)\right) \cdot t_{f}\left(t^{\prime}\right) d t^{\prime}
\end{aligned}
$$

The relative sliding distance $\Delta(\ell)$ at the fiter end $z=0$ is then given by equation $(18)$. Carrying out the integral of differential axial strain with respect $t 0 \geq$ over the sliding length $L_{s}$, the following expression is obtained for $\Delta i t$;

$$
\begin{aligned}
\Delta(t)= & -\Delta \epsilon_{\imath n} L_{s}+\frac{1}{E_{f}(0)} \int_{0}^{L,} \sigma_{z}^{f}(z, t) d z-\frac{1}{E_{m}} \int_{0_{1}}^{L_{s}} \sigma_{z}^{m}(z, t) d z \\
& -2\left[\frac{\nu_{f}}{E_{f}(0)}+\frac{\nu_{m} f}{E_{m}(1-f)}\right] \int_{0}^{L s} q(z, t) d z \\
& +\int_{0}^{t} d t^{\prime} j_{f}\left(t^{\prime}\right) \int_{0}^{L s}\left(\sigma_{z}^{f}\left(z, t-t^{\prime}\right)-2 \nu_{f} q\left(z, t-t^{\prime}\right)\right) d z
\end{aligned}
$$

where the $z$-dependence of the quantities $\sigma_{z}^{f}, \sigma_{z}^{m}$ and $q$ is depicted in equations (35) through (38). Some representative results for the distance $L_{s}$ and $\Delta$ are shown in Figs. 9 through 14 , for step and ramp stresses applied at the fiber's end. It can be shown that high values of the friction coeflicient $\mu$ mav severely impede the pull-out of fibers, and in turn, lower the composite toughness (Figs. 11 and 12). The decrease of the $L_{s}$ with time for a step applied stress, Figs. 9 , represents a localization of 


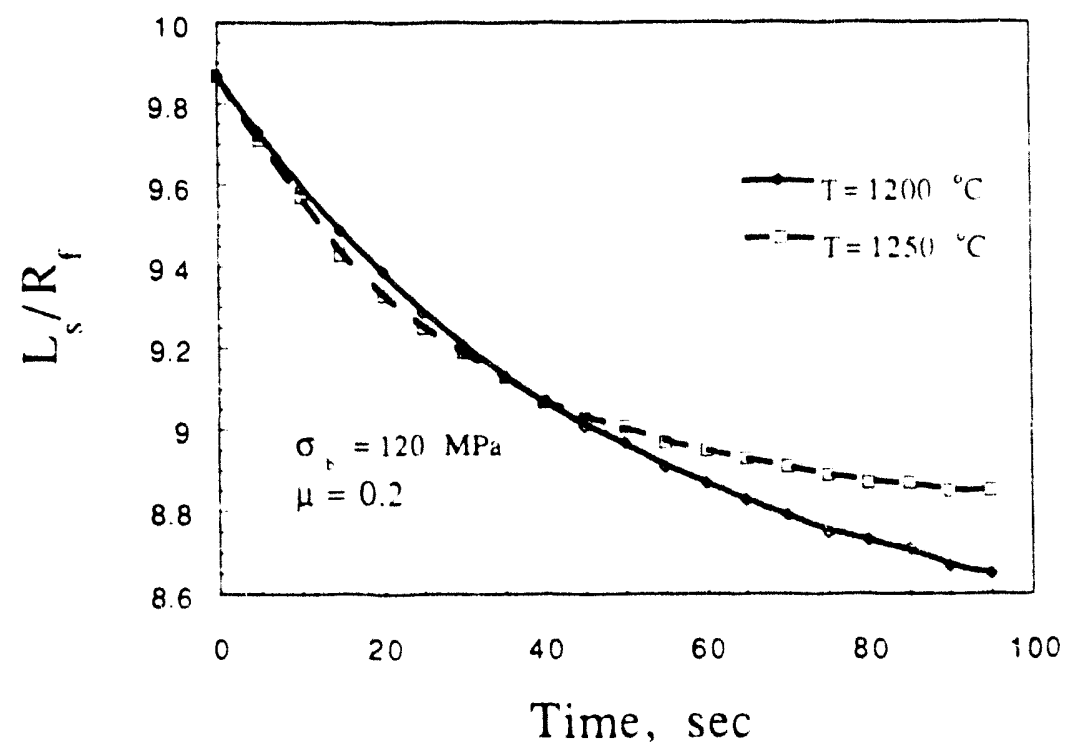

Figure 9: Evolution of the sliding length, $L_{g}$, for a step input (Pull-outi.

creep strain in the portion of the fiter close to the fiber's end. For an applied stress that is increasing in time, the initial decrease in $L$, due to strain localization is recovered (Fig. 13). It can be also noted that the faster the ramping of the applied stress the faster the recovery of $L_{s}$. It is highly probable that fibers would fail at sections which accumulate the highest amount of creep strains (e. g. between the two faces of a matrix crack rather than in the matrix). In this case, the frictional energy dissipation due to total pull-out of broken fibers is essentially negligible. This might have a serious effect on the energy dissipation by friction and, in turn, on the high-temperature fracture toughness of the composite. Therefore, the micro structure must be designed so as to consume more: energy by viscoelastic dissipation to counterbalance that effect.

So far, the problem of finding the stresses $\sigma_{z}^{f}(z, t)$ and $\sigma_{z}^{m}(z, t)$ and the interface pressure $q(z, t)$, the sliding length $L_{s}(t)$ and the relative sliding distance, corresponding to an arbitrary stress history is solved. Caution must be taken in implementing this methodology in case of a decreasing applied stress. It must be guaranteed at all times that the relative sliding velocity between fiber and matrix does not change its direction during the course of changing the applied stress. This is implied by the fact that the sign of the interfacial shear stress, which is responsible for load transfer between the fiber and matrix, must be the same at all times. In other words, the consistency between the fiber sliding direction and the axial equilibrium condition of fiber and matrix (Eqs. (5) and (6)) must be kept.

\section{Viscoelastic solution: Crack bridging}

In crack bridging analysis, the relationship of the bridging stress $\sigma_{b}$ and the crack-opening displacement $\delta$ is usually required. The latter can be related to the relative sliding distance $\Delta$ at the fiber's end. The crack opening displacement must be defined such that $f \sigma_{b}(t) d \delta / d t$, where $f$ is the fiber volume fraction, is equal to the instantaneous rate of extra work, per unit area of crack surface, which occurs due to dissipation of energy by frictional sliding and viscoelastic straining of the fibers. Our interest in this article, however, is to find the bridging stress history $\sigma_{b}(t)$ due to an arbitrarily increasing $\Delta($ or $\delta$ ) such that a time dependent crack bridging mechanics problem can be formulated. 


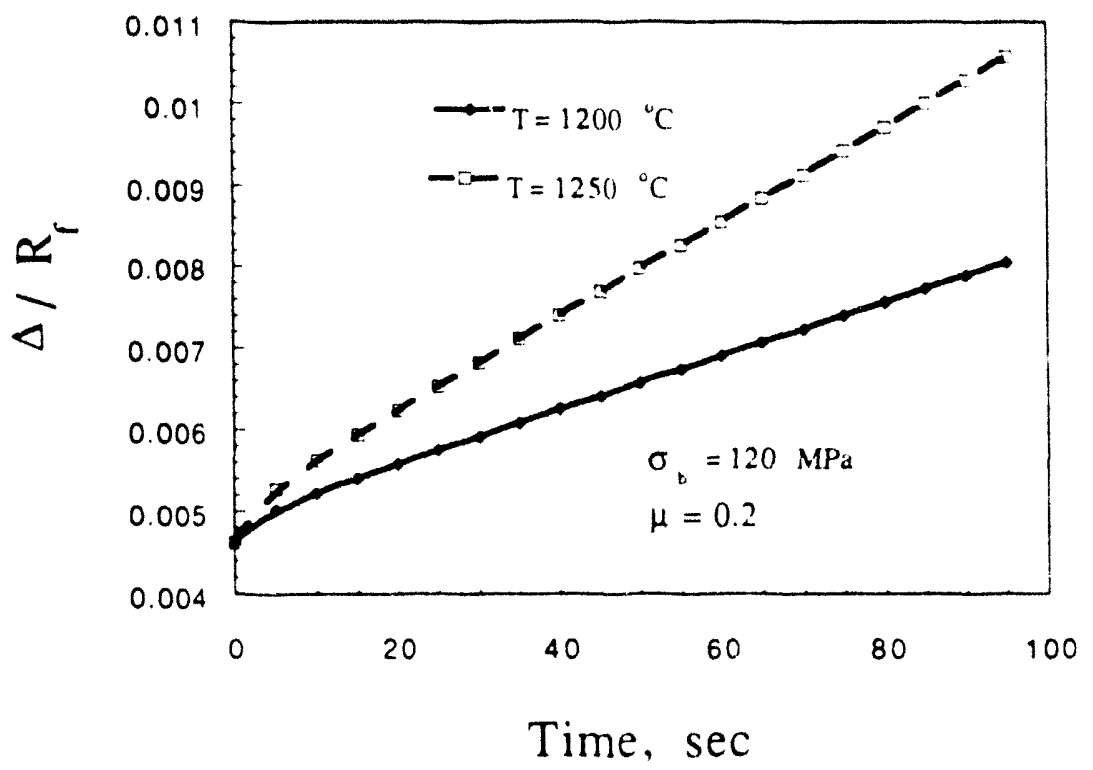

Figure 10: Evolution of the relative sliding distance, $\Delta$ for a step input (Pull-out).

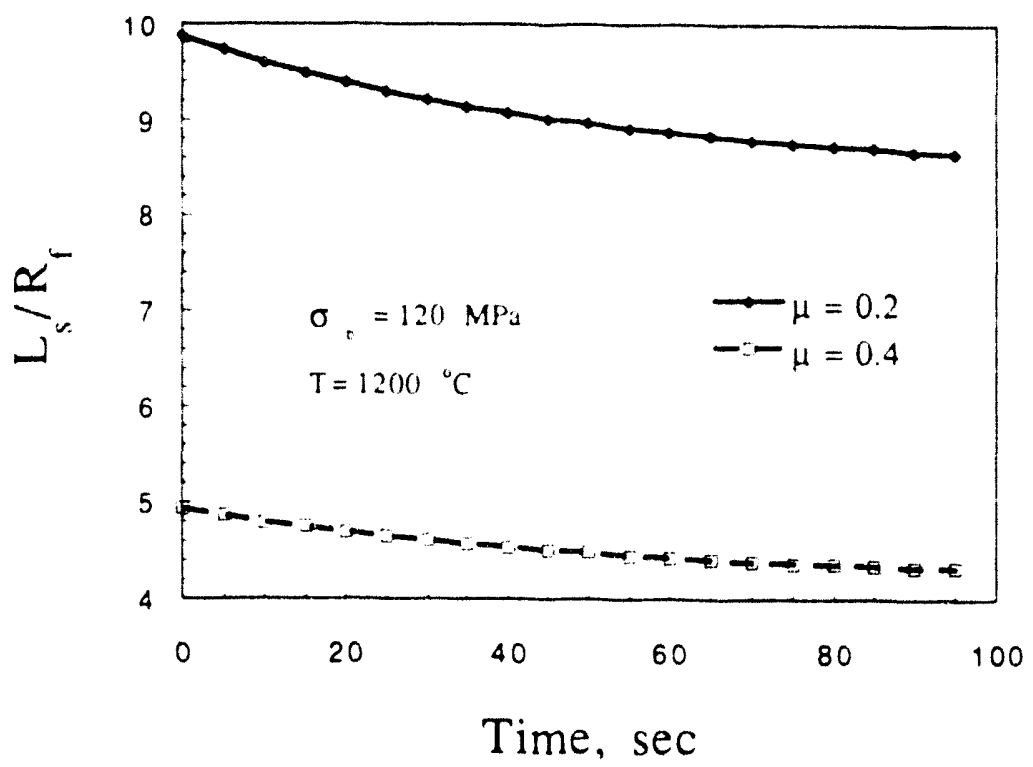

Figure 11: Effect of $\mu$ on evolution of $L_{s}$ for a step input (Pull-out). 


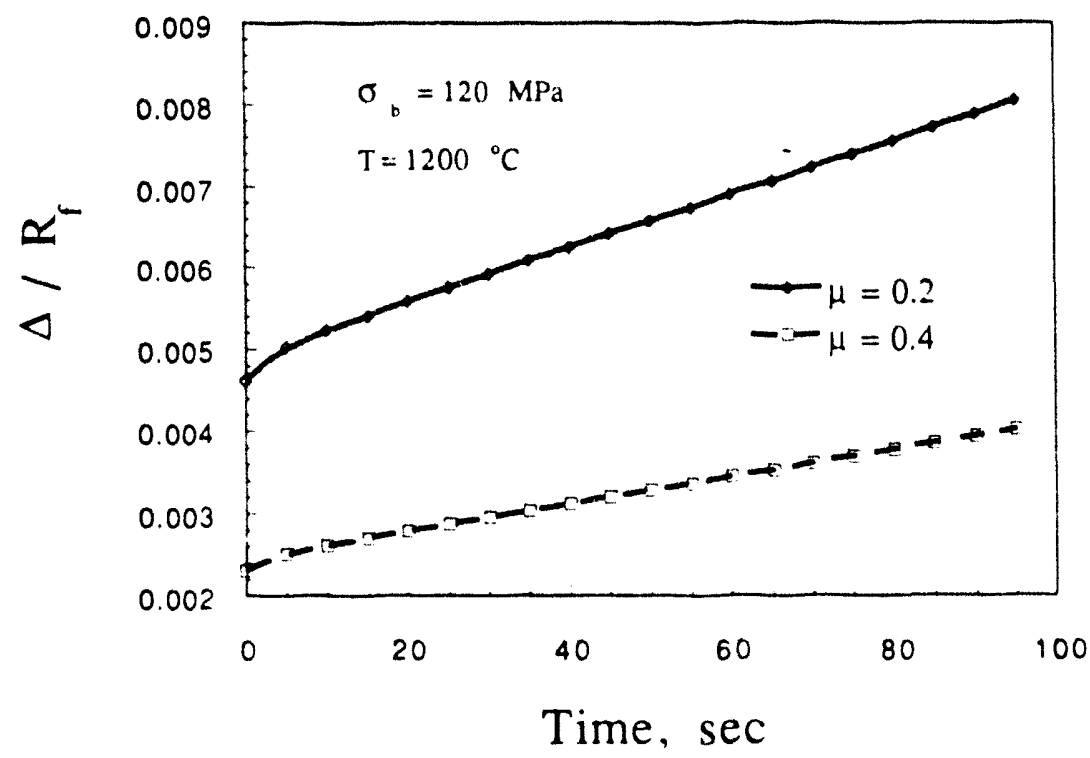

Figure 12: Effect of $\mu$ on evolution of $\Delta$ for a step input (Pull-out).

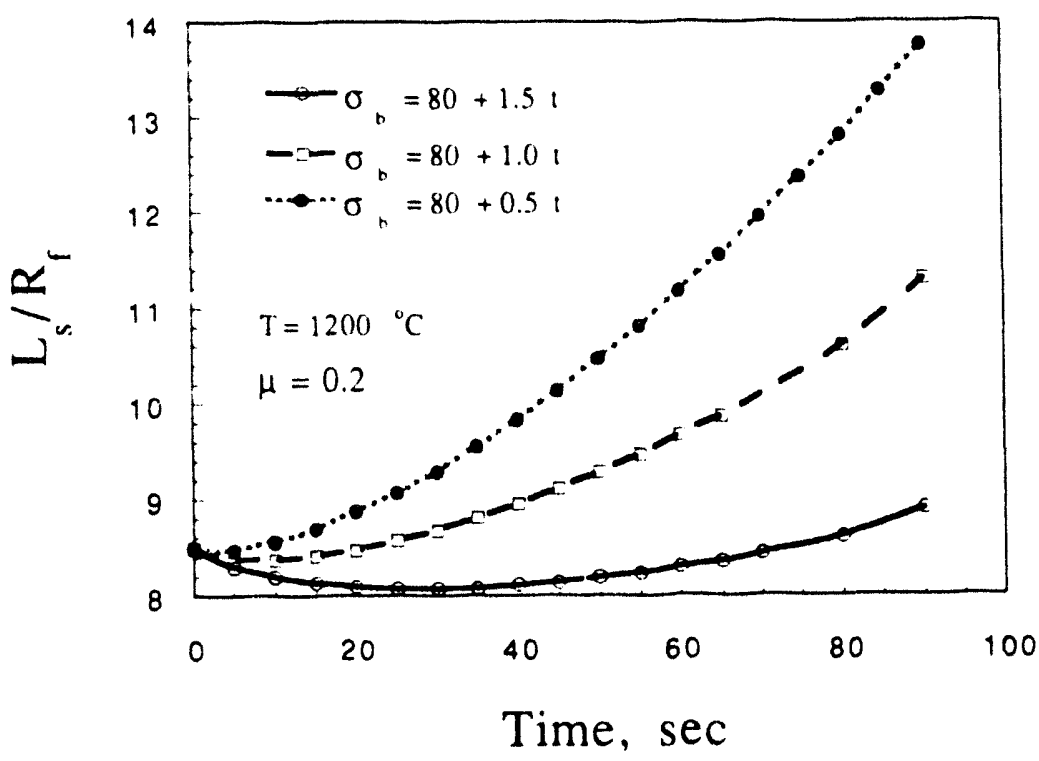

Figure 13: Effect of ramping of $\sigma_{b}$ on evolution of the sliding length, $L_{s}$ (Pull-out). 


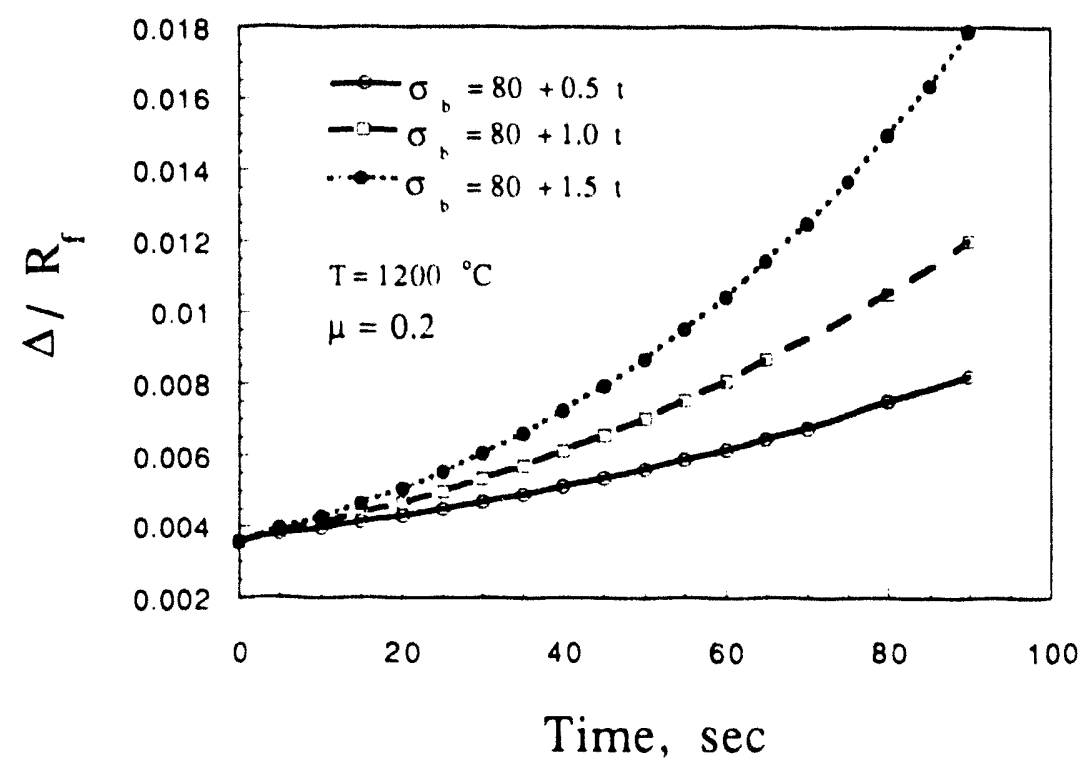

Figure 14: Effect of ramping of $\sigma_{b}$ on evolution of the relative sliding distance, $\Delta$ (Pull-out).

The elastic and viscoelastic relationships developed for pull-out problem give the distance $\Delta$ in terms of the applied stress. In case of elastic solution such a relationship woks both ways, i. e., if $\Delta$ is given in terms of the bridging stress $\sigma_{b}$, then the latter can be represented in terms of $\Delta$ using the developed relation. Under fiber creep condition, however, this is difficult due to two factors: First, the hereditary integrals involved in that relation, and second, the relationship is non-linear because the sliding length shows a logarithmic dependence on the applied stress. It is therefore needed to solve the new problem of finding bridging stress history due to a relative displacement history at the fiber end.

Although, in principle, the solution to this new problem can be formally obtained starting with the basic equilibrium conditions and the viscoelastic constitutive relations of fibers, the solution can be greatly simplified if we assume a constant sliding length (creeping length) for fibers. This assumption is consistent with the physical situation in case of an initially bonded fiber/matrix interface, which debonds over a certain distance $L_{d}$ upon the first application of load at the fiber's end. The solution for $L_{d}$ can be totally elastic. Analytical approximate methods for finding the debond length in terms of the applied load are presented by SIGL and EVANS (1989) and HUTCHINSON and JENSEN (1990), which can be coupled with the present analysis. If this is the case, it is possible to make use of the developed elastic solution as follows. In the $\Delta-\sigma_{z}^{f}(0)$ (Eqs. (17) and (18)), $L_{s}$ can be replaced by $L_{d}$ which is a constant. The rest of the terms included in that relation show: linear dependence on $\sigma_{z}^{f}(0)$. With this in hand, the same relationship can be solved for $\sigma_{z}^{f}(0)$, in the elastic case in terms of $\Delta$. This yields the following linear relation

$$
\sigma_{z}^{f}(0)=f_{1}\left(f, E_{f}, E_{m}, \nu_{f}, \nu_{m}\right) \Delta \epsilon_{1 n}+f_{2}\left(f, E_{f}, E_{m}, \nu_{f}, \nu_{m}\right) \Delta
$$

where expressions for $f_{1}$ and $f_{2}$ are included in Appendix $B$. The bridging traction $\sigma_{b}$ is then found, using equation (10), as

$$
\sigma_{b}=-\sigma_{R}^{f}+f_{1} \Delta \epsilon_{\imath n}+f_{2} \Delta
$$

The above developed elastic: solution can be used to formulate the Laplace transformed viscoelastic solution for a step input $\Delta$ as shown below 


$$
\hat{\sigma}_{b}(s)=-\hat{\sigma}_{R}^{f}(s)+\hat{f}_{1}(s) \frac{\Delta \epsilon_{i n}}{s}+\hat{f}_{2}(s) \frac{\Delta}{s}
$$

In which $\hat{f}_{1}(s)$ and $\hat{f}_{2}(s)$ are obtained by replacing $E_{f}$ and $\nu_{f}$ by their $s$ - multiplied transforms in the original expressions for $f_{1}$ and $f_{2}$. The solution in the time domain is then given by

$$
\sigma_{b}(t)=-\sigma_{R}^{f}(t)+f_{1}(t) \Delta \epsilon_{\text {in }}+f_{2}(t) \Delta
$$

In inverting equation (44), Schapery's method is used. In obtaining the solution for arbitrary history $\Delta(t)$, the last term in (45) is replaced by a convolution integral. The final form of the solution can be written as

$$
\begin{aligned}
\sigma_{b}(t)=-\sigma_{R}^{f}(t) & +f_{1}(t) \Delta \epsilon_{\mathrm{in}}+f_{2}(t) \Delta(0) \\
& +\int_{0}^{t} f_{2}\left(t-t^{\prime}\right) \dot{\Delta}\left(t^{\prime}\right) d t^{\prime}
\end{aligned}
$$

or alternatively by

$$
\begin{aligned}
\sigma_{b}(t)=-\sigma_{R}^{f}(t) & +f_{1}(t) \Delta \epsilon_{\text {in }}+f_{2}(0) \Delta(t) \\
& +\int_{0}^{t} \dot{f}_{2}\left(t^{\prime}\right) \Delta\left(t-t^{\prime}\right) d t^{\prime}
\end{aligned}
$$

The relaxation of the bridging stress is shown in Figs. 15 and 16 for time dependent $\Delta$, which represents a time dependent crack opening displacement. The parameter $\Delta$ is linearly related to the crack opening displacement (HUTCHINSON and JENSEN, 1990). In Fig. 15 the effect of the fiber creeping length, $L_{d}$, is shown. That length, which is considered as a debond length, depends on the initial applied stress (or initial crack opening displacement) and the energy release rate of the fiber/matrix interface. The latter depends on the initial manufacturing conditions. It can be shown that while shorter $L_{d}$ maintain higher bridging stress, the localization of the fiber creep between the faces of the matrix leads to a faster thinning of the bare fibers in that zone and, in turn, faster failure of the bridging. The stability of a bridged matrix crack, however, may require bridging stresses that are maintained for longer times. The question of stability can only be resolved by incorporating the present micro mechanical model into a formal stability study of bridged matrix cracks. The effect of the initial thermal strain mismatch is dipected in Fig. 17, where a comparison of the relaxation of the stress in a bridging fiber is compared to that of a bare fiber of the same length and subjected to the same displacement condition. It can be shown that at times greater than a 100 seconds the stresses in both fibers aproach the same value, which means that the matrix clamping effect, due to the initial strain mismatch, is greatly reduced.

\section{Concluding remarks}

It has been previously demonstrated that the residual thermal mismatch stresses and the fibermatrix interface frictional characteristics are two important factors which impact the low temperature toughness of ceramic matrix composites. At high temperatures, however, creep and/or stress relaxation in one or more of the composite phases may control the toughening behavior. In this work we have explored only the effect of fiber creep on the fiber pull-out and crack bridging relaxation. The results, however, give some insight into composite behavior under conditions where other inelastic effects are present ( e. g. irradiation creep and swelling). However, based on the results presented here, the following specific conclusions are derived: 


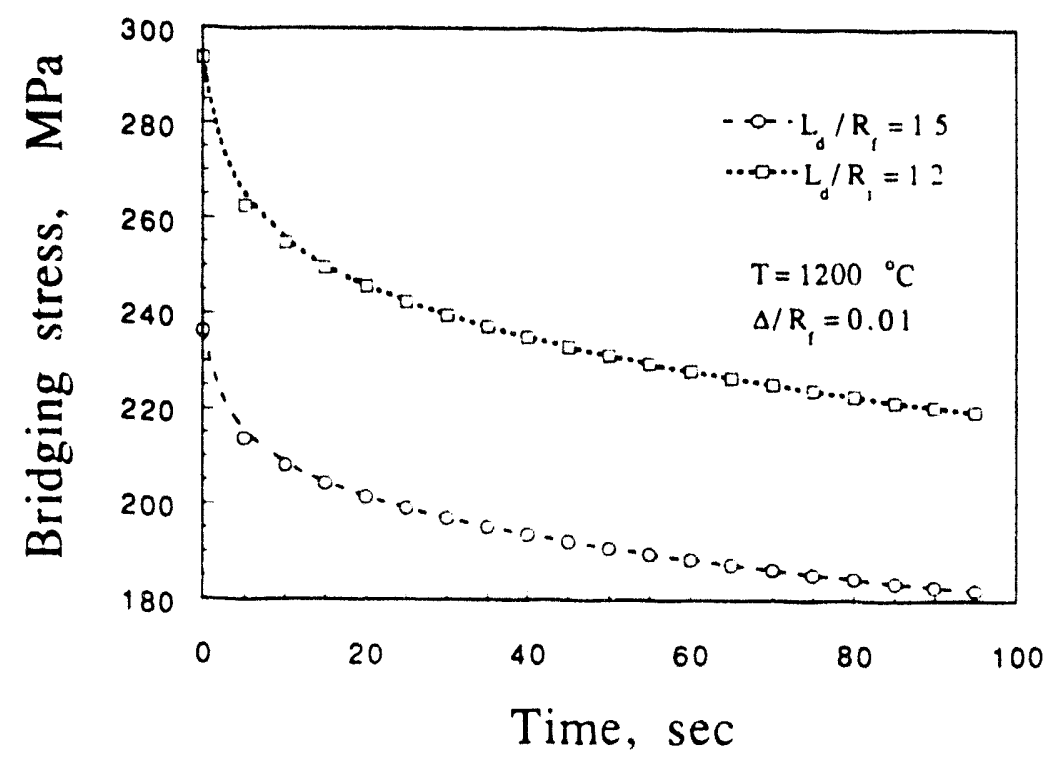

Figure 15: Relaxation of the: bridging stress, $\sigma_{b}$, for a step crack opening.

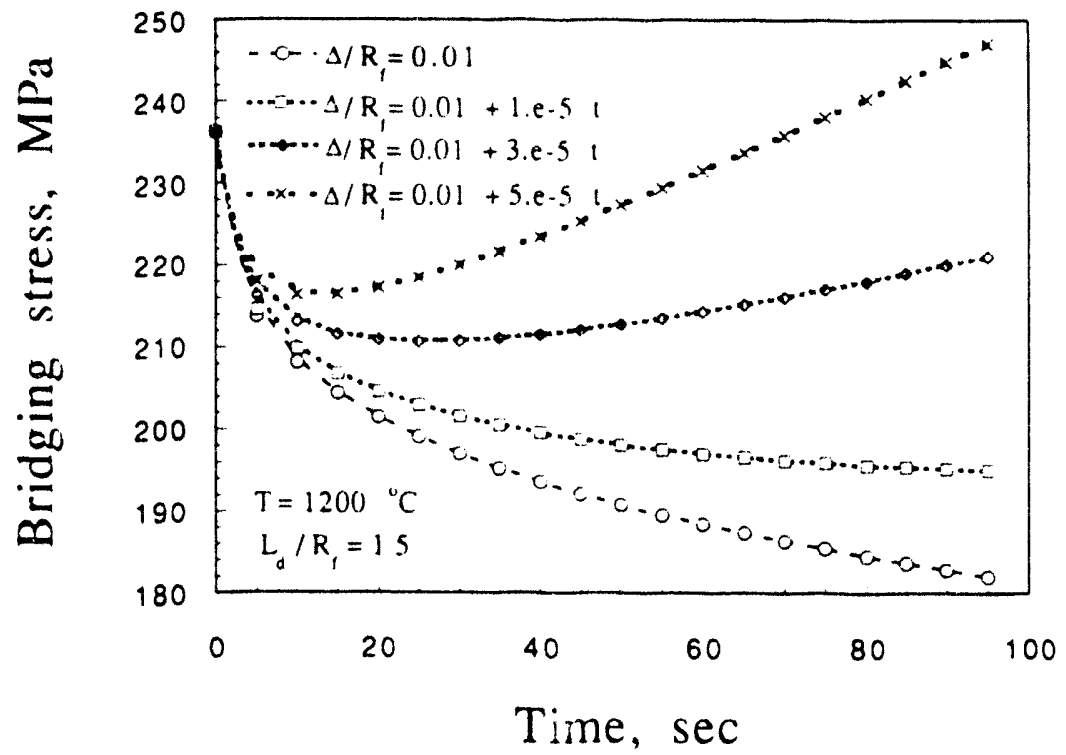

Figure 16: Relaxation of the bridging stress, $\sigma_{b}$, for a ramp crack opening. 


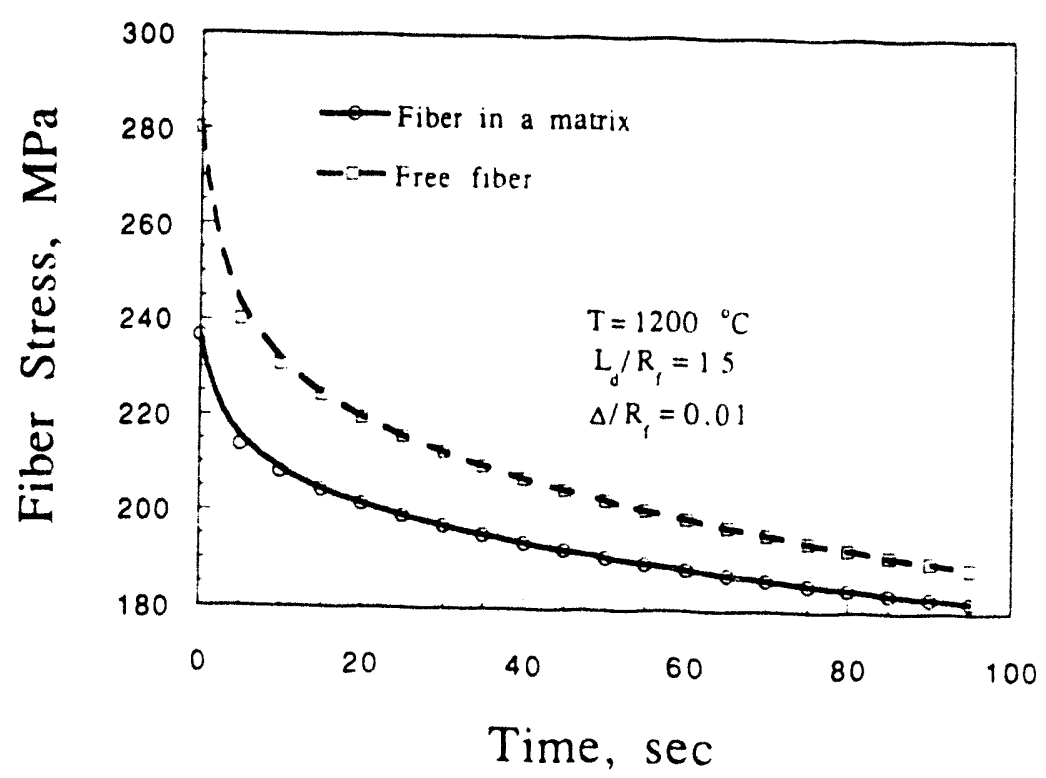

Figure 17: Relaxation of the bridging stress, $\sigma_{b}$, in comparison to bare fiber subjected to the same displacement condition.

1. The fiber-matrix interface friction coefficient, $\mu$, is a primary factor which influences the hightemperature fiber pull-out and crack bridging. This conclusion is based on the results presented in Figs. 11 and 12, where it is clearly shown that for higher values of the friction coefficient the sliding length $L_{s}$ is dramatically reduced. Under creep condition, this may lead to accumulating the fiber creep over smaller distances close to the matrix crack surface, hence, to a faster fiber failure in such zones.

2. From the composite toughness point of view. there exists an optimum thermal strain mismatch, which maximizes the matrix cracking stress and the toughness of the composite. However, at elevated temperatures where crecp of one or more of the composite phases is operable, such a thermal mismatch may not be important since it relaxes in time( Fig. 17). The time scale for such a relaxation process is controlled by the operating temperature (Figs. 5, 6). Therefore, in designing the micro structure for optimum toughness other means of optimization may need to be investigated.

3. At low temperatures, energy dissipation be frictional pull-out of failed fibers is a key term in the composite toughness. Under fiber creep conditions, the localization of creep strain close to the matrix crack surface may lead to failure of fibers close to the matrix surface. If this is the case, frictional energy dissipation by total pull-out of failed fibers may be negligible. Therefore, at high temperature, such a dissipation mechanism may be only important if the fibers remain intact for longer times, which allows a continuous frictional dissipation of energy before fiber failure.

4. A new factor, which may highly influence the composite toughness at elevated temperature, is the energy dissipation by viscoelastic straining of fibers. Significant amounts of energy may be dissipated in this way if the composite micro structure allows fiber survival for long times.

Some of the important features of the present model can also be summarized as follows:

1. The developed model can be utilized in designing and analyzing high-temperature fiber pullout experiments in composite systems, where time-dependent inelastic effects dominate the composite behavior. 
2. The model can be applied to solving problems of mechanics of bridged cracks at high-temperature, as well as studying the stability and growth of crack bridging.

3. The model can be used to optimize the micro structure of the composite system for maximum toughness by systematically exploring the effects of different parameters such as the friction coefficient, the initial inelastic strain mismatch, viscoelastic straining of fibers, and the effect of fiber sliding length on energy dissipation by frictional sliding and viscoelastic straining of fibers.

\section{FUTURE WORK}

The developed micro mechanical model will be used to optimize the micro structural design of SiC$\mathrm{SiC}$ composite systems for maximum toughness under conditions relevant to fusion applications. This will be accomplished by systematically exploring the effects of different parameters (e. $g$. the friction coefficient, the residual stresses, and fiber creeping length) on the energy of fracture of these composite systems. The model will also be used to study the mechanics of matrix cracks bridged by fibers, at high temperatures, and determine the stability of crack bridging processes in SiC-SiC composite systems.

\section{Appendices}

Appendix A: Residual axial stress in fibers

To find $\sigma_{R}^{f}$, an infinite copmosite cylinder is considered, which is cooled down from the initial stressfree temperature. Three conditions are used to determine $\sigma_{R}^{f}$, the initial interface pressure $q_{R}$, and the axial matrix stress in the intact matrix $\sigma_{R}^{m}$ (only $\sigma_{R}^{f}$ is important in analyzing crack bridging problems). These conditions are:

1. Continuity of radial displacement at fiber matrix interface:

$$
c_{\theta}^{f}\left(R_{f}\right)=\epsilon_{\theta}^{m}\left(R_{f}\right)
$$

2. Continuity of the axial displacement:

$$
\epsilon_{z}^{f}=\epsilon_{2}^{m}
$$

which is a uniform strain component along the composite cylinder.

3. Self-equilibrium condition for the composite cylinder:

$$
f \sigma_{R}^{f}+(1-f) \sigma_{R}^{m}=0
$$

The first two conditions make use the strain-stress relations (2) given in Section 2, along with replacing $\sigma_{z}^{f}$ by $\sigma_{R}^{f}, \sigma_{z}^{m}$ by $\sigma_{R}^{m}$, and $q$ by $q_{R}$. The third condition is used to eliminate $\sigma_{R}^{m}$ in the first two conditions. The final form of the solution can be written as

$$
\begin{aligned}
\sigma_{R}^{f} & =E_{f} E_{m}(1-f) \Delta \epsilon_{i n}\left(\frac{d_{2}-d_{1}}{c_{1} d_{2}-c_{2} d_{1}}\right) \\
q_{R} & =E_{f} E_{m}(1-f) \Delta \epsilon_{i n}\left(\frac{c_{1}-c_{2}}{c_{1} d_{2}-c_{2} d_{1}}\right) \\
\sigma_{R}^{m} & =\left(\frac{-f}{1-f}\right) \sigma_{R}^{f}
\end{aligned}
$$


where

$$
\begin{aligned}
& c_{1}=f E_{f}+(1-f) E_{m} \\
& c_{2}=f \nu_{m} E_{f}-(1-f) \nu_{f} E_{m} \\
& d_{1}=-2\left[(1-f) \nu_{f} E_{m}+f \nu_{m} E_{f}\right] \\
& d_{2}=(1-f) E_{m}\left(1-n u_{f}\right)+E_{f}\left[1+\nu_{m}+f\left(1-\nu_{m}\right)\right]
\end{aligned}
$$

Appendix B: Expressions for $f_{1}$ and $f_{2}$

This appendix contains expressions for the constants $f_{1}$ and $f_{2}$ appearing in equation(42). The derivation starts by considering equations (17) and (18) and replacing $L_{s}$ by $L_{d}$.

$$
\begin{aligned}
e & =\exp \left(\frac{2 \mu c L_{d}}{R_{f}}\right)-1 \\
e_{1} & =\left[\frac{1}{E_{f}}-\frac{a_{1}}{a_{4} c E_{f}}-\frac{a_{1}}{a_{4} c E_{m}}\left(\frac{f}{1-f}\right)\right] L_{d} \\
e_{2} & =\frac{a_{1} R_{f}}{\mu c a_{4}}\left[\frac{1}{2 c E_{f}}-\frac{\nu_{f}}{E_{f}}+\frac{f}{2 c(1-f) E_{m}}-\frac{\nu_{m} f}{(1-f) E_{m}}\right] e \\
e_{3} & =-\left[1+\frac{a_{3}}{a_{4} c E_{f}}+\frac{a_{3}}{a_{4} c E_{m}}\left(\frac{f}{1-f}\right)\right] L_{d} \\
e_{4} & =\frac{a_{3} R_{f}}{\mu c a_{4}}\left[\frac{1}{2 c E_{f}}-\frac{\nu_{f}}{E_{f}}+\frac{f}{2 c(1-f) E_{m}}-\frac{\nu_{m} f}{(1-f) E_{m}}\right] e
\end{aligned}
$$

Expressions for $f_{1}$ and $f_{2}$ are then written as

$$
\begin{aligned}
& f_{1}=-\left(\frac{e_{3}+e_{4}}{e_{1}+e_{2}}\right) \\
& f_{2}=\left(\frac{1}{e_{1}+e_{2}}\right)
\end{aligned}
$$

\section{References}

[1] BRUN, Milivoj . K. and BOROM, MARCUS. P. (1989) J. Am. Ceram. Soc.72 No. 10, 1993-1996.

[2] CARTER, C. H. and DAVIS, R. F. (1984) J. Am. Ceram. Soc. 67 No. 11, 732-740.

[3! CARroll, DOUglas R. and Dharani, L. R. (1992) J. Am. Ceram. Soc. 75 No. 4, 786794.

[4] DICARLO, JAMES A. (1986) J. Mater. Sci. 21, 217-224.

[5] DICARLO, JAMES A. and MORCHER, GREGORY N. (1991) Failure Mechanisms of High Temperature Composite Materials, pp. 15-22 AD-Vol.22 -AMD-Vol.122, The American Society pf Mechanical Engineers.

[6] FU, S. Y., ZHOU, B. L., CHEN, X., HE, G. H. and LUNG, C. W. (1993) Composites 24 No. $1,5-11$.

(7) FU, S. Y., ZHOU, B. L., CHEN, X., HE, G. H. and LUNG, C. W. (1993) Composites 24 No. 1, 13-17. 
[8] GAO, YU-CHEN, MAI, YUI-WING and COTTERELL, BRIAN (1988) J. Appl. Math. Phys.39, 550-572.

[9] GOLDEN, J. M. and GRAhAM, G. A. C (1988) Boundary Value Problems in Linear Viscoelasticity, Springer-Verlag.

[10] GULDEN, T. G. (1969) J. Am. Ceram. Soc. 52 No. 11, 585-590.

[11] HSUEH, CHUN-HWAY (1988) J. Mat. Sci. Letters 7, 497-500.

[12] HSUEH, CHUN-HWAY, FERBER, MATTISON K. and BECHER, PAUL, F. (1988) J. Mater Res. 4 No. 6, 1529-1537.

[13] HSUEH, CHUN-HWAY (1990) J. Mat. Sci. 25, 811-817.

(14) HUTCHINSON, JOHN. W. and JENSEN, HENRIK M. (1990) Mechanics of Materials 9, 139163.

[15] JIANG, K. R. and PENN, L. S. (1992) Composites Sci. Tech. 45, 89-103.

[16] LIANG, C. and HUTCHINSON, J. W. (1993) Mechanics of Materials 14, 207-221.

[17] LUH, ELliCE Y. and EVANS, A. G. (1987) J. Am. Ceram. Soc. 70 No. 7, 466-469.

[18] MARShall, D. B. and EVANS, A. G (1985) J. Am. Ceram. Soc. 68 No. 5, 225-231.

(19) MARShall, D. B., COX, B. N. and EVANS, A. G. (1985) Acta Metall. 33 No. 11, 2013-2021.

(20) MARShAll, D. B., SHAW, M. C. and MORRIS, W. L. (1992) Acta Metall. Mater. 40 No. 3, 443-454

(21) MARSHALL, D. 13. (1992) Acta Metall. Mater. 40 No. 3, 427-441.

[22] NAIR, S. V., JAKLS, K. and LARDNER, 'T. J. (1991) Mechanics of Materials 12, 229-244.

[23] PIPKIN, A. C. (1986) Lectures on Viscoelasticity Theory, Applied Mathematical Sciences-Vol.7, Springer-Verlat.

(21) SIGL, L. S. and EVANS, A. G. (1989) Mechanics of Materials 8, 1-12.

[25] SUZUKI, TAKAYLKI, SATO, MASAHIRO and SAKAI, MOTOTSUGU (1992) J. Mater. Res. 7 No. 10, 2869-2875.

[26] SHAPERY, R. A. (1962) Proceedings of the Fourth U. S. National Congress of Applied Mechanics, pp. 1075-108i).

[27) SHETTY, DINESI K. (1988) J. Am. Ceram. Soc. 71 No. 2, C-107 - C-109.

[28] THOLless, M. D. and EVANS, A. G. (1988) Acta Metall. 36 No. 3, 517-522.

[29] ZHOL, LI-MIN. KIMI, JANG-KYO and MAI, YU-W'ING (1992) Composites Sci. Tech.45, 153160. 
Distribution

1-16. Argonne National Laboratory, 9700 South Cass Avenue, Argonne, IL 60439
M. C. Billone
Y. Gohar
L. A. Niemark
O. K. Chopra
A. B. Hull
J. H. Park
H. M. Chung
C. E. Johnson
D. L. Smith
D. R. Diercks
F. Kassner
S. W. Tam
R. Erck
B. A. Loomis
II. C. Tsai
A. K. Fisher
R. F. Maltas
H. Wiedersich

17-18. Argonne National Laboratory, EBR-II Division, P.O. Box 2528, Idaho Falls, ID 83403-2528
H. P. Planchon
D. L. Porter

19. Auburn University, Departunent of Mechanical Engineering, 201 Ross Hall, Auburn, Al 36849

B. A. Chin

20-33. Battelle-Pacific Northwest Laboratory, P.O. Box 999, Richland, WA 99352
J. L. Euhridge
M. L. Hamilton
R. H. Jones
F. A. Gauner (5)
Il. L. Heinisch
W. W. Laity
D. S. Gelles
G. W. Hollenberg
O. D. Slagle
L. R. Greenwood

34. Carnegie Institute of Technology, Carnegic-Mellon University, Schenley Park, Pittsburgh, PA 15213

W. M. Garrison, Jr.

35-36. EG\&G Idaho, Inc., Fusion Safety Program, P.O. Box 1625, Idaho Falls, ID 83415-3523

D. F. Holland

S. J. Piet

37. GE Astrospace Division, San Jose Operations, 6834 via Deloro, P.O. Box 530954, San Jose, CA 95153-5354

Mike Kangilaski

38-41. General Atomics, P.O. Box 85608, San Diego, CA 92138
T. A. Lechtenberg
D. I. Roberts
K. R. Schultz
C. Wong

42. General Dynamics Corp., 5001 Kearny Villa Rd., San Diego, CA 92138

T. L. Cookson

43. Georgia Institute of Technology, Fusion Research Center, 0225, Allanta, GA 30332 W. M. Stacey

44. Grand Canyon University, Departunent of Natural Science, 3300 W. Camelback Rd., Phoenix, AZ 85017

W. A. Coghlan

45-47. Lawrence Livermore National Laboratory, P.O. Box 808, Livermore, CA 94550

E.C.N. Dalder J. Perkins

M. Guinan

48-55. Los Alamos National Laboratory, P.O. Box 1663, Los Alamos, NM 87545
J. L. Anderson
H. M. Frost
W. F. Sommer
F. W. Clinard
J. C. Kennedy
K. E. Sickafus
E. H. Farnum
R. E. Siemon 
56. Manlabs, Inc., 231 Erie Street, Cambridge, MA 02139

D. Tognarelli

57-59. Massachusets Institute of Technology, Deparunent of Metallurgy and Materials Science, Caunbridge, MA 02139
L. W. Hobbs
K. C. Russell
N. J. Grant

60-61. Massachusette Institute of Technology, Plasma Fusion Center Headquarters, Cambridge, MA 02139
H. D. Becker
D. B. Montgomery

62. McDonnell-Douglas Missile Systems Company, Mail Code 306 4204, P.O. Box 516, St Louis, MO 63166 J. W. Davis

63-65. National Institute of Standards and Technology, Boulder, CO 80302
F. R. Fickelt
R. P. Reed
II. I. McHenry

66. National Materials Advisory Board, 2101 Constitulion Avenue, Washington, DC 20418 K. M. Zwilsky

67-68. Naval Restarch L aboratory, Code 6506, Washington, DC. 20375
D. L. Gibson
J. ^. Sprague

69-109. Oak Ridge Nationad Laboratory, P.O. Box 2008, (aak Ridge, I'N 37831
Central Research Library
R. II. Goulding
Document Reference Section
M. L. Grossbeck
A. F. Rowcliffe (9)
Laboratory Records Departument (2)
E. A. Kenik
R. L. Senn
Laboratory Records-RC.
R. L. Kluch
J. Sheffield
Patent Section
E. II. Lee
D. J. Alexinnder
A. W. Longest
L. L. Sncad
C. C. Baker
L. K. Mansur
R. E. Stoller
J. Bentley
P. J. Mazias.
K. R. Thoms
E. E. Bloom
J. E. Pawel
P. F. Tortorelli
'T. D. Burchell
J. H. DeVan
T. C. Reuther
C. A. Wang
D. P. White
T. K. Roche
S. J. Zinkle

110. Oregon Graduate Instilute, Dept. of Materials Science \& Engineering, 19600 N.W. Von Neumann Drive, Beaverton, OR 97006 J. M. McCarthy

111-113. Princeton University, Princeton Plasma Physics Laboratory, P.O. Box 451, Princeton, NJ 08540
C. Bushnell
H. Furth
Long-P(sc Ku

114. Reactor Materiads Technology, 272 Baywood Avenue, Pittsburgh, PA 15228
A. Boltax

115-116. Rensselaer Polytechnic Institute, Troy, NY 12181

D. Steiner

David Duquelle

117. Rockwell International Corporation, NA02, Rocketdyne Division, 6633 Canoga Avenue, Canoga Park, CA 91304

D. W. Kneft 
118-120. Sandia National Laboratories, Fusion Technology Dept., Dept. No 6531, P.O. Box 5800, Albuquerque, NM 87185-5800
M. J. Davis
R. D. Watson

W. B. Gauster

121-122. Sandia National Laboratories, Livermore Division 8316, Livermore, CA 94550
W. Bauer
W. G. Wolfer

123. San Diego State University, Mechanical Engineering Dept., San Diego, CA 92182-0191

L. D. Thompson

124. TSI Research, 225 Stevens Ave., \#110, Solana Beach, CA 92075

E. T. Cheng

125-126. University of California, Dept. of Chemical and Nuclear Engineering, Santa Barbara, CA 93106
G. E. Lucas
G. R. Odette

127-129. University of California, Dept. of Chemical, Nuclear , and Thermal Engineering,

Los Angeles, CA 90024
M. A. Abdou
N. M. Ghoniem
R. W. Conn

130. University of California. IPFR, 405 Hilgard Avenue, Los Angeles, CA 90024-1600

S. Sharafat

131. University of Michigan, Dept. of Nuclear Engineering, Ann Arbor, MI 48109

T. Kammash

132. University of Missouri, Department of Nuclear Engineering, Rolla, MO 65401

A. Kumar

133-134. University of Wisconsin, Nuclear Engineering Dept., 1600 Johnson Drive, Madison, WI 53706
J. B. Blanchard
G. L. Kulcinski

135. Washington State University-Tri-Cities, 6012 W. Ridgecrest Drive, Spokane, WA 99208

D. G. Doran

136-139. Westinghouse Hanford Company, P.O. Box 1970, Richland, WA 99352
R. E. Bauer
F. M. Mann
A. M. Ermi
R. J. Puigh

140-142. Hokkaido University, Faculty of Engineering, Kita 13, Nishi 8, Kita-ku, Sapporo 060, Japan Heischichiro Takahashi Akira Okada Somei Ohnuki

143-144. Japan Atomic Energy Research Institute, Tokai Research Establishment, Tokai-mura, Naka-gun, Ibaraki-ken 319-11, Japan Tatsuo Kondo

Akimichi Hishinuma (3)

145. Kyushu University, Dept. of Nuclear Engineering, Faculty of Engineering, Kyushu University 36, Hakozaki, Fukuoka 812, Japan C. Kinoshita

146. Kyushu University, Research Institute of Applied Mechanics, 6-1, Kasuga-Koen, Kasuga-Shi, Fukuoka-Ken 816, Japan

Takeo Muroga 
147-148. Muroran Institute of Technology, Dept. of Metallurgical Engineering, 27-1 Mizumoto-cho,

Mororan 050, Japan

Toshihei Misawa

Akihiko Kimura

149. Nagoya University, Dept. of Nuclear Engineering, Furo-Cho, Chikusa-ku, Nagoya 464-01, Japan Michio Kiritani

150-152. National Institute for Fusion Science, Furo-cho, Chikusa-ku, Nagoya 464-01, Japan Osamu Motojima Chusei Namba Nobuaki Noda

153-155. National Research Institute for Metals, Tsukuba Branch, Sengen, Tsukuba-shi, Ibaraki-ken, 305, Japan Fujio Abe Josei Nagakawa Haruki Shiraishi

156. Osaka University, Dept. of Nuclear Engineering, 2-1 Yamadaoka, Suita, Osaka 565, Japan Tetuo Tanabe

157. PNC Oarai, 4002 Narita, Oarai, Ibaraki 311-13, Japan Itaru Shibasaki

158. Science University of Tokyo, Dept. of Materials Science \& Technology, 2641 Yamazaki

Noda City, Chiba Prefecture 278, Japan Naohira Igata

159. Teikyo University, Otsuka, Hachioji, Tokyo 192-03, Japan Akira Miyahara

160. Tohoku University, Institute for Materials Research, Katahira 2-2-1, Sendai 980, Japan Hideki Matsui

161-162. Tohoku University, Institute for Materials Research, Oarai Branch, Oarai, Ibaraki 311-13, Japan Tatsuo Shikama Hideo Kayono

163. Tohoku University, Dept. of Nuclear Engineering, Tohoku University, Aoba, Aramaki, Sendai 980, Japan Katsunori Abe

164-166. University of Tokyo, Dept. of Nuclear Engineering, 3-1, Hongo 7-Chome, Bunkyo-Ku, Tokyo 113, Japan Shiori Ishino (2) Naoto Sekimura

167-168. University of Tokyo, Dept. of Materials Science, 3-1, Hongo 7-Chome, Bunkyo-ku, Tokyo 113, Japan Akira Kohyama Yutaka Kohno

169. Commission of European Communities, Directorate-General for Research Science and Education, Fusion Programme RUE De La Loi 200, B-1049 Brussels, Belgium J. Darvas

170-171. Chalk River Nuclear Laboratories, Atomic Energy of Canada, Ltd., Chalk River, Ontario KOJ 1J0, Canada
I. J. Hastings
D. P. Jackson

172. Southwestern Institute of Physics, P.O. Box 432, Chenedu 610041, Sichuan, P.R. China J. P. Qian 
173. Institute of Atomic Energy, Academia Sinica, P.O. Box 275-51, Beijing, P.R. China J. Yu

174 Riso National Laboratory, Materials Dept., P.O. Box 49, DK-4000, Roskilde, Denmark B. N. Singh

175. Centre d'Etudes Nucleaires, Saclay, DLPC/SMCM, Commissariat a IEnergie Atomique, 91191 Gif-Sur-Yvette, Cedex, France N. Roux

176. Commission for European Communities, Joint Research Centre, I.A.M. Ispra Establishment 21020 Ispra (Varese), Italy P. Schiller

177. EURATOM/CIEMAT Fusion Association, Avenida Complutense 22, 28040, Madrid, Spain E. R. Hodgson

178. Paul Scherrer Institute, CH-5232 Villigen, Wuerenlingen PSI, Switzerland M. Victoria

179. Harwell Laboratory, B393, Radiation Damage Dept., Oxfordshire, OX11 ORA, United Kingdom C. A. English

180. Metallurgical and Nuclear Consultant, 9A Cumnor Rise Road, Cumnor Hill, Oxford OX2 9HD, United Kingdom

D. R. Harries

181. Culham Laboratory, U.K. Atomic Energy Authority, D5/117, Abingdon, Oxon OX14 3DB, United Kingdom

G. J. Butterworth

182. Hahn-Meitner-Institut fur Kernforschung Berlin, Glienicker Str. 100, D-1000 Berlin 39, Germany H. J. Wollenberger

183. Institut fur Festkorperforschung der Kernforschungsanlage, D-5170 Julich 1, Postfach 1913, Germany H. Ullmaier

184-185. Kernforschungszentrum Karlsruhe, Postfach 3640, 75 Karlsruhe 1, Germany
M. Dalle-Donne (INR)
K. Erlich (IMF-II)

186. A. A. Baikov Institute of Metallurgy, USSR Academy of Sciences, Leninsky Prospect 49, Moscow, Russia

L. I. Ivanov

187. CRISM "Prometey," Naberezhnava r. Monastyrick 1, 193167, St. Petersburg, Russia V. V. Rybin

188. D. V. Efremov Institute of Electro-Physical Apparatus, 189631, St. Petersburg, Kussia Yu. G. Prokofiev

189. Institute of Power Engineering, 218 M. Krasnosel's Kaji St., 107113 N.uscow, Russia G. M. Kalinin

190. Kharkov Physical-Technical Institute of Atomic Reactors, Kharkov, Academishen, 1, Moscow, Russia I. M. Neckludov 
191. V. I. Lenin Research Institute of Atomic Reactors, 433510 Dimitrovgrad-10, Ulyanovsk Region, Ukraine

V. K. Shamardin

192. Department of Energy, DOE Oak Ridge Field Office, P.O. Box 2008.

Oak Ridge, IN 37831-6269

Assistant Manager for Energy Research and Development

193. Department of Energy, DOE Oak Ridge Field Office, P.O. Box 2008, Oak Ridge, TN 37831-6269

S. D. Frey

194. Department of Energy, Office of Basic Energy Sciences, Washington, D.C. 20585

J. B. Darby

195-202. Department of Energy, Office of Fusion Energy, Washington, D.C. 20585
S. E. Berk
N. A. Davies
R. E. Price
M. M. Cohen
W. F. Dove
F. W. Wiffen
D. H. Crandall
T. R. James

203. Department of Energy, Richland Operations Office, Federal Bldg., MS-A590,

Richland, WA 99352

D. Segna

204-253. Department of Energy, Office of Scientific and Technical Information, Office of Information Services, P.O. Box 62, Oak Ridge, TN 37831

For distribution as shown in DOE/TIC-4500, Distribution Categories UC-423 (Magnetic Fusion Reactor Materials) and UC-424 (Magnetic Fusion Energy Systems) 

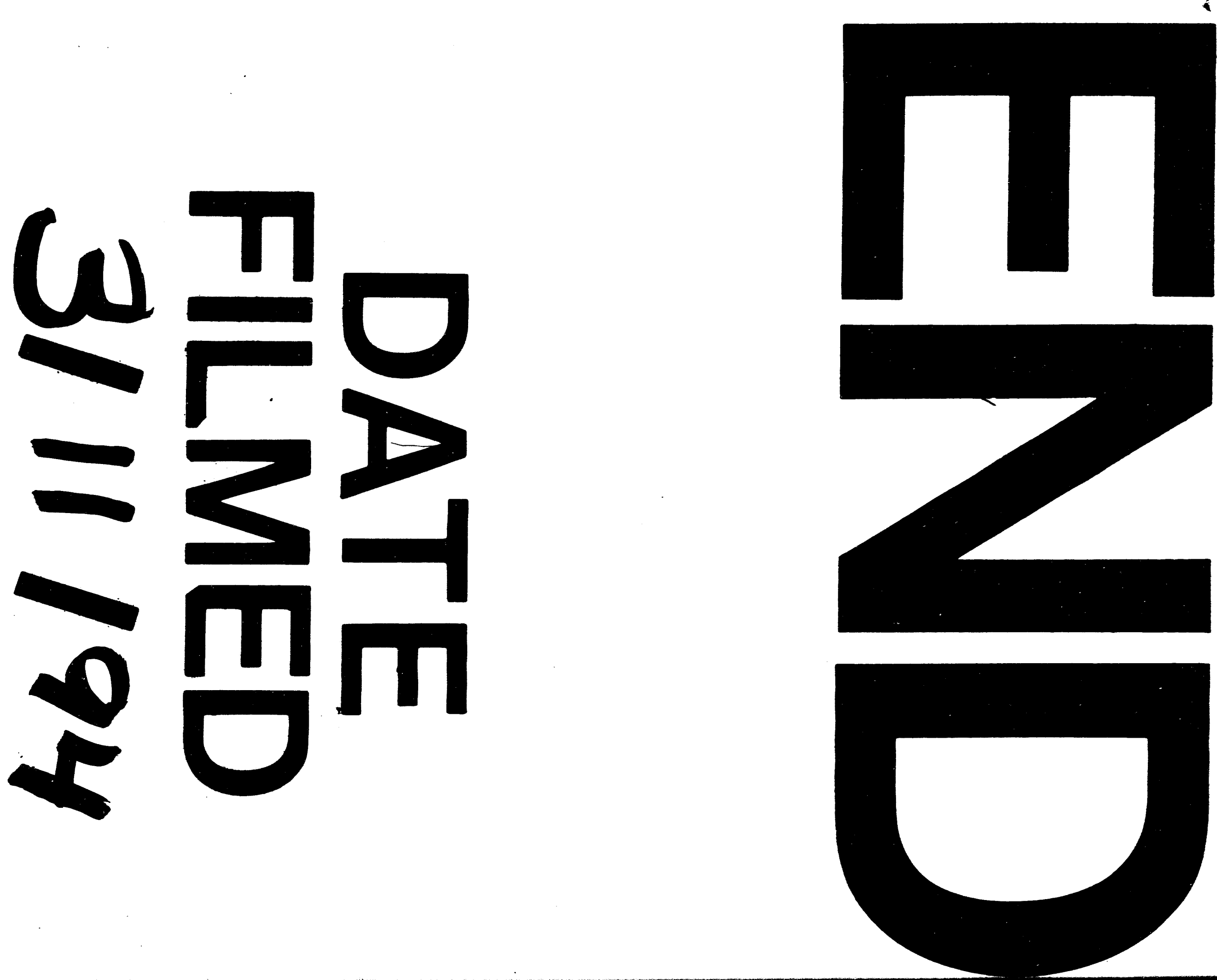


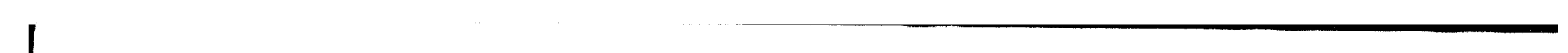

